[Inmaculada Adrián Gálvez, Ángeles Mera Costas, Guillermo J. Pérez Casanova, Ignacio Tébar RubioManzanares, Sara Hidalgo García, Vicent Bellver Loizaga, Isabel Ferrándiz Armero, Garikoitz Gómez Alfaro, Iratxe Hernández Simal, Bárbara Ortuño Martínez, Aurelio Velázquez Hernández, Marcela I. Lucci, Pablo Aguirre Herráinz, Lidia Bocanegra Barbecho, Élodie Das Neves, Jorge de Hoyos Puente, Aubin González, Christof Van Mol, Toni Morant i Ariño, Rubén Pallol Trigueros, Roberto Gallardo Pérez, Santiago de Miguel Salanova, Daniel Oviedo Silva, Alejandro Pérez-Olivares, Jose $M^{a}$ RodríguezVigil Reguera, Luis Manuel Sanmartín Cava, Matthew Kerry, Gloria Román Ruiz, Julio Lisandro Cañón Voirin, Paula Escribano Castaño, Francesco D’Amaro, Rosy Rickett, Pablo Giori, Ignacio SuayMatallana, Mar Cuenca-Lorente, Juan Marcos Bonet Safont, Miquel Carandell Baruzzi, Elvira Fente, Fátima Ferni Álvarez, Clara Florensa, Carlos Fuertes Muñoz, Fernando García Naharro, Andrea Graus, Imanol Herreros Chandro, Rubén Mirón González, Òscar Montero Pich, María Rosa Muñoz Bell, Carles Sirera Miralles, Lorena B. Valderrama, María Valls, Natxo Escandell, Cristina Alquézar Villarroya, Sandra Blasco Lisa, Juan Carlos Colomer Rubio, Elena Díaz Silva, Cristian Ferrer González, Rosario Fombuena Borrás, Jon Martínez Larrea, Antonio Muñoz de Arenillas Valdés, Alfonso Natividad Hernandis, Joel Sans Molas, Fátima Martínez Pazos]

\section{"OTRAS VOCES, OTROS ÁMBITOS": LOS SUJETOS Y SU ENTORNO. NUEVAS PERSPECTIVAS DE LA HISTORIA SOCIOCULTURAL}

Vicent Bellver Loizaga, Francesco D’Amaro, Isabel Molina Puertos, Jorge Ramos Tolosa (coord.) 

[Inmaculada Adrián Gálvez, Ángeles Mera Costas, Guillermo J. Pérez Casanova, Ignacio Tébar RubioManzanares, Sara Hidalgo García, Vicent Bellver Loizaga, Isabel Ferrándiz Armero, Garikoitz Gómez Alfaro, Iratxe Hernández Simal, Bárbara Ortuño Martínez, Aurelio Velázquez Hernández Marcela I. Lucci, Pablo Aguirre Herráinz, Lidia Bocanegra Barbecho, Élodie Das Neves, Jorge de Hoyos Puente, Aubin González, Christof Van Mol, Toni Morant i Ariño, Rubén Pallol Trigueros, Roberto Gallardo Pérez, Santiago de Miguel Salanova, Daniel Oviedo Silva, Alejandro Pérez-Olivares, Jose $M^{a}$ RodríguezVigil Reguera, Luis Manuel Sanmartín Cava, Matthew Kerry, Gloria Román Ruiz, Julio Lisandro Cañón Voirin, Paula Escribano Castaño, Francesco D’Amaro, Rosy Rickett, Pablo Giori, Ignacio SuayMatallana, Mar Cuenca-Lorente, Juan Marcos Bonet Safont, Miquel Carandell Baruzzi, Elvira Fente, Fátima Ferni Álvarez, Clara Florensa, Carlos Fuertes Muñoz, Fernando García Naharro, Andrea Graus, Imanol Herreros Chandro, Rubén Mirón González, Òscar Montero Pich, María Rosa Muñoz Bell, Carles Sirera Miralles, Lorena B. Valderrama, María Valls, Natxo Escandell, Cristina Alquézar Villarroya, Sandra Blasco Lisa, Juan Carlos Colomer Rubio, Elena Díaz Silva, Cristian Ferrer González, Rosario Fombuena Borrás, Jon Martínez Larrea, Antonio Muñoz de Arenillas Valdés, Alfonso Natividad Hernandis, Joel Sans Molas, Fátima Martínez Pazos]

\section{"OTRAS VOCES, OTROS ÁMBITOS": LOS SUJETOS Y SU ENTORNO. NUEVAS PERSPECTIVAS DE LA HISTORIA SOCIOCULTURAL}

Vicent Bellver Loizaga, Francesco D’Amaro, Isabel Molina Puertos, Jorge Ramos Tolosa (coord.) 
"Otras voces, otros ámbitos": los sujetos y su entorno. Nuevas perspectivas de la historia sociocultural"

\section{ISBN: 978-84-606-5875-7}

DOI: $10.7203 / 10550.42837$

Coordina: Vicent Bellver Loizaga, Francesco D’Amaro, Isabel Molina Puertos, Jorge Ramos Tolosa

Edita: Universitat de València. Valencia, 2015

Asociación de Historia Contemporánea

Diseño y maquetación: Carles Rodrigo Monzó (www.carlesrodrigo.es)

Autores: Inmaculada Adrián Gálvez, Ángeles Mera Costas, Guillermo J. Pérez Casanova, Ignacio Tébar Rubio-Manzanares, Sara Hidalgo García, Vicent Bellver Loizaga, Isabel Ferrándiz Armero, Garikoitz Gómez Alfaro, Iratxe Hernández Simal,

Bárbara Ortuño Martínez, Aurelio Velázquez Hernández, Marcela I. Lucci, Pablo Aguirre Herráinz, Lidia Bocanegra Barbecho, Élodie Das Neves, Jorge de Hoyos Puente, Aubin González, Christof Van Mol, Toni Morant i Ariño, Rubén Pallol Trigueros, Roberto Gallardo Pérez, Santiago de Miguel Salanova, Daniel Oviedo Silva, Alejandro Pérez-Olivares, Jose $M^{a}$ Rodríguez-Vigil Reguera, Luis Manuel Sanmartín Cava, Matthew Kerry, Gloria Román Ruiz, Julio Lisandro Cañón Voirin, Paula Escribano Castaño, Francesco D’Amaro, Rosy Rickett, Pablo Giori, Ignacio Suay-Matallana, Mar Cuenca-Lorente, Juan Marcos Bonet Safont, Miquel Carandell

Baruzzi, Elvira Fente, Fátima Ferni Álvarez, Clara Florensa, Carlos Fuertes Muñoz, Fernando García Naharro, Andrea Graus, Imanol Herreros Chandro, Rubén Mirón González, Òscar Montero

Pich, María Rosa Muñoz Bell, Carles Sirera Miralles, Lorena B. Valderrama, María Valls, Natxo Escandell, Cristina Alquézar

Villarroya, Sandra Blasco Lisa, Juan Carlos Colomer Rubio, Elena Díaz Silva, Cristian Ferrer González, Rosario Fombuena Borrás, Jon Martínez Larrea, Antonio Muñoz de Arenillas Valdés, Alfonso Natividad Hernandis, Joel Sans Molas, Fátima Martínez Pazos. 
1.Teoría e Historia del poder: el Estado y sus instituciones

Inmaculada Adrián Gálvez - Las Procuradoras a Cortes. Una aproximación prosopográfica a las elites políticas femeninas del franquismo.

Ángeles Mera - De políticas y personas: la Ley $22 / 78$, de 26 de mayo, sobre la despenalización del adulterio y el amancebamiento.

Guillermo Pérez Casanova - El europeísmo de entreguerras, ¿una alternativa al Estado?.

gnacio Tébar Rubio-Manzanares - Gobierno e individuo. Algunas

posibilidades teóricas del concepto de "Gubernamentalidad".

2. Corporalidad, emoción y experiencia: la construcción de las subjetividades entre sujeto y colectividad

Sara Hidalgo García - Corporalidad, emoción y experiencia: la construcción de las subjetividades entre sujeto y colectividad.

Vicent Bellver Loizaga - Escrito en el cuerpo: cuerpos "respetables" en la España decimonónica. Líneas para una posible renovación de la historia sociocultural del XIX español.

Isabel Ferrándiz Armero - De pelos, barrigas y otras disidencias corporales.

Una breve aproximación a la corpografía 'bear'.

Garikoitz Gómez Alfaro - Los fantasmas de Portbou. Regímenes de memoria y emoción.

Iratxe Hernández Simal - La extraña experiencia del espejo que no refleja.

La obra de Juan Muñoz a escena.

3. Movimientos migratorios desde una perspectiva global y comparada

Bárbara Ortuño Martínez, Aurelio Velázquez Hernández y Marcela I. Lucci-

Movimientos migratorios desde una perspectiva global y comparada.

Pablo Aguirre - Colonias emigrantes y comunidades exiliadas en la Francia

de las tres guerras (1914-1945)

Lidia Bocanegra Barbecho - La web 2.0 y el estudio del exilio republicano español:

el análisis de la movilidad social y el retorno a través del proyecto e-xiliad@s.

Elodie Das Neves - La emigración económica española a Francia (1956-1975):

políticas migratorias e inserción.

Jorge de Hoyos Puente - La cultura institucionista en el exilio republicano:

continuidades y fracturas.

Aubin González - Del conformismo al distanciamiento: los grupos católicos

españoles en Francia (1950-1975).

Toni Morant i Ariño y Christof Van Mol - La movilidad internacional de

estudiantes en los siglos XX y XXI.

\section{Transformaciones sociales, políticas y culturales en el mundo urbano contemporáneo}

Rubén Pallol Trigueros y Fernando Vicente Albarrán - Las transformaciones sociales, políticas y culturales en el mundo urbano contemporáneo. Notas sobre los nuevos caminos de la historia urbana en España.

Roberto Gallardo Pérez - La historia de Móstoles (1975-2000): 25 años de

transición y democracia.
Santiago de Miguel Salanova - Movilidad residencial en el Madrid de principios del siglo XX.

o8 Daniel Oviedo Silva - "La extinción de los focos irredimibles": Política de reconstrucción y control en el extrarradio madrileño. El caso de la barriada 13 del Tercio y el Terol.

Alejandro Pérez-Olivares - "Qué hizo usted al estallar el Glorioso Movimiento

17 Nacional?" Sobre viejas identidades y nuevas lealtades en el Madrid de la posguerra.

21 José $M^{a}$ Rodríguez-Vigil - Arquitectura, consumo y sociedad: Galerías Preciados y otros grandes almacenes en la ciudad de Oviedo.

Luis Manuel Sanmartín Cava - Enmarcando el Escrache: conflicto entre narrativas.

5. Construir comunidades

Matthew D. Kerry - Construir comunidades.

Gloria Román Ruiz - Pan blanco para los vencedores, pan negro para los

29 vencidos. La exclusión de los pequeños estraperlistas granadinos del “Nuevo Estado" franquista.

Argentina 1955-1983.

Paula Escribano - Comunidades en el post-socialismo. El caso de una eco-aldea húngara.

43 Francesco D'Amaro - Dos ejemplos de gestión comunitaria del agua (en España e Italia en siglo XX).

Rosy Rickett - Una comunidad imaginada: correspondencia entre los exiliados españoles y los que se quedaron en España, 1952-1975

la nacionalización cultural, la comunidad y los grupos: estado actual, faltas y propuestas.

Ciencia, medicina y sociedad: debates y perspectivas en historia de la ciencia

Ignacio Suay Matallana y Mar Cuenca Lorente - Ciencia, medicina y sociedad: debates y perspectivas en historia de la ciencia.

66 Juan Marcos Bonet Safont - La historia de la ciencia según Paul K. Feyerabend (1924-1994): el caso de Carlos Castaneda.

70 Miquel Carandell Baruzzi - "Hemos venido, hemos visto y se nos ha conquistado": Los congresos como instrumentos de validación en controversias.

74 Elvira Fente: Mujer y ciencia - de hombre defectuoso a ciborg.

Fátima Ferni Álvarez - Intereses y contradicciones en la introducción de la

79 lactancia artificial en España. Alexandre Frias i Roig y la revista Puericultura (1921-1936).

Clara Florensa - Por una ciencia católica en España: la asociación Menéndez Pelayo, una red de contactos.

Carlos Fuertes Muñoz - Propuestas didácticas para una historia social de la odontología a través de las fuentes orales.

Fernando García Naharro - CSIC. el discurso institucional sobre la ciencia una

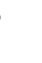
".

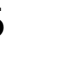


Andrea Graus - Ciencia y pseudociencia: el boundary-work como herramienta historiográfica.

Imanol Herreros Chandro - La visión popular de la ciencia española durante

el franquismo y su impacto en el sistema nacional de ciencia e innovación.

Un análisis desde el mundo de la imagen.

Rubén Mirón - Fuentes archivísticas para el estudio sanitario del exiliado español en el sur de Francia (1936-1945).

Òscar Montero Pich - Intersecciones entre historia local, historiografía y

narración multidisciplinar.

Rosa Muñoz Bello - Los libros de texto de Química en España en la primera

mitad del siglo XIX: escribir, comunicar, negociar, construir ciencia.

Carles Sirera Miralles - Financiando la ciencia en el siglo XIX: el caso del Instituto

Provincial de Valencia 1866-1902.

Lorena Valderrama - Construir un país en la catástrofe: Ciencia, Políticas

Públicas y Terremotos.

7. Los agentes del cambio. De la crisis del franquismo a la consolidación de la democracia: participación social, culturas colectivas y prácticas políticas.

María Valls y Natxo Escandell - Los agentes del cambio. De la crisis del

franquismo a la consolidación de la democracia: participación social,

culturas colectivas y prácticas políticas.

Cristina Alquézar Villarroya - La revista Esfuerzo Común, la crisis de la dictadura franquista y la construcción de una cultura política democrática (1968-1974). Sandra Blasco - asociacionismo femenino y movimiento feminista en Aragón. Juan Carlos Colomer Rubio - Elecciones por tercios y renovación de un consistorio franquista. Valencia (1969-1979).

Elena Díaz Silva - Entre la conciencia femenina y la conciencia feminista:

el movimiento de las amas de casa durante el tardofranquismo.

Cristian Ferrer Gonzàlez - Municipalismo y cambio político (1976-1979):

la construcción de la democracia en el mundo rural.

Rosario Fombuena Borrás - Lagunas de autoridad. Relaciones e influencias entre las "fuerzas del trabajo" y las "fuerzas de la cultura".

Jon Martinez Larrea - El movimiento vecinal en Álava durante la Transición. Antonio Muñoz de Arenillas Valdés - Denuncia y reivindicación a través de la canción en Andalucía.

Alfonso Natividad Hernandis - Del franquismo a la democracia. La aportación del valencianismo político a la ruptura democrática valenciana: 1974-1977. Joel Sans Molas - L'esquerra revolucionària i el seu paper en la mobilització social i el canvi polític dels anys 70 - estat de la qüestió i alguns apunts per al seu estudi.

Fátima Martínez Pazos - El movimiento vecinal en la Galicia Urbana (1970-1980) 
Parte 1.

TEORÍA E HISTORIA DEL PODER:

EL ESTADO Y SUS INSTITUCIONES 


\section{LAS PROCURADORAS A CORTES. UNA APROXIMACION PROSOPOGRAFICA A LAS ELITES POLITICAS FEMENINAS \\ DEL FRANOUISMO}

Inmaculada Adrián Gálvez

Universitat de Valencia

\section{Introducción}

A finales del siglo $\mathrm{XX}$ autores como Joan $\mathrm{M}$. Thomas ponían de manifiesto la escasez de estudios sobre las instituciones políticas franquistas. 'Más cercanos en el tiempo, Mercedes Peñalba o Pere Ysas han vuelto a hacer hincapié en el desconocimiento que se mantiene sobre estas instituciones, sobre todo en lo que se refiere a la etapa conocida como tardofranquismo.

Las razones que se han sostenido para estas ausencias han sido tanto las interpretaciones que sostenían la debilidad falangista, así como las interpretaciones nominalistas que se han realizado sobre las culturas políticas que dieron soporte ideológico al régimen. ${ }^{3}$ Pero este tipo de interpretaciones, que convertían a las instituciones falangistas y a sus protagonistas en actores poco relevantes, ya no se sostienen. ${ }^{4}$ Por el contrario la historiografía más reciente da muestras de un renovado interés hacia espacios antes devaluados como las Cortes franquistas, así como por el estudio de las elites políticas que los conformaban. Así, a los estudios clásicos que han abordado las Cortes como mecanismo institucional del franquismo como los de Diaz-Nosty o Bañón Martínez, se unen en la actualidad a publicaciones como las de Miranda Rubio, Monfort i Coll o Giménez Martínez. ${ }^{5}$ Por lo que respecta a las elites políticas, la figura de los Procuradores de las Cortes ha pasado de ser analizada de forma tangencial en obras de carácter general a formar parte de diccionarios biográficos o trabajos prosopográficos. ${ }^{6}$

1 Joan THOMAS: “La configuración del franquismo. El partido y sus instituciones”, Ayer, 33 (1999), pp. 41-63.

2 Mercedes PEÑALBA: "La Secretaria General del Movimiento como pilar estructural del primer franquismo, 1937-1945". Pere YSAS: "El Consejo Nacional del Movimiento en el Franquismo tardio", ambos en M. Angel Ruiz Carnicer (ed,): Falange. Las culturas políticas del fascismo en la España de Franco (1936-1975), Zaragoza, Marcial Pons, 2013

3 Pere YSAS: “El Consejo Nacional..." pp 365. Ismael SAZ: “Mucho más que crisis políticas: el agotamiento de dos proyectos enfrentados", Ayer, 68, (2007), pp 137-163.

4 Carme MOLINERO: "Falange y la construcción del régimen, 1939-1945. La búsqueda de unas bases sociales ", M. Ángel RUIZ CARNICER (ed.) Falange. Las culturas políticas del fascismo en la España de Franco (1936-1975), Zaragoza, Marcial Pons, 2013. Para C. Molinero en los últimos años el protagonismo falangista en el régimen se ha abordado desde diversas perspectivas.

5 Bernardo DIAZ-NOSTY: Las Cortes de Franco: 30 años orgánicos. Madrid, Ediciones Dopesa, 1972. Rafael BAÑON MARTINEZ: Poder de la burocracia y Cortes franquistas. 1943-1971, Madrid, Instituto Nacional de Administración Pública, 1978. Francisco MIRANDA RUBIO: "Los procuradores de representación familiar en la novena legislatura franquista (1967-1971), Actas $53^{\circ}$ Congreso de la Comisió Internacional per a l'estudi de la Historia i les institucions representatives parlamentaries, Barcelona, 2010, pp.615-637. Aram MONFORT I COLL: “Las Cortes franquistas", op.cit, pp.1040-1062. Miguel A. GIMEENEZ MARTíNEZ: Las Cortes Españolas en el régimen de Franco. Nacimiento, desarrollo y extinción de una Cámara Orgánica, Madrid, Colección monográfias, Congreso de los Diputados, 2012.

6 Emilio J. BANDE FUENTES: “Prosopografía de procuradores castellano-leoneses en el último franquismo (1967-1975)", opcit, pp 1411-1430. Joseba AGUIRREAZKUENAGA y Mikel UROUIOO (eds) Bit-
Aunque con un menor alcance, esta renovación metodológíca y conceptual en la historia política se ha asumido también en los estudios de género y, en concreto, en aquellos que han prestado una especial atención a las elites de las organizaciones femeninas, tanto locales como estatales?

Esta comunicación se centra en la presencia dentro de estas elites de trece mujeres que accedieron al cargo de Procurador en Cortes durante el franquismo. Un reducido pero significativo grupo de mujeres que pensamos puede ampliar el conocimiento sobre el proceso de institucionalización de este régimen.

\section{La institucionalización del régimen. Las elites franquistas}

El principal rasgo de la institucionalización del franquismo fue su nivel de ruptura con e Estado anterior. Sus pretensiones fueron la creación de un estado ex novo, un Nuevo Estado cuyo principal objetivo fue acabar con cualquier vestigio del proceso democratizador emprendido por la II Republica, lo que significaba acabar con la democracia representativa y la pluralidad de partidos políticos. ${ }^{8}$

Esta institucionalización fue temprana pero también lenta y fragmentada. Se inició en julio de 1936 y en abril de 1937, mediante el Decreto de Unificación, Franco agrupó en una sola organización a Falange Española y de las JONS y Comunión Tradicionalista dotando al régimen de un instrumento legal de acción política y de base ideológica. Este Decreto supuso el inicio del proceso de fascistización del régimen ya que se aplicó el ideario ideológico falangista con la aprobación de los Estatutos de Falange. Continuó en 1938 con la confirmación del poder absoluto del Jefe del Estado y así en 1939 acabada la guerra, el Estado franquista quedo definido como "centralista, profundamente autoritario y fuertemente fascistizado". 9

Dentro de ese marco institucional fascista que toma el régimen el 28 de diciembre de 1939 y mediante Decreto, Franco le otorga a la Sección Femenina (SF) el monopolio en "la formación político y social de las mujeres españolas". A partir de ese momento, la que había sido una pequeña organización de mujeres creadas en 1934, lejos de quedar convertida en una fuerza residual, pasa a convertirse en una Delegación Nacional del partido único.

A partir desde este momento y desde esta organización Pilar Primo de Rivera defenderá ese espacio político frente a otras organizaciones falangistas femeninas que dentro del Movimiento habían conseguido una posición consolidada, como el Auxilio Social y la Asistencia al Frente y Hospitales y, a partir de 1941, frente a la reorganización de la rama femenina de Acción Católica (AC).A partir de este momento la SF cumpliría una doble función que articulará a través de un doble discurso ${ }^{10}$. Por un lado se convirtió en el instrumento del régimen para la integración ordenada de las mujeres y, por otro, se convirtió en el único cauce permitido a las elites femeninas para la participación en la acción política.

Con la llegada de los años cuarenta y hasta el final de la ll Guerra Mundial, se abrió un periodo fundamental en la institucionalización del régimen. Este periodo que estuvo marcado

bao desde sus alcaldes. Diccionario biográfico de los Alcaldes de Bilbao y gestión municipal de la dictadura, $3^{\circ}$ vol. Bilbao, Ayuntamiento de Bilbao, 2008

7 Ma Angeles DURAN y Rosa CAPEL (aut.): Mujer y Sociedad en España (1700-1975), Madrid, Ministerio de Cultura,1986. Montserrat DUCH: Dones Publiques. Política i genere a l'Espanya del segle XX Tarragona, Arola Editors, 2005

8 Julián SANZ HOYA: “El Partido fascista y la conformación del personal político local al servicio de las dictaduras de Mussolini y Franco". Historia Social 71, (2011), pp. 107-123.

9 Julian SANZ: " El Partido fascista..." pp 107.

10 Aline BARRACHINA: "Ideal de la mujer falangista. Ideal falangista de mujer" en VV.AA.: Las mujere yla guerra civilespañola, Actas III Jornadas de estudios monográficos, Direción de Aichivo tales, Madrid, pp 211-217. 
por los enfrentamientos y las presiones de los tradicionalistas y católicos con los falangistas, y cuyo origen no era otro que el excesivo protagonismo de la Falange en las instituciones, derivó en la tramitación de dos proyectos legislativos: la creación de las Cortes y la regularización de las Asociaciones.

El primer intento de creación de las Cortes se produjo en 1941 de la mano de Serrano Suñer que presentó el primer proyecto de Ley de Organización del Estado y que contó con la oposición de los tradicionalistas. En 1942 se presentaron dos proyectos alternativos para la constitución de esta cámara: el proyecto tradicionalista fue defendido por el Conde Rodezno y el falangista defendido ahora por José Luis Arrese y que retomaba parcialmente el proyecto de Serrano Suñer. Fue aprobado este último y se promulgó la creación de las Cortes mediante la Ley de 17 de junio de 1942, como asamblea unicameral de elección indirecta estableciéndose una participación limitada y corporativa que tenia como fin la representación de los "elementos constitutivos de la vida nacional", pero no al cuerpo electoral." Esta cámara no se constituyo por primera vez hasta el 17 de marzo de 1943

Ese mismo año fue Eduardo Aunós quien presentó un nuevo proyecto institucional que planteaba modificaciones a la Ley de Cortes, pero esta no sería modificada hasta 1946. Posteriormente sería alterada en dos ocasiones más, 1955 y 1967, todas ellas con un objetivo, la reforma de la participación de las elites que se integraban en la cámara a través de los órganos de representación recogidos en el art. 2 de la Ley de 1942 que establecía la composición y cauce de elección de los Procuradores..12

Inicialmente, el rasgo principal que definía a estas elites políticas era la cooptación, ya que eran designadas y no elegidas, y su fuente de legitimación estaba basada en la victoria de la guerra civil y la unificación ideológica de las fuerzas que en ellas participaron. Las tres modificaciones citadas no fueron nunca encaminadas a modificar su naturaleza corporativa, su falta de renovación y su inmovilismo político pero si fueron intentos de modificar el peso de las fuerzas políticas. Las Cortes se conformaron como un escenario de confrontación desde el cual falangistas, católicos y tradicionalistas escenificaron la confrontación de proyectos ideológicos distintos y que fundamentalmente tuvieron como fin frenar las aspiraciones fascistas de apropiación del Estado a través del partido.13

El 17 de marzo de 1943, con la constitución de la cámara, Pilar Primo de Rivera y Mercedes Sanz Bachiller accedieron a su escaño de Procuradoras como miembros natos del Consejo Nacional del Movimiento. Ambas se integraron en la comisiones de trabajo que tradicionalmente fueron consideradas de influencia falangista como Gobernación, Agricultura, Educación Nacional o Trabajo. ${ }^{14}$

Pero el verdadero reto para el falangismo, tanto masculino como femenino, durante estas décadas estuvo fuera de esta cámara y fue el de intentar dar cauce a la participación pero intentando mantener su control institucional, todo ello en un escenario donde el falangismo en general, y la SF en particular, iban a tener que hacer frente a la pérdida de influencia en la acción social y al descenso en la afiliación.

Las causas de esta pérdida de influencia para la SF fueron varias. Por una parte, la reorganización de la Acción Católica femenina (AC) y, por otra, la posibilidad que se les abrió a las mujeres de crear asociaciones de interés social o cultural, como serían las asociaciones de amas de

11 Frase de Fraga Iribarne citada en Miguel A. RUIZ DE AZUA: “Las elecciones franquistas (1942-1976), Historia 16 Suplemento, Historia Viva Editores, Madrid, 1977, pp 87.

12 Boletín Oficial del Estado $n^{\circ} 200$ de 19/07/1942.

13 Ismael SAZ: "Mucho más que..."pp 137-163; e ID.: "Las culturas de los nacionalismos franquistas", Ayer, 71 (2008), pp. 153-174

14 Miguel JEREZ MIR: Elites políticas y centros de extracción en España 1938-1957. Madrid, Centro de Investigaciones Sociológicas, 1982 casa, y que supusieron una opción alternativa a los cauces gubernamentales de participación para las mujeres en la esfera pública. Y por último, la desmotivación de su propia afiliación que veía como la legislación del régimen y la jerárquica estructura de la SF hacía inviable la tan manida "promoción social".

\section{Los años oscuros.}

A principios de los 40 las presiones de las distintas fuerzas políticas para dar cauce a una cierta participación al margen de las estructuras del Partido llevaron a que el régimen regulara, por Decreto de 25 de enero de 1941, la constitución de asociaciones.

Este decreto permitía la creación de asociaciones que tenían fines culturales, benéficos, deportivos, artísticos o de cooperación entre vecinos y que dependían del Ministerio de Gobernación. ${ }^{5}$ No obstante, significó igualmente la reorganización de la AC bajo la dependencia exclusiva de la Iglesia católica, proceso que culminó en 1946 cuando se permitió la creación de su rama obrera, las HOAC. El objetivo, tanto de la AC como de las HOAC, era reforzar y promocionar a sus miembros en los organismos del régimen.

Este nuevo escenario supuso que la legislación que regulaba la participación social estaba sometida a 3 jurisdicciones distintas: la iglesia católica, el Ministerio de la Gobernación y el Partido, ya que las organizaciones falangistas estaban sujetas a la disciplina de Falange, pero también que la Iglesia tomaba así una situación de privilegio equiparable a la Falange.

Sin embargo este periodo de mayor actividad institucional se frenó con el fin de la II Guerra Mundial. De 1945 y hasta 1956 hubo años de gran inanidad institucional, que Joan M. Thomas ha denominado "los años oscuros", en los que por ejemplo el Consejo Nacional no volverá a ser convocado hasta 11 años después, en $1957 .^{16}$

Ya en la década de los 50, fracasado el proyecto institucional de Arrese, y con la llegada de José Solis a la Secretaría General del Movimiento (SGM), los falangistas lejos de resignarse a perder peso político y social, apostaron por revitalizar la vía sindical y encontraron una nueva vía en la línea del control social y la movilización de las masas, con un nuevo proyecto de participación política: las asociaciones familiares.

Su objetivo fue desarrollar la vía para la participación de las asociaciones abierta en 1941, intentando que estas tuvieran capacidad representativa pero sin nombrar la creación de asociaciones políticas.

En 1957 se produjo una restructuración en la SGM y entre las novedades se encontraba la creación de la Delegación Nacional de Asociaciones. Su primer delegado fue Manuel Fraga Iribarne que dejaría la presidencia del Instituto de Estudios Políticos para presidir este organismo que entre sus objetivos, contaba con dar contenido a las Asociaciones de Cabeza de Familia e intentar que la participación de este movimiento asociativo se realizara a través del Movimiento a lo que se opuso frontalmente el Ministro de Gobernación Camilo Alonso Vega ${ }^{17}$

Esto marcó el inicio de una serie de conflictos por el control de las asociaciones entre la Secretaria General y el Ministerio de la Gobernación, al que se le uniría posteriormente López Rodó. El primero de estos enfrentamientos se produjo con la elaboración de un anteproyecto de Estatuto de Asociaciones que recogía la plena autonomía y la dependencia única de estas asociaciones de la Secretaria General, anteproyecto que finalmente no fue aprobado. El siguiente enfrentamiento llegó con la redacción de un Anteproyecto de Decreto de las Asociaciones de Cabezas de Familia para conseguir "un mayor grado de institu-

15 Este decreto se modificó en por Ley 191/1964 de 24 de diciembre de Asociaciones.

16 Joan THOMAS: “La configuración...”, pp. 41-63.

17 Pedro COBO: "Las asociaciones de cabezas de familia como cauce de representación: un fallido intento de apertura del régimen franquista"- Espacio, tiempo y Forma, Serie V, Historia Contemporánea, 14 (2001), pp. 449 
cionalización a las asociaciones representativas de la familia española" pues consideraban, que si bien la Organización Sindical y el Municipio estaban suficientemente organizados, no ocurría así con la tercera entidad natural, la familia ${ }^{18}$.

En este enfrentamiento Alonso Vega contó con el apoyo de López Rodó, de tal forma que este decreto solo se aprobaría en 1964 y con importantes modificaciones; por un lado estas asociaciones no tendrían ninguna atribución política contrariamente a los deseos falangistas, y tampoco se permitiría autonomía a las asociaciones de la iglesia para proponer candidatos, lo que significó un choque frontal con la iglesia. Tanto falangistas como católicos eran los más interesados en que estas asociaciones tuvieran la competencia exclusiva a la hora de presentar candidatos ya que ambos contaban con una estructura y una organización así como con un personal formado políticamente.

El fracaso de ambos proyectos, Estatuto y Anteproyecto, no hizo renunciar a los falangistas en su intención de seguir tutelando estas asociaciones y se convocaron sendos Congresos de la Familia en 1959 y 1960

Lo cierto es que el movimiento asociativo se empezó a desarrollar en previsión de la participación de la familia en las tareas públicas ya que, según Federico Silva, ya en 1964 se veía próxima la incorporación de los Procuradores familiares. ${ }^{19}$ Pero si bien a la familia le llegó su oportunidad el 14 de diciembre de 1966 con la aprobación de la Ley Orgánica del Estado (LOE) que prevé la inclusión de un tercio de los procuradores por elección directa a través de esta entidad, y la Ley de Representación Familiar de 28 de junio de 1967, la cuestión del asociacionismo no se resolvió hasta 1974 con el Estatuto de Asociaciones Políticas. ${ }^{20}$

\section{El cenit de la institucionalización y las Procuradoras a Cortes.}

Fracasado el proyecto institucionalizador de Arrese en 1957 se produjo un cambio de escenario con la consolidación en el equipo ministerial de los "tecnócrata" y la relativa postergación de católicos, tradicionalistas y falangistas. Este cambio significó que si bien el proyecto institucional del régimen no desapareció por completo de la agenda política si pasó a un segundo plano a favor de la política económica.

Aun así, la cuestión de la institucionalización se retomó en tres ocasiones: 1961, 1964 y junio de 1966, cuando se redactó el Proyecto de Ley al que López Rodó presentó cuatro modificaciones entre las que se encontraba la inclusión en la Ley el derecho al voto para la mujer casada. Este proyecto se consolidó con la entrada en vigor el 10 de enero de 1967 de la Ley Orgánica del Estado, y las posteriores leyes del Consejo Nacional del Movimiento y de Representación Familia. La tramitación de esta última fue muy controvertida, ya que se presentaron 106 enmiendas. Los artículos mas polémicos fueron el seis y el siete que eran los referidos a las condiciones exigidas para ser candidato a Cortes por dicha representación. ${ }^{21}$

Pero el inicio de la década de 60 puso de manifiesto que la capacidad de movilización falangista estaba en sus horas más bajas. Las cifras demostraban el descenso general de afiliación en las organizaciones del Movimiento y la SF no fue ajena a esta crisis, ya que en 1969 contó con solo "2.916 ingresos, ninguno en 19 provincias y por ejemplo, solo 4 en la provincia de Barcelona".22

18 Pedro COBO: “Las asociaciones de....", pp. 437-488

9 Pedro СОВО: “Las asociaciones de...", pp 458 donde cita textualmente "se veía próxima la incorporación de un tercio de procuradores familiaristas" en Federico SILVA MUÑOZ, Memorias Políticas, Barcelona, Editorial Planeta, 1993.

20 Miguel A. JIMÉNEZ MARTINEZ: Las Cortes Españolas en el Régimen de Franco, Madrid, Congreso de los Diputados, 2012 .

$21 A B C$ de 16 de mayo de 1967

22 Ángela CENARRO: “Encuadramiento y consenso en la obra del Movimiento: Mujeres, jóvenes y

obreros", en M. Ángel RUIZ CARNICER (ed,): Falange. Las culturas politicas del fascismo en la España
Este descenso en sus apoyos sociales intentó ser contrarrestado desde el nuevo marco de acción sindical diseñado por Solís con un tímido incremento de la representación femenina en las Cortes en abril de 1961. Con el inicio de la VII Legislatura se incorporó a la cámara Purificación Sedeño y Fuentes desde la Organización Sindical. Esta incorporación se produjo un mes después de la celebración del Primer Congreso Sindical y una vez que se completó el proceso electoral para la renovación parcial de 35 procuradores a Cortes de la Organización Sindical a que se presentaron 85 candidaturas. Designada por cooptación, que no elegida, se incorporó a su cargo en representación del Sindicato de Transportes y Comunicaciones con el inicio de la séptima legislatura el 2 de junio de 1961.

Las claves para entender esta incorporación son varias: la revitalización de la vía sindical por parte de Solís, la creciente industrialización en la que el control por la acción social es clave, y la competencia con los grupos católicos que estaban experimentando un auge de afiliación en sus organizaciones. ${ }^{23}$

Purificación Sedeño era enlace sindical en la compañía Telefónica desde 1947 y posteriormente vocal Jurado de Empresa. Junto a Mercedes Sanz Bachiller fueron las dos únicas Procuradoras en representación de la Organización Sindical, que por otra parte fue el órgano precursor en promover la presencia femenina en la cámara.

En 1961 participó junto a Pilar Primo de Rivera y Mercedes Sanz en la comisión del Leyes Fundamentales que redactó el proyecto Ley sobre Derechos políticos, profesionales y de trabajo de la mujer que presentó Pilar Primo de Rivera en las Cortes el 22 de Julio de ese mismo año. Proyecto de Ley que antes de ser defendido en la cámara por Pilar Primo de Rivera, fue remitido para su revisión al Instituto de Estudios Políticos por decisión personal de esta última. ${ }^{24}$

Tanto Purificación Sedeño como Mercedes Sanz repitieron cargo en la octava legislatura iniciada en junio de 1964. Mercedes Sanz por su condición de miembro del Consejo Nacional en representación de la Obra Sindical, y Purificación Sedeño porque se presentó como candidata a las elecciones sindicales en 1963 por el Sindicato de Transportes y Comunicaciones junto a Elvira Espargallá Gracia, siendo elegida solo la primera. ${ }^{25}$

Pero este proyecto de representación sindical femenino iniciado en 1961 concluyó de forma abrupta con la aprobación de la LOE. A partir de ella serían los 109 representantes de Congreso de la Organización Sindical los que eligieran la representación de este organismo. Esta modificación en el sistema de elección se tradujo en que tanto Purificación Sedeño como Mercedes Sanz no fueron reelegidas por sus compañeros de organización.

Mercedes Sanz mostró su decepción por lo que consideraba un retroceso para la Organización Sindical y para la defensa de la mujer trabajadora, en un artículo publicado en el diario Ya ${ }^{26}$

La VIII legislatura iniciada en junio de 1964, traerá la nueva incorporación femenina a la cámara de Teresa Lóring Cortes, en esta ocasión en representación del Consejo Nacional del Movimiento, para el que había sido designada meses antes en la celebración del X Consejo Nacional. Perteneciente a la estructura provincial de SF como Delegada Provincial en Málaga a la que pertenecía desde 1935, dirigió durante años la Escuela de Instructores de la SF "Isabe la Católica". Amiga personal de Pilar Primo de Rivera será la última Secretaria Nacional de la

de Franco (1936-1975), Zaragoza, Marcial Pons, 2013

23 Rosario RUIZ FRANCO: “Consignas, propaganda y socialización política: los discursos de Pilar Primo de Rivera en los Consejos Nacionales". Memoria e Historia del Franquismo. VI Encuentro de Investigadores sobre el Franquismo, Zaragoza, 2006, pp. 798-812.

24 Entrevista personal con Belén Landáburu, 15 de enero de 2010.

$25 A B C, 5$ de noviembre de 1963

26 Mercedes SANZ BACHILER "La representación sindical en Cortes no tiene a ninguna mujer", $Y a$ 13 de octubre de 1967 
organización y una de las fundadoras en 1977 de la Asociación Nueva Andadura. ${ }^{27}$

A la altura de 1966, y como dijo Herrero Tejedor "la realidad se imponía" y en abril de ese mismo año Purificación Sedeño y Teresa Lóring solicitaron la supresión de las limitaciones establecidas a la mujer en la Ley de 22 de julio de 1961 sobre derechos de la mujer. Ya en solitario Purificación Sedeño presentó un ruego al ministro de justicia con relación al acceso a la mujer a los puestos de Juez, Presidente, Vicepresidente y Secretario de los Tribunales Tutelares de Menores. Estas limitaciones a la carrera judicial que fueron modificadas mediante la Ley de 28 de diciembre de 1966, que se presentó en el Consejo de Europa por Teresa Lóring que, además de Procuradora, era en esos momentos Subdelegada Nacional de la SF.

En ese mismo año Purificación Sedeño integrada en las Comisiones de Justicia y Leyes Fundamentales presentó diversos ruegos solicitando la modificación de varios artículos de la Ley de enjuiciamiento civil. También participó en la comisión de Hacienda para tratar las retribuciones de los funcionarios.

Hasta la aprobación de la LOE y de las Leyes de Representación Familiar y del Consejo Nacional, no se incrementó el número de mujeres Procuradoras, pero sí que se nombró a la primera mujer Directora General de Enseñanza Media $M$ a Ángeles Galino Carrillo que procedía de las filas de la $\mathrm{AC}^{28}$. Pero el alcance de su aplicación fue diverso: institucionalizaron el Consejo Nacional, significaron el desarrollo completo de los cauces de representación franquistas "familia, municipio y sindicato" y fueron un elemento de movilización de las bases sociales femeninas, ya que para la mujer española supuso el acceso al derecho de ciudadanía política puesto que pasaba a ser electora y elegible, y para el caso concreto de su participación en la política nacional supuso la apertura a la incorporación más numerosa de la cámara.

En definitiva estos proyectos vendrían a dar respuesta a las dos grandes cuestiones que habían marcado la política franquista desde mediados de la década de los cuarenta: su institucionalización y el principio de representación y desarrollo político, siempre dentro del marco de la "democracia orgánica" y fuera de cualquier intento democratizador.

Al mismo tiempo significaba una nueva perspectiva de participación para la SF que no fue desaprovechada por Pilar Primo de Rivera, al contrario, fue la oportunidad de recuperar posiciones de poder dentro del entramado institucional del régimen, que había ido perdiendo en la década anterior y que como el resto de falangistas, se resistía a perder. De hecho desaparecida la representación femenina sindical, la apertura que posibilitaba la controvertida vía del tercio familiar fue ampliamente manipulada por el falangismo en general y por la SF en particular.

Y así, con la constitución de la IX Legislatura el 16 de noviembre de 1967, la gran expectación de esta legislatura fueron la incorporación de los 108 Procuradores en representación del tercio Familiar y la presencia femenina entre sus componentes pues se produjeron cuatro nuevas incorporaciones: Mónica Plaza, Ana Ballenilla, Josefina Veglison y Belén Landáburu, estas cuatro mujeres pertenecían todas a la estructura nacional o provincial de la SF.

Mónica Plaza accedió como miembro del Consejo Nacional tras una larga trayectoria dentro de la SF y en la Administración Local. Fue la mujer más joven en acceder a un cargo de la política municipal al ser elegida concejala del Ayuntamiento de Palencia con 25 años. Tanto Ana Ballenilla como Josefina Veglison y Belén Landáburu, accedieron en representación del tercio familiar, y el programa que presentaron era muy esclarecedor, pues su objetivo era llevar a la cámara "el ideal joseantoniano de concepción del Estado" según declaró Belén Landáburu. ${ }^{29}$

La presencia de estas mujeres en la política nacional fue reivindicada por el franquismo como un elemento de modernidad y de evolución del régimen, y de ellas se destacaron valores com-

27 La Asociación Nueva Andadura fue legalmente constituida en noviembre de 1977

28 Catalogo exposición "100 Mujeres del siglo XX que abrieron el camino a la igualdad en el siglo XXI".

Consejo de la Mujer de la Comunidad de Madrid. Madrid. 2001.

29 "Dos mujeres en las Cortes", El Alcazar 21 de octubre de 1967. patibles entre su concepto de feminidad y el desempeño de la función pública, pero sin ninguna intención de competitividad, puesto que como dejó claro Josefina Velasen: "la acción polític legitima para la mujer debía ser una colaboración nunca una competencia para el hombre".30

El otro factor que hizo que el inicio de la IX legislatura cobrara mayor interés, fue la elección de los representantes familiares, porque se les interpretó como una vía para la participación de candidatos independientes. No obstante la composición definitiva de este grupo puso de manifiesto la falta de renovación de las elites y el continuismo del régimen ya que "dos de cada tres procuradores de las nuevas Cortes lo había sido en las legislaturas anteriores". Otro elemento a tener en cuenta fue el perfil de los 316 candidatos que se presentaron, incluidas las nuevas procuradoras, ya que este era muy definido puesto que la mayoría ejercía profesiones liberales o era funcionario y contaban con un nivel económico que les permitió afrontar los gastos del proceso electoral. Todo esto se tradujo en que a las siguientes elecciones en $1972 \mathrm{e}$ número de candidatos descendió abrumadoramente.

A pesar de ello, entendemos que un reducido número de los componentes de este grupo planteo un reto tanto a la Cámara como al Ministro de Gobernación, ya que para escapar de rígido funcionamiento de la cámara e intentar coordinar sus acciones proyectaron reunirse fuera del hemiciclo para establecer una estrategia conjunta, reuniones que dieron comienzo en 1968 y que se celebraron en diferentes localidades españolas, grupo al que la prensa de la época denominó como el de los "trashumantes". En la segunda reunión que celebraron en febrero de 1968 se unieron a este grupo dos Procuradoras Josefina Veglison y Belén Landáburu.

Pero lo cierto es que a la altura de 1967 , el impacto que todas estas medidas tuvieron sobre los grupos políticos, cuya pretensión era dar salida a la pluralidad sin recurrir al sistema de partidos, se demostró fracasado. Las bases ideológicas del régimen se encontraban frag mentadas y alejadas de la homogeneidad característica de un bloque de poder, pero, aun así, compartían la finalidad de objetivos que no eran otros que ampliar la base social legitimadora del régimen y el modo de articular la representatividad y dar vigencia al corporativismo sin recurrir a los partidos políticos. La cuestión de fondo no será otra que el "como" y "desde donde" se debía llevar a cabo la unidad política del Movimiento. En definitiva, la aplicación de este paquete de medidas institucionalizadoras no consiguió dar salida a los intentos integradores, y el resultado fue la incapacidad de estas elites para mantener una unidad de acción. ${ }^{3}$

Esta incapacidad y fragmentación se fue haciendo igualmente evidente en la representación femenina de las Cortes a la hora de fijar posiciones respecto a proyectos políticos tan importantes como el del nombramiento de Juan Carlos de Borbón como sucesor en 1969, en cuya votación Mónica Plaza se abstuvo. ${ }^{32}$ Con la X y última legislatura de la cámara se incorporaron Ana Bravo, Monserrat Tey, Mercedes Sanz Punyed, Carmen Cossio y Pilar Careaga. Esta última contaba con una larga trayectoria política en el tradicionalismo iniciada en las filas de Renovación Española,y que luego desarrollo en la Diputación y como Alcaldesa del Ayuntamiento de Bilbao. Se incorporó a la cámara por el tercio municipal a instancias del Ministro de Gobernación Camilo Alonso Vega.

Monserrat Tey y Mercedes Sanz Punyed se incorporaron como miembros del Consejo Nacional, ambas procedentes de la estructura provincial de SF. Otra de las incorporaciones fue la de Ana Bravo, en este caso por el tercio familiar, pero también procedente de la estructura provincial de SF ya que en esos momentos era la Delegada Provincial de la organización en Sevilla.

La última representante del tercio familiar fue Carmen Cossio. Accedió a las Cortes desde el tradicionalismo enfrentándose a la candidatura oficial desde su cargo de Consejera Provincia del Movimiento, pero sin estar afiliada a la SF. Participó en 1970 en la celebración del Congreso

$30 A B C 19$ de septiembre de 1971 .

31 Ángel GARRONERA MORALES: Autoritarismo y control parlamentario en las Cortes de Franco. Mur-

cia, Universidad de Murcia, 1977.

32 BOC nº 1061 , página 25893 
Internacional de la Mujer en el que presentó una ponencia en la que hizo una encendida defensa del asociacionismo femenino.

El escenario que presenta esta legislatura está caracterizado por dos rasgos. Por un lado la fragmentación en el grupo de Procuradoras es ya evidente, pues la SF ya no monopolizaba los cargos con representación femenina, e incluso no duda en escenificar en esta cámara las diferencias existentes entre ellas, como la protagonizada entre Monica Plaza y Carmen Cossio. ${ }^{33} \mathrm{EI}$ otro es la revitalización del Consejo Nacional como vía de acceso a la cámara, puesto que a las ya citadas hay que unir a Belén Landáburu que en esta legislatura simultaneo su cargo Procuradora por el tercio Familiar con el de Procuradora por el Consejo Nacional, del que además fue Secretaria Segunda y miembro de la Comisión Especial de Derechos y Libertades.

Aunque a principios de esta legislatura las Procuradoras declaraban que eran "un frente unido sin imposiciones", dando muestras de un elevado grado de cohesión como grupo de poder dentro de la cámara, la fragmentación y el nivel de ruptura se hizo patente en la necesaria toma de posición respecto de los dos grandes proyectos políticos del final de la dictadura, la Ley de Asociaciones y la Ley para la Reforma Política.

Respecto a la Ley de Asociaciones votada en 1974, las posturas más inmovilistas fueron adoptadas por Pilar Primo de Rivera, Teresa Lóring y Mónica Plaza, que votaron en contra de esta Ley. Esta negativa inicial no les impediría que en 1976 después de que Fernández-Miranda impulsara, a través de la Comisión de Reglamento de las Cortes, el funcionamiento de los grupos parlamentarios, se adscribieran a las dos asociaciones que presentaban una línea más continuista y próxima al bunker.

Teresa Lóring y Pilar Primo de Rivera se integraron en Acción Institucional y Mónica Plaza en Unión del Pueblo Español. Esta última liderada por Adolfo Suárez y que posteriormente junto a otras asociaciones fundarían el partido de Alianza Popular. Ana Bravo y Mercedes Sanz Punyed se abstuvieron, solo Carmen Cossio y Belén Landáburu votaron a favor de la ley que regulaba las asociaciones políticas.

Nuevamente la fractura entre el grupo femenina de Procuradoras se hizo patente con la tramitación de la Ley para la Reforma Política. Previamente a su llegada al pleno de las Cortes, el Consejo Nacional emitió informe favorable aprobando el texto por 80 votos a favor, 6 abstenciones y 13 votos en contra pero incorporando la sugerencia realizada por Fernando González de la Mora que intentaba asegurar la representación corporativa. De esta forma el Consejo Nacional asumía el bicameralismo y el sistema parlamentario de sufragio universal pero entendía que el Senado debía constituirse como la cámara que "asegure la presencia de la representación de intereses económicos, sociales, culturales y profesionales". ${ }^{34}$

En su tramitación en el pleno de las Cortes, mientras que Belén Landáburu fue uno de los cinco miembros que componían la Ponencia encargada de defender esta Ley en las Cortes, Monserrat Tey junto al grupo de Procuradores de Acción Institucional y, siguiendo la dirección marcada por el CN presentaron enmiendas intentando que se reforzara el papel del Senado. ${ }^{35}$ Otra de las Procuradoras que también presentó enmiendas al artículado de esta Ley fue Carmen Cossio, quien junto al Grupo Parlamentario Independiente, defendió la inclusión de un Preámbulo en el articulado, enmienda que finalmente fue desestimada.

A la hora de la votación del Proyecto de Ley, Teresa Lóring, Mónica Plaza y Pilar Primo de Rivera se abstuvieron y las cinco restantes procuradoras dieron su voto afirmativo a la Ley que puso fin a la dictadura franquista.

33 ARRIBA 1 de mayo de 1975

34 "Reforma Constitucional. Proyecto de Ley para la Reforma Política". Catalogo de Publicaciones de la Administración General del Estado, Ministerio de la Presidencia, Madrid, 1976.

Los cincos miembros designados fueron: Belén Landáburu, Lorenzo Olarte, Fernando Suarez, Noel 35 Los cincos miembros designados
Zapico y Miguel Primo de Rivera.
Varias de estas mujeres intentarían integrarse en la política democrática. Mónica Plaza desde el partido de Alianza Popular presentó candidatura al Senado por Palencia. Carmen Cossio también fue candidata al Senado por Santander, en este caso dentro de las filas del Partido Socialista Democrático como independiente, pero ninguna de las dos resultó elegida. Solo Belén Landáburu formó parte de las primeras Cortes democráticas como Senadora por Designación Real, prerrogativa que desapareció con la redacción de la Constitución de 1978, lo que supuso el fin de su carrera política.

\section{Conclusiones}

Para poder entender plenamente la presencia de estas mujeres hay que partir de un contexto y un marco cronológico que arranca en las primeras décadas del siglo XX. Las primeras décadas del siglo pasado supusieron una quiebra del marco simbólico de las identidades de género tradicionales y un giro radical dentro de las pautas de sociabilidad femenina, su movilización y su politización.

Además fueron los años en los que se constituyeron las asociaciones femeninas tradicionalistas, católicas y falangistas que van a tener transcendencia en el régimen franquista. Este, consecuentemente con su proyecto político fascistizado concederá desde los primeros momentos el monopolio de la acción política femenina a la Sección Femenina de Falange, lo que además pone de manifiesto que la política de género del régimen está íntimamente ligada a su proyecto institucionalizador y legitimador.

Y si bien los estudios sobre estas organizaciones son numerosos, los aspectos más destacados como organizaciones de base femenina han sido sus rasgos comunes, presentando a las mujeres del régimen como un colectivo homogéneo. Atendiendo a sus respectivas bases ideológicas, se ha hecho hincapié en la debilidad falangista, en la función de la organización como elemento de consenso del régimen y por tanto en su dimensión de instrumento al servicio del régimen.

Tomando como referentes a las trece mujeres Procuradoras hemos intentado poner de manifiesto que su presencia no es un anacronismo, ni sus acciones son fruto de un cierto desorden o aporía. Su trayectoria política demuestra que no fueron ajenas a la diversidad de intereses y a la fragmentación de la clase política, sino que es completamente acorde al desarrollo tanto del devenir del partido al que se les exigía absoluta fidelidad como a las necesidades de un régimen al que fueron leales. Como sujetos políticos sus acciones hay que entenderlas a partir de percibir en ellas un compromiso ideológico basado en la lealtad pero también a una "intencionalidad de poder" que asumen en sus estrategias políticas y que las llevó a enfrentarse con otros grupos de la estructura franquista con un objetivo claro, el control de la acción política y social femenina. 


\section{DE POLÍTICAS Y PERSONAS: LA LEY 22/78, DE 26 \\ DE MAYO, SOBRE LA DESPENALIZACIÓN DEL \\ ADULTERIO Y EL AMANCEBAMIENTO}

Ángeles Mera Costas

La política señala vías, opciones, derechos y obligaciones encaminadas a organizar la vida pública de la sociedad en la que vivimos. Para ello se sirve de la ayuda de diversos recursos y mecanismos, así como de una serie de instituciones dedicadas a llevar a la práctica todo aquello que la política establece. Sin embargo, en ocasiones, esas instituciones acaban interfiriendo en cuestiones muy personales del individuo. La consideración generalizada es que determinados aspectos son más privados que públicos, y que cuando la política se inmiscuye en ellos, pueden generarse conflictos. ¿Es su intención regular hasta las relaciones más íntimas y personales de los ciudadanos o estos ámbitos no llegan siquiera a verse amenazados? El propósito de este texto es intentar responder a varios interrogantes: ¿Es real este conflicto? ¿Hasta qué punto afecta la política a la vida cotidiana del individuo? ¿En alguna ocasión llega a inmiscuirse en las esferas más íntimas de su vida? Dentro de los diferentes ejemplos en los que se produce la tensión entre lo público y lo privado, el texto dirige su atención a uno especialmente privado e íntimo, el de las relaciones personales. Cómo la política intenta regularlas a través de la ley. El objetivo preciso de la investigación es analizar el alcance y contenido de la Ley 22/78 sobre la despenalización del adulterio y el amancebamiento y de sus predecesoras, como ejemplo tanto de la distancia entre la teoría expuesta en la norma y su aplicación real, como de la influencia de las instituciones en la vida cotidiana y costumbres de nuestra sociedad. En este contexto no se puede perder de vista la discriminación que sufre la mujer, que no es teórica ni simbólica sino que es la propia legalidad la que la convierte en algo real y reconocido. Una diferencia entre sexos desde la política que ha perdurado sobre el papel hasta fechas muy recientes.

Esta investigación forma parte de un proyecto más amplio, si bien el espacio limitado y el hecho de ser un texto orientado al debate me obliga a realizar un simple esbozo de las líneas de investigación sobre las que trabajo. Se trata de una primera aproximación al tema a través del estudio de un caso práctico, precedido de un breve recorrido histórico-legal sobre la cuestión. En el último apartado se plantean las dudas y preguntas que surgen y que, junto con el debate, permitirán enriquecer el texto y avanzar en la investigación en busca de conclusiones válidas. Se trata de un estudio que parte de una disciplina específica, el Derecho, pero orientado desde una perspectiva histórica y en cuyo desarrollo me apoyo en herramientas de otras disciplinas, como la Sociología. La realidad es compleja e intentar analizarla recurriendo a todos estos mecanismos permite hacerlo de una manera más completa.

\section{Un recorrido histórico por la legislación}

El 26 de mayo de 1978 se publicaba en el BOE la Ley 22/78, sobre despenalización del adulterio y del amancebamiento, a la que se añadía una breve corrección de errores el 2 de junio. Esta ley modificaba, entre otras cuestiones, la consideración del adulterio y del amancebamiento como ilícito penal y surgió a raíz de los llamados Pactos de la Moncloa de 1977, al inicio de la Transición. El objetivo de dichos pactos era conseguir una serie de acuerdos que permitiesen desbloquear la situación económica de crisis que se vivía y avanzar hacia la consolidación de la democracia. Aunque se centraron sobre todo en temas económicos, en un intento de que la crisis no interfiriese en el proceso de construcción democrática, también se acordaron medidas políticas y sociales de calado.' En total fueron cincuenta y una y, no sólo apuntalaron el nuevo sistema, sin que supusieron una revolución para una sociedad recién salida de la dictadura. Además de los que nos ocupan, se reformaron aspectos como la prohibición de la censura previa, la regulación de la venta de anticonceptivos o la ampliación del derecho de reunión y asociación.

Pero hasta llegar a este punto hubo que recorrer un largo camino lleno de altibajos. El Código Penal de 1848 , aprobado el 19 de marzo, incluía en su Libro II,Título X, los "Delitos contra la honestidad", esto es, el adulterio y el amancebamiento. El artículo 349 establecía que "Cometen adulterio la mujer casada que yace con varón que no sea su marido y el que yace con ella, sabiendo que es casada, aunque después se declare nulo el matrimonio". Se castigaba con la pena de prisión menor (llamada prisión correccional en el código de 1870, cuya duración iba desde seis meses y un día a seis años), si bien sólo podía imponerse cuando mediara querella del marido ofendido. Este podía remitir la pena de su consorte en cualquier tiempo, lo que redundaba en beneficio del adúltero Por otro lado, el artículo 339, que añadía una disposición general dentro del capítulo de las lesiones decía lo siguiente: "El marido que sorprendiendo en adulterio a su mujer, matare en el acto a esta o a la adúltera, o les causare alguna de las lesiones graves, será castigado con la pena de destierro (cuya duración era la misma que la de la prisión menor). Si les causare lesiones de otra clase, quedará exento de pena". Estas reglas se aplicaban, en iguales circunstancias, a los padres respecto a sus hijas menores de veintitrés años y sus "corruptores", siempre que aquellas vivieran en la casa paterna.

Este código del 48 ha sido el más duradero en la historia española y la base de los posteriores hasta el de 1995 . Y la rúbrica ${ }^{2}$ ha sido reproducida, y prácticamente su contenido también, con leves variaciones en casi todos los posteriores a él hasta las reformas derivadas de los Pactos de la Moncloa.

En la época anterior a este código, la manera de entender la sociedad y las normas era diferente. El derecho penal entendía que la justicia debía extenderse al ámbito de la conciencia personal es decir, lo legal y lo moral se fundían en un único concepto. La Revolución Francesa introdujo las ideas ilustradas de la razón y el humanismo. A mediados del siglo XIX ya estaba presente en el pensamiento español la idea de reforma y prevención, pese a que prevaleciera la de expiación. La derogación del Código Penal de 1822 prolongó hasta el de 1948 la legislación penal del Antiguo Régimen. Es, además, el primer código que sistematiza las normas penales que existían. Desde el punto de vista político, representaba los principios de la ideología moderada del gobierno de Narváez. Su sistema estructural, basado en libros compuestos de artículos, se mantuvo hasta la actualidad. ${ }^{3}$ En definitiva, su promulgación supuso la aparición de novedades destacadas en el ámbito legislativo, muchas de las cuales se mantuvieron como referencia de códigos posteriores. ${ }^{4}$ El derecho penal, como creación cultural que es, constituye un factor decisivo a la hora de crear y mantener discriminaciones sociales. ${ }^{5} \mathrm{Y}$ este código del 48 es un ejemplo claro de ello.

"El clima favorable del consenso que hizo posible los Pactos de la Moncloa también introdujo un cambio importante en el clima político del país. Un clima favorable que permitió llegar, sin el trauma de una desestabilización caótica, a la Constitución democrática, aceptada por todas las fuerzas políticas parlamentarias en diciembre de 1978. Esa meta política constituiría, en realidad, la principal pretensión, el objetivo básico de los Pactos de la Moncloa, y es obvio que se alcanzó". Enrique FUENTES QUINTANA: De los Pactos de la Moncloa a la entrada en la Comunidad Económica Europea (1977-1986),Revista ICE, 75 años de política económica española, nº 826 (2005), pp. 52-53.

2 Epígrafe o rótulo.

3 Emilia, IÑESTA PASTOR: El Código Penal español de 1948. Valencia, Tirant lo Blanch, 2011. Revista de Estudios Jurídicos, 2011

4 El Derecho moderno (1848-1850)

5 “... hay que preguntarse, de un lado, de qué manera el sistema de control penal ha contribuido a 
La diferente regulación del adulterio en función del sexo de la persona que lo cometía queda patente en el artículo 349. En primer lugar, porque sólo era delito cuando la que cometía adulterio era la mujer. Si lo hacía el hombre, se llamaba amancebamiento y únicamente se castigaba cuando se trataba de un caso de gran notoriedad, lo que significaba que para poder llevar al hombre a los tribunales no bastaba una mera infidelidad sino que debía existir una relación continuada y, además, pública. En segundo lugar, porque el marido tenía en su mano la posibilidad de perdonar a su esposa adúltera, comunicando ese perdón al hombre con quien lo había cometido, pero nada se decía cuando el caso era el contrario, es decir cuando quien cometía adulterio era el esposo. En tercer lugar, se establecía esa especie de eximente a favor de los "hombres de la casa" que mataban al hombre adúltero cuando se sorprendía a la mujer en flagrante adulterio, o de las hijas solteras a cargo del padre. Nuevamente esta posibilidad queda vetada para las mujeres que, en caso de matar al marido por esta causa, eran condenadas a cadena perpetua. Todo quedaba reducido, en definitiva, a la salvaguarda del honor masculino, bien del marido, bien del padre. ${ }^{6}$ Esta situación era muy similar en los demás países de Europa occidental, cuyas legislaciones eran afines.

Este estado de cosas se mantuvo sin variación hasta la llegada de la II República. El 15 de abril de 1931, el Gobierno provisional, en una de sus primeras actuaciones, anuló el Código Penal de 1928, lo que devolvió la vigencia al de 1870, aunque este no dejaba de ser una nueva edición del de 1848 , al igual que uno promulgado en $1850.7^{7} \mathrm{El} 5$ de noviembre se publicó el Código Penal de 1932, de acuerdo con las bases establecidas en la Ley de 8 de septiembre. Este código no fue sino una reforma realizada sobre la base del antiguo de 1870 , al que se le introdujeron una serie de modificaciones. ${ }^{8}$ La intención era darle un carácter provisional, en espera de la realización de un nuevo cuerpo legal, que nunca llegaría a realizarse.

crear y reforzar las distinciones injustas entre los géneros en detrimento del femenino y, de otro lado, cómo dicho control ha tratado a las mujeres individuales con relación a la clase persona de sexo femenino. Ha mantenido y acentuado la distinción, fuente de discriminación, mediante la regulación normativa de las manifestaciones sexuales, la misma que siempre está en relación a la situación social y cultural en que se encuentran las mujeres. Por esto, sin dejar de ser útil, lo fundamental no es el análisis del poder represivo, sino más bien los diversos y sutiles mecanismos por los que se fabrican los sujetos (entre otros, el sujeto mujer), se les somete a determinados moldes de conducta y se elabora un discurso sobre sujetos y comportamientos que, aún en apariencia critico de la represión, forma parte del sistema que denuncia. Ejemplos relevantes son la regulación... del adulterio respecto al supuesto honor del hombre y de la familia". José HURTADO POZO: Moral, sexualidad y derecho pena. Derecho Penal y discriminación de la mujer: Anuario de Derecho Penal, 1999-2000. http://www.googlebooks.es/books? 1d=ekJXX433U5AC\&pg=PA85\&l-

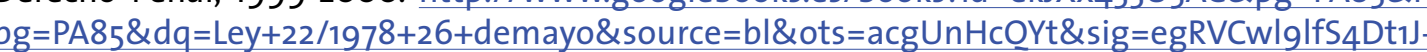
\&ved=oCEkO6AEWBzgK\#v=onepage\&q=Ley\%2022\%2F1978\%2026\%20de\%20mayo\&f=false

6 "Por el contrario, si la mujer era la que atentaba contra la vida de su marido por idéntica causa el resultado de la condena era la cadena perpetua. En este caso no había atenuantes posibles." Sonia GONZÁLEZ GARCÍA: La situación jurídica y legal de las mujeres en la España contemporánea. Las mujeres como sujetos de derecho, http://www.ahistcon.org/docs/murcia/contenido/pdf/14/ sonia_gonzalez_garcia taller14.pdf

7 "El artículo $1^{\circ}$ del decreto tenía este tenor: Queda anulado y sin ningún valor ni efecto, el titulado Código penal de 1928. El preámbulo basaba la medida en "haber sido uno de los mayores desafueros dictatoriales, contrario a los principios básicos de cultura jurídica, el uso y abuso de las ordenanzas penales absolutamente nulas..." JIMÉNEZZ DE ASÚA: Tratado de Derecho penal, Buenos Aires, 1964, I ( $3^{\mathrm{a}}$ ed.), p. 781 .

8 Los motivos políticos y la rapidez de su preparación -escribe uno de sus redactores- recuerdan la Los motivos políticos y la rapidez de su preparación -escribe uno de sus redactores- recuerdan la tución obligó a la reforma oue ocasión el estrecho parentesco entre un Código Penal y la Constiimposibilitarian por largo tiempo la producción de un cuerpo legal enteramente nuevo. Antón ÓNECA: Derecho Penal, Madrid, 1949 , cit, p. 67.
Se realizaron cuatro clases de modificaciones: las impuestas por la Constitución, las correctoras de errores técnicos, las de carácter humanizador y las demás que no cabían en las tres anteriores. Se pretendía conciliar los contenidos del código de 1870 con la recién estrenada Constitución republicana y adaptarlos a los principios del nuevo régimen. Destaca en el texto la humanización de las penas y la introducción de criterios más flexibles en su aplicación.

Las modificaciones directamente relacionadas con la mujer supusieron un punto de inflexión jurídico en nuestro país. En el ámbito privado, el artículo 43 reconocía la igualdad de los sexos en el matrimonio y la disolución del matrimonio a petición de cualquiera de los cónyuges, previa justa causa. La instauración del divorcio (Ley de 2 de marzo de 1932) estableció la igualdad de los hijos, el reconocimiento de la autoridad tanto paterna como materna. En relación con el tema que nos ocupa, el Título $X$ (Delitos con la honestidad) vació de su contenido cualquier rastro de punibilidad del adulterio (la infidelidad pasó a convertirse en causa de divorcio con la consiguiente eliminación del reproche penal) y abolió el artículo 438 , que reconocía al marido una excusa absolutoria si lesionaba no gravemente a la esposa sorprendida en adulterio, así como una atenuación especialísima si las lesiones eran graves o la mataba. Asimismo, en su exposición se aclara que

se ha tocado la médula del Código y se ha ensanchado sobremanera el libre arbitrio de los jueces. Esta modificación tiene un doble designio: hacer menos rígido y más humano el Código de 1870 y ofrecer a los jueces coyuntura para que demuestren ser merecedores de que el nuevo Código por venir les otorgue en plenitud la facultad de escoger las penas apropiadas al caso concreto y al delincuente vivo y efectivo.

El hecho de que la reforma fuera parca es, quizás, la razón por la que esta norma permaneció en vigor hasta 1944, en plena etapa franquista. Eso sí, con la introducción de nuevas reformas para compatibilizarlo con el nuevo orden, que desvirtuarían en buena medida las operadas durante la república. El código fue derogado y sustituido por uno nuevo ese mismo año, código que otra vez volvió a ser una reforma profunda del anterior.

El franquismo volvió a tipificar como delitos, entre otros temas que afectaban directamente a las mujeres, el adulterio y todos aquellos actos que atentasen contra la moralidad. La Ley de 11 de mayo de 1942 estableció la prohibición, que pasó a incluirse en el nuevo código. Así, encontramos el artículo 466 bis a), que castiga con prisión menos a la mujer adúltera y a su amante correspondiente, cuando sabía que estaba casada; el 466 bis b), que hace preceptiva la querella del marido para poder sancionar; y el 466 bis c), que pena con prisión menor el amancebamiento del marido cuando este es notorio, y con la misma pena o con destierro a la manceba. Además, se vuelve a incluir el "uxoricidio por causa de honor". Otra vez pues, y literalmente, se retorna a la misma situación que un siglo atrás. Resulta chocante, además de incoherente, el hecho de que las mujeres, pese a ser de nuevo prácticamente incapaces civilmente, tuviesen una responsabilidad penal grande en ciertos apartados. La norma pena se utilizó para moralizar, orientada a la represión y a la anulación del derecho a la intimidad especialmente en el caso femenino, estableciendo una relación seria entre ley y moralidad. De nuevo prima el honor del marido por encima de los derechos y de la protección de las muje9 "Ese mismo artículo 25 de la Ley política establece la igualdad de sexos. Ello trae, como indeclinable consecuencia, la abolición del famoso artículo 438 , en que se reconocía en favor del marido, en casos de uxoricidio o lesiones por causa de adulterio, una excusa absolutoria o una atenuación especialísima. Esta razón de igualdad de sexos nos ha llevado a irradiar la llamada excusa absolutoria en favor del marido que descubra los secretos de su mujer, establecida en el viejo articulo Motivos, III Modificaciones impuestas por la nueva Constitución, BOE 5 de noviembre de 1932. 
res..$^{10}$ Este régimen devolvió a la mujer a su papel de madre y esposa, la obligó a permanecer en el hogar paterno y eliminó la posibilidad de divorcio, eso sí, para ambos sexos.

En momentos posteriores de esta etapa se publicaron dos nuevos códigos. El primero, Texto Revisado de 1963 según la Ley de Bases de 23 de diciembre de 1961, con menos modificaciones que la del 44, afectó a la parte especial sobre todo y tenía como objetivos adaptar la legislación a la nueva realidad social e introducir los avances y técnicas penales. Por lo que a este artículo respecta, la única modificación señalada es la eliminación del uxoricidio." El segundo, Texto Refundido de 14 de septiembre de 1973, se limitó a introducir las modificaciones realizadas por la Ley de 15 de noviembre de 1971, ninguna de las cuales guardaba relación con el tema que se trata. La cuestión del adulterio pues, continuó como hasta entonces.

Y con este panorama se llegó a la Ley $22 / 78$, de 26 de mayo, sobre despenalización del adulterio y del amancebamiento. Este proyecto quedó recogido en los Pactos de la Moncloa, en su segundo programa referente al acuerdo sobre actuación política y jurídica, aprobado por el Congreso el 27 de octubre del 77 y por el Senado el 11 de noviembre del mismo año. La infidelidad pasó a ser, desde entonces, una cuestión personal..$^{12}$ Se derogan los artículos 449 a 452 del Código Penal de 1973, con lo que desaparece el capítulo llamado "adulterio". ${ }^{13}$ La ley de 7 de octubre, que introduce una reforma parcial en el código, elimina el concepto de honestidad como criterio valorativo. Esta es una de las reformas con valor simbólico encauzadas a través de los Pactos de la Moncloa como factor de consenso en torno al nuevo sistema político. Hemos dicho que estos pactos surgieron durante la transición democrática, largamente esperada, pero cuya llegada coincidió con una situación de crisis internacional, intensa, grave y compleja. La coincidencia de ambas se consideró un problema político fundamental, que debía afrontarse con la participación activa de todas las fuerzas políticas que habían obtenido representación parlamentaria en las elecciones del 77. Para ello se necesitaba el beneplácito de todas ellas, lo que implicaba la necesidad de incorporar un nuevo sistema de valores concordante con la realidad social y desterrar un falso entendimiento de los valores tradicionales. Entre otras cuestiones, era requisito la integración progresiva de la mujer en la vida colectiva. En relación con esto y con el tema específico del texto, hay que recordar que alrededor de los setenta se desarrolla la segunda gran etapa del movimiento feminista. Basta citar, como ejemplos, que la ONU declaró 1975 como Año Internacional de la Mujer y se manifestó contraria a la discriminación femenina, o que en diciembre de ese año se celebraron en España las primeras Jornadas de Liberación de la Mujer. Existía pues, una atmósfera de cambio que necesariamente tuvo que llegar a las instancias políticas, a través del diálogo entre las fuerzas dominantes. Ese clima favorable de consenso que se consiguió varió también el clima político, y permitió la aprobación de cuestiones como las relativas a la situación de la mujer, entre otras. La Ley 22/78

10 "Las leyes penales franquistas asimilaban las mujeres a los incapaces y además sólo daban protección a las mujeres que eran consideradas "honestas", ya que si no lo eran, eran tratadas como un simple objeto, a disposicion del varon, quien podia incluso llegar a violar a su mujer sin temor a ser sancionado penalmente". Ma. Ángeles MORAGA GARCíA: Notas sobre la situación jurídica de la mujer en el franquismo, Universidad de Alicante, Feminismo/s 12, diciembre 2008, pp.229-252.

11 Legislación penal y penitenciaria española entre 1936 y 1975, Ignacio SERRANO BUTRAGUEÑO, Instituto de Estudios Penales Marqués de Beccaría.

12 "Así, el Proyecto de Código Penal parte del «principio básico de que la intervención de la Ley penal en la esfera de la actividad sexual del individuo debe limitarse a aquellos supuestos en los que con el ejercicio de tal actividad, se causa un perjuicio real e injusto a otra persona o a la comunidad». Consecuentemente el acento de la protección se ha desplazado de la honestidad a la libertad sexual". Juan DE MIGUEL ZARAGOZA, Letrado del Ministerio de Justicia: Criminalización y descriminalización en el periodo de transición política en España, http:// www.mjusticia. gob.es/cs/ Satellite/12923440600.

13 Ley $22 / 78$, de 26 de mayo, BOE $n^{\circ} 128$, 30 de mayo de 1978. contribuyó a igualar el estatus femenino en el ámbito penal y, por extensión, en la sociedad. Este proceso legal culminaría con la llegada de la Constitución y la declaración de ambos sexos como iguales ante la ley.

\section{Algunos casos prácticos}

Durante todo el tiempo que estuvo vigente la penalización del adulterio, numerosos casos fueron llevados a los tribunales, incluso en épocas cercanas a su abolición. En 1976 cuando ya esta legislación daba sus últimos coletazos, casos como el de $M^{a}$ Ángeles Muñoz, en Barcelona o el de Inmaculada Benito, en Zaragoza (cuyo caso fue sobreseído), llegaron a las páginas de los periódicos de la época y provocaron manifestaciones masivas de grupos feministas frente a los juzgados. ${ }^{14}$

Como ejemplo de lo que pretendo hacer a mayor escala tomaré uno de los últimos casos que fueron juzgados en nuestro país por esta causa. El 16 de noviembre de 1976 se celebró, ante la sección primera de la Audiencia Provincial de Madrid, el juicio contra Cecilia G. F. y Avelino M. R. De acuerdo con el escrito de la acusación particular (llevado a cabo por el abogado Fernando Muñoz Perea), ambos se conocieron a finales del 73, cuando ella entró a trabajar en el hotel del que Avelino era encargado. Los dos estaban casados. ${ }^{15}$ Tras un tiempo en el que mantuvieron una relación de amistad, pasaron a convertirse en amantes. El 9 de diciembre de 1975, avisada por el marido y el cuñado de la mujer, la policía sorprendió a la pareja desnuda y en la cama del apartamento que Cecilia tenía alquilado. Como pena, el acusador solicitaba seis años de prisión para cada uno (la pena máxima establecida) y una indemnización de varios millones de pesetas para el marido agraviado. El abogado defensor, Juan Ignacio Ortiz de Urbina Pinto, por su parte, negaba los hechos expuestos y pedía la libre absolución de Cecilia. Hay que señalar que Cecilia y su marido ya se encontraban separados. ${ }^{16}$ Finalmente, la pareja fue condenada a siete meses de prisión y a pagar una indemnización conjunta de cincuenta mil pesetas. La sentencia consideraba probados los hechos de adulterio y que estaban comprendidos en el supuesto del artículo 449.

Ya hemos dicho que este proceso, junto con otros, detonó reacciones de la opinión pública a favor de la eliminación del Código Penal de los delitos que discriminaban a la mujer. El abogado de la acusación, Fernando Muñoz Perea, era uno de los que se mostraban radicalmente en contra de la consideración del adulterio como delito. ${ }^{17}$ Debates publicitarios en RTVE, cartas al director en referencia a este tema... La mañana en que se celebraba el juicio contra Cecilia, alrededor de mil mujeres se manifestaron frente al Palacio de Justicia con pancartas en las que pedían la abolición del adulterio, el reconocimiento del divorcio y, en definitiva, la igualdad de la mujer. La Policía, que custodiaba el Palacio, la disolvió varias veces, lo que pone de manifiesto el ambiente en el que se vivía el proceso. Además, el escrito que recibió la Comisión General de Codificación del Ministerio de Justicia manifestaba la opinión extendida de que esa discriminación legislativa daba lugar a actuaciones contrarias a la dignidad de las personas.

14 "Poco antes de comenzar el juicio, un grupo de mujeres entregó un escrito en la Comisión General de Codificación (Ministerio de Justicia),avalado por más de 12.000 firmas, en el que solicitan la supresión del artículo 449 del Código Penal..., por considerarlo injusto y discriminatorio". Madrid, 16. "También en Madrid: Una mujer juzgada por supuesto delito de adulterio. Grupos feministas se manifestaron repetidas veces contra la existencia del referido delito. La Vanguardia, miércoles, 17 de noviembre de 1976, pp.13.

15 "A. M. R. casado, quien, por su cargo, sabía igualmente el estado civil de la nueva empleada”. Ibid., pp. 13.

16 "Por lo tanto se puede deducir que el marido agraviado ha puesto en marcha el aparato judicial con el único fin de vindicar su honor". El Pais, viernes, 12 de noviembre de 1976.

17 "Es una aberración que el adulterio sea una figura jurídica, más aún en un país donde no existe el divorcio. A lo más el adulterio podría ser determinante de una alteración del vínculo matrimonial". El País, viernes, 12 de noviembre de 1976. 
Este caso no fue el único que consiguió publicidad en la prensa. Ma Ángeles Muñoz, en Barcelona, cuyo marido la había abandonado con una niña de dos meses, fue acusada por este de adulterio al saber que estaba embarazada. La autoridad judicial pretendía poner a su hija bajo la custodia de los abuelos paternos. Unas mil mujeres se manifestaron por el barrio del Besós hasta la Avenida de la Meridiana, frente al domicilio de aquellos, exigiendo que se retirara la denuncia contra $M^{a}$ Ángeles e invocando frases como "Jo també soc adúltera" $y$ "No a las leyes que discriminan a la mujer". El día anterior, otra concentración había finalizado en la Plaza de Cataluña. Además, L'Associació Catalana de la Dona se encargó de recoger firmas para enviar al Ministerio de Justicia con la petición de amnistía para los hechos delictivos discriminatorios y la derogación de las leyes que los penalizaban ${ }^{18}$. Y así, otras muchas, algunas de ellas duramente reprimidas por la Policía. ${ }^{19}$ Es obvio que, al menos para muchos sectores, esta norma era obsoleta e impracticable ya en la sociedad de esa época.

Pese a su fecha, ya tardía, el juicio culminó con una sentencia condenatoria.

\section{Algunas consideraciones finales}

Hemos visto que, desde que existen leyes penales en sentido moderno, la situación de la mujer en su plano más personal ha estado sometida a claras diferencias respecto a la de los hombres, con la única excepción de la ll República, que mostró su intención de corregirla. También que esta orientación se ha mantenido hasta fechas muy cercanas, y que el cambio fue posible porque las circunstancias económicas y sociales fomentaron una política de unión y acuerdo. Se trata de un ejemplo claro en el que observar cómo lo que unos legisladores plasman en una norma acaba por afectar a las esferas más íntimas de una persona. Sin embargo, se trata de una injerencia en la vida personal que no ataca a todos por igual, ya que las consecuencias para el sector femenino son notoriamente más negativas que para los hombres. Esta situación discriminatoria ya desde la ley no deja de ser un reflejo de la consideración tradicionalmente inferior de la mujer por parte de la sociedad y del deseo de relegar su pape a la faceta de esposa, madre y ama de casa. En una historia poblada de sociedades en las que mayoritariamente las mujeres gozaban de menores libertades y derechos que los hombres, veían reducidas o eliminadas sus posibilidades de formarse y elegir empleo o donde sus opiniones no se tenían en cuenta (cuando no eran tomadas como asunto cómico), no es extraño que su sexualidad también se viera sometida a control.

La consideración de la mujer como una niña en sus capacidades y habilidades y como posesión de un hombre adulto, bien del padre o del hermano, bien del marido, hace comprensible que la ley también quisiera jugar su papel, limitando sus actuaciones y regulando sus comportamientos. Cuestión aparte es que se haya mantenido hasta casi las puertas del siglo XXI, apenas veinte años antes. Los casos de $M^{a}$ Ángeles o de Cecilia ponen de manifiesto que la sociedad ya estaba cambiando. Que los pequeños pasos de las mujeres que gestaron la igualdad ya encontraban eco entre los ciudadanos. Aunque sobre el papel la mujer siguiera considerada de la misma manera que siglo y medio antes, en la calle la opinión era distinta. Las circunstancias económicas y coyunturales que fueron variando las funciones de la mujer chocaban con ese control de la vida privada. Prueba de ello son las manifestaciones públicas que provocaban estos casos. La reacción legal tan tardía puede encontrarse, en mi opinión, en el hecho de que la ley nunca es precursora. Los grandes cambios legales, cuando se producen, están motivados porque la sociedad los está reclamando desde más o menos tiempo atrás. Y en cuanto al aspecto femenino, no ha sido distinto.

A partir de aquí, y sin perder de vista lo expuesto en los párrafos anteriores, se plantean

18 "Crece la solidaridad con María Ángeles", Diario de Barcelona, 17 de noviembre de 1976, p.5.

19 "Trabajo: mujer de la limpieza", Diario de Barcelona, 10 de noviembre de 1976, p. 5. preguntas a las que me gustaría encontrar respuesta. ¿Qué importancia real tenía la penalización del adulterio en la vida de las mujeres? ¿Fueron muchas las denuncias que llegaron a los juzgados? ¿Cómo eran las denuncias? ¿Existen diferencias territoriales? ¿En función de que el adulterio se cometiera en la ciudad o en el campo? ¿En ciudades grandes o pequeñas? ¿Cuántas condenas y absoluciones? La jurisprudencia exigía la prueba del hecho: ¿Era fácil obtenerla o no? ¿Cómo se conseguía? ¿Se cumplían efectivamente las penas de prisión? ¿Cómo regulaban estas cuestiones los países vecinos? ¿La denuncia por adulterio servía como venganza? ¿Había más denuncias reales que falsas? Estas y otras preguntas están todavía a la espera de respuesta y marcan las líneas de investigación por las que espera desarrollarse mi trabajo. 


\section{EL EUROPEÍSMO DE ENTREGUERRAS,} ¿UNA ALTERNATIVA AL ESTADO?

Guillermo J. Perez Casanova

Universidad de Alicante

\section{Introducción}

La unión política y económica de Europa ha estado siempre presente en el pensamiento político e intelectual del viejo continente; no obstante, no fue hasta mediados del siglo xx cuando este anhelo se convirtió en realidad. Este éxito, sin embargo, no debe enmascarar la influencia de otros proyectos anteriores. En este sentido, la experiencia del periodo de entreguerras fue clave para configurar el pensamiento europeísta posterior. El concepto de Europa, lejos de ser unívoco, planteó interesantes debates a lo largo de las décadas de 1920 y 1930 en torno a su naturaleza, límites geográficos, unidad moral, relación con el nacionalismo, etc. Esto nos lleva a plantear la existencia de distintos europeísmos que dibujaron, a su vez, distintas Europas. El Proyecto de Pacto Europeo de Coudenhove-Kalergi y el Memorándum para una unión federal europea, presentado por Aristide Briand en el Consejo de la Sociedad de Naciones (SDN), son los ejemplos más significativos.

La Unión Paneuropea, fundada por el conde austríaco y diplomático Richard N. Coudenhove-Kalergi se configuró como un proyecto para la formación de una Europa unida y una organización transnacional con sede en Viena. Su principal contribución, además del libro programático Paneuropa, publicado en 1923, y la revista homónima, fue el Proyecto de Pacto Europeo que presentó en febrero de 1930, sólo unos meses antes que el Memorándum francés.

Aristide Briand se convirtió en el otro gran protagonista del europeísmo de entreguerras. Si Coudenhove trató de impulsar la necesidad de una unión europea, el objetivo del estadista francés fue trasladar el movimiento europeo a la esfera política. El llamado memorándum Briand se constituyó como el principal punto de referencia del europeísmo de entreguerras, puesto que generó un intenso debate tanto en las cancillerías europeas como en la opinión pública de los países implicados. ${ }^{2}$

Ambos deberían ser considerados, si no lo son ya, como los precursores directos del proceso de integración europea que se inició al finalizar la Segunda Guerra Mundial. A los aciertos y

1 El Proyecto de pacto europeo puede consultarse en Franck THÉRY: Construire l'Europe dans les années vingt, Genève, Euryopa études, 1998, pp. 160-176. Para el Memorándum Briand nos hemos basado en la edición bilingüe francés-inglés del texto que se conserva en el Archivo del Ministerio de Asuntos Exteriores de España, Unión Federal Europea (propuesta de M. Briand), Despatch to

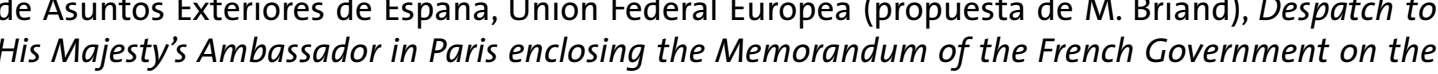
His Majesty's Ambassador in Paris enclosing the Memorandum of the French Government on the (R.818 Exp. 13) Para una mejor comprensión se ha citado directamente al articulado de ambos documentos y se ha traducido al castellano.

2 Aunque tradicionalmente se ha conocido este proyecto como "Memorándum Briand", lo cierto es que fue redactado por el diplomático francés Alexis léger. Henry BRUGMANS: La idea de Europa 1920-1970 Madrid Mo el dilóna (1) carencias de estos dos europeístas durante el periodo de entreguerras debe mucho el movimiento europeo nacido después de 1945 que, esta vez sí, consiguió concretar su proyecto en lo que sería embrión de la actual Unión Europea.

\section{Lociedad de Naciones como marco de referencia}

La delimitación del espacio geográfico de la futura Europa unida ofrecía muchas dudas y vacilaciones. Cuestiones como la inclusión o exclusión del Reino Unido, la URSS o Turquía se convirtieron en esenciales para configurar un concepto geográfico de Europa. A pesar del aparente consenso final respecto a la cuestión británica, era evidente que la discusión sobre los límites geográficos (y políticos) del continente europeo no era, ni mucho menos, el objetivo de los proyectos europeístas durante la primera parte del periodo de entreguerras, sino más bien la piedra de toque o la base para alcanzar ese "lazo federal" del que hablaba Briand. Al mismo tiempo que se trataba este asunto, surgía otra cuestión no menos importante y mucho más práctica: dónde enmarcar y como justificar una federación europea que sería de nueva planta.

Con el final de la Primera Guerra Mundial, los aliados impulsaron bajo el liderazgo de Woodrow Wilson la creación de un organismo mundial que fomentara la cooperación internacional y salvaguardara la frágil paz obtenida en los tratados de París. A mediados de 1919 todos estos anhelos fructificaron, como es sabido, en la Sociedad de Naciones que, con más dificultades de las inicialmente previstas, se puso a funcionar para lograr estos objetivos. La SDN se convirtió, pues, en el punto de referencia de las relaciones internacionales, y todo parecía indicar que el contexto para lograr el acercamiento entre los países europeos era el idóneo.

A pesar de que la SDN fue una organización fuertemente vinculada con el viejo continente -su sede fue establecida en Ginebra, y prácticamente la mitad de los miembros eran europeos en 1930-, en esta primera etapa no se produjeron sinergias entre los partidarios de una Europa unida (con todos los matices que hubo) y los defensores de un modelo intergubernamental de carácter mundial. Es más, puede decirse que hubo un recelo mutuo entre universalistas y continentalistas: hasta el memorándum propuesto por Briand, los miembros de la Sociedad de $\mathrm{Na}$ ciones no mostraron mucho entusiasmo por la posibilidad de una Europa unida, y las principales cabezas del europeísmo consideraban que el organismo mundial era poco menos que un obstáculo que frenaba las aspiraciones de integración europea. ${ }^{3}$ Entre las críticas que se registraron, hay que destacar las que realizó el conde austriaco Coudenhove-Kalergi en su obra Paneuropa.

Coudenhove criticaba que el nuevo organismo internacional no era universal y que no había cumplido los objetivos que Wilson marcó en su génesis. De hecho, el diplomático austriaco subrayaba que, en realidad, la SDN sólo representaba al 50\% de la humanidad en términos de población. Además de cuestionar los fundamentos de la SDN, Coudenhove-Kalerg también discutía el funcionamiento interno de una organización en la que "Suiza no está más cerca de su vecina Austria que de Siam o de Ecuador". En este sentido, el autor de Paneuropa defendía una reestructuración de la SDN que pasaría a estar dividida en cinco continentes políticos: Panamérica, Paneuropa, el Imperio Británico, la Unión Soviética y el mundo mongol, formado por Japón y China. ${ }^{4}$

Dejando a un lado la más que discutible división mundial que realizó Coudenhove, lo que realmente importa es que planteaba la unificación de la humanidad desde abajo, es decir, a partir de las integraciones regionales y no a partir de la dirección de una organización mundial. Si bien Coudenhove-Kalergi no profundizó en esta cuestión, podemos afirmar que, de llevarse a cabo la reforma propugnada por el diplomático austriaco, la independencia de $\mathrm{Pa}$ -

3 Carl H. PEGG: Evolution of the European Idea, 1914-1932, Chapel Hill and London, The University of North Carolina Press, pp. 12-14.

4 Richard N. COUDENHOVE-KALERGI: Paneuropa. Dedicado a la juventud de Europa, Madrid, Tecnos, 2002, pp. $73-85$. 
neuropa respecto de la SDN sería sustancial, que quedaría como un mero árbitro mediador para resolver disputas intercontinentales.

Durante la segunda mitad de la década de 1920 se produjo una mayor voluntad de lograr un acercamiento entre la idea de Europa y la SDN, o entre el continentalismo y el universalismo. Esta aproximación entre las dos corrientes se hallaba, curiosamente, dentro del articulado del Pacto de la Sociedad de Naciones, cuya base partía de la propuesta que realizó Wilson durante los tratados de paz en París en 1919. Sin embargo, el apartado que nos interesa, el artículo 21, se añadió con posterioridad: ${ }^{6}$

Los compromisos internacionales, tales como los tratados de arbitraje, y de las inteligencias regionales, (ententes regionales), como la doctrina de Monroe, que aseguran el mantenimiento de la paz, no se consideran incompatibles con ninguna de las disposiciones del presente acto.

Con este artículo, el organismo radicado en Ginebra daba su beneplácito a posibles ententes regionales que podrían convivir con el organismo internacional de Ginebra. Aunque Coudenhove no citó expresamente el artículo 21 en la obra Paneuropa, si reconoció la necesidad de crear una doctrina Monroe a la europea que abogara por una "Europa para los europeos".7 Sin embargo, en el Proyecto de pacto europeo, presentado en 1930, se afirmaba que "la Federación europea será considerada como entente regional en el sentido [que le otorga] el artículo 21 del Pacto de la Sociedad de Naciones". ${ }^{8}$ Este compromiso, aunque puede parecer un cambio de opinión respecto a lo publicado en Paneuropa sólo seis años antes, en realidad no se alejaba demasiado de la relación entre Paneuropa y la SDN que defendía Coudenhove. Según el artículo 6 del proyecto de pacto europeo, cualquier problema entre las dos instituciones sería solucionado por un tribunal de arbitraje mixto. ${ }^{9}$

El memorándum para la organización de una Unión Federal Europea, impulsado por el gobierno francés y Aristide Briand, también hacía explícita la importancia del artículo 21. En este caso, la relación entre la SDN y la planeada Federación Europea era mucho más estrecha, e incluso se dejaba claro desde el primer momento que la Federación estaría subordinada a los intereses del organismo internacional, hasta el punto de remarcar que "incluso en el propio campo de la organización de Europa, aun así debería coordinar su actividad particular con las actividades generales de la Sociedad de Naciones"..0 Por si no quedaba claro, en el prefacio se aludió de forma velada a otros proyectos que no le otorgaban tanto protagonismo a la SDN como el de Coudenhove: "En ningún caso se propone formar un grupo europeo fuera de la Sociedad de Naciones, sino armonizar los intereses europeos bajo el control y en el espíritu de la Sociedad de Naciones, integrando en su sistema universal un sistema más limitado que sería más efectivo"."

Debido a que Briand presentó su propuesta en el seno de la SDN, resulta lógico que la futura Federación Europea -también denominada Conferencia europea- estuviera tan vinculada con Ginebra y que la sede de la organización estuviera en la ciudad suiza. El ar-

5 Ibid, pp. 78-80.

6 Pacto de la Sociedad de Naciones, art. 21. Recuperado de internet (http://www.ehu.es/ceinik/bdPacto de la so
doc.htm)

7 Richard N. COUDENHOVE-KALERGI: Paneuropa..., p. 77

8 Proyecto de Pacto Europeo, art. 6

9 ld

10 Memorándum Briand, l., observaciones 3 y 4.

11 Ibid., pp. 6-7. tículo 21, por tanto, se utilizó para sustentar jurídicamente la creación de una Federación europea, aunque como hemos visto sus implicaciones fueron muy distintas: mientras Coudenhove-Kalergi simplemente reconocía a la Sociedad de Naciones como un marco de referencia no vinculante, Aristide Briand integró su fallido proyecto europeísta en el seno del organismo mundial.

\section{La arquitectura del europeísmo de entreguerras}

A pesar de las diferencias entre los proyectos europeístas del periodo de entreguerras, es posible encontrar puntos de contacto o un marco común. Desde el siglo XIX, cuando la idea de Europa empezó a consolidarse en los círculos intelectuales, el europeísmo siempre ha estado estrechamente vinculado con el republicanismo y, sobre todo, con el federalismo. Muchos au tores se inspiraron en los modelos federales de Suiza y EE.UU., que se consideraron canónicos y adecuados para lograr la unión política y económica del continente europeo. El país helvético era admirado por su capacidad de integrar en un mismo cuerpo ejecutivo y legislativo cantones con lenguas distintas. Por otro lado, los Estados Unidos de América fueron utilizados como modelo por pioneros de la idea de Europa; es el caso de Víctor Hugo, al que se atribuye, precisamente, la creación del concepto de los Estados Unidos de Europa. ${ }^{12}$

Así pues, no es casualidad que Coudenhove-Kalergi esbozara en el texto de Paneuropa una estructura del poder legislativo muy similar al que recoge la constitución de los Estados Unidos de América: ${ }^{13}$

Paneuropa tendría dos asambleas: una popular y la otra elegida por cada uno de sus Estados. La Asamblea popular se compondría de trescientos diputados, a razón de un diputado por millón de habitantes La Cámara federal estaría compuesta por veintiséis delegados, representantes de los veintiséis gobiernos europeos.

En este modelo no se explica el método de elección para la asamblea popular, por lo que desconocemos si sería por elección directa o indirecta. La composición cámara federal, sería elegida presumiblemente por los Estados miembros.

En su Proyecto de pacto europeo, el conde austríaco modificó en parte la organización política que dibujó unos años antes: si bien mantuvo las dos cámaras legislativas, matizó su composición y funcionamiento. La cámara federal, rebautizada ahora como consejo federal, seguía estando compuesta por representantes de los Estados miembros. Además, se resaltaba que el Consejo era la "Cámara alta de la Federación europea" y el lugar donde se dirigiría la política paneuropea. Esta apuesta por el intergubernamentalismo venía refrendada por la obligación de aprobar por unanimidad todas las decisiones relacionadas con las cuestiones internas de los Estados, siempre que no afectaran a la soberanía. ${ }^{14}$

Como se puede ver, la preocupación por mantener un equilibrio entre el poder de decisión de la Federación y la soberanía nacional de los Estados siempre estuvo presente, aunque Coudenhove era consciente de que la progresiva sustitución del sistema de la unanimidad por el de la mayoría simple era una cuestión de tiempo; el éxito de la empresa unificadora desequilibraría la balanza a favor de los intereses de la Federación y no de los Estados.

En cuanto a la Asamblea federal, el texto del pacto la considera la segunda cámara de los Estados federados. Estaría compuesta por delegados del poder legislativo de cada Estado ele-

12 Rogelio PÉREZ-BUSTAMANTE y Enrique SAN MIGUEL PÉREZ: Precursores de Europa, Madrid, Dykinson, 1998, pp. 53 y ss.

13 Richard N. COUDENHOVE-KALERGI: Paneuropa..., p. 143.

14 Proyecto de Pacto Europeo, art. 15.A. 
gidos por las cámaras nacionales, por lo que la elección sería indirecta. Las funciones reservadas para este cuerpo legislativo incluyen el control financiero, la elección de los principales cargos de la Federación -Canciller, vicecanciller, tesorero y poder judicial-, y además ser el contrapeso a los intereses nacionales que se defenderían en el Consejo federal.

De haberse llevado a cabo la Federación europea propuesta por Coudenhove-Kalergi nos habríamos encontrado con una asamblea muy fraccionada en la que sería imposible imponer la voluntad de los países más poderosos. Por poner un ejemplo, los países más poblados -Alemania, Reino Unido, Francia e Italia- tendrían cinco diputados cada uno de un total de setenta y un escaños.

En suma, se puede decir que el cuerpo legislativo que propuso Coudenhove-Kalergi estaba facultado para colegislar junto con el Consejo -podía tener iniciativa propia- y controlar a éste, si bien la Cámara alta, controlada por los Estados, seguiría siendo la institución principal.

El Memorándum presentado por Briand no fue tan prolijo en detalles como el Pacto Europeo de Coudenhove, si bien en el apartado dedicado al funcionamiento interno de la federación observamos la primera diferencia puntual. Briand expresa la necesidad de crear una "Conferencia Europea" compuesta por representantes de los miembros europeos de la Sociedad de Naciones. Aunque no se refiere a esta conferencia como poder legislativo, la define como un "cuerpo representativo y responsable en forma de una institución regular". ${ }^{15}$ La falta de concreción -la explicación de este apartado ocupa solamente dos párrafos- se repite en el resto de memorándum que, a diferencia del Pacto de Coudenhove, tiene la estructura de un documento de trabajo que pudiera servir de base para lograr acuerdos en reuniones posteriores.

Dicha Conferencia Europea sería el principal cuerpo directivo de la Unión Europea, pero trabajaría conjuntamente con la SDN. ${ }^{16}$ Por encima de este cuerpo legislativo, el Memorándum sitúa un cuerpo ejecutivo que haría las veces de "comité político permanente", que sería el encargado de estudiar el método a seguir para lograr la unión política, económica y social. Además, estaría compuesto por una parte de los miembros europeos de la sociedad ginebrina. Al igual que en la Conferencia Europea, en el Memorándum se insistía en que el trabajo de este comité "tiene que ser llevado en el marco de la Sociedad de Naciones, sus reuniones deber celebrarse en la misma Ginebra, donde sus sesiones ordinarias podrían coincidir con las del Consejo de la Sociedad de Naciones" 17

Esta estructura colegiada fue criticada por algunos autores al considerar que podía interferir en el trabajo instituciones de la propia SDN, que contaba con una Asamblea general, de carácter anual, un Comité ejecutivo permanente en el que participaban tanto miembros natos como no natos. Como se puede ver, de haberse llevado a cabo la Federación Europea, se habría repetido la estructura interna de la SDN, lo que podría dificultar el funcionamiento interno del organismo internacional. ${ }^{18}$ Además, también existirían limitaciones legales, ya que estas instituciones europeas, emanadas de la SDN, no estaban comprendidas en el pacto que fundaba la Sociedad. ${ }^{19}$ Por tanto, se puede afirmar en este sentido que la decisión de Briand de integrar la Federación Europea dentro de la SDN podía tener, según los expertos, un resultado perverso: la propia desestabilización del principal organismo internacional del periodo de entreguerras.

\section{Memorandum Briand, II.A., pp. 12-13.}

610

17 Ibid., II. B., pp. 13-17.

18 Estas críticas fueron difundidas por el británico Arthur J. SALTER en su libro The United States of Europe and other papers (Existe una copia digital en Archive org: 1600208 us. archive 0 rg/13/ of Europe and other papers (Existe una copia digital en Archive.org:
items/unitedstatesofeuo13102mbp/unitedstatesofeuo13102mbp.pdf)

19 Hay que recordar que el artículo 21 hacía compatible con la existencia de la SDN la creación de ententes regionales, pero en ningún caso obligaba a dichas ententes a integrarse dentro de la estructura de la SDN.
A largo plazo la Federación Europea asumiría más competencias y la SDN se convertiría en un organismo mediador sin grandes competencias, próximo paradójicamente a la reforma que planteó Coudenhove-Kalergi en sus escritos. ${ }^{20}$

\section{Interés nacional y cooperación europea}

En los proyectos europeístas que hemos analizado han ido apareciendo cuestiones que ayudan a formar una conciencia europea. Podemos citar varios ejemplos, como la cooperación europea en transportes, la colaboración en temas económicos o la unión aduanera que planteó Coudenhove-Kalergi.

En este sentido, también resulta importante la estructura federal que dibujó el conde austriaco: además de las instituciones ya señaladas, en las páginas del Proyecto de Pacto Europeo se apostaba por crear un distrito federal que haría las veces de capital europea. En esta ciudad - Coudenhove propuso Berna, Bruselas, Luxemburgo o Viena como opciones- se situarían el Consejo y la Asamblea, así como el funcionariado de la Federación y sus representantes. La idea de Coudenhove era crear un distrito análogo al de Columbia en Estados Unidos, o el microestado de la Ciudad del Vaticano. ${ }^{2}$

Esta estructura, que recordaba a la que de cualquier estado federal, se complementaba con la nacionalidad europea que el Proyecto de Pacto Europeo del conde austriaco reservaba para todos ciudadanos europeos. En este sentido, el proyecto europeísta paneuropeo fue uno de los primeros en hablar del reconocimiento de este derecho que desde el Tratado de Maastricht podemos disfrutar todos los miembros de la Unión Europea. ${ }^{22}$

Desde un punto de vista más teórico, ambos proyectos insistían en la necesidad de reforzar los vínculos de unión entre los Estados europeos. Mientras Coudenhove instaba a "despertar el sentimiento de solidaridad europea", algo que se podría conseguir precisamente con la nacionalidad europea, ${ }^{23}$ el Memorándum francés apelaba a la "unión moral de Europa" para superar las dificultades que entrañaba la "falta de cohesión interna" dentro del continente. ${ }^{24}$

Este compromiso con la idea de Europa no se vio, sin embargo, apoyado por una defensa clara y contundente de la cesión de soberanía para lograr el objetivo común que perseguían. Coudenhove y Briand expresaron de manera explícita su compromiso de no comprometer la soberanía nacional de los Estados miembros en sus respectivos proyectos europeístas. Esta decisión fue discutida y debatida por reconocidos europeístas e incluso por gobiernos nacionales.

Antes de entrar en detalle con las críticas, es conveniente clarificar cuál fue la postura de Coudenhove y Briand respecto a la soberanía nacional de los Estados y su integración dentro de una Federación europea que, por hipotética que sea, implica necesariamente cesión de soberanía por este motivo, resulta sorprendente que tanto Coudenhove como Briand aseguraran que no se iba a poner en riesgo la soberanía de los Estados. La historiografía ha dado dos explicaciones complementarias: en primer lugar, se trataría de una estrategia para ganar apoyos y neutralizar los miedos de los antifederalistas. Era evidente que tenían que conseguir el respaldo de los gobiernos europeos a toda costa, sea como fuere. ${ }^{25}$ En segundo lugar, también observamos una

20 Ver Lubor ILEK: “La réforme de la Société des Nations dans les options de Coudenhove”, en Sylvain SCHIRMANN (ed.): Organisations internationales et architectures européennes. 1929-1939, UniverSCHIRMANN (ed.): Organisations in
sité de Metz, Metz, 2003, pp. 93-115.

21 Proyecto de Pacto Europeo, artículos 3 y 4 .

22 Ibid., art. 5 .

23 Ibid., prefacio y comentario art. 5 .

24 Memorandum Briand, pp. 5-7.

25 Ariane CHEBEL D'APPOLLONIA: “European Nationalism and European Union”, en Anthony PAGDEN: The Idea of Europe: From Antiquity to the European Union, New York, Cambridge University Press, 2002, p. 177 . 
indefinición en el discurso europeísta que fue provocado por el doble lenguaje utilizado. Por ejemplo, en el caso de Coudenhove, el conde austriaco sostenía, en un principio, que la entrega de derechos de soberanía era algo inevitable, e incluso en 1923 llegó a asumir que los Estados europeos deberían sacrificar un poco de su independencia nacional. Sin embargo, en 1930, en su Proyecto de pacto europeo, Coudenhove propuso, como ya hemos visto, un modelo federal europeo en el que no estaba previsto ningún recorte en la soberanía de los Estados. ${ }^{26} \mathrm{Además,} \mathrm{el}$ movimiento paneuropeo nunca fue del todo claro sobre su forma de gobierno: se habló de autonomía y de federación, y también se propuso un modelo confederal. El problema de la soberanía nacional, pues, estaba inserto en el propio desarrollo de la idea de Paneuropa. ${ }^{27}$

El memorándum tampoco se caracterizó por la falta de claridad a la hora de transmitir su mensaje, sobre todo en lo referente a la soberanía nacional, ya que primero se propuso un "lazo federal", pero al mismo tiempo se aseguraba que no afectaría a la soberanía de los Estados. Otros autores contemporáneos tacharon de desfasada la concepción de una soberanía nacional que había evolucionado en el trascurso de los siglos. Además, los nuevos tiempos obligaban en parte a superar este marco teórico y a impulsar instituciones que promovieran la cesión de soberanía, como por ejemplo la Sociedad de Naciones.

Las dudas reflejadas en las respuestas de los gobiernos europeos muestran que la cuestión de la soberanía nacional no estaba ni mucho menos aclarada. Fue, de hecho, la principa crítica que realizaron los gobiernos consultados, que veían con recelo las posibles injerencias de la Federación en sus competencias. De nada sirvieron los términos utilizados en el Memorándum, tales como "lazo federal", "flexibilidad" o "unión" en lugar de "unidad", ya que sólo consiguieron incrementar las dudas y las suspicacias, justo lo que se trataba de evitar. ${ }^{28}$ Junto a la polémica sobre la soberanía de los Estados, los países consultados también expresaron su temor a que la estructura europea afectara al funcionamiento de la SDN, aunque ya hemos visto que en el Memorándum quedaba clara desde el principio la subordinación de la futura Federación Europea al máximo organismo internacional, un hecho que sin duda cortaba las vías de crecimiento e independencia de la Unión Europea. ${ }^{29}$

En el fracaso del Memorándum Briand jugó un papel fundamental el denominado "Big Three", compuesto por Reino Unido, Italia y Alemania, ya que por diversos motivos los principales países europeos acogieron con poco entusiasmo la propuesta francesa. El gobierno británico mostró su preocupación por las consecuencias negativas que una federación europea podía tener en la Commonwealth o el prestigio de la SDN; Alemania, por su parte, se opuso porque un acuerdo de este tipo perjudicaría las relaciones germano-rusas, ya que Rusia no formaría parte de la Federación, al menos de forma directa; finalmente, rechazó de pleno las ideas del memorándum, entre otros motivos por las tensas relaciones entre Francia e Italia. ${ }^{30}$ Las reservas que realizó el gobierno español fueron parecidas a las del "Big Three", ya que, entre otros matices, interpretó que el proyecto de Briand podía obstaculizar las especiales relaciones entre el Estado español e Hispanoamérica. ${ }^{3}$

26 Véase Katiana ORLUC: “Caught between Past and Future. The Idea of Pan-Europe in the Interwar Véase Katiana ORLUC: “Caught between Past and Future. The Idea of Pan-Europe in the Interwar
Years", en Hans-Åke PERSSON, H-A y Bo STRATTH (eds.): Reflections on Europe. Defining a Political Years", en Hans-Åke PERSSON, H-A y Bo STRÅTH (eds.): Reflections
Order in Time and Space, Brussels, Peter Lang, 2007, págs. 104-105.

27 Henry BRUGMANS, H.: La idea europea..., p. 66.

$28 M^{a}$ Teresa MENCHÉN BARRIOS: "Las causas del fracaso del proyecto Briand de federación europea", en VV.AA.: Estudios históricos. Homenaje a los Profesores José $M^{a}$ Jover Zamora y Vicente Palacio Atard, Tomo I, Madrid, Universidad Complutense, pp. 411-414.

$29 \mathrm{lbid}$, p. 414.

30 Carl H. PEGG: Evolution of the European Idea..., pp. 150-152.

31 María Teresa MENCHÉN BARRIOS: “La actitud de España ante el Memorándum Briand (1929-1931)",

Revista de Estudios Internacionales, vol. 6, 2, (1985), pp. 430-437.
Como se puede observar, en los principales países europeos prevalecieron los intereses nacionales sobre los continentales, que quedaron en un segundo plano. Esto explica la insistencia tanto de Coudenhove como de Briand por asegurar que no se limitaría la soberanía naciona de los Estados. El peso de los intereses de cada país hizo que los dos principales arquitectos de europeísmo durante el periodo de entreguerras frenaran su ambición y presentaran proyectos mucho más modestos en cuanto a la modificación del statu quo que dejó la Gran Guerra. En este sentido, la insistencia en mantener intacta la soberanía nacional se convirtió en el principal obstáculo para una posible integración en el periodo de entreguerras, y en ello tuvieron mucho que ver tanto Coudenhove y Briand como la gran mayoría de los Estados europeos. ${ }^{32}$

\section{Conclusiones}

Como hemos visto, la década de 1920 fue un periodo clave para el desarrollo del europeísmo político. La publicación de Paneuropa, el Proyecto de Pacto Europeo de Coudenhove-Kalergi y el Memorándum francés apadrinado por Briand fueron las principales aportaciones en este sentido. A pesar de que compartían un mismo objetivo y de que incluso llegaron a sumar esfuerzos -Briand fue presidente de honor de la Unión Paneuropea-, existieron diferencias entre los proyectos de signo europeísta que sin duda debilitaron su poder de convocatoria y su influencia. Asimismo, la diversidad dentro del movimiento europeísta impidió la articulación de un discurso único que abogara por la unión de Europa en distintos ámbitos.

Las divergencias más notables las encontramos en la falta de consenso en el concepto de Europa, los mecanismos de funcionamiento en las organizaciones que intentaron impulsar y su relación con la SDN. Este disenso se encuadra dentro de la polémica entre el universalismo y el continentalismo, es decir, entre los partidarios de la existencia de un organismo universal que vele por la seguridad y la paz y los que defendieron la creación de ententes regionales que que vele por la seguridad y la paz y los
facilitaran el desarrollo continental.

Si por algo destacaron los proyectos europeístas del periodo de entreguerras fue por poner el acento en aquello que era capaz de unir a todos los europeos. Precisamente, la difícil definición de estos rasgos comunes, que no lograron abandonar la esfera teórica, explica en parte el fracaso de estos movimientos, sobre todo a la hora de movilizar a la opinión pública. 33 El propio interés de los Estados europeos, más centrados en sus intereses nacionales, muestra también que la idea de Europa no estaba todavía madura y que la presión ejercida por los grupos europeístas apenas modificó la agenda de los gobiernos del viejo continente.

Los proyectos de federación europea propuestos por Coudenhove y Briand, aunque tienen elementos que podían sustituir a una estructura estatal -la cesión de soberanía o el grado de unión federal existente- lo cierto es que su indefinición y la ausencia de voluntad por parte de los países involucrados dejaron estas iniciativas en meros ensayos de política-ficción, ya que no era viable discutir la soberanía de los Estados. El problema de la indefinición, tanto en esta cuestión como en tantas otras, fue un lastre demasiado grande para un movimiento que anticipó problemas y soluciones que sí se tendrían en cuenta, por ejemplo, en la génesis de la Comunidad Económica Europea.

32 Anita PRETTENTHALER-ZIEGERHOFER: "Aristide Briand und Richard Nikolaus Coudenhove-Kalergi Zwei Europa-Protagonisten und ihre Entwürfe für ein vereintes Europa aus dem Jahr 1930", en Andreas BAUER y KarI WELKER: Europa und seine Regionen. 2000 Jahre Rechtsgeschichte, Köln, Böhlau Verlag, 2007, pp. 701-702.

33 Henry BRUGMANS: La idea europea..., p. 65 


\section{GOBIERNO E INDIVIDUO.}

\section{ALGUNAS POSIBILIDADES TEÓRICAS}

\section{DEL CONCEPTO DE “GUBERNAMENTALIDAD”}

Ignacio Tébar Rubio-Manzanares

Becario FPU Universidad de Alicante

nacho.tebar@ua.es

El objetivo de esta comunicación es presentar el concepto de "gubernamentalidad" y otras nociones que lo acompañan para debatir acerca de su posible utilidad como "herramienta» terminológica para el conocimiento histórico. Por "gubernamentalidad", nos referimos a neologismo empleado por Michel Foucault para hablar de la «racionalidad gubernamental» o del «arte de gobierno". En concreto se hablará de la crítica a la representación tradicional del Estado como centro político del que mana todo poder, así como del análisis que se sigue haciendo de «el poder» en general. La finalidad es plantear para el debate las posibilidades, dudas y limitaciones que ofrecen las obras de Foucault en la labor historiográfica.

\section{Introducción}

Nadie puede negar hoy la gran influencia que ha ejercido la obra de Foucault sobre la historiografía desde la publicación de sus primeros libros,' a pesar de que su relación con la disciplina haya sido siempre problemática. Se ha criticado en muchas ocasiones que el filós ofo hizo un uso instrumental de la Historia. ${ }^{2}$ Las conclusiones preceden a la investigación, no son "falsables», sus generalizaciones son excesivas, los procesos narrados son difícilmente extrapolables al resto de países, o su mismo estilo de escritura es ambiguo. Por lo general, hay que prevenir, son críticas que olvidan que el objetivo del autor no era «trazar un relato bien formado, exacto y lo más neutro posible ${ }^{3}$ de ciertas formas de pensar, no hace «historia de las mentalidades», sino que sobre todo intenta "eventualizar», de "historizar» radicalmente lo que en cada momento se percibe como incondicionado y obvio. Foucault llegó incluso a identificarse con los sofistas frente a los filósofos, ${ }^{4}$ al concebir el discurso como una lucha de poder, frente a la tradición platónica, que buscaba hablar de «verdad». Se planteaba el discurso como un acto material y estratégico -al modo de la lingüística anglosajona-, y hablaba más bien de «verosimilitud», a negar la «verdad" como resultado de la acumulación de conocimiento -como Thomas S. Kuhn entiende los cambios científicos-, por considerar que los contextos en que se presenta la «ver-

1 Un resumen y bibliografía sobre el tema en Francisco VÁZQUEZ GARCíA: "Foucault y la Historia Social", Historia Social, 29 (1997), pp. 145-159. Sobre su relación con la historiografía de su momento, ÍD: Foucault y los historiadores. Análisis de una coexistencia intelectual, Cádiz, Universidad de Cádiz, 1988. Alguna referencia de pasada para el caso de España se hace en ÍD: "La historia social española y los nuevos paradigmas: encuentros y desencuentros", en Carlos BARROS (ed.): Actas del II Congreso Internacional Historia a Debate celebrado en Santiago de Compostela los dias 14-18 de julio de 1999, Santiago de Compostela, Historia a Debate, 2000, pp. 219-230.

2 Justo SERNA ALONSO: "¿Olvidar a Foucault? Surveiller et punir y la historiografía veinte años después", Historia Contemporánea, 16 (1997), pp. 29-46.

3 Francisco VÁZQUUEZ GARCíA: “Foucault y la Historia Social...”, p. 148.

4 Michel FOUCAULT: La verdad y las formas juridicas, Barcelona, Editorial Gedisa, 1996, p. 154 dad" en cada momento son resultado histórico y puntual de condiciones que no son propias del orden del conocimiento. Desde esta metodología "genealógica», Foucault fue descubriendo toda una serie de categorías al aplicarla a la episteme, al poder, a las formas de normalización o a propio sujeto, al mismo tiempo que tejí relaciones entre estos campos de estudio. Es ahí donde su influencia en la historiografía se diluye en el relativo éxito del giro lingüístico o la multidisciplinariedad (sobre todo en la incorporación de elementos de la antropología), lo que hace por otro lado que su impacto quizá sea más derivado que explícito, aunque por lo menos ha condicionado la «mirada" y la lectura de un buen número de historiadores. ${ }^{6}$

El propio Foucault planteaba sus contribuciones como una «caja de herramientas» de la que extraer útiles para comprender la realidad o transformarla. En España, quienes más han trabajado la «historia de la subjetividad» en el período contemporáneo dentro de una perspectiva plenamente foucaultiana han sido autores de formación filosófica. ${ }^{7}$ Se podría citar, sin ánimo de exhaustividad, a Javier Ugarte Pérez, Francisco Vázquez García, la reciente tesis de Salvador Cayuela, o los sociólogos como Fernando Álvarez Uría, Julia Varela e Ignacio Mendiola Gonzalo, autores que han introducido en nuestro país las temáticas foucaultianas y las han aplicado a la historia contemporánea. En la «tribu» académica de los historiadores, el filósofo francés ha acabado convirtiéndose en referencia obligada cuando se habla de historia y sexualidad, marginalidad, exclusión, locura, ciencias sociales, delincuencia o Derecho penal además de la historia del "poder" y sus resistencias. Por citar algunas obras, me vienen a la mente las referencias que hacen Conxita Mir y Carme Agusti $i^{8}$ para hablar sobre marginalidad y resistencia durante el franquismo, aunque no desarrollan demasiado sus propuestas. Cultivan algo más el género "foucaultiano" ${ }^{9}$ los estudios sobre penalismo de Pedro Oliver $\mathrm{Olmo}^{10} \mathrm{O}$ de Gutmaro Gómez Bravo," integrantes del Grupo de Estudios sobre la Historia de la Prisión. ${ }^{12}$

6 Fernando SÁNCHEZ MARCOS: Las huellas del futuro. Historiografia y cultura histórica en el siglo XX Barcelona, Universitat de Barcelona, 2012, p. 135.

7 Un estudio meramente numérico: Valentín GALVÁN GARCíA: “La recepción del pensamiento de Michel Foucault en las tesis doctorales de las universidades españolas (1979-2005)", Trocadero, 19 (2007) pp. 135-154.

8 Por ejemplo, Conxita MIR y Carme AGUSTí: “Delincuencia patrimonial y justicia penal: una incursión en la marginación social de posguerra (1939-1951)", en Carme AGUSTí, Josep GELONCH, Conxita MIR (coords.): Pobreza, marginación, delincuencia y políticas sociales bajo el franquismo, Lleida Universitat de Lleida, 2005, pp. 69-92.

9 El filósofo Francisco VÁZOQUEZ hace una distinción entre los «foucaultistas», «(...) sacerdotes -en sentido weberiano- empeñados en descifrar con minucia los textos del maestro y en encuadrarlos dentro del canon de obras y autores que jalonan la vía regia en la historia de la subjetividad" y los autores "foucaultianos", que tratan de «(...) usar la "caja de herramientas" legada por el filósofo, invirtiéndola en investigaciones empíricas conectadas con una interrogación crítica y política del presente», "Presentación. Foucaultistas y foucaultianos en la hondonada filosófica de la Transición", en Valentín GALVÁN GARCíA: De vagos y maleantes. Michel Foucault en España, Barcelona, Virus, 2010, pp. 8-9.

10 Pedro OLIVER OLMO (coord.): El siglo de los castigos. Prisión y formas carcelarias en la España del siglo XX, Barcelona, Anthropos, 2013

11 Gutmaro GÓMEZ BRAVO: "Paisaje de la violencia", Cuadernos de historia contemporánea, 26 (2004), pp. 161-180, ÍD:Crimen y castigo. Cárceles, justicia y violencia en la España del siglo XIX, Madrid, Libros de la Catarata, 2005. 12 El Grupo de Estudios sobre la Historia de la Prisión [http://historiadelaprision.wordpress.com/], que coordina el propio Pedro Oliver, y del que forman además del propio Gutmaro Gómez, Ana
Isabel Simón, César Lorenzo Rubio, Fernando Hernández Holgado, Fernando e Ignacio Mendiola Isabel Simon, Cesar Lorenzo Rubio, Fernando Hernández Holgado, Fernando e Ignacio Mendiola el legado del Grupo de Información sobre las Prisiones (GIP) fundado en Francia por el propio Fouel legad de crupo de Información sobre las Prisiones (GIP) fundado en Francia por el propio FouPresos Españoles en Lucha (COPEL), que apoyaron, en su mionento, José Luis Araodinadora de
5 Thomas S. KUHN: La estructura de las revoluciones cientificas, Madrid, Fondo de Cultura Económica, 1971. 
Asimismo, Foucault ha ejercido una gran influencia sobre aquellas «escuelas» que tienen interés por la "subjetividad", léase por ejemplo la teoría e historiografía de género. ${ }^{13}$ Para este tipo de enfoque, directamente o a través de Joan W. Scott ${ }^{14}$, el filósofo francés no solo ofrece un soporte teórico válido para negar las categorías estáticas y ahistóricas' ${ }^{15}$ (como han sido entendidas tradicionalmente las relaciones de género), sino que ofrece un fecundo campo de estudio sobre la individualización o la entrada del «cuerpo» en la Historia cultural (como vemos en otra mesa de este mismo encuentro), más allá de la historia de las mediciones biológicas o demográficas.

\section{Técnicas de gobierno}

La lectura del filósofo francés puede ayudar, como decimos, a realizar una historización radical de los conceptos empleados habitualmente por el investigador, a la vez que puede inspirar nuevos enfoques y campos de estudio. ${ }^{16}$ Lo hace reintroduciendo el acontecimiento o la contingencia, no en el sentido de la historia clásica de batallas, tratados o grandes hombres, sino en el "genealógico", con la disolución de las realidades e identidades que consideramos más sólidas, naturales o invariantes antropológicas (incluidos los sentimientos, instintos, el cuerpo y sus regímenes, leyes morales, identidades, etc.). Una operación que Foucault designa con el nombre de "eventualización", y cuyo objetivo es disolver teleologías o universales ahistóricos en construcciones históricas más o menos arbitrarias, resultado de conflictos azarosos y sólo racionalizados a posteriori como justificación.

Al «historizar» así las distintas técnicas de poder, Foucault se diferenció de la concepción del poder que se venía haciendo en el análisis político de su época, de tipo negativo y «sustancialista». Ésta visión compartía una representación del poder como algo negativo, que sustrae fuerzas, que prohíbe o reconduce, y que emana de un foco de soberanía («aparatos del Estado", o una clase sobre otra). Dicha generalización, que Foucault consideró propia de un modelo «jurídico» de poder, le resultaba insuficiente y por ello realizó una serie de proposiciones con las que analizar las técnicas concretas de poder tratando de huir de ese «sustancialismo». Propone concebirlo como la multiplicidad:

«(...) de relaciones de fuerza inmanentes y propias del campo en que se ejercen, y que son constitutivas de su organización; el juego que por medio de luchas y enfrentamientos incesantes las transforma, las refuerza, las invierte; los apoyos que dichas relaciones de fuerza encuentran las unas en las otras, de modo que formen cadena o sistema, o, al contrario, los corrimientos, las contradicciones que aíslan a unas de otras; las estrategias, por último, que las tornan efectivas, y cuyo dibujo general o cristalización institucional toma forma en los aparatos estatales, en la formulación de la ley, en las hegemonías sociales»."7

García Calvo, Sánchez Ferlosio o Fernando Savater. Sobre COPEL, y Foucault ver Valentín GALVÁN GARCÍA: "Sobre la abolición de las cárceles en la Transición española" Historia Actual Online, 14 GARCíA: "Sobre la abolición de las cárceles en la Transición
(Otoño, 2007), 127-131 e íD: De vagos y maleantes... p. 104 y ss.

13 Por ejemplo, el IV Seminario Internacional de la Asociación Española de Investigación Histórica de las Mujeres (AEIHM) del 7 y 8 de octubre de 2011, llevaba por título "Las huellas de Foucault en la Historiografía. Poderes, cuerpos y deseos" (actas pendientes de publicación).

14 Joan W. SCOTT: “El género: una categoría para el análisis histórico", en AMELANG, J. S., y NASH, M. (eds.): Historia y género: las mujeres en la Europa Moderna y Contemporánea, Valencia, Alfons el Magnànim, 1990, pp.23-56.

15 Por ejemplo, Nerea ARESTI: Masculinidades en tela de juicio, Madrid, Cátedra, 2010.

16 Si se tiene interés en los «usos» posibles de la obra del filósofo de puntos, véase el artículo de Francisco VÁZOUEZ GARCíA: “Cómo hacer cosas con Foucault", ER. Revista de Filosofía, 28 (2000), pp. 71-83 y al ya citado, ÍD: "Foucault y la Historia Social..."

17 Michel FOUCAULT: Historia de la sexualidad. Vol. 1. La voluntad de saber, Madrid, Siglo Veintiuno, 2006, pp. 97 yss.
La esencia del poder para Foucault es relacional, no surge después que se ha estructurado el todo social, sino que es elemento de su conformación, surge de innumerables puntos, en el juego de relaciones móviles y no igualitarias. El dibujo que nos lleva hasta «el» poder tradicional (estatal o de clase) en Foucault es más bien ascendente y carece de sustancia, es una imagen «capilar» del poder, no piramidal; "las grandes dominaciones son los efectos hegemónicos sostenidos continuamente por la intensidad de todos estos enfrentamientos». Había que ser nominalista, «el poder no es una institución, y no es una estructura, no es cierta potencia de la que algunos estarían dotados; es el nombre que se presta a una situación estratégica compleja en una sociedad dada». ${ }^{18}$

A través de esta concepción capilar del poder, Foucault fue esbozando y matizando distintos modelos de poder según fue avanzando su investigación. En Vigilar y Castigar, en 1975, ${ }^{19} \mathrm{el}$ autor trató de mostrar como la teoría jurídico-política de la soberanía (que dice «no», prohíbe, castiga, sustrae bienes y fuerzas), que contaba con «el derecho de hacer morir o de dejar vivir», perdió importancia ante el mecanismo "disciplinario", que actuaba con una lógica productiva, esforzada en controlar y dirigir las operaciones del cuerpo de cada uno de los individuos mediante el establecimiento de estándares de normalidad y de vigilancia sobre cada sujeto. EI "progreso" del penalismo moderno, que sustituyó los tormentos y la horca por la prisión y el encierro en el reformatorio, era discutido en tanto que progreso, ya que al sustituirse el poder «inhumano» pero discontinuo y torpe del absolutismo por un Estado liberal más «racional» y "humanitario" se instauró el dominio de la prisión como castigo a todo tipo de infracción y se comenzó a someter a vigilancia constante a cada sujeto, gracias en gran medida al descubrimiento técnico del panóptico. Así, toda una serie de mecanismos y de técnicas de gobierno que se desarrollaron entre el XVII y XVIII tenían como objetivo someter a cada uno de los «cuerpos individuales», inscribiéndose en su interior, y extrayendo de ellos la mayor eficacia. Es un poder "productivo", que produce sujetos útiles y dóciles, mediante líneas de separación que convierten la Ley en el cumplimiento de la norma; qué es normal, qué no lo es, qué es incorrecto o no lo es, qué se debe hacer, etc. ${ }^{\circ}$ Teóricamente, a través de toda una serie de instituciones sociales y económicas -las prisiones, los hospitales, las escuelas, las fábricas o el ejército- la disciplina se interiorizó de manera capilar mediante instrumentos de separación, estudio y transformación de los desviados, aquello que llamó «ortopedia social», para vencer las resistencias y corregir lo anormal. ${ }^{21}$ Por ejemplo, en el campo del Derecho penal, mientras que el modelo jurídico funcionaba imponiendo sanciones a la acción prohibida y trabajaba mediante un sistema binario (permitido-vedado), a partir del XVIII se le añade un tercer factor que es la persona del culpable. El modelo disciplinario es individualizador, aparece la figura del «delincuente», y se elaboran a su alrededor toda una serie de técnicas de conocimiento y de control cuya finalidad es la transformación del individuo mediante toda una serie de técnicas adyacentes (policiales, médicas, psicológicas), que corresponden a la vigilancia, el diagnóstico, la transformación eventual del sujeto, con el objetivo de hacerlos más "sanos", «normales" y "productivos».

Hasta aquí, dos metáforas de poder, la jurídica y la disciplinaria, en las que la historiografía española se ha centrado generalmente desde el impacto de Vigilar y castigar en los ochenta, ya sea para negar sus hipótesis o completarlas. Sin embargo, como se ha apuntado, existe un tercer mecanismo, el de "seguridad", que es el que nos llevará al modelo de "gobierno" y que no ha despertado la misma atención. En el primer volumen de la obra Historia de la sexua-

18 Loc. cit.

19 Michel FOUCAULT: Vigilar y castigar, el nacimiento de la prisión, Madrid, Siglo Veintiuno, 1984

20 Michel FOUCAULT: La verdad y las formas jurídicas, Barcelona, Gedisa, 1980, p. 100.

21 Francisco VÁZOUEZ GARCíA: La invención del racismo..., p. 10. 
lidad, ${ }^{22}$ y en las conferencias en el Collège de France a partir de 1976,,$^{23}$ Foucault adoptó una concepción ligeramente distinta respecto del modelo disciplinario. El poder que se ha descrito, de tipo bélico, perdió interés ante una tecnología de poder que trascendía a la extracción de utilidad del cuerpo individual. El «dispositivo de sexualidad», argumentó, es un cruce entre los mecanismos disciplinarios (es corporal, individualizador, en forma de vigilancia permanente) y los biopolíticos, que conciben el cuerpo humano como si se tratara de la fisionomía de cualquier grupo de mamíferos, con su propia naturaleza (por sus consecuencias procreadoras sobre la población, no sólo sobre el cuerpo individual). El derecho de muerte se apoyó desde entonces en un poder de incitación, reforzamiento, vigilancia, aumento y organización de las fuerzas que sometía, un poder que administra la vida, que la aumenta, la multiplica y la invade. ${ }^{24}$ Las técnicas de seguridad son correlativas a la aparición del problema de la población en la teoría política a partir de la segunda mitad del XVIII, en dos polos entrelazados, el sistema legal-jurídico (soberanía), que da forma aceptable al «disciplinario-normativo»; y el de «seguridad $" .{ }^{25}$ Hay que aclarar que dichas técnicas coexisten, se superponen, se apoyan unas en otras, no siguen una evolución teleológica hacia ningún perfeccionamiento (primero legal, luego disciplinaria y, por fin, de seguridad), sino que más bien se convierten en dominantes en determinados contextos, o se pueden rastrear esas técnicas aisladas en otras, y como cualquier modelo, es imposible imaginar esas formas de poder «puras».

Foucault considera, pues, que con el nacimiento de la biopolítica, el Estado se puso como objetivo la población, entendida como especie sujeta a una serie de procesos biológicos de natalidad, mortalidad, nivel de vida, longevidad, etc. y fue entonces cuando cobraron importancia lo que llamó «mecanismos de seguridad" o «tecnologías políticas de regulación » ${ }^{26}$ -también llamados indistintamente biopolítica o biopoder, lo que puede llevar a confusiónque invadieron todos los aspectos vitales. Los individuos, los grupos de individuos, serían a partir de entonces instrumento, no objeto, para obtener algo en el plano de la población, y la forma en que el poder se ejercía no era tanto para «normalizar» al individuo concreto venciendo sus fuerzas y siguiendo una norma previamente trazada, sino regulando y calculando «riesgos" generales. Por seguir con el ejemplo del Derecho penal, se insertó el fenómeno delictivo dentro de una serie de acontecimientos probables. Las reacciones del poder frente a ese fenómeno se incorporan a un cálculo de costos, y en lugar de interesar tanto la división binaria entre lo permitido y lo vedado, se fija por una parte una media considerada como óptima y por otra los límites de lo aceptable, más allá de los cuales ya no habrá que pasar. En la actualidad ningún gobierno pretendería acabar con la delincuencia, como podría trata de hacer un modelo disciplinario, sino que se trabaja con unos máximos y mínimos estadísticos, «mecanismos de seguridad».

22 Michel FOUCAULT: Historia de la sexualidad. Vol. 1. La voluntad de saber, Madrid, Siglo Veintiuno, 2006 23 Michel FOUCAULT: Hay que defender la sociedad. Curso del Collège de France (1975-1976), Madrid, Akal, 2003; ID: Seguridad, territorio, población. Curso del Collège de France (1977-1978), Madrid, Akal, 2008; íD: Nacimiento de la biopolitica. Curso del Collège de France (1978-1979), Madrid, Akal, 2004. 24 Michel FOUCAULT: Historia de la sexualidad..., pp. 143-169.

25 Michel FOUCAULT: Seguridad, territorio, población..., p. 16 y ss.

26 Sobre los mecanismos reguladores o de seguridad y las diferencias con respecto a los demás me-

canismos: Michel Foucault: Seguridad, territorio, población..., pp. 34-36, 57 y ss. y 66-75.

\section{Modelo de gobierno y gubernamentalidad}

La biopolítica, como hemos visto, se apoya en los sujetos que forman parte de la población. ${ }^{27}$ Lleva implícita la noción de "gobierno". ${ }^{28}$ Ese modelo, entendido como «conducción de conductas", esto es, la actividad que busca dar forma, guiar o influir sobre la conducta de otras personas, sea el gobierno de la casa, de las almas, de las familias, o como ejercicio de la soberanía política, ${ }^{29}$ presupone desde el gobernante cierto espacio de libertad y de capacidad de acción de aquellos a los que se desea gobernar, no pretende anular su iniciativa. Ello le permitía definir un tipo de relaciones de poder que encontró en los Estados modernos, pero que no encajaban en el modelo bélico, de sometimiento físico o de antagonismo, sino que se establecían en un tipo de agonismo.

En un sentido de gobierno más restrictivo, la gubernamentalidad, conocida también como racionalidad de gobierno o arte de gobierno, ${ }^{30}$ se define como un modo o sistema de pensamiento acerca de la naturaleza y práctica del gobierno, de la conducción de conductas (quién puede gobernar, qué se entiende por gobernar y qué o quienes son los gobernados), dentro de cada contexto histórico. ${ }^{31}$ El estudio de esa "gobernabilidad", trata de distinguir las distintas racionalidades, artes y regímenes de gobierno y administración que han surgido en la Europa moderna resaltando su historicidad. Para su estudio, analizó los cuatro contextos históricos en los que detectó su aparición: el "gobierno de la ciudad" en la filosofía grecolatina confrontado al «poder pastoral» del cristianismo primitivo; las doctrinas de gobierno de la Europa moderna asociadas a la idea de razón de Estado, Estado de policía, cameralismo y mercantilismo; el inicio del liberalismo durante el XVIII como una concepción de arte de gobierno; y finalmente, la gubernamentalidad neoliberal en Alemania, EEUU y Francia, considerada como formas de replantear la racionalidad de gobierno durante el XX.

Por ejemplo, el arte de gobierno grecolatino consideraba impracticable algo parecido al gobierno pastoral -el cuidado individual de cada oveja del rebaño- por lo que pensaban en el gobierno de la ciudad, el manejo de la «nave», a través de la Ley y del ciudadano, mediante un juego indirecto, más que el poder pastoral individualizado que sí se cultivó en el cristianismo. En Seguridad, territorio, población, las clases del curso del 1978, Foucault explica que ambos modelos se apoyan con la secularización de la política en la Edad Moderna, cuando se unen «individualización" y la «totalidad» de la población, omnes et singulatum. Ese sería el punto de partida: la razón de Estado del siglo XVI, con el nacimiento de la gubernamentalidad como

27 Hay un hilo común entre la relación dinámica dominante-dominado del modelo bélico al gubernamental, como conducción de conductas: ambos sostienen las capacidades de los agentes, pero el modelo gubernamental resalta que estos actúan a través de una serie abierta de posibilidades éticas y prácticas. Colin GORDON, “Governmental rationality...", p. 5.

28 El estudio de la biopolítica sólo puede hacerse cuando se comprende el régimen general de una determinada razón o lógica gubernamental, tienen un carácter histórico y existen tantas formas de biopolítica como maneras de gobernar. Michel FOUCAULT: Nacimiento de la biopolitica. Curso del Collège de France (1978-1979), Madrid, Akal, 2004, p. 35; Francisco VÁZOUEZ GARCíA: La invención del racismo, p. 15 .

29 Michel FOUCAULT: Nacimiento de la biopolítica..., p. 17.

30 Michel FOUCAULT: "La gubernamentalidad", en Michel FOUCAULT et alii, Espacios de poder, Madrid, La Piqueta, 1991, pp. 9-26.

31 Colin GORDON, “Governmental rationality...", p. z; Francisco VÁZOUUEZ GARCÍA: La invención del racismo p. 12. "Cin racismo..., p. 12. Sin embargo, hay que añadir que en esa serie de preguntas se dio más relevancia y del enfoque jurídico tradicional. Estas uprecauciones metodológicas" partian de una serie de principios que no se abandonan y que se resumen en la capilaridad (el cómo de us instituciones frente al dónde y al cómo fundador de la soberania), en el análisis ascendente del poder (mecanismos infinitesimales que son utilizados por los mecanismos generales) y en los dispositivos de saber. Mr. Michel FOUCAULT: Defender la sociedad..., PP. 35 y 
racionalidad autónoma, no subordinada a un orden teológico del mundo, con sus propios secretos, intereses y saberes inaccesibles para los gobernados.

La Polizeiwissenschaft o «ciencia de la policía» de la Alemania del XVIII compartía con el mercantilismo o el cameralismo la idea de querer aumentar el tesoro del soberano, pero enfatizaba que la riqueza estaba en la población, en la fuerza y productividad de todos y cada uno. Estas teorizaciones y prácticas de gobierno concibieron un nuevo tipo de Estado, el «pastoral» o gubernamentalizado, al colocar como su objeto el hombre individual. La teoría de la policía, que se encuentra de un modo u otro en los Estados de la Europa de la Paz de Westfalia abarcaba todos los aspectos de la vida; aspiraba a imponer un orden artificial, a gobernar la conducta personal para lograr la grandeza del conjunto. Gobernaba por decreto, no se limitaba a la forma de la Ley, regulaba lo específico e imponía su modelo sobre la realidad. La racionalidad gubernamental mercantilista propició la aparición de los mecanismos disciplinarios, eventualmente reguladores, propios de una «biopolítica absolutista».32

Finalmente, los mecanismos de seguridad son un elemento característico de la «gubernamentalidad liberal». Más allá de una ideología o doctrina económica y política, Foucault consideró al liberalismo como un estilo de pensamiento preocupado por el arte de gobierno. ${ }^{33}$ Los planteamientos de Adam Smith transformaban la relación saber-poder con la introducción de la «economía política»: para la ciencia de policía «ciencia» y acción de Estado eran inseparables, mientras que en la economía política el Estado como sujeto cognoscente era incapaz, por lo que su actividad debía limitarse internamente para no interferir sobre la «naturaleza». La sociedad y su economía pueden y deben ser gobernadas respetando leyes naturales, la capacidad de la sociedad civil para generar su propio orden y prosperidad. No es, pues, el contrato lo que funda la sociedad política en el liberalismo, la Ley más bien limita las medidas excepcionales e impredecibles, y la participación de los gobernados en la elaboración de esas Leyes (y la «sociedad civil») constituye el sistema más efectivo de gobierno económico. Este modelo de técnica de gobierno necesitaba otra categoría diferente a la puramente legal o económica: la de «seguridad». Conservar el equilibrio era muy frágil, abandonadas a su suerte esas fuerzas de la naturaleza podían extraviarse, pero una intervención excesiva era igualmente perjudicial, por lo que era necesario a la vez que se incentivaba la libertad y el interés del individuo, reducir los riesgos posibles dentro de un rango tolerable. Mientras la soberanía tiene por objeto el territorio y la disciplina el cuerpo individual, los mecanismos de seguridad se encargan del conjunto de la población, se apoyan en ella (procedimientos como las campañas de vacunación infantil, la esterilización de débiles mentales, medidas fiscales para incentiva la natalidad, las políticas de vivienda, etc.), no busca vencer la resistencia individual, sino «calcular riesgos», coordinando la iniciativa individual con las metas de la nación. ${ }^{34}$

\section{Conclusiones}

Foucault y la historiografía francesa de su época plantearon algunos de los caminos por los que siguió la investigación histórica del Estado, el Derecho y sus instituciones: ni una historia de las ideas (que veía al Estado como un castillo en el aire que se reforma a sí mismo a través de ser pensado jurídicamente); ni una historia de las instituciones (Estado o Derecho como

32 Obviamente son modelos ideales. Sobre esta "biopolítica absolutista" en España ver VÁZOUEZ GARCIA: La invención del racismo..., pp. 19-182.

33 Michel FOUCAULT: Nacimiento de la biopolitica..., p. 37 y ss.

34 Francisco VÁZOUEZ GARCiA: La invención del racismo P. 10 ID: "Empresarios de nosotros mismos. Biopolitica mercado y soberanía en la gubernamentalidad neolibera", en Javier UCARTE PÉREZ (coopolitica, mercado y soberanía en la gubernamentalidad neoliberal, en Javier UCARTE PEREZ (coord.): La admintrtración de la vida. estudios biopolticos, Barcelona, Anthropos, 2005, p. Foucault nazi pero sobre todo se interesó por a biopolitica neoliberal, temas en losque ahor no seva a ntrar. aislados de la realidad). Por otra parte, aportaron algunos elementos que hoy llamaríamos "culturalistas» de la Historia social, al superar la mera interpretación del Estado, el Derecho o la economía política en clave social. Es decir, liberaron al Estado de las interpretaciones que lo estudiaban como «el» Poder que domina sobre la sociedad, o que por el contrario lo interpretaban automáticamente como "siervo" de los medios de producción. ${ }^{35}$

No obstante, a la vez que se resalta la importancia de la contribución al estudio de los «márgenes", hay que señalar el peligro que supondría desnaturalizar y restarle importancia al pape político del Estado en todo este esquema de «micropoderes». El interés por la obra de Foucault está en las posibilidades teóricas que ofrece justamente la coordinación y articulación de la escala "macro" y lo "micro", que deshace en prácticas infinitesimales las relaciones de poder que pueden ser consideradas relevantes política, social o culturalmente, en lugar de estudiar "al poder» político sin más, entendiendo por tal al Estado y sus intervenciones sobre la sociedad. La brillante imbricación que describió entre los modos de subjetividad, artes de gobierno y poder, que abrieron un abanico enorme de estudios que van desde las tecnologías de gobierno a escala Estatal hasta el "gobierno del yo" o de la empresa, se han convertido en fundamentales para conocer las vías y estrategias que imponen las transformaciones de, por ejemplo, una determinada noción gubernamental, un determinado modelo moral o una teoría económica.

Sería interesante, por tanto aplicar el estudio de la gubernamentalidad a la historia de la España contemporánea, un campo que algunos en el mundo anglosajón llegan a considerar una nueva subdisciplina. ${ }^{6} \mathrm{El}$ modelo de gobierno puede servir para describir un poder estatal que delega su soberanía en sus ciudadanos -hecho que explica ese incremento de estudios sobre gubernamentalidad en el contexto de fortalecimiento político neoliberal en los países anglosajones, y el silencio hasta el momento en nuestro país-37, mientras que el concepto de biopolítica ha sido más empleado para estudiar contextos dictatoriales, al articular un poder estatal sobre la población, que se «nacionaliza», y las pequeñas disciplinas cotidianas y mecanismos de regulación.

35 Antonio SERRANO GONZÁLEZ: Michel Foucault. Sujeto, derecho, poder, Zaragoza, Universidad de Zaragoza, 1987, p. 46 y ss.

36 Francisco VÁZQUUEZ GARCíA: “Empresarios de nosotros mismos...”, p. 74.

$37 \mathrm{lbid}, \mathrm{p}$. 77. Artículo muy completo para entender el concepto y conocer las actuales corrientes en la investigación desde un punto de vista crítico. 
Parte 2.

CORPORALIDAD, EMOCIÓN Y EXPERIENCIA:

LA CONSTRUCCIÓN DE LAS SUBJETIVIDADES

ENTRE SUJETO Y COLECTIVIDAD 


\section{CORPORALIDAD, EMOCIÓN Y EXPERIENCIA: \\ LA CONSTRUCCIÓN DE LAS SUBJETIVIDADES ENTRE \\ SUJETO Y COLECTIVIDAD}

Sara Hidalgo García

Universidad de Santiago de Compostela timenta, estilismo de pelo, ...actúan como significantes del mundo social y moral local, ${ }^{3}$ una idea que aparece reflejada en algunas de las comunicaciones presentadas.

Pero además la categoría cuerpo nos muestra otra interesante dimensión, y es la de la indisolubilidad entre lo psíquico y lo corporal. Esto lleva a algunas reflexiones sobre la propia materialidad del cuerpo, que no sería natural, y en cuya formación tendría una gran relación con el lenguaje, tal y como afirma J. Butler: "el lenguaje y la materialidad no se oponen, porque el lenguaje es y se refiere a aquello que es material y lo que es material nunca escapa el todo al proceso por el cual se le confiere significación". 4

La idea de la indisolubilidad entre lo psíquico y lo corporal, negando por tanto el famoso dualismo cartesiano, no solamente lleva a una reconsideración de la categoría cuerpo, sino también de la categoría emoción. En 1994, el neurobiólogo Antonio Damasio publicó su famoso El Error de Descartes, abriendo toda una serie de reflexiones en torno a esta categoría de emoción. La reconsideración de la emoción como parte del proceso cognitivo, junto con la razón, ha sido un elemento fundamental en la renovación teórica que ha vivido las ciencias sociales estos últimos años.

La emoción como un elemento explicativo del proceso histórico, aunque hoy día ha alcanzado una gran importancia, no es un tema nuevo. De hecho, las emociones y su influencia en la acción humana ha sido un tema que ha preocupado a las ciencias sociales a lo largo de todo el siglo XX. Desde la filosofía, la fenomenología prestó gran atención a esta cuestión, de la mano de Merleau-Ponty, quien establece una estrecha relación entre el concepto de cuerpo y el de emoción: "No sólo el gesto es contingente respecto de la organización corpórea, también la manera de acoger la situación y vivirla"-y añade- "lo que importa es la manera como utilizan su cuerpo, es la puesta en forma simultánea de su cuerpo y de su cuerpo en la emoción". ${ }^{5}$

Por su parte, desde el campo de la historia también asistimos a un largo recorrido temporal. El trabajo pionero de J. Huizinga The Waning of the Middle Ages data de 1919, y el famoso El proceso de civilización, del sociólogo Norbert Elias de 1939. A partir de ahí se produce un cierto estancamiento de esta corriente, que será retomada a partir de los años 70.

Algunas de las razones por las cuales se reactiva este campo son los debates que se suscitan al calor del giro etnográfico de E.P. Thompson, de los trabajos de género, de la teoría del discurso de Foucault, y de los estudios de Jurgen Habermas y su concepción de la esfera pública y privada. En los años 80 aparecen los trabajos pioneros de Peter y Carol Stearns y su concepto emotionology. Este concepto es definido en un artículo aparecido en la American Historical Review del año 1985 de la siguiente manera: actitudes o estándares que un sociedad, o un grupo concreto de esa sociedad, mantiene hacia las emociones básicas y su apropiada expresión; modos en que las instituciones reflejan y estimulan estas actitudes en la conducta humana. ${ }^{6}$

Una visión que se hace eco también de los avances que se dan en antropología, liderados por antropólogas como Michelle Rosaldo, Lila Abu-Lughod o Catherine Lutz,7 que en estos años 80 publican interesantes trabajos que reflexionan sobre la gestión y expresión emocional en

3 Margaret LOCK: "Cultivating the body: anthropology and epistemologies of bodily practice and knowledge" Annual Review Anthropology, 22 (1993), pág. 135

4 Judith BUTLER: Cuerpos que importan. Sobre los límites materiales y discursivos del "sexo", Buenos Aires, Paidós, 2008, pág. 110.

5 Maurice ME-PONTY, M: Fenomenología de la percepción,Barcelona, Península, 1994, pp. 205-206 6 Peter STEARNS y Caroline STEARNS: "Emotionology: Clarifying the history of emotions and emotional standards", American Historical Review, vol. 90 (4), oct. 1985, pág. 813 7 Michelle ROSALDO: Knowledge and passion. llognot notions of self and social life. Cambridge. Cambridge University press. 1980. Lila ABU-LUGHOD: Veiled sentiments. Honor and poetry in a Bedouin society. Callfornia, University of Callfornia Press, 1986. Catherine LUTZ: Un patural emogo, Chicago University Press, 1988 .
Autores como P. Joyce proponen un "giro material" que renueve la relación "entre acción humana y cultura material" como "factor explicativo de los procesos históricos": Patrick JOYCE "Materialidad e historia social" Ayer, 62, 2006 (2), pág. 73. G. SPIEGEL por su parte, pide una vuelta a la
práctica: Gabrielle M. SPIEGEL: "La historia de la práctica: nuevas tendencias en historia tras el giro práctica: Gabrielle M. SPIEGEL: "Lyer, 62 (2006), pp.19-50.

2 Mark JOHNSON: El cuerpo en la mente, Madrid, Debate, 1991, pp. 17-18. 
diferentes culturas, negando la universalidad de las emociones y poniendo en un primer plano el papel de la cultura en la construcción de las mismas.

Todo ello nos conduce hasta los años 90 , cuando una serie de reflexiones abren la puerta al actual giro emocional de las ciencias sociales, y en especial en el mundo de la historia. E trabajo de historiadores como W. Reddy o B. Rosenwein, junto al ya aludido de Stearns, ha sido clave y pionero en esta renovación.

La propuesta pionera del historiador y antropólogo William M. Reddy constituye una crítica tanto al concepto de "cultura" como al de "lenguaje" como elementos explicativos de la acción humana. Según este autor la lógica de la acción es fortuita y combinatoria, por lo que no se puede condicionar a ninguna de esas dos categorías. De hecho, defiende que el campo de nuestras intenciones está dedicado en una sola situación, y que no se puede entender fuera de la propia situación. ${ }^{8}$ En el análisis de la acción, Reddy propone usar la categoría de "expresión emocional", que él denomina emotive, ${ }^{9}$ como un instrumento que ayuda a lograr un movimiento coherente en el desarrollo de la acción..$^{10} \mathrm{El}$ emotive daría forma al afecto, parte inconsciente de nuestra experiencia. Además los emotives darían forma a lo que él denomina el régimen emocional, que define como un set de emociones normativas, rituales oficiales, prácticas y emotives que se expresan y se inculcan, constituyendo el necesario fundamento para cualquier régimen político estable. Ahora bien, el régimen emocional puede provoca lo que Reddy denomina sufrimiento emocional, un agudo conflicto de objetivos que puede esconder imprevistas acciones que lleven a un cambio. Las implicaciones que para el análisis político tiene esta visión son amplias y dan nuevas claves.

La historiadora medievalista B. Rosenwein por su parte, ha analizado el papel social de las emociones como creadoras de comunidades, lo que ella llama la comunidad emocional, que define como un grupo en el cual las personas que a él pertenecen tienen unos objetivos, intereses y valores comunes. Un concepto que se adapta tanto a la comunidad social, como a la comunidad textual." Además Rosenwein es autora un interesante artículo en que establece la metodología a seguir en el estudio de las emociones en historia."

Pero, a pesar de todos estos avances, todavía no se ha hecho una historia de las emociones, tal y como afirmó P. Burke, ${ }^{13}$ y en cualquier caso, los desafíos todavía parecen mayores que los logros conseguidos.

Las comunicaciones presentadas en esta mesa son un reflejo de estos debates y de la multidisciplinariedad que hoy día se ha generalizado en el ámbito de la historia. Así, tenemos no solamente trabajos que indagan sobre procesos del pasado, sino también aportaciones que reflexionan sobre el mundo del arte, de la filosofía o de la antropología. Todas ellas en cambio mantienen un vínculo de unión, un elemento en común, que es la preocupación por la definición de las categorías analíticas del cuerpo y de la emoción.La comunicación de Vicent Bellver Loizaga Escrito en el cuerpo: cuerpos “respetables" en la España decimonónica. Líneas para una posible renovación de la historia sociocultural del XIX español una reflexión sobre los Ilamados "grespetables" de las clases medias y su representación y uso en la política del

8 William REDDY: "The logic of action: Indeterminacy, Emotion and Historical Narrative", History

and Theory, vol. 40, (4), pág. 11.

9 Desarrollo de este concepto en Willian REDDY: The navigation of feeling. A framework for the history of emotions, York, Cambridge University Press, 2001

10 William REDDY: “The logic of action ..." , pág, 25.

11 Barbara ROSENWEIN: Emotional communities in the early middle ages, , Ithaca, 2006, pp. 24-25.

12 Barbara H. ROSENWEIN: "Problems and Methods in the History of Emotions", Passion in context I $(1 / 2010)$.

3 Peter BURKE: "Is there a cultural history of the emotions?" P. GOUK y H. HILLS: Representing emo-

tions: New connections in the Histories of Art, Music and Medicine, , Ashgate, pp. 35-48
XIX español. Bellver reflexiona sobre una recuperación de lo social, sobre cómo repensar la modernidad dentro de lo que denomina el "postgiro lingüístico". En este sentido, analiza cómo diferentes acontecimientos ocurridos durante el Trienio Liberal y el posterior exilio hace que muchos liberales abandonen algunos de los principios del primer liberalismo en favor de una visión más elitista y oligárquica de la política y de la sociedad. Esto llevaría a un desplazamiento de esa visión del liberalismo radical hacia los sectores populares urbanos. Una lucha que se produciría no solamente en términos políticos, sino también en el terreno de lo corporal.

También encuadrada en una reflexión sobre el cuerpo, aunque en su caso haciendo un análisis etnográfico, se sitúa la propuesta de Isabel FerrándizMasculinidades ambivalentes. Pelos, barrigas, y otras disidencias corporales. Este es un análisis del colectivo de los llamados bearsen la ciudad de Barcelona. Este colectivo está compuesto por hombres que se declaran homosexuales y exaltan de manera positiva el vello corporal, el cuerpo orondo y la barriga, constituyendo además una subcultura consolidada dentro del colectivo gay. Ferrándiz propone hacer una corporagrafía este colectivo en aras de repensar el mundo de las masculinidades. Se y desarrollan tres aspectos o ideas: la idea de que el cuerpo bearconstituye una rebelión contra el estereotipo gay; el modo en que el cuerpo bearconstituye un objeto de deseo, debido a su apariencia hipermasculina; y cómo el cuerpo bearse sitúa entre el ser macho y la ternura e inocencia que encarna el oso de peluche. Esta comunicación vuelve a traer al primer plano el análisis del cuerpo como una materialidad en que se afirma la identidad o una subcultura, en este caso la bear.

Volviendo al campo de la historia, la propuesta de Aintzane Rincón Cuerpos entransición. La ruptura del ideal de feminidad franquista én lleva intrínseca la ón sobre la categoría cuerpo. Rincón estudia la figura de Marisol/Pepa Flores durante la transición y los desafíos que esa figura supuso. Su reflexión parte de su análisis al repertorio musical compuesto por Marisol/Pepa Flores en Galería deperpetuas (1979), donde se ponía voz a una serie de problemas de género que subyacían la sociedad española. Rincón resume así este proceso: "Pepa Flores ofreció, con su repertorio musical, una banda sonora a la agenda feminista de los años setenta". Según el análisis de Rincón, Marisol corporeizó la voluntad de romper tanto con el franquismo como con los modelos de feminidad que este régimen imponía. La propia trayectoria y gran popularidad de Marisol hacen que esta ruptura tenga un gran carácter simbólico en la sociedad de la época.

Más cercano a un análisis de las emociones es la propuesta de Garikoitz Gómez Alfaro Tras el maletín de Benjamin. Cuerpo, memoria y paisaje en un estudio de casosobre el giro afectivo. este trabajo se aborda el estudio de la ciudad fronteriza de u (Girona), famosa por albergar la tumba deW. Benjamin, como un escenario donde abordar cuestiones como la memoria pública, la experiencia (tanto de visitantes como de locales) así como el papel de los afectos y las emociones. En esta ciudad, en palabras de Gómez,"se ha materializado la influencia de lo que podemos llamar la canonización del Holocausto como eje de la memoria pública europea”. Además, se entiende que estas emociones y esta experiencia tienen en el cuerpo la superficie donde manifestarse.

La propuesta de Sonsoles Hernández Barbosa Los discursos en torno a unanueva sensorialidad en el fin de siglo español, también constituye un análisis usando la ía de emoción. En este trabajo se realiza un estudio de los discursos sobre las emociones y el modo en que éstos constituyen un importante elemento de configuración de la realidad. A través de una observación de la obra de Valle Inclán, Hernández nos introduce en el proceso de renovación que lo sensorial vive al calor del modernismo. Hernández estudia los nuevos discursos que nacen en el último cuarto del siglo XIX que incorporan los sentidos como filtro necesario a la hora de pensar la relación del individuo con el universo. En especial los avances en el campo de la psicología suponen un gran impacto en el mundo cultural español. Estos discursos se sitúan por un lado dentro del ámbito de la filosofía, en especial dentro de la corriente krausista, pero por otro lado dentro de la corriente científica de la psicofisiología. La Institución Libre de Enseñanza será el marco donde convergen esos dos ámbitos. Hernández además reivindica la historia de la cultura como una historia de los sentidos, integrada en un más amplio estudio de las emociones. 
Desde el campo de la filosofía nos llega la propuesta de Antonio Gómez Villar De H. Arendt a P. Virno: de la fábrica muda a la fábrica locuaz.En este trabajo Gómez analiza y compara los modelos de producción del fordismo y el postfordismo, y los modos de comunicación que en él se desarrollan. Así, y apoyado en el trabajo del filósofo del lenguaje Paolo Virno, se analiza el paso de una producción muda constituida a través de una cadena silenciosa, a los modos de producción postfordistas, que se caracterizaría por la irrupción del lenguaje en el mismo. Es lo que denomina una fábrica locuaz, donde el "verbo se hace carne". En este sentido, el postfordismo como un modo de producción que "pone al lenguaje a trabajar", oponiéndose as al lema que rezaba en muchas fábricas de producción fordista "silencio, estamos trabajando".

Ya centrados en el campo del arte, se nos presentan interesantes aportaciones que expresan las mismas preocupaciones que hemos observado en el campo de la historia. Iratxe Hernández Simal y su propuesta de "La extraña experiencia del espejoque no refleja. La obra de Juan Muñoz a escena" la puesta en escena en la obra escultor Juan Muñoz, con sus estrategias teatrales inherentes, que replantea las condiciones del encuentro entre arte y público tardo-modernistas. Se analiza el impacto emocional que la obra de este escultor tiene en el espectador contemporáneo, por ejemplo, al observar cien estatuas de chinos con un tamaño casi igual al del espectador. Se tiene en cuenta la experiencia del espectador, cómo vive su encuentro con la obra de arte. La mirada del observador -dotada de corporalidad física y emocional- multiplica sus puntos de vista en la instalación o construye imágenes a través de la escucha radiofónica, topándose con el profundo extrañamiento de lo familiar.

También la propuesta de Ana González Hernández, “Lo que encontré allí, através del espejo. Poéticas de la representación íntima en el Arte Contemporáneo asturiano: Bosquejos de un caso representativo" constituye una reflexión desde el del arte. Una reflexión que trata los temas de la corporalidad, las emociones y el diálogo que se establece entre el individuo y la colectividad. En este sentido, la propuesta de González parte de una consideración teórica sobre los rastros de la construcción identitaria que podemos encontrar en la plástica contemporánea asturiana. Lo hace a través de la observación de los espacios culturales en los cuales se produce el contacto y el diálogo entre artista-obra-público. González analiza una performance y una experiencia expositiva, comisariada por ella misma, a través de las cuales puede observar cómo el contacto entre la obra y el público están generados por la corporalidad y la emoción y en el mismo, lo individual y lo colectivo se funden. Analizando estos lugares participaremos de un complejo engranaje comunicativo que posee una doble dimensión, individual y colectiva, que germina entre la trama de la libertad creativa y de los constreñimientos estructurales y sistémicos.

Todas las comunicaciones presentadas han enriquecido el debate y han hecho interesantes Una de las ideas que más consenso ha alcanzado en la mesa es ha definido para qué sirve la emoción, cómo hay que usarla, qué fuentes hay que utilizar, y en definitiva, qué metodología se propone. Nuevos desafíos que seguirán marcando la agenda de la historiografía, ya que la categoría emoción ha venido para quedarse. 
ESCRITO EN EL CUERPO: CUERPOS «RESPETABLES»

EN LA ESPAÑA DECIMONÓNICA. LÍNEAS PARA

UNA POSIBLE RENOVACIÓN DE LA HISTORIA

SOCIOCULTURAL DEL XIX ESPAÑOL

Vicent Bellver Loizaga

Universitat de València

Hoy el Poeta, cuando trata de imaginar

estas grandezas originarias, en los lugares donde se dejan ver,

la desnudez del hombre y la de la mujer

siente que un tenebroso frío le envuelve el alma

ante este oscuro cuadro repleto de terror.

¡Oh, monstruosidades lamentando su ropa!

Oh, ridículos troncos!, jtorsos dignos de máscaras!

¡Oh, pobres cuerpos torcidos, enjutos, panzudos, o fláccidos!

Charles BAUDELAIRE: Las flores del mal

La revolución liberal, la época del liberalismo «respetable» y la(s) renovación(es) historiográfica(s)

Desde la década de 1980 se ha llevado a cabo, dentro de la historiografía desarrollada en España (aunque también con algunas destacadas aportaciones de otros ámbitos), una relectura de la trayectoria española en la contemporaneidad. Dicha relectura ha estado centrada, sobre todo, en la matización, discusión o impugnación de la interpretación que había sido hasta entonces dominante: la denominada por sus críticos como "paradigma del fracaso». Según dicha interpretación, la historia contemporánea española habría estado jalonada de fracasos (el de la transformación sociopolítica de la revolución liberal, el del proceso industrializador, el de la nacionalización española) que concluían, y no de manera casual, con un gran desastre: la guerra de 1936 y la instauración de la larga dictadura franquista. Esta revisión, que ha venido, en buena medida, de la mano de cierto "optimismo", consecuencia de los cambios sociopolíticos de la historia reciente española (el proceso de transición a la democracia, la victoria socialista y la entrada a la Unión Europea), así como, desde una perspectiva más global, del abandono de los grandes modelos explicativos en la historiografía y las ciencias sociales (las diversas corrientes derivadas del marxismo, las teorías de la modernización), el «giro cultural» que se ha producido en estas ${ }^{1} y$ también la revisión que se ha hecho de las trayectorias de otros países de Europa occidental; ${ }^{2}$ ha destacado que España fue "un país tan extraño como cualquier otro"

1 Una buena muestra de todo esto es la selección de artículos recogida en Mónica Burguera y Christopher Schmidt-Novara (eds.): Historias de España contemporánea. Cambio social y giro cultural, València, Publicacions de la Universitat de València, 2008.

2 Especialmente de otros países cuya trayectoria se consideraba también peculiar o desviada -Sonderweg-como Alemania o Italia, pero no sólo. De hecho, algunos de los paises que se consideran modélicos a la hora de trazar las visiones globales de la contemporaneidad o modernidad, como son Francia e Inglaterra, también han sido sometidos a un proceso de revisión.

3 Utilizo la expresión de Ferran Archilés y Manuel Martí. El texto clave que inició esta revisión fue y que, aunque con ritmos y peculiaridades propias, su trayectoria se enfrentó con desafíos y dinámicas similares a los del resto de países de Europa occidental.

En la actualidad, por tanto, y para el tema que aquí nos interesa, el mundo de la España postrevolucionaria, el panorama historiográfico que nos encontramos es que se ha llevado a cabo -o está llevándose a cabo- un redimensionamiento de la ruptura política y sociocultural que supuso la revolución liberal en España. Podemos, por tanto, siguiendo dichos estudios, trazar una breve panorámica: la experiencia del Trienio Liberal (1820-1823) y el exilio, el (para muchos, traumático) decantamiento del liberalismo por la vía revolucionaria (en un momento la década de 1830, además, en que el uso de la violencia revolucionario estaba circunscribiéndose a hechos puntuales -la experiencia francesa- o simplemente a una amenaza -el caso inglés- ) debido al enfrentamiento armado con el carlismo y las dificultades que supuso el papel de la (débil) Corona, que imposibilitó un pacto «transaccional» ( tal y como ocurrió en otras experiencias europeas) y la alteración de las realidades sociales que supuso la progresiva consolidación del capitalismo en Europa, implicó que muchos liberales redefinieran y/o abandonaran muchos de los principios que el primer liberalismo había supuesto (tal y como el sufragio universal masculino o ciertas referencias al iusnaturalismo) a favor de opciones de carácter más elitista y oligárquico mientras que, en cambio, el radicalismo liberal continuó presente en la esfera pública y la acción política, muchas veces apoyado por sectores populares urbanos. Tampoco podemos dejar de lado, como muestra la guerra carlista, la persistencia de una "cultura política tradicional», con cierta fuerza en algunos ámbitos geográficos y que impregnó algunos de los sectores moderados del liberalismo y la Corte, cosa que complica todo este panorama. Dentro de todo este magma de ebullición política y social, por tanto, el liberalismo hubo de redefinir, en los discursos presentes en la esfera pública y en las prácticas y experiencias, cómo se entendían los vínculos e identidades sociales (que, en parte, venían ya redefiniéndose desde finales del siglo XVIII con el lenguaje del liberalismo y la «utopía igualitaria» de éste), políticos, nacionales y de género, muchas veces, como veremos, entrelazados.

Pero, pese toda esta revisión que estamos trazando y la publicación de trabajos que están iluminando de manera bien diferente los años del reinado isabelino, ${ }^{4} \mathrm{M}^{\mathrm{a}} \mathrm{Cruz}$ Romeo Mateo hace ya más de una década, calificó de "incipiente" la historia del liberalismo en el período isabelino, pues aspectos como los citados más arriba (la construcción de la identidad individual y colectiva, la acción colectiva,...), a diferencia de lo ocurrido en otros ámbitos como el anglófono, han sido - al menos, hasta hace pocos años- poco explorados, 5 en parte, debido al gran peso que la historia política ha mantenido y mantiene en la historiografía española, así como al hecho de que el desafío del "giro cultural» y su recepción han llevado a muchos historiadores e historiadoras sociales a deslizarse hacia el terreno más "cómodo" de la historia política.

Como podemos ver, todos estos movimientos están marcados, de manera más o menos directa, con el "giro cultural», un movimiento amplio y de difícil síntesis que ha venido afectando a la historiografía internacional desde finales de la década de 1970. Pero dicho "giro", pese a la potencialidad que ha demostrado tanto en la recuperación de sujetos históricos como de campos de trabajo, ha estado, en los últimos años, puesto en cuestión, matizado y repensado

Santos JULIÁ: “Anomalía, dolor y fracaso de España”, Claves de razón práctica, 66 (1996), pp. 10-21. Más reciente encontramos el libro, aunque bastante irregular en sus aportaciones, coordinado por Nigel TOWNSON: iEs España diferente? Una mirada comparativa (siglos XIX-XX), Madrid, Taurus, 2010

4 Un ejemplo destacable de esto, en mi opinión, el es trabajo de Mónica BURGUERA: Las damas del liberalismo respetable. Los imaginarios sociales del feminismo liberal en España (1834-1850), Madrid, Cátedra, 2012

5 María Cruz ROMEO MATEO: “Una historia incipiente: los liberales en el reinado de Isabel II", Ayer, 44 (2001), pp. 253-264. Tenemos una buena muestra de trabajos realizados en el ámbito anglófono Publicacions de la Universitat de València, 2011 (original inglés de 2006). 
por los desarrollos y evoluciones de la propia historiografía "culturalista» y de la reflexión teórica y epistemológica global. ${ }^{6}$ De manera muy breve, podemos decir que la teoría cultura ha ido dejando de lado (y con esto no quiero decir abandonando) el aspecto más textualista (y más paralizante de ésta) a favor de un nuevo "giro" (práctico, material o social, según las diferentes teorizaciones) que recupere y ponga en valor aspectos como las prácticas, las experiencias, los cuerpos, las agencias,7 un movimiento, que a falta de una nomenclatura mejor podríamos denominar "postgiro lingüistico", en el que se inserta esta mesa. Aquí, concretamente, proponemos ver cómo en las representaciones de los cuerpos vivieron un proceso por el cual se inscribieron en ellos los valores «respetables» de las clases medias y como se utilizaron éstos como arma en la conflictividad política y social.

Este ensayo, pues, teniendo en cuenta las problemáticas historiográficas vistas, vinculadas en mi caso con preocupaciones extracadémicas -una recuperación de la historia de «lo social» y repensar la «Modernidad» en estos tiempos de embate del neoliberalismo, la necesidad de un desplazamiento interdisciplinario, la importancia del cuerpo en nuestra actual cultura y la experiencia vivida de no ajustarse a esos cánones)- intenta ofrecer una(s) posible(s) línea(s) de análisis. En este sentido cabe dejar claro que el paper que aquí presentamos se trata de un work in progress, un documento abierto que se inserta dentro de un proyecto de Trabajo de Fin de Máster sobre la gubernamentalidad postrevolucionaria en España.

\section{El cuerpo «respetable»}

El «largo siglo XIX» ha estado caracterizado (junto con otros calificativos como el de la "época del Estado-nación» o «del imperialismo» e incluso «de la monarquía») como el «siglo burgués». De hecho, a partir de las décadas de 1830 y 1840 y hasta la Gran Guerra, se puede hablar de un predomino sociocultural de "lo burgués». Cabe decir, pero, que cuando hablamos de burguesía o clases medias no debemos identificarlas, tal y como nos han demostrado muchos de los estudios de historia social y sociocultural de las últimas décadas, con el tópico, la imagen fija, presente en muchas metanarrativas del cambio social o algunas culturas políticas, que identifica la burguesía con el innovador «emprendedor», racional, despiadado incluso, protagonista del progreso económico y de la política del Estado-nación. Más bien, debemos tener presente un grupo social complejo y heterogéneo, que conjugaba fórmulas económicas individualistas y capitalistas con modales y pautas aristocráticas y que se expresaba con diferentes y cambiantes semánticas, según las realidades de los diferentes países. Por tanto, «lo burgués» o lo "respetable» comprendería unas nuevas formas de visión de las jerarquías sociales y de los ideales políticos, dentro de los cuales podían desarrollarse diferentes proyectos, asi como valores, aspectos morales y culturales (ideales de «lo privado» $y$ «lo público», ordenes de género). ${ }^{8}$ Son, sin embargo, estos aspectos aquellos que más frecuentemente se han dejado de lado en muchos de los análisis, con excepción de los trabajos de inspiración foucaltiana que

6 GeoffELEY: Una línea torcida. De la historia cultural a la historia de la sociedad, València, Publicacions de la Universitat de València, 2008; Geoff ELEY y Keith NIELD: El futuro de la clase en la historia. ¿Qué queda de lo social?, València, Publicacions de la Universitat de València, 2010; Gabrielle M. SPIEGEL: "La historia de la práctica: nuevas tendencias en historia tras el giro lingüístico", Ayer, 62(2006), pp. 19-50. De manera parcialmente diferente Simon GUNN: Historia y teoría ...

7 William H. SEWELL: “Por una reformulación de lo social”, Ayer, 62 (2006), pp. 51-72, Patrick JOYCE: "Materialidad e historia social", Ayer, 62 (2006), pp. 73-87. Un a propuesta teórica desarrollada dentro del ámbito historiográfico español J.J. DÍAZ FREIRE: "Cuerpo a cuerpo con el giro lingüístico", Arenal, 14:1 (2007), pp. 5-29.

8 Josep Maria FRADERA y Jesús MILLÁN: “Presentación” en Josep Maria FRADERA y Jesús MILLÁN Las burguesias europeas del siglo XIX. Sociedad civil, politica y cultura, Madrid, Biblioteca Nueva.Universitat de València, 2000, pp. 11-20. han solido tender, no obstante, a una visión unilateral. ${ }^{9}$ Sorprendentemente, el acercamiento a las fuentes revela que elementos de este tipo estuvieron bien presentes.

En lo que aqui nos ocupa he decidido plantear todo estas cuestiones, como decía más arriba, en las representaciones de los cuerpos (y los habitus que se derivaron de éstas), ya que pienso que esto contribuyó a mediar, seguramente de manera conflictiva, las experiencias vividas, tanto de los grupos que se consideraron y se construyeron como «respetables» como aquellos que se vieron excluidos de esta categoría y hubieron de redefinirse en relación con ésta, rechazandola abiertamente o redefiniendola. En relación con esto, me gustaría, por un lado, destacar que la construcción de los cuerpos es un fenómeno histórico (e historizable) que, a su vez, se encuentra en la intersección entre lo discursivo, lo material y lo social. Por otro, recordar, con Michel Foucault, que los cuerpos, pese a su olvido historiográfico, están también insertos en las relaciones de poder (y son seguramente uno de los lugares donde de manera más directa las experimentamos): "[E]I cuerpo está (...) directamente inmerso en un campo político; las relaciones de poder operan sobre él una presa inmediata; lo cercan, lo marcan, lo doman, lo someten a suplicio, lo fuerzan a unos trabajos, lo obligan a unas ceremonias, exigen de él unos signos."

Hemos decidido centrarnos en el período que se desarrolla a partir de 1830 por dos razones: por un lado, porque la revolución liberal, consolidada en España es esos momentos, introdujo una ruptura social y política y, por otro, porque a partir de la década de 1830, con la progresiva consolidación del capitalismo en Europa occidental y la irrupción tanto en las experiencias como en los imaginarios de la llamada "Revolución Industrial», se produjo, siguiendo a Pierre Rosanvallon, una fractura en la concepción de las relaciones sociales que había inspirado las revoluciones desde finales del siglo XVIII, la visión de la sociedad como una «sociedad de iguales"." Esta ruptura daría paso, entre otros movimientos políticointelectuales, a una redefinición de buena parte del liberalismo, la llamada «ideología liberal-conservadora», que remarcaría y naturalizaría la presencia de desigualdades sociales, poniendo además el acento en las responsabilidades individuales de las personas afectadas por dichas desigualdades. "Vale más ser amo que criado, director de un taller que simple jornalero del mismo, etc, Sin embargo, ambos estados son necesarios,y por tanto naturales, ya que la jerarquía y la subordinación están en la propia Naturaleza"12 escribía en la década de 1840 un destacado médico'3 que en los años treinta había estado cercano al radicalismo liberal de la Barcelona, el mismo que recordaba que "la miseria conlleva degeneración física, corrupción moral, enfermedades, tristes pasiones, prostituciones, delitos, revueltas".14 Como podemos ver, esto se encuentra vinculado a la construcción y negociación de la ya comentada «respetabilidad».

Desde otra perspectiva, algún autor ha hablado, tomando como imagen paradigmática la iconografía de La libertad guiando al pueblo de Eugéne Delacroix, de la elaboración, a lo largo de la primera mitad de la centuria, de una matriz visual de lectura social y política. ${ }^{15}$ Siguiendo

9 íbid., pág. 19, Simon GUNN: Historia y teoria ..., pp.127-130.

10 Michel FOUCAULT: Vigilar y castigar. Nacimiento de la prisión, Madrid, Siglo XXI, 2009, pág, 32.

11 Pierre ROSANVALLON: La sociedad de los iguales, Barcelona, RBA, 2012

12 Pedro Felipe MONLAU: Elementos de higiene privada o arte de conservar la salud del individuo, Madrid, Librería de Moya y Plaza, 1864 ( $3^{\circ}$ edición revisada y aumentada, original de 1846 ).

13 Tenemos que tener en cuenta que esa ruptura de la «sociedad de iguales» atravesó toda la cultura y no debe sorprendernos que acudamos a un médico, de hecho, y no de manera casual, coincide con la puesta en valor de la frenología.

14 Íbid. En momentos más tardíos, ya en la década de 1870 (coincidiendo con la consolidación del postivismo) el mismo Monlau extendería esto a una especie de leyes sociales, como puede verse en su discurso de entrada en la Real Academia de Ciencias Morales y Políticas (Patología socialBreve estudio sobre la criminalidad).

15 Alain CORBIN: Historia del cuerpo. Volumen 2: De la Revolución Francesa a la Gran Guerra, Madrid, Taurus, 2005, pp. 117-138. 
este tipo de propuestas, que se han pensado para el caso francés para los «tipos» burgueses aparecidos en las caricaturas y las fotografías,... ${ }^{16}$, y teniendo en cuenta todo lo anterior, creo que sería interesante analizar las imágenes producidas y difundidas en esos momentos en la prensa, la literatura y las representaciones artísticas españolas referentes a los diferentes prototipos sociales y políticos y ver si estas, aunque seguramente encontraremos problemas de fuentes, dieron posibilidad a lecturas disidentes. Antes de ilustrar esto con un par ejemplos extraídos de dos cuadros expuestos hoy en día en el Mueso del Prado, me gustaría también señalar que de manera paralela e imbricada a todo esto se estaba generando, tal y como estudió Laqueur, un «modelo inconmesurable de dos sexos ${ }^{17}$ derivado de la epistemología de la llustración que, aunque no sustituiría totalmente el anterior jerárquico de un único sexo, ${ }^{18}$ cosificaría, corporizaría las experiencias masculinas y femeninas. Elementos de género, por tanto, que cabe también tener en cuenta.

Como decía, me gustaría ilustrar la propuesta de la elaboración y fijación de la «respetabilidad" con dos imágenes que creo pueden ser ilustrativas: por un lado, con un retrato (nos encontramos en un momento de auge del retrato - individualización?-) de un mujer de filiación aristocrática y como es representada (imagen 1) y, por otro lado, con un polémico - en su momento- cuadro donde aparece un grupo de hombres, literatos y políticos concretamente de mayoritaria filiación moderada. ${ }^{19}$

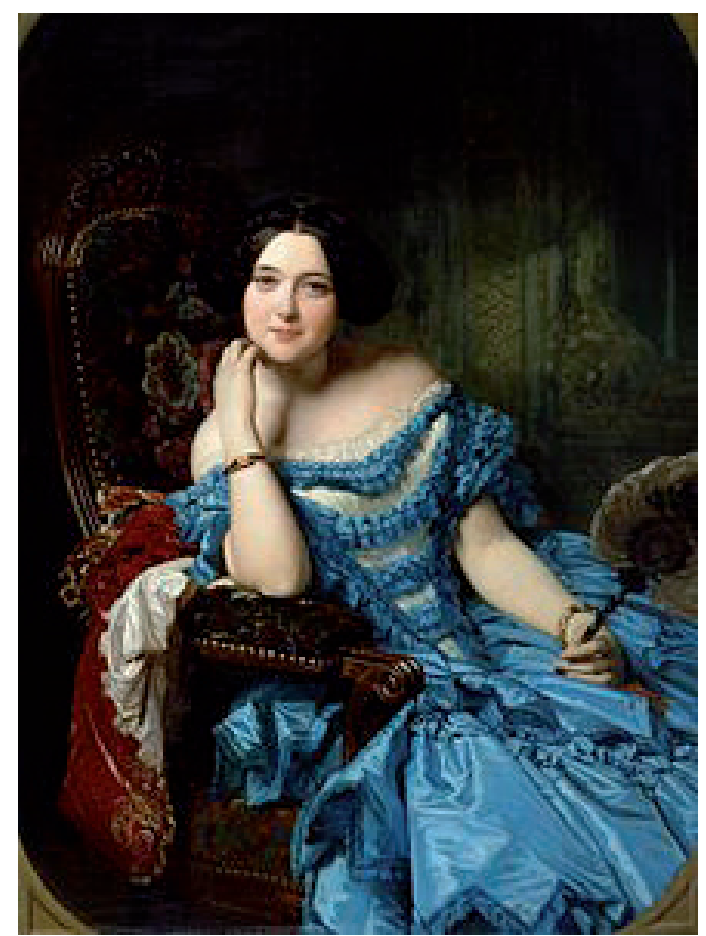

Img. 01 Doña Amalia de Llano y Dotres, condesa de Vilches, Federico Madrazo

16 Prototipos que se corresponderían a: Mayeaux (cuerpo grotesco pequeño burgués que se usó, entre otras cosas, en las representaciones criticas con el rey Luis Felipe), Monsieur Proudhomme (el "burgués medio") y Robert Macaire (imagen del burgués estafador, crápula). lbíd.

17 Thomas LAQUEUR: La construcción del sexo. Cuerpo y género desde los griegos hasta Freud, Madrid, Cátedra-Publicacions de la Universitat de València, 1994

18 Este matiz de Laqueur nos interesa ya que para el caso español se podría hacer una traslación del mantenimiento de un modelo único de sexo a los planteamientos defendidos por la Iglésia católica y los círculos ligados a ella.

19 Referencia a este cuadro y la polémica que suscitó en Xavier ANDREU: "La cultura” en Isabel BURDIEL (coord): España La construcción nacional, Madrid, Taurus- Fundación Mapfre, 2012, pp. $335-425$.

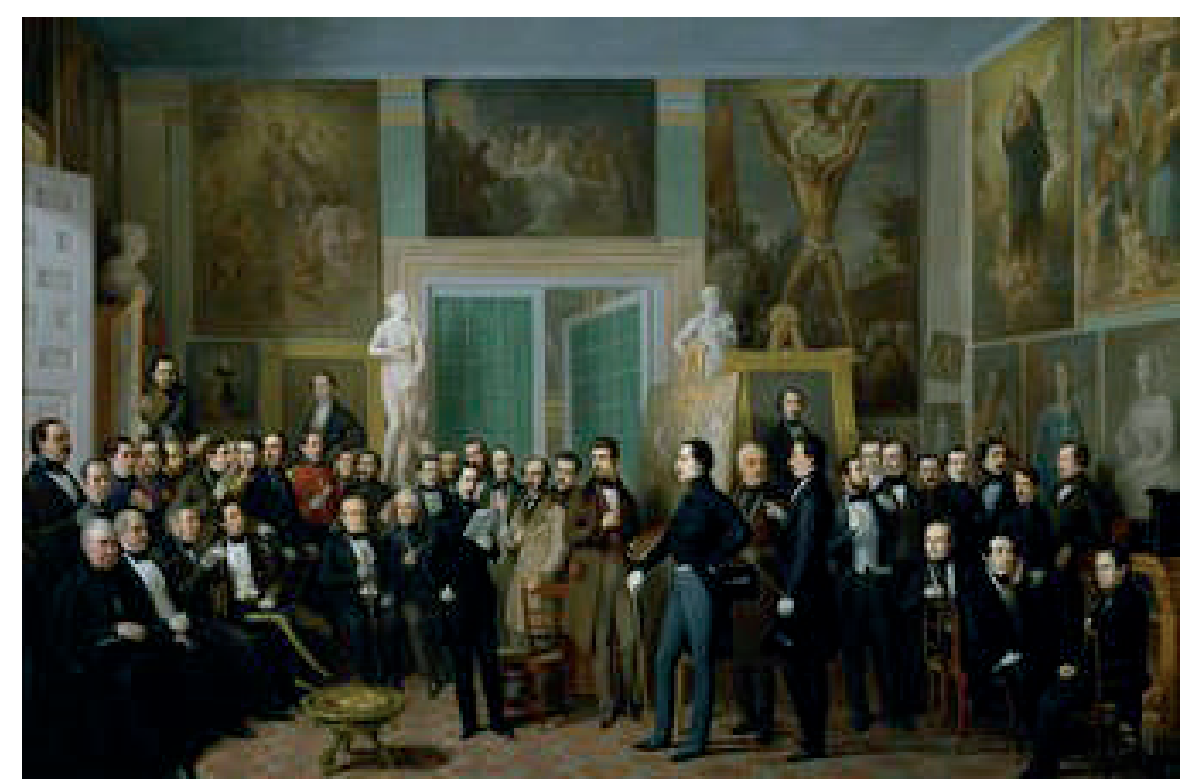

Img. 02 Los poetas contemporáneos. Una lectura de Zorrilla en el estudio del pintor, Antonio María Esquivel

En relación con este cruce de elementos, recientemente Isabel Burdiel ha publicado un sugerente estudio para los temas que aquí nos interesan en la introducción a la obra firmada por SEM Los Borbones en pelota ${ }^{20}$. En éste, dicha autora, analiza la construcción cultural de la monarquía constitucional, una institución que, pese a algunos tópicos, estuvo muy ligada a la consolidación del liberalismo en Europa occidental en un difícil proceso de adaptación mutua y de progresiva, aunque no definida de antemano, inscripción de la Corona en el mundo de los valores y de lo cultural. Este "descenso de los reyes", aunque mantuvo una aureola de excepcionalidad, fue parejo a una "apropiación" por parte de las clases medias de la familia real, que debió representar, además de manera ejemplar, los valores de «respetabilidad" propuestos por aquellos. La adecuación o no a estos se convirtió, tal y como Burdiel argumenta utilizando la pornografía política, en un arma no sólo cultural, sino también política, como puede verse en el caso del tratamiento de Isabel II y su familia durante «la Gloriosa».

El cuerpo de la nación, los cuerpos nacionales

El siglo XIX es considerado también, como hemos señalado anteriormente, como la «época del Estado-nación». Tal y como algunos estudios han puesto de relieve, las representaciones de la nación se corporizaron (como es el caso de la Marianne para Francia o la matrona con el león para España), cruzadas, además, por representaciones de género. A su vez, las representaciones de género adquirieron particularidades nacionales ${ }^{21}$. Este fenómeno, el de la nacionalización de las representaciones, que, aunque no está bien estudiado, cruzó también las identidades sociales, como puede verse en la obra costumbrista Españoles pintados por si mismos, en cuyo prólogo se señalaba que los diferentes tipos sociales habían sido vestidos con "traje nacional". Esto incluso traspasaría la imaginación literaria para naturalizarse en descripciones científicas, como es el caso de la de Pedro Felipe Monlau:

20 Isabel BURDIEL: "El descenso de los reyes y la nación moral. A propósito de Los Borbones en pelota" en SEM: Los Borbones en pelota, Zaragoza, Institución Fernando el Católico, 2012.

21 Xavier ANDREU: "Retratos de familia (nacional): discursos de género y de nación en las culturas Xavier ANDREU: "Retratos de familia (nacional): discursos de género y de nación en las culturas liberales españolas de la primera mitad del siglo XIX en Ferran ARCHILÉS e Ismael SAZ: Estudios Zaragoza, 2011, pp. 79-111 
La nacionalidad es una circunstancia individual tanto o más marcada que la raza. La diferencia que media entre los hombres de diferentes naciones, y aún de diferentes provincias ${ }^{22}$ (bien que todos -ellos- de una misma raza) salta a los ojos de cualquiera. A primer golpe de vista se distingue de manera ordinaria un español de un inglés, un andaluz de un gallego,etc La nacionalidad es el producto de la influencia combinada del clima, de la localidad, de las aguas, de los alimentos, de las costumbres, de los intereses materiales y morales,... de cada país. - El higienista, pues, en su estudios no deberá tampoco perder de vista la constitución orgánica y el carácter moral diverso que imprime la nacionalidad. ${ }^{23}$

\section{El cuerpo piadoso}

Por último, creo que es importante tener en cuenta el debate, aunque aún no ha irrumpido con fuerza en el panorama historiográfico español (mención aparte de algunos trabajos como los de Inmaculada Blasco, Joseba Louzao o Gregorio Alonso), sobre la «secularización" (vinculado a las llamadas "teorías de la modernización", una de las metanarrativas de la Modernidad). En este sentido, la relación del cuerpo y la religión se ha tenido en cuenta ya en algunos estudios de síntesis ${ }^{24}$. En estos se ha señalado que el imaginario y la práctica religiosa del catolicismo están cruzados por las representaciones del cuerpo.

Mas allá de esto, pienso que el análisis del cuerpo, la religión y la defensa de ésta puede dar resultados fructíferos. A modo de ejemplo, debemos hacer referencia al episodio en que la monja Sor Patrocinio, en plena revolución liberal, afirmó que "se le abrían dolorosas y espectaculares llagas con cada atentado de la monarquía absoluta contra la Iglesia y el viejo mundo" ${ }^{25}$, lo que puede llevarnos, más allá de lo anecdótico, al uso del cuerpo en el conflicto político de ruptura del Antiguo Régimen.

\section{Conclusión: ¿cuerpos y espacios encarnados?}

A través de esta comunicación he querido abrir y plantear, más que responder, una serie de propuestas de análisis, muchas veces de difícil realización (no sólo por la necesidad de una formación interdisciplinar que combine elementos de semiótica, estética,... sino por el grave problema presente de fuentes para acceder a las clases populares). En mi opinión, a grandes rasgos y aún a falta de una importante tarea de investigación empírica, desde las décadas de 1830-1840 se produjo una serie de complejos procesos interrelacionados, a través de los cuales los cuerpos de los españoles y la españolas fueron «encarnando» una serie de discursos sobre ellos, hegemónicos y contrahegemónicos, que mediaron sus experiencias, las cargaron de emotividad y conformaron sus su identidades (el "miedo de los acomodados", la progresiva reapropiación de la "respetabilidad" por partes de asociaciones obreras). Un proceso de «encarnación» que además es ampliable al espacio, especialmente de las ciudades. De hecho, Chris Otter ha hablado, en un estudio sobre el liberalismo como gubernamentabilidad en un sentido foucaltiano, de la progresiva materialización de una ciudad «respetable" y un burgeois visual environment por tal de hacer creíble y naturalizar, hacer durable como indica título de dicho artículo, el sistema liberal ${ }^{26}$.

22 Cabe tener en cuenta que Ferran ARCHILÉS en alguno de sus trabajos ha defendido que el proceso de construcción de la nación española se construyó a partir de la resignificación y difusión de las identidades regionales, de manera que éstas debieron ser de importancia y estar bien presentes, cosa que, aquí al menos, parece presente.

23 Pedro Felipe MONLAU: Elementos de higiene..., pág. 464. Las cursivas son del texto original.

24 Alain CORBIN: Historia del cuerpo..., pp. 57-86.

25 Isabel BURDIEL: Isabel II. Una biografía (1830-1904), Madrid, Taurus, 2010, pág. 41.

26 Chris OTTER: “Making liberalism durable: Vision and civilty in the late Victorian city”, Social History, 


\section{DE PELOS, BARRIGAS Y}

\section{OTRAS DISIDENCIAS CORPORALES.}

UNA BREVE APROXIMACIÓN A LA

CORPOGRAFÍA 'BEAR'.

Isabel Ferrándiz Armero

Introducción. ¿Por qué los osos y el cuerpo?

Los osos,' o bears - como internacionalmente se le conoce-, constituyen un subgrupo dentro de la subcultura gay, ${ }^{2}$ nacido al calor de los ochenta en Estados Unidos, pese a que actualmente se encuentra presente a lo largo y ancho de los cinco continentes. Pese a la relativa escasez bibliográfica, la totalidad de los autores consultados - Les K. Wright, Javier Sáez, Ron Suresha o Eric Rofes-coinciden en señalar desde un primer momento las dificultades existentes para determinar qué define exactamente a un oso. ${ }^{3}$ Aunque de forma superficial, entre dichos autores existe cierto consenso para referirse a los osos como hombres robustos y vellu$\operatorname{dos}^{4}$ que muestran sin tapujos sus barrigas con el propósito de traer al frente, de recuperar y reivindicar cuerpos que para el mercado de la moda y la publicidad resultarían «imperfectos». Pero, ¿es esta focalización en el cuerpo algo que sólo se registra desde la teoría?

Lanzo esta pregunta como ventana para abordar una cuestión que, además de ser clave en el sentir general, entronca también con el enfoque desde el cual he partido para realizar esta pequeña investigación: un trabajo breve, pequeño, que emerge con la intención de ser una prospección etnográfica. Esto último significa que, al tratarse de una realidad completamente ajena a mí, contemplé las técnicas etnográficas como una forma de entrar a ver qué hay, de tratar de identificar los "grandes» temas que ofrece —importan y preocupan- a este grupo;

* Gracias a todos los entrevistados e informantes las horas y los retales de intimidad que me han regalado. He decidido mantener el anonimato de todos ellos, de manera que no he procedido a presentar los fragmentos de entrevista tal y como se requiere en las normas de edición.

1 Utilizaré la cursiva para bearsy osos en un intento de desambiguación para evitar confusiones con el termino oso - animal-

2 A sabiendas de la redundancia, utilizo doblemente subcultura porque generalmente hablar en singular de «comunidad" gay no me resulta apropiado: posiblemente al utilizar este último concepto una puede estar corriendo el riesgo de fortalecer esos límites que parecen crear una imagen homogeneizada de las sexualidades no heternormativas cuando la realidad muestra, en contraposición, una multiplicidad de diferencias internas. Por ello utilizaré el término de subcultura gay que también escoge Óscar Guasch (2007), pues permite entender no sólo que existen continuidades con el «afuera» de la comunidad - con la cultura matriz de donde emerge la subculturasino que también aporta cierta noción de heterogeneidad interna.

3 Ver en Les K. WRIGHT: “Introduction: theoretical bears", en Les K.WRIGHT: The Bear Book. Readings in the History and Evolution of a Gay Male Subculture, New York, Harrington Park Press, 1997; Suresha, Ron J.SURESHA (2002): "Chapter I: Bears as Subcultural Subversives. An Interview with Eric Rofes", en Ron J. SURESHA: Bear on bear: interviews and discussions. New York, Allyson books, 2002; Peter HENNEN: “Bear bodies, bear masculinity: Recuperation, resistance, or retreat?", Gender \& Society. $n^{\circ} 19$, (2005), pp. 25-43.

4 Utilizo esta vez la cursiva porque soy consciente de las preguntas que suscita utilizar estos adjetivos: ¿más robusto que quién? ¿más velludo que quién? en definitiva, una forma de acercarse y empaparse del mundo de significaciones que operan en él, aunque sea a grandes rasgos.

Si bien yo venía buscando indagar en las masculinidades todavía no sé cómo, pronto me di cuenta de cuan necesario es tomar en consideración la impronta material que las categorías abstractas y analíticas dejan en el cuerpo, en este caso el género. Aunque para algunas esto último puede parecer una perogrullada, llegué a este punto tras darme cuenta de que el interés por el cuerpo aparece como un elemento inherente a los osos; esto es, constituye uno de los ejes que vertebran y articulan su «razón de ser» como grupo: los bears no sólo interpretan su nacimiento como forma de liberar al sujeto de las ataduras del propio cuerpo, sino que además, desde un juego de doble direccionalidad, ese mismo cuerpo liberador es exaltado continuamente. Atendiendo por tanto a este interés, me propuse ordenar y descifrar de qué manera se lee y se significa el cuerpo oso, para así entender cómo éstos se revalorizan en diferentes dimensiones.

\section{¿Qué nos dice el cuerpo oso? Un ejercicio corpográfico.}

El escrito que aquí sigue es producto - entre otras muchas cosas- de su función como ponencia en este IV Congreso de Jóvenes Historiadoras, y con ello, por tanto, entiendo que e acta de este debería reflejar lo aprendido e intercambiado en él. Es decir, la misma ponencia que, en el acto de serlo, se da cuenta de sus límites, sus errores, y se nutre de los mismos. Entre algunas de las ideas con las que me encontré durante las ponencias y su posterior extensión entre cervezas, una de ellas fue las diferentes formas de enfocar la mirada hacia el cuerpo: ¿qué entendemos por este? La pregunta no sólo me devino a mí, sino que, bajo este mismo razonamiento, Sara Hidalgo nos lanzó a todas la misma pregunta. Pese al tiempo que ha pasado desde que esa pregunta se quedara allí abierta, haré un intento -incompleto, por supuestopor pensar el cuerpo desde la mirada antropológica.

David Le Breton, muy acertadamente, afirmaba que el estudio del cuerpo resulta extremadamente difícil no sólo por la multiplicidad disciplinar con la que se aborda —-diluyéndose así el objeto de estudio-, sino, sobretodo, por los peligros que entraña abordarlo bajo una visión dualista inherente al propio concepto de cuerpo. ${ }^{5}$ En este sentido, el cuerpo moderno, como ya señalaría Durkheim, constituye uno de los primeros factores de individuación y existe en relación a nuestra noción construida de individuo: 1) implica entender al ser humano como ente separado del cosmos, pues presenta una anatomía que solo existe en él, 2) entenderse también aparte de un 'otro', dado que el cuerpo actúa como frontera de una misma, 3) y finalmente divorciado del mismo individuo bajo el ya clásico mente vs. cuerpo o razón vs. emoción. Bajo esta noción de cuerpo, las líneas que han guiado su estudio - entre muchas- pueden agruparse en tres: 1) aquellas referidas al cuerpo como experiencia vivida; 2) los estudios referentes al estudio social del cuerpo, en el sentido de los usos de sus representaciones como guía para comprender la sociedad de forma más profunda; y 3 ) aquellas referidas al estudio del control político del cuerpo, de su disciplinamiento así como también de la resistencia que del control político del cuerpo,
también pasa por el mismo.

Dicho esto, por cuerpo podríamos entender las emociones, los sentidos y la sensorialidad, pero también la anatomía y los discursos socio-culturales atribuidos a según qué rasgos corporales. Es, precisamente, en el último de estos sentidos donde ubico el presente trabajo.

Siguiendo con David Le Breton, éste señalaba que el cuerpo es un espejo social que actúa como soporte de las escenificaciones, de discursos y prácticas que provoca o acarrea, y que por

5 David LE BRETON: Sociología del cuerpo, Buenos Aires, Nueva Visión, 2002, pp. 33-39

6 Nancy SCHEPET-HUGHES, Margaret M. LOCK, «The Mindful Body: A Prolegomenon to Future Work in Medical Anthropology", Medical Anthropology Quarterly, 1/1, 1987, pp. 6-41. 
ello la apariencia física esta inherentemente ligada a la forma en que nos presentamos ante el mundo y la sociedad, pero también el punto de mira más elemental sobre el que los demás nos juzgan. ${ }^{7}$ De esta manera, lo que aquí pretendo es mapear, cartografiar, recorrer el cuerpo y su orografía simbólica con el fin de identificar los correlatos y discursos sociales que se desprenden o que provoca el cuerpo, y con los que a menudo jugamos y operamos para habitar en el mundo. Podríamos decir, en definitiva, que trataré de otear el cuerpo de los osos desde su representación social: como se piensa, como se imagina, para así poder empezar a entender en un futuro por qué se produce una apropiación o identificación con el oso por parte de las diferentes subjetividades que reúne.

Lejos de ambicionar una visión cerrada o conclusa de la realidad de los osos, considero pertinente mostrar, aunque de forma breve, algunos de los límites metodológicos que presenta este estudio. Con el fin de comprender los significados que operan en la realidad de los osos, realicé entrevistas semi-estructuradas a once individuos diferentes vinculados al colectivo de los osos por razones diversas - por autoidentificarse como bears, por sentirse atraídos eróticamente por ellos, por sentir en él la posibilidad de abrir un espacio de socialización ...Además, la buena relación con muchos de ellos constituyó el punto clave mediante el cual pude acudir a algunas de las fiestas y pasar horas en los bares específicos para osos, llegando a adquirir cierta información de las prácticas que allí tenían lugar y que, sin duda, constituyen una fuente de información valiosísima. La combinación de sesiones de observación -en este caso no-participante- con entrevistas abiertas me permitió captar las maneras de pensar con respecto al "ser oso", pues sólo con la observación no habría podido comprender buena parte del mundo de significaciones que se produce. Como ya había anunciado, el cuerpo oso es relevante porque vertebra buena parte de su razón de ser como grupo - la práctica totalidad de los testimonios recogidos coincidian en definir la categoría oso, en primera instancia, bajo términos corporales-; ello implica que el cuerpo se halle inserto en una trama que lo dote de sentido. En este caso, el cuerpo se entiende desde una narrativa histórica —un pasado que conduce hacia un presente-, así como también desde un esquema binario de opuestos que permite a los osos construirse respecto a unos 'otros'.

La rebelión de los cuerpos

Lejos de numerar tan sólo una serie de atributos corporales, las características corporales bears respondían a una cierta narrativa que explicaba el porqué era ese el cuerpo de los osos y no otro. Un cuerpo masculino, velludo, mayor y grueso se convertía así en un cuerpo bear a inserirse en una trama de significación, que configura al bear como categoría construida al calor de una causa resistente: la cosificación corporal de la experiencia del «ser gay» o — como mínimo- del mantener relaciones homoeróticas. De esta manera, todos ellos llevaban a cabo un ejercicio narrativo para insertar al oso en el centro de una rebelión contra el estereotipo gay dominante que otorga excesiva atención al cuidado del cuerpo; rebelión que no sólo se interpreta casi como un alzamiento voluntario sino que además resulta triunfante en tanto que visibilizado en diversas ciudades del mundo:

[...] tienen unas características que a veces son percibidos por los demás de la comunidad gay como descuidados, en un sentido despectivo de:“¿Cómo eres gay y no te cuidas el cuerpo?" Como si fuera la única cosa importante... y yo creo que el movimiento de los osos ha nacido precisamente por eso, para rebelarse a esta cultura del cuerpo. ${ }^{8}$

7 David LE BRETON: Sociología del ..., pág. 8

8 Entrevistado 2. Día: 14/04/2013.
Inserido en una trama histórica, el cuerpo de los osos pasa a construirse y situarse como opuesto a lo que ellos definen como un estereotipo corporal gay dominante, creándose así un esquema binario de opuestos entre un nosotros y un otros que inicialmente se imaginan como opues, pese a que la realidad como ellos admiten - acabe por reflejar una complejidad mucho mayor. Óscar Guasch, concretamente, define este estereotipo dominan-
te como la subcultura gay, la cual se encuentra atravesada "por los mitos de la juventud, la metáfora de la masculinidad y el culto al cuerpo, un tipo gay ideal masculino tan irreal como inalcanzable", 9 y que a menudo constituye la causa de muchas ansiedades sobre los sujetos que sienten no adecuarse a este referente.

Autores como este último, Alberto Mira10 o Juan Vicente Aliaga y José Miguel G. Cortés," coinciden en señalar, por otro lado, unas mismas causas históricas para el surgimiento de este estereotipo dominante. En términos generales, todos ellos refieren al nacimiento del cuerpo musculado y masculinizado en contraposición al modelo efébico que imperaría desde mediados del siglo XVIII hasta principios del XX en Europa-entendido como un cuerpo dócil y pasivo en tanto que afeminado-, aunque su expansión más global no se produciría hasta los años ochenta con la crisis del VIH — que afectó más visiblemente a los Estados Unidos- y la transformación física entendida como estrategia frente al temor de una delgadez extrema, signo corporal del SIDA.

Si bien los osos, en efecto, se piensan y se significan como rebelión corporal, lo cierto es que también mantienen continuidades con respecto a la coyuntura histórica que hizo surgir la subcultura gay dominante: los osos se construyeron asimismo en relación también a la crisis del $\mathrm{VIH}$, tal como señala Les $\mathrm{K}$. Wright, único autor que, hasta la fecha, ha realizado un intento por historiar el nacimiento del grupo bear en los Estados Unidos ${ }^{12}$. Como apunta este último autor, tras la conmoción sufrida por la propagación del VIH, los osos aparecen en escena fomentando los lazos de solidaridad y de recuperación de la autoestima entre aquellos cuerpos estigmatizados por la extrema delgadez, pero también aquellas corporeidades afectadas por el estereotipo corporal que empezaba a imponerse.

No es sólo un cuerpo, es también una filosofía de vida

Afirmaba que el cuerpo bear se entendía inserto en una narrativa histórica, pero también lo hacía bajo las lentes de un esquema dicotómico. En este sentido, el cuerpo de los osos es entendido como un cuerpo natural -en tanto que menos intervenido- frente a un cuerpo artificial. El exceso de cuidado y, lo más importante, la voluntad clara por trabajar el propio cuerpo para modificarlo es concebido como artificial, de ahí que muchos de mis informantes señalen ser osos sin haberlo buscado:

Jo de fet sempre he tingut una estètica que ara dirien bears, perquè clar porto barba des dels vint-i-cinc anys, [...] i anava amb camises de quadres perquè anava d'excursió, jo sóc d'aquells excursionistes d'abans de la motxilla de tal... [...] ara m'he anat engreixant, però dic, que una part de l'estètica que ara se'n diu bears, pues jo, inclús quan em vaig separar tenia 45 , ja era estètica bear però sense etiqueta, sense nom. ${ }^{13}$

9 Óscar GUASCH: La crisis de la heterosexualidad, Barcelona, Laertes, 2007, pág.103.

10 "Coda. Acabó la fiesta: evolución de las culturals homosexuales hasta el fenómeno Chueca (19841992)" en Alberto MIRA: De Sodoma a Chueca. Una historia cultural de la homosexualidad en España en el siglo XX, Ed. Egales, 2004, pp. 609-612.

11 José Miguel CORTÉS: "Acerca de modelos e identidades" en Juan Vicente ALIAGA y José Migue CORTÉS: Identidad y diferencia sobre la cultura gay en España, Madrid, Egales, 2000, pp. 126-162.

12 WRIGHT, L. K (ed): “Theoretical ..., pp. 14-16.

13 Entrevistado 9. Día: 07/05/2013. 
Esta naturalidad'4 se contrapone, como mencionábamos en el apartado anterior, al modelo idealizado del gay que exalta el trabajo del cuerpo o la atención por el cuidado estético en general: a ellos los testimonios recopilados denominan la musculoca o la marilicra, la marica fashion o la marica moderna. Así pues, desde el lado contrario, los osos se imaginan como hombres gruesos, o de cierta complexión robusta y fuerte, derivada de «la genética» como refería uno de los chicos con los que mantuve una conversación esporádica o bien del trabajo físico que el oso lleva a cabo en su actividad diaria o laboral, pero nunca como resultado de una voluntad clara y definida por cuidarse.

El rechazo al cuerpo de la subcultura gay dominante se debe a la actitud que, los testimonios recogido decían, se desprendía de estos modelos corporales: la soberbia, la superficialidad, el narcisismo o la vacuidad intelectual. Frente a la construcción de esos «otros» en negativo, la naturalidad corporal pasa a construirse en positivo y a situarse como el punto central de lo que a menudo ha sido interpretado como la filosofía o ideología de la comunidad de los osos: la auto-aceptación del propio cuerpo. Consecuentemente, de esta aceptación del propio ser corporal se derivan toda una concatenación de virtudes que resignifican y revalorizan cuerpos hasta ahora desplazados sexualmente o estigmatizados socialmente - los cuerpos mayores y gruesos-:

[...] jo penso que a la nostra cultura mediterrània, jo ho veig aqui o Itàlia, els madurs estem molt bé valorats; en canvi als Estats Units, que també hi he estat però per coses de feina, de pintura, o en altres llocs, i sembla que els madurs no estan tan ben valorats. ${ }^{15}$

Claro, tú ten en cuenta, a ver no diré que sea nazismo porque yo no trabajo en el gobierno, no soy la Cospedal (reímos), pero los osos, los gordos hemos estado sometidos a un vilipendio social durante mucho tiempo. $O$ sea: no está bien estar gordo porque es antiestético, crea enfermedades, y muchas cosas... Yo he sufrido mogollón cuando era pequeño porque a mi me acosaban por estar gordo..16

La tranquilidad con uno mismo a menudo se torna, para muchos informantes, en tolerancia, sencillez y trato fácil y sociable para con el resto. De hecho, esa propia aceptación corporal que desarrollan los osos a nivel colectivo para muchos será leído como un signo de confianza y seguridad, y por ende, protección frente a un «exterior a la comunidad» donde sí se sienten juzgados ante "los otros». Aunque tal vez es demasiado arriesgado afirmarlo, uno de los símbolos que a menudo se encuentran entre los osos es precisamente el oso de peluche, el cual remite inmediatamente a la ternura, así como a su asociación, desde el abrazo, ${ }^{17}$ con un elemento de protección. No sería descabellado, por tanto, pensar en el oso de peluche como el símbolo que integra esa función de protección que constituye, para muchos, el grupo de los osos: "Se supone que tiene también actitud, que no sólo porque sea gordo con barba eres ya un oso. Se supone que hay detrás una actitud de tolerancia."18

14 Todos estos valores están en cursiva dado que reflejan el significado que los propios sujetos han querido expresar en sus discursos o bien han expresado de forma literal.

15 Entrevistado 9. Día: 07/05/2013

16 Entrevistado 1. Día: 03/05/2013.

17 Peter Hennen, especialmente, hace mención a los continuos abrazos y el gusto por el contacto corporal -en un sentido afectivo, más allá del sexual-que tiene lugar dentro del colectivo de los osos. Si bien es cierto que existe este placer por el sentir afectivo de los cuerpos dentro de este grupo, tampoco contamos con otros referentes sobre los que comparar para afirmar que pudiera Ilegar a ser un rasgo propio de este colectivo. Peter HENNEN: “Bear Bodies,..., pp. 38-39.

18 Entrevistado 10. Día: 13/04/2013.
De esta manera, el cuerpo de los osos pasa a significar y vehicular «la liberación» del cuerpo bajo valores positivos; no obstante, los osos aún dan una vuelta de tuerca más, y pasarán a interpretar el cuerpo bear como la liberación del deseo, al erigirse como una imagen erotizada.

«iOh, mira que hombre...!»

El cuerpo de los osos pasa a representar también la libertad del deseo, pues estos emergen como un lugar desde donde desear aquél modelo de hombre que hasta entonces no sabían que fuera posible, o incluso legítimo, desear.

Desde pequeño siempre me fijaba yo en hombres con barba mayores que yo, y había ah algo raro. Cuando me pusieron Internet fue lo que empecé así a investigar un poquillo: primero en chats de gays normales, y vi eso de gay oso y dije: «Uy, ¿esto que será?». Me metí, me explicaron lo que era y dije: "Coño, jsi esto es lo que siempre me ha gustado! ¡Me siento identificado por primera vez!».19

El cuerpo bear se convierte en objeto de deseo, o tal vez, en imagen a desear. Matizo la cuestión de la imagen por dos razones. Por un lado porque, efectivamente, en los espacios de socialización de osos - páginas web o locales-abundan las imágenes de osos descamisados, mostrando sus torsos desnudos en actitud erótica. El énfasis por conducir la mirada de quien entra a un bar o a una página web hacia estos desnudos y semidesnudos, ayuda a sustentar la erotización de los cuerpos bears. De ahí que a menudo muchos de mis testimonios confesaran sentirse mucho mejor en un local oso - donde se les valora como deseables-que no en otros ambientes. En segundo lugar porque este excesivo flujo de imágenes pasa a reforzar no solo el deseo hacia los osos, sino que redimensiona, más concretamente, la imagen del oso deseado como veremos a continuación.

Si bien las causas del deseo sexual hacia los osos podrían ser múltiples, generalmente la mayoría de los testimonios recogidos señalaban como principal elemento de atracción su apariencia masculina, o mejor dicho, su cercanía a una masculinidad natural. Como veíamos, los osos utilizan unas categorías generales para definirse con respecto a un otro - artificialidad vs. naturalidad-, pero posteriormente unas menos específicas que, aunque derivan de las primeras, no están tan marcadas por la oposición binaria: como es el caso de esta -más que cursiva - masculinidad natural. Evidentemente, ésta última se entiende bajo una óptica enteramente heteronormativa en tanto que refiere a una masculinidad más cercana a la heterosexualidad dado que hasta el momento los osos no habían ocupado el lugar de un modelo gayificado: no presentaban rasgos que culturalmente se hayan asociado a la «homosexualidad" o a "lo gay». Javier Sáez, por ejemplo, sugería esta idea cuando afirma que "la estética de los osos es cercana para el mundo heterosexual, demasiado cercana: el carnicero del barrio de la barba negra que te vende las morcillas o el fontanero de brazos peludos y bigotes que viene a repararte las cañerías pueden ser gays ("iquién lo iba a decir!»). . ${ }^{20}$

El vello corporal y la barba remiten directamente a un modelo concreto de masculinidad dentro de nuestro imaginario. Al valor masculino del vello corporal, se añade también la ropa: camisas de cuadro y vaqueros, estética que Javier Sáez por ejemplo tildaba de 'leñador'21; una masculinidad que se imagina asociada con la dureza física y mental:

19 Entrevistado 10. Día: 13/04/2013.

20 Javier SAEZ : "Excesos de la Masculinidad: ..., pág. 143.

21 Ibid, pág. 142. 
[...] es el tema de esa masculinidad excesiva y de esa... que es la fantasía de todos: que eres un leñador que vive en el bosque, que no usas luz eléctrica, que no usas agua caliente, y ... una cosa así como muy ruda. Digamos que sería la fantasía de todos, pero la realidad es que no, no. ${ }^{22}$

El cuerpo de los osos se lee y percibe, literalmente, como el cuerpo más romántico del trabajador masculino: el camionero, el albañil, el leñador, ... No obstante, la configuración de esta masculinidad - marcada por un modelo específico de trabajador-como objeto de deseo no es exclusiva de los osos. Hablaba Demetriou de que la traslación de elementos propios de la cultura masculina heterosexual —como son los uniformes de trabajo por ejemplo- hacia la subcultura gay masculinizada - traducción mía del original gay male sub-culture- resignificaba su sentido original para connotarse de manera sexual, de forma erótica ${ }^{23}$. Paralelamente, Guasch menciona que a partir de la década de los 60 la revolución sexual gay visibiliza al macho, si bien a partir de los ochenta Aliaga y Cortés señalan que se impondrá a través del modelo musculado -ese falo permanentemente erecto que representa el cuerpo masculino de gimnasio como mencionaban ambos autores ${ }^{24}$. En este sentido, Wright sí que hace referencia a la vinculación de los osos desde un principio con el sector «butch» - macho, que no masculino- más que con la vertiente «queen» o «faeries» —afeminado-, llegando a albergar en muchos casos a la subcultura leather ${ }^{25}$. Lo que reluce de esta relación es que los osos y sus "otros» comparten códigos culturales pese a saberse inicialmente opuestos.

Sin embargo, lo cierto es que, a pesar de este flujo cultural compartido, sí se marca una cierta distancia con respecto al sector más butch o masculinizado, o mejor dicho, se abre una puerta distinta a la interpretación: el cuerpo de los osos no marca tantos músculos y generalmente es más mayor que la media de edad asociada a este modelo gay musculado. En este sentido el cuerpo bear se muestra como un cuerpo más frágil en tanto que exhibe sus imperfecciones, y es aqui donde nace su ambivalencia con respecto a la figura del macho vigoroso: "Lo bonito de los osos es que lucen cuerpos que son casi perfectos, y es este casi el que hace la diferencia".

El espesor cárnico de los osos se siente abrazable —decían muchos-, y la exhibición de sus imperfecciones corporales, a menudo hace pensar y sentir al oso como un cuerpo tierno ternura que, además, también comportaba para buena parte de mis testimonios, un valor erótico añadido. El oso se sitúa así en una frontera entre el ser macho - la agresividad y fuerza dominante del oso animal-, y la ternura e inocencia que encarna el oso de peluche, una hibridación que refuerza su potencia polisémica, y que permite aglutinar en su seno masculinidades y formas de sexualidad dispares y diferentes - algunas más tangenciales que otrasUna idea que ya parece presente incluso en los momentos de gestación del grupo de los osos: según Wright durante los 60 la idea del oso ya circulaba en algunas ciudades de EEUU, pues muchos utilizaban la imagen del oso de peluche para mostrar su rechazo frente al código de pañuelos, enfatizando así una voluntad por desmarcarse de las clasificaciones sexuales, as como también enfatizar el carácter afectivo de las relaciones homoeróticas.

22 Entrevistado 7. Día: 09/05/2013.

23 Demetriakis Z., DEMETRIOU: "Connell's Concept of Hegemonic Masculinity", Theory and Society, 30 (3), 2001, pág. 351.

24 José Miguel CORTES: "Acerca de modelos e identidades" en Juan Vicente ALIAGA y José Miguel CORTÉS: Identidad y diferencia sobre la cultura gay en España, Madrid, Egales, 2000, p.ág 144.

25 Javier Sáez por ejemplo en su artículo trata las subculturas leather y bear, aunque de manera separada, por ser las principales exponentes, y apropiarse, del imaginario del macho dentro de la comunidad gay.

26 Entrevistado 2. Día: 14/04/2013.

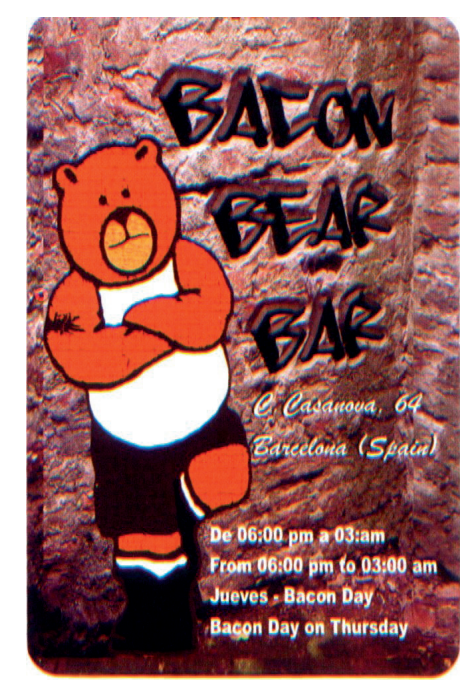

Img. 01 Fuente: Bacon Bear Bar

\section{In-conclusiones}

Aunque de manera esquemática, lo expuesto aquí nos conduce a pensar que efectivamente los osos construyen una imagen de sí mismos deseable a través de una concatenación de correlatos y discursos socialmente valorados de forma positiva. Además, la fuerza del oso radica en su esencia metafórica: facilita la comprensión de una realidad corporal polisémica e hibridada que se escurre a través de múltiples canales y crea la noción de un 'algo compartido'. Hace inteligible una realidad compleja: la cantidad de valores y correlatos a veces contradictorios, o supernumerarios que se imprimen en un mismo cuerpo permite aglutinar ya no sólo diferentes subjetividades y sino incluso diferentes cuerpos que se apropian del oso.

Teniendo en cuenta esta última idea, se entiende mucho mejor la ruptura que, a modo de final abierto, presento para el final. Si hasta el momento habíamos visto que el cuerpo oso remitía a una imagen corporal relativamente homogénea, lo cierto es que en su interior estos admiten toda una clasificación corporal interna que son capaces de sostenerse gracias al recurso de la metáfora con el oso: entre sus categorías encontramos al oso, al cachorro - cubal daddy -o papá oso-, al chubby —éste término no se traduce-, al chaser - traducido como cazador-, al admirer - que dista del cazador porque no sólo se siente atraído eróticamente por osos sino por otro tipo de hombres-, encontramos a la nutria, al muscul-oso, al oso polar, ... y así un sin fin de categorías que se multiplican en función de cada lugar.

De esta manera, forzosamente dejo inconcluso este artículo por los interrogantes que se plantean, y por ser, en definitiva, un pequeño trabajo final de máster que pretende abrir más ventanas. No obstante, tras este breve mapeado simbólico por el cuerpo de los osos, es evidente que las posibilidades semánticas que ofrecen, sin duda constituye una de las principales cuestiones por las cuales su definición como sujeto constituido aún parece complicada. En este sentido, nos parece que el colectivo de los osos ofrece a muchos ya no sólo un espacio desde donde desear y ser deseado; sino también un espacio desde donde pensar y abrir espacios de discusión con respecto a como se piensan las masculinidades —asignatura aún poco tratada desde la academia hispanohablante- al margen de listados de atributos en negativo asociados a la dominación, a la hegemonía o a la subordinación -como se desprendía de concepto de «masculinidad hegemónica» de Connell27-sino como bloques híbridos en los que se negocian, articulan e incorporan elementos diferentes e incluso opuestos.

27 TOny JEFFERSON: «Subordinating hegemonic masculinity», Theoretical criminology, vol 6 (I), 2002, pp. 69-72. 


\section{LOS FANTASMAS DE PORTBOU.}

\section{REGIMMENES DE MEMORIA Y EMOCIÓN}

Garikoitz Gómez Alfaro

University of Brighton

(g.gomezalfaro@brighton.ac.uk)

\section{Introducción}

En las últimas décadas la historiografía y, sobre todo, los estudios culturales, se han beneficiado de la evolución, en los talleres del trabajo conceptual, de todo un campo semántico relacionado con el mundo de las emociones y los afectos. Del mismo modo, y al abrigo de estos mismos debates, los estudios sobre la memoria han redefinido y reorientado buena parte de su metodología e intereses desarrollando nuevas líneas de indagación que enlazan, por ejem plo, la corporalidad y el uso público del pasado. De estos debates interdisciplinarios surgen nuevos interrogantes que van más allá de los marcos conceptuales centrados en lo lingüistico, la representación o lo semiótico y/o simbólico.

El objetivo de este trabajo es conectar algunos de estos debates teóricos sobre lo emocional y lo afectivo con algunas herramientas conceptuales "propias" del campo de los estudios sobre memoria y, en menor medida, la geografía cultural. Para ello, la ponencia se centrará en un estudio de caso: el de la pequeña localidad fronteriza de Portbou (Gerona), generalmente conocida, entre otras cosas, por albergar la tumba del pensador alemán Walter Benjamin (1892-1940). Como procuraré demostrar, el estudio del paisaje de memoria (memoryscape) de Portbou nos permite revisar las implicaciones ético-políticas que recaen sobre la construcción de la memoria pública de la Europa Occidental del periodo posterior a la caída del muro de Berlín. La localidad funciona como el teatro de la memoria pública contemporánea; es decir como el punto de fuga donde converge la herencia de las múltiples tragedias de lo que supuso lo que Enzo Traverso (2009) ha llamado "guerra civil europea". Dicho de otro modo, en Portbou se ha materializado la influencia de lo que podemos llamar la canonización del Holocausto como eje de la memoria pública europea. Así, el demoledor relato de la derrota de la ética en Auschwitz contrasta con el occidentalista relato triunfal de la formación de la Unión Europea. El rechazo al evento-otro de las matanzas pertrechadas por la maquinaria de guerra fascista aparece por tanto como el paradigma de lo que está llamado a superar el modelo auto-complaciente de la integración europea.

Asimismo, a lo largo del trabajo procuraré distinguir a grandes rasgos, entre distintos modelos discursivos o "regímenes de memoria" (Hodkin y Radstone, 2003) que han tenido lugar desde 1939 hasta 2012 en Portbou. Este concepto será puesto en diálogo con la noción de "régimen emocional" acuñada por William Reddy (2001) para subrayar la capacidad de estos sistemas para desplegar toda una serie de relatos ejemplarizantes sobre el pasado, valores morales, cá nones emocionales e incluso expectativas políticas. La hipótesis central será que, a través de la figura de Walter Benjamin, la comunidad internacional (o, más concretamente, los arquitectos de la integración europea) ha proyectado un imaginario traumatizado basado en el victimismo; un proceso en el que no han participado los vecinos de la localidad, que permanecen pasivos ante las conmemoraciones oficiales que alli se celebran. Dicho esto, en ningún caso debemos obviar la existencia de estrategias de subversión o contestación de estos modelos.
En este contexto, Portbou hará las veces de fragmento desde el cual lidiar con problemas que trascienden sus fronteras estrictamente geográficas. Al fin y al cabo era precisamente el fragmento lo que atraía a Benjamin en la medida en la que consideraba que, debidamente dispuestos, podían llegar a conformar un relato historiográfico que peinase la historia "a contrapelo". Es por ello que Portbou tiene, al menos desde el sentido que se le pretende dar aquí, ciertas similitudes con el Mennochio de Ginzburg o el Martin Guerre de Zemon Davis y hace posible, a pesar de (o precisamente gracias a) la limitación del estudio, profundizar hasta niveles cualitativos que no serían posibles en otros estudios empíricos más extensos (Candea, 2007). Por último, procuraré enlazar las reflexiones teóricas con una serie de cuestiones abiertas sobre las consecuencias éticas de estas exploraciones sobre la memoria en la actualidad.

\section{Constelaciones teóricas: por una materialización del pasado}

El sentido de esta materialización es doble; por un lado, es un guiño al propio Benjamin y su proyecto de aplicar la dialéctica materialista como herramienta contra el positivismo y la historia lineal. Dicho proyecto se apoyaba en una concepción abierta de la historia; Benjamin entendía que el tiempo no dibujaba una trayectoria imborrable, sino que se componía de saltos, discontinuidades y repeticiones; un planteamiento que conserva ciertas similitudes con la lectura que Deleuze y Bergson harían del tiempo (Al-Saji, 2004). Esta postura permitía asomarse al pasado desde una postura fundamentalmente política, ya que como explica Migue Á. Hernández Navarro $(2012,194)$, es así que "el tiempo se vuelve denso y espeso, si lo sentimos presente, si percibimos que podemos agarrarlo, retorcerlo, manipularlo y transformarlo".

Por otro lado, la idea de materializar el pasado (y, con él, las herramientas y las preocupaciones de los historiadores) aspira a aliviar el peso de cuestiones, por así decirlo, más idealistas (por ejemplo: la representación, la construcción nacional, la historia de las ideas) para poner el acento en aspectos más centrados en la corporalidad, la experiencia o la puesta en escena ${ }^{2}$ Los resultados más obvios de esta rematerialización de la historia pueden verse, quizás, con los últimos diálogos entre la geografía y la historiografía (Schlögel, 2007). Lo cierto es que, dentro de la geografía se han producido debates similares a los que tuvieron lugar entre los historiadores (Eley, 2008). La cronología es similar: tras una corriente dominada por la cartografía de los significados y la idea de "el paisaje como texto", nuevos impulsos que beben de planteamientos neo-materialistas y de la fenomenología del cuerpo están explorando conceptos tan interesantes como el de "geografía emocional" o "paisaje afectivo" (Wylie, 2007). Con todo, ha sido el trabajo de geógrafos como Soja (1989) o Harvey (2007), un tanto al margen de estos debates, los que han conseguido atraer la atención de la historiografía. Es desde los cruces de caminos de estas subdisciplinas donde a menudo se formulan las preguntas más interesantes. De hecho, ya desde los origenes de lo que hoy se considera, retrospectivamente, estudios de memoria, las coordenadas espaciales han estado bien presentes ${ }^{3}$. Consiguientemente, a través del giro espacial de la historiografía y las nuevos aportes teóricos de lo que se ha venido llamando "geografía no-representacional" (Thrift, 2007), quienes nos interesamos en el uso público del pasado hemos podido entender mejor cómo "the past is constructed socially -and

Este método de montaje pretendía hacer saltar el contínuum de la historia, una historia en la que "el enemigo no ha cesado de vencer" (Löwy, 2002).

2 Esto nos permite por ejemplo abordar los problemas teóricos en torno al género no tanto desde el aparato discursivo que lo envuelve sino desde la escenificación o encarnación de posturas y prácticas masculinas (es decir, la escenificación de la masculinidad). Para una introducción ver Blackman (2008). 3 Esta relación puede comprobarse perfectamente en el último de los trabajos de Maurice Halbwachs
(2008), a la sazón considerado "el padre" de los estudios sobre memoria colectiva, en el cual se pone de manifiesto el papel del espacio como un "entorno" o "ambiente" [milieu] para la memoria. 
expressed materially in landscape, public space, art, popular media, and architecture" (Foote y Azaryahu, 2007, 25).

En el propio campo de los estudios sobre memoria, cabe destacar la aportación de Paul Connerton (1989), quien criticó la tendencia entre los antropólogos de favorecer un modelo de investigación basado fundamentalmente en una memoria colectiva "inscrita" (mediada o trasmitida a través de novelas, discursos políticos, placas, etc....). Frente este modelo, Connerton proponía desplazar el foco de atención hacia sistemas de incorporación de la memoria que situasen al cuerpo en el centro de la ecuación. De esta guisa, las prácticas y rituales sociales mediante los cuales la relación con el pasado, por así decirlo se encarna o escenifica desde o a través del cuerpo de los actores sociales, fueron cobrando cada vez más relevancia para los investigadores (Kleinman y Kleinman, 1994; Fassin, 2007). Este movimiento había sido anticipado ya por una historiografía social que buscaba renovarse ante el agotamiento de modelos basados generalmente en los avances del giro lingüístico (Díaz Freire, 2008). Básicamente, lo que se pretendía poner de manifiesto es precisamente la dimensión material de la creación de significado; así pues, del lenguaje como estructura simbólica que lo condiciona todo, se pasa a un sistema en el que, de pronto, se estudia el "uso" del lenguaje como práctica (Sewell, 2006).

Uno de los principales debates en torno a la re-materialización del pasado gira en torno al problema de las emociones y los afectos. Conviene detenerse aquí un instante para aclara que si bien estos dos términos suelen entenderse como sinónimos, es importante comprender que a menudo podemos estar hablando de escuelas filosóficas diferentes. Por un lado existe un tendencia de corte spinoziano-deleuziano que se decanta por la noción de "afecto" y se refiere a un nivel relacional en el que los cuerpos se atraviesan entre sí (es decir, que pueden afectar y ser afectados) mediante líneas de intensidad y movimiento que escapan el significado (Massumi, 2002). Al mismo tiempo nos encontramos con las emociones entendidas desde el punto de vista psicosocial, tal y como las han teorizado autoras como Sedwick (1995; 2003) o el propio Freud. Hay que evitar, por tanto, caer en la trampa de la homonimia: para Spinoza, los afectos son fundamentalmente físicos y operan como modificación en unos cuerpos que no han de ser únicamente cuerpos humanos (Deleuze, 2001). Consecuentemente, la producción de cuerpos se describe a través de líneas, planos y superficies que pueden entre las cuales se mueve, mediante incursiones intermitentes y en constante redefinición, el sujeto. Pueden referirse, también, a "states of being, rather than to their manifestation or interpretation as emotions" (Hemmings, 2005, p. 551). Las emociones, en el sentido más psicológico del término, harían por tanto referencia a uno de los niveles de experiencia de estas modificaciones corporales. En resumidas cuentas, y como afirma Leila Dawney, las emociones no son tanto "'the sociocultural expression of this felt intensity' [sino] a sociocultural expression of this felt intensity" (Dawney, 2011, 3; la referencia dentro de la cita es de McCormack, 2010, 643).

Centrándonos ya de lleno en las emociones, conviene explicitar de entrada una complicidad con las posturas defendidas por autores como Ute Frevert, Barbara Rosenwein o el propio William Reddy. La primera, por ejemplo, argumenta que "although clearly resting on a physiological basis grounded in human (and animal) biology, [las emociones] acquire culturally specific forms and meanings" (Frevert, 2011, 211). Así pues, lo psicosomático está condicionado (que no necesariamente predeterminado) por estructuras sociales, hábitos y/o, recuperando los debates del anterior párrafo, ciclos o ensamblajes afectivos (Wetherell, 2012). En este sentido, el trabajo de los historiadores de las emociones ha sido fundamental a la hora de trazar el surgimiento y la decadencia de dos conceptos estrechamente ligados: "comunidades emocionales" y "regímenes emocionales". Mediante el primer concepto, la medievalista Rosenwein pretendía referirse a aquellos grupos sociales que comparten ciertas pautas o vías de validación de emociones ( $y$, por lo tanto, de la expresión o escenificación de las mismas) (Rosenwein, 2006; 2010). En una línea similar, William Reddy habla de "regímenes emocionales" (2001) para referirse a la prescripción o imposición de sistemas de sentimiento que despliegan una serie de orientaciones sobre lo permitido, lo prohibido, lo deseable, lo normal/abjecto, etc. Estos sistemas pueden ser implementados mediante diversas herramientas, siendo la censura o los aparatos represivos del Estado uno de los tantos ejemplos paradigmáticos que se han ido perfeccionando hasta el punto de que el biopoder contemporáneo no puede entenderse sin su faceta de gestión de los afectos (miedo, ansiedad, etc.). Dentro de estos "regímenes emociales" encontramos resistencias o "refugios emocionales", estrategias de fuga para desviar o contrarrestar estos mecanismos de supervisión o represión.

Una manera, a mi entender, muy productiva de ligar los interrogantes en torno a las emociones, los afectos y la manera en la que estos dos elementos dialogan con un pasado abierto es desde la noción de "régimen de memoria". Propuesto por Susannah Radstone y Katharine Hodgkins (2003), este concepto se refiere a las instituciones y los discursos mediante los cuales se regula una cierta relación con el pasado, es decir, los lugares e imágenes a través de los cuales la legitimidad memoria pública (pero no solo la pública) es negociada. Del mismo modo, estos regímenes discursivos están ligados tanto a las líneas desiguales que distribuyen las concentraciones de poder como a la circulación y la producción de conocimiento. Así las cosas, estos regímenes (de memoria y emocional) se confunden, participan el uno del otro, se complementan.

\section{Portbou. Unas ruinas Ilamadas "progreso"}

"Ningún otro lugar combina la conmemoración de un gran intelectual, el peso de la historia y un frágil rayo de esperanza de forma tan impactante"4; así describía la prensa alemana la pequeña localidad catalana en 1994, tras la inauguración del memorial de Dani Karavan en honor a Benjamin. Para entonces, la economía de Portbou había dejado de ser bombeada por la aduana: la "Europa sin fronteras" venía de la mano de la entrada de Portbou en el imaginario de la memoria pública europea ${ }^{5}$.

De ser un pequeño pueblo pescador pasó, tras la llegada del ferrocarril en 1878, a ser presa de un crecimiento exorbitante que desembocó en la enorme estación actual, construida en 1929 como puerta de entrada para la Exposición Internacional de Barcelona. Duramente bombardeada durante la guerra civil, especialmente en las últimas semanas de la retirada republicana, Portbou fue capturada por los rebeldes el 10 de febrero de 1939. Ernesto Giménez Caballero, quien formaba parte de la columna falangista que tomó la ciudad, comentaba lo siguiente sobre Portbou en sus memorias: "estos pueblos fronterizos parecen todos para los judios. De hecho, es donde suelen refugiarse más los hebreos" $(1939,63)$. Para Giménez, la situación fronteriza de Portbou era un nicho de apátridas, clara amenaza para la revolución nacional por la que decía haber combatido. Los sin nacionalidad, los judíos, los rojos, habían cruzado la frontera en masa durante los días anteriores. Una placa instalada en 2009 rinde homenaje a los más de 100.000 hombres y mujeres que abandonaron por el Coll de Belitres, justo en frente del monolito que fue colocado en 1940 para rendir homenaje a los "caídos" de la 4 a división de Navarra. Este monolito fue acompañado por otros elementos que marcaban el cambio de "régimen de memoria" como, por ejemplo, el cambio de nombre del pueblo (Port-Bou) o la introducción de un nuevo callejero con los nombres de protagonistas de la victoria franquista. Toda una serie de prácticas sociales fueron introducidas en la vida cuotidiana de la localidad para sancionar el nuevo régimen simbólico; así las cosas, tras la llegada de las tropas se oficio que duró el régimen franquista, no solo las emociones (p.e. duelo) fueron gestionadas y ad-

Manfred SCHNECKENBURGER: "Kleinmut siegt. Ein Denkmal für Walter Benjamin wird Gekippt", Frankfurter Allgemeine Zeitung, 6 de junio de 1992. La traducción es mía.

5 La ciudad a la que llegó Benjamin (1940) tenía 3 veces más población que el Portbou actual (1296 habitantes). 
ministradas (Rosaldo, 1984) sino que también se gestionaba qué era recordado, sobre qué se decreta un crudo silencio y, sobre todo, qué sentido político se le daba a estos encuentros con el pasado (determinando, por seguir con el caso de las conmemoraciones en honor a los caídos, que existe una deuda con respecto a un sacrificio dedicado a "dios y a España") (Cuesta, 2008)

Precisamente fue Benjamin, un autor de origen judio, quien cruzó la misma frontera en dirección contraria 18 meses después de la caída de Portbou. Judío sin estado, pues se le había denegado la nacionalidad en 1933. Tras haber recorrido Europa, se había instalado en París para finalizar la que estaba llamada a ser su mayor obra, El libro de los Pasajes, que quedó incompleta. Resistiéndose a dejar la Bibliothèque Nationale, cuyo archivo era esencial para la obra que alumbraba, Benjamin no abandonó Paris hasta que los alemanes estuvieron a solo unos pocos kilómetros de la capital francesa. Incapaz de obtener los documentos que le permitiesen dejar Europa hacia destinos como La Habana o Nueva York desde puertos franceses, Benjamin decidió cruzar los Pirineos para, acto seguido, dirigirse a Lisboa. Cruzó con la ayuda de Lisa Fitko, que formaba parte de la incipiente red de apoyo a exiliados del sureste galo que posteriormente desarrollaría con fondos estadounidenses el periodista Varian Fry (Palmier, 2006). Lo hizo acompañado de Henny Gurland y su hijo, si bien un poco antes de la llegada al pueblo catalán se les unieron otras cuatro mujeres alemanas que también huían de la policía alemana y sus aliados franceses de la "Zona Libre" de Vichy. A su llegada, la guardia civil española les denegó el permiso de paso. Encerrado entre dos frentes, y ante el miedo de ser puesto en manos de las autoridades francesas, Benjamin se suicidó la noche del 26 de septiembre de $1940^{6}$. A partir de este momento, lo que sabemos actualmente se confunde con aquello que Greenberg (2008) ha llamado la "Benjamin industry". Un maletín desaparecido que parecía contener un último y desconocido manuscrito, una carta de suicidio que es destruida y reproducida de memoria, un cuerpo ausente, una tumba falsa y una obra cumbre por terminar son solo algunos de los ingredientes de la retahíla de historias que revisitan los últimos días de Benjamin.

Estos acontecimientos no pasaron desapercibidos para la población local. Sin embargo, el impacto de los mismos fue ciertamente limitado por cuanto Benjamin era, fundamentalmente, un desconocido que no ha llegado a tener, por así decirlo, un público nutrido hasta hace relativamente poco (Maura, 2013, 190). En realidad, no es hasta finales de la década de los setenta cuando la historia de Benjamin comienza a abrirse. En 1979, componentes del gerundense grupo "Praxis 75" publican un artículo revisitando el relato comúnmente aceptado sobre la muerte del pensador alemán, barajándose la posibilidad de que hubiese muerto a manos de una Gestapo que colaboraba activamente con las autoridades franquistas. El mismo año diversos grupos, entre los que destaca la Assemblea Democràtica d'Artistes de Girona (ADAG) y el Partit dels Socialistes a Catalunya, organiza un homenaje a Benjamin que culmina con la colocación de una placa en la entrada del cementerio que reza "A Walter Benjamin - Filòsof alemany - Berlin 1892 Portbou 1940". El homenaje tiene lugar en el epicentro de la Transición española, durante la cual, y al menos para la izquierda de Gerona, Benjamin va a jugar el pape de "intelectual modelo" que permite ligar la represión franquista y en la prensa se hacen claras analogías entre el fascismo alemán y la España de franquista (Puigdemont y Sellés, 2012, 36).

Es precisamente este momento cuando se revisa de forma descoordinada e incompleta (aunque indudablemente, con un entusiasmo no exento de temores) el régimen de memoria de la dictadura franquista, llegándose incluso a exhumarse alguna fosa común?7. Al mismo tiempo, la

6 Esta versión ha sido, sin embargo, puesta en duda por el interesantísimo documental de David Maus iQuién mató a Walter Benjamin? (2005). La última y, quizás, más rigurosa biografía de Benjamin la ha escrito Bruno Tackels (2009).

7 Parece que estas exhumaciones se concentraron principalmente en la zona de la meseta-norte española, concentrándose en Navarra y La Rioja, aunque no fue un fenómeno exclusivo de estas dos. Para ver uno de estos casos de cerca, es recomendable consultar Josefina CAMPOS ORDUÑA: transición de una dictadura militar a una monarquía parlamentaria estuvo marcada por la explosión de movimientos utópicos que generaban otros futuros posibles que finalmente no fueron materializados ${ }^{8}$. En el paisaje memorial de Portbou, las fisuras del proceso de "normalización democrática" dejaron paso a ciertas acciones simbólicas que procuraban retirar el régimen de memoria del franquismo, como por ejemplo la recuperación del nombre catalán del pueblo o la renovación del callejero: así pues, la "Avda. General Mola” pasó a ser el "Carrer del mar", mientras que la "Plaza Sanjurjo" era rebautizada como "Plaza Pompeu Fabra". El miedo y el recelo fueron una de las facetas del régimen emocional impuesto por la dictadura, algo que estaba especialmente presente en Portbou debido a la cuantiosa cantidad de policía de localidad fronteriza. De hecho, el propio homenaje a Benjamin estuvo acompañado por un grupo de Guardias Civiles que tomaban acta de lo sucedido, apuntando los nombres de los asistentes, que todavía hoy recuerdan la velada amenaza que aquello implicaba para los locales. En cualquier caso, como en muchos otros puntos de la geografía española, las reivindicaciones que tenían como objetivo indagar en el pasado llegaron, tras el intento de golpe de Tejero de 1981.

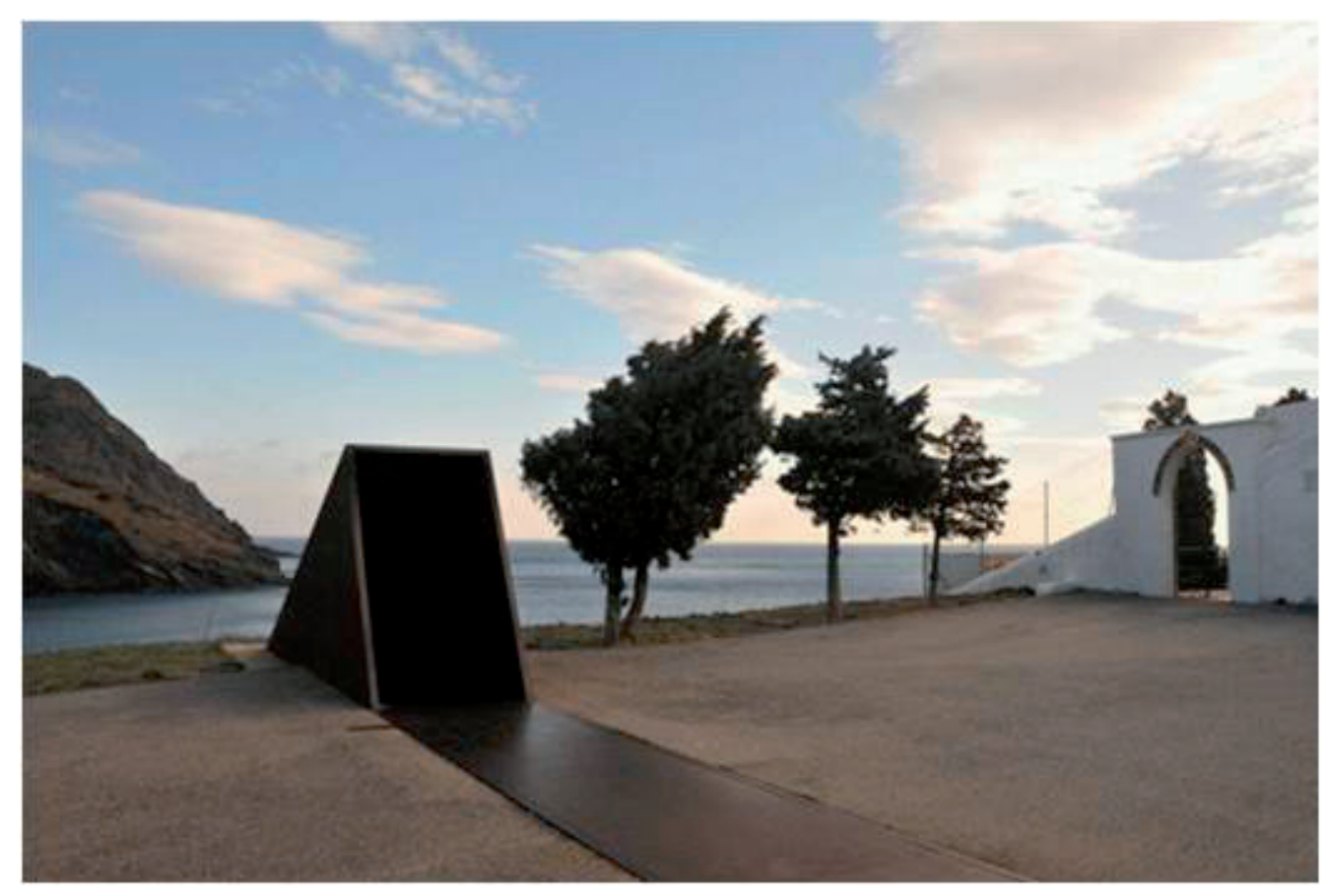

Fig. 01 Memorial Passages (Dani Karavan, 1994, Portbou)

Actualmente, los turistas no suelen visitar el monolito que rinde culto a "los caídos" de un solo bando. Del mismo modo, los paneles que homenajean a Antonio Machado entre otros miles de exiliados que abandonaron España por el último trozo de república catalana que quedaba tampoco son el objeto más buscado por los visitantes. Sin embargo, muchos son los que se acercan para visitar el memorial construido en 1994 por Dani Karavan [Figura 1.]. La instalación del artista israelí se compone de varios elementos, el más célebre de los cuales es la escalinata parcialmente recubierta que da a parar al acantilado al que se asoma el cementerio de Portbou. Al final de la escalinata, poco antes del abrupto final del trayecto, una mampara de metacrilato con la siguiente cita de Benjamin nos impide caer:

Los fusilados de Peralta, la vuelta a casa (1936-1978) Operación retorno, Pamplona, Pamiela, 2008. 8 Para una narración en primera persona de aquella experiencia, si bien desde la nostalgia de una mirada retrospectiva que se proyecta desde la actualidad, es interesante revisar Pepe RIBAS, Los '70 a destajo. Ajoblanco y la libertad, Barcelona, Booket Destino, 2011. 
Es tarea más ardua honrar la memoria de los seres anónimos que la de las personas célebres. La construcción histórica es consagrada a la memoria de los que no tienen nombre.

Sin embargo, si revisamos el contexto en el que fue construido el memorial, la mención a los "sin nombre" puede parecernos enigmática. ¿Quería Karavan homenajear a todos los sin-parte de la historia? ¿Se refería, concretamente, a aquellos que, como Benjamin, reposaban en fosas comunes a lo ancho y largo de la geografía española? ¿o se limitaba a rendir homenaje a los exiliados antifascistas y judíos de la II Guerra Mundial? A decir de los principales coordiandores del proyecto (Scheurman, 1992a; Scheurman y Scheurman, 1992b), fue el propio Richard von Weizsäcker, primer presidente de la Alemania Unificada, quien impulsó el homenaje a Benjamin. Personaje clave en el diseño de la relación de la recién unificada Alemania con los fantasmas del pasado, von Weizsäcker impulsó lo que Kattago (2001) denomina una "memoria ambigua" a medio camino entre el ejercicio de reflexión abierta, aunque parcial, sobre la herencia nacionalsocialista y por otro lado la imprecisa retórica redentora del "todos fuimos culpables".

Benjamin fue solo uno de los muchos alemanes exiliados, de hecho, ni tan solo fue el único que murió intentando cruzar los Pirineos (Carl Enstein, por ejemplo, acabó sus días en Pau). La elección del autor de las Tesis sobre la filosofía de la historia requiere una aclaración, no solo debido a su supuesto final accidentado, sino también debido al perfil político, a medio camino entre el compromiso desde el marxismo heterodoxo y el misticismo mesiánico. Esta compleja mezcla ha hecho de Benjamin una figura imbuida en "political ambiguity" (Greenberg, 2008) que pudo encajar en el "cambio semántico" descrito por Reinhart Koselleck, a saber, el giro ontológico presente en los discursos institucionales en Alemania (y, en cierto sentido, en Europa) a partir de la década de 1980 . Este giro proyectaba en la esfera pública una imagen de la víctima como sujeto por excelencia, segando la agencia y, con ella, la responsabilidad del pasado. A pesar de algunos problemas sobre la financiación del memorial, finalmente se inauguró ante la presencia de varias personalidades de la política alemana y catalana. La propia Lisa Fittko se desplazó hasta Portbou para el homenaje. En la ceremonia se alertó sobre el peligro de la nueva derecha alemana, sobre el conflicto en los Balcanes y sobre la necesidad de mantene vivo el recuerdo de Benjamin, pero nadie, ni tan solo las autoridades locales, hicieron ademán de ligar ese nudo de la historia con otras tantas derrotas locales. El paréntesis de la memoria española impuesto tras 1981 funcionó a la perfección: el recuerdo sancionado por las instituciones de la nueva Europa se cernía así sobre un olvido en la "moderna" monarquía española. El Presidente del estado alemán de Essen llegó a describir el final trágico de Benjamin como un "trauma colectivo", algo que, como recuerda Wulf Kansteiner $(2002,18)$, ha de matizarse cuidadosamente pues muchas veces la memoria trabaja sin necesidad de acudir al diván, centrándose en intereses económicos y oportunidades políticas.

Ahora bien ¿cómo ha sido percibido este espacio por los visitantes? Martínez Bachrich $(2008,48)$, un periodista venezolano que andaba tras los pasos de Benjamin, escribió que:

Ouien circula por las calles, playas o montañas de este pueblo cincelado a golpe de agua y de roca entre la Costa Brava y los Pirineos se da cuenta tarde o temprano de su atmósfera enrarecida, de su inexorable afantasmarse

Bachrich no es más que uno de los muchos que dan cuenta de la superficie espectral de la población catalana. La dimensión evocadora de Portbou no está ligada únicamente a su pasado problemático, sino que muy probablemente tenga que ver con el manifiesto deterioro de la arquitectura local, en claro declive debido a la depresión económica post-Masstricht que deshizo el comercio de las aduanas. El encuentro afectivo entre el paisaje de Portbou y los peregrinos de la memoria debe situarse, no obstante, en medio de una serie de planos superpuestos que fueron adquiriendo en los años que siguieron a la unificación alemana. El nuevo régimen emocional del Portbou en los albores del siglo XXI se centraba ahora en una nostalgia polisémica (nostalgia reflexiva causada por la derrota que marca la geografía de Portbou a tra- vés de refugios aéreos, bunkers o memoriales; nostalgia inflingida por el desempleo y el exilio económico de las generaciones jóvenes, etc.).

Es complejo situar históricamente este paso hacia la geografía de la nostalgia, ya que cada centímetro de terreno mantiene, por reducido que sea, su propia guerra civil por el significado. En este sentido, lo que en 1940 era una orgullosa conquista era para otros la puerta a la esperanza para poder llegar a los puertos de Portugal. En la creación de la "fría atmósfera" que pende sobre Portbou tiene un papel importante Walter Benjamin. Su figura encarna el proceso dialéctico a través del cual personaje y lugar se afectan mutuamente. El aislamiento natural de la localidad y el carácter taciturno, por no decir su final trágico, del autor alemán parece confundirse. Es por ello, quizás, que Reyes Mate (2010) ha apuntado que Portbou "es un lugar privilegiado para la comprensión y desarrollo de [la] cultura de la memoria"9.

Es interesante detenerse en algunas de las producciones literarias de los últimos años que se han referido, de una manera u otra, a esta localidad. Aquí me interesa llamar brevemente la atención sobre tres: las novelas Nocturn de Portbou (Jaume Benavente, 2003) y La meitat de l'ànima (Carme Riera, 2004) y el poemario Elegía en Portbou (Antonio Crespo Massieu, 2011). En las dos primeras novelas, el espacio es una clave narrativa fundamental que da lugar, por un lado, a una exploración de un pasado que se presenta como incómodo y problemático. Portbou es el escenario de esta indagación arqueológica que busca hacer visibles compuertas aparentemente ocultas en la memoria. En el primer caso, la estación de Portbou es la ecología contemplativa de un pasado que está plagado de relaciones sentimentales tormentosas, vacíos existenciales y tragedias humanas; en el segundo, la autora viaja a Portbou para descifrar la desaparición de su madre, que siendo una agente doble que trabajaba para el gobierno francés. Resulta particularmente revelador que este tipo de narrativas conserven una poética fragmentaria, acaso un guiño a la obra aporética de Benjamin. Del mismo modo, se registra en las referencias a este pasado problemático un tono nostálgico compartido: sin renunciar a potencial redentor del pasado, cepillar a la historia a contrapelo se revela una operación mucho más compleja de lo que las instituciones españolas pretenden.

Esta cadencia o armonía afectiva se cumple a la perfección en el poemario de Crespo Massieu, donde además radica un principio benjaminiano fundamental: la de la apertura en horizontal del tiempo-ahora. La derrota de Portbou es, en el instante de la lectura, la derrota de un proyecto ético, de una piel común; es, también, la hoguera en la que se apagaron muchos otros fuegos y el escenario desde donde construir una nostalgia regenadora. Como el trapero de las Tesis sobre la filosofía de la historia, Antonio Crespo Massieu realiza una colección de nombres a partir de fragmentos olvidados para crear (para mostrar y/o liberar) la potencia del pasado. Desde Portbou, suburbio de las conmemoraciones engalanadas, el poeta recoge así los pedazos que va dejando la tormenta del progreso (y del olvido):

Estoy aquí con los que lloraron / arena en los campos, los que fueron ceniza, /los que siguieron viajando como fuga sin sentido, [...]

Pues al fin este es el mismo azul, / el mismo cuadro, la misma belleza, / el mismo dolor idénticas huellas de ausencia, / aquí en Portbou / en la frontera de la luz y la historia. (Crespo Massieu, 2011, 73-75)

\section{Una conclusión que es una apertura y un prólogo a otra historia.}

Crear las herramientas para poder pensar históricamente la relación entre espacio y tiempo desde (o a través) la noción de experiencia es una tarea todavía pendiente. En este trabajo se ha querido apuntar algunas de las vías posibles para comenzar a explorar este camino. Portbou demuestra tener un fascinante potencial para crear un espacio para distintas formas de 
relacionarse con el pasado, incluso cuando se trata de distintas temporalidades. Obviamente, que el tejido urbano de la localidad catalana haya que entenderse como un palimpsesto no es, ni mucho menos, algo exclusivo. Sin embargo, es un buen escenario desde donde comprender el funcionamiento de los distintos (no siempre consecutivos) regímenes ideales de memoria y emoción. Actualmente, la memoria pública de Portbou es cautiva de unos sin nombre que vienen avalados por aquellos que no solo tienen nombre y apellidos, sino cargos públicos. Mientras tanto, la nostalgia material que exuda el paisaje de Portbou, que va perdiendo la vida debido a la sangría de jóvenes víctimas de un modelo económico agotado, no se reconoce ante una nostalgia importada. Una melancolía cristalizada en memoriales cuya ambigüedad ha descendido con poca suavidad desde los cielos académicos al suelo de las necesidades y los imaginarios sociales de los vecinos de Portbou.

Pero eso no es todo: la frontera europea, lejos de desaparecer, se ha desplazado hacia el sur ¿Cómo abrir la historia para dar cabida en nuestra derrota, en nuestro lenguaje emocional, la experiencia de otros nuevos cuerpos que vienen a trasgredir los límites impuestos por los nuevos fascismos de baja latencia? ¿Con qué palabras y con qué empatía hacer hueco a esos nuevos "sin nombre", a estos nuevos "sin parte" (en definitiva, a estos nuevos sin papeles) para dotar de sentido a este trauma en diferido? En Ceuta, Melilla, Zona Franca de Barcelona, Gran Canaria o Zapadores en Valencia, los cuerpos derrotados (las ruinas) se amontonan. Ante este escenario, tan solo una pregunta; una pregunta ambigua desde lo alto de un nombre cualquiera ¿hasta cuándo?

“Tampoco los muertos estarán seguros ante el enemigo cuando éste venza. $Y$ este enemigo no ha cesado de vencer" (Benjamin, 1989)

\section{Bibliografia}

Alia AL-SAJI: "The memory of another past: Bergson, Deleuze and a new theory of time", Continental Philosophy Review, 37: 2 (enero 2004), pp. 203-239.

Walter BENJAMIN: "Tesis de filosofía de la historia", en Discursos interrumpidos, Buenos Aires, Taurus, 1989, pp. 175-192.

Lisa BLACKMAN: The Body: The Key Concepts, New York/Oxford, Berg, 2008.

Matei CANDEA: "Arbitrary locations: in defence of the bounded field-site", Journal of the Royal Anthropological Institute, 13 (2007), pp. 167-184.

Josefina CUESTA: La odisea de la memoria. Historia de la memoria en España, Siglo XX, Madrid, Alianza Editorial, 2008.

eila DAWNEY, "The motor of being: a response to Steve Pile's 'Emotions and affect in recent human geography", Transactions of the Institute of British Geographers, 36:4 (2011), pp 599-602.

Gilles DELEUZE: Spinoza: Filosofía práctica, Barcelona, Tusquets, 2001.

Geoff ELEY: Una línea torcida. De la historia cultural a la historia de la sociedad, Valencia, PUV, 2008.

Didier FASSIN: When Bodies Remember: Experiences and Politics of Aids in South Africa, Berkeley/Los Angeles, University of California Press, 2007.

Ernesto GIMÉNEZ CABALLERO: jHay Pirineos! Notas de un alférez en al IV de Navarra sobre la conquista de Port-bou, Madrid, Editora Nacional, 1939.

Udi E. GREENBERG: "The politics of the Walter Benjamin Industry", Theory, Culture \& Society, 25:3 (2008), pp- 53-70.
Maurice HALBWACHS: La topographie légendaire des Évangiles en Terre Sainte. Étude de mémoire collective, Paris, PUF, 2008 [1941].

David HARVEY: Espacios del capital: Hacia una geografía crítica, Madrid, Akal, 2007

Claire HEMMINGS: "Invoking Affect. Cultural Theory and the ontological turn", Cultural Studies, 19:5 (septiembre 2005), pp. 548-567.

Miguél Á. HERNÁNDEZ-NAVARRO: Materializar el pasado. El artista como historiador (benjaminiano), Murcia, Micromegas, 2012.

Katherine HODGKIN y Susannah RADSTONE (eds.): Contested pasts: the politics of memory London, Routledge, 2003

Wulf KANSTEINER, "Finding meaning in memory. A methodological critique of collective memory studies", History and Theory, 41 (2002), pp 179-197.

Siobhan KATTAGO,: Ambiguous Memory: The Nazi Past and German National Identity, Westport, Praeger, 2001, p. 139

Arthur KLEINMAN y Joan KLEINMAN: "How Bodies Remember: Social Memory and Bodily Experience of Criticism, Resistance, and Delegitimation following China's Cultural Revolution”, New Literary History, 25: 3 (Verano 1994), 707-723.

Michael LÖWY: Walter Benjamin. Aviso de Incendio, Buenos Aires: F.C.E., 2002.

Roberto MARTíNEZ BACHRICH: "Memoria de Portbou", Revista Universidad de

Antioquia, 2008, pp. 44-49.

Brian MASSUMI: Parables for the Virtual: movement, affect, sensation, London, Duke University Press, 2002.

Reyes MATE: "Portbou, lugar de memoria", El Periódico, 13 de octubre de 2010

Jan PLAMPER: "The history of emotions: an interview with William Reddy, Barbara Rosenwein, and Peter Stearns", History and Theory, 49 (mayo 2010), pp. 237-265.

Eve SEDGWICK y A. FRANK (eds.): Shame and its Sisters: A Silvan Tomkins Reader, Durham, Duke University Press, 1995

William H. SEWELL: "Para una reformulación de lo social”, Ayer, 62 (2006), pp. 58-68.

Edward SOJA: Postmodern geographies: the reassertion of space in critical social theory, London, Verso, 1989

Barbara ROSENWEIN: Emotional Communities in the Early Middle Ages, Ithaca, Cornell University Press, 2006.

Barbara ROSENWEIN: "Problems and Methods in the History of Emotions", Passions in Context: Journal of the History and Philosophy of Emotions, 1 (2010). Disponible en < http://www. passionsincontext.de/uploads/media/o1 Rosenwein.pdf> (consulta 14/06/2013).

Enzo TRAVERSO: A sangre y fuego. De la guerra civil europea (1914-1945), València, PUV, 2009.

Renato ROSALDO: "Grief and a Headhunter's Rage: On the Cultural Force of Emotions" en Edward M. BRUNER (ed.): Text, Play, and Story: The Construction and Reconstruction of Self and Society, Washington D.C., American Anthropological Association, 1984, pp. 178-195.

Carles PUIGDEMONT i CASAMAJÓ y Narcís SELLES, Grupo Praxis 75 (1975-1990) Una guerrilla comunicativa, Girona, Ajuntament de Girona, 2012, [Catálogo de exposición].

SCHLÖGEL, Karl: En el espacio leemos el tiempo. Sobre Historia de la civilización y Geopolítica Madrid, Siruela, 2007,

Bruno TACKELS: Una vie dans les textes, Arles, Actes du Sud, 2009 
Jean-Michel PALMIER: Weimar in exile. The Antifascist Emigration in Europe and America, London, Verso, 2006.

Ingrid SCHEURMAN, Neue Dokumente zum Tode Walter Benjamins, AsKI/Ajuntament de Portbou, Bonn, 1992a.

Ingrid SCHEURMAN y Konrad SCHEURMAN (eds.) Für Walter Benjamin. Dokumente, Essays und ein Entwurf, Frankfurt am Main, Suhrkamp, 1992b.

Margaret WETHERELL: Affect and Emotion. A New Social Science Understanding, London, Sage, 2012.

John WYLIE: Landscape, Abingdon, Routledge, 2007.

Maura ZORITA: Las teorías críticas de Walter Benjamin. Temas contemporáneos, Barcelona, Edicions Bellaterra, 2013. 


\section{LA EXTRAÑA EXPERIENCIA DEL ESPEJO QUE NO \\ REFLEJA. LA OBRA DE JUAN MUÑOZ A ESCENA}

Iratxe Hernández Simal

Facultad de Bellas Artes de la Universidad del País Vasco/ Euskal Herriko

Unibertsitatea

\section{Una experiencia a modo de introducción}

A menudo me encuentro en la tesitura de tener que aportar un dato identificativo para que mi interlocutor caiga en cuál es el objeto de estudio de mi investigación. El nombre del artista, Juan Muñoz, resulta un dato anodino frente al impacto emocional producido por el encuentro con cien estatuas de sonrientes 'chinos' de un tamaño ligeramente inferior a una misma ocupando una gran sala de exposiciones en una suerte de gran escenario.

Permítaseme la experiencia en imágenes. Aquel miércoles de 2008 Sara visitó el Guggenheim Bilbao durante un descanso y se topó con una visión del conjunto desde la gran balconada del piso superior que corona la sala 208. Reunidos por grupos de entre dos y doce componentes parecían compartir... ¿charla? y acaso deseó descender para escuchar el murmullo que se intuía, para conocer y hasta participar del motivo de aquella animada congregación que no terminaba de aprehender. Ya en la segunda planta, aún en la distancia pero camino a la sala, se sorprendió por la atención que parecía dispensarle en la entrada una pareja que se orientaba hacia ella de entre el centenar. Con sus cuerpos ligeramente inclinados, brazos a la espalda y rostro sonriente -en ademán ambiguo entre el saludo y una divertida curiosidad-invertían los papeles de aquella representación, convirtiendo a Sara, súbitamente, en objeto de observación. Pasó de ver a ser vista. Una cierta incomodidad se apoderó de ella. Siguió aproximándose y experimentando cómo a cada zancada en sentido al centenar de 'chinos' aquella sensación de comunicación inicial retrocedía al menos otros $80 \mathrm{~cm}$. La posibilidad de diálogo, de contacto, tornaba distancia insalvable otra vez, pura ilusión. Dentro ya de la estancia, la evidencia de
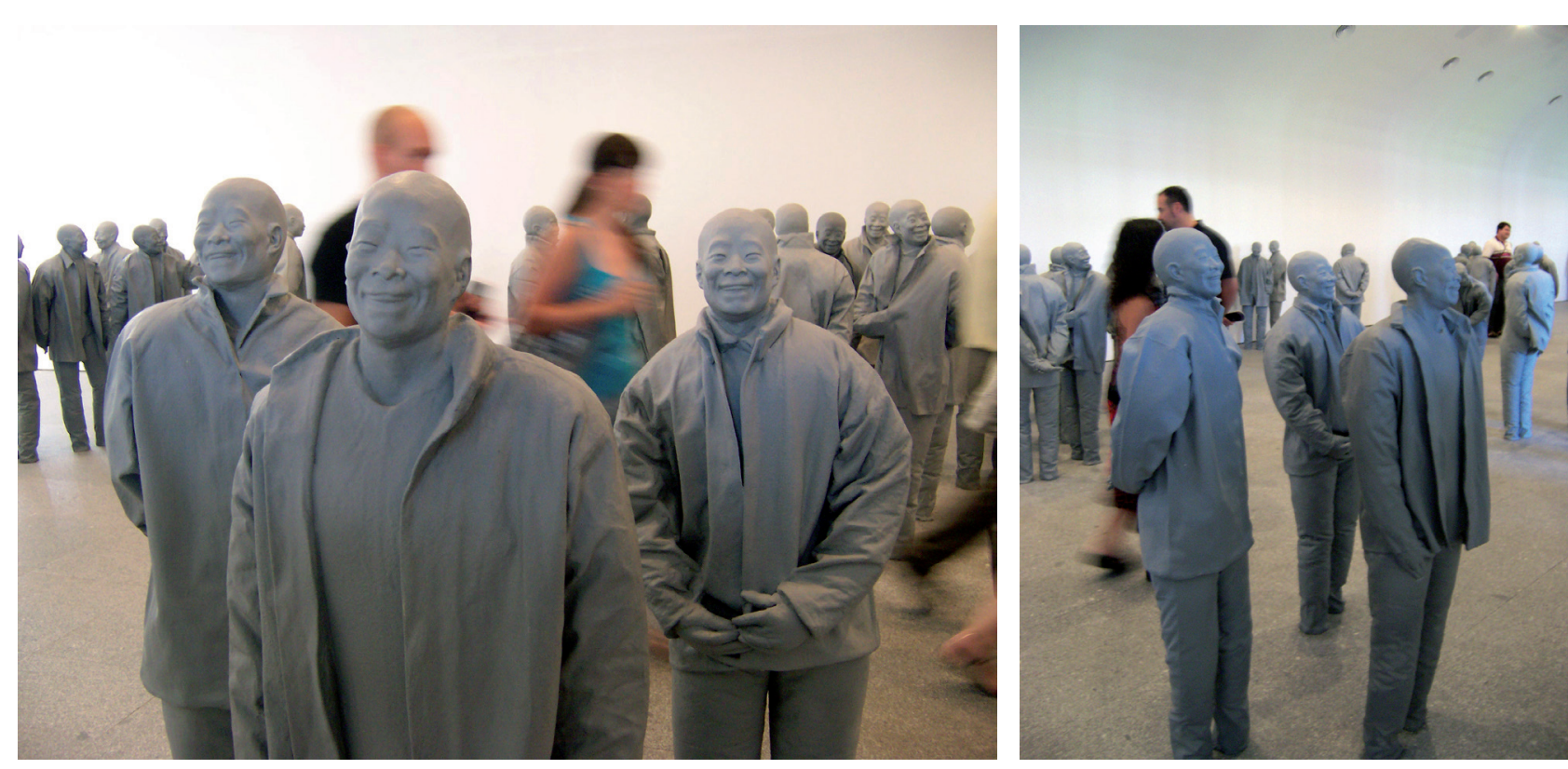

que aquellas figuras ignoraban por completo su presencia, excluyéndola de aquel 'asunto' aún por definir, permaneciendo en un tiempo y espacio suspendidos que nada tenían que ver con el transcurso de su vida, resultó mucho más honda por contraste. Minutos después pudo obequel otro espectador que se introdujo en el interior del grupo circul más numeroso para convertirse en el protagonista efímero de sus risueñas miradas. Tal vez éste decidió suspender su incredulidad y sumergirse de pleno en el drama.

La previa sólo alude una de las diversas puestas en escena a que ha dado lugar el despliegue, en diferente número y sobre contenedores disímiles, de las figuras orientales. El término francés original para puesta en escena, mise-en-scène deriva de la perspectiva unificadora del espectáculo teatral que emergió en paralelo a la figura del director de escena a principios de siglo XX y que he dado en definir, a efectos operativos, como la ordenación necesaria de los elementos (escénicos) para estructurar una determinada representación.

\section{Puesta en escena y teatralidad}

La obra Juan Muñoz (Madrid 1953 - Ibiza 2001) escabulle una acotación basada en el medio gracias a su carácter diverso (gráfica, escultórica, instalativa, performativa y radiofónica) que excede ampliamente la especialización académica londinense de su autor en grabado. El calificativo 'teatral' acompaña a una creación que asume como objetivo la generación de ilusión la idea de añadir posibilidades a la realidad desde la representación, si bien esto no supone un ajuste neto al arte del teatro -en el supuesto de que quepa definir el teatro como arte, puesto que, atendiendo al doctor José Antonio Sánchez', las experiencias híbridas, marginales o para-teatrales parecen superar las orientadas al instituido como núcleo de la teatralidad-. Por otra parte, el título de 'escultor', ganado a fuerza de persistir en la creación de discontinuidades espaciales, también figura insistentemente junto al nombre del artista sin conseguir arropar el conjunto de su obra. Se podría decir que la expansión de los campos artísticos definidos en torno a su esencialidad durante la modernidad dibuja y difumina simultáneamente áreas limítrofes entre escultura y teatro que esbozan un territorio muñoziano que bien pudiera ser descrito, parafraseando una de sus grandes instalaciones, como Un lugar llamado extranjero.

La experiencia de Sara en el interior de la sala 208 soporta la afirmación de Bryan O'Doherty de que con los tableau, el espacio ilusionista del cuadro se actualiza en la galería-contenedor, si bien formula tal idea en paralelo a la opinión de que "en la galería las convenciones teatrales se mueren"2. Sin embargo, la teórica y performer Bojana Cvejic ${ }^{3}$ defiende la existencia de un horizonte ideológico de expectativas derivado del teatro como aparato de representación establecido en la Europa moderna -cuyos ideales datan de la Grecia y Roma de la Antigüedadque llegando a desplegarse sobre una variedad de campos como el escultórico, define como teatralidad. Tal aparato de representación implicaría un sistema de operaciones materiales -enmarcado de la escena, posicionamiento del lugar del espectador y disposición de la figura

Según la conferencia "El teatro en el campo expandido" impartida por doctor José Antonio Sánchez con motivo de la exposición "Un teatro sin teatro" organizada en el Museo de Arte Contemporáneo de Barcelona en 2007. Disponible en www.macba.es/uploads/20081110/OP 16 Sanchez. pdf, SÁNCHEZ, José Antonio “El teatro en el campo expandido"

2 Bryan O'DOHERTY: Inside the white cube: the ideology of gallery space, Berkeley, University of California Press, 1999, pp.49-51. Cabe recordar a este respecto el enfoque pictórico que la escenografía teatral ha mantenido como convención durante largos años según la bibliografía sobre la materia. 3 Dentro del programa “Egonaldiak. Artium bildumaren inguruko lehengoratze jarduerak/ Estancias. Prácticas reconstituyentes sobre la colección Artium" la escultura Homenaje a Velázquez de Oteiza fue puesta en escena sobre una plataforma giratoria, bajo proyecciones de luz cambiantes, durante elaborados al efecto entre los que se encuentra el ensayo sobre teatralidad que tomamos como referencis B 
en el interior del marco- que resultan altamente pertinentes para analizar la obra de Juan Muñoz desde la perspectiva clave de la puesta en escena, definitoria de las condiciones del encuentro entre obra y espectador.

En el Many Times de Bilbao los planos de la propia estancia/contenedor-suelo, paredes, techo- constituirían el marco/encuadre de la escena -espacio escénico-. Constituirían los límites que 'recortan' el espacio en cuyo interior han sido dispuestas las figuras antropomorfas en lo que cabe interpretar como una dinámica socio/comunicativa dispersa. La posición estratégica del lugar de la mirada sobre la escena -espacio del público- se plantea en términos dinámicos y diversos. Por una parte, la separación entre el espacio escénico y el del público que proporciona la balconada semeja la visión privilegiada en unidad de campo que preserva la configuración convencional de los teatros 'a la italiana'. Desde esta posición la distancia física redunda en un cierto distanciamiento emocional. Por otra parte, la posibilidad de tránsito en el interior de la misma sala en que las figuras han sido dispuestas, fusionando el espacio escénico y el de público a nivel físico -ya que la exclusión del espectador con respecto a la situación dramática finalmente persiste-, no incorpora dispositivo de participación alguno, aunque multiplica los puntos de vista parciales e incrementa la intensidad emocional generada por proximidad con tales figuras. El acercamiento a la sala desde el pasillo provoca una paradoja -fenómeno característico de Muñoz-, la lejanía física que implica cercanía emocional y viceversa.

La descripción alude a la puesta en escena de ciertos elementos propios del particular lenguaje plástico de Juan Muñoz -en este caso cien 'chinos'- en un contenedor específico que juega con la confusión inducida a través de creencias y conocimientos previamente adquiridos por el receptor mediante inferencias y expectativas inconscientes que intervienen en su proceso perceptivo (interpretativo) e imaginativo. Continuaré exponiendo el sentido de un elemento clave -en el caso de Many Times el único elemento instalado- la figura antropomorfa, a la luz de los planteamientos comunes en el encuentro -experiencia, corporalidad y emociones-.

\section{Figura despersonalizada. Alteridad}

Muñoz, en un contexto escultórico coetáneo hostil a la estatuaria, retoma la representación del cuerpo humano-humanoide 4 bajo presupuestos alejados de los principios históricos tradicionales. A saber, la idea neoplatónica de que el auténtico artista-genio es capaz de atravesar el velo de las meras apariencias para revelar la realidad profunda, el alma, la esencia del referente. Dicho planteamiento es descartado por Muñoz para abrazar la idea del cuerpo de la estatua como cáscara, como corteza exterior, como aparato 5 . El sentido de la estatuaria del madrileño muestra vías de concurrencia con la idea del filósofo lévinas de que el arte trataría más del acontecer del oscurecimiento -opuesto a la inteligibilidad y efecto de evidencia- dejando a un lado tecer del oscurecimiento -opuesto a la inteligibilidad y efecto de evidencia- dejando a un lado
el orden de la revelación para abordar la sombra, la imagen no-ser que toda realidad conlleva ${ }^{6}$. Así, el mismo proceso productivo de las figuras muñozianas procura una despersonalización que nos aproxima a la idea de alteridad, basándose en formatos convencionales de la historiografía artística -terracotas, tallas toscas-, sustitutivos de humanos -muñecos-, réplica a partir de un molde realizado sobre modelos que constituyen en sí mismos una representación -los orientales toman por modelo un busto- o modelos inusuales del natural-como en la figura del enano/a cuya fisonomía concreta del modelo se difumina mediante la interposición de una tela -

4 Cabe precisar que sus obras primeras no incluyen explícitamente el elemento antropomorfo sino que lo pre-figuran su posterior aparicion a partir de elementos arquitectónicos auxiliares de uso corriente - escaleras, balcones, pasamanos, etc.-

5 Juan MUÑOZ "[Hablando en Alburquerque]" en Adrian SEARLE (ed.): Juan Muñoz. Writings/Escritos, Madrid, Ediciones de La Central, 2009, p.201

6 Emmanuel LÉVINAS: La realidad y su sombra. Libertad y mandato, Transcendencia y altura, Madrid, Trotta, 2001, pp.46-51
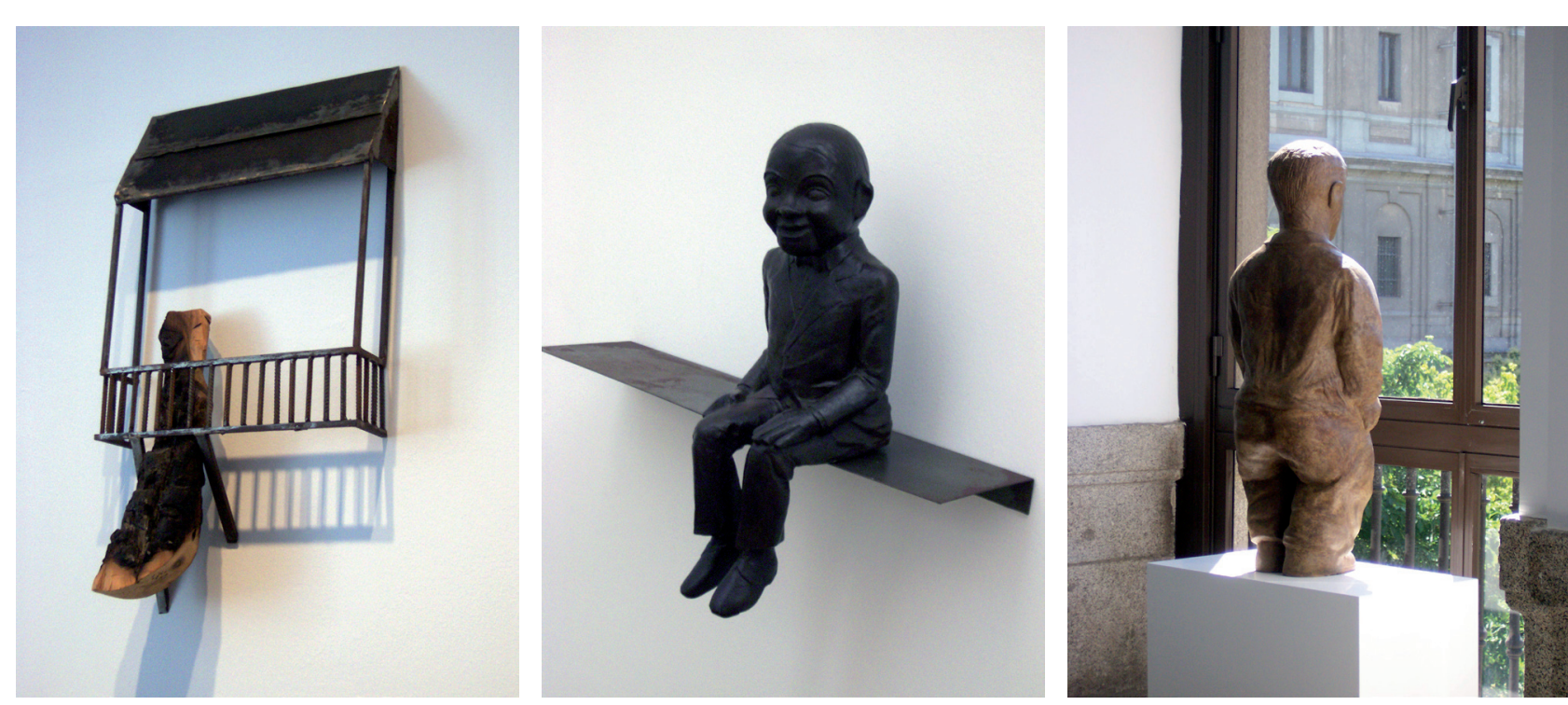

Los personajes de Muñoz nos muestran tipologías antropomórficas aproximativas a tipos genéricos representativos de la idea de alteridad, eludiendo la identificación individualizada. Pero tal elusión resulta complicada sin que el rostro suscite en el observador la interpretación de un contenido mayor. No es casual nuestra tendencia a leer en clave de rostro cualquier par de puntos acompañados de una línea -como ejemplo recordemos el origen de los emoticonos como combinaciones de signos de puntuación ; ) -. Un rostro que dotamos de expresividad a partir de levísimos matices. De ahí la dificultad de representar una máscara neutra, cercana a algunas de las figuras de Muñoz como los enanos o las terracotas, o un rostro verosímil no identificativo de un individuo en particular. Volviendo a los 'chinos', veamos qué engaños perceptivos entran en juego.

Gombrich aborda en su ensayo "La máscara y la cara: la percepción del parecido fisonómico en la vida y en el arte"7 la captación de semejanza fisonómica en arte desde la psicología de la percepción. Explica que la experiencia del reconocimiento del rostro de un individuo -identidad fisonómica- trasciende las circunstancias variables de su visualización como el ángulo de visión o la iluminación, así como las alteraciones morfológicas de dicho rostro a raíz de cambios expresivos e incluso estructurales, manteniendo, a través de la fusión de configuraciones disímiles, una constancia fisionómica que permite reconocer la identidad en el cambio, la unidad en la diversidad. No obstante, el campo de la percepción fisionómica acusa una paradoja. La compleja forma de reconocimiento de las constantes subyacentes a la cara a menudo se la captación de la máscara, un mecanismo de reconocim que puede contribuir a la confusión. Este mecanismo favorece al actor que aparenta ser una persona diferente según el papel correspondiente dotándose de un mero atributo -la bata blanca en el médico- o ademán -tono muscular-. Nuestra extrema sensibilidad a los signos exteriores contribuye a que la categorización de las personas no requiera del objeto-máscara o un exótico maquillaje de caracterización. Combrich alude a los sociólogos que recuerdan con insistencia el dócil desempeño de roles sociales por parte de todos nosotros dentro de los tipos aprendidos que conforman "el elenco de la comedia de la vida". A menudo la captación de un rasgo distintivo, incluso anecdótico siempre que llame la atención, resulta suficiente para que veamos un 'tipo' al que ajustamos nuestras expectativas, ahorrándonos de esta forma mucha energía en nuestras relaciones con los demás. En consecuencia Gombrich deduce que

7 Ernst Hans Josef GOMBRICH: "La máscara y la cara: la percepción del parecido fisonómico en la vida y en el arte" en Ernst Hans Josef GOMBRICH: Arte, percepción y realidad: conferencias en memoria de Alvin y Fanny Blaustein Thalheimer, 1970, Barcelona, Paidós, 1983, pp.15-67 
estamos programados para captar la diferencia -el rasgo distintivo, la desviación- más que para la semejanza. Con los 'chinos' nos encontramos ante un uso de este mecanismo de reconocimiento que induce deliberadamente a la confusión, el efecto enmascarador, que consiste en introducir un rasgo distintivo tan fuerte -rasgos étnicos orientales entre los que destacan los ojos rasgados- que impide la captación de matices más sutiles que nos permitan identificar individualmente a cada una de las figuras. La sonrisa que lucen todos los rostros y las ligeras variaciones en posturas y vestuario no contribuyen sino reforzar la idea de uniformidad y actitud social. De esta forma Muñoz consigue una imagen alegórica de la alteridad para el occidental ${ }^{8}$ sin prescribir identidad.

\section{El espejo que no refleja}

El caso es que la visualización de la figura antropomorfa evoca al semejante, induciendo una cierta expectativa de identificación que, sin embargo, queda defraudada por el poder del factor diferencial -nunca llegan a ser completamente humanas o proyectan la imagen de un humano que acusa una distorsión morfológica potenciadora de la desemejanza-, cumpliendo la afirmación del autor "My characters sometimes behave as a mirror that cannot reflect. They are there to tell you something about your looking, but they cannot, because they don't let you see yourself"

Más allá de la configuración de la figura antropomorfa, las expectativas derivadas del aparato de representación teatral mentadas por Cvejic incluyen la aspiración del espectador al diálogo especular (idea de reflejarse en y dialogar con el mundo representado) que se mantendría incluso en ausencia de obra dramática, como sería el caso que nos ocupa. El espectador-receptor aspiraría a la interacción con aquello que queda enmarcado y que constituye la escena en forma de reflejo (identificación) y diálogo (intercambio en un plano común), aun cuando su consecución sea tan solo aparente. Cuando uno se introduce en el interior de un grupo de figuras de 'chinos' a menudo percibe, aun de forma momentánea, la sensación de constituir el objeto de observación, saludo, e incluso de mofa por parte de las figuras. La pieza Contra la pared explota este efecto situando siete figuras sentadas o apoyadas sobre gradas y orientadas hacia una esquina de la estancia donde el espectador se sitúa con objeto de observarlas de frente y se ve sorprendido por su posición cual actor sobre el escenario.

Bajo parámetros racionales la escena termina irremediablemente por convertirse en una ventana -la tradicional finesta aperta pictórica que permite visualizar otro mundo, el representado, separado del 'real'- pero cabe señalar que los factores racionales ceden ante creencias profundamente arraigadas en nuestro subconsciente como sostiene una de las lecturas decisivas en Muñoz, La leyenda del artista $^{10}$. Sus autores, Ernst Kris, y Otto Kurz establecían un paralelismo entre leyendas de origen intercultural en torno al artista, temas que pululan por la fantasía del ser humano y ciertos rasgos invariables de la psicología humana que los psicoanalistas habían comenzado a discernir. Es el caso de las anécdotas en torno al pode ilusorio de la obra de arte que los autores interpretan como reminiscencia de la creencia en el artista mítico capaz de crear vida y movimiento, así como relatos de obras de arte que fueron confundidas con seres vivos, concluyendo que las circunstancias en que esta confusión se dio incluían el influjo de fuertes emociones. Por absurdo que parezca bajo el paradigma racional contemporáneo, corroboro la vigencia de dichas creencias profundas por dos vías aplicadas a

8 En una de sus entrevistas Muñoz (Third Ear, 1992) habla de sus cavilaciones en torno a la idea de extraterrestre, figura que indicaría alteridad para todos y cada uno de los "terrestres".

Juan MUÑOZ en su entrevista con Paul Schimmel en Neal BENEZRA (et al.): Juan Muñoz, Washington, Hirshhorn Museum and Sculpture Garden, 2001, p.150

10 Ernst KRIS y Otto KURZ: La leyenda del artista, Madrid, Cátedra, 1991 nuestro caso. Muñoz narra en la misma entrevista con Schimmel" en relación a dos de sus asistentes la misma emoción que me manifestó una trabajadora del museo Guggenheim Bilbao durante la exposición retrospectiva, la inquietud por quedarse con las figuras de 'chinos' en el estudio en horario nocturno. Un ancestral temor desencadenado en nuestra imaginación sigue uniendo efigie y emoción.

\section{Un espacio-tiempo suspendido y amenazante}

La sensación inquietante no se circunscribe en la obra de Muñoz a la figuras. La propia integridad física del espectador también se ve expuesta a una amenaza bajo ciertas obras como en la instalación $N^{\circ} 9$ (Ganchos), en que el suelo simula profundidad por medio de un entramado geométrico que ópticamente aparenta plagado de huecos por los cuales el cuerpo en desplazamiento del espectador podría caer. La instalación se completa con un elemento pequeño que activa el conjunto del espacio, los ganchos de carnicero que, en caso de caída, constituirían un agarre igualmente peligroso, poniendo en jaque y desequilibrando la corporalidad del propio receptor. La inclusión de elementos amenazantes persiste en piezas como Primer pasamanos donde el elemento auxiliar cuya funcionalidad se asocia a la seguridad en el desplazamiento esconde tras de sí una navaja que contradice dicha expectativa incorporando la paradoja. La apariencia completamente convencional del asidero no previene de la amenaza. La puesta en escena en un lugar donde en principio no se requiere de asidero alguno -en un corredor ampliamente más largo y continuo o en la pared de una estancia- apercibe de forma sutil del engaño, proporcionando el extrañamiento de un elemento común y perfectamente reconocible.


11 Juan MUÑOZ en su entrevista con Paul Schimmel en Neal BENEZRA (et al): Juan Muñoz, Washington, Hirshhorn Museum and Sculpture Garden, 2001, p.147 


\section{De la visión descorporeizada a la mirada}

Hablamos de la experiencia, atribución y frustración de expectativas en un espectador que se sumerge y transita un ambiente determinado por una puesta en escena escenográfica que remite a la noción de teatralidad. Precisamente el término teatralidad centró la controversia del célebre artículo Arte y Objetualidad que Michael Fried publicara en 1967 en su condición de crítico de arte afín al paradigma esencialista tardo-modernista establecido por su predecesor Clement Greenberg. El tono beligerante de tal artículo consideraba la teatralidad enemiga de arte y elemento contaminador. Nótese que en un contexto escultórico expansivo como los 60 70 en que irrumpían nuevos géneros como la performance o el happening, Fried centraba sus acusaciones de teatralidad en la mise-en-scène de las instalaciones minimalistas -'Iiteralistas', en su escrito- por envolver en una experiencia efectista al espectador, distinta de la supuestamente adecuada:

Mi idea recurrente del singular efecto que provocaba el literalismo, especialmente [...] como mise-en-scène [...] era como si sus instalaciones proporcionasen de modo infalible a sus espectadores una forma elevada de experiencia perceptiva [...]. Me di cuenta, rápidamente, que la base de dicho efecto era que tanto la obra como la instalación (en cierto sentido la instalación era la obra, como ha subrayado Thierry de Duve) requerían e involucraban al espectador de una forma fundamentalmente antitética con respecto al carácter expresivo y representacional de la pintura reciente que yo más admiraba. ${ }^{12}$

La experiencia adecuada a la que hace Fried referencia es denominada absorción. Una forma de visión pura y desinteresada que capta la atención del espectador al margen de toda pulsión corporal y, olvidado de sí mismo, sublimado, es absorbido de forma análoga a la experiencia de visualización de ciertos fenómenos naturales como las llamas de un fuego. A diferencia de Greenberg, Fried admite la absorción en la contemplación de arte figurativo bajo determinados presupuestos, así como la existencia de un tiempo de observación que transcurre a nivel imaginativo -análogo al 'espacio visual' descrito por Greenberg-.

Rosalind Krauss reaccionaba ante el debate de teatralidad y temporalidad en arte -que aún actualmente suscita reflexiones varias- aportando en sus Passages in modern sculpture ${ }^{13}$ toda una historiografía teatral en arte, además de revisar la teoría de la visualidad pura para cuestionarla y entenderla en el conjunto de una anatomía impulsada por automatismos in conscientes. No podemos establecer una adscripción exclusiva de Muñoz a ninguno de los dos extremos puesto que encontramos indicios de ambos. La representación de figuras absortas en una mínima actividad recurrente nos aproximarían a las pinturas de Fried, mientras que resulta imposible ignorar la implicación de la corporalidad del espectador en su dimensión física (posición, desplazamiento, desequilibrio...) y emocional (extrañamiento, inquietud,...). Y es que la posibilidad de incursión en el espacio escénico permite un desplazamiento de su cuerpo hasta cierto punto necesario para el despliegue de ciertos efectos teatrales, convirtiéndole de alguna forma en actor -aun cuando el artista lo conciba como actor inmóvil-, multiplicando los puntos de vista posibles. La fragmentación de la obra escultórica en diferentes elementos que se disponen de una forma estructurada en un contenedor espacial también desvía la centralidad de la obra en favor del espectador, quien se configura como eje de los puntos de vista, tal y como describe Maderuelo ${ }^{14}$.

12 Michael FRIED: Arte y Ojetualidad. Ensayos y reseñas, Boadilla del Monte, Machado libros, 2004 p.67-68

13 Rosalind E. KRAUSS: Pasajes de la escultura moderna, Madrid, Akal, 2002

14 Javier MADERUELO: El espacio raptado: interferencias entre arquitectura y escultura, Madrid, Mondadori, 1990
En este sentido procede considerar las reflexiones de Claire Bishop en torno al sujeto inscrito en las obras de arte en relación a las instalaciones ${ }^{15}$. Si bien el conjunto de la obra de Muñoz provee la experiencia en un ámbito intermedio entre la contemplación y las posibilidades que el espacio literal proporciona al espectador, incluso sus piezas gráficas implican un sujeto descentrado. La relación jerárquica que establecía Panowsky en su análisis de la perspectiva renacentista por la cual el espectador era situado en el centro del mundo representado en virtud de la conexión entre sus ojos y las líneas de perspectiva y el punto de fuga del horizonte es rota en los Dibujos de Gabardina. Si la perspectiva renacentista proyecta la idea de un sujeto racional estable en el entramado tipo ventana del cuadro, cuya composición tiende a estar cerrada y dirigida hacia el interior del marco, Juan Muñoz, en sus dibujos de interiores escasamente amueblados, desplaza al exterior del marco el punto de fuga de la representación ilusionista alcanzando una mayor inestabilidad aún en los grabados Mobiliario.

La imagen adjunta revela una posición interpretable como de caída -recuérdense con los huecos planteados en la instalación $N^{\circ} 9$ (Ganchos)- por ausencia de referencias como la línea de horizonte o una eventual superficie de reposo común para los dos elementos de mobiliario. Más aún, el descentramiento también incumbe al motivo representado pues en los Dibujos de gabardina, el enmarcado, lejos de privilegiar la representación de un solo punto centra ilustrativo, explicita intersticios, espacios de tránsito, residuales y marginales, dejando fuera de marco o de percepción información relevante, despertando la sensación de falta o ausencia en el espectador.

\section{Escena: los fragmentos de la historia}

Esta imposibilidad de lectura completa y comprensión de la escena se erige en constante del objeto de estudio. La interpretación de la situación dramática planteada en la escena acusa una falta, una ausencia que queda fuera de marco. En términos perceptivos, lo que falta podría ser la dimensión sonora de la conversación. En términos literales la figura presente podría estar mirando hacia algo que no ha sido representado. La sensación de falta, olvido o ausencia llena una atmósfera que induce a una búsqueda de significación que jamás queda satisfecha, porque la historia no está cerrada, los personajes dejaron su razón atrás, el murmullo es inaudible, las relaciones sociales ilegibles.... Permítanme otra anécdota que, mediante una metáfora corporal, enlaza las interpretaciones históricas y la polisemia deliberada de la obra muñoziana. El arquitecto y precursor de la idea de obra de arte total [atribuida generalmente a Wagner] Gotfriett Semper (1803-1879) disentía de la interpretación histórica que sobre la arquitectura monumental griega habían realizado estudiosos como Winckelmann. La presunta transparencia comunicativa de la cultura clásica, su expresión pura, exenta de policromía y ornamentación era atribuida por Semper a un error, a la confusión entre fragmento y totalidad que se derivaba del estudio de las ruinas:

[...] y ahí radica el error interpretativo que Semper denuncia: el 'tomar los huesos de mamut" por el mamut mismo, el creer que la ausencia de decoración y carnalidad de las ruinas de la Antigüedad representan la Antigüedad misma, cuando lo que estamos observando no son más que restos..$^{16}$

Es precisamente "Ia falacia de la historia como agregado de textos disponibles" denunciada por Semper en lo que se recrea Muñoz estéticamente, proporcionando una experiencia de

15 Claire BISHOP: “El arte de la instalación y su herencia”, scribd, http://es.scribd.com/doc/50978863/ BISHOP-la-instalacion-y-su-herencia

16 Fernando OUESADA: La caja mágica: cuerpos y escena, Barcelona, Fundación Caja de Arquitectos, 2005, p.79 
"imposibilidad de construir una nueva totalidad desde el fragmento y su ensamblaje abstracto"17 como propuesta estética que desemboca en extrañamiento. Una obra abierta en extremo a significaciones varias. La obra de Muñoz aborda los fragmentos de la historia y la interpretación que en cada momento se hace de los mismos, entendiendo, como Borges, que el olvido es una alta forma de memoria y reafirmando su idea de que "La escultura es como la electricidad. Es tan solo nuestra comprensión de ella la que cambia." 18



17 Ibid., p.83

18 Juan MUÑOZ: "Del oficio de ser visto" en SEARLE, Adrian (ed.): Juan Muñoz. Writings/Escritos, Madrid, Ediciones de La Central, 2009, p.65 



\section{MOVIMIENTOS MIGRATORIOS DESDE UNA}

\section{PERSPECTIVA GLOBAL Y COMPARADA}

Bárbara Ortuño Martínez

CONICET-Universidad Nacional de Mar del Plata

Aurelio Velázquez Hernández

CH-CIALC/UNAM

Marcela I Lucci

Universitat Autònoma de Barcelona

Los movimientos poblacionales, como es sabido, representan una constante en la historia de la humanidad Las tensiones económicas, las cuestiones políticas, las guerras y las catástrofes naturales, entre otros, han provocado y continúan propiciando desplazamientos constantes de hombres y mujeres a lo largo de la geografía mundial con mayor o menor intensidad. En el caso de España, si bien la emigración exterior se convirtió en un fenómeno habitual desde la época colonial, no tomó un cariz masivo hasta la segunda mitad del siglo XIX. Entre 1860 y 1930 tuvo lugar la llamada "etapa masiva de la emigración". Alrededor de 4 millones de españoles se desplazaron al continente americano, en especial a América del sur, alentados por la revolución de los transportes y las posibilidades que progreso que ofrecían las nuevas repúblicas americanas. Otros destinos privilegiados fueron Argelia, Marruecos, Francia y en determinados casos Portugal. Salieron de España sobre todo personas motivadas por intereses del momento, liberales, carlistas, progresistas, anarquistas, republicanos. En su mayoría hom bres, y en general nuevos profesionales, pertenecientes a las clases medias, cuya formación e inquietudes laborales, unidas al descontento que les había producido el régimen político de la Restauración, provocaron su desplazamiento. Para algunos autores se trató de "emigrantes políticos", de "expatriados" (DUARTE, 2000, 57-59), para otros fueron "exiliados". Incluso hay quienes como Henry Kamem afirman que España ha sido el único país con exilios a lo largo de toda su historia (2007)

En 1930 la crisis mundial provocó una fuerte recesión en las economías de los países latinoamericanos, donde además, como en el caso de Argentina, principal foco de recepción, comenzaron a proliferar los gobiernos militares que impulsaron legislaciones restrictivas a ingreso de extranjeros. Esto, sumado al advenimiento de la II República española en 1931, propició un buen número de retornos y la contracción de los flujos migratorios. No obstante, tras el final de la Guerra Civil y la implantación de la dictadura franquista en 1939 más de medio millón de personas se vio obligado a marcharse de España, en algunos casos por segunda vez. Francia, México, Argentina, Argelia, la URSS, Túnez y República Dominicana fueron los principales destinos, seguidos de Marruecos, Chile, Inglaterra, Venezuela, Colombia, Cuba, Uruguay, Estados Unidos, Puerto Rico, Bélgica, Suiza, Perú y Bolivia (ALTED, 2010, 192; PLA, 2007, 30-31). Su volumen, la dilatación en el tiempo (1939-1975), la repercusión internacional, la herencia dejada en los países de destino, así como el tiempo que ha tenido que transcurrir para que las nuevas generaciones comiencen a identificar abiertamente los nombres de artistas, políticos/ as e intelectuales que compusieron el grueso humano de ese fenómeno son algunos de los aspectos que diferencian al exilio de 1939 del sinfín de emigraciones políticas y económicas que marcaron los siglos XIX y XX (GIRONA, MANCEBO, 2005, 196).

Por otro lado, en el Convenio Comercial y de Pagos firmado entre España y Argentina en 1946 se fijó un apartado sobre emigración en el que el Gobierno franquista se comprometía a no adoptar trabas que entorpecieran la emigración. De hecho, ese mismo año se reinstauró la Ley de Emigración de 1924 y hasta 1956 aproximadamente 200.000 personas, el $43,9 \%$ de la emigración total a América, se desplazaron al país austral (VILLARES, FERNÁNDEZ, 1996, 153). El resto se dirigió a Venezuela, que despuntó como país de inmigración gracias al crecimiento económico experimentado por la venta de hidrocarburos, y en menores cantidades a Brasil y a Uruguay (PALAZÓN, 1995, 300-344). Esta nueva emigración de posguerra tuvo mayor complejidad de la admitida, ya que no estuvo compuesta en exclusiva por emigrantes con motivaciones económicas, sino también por emigrantes políticos y exiliados tardíos, como quienes se vieron atrapados en Francia por lall Segunda Guerra Mundial o no pudieron retomar sus vidas en la España de Franco tras haber salido de las cárceles y los campos de concentración (ORTU$\tilde{N} O, 2012)$. Junto a ellos también abandonaron la península un abultado número de personas educadas dentro del régimen dictatorial que aceptaron de una forma acrítica sus postulados y que huían por la penosa situación económica y social, pero no formaban parte de la oposición (NÚÑEZ, 2006, 49-51).

Finalmente, a partir de 1956 la emigración española, además de revitalizarse en el interior dirigiéndose a las regiones más favorecidas en materia económica, como Madrid, Barcelona el País Vasco y en la década siguiente la Comunidad Valenciana, comenzó a desplazarse hacia los países europeos. Esto se debió a múltiples factores, pero los más señalados fueron el declive de las economías latinoamericanas y su inestabilidad política, el impulso propiciado por el Instituto Español de la Emigración, así como las posibilidades labores que ofrecían los países vecinos, que al mismo tiempo por su condición de cercanía física contribuían a crear proyectos migratorios más a corto plazo que en el caso americano. De este modo entre 1960 y 1973 más de dos millones de trabajadores y trabajadoras españoles se desplazaron a Suiza, Alemania y Francia, en un elevado porcentaje frecuentando las vías de la ilegalidad y recurriendo a las cadenas migratorias, sobre todo en países como el galo, donde existía la colonia española más abultada dentro de Europa.

En este sucinto repaso a los movimientos migratorios españoles de los siglos XIX y XX podemos comprobar que en todas las etapas emigrantes económicos, políticos y exiliados, más allá de su categoría migratoria, determinada por los motivos de salida, su actitud en el lugar de acogida y sus posibilidades de retorno, coincidieron fuera de las fronteras españolas, con mayor o menor intensidad, y formaron parte del mismo colectivo de extranjeros en los países de recepción. Así lo han demostrado ciertas investigaciones que marcan la línea de trabajo seguida en este taller y en la cual creemos que se debe continuar profundizando (DUARTE, 1998; LILLO, 2005; LUCCI, 2009; ORTUÑO, 2012). Sin duda, como señaló Fernando Devoto, unos y otros tuvieron que recorrer itinerarios semejantes: conocer las oportunidades, lograr auxilio dependiendo de su capital relacional para alcanzar su destino por vías legales o ilegales, obtener la documentación necesaria, o no (DEVOTO, 2003, 403). De una forma u otra sus encuentros y desencuentros fueron inevitables, por otro lado, en numerosas ocasiones los inmigrantes pasaron a convertirse en exiliados y viceversa. De ahí que en la fundamentación del presente taller cobrara una especial importancia el hecho de incluir en los movimientos migratorios tanto a exiliados como a emigrantes.

Sin embargo, en la historiografía española exilios y emigraciones constituyeron dos campos historiográficos paralelos que a penas combinaron sus principales aportaciones. En cuanto al exilio de la Guerra Civil, fueron las elites — catedráticos, intelectuales, artistas o profesionales-, en especial las refugiadas en México, las primeras en acometer la tarea de sistematizar las posturas políticas de los distintos grupos exiliados, el funcionamiento de sus organizaciones, etcétera, y sobre todo la labor artística e intelectual que estaban llevando a cabo. En este sentido, a lo largo de la década de 1950 surgieron una serie de obras o balances, motivadas por la necesidad de enfatizar el alto nivel cultural de los expatriados, que, como señaló Dolores Pla $(2002,110)$, sentaron las bases de la que habría de convertirse en la imagen más consolidada 
sobre el exilio republicano, esto es, que constituía un fenómeno distinto de la tradicional emigración española, y que la mejor prueba de ello residía en su magna obra realizada fuera de las fronteras españolas (PLA, 2002, 110). De ahí que la mayoría de estudios sobre el exilio de 1939 se hayan realizado desde la perspectiva de la Historia de la Literatura, resaltando, las aportaciones de las principales figuras que adquirieron renombre en actividades literarias, aunque no en exclusiva. En este sentido posteriormente ha sido fundamental la labor llevada a cabo por el Grupo de Estudios del Exilio Literario (GEXEL) de la Universitat Autònoma de Barcelona dirigido por Manuel Aznar desde los años noventa del siglo pasado.

Los años finales de la década de 1970 supusieron un período clave para los estudios de exilio en España. De un modo un modo progresivo, tras la muerte de Franco, el interés por los expatriados se fue trasladando de América a Europa. En estos años aparecieron algunos libros con el objetivo de otorgar una visión más general del exilio, que con el paso de los años se han convertido en clásicos (RUBIO, 1977; ABELLÁN 1978). Javier Rubio por primera vez se acercó al tema desde una mirada crítica, hasta el momento inexistente, que le llevó a utilizar fuentes inexploradas, en especial documentación inédita, periódicos, folletos, etcétera, conservada en archivos de Francia y España, y a adoptar una perspectiva más propia de la historia de las migraciones y, en general, de la Historia Social que de la Historia de la Cultura. Además, Rubio consideró que desde mediados de los años cincuenta el exilio se había comportado como una emigración "económica" más; criterio que casi al mismo tiempo fue adoptado por otro estudio clave para el exilio republicano, proveniente de México y de la Antropología (KENNY, 1979). La obra colectiva coordinada por Michael Kenny fue el primer trabajo que se ocupó del conjunto del exilio republicano como grupo humano, prestando una especial atención al que llamó "exilio anónimo". El autor, que utilizó fuentes orales y encuestas para recoger los testimonios de sus protagonistas, partió de la hipótesis de que se trataba de una migración que albergaba a una minoría diferenciada, pero que en general tenía necesidades y estrategias similares a las de la inmigración tradicional española asentada en México, con la que de forma progresiva se fue asimilando en muchos aspectos.

La producción académica sobre el exilio republicano se multiplicó de forma notable a lo largo de los años noventa. Se continuó avanzando en profundidad en el conocimiento del éxodo en sí mismo: quiénes, cuándo dónde -Francia, México y Argentina centraron la atención preferente debido a sus numerosas colonias-, cuál había sido la evolución del Gobierno de la República y de las autonomías, etcétera. A ello contribuyeron, sobre todo, las monografías realizadas desde el enfoque regional (GIRONA, MANCEBO, 1995; SOLDEVILLA, 1998; PLA, 1999).' Asimismo destacados historiadores como Nicolás Sánchez-Albornoz (1991) y Francisco Caudet (1997) llamaron la atención sobre distintos aspectos que se consideraban necesarios para evolucionar en el conocimiento del exilio republicano. Entre ellos destacaron la importancia de llevar a cabo una labor desmitificadora, de incorporar nuevos sujetos de estudio y diferentes perspectivas temáticas y críticas, asi como de inscribir a quienes se expatriaron dentro de los flujos constantes de población española a América, y conocer las condiciones que prevalecían en los países de acogida, las cuales eran indispensables para comprender la inserción del exilio en los mismos.

En este sentido surgieron trabajos que hoy consideramos esenciales como los de las historiadoras Alicia Alted (1994) o Geneviève Dreyfus-Armand (1999), que centraron sus estudios en el exilio de base en Francia, analizando estrategias de integración, y en el caso de la última los vínculos establecidos con la emigración considerada económica; Pilar Domínguez (1994) que incluyó la perspectiva de género en su investigación para rastrear la presencia de las mu-

1 Este impulso, profundizado en la década siguiente, además tuvo como resultado la creación de centros de investigación autonómicos, como el Arquivo da Emigración Galo centros de investigación autonómicos, como el Arquivo da Emigración Galega (1992), Hamaika ingente cantidad de documentación sobre el exilio republicano. jeres y analizar cuál había sido su papel dentro del exilio republicano en México; Clara E. Lida (1997), que circunscribió a los expatriados en la colectividad española del país azteca; y Jesús . Alonso (1998), que transitó dos temas como la infancia y la memoria colectiva, que en la década posterior eclosionaron. Además, no se cesó de profundizar en el exilio literario (ZULETA 1999), y tuvo lugar el nacimiento de la Asociación para el Estudios de los Exilios y Migraciones lbéricos Contemporáneos (AEMIC) en 1996, que hoy en día continúa aglutinando a grandes expertos y expertas en la materia tendiendo un puente entre noveles y consolidados, entre Europa y América, y sobre todo, entre migraciones y exilios.

Por último, desde el comienzo del siglo XXI hasta la actualidad hemos sido testigos de una multiplicación de las líneas de investigación y de la bibliografía referente al exilio de la Guerra Civil, en gran parte propiciada por el desarrollo de la propia historiografía pero también provocada por los aniversarios emblemáticos del fin de la contienda y la eclosión de la llamada "memoria histórica", hasta hace unos años alentada por las políticas públicas españolas. Como ha señalado Encarnación Lemus en un reciente estado de la cuestión sobre el exilio republicano (2013), resulta forzado, y en este espacio casi imposible, dar cuenta de la expansión global que ha sufrido en este siglo el estudio del éxodo de la Guerra Civil. Además el mismo ha traspasado las fronteras de la Academia propiamente dicha y ha despertado un notable interés público a través del desarrollo de las nuevas tecnologías, las numerosas asociaciones de descendientes del exilio y el interés de los periodistas. Por tanto, en la última década han tenido vigencia en su análisis todas las fuentes y cualquier método de análisis, desde la vivencia testimonial alentada por la profusión de diarios, cartas, entrevistas, archivos personales, etcétera- hasta el estudio estadístico, todos los espacios de salida y de acogida, todas las temáticas, los grupos sociales y las individualidades.

No obstante, la reflexión teórica y metodológica ha tenido una menor cabida en esta proliferación de trabajos, cuestión que en parte se ha tratado de solventar a través de diversos monográficos de revistas académicas especializadas, sobre todo de España y de Francia, y que confiamos en que se siga profundizando en los numerosos congresos y seminarios dedicados al estudio republicano que se celebrarán a lo largo de 2014 con motivo del 75 aniversario del fin de la Guerra Civil. Del mismo modo resaltamos que hoy en día están en curso numerosas investigaciones predoctorales y postdoctorales sobre el exilio republicano. En este sentido, es muy notable la labor que están llevando a cabo jóvenes investigadores e investigadoras tanto desde la Historia como desde la Sociología, la Antropología o los Estudios Hispánicos en el caso de Francia. ${ }^{2}$

Por su parte, los estudios migratorios comenzaron a adquirir cierta notabilidad en la península a principios de los años noventa con motivo de la conmemoración del quinto centenario del Ilamado "descubrimiento de América", que alentó la publicación de numerosos catálogos de exposición y monografías (SÁNCHEZ-ALBORNOZ, 1991; SÁNCHEZ, 1992; VV. AA., 1992; YA$\tilde{N} E Z, 1994)$. Sin embargo, la mayoría de esas obras evidenciaron dos de los principales defectos de este campo en España: la falta de reflexión teórica y la dispersión de enfoques (NÚÑEZ, 2 Véase, por ejemplo: Luca Chao (Universidad de A Coruña), "Las repercusiones migratorias de la Université de Potsdam) "Les réfugiés politiques dans le bloc de l'Est: le cas des communistes espanols en RDA suite à leur expulsion de France en septembre 1950", Diego C Celay (Universipagnols en RDA suite à leur expulsion de France en septembre 1950"; Diego G. Celaya (UniversiVelázquez Madrid) “La evacuación y acogida de los niños españoles a Francia: cartografía de una movilización transnacional (1936-1942)"; Eva Leger (Paris Ouest Nanterre la Défense), “Les républicains espagnols en Limousin (1939-2009)"; Federica Luzi (EHESS) "'’exil espagnolde, "Les republicains espagnols en Limousin (1939-2009)"; Federica Luzi (EHESS), "Lexil espagnol de 1939 en Fran-
ce: fragmentations et recompositions des mémoires"; o Rosy Rickett (University of Manchester), que preparara su tesis doctoral sobres España y exiliados españoles en México, Inglaterra, Francia y el norte de África. 
2001), los cuales, en parte, han estado vigentes en la actualidad. El primero supuso una escasa creatividad en teoría y praxis, lo cual hizo a los estudiosos y estudiosas depender de tendencias procedentes de otros países que no siempre han sido asimiladas correctamente, en la mayoría de los casos por haberse importado a destiempo y por seguir un proceso de evolución distinto (SILVESTRE, 2000; DEVOTO, OTERO; 2003; GARCíA, 2003).

El segundo lugar, la desconexión fue generalizada entre las disciplinas científicas y sociales que se dedican a las migraciones - Sociología, Economía, Antropología, Geografía, Demografía, etcétera-; dentro de la Historia, entre modernistas y contemporaneístas, entre los últimos y los latinoamericanistas, entre especialistas de la emigración y de exilios, entre las metodologías cuantitativas y cualitativas. Lo cual se agudizó en un panorama estatal en el que se consolidaron núcleos regionales dedicados a los estudios migratorios, pero que en casos como el gallego han contribuido a renovarlos (DA ORDEN, 2010, 16) y han establecido redes de estudios transnacionales, en especial con Argentina. Sin embargo, el hecho de, salvo excepciones, ignorar lo que el resto de investigadores está desarrollando no permite consolidar los estudios migratorios dentro de la Academia española, al menos dentro de la Historia Contemporánea. Es significativo que en los últimos congresos celebrados por la Asociación de Historia Contemporánea $(\mathrm{AHC})$ no hubiera mesas temáticas dedicadas a los estudios migratorios.

En suma, de forma inevitable, esta dispersión también influyó en la temática abordada y en la metodología y fuentes empleadas, estableciendo barreras entre quienes trabajan desde la clásica perspectiva que privilegia los factores de salida o expulsión y atracción; quienes desde la microhistoria se centran en los análisis estadísticos de materiales seriales - como por ejemplo, las listas de pasajeros, las fichas de inscripción de socios en asociaciones voluntarias en los países de destino, etcétera-, en el funcionamiento de las cadenas migratorias; quienes ponen el acento en la utilización de fuentes cualitativas - memorias, epistolarios, autobiografías y fuentes orales- para la reconstrucción de memorias, imaginarios o representaciones quienes trabajan desde el punto de vista del país de expulsión ignorando las condiciones de la sociedad de recepción y viceversa; quienes analizan la dinámicas de inserción socio-laboral en los países de inmigración; quienes observan la impronta colectiva o individual en el país de acogida; quienes ahondan en las formas de articulación comunitaria; o quienes abordan la relación entre el género y la emigración.

No obstante, en los últimos años se apunta a una mayor integración de perspectivas cuyos resultados ya empiezan a ser avistados. Una labor encomiable fue la llevada a cabo por Amancio Liñares Giraut que coordinó entre 2008 y 2011, bajo el patrocinio del Grupo España Exterior cuatro obras destinadas al estudio de los fenómenos migratorios donde reunió a algunos de los mejores expertos y expertas en la materia, quienes mostraron los avances que se habían realizado en la materia y los temas presentes en las agendas investigadoras. Sus títulos son una buena muestra de ello: Ciudadanos españoles en el mundo. Situación actual y recorrido histórico, El protagonismo de la mujer en las corrientes migratorias, La emigración española a Europa en el siglo XX. Hijos y nietos de la emigración española. Las generaciones del retorno y La memoria de la emigración. Fuentes históricas, centros y archivos para el estudio de los flujos migratorios españoles. ${ }^{3}$ Del mismo modo, el vacío existente sobre la emigración española en Francia a lo largo del siglo XX, eclipsada por el exilio republicano, que señaló Natacha Lillo (2005), en parte comienza a cubrirse con los resultados parciales extraídos de las investigaciones doctorales que están llevando a jóvenes investigadores, en su mayoría franceses, con cuya presencia contamos en este taller. ${ }^{4}$

3 Todos ellos pueden consultarse en: http://www.espanaexterior.com/libros

4 Véase, por ejemplo: Elodie Das Neves (Toulouse II -Le Mirail), “'Limmigration espagnole en Midi-Pyrénées et Languedoc-Roussillon (1955-1975)” o Aubin González (Université de Bordeaux), “Les ouvriers catholing dans l'émigration sous le franquisme: une stratégie de surve entre confor-
Por último, resta señalar que a pesar de los avances nos queda un amplio camino por recorer. Creemos, coincidiendo con los especialistas en estudios migratorios reunidos en Sidney en 2005 (CUESTA, 2004), que algunas de las claves pueden hallarse en la aplicación de las perspectivas transnacionales y comparadas, entre emigrantes y exiliados, entre distintos destinos, diferentes etapas, diversos colectivos étnicos, etcétera. Así lo demuestran los buenos resultados de publicaciones recientes (GIL, MARTíN, PÉREZ, 2013; MORENO, ORTUÑO, 2013). Por ello, y confiando en su potencialidad hermenéutica, hemos querido estimular a nuestros/as colegas a realizar este ejercicio a través de la realización del presente taller.

Los siete trabajos que respondieron a nuestra propuesta temática conformaron un núcleo complejo por diversas razones. En primer lugar por la experiencia de los autores, ya que científicos cuyas carreras están más encaminadas compartieron el foro de discusión con aquellos que todavía están en un estadio anterior y encontraron en el contexto del Encuentro de Jóvenes Historiadores un ámbito fructífero en el cual dar a conocer sus primeras reflexiones y conclusiones científicas. En segundo término, porque provenían de diferentes centros de estudios europeos, hecho que permitió a nuestro taller incluir prácticas metodológicas y abordajes teóricos heterogéneos que enriquecieran el debate. En tercer lugar, por la aportación de análisis cimentados en un ejercicio interdisciplinario, hecho que favoreció la plasmación de investigaciones que superaran cuestionamientos maniqueos y fragmentarios. Y finalmente, a causa de la multiplicidad de perspectivas desde las cuales abordaron el eje central que habíamos propuesto, que incluía el exilio, la relación entre exiliados y emigrantes económicos, la evolución de las políticas migratorias, las culturas políticas, la construcción de imaginarios colectivos y la redefinición de espacios geográficos provocados por los movimientos de población. En este sentido esta complejidad fue fundamental para constatar que las experiencias exiliares y migratorias del devenir histórico peninsular no constituyen campos historiográficos estancos o inconexos. La variedad apuntada decidió la organización formal del taller de Migraciones y Exilios, que conformamos a partir de relacionar los trabajos que se complementaban temáticamente, con el fin hacer fructífera la interacción entre los autores y también en el momento del debate.

Los primeros dos trabajos dan cuenta del interés por la cuestión europeísta y tienen puntos de contacto con la problemática de la historia cultural aplicada al estudio del ámbito pedagógico y universitario. "La movilidad internacional de estudiantes en los siglos XX y XXI", de Christof Van Mol y Toni Morant i Ariño destaca por su originalidad. Los autores se centran en la construcción del concepto de Europa en las etapas previas a la constitución de la Unión Europea, con la intención de establecer el rol que la juventud ha tenido en ese proceso. El trabajo explora las semejanzas y los contrastes entre los programas de movilidad 'Erasmus' en el siglo XXI y el intercambio estudiantil que se llevó a cabo entre organizaciones de jóvenes falangistas y nazis durante las décadas de 1930 y 1940. Desde un punto de vista poco trabajado, plantea con concisión la necesidad de profundizar los estudios referentes a la movilidad de estudiantes dentro del espacio geográfico europeo para indagar en los procesos de creación y reproducción de una identidad común. El desarrollo de los objetivos planteados descansa en un sólido conocimiento del método científico y da cuenta de una destacable habilidad para el análisis del pensamiento europeo contemporáneo. Así, el texto es una propuesta que, desde la convergencia de recursos de la Sociología y la Historia, estudia los mecanismos del diseño de una cosmovisión específica sirviéndose de dos ejemplos que evidencian contextos históricos e ideológicos disímiles. Van Mol y Morant exponen con claridad las similitudes y diferencias entre los dos casos estudiados y presentan a la identidad europea no como un concepto cristalizado, sino como una idea que ha sido dotada de contenidos diversos a lo largo del tiempo. Es una aportación preliminar que constituye un punto de partida para plantear vías de investi- 
gación en el campo de la historia de las mentalidades desde aspectos novedosos que iluminen el estudio de la conformación de Europa como proyecto.

La propuesta de Jorge de Hoyos Puente, "La cultura institucionista en el exilio republicano: continuidades y fracturas", constituye un trabajo clásico sobre la cosmovisión del colectivo exiliado en México. De Hoyos profundiza su examen de la evolución del imaginario institucionista durante los primeros años del exilio republicano. Nos encontramos con un texto producto del trabajo sistemático del autor en este tema, lo cual constituye un aspecto fundamenta de la solidez de su discurso. El institucionismo exiliado aparece aquí estudiado en perspectiva comparada a partir del análisis del derrotero de sus principales exponentes en México y los Estados Unidos. El autor se centra en el examen de la transformación de las prácticas institucionistas a partir del impacto producido por la derrota de la II República y el conflictivo panorama internacional derivado del estallido de la Segunda Guerra Mundial. Es un texto muy bien estructurado que confirma la evolución científica de De Hoyos; está concebido de manera ágil, con un discurso histórico fluido que da forma a un trabajo con entidad en sí mismo pero que deja abierta la puerta para continuar con la exploración del tema. Esta estructura contiene una investigación desarrollada con rigurosidad teórica que ahonda específicamente en las fracturas de la cultura institucionista: indaga en la pluralidad con que afrontó los cambios de mundo moderno y el exilio, en la quiebra de su cosmovisión evolucionista del mundo y en la manera en que los totalitarismos influyeron en su pensamiento, así como en el trabajo por su reorganización política durante los primeros años del franquismo. La perspectiva comparada le permite establecer la magnitud de las fracturas que marcaron el declive de la cultura política del institucionismo y atisbar la permanencia de sus postulados en el campo pedagógico.

El tercer texto que recibimos en nuestro taller constituye un punto de inflexión temática que ha servido como introducción al tratamiento de la problemática específica del exilio. "La web 2.0 y el estudio del exilio republicano español: el análisis de la movilidad social y el retorno a través del proyecto e-xiliad@os", de Lidia Bocanegra Barbecho, está ligado también al propósito de estudiar el ámbito universitario español, pero su innovador enfoque busca difundir los esfuerzos que se llevan a cabo para dotar al entorno académico de nuevas herramientas con las que optimizar el examen del exilio republicano. El trabajo ofrece un análisis del Proyecto E-xiliad@os, que desde 2009 está abocado a potenciar la Internet como recurso para concentrar información online sobre el exilio español durante la Guerra Civil y el primer franquismo, a fin de profundizar su estudio desde la Historia Social. La aportación fundamental de este trabajo radica en el análisis del recurso informático que utiliza, la Metodología 2.0 como herramienta para recoger en línea y poner a disposición del investigador, a escala global, fuentes inéditas sobre el exilio republicano que se encuentren en repositorios privados. El texto es claro, conciso y directo, integra el objetivo científico y el didáctico con solvencia y pone el acento en la importancia de contar con herramientas que promuevan el desarrollo de investigaciones para potenciar la evolución de la historiografía peninsular. En ese sentido, sobre todo, enfatiza la necesidad de que las ciencias humanas y sociales puedan generar en la Academia española programas que impulsen la transferencia de conocimiento y tecnología a la sociedad, de forma tal que acerquen la tarea científica al cuerpo social.

Con el trabajo de Pablo Aguirre Herráinz "Colonias emigrantes y comunidades exiliadas en la Francia de las tres guerras (1914-1945). El caso de los Pyrénées Atlantiques" accedemos a estudio de Francia como país de acogida de distintas oleadas migratorias españolas durante la primera mitad del siglo XX. El texto analiza de manera conjunta tres movimientos diferentes de población peninsulares desde el prisma cultural del país de acogida. A partir del corpus documental del Archivo Departamental de los Pirineos Atlánticos en Pau (Francia), Aguirre examina la transformación de la comunidad española afincada en la Aquitania meridional desde 1914 hasta el final de la Segunda Guerra Mundial, centrándose en la manera en que los dos conflictos bélicos mundiales y la Guerra Civil española determinaron el flujo migratorio peninsular hacia Francia e incidieron drásticamente en el cambio de rumbo de la política migratoria gala a partir de 1930. El énfasis en el análisis de la cosmovisión francesa es una cualidad remarcable del trabajo, ya que se convierte en una atalaya que facilita la síntesis entre como tierra de paso y acogida en el universo europeo. El texto de Aguirre destaca además por su estructura formal y su planteamiento riguroso, que integra el análisis sociocultural del caso francés con la realidad española con una flexibilidad discursiva que acrecienta el interés del lector. El resultado es un trabajo breve que merece ser profundizado, pues sobresale por su intención de estudiar el éxodo republicano desde una perspectiva longitudinal que lo vincule con experiencias similares previas y coadyuve a percibir la problemática exiliar española como un hecho estructural en su devenir histórico.

La siguiente propuesta de nuestro taller también focalizó su atención en los movimientos de población española hacia Francia. Elodie Das Neves y "La emigración económica española a Francia (1956-1975): políticas migratorias e inserción socioprofesional" analizan la emigración económica durante el tardofranquismo. La autora estudia la lógica de ese proceso - marcado por la grave coyuntura socioeconómica española y la urgente necesidad de fuerza de trabajo de una economía francesa en plena expansión-, desde el punto de vista de las políticas migratorias de ambos países, con el fin de ahondar en el examen de las estrategias de inserción que se implementaron durante aquellos años. El texto exhibe una sólida concepción, que le permite establecer los aspectos centrales de las políticas migratorias española y francesa y los puntos de convergencia y desacuerdo que las caracterizaron. En ese sentido, el trabajo con las fuentes primarias otorga solidez a su ejercicio metodológico. Sin embargo, la cualidad más destacable es la lucidez de Das Neves para privilegiar la perspectiva cultural de su análisis, que redunda en un examen más completo del fenómeno migratorio peninsular, en el cual la arista económica se revela supeditada a otras variables igualmente importantes. Esta elección le permite reforzar los tres aspectos centrales de su investigación. Por un lado, el patrón de la política migratoria española del franquismo, a partir de dos elementos de su discurso: la explotación del miedo a lo desconocido que entrañaba la emigración y el uso de la religión como mecanismo de control a distancia. En segundo lugar, la percepción de la diplomacia como espacio de difusión ideológica. Finalmente, la cosmovisión que legitimó los aspectos sociales y económicos del marco legal migratorio francés.

"Del conformismo al distanciamiento: los grupos católicos españoles en Francia (19501975)", de Aubin González, analiza desde la Historia Social la evolución de la red asociativa de colectivo español asentado en Burdeos entre 1950 y 1975. El autor efectúa reflexiones críticas sobre las prácticas sociales que exiliados y emigrados llevaron a cabo en el sudoeste francés y la manera en que el crecimiento de la participación de las organizaciones de izquierda en las agrupaciones católicas y consulares españolas hicieron posible comprobar el fracaso de la política migratoria del franquismo y la decadencia de su discurso en el exterior. El texto descansa en una concepción teórica que, desde los postulados antropológicos de Mary Douglas, las investigaciones de la Fundación $1^{\circ}$ de Mayo y la producción de Natacha Lillo, dota a la investigación de un aparato crítico sólido a partir del cual desarrolla su análisis. La lucidez de González permite que el trabajo encare aristas diversas de la investigación con una solvencia homogénea: establece una perfecta cronología de las etapas migratorias que atraviesan el período, expone con claridad la evolución de la vida de las asociaciones civiles y religiosas de los españoles asentados en Burdeos, presenta los objetivos y la andadura de las entidades consulares españolas en suelo francés y explica con holgura las derivaciones de las relaciones de los grupos católicos peninsulares con las instituciones religiosas galas. Esta cohesión le permite detenerse en el mecanismo de construcción identitaria de los exiliados y emigrados para reafirmar, a partir de los resultados de su análisis, que lejos de estar conformado por las pautas culturales emanadas del discurso hegemónico, el sentimiento de pertenencia e identificación 
con un acervo específico estuvo estrechamente vinculado a las prácticas y a la cosmovisión desarrolladas en el seno de las asociaciones que los congregaron.

Por último, Elvira Fente presentó "Españolas en Francia: identidad y alteridad. Diferencias entre emigración económica y exilio". Su comunicación, una investigación que se encuentra en su fase inicial, acerca la lupa a las experiencias de las mujeres emigrantes y exiliadas con el fin de profundizar en el análisis de la colonia española en Francia desde la conflictiva década de 1930 hasta el final del franquismo. En un contexto cambiante acrecentado por las particularidades de cada una de las sucesivas oleadas de emigrantes provenientes de la península ibérica, la autora bucea en los aspectos esenciales que dificultaron la convivencia, pero que también contribuyeron a solidificar los vínculos de cohesión del colectivo femenino. De esta manera, reflexiona sobre los espacios de sociabilidad y las redes de solidaridad que conformaron entre ellas y con el resto de la colectividad, teniendo en cuenta las tensiones y conflictos generados, ya durante la segunda mitad del siglo XX, por la militancia antifranquista de los refugiados republicanos, por las habituales prácticas de cariz específicamente social que continuaron llevándose a cabo y por el incremento de lo que se conoce como emigración económica. Un aspecto destacable del propósito de Fente es la decisión de incluir en el corpus documental diversas fuentes secundarias, siempre eficaces y necesarias para comprender la manera en que un determinado cuerpo social se percibe a sí mismo través de la interpretación de su historia y su acervo cultural. Esta elección le permite proponer una mirada alternativa a diferentes aspectos del tema trabajado: las estrategias de integración, las diferentes maneras de afrontar el proceso migratorio y la conformación de redes de solidaridad.

Como podemos apreciar, las comunicaciones presentadas forman un conjunto de aportaciones que, desde la reflexión teórica, señalan la posibilidad de aproximarse al análisis de las migraciones peninsulares de manera convergente e integradora. Si bien señalábamos que exilios y migraciones constituían dos campos historiográficos paralelos que solo en escasas ocasiones convergían y combinaban sus principales aportaciones los trabajos presentados en esta mesa nos permiten demostrar que dicho panorama ya está cambiando, y que además viene avalado por una reflexión teórica y convergencia de enfoques que creemos pueden ensayar novedosas vías de tratamiento científico que coadyuven a la renovación del campo de los estudios sobre movimientos de población en el seno de la Academia española.

Recapitulando acerca de los trabajos presentados en esta mesa, la diversidad temática que presentan suscitó no pocas dudas entre los coordinadores acerca de cómo podrían orientarse los debates. No obstante, finalmente se encontraron numerosos puntos en común y el diálogo, establecido no solamente entre investigadores de muy diversas temáticas sino también con enfoques disciplinarios y metodológicos diversos, creemos que ha resultado altamente enriquecedor. Por establecer algunos lineamientos comunes nos ha resultado llamativo el potente conjunto de estudios, cuatro de los siete artículos recibidos, dedicados al exilio y a la emigración española en Francia, demostrando que es una línea de estudio que está lejos de agotarse pues admite una multitud de posibilidades para continuar ahondando en este campo y acercarnos a comprender en su totalidad los movimientos poblacionales que desde España se dirigieron al país galo. También, y como no podía ser de otra manera en estos momentos, ña se dirigieron al país galo. También, y como no podía ser de otra manera en estos momentos,
destacan los estudios que comprenden el marco europeo como objeto y contexto de estudio, esta perspectiva transnacional así como la que estudia la evolución de las intelectualidades en el marco de los flujos migratorios son algunos de los parámetros que marcan numerosos de los estudios que se están realizando en la actualidad. De enorme interés, también nos han parecido los proyectos que van destinados a explorar nuevos enfoques y metodologías de trabajo así como aquellos que tratan de recuperar fuentes de información.

Sin lugar a dudas, todos estos trabajos demuestran que aún quedan marcos temáticos por abordary la ampliación de los enfoques metodológicos e interpretativos de la que nos estamos beneficiando en las últimas décadas está permitiendo a los investigadores encontrar nuevos y fecundos campos de conocimiento. Estudios sobre identidad, culturas políticas e imaginarios así como la perspectiva de género y estudios puramente metodológicos forman parte de esos nuevos enfoques que se muestran en algunas de las propuestas de esta mesa. Por otra parte internacionales que lejos de agotarse, continúan siendo fuente de nuevas aportaciones.

Los trabajos de esta mesa han representado un interesante punto de encuentro que nos ha permitido discutir no solamente aquellos temas académicos en los que venimos trabajando sino también las inquietudes del complejo momento intelectual y profesional que compartimos. Por ello, y tomando las palabras de algunos textos que fueron debatidos, creemos que el futuro de nuestra evolución académica pasa por realizar "un ejercicio conceptual e intelectual con el objetivo de traspasar fronteras disciplinarias y periódicas" 5 ; y es que "todavía queda mucho camino por recorrer y nadie podrá hacerlo de forma aislada, por eso presentamos nuestras reflexiones y apuntes para que nos ayuden a contrastar pareceres e informaciones". ${ }^{6}$ De tal modo, que quizás podamos finalizar creando una "«inteligencia colectiva" (entendida como la capacidad del grupo para resolver problemas que cada individuo del colectivo, de forma personal, no sería capaz de resolver ni, incluso, de entender)".?

\section{Bibliografía}

ABELLÁN, José Luis (dir.): El exilio español de 1939, Madrid, Taurus, 1978.

ALONSO, Jesús J: 1937, Los niños vascos evacuados a Francia y Bélgica: Historia y memoria de un éxodo infantil, 1936.1940, Bilbao, Asociación de niños evacuados en 1937, 1998.

ALTED, Alicia: "Emigración política tras la Guerra Civil (el exilio)", en BLANDIN, Clair (ed.): Atlas de las migraciones. Las rutas de la humanidad, Valencia, Fundación Mondiplo, 2010.

-------: Exilios. Refugiados españoles en el mediodía de Francia, Madrid, Video, 1994.

CAUDET, Francisco: Hipótesis sobre el exilio republicano de 1939, Madrid, Fundación Universitaria Española, 1997.

CUESTA, Josefina: "Migraciones de masas: sus implicaciones económicas, políticas y culturales (Congreso Mundial de Ciencias Históricas, tema especializado $\left.n^{\circ} 19\right)$, Migraciones \& Exilios, 5 (2004), pp. 115-126

DA ORDEN, María Liliana: Una familia y un océano de por medio. La emigración gallega a través de la memoria epistolar, Barcelona, Antrhopos, 2010

DEVOTO, Fernando y OTERO, Hernán: "Veinte año después. Una lectura sobre el crisol de razas. El pluralismo cultural y la historia nacional en la historiografía argentina", Estudios Migratorios Latinoamericanos, 50 (2003), pp. 181-227.

DOMÍNGUEZ, Pilar: Voces del exilio. Mujeres españolas en México (1939-1950), Madrid, Comunidad de Madrid, Dirección General de la Mujer, 1994

DREYFUS-ARMAND, Geneviève: L'e exil des républicains spagnols en France. De la guerre civile à la mort de Franco, París, Albin Michel, 1999.

DUARTE, Ángel: La República del emigrante. La cultura política de los españoles en Argentina (1875-1910), Lleida, Milenio, 1998.

5 Christof VAN MOL y Toni MORANT: "La movilidad internacional de estudiantes en los siglos XX y XXI".

6 Pablo AGUIRRE: “Colonias emigrantes y comunidades exiliadas en la Francia de las tres guerras (1914-1945)".

7 Lidia BOCANEGRA: "La web 2.0 y el estudio del exilio republicano español: el análisis de la movilidad social y el retorno a través del proyecto e-xiliad@s". 
------: El republicanismo español. Madrid, Asociación de Historia Contemporánea, Marcial Pons, 2000.

GARCÍA, Rocío: "Un estado de la cuestión de la cuestión de las teorías de las migraciones", Historia Contemporánea, 26 (2003), pp. 329-351.

GIL, Alicia, MARTín, Aurelio, PÉREZ, Pedro (coords.): El retorno. Migración económica y exilio político en América Latina y España, Madrid, Marcial Pons, Instituto de Estudios Latinoamericanos, 2013

GIRONA, Albert, MANCEBO, Ma Fernanda (eds.). El exilio valenciano en América. Obra y Memoria. Valencia: Instituto de Cultura Juan Gil-Albert, Valencia, Universitat de València, 2005.

KAMEM, Henry: The Disinherited: The Exiles Who Creates Spanish Culture, London, Penguin/ Allen Lane, 2007.

KENNY, Michael et alt: Inmigrantes y refugiados españoles en México (siglo XX), México D.F., Ediciones de la Casa Chata, 1979

EMUS, Encarnación: "El exilio español de 1939. Balance y perspectivas". Ponencia presentada en el VII Taller del de Historia Contemporánea de Andalucía "El exilio republicano andaluz de 1939". Almería, 2 de julio de 2013

LIDA, Clara E.: Inmigración y exilio. Reflexiones sobre el caso español, México D. F., Siglo XXI, Colegio de México, 1997.

LILLO, Natacha: "Exiliados y emigrantes comunistas en Francia: la política como factor de integración", en CASAS, José Luis, DURÁN, Francisco (coords.): Los exilios en España (siglos XIX $X X)$, Priego de Córdoba, Patronato D. Niceto Alcalá-Zamora y Torres, 2005.

LUCCI, Marcela I.: La colectividad catalana en Buenos Aires en el siglo XX: una visión a través de "los catalanes de América". El activismo patriótico de "los catalanes de América" de Buenos Aires: desde 1916 hasta el final del Casal Català, Tesis doctoral, Universitat Autònoma de Barcelona, 2009.

MORENO, Mónica y ORTUÑO, Bárbara: "Exiliadas españolas en Francia y Argentina: identidades transnacionales y transferencias culturales", Storia delle Donne, 9 (2013), en prensa.

NÚÑEZ, Xosé Manoel: "Historiografía española reciente sobre migraciones ultramarinas: un balance y algunas perspectivas", Estudios Migratorios Latinoamericanos, 48 (2001), pp. 269 295.

"Itinerarios do desterro: sobre a especificidade do exilio galego de 1936", en ID., CAGIAO, Pilar (eds.): O exilio galego de 1936: política, sociedade, itinerarios, Sada-A Coruña, Ediciós do Castro, Consello da Cultura Galega, 2006.

ORTUÑO, Bárbara: El exilio y la emigración española de posquerra en Buenos Aires (19361956), Alicante, Biblioteca Virtual Miguel de Cervantes, 2012.

PALAZÓN, Salvador: Capital humano español y desarrollo latinoamericano. Evolución, causas y características del flujo migratorio (1882-1990), Alicante, Instituto de Cultura Juan Gil-Albert, 1995

PLA, Dolores (coord.): Pan, trabajo y hogar. El exilio republicano español en América Latina, México D. F., Instituto Nacional de Migración, Centro de Estudios Migratorios, Instituto Nacional de Antropología, 2007.

--: "El exilio republicano en Hispanoamérica. Su historia e historiografía", Historia Social, 42 (2002), pp. 99-122.

-------: Els exiliats catalans. Un estudio de la emigración republicana en México, México D. F., Instituto Nacional de Antropología e Historia, 1999
RUBIO, Javier: La emigración de la guerra civil de 1936-1939. Historia del éxodo que se produce con el fin de la II República Española, Madrid, Editorial San Martín, 1977.

SÁNCHEZ, Blanca: La inmigración española en Argentina. Siglos XIX y XX, Colombres, Archivo de Indianos, 1992.

SÁNCHEZ-ALBORNOZ: Nicolás (comp.): El destierro español en América: un trasvase cultural Madrid, Instituto de Cooperación Iberoamericano, Sociedad Estatal Ouinto Centenario, 1991.

SILVESTRE, Javier: "Aproximaciones teóricas a los movimientos migratorios contemporáneos: un estado de la cuestión", Historia Agraria, 47 (2000), pp. 157-192.

SOLDEVILLA, Consuelo: La Cantabria del exilio: una emigración olvidada, Santander, Universidad de Cantabria, 1998.

VELÁZOUEZ, Aurelio: Empresas y finanzas del exilio. Los organismos de ayuda a los republicanos españoles en México, 1939-1949, México, El Colegio de México, 2014

VILLARES, Ramón, FERNÁNDEZ, Marcelino X.: Historia da emigración galega a América, Santiago de Compostela, Xunta de Galicia, 1996.

YÁÑEZ, César: La emigración española a América (siglos XIX Y XX). Dimensión y características cuantitativas, Colombres, Fundación Archivo de Indianos, 1994

ZULETA: Españoles en la argentina. El exilio literario de 1936. Buenos Aires, ediciones Atril, 1999 


\section{COLONIAS EMIGRANTES Y COMUNIDADES EXILIADAS}

\section{EN LA FRANCIA DE LAS TRES GUERRAS (1914-1945)*}

Pablo Aguirre Herráinz

Universidad de Zaragoza

\section{Introducción}

Las condiciones geográficas y económicas, unidas a su particular idiosincrasia política e ideológica, han convertido a Francia en una encrucijada de pueblos y culturas. Su escenario físico, en consecuencia, ha canalizado el tránsito de una gran parte de las migraciones europeas que caracterizaron los siglos contemporáneos -entre las que debemos contar, y en proporción considerable, aquellas que protagonizaron nuestros antepasados-, pero es en su escenario simbólico donde más se ha imbricado la noción de territorio y espacio franco, que diríamos, haciendo un guiño al uso histórico y semántico de la expresión. Esta noción, conformada desde el Medioevo encontró razones evidentes para redefinirse y aún potenciarse al calor de los hechos revolucionarios del setecientos, hechos que marcaron el final de una época y que contribuyeron a reformular la noción de un estado tradicional en clave de nación soberana. Integrado fraternalmente por ciudadanos iguales, este nuevo estado nacional estaba preparado para reconocer una serie de principios universales que trascendian las fronteras dinásticas y lingüisticas.

Francia creció en consonancia a estos ideales, y en la medida en que pudo hacer que sus instituciones y leyes creyeran en ellos, construyó la imagen de ser un destino especialmente adecuado para cualquier tipo de exilio y destierro -algo que a su vez venía sucediendo ya con Londres-. Por supuesto, la idea de nación y sus exigentes postulados arrastraron desde un primer momento disfunciones y contradicciones inherentes a las diferencias que siguieron separando a los grupos humanos -bien fueran desavenencias políticas, en algunos casos, o excesivos contrastes socioeconómicos, las más de las veces-, de modo que la Francia del asilo ejemplar se tradujo sobre el terreno en una receptividad no siempre tan decidida.

En la presente comunicación me centraré en abordar cuáles fueron las condiciones y circunstancias que explicaron el porqué un determinado flujo migratorio -que por razones prácticas y culturales será español- encontró un tipo u otro de recibimiento en Francia. Este estudio, que sacrificará la exhaustividad frente a la visión de conjunto, abarcará las tres décadas que se sucedieron entre 1914 y 1945 a ambos lados de los Pirineos, donde casi un año de cada dos fue de conflicto. Aunque me centraré en ofrecer postulados generalizables a todo el solar galo, incluiré algunas notas derivadas del estudio de caso que desarrollé en los Pirineos Atlánticos, departamento francés que ha quedado ligado al devenir de nuestra propia historia por la proximidad de sus pasos fronterizos.

* Esta comunicación se ha elaborado a partir de las lecturas y documentación consultadas para la realización de un Trabajo Fin de Máster defendido en noviembre del año 2012 y titulado: “Exilio republicano en Francia (1939-1940). El caso de los refugiados españoles en Basses-Pyrénées. Una acogida bajo sospecha".

1 Conocido como Basses-Pyrénées en fecha anterior a 1969. El archivo se encuentra instalado en la capital prefectoral de Pau y a él pertenecen todas las fuentes primarias que aquí se citan: Archivo Depital pre

\section{Migraciones e historia.}

Esta comunicación no tiene ni el propósito ni la capacidad de realizar una categorización exhaustiva que ordene las formas y maneras con las que los grupos humanos inician un proceso migratorio. De hecho, hasta podría dudarse en que tal estratificación resultase posible o deseable, habida cuenta de la múltiple causalidad que se esconde detrás de estos fenómenos. Sin embargo, sí que puede resultar útil trabajar conforme a una conceptualización mínima que permita, a grandes rasgos, identificar cuáles son las vías más recurrentes de migración. Todo ello, claro está, dentro de un contexto definido, pues si es cierto que por lo general cada etapa histórica discrimina un tipo migratorio $u$ otro, no es menos razonable pensar que todo ellos puedan conjugarse o sustituirse en un momento dado.

Partiendo de este parecer, se podría establecer una línea provisional que separase lo político de lo económico, diferenciación que quedaría perfectamente caracterizada en el caso de los cuadros de liberales exiliados en las capitales europeas durante el siglo XIX -claro paradigma político-o, en el mismo siglo, el caso de los desplazamientos estacionales de los temporeros agrarios pirenaicos -arquetipo de migración económica periódica, constante en la medida en que iba forjando una colonia permanente en suelo francés-. No obstante, bastaría con echar un vistazo a otros muchos casos y circunstancias históricas para plantearse la idoneidad de este modelo clasificatorio, ¿o es que el constante goteo de emigraciones que se produjeron durante la durísima posguerra española -a la que se suma la europea, en 1945-no puede atribuirse a una compleja mezcolanza de penurias económicas y desafecciones políticas? Si a este dilema se le suma el efecto de la violencia y el enfrentamiento bélico, que amenaza la vida de las personas mucho antes de minar su sostén económico o de perseguir su parecer ideológico, puede preverse la necesidad de convocar otro tipo de criterios explicativos.

Uno de estos criterios podría ser el jurídico, como el que estuvo detrás de las iniciativas legales consagradas a la defensa de las comunidades apátridas durante el primer cuarto del siglo XX-desde los Convenios de la Haya, en 1907, hasta los distintos acuerdos alcanzados en el seno de la Sociedad de Naciones durante los años veinte- ${ }^{2}$ Consagrado a la tarea de proporcionar apoyo jurídico a quienes eran privados de aquél por su respectivo estado-nación, este novedoso derecho internacional visibilizó la figura del refugiado y su doble escala, cuantitativa y cualitativa. Pero como quiera que esta denominación legal no se aplicó siempre con arreglo a su propia definición -los exiliados republicanos fueron hasta 1940 refugiados sólo de facto, puesto que la España de Franco no les privó inicialmente de su nacionalidad-, y que esta se ha incrementado en función de las situaciones a las que da cobijo-desde el desamparo jurídico a la persecución racial o religiosa, pasando por la indefensión de quienes padecen conflictos armados o desastres naturales-, a la postre resulta también equívoca. Quizá es por eso que a la hora de enfrentar la fenomenología migratoria actual los estudios contemporáneos prefieran la utilización de términos polisémicos como "transit migration" o "counter-diasporic-migration", que permiten evitar las categorizaciones dicotómicas tradicionales -en el primer caso salvaguardando la naturaleza dinámica del hecho migratorio, en el segundo subrayando su bidireccionalidad-, al tiempo que permiten establecer nexos de unión hacia otros contextos relacionados, como el exilio, para que puedan redefinirse en coordenadas mucho más adecuadas.

2 Acúdase a la obra de Javier CERVERA GIL: La guerra no ha terminado. El exilio español en Francia: 1944-1953. Madrid Taurus, 2007: í. "Su segunda posguerra. Los refugiados republicanos en el Sur de Francia (1945-1947)", Espacio, tiempo y forma, Serie V (1998), pp. 191-211.

3 Ouiero agradecer a Christof van Mol la orientación bibliográfica realizada al respecto de estas nuevas vias interpretativas Para Mol la orientación bibliografica realizada al respecto de estas tural Geographies of Counter-Diasporic Migration: Perspectives from the Study of Second-Genetural Geographies of Counter-Dlasporic Migration. Perspectives from the Study of Second-GeneHein de HASS: "Developing Dynamic Categorisations of Transit Migration", Population, Space 
Como conclusión a este apartado preliminar, centrándolo ya en el tiempo y espacio histórico con el que trabajo, querría indicar que las migraciones españolas a Francia durante las décadas señaladas, si bien cambiantes y de motivación variada, sí que pueden ordenarse con arreglo a dictámenes de orden económico/político. Sólo será necesario recordar un principio elemental, y es que a las circunstancias personales de cada persona han de sumarse aquellas que afectan a los países de procedencia y acogida. Donde el común de las personas se mueve por motivaciones de estricta supervivencia -encontrar trabajo, seguridad y sustento-, los estados pueden disponer políticas activas que faciliten o estorben la consecución de esas necesidades. Por eso quizá sea más adecuado preguntarse qué sucede en los países para que sus ciudadanos emigren o inmigren entre ellos, antes que preocuparse únicamente por la categoría de desplazamiento que adopta, siempre cambiante.

\section{Laissez passer (1914-1931)}

En vísperas de la Primera Guerra Mundial la cifra de integrantes de la colonia española en Francia se situaba en torno a los 100.000 efectivos, cifra que se disparó en poco años a consecuencia del incremento de la oferta laboral gala. ${ }^{5}$ Esta fue una emigración eminentemente económica y de origen rural, que fue empleada dentro de los márgenes de unos sectores agro-industriales resentidos por la movilización de la fuerza de trabajo masculina. Un conjunto poblacional heterogéneo, en definitiva, que encontró en Francia la posibilidad de una rápida colocación dentro de una economía de retaguardia empleada al cien por cien en el esfuerzo bélico, y que por tanto distaba mucho de parecerse al trabajo habitual al que estas personas estaban acostumbrados: recogida de la cosecha, pequeños encargos, cubrición de puestos puntuales, etc.

Por su oportuna aparición este excedente laboral fue recibido con interés por el Estado $\mathrm{Ma}$ yor francés, si bien el colectivo español, por su extracción social, fue el que menos entusiasmo despertó entre los principales empleadores. La correspondencia prefectoral en Basses-Pyrénées demuestra que las autoridades locales también estuvieron preocupadas por la actitud de la colonia española durante la contienda, todo dentro de un contexto diplomático entre ambos países de mayor envergadura: donde el uno se veía inmerso en la guerra más catastrófica de su historia, el otro observaba desde la inquietante tribuna de la neutralidad. ${ }^{6}$ Sea como fuere, los servicios de seguridad y orden público galos mantuvieron siempre una cierta aprensión hacia los trabajadores extranjeros presentes en sus jurisdicciones, bien porque al ser ciudadanos de otros estados introducían problemáticas propias - como sucedió al calor de la huelga general de 1917, cuyo desarrollo tuvo en vilo a las autoridades fronterizas-, bien porque estos

and Place, 18 (2012), pp. 468-481.

4 Existe una amplia bibliografía en relación a la crónica y periodización de las distintas inmigraciones a Francia. Por señalar algunos títulos: Ralph SCHOR: Histoire de l'immigration en France de la fin du XIXe siècle à nos jours, Paris, Armand Colin, 1996 ; ÍD. : Français et immigrés en temps de crise (1930-1980), Parí, 'L'Harmattan, 2004; Juliette MINCES: Les travailleurs étrangers en France, París, Le Seuil, 1973; Laurent GERVEREAU; Pierre MILZA, y Émile TÉMIME (coords.): Toute la France. Histoire de l'immigration en France au XXè siècle, París, Somogy éditions d'art, 1998; e Yves LEOUIN: Histoire des étrangers et de l'immigration en France, Paris, Larousse, 2006.

5 Se ha contabilizado que durante la Primera Guerra Mundial pasaron a Francia de modo clandestino casi 250.000 españoles en busca de empleo. Javier RUBIO: La emigración a Francia anterior a la guerra de 1936-1939, San Martín, D. L., 1977, pp. 17-34.

6 Los numerososinformes que la prefectura de Pau recibió durante aquellos años sobre el estado de opinión españolon respecto a a que pudieran ejercer los elomentos germanófilos:"curas carlistas, jencitas recupación por la presión


de prefectoras SM, 1M: Administration générale du département; carpeta 166: "Relations franco-epagnoles". individuos no pertenecían en sentido estricto a la población de las pequeñas y desasosegadas comunas francesas, suspicaces por naturaleza hacia el elemento foráneo.?

La paz y la relativa normalidad política que se reinstalaron en Francia tras el conflicto mundial, asi como en España tras el golpe de estado del general Primo de Rivera, crearon un clima adecuado para la reconstrucción de las economías nacionales -la una lastrada por la guerra, la otra desigualmente desarrollada-, lo que a su vez redundó en unas mayores cotas de migración transpirenaica. Si bien es cierto que la desmovilización devolvió a muchos jóvenes y adultos franceses a las líneas de producción industrial que habían abandonado por las trincheras, las elevadas pérdidas afrontadas, combinadas con un deseo de rápida recuperación, permitieron que Francia siguiera siendo un empleador de primer orden en el concierto europeo de su tiempo. Para organizar este suculento mercado - pues no debería olvidare qué tipo de trabajos se reservaban a estos inmigrantes y en qué circunstancias-, surgió en el año 1924 la Societé Générale d'Inmigration, que reclutaría desde los propios países de origen medio millón de trabajadores. ${ }^{8}$ En qué proporción fueron españoles esto empleados es difícil decirlo, pero puesto que el año 1931 se ha ofrecido como cota máxima para el censo de integrantes de la colonia hispanohablante, puede deducirse que en los años veinte se mantuvo una abultada población emigrada de origen español, a lo que habría que añadir la constante adición de hijos naturalizados franceses -quizá hasta 200.000-.9

Aunque las fuentes consultadas no hacen mención de que existieran especiales encontronazos entre estas comunidades y las poblaciones locales o sus autoridades -en todo caso se sucedieron episodios administrativos y penales ordinarios: control de permisos de residencia o trabajo, regularización de contratos, persecución de clandestinos, pequeños delitos, etc. - las cosas estaban a punto de cambiar. Muy pronto una madrugadora ciudad guipuzcoana proclamaba un 14 de abril el advenimiento de la II República española, estableciendo un gobierno que a la larga chocaría con unos ejecutivos galos cada vez más derechizados. La situación económica vivía también con tiempo prestado, puesto que desde el hundimiento de la banca norteamericana una oleada de inflación y de quiebra golpeaba a las economías continentales, amenazando con torcer el sueño del renacimiento francés como potencia y angustiando la conciencia de una clase obrera que comenzaba a ver en el extranjero la imagen de un desleal competidor. Para colmo de males, la violencia se dejaba ver por las calle de una Europa con demasiada frecuencia. Las ansias expansionistas y revanchistas de las potencias fascistas, la pasividad de las democracias liberales y el golpismo de las fuerzas reaccionarias acorraladas por las reformas de la II República española, eran ingredientes más que suficientes para alterar de nuevo la faz del continente. Los caminos, repletos en todo lugar y momento de gentes deseosas de probar mejor suerte, estaban a punto de verse colapsados a fuer de desplazamientos forzosos, deportaciones y exterminio.

Hacia la década de los refugiados (1931-1939)

Aunque es el siglo XX el que ha sido categorizado como "siglo de los refugiados", fue la década de los cuarenta las que con mayor virulencia vio crecer su número como consecuencia de la creciente conflictividad étnica, la persecución racial y la guerra y su posguerra..$^{\circ}$ En este

7 La xenofobia presente en la población francesa fue objeto de una Tesis doctoral dirigida por Gérard Noiriel: Laurent DORNEL: La France hostile. Histoire de la xénophobie en France au XIXe siècle, Tesis doctoral, Universidad de París, 2002.

8 Barbara VORMEIER: “La république française et les rèfugiès et inmigrés d'Europe centrale. Accueil, séjour, droit d'asile (1919-1939)", en Denis PESCHANSKI (coord.): De l'exil à la Résistance: réfugiés et immigrés d'Europe centrale en France (1933-1945), Paris, Arcantère, 1989, pp. 13-26

9 Javier RUBIO: La emigración a Francia... pp. 17-34.

10 Sobre la referencia original al "siglo de los refugiados" véase Alicia ALTED: La voz de los vencidos: el 
panorama los años treinta fueron claves, pues en ellos se fueron estableciendo las condiciones de excepcionalidad jurídica que la guerra impulsaría hasta su oxímoron, al fin de la misma cuando cifras millonarias de deportados, derrotados y desposeídos terminasen por enterrar los delirios de un progreso sin límites.

Por el momento, hasta el estallido de la Guerra civil española el flujo transpirenaico siguió nutriéndose en su amplia mayoría de individuos a los que la necesidad económica impulsaba a emigrar, así como a un reducido número de opositores políticos a la ll República y demás desafectos -es célebre el caso de los jesuitas afectados por el decreto de disolución del 23 de enero de 1932, pero hay otros-. De este modo, y mientras de la parte de España no sucedía nada fuera de lo esperable, habida cuenta de su larga historia de exilios y movilidad transfronteriza, en Francia comenzaba a flaquear esa actitud histórica de "puertas abiertas" que había granjeado al país galo el primer puesto en el ranking mundial de naciones-refugio, a razón de su elevado ratio de extranjeros alojados por número de ciudadanos naturales." Para mediados de los años treinta no eran españoles los únicos contingentes que asilaba Francia. Por delante del grupo español, que suponía unos 250.000 efectivos en vísperas de la Guerra civil, vivían en Francia 720.000 italianos y 420.000 polacos. A ellos se agregarían en 1939 los 470.000 españoles que cruzaron la frontera catalana en "La Retirada", pero también otros 400.000 refugiados alemanes y austríacos llegados en octubre de 1939 desde el Reich. ${ }^{12}$

En este momento Francia era presa, como la mayor parte de Europa, de una xenofobia y desconfianza notables, que en su caso particular no pueden explicarse sin convocar una tupida red de concepciones y raigambres políticas asentadas en el seno de la III República-antisemitismo, antiparlamentarismo, anticomunismo-, a las que hay que añadir toda una sucesión de desórdenes y decepciones acumuladas en un denso crisol donde coinciden la crisis econó mica y el degaste de la izquierda francesa, replegada ante un clima de manifiesta intolerancia cívica y desafección democrática -lo que se conoce, en términos generales, como crisis de identidad francesa-.

Se acusó a los inmigrantes de competir contra la población activa, de modo que su llegada se limitó a través del endurecimiento de las condiciones de acceso al empleo: permisos de trabajo, cuotas evaluables y certificados médicos. La combinación de la política de apaciguamiento auspiciada por el Foreing Office británico, que Francia se avino a respaldar, en conjunción con el viraje de signo político de la República -ante la derrota del "frentepopulismo" de Blum y el ascenso de un partido radical connivente con la derecha ultramontana-, allanaron e camino hacia la construcción de una nueva batería legal con respecto al meteco que se asentó en espacios de excepcionalidad jurídica. Por un lado tomaba consistencia la figura jurídica, inicialmente indeterminada, del indeseable -categoría que incluía no sólo a elementos foráneos, sino también domésticos, como comunistas o poblaciones marginales-, y por otro comenzaba a recuperarse, a raíz de la llegada de los refugiados sarros que huían del Rhur, una vieja práctica de reclusión provisional que no se veía desde la guerra: aquella que representaba el campo de internamiento. ${ }^{13}$ Estos dos espacios quedaron definidos e interconectados a partir de la pro-

exilio republicano de 1939, Buenos Aires, Aguilar, 2005, p. 22

11 Un extranjero por cada veinte franceses. La idea de Francia como país receptor por excelencia se ha obtenido de Denis PESCHANSKI: Les camps français d'internement (1938-1946), París, Thèse d'état de la Universidad Panteón-Sorbona, 2000, p. 33. El cómputo extranjero/ciudadano francés de Barbara VORMEIER: “La république...", pp. 13-26.

12 Denis PESCHANSKI: “Étrangers et refugies en France a l'aube de la guerre...", pp. 31-34

13 No es el propósito de esta comunicación ahondar en el debate terminológico que subyace a la ralidad histórica del campo francés, de modo que mi única voluntad en este sentido es aclarar que la denominación que utilizaré - a de campo de internamiento-, es sólo una de las muchas posibles y que si ha sido privilegiada en este enfoque es sólo por su recurrente aparición en las fuentes consultadas. mulgación, en apenas un año, de una serie de decretos-ley que autorizaron a la repatriación, vigilancia intensiva e internamiento preventivo de toda aquella persona sospechosa desde e punto de vista de la seguridad nacional. ${ }^{14}$ Todo este proceso puede singularizare en el caso de departamento de Basses-Pyrénées.

\section{La Francia de las contradicciones (1939-1945)}

Cuando la Guerra civil española se aproxima a su primer otoño, en el año 1936, el departamento de Basses-Pyrénées se encuentra bien provisto de directrices oficiales con respecto a la admisión de refugiados: si se trata de soldados armados, deben ser devueltos de inmediato a la frontera; si se trata de civiles, pueden ser instalados a título provisional, sólo hasta que su proceso de repatriación pueda iniciarse. ${ }^{15}$ En ningún caso se les puede permitir un desplazamiento libre fuera del departamento donde reciban permiso de residencia, lo que hasta cierto punto recuerda a las mismas restricciones que se aplican en épocas de desconfianza y desempleo a los emigrantes económicos. Salvo por una salvedad: los refugiados no son productivos si las autoridades no les permiten o fuerzan a serlo, y un grupo poblacional que sea tratado así pronto será percibido como inútil, además de peligroso, resultando doblemente estigmatizado.

Esta es la primera de las muchas contradicciones a las que me refiero en este epígrafe, porque conforme la guerra avanza y el tránsito de refugiados se eleva -primeramente por la derrota republicana en el frente Norte y ya en enero de 1939 por la caída de Barcelona-, las autoridades galas se debaten entre el imposible deseo de cerrar la frontera y el deber moral de recibir poblaciones etiquetadas como "peligrosas". ${ }^{6}$ Como estas personas deben permanecer separadas de las poblaciones locales -a excepción de sus elementos más vulnerables, como niños, mujeres y enfermos, que sí serán alojados entre ellas-, sólo pueden ser repatriadas a su país de origen o internadas. La primera opción genera un evidente malestar en la medida en que muchos refugiados tienen motivos para temer por su vida si regresan a España, amén del caos organizativo que se derivaría de semejante operación. La segunda opción parece menos radical pero es con diferencia la que ha de generar mayor sobregasto a la administración, y como a pesar de aquel las condiciones de alojamiento distaron mucho de un nivel aceptable, el ejecutivo además hubo de afrontar críticas provenientes de todos los frentes mediáticos: uno internacional, preocupado por la situación de los campos - pero a la hora de la verdad poco resuelto a hacer más-, al que se aproximan aquellos sectores nacionales simpatizantes con la España republicana; y otro frente mucho más agresivo representando por la Francia conservadora y las organizaciones de extrema derecha.

El análisis de la prensa coetánea matiza mucho más esta pluralidad de pareceres. A título ilustrativo, las reacciones que se produjeron en los distintos órganos de prensa departamentales ante la ordenanza del 16 de octubre de 1937 -por la que se obligaba a regresar a España a todo refugiado varón de entre dieciocho y cuarenta y nueve años-oscilaron entre la indignación furibunda y una desatada celebración, sin olvidar reacciones más intermedias. Así, po ejemplo, periódicos más apáticos como "Le courrier", se lamentaban del perjuicio económico que iba a suponer esta medida entre los comerciantes locales, quienes hacian parte de sus cajas gracias al aporte de los refugiados. ${ }^{17}$ El diario de Biarritz era en cambio mucho más agresi-

14 Me refiero, en orden cronológico, a las medidas tomadas por el ejecutivo Chautemps-octubre de $1937-$ y a los dos decretos-ley aprobados por el gabinete ministerial del radical Édouard Daladier el 2 de mayo y el 12 de noviembre del año 1938 .

15 Circular prefectoral y comunicado del director general de la Süreté Nationale, Charle Magny ( 2 y 11 de septiembre de 1938). Archivo BP-sM, 4M: Police; carpeta 244:"Instructions".

16 Esto lo ha descrito muy bien Geneviève DREYFUS-ARMAND: El exilio de los republicanos españoles en Francia. De la guerra civil a la muerte de Franco, Barcelona, Crítica, 2000, pp. 21-55.

17 "Une mesure contre les réfugies espagnols", San Juan de Luz, 27 de octubre de 1937. Archivo BP-sM, 
vo. Admitiendo que entre aquellos "plus préocupés d'espionnage que de tourisme" se encuentran seguramente muchos refugiados inocentes, concluye que "il n'est pas possible de faire une omelette sans casser des œufs". ${ }^{8}$ El diario de Bayona, "Le patriote", abre un titular así: "A la porte, les agitateurs!", aunque luego se refiere a la medida como inoperativa, en la medida en que gran parte de los afectados se zafan alegando no poder costearse el desplazamiento. ${ }^{19}$ Sólo el diario socialista "Le Travail" se posiciona en contra de la disposición:

Jusqu'à quel point avons-nous le droit de nous faire les pour voyeurs de la mort, d' envoyer se faire mobiliser par exemple, des hommes qui ne demandaient qui a vivre obscurément en marge de la guerre qui déchire leur pays? [...] La solidarité prolétarienne et l'humanité tout court ne peuvent accepter de livrer à la famine et à la mort tant d'innocentes victimes. ${ }^{20}$

Por su parte, del estudio de la correspondencia entre particulares y la prefectura de Pau se descubre un campo de trabajo poco hollado todavía por investigaciones sistemáticas. Me refiero a la política de negociaciones que se estableció entre parientes y autoridades al respecto de la acogida de estos refugiados, donde intervinieron gran número de ciudadanos franceses. Si señalamos que muchos de ellos habían de ser hijos naturalizados de la colonia española de preguerra, estaremos señalando una intersección llamativa entre flujos migratorios de distinto signo que convendría estudiar mejor.

Retomando el hilo de las contradicciones del ejecutivo francés, localizamos otra en el otoño de 1939, cuando Francia declara la guerra a Alemania. Es en esta coyuntura cuando el país galo prepara aceleradamente algo que hasta el momento había parecido improcedente, esto es, la integración de la mano de obra extranjera dentro del esfuerzo bélico. Una integración, todo sea dicho de paso, de carácter cuasi forzosa, si se atiende a la situación en que se hallan los grupos afectados -en su mayoría internados-, a quienes se daba a elegir entre la repatriación, el alistamiento en la Legión Extranjera o las Compañías de Trabajadores Extranjeros. La rápida y "extraña" derrota de Francia, que diría Marc Bloch, trajo consigo nuevas ironías y sinsentidos para estas poblaciones finalmente puestas al servicio de la República, puesto que ahora afrontaban el internamiento, la deportación y la muerte como enemigos de la Alemania nazi y del Régimen colaboracionista de Vichy. Lo que sigue es bien conocido: la penosa -y sangrienta- Liberación; la marcha de la victoria hacia Berlín; el retorno de los supervivientes de la barbarie y el largo exilio de quienes ya no pudieron regresar a su tierra natal, incómodos huéspedes de un país a quien siempre recordarían sus vaivenes autoritarios y sus horas más bajas como tierra de igualdad, libertad y fraternidad. Y mientras tanto, celebraciones y reparaciones asimétricas, pero también la reanudación de aquellos flujos migratorios trasfronterizos de quienes huían de la miseria y de la realidad política que la generaba, componentes a veces inmiscibles de un nuevo tipo emigrante. Un tipo que representó, en la generación de nuestros abuelos, el fruto de esas contradicciones largo tiempo atrás sedimentadas: el gusto por el silencio y el apoliticismo que tan duramente criticaron los supervivientes del exilio histórico republicano, pero también su persistente esfuerzo adaptativo y su exitosa, aunque costosa, integración en las poblaciones de acogida.

4M: Police; carpeta 245: "Opinions face aux réfugiés".

18 ["Más dedicados al espionaje que al turismo"; "no es posible hacer una tortilla sin romper unos huevos"] M. L. : "A propos du refoulement des étrangers", Biarritz, octubre - no consta día- de 1937. Archivo BP-sM, 4M: Police; 245: "Opinions face aux réfugiés".

19 [iA la puerta los agitadores!] Bayona, 7 de noviembre de 1937. Archivo BP-sM, 4M: Police; 245: "Opinions face aux réfugiés".

20 [¿Hasta qué punto tenemos el derecho de convertirnos en voyerus de la muerte, de enviar a que sean movilizados, por ejomplo, a unos hombres que no desean sino vivir aisladamente al maque sean movilizados, por ejemplo, a unos hombres que no desean sino vivir aisladamente al margen ac la guerra que desgarra su pais? [...] La solidaridad proletaria y la humanidad misma no pueden du rapatriment des réfugies espagnols", 7 de noviembre de 1937 Archivo BP-sM. 4 M: Police; 245 :

\section{Conclusiones}

Aunque con semejante enumeración de tiempos y espacios históricos no resulte sencillo establecer un corolario final suficientemente concluyente creo que si es posible y beneficioso avanzar una serie de hipótesis provisionales que se infieren del mismo estudio de las migraciones como proceso sumatorio de experiencias irrepetibles que, por su misma inercia, resulta al mismo tiempo cíclico en algunas de sus coordenadas. Veamos por ejemplo el caso de la guerra como clima propiciatorio para el incremento de los flujos migratorios laborales, lo que a su vez desencadena un marco jurídico para la persecución y exclusión de la figura del otro-situaciones ambas producidas consecutivamente en la Francia transicional entre un conflicto y otro-

Por supuesto, tras todo esto no se esconde una foto fija que nos sirva de modelo explicativo para cualquier caso dado, sino más bien al contrario. Si una situación nacional concreta -una crisis financiera, un periodo de paz, de enfrentamiento o de alza económica-, no nos permite deducir por sí misma el estado de la población o de sus instituciones, aunque ayude a aproximarlo, mucho menos nos ha de ayudar a perfilar la posición de uno de los sectores más vulnerables y expuestos de todos, como es el inmigrado. Lo que pretendo decir es que si bien existen motivos relativamente objetivos y absolutos que pueden explicar las causas que motivan una determinada ola migratoria, resulta mucho más difícil clarificar el porqué aquella encuentra un recibimiento $u$ otro en el país de acogida. Y no es que aquel deje de participar de unas circunstancias coyunturales que privilegien un tipo de recepción u otra, sino que precisamente por poder desplegar políticas moduladoras puede intervenirlas, llegando al extremo de poder modificarlas con una efectividad que está fuera del alcance de los propios países emisores erguidos, en el mejor de los casos, en negociadores de las suertes de sus naturales, pero más frecuentemente impotentes o indiferentes ante ellos-.

Todo esto queda muy lejos de la escala en la que operan los individuos aislados, aunque no por ello hay que ignorar su papel. Al contrario, puesto que como he señalado el efecto de las posiciones e iniciativas particulares obtiene notoriedad en el ajuste definitivo de las recepciones locales. Me estoy refiriendo al estudio de los microprocesos en los que se define la pluralidad de reacciones de una comunidad, donde podemos anticipar que existirán todas las suspicacias y bondades que el ser humano despliega ante aquellos semejantes que reconoce como extraños, quedando sólo como incógnita el grado en el que unas u otras son mayoritarias.

Ya por finalizar, resulta del todo punto atractiva y sugerente la perspectiva que puedan aportar las generaciones emigradas que precedan a las más jóvenes. Perspectiva histórica, en la manera en que comparamos la suerte de cada una desde su estudio en la actualidad, pero más aún coetánea, en función del papel que pudieron jugar en su momento frente a los recién llegados. Este papel tiende a ser cambiante, pero más en el caso que nos ocupa -el exilio republicano-, pues no sin cierta amargura aquel fue a parar alli donde existían colonias de compatriotas mucho menos ideologizados que él, todo para ver llegar al término de la Segunda Guerra Mundial nuevos paisanos poco conocedores -y en consecuencia poco admiradores- de su propia andadura vital.

Lo que la combinación de estas dos perspectivas pueda dar de sí en el caso francés es todavía una incógnita, pero no me cabe la menor duda de que las sucesivas líneas investigadoras terminarán por coronar esta especie de balance global del exilio francés. Sólo que aún queda mucho camino por recorrer, y como ese camino no lo recorrerá nadie de manera aislada, yo he querido aportar aquí una serie de apuntes y reflexiones que nos sirvan a todos para replantearnos qué tipos de sendas se han hollado cumplidamente en la investigación histórica, y cuáles merecen ser revisitadas. 


\section{LA WEB 2.0 Y EL ESTUDIO DEL EXILIO REPUBLICANO ESPAÑOL: EL ANÁLISIS DE LA MOVILIDAD SOCIAL Y EL RETORNO A TRAVÉS DEL PROYECTO E-XILIAD@S}

Lidia Bocanegra Barbecho*

Universitat de Lleida

\section{Introducción}

La presente comunicación pretende ofrecer un moderno enfoque metodológico de obtención y difusión de nuevas fuentes acerca del exilio republicano, así como analizar la movilidad social y el retorno, utilizándose la Red Internet y la web 2.0 como principales herramientas.

Desde hace varios años la Red Internet se ha convertido en una herramienta muy utilizada en el ámbito de las humanidades; cabe destacarse que investigadores y estudiantes la utilizan principalmente para buscar datos y no tanto para difundir y muy poco para recuperar fuentes inéditas. Este comportamiento viene vinculado muchas de las veces a una cierta relajación, por parte de este colectivo, en la adquisición de competencias técnicas de base en el ámbito web 2.o. Todo esto comporta un desconocimiento acerca de la enorme potencialidad que esa herramienta Web puede ofrecer, en tanto que una potente plataforma para obtener y compartir nuevas fuentes ya sea a nivel nacional como internacional.

Cuando se habla de adquirir competencias técnicas al historiador le entra el pánico, pues muchas de las veces le viene en mente la tortura de tener que aprender lenguaje de programación, base de datos, etc. Sin embargo, es mucho más fácil que todo eso ya que en la actualidad existen programas que ayudan a crear tu propia web o, en el caso de orientarse hacia una web 2.0 más profesional, siempre se puede contar con profesionales al respecto: desarrolladores web. Tanto e un caso como en otro, el historiador dialogará con la Web trámite un Sistema de Gestión del Contenido (SGC) lo que le facilitará manejar los datos, establecer análisis, añadir nuevo contenido, modificar información, etc. Cabe destacarse que la mayoría de los proyectos de investigación tienden a olvidar la figura del especialista web, siendo muy necesaria a la hora de crear iniciativas en línea (e-Proyectos) que incluyan base de datos en línea y SGC y que se destinen no solamente a la difusión de los datos obtenidos, sino en la obtención de los mismos.

¿Qué es una web 2.0? Se trata de una web que

Permite a los usuarios interactuar y colaborar entre sí como creadores de contenido generado por usuarios en una comunidad virtual a diferencia de sitios web estáticos donde los usuarios se limitan a la observación pasiva de los contenidos que se han creado para ellos.'

* Doctora en historia, americanista y especialista en Web 2.0 aplicada en las ciencias sociales. Tras su doctorado se ha formado en el ámbito de las nuevas tecnologías-Web aplicadas a la investigación y difusión histórica, con cursos acreditados al respecto y varios e-Projects que avalan su trayectoria profesional. Para mayor información véase su currículum académico en línea: https:// ugr.academia.edu/LidiaBocanegra

1 Web 2.o, Wikipedia, Fundación Wikimedia Inc. Recuperado de Internet (http://es.wikipedia.org/ wiki/Web 2.0)
Dicho de otra forma, se trata de una aplicación en línea en donde el usuario puede añadir y compartir información con otros usuarios, lo que permite procesos de interactividad de contenidos contributiva. ${ }^{2}$ Las ventajas de la utilización de la web 2.0 son varias, algunas mencionadas anteriormente como la de utilizarse para obtener nuevas fuentes (herramienta para trabajar en entornos contributivos - usuarios que añaden información) y difusión de los datos, pero, además, otorga

A la comunidad la posibilidad de ejercer su "inteligencia colectiva" (entendida como la capacidad del grupo para resolver problemas que cada individuo del colectivo, de forma personal, no sería capaz de resolver ni, incluso, de entender). ${ }^{3}$

\section{Proyecto e-xiliad@s}

Las propias características del exilio republicano, en tanto que un movimiento puntual de masas mayoritariamente, $y$ de carácter individual en menor medida, hace que haya numeroso material sin conocer acerca del exiliado anónimo a nivel internacional. Igualmente, hay una exigua documentación en la Red Internet acerca de nuevo material del exilio en contraposición de una amplia prevalencia del formato papel en archivos, asociaciones, bibliotecas, etc. consultables solamente in loco o bien solicitando el documento vía correo postal con los costes de reproducción que conlleva.

Quien haya sido un investigador del exilio republicano habrá notado la cantidad de documentos inéditos con los que se puede encontrar cuando se entrevista a un exiliado, o familiares de los mismos, y que de no ser por la entrevista muy probablemente nunca se hubieran dado a conocer, ya sea a través de la investigación o mediante la divulgación de los mismos. Partiendo de esta base, y con la idea de crear un proyecto internacional de recuperación de nuevas fuentes del exilio, se plantearon las siguientes preguntas: ¿cómo conseguir documentación inédita acerca del exiliado anónimo a nivel internacional por parte de los propios exiliados, o gente afín a los mismos, sin necesidad de la presencia física del historiador? ¿Qué herramienta podemos utilizar para tal propósito? Para llevar a cabo una iniciativa de este tipo se hizo necesario contar desde el principio con la Red Internet y con una web dedicada a recibir información, que fuera creciendo a medida que nuevos datos se iban añadiendo por la comunidad de usuarios registrados, por lo que se optó por la web 2.o. Fue así como nació el proyecto interactivo e-xiliad@s s $^{4}$ el año 2009, saliendo en línea en febrero de 2010. Esta iniciativa ha sido subvencionada en un par de ocasiones por el Ministerio de Trabajo e Inmigración (año 2009) y el Ministerio de Empleo y Seguridad Social (año 2011), a través de la Secretaría Genera de Inmigración y Emigración del Gobierno español.

El principal objetivo del proyecto es recoger en línea a nivel internacional fuentes inéditas acerca de exilio republicano español a partir de 1936-39 hasta el primer franquismo (1959), de manos de los propios exiliados, familiares, amigos o estudiosos del tema. Las fuentes que re-

Xavier RIBES: "La Web 2.o. El valor de los metadatos y de la inteligencia colectiva”, TELOS Cuadernos de Comunicación e Innovación, 73 (Octubre-Diciembre 2007). Recuperado de Internet (http://sociedadinformacion.fundacion.telefonica.com/telos/articuloperspectiva.asp@idarticulo=2\&rev=73.htm)

3 Según Xavier Ribes, las actividades de la "inteligencia colectiva" en Internet pueden dividirse en tres grandes grupos: la producción de contenidos, la optimización de recursos y el control ejercido sobre contenidos e individuos. Esta inteligencia colectiva provocará, por ejemplo, que cierta referencia aparezca mejor o peor situada en Google (trámite los tags -etiquetados- que el usuario incluye en los datos que ofrece, por ejemplo) o será capaz de construir un producto tan monuincluye en los datos que ofrece, por ejemplo) o será capaz de
mental como por ejemplo Wikipedia (www.wikipedia.org). Ibid.

4 El proyecto fue bautizado con el nombre e-xiliad@s: juego de palabras que llama a un proyecto electrónico (e) y al tema del exilio de ambos géneros (@): http://exiliadosrepublicanos.info/ 
coge pueden ser de todo tipo: memorias, documentos escanerizados, fotografías, entrevistas, vídeo, etc.; pero especialmente recoge una serie de datos del exiliado a través de un formulario interno que la persona registrada debe cumplimentar (ej.: si participó en la guerra, en qué campos de concentración estuvo, etc.). Así pues, la iniciativa va orientada a dos tipos de audiencia: por un lado aquella dibujada por el usuario registrado en el proyecto (usuario activo), quien está interesado en ofrecer su propia memoria, o aquella familiar, o amical; por otro lado aquella perfilada por unos usuarios especialistas o simplemente interesados en la temática, quienes visitan el proyecto para obtener información (usuario pasivo).

\section{Metodología 2.0}

Desde el inicio el proyecto ha ido desarrollando una metodología adaptándose a la propia experiencia de los usuarios registrados (quienes ofrecen información mayoritariamente no édita acerca del exilio) y no registrados (quienes contactaban con la iniciativa). Así pues, sin apartarnos del rigor científico que caracteriza toda investigación, la metodología del proyecto se construye contando con la experiencia / opiniones de los usuarios de la iniciativa y de especialistas en la temática, de ahí que haya querido denominar este apartado como 2.0.5

Veamos a continuación cómo está estructurada esa metodología:

Ficha del exiliado / Formulario

El corazón del proyecto, entiéndase la herramienta que se utiliza para obtener datos de primera mano, es un formulario interno que el usuario registrado puede cumplimentar. Se trataría de la arteria principal de la metodología utilizada, dando la oportunidad al usuario de crear una ficha acerca de un exiliado republicano.

Así pues, la ficha es un formulario web con una serie de preguntas a elección, obligatorias o no, algunas de ellas con campo de texto libre y otras con listas cerradas, en donde añadir la información en relación al exiliado. Este formulario está estructurado en secciones principales con una serie de subsecciones dentro de cada una de ellas.

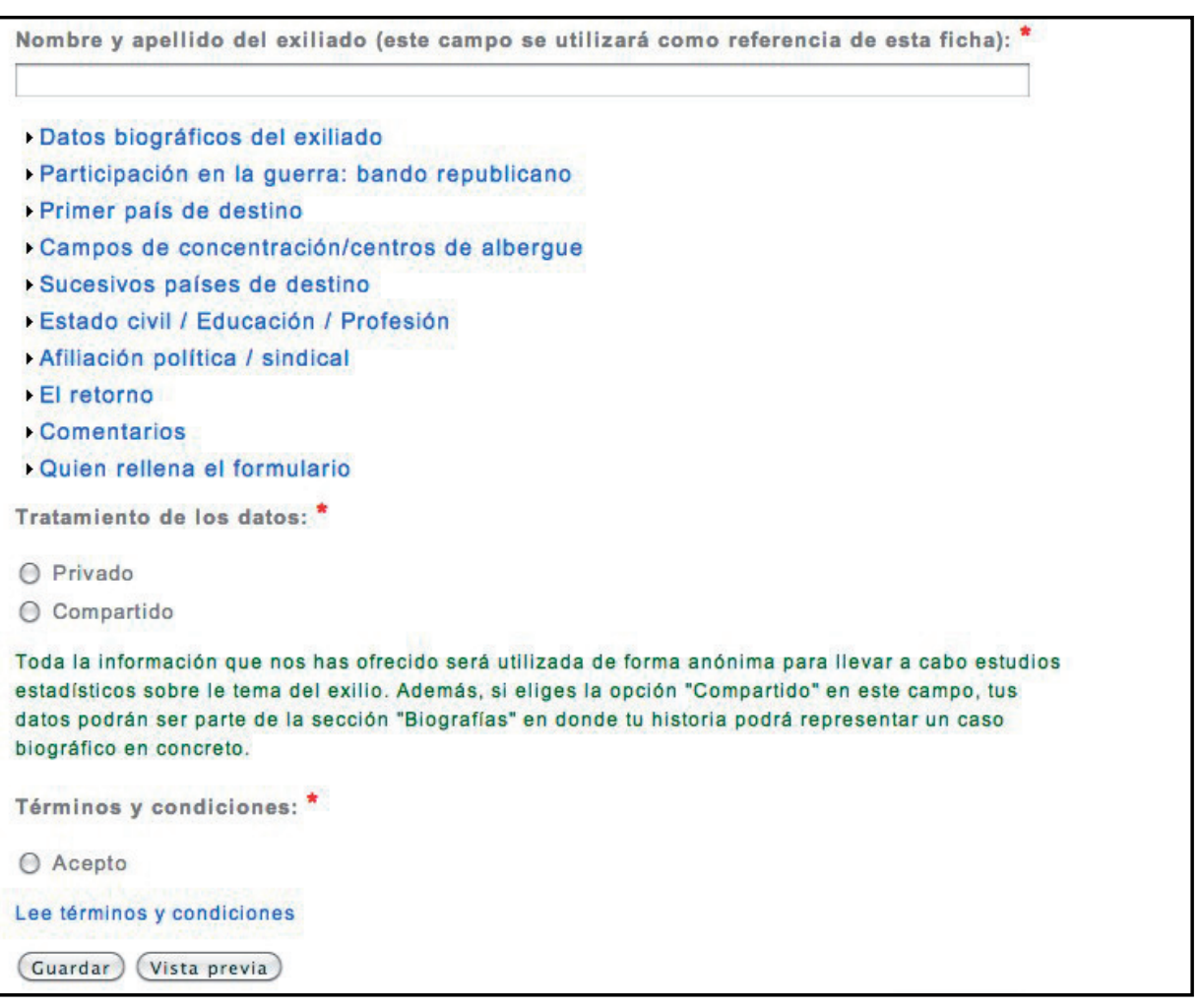

Cuad. o1 Ejemplo de ficha sin expandir (Fuente: Proyecto e-xiliad@s, http://exiliadosrepublicanos. info/es/formulario)

Clicando en cada una de las secciones en azul, marcada con una pequeña flecha negra, nos aparecen los campos asociados a ellas. Véase un ejemplo a continuación.

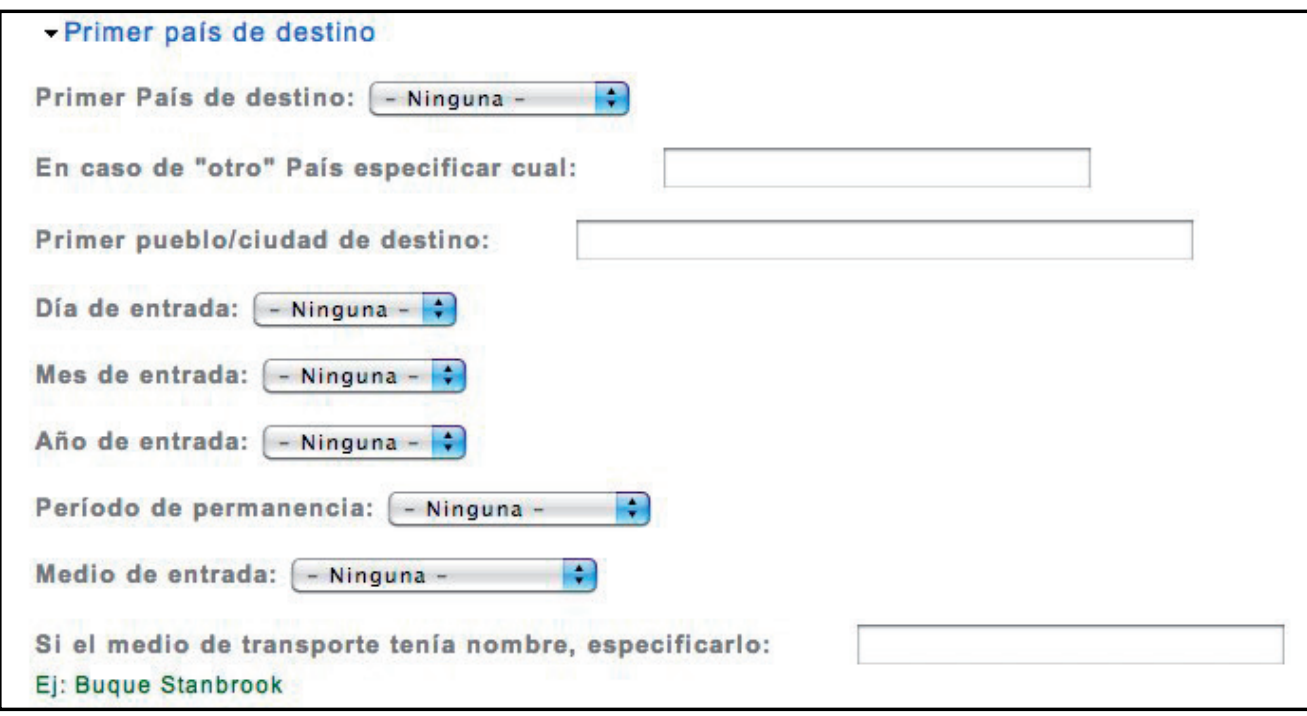

Cuad. o2 Ejemplo de una sección expandida de la ficha del exiliado (Fuente: Proyecto e-xiliad@s, http://exiliadosrepublicanos.info/es/formulario)
La primera vez que utilicé el término Metodología 2.0 fue en el seminario que impartí en la Universidad de Granada en donde explicaba brevemente en qué consistía esta metodología (Lidia BOCANEGRA: "Nuevo enfoque metodológico en el estudio del exilio republicano: la aplicación de la Web 2.o para la obtención de datos y recuperación de la memoria. Proyecto e-xliad@ss", Seminario impartido en el marco del Master: "Claves del Mundo Contemporáneo", Universidad de Granada, o2/abril/2013. Recuperado de Internet (http://Www.academia.edu/3207340/Nuevo en-
foque metodologico en el estudio del exilio republicano la aplicacion de la Web 20 poque_metodologico_en_el_estudio_del_exilio_republicano_la_aplicacion de_la_Web_-2.0 cio el proyecto e-xiliad@s realizó de forma paralela un par de encuestas on-line en el mes de mayo de 2010: uno a académicos y otro a usuarios registrados. El resultado de las mismas se mayo de 2010: uno a academicos y otro a usuarios registrados. El resultado de las mismas se TOSCANO: “Informe 2010", Proyecto e-xiliad@S, 2010, pp. 10-18. Recuperado de Internet (http:/l exiliadosrepublicanos.info/es/informes)) 


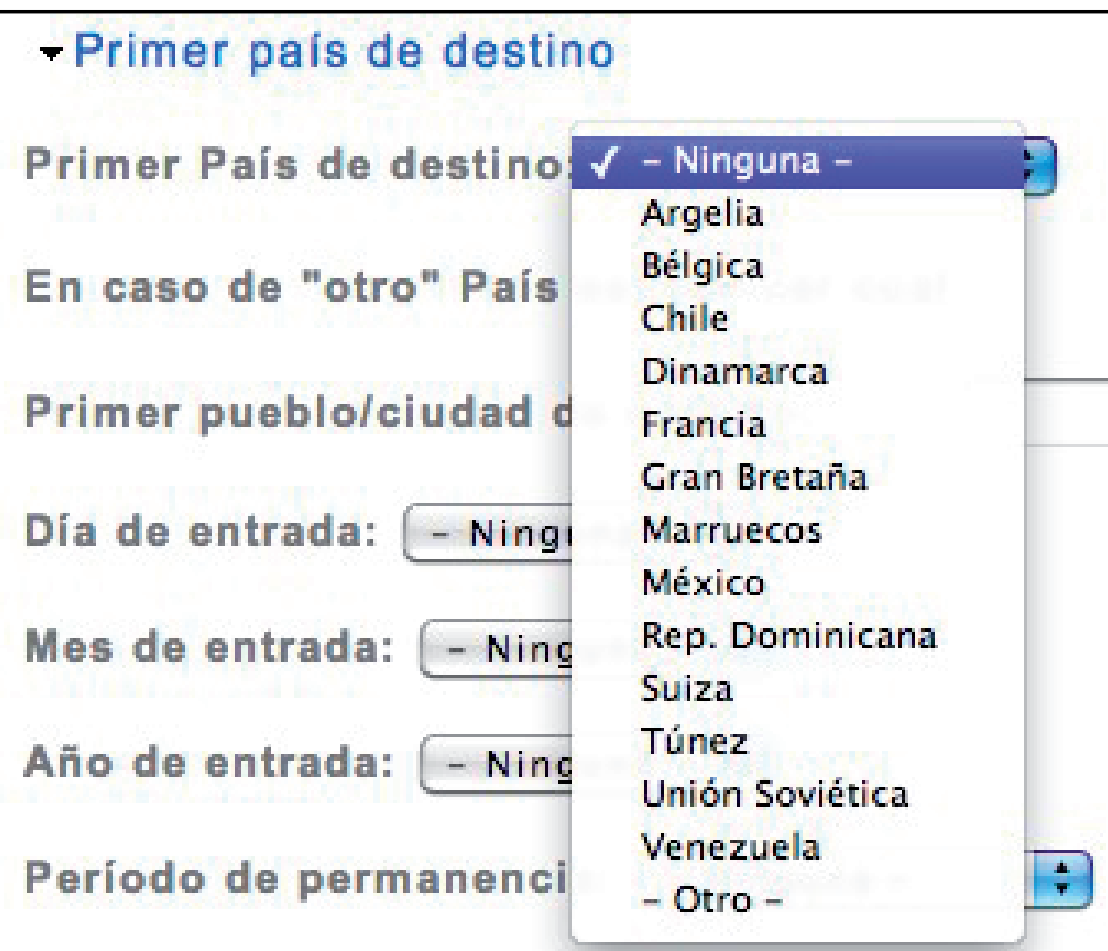

Cuad. 03 Ejemplo de una lista cerrada de la ficha del exiliado (Fuente: Proyecto e-xiliad@s, http:// exiliadosrepublicanos.info/es/formulario)

El porqué de utilizar un formulario en línea con secciones y subsecciones con listas cerradas, y campos de texto libre, responde fundamentalmente a dos motivos:

a) re-direccionar, y a la vez estimular, la memoria de la persona lo máximo posible utilizándose una serie de preguntas posicionadas estratégicamente siguiendo un orden cronológico de los propios sucesos del exilio;

b) organizar el dato de forma estructurada lo más completa posible con el objetivo de realizar análisis a posteriori.

Siguiendo un orden cronológico de los sucesos (datos biográficos del exiliado, participación en la guerra, primer país de destino, campos de concentración, sucesivos países de destinos, etc.) y ofreciendo listas de opciones (ya sean de lugares del exilio como campos de concentración y centros de albergue, etc.) se pretende estimular la memoria familiar del usuario, o la de propio exiliado, facilitando la obtención de datos recuperándose, de esta manera, la memoria del exiliado anónimo. Si a pesar de estos estímulos el usuario no recuerda o no posee datos suficientes, la web del proyecto le permite volver en otra ocasión para seguir rellenando la ficha, la cual se puede modificar cuantas veces sea necesario.

Toda la información y documentación recibida es revisada por el administrador web, especialista en la temática, para luego publicarla, si procede, en la sección biografias ${ }^{6}$ y otros apartados creados al respecto. En la actualidad el proyecto cuenta con un total de unas ciento doce fichas. Los beneficios de realizar una encuesta en línea (ficha del exiliado) a través del formulario web interno son varias:

a) mayor atención cuando se escribe que cuando se habla: a diferencia de las tradicionales encuestas grabadas por historiadores en donde el entrevistado aprovecha inconscientemente la facilidad para hablar para contar argumentos, muchas de las veces, fuera de la

Sección Biografias, Proyecto e-xiliad@s: http://exiliadosrepublicanos.info/es/biografias

7 Datos extraídos a fecha o1/abril/2013. temática de estudio;

b) posibilidad de rellenar la ficha en cualquier momento aportando nuevos datos o modificando otros (todo queda registrado en la base de datos mediante un sistema de versionig). A través del Menú usuario, la persona puede modificar la ficha antes de su publicación, o no, en el proyecto;

c) obtener cuestionarios completados desde cualquier parte del mundo, ayudado por el propio aspecto multilingüístico del proyecto;

d) posibilidad de añadir cualquier tipo de archivo (entrevistas, imágenes, etc.) asociada al a ficha

d) facilidad de interpretar y sonsacar más fácilmente la información recogida ya que las fichas están vinculadas a una base de datos.

\section{Visibilidad}

Para que un proyecto interactivo dedicado a la obtención de datos tenga éxito se necesita fomentar al máximo posible su visibilidad en la Red Internet. De este modo, se ha ido trabajando de forma gradual en varios aspectos que se detallan a continuación.

1. MULTILENGÜAJE: tratándose de una iniciativa de carácter internacional, desde el primer momento el proyecto contó con el idioma inglés y el español, añadiéndose poco más tarde el francés por tratarse del territorio principal de recepción del exilio. El porqué de la inclusión del inglés en un primer momento se debe a su carácter contemporáneo de lengua franca, lo que ha permitido por ejemplo la visualización de la iniciativa incluso en países sin presencia histórica de ese exilio republicano: Canadá, Alemania, China, etc. En los últimos dos años (febrero 2011 - marzo 2013), los Países que mayormente han visitado el proyecto han sido, por orden de importancia: España, Francia, México, Argentina y USA, les siguen Gran Bretaña, Chile, Colombia y Puerto Rico. Asimismo, para ese período 23.000 personas han visitado el sitio, de los cuales el $76 \%$ se tratan de nuevos usuarios.

2. SEO (Search Engine Optimization): el proyecto está optimizado para un mejor posicionamiento en los resultados de los principales motores de búsqueda tales como Google, Yahoo, Bing. Cuando hablamos de optimización referimos a toda una serie de implementaciones internas en la web tales como: palabras claves en las rutas y en el dominio (URL), meta-tags (en particular título y descripción), texto pertinente en el cuerpo de las páginas, enlaces internos y externos, mapa del sitio en XML, rich snippets (microdata), código fuente sin errores (CSS, HTML) y ausencia de contenidos duplicados, entre otros. Actualmente, realizándose una búsqueda en los tres idiomas del proyecto con las palabras claves de: "exilio republicano","republicanos españoles”o "éxodo republicano", e-xiliad@s aparece entre los resultados en la primera página de los principales motores de búsqueda.

3. CONTENIDO PUBLICADO: la visibilidad de una página web viene relaciona también por la cantidad de contenido publicado en la misma. En nuestro caso, no solamente se publica la información proporcionada por los usuarios (aquellos quienes han dado su consentimiento), sino que además se crean nuevas secciones con nuevo contenido elaborado a partir de los datos obtenidos y de información ya publicada: 1939, el éxodo republicano, Bibliografía y webgrafia del exilio, Filmografía del exilio, Mapa, Enlaces, etc.

Referente a las fichas creadas, el $88 \%$ de las mismas los usuarios eligieron la opción de compartido, o sea: hacerlas públicas, frente tan solo a un $12 \%$ en donde se eligió mantenerlas como privadas. Este es un dato importante que denota una predisposición a compartir abiertamente la memoria del exilio por parte de los usuarios, la mayoría de las veces familiares de los mismos, con el objetivo de que esa memoria no caiga en el olvido. 
4. SOCIAL MEDIA: hace poco el proyecto implementó el uso Facebook ${ }^{8}$ y Twitter, $^{9}$ con la idea de canalizar y difundir la información solicitada. A través de los mismos, e-xiliad@s divulga cualquier nuevo dato publicado en el proyecto (nuevas fichas, secciones, etc.), así como cualquier otra información relacionada con el exilio republicano español: conferencias, seminarios, noticias, eventos, publicaciones, etc. Cabe destacarse que desde que la iniciativa implementó las Redes Sociales ha recibido unas 500 visitas directas trámite Facebook.

Intercambio reciproco

El proyecto e-xiliad@s no solamente recibe sino que también ofrece datos. ¿Cómo funciona este intercambio?

RECEPCIÓN: la iniciativa recibe información de primera mano acerca de exiliados trámite

el formulario interno, principalmente, y en menor medida a través del formulario de contacta.

SERVICIOS: la información recibida trámite el formulario es procesada por el administrado web, quien, previo consentimiento, procede a publicarla en el apartado biografías u otras secciones afines creadas ad hoc (ej.; testimonios de los campos, diarios de viaje, etc.);

desde el inicio, la iniciativa ha realizado asesoramiento histórico personalizado (en españo

e inglés), vía correo electrónico, a las personas que contactaban solicitando información en relación a un exiliado en concreto, o solicitudes por parte de investigadores, profesores, estudiantes, etc.;

unido a lo anterior, a través del tablón de $\operatorname{anuncios}^{10}$ el proyecto da la oportunidad de publicar allí la información requerida por parte de esos usuarios, registrados o no. Gracias a la amplia visibilidad de la iniciativa a nivel internacional se facilita la difusión de esa información publicada;

utilización de los medios sociales (Facebook, Twitter) para la divulgación de todo nuevo contenido, incluso las solicitudes, entre una comunidad afín a la temática, favoreciendo de esta manera la transmisión de esos datos;

creación de apartados informativos acerca de la historia del exilio, mapa geolocalizado de la diáspora, amplio registro bibliográfico, etc.

Tanto la recepción de nueva información, como los servicios que el proyecto ofrece, genera un intercambio recíproco colaborando a recuperar la memoria del exilio y, como consecuencia, obteniendo mayor conocimiento acerca del mismo. Asimismo, la difusión a $360^{\circ}$ a través de la propia web y en los medios sociales ayuda a poner en contacto con el proyecto nuevos usuarios factibles de crear contenido en él, a la vez que se incrementa la comunidad virtual: a medida que el proyecto crece genera mayor confianza entre los nuevos usuarios a la hora de colaborar con él. El motivo: un proyecto serio, en donde otros ya han compartido su memoria lo convierte en un espacio fiable en donde depositar la historia familiar.

Personal especializado

Para un correcto funcionamiento de un proyecto interactivo de investigación internacional se hace necesario contar con personal especializado en diferentes áreas. En el caso de e-xiliad@s, cuenta con un informático especialista en SGC, SEO, y base de datos web. Igualmente cuenta con la participación de traductores en relación al idioma francés y del asesoramiento de historiadores especialistas en exilio republicano. Para el caso de los historiadores no siempre son los mismos, ya que la propia dinámica del proyecto hace que contacten con él espe-

8 Página Facebook del proyecto e-xiliad@s: http://www.facebook.com/exiliados.republicanos

9 Perfil Twitter de e-xiliad@s: @exiliadas.

10 Tablón de anuncios del proyecto e-xiliad@s: http://exiliadosrepublicanos.info/es/tablon-anuncios cialistas internacionales, lo que ayuda a tener diferentes puntos de vista conociendo el exilo desde nuevos ángulos.

Diseño User Friendly

Por muy bueno que sea un proyecto interactivo, por ejemplo: con mucha información, o una estructura interna muy elaborada (base de datos), si no posee un diseño de fácil manejo y atrayente pierde gran parte de su potencialidad. En este sentido, el proyecto e-xiliad@s incorpora conocimientos de diseño web del comercio electrónico (E-Commerce). Por ejemplo, organiza el dato por temas y contenidos: barra de navegación izquierda para alojar contenido general acerca del exilio republicano (historia, etc.), y en la barra de navegación principal (horizontal) ubicar los datos aportados por los usuarios (biografías, testimonios de los campos), as como información senso estricto del proyecto (de qué trata). El porqué: cuando un dato está bien organizado facilita la navegación del usuario en el mismo; por lo tanto incrementando su visibilidad y difusión. Otros aspectos incorporados del E-Commerce es la no utilización de párrafos muy amplios, sino el uso de trozos de texto breves (en inglés: Chunking) para hace de la lectura y la comprensión más rápida y fácil, esto se debe a que los lectores tienden a buscar información específica en una página web en lugar de leer la página de forma secuencial, igualmente, la incorporación de un diseño serio, profesional, acorde con el argumento que incorporen frases cortas que inciten a la colaboración con el mismo. Estos son algunos de los ejemplos que se basan en técnicas web del comercio electrónico; el motivo se debe a que este sector lleva muchos años especializándose no solamente en hacer atractiva una web, con logos y coloridos atrayentes, sino en facilitar la navegación del usuario entre el contenido de la misma y en la interacción con ella.

\section{Países de destino: la movilidad social en el exilio}

Del total de ciento doce fichas registradas en el proyecto e-xiliad@s, el pico más alto de edad al momento del exilio es la franja que comprende de los 16 a los 30 años, le sigue de cerca la clase comprendida entre los 31 a los 45 años. El $76 \%$ de las fichas creadas se tratan de hombres, frente a un $24 \%$ que son mujeres. Referente a la movilidad social de estos exiliados, tenemos un total de quince Países como primer lugar de destino, por orden de representación: Francia, Argentina, Gran Bretaña, Argelia, México, Túnez, República Dominicana, Andorra Unión Soviética, Chile, Uruguay, Portugal, Marruecos, Colombia, Brasil.

Para el caso de Francia, primer país de recepción del exilio masivo de 1939 por excelencia, casi la mayoría de los exiliados registrados (49\%) permanecieron menos de un año o estuvieron entre uno y tres años, más tarde emigraron a otros países o retornaron a España. En nuestro caso, se trató en buena medida de un lugar de pasaje. Asimismo, un grupo pequeño pero significativo, un $16 \%$, se quedó a vivir allí para siempre. Debido a la pequeña cantidad de muestras recogidas (112 fichas) las mismas no son suficientes para ofrecer datos significativos que contrarresten los ya ofrecidos por la propia historiografía del exilio. De tal manera, hay que destacar que el mayor contingente de todo el exilio antifranquista se sitúa en Francia, entre el $50 \%$ y el $60 \%$, siendo el más importante de todos los exilios republicanos."

In el año 1939, los españoles exiliados en Francia optaron por establecerse (dos tercios) en el sur de la linea Burdeos-Niza. Para el año 1945 la distribución peoráfica de los españoles sigue siendo de la linea Burdeos-Niza. Para el año 1945, la distribución geográfica de los españoles sigue siendo Javier CERVERA: “De Vichy a la liberación”, en Abdón MATEOS (ed): i Ay de los vencidos! El exilio y los países de acogida, Madrid, Editorial Eneida, 2009, pp. 41-43. 


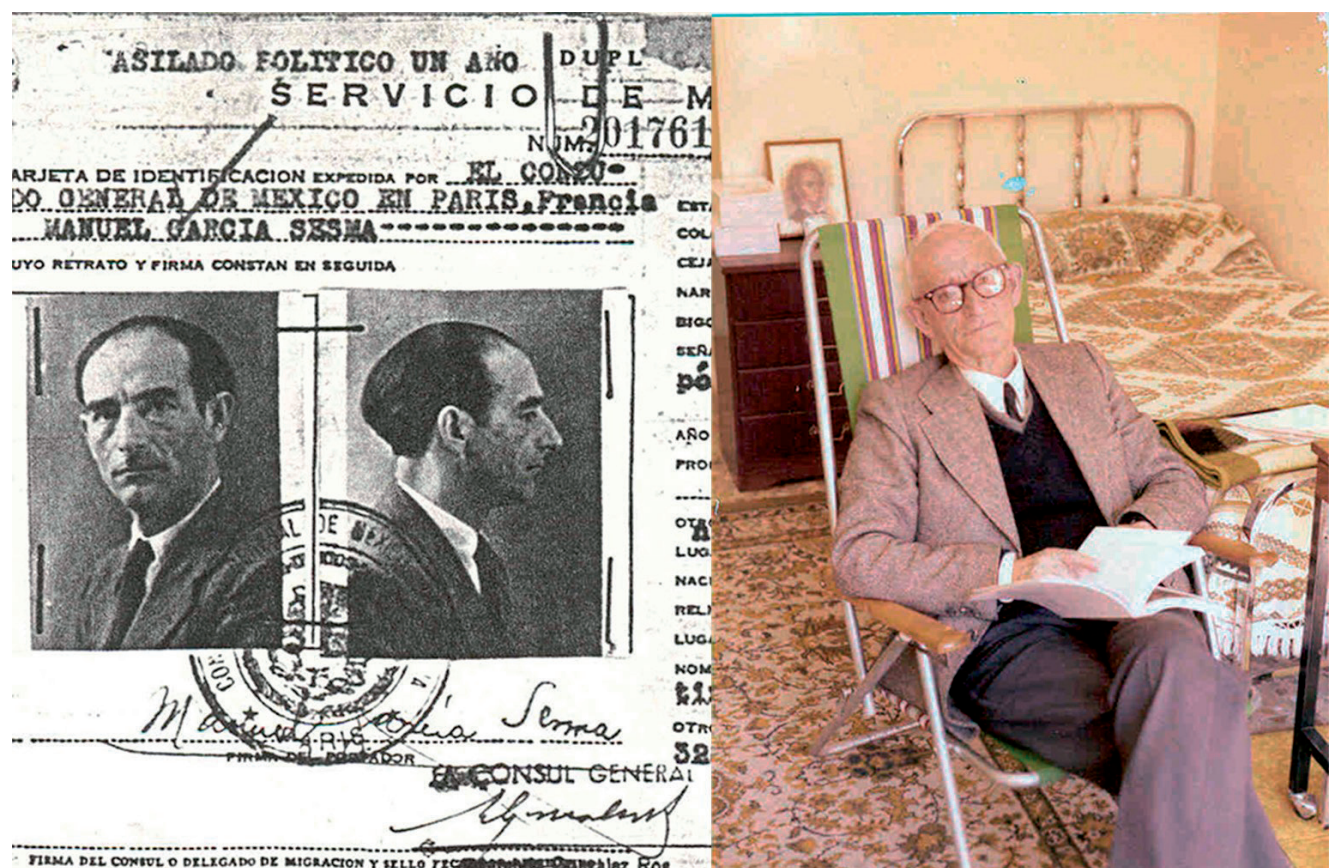

Img. 01 Manuel García Sesma, exiliado primeramente en Francia en 1939 y posteriormente en México, en 1947, en donde continuó su carrera como profesor de enseñanza media, también fue escritor y poeta. Retornó legalmente en España en 1973, ayudado por sus amigos de infancia. Foto de la izquierda: carné de Asilado Politico del Servicio de Inmigración 1947. Foto de la decha. Sesma fotografiado en la Residencia San Raimundo de Fitero ( $\mathrm{Na}$ manuel-garc\% $C_{3} \% A D$-sesma).

Argentina ofrece datos reveladores ya que casi la totalidad de los exiliados que se trasladaron a dicho País se quedaron a vivir definitivamente en él. El $36 \%$ lo hizo antes de que finalizara la guerra en el período comprendido entre 1936-1938; frente a un $45 \%$ que lo hizo entre 19401956 durante el primer franquismo. Argentina fue siempre un país con cierto atractivo para los exiliados republicanos ya sea por proximidad cultural y lingüística pero, sobre todo, por ser un lugar tradicionalmente receptor de emigrantes españoles durante el siglo XIX e inicios del s XX. Hay que señalar que durante la Guerra Civil española, Argentina fue uno de los países que mayor ayuda humanitaria aportó ya que la mayoría de la población, de ascendencia española o no, se posicionaron a favor de la causa republicana. Este hecho tuvo una cierta repercusión entre los exiliados republicanos quienes veían en este País una zona "amiga". Sin embargo, no contaban con que el gobierno de turno, posicionado con el ala más de derechas, no veía con buenos ojos la entrada de esos refugiados considerándolos como una inmigración "no deseable". Este miedo al rojo dificultó su entrada en el País, con lo que los exiliados tuvieron que sortear esas barreras restrictivas haciendo uso de las "cartas de llamada", o bien a través de la condición de turistas o de pasajeros "en tránsito". La primera, regulada bajo decreto en 1938, autorizaba a la Dirección General de Inmigración a conceder los permisos de entrada a parientes de personas radicadas en el País. Para el caso de los turistas y pasajeros en tránsito, aprovechando esa situación temporal los exiliados optaron por la fuga para permanece ilegalmente en Argentina: aquí entraron en juego las conexiones connacionales, algunos con vínculos con las esferas del poder, quienes contribuyeron a legalizar su situación. ${ }^{12}$

12 Lidia BOCANEGRA: "La República Argentina: el debate sobre la Guerra Civil y la inmigración", en Abdón MATEOS (ed.): iAy de los vencidos! El exilio y los países de acogida, Madrid, Editorial Eneida, 2009, p. 220.
Contrasta con el fenómeno argentino el caso de Argelia, en donde los exiliados se quedaron mayoritariamente por un periodo largo, incluso hasta 30 años, pero ninguno se quedó ah toda su vida. ${ }^{33}$ Cabe destacarse la rápida inserción de los exiliados en la sociedad franco-argelina a partir de 1942, fomentado con la clausura de los campos de concentración y de castigo (con la caída del Régimen de Vichy, unida a la presión ejercida por el sector mayoritario de la población europea de Argelia de ideología democrática), el reagrupamiento de los exiliados en centros urbanos y su creciente incorporación en el mercado laboral (algunos de ellos en las entidades españolas de tipo social, cultural y políticas). ${ }^{14}$

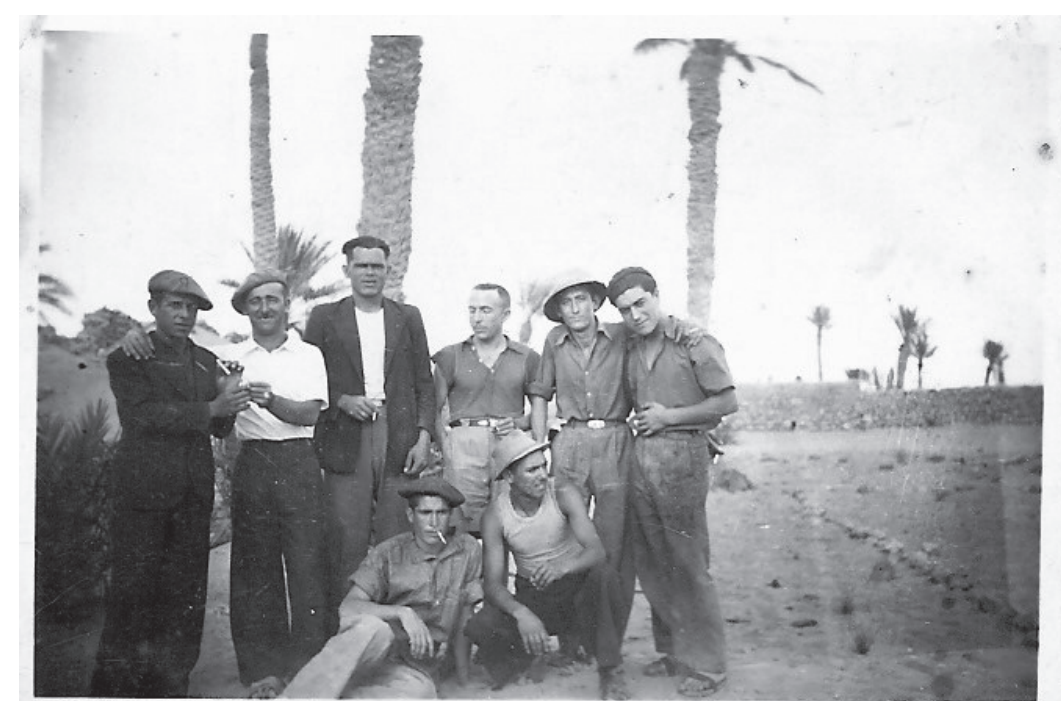

Img. 02 Francisco Barranquero Díaz, tercero por la izquierda de pie, fotografiado con algunos compañeros en uno de los campos de Sahara. Barranquero fue un exiliado del Buque y Hadjerat - Ain Sefra. En 1962 se exila en Francia (Fuente: Proyecto e-xiliad Ks, http:/ exiliadosrepublicanos.info/es/content/federico-barranquero-diaz).

De los que se exiliaron en Francia inicialmente, la mayoría de ellos buscaron refugio en Sur América, eligiendo como segundo país de destino, por orden de representación: Argentina (25\%), México (13\%), Uruguay (3\%), Chile (3\%), República Dominicana (3\%), Venezuela, Costa Rica y Cuba. Sin embargo, un grupo representativo se quedó definitivamente en Francia (16\%) tal y como hemos especificado anteriormente, y otro más pequeño regresó a España: 12\%. Es tos datos reflejan un comportamiento ampliamente analizado por la historiografía del exilio si bien las fichas registradas representan una muy pequeña muestra de esa movilidad social. De los 450.000 expatriados al término de las hostilidades $\left(1^{\circ}\right.$ de abril 1939) en Francia, unos 14.000 se marcharon a América, la mayoría a México (unos 8.000) y en menor medida a Chile y República Dominicana como naciones más destacadas. ${ }^{5}$

13 El éxodo masivo al Norte de África queda reflejado con la huida de la flota republicana desde Cartagena el 5 de marzo de 1939; siendo el destino preferido Orán y su region: Argelia. Al igual que Francia, los refugiados en Argelia se trató de una emigración fundamentalmente popular; a diferencia del exilio en América que, por regla general, lo componían intelectuales, artistas, científicos, políticos y militares de primera fila. Entre abril y diciembre de 1939, Argelia tenía unos 10.000 asilados Juan B. VILAR: “El exilio español de 1939 en el Norte de África", en Abdón MATEOS (ed.): ;Ay de los vencidos! El exilio y los países de acogida, Madrid, Editorial Eneida, 2009, pp. 73-74 $87-89$

14 lbid, p. 91.

15 Javier CERVERA: "De Vichy a la liberación" - p. 41. 
Para el caso de Gran Bretaña, si bien solamente nos ofrecen datos dos de las cuatro fichas rellenadas acerca del mismo, los exiliados utilizaron este país como lugar de pasaje permaneciendo en él menos de un año o máximo tres, trasladándose luego a Argentina. A pesar de contar con pocos datos, se puede considerar este aspecto como un posible indicador de movilidad social en el exilio británico a verificar en el futuro.

Referente Argelia, todos los que se habían exiliado inicialmente en este país se trasladaron en Francia, la mayoría de ellos (60\%) durante el período comprendido entre 1954, que coincide con el inicio de la revolución nacionalista argelina, y su independencia en 1964. Tal y como comenta la historiografía del exilio, la mayoría de los españoles residentes en Argelia estuvieron del lado francés, con lo que tras la independencia muchos de ellos tuvieron que huir precipitadamente del país con pérdidas de su patrimonio, lo que significó un segundo exilio. ${ }^{16}$



Gráf. o1 relación entre primer y segundo país de destino. Gráfico realizado a partir de los dato extraidos de las fichas creadas (Fuente: Proyecto e-xiliad@s)

\section{¿El retorno?}

De las fichas registradas que recogen datos acerca de si retornaron definitivamente o no a España, se ha sonsacado la siguiente información

Solamente el $26 \%$ retornó definitivamente en España;

de los retornados, un $16 \%$ lo hizo entre $1939-1943$, mientras que un $37 \%$ retornó entre 1944 1959. Combinando ambos casos, mas de la mitad de los exiliados registrados retornaron durante la etapa del primer franquismo. Sin embargo, un $26 \%$ volvió a España durante 1960 1975. En definitiva, el $79 \%$ de los retornados regresó definitivamente a España mientras Franco todavía estaba vivo, habiendo regresado el $21 \%$ restante durante la etapa comprendida entre 1976-2000;

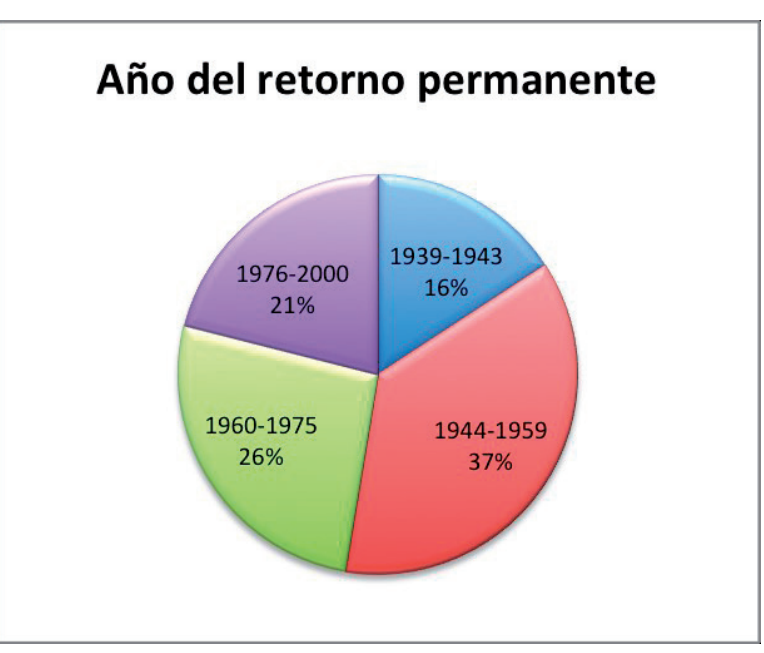

Gráf. 02 diagrama realizado a partir de los datos extraídos de las fichas creadas (Fuente: Proyecto e-xiliad@s)

de las provincias de retorno destacan cuantitativamente Barcelona, Guipúzcoa y Madrid seguidas por Vizcaya y Lleida entre otras;

el lugar de residencia actual, o País de fallecimiento, mayoritario entre el $72 \%$ que no retornó es Argentina, le sigue Francia y México; en menor medida: Venezuela, República Dominicana, Cuba, Austria, Costa Rica, Bélgica, Uruguay, Martinica, Chile y Puerto Rico;

de los que regresaron de forma legal, alguno estuvo vigilado por la policía. Alegan en e retorno motivaciones familiares, por ejemplo que su mujer e hijos no quisieran reunirse con é en Francia; que su mujer extrañara la familia no exiliada; de trabajo, una vez terminada la guerra alguien tenía que hacerse cargo de la tierra y sustentar la familia alli; la no resignación a la idea de no regresar nunca más: factor intrínseco a la propia característica del exilio al tratarse de una salida forzosa y no voluntaria. Otros regresaron como jubilados, aunque sin pensión con la idea de acabar sus últimos días en su tierra y ver a los familiares quedados allí. Durante el franquismo, muchos de ellos regresaron ayudados por familiares en España quienes hacían de enlace con las administraciones correspondientes con el fin de traerlos de forma legal, asegurándose que no tuvieran ningún expediente o denuncia en curso, incluso, facilitándoles salvoconductos de entrada. Sin embrago, algunos de esos regresos no se hicieron de forma legal lo que implicó ser capturado por la policía y ser encarcelados.

Aquí hemos analizado las fichas en su conjunto, algunas de ellas reflejan el retorno inmediato durante el curso de 1939. Volviendo al tema del exilio masivo en Francia, recuérdese que entre abril y diciembre de 1939 hubo un ritmo muy intenso de retornos a España, unos 268.00o, por lo general excombatientes y población civil no especialmente implicados en causas políticas. ${ }^{10}$

\section{Conclusiones}

Se ha pretendido ofrecer sintéticamente un panorama general acerca del uso de la web 2.0 como herramienta en la investigación histórica. Actualmente son muy pocos los historiadores quienes hacen uso de la web como un instrumento para obtener nuevas fuentes, focalizando su utilización sobre todo para difundir información. Igualmente, la reticencia de este colectivo a la hora de ahondar en el conocimiento web de base con el objetivo de sacarle mayor partido. A través de un proyecto web interactivo e internacional, e-xiliad@s, se utiliza a modo de ejemplo para especificar una metodología-web innovadora a la hora de obtener nuevas fuen-

17 Juan B. VILAR: “El exilio español de 1939”..., p. 72 
tes del exilio republicano. La metodología actual en curso, y en continuo desarrollo, demuestra la eficacia de la misma al recoger datos inéditos acerca de exiliados anónimos de manos de los propios usuarios, a nivel internacional. Destacándose de esta metodología la utilización de un formulario web interno (ficha del exiliado), bien estructurado, que ayuda a estimular la memoria familiar del usuario. Igualmente, el uso del intercambio recíproco: recibir y dar información de forma paralela; creación de una comunidad virtual, así como la inclusión de técnicas del comercio electrónico a la hora de la presentación de los datos, entre otros, son algunos de los factores que componen lo que aquí se ha denominado metodología 2.0.

Los datos de las fichas del proyecto e-xilid@s ayudan a analizar la movilidad social y el retorno del exilio republicano, a veces reforzando ideas genéricas de la propia historiografía de exilio, otras veces contrarrestándolas. En un contexto genérico de explicación teórica de comportamiento social pueden perder fuerza, debido a la cantidad de fichas actual; pero a modo particular se convierten en una fuente valiosa de información con memorias muy completas y complejas que incluyen registros documentales muy importantes, algunas de ellas factibles de protagonizar un caso de estudio concreto. 


\section{LA EMIGRACIÓN ECONÓMICA ESPAÑOLA \\ A FRANCIA (1956-1975):}

\section{POLÍTICAS MIGRATORIAS E INSERCIÓN}

Élodie Das Neves

Laboratorio FRAMESPA (Universidad de Toulouse II - Le Mirail)

Con más de 252000 españoles en Francia hoy en día, la nacionalidad española es la quinta nacionalidad más representada entre los inmigrantes en Francia según el último estudio de Instituto nacional de estudios demográficos.' Esta emigración es fruto de oleadas sucesivas y de diferentes índoles a lo largo del siglo XX. Después de una emigración de tipo económico tras la Primera Guerra Mundial, Francia se convirtió en una tierra de acogida para los exiliados republicanos a raíz de la Guerra Civil española. La última oleada que culmina a mediados de los sesenta convirtiendo a los españoles en primera comunidad extranjera más representada en Francia es también de índole económica, al tratarse de una emigración de trabajo. Es precisamente esta emigración, que se extiende desde mediados de los años cincuenta hasta mediados de los años setenta, de la que vamos a tratar en este artículo.

Recordemos primero que se produce este fenómeno migratorio desde una España franquista en una situación económica y social crítica hacia una Europa industrializada y en plena reconstrucción. En este contexto, los países vecinos, España y Francia van ideando y llevando a cabo unas estrategias de movimientos de población con fines propios pero con intereses convergentes. Por lo tanto, procuraremos en estas páginas analizar el enfoque de sus respectivas políticas migratorias y la visión de la inserción de los migrantes en ambos países. Estudiaremos por una parte la posición del Estado español en cuanto a la emigración, y por otra parte la orientación de las autoridades francesas respecto a la inmigración en el periodo. Terminaremos considerando el nexo entre sendos planteamientos al observar los acuerdos bilaterales y sus consecuentes desacuerdos.

\section{La emigración continental como recurso ante la situación económica española}

os años cincuenta están marcados por una reorientación en los flujos y en la política migratoria del Estado franquista. La emigración continental hacia los países industrializados de Europa sustituye progresivamente a la emigración hacia América. El nuevo destino continental de la emigración española, combinado con la orientación desarrollista de la economía española en el segundo franquismo, conducen las autoridades a idear unas políticas migratorias acordes con esos nuevos planteamientos.

Después de una primera fase de aislamiento internacional a raíz de la Guerra Civil y de la Segunda Guerra Mundial, la segunda mitad de la década de los cincuenta advierte cierta apertura. ${ }^{2}$ Por lo demás, en la reestructuración económica impulsada a finales de los años cincuenta la emigración constituye un rasgo decisivo. Para controlarla y asentarla, se toman varias

1 Esta cifra da cuenta de las personas de nacionalidad española, excluyendo de hecho a los españoles o descendientes de españoles naturalizados. France PRIOUX y Magali BARBIERI : "''évolution démographique récente en France", Populations, París, INED, 4 (2012), pp. 597-656.

2 Destacan la entrada en la ONU en 1955, en la OECE, el FMl y el Banco Mundial en 1958. medidas. La más significativa es sin duda la creación del Instituto Español de Emigración (IEE) el 17 de julio de 1956, con el fin de planificar los flujos migratorios.

Cabe señalar que el régimen franquista no es a priori favorable a la emigración exterior, conforme con la índole autoritaria del régimen. A diferencia de las migraciones interiores -dentro de las fronteras nacionales-, la emigración exterior -fuera de las mismas- representa una pérdida de fuerza productiva. De hecho, en una documentación interna de la Organización Sindical Española (OSE) -y más específicamente del Servicio nacional de colocación, encargado de los asuntos de colocación y de emigración- se realiza una comparación entre ambas emigraciones, tratando de apuntar sus ventajas y desventajas:

En el caso de moverse la migración dentro de las propias fronteras nacionales, las pérdidas no son totales, pues sólo expresan un desplazamiento de energía de un punto a otro del propio territorio. (...) En el caso de tratarse de una migración exterior, el país exportador de población pierde 1) energía demográfica y productiva, y 2) por contrapartida, hace ganarla a las naciones importadoras.

Ahora bien, la visión de la emigración exterior como una pérdida humana nefasta, particularmente vigente en el primer franquismo, es entonces relativizada por las autoridades, quienes empiezan a considerar la otra cara de la moneda, al divisar la posible "capitalización de la emigración". ${ }^{4}$ Así pues, en la ley en la que se crea el IEE, por una parte se asume "el sacrificio que representa para una nación la salida de grandes contingentes que han pesado sobre su economía durante el periodo de educación y crecimiento y que van a rendir su fruto fuera de ella", y por otra parte se insiste en el "foment[o] y encauza[miento] del ahorro entre los emigrantes, facilitando, cuando proceda, su transferencia a los familiares residentes en España".5 El recurso a la emigración se considera pues económicamente positivo siempre y cuando sea objeto de un control estricto por parte del régimen. Para garantizar el control del flujo migratorio pero también mirando por la facilitación de la circulación de las divisas que mandarían los expatriados a España, se firmados acuerdos bilaterales con los países de acogida: con Bélgica en 1956, con la República Federal de Alemania en 1960, con Francia, Suiza y los Países Bajos en 1961.

España concibe pues la emigración como una solución económica a medio plazo, que se inscribe en un doble objetivo: por una parte reducir la cantidad demasiado elevada de mano de obra en el territorio, y por otra parte beneficiarse de las divisas que los inmigrantes manden a su país de origen. Cumple una función de válvula de escape, siendo estimadas por el mismo IEE las necesarias salidas anuales a unos 80 ooo emigrantes. Las autoridades consideran por lo tanto la emigración como una solución temporal: la mano de obra excedentaria saldría del territorio hasta que la situación española se recupere y pueda emplearla de nuevo. Correspondería en este sentido a una "migración de mantenimiento", es decir una emigración en la que el país de acogida se reduce a un instrumento provisional, y en la que los proyectos a largo plazo se circunscriben al país de origen. ${ }^{6}$ En este sentido, la publicación que emana del Ministerio de trabajo en el año 1966 es concluyente:

3 Informe del Consejo social de la OSE, AGA, Organización sindical, Servicio nacional de colocación caja 16599, s.a. [1960]

4 Axel KREIENBRINK: “La lógica económica de la política emigratoria del régimen franquista", en Joseba DE LA TORRE CAMPO y Gloria SANZ LAFUENTE (eds.): Migraciones y coyuntura económica del franquismo a la democracia, Zaragoza, Prensas Universitarias de Zaragoza, 2008, pp. 221-235.

5 BOE $n^{\circ} 200$, Ley del 17 de julio de 1956 por la que se crea el Instituto Español de Emigración.

6 Teoría desarrollada en Paul-André ROSENTAL: "Maintien/rupture : un nouveau couple pour l'analyse des migrations", Annales ESC, 6 (1990), pp. 1403-1431. 
La emigración ha cambiado de signo y al trasladarse a Europa se convierte fundamentalmente en un movimiento temporal y de motivación económica. Y es precisamente esta temporalidad la que obliga al país de emigración a preocuparse de esos trabajadores que en un futuro próximo, una vez que hayan conseguido los ahorros suficientes, regresarán a la Patria.?

Así pues, al "preocuparse" por sus expatriados, el Estado español mira por la perduración de régimen, intentando mantener vínculos entre sus residentes en el extranjero y la nación española. Para ello, la asistencia española, concebida como una entidad protectora, se estructura en torno a diferentes centros de representaciones diplomáticas y consulares de España así como a redes asociativas en los países de emigración. De hecho, en una lógica patriota, el lazo que constituye la cultura española es la base de un proceso que aspira a luchar contra la "deshispanización" de aquéllos que han emigrado a Europa. ${ }^{8}$ Pero, como lo hemos señalado también constituye un recurso del aparato franquista para mantener cierta influencia ideológica sobre los expatriados que en teoría volverán pronto a España, especialmente sobre aquéllos que emigren a unas zonas de fuerte presencia de exiliados republicanos, como es el caso de Francia. Una de las estrategias ideadas por el Estado español es la difusión de medios de comunicación españoles en los países de acogida. Ya en la ley de 17 de julio de 1956 se especifica el "foment[o] del envío de prensa, libros y otros medios de difusión de cultura" así como la promoción de "cuantas iniciativas se encaminen a valorar y proteger la emigración española en el orden moral, económico y cultural". Para mantener dicho "orden moral", se garantiza en el mismo texto legislativo una "asistencia espiritual a los emigrantes". A la voluntad de control político y económico se añade pues la voluntad de un control ideológico mediante una propaganda religiosa. Se planea asimismo que la propaganda franquista actúe fuera de las fronteras nacionales para que los emigrantes, cuando vuelvan, no introduzcan ideas contrarias al régimen. Un informe acerca de la edición del diario Pueblo para los trabajadores emigrantes viene a confirmar este postulado ya que prevé un refuerzo de la "acción protectora del emigrante en el exterior y, fundamentalmente, respecto a los trabajadores del área europea" facilitando a los "trabajadores en el extranjero la adecuada información de la totalidad de nuestra vida nacional y política".9

Aparte, la inserción laboral queda fijada en los acuerdos bilaterales firmados con los países de acogida y preocupa a las autoridades españolas que intentan estar pendientes de las condiciones de alojamiento y de remuneración de los emigrantes. El Estado español parece estar sensibilizado a las dificultades que supone la emigración al nivel individual, como podemos comprobarlo en la documentación interna de la OSE previamente citada, en la que se hace referencia a la "innumerable cantidad de problemas" con los que se enfrenta el emigrante fuera del territorio nacional. El informe destaca las dificultades en cuanto al desarraigo que supone el hecho de dejar su tierra y muchas veces su familia, en cuanto a la adaptación a las costumbres locales, y subraya además las dificultades relativas a la integración socioprofesional aludiendo a "tensiones interpersonales y étnicas, y la competencia brutal que, para el éxito económico y social, está obligado a sobrellevar en su nueva sociedad el hombre que ha salido de su Patria".

7 Fernando MAGARIÑOS TORRES: La asistencia en el exterior a la emigración española, Madrid, IEE, 1966, pp. 5-31.

8 Informe del Consejo social de la OSE, AGA, Organización sindical, Servicio nacional de colocación, caja 16599, s.a. [1960]

9 Informe acerca de la edición especial del diario Pueblo para los trabajadores emigrantes, AGA, Organización sindical, Servicio nacional de colocación, caja 16601, 21 de mayo de 1962.

10 Informe del Consejo social de la OSE, AGA, Organización sindical, Servicio nacional de colocación, caja 16599, s.a. [1960].
Sin embargo, las preocupaciones patrióticas respecto a las condiciones de inserción socioprofesional en el país de acogida se contemplan de manera muy relativa, en la medida en que la estancia fuera de España debía ser temporal, tanto para el gobierno como para el emigrante, que salía de España con el objetivo de ahorrar durante unos años y volver. La encuesta realizada por el gobierno español -mediante la comisión internacional católica para las migraciones- entre las familias de los trabajadores migrantes en seis países europeos, viene a confortar la concepción efímera de la emigración para los trabajadores españoles, que a diferencia de los italianos "consideran más bien la emigración como una situación transitoria" lo cual explica que se conformen con pésimas condiciones de alojamiento "dado que las familias españolas tienen tendencia a considerar su estancia como temporal, ellas se acomodan más fácilmente a una situación menos cómoda"." Así pues, en la medida en que a la vez los emigrantes y las autoridades consideran la salida del territorio como provisional, la cuestión de la inserción social no parece ser objeto de planes estructurales.

\section{La inmigración como recurso ante la situación económica y demográfica francesa}

Las consecuencias demográficas de la Segunda Guerra Mundial y la necesidad de mano de obra característica del periodo de reconstrucción y de crecimiento económico de los Treinta Gloriosos llevan Francia a optar por la inmigración. No obstante, el enfoque de las políticas migratorias instauradas en el periodo viene heredado de un debate ideológico que tiene lugar en la inmediata posguerra.

Ante todo, la construcción y la orientación de una política migratoria en Francia están marcadas en los primeros años de reconstrucción por una necesidad de recuperación demográfica, para la que la inmigración se impone como un recurso evidente. Recordemos que a consecuencia de la guerra, Francia conoce una pérdida de 1.700 .000 habitantes aproximadamente y pese a un aumento de la tasa de natalidad, la pirámide de edades deja entrever un desequilibrio de edades y de sexos. ${ }^{12}$ Es entonces cuando se echan las bases de una política migratoria, presentada por el General de Gaulle -entonces presidente del gobierno provisional de la República francesa- el 2 de marzo de 1945, al invitar la Asamblea consultativa a solucionar la crisis demográfica. Aparte del incremento de la natalidad, propone la inmigración como un recurso clave del estímulo demográfico, recalcando la necesidad de seleccionar a "buenos elementos de inmigración". ${ }^{13}$ De ahí brota el debate entre demógrafos y economistas después de la Liberación: los demógrafos -del Instituto nacional de estudios demográficos- consideran que a la necesidad de mano de obra se suma la necesidad demográfica; los economistas por su parte solamente consideran la dimensión productiva de la inmigración, y abogan por una inmigración de trabajadores y no una inmigración de población.

Las bases de la política migratoria francesa se encuentran en dos ordenanzas: la del 19 de octubre y la del 2 de noviembre 1945. La primera se centra en la cuestión de la nacionalidad. Por una parte refuerza las exigencias en cuanto a la naturalización -se tienen que justificar como mínimo cinco años de residencia en Francia antes de solicitarla-, y por otra parte parece facilitarla

11 Encuesta entre las familias de los trabajadores migrantes en seis países europeos realizada por la Comisión internacional católica para las migraciones, AGA, Organización sindical, Servicio nacional de colocación, caja 16601, 1963.

12 Ralph SCHOR: Histoire de l'immigration en France de la fin du XIXe siècle à nos jours, París, Armand Colin, 1996, pp. 192-212. 13 El mismo 2 de marzo de 1945, el General de Gaulle declara en la Asamblea constitutiva que se inmigración en la colectividad francesa". Traducción del autor a partir de "introduire au cours des prochaines années, avec méthode et intelligence, de bons éléments d'immigration dans la collec-

prochaines années,

(n).


-se restablece el derecho de suelo, y la persona extranjera que se case con una persona francesa adquiere la nacionalidad- con el fin de integrar los inmigrantes a la nación francesa así como de invertir la curva demográfica. La teoría de los demógrafos parece por lo tanto imponerse a optarse por una inmigración familiar, enfocada hacia la instalación definitiva. La inmigración económica y la inmigración demográfica son pues consideradas compatibles, en la medida en que los trabajadores y sus familias tienen vocación a ser naturalizados. La segunda ordenanza concierne las condiciones de entrada y de residencia de los extranjeros que trabajan en Francia. En ésta se crea la Oficina Nacional de Inmigración (ONI) que se encargará a partir de entonces del reclutamiento y de la introducción de los trabajadores extranjeros. Son establecidos tres tipos de permisos de residencia: el de residente temporal -con una duración de un año-, el de residente ordinario -con una duración de uno a tres años-y el de residente privilegiado -con una duración de diez años, que puede solicitarse con cuatro años de residencia en Francia-. Si la cuestión de la selección étnica irrumpió en el debate, los ministros del gobierno provisional decidieron descartarla, por oponerse a los valores de la República. En cambio sí se entendía privilegiar una inmigración joven, cuyos sectores de inserción profesional correspondieran con los sectores que conocían un déficit de mano de obra. Este conjunto de medidas enfocadas hacia una inmigración de población inicia pues una primera etapa de inmigración más bien moderada hasta $1955 .{ }^{14} \mathrm{En}$ efecto, la alta exigencia de control conlleva una maquinaria administrativa pesada que resulta bastante ineficiente ya que la inmigración ilegal seguirá creciendo.

Si bien en la primera etapa las autoridades pretenden sentar las bases de una política de control estrecho de los movimientos de población que llegan del extranjero, la segunda etapa, que comprendería los años 1956 hasta 1974, se caracteriza por una explosión de la inmigración. Se firman acuerdos con los países europeos: con España en 1961, Portugal en 1963 Yugoslavia y Turquía en 1965. Pese a esto, los flujos migratorios resultan cada vez menos controlados. Los trámites con un contrato de la ONI se hacen cada vez más contados, mientras que la entrada en Francia con un pasaporte de turista se hace cada vez más frecuente. Al poder ser regularizados a posteriori y sin dificultades, los inmigrantes optan masivamente por esta opción. De hecho, la tasa de regularización ya representa un $50 \%$ en el año 1957 y alcanzará un $82 \%$ en el año 1968. La cifra es todavía más significativa en lo que se refiere a la regularización de las familias extranjeras, que pasa de un $85 \%$ en 1966 a un $91,7 \%$ en $19711^{15}$

No obstante, esta estrategia improvisada se inscribe en contradicción con la idea prima de las autoridades francesas de organizar una emigración de población, ya que los trabajadores que llegan están en situaciones precarias, con un permiso de residente de un año en la mayoría de los casos. Sin embargo, el recurso a la inmigración corre parejo con el crecimiento económico de los Treinta Gloriosos en Francia, por lo que los contratos y permisos de residente se ven prorrogados. Cabe recordar que la población extranjera en Francia se duplica en dos décadas, pasando de 1765 ooo en 1954 a 3442 ooo en $1975 .{ }^{16}$

Por lo demás, en Francia, la inserción social se plantea ya desde finales del siglo XIX en términos de asimilación. Así pues, se considera que los inmigrantes que se instalan en Francia deben adoptar la cultura e identidad francesas, lo cual parece más realizable según las autoridades con emigrantes procedentes de países vecinos. Tras contar con los italianos, el gobierno francés cuenta con los españoles para aumentar la proporción de inmigrantes europeos, en una dinámica de preferencia continental. Asimismo, si nos fijamos en la percepción de la po-

14 Se evalúan a menos de 100 ooo los inmigrantes a Francia en los primeros años, e incluso a menos de 30000 a partir de 1950 según Marie-Claude BLANC-CHALEARD: Histoire de l'immigration, Paris, L'Harmattan, 2001, pp. 57-72.

15 Christophe VERNEUIL: La France et les étrangers du milieu du XIXe siècle à nos jours, París, Ellipses, 2010, pp. 137-167.

16 lbid., pp. 137-167. blación francesa respecto a los españoles, destacan como trabajadores discretos y fácilmente asimilables al ser, según Yvan Gastaut, "poco visibles", 17 es decir física y culturalmente asimilables. La inserción social de los inmigrantes españoles está por consiguiente vinculada con su inserción laboral en la medida en que se aplica la causa de su inmigración a una característica intrínseca de los migrantes, los españoles son pues percibidos como trabajadores. Aun así, para lograr una asimilación efectiva, una de las mayores herramientas del Estado es la escuela republicana. Los hijos de los españoles al estar escolarizados en francés, en las mismas escuelas que los autóctonos han conocido "el modelo asimilacionista (...) en las aulas", 8 alentados por unos padres deseosos de que sus hijos dominen el idioma y se integren en la sociedad francesa,"el mensaje que reciben de los padres, [es] de integrarse en la sociedad que les acoge y aprovechar las nuevas oportunidades educativas que se les ofrece".19

El estudio del enfoque de las políticas migratorias de los países vecinos ha permitido destacar rasgos comunes -la voluntad de control- y divergentes -la función e índole temporal o duradera de la migración-. Observemos por fin el punto de contacto de ambas políticas migratorias mediante los acuerdos bilaterales.

\section{Las migraciones españolas a Francia: entre acuerdos y desacuerdos}

Después de la Segunda Guerra Mundial, las relaciones diplomáticas entre España y Francia están fracturadas, y cuando se retoman resultan "especialmente tensas y difíciles".20 En la década de los cincuenta, firman diversos acuerdos y convenciones relativos a los trabajadores de temporada -en marzo de 1956-, a la seguridad social -en febrero de 1957- y a la reagrupación familiar -en octubre de 1958-, antes del acuerdo hispano-francés, firmado el 2 de enero de 1961 Inscrito en el ámbito del Tratado de Trabajo y Asistencia del 2 de noviembre de 1932, el propósito del acuerdo aparece como un deseo conjunto de los gobiernos de "regular [...] el régimen de los trabajadores permanentes españoles en Francia". ${ }^{21}$ Ahora bien, más que el acuerdo en sí, nos interesa saber en qué medida se satisfacen o no las exigencias de cada país, en esto que nos permite observar la evolución de sendos planteamientos y por lo tanto del fenómeno migratorio.

El acuerdo, conforme con la voluntad francesa de establecer un "acuerdo de inmigración de población" es aceptado como tal por las autoridades españolas. De hecho estipula que el IEE "adoptará todas la medidas adecuadas para ayudar a las familias y facilitar su emigración en el más breve plazo"..22 Este planteamiento resulta bastante paradójico si lo comparamos con la inicial visión española de la emigración. Una paradoja que se puede explicar en parte por la influencia de la Iglesia católica defensora de un modelo familiar tradicional y por lo tanto de la reagrupación familiar. En la misma veta, cabe recordar que en la ley del 23 de diciembre de 1960 se hace referencia a "un sentido cristiano de la vida [que] tiende a facilitar la reunión del emigrante con su familia". Además, las autoridades españolas son conscientes de la voluntad francesa de fomentar una inmigración duradera ya que en mayo de 1972 un documento de trabajo del IEE recuerda que "desde el punto de vista demográfico, Francia está fomentando la inmigración permanente de familias completas para conseguir su ansiado aumento de población".23

17 Vvan GASTAUT: L'immigration et l'opinion publique en France sous la V Vépublique, Paris, Seuil, 2000, pp. 94-96.

18 Laura OSO CASAS: Trans-ciudadano: Hijos de la emigración española en Francia, Madrid, Fundación Francisco Largo Caballero, 2007, pp. 64-102.

9 lbid., pp. 64-102.

20 Juan Bautista VILAR y María José VILAR (eds.): La emigración española a Europa en el siglo XX, Madrid, Arco Libros, 1999, pp. 41-62

21 BOE $n^{\circ} 50$ del 28 de febrero de 1961.

$22 \mathrm{BOE}{ }^{\circ} 307$ del 23 de diciembre de 1960 .

23 Documento de trabajo del gabinete de estudios del servicio de emigración exterior del IEE, AGA, 
Por su parte, las autoridades españolas desean ante todo zanjar la cuestión de las remesas de sus expatriados y obtienen una salida favorable, de ahí el artículo 9 "los trabajadores españoles permanentes en Francia [...] podrán transferir a su país de origen los ahorros procedentes de sus salarios". El segundo punto, que no resultará tan satisfactorio, radica en la lucha contra la emigración espontánea, permitida e incluso fomentada por las regularizaciones masivas y sin trabas de los inmigrantes españoles entrados en Francia con un pasaporte de turista. Esta estrategia dominante entre los emigrantes españoles va en contra de la estricta voluntad de control deseada por las autoridades españolas. Por lo cual, el Ministerio de trabajo difunde documentos dirigidos a los españoles susceptibles de emigrar al extranjero. En la Guía del emigrante español por ejemplo, el gobierno pretende informarle y aconsejarle, dándole los pasos a seguir. En este sentido, se presentan dos formas de emigrar: la espontánea y la planificada, intentando convencer a los lectores para que elijan la vía asistida. Así pues, a la emigración individual, en la que el emigrante "marcha solo a otro país a buscar trabajo", se prefieren las emigraciones colectivas "convenidas de antemano entre las Autoridades españolas y los Gobiernos de los países receptores". De hecho, la guía insiste en la protección que el IEE puede brindar al emigrante si éste opta por una emigración asistida:

En las operaciones planificadas el emigrante sabe dónde va y a lo que va; conoce de antemano en qué va a consistir su trabajo; cuál va a ser su jornal o sueldo; qué duración tendrá su contrato de trabajo; cuáles son los derechos sociales que le van a asistir y qué protección van a tener él y su familia en el país de asentamiento. El emigrante no tiene que "andar buscando colocación", sino que el Instituto se la procura (...) y les proporciona el medio de transporte, amparándolos y protegiéndolos antes del viaje, durante y después de su asentamiento.

Al contrario, la emigración espontánea se describe como peligrosa ya que el emigrante corre el riesgo de enfrentarse "a la explotación de ganchos, pseudoagentes y mediadores de toda clase, dedicados a explotar al emigrante con tendenciosas informaciones, reclutamientos clandestinos y falsos contratos". ${ }^{24}$

En los hechos, a diferencia de la voluntad común por parte de los gobiernos español y francés de regular el flujo migratorio, Francia no vacila en flexibilizarlo facilitando los trámites. Los opúsculos, publicados en Francia a lo largo de los años sesenta por el servicio social de ayuda a los emigrantes en versión bilingüe para las comunidades extranjeras más representadas en el territorio francés, se proponen informar a los recién llegados sobre sus derechos y deberes. La flexibilidad de la administración francesa en cuanto a los trabajadores inmigrantes es mencionada en varias ocasiones. Si nos fijamos en la versión franco-española, El trabajador español y la familia española en Francia, vemos que la facilitación de los trámites de regularización a posteriori se menciona implícitamente ya desde la introducción: "Si algunas limitaciones administrativas le son impuestas al principio de su estancia, debe saber que con el tiempo estas condiciones irán flexibilizándose a su favor".25

La ausencia de acuerdo con Francia sobre este aspecto iba a conducir a una limitación de facto del control de las autoridades sobre los movimientos migratorios. Del lado español, la emigración espontánea, al resultar más rápida y eficiente que una emigración de tipo legal, ${ }^{26}$

Organización sindical, Servicio nacional de colocación, caja 16604, mayo de 1972.

24 Guia del emigrante español, Ministerio de trabajo, IEE, 1958, pp. 5-10.

25 René MONGÉ: Le travailleur espagnol et la famille espagnole en France / El trabajador español y la familia española en Francia, París, Editions sociales françaises, 1966, pp. 3-8.

26 Recordemos que la salida de España con un pasaporte de turista se consideraba como una opción irregular pero no ilegal, la ilegalidad remitiendo a la emigración clandestina. no se agotó, sino que llegó prácticamente a convertirse en la norma. Del lado francés, la explosión de la inmigración y las facilitaciones de las regularizaciones condujeron también a un descontrol manifiesto por parte de las autoridades.

\section{Conclusiones}

Si la emigración española a Francia durante los Treinta Gloriosos respondía a unos intereses convergentes de los países vecinos, la cuestión de la regulación del flujo migratorio siguió constituyendo un factor de discrepancias, dado que cada país quiso adaptar las políticas migratorias a sus intereses propios. Una teoría sobre la emigración, publicada en 1978 por el Ministerio de Trabajo viene a confirmar este postulado, al considerar que "las políticas migratorias de los países europeos no son más que meras políticas de control, de puesta en práctica de un aparato jurídico cuyas formas se modelarán con decisiones de circunstancias, para asegurar el dominio del flujo migratorio". ${ }^{27}$ Sin embargo, la carencia de consenso sobre el tema llevó tanto a las autoridades españolas como a las autoridades francesas al desborde. En este sentido, el periodo de crisis de los años setenta vino a marcar un giro en las políticas migratorias.

En consecuencia, los planteamientos iniciales de cada país acerca de las políticas migratorias y de la inserción de los migrantes se vieron alterados. Al dispararse el paro en Francia tras la crisis del petróleo, el gobierno francés de Valéry Giscard d'Estaing decidió interrumpir los flujos migratorios el 3 de julio de 1974, en un principio de manera provisional. Incluso, contrariamente a la estrategia de los primeros años en los que se había planificado una inmigración de población, se impulsó una política de incitación al retorno de los inmigrantes a sus países de origen. Los planteamientos españoles también evolucionaron en cuanto al carácter transitorio de la emigración: lejos de limitarse a una inmigración de mantenimiento, la instalación definitiva de la mayoría de los españoles en Francia se alejó considerablemente de la intención inicial tanto de las autoridades españolas como de los propios emigrantes.
27 Santiago MANCHO: Emigración y desarrollo español, Madrid, Ministerio de Trabajo, IEE, 1978, pp. $13-35$ 


\section{LA CULTURA INSTITUCIONISTA EN EL EXILIO}

\section{REPUBLICANO: CONTINUIDADES Y FRACTURAS*}

Jorge de Hoyos Puente

El Colegio de México/Universidad de Cantabria

\section{Introducción}

Pocas culturas políticas influyeron más en la formación de los elementos institucionales que pasarán a la Historia como el legado más importante de la II República que la cultura institucionista. No es necesario hacer aquí un repaso a las contribuciones que el institucionismo aportó al bienio reformista, especialmente en materia educativa, ni la relevancia que algunos de sus miembros más destacados que ejercieron diversas labores desde las Cortes y el Gobierno. Sin embargo, el institucionismo como cultura política parece haber quedado diluida de la memoria colectiva, en gran medida por la ausencia de un partido aglutinador durante el periodo republicano. Como toda cultura política su evolución tiene un desarrollo histórico determinado por muy diversos factores, sobre los que conviene detenernos brevemente. El institucionismo se forja como una cultura política liberal, que bebió de dos fuentes principalmente, el idealismo krausista y el positivismo. Siguiendo la caracterización realizada por el profesor Manuel Suárez Cortina, sus ideas fuerzas se articulan en torno a los conceptos de progreso, libertad, derecho, armonía, evolución y ley. A lo largo de los años se fue configurando como una cultura plural, de carácter reformista, que apostaba por la democracia representativa, de corte evolucionista, como instrumento de vertebración de la sociedad. Situado al margen del Estado liberal dinástico de la Restauración, se conformó como una corriente de pensamiento liberal democrática.

A lo largo de las décadas, el institucionismo dio origen a varios proyectos políticos. En primer lugar el Partido Centralista de 1891, más tarde en 1903 Unión Republicana y, por último, el Partido Reformista en 1912. A pesar de estar situado al margen del sistema de la Restauración, la creación de instituciones educativas de diversa índole, contribuyeron de forma exponencial a la modernización del país, al menos de una elite rectora que influiría en la llegada de la Segunda República. Por la evolución de los acontecimientos acaecidos con la Dictadura de Primo de Rivera, la mayor parte de los institucionistas optaron claramente por la República como único mecanismo capaz de garantizar la existencia en España de un gobierno representativo y democrático. En ese sentido, la incorporación de muchos institucionistas a partidos políticos republicanos y obreros, diluyó la visibilidad del institucionismo como una cultura política, que se desempeñó sin partido definido a lo largo de la década de los treinta. Desde diversas posiciones, los institucionistas pusieron en marcha su programa político educativo, que quedó consagrado como logros del bienio reformista. Importante fue el papel de Fernando de los Ríos y Rodolfo Llopis en el ministerio de Instrucción Pública.

1 Manuel SUÁREZ CORTINA: "El institucionismo y la cultura política republicana en la Restauración" en Fernando MARTINEZ LÓPEZ (ed): Nicolás Salmerón y el republicanismo parlamentario Madrid en Fernando MARTINEZ LOPEZ (ed.): Nicolás Salmerón y el republicanismo parlamentario. Madrid, cia. La cultura institucionista en la España contemporánea, Madrid, Tecnos, 2011.
El fracaso de las izquierdas en las elecciones de 1933 y la subida al poder de las derechas evidenciaba una polarización de la vida política española. El institucionismo perdía así protagonismo frente a proyectos políticos dotados de un lenguaje de combate, que polarizaban el país cidad de adaptación a un nuevo escenario político, provocando una fractura importante entre sus miembros. La cultura institucionista reformista se dividida entre aquellos que, como José Castillejo, habían mantenido una postura alejada de la actividad política y los que participaban activamente en ella desde los escaños. Una escisión que quedó marcada claramente con elinicio de la Guerra Civil A continuación analizaremos las claves que marcaron las fracturasy las continuidades del institucionismo y su ocaso como cultura política en el exilio republicano.

\section{Las fracturas del institucionismo}

Si tomamos a José Castillejo como el institucionista vivo más relevante en 1936 y vemos su actitud hacia la República asediada, podemos comprobar algunas cuestiones relevantes para comprender las claves de las fracturas del institucionismo. Exiliado en Londres en 1936, Castillejo se dedicó a difundir su pensamiento acerca de lo que había ocurrido en España. Según su visión de la historia reciente de España, la dictadura de Primo de Rivera había roto el orden de la Restauración y su evolución lógica, aunque lenta, hacia un sistema democrático. Desde la Universidad de Columbia, donde impartió conferencias en 1937 y elaboró el texto Democracias destronadas, no dudó en criticar la actitud de muchos institucionistas que habían dejado sus funciones educadoras y sus cátedras para desempeñar cargos políticos, apartando los ideales primigenios del institucionismo. ${ }^{2}$ Una de sus principales críticas se sustentaba en que muchos habían optado por la vía fácil y rápida para alcanzar el poder, sin proyecto claro y definido, abriendo demasiados frentes simultáneamente y granjeándose enemistades en amplios sectores sociales como la iglesia católica, el ejército o los terratenientes. Castillejo representa en ese sentido el paradigma del institucionista desencantado con la República, incapaz de toma partido entre leales y sublevados durante la Guerra, estableciendo una equidistancia, marcada por la amargura y la frustración por la oportunidad perdida.

La Guerra Civil puso de manifiesto la pluralidad del institucionismo y la variedad de modos de afrontarlo que tuvieron la mayoría de los miembros, que habían tenido un protagonismo claro dentro de esa concepción del mundo moderno. Si Castillejo es la figura más significativa del derrotismo, otros como Pedro Salinas optaron por una actitud mucho más ponderada. Tras el cierre de la Universidad Internacional de verano de Santander de la que fue máximo ideólogo e impulsor se trasladó a los Estados Unidos en 1936 para cumplir un compromiso previo como profesor invitado en el Wellesley College. Hombre sin partido, mantuvo durante todo el tiempo su fidelidad a la causa republicana en la distancia, tomando conciencia de la profunda brecha que entre los republicanos estaba causando el conflicto bélico. También desde Estados Unidos, donde fue enviado como embajador de la República en octubre de 1936, Fernando de los Ríos representa el compromiso decidido de un institucionista que había optado muchos años atrás por la militancia socialista como mejor camino para construir una sociedad democrática.

A pesar de las distintas actitudes, todos ellos sufrieron, especialmente tras la derrota republicana en 1939 y el inicio de la guerra europea, una profunda fractura en su concepción optimista y evolucionista del mundo. La quiebra en la fe en el progreso marcó su pensamiento y la necesidad de buscar nuevas vías. En ese sentido, la crítica a la modernidad, al desarrollo tecnológico desmedido, sin valores éticos y políticos que pusieran coto a la irracionalidad destructiva de una técnica al servicio de los totalitarismos, jugaron un papel esencial que influyó

José CASTILLEJO: Democracias destronadas, Un estudio a la luz de la revolución española 1923-1939. Madrid, Siglo XXI, 2008. 
en su pensamiento y obra a lo largo del exilio. Para los institucionistas la derrota era total, tanto aquellos que habían optado por la transformación lenta pero segura del país, como para los que se habían implicado activamente en la experiencia republicana, la pérdida de España suponía un golpe durísimo a su concepción nacionalista. Lo ocurrido en España ponía en tela de juicio su visión optimista y progresiva del mundo, tomando conciencia de los retrocesos que podian ocurrir desde la barbarie y el fundamentalismo. También el desencanto producido al ver cómo algunos compañeros, los menos, formados en las aulas de la Institución Libre de Enseñanza o becados por la Junta de Ampliación de Estudios, tomaban partido decididamente por los victoriosos sublevados.

A pesar de que la mayoría de los institucionistas no pasaron directamente por la dura experiencia de los campos de concentración que vivieron centenares de miles de compatriotas a partir de febrero de 1939, la situación de desamparo resultaba total. Las circunstancias de la muerte de un institucionista significado como Antonio Machado marcaron, sin duda, a muchos de ellos, que mostraron su preocupación por la situación de sus compatriotas. Tras la derrota de la República en abril de 1939, muchos de los institucionistas que se encontraban fuera de España, trabajaron denodadamente para tratar de ayudar a la llegada de los nuevos exiliados buscando acomodo e influencias. Así fue en el caso de Estados Unidos, un exilio todavía poco conocido, donde el institucionismo, junto con México, tuvo más influencia. ${ }^{3}$ Las redes tejidas por la Junta de Ampliación de Estudios durante décadas en aquel país, y especialmente La Casa Hispánica de la Universidad de Columbia, dirigida por Federico de Onís, se convirtió en una oficina de búsqueda de puestos universitarios para no pocos institucionistas. En México, su actividad intelectual sirvió como carta de presentación para un contingente diverso y numeroso a través primero de La Casa de España y más tarde de otras instituciones educativas mexicanas. ${ }^{4}$ Este hecho de privilegio supuso en alguna medida una segunda fractura entre el institucionismo y el grueso del exilio, que contó con muchas menores oportunidades para reorganizar sus vidas.

Lo cierto es que el institucionismo en su conjunto fue denostado por exiliados como Luis Araquistáin o intelectuales ajenos a esta cultura como Eduardo Nicol, al mismo tiempo que eran demonizados por los vencedores en obras que los acusaban de representar lo peor de la "antiespaña". ${ }^{\text {P }}$ or formación y mérito, dentro de un exilio de masas, plural y contradictorio, los institucionistas conformaron dentro del colectivo singular. A pesar de que la mayoría había tenido contacto previo con el exterior, de hablar diferentes idiomas y encontrar posiciones dignas para desenvolverse económicamente, su fractura personal fue en ocasiones muy superior a la de otros exiliados menos preparados teóricamente para vivir fuera de España. El nacionalismo institucionista, la quiebra de muchos de los paradigmas sobre los que habían construido su ideal de España, pasaron una importante factura. Los institucionistas en el exilio se refugiaron en elementos casticistas y místicos que les llevan a elevar a los altares laicos a sus principales referentes, proliferando las obras sobre Giner o Bartolomé Cossío. ${ }^{6}$ El institucionismo

Sebastiaan FABER y Cristina MARTINEZ CARAZO (eds.): Contra el olvido. El exilio español en Estados Unidos, Madrid, Universidad de Alcalá de Henares, 2009

4 Clara E. LIDA: La Casa de España en México, México, El Colegio de México, 1988.

5 Luis ARAOUISTÁIN: El pensamiento español contemporáneo, Buenos Aires, Losada, 1968, [1 ${ }^{\mathrm{a}} \mathrm{Ed}$ 1962] pp. 39-4O. Fernando MARTíN-SÁNCHEZ JULLÁ: “Orígenes, ideas e historia de la Institución Libre de Enseñanza" en VVAA: Una poderosa fuerza secreta, la Institución Libre de Enseñanza, San Sebastián, Editorial Española, 1940.

6 Joaquín XIRAU: Cossío y la Educación en España, México, El Colegio de México, 1945. Martín NAVAJoaquin XIRAU: Cossioy la Educación en España, Mexico, RRO: Vida y obra de don Francisco Giner de los Ríos, México, Orion, 1945. Luis SANTULLANO: El penGiner de los Rios, Buenos Aires, Giner de los Rios, Buenos Aires, Losada, 1949. Rafael ALTAMIRA: Biografía intelectual y moral de don forma del hombre", Cuadernos del Congreso por la libertad de la Cultura, 16, (enero-febres la re- intuye su propio ocaso, refugiándose en el pasado ejemplificador de sus iconos morales. Para algunos, como Castillejo la derrota era total, para otros como Fernando de los Ríos o Joaquín Xirau, a pesar de la amargura, había que seguir trabajando con la mirada puesta en España.

El modo de afrontar el exilio también jugó un papel rupturista entre los institucionistas. Los hubo que no tardaron demasiado en pasar página y buscar el acomodo institucional que algunas universidades estadounidenses les permitió, centrando toda su actividad en sus carreras universitarias. Sin embargo, el grueso del institucionismo siguió pensando en España y en las circunstancias que causaron su derrota total. En términos generales, los institucionistas disfrutaron de su marchamo de prestigio en los países de acogida, asociados a la imagen de educadores, profesores universitarios y pedagogos. Entre 1939 y 1942, la zozobra existencial agudizó su crisis de conciencia a la par que fueron reconstruyendo sus vidas en los países de acogida.

\section{Las continuidades del institucionismo}

Si las fracturas fueron importantes dentro del institucionismo, no es menos cierto que existieron también ciertas continuidades que afloraron a partir de 1942, cuando la mundialización de la guerra, con la entrada en el conflicto de Estados Unidos y la Unión Soviética, supuso un halo de esperanza para el exilio republicano en su conjunto. Si en los primeros momentos la crisis de conciencia, la pérdida de la fe en el progreso y en el desarrollo ilimitado marcaron el grueso de las reflexiones, la situación fue cambiando en un intento de buscar alternativas para la creación de un nuevo orden mundial, basado en la paz, el derecho internacional y la cooperación, donde una España democrática debía jugar un papel esencial. La visión organicista y armónica del institucionismo surgía como una alternativa ante la dialéctica y confrontación de la situación vivida. Una revisión del capitalismo, un rechazo abierto al totalitarismo y la apuesta por una democracia política pero también económica, serían las propuestas de los institucionistas, que consideraban nuevamente el dramático estado del mundo como el resultado de una falta de educación cívica. A pesar de la fuerte disgregación que existió en la cultura política institucionista, si podemos encontrar una cierta continuidad en el exilio de principios, así como una evolución paralela de aquellos que mantuvieron su apoyo a la II República de forma clara, en torno a varios temas que, de forma autónoma, provocaron interés en sus miembros.

En primer lugar, el interés prioritario por los temas educativos continuó marcando la agenda de los institucionistas en el exilio. Tanto la crisis española como la mundial tenían su origen en un importante déficit educativo y cívico, que partía de las universidades. En 1943 Pedro Salinas impartía en Puerto Rico dos conferencias con el título "Defensa del estudiante" y "Conferencia sobre la Universidad". En ellas señalaba el papel de la universidad como un lugar donde debía producirse una elevación moral de los estudiantes.? Las universidades debían tener una función social más allá que la capacitación profesional al servicio de los intereses productivos, una tendencia creciente en el mundo universitario. Era el lugar de selección de los alumnos "conscientes", que debían cumplir con una mayor responsabilidad social, frente a los alumnos "inconscientes", la mayoría, que solo buscaban obtener una mejor posición social. La universidad se había convertido en un reflejo de la sociedad en guerra, y había hecho de la técnica una nueva religión al servicio del capitalismo moderno, en detrimento de la búsqueda de la verdad. El segundo de

pp. 6o-67. Jerónimo MALLO: “Francisco Giner y la renovación de la cultura en España”, Cuadernos Americanos, LXXXVII, (mayo-junio 1956), pp. 163-173. Lorenzo LUZURIAGA: La Institución Libre de Enseñanza y la Educación en España, Buenos Aires, Departamento Editorial de la Universidad, 1957 Antonio JIMÉNEZ LANDI: “Don Francisco Giner de los Ríos y la Institución Libre de Enseñanza”, Revista Hispánica Moderna, XXV, (1959) pp. 1-52. Rubén LANDA: “D. Francisco Giner como educador" Cuadernos Americanos, CXXIX, (julio-agosto 1963), pp. 88-112.

7 Pedro SALINAS: Defensa del estudiante y de la universidad, Edición de Natalia VARA FERRERO, SeviIlla, Editorial Renacimiento, 2011. 
los discursos se enmarca dentro de un hecho concreto, la propuesta de reforma universitaria debatida en Puerto Rico en 1943 para reducir en un año las titulaciones académicas en pro de las necesidades de hombres en los frentes de la Guerra Mundial. Salinas se mostraba contrario a este tipo de cambios que no hacían sino restar tiempo a la formación integral del estudiante universitario. El ritmo de la universidad no podía estar marcado por los intereses del mercado, o las diferentes coyunturas, la universidad debe enseñar a trabajar bien y no deprisa. ${ }^{8}$

Desde México, Joaquín Xirau también reflexionaba sobre el papel de la universidad y la educación, defendiendo la formación integral del individuo, basada en la coeducación, la educación no dogmática y la formación del profesorado. ${ }^{9}$ La universidad debía transformarse para ser útil y para poner fin a "la quiebra de las raíces de la cultura occidental". ${ }^{\circ}$ Para ello, era necesario establecer un debate en torno a la idoneidad de diferenciar claramente dos ramas dentro de la institución, por un lado la destinada a la capacitación profesional y, por tanto, a la mayoría de los estudiantes, y por otro la dedicada a la formación de una minoría selecta capaz de aportar avances científicos en todos los órdenes. La universidad debía cumplir tres elementos fundamentales, la formación y capacitación profesional, la creación de la ciencia y la difusión del conocimiento, pero para ello, debía tener una estructura adecuada. La universidad debía tender a la especialización pero sin perder perspectiva, por ello era imprescindible la formación integral del investigador. Ambos eran deudores de la visión universitaria de Giner, recogida en sus obras completas y compartían, por tanto, proyecto de futuro."

Un segundo elemento de continuidad es la búsqueda de soluciones organicistas y armónicas a los conflictos mundiales. La creación de grandes organizaciones supranacionales, organizadas en torno a principios federativos y colaborativos, debía ser el futuro tras el conflicto bélico. En ese sentido, Fernando de los Ríos desarrolló una intensa labor desde su posición de profesor en la New School for Social Research en Nueva York hacia el europeísmo pero también hacia Latinoamérica. La experiencia dramática vivida en España debía englobarse en un proceso más amplio de desajustes del sistema mundial y de crisis del modelo surgido del liberalismo. Para superar ese estado había que construir un nuevo modelo. Si Joaquín Xirau apostaba por una unidad Latinoamericana, basada en un hispanismo inclusivo y no impositivo bajo una organización federal o confederal' ${ }^{12}$, Fernando de los Ríos exploraba las posibilidades de una futura integración europea. En marzo de 1943 se inició una conferencia paneuropea organizada por la Universidad de Nueva York a instancias del austriaco Richard Coudenhove-Kalergi. Fernando de los Ríos presidió una de las comisiones de trabajo que formularon la "Declaración de propósitos y principios para una Federación europea” y más tarde un proyecto de constitución europea. ${ }^{13}$ Desde su concepción del socialismo humanista, de los Ríos indagó en lo que consideraba una crisis de los valores occidentales y el fracaso de un modelo que había olvidado a los ciudadanos frente a intereses que atentaban incluso contra la soberanía de las naciones. La raíz de buena parte de los conflictos estaba, según su visión, en el proceso de descomposición humana y en la necesidad de construir valores diferentes, basados en el respeto a los derechos humanos básicos. ${ }^{14}$ Así, en varias de sus conferencias, especialmente las impartidas

8 "Conferencia sobre la Universidad" en Pedro SALNAS: Defensa del estudiantey de la universidad 0.61 9 Joaquín XIRAU: “La educación y la vida humana”, Revista de educación, México (1940).

10 Joaquín XIRAU: "Sentido de la Universidad", Revista de la Universidad de La Habana, Cuba (1943).

11 Francisco GINER DE LOS RÍOS: La Universidad española, Obras completas, Tomo II, Madrid, Imprenta Clásica Española, 1916.

12 Joaquín XIRAU: "Integración política en Iberoamérica", Jornadas, Centro de Estudios Sociales de El Colegio de México, 19 (1945)

13 "Draft Constitution of the United States of Europe", NY University, 1944.

14 Fernando de los Ríos impartió en la New School un seminario en 1940 acerca de la "Necesidad de volver al hombre interior". en la Universidad de La Habana en agosto de 1941, abordó las claves del "Sentido de la actual descomposición política del mundo". En ellas se evidenciaban el cuestionamiento de la propia idea de "progreso" y la necesidad de establecer notables cambios a la hora de construir un mundo alternativo desde prismas morales radicalmente diferentes. En sus explicaciones podemos ver como señala la fractura del humanismo como el origen del problema, donde no faltan críticas hacia la utilización bélica del desarrollo tecnológico y una cierta deshumanización de la existencia de los seres humanos. Fernando de los Ríos reflexionó sobre el papel jugado por la ciencia en ese proceso y la necesidad de partir, como planteaba Giner de los Ríos, de la conciencia a la hora del desarrollo científico.

Fernando de los Ríos reflexionó sobre los cauces que debían configurar la paz venidera. ${ }^{5}$ Recurriendo a Jean Bodin, analiza el papel de la soberanía en la constitución de los Estados modernos y su traslación al derecho internacional. Buscaba trazar las claves para construir un difícil equilibrio entre la soberanía de los Estados y el respeto escrupuloso al derecho internacional, único garante de la paz. En su análisis, los conflictos ponían de relevancia la crisis moral en la que está sumido el mundo. Esta preocupación, que en ocasiones denomina crisis de fe, estará presente hasta el final de sus días. Esa crisis de fe, o de moralidad, ha favorecido la implantación de un modelo de sometimiento que deja al individuo en un lugar relegado. De ahí que su modelo vaya a ser la afirmación al humanismo socialista y el horizonte político sea federal. Humanismo socialista tal y como lo concibe que forje unos ideales básicos de respeto al ser humano por encima de cualquier consideración, que provea de las necesidades materiales para su libre desarrollo; el federalismo universal, para soslayar los problemas políticos, las pugnas de soberanía con una constitución internacional y que facilite el desarme. Para llevar a cabo ese proyecto, es necesario un espíritu y una moral renovada.

Desde los primeros viajes de Rafael Altamira por Latinoamérica, los institucionistas habían descubierto una nueva oportunidad en un hispanismo no imperialista, una realidad que el exilio contribuyó a profundizar. Muchos institucionistas tomaron conciencia de la dimensión cultural del mundo hispánico y de la necesidad de rescribir muchas categorías históricas, filosóficas y literarias, partiendo de esa visión plural y mestiza. ${ }^{16} \mathrm{El}$ desarrollo de la II Guerra Mundial marcaba la agenda política internacional y Xirau consideraba la conformación de un gran bloque hispano dentro del escenario futuro. Para Xirau, el conflicto iniciado con la guerra de España y continuado en la II Guerra Mundial ponía de manifiesto una crisis del modelo de pensamiento occidental, que solo podía asentarse desde una visión cultural y política integradora, armónica, que restañase las heridas tras la contienda, construyendo un orden mundial que hiciese compatible los sentimientos nacionales e internacionales, y trabajase en torno a la integración europea, también bajo un esquema federal.

\section{El ocaso de la cultura política institucionista}

Después de tres años desperdigados por el mundo y trabajando intensamente sobre los mismos temas de reflexión, los participantes de la cultura institucionista celebraron un acto de reorganización política en la Primera Reunión de profesores Universitarios Españoles Emigrados en La Habana en octubre de 1943. Si bien la UPUEE había nacido en Francia en 1939 como una asociación de profesores universitarios en el exilio y con el objetivo claro de ayudar al acomodo de académicos españoles en el extranjero, su gran acto político se realizó en Cuba en aquel año. ${ }^{77}$ Ante las divisiones políticas que lastraban las organizaciones políticas, la cri-

15 Fernando DE LOS RíOS: "Sovereignty and the coming peace”, Social Research, 8 (1941), pp. 331-349. 16 Joaquín XIRAU: "Humanismo español (Ensayo de interpretación histórica)", Cuadernos Americanos, México, I, $\mathrm{n}^{\circ} 1$ (1942), pp. 132-154.

17 José Miguel COBOS, Manuel PULGARÍN y Cristina CARAPETO: "Reunión de la Unión de Profesores

Universitarios Españoles, UPUEE", Ábaco, revista de cultura y ciencias sociales, 42 (2004), pp. 61-74. 
sis de legitimidad de las instituciones republicanas en el exilio, los institucionistas tomaron la iniciativa política para presentar una voz clara de la España democrática ante el mundo. De la reunión salió la Declaración de La Habana que se adhería a los principios promulgados en la Carta de Atlántico. ${ }^{18}$ En la reunión se reivindicó el programa modernizador de la República y la vigencia de su legitimidad. Los profesores reunidos, la inmensa mayoría procedentes del institucionismo, trabajaron en tres comisiones que dieron como resultado un programa político. Estas giraron en torno a tres grandes ejes: "los problemas de la educación y la cultura", "los problemas sociales" y "los problemas jurídicos y económicos". Por cuestiones de espacio, no puedo analizar aquí en todo su contenido el programa político que resultó de la Conferencia de La Habana, pero sí debemos señalar algunos principios rectores. La educación era concebida como el principal instrumento de transformación. Para ello, partieron de una afirmación filosófica y moral en el modelo que había consagrado los principios liberales y antidogmáticos en todo el sistema educativo. Pocos eran los elementos que habian cambiado desde los orígenes de la conformación de la cultura institucionista. Si acaso, las coyunturas habían puesto mayor énfasis en algunos temas, como la imperiosa necesidad de hacer más humano el capitalismo, de fomentar la organización social a través de cooperativas de propietarios, o de buscar la armonización del desarrollo con el respeto al medio ambiente, conceptos que ya están presentes en el institucionismo. La defensa de la pluralidad de España, también estará presente, así como su indivisibilidad. La integración europea e iberoamericana será otro de los puntos fuertes de programa. Dentro de sus objetivos centrales era construir una sociedad donde los aparatos productivos estuviesen plenamente conectados con el mundo académico, de tal forma que las universidades y los centros de investigación y enseñanza pudiesen desarrollar nueva técnicas al servicio de la sociedad en muy diversas materias. Así proyectaban la introducción de un Instituto de Investigación económica y la creación de las facultades de ciencias económicas, estudios no existentes en la España de la época. El objetivo último era la creación de una economía del bienestar. En esta visión transformadora hay una evidente crítica a la evolución de la modernidad capitalista y sus efectos, pero también una crítica al modelo soviético ya que los principios rectores se construyen en torno a la libertad individual del ciudadano, como sujeto de derechos y deberes y como eje central de la vida social. Lo que se desprende de la lectura de estos materiales es el intento por construir una vía alternativa, desde el reformismo social, el librecambismo y la libertad de conciencia. En ese sentido, la teorización de la reunión apostaba por la erradicación del anticlericalismo, consolidando la libertad de conciencia, que solo se puede practicar con una efectiva separación entre la Iglesia y el Estado.

Aquellas jornadas en la universidad cubana representaron un impulso político del exilio en su conjunto. El llamamiento realizado en la Declaración de La Habana para la creación de una plataforma política se materializó, solo en parte, con la fundación de la Junta Española de Liberación el 25 de noviembre de 1943, como instrumento de trabajo para visualizar la cercanía a las potencias aliadas. ${ }^{19}$ Sin embargo, la JEL no consiguió ser un elemento aglutinador, ya que negó la legitimidad del gobierno en el exilio presidido por Juan Negrín, para disgusto de los profesores universitarios que pedían la máxima integración política. ${ }^{20}$

José María LÓPEZ SÁNCHEZ: Los refugios de la derrota. El exilio cientifico e intelectual republicano de 1939, Madrid, Catarata, 2013

18 La documentación del encuentro se puede consultar en la Universidad de La Habana. Para una adecuada consulta véase VV.AA: Libro de la primera reunión de profesores universitarios españoles emigrados, La Habana, Talleres tipográficos “La Mercantil”, 1944.

19 El acuerdo fue firmado por Izquierda Republicana, Unión Republicana, el Círculo Pablo Iglesias, Ezquerra Republicana de Cataluña y Acción Republicana. El acta fundacional de 25 de noviembre de 1943 está reproducido en el apéndice documental del trabajo de Javier RUBIO: La emigración de la guerra civil, 1936-1939, Madrid, Editorial San Martín, 1977, 3 vols, pp. 964-966.

20 A título individual, un importante colectivo de intelectuales provenientes de distintas corrientes
De la Declaración de la Habana surgió en México el compromiso de constituir la "Comisión de Estudio de los Problemas de los Españoles", una organización de marcado perfil técnico, donde los profesores universitarios volcaron su compromiso con España en un proceso de conformación de informes analizando los principales problemas del país. La comisión de estudios realizó sus trabajos entre 1944 y 1945 publicando sus resultados a modo de cuadernillos donde destaca el Anteproyecto de Carta Política transitoria. ${ }^{21}$ Desde la defensa de la vigencia constitucional de la República, plantearon unas normas básicas de funcionamiento para gestiona la transición, desde una Junta de Estado que convocase unas elecciones generales. Manue Márquez, en su calidad de presidente de la comisión, planteó la necesidad de abrir un nuevo tiempo político que, siguiendo los pasos de la cuarta República francesa, instaurase en España la Tercera República española con vistas a resolver los principales problemas del país. A pesar de sus intentos por recuperar la iniciativa política, lo cierto es que se fueron imponiendo las tesis rupturistas de las dos vías políticas, la JEL por un lado y la legitimidad negrinista por otro Ambos desarrollaron una intensa tarea en muchos frentes. A pesar de ello, tras la conferencia de San Francisco y con la reunión de las Cortes republicanas dos institucionistas como José Giral y Fernando de los Ríos se hicieron con el control del gobierno republicano en el exilio, constituyendo el gobierno de la Esperanza. De su fracaso definitivo saldrá el fin definitivo de institucionismo como cultura política, quedando su recuerdo exclusivamente en el legado pedagógico, la actividad en la que se refugiaron la mayoría de ellos en el exilio. ideológicas tan dispares como José Giral, Mariano Ruiz Funes, Ignacio Bolívar, Wenceslao Roces, o José Ramón Arana, firmaron un manifiesto contrario a la política de exclusión realizada por la Junta. Manifiesto sin fecha, firmado por un centenar de intelectuales, profesores universitarios y artistas de distintas tendencias. Copia en el Archivo Amaro del Rosal, 357-3. Fundación Pablo Iglesias.

21 En el Archivo del Ateneo Español de México se conserva además de este anteproyecto, el resultado de la Comisión de Educación. Además de estas secciones, realizaron informes sobre Sanidad y el problema religioso, Economía, Industria y Fuerzas Armadas. 


\section{DEL CONFORMISMO AL DISTANCIAMIENTO:}

\section{LOS GRUPOS CATOLICOS ESPAÑOLES EN FRANCIA}

Aubin González

Université Bordeaux 3-S.P.H. EA 4574

\section{(1950-1976) *}

En su gran mayoría formada de misiones católicas, las asociaciones apoyadas por el Estado franquista, van tomando distancia con la institución de tutela confirmando así el fracaso de la política de emigración asistida justamente por esta falta de asistencia al emigrado. Dada como tal esta hipótesis nos lleva ineluctablemente a validar o bien infirmar que se establece un progresivo diálogo entre los círculos católicos españoles en Francia y las organizaciones de izquierda francesas durante estos años. Aunque al margen de los acontecimientos del 1968 este dialogo se hace más intenso, pensamos que el preámbulo remite a los cambios que lleva el fin de la Segunda Guerra Mundial dentro de la comunidad española en Francia.

De hecho el objeto de artículo es proponer a la crítica algunas reflexiones sobre las etapas de este diálogo, partiendo del caso de la colonia española de Burdeos. Más allá de la procedencia de las fuentes orales que utilizamos en el marco de esta ponencia, nuestro interés por el ambiente español bordelés se debe a la particularidad del Sudoeste francés dentro de la emigración española durante el último siglo. Queda mucho que escribir sobre la presencia española en el periodo de entreguerras. Sin embargo, esto no es el objeto de este artículo. Este se centra más bien en un periodo que va del fin de la Segunda Guerra Mundial hasta 1976 se centra más bien en un periodo que va del fin de la Segunda Guerra Mundial hasta 1976. Burdeos y cómo sus tensiones respectivas favorecen la emergencia de una red que supera las identidades de partida.

\section{La presencia española en Burdeos después de la Segunda Guerra Mundial: una diáspora con} varias facetas

Después de la Segunda Guerra Mundial, la idea del retorno y de restaurar la República como régimen legítimo en España se aleja cada vez más pero nunca quedó en letra muerta. El exilio al otro lado de los Pirineos fue, para una parte de los grupos de la oposición, una oportunidad de romper el silencio que les había impuesto el franquismo. La estigmatización de aquellos grupos vencidos por los "nacionales" hizo necesario la restauración de su legitimidad como apoyo de un régimen destituido por rebeldes "nacionales" y como combatiente contra el fascismo. Con una producción discursiva en la que las huellas del pasado eran patentes, los grupos del exilio se dedicaban a mantener vivas su memoria. En este sentido, seguimos la progrupos del exilio se dedicaban a mantener vivas su memoria. En este sentido, seguimos la pro-
puesta de la antropóloga Mary Douglas para quien producir un discurso dominante supone la agregación de un pasado individual que se convierte, de hecho, en pensamiento colectivo. También ella añade que la constante interacción entre el colectivo y este mismo discurso funda analógicamente la institución como depositario de la memoria de un grupo social. ${ }^{4}$ Tanto la capitalización de los traumatismos o de los hechos de armas desde abajo, como la identificación paralela o desde arriba, forjó por consiguiente una cultura del exilio institucionalizada. En 1950 fue aquella cultura del exilio la que dominaba en la colonia española, tanto en Burdeos como en el resto de Francia, dejando a los otros grupos en la sombra.

Más adelante si nos remitimos a principios de los cuarenta, la entrada de algunos exiliados en la Resistencia francesa, al lado de los comunistas y socialistas franceses, les animó seguramente a continuar el combate contra Franco desde el exterior. En efecto, a la hora de emprender el camino hacia Francia miembros del Partido Comunista de España, (PCE) y del Partido Socialista Obrero Español, (PSOE) pudieron contar con la benevolencia del Parti Comuniste Français, (PCF). El combate contra el fascismo en las redes de resistencia comunista y socialista se convierte por consiguiente en el combate contra el franquismo.

En 1950, la presencia española en Francia se caracteriza por su fuerte carga ideológica y memorial que sigue articulándose en torno a la oposición al franquismo pero también a la temporánea que se celebró en Valencia en septiembre de 2013. También se inscribe en el marco de un proyecto de tesis doctoral financiado por el Ministère de l'Enseignement Supérieur et de la Recherche y apoyado por la Université de Bordeaux Montaigne, a la que estoy especialmente agradecido.

1 Ana FERNANDEZ: “Emigración española, asociacionismo y cultura política en Francia”, en Ana FERNÁNDEZ (dir.): Gente que se mueve, Madrid, Fundación $1^{\circ}$ de Mayo, 2010.

2 Véase por ejemplo los trabajos de Natacha Lillo, José Babiano Mora y Ana Fernández Asperilla.
3 Mary DOUGLAS: Comment pensent les institutions?, La Découverte, Paris, 1999 
responsabilidad de la derrota. De allí que en su conjunto la cultura del exilio no es ajena a las tensiones entre los diferentes grupos que la componen. De modo que el ambiente español a principios de los cincuenta tiene una dimensión exclusiva que le impide pensar en la convivencia con grupos culturalmente educados en la España de Franco.

Así que, en el momento en que llegaron los emigrados de los cincuenta, el Solar Español, la Casa Republicana rue de Labrède, el cours de l'Ysère, y el barrio Saint Michel eran unos de los lugares más importante de la colonia española de Burdeos. Básicamente, encontraban un ambiente marcado por una franca oposición al franquismo. Era con reticencia que los habitantes del barrio orientaban a los recién llegados hacia el Solar. En aquel entonces, la misión jesuita era un punto de encuentro de referencia e histórico en la colonia que padecía de ciertos reproches.

Entre otras cosas, la acusaron de estar a favor de los franquistas durante la Guerra Civil española y sobre todo, de tener buenas relaciones con el régimen de Vichy. ${ }^{5}$ En efecto, un testimonio viene a confirmar esta acusación ${ }^{6}$ insistiendo sobre las excelentes relaciones que llevaban el Solar y el Consulado y más tarde las autoridades derechistas de Vichy.

Aquellas palabras permiten afirmar que la cultura del exilio republicano no era la única dentro de la colonia española bordelesa. Existía también una red consular durante y después de la Segunda Guerra Mundial que subraya una presencia franquista en el suelo francés. Más allá de la vigilancia que intenta ejercer el franquismo sobre los españoles del exterior, la presencia franquista en Francia desempeña sobre todo un papel propagandístico que se diferenciaba de lo que se hacía en América Latina.7 Si entonces por un lado del Atlántico, teníamos una tarea propagandística que básicamente partía de una visión metahistórica -la hispanidad-, la cosa era diferente del otro lado; en Europa, se trataba más bien de legitimar el régimen franquista dentro de la colonia francesa. De allí la presencia de oficinas exteriores de la fuerzas del Movimiento nacional que desarrollaron una intensa red de difusión entre 1936 y 1945. Así como se intentaba exportar publicaciones españolas al territorio francés que, hacia 1939, contaba con dos instituciones: la Junta Carlista de Propaganda, cuyo papel era muy activo en el Sudoeste francés hasta aquella fecha en la que desapareció, ${ }^{8}$ y la delegación de Prensa y Propaganda de Falange Exterior cuya sede se hallaba en París pero tenía también lugares anexos principalmente repartidos en el Sudoeste francés. ${ }^{9}$

En el caso que nos ocupa, el Solar tuvo entonces un papel muy activo antes y durante la Segunda Guerra Mundial. De 1938 hasta 1942 fue convertido en un centro de operación de Falange Exterior, es decir, servía para la difusión de la propaganda falangista y franquista. Pero el peso del exilio en la región cambió mucho las cosas porque, como lo certifica Gabriel T.," durante la ocupación de Francia por los Nazis el Solar acogió también a muchos niños de refugiados políticos. A raíz de la simpatía existente entre el Cónsul General de España y el Solar es posible pensar que las autoridades consulares favorecieran aquella tarea de educación infantil probablemente para formar a jóvenes franquistas dentro de la inmigración española."

5 María SANTOS-SAINZ et François GUILLEMETEAUD: Les Espagnols à Bordeaux et en Aquitaine, Bordeaux, Editions Sud-Ouest, 2006, p. 219

6 Gabriel Tapia Hernando, 3 de mayo de 2013. Entrevista realizada por Aubin González, Burdeos. Jubilado de 80 años, permanente y secretario de la asociación "el Solar Español".

7 Sobre los servicios de prensa exterior durante el franquismo véase Antonio Cesar MORENO: Los servicios de prensa extranjera durante el primer franquismo (1936-1945), tesis doctoral bajo de la dirección de Feliciano Montero, Universidad de Alcalá, 2008

8 Pedro BARRUSO: El Frente Silencioso, la Guerra civil española en el Sudoeste de Francia: Guerra civil, diplomacia y espionaje, Hiria, Alegia, 2011.

9 Según los trabajos de Pedro Barruso, el Sudoeste francés desempeñó un papel capital en el espionaje y la diplomacia franquista por ser un lugar incontrolable del exilio republicano. Ibid.

10 Gabriel T., 3 de mayo de 2013. Entrevista realizada por Aubin González, Burdeos.

11 En la posguerra, el régimen franquista intentó recuperar la misión evangelizadora de los jesuitas
Esta hipótesis parece aún más probable cuando vemos que el mismo testimonio precisa que el Solar benefició del apoyo del Auxilio Social'12 y que el Cónsul General de España estaba "convencidísimo de la buena cosa que era el franquismo". También conviene precisar que el cónsu era el propio jefe del servicio de propaganda exterior de la Delegación Nacional del Servicio Exterior de Falange (DNSEF) en Burdeos y, por tanto, administrador del Solar. Así, se evitaban los problemas de doble poder en las relaciones entre el servicio de propaganda exterior de la DNSEF y las autoridades diplomáticas. Según Moreno Cantano, esto no debía ser un obstáculo público en las tareas consulares que constituían la máxima representación estatal española en el extranjero. El ministerio de Asuntos exteriores opinaba entonces que para solucionar ese problema de doble poder y acabar con las tensiones en el seno del Movimiento Nacional en el exterior, el Cónsul tenía que asumir la administración de los centros operativos. ${ }^{13}$

No obstante, esto no indica que la vocación del Solar correspondiese completamente con la voluntad de empresa ideológica del consulado aunque el orden jesuita tuviera la plena confianza del Estado español para llevarla a cabo. En efecto, en la misma entrevista se insiste en el carácter apolítico de la acción en favor de los emigrados. De igual modo, un testimonio nos cuenta que las relaciones cordiales que el Solar mantenía con el Cónsul obedecían a una lógica de intereses para que la institución jesuita siguiera cumpliendo el papel de asistencia a los Españoles en Burdeos. ${ }^{14}$ Por consiguiente, el discurso misionario es distinto del discurso nacional católico. ${ }^{15}$

Las tensiones se situarían más bien en otra parte, puesto que después de la Liberación de Francia los tiempos se hicieron difíciles para el Solar. Aquella dificultad radica en la inestabilidad de las relaciones con las instituciones religiosas francesas que intentaban tomar sus distancias con el régimen colaboracionista de Vichy. Esta fase de distanciamiento que supone silenciar las oscuras horas de la colaboración con el ocupante alemán se manifestó en el caso bordelés con las palabras del arzobispo de Burdeos Monseigneur Feltin. ${ }^{16} \mathrm{Al}$ saludar a los résistants de la Pointe du Grave, el Primado de Aquitania esperaba entonces hacer olvidar su fuerte compromiso en favor del Servicio del Trabajo Obligatorio, (STO). ${ }^{17}$ Con tales actitudes, el Solar se benefició de la relativa indulgencia de los comunistas, que tenían un fuerte predicamento político en aque entonces. Pero la supervivencia del Solar como institución representativa de la colonia española bordelesa dependió también de las ayudas financieras proporcionadas por el Consulado, de tal modo que la institución se encontraba en una posición ambigua entre el mantenimiento de las

para servir a su propia propaganda. De allí, la plena confianza de la autoridades franquistas a favor de ciertas congregaciones religiosas en particular a la compañia de Jesús que tenia mas influenza. Sobre este tema véase Javier BURRIEZA: Los jesuitas en España y en el mundo hispánico, Madrid, Marcial Pons, 2004

12 Gabriel Tapia Hernando, 3 de mayo de 2013. Entrevista realizada por Aubin González, Burdeos.

13 Antonio Cesar MORENO: “Los servicios exteriores de falange (1936-1945)”, Franquismo y antifran quismo, Madrid, CHIDE, UNED, octubre 2006. Disponible en http://cihdez.redestudios.org/sites/ default/files/seminarios/pdf/Moreno-2006.pdf.

14 Gabriel T., 3 de mayo de 2013. Entrevista realizada por Aubin González, Burdeos.

15 Hervé YANNOU: Jésuites et compagnie, Paris, Lethielleux, 2008.

16 El Cardenal Maurice Feltin fue Arzobispo de Burdeos y Primado de Aquitania desde 1936 hasta 1949, antes de conseguir el título de Arzobispo de Paris.

17 Frédéric LE MOIGNE, Les Evêques français de Verdun à Vatican II: une génération en mal d'héroïsme Frédéric LE MOIGNE, Les Evêques français de Verdun à Vatican II: une génération en mal d'héroisme, Rennes, PUR, p.170: "Ces prélats ne pouvaient se résoudre à être mis au ban de la nation eux qui avaient jusque-la occupe la premiere place de la representation, particulièrement sous Vichy (...). ve lors du siège de Royan: “Soldats admirables de courage et de bon esprit, ces jeunes de 17 à 25 ve lors du siège de Royan: "Soldats admirables de courage et de bon esprit, ces jeunes de 17 à 25 ans en général, qui pour la plupart ont tenu précédemment le maquis (...), ont vraiment un cran 
buenas relaciones con el Estado español y el acercamiento a la izquierda francesa. ${ }^{18}$ Cierto es que esta elección no mejoraba la fama de la institución jesuita en la colonia española de Burdeos. Sin embargo, nos permite hacer una hipótesis según la cual la Liberación es el período en el que fueron iniciados realmente los primeros contactos entre los círculos católicos españoles, la izquierda francesa y las organizaciones del exilio. Aquellos contactos también podrían tener que ver con el distanciamiento del Solar respecto a las autoridades del Estado franquista.

Dejando aparte el carácter local de nuestro propósito, notamos que esta toma de distancia con el franquismo la experimentaron otras instituciones católicas como la Petite Espagne de la Plaine Saint-Denis, sobre la que trabajó Natacha Lillo. ${ }^{19}$ De la misma manera que el Solar bordelés, los claretianos de la Plaine, cuando estalló la Guerra Civil, dedicaron su acción pastoral a los refugiados republicanos hasta tal punto que la sensibilidad republicana era la que dominaba en 1936 en la Plaine. Aquella sensibilidad no desapareció de la Petite Espagne hasta los cincuenta, por tener en su seno muchos comunistas españoles cuyas condiciones de vida preocupaban al ayuntamiento comunista también de la Plaine Saint-Denis. ${ }^{20}$

De modo que desde nuestro punto de vista, las redes asociativas en Francia constituyen un punto de encuentro de las dos olas migratorias y más bien un punto en el que converge la cultura antifranquista hacia los años sesenta. En efecto, como se ha dicho en introducción, algunos autores insistieron en el eclectismo de la red asociativa española en Francia hacia 1960 En este sentido los trabajos de Ana Fernández Asperilla ${ }^{21}$ y de José Babiano evidencian una red centrada en tres tipos de instituciones asociativas. Frente a las asociaciones y círculos próximos al consulado estos autores notan que a partir de los cincuenta, se van creando otras asociaciones bajo el impulso de los partidos de izquierda en exilio. Aquí entonces, tenemos la señal de la evolución cualitativa del ambiente español en Francia porque tanto las asociaciones consulares como las nuevas asociaciones de izquierdas insisten en el carácter apolítico de su labor. Oue cada una de las redes tenga su propia concepción del apoliticismo, esto queda claro, pero también, Fernández Asperilla y Babiano notan que las reivindicaciones ya no se formulan sólo en los discursos políticos. ${ }^{22}$ Desde los cincuenta hasta los setenta, las críticas y la acción colectiva por la que se expresan las reivindicaciones de los españoles en Francia pasaban po unas preocupaciones en torno a la vida cotidiana, las libertades democráticas y la solidaridad con los españoles del interior. ${ }^{23}$ Las constataciones de los dos autores nos dan a pensar que la carga ideológica no sería, desde entonces, el criterio exclusivo del antifranquismo.

Dicho de otro modo, desde la perspectiva de la transmisión de la cultura del exilio, nuestra hipótesis sería que, al privilegiar las preocupaciones materiales y concretas de la ola de trabajo dentro de sus discursos, los grupos sociales del exilio pudieron enriquecer e impulsar una evo作 se como una cultura que se nutre de las dos olas. Siguiendo este camino, es lógico entonces que más allá de las preocupaciones materiales se atacaba al régimen de Franco.

\section{La progresiva difusión de la cultura antifranquista en las redes consulares (1950-1973)}

Este recorrido por la evolución de la presencia española en Francia después de la Segunda Guerra Mundial no es algo fuera del tema que nos ocupa aunque pudiera parecerlo. Con esto, aparecen claramente los diferentes grupos de la inmigración española. A la luz de este primer

18 Según las fuentes a disposición.

9 Natacha LILLO, La Petite Espagne de la Plaine Saint-Denis 1900-1980, Paris, Autrement, 2004

20 lbid.

21 José BABIANO y Ana FERNANDEZ: La patria en la maleta: historia social de la emigración española en Europa, Madrid, Fundación de $1^{\circ}$ de Mayo, 2008.

22 Ana FERNANDEZ (dir.), Gente que se mueve.

23 Ibid. apartado, las identidades ya no serían nada más que una red en la que circulan continuamente unos discursos que caracterizan a un grupo social de modo reflexivo o no. Así que el sentimiento de pertenencia y la identificación no son elementos del mecanismo de construcción identitaria, no son elementos innatos, sino que son unos ejemplos de caracterización que resultan de una producción discursiva. ${ }^{24}$ En el tema que nos ocupa, la intensidad de la progresión de la cultura antifranquista en la red consular entre 1950 y 1973 nos muestra que la asignación del estatuto jurídico de emigrante asistido ${ }^{25}$ por parte de los servicios consulares franquistas, resulta de una producción discursiva dominante que se va diluyendo entre aquellas fechas cuando el dialogo entre las asociaciones consulares y las diferentes organizaciones de izquierdas va intensificándose.

Con la progresiva entrada de los tecnócratas en algunos ministerios claves del franquismo se dibuja efectivamente otra política migratoria basada en la asistencia al inmigrante. A la diferencia del fracaso ideológico que constituyo el mantenimiento de una cadena migratoria tradicional hacia America latina, la política de emigración asistida hacia Europa de Oeste representaba una manera de satisfacer las exigencias internacionales para oficializar la incorporación en la Europa de Oeste. ${ }^{26}$ Bajo las responsabilidades de los tecnócratas recientemente entrados en el ministerio de Asuntos exteriores, se creó el Instituto Español de Emigración (IEE) en 1956.27 La institución fue entonces la principal organización de tutela oficial de la emigración a partir de esta fecha. Por lo tanto, trabajó estrechamente con los consulados en tejer una red consular cuya meta era el mantenimiento de los residentes en la cultura franquista y por consiguiente la ilusión del retorno próximo. ${ }^{28}$ Desde esta perspectiva, apoyó entonces diferentes tipos de las asociaciones, como las misiones católicas y una red de publicaciones de la que algunas siguen editándose a día de hoy. ${ }^{29} \mathrm{~A}$ través de este apoyo, la red consula contaba con un constante recurso al folklore ${ }^{30}$ de España. En efecto, la historiografía sobre el asociacionismo español en Francia subraya el carácter tradicional de muchas manifestaciones y de publicaciones periódicas en las asociaciones apoyadas por el franquismo. ${ }^{31}$

También como dicho antes, dentro de este asociacionismo consular, las misiones católicas eran muy importantes tanto desde del punto de vista de los emigrados como del de la presencia consular. Su papel era doble. Por un lado, las misiones católicas tenían una vocación de asistir espiritualmente ${ }^{32}$ al emigrado y por otro lado, la acción pastoral a favor de los emigrados se centraba en la ayuda material. Pero si estamos de acuerdo con el sentido que dar a la asistencia material, lo estamos mucho menos respeto a su carácter espiritual.

24 La siguiente observación parte de la lectura de Martina AVANZA; Gilles LAFERTÉ: "Dépasser la "construction des identités?", Genèse, 61 (2005), pp. 134-152.

25 Este estatuto es definido en el marco de la Ley de Ordenancia de Emigración (LOE) del 23 de Diciembre de 1960 . cf. BOE 23 diciembre 1960.

26 Aquellas exigencias tenían como meta la de oficializar la reapertura del diálogo diplomático entre el Estado español y las potencias del Oeste con el apoyo de Estados Unidos. Una de las principales concuestión fue on parte rasula en mostoón fue en parte resuelta con el envio de mano de obra mistente la emigración asistida de modo que el paro disminuye. Aubin CONZALEZ, Lemigration sous le franquisme: etudes des politiques

.

27 Sobre la historia del IEE véanse los trabajos de María José FERNÁNDEZ, Axel KREIENBRICK, et al., Historia del Instituto Español de Emigración, Madrid, Publicaciones del Ministerio de Trabajo e Inmigración, 2009,

28 Ana FERNANDEZ: Gente que se mueve.

29 Cf. Carta de España, Ministerio de Trabajo e Inmigración, enero 1961 primera publicación.

30 Esta palabra se entiende según su etimología, es decir, la cultura del pueblo, lo que implica el conjunto de las actividades populares culturales.

31 Por ejemplo, Carta de España dedicó uno de sus números al asociacionismo gallego.

32 Véase $L O E, 23$ de Diciembre de 1960, BOE. 
En realidad, el sentido que se puede dar a esta palabra depende del discurso institucional en el que se inscribe, porque el espiritu se moviliza tanto en el discurso franquista, o nacional-católico, como en el discurso universalista del Cristianismo. Sin embargo, si aludimos a la importancia del folclor dentro del asociacionismo consular, constatamos que para el franquismo, la asistencia espiritual remite a este mantenimiento en la cultura franquista, en el espiritu del 18 de julio.

El discurso nacional-católico se aleja entonces de la posición vaticana sobre las migraciones que quedaba expresada en la bula papal de 1952: Exsul Familia. La amplitud del traumatismo que resultó de la Segunda Guerra Mundial animó al Papa Pío XII a englobar la cuestión migratoria como parte de la doctrina social de la Iglesia. ${ }^{33}$ Dentro de este marco, su actitud evolucionó hacia un discurso más universalista que no corresponde a un ámbito forzosamente nacional. Por consiguiente, el papel de las misiones católicas de lengua extranjera, sobre lo que insistía Exsul Familia, consistía en facilitar la integración de los emigrados en los países de acogida a través del recurso al estatuto canónico de las parroquias.

Desde esta perspectiva, el Solar español de Burdeos se dedicaba a responder a las necesidades de los emigrados cualquiera que fuese su pertenencia ideológica o su pasado individual. En efecto, las entrevistas realizadas indican claramente que el peso ideológico de los que llegaron entre los cincuenta y los setenta, se convierte en elemento de segundo plano. Dicho de otro modo, la ideología no sería un elemento caracterizador de la memoria familia de la misma manera que lo es, por ejemplo, el lugar de origen. Siguiendo la pista de Elisabeth Gessat Anstett que realizó un estudio antropológico de la memoria en la Rusia postsoviética, el primer elemento de caracterización sería el espacio domestico que los emigrados españoles intentaron recrear. ${ }^{34}$ Esta hipótesis nos recuerda también el carácter familiar de la emigración entre 1950 y 1975, de igual modo que buena parte de las fuentes orales actualmente a nuestra disposición. En efecto, muchos de los entrevistados pertenecen a la segunda generación como los hermanos Paquito y Pepito A., cuyo padre salió de España en 1953.35 En conjunto, ellos conservaban un agradable recuerdo de su infancia con los jesuitas de la calle Dubourdieu pero las anécdotas que cuentan se centran específicamente en los momentos recreativos incluso en el catecismo. Por consiguiente, esto nos indica que carácter familial de la emigración supone también un fuerte peso de las preocupaciones educativas y escolares en dirección a los hijos de emigrados. La relevancia de este peso impulsó también la creación de otras asociaciones en los setenta como la asociación de Padres Españoles Emigrados en Francia (APEEF). La originalidad de esta asociación que contaba con unas antenas locales repartidas en todo el territorio francés, ${ }^{36}$ estriba en la colaboración estrecha entre padres de familias y sacerdotes jesuitas para defender el derecho a la educación de los hijos de españoles en Francia. Entre todas las reivindicaciones de esta asociación tanto los padres como los sacerdotes lamentaban la falta de recursos para asegurar la formación de los hijos en la enseñanza segundaria. Frente a esta situación, reprochaban también al franquismo de estar sordo a la desesperanza de los padres y de los sacerdotes que compartían la miseria de la inmigración española. De hecho, las misiones católicas no constituyen una fuerza de canalización de las voces de fuera sino que se comprometían a lado de los emigrados reforzando de este modo la cultura antifranquista.

33 Doctrina social que se traduce por la encíclica Rerum Novarum de León XIII en 1891. Véase Gerard CHOLVY: La France Religieuse, 1945-1975, Toulouse, Privat, 2002

34 Elisabeth GESSAT-ANSTETT, Un Atlantide russe: anthropologie de la mémoire en Russie postsoviétique, Paris, La Découverte, 2003

35 Paquito A., 4 de marzo del 2013. Entrevista realizada Aubin Gonzalez, Burdeos. Es hijo de emigrados nacido en Francia en los cincuenta que frecuento el Solar de pequeño con su hermano menor Pepito. Sigue viviendo en el barrio histórico con su madre (rue La fontaine, Burdeos). Pepito A., 15 de marzo del 2013. Entrevista realizada por Aubin Gonzalez, Burdeos. Electricista, hermano menor de Paquito con el que frecuentó el Solar de pequeño.

36 La APEEF de Gironde se ubica en la calle Dubourdieu y fue creada en 1973.
Esto porque lo que parece como una marca de desprecio para las autoridades consulares era para los sacerdotes jesuitas un freno para el justo cumplimiento de su misión de asistencia.

Desde de esta perspectiva, el apoliticismo de las asociaciones de la red consular viene a mo-

dificar considerablemente el rostro del antifranquismo sobre todo después de 1968. Primero detrás del simple carácter reivindicativo de las acciones colectivas, tal como lo desarrolló la AFEEP, se disimula en realidad una crítica de la acción o inacción de los consulados franquistas en Francia. Luego, la incorporación de las asociaciones en la legislación francesa, (ley 1901) permitió también la creciente participación de los franceses en la vida asociativa española que constituye de hecho una nueva aportación al antifranquismo en Francia. ${ }^{37}$

\section{El Solar Español de Burdeos: un ejemplo de la transferencia y del uso de la asistencia al emi-} grado, (1950-1975)

Por fin nos dedicamos a una de las más importantes instituciones de la colonia española bordelesa que ya citamos más arriba. El Solar español de Burdeos es un testigo privilegiado de la larga presencia española en la ciudad de Burdeos. Su evolución en el tiempo refleja en efecto la evolución de los católicos españoles hacia el antifranquismo. Por lo tanto, esta misión jesuita constituye un buen ejemplo para poner de realce la política migratoria española en la región de Burdeos.

Así que la fundación de este lugar nace de la preocupación de unos sacerdotes jesuitas padres Simon y Fabre por la extrema miseria de los españoles que vinieron en el suroeste francés para prestar apoyo a las mujeres francesas en las fábricas..$^{38}$ En 1920, debido a la importancia del balance humano de la primera guerra mundial, Francia necesitaba efectivamente mano de obra barata para la recuperación económica. De allí, se privilegiaba el reclutamiento de mano de obra extranjera en los sectores claves de la economía francesa como la industria y la agricultura. Del otro lado de los Pirineos, la crisis agrícola que conocía Castilla durante el reinado de Alfonso XIII hizo que muchos de los patrones franceses, fueran a buscar la mano de obra en los pueblos castellanos. 39

Sin embargo, no nos atrevimos a desarrollar este tema que indudablemente se inscribe en trabajos futuros aunque pudiera ser muy útil para comprender los motivos de la existencia de Solar. En cualquier caso, las preocupaciones familiares siempre fueron el centro de gravedad de la acción pastoral a favor de los emigrados. De modo que para el tema que nos ocupa, la misión de asistencia a la que se dedicaron los jesuitas del Solar después de la Segunda Guerra Mundial respondía a aquellas preocupaciones como dicho antes. Fue el peso del carácter familial, de las necesidades materiales y cotidianas, el que favoreció también la evacuación del peso ideológico patente en el discurso franquista. De allí, la relevancia de la asistencia material proporcionada por el Solar entre los cincuenta y los setenta que oculta en gran parte e interés por el pasado político de los que acudían. En efecto, además de la indiferencia ante el pasado de los individuos, el peso de la asistencia material puede explicar las conexiones entre buena parte de los españoles del cours de l'Yser y la misión jesuita. Según nuestras fuentes, muchos de los que vivían entre el cours de l'Yser y el marché des Capucins frecuentaron el lugar. Por lo tanto, constatamos que el Solar constituía uno de los principales puntos de información y ayuda para las familias. Esta ayuda se materializó entonces en la búsqueda de alojamiento y la búsqueda de trabajo.

37 Sobre el tema de los estatutos asociativos vease José BABIANO y Ana FERNANDEZ: La patria en la maleta...; también, Maria SANTOS-SAINZ, François GUILLEMETEAUD: Les Espagnols à Bordeaux et en Aquitaine...

$38 \mathrm{El}$ Solar español de Burdeos (Francia): su origen, su labor, sus frutos y esperanzas. Testimonios favorables, Tipografia catolica de Alberto Fontana, Madrid, 1927.

39 Nata 
No obstante, notamos a partir de nuestras fuentes que el Solar tenía un público privilegiado. Aunque servía de punto de información y ayuda para los que no tenían contactos en el país de acogida, se dedicaba más bien a las mujeres y a los niños.

A partir de los sesenta, la salida de España de muchachas jóvenes se hizo más importante. Por primera vez, las muchachas pudieron emprender la ruta de la emigración sin la autorización previa del marido y sobretodo sin ser acompañadas. Pero la salida de jóvenes mujeres, que eran a menudo solteras, se convirtió en un problema para las autoridades franquistas porque las bodas mixtas con franceses anulaban la perspectiva del retorno. Detrás de un discurso alarmista sobre la situación de estas muchachas pero que les criminalizaba al mismo tiempo, el franquismo mandó a la red consular que prestara una atención particular a la asistencia a la emigración femenina. El Solar facilitó entonces más bien la integración femenina que la masculina que, como lo hemos visto antes, se vinculaba sobretodo con el trabajo y la vida asociativa. Fue con el apoyo de los jesuitas de la misión bordelesa que las muchachas tuvieron los primeros contactos con la sociedad francesa. Esto porque en aquella época las francesas iban a reclutar des bonnes à tout faire o chachas lo que convertía al hogar jesuita en una verdadera oficina de empleo sustituyendo a veces la agregaduría laboral al principios de los setenta ${ }^{40}$. En este sentido, sería interesente en trabajos futuros comparar la situación de las chachas bordelesas con la de las chachas parisinas que es actualmente objeto de investigaciones doctorales. (Trabajos de Bruno Tur que dentro de su tesis doctoral estudia la representación de las chachas parisinas en la sociedad francesa y española).4

Respecto al tema de la niñez, el papel del Solar era especialmente relevante en las actividades recreativas y educativas para los hijos de los emigrados. En efecto, ya hemos dicho que buena parte de nuestros entrevistados son hijos de emigrados nacidos en Francia que frecuentaron el Solar para mantener un vínculo con la cultura española. Sin embargo, desde el punto de vista de los jesuitas y según las fuentes, estas actividades estaban desprovistas de todo contenido político e incluso ideológico. Lo que era patente fue que en su seno se formaban amistades que a veces eran mixtas. Entonces, se rompía la tradicional separación de género característica de la moral franquista y se fue creando un nuevo espacio de socialización. Recreación que se reforzaba con la dimensión cultura de ciertas manifestaciones o actividades culturales como el cine y los bailes o más simplemente las fiestas. A través de la preocupación por los niños, que entierra definitivamente el peso de la ideología sobre el individuo, los emigrados intentaron recrear el ambiente del pueblo que habían dejado, y que se confundía con el de la familia. A la luz de estos elementos, proponemos una hipótesis: los emigrantes pudieran hubieran recuperado el concepto de familia para reapropiárselo. Pero nuestra hipótesis supone que la familia ya no se entiende como un elemento discursivo en la formación ideológica de los individuos como lo da a entender la aceptación franquista del término. La santificación de la familia por el franquismo amenaza las acepciones particulares de esta institución y toda la dimensión memorial que se vincula con ellas. Frente a la concepción franquista que muchos de los inmigrados habían conocido entonces, empieza a dibujarse en los setenta la visión de una familia más universalista, y entendida como parte de la comunidad cristiana. Además, conociendo los vínculos ideológicos entre la mujer y la familia sería útil de interesarse por la cuestión de género bajo el franquismo. ${ }^{42}$

40 Virginia A., 22 de Febrero de 2013. Entrevista realizada por Aubin Gonzalez, Burdeos. Hija de emigrado llegada A Francia con su padre, quien se benefició de la emigración asistida en 1963

41 Bruno TUR, Les Espagnols à Paris : émigration, immigration et représentations, (de 1960 à nos jours) thèse de doctorat actuellement en préparation sous la direction de CHAPUT Marie Claude, Université de Paris X, Nanterre.

42 Entre los numerosos trabajos sobre la cuestión del género bajo el franquismo podemos citar los trabajos de Mercedes Yusta Rodrigo.

\section{Conclusión: el alistamiento de la familia cristiana contra Franco}

A modo de conclusión, el presente artículo es una reflexión en torno a la noción de identidad partiendo de un grupo social: los católicos españoles emigrados en Francia entre 1950 y 1976. En efecto, lo que sucedió con en el caso bordelés nos muestra el peso determinante de las instituciones en la asignación de la identidad de los grupos. Esta asignación además de poner de realce que las identidades ya no son nada más que el resultado de una producción discursiva y que no existen como tal, evidencia también las tensiones que se expresan dentro del ambiente español. De allí, lo de que el conjunto de las relaciones después de la Segunda Guerra Mundial oscila siempre entre una tendencia pro o antifranquista. Sin embargo, esa distinción se va borrando a partir de un nuevo discurso que aparece después de los cincuenta con la llegada de nuevos emigrantes.

La doble caracterización del ambiente español en Burdeos se borra en efecto a través de discurso que tienen las asociaciones de inmigrantes en Francia, en particular en la red asociativa consular a partir de 1960. Por un lado entonces, la incorporación de las organizaciones de izquierdas tuvo un papel importante en la elaboración de este discurso. Sin embargo a este papel ya conocido por la historiográfica habría que añadir el papel desempeñado por las misiones católicas jesuitas. Ellos, a partir de los setenta, se distancian del régimen franquista por la proximidad, y a veces el compromiso de los sacerdotes con las masas preocupadas por el porvenir de la juventud emigrada.

A través de la acción de los jesuitas bordeleses, la familia se entiende como una institución alternativa, con una cultura alternativa también, diferente de la que proponía el franquismo. Con esto, los grupos católicos en Francia constituyen la ilustración de las posiciones de la Iglesia vaticana sobre las migraciones. Esta visión de carácter universalista sigue patente en lo de que el Solar fue algo más que una misión católica española cuando llegaron los portugueses a finales de sesenta. En efecto, conviene recordar la posición del arzobispo de Burdeos Monseigneur Richaud que, en 1954, consideraba el Solar como un punto de encuentro entre españoles y portugueses. ${ }^{43} Y$ es la particularidad de este encuentro que conviene estudiar en trabajos futuros. 


\section{LA MOVILIDAD INTERNACIONAL DE ESTUDIANTES}

\section{EN LOS SIGLOS XX Y XXI}

Christof Van Mol (NIDI/ CeMIS)

Toni Morant i Ariño (WWU Münster)**

\section{Resumen}

La movilidad intraeuropea de estudiantes ha captado la atención de las ciencias sociales sólo de forma relativamente reciente. Ello puede ser atribuido principalmente al aumento de número de participantes en el programa Erasmus, iniciado en 1987, uno de cuyos principales objetivos es el fomento de una identidad europea. No obstante, la idea de que un proyecto político debe ser apoyado por la población es anterior y se encuentra, entre otros, en las reflexiones de Max Weber sobre el concepto de Legitimitätsglaube. Sin embargo, los análisis en las ciencias sociales sobre la influencia de la movilidad juvenil en la creación de una identidad europea no mencionan al respecto precursores históricos. La presente comunicación es, por tanto, un intento de aunar perspectivas sociológicas e históricas.

Nuestra propuesta constituye un ejercicio exploratorio de semejanzas y diferencias entre, por un lado, la movilidad juvenil dentro del programa de intercambio Erasmus y, por el otro, los visitas entre los - y las - jóvenes falangistas y nazis en los años treinta y cuarenta del siglo XX. Aunque la idea pueda parecer en sí provocadora demostramos que, pese a las grandes diferencias de contexto, contenido y - especialmente - objetivos, se pueden también encontrar determinadas similitudes. Para desenmarañar unas de otras, en nuestra reflexión nos centramos en el discurso político y las finalidades atribuidas a ambos tipos de intercambio. Demostramos que ambas formas de movilidad juvenil pivotan alrededor de un eje central: la creación a través del viaje de una identidad o proyecto europeo común. Sin embargo, podemos constatar a la vez la existencia de considerables diferencias entre ambas formas de movilidad juvenil, principalmente el carácte democrático o radicalmente antidemocrático de sus respectivos objetivos últimos.

En resumen, nuestra reflexión demuestra, por un lado, cómo el concepto de Europa en tanto que proyecto político puede contener ideas y valores diferentes (e, incluso, diametralmente opuestos) y, por el otro, cómo a los viajes de estudios se les ha atribuido ya históricamente un papel decisivo para promover una identidad común que haga progresar un proyecto político entre las generaciones futuras. En conclusión, pretendemos tender un puente entre dos disciplinas y dos periodos históricos diferentes para las que hasta el momento se ha realizado escaso trabajo científico conjunto.

* Dr. Christof Van Mol, Netherlands Interdisciplinary Demographic Institute (NIDI), Lange Houtstraat 19, 2502 AR Den Haag Paises Bajos / Centre for Migration and Intercultural Studies (CeMIS) Universiteit Antwerpen, Prinsstraat 13, 2000 Antwerpen, Bélgica. E-mail: Christof.VanMol@uantwerpen.be

** Dr. Toni Morant i Ariño, Cluster of Excellence Religion and Politics, Westfälische Wilhelms-Universität Münster Jhannisstraß 4873 Münster, Alemani E-mill tonimorant@uni-muensterde El coautor participa del proyecto de investigación "De la dictadura nacionalista a la demster.de. de las autonomias: politica, cultura, identidades colectivas" (HAR2011-27392), financiado por el ministerio español de Economía y Competitividad.

\section{Introducción}

Como concepto y como realidad cotidiana hace tiempo que 'Europa' resulta omnipresente en la vida de muchos ciudadanos de los estados miembros de la Unión Europea: el euro, los medios de comunicación y las directivas europeas que afectan a la vida de los ciudadanos, entre otros, desempeñan todos ellos su papel. Actualmente, el concepto de 'Europa' es equiparado con frecuencia a la entidad política de la Unión Europea, lo que puede ser considerado el resultado del proceso de integración desarrollado a lo largo de las últimas décadas. Este corrimiento de contenido del concepto es fomentado a través de diversos símbolos adoptados por la Comisión Europea. Siguiendo a Wilken, se puede distinguir dos tipos de símbolos.' El primero abarca aquéllos con una función discursiva o simbólica, que representan la entidad política de una manera abstracta, por ejemplo, la bandera, el himno nacional o la moneda. El segundo tipo de símbolos tiene una doble función: de un lado, es una expresión simbólica de la entidad política pero, de otro, es una herramienta material de esta entidad; es el caso, por ejemplo, de la distinción entre los pasaportes 'europeos' y 'otros' realizada en los aeropuertos. Para promover una identidad común entre sus ciudadanos cada Estado dispone de más herramientas de este tipo.

La idea de que una nación debe ser apoyada por sus ciudadanos empezó a desarrollarse a partir de la Revolución Francesa. Los Estados-nación surgidos posteriormente se vieron obligados a legitimar su existencia y a hacerlo de forma diferente a lo que se había hecho hasta al momento. La famosa frase tradicionalmente atribuida a Massimo d'Azeglio tras la consecución de la unidad del Reino de Italia es buen ejemplo de dicha dinámica: Fatta l'Italia, bisogna fare gli Italiani ('[Una vez] hecha Italia, hace falta hacer a los italianos'). I Ideas similares aparecieron en la Francia de la época, donde el Estado realizó muchos esfuerzos para nacionalizar (civiliser) a sus ciudadanos y convertirlos en 'franceses'.3 Para ello los Estados-nación tenían a su alcance poderosas herramientas, como la prensa de masas, el sistema educativo y regulaciones administrativas. ${ }^{4}$ La imposición de un idioma común o la invención y difusión de una historia nacional son ejemplos de acciones dirigidas a la promoción de la idea de un Estado nacional. ${ }^{5}$ En las sociedades 'nacionalizadas' se tendió a la homogenización lingüística, que conllevó una notable reducción de la variedad de lenguas, a la par que se multiplicaban los intercambios entre las diversas poblaciones que ahora habitaban en un mismo Estado, con la idea de que el intercambio fomentaría una identidad nacional común. ${ }^{6}$ Dicho proceso de 'asimilación', basado en la creencia de que con el paso del tiempo la educación y la movilidad harían disminuir tales diferencias, se halla en el centro de la idea del Estado-nación, lo que Noiriel denominó 'la tyrannie du national'.? Así pues, aparece ya aquí la idea de que la movilidad puede ser una herramienta para promover una unidad nacional.

Lisanne WILKEN: "Anthropological Studies of European Identity Construction" en Ullrich KOCKEL, Máiréad Nic CRAITH y Jonas FRYKMAN (eds): A Companion to the Anthropology of Europe, Malden y Oxford, Blackwell Publishing, 2012.

2 "Avanti”, The Economist, 24 de febrero de 2011. Stephanie MALIA HOM: “On the Origins of Making Italy: Massimo D'Azeglio and 'Fatta l'Italia, bisogna fare gli Italiani"', Italian Culture, 21 (2013), pp. 1-16. 3 Eugen WEBER: Peasants into Frenchmen. The Modernization of Rural France, Stanford, Stanford University Press, 1976

4 Benedict ANDERSON: Imagined Communities. Reflections on the Origin and Spread of Nationalism, Londres y Nueva York, Verso, 2006 [1983].

5 Eric HOBSBAWM y Terence RANGER (eds.): The Invention of Tradition, Cambridge, Nueva York, Melbourne, Madrid y Ciudad del Cabo, Cambridge University Press, 1983.

6 Dominique SCHNAPPER: "De l'Etat-nation au monde transnational. Du sens et de l'utilité du concept de diaspora", Revue Européenne des migrations internationales, 17 (2001), pp. 9-36.

7 Gérard NOIRIEL: La tyrannie du national. Le droit d'asile en Europe 1793-1993, Paris, Calmann-Lévy, 1991, citado a partir de Dominique SCHNAPPER, 2001, p. 13. 
La educación ha sido desde hace tiempo una herramienta importante para influir en la opinión de la gente sobre las entidades políticas en las que habitan. Hoy en día dicha valoración de la educación existe también a nivel supranacional, por ejemplo, en las políticas de la Unión Europea. Aunque más allá de las escuelas europeas no dispone de un sistema educativo propio, en las últimas décadas la Unión ha expandido progresivamente su influencia en el ámbito de la educación y la formación. En esta área, considerada clave para la promoción de la ciudadanía europea, la Comisión atribuye una considerable importancia a los programas de movilidad, con la idea de que un periodo de estudio/trabajo en el extranjero promoverá el sentido de una identidad europea. El hecho de que una determinada entidad política intente promover una identidad supranacional parece nueva o, cuando menos, reciente. Sin embargo, en nuestra reflexión argumentamos la existencia de precursores históricos, en los que la movilidad juvenil ha sido considerada de importancia a la hora de promover la identificación de sus participantes con un proyecto político común más allá de las fronteras del Estado-nación.

La elección de los dos casos considerados en este trabajo - el programa Erasmus y una determinada movilidad juvenil en la denominada 'época de los fascismos' - surgió en un primer momento por motivaciones pragmáticas: los autores de ambos proyectos de investigación se conocían previamente. Así, Christof van Mol analiza desde una perspectiva sociológica el programa Erasmus hoy en día y, entre otros aspectos, la influencia que una estancia Erasmus puede ejerce en la respectiva identificación con Europa por parte de quienes participan en el programa. ${ }^{8}$ Por su parte, Toni Morant ha centrado sus análisis en los contactos y las visitas entre organizaciones juveniles fascistas en la Europa de finales de los años treinta y principios de los cuarenta del siglo $X X$, desde una perspectiva histórica. ${ }^{9}$ Sin embargo, la combinación de las respectivas investigaciones, fruto de nuestras inquietudes e intereses, ha dado pie a un ejercicio en el que intentamos tender un puente entre dos disciplinas y dos periodos históricos diferentes para las que hasta el momento se ha realizado escaso trabajo científico conjunto, para demostrar la presencia de determinados paralelismos históricos entre nuestros respectivos objetos de estudio.

\section{El papel de la juventud como apoyo de los proyectos políticos}

La idea de que un proyecto político debe contar con el apoyo de la población se encuentra ya, entre otros, en las reflexiones de Max Weber sobre el concepto de Legitimitätsglaube. ${ }^{\circ}$ No obstante, también anteriormente autores como Jean-Jacques Rousseau y, ya en el siglo XX, Benedict Anderson, hicieron referencia a la importancia de crear una 'comunidad imaginada' para sostener un proyecto político." Éste no tiene que por qué ser sólo un estado, sino que se puede defini más ampliamente, como por ejemplo un ideario. Como Ulrich Beck y Edgar Grande escribieron: "Europa no puede ser descubierta [gefunden], tiene que ser inventada [erfunden]". ${ }^{2}$

8 Véase, por ejemplo, Christof VAN MOL: Intra-European student mobility in international higher education circuits: Europe on the Move, Basingstoke, Palgrave Macmillan, en prensa. Así como, del mismo autor, "Intra-European Student Mobility and European Identity: A Successful Marriage?", Population, Space, and Place, 19 (2013), pp. 209-222.

9 Véase Toni MORANT I ARIÑO: Mujeres para una "Nueva Europa". Las relaciones y visitas entre la Sección Femenina de Falange y las organizaciones femeninas nazis, 1936-1945, tesis doctoral, Universitat de València, 2013. Así como, del mismo autor: “Kameradinnen jenseits der Grenzen'. Politische Beziehungen zwischen der weiblichen Organisation der Falange und den Frauen- und Mädelorganisationen der NSDAP, 1936-1945", en: Gabriele WILDE y Stephanie FRIEDRICH (eds.): Im Blick der Disziplinen. Geschlecht und Geschlechterverhältnisse in der wissenschaftlichen Analyse, Münster, Westfälisches Dampfboot, 2012, pp. 238-256.

10 Max WEBER: The Theory of Social and Economic Organization, Nueva York, The Free Press, 1964.

1 Jean-Jacques ROUSSEAU: Du Contrat Social. Livre l et II, Paris, Hachette Livre, 1996 [1762]. Benedict ANDERSON, Imagined Communities.

12 Ulrich BECK y Edgar GRANDE: Cosmopolitan Europe, Cambridge y Malden, Polity Press, 2008, p. 7.
Lo podemos observar también en el siglo XIX a raíz del surgimiento de los Estados-nación. Poco a poco los gobiernos centrales intentaron establecer una identidad común. Los jóvenes desempeñaron al respecto un papel cada vez más importante: se les consideraba los encargados de continuar y llevar adelante el proyecto común. Por lo tanto, no puede sorprender que a lo largo de la historia numerosas acciones hayan estado dirigidas a jóvenes. No obstante, la importancia de la juventud en el cambio de las relaciones de poder y autoridad en las sociedades modernas no atrajo la atención historiográfica hasta hace muy pocas décadas y entonces sólo de forma paulatina. ${ }^{13}$

La Juventud durante el periodo de entreguerrasTanto como sujeto histórico como también como objeto de debate la juventud estuvo muy presente en los discursos del periodo de entreguerras. Concepto casi inexistente apenas unas décadas antes, la juventud irrumpió con fuerza en el espacio público europeo tras $1919 .{ }^{14} \mathrm{En}$ el 'nuevo mundo' que había de surgir de los grandes sacrificios de la Primera Guerra Mundial (estilizada a la categoría de the War to end War) las jóvenes generaciones recibieron - y se asignaron a sí mismas - un papel protagonista; de ellas se esperaba que encabezaran el futuro renacer. Por un lado, los diferentes gobiernos y partidos desarrollaron numerosas políticas dirigidas a la juventud, mientras que, por el otro, ésta experimentaba una movilización política sin precedentes. A la hora de romper con el 'viejo' mundo anterior a 1914 las nuevas ideologías del fascismo y el comunismo parecieron tene más éxito. ${ }^{15}$ En este sentido, la relación entre fascismo y juventud parecía especialmente estrecha: el Nationalsozialistische Deutsche Arbeiterpartei (Partido Nacionalsocialista Alemán de los Trabajadores) y el Partito Nazionale Fascista (PNF) no sólo eran partidos en sí muy jóvenes (fundados inmediatamente tras la guerra), con una militancia cuya media de edad era muy inferior a la de los demás partidos (a excepción de los comunistas), sino que además intentaron presentarse como portavoces de las aspiraciones juveniles. Recurrieron para ello a una simbología muy identificada con el 'mito de la juventud' (el PNF se había apropiado como him no de la canción Giovinezza) y lemas (como Largo ai giovanni, en Italia, o "Haced sitio, viejos", en Alemania) derivados de la metáfora biológico-vitalista que habría de superar el 'obsoleto', 'moribundo' sistema liberal-parlamentario. Sus organizaciones juveniles alcanzaron millonarias cotas de afiliación, ciertamente nunca antes de llegar al poder, pero sí mucho antes de resultar obligatorias. Como afirmaba una de las máximas acuñadas por los nazis: "Ouien tiene la juventud, tiene el futuro" (Wer die Jugend hat, hat die Zukunft), porque el futuro - se decía pertenece a la juventud. ${ }^{16}$

Youth on the Move - Hoy en dia

En un contexto histórico muy diferente surgieron, a partir de la década de 1970, los programas de movilidad en la educación promovidos por la Comisión Europea con el desarrollo de los Joint-Study Programs. No obstante, la importancia de la movilidad juvenil había sido reconocida con anterioridad, si bien vinculada principalmente a una finalidad económica.

3 Harald SCHOLTZ: Erziehung und Unterricht unterm Hakenkreuz, Göttingen, Vandenhoeck \& Ruprecht, 1985, p. 8

14 Luisa PASSERINI: "La juventud, metáfora del cambio social (Dos debates sobre los jóvenes en la Italia fascista y en los Estados Unidos durante los años cincuenta", en Giovanni LEVI y Jean-Claude SCHMITT (eds.): Historia de los jóvenes. La edad contemporánea, Madrid, Taurus, 1996, v. 2, pp. 383 453,385 .

15 Sandra SOUTO KUSTRÍN: "El mundo ha llegado a ser consciente de su juventud como nunca antes'. Juventud y movilización política en la Europa de entreguerras", Mélanges de la Casa de Velázquez, 34/1 (2004), pp. 179-215.

16 Arno KLÖNNE: "Jugend im Dritten Reich", en Karl-Dietrich BRACHER y otros (eds.): Deutschland Arno KLONNE: "Jugend in Dritten Reich", en Karl Dietrich BRACHER y otros (eds): Deutschland 1933-1945. Neue Studien zurnatio
Bildung, 1993, pp. 218-239, 239. 
Así, la educación profesional ya formaba parte de la agenda europea desde el Tratado de Roma (1957), porque se consideraba que habría de suponer una herramienta adicional para las finalidades económicas de la Comunidad Europea."

Sin embargo, la primera acción iniciada desde el nivel europeo fue la creación del programa Erasmus en 1987, con la idea de servir a los fines políticos, culturales, económicos y sociales del proyecto europeo: al volver a sus respectivos países los estudiantes Erasmus se sentirian más europeos y posteriormente serían más móviles en sus futuras carreras profesionales, lo cual fomentaría la competitividad económica europea entre las economías de conocimiento.$^{18}$ Desde entonces Europa ha expandido progresivamente su influencia en temas de educación y movilidad, con la idea de que la movilidad podría crear 'europeos'. Al inicio, casi todos los programas se centraban en la acción Erasmus, pero hoy en día este panorama ha cambiado. El programa Youth on the Move ha reunido bajo un mismo techo diferentes programas de movilidad: Erasmus, Erasmus Mundus, Comenius, Leonardo da Vinci, etc. El programa está circunscrito como "una iniciativa para explotar el potencial de los jóvenes para alcanzar un desarrollo inteligente, sostenible e inclusivo en la Unión Europea". ${ }^{9}$ La propia página web del programa Erasmus ilustra el papel instrumental del programa para los fines políticos a través de afirmaciones como: "Estas experiencias dan a los estudiantes un mejor sentido de lo que significa ser ciudadano europeo. Además, muchos empresarios valoran mucho un periodo de estudio en el extranjero, lo que incrementa la inserción laboral y las perspectivas de trabajo". ${ }^{\circ}$

En resumen, los programas de movilidad juvenil iniciados a nivel europeo tienen unos objetivos de formación identitaria, con la idea de que la participación e interacción de jóvenes universitarios en el extranjero fomentaría la ciudadanía europea y el apoyo por el proyecto económico, político y cultural europeo.

\section{Rol de movilidad}

El descubrimiento a través de los viajes

De la comparación entre nuestros respectivos periodos históricos destaca claramente la constatación de que los dos proyectos políticos aquí referidos poseen su propio concepto de una Europa unida. El contenido del respectivo concepto de 'Europa' es ciertamente bien diferente: un 'Nuevo Orden europeo' para los fascistas, mientras que para la Comisión Europea es una afiliación con una Europa 'unida en la diversidad'. No obstante, la premisa metodológica básica para lograr este cambio en los esquemas de identificación de los jóvenes es similar: el conocimiento a través de los viajes. ${ }^{21}$

17 Christof VAN MOL: Europe on the Move. A study into intra-European student exchanges in higher education, Tesis doctoral, Universiteit Antwerpen, 2013.

8 Vassiliki PAPATSIBA: "Making higher education more European through student mobility? Revisiting EU initiatives in the context of the Bologna Process", Comparative Education, 42 (2006), pp. 93-111. Christof VAN MOL:"Intra-European Student Mobility...”, pp. 209-222.

19 EUROPEAN COMMISSION: Youth on the Move. An initiative to unleash the potential of young people to achieve smart, sustainable and inclusive growth in the European Union, Bruselas, COM (2010), p. 477 - final.

$20 \mathrm{http}: / /$ ec.europa.eu/education/lifelong-learning-programme/erasmus_en.htm (URL: 24.6.2013)

1 Sin embargo hay queremarcarqueno siempre se alcanza elobjetivo de promoveruna determinada imagen de Europa. En el contexto del programa Erasmus, por ejemplo, varios estudios demuestran que la influencia de una estancia en el extranjero a la hora de identificarse con Europa varia según paises. Véase, por ejempto, Emmanuel SIGALAS: "Cross-border mobility and European identity: The effectiveness of intergroup contact during the ERASMUS yor abroad", European Union Politics, 11 (2010) pp. 241-265; Christof VAN MOL. Europe on the Move . ain WIISON: "What Should
En 1932, a los diez años de su llegada al poder, Mussolini afirmó en un discurso que "tra un decennio l'Europa sarà fascista o fascistizzata". ${ }^{22}$ Desde entonces hubo intentos de coordina los diferentes movimientos fascistas nacionales a nivel europeo (principalmente, los Comitati di Azione per la Universalità di Roma). Por su parte, también las Juventudes Hitlerianas mantenían desde mediados de los años treinta contactos con organizaciones juveniles de otros países - principal, pero no exclusivamente - europeos..$^{23}$ Con una evidente finalidad propagandística, estos viajes pretendían transmitir la imagen de una juventud alemana amante de la paz y de entendimiento entre los pueblos mientras, en realidad, su país se armaba a marchas aceleradas. $Y$ de hecho un informe de la embajada alemana en la España nacional constataba, mediada ya la guerra civil, los "resultados [...] muy buenos" alcanzados con "la labor [llevada a cabo] a través de invitaciones" a miembros - masculinos, pero sobretodo femeninos - de la Falange y aconsejaba, más allá de su "continuación sistemática", extenderlos a "personalidades de otros círculos", entre los que se contaba a universitarios, jóvenes catedráticos, médicos y juristas. ${ }^{24}$ En la base de semejante promoción de la movilidad se hallaba la idea de que el contacto entre ellos conllevaría un apoyo creciente a un proyecto o ideario político común. Como proclamó Baldur von Schirach en septiembre de 1942, con motivo de la fundación en Viena de la Asociación Europea de la Juventud: "El mutuo intercambio de opiniones y experiencias, las muchas visitas de mandos juveniles y sus delegaciones crearon poco a poco entre ellos/as una atmósfera de consenso. [..] Los y las mandos de la juventud europea nos hemos ido acercando de un encuentro a otro"

El mismo mecanismo se puede observar tras el programa Erasmus y la movilidad de profesionales dentro del espacio europeo. El principio básico de que la interacción entre ciudadanos de diversos países europeos conduciría a una identidad común aparece ya en el trabajo de Karl Deutsch en los años cincuenta, ${ }^{26}$ mientras que, a nivel político europeo, el concepto de una 'identidad europea' nació en Copenhagen en 1973, cuando los ministros de Asuntos Exteriores de los entonces nueve países miembros de la Comunidad Europea adoptaron una "Declaration concerning European identity". Década y media después la idea de que el contacto entre europeos de diferentes países llevaría a crear un sentimiento común, un 'nosotros', fue incorporada también a los objetivos del programa Erasmus, como hemos argumentado en la sección anterior de esta comunicación.

\section{Concepto de embajador}

En relación con el rol instrumental de la movilidad aparecen conceptos utilizados repetidamente en diferentes momentos y contextos. Es el caso del concepto de "embajador", aplicado aquí a los jóvenes ('jóvenes embajadores', 'embajadores de la juventud') de ciertos países, de Europa o otras entidades/conceptos. Los fascistas españoles utilizaron precisamente este con-

22 Benito MUSSOLINI: Opera Omnia, Florencia, La Fenice, 1958, vol. XXV, p. 147

23 Por ejemplo, con Japón a partir de 1937; cfr. Klaus-Peter HORN et al. (ed.): Pädagogik im Militarismus und im Nationalsozialismus. Japan und Deutschland im Vergleich, Bad Heilbrunn, Julius Klinkhardt Verlag, 2006.

24 Informe "Die Kulturpolitische Lage Spaniens", $n^{\circ}$ 550/37, febrero de 1938, p. 53, en: Politisches Archiv des Auswärtigen Amtes (PA AA, Berlin), fondo Botschaft Madrid (BM), legajo 615.

25 Véase su discurso "Die Einigung der Jugend Europas in Wien", en: Baldur VON SCHIRACH: Revolution der Erziehung. Reden aus den Jahren des Ausbaus, Munich, Franz Eher, 1943, pp. 210-230, 224 Sobre la fundación Asociación de la Juventud Europea, véase: Toni MORANT I ARIÑO: "Die Teilnahme der spanischen faschistischen Frauen- und Jugendorganisationen am Gründungstreffen des Europäischen Jugendverbands, Wien, September 1942", disponible en línea en: Themenporta Europäische Geschichte (2012), http://www.europa.clio-online.de/site/lang en//temID 559 / Europäische Geschichte (2012), http $1 /$
mid 11428/40208214/default.aspx.

$26 \mathrm{Karl}$ W. DEUTSCH et al: Political Community and the North Atlantic Area. International Organization in the light of historical experience, Princeton, Princeton University Press, 1957. 
cepto en 1941 para referirse al intercambio de mandos de las organizaciones juveniles falangista y nazi, al hablar de "jóvenes embajadores que iban a sellar un pacto de amistad sincera indestructible entre dos pueblos". De hecho, según lo había definido ya cuatro años antes un informe de la embajada alemana, los jóvenes falangistas de visita en el Tercer Reich regresaban a España convertidos en "los mejores propagandistas de Alemania". ${ }^{27}$

También en los discursos sobre el programa Erasmus, definido en los discursos políticos europeos como el "programa de intercambio con más éxito en el mundo", encontramos dicho concepto utilizado en similares términos. Así, con motivo de la celebración en 2012 de vigésimo quinto aniversario de la iniciativa, la comisaria europea de Educación, Cultura, Multilingüismo y Juventud, Androulla Vassiliou, se hizo acompañar de unos denominados 'Embajadores Erasmus', estudiantes que habían participado en el programa, en representación de los treinta y tres países participantes. La selección de dichos embajadores se basó en sus declaraciones previas sobre el impacto que su estancia en el extranjero en el marco del programa había tenido en sus vidas profesionales y privadas. Por tanto, se trataba de unos embajadores seleccionados de forma en absoluto aleatoria, sino con una clara finalidad apologética, de promoción del programa Erasmus.

\section{La desigualdad de la movilidad juvenil}

En ambos periodos históricos analizados los intercambios han sido considerados beneficiosos para los fines políticos perseguidos. Ahora bien, hay que remarcar que la promoción de la movilidad para ciertos grupos conlleva siempre la creación de una desigualdad social: ciertos grupos en la sociedad no tienen acceso a estos intercambios, bien por motivos económicos o bien porque las respectivas políticas se dirigen a determinados grupos sociales.

Hoy en día los estudiantes de intercambio son bienvenidos en los diferentes países europeos, porque no son percibidos un 'peligro' para la sociedad de acogida. ${ }^{2}$ De forma simultánea constatamos que jóvenes trabajadores - de su misma edad - encuentran en cambio una aceptación menor, reflejada, por ejemplo, en las discusiones sobre la 'oleada migratoria' que conllevaría la extensión de la Unión Europea hacia el este de Europa. Sociológicamente, la movilidad puede ser considerada como un 'factor de estratificación de nuestros tiempos'.29 Varios estudios demuestran que ni los estudiantes procedentes de estratos sociales más bajos tienen acceso ${ }^{30}$ ni las políticas vigentes en la actualidad se muestran aptas - son adaptadas para aumentar su participación. ${ }^{31}$ Aunque en la retórica política pueda parecer que el acceso a la movilidad está abierto a todos los estudiantes (lo que se refleja, por ejemplo, en el hecho que a partir del 2014 el programa Erasmus se llamará 'Erasmus for all'), está claro que el pro-

27 Cfr., respectivamente, Sancho DÁVILA: De la O.J. al Frente de Juventudes, Madrid, Ed. Nacional, 1941, p. 106, y el informe de Petersen al Deutscher Akademischer Austauschdienst (Servicio Alemán de Intercambio Académico), 6.10.1937, en: PA AA, BM, caja 614

28 Christof VAN MOL: “La migración de estudiantes chinos hacia Europa”, Migraciones Internacionales, 4 (2008), pp. 107-134.

9 Zygmunt BAUMAN: Globalization. The Human Consequences, Cambridge y Oxford, Polity Press, 1998, p. 2.

30 Véase por ejemplo Ulrich HEUBLEIN, Christopher HUTZSCH y Markus LÖRZ: "Ausmaß, Motive und Gründe des Desinteresses", Bildung und Erziehung, 61 (2008), pp. 437-450; Dolores MESSER y Stefan C WOLTER: "Are student exchange programs worth it?", Higher Education, 54 (2007) pp. 647-663; Jannecke WIERS-JENSSEN: Utbytte av utdanning fra utlandet. Overgang fra utdanning til arbeid blant nordmenn med høyere utdanning fra utlandet, Oslo, NIFU STEP, 2005.

31 Friedrich HEGER: "ERASMUS - for All? Structural Challenges of the EU's Exchange programme", en Benjamin FEYEN Y EWa KRZAKIEWSKA (eds): The ERASMUS Phenomenon - Symbol of a New European Generation?, Frankfurt am Main, Peter Lang, 2013, pp. 67-77. grama Erasmus no es para todos. ${ }^{32}$ No solo hay diferencias dentro de un mismo país, sino que también a escala internacional hay significativas diferencias de acceso, en parte debido a la gran variedad internacional en el importe de las becas. ${ }^{33}$ Así pues, se puede considerar a los estudiantes Erasmus como una "migratory elite", 34 puesto que generalmente no provienen de estratos sociales bajos. En resumen, aunque en el discurso político se describe la movilidad Erasmus como inclusiva (Erasmus for all), en la realidad las desigualdades sociales emergen a la superficie cuando estudiamos la composición del cuerpo de estudiantes participantes.

En el caso histórico se trataba de un 'selecto' grupo de jóvenes mandos fascistas. De ellos/ as se esperaba que se formaran y que, a su vuelta, hicieran lo propio con otros/as mandos y éstos, a su vez, con la 'masa' encuadrada en la respectiva organización. Dado que las limitaciones del momento (bélicas, de personal, de tiempo disponible,...) reducían considerablemente el número de participantes, se esperaba de ellos/as un factor multiplicador, especialmente si tenemos en cuenta que se trataba de organizaciones de masa. Es el caso de unas jóvenes mandos del falangista Auxilio Social de visita en Alemania a finales de 1937, a quienes su Delegada nacional les escribía desde España: "Trabajad todo cuanto podáis, a ver si venís preparadas para empezar aquí a formar el personal que ha de servir de profesorado dentro del Servicio Social de la mujer".35 Por otro lado, el concepto fascista de juventud era el concepto de una juventud fascista. La propia afiliación a sus organizaciones juveniles constituía ya un importante filtro: en sus filas no había ni 'rojos', ni liberales, ni judíos. De la misma manera, sólo la afiliación oficial a sus organizaciones hacía posible formar parte de un equipo de fútbol, asisti a un campamento o, en última instancia, viajar al extranjero. ${ }^{36}$

Asi pues, podemos concluir aquí que la movilidad juvenil en muchos casos es una movilidad selectiva. Y, al igual que los resultados que se derivan de ella, dicho carácter selectivo se ve influido por la organización que promueve esa movilidad a través de sus programas específicos.

\section{Diferencias entre ambos casos}

Como se puede observar existen entre ambos discursos políticos paralelismos a la hora de entender el rol instrumental de la movilidad juvenil para crear una Europa unida. Sin embargo hay que destacar la existencia de - notables - diferencias de fondo entre los mencionados intercambios durante los años treinta y cuarenta y las formas de movilidad promovidas hoy en día por la Unión Europea. Así, en aquella época los/as jóvenes falangistas no iban a Alemania por poner un ejemplo, dentro de un sistema reglado de intercambio universitario (aunque hubo ya algunos casos y existían al respecto planes para sistematizarlos en un futuro), sino que lo hacían en una estructura de partidos únicos fascistas y para estudiar sus respectivas organizaciones. ${ }^{37}$ El principio básico del acercamiento a través del intercambio coincide, pero a la hora de aplicarlo las variantes escogidas en cada uno de los periodos históricos analizados difieren considerablemente.

32 lbid.

33 Carlos RODRíGUeZ GONZÁLEZ, Ricardo BUSTILLO MESANZA y Petr MARIEL: “The determinant of international student mobility flows: an empirical study on the Erasmus programme", Higher Education, 62 (2011), pp. 413-430.

34 Frank MUSGROVE: The Migratory Elite, Londres, Heinemann, 1963.

35 Carta de Mercedes Sanz Bachiller (Valladolid), 2.11.1937, en: Archivo General de la Administración (Alcalá de Henares, Madrid), sección Cultura (03), fondo Auxilio Social (122), caja 2067.

36 SCHOLTZ: Erziehung und Unterricht..., p. 146.

37 Una visión de sintesis, en Toni MORANT I ARIÑO: "Estado totalitario y género. Las relaciones entre Uección Femenina de Falange Española y de las JONS y el Bund Deutscher Mädel en la Juventud Hitleriana, 1936-1945", Alcores. Revista de Historia Contemporánea, 13 (2012), pp. 63-83. 
La mayoría de los actuales programas de promoción de la movilidad juvenil, por ejemplo, tienen lugar dentro del marco de programas educativos establecidos. Por tanto, unos/as y otros/as participaban en un intercambio, pero el contenido varía notablemente. Así, los/as falangistas no iban a Alemania a adquirir conocimientos teórico-prácticos de carácter académico, sino a estudiar la estructura de las organizaciones nazis y participar en sus actividades, con el fin de adquirir experiencia(s) durante la respectiva estancia y posteriormente aplicar (o no) las lecciones extraídas a su regreso a España.

Igualmente, resulta innegable que el contenido del concepto de Europa presenta claras diferencias entre unos y otros. He aquí la principal divergencia, además de fondo: lo importante es el contenido político de cada concepto. Los alemanes aspiraban por ejemplo a una autarquía europea, mientras que la Unión Europea afirma trabajar en aras de un sistema económico de libre intercambio de productos y conocimientos. Además, el contenido de su “Joven Europa" fascista no sólo no dejaba lugar para los diferentes (demócratas, judíos, comunistas, gitanos, homosexuales...), sino que en muchos casos justificaba activamente su eliminación física. Hasta tal punto eran el antibolchevismo y la guerra su principal aglutinante que la mayoría de los encuentros multilaterales entre las diferentes organizaciones juveniles fascistas tuvieron significativamente lugar tras la invasión alemana de la Unión Soviética, rápidamente rebautizada como una "Cruzada europea contra el bolchevismo". ${ }^{8}$ Los fascistas se consideraban, primero y sobre todo, representantes de sus respectivas naciones, porque - según afirmaban - sólo quien trabajaba con fidelidad y valentía de definirse como parte integrante de su propia nación podría ser representante de Europa. Por su parte, los falangistas querían a su vez participar, estar en Europa, pero para mandar junto con alemanes e italianos. ${ }^{39}$ El ultranacionalismo fascista español era 'europeísta' y los falangistas "europeístas convencidos", ${ }^{\circ 0}$ pero en una jerarquía de naciones en la que, siempre tras la Alemania nazi y la Italia fascista, la 'Nueva' España tuviera derecho a ostentar un lugar destacado.

En cambio, la Unión Europea no excluye por ideologías y, en realidad, de la libertad de opinión que reina en ella se derivan considerables diferencias en el contenido. Además, mientras que el aglutinante de la Europa continental que querían los fascistas era la guerra (antibolchevique), la integración europea posterior a la Segunda Guerra Mundial parte de y se basa en una idea diametralmente opuesta: la conservación de la paz. Con tal objetivo la integración europea apostó al principio sobre todo en la integración económica, con la idea de que sería la interdependencia de las respectivas economías nacionales la que habría de evitar nuevas guerras entre estados europeos.

\section{Discusión}

En esta comunicación hemos presentado un ejercicio conceptual e intelectual, con la intención de traspasar fronteras disciplinarias y periódicas, conectando dos proyectos de investigación con un enfoque y metodología bien diferentes. Quizá todavía no muy frecuentes, trabajos interdisciplinares de este tipo pueden revelar dinámicas interesantes y estimular el debate

38 Toni MORANT I ARIÑO:“Envers la Nova Europa (i tornada). La col-laboració de la Sección Femenina i del Frente de Juventudes en les activitats 'culturals' de les Joventuts Hitlerianas (1940-1943)", en Ana CABANA, Daniel LANERO y Víctor Manuel SANTIDRIÁN (eds.): VII Encuentro de Investigadores del franquismo. Santiago de Compostela, 11,12 y 13 de noviembre de 2009, Santiago, Fundación 10 de Marzo, 2011, pp. 571-581.

39 Ismael SAZ: "Discursos y proyectos españoles sobre el nuevo orden europeo", en Francesc VILANOVA I VILA-ABADAL y Pere YSÀs I SOLADES (eds.): Europa, 1939. El año de las catástrofes, València, PUV, 2010, pp. 129-145, 129.

40 Ismael SAZ: España contra España. Los nacionalismos franquistas, Madrid, Marcial Pons, 2003, p. $2825 s$. 41 Christof VAN MOL: Europe on the Move... científico más allá de las respectivas parcelas académicas. Además, creemos que este congreso - en tanto que encuentro de jóvenes investigadores/as - supone un foro especialmente adecuado ante el que presentar este tipo de ejercicio interdisciplinar. Un esfuerzo como éste tiene el potencial de iluminar procesos de la construcción de naciones y respectivos idearios, más allá de los contenidos y discursos políticos. Queremos enfatizar de nuevo que de este trabajo no se puede extraer conclusiones simplificadas que tiendan a ver semejanzas y ni mucho menos equivalencias entre el contenido de los proyectos políticos que están detrás y son el origen de los respectivos intercambios. Lo realmente determinante es el contenido de concepto Europa y, como hemos demostrado en este trabajo, éste difiere radicalmente entre ambos proyectos políticos.

No obstante, partiendo de lo discutido a través de este ejercicio interdisciplinar, nos gus taría terminar la presente comunicación con algunas reflexiones de carácter conclusivo. En primer lugar, constatamos que el concepto de Europa aparece en ambos periodos históricos como un 'depósito': Europa es - hasta cierto punto - un ánfora vacía a la que dotar de un contenido determinado $\mathrm{u}$ otro. El resultado puede ser el movimiento paneuropeo de Coudenhove-Kalergi en los años veinte; una Europa del mercado libre, oportunidades, de derecho humanos y democracia como en la posguerra, pero también una Europa fascista con un marcado acento cultural, pero furibundamente antidemocrática, antisemita y antibolchevique.

En segundo lugar, observamos que el concepto de Europa no sólo ha sido promovido por la Unión Europea, sino que hay antecedentes históricos (algunos de signo radicalmente opuesto), además inmediatos a los propios orígenes de la propia UE. Aunque puede parecer lógico, este punto se tiende a olvidar con facilidad, si bien ello resulta comprensible a la vista de las desastrosas consecuencias que tuvieron las acciones de sus promotores.

En tercer lugar, queda claro que la juventud desempeña un rol destacado en los discursos políticos para promover dichas identidades europeas. Al mismo tiempo, hay un sistema de selección - de desigualdad - social: no todos los jóvenes tienen acceso a esa movilidad, pero tampoco la clase política hace siempre lo suficiente para que todos los grupos sociales puedan acceder a ella. Se trata, por tanto, de un concepto de juventud relativo y selectivo, delimitado.

$Y$, en cuarto y último lugar, observamos que, a pesar de que ambos conceptos/ proyectos de Europa aquí referidos presentan contenidos (muy) diferentes, lo cierto es que recurren a la misma metodología y parten del mismo principio estructural: el viaje, la movilidad y el intercambio de experiencias como método para acercarse y crear gracias a ello una identidad común. La idea subyacente en ambos casos es que el contacto directo entre diferentes personas o grupos de diferentes países conduce a una identificación relacional, lo que a su vez lleva a una identificación estructural: nos entendemos porque nos conocemos. En resumen, creemos poder demostrar en esta comunicación que en diferentes periodos históricos se ha atribuido a poder demostrar en esta comunicación que en diferentes periodos históricos se ha atribuido a
la movilidad de jóvenes un rol instrumental para promover una Europa unida. Sin embargo, el contenido del propio concepto de Europa difiere según la época y según los promotores, incluso en una misma época. Eso nos lleva a concluir que los intercambios juveniles desempeñan una función instrumental de promoción de un determinado ideario. No obstante, lo verdaderamente importante aquí es reflexionar sobre el contenido de ese ideario, preguntarse: ¿Qué ramente importante aquí es reflexionar sobre el contenido 
Parte 4.

TRANSFORMACIONES SOCIALES, POLÍTICAS

$Y$ CULTURALES EN EL MUNDO URBANO

CONTEMPORÁNEO 


\section{LAS TRANSFORMACIONES SOCIALES, POLITICAS \\ Y CULTURALES EN EL MUNDO URBANO \\ CONTEMPORÁNEO. NOTAS SOBRE LOS NUEVOS \\ CAMINOS DE LA HISTORIA URBANA EN ESPAÑA*}

Rubén Pallol Trigueros

Seminario Complutense Historia Cultura y Memoria

Universidad Complutense de Madrid

Desde hace tiempo, en España, se ha impuesto una imagen muy restrictiva de la ciudad como objeto de estudio de la historia contemporánea. En general, se asocia la historia urbana con una serie de estudios que caen del lado, o bien en la historia demográfica y económica, o bien en la historia del urbanismo, la arquitectura o la historia del arte. Por un lado, parece que la ciudad solo interesa para investigar el crecimiento de su número de habitantes y su concentración a lo largo del tiempo o para indagar cuáles son las pautas de reproducción particulares de los grandes agregados de población. Así existe una primera historia urbana, construida con cifras de población y tasas de natalidad y mortalidad, interesada, entre otros muchos asuntos, por el peso del crecimiento vegetativo y de la inmigración en la evolución y desarrollo de las ciudades, su impacto económico y su vínculo con el desarrollo industrial. Esta historia urbana de cifras de habitantes, tasas y gráficos de evolución de la población, encuentra su lugar propicio de expresión en las revistas de historia económica y demográfica pero ha quedado desterrada de las revistas más reputadas de historia contemporánea españolas, donde desde hace tiempo se vetó la entrada, o por lo menos se limitó, a toda aquella investigación que llegara lastrada de estadística y otros presuntos vicios de una historia serial y social considerada como periclitada y pasada de moda.

La otra especie superviviente, la que hibrida historia y urbanismo o arquitectura, es un tipo de investigación que se preocupa más por el diseño de los edificios y de las calles que los albergan que de quienes los ocupaban y les daban vida. Esta vertiente, más exitosa en los departamentos de historia contemporánea, suele ir ligada a una preocupación por la manera en que los diseños urbanos condicionan, si no determinan, la vida de los habitantes de las ciudades. Seducidos por la fuerza de los panópticos, la investigación suele girar en estos estudios en torno a la forma en que el diseño de la ciudad o de sus edificios logró imponer el modo de vida burgués o capitalista (la terminología varía según escuelas y adscripciones teóricas), convirtiendo a los habitantes y vecinos en meras hormigas, incapaces de romper con las lógicas y los caminos que les impone un terrario que construyó una mente superior. Así se estudian los planos de Ensanche como proyectos de disciplinamiento de los ciudadanos o la tipología de la vivienda obrera como medio de internalización de la moral burguesa, cuando no simplemente un monumento o un edificio como símbolo del triunfo político franquista e instrumento de violencia simbólica sobre el viandante. Estas aproximaciones, que han tenido la virtud de acercarse al terreno de lo mental y de lo simbólico, escapando de una historia excesivamente material, pecan a menudo

Este texto forma parte de las actividades del Grupo de investigación UCM Historia de Madrid en la edad contemporánea, $n^{\circ}$ ref.: 941149 , dirigido por Luis Enrique Otero Carvajal y ha sido posible por la concesión de dos proyectos de investigación del PLAN NACIONAL DE I+ D + I: MINISTERIO DAD, HAR2011-26904, Investigador principal: Luis Enrique Otero Carvajal. de los mismos vicios que se denunciaron en la historia social más dura y cuantitativa, olvidar a los individuos, carecer de un rostro humano que se preocupe por las experiencias vividas. A centrarse en planos de casas y calles, al describir edificios y desvelar lógicas detrás de las faen sentido estricto son historias de la idea de la ciudad o de las ideas arquitectónicas de la vivienda o de las calles. Y aquí suele llegar además su más grave defecto, pues estas historias que se centran en el estudio de planos y diseños, muchas veces olvidan (por no decir renuncian a) estudiar la manera en que se llevaron a la práctica. Así, los relatos se quedan en la mera ciudad imaginada y no en la ciudad real y vivida, en la ciudad deseada que, por otra parte, solo lo fue por una fracción de la población, la de los técnicos y profesionales de la arquitectura y el urbanismo. En fin, una historia de las ideas, más que una historia cultural de las ciudades.

Todavía se puede distinguir una tercera especie de historia urbana que tampoco lo es de todo plenamente. La historia de las ciudades, que es una historia que ha proliferado en los últimos cuarenta años al calor del desarrollo de las historias regionales, nacionales y locales tras el fin de la dictadura franquista. Algunos de estos relatos salieron de los medios académicos y universitarios, otros fueron firmados por eruditos y periodistas y muchos vieron la luz cuando se produjo el fin del relato histórico centralista dio lugar a una explosión de relatos particulares, centrados en localidades de mayor o menor tamaño, desde las capitales de provincia a ciudades de tamaño medio o pueblos. La descentralización política y el desarrollo autonómico también fomentó este tipo de estudios que pretendieron rescatar unas historias olvidadas y descuidas por el excesivo énfasis puesto hasta entonces en la nación y el estado como sujeto protagonista. Sin embargo, estas historias de ciudades no son en realidad historia urbana en sentido propio, en tanto que no suelen introducir un acercamiento ni teórico ni metodológico diferente a las investigaciones que se realizaban hasta el momento. Son meras historias locales y cuyo rasgo fundamental ha sido el de reducir el objeto de estudio, circunscribiéndolo a un municipio de mayor o menor tamaño pero manteniendo las mismas formas de hacer que las historias tradicionales que seleccionaban el marco nacional o estatal: son historias políticas, menos frecuentemente económicas y sociales, que no suelen reflexionar sobre cómo el contexto urbano influye de manera específica en la transformación social.

Ouizá el síntoma más evidente de esta cierta anemia de la Historia urbana en España es la ausencia de una publicación específica sobre el tema (la revista Historia Urbana solo permaneció activa entre 1992 y 1997) mientras que sí existen en Francia (Histoire Urbaine), In glaterra (Urban History), Estados Unidos (Journal of Urban History) o Canadá (Urban History Review). También es significativo que no exista una asociación de historiadores dedicados al tema como las de otros países (The Urban History Group, La Société Française d'Histoire Urbaine o The European Association of Urban History) o que no se realicen congresos ni reuniones científicas sobre el tema de una manera asidua. En fin, la historia urbana contemporánea no tiene un espacio específico en los estudios de grado y solo de una manera muy tímida y reciente en los de máster y posgrado. Y si se analizaran pormenorizadamente los programas de asignaturas troncales y obligatorias, los índices de manuales y obras de sintesis seguramente se constataría que lo urbano solo aparece como un apéndice anecdótico, si aparece, dentro de relato general de la evolución de la historia contemporánea que se enseñan en las aulas y que conforma el canon de la profesión de investigador en la actualidad.

Este retrato desolador no tiene nada de excepcional en un cuadro más amplio de una historiografía contemporánea que en España, de una manera particularmente acusada, ha huido de la historia social (y sobre todo de la económica) en las últimas décadas. Y eso a pesar de que lo urbano debería ser un eje de análisis fundamental para comprender la contemporaneidad. Se podría profundizar la ya muy manida sentencia de que "toda historia es historia social" con la afirmación de que "toda historia contemporánea es historia urbana". El francés Henr Lefebvre así lo entendía cuando en su libro La revolución urbana proponía conceptualizar los 
tiempos postindustriales como los del advenimiento de la sociedad urbana, en detrimento de otras imágenes más o menos oportunistas y pasajeras que se proponían en la década de los 70 y que iban desde la sociedad como espectáculo o la sociedad del ocio a la no escasamente descriptiva denominación de postmodernidad.' Al margen de lo que en Lefebvre tuviera esta propuesta de intento de remendar el marxismo con la acuñación de un nuevo modo de producción para añadirlo a la secuencia de la historia como lucha de clases, lo cierto es que ese énfasis en lo urbano como definitorio de la sociedad moderna ha sido común a los principales pensadores sociales que vieron nacer la contemporaneidad. Desde Marx y quizá sobre todo Engels, seguidos por Durkheim y Weber, por señalar los principales, la naciente sociología vio en la ciudad el semillero de los cambios que alumbraban el mundo moderno. $Y$ también los grandes males, pues la ciudad era el escenario donde sufría las nuevas formas de explotación la clase obrera, tal y como lo mostraba Engels en su retrato de Manchester; donde se instalaba la anomia generadora de comportamientos patológicos que inquietaba a Durkheim y surgían las estructuras que encorsetaban la acción del individuo que Weber pretendía liberar.

De entre los padres de la Sociología fue Georg Simmel el que más atención prestó al asunto en su célebre conferencia de 1903 "Las grandes ciudades y la vida del espíritu" donde supo detectar hasta qué punto las nuevas condiciones de vida creadas por las metrópolis en expansión estaban transformando radicalmente la manera de relacionarse socialmente. ${ }^{2}$ Las personas ya no serían las mismas una vez que hubieran entrado en contacto con la vida en las grandes ciudades y, sobre todo, no serían los mismos los vínculos que establecieran entre unas y otras. No se trataba de que los seres humanos actuaran ahora en un escenario de diferente estructura o sobre un paisaje de fondo de un color de tono ligeramente diferente, sino que dicho escenario y paisaje se habían incorporado a la naturaleza del ser humano para convertirlo en un ser completamente nuevo: el urbanita o citadino. Simmel aludía a la multiplicación de relaciones sociales, a la fragmentación de estas en diferentes naturalezas (familiares, políticas, económicas, cada una con una forma y un espacio concretos), a la instauración del cálculo frente a las relaciones afectivas, a la despersonalización y al utilitarismo propio de la vida urbana frente a la vida rural y, sobre todo, a la reserva, al distanciamiento que exigía el advenimiento de las masas. En lo que interesa aquí, Simmel supo subrayar que las nuevas ciudades estaban trastocando las relaciones sociales a todos los niveles suprimiendo lo personal por lo simbólico y estandarizado, rompiéndose los vínculos primarios para imponerse otros secundarios y abstractos, proceso que se resumía en la hegemonía de la filosofía del dinero como forma de relación entre los individuos. ${ }^{3}$ Estas ideas, fueron recogidas y desarrolladas la Escuela de Sociología de Chicago y particularmente por Louis Wirth quien en su texto de 1935 "El urbanismo como modo de vida" 4 además llevaba el proceso de transformación un paso más allá: la vida urbana ya no era un fenómeno circunscrito a las grandes ciudades sino que estas, convertidas en centros hegemónicos en la organización del territorio, se habían impuesto sobre el resto del hábitat humano irradiando su influencia y transformando las formas de vida. La dinámica de desarrollo económico había sometido a las áreas rurales, todas, al dominio y las lógicas de las ciudades y los medios de comunicación, en expansión y en intensificación del flujo de contenidos que emitían, habían difundido los rasgos y pautas de comportamiento de las ciudades más allá de sus límites físicos y administrativos. La cultura urbana, en el sentido antropológico, se difundía y sobrevivía más allá de las condiciones sociales en que se había producido. Para experimentar la vida urbana ya no era necesario residir en la ciudad, en un tiempo que comen-

Henri LEFEBVRE: La révolution urbaine, Paris, Gallimard, 1970.

2 Hay traducción reciente en Georg SIMMEL: Roma, Florencia, Venecia, Madrid, Casimiro, 2013, pp. 39-58.

3 Ideas que desarrollaría más en Georg SIMMEL: La filosofía del dinero, Madrid, Capitán Swing, 2013 (edición original de 1900).

4 Hay traducción, por ejemplo en Bifurcaciones, $n^{\circ} 2$ (2005). zaba a ser gobernado por los automóviles, las radios y televisiones, que conectaban de forma cada vez más inmediata a la sociedad contemporánea.

Tanto Simmel como Wirth supieron ver que la vida urbana era algo más que un mero estilo de vida, una especie de ropaje superficial que a modo estético recubría la vida moderna. Todas las dimensiones de las relaciones humanas quedaban afectadas por la vida urbana y determinados fenómenos de la ciudad, como la segregación social en el espacio y la aparición de los ghettos, trastocaban de forma definitiva tanto la vida familiar y privada como la política, la economía y la vida cultural. El espacio que se ocupaba en la ciudad se convertía en el espacio que se ocupaba en la sociedad y para analizar las interacciones entre los individuos era necesario partir de una reconstrucción de las estructuras o morfologías urbanas. En esta brecha abierta de reflexión se situaron muchos pensadores sociales posteriores, llegados de diferentes disciplinas para pensar en los modos en que la ciudad moderna había cambiado y seguían cambiando la vida humana: el ya citado Henri Lefebvre, Richard Sennet, Manuel Castells, David Harvey, Edward W. Soja o Mike Davis son solo algunos de los más célebres autores que todavía aún hoy siguen siendo referentes en distintas disciplinas que se interesan por lo urbano. 5 La historia contemporánea, ya se ha dicho antes, no fue ajena a esta influencia y también ha contado con un desarrollo de los estudios urbanos de gran importancia, convertidos en disciplina y en forma de historia social de vigoroso desarrollo en los comienzos del siglo XXI y que se ha plasmado, por ejemplo, en las obras de síntesis sobre la historia urbana de diferentes países o sobre el conjunto de Europa. ${ }^{6}$ Otra cosa es que en España, a veces ensimismada en una historia particular y local, cerrada a problemas propios, se rehúyan las reflexiones en torno a problemáticas más amplias, que puedan inscribirse en procesos generales de carácter europeo o transnacional. La obsesión con determinados temas, como la de la nacionalización o no de las masas en el contexto del estado o de las naciones y nacionalidades tiene algo que ver con esto. La alergia que se ha propagado entre profesores y estudiantes hacia la historia social y hacia todo lo que tenga asomo de materialismo, incluidos hasta los que se proclaman de izquierdas, quizá tenga incluso más responsabilidad. El caso es que, al menos desde un punto de vista institucional, no se puede hablar de que en España exista la historia urbana como una veta de desarrollo como si existen estudios en otros filones más o menos ricos de investigación como la historia de género, las relaciones internacionales, la memoria y sus vínculos con el pasado o la historia política de más o menos innovación metodológica. En estas corrientes historiográficas, de actualidad en medios académicos de otros países, a veces sí parecemos al día; en historia urbana, no es el caso.

De todas maneras este diagnóstico negativo debe ser sobre todo emitido en lo que se refiere a la práctica historiográfica hegemónica. La historia urbana está ausente de los manuales célebres, de los monográficos aceptados en las revistas canónicas, de los programas de másteres, de las páginas de los periódicos donde se obtiene la popularidad que emparienta al historiador con el escritor de best-sellers o de los premios nacionales que encumbran en la nobleza intelectual. Todo esto es cierto, pero no quita que desde hace décadas se hayan publicado

5 Citando solo una por autor, cabría señalar como obras de referencia, Henri Lefebvre: La producción del espacio, Madrid, Capitan Swing, 2013 (ed. or. 1974); Richard SENNET: Carne y piedra. El cuerpo y la ciudad en la civilización occidental, Madrid, Alianza editorial, 1997 (ed. or. 1994); Manue
CASTELLS: La ciudad informacional. Tecnologías de la Información, reestructuración económica y el proceso urbano-regional, Madrid, Alianza Editorial, 1995; David HARVEY: Ciudades rebeldes. Del el proceso urbano-regional, Madrid, Alianza Editorial, 1995; David HARVEY: Ciudades rebeldes. Del
derecho a la ciudad a la revolución urbana. Madrid, Akal, 2013 (ed. or. 2012). Edward W. SOJA: Postderecho a la ciudad a la revolucion urbana. Madrid, Akal, 2013 (ed. or. 2012). Edward W. SOJA: Post-
metropolis. Estudios criticos sobre las ciudades y as regiones, Madrid, Traficante de Sueños, 2012 (ed. or. 2003). Mike DAVIS: Planeta de ciudades miseria, Madrid, Akal, 2014 (ed. or. 2006).

6 Peter CLARK (ed.): The Cambridge Urban History of Britain, Cambridge, Cambridge University Press, 2000, 3. vols. Georges DUBY (dir.): Histoire de la France urbaine, Paris, Seuil, 1980-1985, 5 vols. Jean-Luc PINOL : Historia de la Europa urbana, Valencia, PUV, 2010 (ed. or. 2003). 
algunas obras excepcionales de historia urbana en España, ya firmadas por francotiradores que supieron recibir las influencias y propuestas extranjeras que se señalaban más arriba, ya como producto de algunos grupos de investigación cada vez más activos y que han sabido entender que lo urbano juega un papel central en toda actividad humana en la Era Contemporánea. Así, por ejemplo, fueron pioneros los trabajos de Ángel Bahamonde sobre Madrid, que adaptaron la historia social del siglo XIX en el marco del desarrollo de la capital española, vinculando la formación de las elites burguesas con los procesos de transformación urbana, uniendo construcción de los nuevos barrios y remodelación del casco antiguo a las estrategias de inversión de las clases sociales emergentes; también abrió novedosos campos de estudio al abordar el análisis de los mercados laborales en el mundo urbano o el desarrollo de los sistemas de telecomunicaciones y su repercusión en el desarrollo de la trama urbana. ${ }^{7}$ Además Ángel Bahamonde impulsó con otros investigadores, discípulos suyos, que ramificaron la Historia de Madrid en diferentes ámbitos temáticos. Luis Enrique Otero Carvajal ha impulsado recientemente su estudio concentrándose en la transformaciones sociales de la capital y de las ciudades cercanas, conformando un prolífico equipo de investigación ${ }^{8}$ Francisco Sánchez Pérez renovó la interpretación de la política en la ciudad extendiendo y revisando los estudios que habían abierto en su día Antonio Elorza o Santos Juliá; ${ }^{9}$ finalmente Ángel Bahamonde ha estimulado las tesis e investigaciones sobre el ocio en la ciudad y particularmente de la expansión del deporte como espectáculo de masas. ${ }^{10}$ Otro núcleo geográfico donde proliferaron las investigaciones sistemáticas fue Bilbao, paradigma de la ciudad industrial contemporánea y que ha sido objeto de numerosos estudios bajo el liderazgo de Manuel González Portilla, quien ha creado un nutrido grupo de investigación que, en la línea de la historia económica y demográfica, se han ocupado de los diversos procesos que ayudan a explicar la conformación de la metrópolis vizcaína entre el siglo XIX y comienzos del XX: las corrientes migratorias, el desarrollo industrial, la modernización de las infraestructuras o el mercado de suelo urbano

7 Ángel BAHAMONDE: El horizonte económico de la burguesía isabelina. Madrid, 1856-1866, Madrid, drid en el siglo XIX, Madrid, Siglo XXI, 1978. Ángel BAHAMONDE: "El mercado de mano de obra madrileño (1850-1874)" en Estudios de Historia Social, nº ${ }^{15}$, (1980), pp. 143-175.Ángel BAHAMONDE, Luis Enrique OTERO CARVAJAL y Gáspar MARTÍNEZ: Las comunicaciones en la construcción del estado contemporáneo en España: 1700-1936: el correo, el telégrafo y el teléfono, Madrid, Ministerios de Obras Públicas, Transporte y Medio Ambiente, 1993.

8 Luis Enrique OTERO CARVAJAL: “Las ciudades en la España de la Restauración, 1868-1939" España entre repúblicas 1868-1939. Actas de las VII Jornadas de Castilla-La Mancha sobre Investigación en Archivos, Guadalajara, ANABAD, Vol. 1, 2007, pp. 27-80. Luis Enrique OTERO CARVAJAL:, Pablo Carmona Pascual y Gutmaro Gómez Bravo: La ciudad oculta. Alcalá de Henares 1753-1868. El nacimiento de la ciudad burguesa, Alcalá de Henares, Fundación Colegio del Rey, 2003. Borja CARBALLO, Rubén PALLOL y Fernando VICENTE: El Ensanche de Madrid. Historia de una capital, Madrid, Editorial Complutense, 2008. Nuria RODRIGUEZ MARTíN: La capital de un sueño. Madrid, 1900-1936: la formación de una metrópoli europea, tesis doctoral, Universidad Complutense de Madrid, 2013 Director: Luis Enrique Otero Carvajal. 9 Francisco SÁNCHEZ PÉREZ: La protesta de un pueblo. Acción colectiva y organización obrera. Madrid clases, Madrid, Siglo XXI, 1984. Antonio ELORZA: "Socialismo y agitación popular en Madrid (19081920)", Estudios de Historia Social, no $\mathrm{n}^{\circ}$ 18-19 (1981), pp. 229-261.

10 Ángel Bahamonde: El Real Madrid en la historia de España, Madrid, Taurus, 2002. Juan Antonio SIMON SANUURIO:“La mercantilización del fútbol españo en los años vaus, 2002 Juan Antonio SIprofesinalismo al nacimiento del campeonato nacional de liga" Esporte e sociedade, no 18 (2011); en esta misma línea véanse los trabajos en la época contempónse los trabas Madrid, UGT-Centro de Estudios Históricos, 1996. dentro de un amplio abanico temático." Esta corriente de historia urbana, claramente enraizada en la historia social cuantitativa, tiene además otros representantes que a partir de fuentes estadísticas y censales han analizado el desarrollo demográfico y la transformación social de ciudades en Andalucía, Aragón o Galicia. ${ }^{12}$ También ha habido una aproximación cultural a la ciudad, que ha querido mostrar como el escenario urbano creado era producto tanto de nuevas y viejas sensibilidades como el marco de interpretación que hacía posible el surgimiento de nuevos comportamientos y actitudes sociales y políticas. En esta línea fue novedosa y origina La Ciudad extensa, firmada por Anaclet Pons y Justo Serna, que mostró que la burguesía urbana tejía nuevas redes sociales al tiempo que expandía la ciudad; ${ }^{13}$ también ha destacado la obra de Javier Ugarte Tellería que mostró una Pamplona que se convertía en el contexto urbano excepcional en el que pudo surgir un movimiento político de nuevo cuño, el carlismo de principios de siglo XX, que se aprovechaba de las modernas condiciones creadas por la vida urbana precisamente para denunciar los males que se percibían en el cosmopolitismo y abogar por la vuelta a una tradición inventada. ${ }^{14}$ Sin embargo, estos brillantes estudios no han creado escuela y han quedado como sugerentes propuestas de una historia cultural de la ciudad que permanece subdesarrollada en España. También cabría destacar como otro certero francotirador al urbanista José Luis Oyón, que ha firmado las mejores estudios de historia sobre política en la ciudad - centrados en la clase obrera y el anarquismo barceloneses-, además de ser responsable de algunos de los textos teóricos más sugerentes para enfocar este objeto de investigación. ${ }^{15}$

La lista es incompleta y seguramente injusta y deja fuera estudios y estudiosos dignos de mención pero parece suficiente para mostrar las principales tendencias que recorren la historia urbana y evaluar sus principales logros y defectos en la historiografía española: es una disciplina con importantes logros particulares y algunos grupos y líneas de investigación ya consolidados, pero a la que le falta la solidez de otras historiografías extranjeras y desde luego

1 Manuel GONZÁLEZ PORTILLA (dir): Los origenes de una metrópoli industrial: la ría de Bilbao, Bilbao, Fundación BBVA, 2001, 2 vols. Rocío GARCíA ABAD: Historias de emigración. Factores de expulsión y selección de capital humano en la emigración a la Ría de Bilbao (1877-1935), Bilbao, Universidad del País Vasco, 2005. José María Beascoechea: Propiedad, burguesía y territorio. La conformación urbana de Getxo en la Ría de Bilbao (1850-1900), Bilbao, Universidad del País Vasco, 2007. Arantza PAREJA: “Las mujeres y sus negocios en la gran ciudad contemporánea. Bilbao a principios del siglo XX", Historia contemporánea, № 44, 2012, pp. 145-182. Manuel GONZÁLEZ PORTILLA, Karmele Zarraga Sangroniz, José Urrutikoetxea Lizarraga: Vivir en familia, organizar la sociedad: familia y modelos familiares: las provincias vascas a las puertas de la modernización (1860), Bilbao, Universidad del País Vasco, 2003. Pedro A. Novo López: "El agua potable a domicilio y los residuos urbanos bailan un complejo "pas a deux" (1850-1930): una aproximación metodológica e historiográfica", Historia contemporánea, $n^{\circ} 24$ (2002), pp. 281-322.

12 David Martínez y Gracia Moya: “La inmigración y el cambio social (Granada, 1890-1930)",en Arantza PAREJA: El capital humano en el mundo urbano: experiencias desde los padrones municipales (1850-1930), Bilbao Universidad del Páis Vasco, 2011, pp. 283-300. Luisa Muñoz Abeledo: “The Labour Market in the Spanish Fish-canning Industry, 1880-1977: Labour Contracts and Work Organization", International journal of maritime history, vol. 17, $n^{\circ} .2$ (2005), págs. 211-230. Javier SILVESTRE RODRÍGUEZ: "Inmigraciones interiores e industrialización: el caso de la ciudad de Zaragoza durante el primer tercio del siglo XX", Revista de Demografia Histórica, vol. 21 nº $^{\circ}$ (2003), pp. 59-92.

13 Justo SERNA y Anaclet PONS, Anaclet: La ciudad extensa. La burguesía comercial-financiera en al Valencia de mediados del XIX, Valencia, Diputación de Valencia, 1992.

14 Javier UGARTE TELLERÍA: La nueva Covadonga insurgente: origenes sociales y culturales de la sublevación de 1936 en Navarra y el Pais Vasco, Madrid, Biblioteca Nueva, 1998.

15 José Luis OYÓN: La quiebra de la ciudad popular. Espacio urbano, inmigración y anarquismo en la José Luis OYON: La quiebra de la ciudad popular. Espacio urbano, inmigración y anarquismo en la Barcelona de entreguerras, 1914-1936, Barcelona, Ediciones del Serbal, 2008. José Luis OYÓN y Mar-
ta Serra Permanyer: “Historia urbana: el espacio no es inocente", Historia contemporánea, no ta Serra Permanyer: "Historia urbana: el espacio no es inocente", Historia contemporánea, $n^{\circ} 39$ Barcelona. Clase, cultura y conflicto, 1898-1937, Madrid, Alianza, 2005. 
la presencia en los debates generales y en los programas académicos de la que goza en otras latitudes. Además, como balance general sirve para evaluar y entender los caminos que se abren en el futuro a quienes se lancen al estudio de la ciudad en la historia contemporánea o a quien, en un programa más maximalista que siga las propuestas de Louis Wirth o Henri Lefebvre, pretenda hacer de la "revolución urbana" o del "urbanismo como forma de vida cada vez más hegemónica" los procesos que convierten en inteligible la evolución social en la época contemporánea. En el horizonte marcado por estos polos, el estudio de la ciudad contemporánea y la historia urbana, se comprenden las nueve comunicaciones presentadas a la mesa que sobre el tema se celebró en el IV Encuentro de Jóvenes Investigadores en Historia Contemporánea, en septiembre de 2013, bajo el título "Transformaciones sociales, políticas y culturales en el mundo urbano contemporáneo".

Entre las comunicaciones presentadas había propuestas que bebían claramente de la historia social de la ciudad y las técnicas importadas de la historia demográfica y económica, para estudiar procesos demográficos o análisis de la movilidad dentro del espacio urbano, pero con aires renovadores. Así, Santiago de Miguel Salanova se acercó al estudio de la movilidad residencial en Madrid, mostrando como las mudanzas y los trasiegos de los hogares de los vecinos de la capital ayudan a entender las dinámicas de cambio social, aplicando una técnica que ya había sido ensayada en otras capitales europeas. Un viejo tema de historia social, el ascenso y cambio de estatus, es abordado con nuevas técnicas y representado con la elocuencia que ofrecen los planos temáticos. Por su parte, Alejandro Martín Sanz, al acercarse al asociacionismo de los inmigrantes tiende puentes entre viejas formas de historiar (el estudio de los flujos de población, campo-ciudad como tema de la historia cuantitativa y serial) y los nuevos temas que se reclaman de una aproximación más simbólica y cultural, como son las identidades nacionales, regionales y locales. Con ello muestra la vigencia de una determinada tradición de historia social, que sigue creyendo que para entender plenamente comportamientos y representaciones en la sociedad se debe partir y hacer referencia a la base material, en este caso demográfica, sobre la que se construyen. Finalmente, en esta línea también se sitúa el trabajo de Roberto Gallardo sobre el desarrollo de Móstoles en la Transición democrática y que se reclama a la vez de la microhistoria y la historia social, tratando de aprovechar la pequeña escala como marco y estrategia metodológica para explicar los grandes procesos que alteran y modifican nuestra vida cotidiana. Estos tres trabajos nacen en parte de esas corrientes de investigación consolidadas en grupos dentro del panorama de la historia urbana española si bien se han desarrollado con el valor añadido de la innovación, de la superación de los modelos en cuya contemplación se han construido.

Una segunda corriente de trabajos parecía replicar a los francotiradores que abren fuego sobre nuevos campos temáticos, cuyo abordaje puede renovar la comprensión de lo que supone la experiencia urbana. El ocio y consumo, como dos vectores de definición de la nueva sociedad alumbrada en la gran ciudad parecen presidir otras tres comunicaciones, aunque con metodologías e implicaciones teóricas relativamente diferentes. José $M^{a}$ Rodríguez-Vigi, al retratar el desarrollo de los grandes almacenes en Oviedo no solo pulsaba un tema fundamental para caracterizar las ciudades modernas como es la modernización económica a través de la distribución comercial; el autor también retrataba las tensiones entre lo local y lo global, entre el comercio tradicional y las fuerzas del capitalismo de gran escala, cuyo rastro quedaba inscrito en las formas de comprar y vender en el siglo XX. Como muestra en su texto, una metodología híbrida, que beba tanto de la historia del arte como del análisis publicitario, de la prosopografía como de la historia económica, es la única capaz de aprehender una temática en la que se entremezclan diversos procesos de cambio social. En una problemática similar entre la reivindicación de la identidad local y la adopción de pautas estandarizadas de ocio y sociabilidad se sitúa el estudio de Lucía Montejo Arnaiz sobre el entretenimiento de las clases populares urbanas y el fútbol y en el que se rastrea la vida asociativa de los primeros clubes de este deporte en la ciudad de Oviedo. Berta Etxeberría, por su parte, vuelve sobre la vocación turística de San Sebastián como motor de su desarrollo urbano (un fenómeno que se dio en toda Europa), aunque con intenciones nuevas: descubrir y retratar fenómenos que la imagen publicitaria trató de esconder como la prostitución o el consumo de drogas pero que también eran parte del reclamo con que las nuevas formas de ocio seducían al visitante.

Un tercer eje de estudios se preocupó por la ciudad como marco de expresión de protesta y control político, como bandera de movilización desde abajo frente a la obsesión de disciplinamiento de las autoridades. Alejandro Pérez-Olivares muestra las posibilidades de estudiar la represión política de la inmediata posguerra en la gran ciudad. Así retrata los afanes para crear nuevas lealtades sobre las que ejercer el control político en una ciudad que por los sublevados del 18 de Julio, Madrid, se observaba como una Babilonia moderna. Las nuevas instituciones, gobierno municipal y diputación provincial, debían irradiar el espíritu de familia nacional que se quería imprimir a la ciudad. Por su parte, Daniel Oviedo rastrea estas estrategias de control en las prácticas urbanísticas y arquitectónicas, localizadas en un barrio obrero de Madrid, donde se trató de diseñar un nuevo hábitat que neutralizara los problemas que se percibían en el espacio público y se recluyera a la familia trabajadora en el ámbito de la ciudad: ruralización, prohibición de la interacción en las calles, vigilancia a través de la lglesia, fueron los nuevos valores inscritos en los planos de arquitectos y planificadores. Finalmente, Luis Manue Sanmartín Cava se atrevió a un ejercicio de audaz Historia del presente para indagar en los discursos en torno a la protesta contra los desahucios en el inmediato pasado. Aportando un marco conceptual nacido de la antropología, reflexionó sobre las tensiones generadas en la vivienda - tema de constante referencia movilizadora en la Historia Contemporánea desde comienzos de la industrialización- y la calificación en el discurso social de las nuevas formas de acción ciudadana como son los escarches.

Los nueve trabajos presentados son no solo promesa de futuras investigaciones más amplias sino también propuestas maduradas de renovación en el campo de la historia urbana. Un ejercicio necesario aún en nuestro país, y en las que quizá tan solo se pueda achacar - no en particular a los autores, sino en general al grupo de investigadores que nos hemos dedicado al tema - la falta de una marco de referencia problemático común. Se echa de menos un ámbito de estudio colectivo, más espacios de reflexión conjunta en el que generar un debate que enriquezca los estudios particulares. Y quizá, para ser fieles a las propuestas de los teóricos de los estudios urbanos, se echa de menos que las investigaciones dejen de ser análisis de casos particulares, historias de ciudades, para evaluar los fenómenos en las tramas y redes urbanas, comparando casos de núcleos de población y no solo en el limitado espacio localista de un municipio. Pero estos problemas no parecen ser responsabilidad de quienes aún están empezando y se expresan en un encuentro de jóvenes investigadores proponiendo nuevas vías que rompen con la negligencia y abandono que la historia urbana ha sufrido en revistas consagradas, congresos nacionales y programas de estudios en los últimos tiempos. 


\section{LA HISTORIA DE MÓSTOLES (1975-2000): \\ 25 AÑOS DE TRANSICIÓN Y DEMOCRACIA}

Roberto Gallardo Pérez

Departamento de Historia Contemporánea

Universidad Complutense de Madrid

\section{Introducción}

El presente trabajo de investigación tiene como finalidad analizar de manera muy sintética los cambios sociales, políticos y culturales que se desarrollaron durante la Transición en Móstoles y los veinticinco años de democracia. Móstoles tradicionalmente ha sido una encrucijada de caminos, por su privilegiado emplazamiento. Actualmente, se halla ubicado en la zona sur del Área Metropolitana de Madrid, situándose en la segunda ciudad más poblada de la Comunidad Autónoma de Madrid, después de la ciudad de Madrid, y entre los 28 municipios más poblados de España con 206.031 habitantes.'

El objeto de nuestro estudio es la ciudad, si como tal entendemos algo que se ha producido socialmente. ${ }^{2}$ Vamos a exponer de manera muy sumaria los elementos más relevantes que contribuyeron a la metamorfosis que ha tenido este municipio en la historia democrática. El objeto de esta investigación descansa en el modelo de sociedad, y las transformaciones, que se han configurado tras la dictadura franquista, durante la transición y la democracia de finales del s.XX en Móstoles. "La economía de la ciudad, la cultura de la ciudad, la sociedad de la ciudad o la construcción de la ciudad dentro de un determinado contexto económico, social, político o cultural". ${ }^{3}$

Por consiguiente, pretendemos, siendo conscientes del presentismo del que es objeto esta investigación, analizar la relación entre los ámbitos macro y micro, con el objetivo de proporcionar una imagen global del desarrollo de los cambios producidos en el marco urbano. Como afirma María Eugenia Salinas Zárate:

La interrelación, por lo tanto, entre lo espacial (transformaciones del espacio urbano) y lo social (procesos demográficos, económicos, culturales, etc.), centra cada vez más la atención del debate urbanístico, sin olvidar, el concurso del factor urbano y los elementos que en él confluyen, en el desarrollo de la región, puesto que la emergencia de un sistema urbano es un paso crucial en el progreso regional, en cuanto que proceso a través del cual los recursos sociales y culturales, económicos y políticos, se multiplican, se despliegan más efectivamente. ${ }^{4}$

Datos aportados del INE de 2012

2 Alfonso ÁLVAREZ MORA: “La necesaria componente espacial en la Historia Urbana”, Ayer, 23 (1996), pp. 29-59.

3 Ángel BAHAMONDE MAGRO: “La historia urbana”, Ayer, 10 (1993), pp. 47-61.

4 Maria Eugenia SALINAS ZÁRATE: "Aproximación a la historia urbana de Logroño a través de la prensa periódica local: 1886-1936", en Instituto de Estudios Riojanos: Investigación humanistica y cientifica en La Rioja: homenajea Julio Luis Fernández Sevillas Riojayos: Investigad Aróspide, Logroño, 2000.
Este trabajo pretende poner de relieve las oportunidades que nos concede la ciudad como objeto de análisis. "La ciudad, hoy más que nunca, constituye un campo privilegiado de los estudios interdisciplinarios, ya que ella sola resume el conjunto de la sociedad y sus relaciones con el territorio". ${ }^{5}$

\section{Metodología y marco teórico}

Esta investigación se cimenta sobre la aplicación de diferentes metodologías y técnicas, que comparten lugares comunes, como son la nueva historia social, la microhistoria, la antropología cultural, la demografía histórica y la historia de la vida privada que han contribuido de manera notable a la historia urbana. Almandoz ${ }^{6}$ nos ofrece una propuesta basada en una historia cultural urbana que descansa en la integración de la microhistoria y la gran narrativa. Para aproximarnos a esta investigación estudiaremos la prensa local y la prensa de tirada nacional.

Hemos construido un trabajo de investigación sistemático y empírico, centrado en la información que nos proporciona la prensa. "Desde nuestro punto de vista, lo que la historia local -esa historia local digna que aquí postulamos- es hacer uso de una red densa, muy densa, hasta el punto de capturar todo aquello que la porosidad de la malla no deje escapar en ese fragmento de mar".

Finalmente, la Constitución Española y la articulación del Estado de las Autonomías impulsó el Estatuto de Autonomía de la Comunidad de Madrid, que se consiguió por la vía ordinaria mediante Ley Orgánica 3/1983 de 25 de febrero de 1983, y, por consiguiente, la consolidación del Estado de las Autonomías, que consagra el título VIII de la Constitución Española de 1978 Por último, no podemos olvidarnos de la Ley Electoral 39/1978 de 17 de julio que da luz verde a los comicios. Este marco general contribuye a entender el estudio micro. "Las historias generales deberían servir para encuadrar y facilitar la visión de conjunto a los historiadores locales. Las historias locales, para matizar y enriquecer las generales".

\section{Análisis crítico de las fuentes}

Las principales fuentes que hemos utilizado para esta investigación han sido los documentos conservados en el Archivo Municipal de Móstoles, los más significativos son los libros de actas municipales, los padrones y censos, los programas y publicaciones de los principales partidos y finalmente la información que nos facilita la prensa generalista y local.

Las actas de las sesiones plenarias de la Corporación municipal conservadas en el Archivo Municipal de Móstoles nos proporcionan una ingente cantidad de información relativa a la acción de gobierno local, desde actuaciones urbanísticas, como en materia política, social, o educativa, conformando las fuentes más ligadas al estudio del proceso de democratización. Estas actas nos permiten analizar los debates que tienen los principales actores de la vida pública, como son los ediles municipales, pero también movimientos, asociaciones, sindicatos, clubs u organizaciones empresariales.

Finalmente, debemos subrayar la trascendencia que ocupa la hermenéutica en el análisis de los editoriales, los artículos de opinión, las cartas al director, la sección de Sociedad y de Madrid de la prensa local y nacional, que desde 1975 al año 2000, hemos analizado sobre la Transición y la democracia en Móstoles.

5 Carles CARRERAS VERDAGUER y Joan VILAGROSA IBARZ: "Los estudios urbanos en Catalunya un campo interdisciplinar”, Cuadernos de Sección Historia-geografia, 1, (1983), pp. 203-230.

6 Simón CASTILLO FERNANDEZ: "Entre libros de historia urbana. Para una historiografía de la ciudad y el urbanismo en América Latina", Eure, 106 (2009), pp.171-176.

Justo SERNA y Anaclet PONS: "En su lugar. Una reflexión sobre la historia local y el microanálisis", Contribuciones desde Coatepec, 4 (2003), pp. 35-56.

8 Pere ANGUERA: "La historia local. Una sintesis catalana", Studia Zamorensia. Segunda Etapa, 5 (1999), pp.245-257. 
En primer lugar, las publicaciones municipales más sobresalientes son: Albatros: revista independiente de información local; Ecos Ciudadanos: publicación informativa mensual de Móstoles; Habla Móstoles: semanario local independiente; La Gaceta de Móstoles: boletín informativo; La Gaceta de Móstoles, La Gaceta de Móstoles: lo que ha pasado, pasa y pasará en Móstoles; Móstoles: Informaciones municipales; Primeras noticias. Revista de Literatura; Sepa de Móstoles: periódico semanal independiente de información general de Móstoles; 30 días Móstoles: periódico mensual de información municipal; Sur Madrid, Zona sur: guía del ocio y revista; Móstoles 15 días: información cultural y deportiva; Diario ciudad de Móstoles, y Página Sur: periódico independiente de la zona sur de Madrid.

En segundo lugar, los diarios nacionales que hemos trabajado más relevantes son el $A B C$ El País, Diario 16, La Vanguardia, y El Mundo. "Al objeto de establecer esta clasificación, consideramos como diarios nacionales a aquellos cuya estructura de secciones está orientada a destacar principalmente las noticias de ámbito nacional e internacional y cuya difusión diaria supera holgadamente los 100.000 ejemplares". ${ }^{9}$

Las publicaciones nos facilitan información, tanto municipal como estatal, permitiéndonos realizar un análisis comparativo, y por consiguiente observar la esfera local y la esfera nacional en este marco urbano. La prensa nos ofrece información muy interesante, en relación a la realidad del momento como es la fotografía. "La prensa, especialmente en caso de publicaciones periódicas no especializadas, fue el soporte más adecuado para la difusión de aquellas imágenes".

Podemos destacar de las mencionadas publicaciones las siguientes:

- Móstoles: Informaciones municipales, por la pertinencia de los temas que trata, así como la relevancia de las informaciones utilizadas. De esta manera, nos acerca a través de reportajes y entrevistas, a personajes de la vida política, social y cultural del municipio, como los concejales y alcalde del Consistorio.

Las personalidades más destacadas de esta publicación fueron, Joaquín Pertierra de Rojas Román, Concejal Delegado de Interior; Julio Alberto Rodríguez, Concejal Delegado de Servicios; José María Arteta Vico, Concejal Delegado de Urbanismo, Vías y Obras; José Baigorri, Concejal Delegado de Sanidad y Bienestar Social; Manuela García Orejudo, Concejal Delegada de Consumo y Abastos; José Luis Gallego Picó, Segundo Teniente de Alcalde y Concejal de Cultura, Juventud y Deportes; Andrés Martín Martínez, Concejal Delegado de Educación y Olegario Oubiña Domínguez, Primer Teniente de Alcalde y Concejal Delegado de Hacienda.

Así como actores políticos que superan el marco urbano que estamos analizando como por ejemplo, José María Rodríguez Colorado, Gobernador Civil de Madrid; Rafael González Ibáñez Director de Radio SER Móstoles; Agapito Ramos Cuenca, Consejero de Trabajo, Industria y Comercio de la Comunidad de Madrid; María Gómez Mendoza, Consejera de Salud y Bienestar Social del gobierno regional madrileño; Javier Moscoso, Ministro de la Presidencia y Joaquín Leguina, Presidente de la Comunidad de Madrid. También hay espacio para dar visibilidad a la vida cultural municipal, como son los gemelos Algora célebres por sus porcelanas.

- Habla Móstoles, es otro periódico de notable interés, tanto en sus editoriales, como en sus artículos, era recurrente el tratamiento sobre los movimientos ciudadanos. También nos muestra la normalidad de la confrontación política entre los diferentes partidos representados en el pleno municipal, así como, las diferencias surgidas en el seno dentro de los propios partidos políticos locales. Después de casi cuarenta años de cultura nacional-católica municipal, este periódico incorpora información de las principales compañías de danza, ballet, o teatro, que vienen de los países socialistas, que estaban en la órbita soviética, Ucra-

9 Luis IZQUIERDO LABELLA: Manual de periodismo local, Madrid, Fragua, 2010, pág.20. 10 Nieves BASURTO y María Jesús PACHO. “Ascenso social y espacio doméstico en Bilbao La arquitectura como escenografía del poder", Historia Contemporánea, 39, (2009), pp. 481-512. nia, Georgia...etc. Así como las diferentes expresiones artísticas que se desarrollaban en la ciudad como el Rock, Folk, o punk. Uno de los artículos más sobresalientes es el publicado por Osvaldo Hagel y Jesús González titulado "¿Qué cultura para Móstoles?"

Habla Móstoles en sus páginas interiores, nos informa de problemas sociales como el paro, el aborto, la droga, la sexualidad, el cáncer, los derechos de la infancia, el papel que ya empezaba a tener la informática al servicio del ciudadano, además del apoyo que se le ofreció a aquellas asociaciones o casas regionales, de las que podemos subrayar la extremeña y la andaluza.

manejar las informaciones por parte de la prensa local, y en el Habla Móstoles en particular, fue con ocasión de la entrevista que realizaron a Juan López López, un párroco protestante que representaba a una comunidad religiosa minoritaria, que se publicó en 1985, impensable que se pudiese publicar 10 años antes. "Un análisis que se centra en objetos reducidos, sobre todo en comunidades o grupos sociales, pero también en individuos, y que no pretende tomarlos solamente en cuanto tales, sino como parte de un tejido de relaciones que a su vez se insertan en contextos más amplios".12

Según la encuesta que se realizó sobre la población juvenil de Móstoles, los resultados desvelan que el $29,1 \%$ se considera no creyente o agnóstico, un $61,5 \%$ se consideraba católico aunque la mayoría de este porcentaje reconoce no ser practicante, y solamente un 1,7\% reconoce ser creyente de otra religión. ${ }^{13}$

Si bien Móstoles: Informaciones municipales y el Habla Móstoles nos enseña la realidad mostoleña durante la década de los ochenta para la vida municipal durante la década de los noventa nos arroja luz el periódico de Sur Móstoles, informando de las noticias más relevantes del ámbito local de la sociedad, la política, la cultura, la economía, y los deportes.

\section{La Transición política municipal}

Con el restablecimiento de la democracia, Móstoles, como el resto de municipios españoles, ha sufrido importantes cambios. Durante la dictadura, Móstoles tenía unas reducidas competencias y una ausencia de cualquier tipo de control democrático de la gestión municipal lo que provocó que el planeamiento urbano, hasta el P.G.O.U.M.14 de 1985, tuviera importantes lagunas. José María Arteta, que fue Concejal Delegado de Urbanismo, Vías y Obras en la segunda legislatura del PSOE de Móstoles, escribirá un interesante artículo publicado el 8 de mayo de 1984, con el siguiente título "Móstoles tiene solución".15

Cuando se convocaron las primeras elecciones democráticas en 1979 la planificación urbana, las infraestructuras y los equipamientos eran una de las grandes asignaturas pendientes de la incipiente España democrática. "Durante la dictadura se exacerbarían estas características unitarias, pues los Entes Locales carecían totalmente de autonomía, estarían totalmente subordinados al Estado, actuaban como agentes estatales exclusivamente".16

Móstoles es una población de aluvión que tuvo una singularidad que comparte en esos momentos con otros municipios del cinturón industrial madrileño: su fuerte crecimiento poblacional, y el impacto que este fenómeno tuvo sobre el ordenamiento urbanístico y los equipamientos de la ciudad, y por ende, las consecuencias políticas después de casi cuarenta años de

11 Osvaldo HAGUEL y Jesús González: "Oue cultura para Móstoles", Habla Móstoles, 11 de Junio de 1983. pág.16.

12 Opcit.pp.35-56.

13 La juventud de Móstoles, Concejalía de la Juventud, Móstoles, 1983.

14 Plan General de Ordenación Urbana de Móstoles, 17 de abril de 1985.

15 José María ARTETA VICO y Carlos De La GUARDIA PÉREZ-HERNÁNDEZ: “Móstoles tiene solución", El Pais, 8 de febrero de 1984, http://elpais.com/diario/1984/02/08/madrid/445091054 850215.htm

16 Vanessa SUETT COCK: Federalismo en teorías y práctica: el caso español como proceso Federal Estudio de la Autonomía Regional y Local en los Sistemas Federales, Lisboa, Jurúa 2010, pág.442. 
dictadura. "Por municipios, han sido cuatro de la provincia de Madrid los que mayor incremento han experimentado en el periodo de 1970 a 1975, en concreto, Móstoles (428,7 por 100 de incremento), Leganés (242,8 por 100), Alcorcón (224,3 por 1800) y Alcobendas (200 por 100)",77

Las tasas de desempleo en Móstoles estaban en el $20 \%,{ }^{18} \mathrm{e}$ incluso en algunos momentos llegó hasta el $30 \%$, consecuencia de la crisis inmobiliaria, que en el caso del municipio, suponía la tercera actividad más importante. La conflictividad en las calles, supuso que, "la vida en la calle era la simple extensión cotidiana de la vivienda hacia el espacio público".19

El primer gobierno democrático municipal heredó una mala gestión, siendo recurrente el profundo descontento expresado por los ediles de la Corporación, por los compromisos realizados por la anterior Corporación donde primaban los intereses particulares sobre los generales, el P.G.O.U.M. definitivo del 17 de abril de 1985 expone textualmente: "Si la "tolerancia administrativa" que la falta de control supone y a la proximidad y buena accesibilidad se le añade la existencia de gran cantidad de suelo en pocas manos y a precio comparativamente más barato, se tiene el conjunto de la oferta". ${ }^{\circ}$

Bartolomé González como presidente del boletín Móstoles. Informaciones municipales, publicó el siguiente editorial con el título Herencia recibida, ${ }^{21}$ hace una descripción de los problemas que tiene, el abastecimiento de agua, insuficiencia de centros escolares, sanidad y transporte, y la problemática política y administrativa para resolverlos, que coincide en lo esencial con la opinión de Edistio González, ${ }^{22}$ último alcalde del periodo franquista.

Históricamente, los pozos han dado suministro a toda la población, sin embargo, el notable crecimiento demográfico, provocó una situación insostenible, no consiguiendo agua corriente canalizada hasta el 28 de junio de $1980,{ }^{23}$ a pesar de llevar más de cinco años en conversaciones con el Gobernador Civil, el Ministerio de Obras Públicas, la Confederación Hidrográfica de Tajo y el Canal de Isabel II.

La asociación de vecinos más antigua se llamaba la Asociación de Vecinos Juan XXIII, fundada en 1970, obligando la ley del momento a adoptar el nombre de Asociación de Cabezas de Familia, cuya revista editaban Ecos Ciudadanos: publicación informativa mensual de Móstoles, con una tirada de cuatro mil ejemplares. Muchos de los integrantes de los movimientos urbanos tuvieron cargos de responsabilidad en la corporación: el más visible fue Carlos Madrid, que fue concejal de urbanismo durante el primer gobierno municipal; Salvador Torrecilla Montal, en primer lugar, Diputado de la Asamblea de Madrid, además de formar parte de diferentes comisiones informativas y la portavocía del Grupo Municipal de Izquierda Unida, y Primer Teniente de Alcalde o Luis Hinarejos, que ostentó la portavocía del Grupo Municipal de Izquierda Unida.

Los representantes políticos, mayoritariamente, tenían un perfil socio-profesional que era una radiografía de la sociedad mostoleña: Bartolomé González, ganador de las primeras elecciones municipales celebradas en 1979, era Técnico Administrativo y periodista. A diferencia del periodo franquista, donde la Corporación estaba formado por las personas más acomo-

17 Javier ANGULO URIBARRI: Municipio, Elecciones y vecinos: Por unos ayuntamientos democráticos, Madrid, Ediciones de la Torre, 1978. pág.147.

18 Francisco MOLINA MARTIN: “Uno de cada cinco. El desempleo afecta a más del veinte por ciento de la población activa", Móstoles, Móstoles. Informaciones municipales, 35, Mayo de 1982.

19 José Luis OYÓN y Marta SERRA PERMANYER: “Historia urbana: el espacio no es inocente”, Historia Contemporánea, 39, (2009), pp.387-401.

O.G.O.U.M. Consejería de Ordenación del Territorio, Medio Ambiente y Vivienda, 17 de Abril de 1985, Sig. 2087.1. Folio 3.

21 Bartolomé GONZÁLEZ LORENTE: "Herencia recibida”, op. cit., 2, Agosto de 1979.

22 Isabel MONTEJANO MONTERO: “El crecimiento, problema número uno", $A B C, 2$ de Mayo de 1978

23 Bartolomé GONZÁLEZ LORENTE: "Desde el día 28 agua a toda horas. A vosotras gracias", Móstoles,

op. cit., 12, Junio de 1980 . dadas del pueblo. El ejemplo más visible fue la familia Medem²4, que ostentaban aproximadamente 2.500 ha. en 1950, cuando el término municipal es de 4.600 ha., donde compartió momentos de cacería con Franco.

La mujer como sujeto histórico ha sufrido una auténtica transformación, tanto en lo concerniente al sufragio pasivo, como al sufragio activo, si bien habitualmente se producía un techo de cristal, que impedía a las mujeres ocupar un puesto en el gobierno municipal, esta realidad fue superada después de veinticinco años de democracia. Durante todo el período franquista, ninguna mujer ocupó un puesto en el Consistorio, a excepción del tardofranquismo donde una concejala, $M^{a}$ Santa Perea Ruíz, desempeñó el cargo de edil en la Corporación presidida por Edistio González.

En las primeras elecciones democráticas, consiguieron el acta de concejal dos mujeres: la primera mujer edil en el período democrático fue Amaya Ciutat Armengol del PCE y médico de profesión, y en las elecciones municipales del 13 de junio de 1999, 10 mujeres obtuvieron e acta de concejal, con áreas de responsabilidad que iban más allá de la histórica concejalía de bienestar social. La génesis marca una tendencia a la convergencia en los cargos de representación municipal, y por consiguiente, la paridad de sexo. "Sólo intentamos constatar un hecho que está presente en una sociedad democrática y cada vez más igualitaria". 25

Móstoles en 1987 conserva algunas diferencias respecto a las del resto del país, que podemos mostrar a continuación. En primer lugar, la población entre los 0-15 años supone el 35,3\% de toda la población total, mientras que, a nivel estatal, es sensiblemente inferior, con un $28 \%$. En segundo lugar, la población mostoleña que se encuentra entre los 15 y los 65 , suponen el $59,5 \%$, entretanto en España se encuentra en el $62 \%$. Finalmente, en Móstoles, solamente el $3,17 \%$ son mayores de edad, mientras que en el resto del país, llega al $10 \%{ }^{26}$

\begin{tabular}{|l|l|l|l|l|l|l|l|}
\hline AÑO & 1970 & 1975 & 1980 & 1985 & 1990 & 1995 & 2000 \\
\hline POBLACION & 17.970 & 76.272 & 149.132 & 169.114 & 189.707 & 199.411 & 196.289 \\
\hline
\end{tabular}

Tab. 01 Evolución demográfica en Móstoles (1970-2000). Fuente: Datos aportados a partir de la documentación conservada en el AMM.

La tabla 1 nos muestra el fuerte crecimiento demográfico que se concentra entre los años 1970 y 1980. En 1980, "de esta población considerada oficial por la Administración Central a los efectos de las aportaciones que tiene que hacer a Móstoles en materia económica, escolar sanitaria, etc., 75.384 corresponden a varones y 74.875 a mujeres". ${ }^{27}$ La población se duplicó en seis años, $1975-1981,{ }^{28}$ según el Padrón de 1981, el 11, $6 \%$ de la población que venía de fuera de la provincia de Madrid procedian de la provincia de Toledo. La densidad media para el municipio, que estaba prevista dentro del P.G.O.U.M. del 17 de abril de 1985, era de 170,7 hab/ha, llegando a $508,9 \mathrm{hab} / \mathrm{h}$ a en el Dos de Mayo, o 1,9 hab/ha, en el Parque Coimbra, siendo la Densidad Bruta del término municipal de 34,7 habitantes por hectárea.

24 Roberto MEDEM SANJUAN: 100 años de perdiz en ojeo., s.l., Ciprea, 1996, Tomo I.

25 Isabel PARRA JIMÉNEZ y Esther SALVADOR MERINO: “Las concejalas en el ayuntamiento de Móstoles", en INSTITUTO DE ESTUDIOS HISTÓRICOS DEL SUR DE MADRID "Jiménez de Gregorio" $\left(2^{\circ}\right.$. 2011. Móstoles). Segunda jornada del Instituto de Estudios Históricos del Sur de Madrid, Fundación Móstoles 1808-2008, 30 de noviembre de 2009, Alcorcón, I.E.H.S. “Jiménez de Gregorio”, D.L. 2011. 26 Datos aportados a partir del Informe Especial, Habla Móstoles, 16 a 23 de octubre de 1987, pág.9. 27 "Aprobado el Padrón de Habitantes. En seis años se ha duplicado la población", op. cit., Noviembre de 1981, pág.2.

28 lbid pág.2.

nio de 1980. 
Este municipio con la caída del régimen franquista tenía unos importantes déficits de equipamientos: sin agua canalizada, sacada únicamente a través de pozos; sin apenas colegios, parques, jardines, ni casa de socorro, consultorios, centros culturales, centros de planificación familiar, psicosocial, psicopedagógico, juventud, pistas deportivas, polideportivos cubiertos, zonas y calles urbanizadas, guarderías, oficinas de empleo, universidades, servicios municipales, colegios de educación especial, zona forestal de El Soto, residencias para la tercera edad ni hospitales, que tras veinticinco años de gobierno democrático se hicieron realidad.

Tan pronto como 1980, el gobierno municipal puso en marcha la primera emisora municipal, Radio Móstoles, y posteriormente la televisión local, Móstoles Televisión. La primera Guardería municipal se construyó el 16 de octubre de 1981 en IVIASA, ante la fuerte demanda social, el mismo año que se construyó la Casa de Socorro. Sin embargo, lo que lleno los titulares de los principales periódicos fue la nueva estación de RENFE en Móstoles el viernes 29 de octubre de $1976,{ }^{29}$ de esta manera se vertebraba el sur del Área Metropolitana con la capital de España, y por lo tanto, poner la ciudad en el mapa. Esta medida, que conectó a más de cien mil personas, junto al desdoblamiento de la $\mathrm{N}-\mathrm{V}$, que tradicionalmente pasaba por el centro de la población serán dos medidas esenciales orientadas a mitigar la congestión que se producía en este punto.

A través del Centro de Planificación Familiar creado en 1981, cuyo Director era Leonardo Hagel, divulgaron entre la juventud la educación sexual, un tema que hasta estos momentos estaba restringido a la vida privada, gracias a la libertad democrática, y los medios de comunicación, estos se hicieron eco de una problemática, que consistía en los profundos déficits de información existentes entre la población municipal, y sobre todo entre las mujeres y la población más joven.

Las drogas ocuparon el interés de los periodistas que publicaban en el Municipio, con un Extraordinario, analizaban las causas, la problemática familiar y social que generaba, y los canales que la administración local ponía a disposición de los afectados. Respecto al aborto Habla Móstoles abre en portada de la siguiente manera: "En Móstoles se practican el 50\% de los abortos legales que se realizan en España".30

Esta ciudad ha sufrido una metamorfosis cultural, pasando de un analfabetismo de cas el $25 \%$, cuando cae el régimen franquista a ser algo testimonial a finales del siglo XX; de no haber suficientes centros educativos, a implantarse una de las universidades más dinámicas y modernas de la Comunidad Autónoma de Madrid: la Universidad Rey Juan Carlos. "La composición social es básicamente trabajadores industriales y de servicios (6o por 100 de la masa laboral son obreros). Población joven y con alto índice de analfabetismo (absoluto y por desuso: 30,1 por 100 en los mayores de veinte años)". ${ }^{11}$ El primer centro sociocultural se inauguró en diciembre de 1982, ya que hasta el momento no se disponía de ninguno. La Revista Informaciones de Móstoles lo llevó en su portada en su tirada de diciembre de 1982.

Paddy Ahumada Gallardo, Director de Cultura, impulsó la cultura municipal mediante representaciones teatrales, ciclos de cine, cursos con instrumentos musicales, dibujo, fotografía y puso en funcionamiento la Biblioteca Municipal, que desde su creación no ha dejado de ser literarios, donde era una ocasión excepcional, para poner en valor aquellos géneros literarios que no son conocidos por la población, así como seminarios y exposiciones.

29 "Se inauguro el ferrocarril de Aluche-Móstoles", $A B C$, Madrid, 29 de diciembre de 1976. pág.51, http://hemeroteca.abc.es/nav/Navigate.exe/hemeroteca/madrid/abc/1976/10/29/051.html

30 "En Móstoles se practican el 50\% de los abortos legales que se realizan en España", op. cit., 29 de Noviembre de 1986

31 Paddy AHUMADA GALLARDO: “La animación sociocultural en los ambientes urbanos", Documentación social. Revista de estudios sociales y de sociología, 49 (1982), pp.79-86.
Sin embargo, este período no estuvo exento de consecuencias negativas: la profunda crisis económica, la exaltación colectiva de la sociedad civil por las expectativas que ofrecía la Transición, una población mayoritariamente joven, en un contexto contracultural como fue la movida madrileña, desencadeno que algunos jóvenes quedarán atrapados en la droga, principalmente en la heroína. "Las drogas son omnipresentes en ciudades y zonas suburbanas y rurales de todo el mundo".32

La prensa municipal trató un heterogéneo número de temas, de forma pluralista, a través de géneros como el reportaje, la entrevista, temas monográficos, encuestas que nos acercaron las corrientes musicales, cinematográficos, literarias, y pictóricas, invitando a figuras relevantes de la cultura regional y local, podemos subrayar el movimiento Okupa, y otros movimientos undergrounds, como el movimiento punk, ligado en muchas ocasiones a la música rock, y colectivos squatters en Móstoles.33 Finalmente, el aggiornamento de la Iglesia, sobre todo de las Parroquias de barrio, por parte de los curas de los lumpen urbano, consiguió en muchas ocasiones, evitar la exclusión social.

La violenta expansión capitalista en la España de la década del 60 tuvo reflejo en la edificación acelerada de muchas ciudades semejantes a Móstoles. El emigrante interior que llegaba a habitarlas no sólo perdía su cultura original, sino que el entorno estaba diseñado de tal manera que retroalimentaba esta desculturización (otros dirían que alimentaba al franquismo). 34

Las tribus urbanas, eran un arquetipo de lo que serán un forma de subcultura. En esta ciudad, se desarrollaron movimientos punk y skaters, además de artistas callejeros como los escritores de graffiti, o la música de autor hecha poesía como los hip-hop. Los miembros comparten gustos musicales, estilos y costumbres, que superan las fronteras urbanas. "Los que construyen los cimientos culturales son los audaces con una visión más amplia, que se dan cuenta de que el fenómeno es más global, de que hay grupos afines a los que no conocen". ${ }^{5}$

De tal manera, "la cultura urbana, está estrechamente relacionada con los flujos migratorios, por consiguiente, lo urbano, en el contexto de la globalización, está relacionado con flujos y redes trans-locales, pero al mismo tiempo depende de espacios y territorios que hacen puntos nodales de esos flujos. ${ }^{36}$ Por lo tanto, "Los medios de comunicación proporcionan una difusión de estos mensajes, aunque el graffiti tiene muchos rasgos en común y es un fenómeno mundial, las mejores piezas mantienen un marcado carácter local". ${ }^{37}$

Isaac Montero ${ }^{8}$ nos muestra a través de su novela, El sueño de Móstoles, el deseo de una pareja de compartir una vida en común en una ciudad como esta, un proyecto que fue compartido por individuos de profesiones liberales de la sociedad madrileña, que vivieron en los barrios más populares de la capital española, y preferían vivir como cabeza de ratón en vez de cola de león.

32 Roger GASTMAN: Cultura urbana, Barcelona, Océano, 2007, pág.359.

33 Amelia CASTILLA Y Juan ANTONIO CARBAJO: "60 jóvenes de Móstoles ocupan un edificio vacío desde hace cuatro años", El Pais, 28 de abril de 1988,http://elpais.com/diario/1988/04/28/madrid/578229855_850215.html.

34 Op. cit., pp. $79-86$.

35 Op. cit., pág. 30

36 Eduardo KINGMAN GARCÉS: “Lo urbano, lo social: la historia social urbana”, en Eduardo KINGMAN GARCÉS: Historia social urbana: espacios y flujos, Quito, FLACSO - Sede Ecuador: Ministerio de Cultura del Ecuador. 2009.

37 Op. cit., p.162.

38 Isaac MONTERO: El sueño de Móstoles, Madrid, Anaya \& Mario Muchnik, 1995 
Uno de los acontecimientos más sobresaliente de la Transición en Móstoles, tuvo lugar el 23 de febrero de 1981 con el fallido golpe militar. El Alcalde de Móstoles, D. Bartolomé González Lorente, condujo la política municipal de manera correcta, con la prudencia necesaria y, a su vez, con la firmeza democrática para visibilizar un mensaje de compromiso de libertad y democracia. Diario 16, publicó "Móstoles vivió otro 2 de Mayo".

Habrá que esperar hasta 1985, para que se firmara la declaración de paz, entre España y Francia, 177 años después del inicio de "La Guerra de la Independencia". El alcalde de Móstoles, Bartolomé González, y el embajador de Francia en España, Pierre Guidoni, firmaron la paz el 2 de mayo de 1985. El 30 de abril de 1985, se celebró una sesión Extraordinaria por la Corporación pleno de este Ayuntamiento en primera convocatoria, del cual se extrae:

[...] Hace ciento setenta y siete años, ante la presencia de tropas extranjeras en nuestro territorio, y desaparecidas las instituciones que encarnaban la soberanía racional, el alcalde de Móstoles, D. Andrés Torrejón, asumió el papel histórico de la representación popular, plasmado en el célebre bando que concitaba a los españoles a la lucha por la independencia y la libertad, y declarada la guerra al invasor.

Hoy, dos de Mayo de 1985, cuando el espíritu de los pueblos clama por un mundo en paz, entendemos que todo acto que simbolice este espíritu, colabora al entendimiento entre los hombres.

Hubo en 1.808 una declaración de Guerra. En este día Móstoles, pueblo pacífico y laborioso, quiere hacer una simbólica declaración de paz con el pueblo vecino y hermano de Francia. [...] $]^{39}$.

Ese mismo mes de la firma de la declaración de paz entre Móstoles y Francia, Felipe González realizó una visita privada a Móstoles, el 27 de Mayo de 1985, con su posterior rueda de prensa, en un acto acordado por la Federación Socialista Madrileña, en unión de la Agrupación de Móstoles, el acto tuvo lugar en el Centro Cultural $\left\langle\langle\right.$ Villa de Móstoles $\rangle,^{\circ}{ }^{\circ}$ que solamente recogió la prensa municipal.

Otro de los momentos más controvertidos, se produjo con ocasión del Referéndum realizado en 1986, con la siguiente pregunta: "iConsidera conveniente para España permanecer en la Alianza Atlántica en los términos acordados por el Gobierno de la Nación?". Según una encuesta municipal realizada por Habla Móstoles, ${ }^{41}$ destacan algunos aspectos, en primer lugar el $67,5 \%$ deseaba que se realizase dicho Referéndum, con apenas un 15,2 \% de indecisos. Dentro de los segmentos socio-profesionales, se puede subrayar que el colectivo más contrario a la permanencia de España en la OTAN son las profesiones liberales con un 71,4\%, seguidos de los estudiantes (65,3\%). Por el contrario, los más favorables a dicha permanencia están los funcionarios, con un $47,3 \%$, que por otro lado coincide en porcentaje, con los funcionarios desean no permanecer en la OTAN.

Finalmente el Habla Móstoles abrió en portada en su número 97, el 13 de marzo de 1986, el "sí ganó con un $56 \%$ y el no con un $38 \%$ ", los resultados arrojaron luz sobre la voluntad de los mostoleños. Si observamos el comportamiento electoral por los diferentes distritos, observamos una uniformidad, habiendo una diferencia entre los mismos, inferior al punto porcentual.

39 Acta de la Sesión Extraordinaria celebrada por la Corporación Pleno de este Ayuntamiento en primera convocatoria, 30 de abril de 1985. Sig.176.1. Folio 52-53.

40 "Visita privada de Felipe González", op. cit., 4 de Junio de 1985. pág. 3.

41 "Hoy un 54,7\% de los mostoleños está en contra de la permanencia de España en la OTAN", op. cit., 22 de noviembre de 1985. pág. 8.

\begin{tabular}{|l|c|c|c|c|c|c|c|}
\hline CANDIDATURAS & 1979 & 1983 & 1987 & 1991 & 1995 & 1999 & TOTAL \\
\hline PSOE & 13 & 20 & 13 & 11 & 8 & 11 & 76 \\
\hline IU42 & 10 & 2 & 3 & 5 & 6 & 3 & 29 \\
\hline UCD 43 & 4 & 0 & 6 & 1 & 0 & 0 & 11 \\
\hline PP 44 & 0 & 5 & 5 & 10 & 13 & 13 & 46 \\
\hline OTROS & 0 & 0 & 0 & 0 & 0 & 0 & 0 \\
\hline
\end{tabular}

Tab. 02 Candidaturas y concejales durante los comicios municipales (1979-1999). Fuente: Datos aportados a partir del Ministerio del Interior.

La tabla 2 nos muestra como los primeros comicios municipales tuvieron lugar en 1979, con victoria del PSOE, cuyo alcalde fue Bartolomé González Lorente, que se mantuvo en el cargo hasta 1991, cuando le sucedió José Luis Baigorri. Este gobernó el municipio apenas dos años, ya queen 1993 cogió el bastón de mando José María Arteta, quien gobernó hasta 2003.

Desde 1979 los comicios municipales han tenido como resultado, la victoria del PSOE hasta 1991, gobernando primero con el PCE y posteriormente con IU, salvo en 1983 que consiguió mayoría absoluta. EI PCE fue un paradigma en los primeros años de democracia, por la relevancia que tuvieron los movimientos vecinales, para influir en las decisiones políticas del municipio a través de una comunicación directa y una participación amplia de la sociedad mostoleña.

La hegemonía de la izquierda hasta 1991, liderada por el PSOE, solamente consiguió una mayoría absoluta en los veinticinco años de democracia, teniendo que pactar con el PCE en la primera legislatura, y con IU en la tercera, cuarta, quinta y sexta legislatura, con un desgaste político del PSOE. Hay diversos motivos de este desgaste: en primer lugar, por causas endógenas al PSOE de Móstoles, como son los casos de transfuguismo y, en segundo lugar, por causas exógenas, como fue el contexto de crisis económica y corrupción que sacudió al gobierno central, que hábilmente supieron utilizar los principales medios de comunicación afines a la oposición de aquel momento.

El espacio político que sustentaba al centro, a través del CDS, ofreció una mayor resistencia a nivel local que a nivel estatal, aunque, finalmente en los años noventa fue fagocitado por el principal partido conservador, el PP. Debido, a causas internas, el CDS ofreció un apoyo a la izquierda, que era mayoritaria en el pleno, y al mismo tiempo, construía un discurso duro de oposición a la forma de ejercer el poder, por parte de la Corporación que la sociedad mostoleña no comprendió por lo incohernte de su posición, sumado al inexistente espacio político central, a nivel estatal, terminó por sumarse al proyecto político que ofrecía el Partido Popular. De esta manera, el PP a partir de los comicios de 1995, se convierte en un catch-all party, colocando como cabeza de cartel a Fernando Bastarreche, un ex concejal del CDS, lograron de esta manera mostrar una cara más amable de cara a un electorado más centrista, necesario para conseguir grandes mayorías en el pleno municipal.

Por su parte, la extrema izquierda parlamentaria, liderada por el PCE tuvo un enorme

42 Hasta 1986 momento que se constituye I.U (Izquierda Unida), los comicios anteriores de 1979 y 1983 , se presentó ante los electores con las siglas P.C.E.

43 Se presento UCD en 1979 consiguiendo 4 concejales, en los comicios municipales de 1987 y 1991 consiguieron representación en el Pleno municipal, a través de la marca CDS.

44 Coalición Democrática se presentó en 1979, AP-PDP-UL son las siglas con las se presentaría en 1983, denominándose AP en 1987, y finalmente con la refundación del partido en 1989, acudió a siguientes comicios de 1995 y 1999. 
éxito consiguiendo sus mejores resultados en los primeros comicios, como consecuencia de que sus principales candidatos eran reconocidos por los electores como defensores de las libertades desde el tardofranquismo a través de las principales asociaciones vecinales, como Carlos Madrid y otros candidatos que venían de CC.OO, y que a través del entrismo en las fábricas más importantes de la ciudad, lograron colocarse en estos primeros comicios en una posición favorable, respecto a otros partidos políticos. Sin embargo, si bien es verdad que ha demostrado tener un suelo electoral por encima del $10 \%$ que le garantiza representación en el pleno, en estos veinticinco años de democracia, se han dejado por el camino más de la mitad de sus electores.

Finalmente, el voto extraparlamentario tuvo su momento más álgido en los primeros comicios por la fuerte atomización de las candidaturas, así como la débil estructura de las mismas. Una vez estas se institucionalizaron la concentración del voto en tres partidos políticos (PP PSOE e IU) que aglutinaron más del $90 \%$ del voto municipal.

Para poder comprender el vuelco electoral que se produce en Móstoles durante la década de los noventa es esencial analizar la política ejercida desde Madrid a través de los medios de comunicación con el objetivo de influir en la opinión pública del cinturón rojo con una política grandilocuente en lo que concierne a las infraestructuras, como supuso la construcción de Metrosur ${ }^{45}$ o la Universidad Rey Juan Carlos. El ABC publicó el siguiente titular "Leguina o GaIlardón: el Sur tiene la palabra". ${ }^{6}$ El objetivo era conseguir romper el cinturón rojo. A parte de los medios impresos, algunos medios audiovisuales, colaboraron con esta estrategia como por ejemplo Telemadrid. ${ }^{47}$

En clave interna, el Partido Popular de Móstoles supo canalizar el voto de protesta mostrándose ante la sociedad como un partido desideologizado y, por tanto, que solo responde a las necesidades ciudadanas, consiguiéndose ganar un espacio político que le fue negado en la década de los ochenta porque estaban estigmatizados por una herencia política que, para amplios sectores de la sociedad mostoleña, eran herederos del franquism, y por ende del establishment político.

\section{Conclusiones}

En esta comunicación estudiamos un periodo muy sugerente por lo que tuvo de innovación, de cambio, y de alguna manera, también de ruptura con la etapa precedente. La población de Móstoles en 1975 se encontraba en un proceso de transformación, demográfico, social, cultura y político, situada en el sur del Área Metropolitana de la capital de España. A lo largo de estos veinticinco años que han transcurrido desde la celebración de las primeras elecciones municipales democráticas, celebradas en 1979, Móstoles ha cambiado radicalmente, corrigiéndose los grandes déficits estructurales heredados.

El municipio de Móstoles sufrió una transformación: de ser un caserío agrícola y, en menor medida ganadero, a ser una ciudad dormitorio, basando su tejido productivo en el sector servicios, seguido de cerca por la industria. El crecimiento tan significativo demográficamente descansa sobre dos razones: en primer lugar, las demandas que provienen del área metropolitana como espacio socio-económico y las ofertas que Móstoles ofrece. Este crecimiento

45 Javer UBEDA: El PP promete llevar el metro a 850.000 habitantes del sur la proxima legislatura", Madrid, $A B C$, 4 de octubre de 1998, http://hemeroteca.abc.es/nav/Navigate.exe/hemeroteca/madrid/abc/1998/10/04/080.html.

4 A. de G.: “Leguina o Gallardón: el Sur tiene la palabra”, op. cit., 11 de Mayo de 1991, http://hemeroteca.abc.es/nav/Navigate.exe/hemeroteca/madrid/abc/1991/05/11/039.html.

47 Raúl CASTILO: “Telemadrid planta a los alcaldes del Sur en la reunión sobre su política informativa", Cetafe op cit, 9 de noviembre de 1993, htp: $/ /$ hemelotecabces/nav/Navigate.exe/he va", Cetafe, op clt, gdend demográfico fue consecuencia de la inmigración durante los primeros años de la Transición. Los flujos migratorios eran sensiblemente predominantes de fuera de la provincia de Madrid pero ,a partir de 1981, se acentúan los flujos migratorios hacia la población de Móstoles dentro de la misma provincia, buscando un suelo más barato para la implantación de sus industrias y viviendas. Los inmigrantes de fuera de la provincia provenían sobre todo de poblaciones que se encuentran en el área meridional, es decir, Castilla La Mancha, Extremadura y Andalucía.

La ciudad sufrió un crecimiento desordenado de población que tuvo unas consecuencias urbanísticas nefastas desde 1965 hasta 1980. A partir de 1980, se apostó por un desarrollo de la ciudad, que humanizase el espacio urbano, dirigido hacia las personas, gracias al esfuerzo por incorporar equipamientos esenciales para la vida diaria de los ciudadanos.

Durante los veinticinco años de democracia, este municipio ha sufrido un cambio profundo, en los niveles educativos, en la democratización del espacio público, dejando atrás el modelo de ciudad-dormitorio para dar paso a una ciudad con identidad propia. Los movimientos sociales, y principalmente las asociaciones de vecinos, fueron el motor de cambio, frente a la resistencia de sectores inmovilistas, apelando al miedo, y Contre-coeur, finalmente, se impuso el cambio.

Estos cambios fueron canalizados por los movimientos ciudadanos. En el caso de Móstoles, los principales protagonistas de este cambio lo canalizaron las asociaciones de vecino que presionaron desde abajo para conseguir una democracia homologable a las democracias occidentales, combatiendo en los espacios públicos el timing marcado por la élite económica social, política y cultural. En el caso de Móstoles, los dirigentes franquistas desaparecieron de la vida pública, la mayoría volvieron a sus profesiones, y se abrieron las ventanas del Ayuntamiento, después de casi cuarenta años de dictadura, consolidando el mayor periodo democrático municipal, en la historia contemporánea de España. 


\section{MOVILIDAD RESIDENCIAL EN EL MADRID}

\section{DE PRINCIPIOS DEL SIGLO XX*}

Santiago de Miguel Salanova

Universidad Complutense de Madrid

El asentamiento de una familia en un gran núcleo urbano era una estrategia temporal que venía impuesta por las características de los propios espacios residenciales, las circunstancias laborales y demográficas de los inquilinos e incluso por políticas institucionales y gubernamentales. Su influencia lleva a hablar de una acusada movilidad residencial en Madrid a principios del siglo XX, entendiéndose aquella como el mecanismo que permite inferir si el carácter de cada área social en una aglomeración urbana persistía o cambiaba a lo largo del tiempo.' Su importancia no debe ser obviada, al representar el porcentaje más elevado de las migraciones totales durante el siglo XIX. ${ }^{2}$ Diversos estudios pioneros en este apartado temático relacionaron este fenómeno con las transformaciones acaecidas en la estructura espacia de la ciudad y descubrieron que a pesar de que la población se movía con una inusitada frecuencia, casi siempre lo hacía en cortos recorridos. ${ }^{3}$

El sistema de propiedad de Madrid, definido desde 1842 por la Ley de Inquilinatos y basado casi exclusivamente en el alquiler de la vivienda, provocó que la permanencia a largo plazo en un mismo domicilio fuera la nota discordante, siempre adscrita a las familias de mayor pode adquisitivo ${ }^{4}$ Cambiar de piso era un acontecimiento cotidiano que estaba lejos de constituir una actividad disruptiva para el inquilino. ${ }^{5}$ La necesidad del desplazamiento sobrevenía en

* Este texto forma parte de las actividades del Grupo de investigación UCM Historia de Madrid en la edad contemporánea, $n^{\circ}$ ref:: 941149 , ha sido posible por la concesión de dos proyectos de investigación del PLAN NACIONAL DE I + D + I: MINISTERIO DE EDUCACIÓN Y CIENCIA, HUM200764847/HIST; MINISTERIO DE ECONOMÍA Y COMPETITIVIDAD HAR2011-26904, Investigador principal: Luis Enrique Otero Carvajal.

1 Jacques BRUN y Yves GRAFMEYER: Études sur la mobilité dans la société française, Laboratoire des Sciences Sociales de l'École Normale Supérieure, 199

2 Colin POOLEY y Jean TURNBULL: Migration and mobility un Britain since the 18th Century, Londres, UCL Press Limited, 1998, p. 135

3 Harold James DYOS: Victorian Suburb. A study of the growth of Camberwell, Leicester, Leicester University Press, 1961; Michael ANDERSON: Family Structure in Nineteenth Century Lancashire, Cambridge, Cambridge University Press, 1971; Roger Martin PRITCHARD: Housing and the spatial structure of the city: residential mobility and the housing market in an English City since the Industrial Revolution, Londres, Cambridge University Press, 1976 y Martin DAUNTON: Coal Metropolis. Cardiff, 1870-1914, Leicester, Leicester University Press, 1977.

4 Rubén PALLOL, Borja CARBALLO y Fernando VICENTE: “Oferta de vivienda de alquiler en el Madrid del primer tercio del siglo XX", Comunicación presentada al Congreso Ciudad y Modernización. Transformaciones urbanas siglos XIX XXX, Universidad de Granada, septiembre de 2011; Santiago DE MIGUEL SALANOVA: "Bajo los tejados de Madrid. Segregación residencial en el primer tercio del siglo XX", Comunicación presentada al Congresso Historico de Guimaraes, octubre de 2012 (en prensa).

5 Michael ANDERSON: "Indicators of population change and stability in 19th century cities: some sceptical comments", en James H. JOHNSON y Colin POOLEY: The structure of Nineteenth Century cities, Nueva York, St. Martin's Press, 1982. cualquier momento, ya fuera por una mala situación laboral del inquilino, por la reducción de ingresos en el núcleo familiar o por un acontecimiento trágico como la muerte del marido. En otros casos, la movilidad podía llegar por elementos externos como las expropiaciones forzosas o el impago del alquiler del piso. Estos fenómenos obligaban a buscar un domicilio más asequible y cercano en la medida de lo posible al anterior. En realidad, tanto uno como otro proceso no supusieron grandes problemas para la población madrileña en la medida en que los nuevos domicilios apenas estaban separados en unos pocos metros de los antiguos y los inquilinos disponían de escasas pertenencias que trasladar y de pocos servicios que organizar. En consecuencia, el coste social de esos desplazamientos intraurbanos era muy bajo, influyendo además el hecho de que los inquilinos no forjaban un compromiso personal con la vivienda ocupada inicialmente.

\section{Introducción}

La tasa de movilidad residencial del centro de Madrid alcanzaba el 22,26\% para el período 1905-1910, cifra que aun siendo más alta que la registrada para las zonas este y sur del Ensanche $(17,8$ y $17,4 \%)$ resulta exigua comparada con la de otras ciudades europeas. ${ }^{6}$ Las múltiples circunstancias que influían en la recogida del cambio residencial en los padrones de habitantes, entre las que destacaban desde la voluntad del inquilino de consignar su desplazamiento hasta el desconocimiento de la obligación de señalar tal dato, pueden explicar este subregistro. Un análisis fehaciente de la movilidad residencial requeriría así una comparación directa de hogares y habitantes por barrios a través de directorios, libros de contribución industrial o territorial y censos electorales.7 No obstante, todos estos métodos revisten limitaciones particulares, al privilegiar el registro de las clases medias y altas dejando en un plano secundario los sectores populares. Los motivos expresados y la rica información demográfica que ofrecen los padrones (expresando la calle a la que se desplaza el cabeza de familia y el momento exacto del movimiento) nos llevan a confiar en la información cualitativa aportada por esta fuente.

\begin{tabular}{|c|c|c|}
\hline Movilidad del inquilino & Número de casos & Tasa movilidad (\%) \\
\hline Se mueve & 4.427 & 22,26 \\
\hline No se mueve & 15.465 & 77,74 \\
\hline Total hogares & 19.892 & 100 \\
\hline
\end{tabular}

Fig. 01 Movilidad residencial de las familias residentes en el centro de Madrid (1905-1910). Fuen te: Elaboración propia a partir de los datos extraídos de las hojas de empadronamiento municipal de 1905, AVM, Estadistica.

El grado de persistencia residencial observaba un movimiento pendular que dependía de la categoría social del barrio en el que se hallase la vivienda. Por esta razón, las zonas más degradadas del centro urbano (Estrella, Senado, Tudescos, Álamo) presentaban tasas de movilidad superiores a la media del espacio urbano en el que se adscribían. El comportamiento de los

6 Para el caso del Ensanche Sur: Fernando VICENTE: Los barrios negros: el Ensanche Sur en la formación del Moderno Madrid (1860-1931), Tesis Doctoral, UCM, 2012. Para las ciudades británicas: Colin POOLEY: "Residential mobility in the Victorian City", en Transactions of the Institute of British Geographers. New Series, vol. 4, $\mathrm{n}^{\circ}$ 2, 1979, pp. 258-277.

7 J. L. OLIVER: "Directories and their use in geographic enquiry", Geography, no. 49, 1964, pp. 400 409.R. S. HOLMES. "Ownership and migration from a study of rate books" Area 59, 1973 . Pp. $242-251$ 409; R.S. HOLMES: "OWnership and migration from a study of rate books", Area 5, 1973, pp. 242-251; Geographers, vol. 2, no 3.1977, pp. 349-36 
vecinos de estos barrios seguía una regla arquetípica basada en el desplazamiento a los espacios colindantes. Eran las alternativas más baratas y las que ofrecían la posibilidad de salir de centro urbano sin perder el contacto con las relaciones allí formalizadas.

En el polo opuesto, los barrios acomodados, revalorizados a través de sucesivas alineaciones y reformas, evidenciaban una movilidad más limitada que en la mayoría de los casos presentaba un tono descendente. Aún así, la escasa persistencia residencial de alguno de estos espacios podía ser sinónimo de la mayor capacidad de sus vecinos para afrontar traslados a zonas más amplias y lujosas de un contenido social menos popular. Esto explica la frecuente tendencia de los inquilinos del barrio de Las Torres para alquilar nuevos pisos en zonas como Almirante, Góngora o Campoamor e incluso para dar el salto a otros barrios más alejados del casco antiguo pero igualmente proclives para facilitar unas buenas condiciones de vida como Biblioteca, Conde de Aranda, Retiro y Fernando el Santo.

\begin{tabular}{|c|c|c|}
\hline Barrio & Tasa movilidad & Alquiler mensual (pesetas) \\
\hline Álamo & 22,95 & 48,12 \\
\hline Carlos III & 19,68 & 121,06 \\
\hline Carmen & 19,20 & 160,63 \\
\hline Constitución & 15,76 & 125,14 \\
\hline Correos & 14,60 & 139,91 \\
\hline Espejo & 22,98 & 74,46 \\
\hline Estrella & 27,31 & 70,36 \\
\hline Floridablanca & 21,78 & 208,87 \\
\hline Isabel II & 24,68 & 126,33 \\
\hline Jardines & 24,05 & 113,90 \\
\hline Las Torres & 26,19 & 177,33 \\
\hline Muñoz Torrero & 22,21 & 77,25 \\
\hline Puerta del Sol & 16 & 333,06 \\
\hline San Luis & 21,77 & 91,35 \\
\hline San Martín & 23,75 & 156,29 \\
\hline Senado & 26,58 & 63,45 \\
\hline Tudescos & 24,27 & 71,58 \\
\hline
\end{tabular}

Fig. 02 Movilidad residencial de la población residente en el centro de Madrid por barrios (19051910). Fuente: Elaboración propia a partir de los datos extraídos del Padrón Municipal de Habitantes de 1905, AVM Estadistica.

\section{Nativos e inmigrantes en el mercado residencial madrileño.}

La mayoría de los estudios centrados en el análisis de la movilidad residencial han destacado la menor predisposición de los nativos a mudarse y la fuerte itinerancia de la población inmigrante. En el centro de Madrid, el grado de persistencia mostraba una tendencia más baja para los primeros. Para explicar este fenómeno puede sugerirse el elevado conocimiento que del espacio urbano tenían los cabezas de familia madrileños, capaces de explotar con mayor eficacia las posibilidades de alojamiento que ofrecía la ciudad en sus infinitas callejuelas y recovecos. Para los inmigrantes tenía más sentido permanecer en la zona en que se había arrenban de llegar a la capital. Su movilidad crecía a la par que lo hacía la distancia de Madrid con respecto a su área de procedencia. Las familias que llegaban del hinterland rural de la capita se mudaban con mayor frecuencia, pero no así las llegadas de regiones colindantes como Toledo, Segovia y Guadalajara. Este fenómeno respondía a la mayor tendencia de desplazamiento registrada para los inmigrantes nacidos en capitales de provincia, mejor aclimatados a la vida urbana que les ofrecía Madrid y más habituados a la movilidad que los inmigrantes rurales.

\begin{tabular}{|c|c|c|}
\hline Origen & Grado de movilidad & $\begin{array}{c}\text { Diferencia con movilidad } \\
\text { media de la zona }\end{array}$ \\
\hline Madrileños & 24,58 & $+2,32$ \\
\hline Inmigrantes & 21,64 & $-0,62$ \\
\hline Recién llegados a Madrid & 18,94 & $-3,32$ \\
\hline Nacidos en capital de provincia & 25,47 & $+3,21$ \\
\hline Nacidos en provincia & 22,42 & $+0,16$ \\
\hline
\end{tabular}

Fig. 03 Movilidad residencial de las familias por naturaleza y distancia geográfica (1905-1910). Fuente: Elaboración propia a partir de los datos extraídos del Padrón Municipal de Habitantes de 1905, AVM, Estadística.

Independientemente de su origen, las familias organizaban desplazamientos muy dispersos hacia la periferia, con lo que su movilidad no tenía repercusiones significativas en la geografía global de la ciudad. Cuando los recursos económicos escaseaban, siempre se podía alquilar un piso en torno a las vías principales que servían de eje de separación para los espacios más acomodados del norte del casco y los más degradados y populares del sur. Los barrios meridionales de los distritos de Hospital, Latina e Inclusa constituian alternativas que ni siquiera eran contempladas por las familias más desaventajadas del centro. Solo una caída en desgracia de dimensiones incalculables podía llevar a alquilar una vivienda en áreas mortíferas e insalubres del sur, donde el hacinamiento en casas de vecindad estaba a la orden de día. Todo ello hace suponer que en el caso de Madrid, las condiciones sociales, económicas y demográficas preexistentes de la urbe influyeron en las decisiones tomadas por los individuos a la hora de buscar nuevas viviendas.

8 Esta situación coincidía con la presentada en las ciudades británicas de finales del siglo XIX: Colin POOLEY. "Choice and constraint in the Nineteenth-Century City: a basis for residential differentiation", en Janes $\mathrm{H}$. JOHNSON y Colin POOLEY (eds). The structure of Nineteenth Century Cities, Nueva York, St. Martin's Press, 1982, pp. 199-233. 

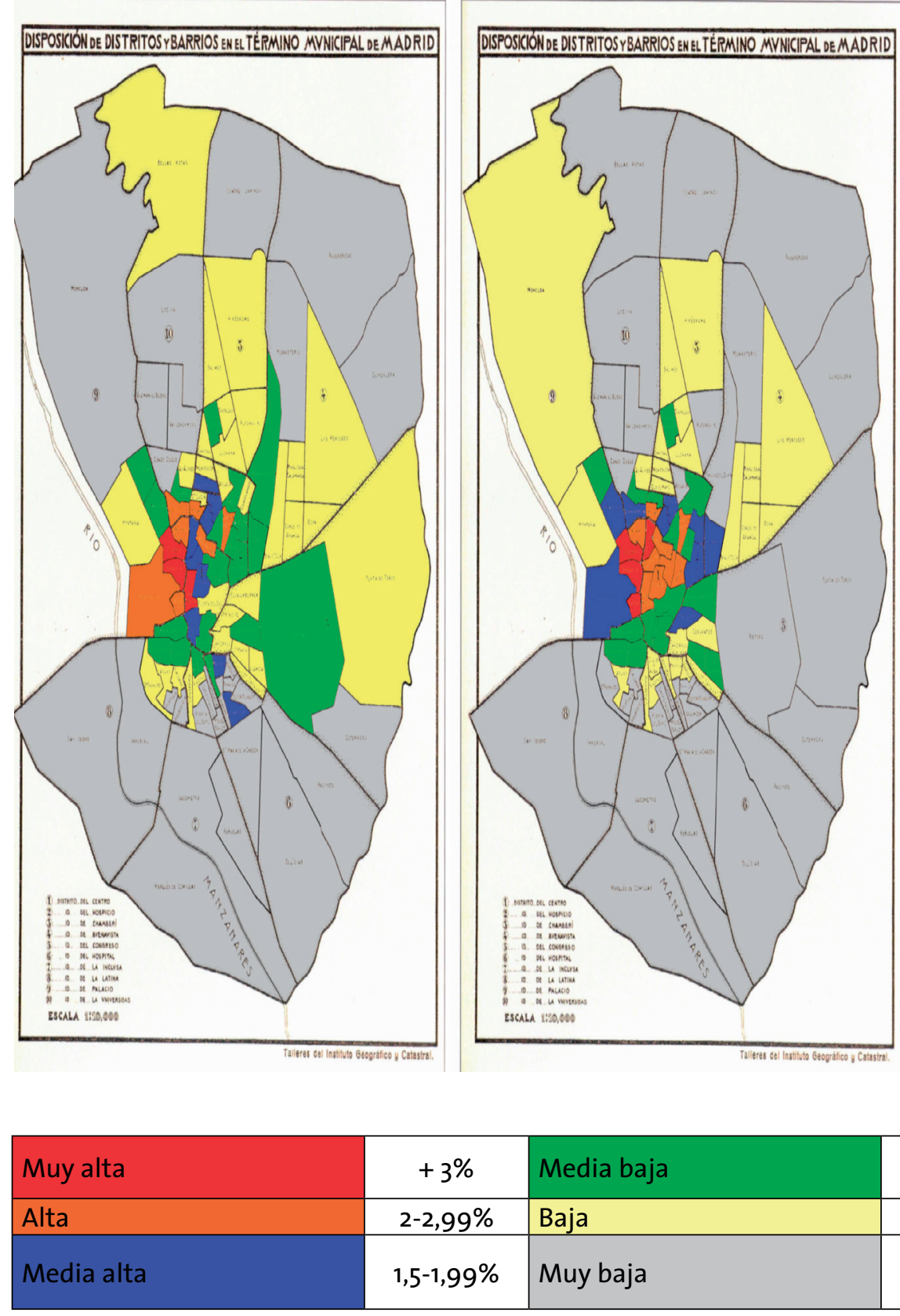

$1-1,49 \%$ $0,5-0,99 \%$

Gráf. o1 Movilidad residencial de las familias encabezadas por madrileños e inmigrantes asentados en el centro de Madrid (1905-1910). Fuente: Elaboración propia a partir de los datos extraídos del Padrón Municipal de Habitantes de Madrid de 1905, AVM, Estadística.

El criterio económico es otro de los factores decisivos que explica la escasa voluntad para Elquilar viviendas en los barrios definidos por una acusada concentración de servicios. dablanca y Puerta del Sol, recorridos en buena parte por algunas de las calles que en los años venideros vieron cristalizar el principal eje financiero y bancario de la ciudad, no resultaban ni atractivas ni rentables para el asentamiento. Eran pocos los inquilinos que podian competi con las compañías y empresas privadas que situaban allí sus oficinas y con los grandes comerciantes cuya principal ensoñación era crear, en torno a este espacio, un moderno y próspero negocio que captara la mayor clientela posible.

Los cabezas de familia nacidos en la capital evidenciaban una tendencia algo más acusada que los inmigrantes a emprender movimientos hacia zonas cada vez más desarrolladas, espaciosas y baratas del Ensanche Norte y, sobre todo, del Ensanche Este. Aquí podía entra en juego el grado de conocimiento de la ciudad por parte de la población que había crecido en ella y su mayor capacidad a la hora de valorar cada espacio residencial. Las diferencias podían ser especialmente relevantes con respecto a los inmigrantes de reciente llegada, quienes como consecuencia de una población urbana que se expandía a un ritmo claramente superio nuevos hogares. ${ }^{9} \mathrm{~A}$ ello se unía una férrea competencia en dicha búsqueda con el resto de residentes, lo que podía restringir las opciones de asentamiento.

La posición que ciertos barrios ocupaban en el imaginario social de la población era también un condicionante poderoso en la elección de la futura vivienda. Los factores que más coartaban a los inquilinos tenían que ver con la mala reputación de ciertos barrios propagada por informes de sanidad y noticias de prensa donde continuamente se aludía a aspectos como la delincuencia, prostitución, miseria y pobreza, tasas de mortalidad e impacto de epidemias. Salir de un barrio humilde del centro para afincarse en otro situado al sur de la antigua cerca era así el último recurso a utilizar ante una situación de marcada necesidad económica.

La influencia de la comunidad y del ciclo vital en los procesos de movilidad residencial.

Mudarse a otra vivienda no era una decisión aleatoria. Estaba marcada por las contingencias de los individuos a lo largo de su ciclo vital y se relacionaba con aspectos como el matrimonio o los cambios producidos en el tamaño familiar, que podían obligar a buscar hogares más caros o más asequibles dependiendo de la condición social y económica del cabeza de familia. El hecho de que éste pudiese alcanzar unos ingresos más elevados podía ser un estímulo para emprender el desplazamiento a casas más modernas y amplias, si bien el desempleo o una movilidad profesional descendente podían llevar a escoger el camino contrario.

Al margen de las circunstancias individuales pesaba, y mucho, la importancia del espacio de acción cotidiana en el que se trabajaba, se compraba y se tejían relaciones con amigos, familiares y vecinos. Los inquilinos podían mostrarse reacios a abandonar un barrio si ya eran conocidos en él, si se habían ganado la confianza de los comerciantes de la zona para beneficiarse de las prácticas del crédito y del fiado y si disponían de inestimables apoyos en tiempos de necesidad Salir de aquellas áreas para instalarse en otras completamente distintas y distantes de los anteriores suponía repetir todo el proceso que había permitido conseguir esas credenciales a nivel comunitario.

Los barrios más populares del centro urbano eran además centros de actividad social donde la pequeña tienda de comestibles o la taberna jugaban un papel muy relevante a la hora de intercambiar información sobre el vecindario..$^{10} \mathrm{El}$ grado de asimilación social del individuo al paisaje de un determinado barrio y las influencias dominantes ejercidas por pequeñas comunidades, basadas siempre en una calle, actuaban como razones de peso para buscar una vivienda en un corto radio de acción. Esta solución evitaba una ruptura emocional manteniendo intacta la interacción con antiguos vecinos. Este fenómeno adquiere más relevancia si consideramos que a principios del siglo XX no se presentaba más que en unas pocas zonas e modelo de vivienda cerrada y encapsulada que triunfaría en Europa durante el primer tercio del Novecientos."

Uno de los estudios clásicos en que se valora esta cuestión es: Enid GAULDIE: Cruel habitations: $A$ history of working-class housing, 1780-1918, Nueva York, Barnes and Noble, 1974.

10 La función de los comercios tradicionales como espacios de sociabilidad en los barrios más populares de los centros urbanos venía favorecida por las escasas diferencias que sus dueños presentaban con respecto a la clientela desde un punto de vista social y económico y por su participación ban con respecto a la clientela desde un punto de vista social y económico y por su participación
cotidiana en las actividades rutinarias de los barrios. Geoffrey CROSSICK y Heinz-Gerhard HAUPT: The petite bourgeoisie in Europe, 1780-1914, Londres, Routledge, 1995, pp. 118-120.

11 Martin DAUNTON: House and home in the Victorian City, Londres, Edward Arnold, 1983. 
De esta forma, las opciones residenciales se repartían en torno a unos quince o veinte barrios que recorrían longitudinalmente el centro urbano. Casi una cuarta parte de los desplazamientos se producían entre barrios contiguos, sin que ello supusiera más que mudarse a una casa situada en los numeros pares o impares de una via principal o en sus traseras: Un mayor sentimiento de comunidad podía provocar que la mudanza no supusiera cambio alguno a efectos administrativos y que el cabeza de familia siguiera viendo las mismas caras de camino al trabajo, acudiendo a la misma taberna, realizando sus compras en los mis mos establecimientos e incluso ejerciendo su derecho de voto en el mismo colegio electoral. Asimismo, y dado que el centro era un espacio abarcable a pie que apenas recorría 2,5 kilómetros entre sus polos opuestos, existía la posibilidad de trasladarse a otra zona también próxima que, aun no siendo adyacente, era familiar para el inquilino y sus acompañantes. EI resto de casos se correspondía con desplazamientos hacia otros barrios y distritos, algo más comunes entre los nacidos en la capital aunque casi siempre dirigidos a espacios situados en los límites del casco antiguo. Un mayor alejamiento del centro urbano implicaba, en la mayoría de los casos, una movilidad residencial descendente, siempre y cuando el desplazamiento no se hubiese realizado hacia uno de los nuevos y majestuosos barrios de hotelitos y viviendas unifamiliares del Ensanche.

\begin{tabular}{|l|l|l|l|l|l|}
\hline Tipo de movilidad & Madrileños & $\%$ & Inmigrantes & $\%$ & Dif. madrileños/inmigrantes \\
\hline $\begin{array}{l}\text { Hacia barrios } \\
\text { adyacentes }\end{array}$ & 220 & 22,54 & 819 & 25 & $-2,46$ \\
\hline En el mismo barrio & 92 & 9,43 & 301 & 9,19 & $+0,24$ \\
\hline En el centro urbano & 126 & 12,91 & 471 & 14,38 & $-1,47$ \\
\hline Hacia otros distritos & 538 & 55,12 & 1705 & 52,05 & $+3,07$ \\
\hline
\end{tabular}

Fig. 04 Movilidad de las familias residentes en el centro urbano en función de su procedencia geográfica y barrio de destino. Fuente. Elaboración propia a partir de los datos extraídos del Padrón Municipal de Habitantes de 1905, AVM, Estadistica.

En cuanto a los protagonistas de estos movimientos, predominaban los desplazamientos en pareja o en familia. El nacimiento de un hijo, la llegada de un pariente cercano en busca de trabajo o la acogida de uno de los padres cuando enviudaban y se veían amenazados por un posible empobrecimiento generaban la necesidad de buscar una vivienda más amplia o más barata lejos del emplazamiento original. La mayor parte de las familias que emprendían los desplazamientos eran nucleares, aunque las cifras alcanzadas por las extensas basadas en la corresidencia con otros parientes era muy significativa. Las necesidades económicas de las mujeres viudas que residían junto a sus hijos y de las familias que recurrían al realquile de habitaciones eran también factores decisivos a la hora de buscar viviendas más baratas, mostrando una movilidad similar e incluso superior a la mostrada por jóvenes matrimonios.

12 La persistencia de estas familias en torno a una misma área y la movilidad entre barrios contiguos ha sido relacianada con la existencia de sistemas migratorios cerrados entre diversos centrosur banos: Richard DENNIS: "People and Housing in Industrial Society", en M. PACIONE (ed): Historical Geography: Progress and Prospect, Londres, Croom Helm, 1987, pp. 184-216.

\begin{tabular}{|c|c|c|}
\hline Clasificación familiar & Número de familias & Porcentaje \\
\hline Solitario & 209 & $5,56 \%$ \\
\hline Familiares sin núcleo & 184 & $4,90 \%$ \\
\hline Pareja & 403 & $10,72 \%$ \\
\hline Nuclear & 1.036 & $27,57 \%$ \\
\hline Monoparental & 460 & $12,24 \%$ \\
\hline TOTAL NUCLEARES & $\mathbf{2 . 2 9 2}$ & $\mathbf{6 0 , 9 9 \%}$ \\
\hline Extensa & 802 & $\mathbf{2 1 , 3 4 \%}$ \\
\hline Troncal & 51 & $\mathbf{1 3} \% \%$ \\
\hline Múltiple & 86 & $\mathbf{2 , 2 9} \%$ \\
\hline TOTAL COMPLEJAS & $\mathbf{9 3 9}$ & $\mathbf{2 4 , 9 9 \%}$ \\
\hline Realquilados sin núcleo & 87 & $\mathbf{2 , 3 2} \%$ \\
\hline Pseudoextensa & 367 & $9,77 \%$ \\
\hline Múltiple realquilado & 73 & $\mathbf{1 , 9 4} \%$ \\
\hline TOTAL REALOUILADOS & $\mathbf{5 2 7}$ & $\mathbf{1 4 , 0 3 \%}$ \\
\hline
\end{tabular}

Fig. 05 Estructura familiar de las familias móviles residentes en el centro de Madrid, 1905-1910. Fuente. Elaboración propia a partir de los datos extraídos del Padrón Municipal de HabiFuente. Elaboración propia a pa
tantes de 1905, AVM, Estadística.

\section{Criterios sociales y profesionales en la movilidad residencial.}

El nivel de estatus social, determinado por la ocupación profesional del cabeza de familia, abría paso a unas primeras diferenciaciones claras en la frecuencia de los desplazamientos de la población madrileña. ${ }^{13}$ Las categorías sociales más desahogadas se trasladaban con menos frecuencia y las más necesitadas, protagonizadas por jornaleros y artesanos poco cualificados, cambiaban de vivienda en numerosas ocasiones a lo largo de su ciclo vital. Esta es una característica detectada en buena parte de los estudios de movilidad residencial centrados en otras ciudades europeas, sin embargo, no parece evidente que las familias de mayor estatus social tiendan a protagonizar desplazamientos de mayor distancia en comparación con las menos aventajadas. ${ }^{14}$ Esta diferencia se explica por la propia estructura de la ciudad, que concentraba los barrios más opulentos en el centro y en el este, a pocas manzanas de distancia de los principales puntos de partida del mencionado sector.

Los hogares encabezados por los grupos profesionales más avanzados y los de clase media sentían con menor intensidad las presiones económicas que actuaban sobre jornaleros y trabajadores poco cualificados. Su tasa de permanencia en una misma vivienda era más alta y el cambio sobrevenía como resultado de un deseo por mejorar sus condiciones de vida. Este factor generaba una cierta preferencia por los barrios del este del casco antiguo situados por encima de la línea de la calle de Atocha, por zonas cada vez más aptas para una cómoda y apacible convivencia en torno al eje Prado-Recoletos-Castellana y por las modernas residencias dispuestas en los espacios de clase media del Ensanche Este. Retiro, Conde de Aranda, Marqués

13 Un análisis de la segregación social en relación al mercado inmobiliario en: Fernando VICENTE, Borja CARBALLO y Rubén PALLOL: "Luces y sombras en la gran ciudad. Radiografía de la segregación social en el Madrid del Ensanche (1860-1905)"en Coloquio sobre la ciudad y la modernización en la España Contemporánea, Cádiz, 2009.

14 Jean Luc PINOL: "La mobilité dans la ville, révélateur des sociétés urbaines", en Faire son chemin

dans la ville: la mobilité intraurbaine, Annales de démographie historique, $n^{\circ}{ }_{1,1999}, \mathrm{pp} .7-16$. 
de Salamanca, Monasterio, Biblioteca y Fernando el Santo robaron claramente protagonismo a ciertos puntos del centro como Tudescos o Jardines, cuyo estado degradado, congestionado y hasta ruinoso había sido advertido poco antes por José López Sallaberry y Francisco Andrés Octavio en la elaboración de la memoria del proyecto de la Gran Vía. Alquilar o comprar una casa en el nuevo espacio residencial de la burguesía y las élites madrileñas suponía una inyección de prestigio social para aquellas familias que decidieron abandonar el casco antiguo.

Pese a todo, los profesionales liberales también permanecieron en ciertos barrios del centro como Isabel II, Carlos III y San Martín, aunque siempre concentrados en las viviendas más caras y lujosas. Otros optaban por escapar hacia el recién construido barrio de Argüelles, donde se podían encontrar viviendas de grandes dimensiones dispuestas en espacios ajardinados que cumplían con las medidas higienistas de la época. ${ }^{15} \mathrm{El}$ sagrado respeto de las mismas explica el rechazo de los barrios del sur del casco antiguo, desconocidos por completo para este grupo social y asociados a la peligrosa congregación masiva de sectores populares.
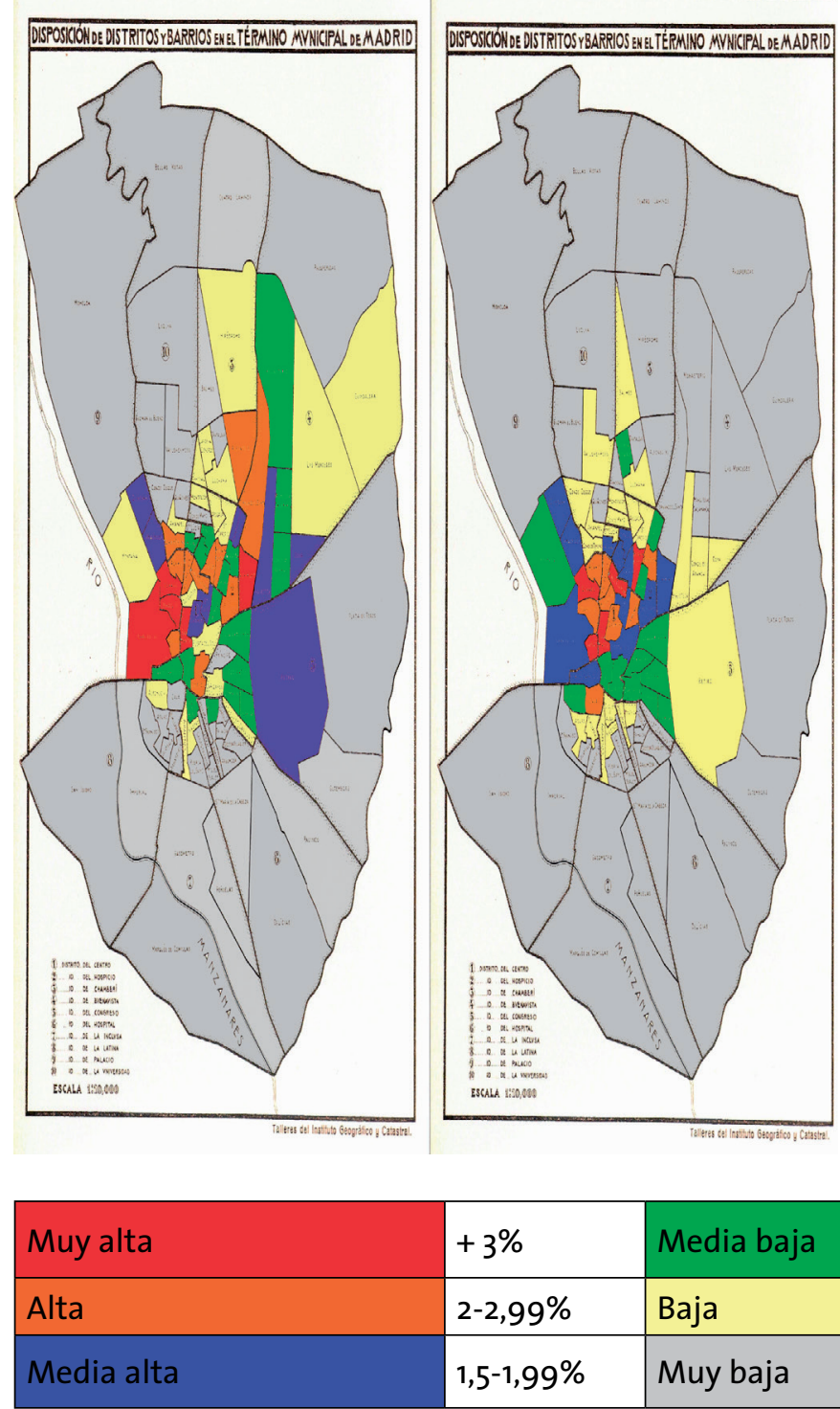

\begin{tabular}{|l|l|l|}
\hline$+3 \%$ & Media baja & $1-1,49 \%$ \\
\hline $2-2,99 \%$ & Baja & $0,5-0,99 \%$ \\
\hline $1,5-1,99 \%$ & Muy baja & $-0,5 \%$ \\
\hline
\end{tabular}

Gráf. 02 Movilidad residencial de las familias encabezadas por profesionales liberales y empleados de cuello blanco en el centro de Madrid (1905-1910). Fuente: Elaboración propia a pardir de los datos extraídos del Padrón Municipal de Habitantes de 1905, AVM, Estadística.

15 Alicia DíEZ DE BALDEÓN GARCíA: “El nacimiento de un barrio burgués: Argüelles en el siglo XIX", en Norba- Arte, $n^{\circ} 13,1993$, pp. $231-268$
El heterogéneo grupo de empleados de cuello blanco, en el que tenían cabida desde trabajadores del sector de la banca y seguros hasta agentes de seguridad, ordenanzas y vigilantes pasando por pequeños comerciantes, y los diversos rangos de estatus social presentados en aquel dan como resultado una movilidad algo menos dispersa que la ofrecida por el grupo anterior. La tendencia general fue la de protagonizar traslados de corta distancia y una preferencia casi absoluta por los barrios que rodeaban a la Puerta del Sol. El grado de movilidad hacia aquella zona era notable, determinada por la apertura de un negocio en alguna de sus calles adyacentes y por la necesidad de vivir en un entorno próximo cuando concluía la jornada laboral. Aumentaban los casos de movilidad residencial descendente hacia zonas más baratas y peor consideradas como los barrios de Aguas y Humilladero en Latina y Amazonas, Rastro, Jesús y María y Ministriles en Inclusa y Hospital. No obstante, aquellas elecciones no deben enmascarar una predilección por las áreas del este y norte del casco antiguo, cuyos límites podian ser cruzados en algunas ocasiones para asentarse en ciertos espacios de Chamberí.

Dentro de este grupo social, los pequeños comerciantes eran especialmente proclives a desplazarse a otros barrios en función del estado de salud de sus negocios. Aún siendo cierto que el centro de Madrid reunía las empresas comerciales más prósperas, también constituía un espacio en el que se refugiaban humildes tenderos, cuyas ambiciones eran ampliamente superadas por sus exiguos recursos económicos. Estos últimos se veían particularmente presionados por problemas derivados con la inestabilidad, la quiebra o la necesidad de traspasar sus negocios. Pero en realidad, era la misma facilidad de entrada en el sector una de las principales causas de su inestabilidad, algo que no era tan frecuente en el sector artesanal, en el que con frecuencia era necesaria una base previa para la especialización de que se tratara.

Volatilidad y fragilidad fueron asi dos características inherentes al sector de la distribución ya señaladas por otros autores para el continente europeo durante el siglo XIX, llegando incluso a aludir a la existencia de un proletariado mercantil. Sus componentes no se empobrecían como consecuencia de la bancarrota de sus negocios, ya que eran las propias necesidades económicas las que les convertían en comerciantes. Se veían entonces en la obligación de erigir modestos establecimientos para así aportar ingresos subsidiarios a la unidad familiar. Buena parte de estas pequeñas tiendas eran abiertas por trabajadores con pocos ahorros que dejaban el control de aquellas en manos de sus mujeres mientras desempeñaban otro empleo remunerado. ${ }^{16}$

El análisis de la movilidad residencial de artesanos y trabajadores manuales evidencia una concentración muy significativa en los barrios más asequibles y de condición popular del centro de la ciudad (Álamo, Senado, Estrella, Jardines y Muñoz Torrero) cuya influencia se extendía hacia áreas de similares condiciones del norte del casco antiguo. Los desplazamientos se expandían como una mancha de aceite hasta alcanzar los enclaves situados en los distritos de Chamberí, Latina, Inclusa y Hospital e incluso áreas como Gasómetro en el Ensanche Sur. Los que protagonizaban traslados con un criterio descendente eran, generalmente, los trabajadores manuales situados en los estratos peor remunerados del sector. La progresiva subdivisión y redistribución de las tareas desempeñadas por los artesanos provocó que su posición en la economía urbana pasara de central a marginal y que muchos se convirtieran en trabajadores a destajo con retribuciones salariales mínimas y en situación de equidad con los jornaleros.

Pero independientemente del grado de movilidad que manifestasen los anteriores grupos sociales, en ningún caso era superior al mostrado por los jornaleros. Sus movimientos residenciales estaban definidos por el carácter eventual de su actividad laboral y por la necesidad

16 Estos factores sirven para establecer una división entre los establecimientos más vinculados a la comunidad inmediatamente colindante a su negocio, más tendentes a la desaparición, y otros comercios de impacto geográfico mucho más notable extensible a toda la ciudad. Thea VIGNE y (ed.), The Lower Middle Class in Britain, 1870-1914, Londres, Croom Helm, 1977, pp. 184-209. 
de garantizar un corto desplazamiento entre el lugar de trabajo y su residencia. Las escasas posesiones materiales de sus familias y la alta disponibilidad de vivienda de alquiler a bajo precio provocaban que sus traslados no supusieran problema alguno y se convirtieran en un comportamiento típico de su existencia en el mundo urbano.

En el centro de la ciudad los desplazamientos eran de corta distancia y siempre producidos entre los barrios más asequibles (Álamo, Senado, Estrella, Espejo o Minas). Sin embargo, las áreas del sur del casco antiguo y del Ensanche, así como Plaza de Toros en el este, ganaron un mayor protagonismo entre sus nuevos asentamientos. También lo hicieron los barrios más populares del Ensanche Norte e incluso las zonas más alejadas del extrarradio como Cuatro Caminos y Bellas Vistas, a donde llegaron familias inmigrantes de origen rural inicialmente ubicadas en el centro de la ciudad. Su dificultad de adaptación a la ciudad, especialmente si venían de núcleos rurales muy alejados, podía ser otro estímulo de relevancia para incrementar su grado de itinerancia y el área de influencia en sus desplazamientos.
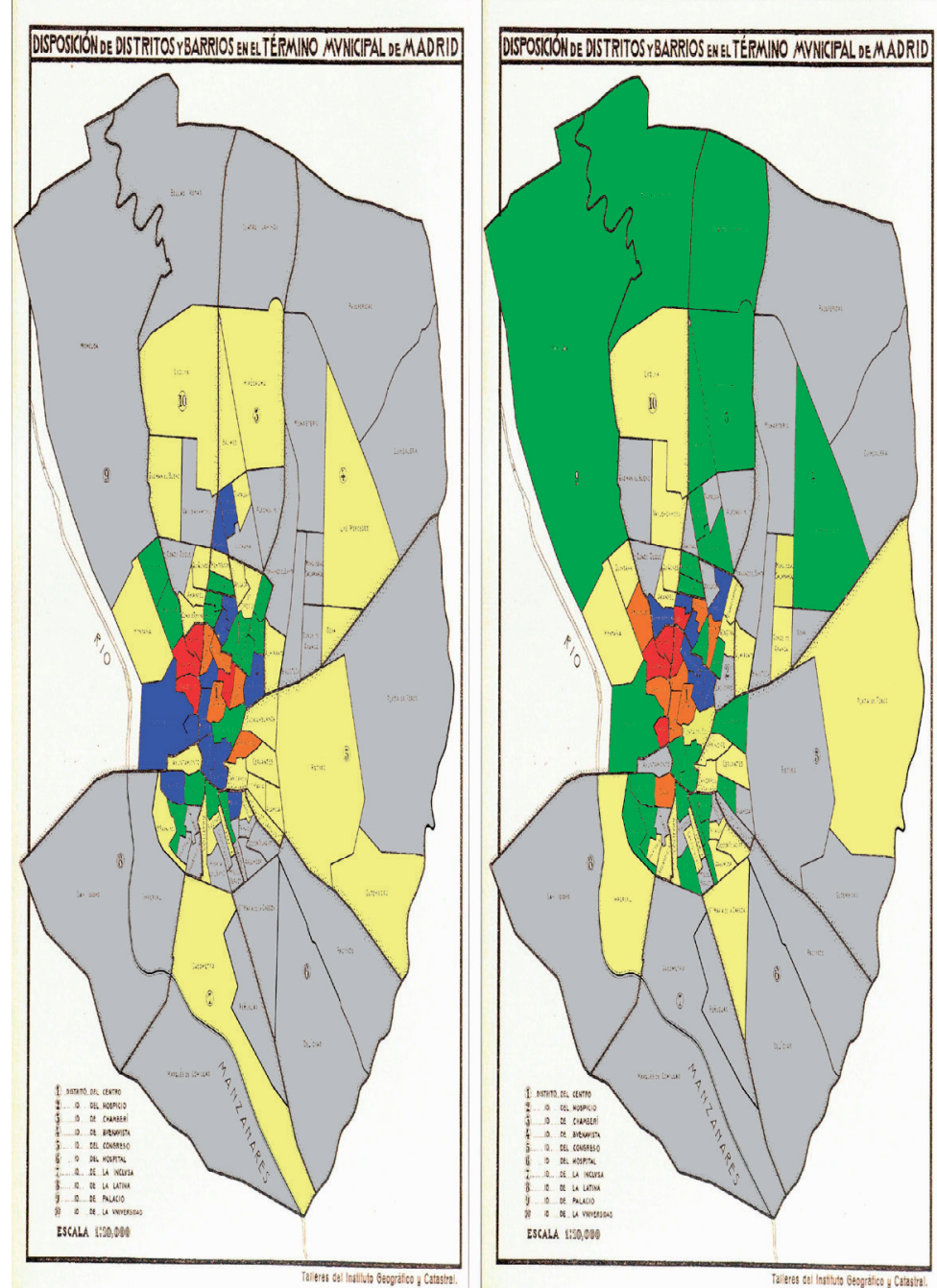

\begin{tabular}{|l|l|l|l|}
\hline Muy alta & $+3 \%$ & Media baja & $1-1,49 \%$ \\
\hline Alta & $2-2,99 \%$ & Baja & $0,5-0,99 \%$ \\
\hline Media alta & $1,5-1,99 \%$ & Muy baja & $-0,5 \%$ \\
\hline
\end{tabular}

Gráf. 03 Movilidad residencial de las familias encabezadas por trabajadores manuales y por jornaleros en el centro de Madrid (1905-1910). Fuente: Elaboracion propia a partir de los datos extraídos del Padrón Municipal de Habitantes de 1905 AVM, Estadistica.
Los diferentes tipos de movilidad intraurbana no eran, por tanto, independientes del nive de estatus social de las familias residentes en el centro de Madrid. Las categorías más desfavorecidas cambiaban de vivienda con mayor frecuencia y, aunque diversos estudios han destacado su preferencia por las cortas distancias, es evidente también como, en el caso de la capital española, los traslados podían llegar a incidir hasta en los barrios más periféricos. Madrid era una ciudad en permanente recomposición social como consecuencia de unas costumbres residenciales que seguían distando de ser permanentes o sedentarias y que tendían a favorecer la segregación social del espacio urbano. 
"LA EXTINCIÓN DE LOS FOCOS IRREDIMIBLES":

\section{POLIITICA DE RECONSTRUCCIÓN Y CONTROL EN EL}

EXTRARRADIO MADRILEÑO. EL CASO DE LA BARRIADA

\section{DEL TERCIO Y EL TEROL.*}

Daniel Oviedo Silva

Seminario Complutense "Historia Cultura y Memoria"

Universidad Complutense de Madrid

¿Es la ciudad (o un conjunto de ciudades) un sitio meramente pasivo o red preexistente, el lugar donde aparecen y se expresan corrientes más profundas de la lucha política? A primera vista podría parecer así; pero también está claro que ciertas características ambientales urbanas son más propicias a las protestas rebeldes que otras [...] El poder político suele tratar por eso de reorganizar las infraestructuras y la vida urbana atendiendo al control de las poblaciones levantiscas

David Harvey, Ciudades Rebeldes.

La reconstrucción de los barrios devastados ha de remediar tan grandes defectos, precisando cuáles tienen posibilidades de entrar en una ordenación mínima con todos los servicios previstos, y decidiendo sin debilidades la extinción de todos los focos irredimibles, por otro la fe en una España nueva.

Pedro Bidagor, Primeros problemas de la reconstrucción de Madrid. ${ }^{2}$

\section{La redención del espacio}

En abril de 1940 Pedro Bidagor ofrecía a los lectores de la revista Reconstrucción su receta para la actuación en la maltrecha capital. Tras su paso por la Sección de Arquitectura de la CNT, Bidagor se situaba entonces al frente de la Junta de Reconstrucción de Madrid siendo por ello uno de los máximos responsables del modelo y política a seguir para remediar la situación legada por la contienda. ${ }^{3}$ En aquel artículo, el urbanista repasaba las líneas maestras de su propuesta y las principales tareas a completar, pero, muy particularmente, se detenía en aquellos "focos naturales de insubordinación" en que "la vida es agria y propensa a cualquier género de revolución": el extrarradio. ${ }^{4}$ aprovechando esta circunstancia única que nos ofrecen por un lado las destrucciones y

Su diagnóstico de errores se resumía en tres defectos fundamentales presentes y reconocibles en estos barrios: especulación, la suciedad y la insolidaridad. El carácter rebelde de aque llos espacios tendría que ver, a su juicio, con el hecho de haber relegado a las clases humildes fuera de la ciudad a enclaves carentes de orden y servicios, "en la anarquía más completa, sin posibilidad de sentirse incorporados a la misión colectiva de la ciudad". Favorecía igualmente este perfil subversivo una "anarquía moral" atribuida a la falta de una organización que socorriese sus necesidades y agravada por la carencia de iglesias, plazas de reunión, mercados, escuelas, centros sanitarios o lugares de esparcimiento. Hacía ya largo tiempo que aquellos incontrolables brotes urbanos empañaban la imagen de la capital y entrañaban un grave trastorno para los gestores de la ciudad. Demasiado tiempo. ${ }^{5}$

Ciertamente el análisis del autor carecía de originalidad. En él resonaban interpretaciones previas a la guerra y no pocos especialistas y profanos se expresaban en términos semejantes en aquellos momentos de inmediata posguerra. Todos proferían torrentes de palabras vejatorias sobre el extrarradio proyectando un tupido collage de estampas urbanas a medio camino entre el odio de clase y los pánicos morales con denominación de origen. Periódicos, publicaciones especializadas o ponencias de lo más variado se referían a un "cinturón sucio, hosco, aguardentoso y cochambre" que encerraba "miserias materiales y morales", una "existencia infrahumana" y, por tanto, un "dolor permanente". Aquellas miserias provocarían tanto una "contaminación de los espíritus" como una "depauperación física y moral de la raza", alimentarían "bajas pasiones y malvados instintos" e "ideas de venganza y rencor" y crearían, en definitiva, verdaderos "brotes de gangrena social". En el mapa madrileño de los horrores todos parecían convenir al situar la guarida del mal. De aquellos barrios de miseria y degeneración habrían salido los "tarados", "asesinos" o "antropoides" responsables de la "revolución comunista" y la violencia de retaguardia. ${ }^{6}$

Y Bidagor sentenciaba: a la destrucción material había acompañado más de un siglo de destrucción moral del orden urbano. Su reconstrucción y reproducción se antojaba intolerable. Insistiendo en el desorden como motivación, aunque revistiendo siempre el argumentario de un barniz de humanitarismo y paternalismo, el hombre fuerte de la Junta de Reconstrucción lanzaba su propuesta; la apuesta del régimen: la tarea en el extrarradio no debía consistir en reunir los fragmentos legados por el colapso físico y simbólico provocado por la guerra, sino en hacer tabula rasa: construir sobre los escombros de lo viejo una nueva realidad adecuada al proyecto del nuevo estado. El régimen tallaba piezas nuevas para un viejo rompecabezas. En caso contrario se reconstruiría el "caos pasado dejando viva una fuente constante e importantísima de desorden". La coyuntura exigía, por lo tanto, discernir entre los espacios que podrían adecuarse a la nueva ordenación de carácter orgánico y aquellos otros "focos irredimibles" cuyos restos serían eliminados aprovechando las "destrucciones" y la "fe en una España nueva".

5 Ibid., pp. 17-18.

6 El entrecomillado procede de artículos anónimos en prensa y de textos de Luis Pérez Mínguez, José Moreno Torres y el propio Bidagor recogidos en Sofía DIÉGUEZ: un nuevo orden urbano: $E$ Gran Madrid (1939-1951), Madrid, Ministerio para las Administraciones Públicas y Ayuntamiento de Madrid, 1991. Pp. 148-155; Gabriel UREÑA: Arquitectura y urbanistica civil y militar en el periodo de Madrid, 1991. Pp. 148-155; Gabriel URENA: Arquitectura y urbanistica civil y militar en el periodo de la autarquia (1936-1945): Analisis, cronologia y textos, Madrid, Istmo, 1979; Olivia MUNOZ-ROEastbourne; Portland, Sussex Academic Press, 2011, pp. 24, 28.

moria de la UCM. Agradezco a los miembros del Seminario sus comentarios, que han contribuido decisivamente a mejorar el texto. David HARVEY: Ciudades Rebeldes, Madrid, Akal, 2013, pág. 173

1 David HARVEY: Ciudades Rebeldes, Madrid, Akal, 2013, pág. 173

2 Pedro BIDAGOR: “Primeros problemas de la reconstrucción de Madrid", Reconstrucción, $n^{\circ}{ }_{1}$, Abril 1940, pp. 17-21

3 Sofía DIÉGUEZ: "Pedro Bidagor. Dos contextos: los años de guerra y posguerra en Madrid. De la Sección de Arquitectura de CNT a la Junta de Reconstrucción" en Carlos SAMBRICIO (ed.): Plan Bidagor 1941-1946, Madrid, Nerea, 2003, pp. 19-34.

4 Pedro BIDAGOR: “Primeros problemas de...", pp. 17-18.

7 Pedro BIDAGOR: “Primeros problemas de...", pp. 17-18. Superando los vicios implantados por el zoning y la iniciativa privada desbocada "Ia posición tradicional y orgánica" estaba llomad a ning y la iniciativa privada desbocada "la posición tradicional y orgánica" estaba llamada a provivos", definidos para cumplir el papel que tenía raservado "en la misión conjunta de la ciudad como órgano del estado". 
Bidagor y las autoridades franquistas aspiraban, en definitiva, a ordenar nuevos espacios que ayudasen a moldear la vida social de acuerdo con los patrones propugnados del régimen. Suprimir los focos del "desorden" y con ellos cualquier vestigio de la esfera pública de los trabajadores para sustituirlos por barrios controlables en que los nuevos símbolos del poder deviniesen hitos fundamentales del paisaje y lo estructurasen. Un proceso de ingeniería social encaminado a la domesticación del Madrid rebelde.

Esta comunicación forma parte de un proyecto más amplio en que se parte del convencimiento de que, tal y como señala Rojo de Castro, estos "planes de viviendas y sus múltiples variantes permiten ordenar físicamente no únicamente el tejido urbano sino también el tejido social". ${ }^{8}$ Se pretende atender al potencial del urbanismo como instrumento de control y su papel en la desarticulación del tejido social de aquellos barrios en que con mayor pujanza se había forjado una esfera pública, activismo político y cultura de los trabajadores. Para ello es preciso detenerse en las diversas corrientes de opinión presentes en los organismos involucrados en las labores descritas. Pero se antoja también crucial el estudio de su evolución en el tiempo y la influencia de las ideologías y la coyuntura demográfica, económica o política. Resulta imprescindible asimismo preguntarse por la segregación socioespacial o la política de concesión de viviendas considerada dentro del universo de recompensas y castigos del momento. Bucear en el problema de la vivienda y el urbanismo franquista requiere andar muchos caminos, de la vivienda de lujo a la de autoconstrucción, de la legislación a la experiencia, de la promoción pública al sector privado, etc. Un estudio de mayor alcance debe igualmente tener en cuenta las dinámicas previas y detenerse en los problemas y repertorios de control urbano-espacial operativos ya antes de la guerra. Ello permitirá reflexionar sobre la medida en que se asiste a la puesta en escena de nuevas tecnologías de poder o a la reformulación de la experiencia previa a través de la poderosa cultura de exclusión política presente en el periodo franquista.

Dado que la extensión y las características del trabajo planteado no permiten abordar en toda su profundidad tales cuestiones, se ha optado por un primer acercamiento a la materia a través del barrio del Tercio y el Terol. Localizado en lo que entonces constituía el término municipal de Carabanchel Bajo, el barrio fue erigido a partir de un primer plan de 1941. Durante los años finales del siglo XIX y el primer tercio del XX, la zona había protagonizado un acelerado proceso de urbanización desordenada propia del extrarradio y, en la guerra, el frente se localizó en sus inmediaciones provocando que, junto al resto de Carabanchel Bajo, fuese declarada zona devastada y adoptada por Franco para su reconstrucción. Con las cicatrices de la contienda muy presentes, diversas instituciones participarían en la construcción de este barrio de particulares características al que siempre rodeó un archipiélago antiguo y nuevo de infravivienda sólo recientemente liquidado. En los últimos tiempos se hemos asistido a una revalorización del lugar -rebautizado por Nancho Novo como "Beberly Urgel"- e incluso hay quien vaticina que podríamos presenciar un paulatino proceso de gentrificación de Carabanchel a partir de la pinza que integrarían el Tercio y el Terol y el tándem PAU/Islazul.9

\section{El extrarradio en disputa}

Desde las últimas décadas del siglo XIX, un insistente flujo migratorio y los problemas del ensanche, provocarían la irrupción de un fenómeno de urbanización marginal, informe y es pontánea que daría lugar al extrarradio madrileño. Las zonas periféricas, generalmente en torno a las vías de acceso desde municipios cercanos, resultaron las más afectadas por la implantación de estos grupos de infravivienda huérfanos a menudo del más elemental equipa-

8 Luis ROJO DE CASTRO: "La vivienda en Madrid durante la posguerra. De 1939 a 1949" en Carlos SAMBRICIO (ed.): Un siglo de vivienda social (1903/2003), Tomo I, Madrid, Nerea, pp. 226-243, pág. 234.

9 Sergio GARCíA:Co-producción (y cuestionamientos) del dispositivo securitario en Carabanchel, Tesis

Doctoral, Universidad Complutense de Madrid, 2012, pp. 117, 211-212. miento e infraestructura. Tetuán, Guindalera, Prosperidad, Puente de Vallecas o los núcleos en torno a la carretera de los Carabancheles, fueron algunos de los ejemplos más representativos. Espacios que iban a ser ocupados preferentemente por inmigrantes que desempeñaban los empleos más precarios de la capital como jornaleros y trabajadores no cualificados. El patrón de ocupación del espacio por lo tanto, proyectaría una segregación socioespacial de importantes consecuencias en la historia social de la capital. ${ }^{10}$

Aquellos espacios se convertirían pronto en fuente de preocupación por el desorden urbanístico que implicaban pero también por su potencial como focos de insubordinación en que se gestaban comportamientos "no deseados" y una desafiante cultura obrera contestataria. Sin duda, es Barcelona la ciudad que ha inspirado los estudios más atinados en que se conjugan espacio, sociedad, barrialidad y procesos de politización." Los barris, tal como los estudia Ealham constituían un entorno social completo para los trabajadores con un orden propio basado en la reciprocidad colectiva. En ellos, la experiencia cotidiana, la lucha por la supervivencia y el aprendizaje de la opresión y la explotación generaban un sentimiento de comunidad, una conciencia local y un conocimiento de las relaciones de poder localizado en un espacio determinado. Aquellos lugares serían "espacios culturales, éticos, psicológico, sociales y físicos de contestación", organizados desde abajo y con un grado considerable de autonomía, en que los marginados "crearon la base de una fuerte resistencia obrera al capitalismo y al estado". Esta cultura de barrio sería, por lo tanto, crucial para la emergencia de una "esfera pública proletaria". En su análisis de la lucha por el espacio en el primer tercio del siglo XX, Ealham estudia también los mecanismos de control de diversa naturaleza - de los cuerpos policiales a las casas barataspromovidos a fin de pacificar estos barrios y demuestra que "el espacio urbano se desarrolla a imagen y semejanza de una determinada estratificación social". Sus trabajos ofrecen por ello un modelo inspirador para la espacialización del análisis de las relaciones de poder. ${ }^{12}$

Este tipo de investigaciones demuestran asimismo que la comprensión de la problemática del extrarradio en la posguerra requiere estudiar su trayectoria previa tanto en términos materiales como en lo relativo a la construcción cultural de espacios de alteridad. Son muchas las preguntas que pueden vehicular la investigación en este sentido ¿Qué papel tuvo en Madrid el extrarradio en la creación de una esfera pública proletaria? ¿Qué se hizo por controlar estos espacios ya antes de la guerra? ¿Acaso no se forjó desde la segunda mitad del siglo XIX una

10 Ángel BAHAMONDE y Luis Enrique OTERO CARVAJAL: Madrid. De territorio fronterizo a región metropolitana, Madrid, Espasa Calpe, 1989; Rubén PALLOL, Borja CARBALLO y Fernando VICENTE: $E$ ensanche de Madrid. Historia de una capital, Madrid, Editorial Complutense, 2004; Santos JULIÁ, David RINGROSE y Cristina SEGURA: Madrid: historia de una capital, Madrid, Alianza Editorial, 2008; Charlotte VORMS: Bâtisseurs de banlieue à Madrid. Le quartier de la Prosperidad (1860-1936), Paris, Creaphis Éditions, 2012; Javier GONZÁLEZ LÓPEZ: Madrid y su extrarradio: El distrito de Tetuán en el primer tercio del siglo XX, TFM, Universidad Complutense de Madrid, 2010.

11 Chris EALHAM: La lucha por Barcelona. Clase, cultura y conflicto 1898-1937, Madrid, Alianza, 2005 José Luis OYÓN y Juan José GALLARDO (Coords.): El cinturón rojinegro. Radicalismo cenetista y obrerismo en la periferia de Barcelona, Barcelona, Carena, 2005 12 Chris EALHAM: La lucha por... pp. 43-45, 63, 68-69, 71-72, 77-78. En esta comunicación se parte de esa identificación entre el extrarradio y determinadas culturas políticas contestatarias. Se ha opmás detenido y oportunas puntualizaciones Se entiende que tal punto de mertida es válido pero ello no implica que se afirme una correspondencia e identidad inamovible, homas allido pero ello no implica que se afirme una correspondencia e identidad inamovible, homogénea y excluresulta imprescindible evitar una simplificación excesiva derivas de una lectura escritica de las fuentes que lleve a dar por buenas las generalizaciones franquistas Precisamente de la de las comprensión e interpretación de ciertas construcciones culturales inscritas en la de la correcta na y su relación compleja con la realidad de agitación política depende un adecuagro áálisis en profundidad de las problemáticas planteadas. 
tenebrosa geografía imaginada del extrarradio? ¿Qué papel jugaron los procesos de criminalización en este fenómeno? ¿Empeoró aquella imagen proyectada con el giro hacia el defensismo social de la Segunda República? Es preciso estudiar, en definitiva, qué ingredientes previos podemos detectar en el surgimiento y consolidación de unos "condenados de la ciudad", y cómo trascienden o son reciclados y reformulados en el franquismo a la luz de una poderosa cultura de exclusión política. ${ }^{13}$

Carabanchel Bajo fue uno de los municipios limítrofes sometidos a estos procesos. Desde las últimas décadas del siglo XIX, había experimentado un notable aumento de su población vinculado, principalmente, a la atracción de la capital. Este reclamo indujo el crecimiento de barriadas próximas a Madrid habitadas por clases populares y llevó la localidad hasta los 31.00o habitantes en 1931. En los vastos terrenos que comprendía su término municipal, y a ambos lados de la carretera de Madrid a Fuenlabrada, brotaron diferentes asentamientos que irían conformando barriadas como la del Terol, Blandón, Opañel o El Tercio. Aquellos lugares, si bien se situaban en terreno perteneciente a Carabanchel Bajo, formaban parte de ese emergente extrarradio madrileño. ${ }^{14}$

Cuando en noviembre de 1936 la guerra llegó a las puertas de Madrid, el pueblo de Carabanchel Bajo fue rápidamente tomado por las tropas sublevadas. No obstante, los defensores redoblaron el ímpetu resistente en aquellos barrios nacidos del crecimiento desordenado obligando a que la lucha se desarrollase casa por casa. En un frente con escaso avance y excesivo castigo durante la contienda, los rigores de la batalla legaron un panorama de destrucción especialmente sangrante en los barrios próximos al Manzanares. Esta circunstancia valió al municipio la calificación de zona devastada y adoptada por Franco. Así, en la posguerra, además de alojar la nueva cárcel y un sinfín de instituciones benéficas, asistenciales y disciplinarias, la localidad de Carabanchel Bajo sería escenario de una actuación intensiva en materia de reconstrucción. Fueron muchas y de muy diverso cariz las actuaciones que varios organismos (Instituto Nacional de la Vivienda, Dirección General de Regiones Devastadas, Dirección General de Arquitectura, etc.) desplegaron en la localidad. Entre estas se encontraba la construcción de un nuevo barrio llamado a erigirse sobre parte de aquellos enclaves destruidos en el combate: el barrio del Tercio y el Terol. ${ }^{15}$

13 Sobre la proyección de imágenes negativas en ciertos espacios madrileños véase la interpretación sobre los "barrios del miedo" en Fernando VICENTE: Los barrios negros: el Ensanche Sur en la formación del moderno Madrid (1860-1931), Tesis Doctoral, Universidad Complutense de Madrid, 2011. "Geografía imaginada" en Edward SAID: Orientalism, London, Penguin, 1995. El “defensismo social" en Luis GARGALLO y Pedro OLIVER: "Desarrollo y colapso del penitenciarismo liberal" en Pedro OLIVER (Coord.): El siglo de los castigos. Prisión y formas carcelarias en la España del siglo XX, Barcelona, Anthropos, 2013. Los "condenados de la ciudad" tomado de Loï WACOUANT: Los condenados de la ciudad: gueto, periferias y Estado, Buenos Aires, Siglo XXI, 2007.

14 Antonio MORENO JIMÉNEZ: Carabanchel. Recuperar el espacio vivido Madrid, Junta Municipal de Carabanchel, 1983, pp. 59-128. 15 Carabanchel Bajo fue adoptado por decreto de 9 marzo de 1940. BOE, 16-03-1940. El 18 del mismo, el pleno del ayuntamiento acordaba la incoación del expediente para la reconstrucción del pueblo de Pueblos an extraordinaria del Pleno de 18 de marzo de 190 . Jorg M REVERTE: L Batalla de Madrido. Barción ex Critica, 200 ; Mi cia pá. 55 . 82. Antonio MORENO gúN. LOs Camanchel Recuperar el pág. 118; José M. SÁNCHEZ pàg. 55, 82; Antonio MOREN distrito con histabanchel. Recupera, el.., pàg. 118; Jose M. SANCHEZ (1) nes La Libreria, 1999, pp. 131-132,141; JUNTA DE RECONSTRUCCION DE MADRID:"Labor realizada por la Junta de Reconstrucción", Reconstrucción, n" 24; Daniel OVIEDO SILVA: "Paisaje urbano y mapa sajes de la memoria: La cárcel de Carabanchel, Madrid, Catarata 2013.

\section{Espacio, poder y control en el barrio del Tercio y el Terol.}

En julio de 1941 la Dirección General de Arquitectura presentaba el proyecto para la construcción de este nuevo barrio localizado entre las barriadas del Tercio y el Terol. Sólo un mes más tarde, el consejo asesor del Instituto Nacional de la Vivienda lo aprobaba y decidía hacerse cargo de emprenderlo directamente con la colaboración de Regiones Devastadas. El plan inicial contemplaba la creación de 640 viviendas -más adelante aumentadas a 682- para "familias modestas". Sobre el papel, aspiraba a dar vivienda a "numerosas familias de la clase trabajadora que vivían en aquella zona del extrarradio cuyos hogares fueron destruidos por la guerra". La constructora Mauricio Arbellay se encargaría de unas obras para las que se concedía un plazo de dos años. Todavía inacabado, y debido a la anexión de los Carabancheles, el grupo pasó a manos del Ayuntamiento de Madrid en 1950. No obstante, tan sólo 3 años des pués volvería a ser propiedad del INV cuando el Patronato Municipal de la Vivienda ${ }^{16}$ devolvió las viviendas ya completas. ${ }^{17}$

El grueso del conjunto lo integrarían viviendas unifamiliares de dos plantas adoptándose la agrupación en hilera. Sólo un pequeño grupo constaba de tres alturas: las unifamiliares con bajo destinado a comercio y algunos bloques para varias familias situados al sur del conjunto. Las viviendas unifamiliares contaban con un patio y espacio destinado a huerta pensado para el desarrollo de actividades semirrurales, como el cuidado de animales domésticos y cultivo de hortalizas. El proyecto original situaba en un extremo el centro cívico, formando una plaza en que se debería levantar la iglesia el mercado y los servicios municipales. También en los bordes debían localizarse unas instalaciones deportivas y grupo escolar, mientras se reservaba una pequeña plaza en el centro del barrio a los servicios sanitarios y Auxilio Social. Según Luis Moya, en la barriada se adivinan influencias de la ciudad jardín y las experiencias previas a la guerra en construcción de vivienda social. Por su parte, la retícula, la parcelación y su relación con la edificación, recuerdan a las siedlungen de los arquitectos del nacionalsocialismo alemán y a las propuestas del fascismo italiano. El modelo responde igualmente a los cánones de la Dirección General de Regiones Devastadas en sus poblados destinados al medio rural.18

¿Cómo podía ejercerse el control a través de la construcción de un barrio semejante? Entre los especialistas más acertados en el análisis crítico de la política urbanística y de vivienda franquista se encuentra sin duda Rojo de Castro, autor también de reflexiones de gran interés sobre el barrio que nos ocupa. Para él, la barriada formaría parte de un proyecto de segregación socioespacial o "estandarización espacial de los niveles sociales", destinada a promover una diferenciación social y económica a través de la localización de diversos grupos en barrios y viviendas que a juicio del nuevo estado les correspondían. ${ }^{19} \mathrm{Su}$ argumentación demuestra asimismo un sobresaliente potencial explicativo y gran aplicabilidad al caso del Tercio y el Terol cuando se refiere a la "fabricación de ambientes". Según esta, el modelo de vivienda rural

16 El papel del Ayuntamiento en materia de vivienda en Manuel VALENZUELA RUBIO: "Ciudad y acción municipal, la politica de vivienda del Ayuntamiento de Madrid (1868-1978)", Anales del Instituto de Estudios Madrileños, $n^{\circ} 15,1978$, pp. 327-361.

17 ARCAM. INV. 56.109, 91.742. Para el análisis del proyecto véase Luis MOYA.: Barrios de promoción oficial. Madrid 1939-1976, Madrid, COAM, 1983, pp. 101-102; ÍD.: “Los barrios del Tercio y el Terol” en SAMBRICIO, Carlos. (ed.): Un siglo de..., Tomo I, Madrid, Nerea, 2003, pp. 292-293.

18 ARCAM.INV. 91.742; “Urbanización y construcción de 640 viviendas entre los barrios de El Terol y El Tercio, Carabanchel Bajo (Madrid)", Revista Nacional de Arquitectura, $n^{\circ}$ 14, 1943, pp. 58-64; Luis MOYA: Barrios de promoción...; íD.,: "Los barrios del Tercio...".

19 No todas las posturas defendían esta segregación, aunque ésta, sin duda, prevaleció. Sobre los debates al respecto y el modelo falangista de cohabitación de clases véase: Jesús LÓPEZ Díaz: "Vivienda social y Falange: ideario y construcciones en la década de los 40 " Scripta Nova Revista electrónica de Ceografia y ciencias sociales, Vol VII núm $146(024)$, 1 de agosto de 2003. http:/l www.ub.edu/geocrit/sn/sn-146(o24).htm\#_ ednref17. 
propuesta para este barrio, con patio y agrupación de baja densidad sería impuesto como una tecnología de poder encaminada a satisfacer las necesidades de control social del régimen en el extrarradio madrileño. El modelo rural, además de adecuarse a la coyuntura económica, aspiraba a relegar los conflictos asociados a la ciudad sustituyéndolo por la estabilidad rural y fomentando una suerte de regeneración moral por medio del modo de vida tradicional. ${ }^{20} \mathrm{Tal}$ y como señala el autor:

La arquitectura del barrio del Tercio y el Terol en Carabanchel Bajo reproducía, por medio del artificio construido, la ficción de un equilibrio social asociado al ambiente rural y ajeno a los conflictos sociales, políticos y de clase que el régimen deseaba suprimir. Escenario más adecuado para el fomento de los valores patrios, como eran el apego a la tierra y sus tradiciones, a la familia o al purificador trabajo manual. ${ }^{21}$

Para Antonio Moreno Jiménez, en este tipo de proyectos "la fachada de ruralismo bucólico encubría unas pretensiones de segregación social inequívocas". ${ }^{22}$ Madrid cuenta con otros planes que guardan semejanzas con las características del barrio del Tercio y el Terol. Es el caso de barrio de la Ventilla, en la zona norte de la capital, cuyos primeros proyectos vieron la luz durante la segunda mitad de la década de los $40 .{ }^{23}$ Quedaban estos resueltos, en su mayoría, con viviendas unifamiliares para clases humildes con patios privados que reservaban igualmente "espacio para el desarrollo de actividades semirrurales" descrito como el del Tercio y el Terol. En cuanto a los deseos de forzar la segregación socioespacial, resulta reveladora la rectificación en 1948 de un primer proyecto del 46, por la que se decidía aumentar la "dignidad" y la "calidad arquitectónica" de las construcciones previstas. El cambio se debía a que los proyectos de prolongación de la Castellana y construcción de la estación de ferrocarril de Chamartín iban a conferir a la zona un protagonismo que hacía recomendable transformar las viviendas en otras de "mayor categoría social" "a tono con la importancia de la zona a que se destina" 24

En el caso del Tercio y el Terol, el barrio aparecía además como un núcleo cerrado e independiente. Tal como señala Luis Moya, la estructura centrípeta y la localización de los bloques plurifamiliares, de mayor altura, en el límite sur, implica un intento de reforzar la unidad e integración del conjunto. ${ }^{25}$ Como ha estudiado Moreno Jiménez, el primer proyecto diseñado por Bidagor en 1940 para el espacio comprendido entre el Puente de Toledo y Carabanche Bajo, contemplaba la creación de varios núcleos separados: uno en el Puente de Toledo, otro en torno al barrio del Tercio y el Terol, y un tercero creado a partir del pueblo de Carabanchel Bajo. El núcleo en que se incluía el Tercio y el Terol quedaba así aislado de su entorno al apartarlo de la ciudad de Madrid un anillo verde y de Carabanchel Bajo una zona industrial. ${ }^{26}$

El nuevo paisaje diseñado por el régimen aspiraba a reemplazar al sinnúmero de viviendas que habían proliferado en las décadas precedentes como consecuencia de la atracción de $\mathrm{Ma}$ drid, ahora ilocalizables en los planos de los proyectos. Se eliminaría uno de esos focos irredimibles, incontrolables y, muy particularmente, un espacio en que se había resistido casa por

20 Luis ROJO DE CASTRO: “La vivienda en..." pp. 226-243.

21 Ibid., pág. 238.

22 Antonio MORENO JIMÉNEZ: Carabanchel. Recuperar el..., pág. 15

23 Véase Enrique FIDEL: "Tetuán de las Victorias: Ayer y Hoy de un barrio de Madrid", Urban Idade, Memorias de las redes urbanas, 2008 (http://urbancidades.wordpress.com/2008/08/07/tetuande-las-victorias-ayer-y-hoy-de-un-barrio-de-madrid/)

24 ARCAM. Comisaría General para la Ordenación Urbana de Madrid y sus Alrededores. 137.047, 216.851

25 Luis MOYA: “Los barrios del...", pág. 292.

26 Antonio MORENO JIMÉNEZ: Carabanchel. Recuperar el..., pp. 155-160; Carlos SAMBRICIO (ed.): Plan Antonio Madrid Nerea, 2003.VV:AA: Los planes de Orden. Is ción General de Urbanismo y Planificación Regional, Comunidad Autónoma de Madrid, 2006. casa al avance de las tropas sublevadas durante el asedio a la capital. Según González Ruibal, parte de las actuaciones del régimen en la localidad durante la inmediata posguerra -entre ellas el planeamiento urbano- se conducirían por la expresa voluntad de tomar represalias po su resistencia. A ello podría añadirse, sin duda, la intención de implementar mecanismos de control efectivos para el futuro. ${ }^{27}$ Barrer el barrio resistente del mapa, rediseñar sus espacios, su planimetría y callejero y convertirlo en un enclave habitacional de baja densidad y segregado contribuirían a la tarea.

Por otra parte, al tratar la cuestión de la vivienda como espacio a habitar, la arquitectura y el diseño son considerados herramientas transformadoras de la vida cotidiana y se les atribuye un decisivo potencial generador de comportamientos. Así, en un artículo publicado en 1942 en Reconstrucción, Luis García de la Rasilla reflexionaba sobre el hogar cristiano, sus características ideales y el papel del arquitecto católico. Partía de la convicción de que "el hogar es un aula abierta. Un taller cotidiano de aprendizaje. Una fragua donde continuamente se modelan los cuerpos y las almas de los hijos"

Recalcaba la obligación de contar con dormitorios independientes "para cada sexo y para cada edad" execrando las soluciones inmorales "que tienden a convertir el hogar en una fonda". Pero ante todo primaba que el hogar fuese el agradable "reino" de cada hombre español y que se convirtiese en "un baluarte contra la injerencia del mundo exterior". Debía así ser capaz de neutralizar "el aliciente de los lugares públicos" previniendo que el cabeza de familia "este deseando salir a la calle". ${ }^{28}$ Es el hogar cristiano como antídoto contra la calle y sus efectos nocivos. La calle como símbolo que reúne todos los males, peligros y pánicos morales. Al fin y al cabo, era en la convivencia, en la vecindad, en la experiencia cotidiana y compartida de la subalternidad; era, en definitiva, en la calle, donde se había forjado buena parte de la esfera pública de los trabajadores, su socialización política y su constitución en verdadero contrapoder y agente transformador. Los años de la república y la revolución dejaban pocas dudas al respecto.

Del planteamiento se desprende que debían encaminarse los esfuerzos a convertir los hogares en reinos en que sus monarcas permaneciesen cautivos. Huertas y patios constituirian un universo indoor que, en el caso del barrio que nos ocupa, merma considerablemente el espacio de uso común disponible. ${ }^{29}$ De puertas afuera las relaciones sociales y la vida pública aparecían estructuradas por los símbolos y espacios del poder. Así, la única plaza de dimensiones considerables proyectada inicialmente para la colonia se abría frente a la iglesia. Esta labor de atomización complementaría a otras operaciones de extirpación de la cultura obrera forjada durante décadas y se completaría con programas de socialización en los valores de nuevo estado.

\section{¿Fracaso de un proyecto?}

Retrasos, variaciones en el proyecto y defectos en la ejecución constituyen los incumplimientos más palpables en el ámbito material del plan inicialmente diseñado Pese a que la obra había sido pensada para un plazo dos años, los trabajos no concluyeron hasta 1951-52. El constructor achacó la demora a la escasez en el suministro de los materiales y productos inter-

27 Alfredo GONZÁLEZ RUIBAL:“Topography of terror or cultural heritage? The monument of Franco's Spain" en Robin PAGE y Guillermo PEREZ (eds.): Europe's deadly century. Perspectives on zoth century conflict heritage, Kemble Drive, Swindon, English Heritage, 2009, pp. 65-72, pág.69.

28 Luis GARCÍA DE LA RASILLA: "Viviendas de renta reducida en Carabanchel Bajo (Madrid)" Reconstrucción, $n^{\circ} 26,1942$, pp. 353-363. Si bien se refiere a otras viviendas de la misma localidad, las reflexiones acerca del espacio a habitar son de carácter general y aplicables a nuestro caso de estudio.

29 Durante la revisión del proyecto en 1941, el propio arquitecto jefe apuntaba que no se había previsto un CAM.INV. Caja 56.109 
venidos, circunstancia agravada por el mal estado en que se encontraba el terreno por haber sido minado durante la guerra. El paso de los años impuso la revisión de precios contradictorios en innumerables ocasiones y el proyecto sufrió varias modificaciones entre las que se cuenta la desaparición de la plaza y la iglesia o el centro sanitario y de Auxilio Social, Ilamado a ocupar el corazón del núcleo. Los elementos más sobresalientes de este último emplazamiento acabarían siendo el depósito de agua y el transformador, todo un símbolo de la prevalencia de la funcionalidad para Moya. ${ }^{30}$ Por su parte, las 176 bocas de riego, pensadas sin duda para las actividades "semirrurales", fueron sustituidas por solo 18, para casos de incendio. ${ }^{11}$ Muchas viviendas presentaron diferentes problemas casi inmediatamente. En el año 1955 en la Calle Gesaleico fueron declarados en ruina dos locales comerciales y se obligó a los inquilinos de otras dos viviendas a abandonarlas por el peligro que su estado representaba. Ese mismo año, los vecinos de 15 viviendas de la calle Amalarico firmarían una petición para que se reparasen una goteras que estaban causando graves deterioros. Los fallos se multiplicarían en aspectos como el tendido telefónico o el suministro de agua y las autoridades debieron proceder muy pronto a estudiar las oportunas reparaciones. ${ }^{32}$

Resulta complicado ponderar la efectividad real del proyecto de control a través de la arquitectura y la planificación urbana. No obstante, parece evidente que muchos de los resortes dispuestos a tal efecto en el plan original quedaron desvirtuados. La construcción de un espacio bucólico y segregado sufrió otros contratiempos aparte de los mencionados. Como era de esperar, y pese a que la versión oficial repetía que el objetivo fundamental del grupo proyectado era paliar la situación de carencia de vivienda de la zona, el barrio del Tercio y el Terol no contribuyó decisivamente a remediar el problema de la infravivienda. No sólo tardó casi una década más de lo proyectado en llevarse a efecto, sino que la zona habría precisado un número mayor de casas a disposición de la creciente población. El propio arquitecto encargado de revisar la memoria original señalaba en agosto de 1941 que los precios de los alquileres de las nuevas viviendas podrían resultar problemáticos en un barrio en que tendían a ser más bajos. Al mismo tiempo, se mostraba en desacuerdo con el patrón de ocupación del suelo adoptado al entender que la política del INV debía ser fomentar el máximo aprovechamiento del mismo y optar por una mayor densidad de población. ${ }^{33}$

En cualquier caso, el grupo continuaba conviviendo con parte de las antiguas construcciones a las que de modo paulatino se sumaban otras nuevas resultado de la riada migratoria. Es incluso posible, dado el retraso, que las obras empeorasen la situación de la vivienda dado que, como apunta una memoria emitida en 1944, el problema se había agravado al sumarse a las destrucciones la "necesidad de desalojar las chozas y barracas de latas que albergaban a los propietarios y vecinos que ha sido preciso expropiar y derribar para la construcción de nuevas viviendas". ${ }^{34} \mathrm{Si}$ bien sería preciso estudiar en qué medida la propia existencia de una brecha entre la infravivienda y la vivienda de mayor calidad preferentemente al alcance de los simpatizantes del régimen, puede ser empleada como instrumento de control y tener efectos pedagógicos, parece que el problema del chabolismo escapaba al control del régimen. Y con el chabolismo, el cumplimiento fiel de un plan de barrio cerrado en que sólo había lugar para la vivienda recogida en los planos.

Los censos de infraviviendas de la segunda mitad de los años 50 documentan centenares de hogares en deplorables condiciones: casas, chabolas, naves o cuevas, tanto en el Tercio y el Terol como en otros enclaves cercanos: Caño Roto, Jauja o el Matadero. Las inmediaciones

30 Luis MOYA: “Los barrios del...", pág. 292.

31 ARCAM, INV. 56.109, 91.742

32 ARCAM. INV. 93.364

33 ARCAM. INV. 56.109

34 ARCAM. INV. 91.742 de la barriada se ven salpicadas por este tipo de viviendas en calles como Sansón Carrasco, el Toboso, Particular o el Camino Viejo de San Isidro. En el patio de una casa de la calle Manuel Zanón, por ejemplo, se descubrieron tres chabolas, una de ladrillo y dos de madera, en que vivían sendas familias. 35 El propio cura de la Parroquia de San Roque y Santa Micaela se dirigía al INV en noviembre de 1956 para hablarle de unos vecinos en los siguientes términos:

en una chabola, en ruinas, de la calle Particular $n^{\circ} 6$ de tras (sic) de Mataderos, barriada Tercio-Terol, [...], reside el matrimonio [...] con tres hijos menores, él vendedor ambulante, ella enferma, en una sola habitación donde tienen dos camas y hacen la comida, y sin más elementos de higiene. Por todo lo cual les es urgente y necesaria una vivienda. ${ }^{36}$

Tampoco la pretensión de destinar una única familia a cada vivienda pudo verse satisfecha. Cuando la titularidad del grupo de viviendas volvió a recaer en el INV, sus informes indican que el PMV ya había autorizado numerosos subarrendamientos y muchos otros se producían sin consentimiento explícito. En un recuento firmado el 21 de febrero de 1955, se cuentan 135 casas en las que se dan bien convivencias autorizadas por el ayuntamiento o subarrendamientos ilegales. En espacios concebidos, según el proyecto, para entre 4-8 personas, se llega a documentar la cohabitación de 20 inquilinos, en una casa de la calle Recesvinto, en que conviven tres matrimonios con 7,3 y 3 hijos respectivamente y un abuelo. Si bien el caso constituye la excepción, son muy numerosos los domicilios en que habitan más de 10 personas casi siempre procedentes de varios núcleos familiares. Con ocasión de una denuncia en que un vecino enemistado con otros se quejaba de que "las viviendas habían llegado a convertirse en verdaderas pensiones" uno de los responsables de la barriada se dirigía a sus superiores asegurando que: cuando este organismo se posesionó de la citada barriada, se les hizo firmar a todos los vecinos una declaración jurada de los que convivían en sus domicilios respectivos y se intentó desalojar a todos los subarrendados no autorizados por el Patronato Municipal de La Vivienda, pero gran número de ellos se paralizó este trámite a consecuencia de órdenes superiores. ${ }^{37}$

En la documentación conservada para la década de los 50, se comprueba como con cierta regularidad los vigilantes notificaban al administrador de la barriada la existencia de alquilados no autorizados, a menudo en casas que ya contaban con varias familias. El procedimiento habitual consistía en ordenar la expulsión en el plazo de 8 días bajo amenaza de emprender otro tipo de acciones que podían comenzar con una sanción pecuniaria. No obstante, también a menudo los argumentos de los titulares de los alquileres lograban que se concediesen permisos temporales o autorizaciones indefinidas. Situaciones de grave penuria económica o enfermedad, e incluso la perspectiva de un crudo invierno al raso, podían favorecer este desenlace. También, en no pocos casos, eran los titulares del alquiler quienes acudían a las autoridades preventivamente para pedir permiso. ${ }^{38}$

La imposibilidad de imponer el modelo de una familia por vivienda en muchos domicilios frustraría el potencial generador de conductas que se atribuía al proyecto pero no implica ausencia de control. Los vigilantes de la barriada prestaban mucha atención a los movimientos de los vecinos e informaban tanto de conductas punibles o inmorales -en los domicilios o en la calle- como de cualquier presencia susceptible de convertirse en un nuevo subalquilado. Pese a la permisividad observada en algunos casos, nadie recibía autorización para alojar nuevos inquilinos en la barriada sin que antes se hiciesen las preceptivas averiguaciones sobre la conducta moral del titular. En cualquier situación que se considerase oportuno se solicitaban los correspondientes informes a la Guardia Civil. Lo fundamental era estar al

35 ARCAM. Comisaría General para la Ordenación Urbana de Madrid y sus Alrededores. 137.673.

$137.456,137439,137.169,137.145$

36 ARCAM. INV. 74.657.

37 ARCAM. INV. 93.364

38 ARCAM. INV. 74.657. 
corriente de quién vivía donde y evitar en la medida de lo posible la llegada de nuevos vecinos, aunque también se solicitó en no pocas ocasiones que se trasladase a los subarriendos a poblados de absorción o a otras colonias. 39

¿Lograron al menos vaciar la calle? Lo cierto es que la trama urbana y la distribución de espacios hacen del barrio un lugar poco propicio para las actividades de exteriores. El propio Luis Moya indica, al referirse a la vida del barrio en los años 80 que "la escasez de lugares de encuentro tanto cerrados como abiertos no generan vida urbana". No puede precisarse a la luz de la documentación consultada hasta qué punto se produjo una vida social o comunitaria más o menos intensa en los espacios comunes del barrio en sus primeros años. Tan sólo conocemos por las acusaciones de algunos vecinos involucrados en riñas y las respuestas de las autoridades que el tráfico rodado era escaso y ello hacía posible que los niños jugasen a la pelota en las calles, para enfado de algunos habitantes. Estos mismos lamentaban que pese a tener espacios privados suficientes algunos vecinos prefiriesen reunirse sentados en las aceras frente a sus casas..$^{40}$

Como se ha visto, la intención de mantener un núcleo "sano" y aislado se topó con graves problemas. Es más que probable que la demora en la finalización de los trabajos jugase en contra del proyecto original. La influencia ideológica y también urbanística del Eje en 1941 se había diluido durante la década, lo que podría explicar que no se hubiese puesto tanto celo en cumplir algunos de los presupuestos más organicistas. Máxime cuando la realidad económica imponía la necesidad de optar por el máximo ahorro. También marcaba ciertos límites la incesante marea humana procedente de la emigración que desbordó el pulcro dibujo trazado a priori. La desesperada situación de la vivienda en la zona podría haber acabado por forzar un cierto funcionalismo que iría dejándose notar en la arquitectura franquista durante los años 50. Desde la segunda mitad de los 40 , ninguno de los planes surgidos en la zona retomaría la idea de la vivienda unifamiliar. Las siguientes décadas iban a presenciar un protagonismo cada vez mayor de la iniciativa privada que acabaría por devenir hegemónico legando un paisaje urbano muy diverso del soñado por el "ruralismo bucólico". ${ }^{41}$ No debe, sin embargo, confundirse esta situación, con la ausencia de resortes efectivos de control de la población n con el abandono de la preocupación por el extrarradio. Al fin y al cabo, sí se cumplió el propósito básico de consolidar la segregación espacial en la ciudad; propósito que sobrevivió a las circunstancias y al tiempo en la urbe madrileña.

\section{Conclusiones}

El objetivo de esta comunicación era delinear a partir de un caso concreto algunas de las características fundamentales de un posible control social vehiculado a través del ordenamiento urbano y la arquitectura en la realidad concreta del extrarradio madrileño. Con apoyo de otros autores y fuentes tanto institucionales como hemerográficas, se han identificado y descrito algunos mecanismos de control y se ha hecho una somera radiografía de las limitaciones más elementales de los mismos a la hora de plasmar el proyecto. Si bien consideramos que la barriada escogida se presta bastante bien al enfoque propuesto y ofrece resultados y un punto de partida sugerentes, un estudio en profundidad exigiría un vaciado sistemático de la documentación conservada de cada una de las instituciones implicadas en las labores de reconstrucción, urbanismo y vivienda del Madrid franquista.

a aproximación microanalítica se muestra acertada por cuanto permite alcanzar un grado de finura en el análisis difícil de lograr de otro modo. Se requiere un enfoque de este tipo para

39 ARCAM. INV. 74.657

40 Luis MOYA: Barrios de promoción..., pág. 101; ARCAM. INV. 74.657, 93.364.

41 VV.AA.: "Del monumentalismo al primer funcionalismo" en Carlos SAMBRICIO (ed.): Un siglo de...,

Tomo II, Madrid, Nerea, 2003 pp. 1-125. desenterrar los mecanismos de dominación ocultos tras estratos de propaganda y rastrear los dispositivos de poder implementados a nivel micro. No obstante avanzar en la consecución de las metas propuestas en la introducción exige una ampliación en diversos sentidos. En primer lugar geográfica y cronológica para estudiar similitudes y discontinuidades a nivel espacial y temporal. Máxime teniendo en cuenta la irrupción paulatina del sector privado. En segundo lugar, el acercamiento más institucional debe complementarse con una mirada desde abajo que prime la experiencia y se apoye sobre fuentes de otra naturaleza como las orales o os egodocumentos. Estas objeciones son aplicables al propio caso de estudio presentado. De entre los numerosos cabos sueltos puede destacarse la posibilidad de acudir a los padrones municipales para determinar la extracción social de aquellos sus habitantes y compararla con la de sus vecinos alojados en las miríadas de infravivienda presentes en los alrededores. Asimismo, poner en relación la política de vivienda con la cultura de exclusión del gobierno pasa por estudiar las concesiones en el barrio y cruzar la documentación relativa a la represión de posguerra con los habitantes del mismo y de sus inmediaciones. 
“¿QUÉ HIZO USTED AL ESTALLAR EL GLORIOSO

\section{MOVIMIENTO NACIONAL?" SOBRE VIEJAS}

IDENTIDADES Y NUEVAS LEALTADES EN EL MADRID DE

\section{LA POSGUERRA*}

Alejandro Pérez-Olivares

Seminario Complutense «Historia, Cultura y Memoria»/ Departamento de Historia Contemporánea (UCM)

aperezolivares@ucm.es

\section{Introducción}

El final de la guerra civil supuso un ajuste de cuentas con el pasado: por un lado, el enemigo interior estaba identificado; por otro, los sectores comprometidos con la sublevación debían ser recompensados. Entre medias, todo un proyecto de control social que se revela en todas sus aristas si atendemos a la interacción entre la sociedad y el nuevo Estado.

En el caso de Madrid, la entrada de los vencedores se sumó al conocimiento que la Quinta Columna tenía de los barrios y sus habitantes. El 1 de abril de 1939 fue el momento de la venganza pero también de la recompensa, un proceso que asentó los cimientos del régimen franquista. Para explicarlo, recurro al concepto de "familia nacional", una forma de comunicación no lineal entre emisor y receptor determinada por la experiencia y por el ambiente que la rodea.

\section{La ciudad del 1 de abril}

La guerra en Madrid terminó el 27 de marzo. Era el momento de la rendición militar de la ciudad y las primeras columnas se entregaban a una tarea que se había demorado tres años: la ocupación militar. En torno a la una de la tarde del 28 de marzo, las Divisiones 16 y $18 \mathrm{de}$ Ejército del Centro, las milicias de Falange y la policía de ocupación comenzaban la recuperación de documentos y de esta forma culminaban el trabajo que la Falange clandestina había realizado bajo la supervisión del Servicio de Información y Policía Militar.

Desde el 1 de abril se sucedieron los nombramientos de algunos organismos que iban a dominar la posguerra. La Diputación Provincial se instaló en el domicilio familiar de José Calvo Sotelo, en la calle Velázquez, en un gesto simbólico que no pasó desapercibido. El Ayuntamiento, con Alberto Alcocer a la cabeza, alcalde ya con Primo de Rivera, tuvo su primera sede en el palacio de los marqueses de Amboage, en la calle Juan Bravo, desde el 1 de abril. Por encima de estos cargos estaba el Gobernador General de Madrid, general Espinosa de los Monteros, jefe del Primer Cuerpo de Ejército, que instaló su sede en el Paseo de la Castellana 43. La Jefatura de Orden Público, situada en Núñez de Balboa 31, pasaba al teniente coronel Francisco Bonel. Respecto al Servicio Nacional de Seguridad, cuyo jefe era el coronel Ungría, en agosto pasó a llamarse Dirección General de Seguridad, a cuyo frente se puso José Finat y Escrivá de Romaní. ${ }^{2}$

* La elaboración de este texto se enmarca dentro del Proyecto "Posguerras" y la labor del Grupo de investigación Complutense "Historia de Madrid en la edad contemporánea", dirigido por el profesor Luis Enrique Otero Carvajal.

1 Gutmaro GÓMEZ BRAVO y Jorge MARCO: La obra del miedo. Violencia y sociedad en la España franquista (1936-1950), Barcelona, Península, 2011, pp. 185-188. Sobre el protagonismo de la Ouinta Columna al final de la guerra, Javier CERVERA: Madrid en guerra. La ciudad clandestina, 1936-1939. Madrid, Alianza, 1998, pp. 411-422.

2 Fernando CASTILLO: Capital aborrecida. La aversión hacia Madrid en la literatura y la sociedad del 98 a la posguerra, Madrid, Ediciones Polifemo, 2010, pp. 562-564
Era el Madrid de la búsqueda del aval, pero poco a poco también se fue extendiendo una red basada en la delación. El 4 de abril se exigió la entrega de periódicos, folletos, impresos, ficheros y libros de actas de entidades que hubieran colaborado con el "Gobierno rojo". Al día siguiente Permanente del "Ejército rojo" del Centro, situado en la calle Miguel Ángel 13, en el Juzgado Militar de la calle General Castaños 1. Convocatorias que tenían como objetivo fomentar la denuncia. Diez días más tarde, el 15 de abril, se invitó nuevamente a declarar, esta vez a todo aque que tuviera que formular una acusación o manifestar cualquier juicio sobre la actuación de tribunal del Primer, Segundo y Tercer Cuerpo del Ejército. A finales de mes comenzaron los llamamientos del juez instructor de la Causa General para que los familiares de los asesinados, los perjudicados por otros delitos y los testigos se presentaran en las oficinas de la calle Victoria. Los funcionarios también fueron reclamados, a finales de abril recibieron un cuestionario que incluía la siguiente orden en su artículo octavo: "Diga quiénes eran los más destacados izquierdistas de su departamento y cuanto sepa de la actuación de los mismos".3

\section{Las instituciones: ayuntamiento y diputación provincial}

La hora de la victoria también era el momento de gestionar Madrid, donde confluían tres niveles de la Administración: la capital, la ciudad y la provincia. Y como propuso Canales Serrano, la victoria social y la victoria política eran dos fenómenos muy distintos. Por un lado, estaba la difusión de los códigos, representaciones y prácticas asociadas a la victoria franquista, bien para hacer patente el triunfo militar en el imaginario popular, bien para tratar de captar nuevos apoyos para el régimen naciente. Por otro lado, no hay que olvidar las maniobras en las nuevas instituciones de la dictadura, donde existían diferentes sensibilidades y trayectorias políticas 4

La construcción de los poderes locales franquistas ha sido objeto de un gran interés historiográfico en los últimos años, cuestionando los enfoques tradicionales acerca de la implantación social del régimen y las dinámicas de su funcionamiento. Así, entre las pervivencias caciquiles y la fascinación por los regímenes nazi y fascista se situaron no sólo los intereses económicos de los empresarios implicados en las redes del mercado negro, sino también difusión de los códigos, representaciones y prácticas asociadas a la victoria franquista, donde la utilización política de la guerra y su recuerdo puede ser una de las claves explicativas de mayor calibre. ${ }^{5} \mathrm{El}$ caso de Madrid es interesante porque las autoridades franquistas no pudieron comenzar su labor hasta el final del conflicto. Tan importante era la capital, escaparate del nuevo régimen, como la ciudad conquistada tras dos años y medio de asedio. Aun así, los equipos gestores que entran a partir del 1 de abril ya existían previamente. Alberto Alcocer, el primer alcalde de Madrid tras la guerra, ya había sido designado por Franco en octubre de 1936, poco antes del comienzo del asalto frontal a la capital. El Ayuntamiento había adoptado la forma de una comisión gestora

Federico BRAVO MORATA: Historia de Madrid, Vol. VIII. La posguerra. Primera parte (1939-1942), Madrid, Trigo Ediciones, 2001, p. 29. El cuestionario en Madrid en la posquerra, 1939-146: los años de la represión, Madrid, Sílex, 2005, p. 46. “Disposiciones y notas oficiales", ABC, 4 de abril de 1939.

4 Antonio CANALES SERRANO: "Las lógicas de la victoria. Modelos de funcionamiento político local bajo el primer franquismo", Historia Social, 56 (2006), pp. 111-130. 5 Francisco COBO ROMERO: "Los apoyos sociales a los regímenes fascistas y totalitarios en la Europa de entreguerras. Un estudio comparado", Historia Social, 71 (2011), pp. 61-88. Peter ANDERSON y Miguel Angel DEL ARCO BLANCO: "Construyendo la dictadura y castigando a sus enemigos. Represión y apoyos sociales del franquismo (1936-1951)", Historia Social, 71 (2011), pp. 125-141; Julián y apoyor sociales (1937-1951), Santander: Universidad de Cantabria, 2009; Óscar RODRÍcUEZ BAy apoyos sociales (1937-1951), Santander: Universidad de Cantabria, 2009; Oscar RODRIGUEZ BARREIRA: Miserias del poder. Los poderes locales y el nuevo Estado franquista, Valencia: Publicacions 
durante la guerra, designada por el Gobernador General del Estado, una figura institucional que se mantuvo hasta marzo de 1939, cuando el Ministerio de la Gobernación dispuso la constitución del Ayuntamiento en Comisión Municipal Permanente y Ayuntamiento Pleno. ${ }^{6}$

Alberto Alcocer tenía claro que las tareas de la corporación municipal no iban a reducirse a lo simbólico. Tras la constitución del Ayuntamiento, el alcalde se expresaba así:

Bajo el caudillaje de SE el Generalísimo, nuevamente España volverá a proclamar el reinado de Cristo Rey, que en feliz consorcio con la voluntad de triunfo y con los principios dogmáticos hará de España uno de los países más grandiosos de Europa.

Yo quiero dar en estos primeros momentos la bienvenida a todos los que habrán de compartir conmigo estas difíciles tareas que por propia voluntad aceptamos para procurar, con arreglo a nuestras capacidades, engrandecer a España, y estas palabras de bienvenida quiero deciros que no es puesto de gloria el que habéis aceptado, sino de sacrificio y abnegación. ${ }^{7}$

En el caso de la Diputación Provincial, se constituyó el 23 de enero de 1938 para atender las necesidades de los 63 pueblos ocupados de la provincia. ${ }^{8}$ El perfil de este organismo, donde predominaban las profesiones liberales y los propietarios, está claramente orientado a la reconstrucción material, social y simbólica de la provincia, aunque siempre en segundo plano por la importancia del binomio ciudad-capital. En la primera sesión ya en Madrid, el 4 de abril, el gobernador general de la provincia, Luis Valdés, que había sido jefe de columna en la Casa de Campo durante la guerra, tomó la palabra para hacer un elogio de aldea y pronosticar el futuro de la institución:

Haremos una España y en ella un Madrid mejor que antes porque tendrá todas las virtudes y buenas calidades, sin los vicios de las grandes poblaciones, los vicios inherentes al hombre, porque en estos momentos purificadores es indudable que el alma, que e corazón es el que mueve e impulsa al hombre. [...] El Ejército español que ha triunfado en la guerra triunfará en la paz porque hoy, al disolverse y al ir a las actividades civiles tendrán los conocimientos específicos y profesionales que han adquirido en los centros de enseñanza y un espíritu militar. ${ }^{9}$

Aunque como muestra el Cuadro 1 ningún miembro del Ejército formaba parte de la Diputación, la consigna estaba clara: la guerra, su recuerdo y su justificación inundarían la posguerra madrileña para no olvidar la importancia de la victoria. Desde esa posición y acordadas las reuniones para los jueves alternos, las tres funciones principales que desarrolló fueron la gestión institucional, la depuración del funcionariado a su cargo y la promoción de gestos que fijaran en el imaginario colectivo las figuras y acontecimientos principales del Movimiento.

6 Archivo de la Villa de Madrid (AVM), Actas 739, "Sesiones celebradas antes de la liberación de la Villa", sesiones del 23/IV/1937 y 15/III/1939.

7 AVM, Actas 739, "Sesiones celebradas antes de la liberación de la Villa", sesión del 15/III/1939. 8 Archivo Regional de la Comunidad de Madrid (ARCAM), Fondo Diputación Provincial, Libros de Actas, 901 199/1, Sesión de 4 abril de 1939

Ibid.

\begin{tabular}{|c|c|c|}
\hline Nombre & Profesión & Cargo \\
\hline Justo Sarabia, marqués de Hazas & Abogado & Presidente \\
\hline José Luis de Vera Fernández & Industrial & Gestor \\
\hline Francisco Escriña Montes & Contratista & Gestor \\
\hline Fernando de Pineda-Sánchez Ocaña & Abogado & Gestor \\
\hline Samuel Crespo Martínez & Sin especificar & Gestor \\
\hline Leonardo Sáinz de Baranda & Abogado & Gestor \\
\hline Gonzalo Pardo Otero & Industrial & Gestor \\
\hline Amancio Portabales & Aparejador & Gestor \\
\hline Juan José Tejedor & Funcionario público & Gestor \\
\hline
\end{tabular}

Cuad. 01 Diputación Provincial de Madrid. Fuente: ARCAM, Fondo Diputación Provincial, Libros de Actas, 901 199/1. Elaboración propia.

Si la primera sesión se suspendió para honrar la memoria de José Calvo Sotelo, en cuyo antiguo domicilio se reunía la Diputación, más adelante se hizo constar el duelo por la muerte de aviador Joaquín García Morato; Sáinz de Baranda propuso una pensión vitalicia a los familiares de los miembros de la Corporación asesinados, se aprobó abrir un concurso para construir una fuente monumental en la Avenida del Generalísimo o la construcción de un monumento en Paracuellos del Jarama en recuerdo de los "mártires por Dios y por España". ${ }^{\circ}$

Pero no todo eran parabienes en los primeros momentos de la posguerra. En un escrito de junio de 1941, Pedro Reija Galán, secretario del Ayuntamiento y antiguo teniente provisional, se dirigía así a José Luna Meléndez, jefe provincial de FET-JONS en Madrid:

Distinguido Camarada:

Por primera vez te pido justicia en este antiguo caso, llevo más de un año privado injustamente del Pan y de la Justicia, que pedí hasta con recomendación y se me dilata o disfraza. No pretendo otra cosa que poder probar ante un juzgado independiente del Ayuntamiento los conceptos de mi escrito. La justicia no resplandece ni triunfó la Falange en el Ayuntamiento actual, que hace buenos a todos los pasados y no se para en falsedades y prevaricaciones y protección a izquierdistas.

Te lo comunico por lo gravísimo del caso. El Camarada Primo de Rivera es conocedor de esto por su paso por el Gobierno Civil. Te saluda brazo en alto y por José Antonio te pide justicia, que sé no me negarás, y mientras llega esta hora por mi tan ansiada, contesto con un ¡Arriba España! al que tú das cuando esta cara palabra y sagrada debe darse."

¿Qué llevó a Pedro Reija a afirmar que en el Ayuntamiento de la capital no había justicia y se protegía a izquierdistas? Una declaración anterior es una perfecta radiografía de los juegos de poder en las instituciones franquistas. Apelando a la justicia de Franco y a la memoria de José Antonio, denuncia la labor de un tal Sr. Górgolas, secretario y jefe de personal en Málaga y hombre cercano a Alberto Alcocer, a la sazón alcalde de Madrid. Según su testimonio, Gór-

10 ARCAM, Fondo Diputación Provincial, Libros de Actas, 901 199/1, Sesión de 13 de abril, 27 de abril y 27 de mayo de 1939

11 Archivo General de la Administración (AGA), Presidencia, Secretaría General del Movimiento (SGM), Delegación Nacional de Provincias, 51/20571, 166, carta del 7/6/1941. El subrayado es mío. 
golas entregó a las milicias a Luis de Altolaguirre y Bolín y Víctor Nicolás Alcántara, secretarios provinciales de Falange y Acción Católica en aquella provincia. Quizá en retribución a sus servicios, pasó al Ministerio de Hacienda, donde se relaciona con destacados políticos republicanos: Andrés Saborit, Pedro Rico, Ramón Lamoneda... Tras la caída de Málaga, Górgolas consigue pasar a zona sublevada y, ya en Valladolid, entra en el círculo íntimo de Alberto Alcocer, a la espera de entrar en Madrid y tomar posesión del Ayuntamiento.

Ya después de la guerra, Reija le denuncia y para ello cuenta con diversos testimonios y avales, entre ellos el de los generales Borbón, Tella y Solana. Pero desde el primer momento queda claro que el procedimiento está manejado desde el poder: los informes de la Auditoría de Guerra de Madrid se supeditan al Ayuntamiento, las declaraciones de los generales no son escuchadas, el encartado no es separado de su cargo... “iCuanto daría Negrín por ser también depurado desde su cargo de hegemonía, pues no es menor el influjo del Sr. Górgolas en el Ayuntamiento!", llega a decir Reija en su declaración.

Más allá de la denuncia a una persona concreta, el fondo de la queja de Reija está claro: el Ayuntamiento de Madrid no estaba a la altura de los caídos, la máxima legitimación del Movimiento. Después de la ocupación de la ciudad, no se hizo justicia: el equipo de Alcocer amparaba a "rojos" en las cartillas de abastecimiento, los ascensos en la Policía Urbana estaban vedados a los perseguidos durante la guerra y se admitió a 500 guardias a espaldas de la Ley de Excombatientes. Y Reija fue expulsado de su cargo en el Ayuntamiento después de su denuncia. Termina la declaración tras apelar a su condición de ciudadano y defensor de la justicia, una situación que no es nueva: "Pido en súplica al Excmo. Sr. Ministro de la Gobernación una inspección al Ayuntamiento madrileño, como lo hizo en su día aquel gran español Primo de Rivera, tan magistralmente secundado por el Sr. Martínez Anido".

Interludio: "familia nacional" como propuesta de análisis socio-político para el Madrid de la posguerra

En el Madrid que amanece el 1 de abril están, por un lado, los vencedores, que ocupan una ciudad destruida por la guerra y de la cual desconfían tras casi tres años de asedio. Sus prácticas y discursos se centrarán en la población civil más comprometida, que tiene la huida o el refugio como alternativas. Por otro, la gran mayoría de los madrileños se afana en la supervivencia, con sus hogares destruidos, las enfermedades acechando y la comida insuficiente. ¿Cómo se gestionó la capital? ¿Cómo se cimentó socialmente el régimen? ¿Cómo explicar este proceso desde el presente?

Mi apuesta es una mirada interdisciplinar sobre la sociedad de posguerra en un entorno concreto. Madrid tuvo un desarrollo particular durante la guerra: capital de la resistencia para unos, ciudad traidora por excelencia para otros. La sublevación de julio representaba una reacción contra el proyecto moderno que condensó la II República y que Madrid representaba: una sociedad abierta al cambio y la promoción social. ${ }^{12}$ Pero la ciudad, campo de batalla, sufrió una transformación paralela a la guerra, pues no era una sociedad uniforme: entre la ciudad resistente y la ciudad clandestina, se alzó la ciudad pasiva, movilizada a la fuerza y hastiada de destrucción. Es en este contexto donde se condensan las representaciones del miedo a la ciudad y las diversas expresiones del conflicto atravesado por la ciudad en el primer tercio del siglo XX: incremento demográfico, conflictos laborales y tensiones sociales en general, e desafío en los patrones culturales que supuso la irrupción de la Modernidad en la ciudad... En la posguerra el miedo a la alteridad, a los ambientes marginados y segregados, se transformó

12 Para el desarrollo de Madrid, Rubén PALLOL: El Madrid moderno: Chamberi (el Ensanche Norte), simbolo del nacimiento de una nueva capital, 1860-1931. Tesis doctoral, Madrid, eprints ucm: 12844, (1860-1931). Tesis doctoral, 2011. en el miedo al enemigo, derrotado militarmente pero no vencido socialmente. Y menos aún en Madrid, que había resistido casi dos años y medio a Franco. El ensanchamiento de las "zonas grises" a medida que transcurría el asedio y, sobre todo, hacia el final de la guerra, no fue óbice para que las autoridades militares que entraron en Madrid el 28 de marzo de 1939 no tuvieran diseñado un importante aparato de control. ${ }^{13}$

La quiebra de la sociedad civil que supuso la guerra no permite, en mi opinión, acudir a concepto de opinión pública según la formulación habermasiana. Primero porque, si en la acción comunicativa el actor es iniciador y a la vez producto de las circunstancias que le rodean en una dictadura no se pueden verificar los presupuestos de verdad, rectitud y veracidad. ${ }^{14} \mathrm{Se}-$ gundo, porque durante el franquismo opinión pública no puede equipararse a debate público, al menos no de forma abierta. Está en duda, incluso, que se pueda hablar de espacio público debido al funcionamiento de los dispositivos e instituciones de control que el régimen estableció. ¿A qué consensos comunicativos podía llegarse? ${ }^{15}$

La Victoria supuso, ante todo, la identificación de un enemigo interno, un ajuste de cuentas con el pasado. Un proceso que no terminó con la rendición y que sobrevivió al primer año de posguerra. La Cultura de la Victoria puede definirse como una cultura de la no-reconciliación sobre la que se construyeron las bases de la década de los cuarenta, apuntando los límites de la comunidad nacional. ${ }^{16}$ Pero para aquellas personas que no comulgaban con el régimen, 0 simplemente pretendían salir adelante, la década de los 40 fue una coyuntura que socializó la lucha por la supervivencia y donde la satisfacción de las necesidades más primarias primó sobre la seguridad individual. El “medio ambiente psicológico" de posguerra se configuró también por las experiencias individuales y colectivas, a través de razonamientos que reciben y entregan información simbólica. ${ }^{17}$

La Cruzada y la sangre vertida por los Caídos en ella fueron consustanciales al franquismo: ahí residía su legitimidad. Pero también fue un discurso movilizador y formó parte de sus prácticas de persuasión, al tiempo que configuraba el espacio entre la integración y la exclusión..$^{1}$ Pero no nos podemos quedar en la producción de discurso, hay que problematizar su funcionalidad y su recepción. De ahí que pueda hablarse de una verdadera "ideología de la muerte", la memoria de la guerra supuso una estrategia de control y paralización angustiosa. Tal y como propuso Herbert Marcuse, ninguna dominación es completa si la muerte no se reconoce como algo justificado y como una justificación. ${ }^{19}$

13 Ángel BAHAMONDE y Javier CERVERA: Así terminó la guerra de España, Madrid, Marcial Pons, Angel BAHAMONDE y Javier CERVERA: Asi terminó la guerra de España, Madrid, Marcial Pons, 2000. Gutmaro GOMEZ BRAVO y Ruben PALLOL: "Orden, delito y subversion. El estudio de la criXX", en Julien LANES, David Marcilha XX, en Julien LANES, David Marcilhacy, Michelle RALLE y Miguel RODRIGUEZ (eds.). De los conflic-

paniques, 2013.

ativa, Madrid, Taurus, 198

15 Ibid., Historia y crítica de la opinión pública. La transformación estructural de la vida pública, Barcelona, Gustavo Gili, 2004 y Jurgen HABERMAS: “La ética discursiva”, en Carlos GÓMEZ (ed.): Doce textos fundamentales de la Ética del siglo XX, Madrid, Alianza Editorial, 2003.

16 Miguel Ángel DEL ARCO: "El secreto del consenso en el régimen franquista: cultura de la victoria, represión y hambre", Ayer, 76 (2009), pp. 245-268; Miguel Ângel DEL ARCO y Claudio HERNÁNDEZ "Más allá de las tapias de los cementerios: la represión cultural y socioeconómica en la España franquista (1936-1951)”, Cuadernos de Historia Contemporánea, Vol. 33 (2011). “Los verdaderos «responsables"”, ABC, 2 de abril de 1939

17 La noción de "medio ambiente psicológico" en Herbert SIMON: Naturaleza y límites de la razón humana, México, Fondo de Cultura Económica, 1989

18 BOX, Zira: España, año cero. La construcción simbólica del franquismo, Madrid, Alianza Editorial, 2010.

19 Herbert MARCUSE: Ensayos sobre politica y cultura, Barcelona, Planeta, 1986, pp. 164-165. 
La coexistencia de estos tres fenómenos (Cultura de la Victoria, medio ambiente psicológico, ideología de la muerte) permite hablar de "familia nacional" en vez de esfera pública. ${ }^{20}$ Este concepto, acuñado desde el ámbito de la comunicación social por David Morley, permite reflexionar sobre su producción y recepción, su incidencia en la formación de una identidad común y la construcción de imaginarios colectivos a partir de experiencias pasadas, marcos cognitivos del presente y la interacción con diversos universos simbólicos. La principal característica de la idea de nación sería su capacidad performativa como "hogar simbólico", una comunicación no lineal, pues tanto emisor como receptor modulan y reelaboran constantemente los mensajes dependiendo del contexto económico, político o social. La información se asimilada de una forma $u$ otra dependiendo de las experiencias particulares, los espacios de convivencia o la solidez de los lazos comunitarios. Se matiza así la idea de un consenso general sobre las "zonas grises" del franquismo y se prima el proyecto político que quiso llevar a cabo el régimen en la primera posguerra, sin olvidar la importancia de la recepción de los discursos de las autoridades. ${ }^{21}$

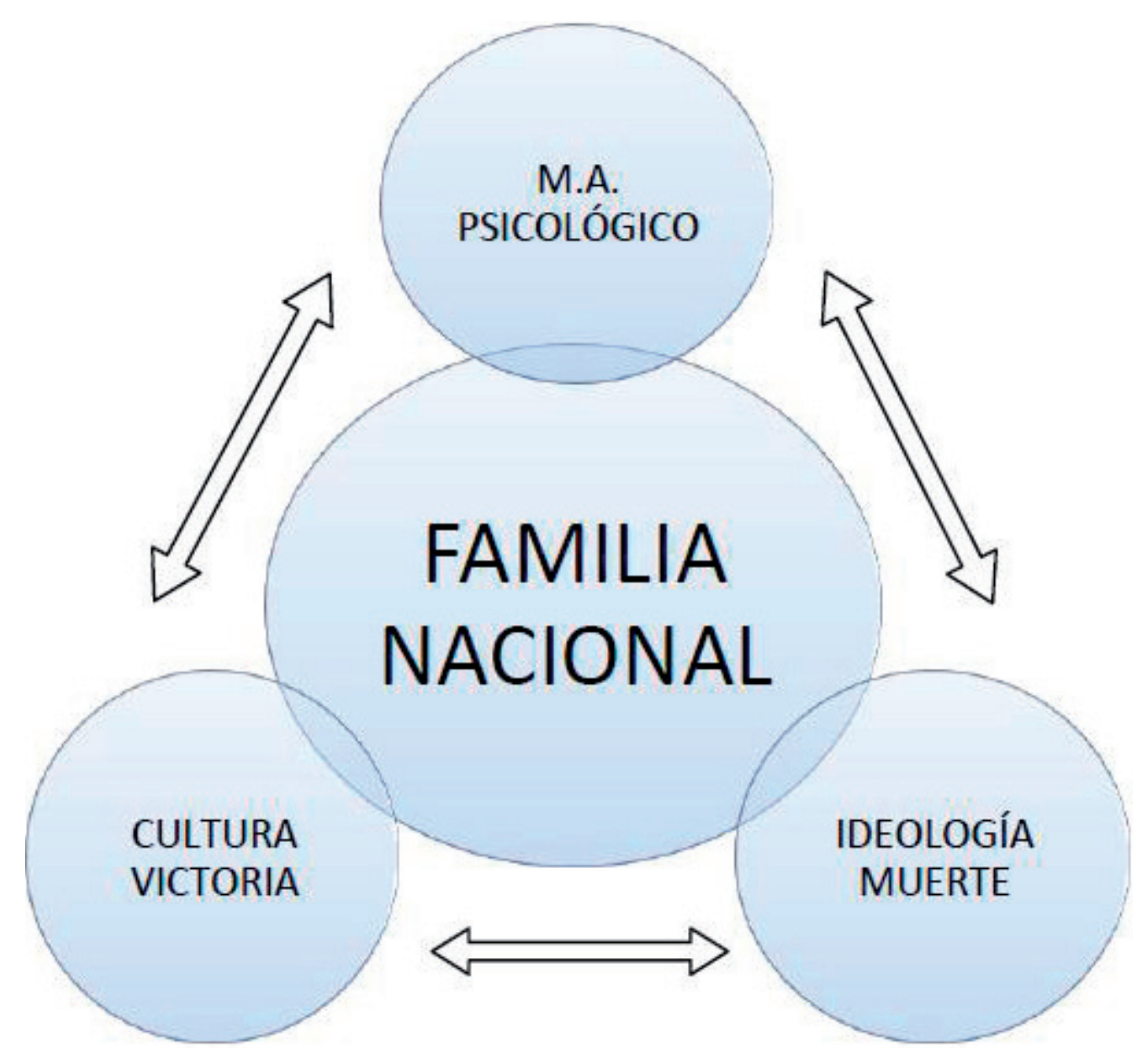

Img. 01 La "familia nacional" como propuesta de análisis.

Desde esta óptica podemos replantear múltiples procesos de la construcción de la dimensión pública del nuevo orden que comenzaba desde los espacios más cotidianos: los propios barrios. La "familia nacional" es una narrativa histórica, pues explica el pasado en sentido ne-

20 David MORLEY: Media, Mobility and Identity, London; New York: Routledge, 2000.

21 Un planteamiento similar en Claudio HERNÁNDEZ BURGOS: Franquismo a ras de suelo. Zonas grises,

apoyos sociales y actitudes durante la dictadura (1936-1976), Granada, Universidad de Granada, 2013. gativo (desorden, caos, alteración del orden natural) y positivo (el sacrificio redentor de los mártires), pero también es un proyecto social y, en el caso de Madrid, un proyecto de ciudad. Cuando el 7 de abril la Puerta de Alcalá amaneció engalanada con la cruz de los Caídos, coto-emblema, se llenó de "avenidas imperiales" y de "plazas de la Victoria" y se trató de volcar el proyecto del régimen sobre el espacio urbano. Los rectores de la Victoria tenían claro que la reconstrucción de Madrid, la capital administrativa y simbólica del nuevo Estado, no podía limitarse a lo material. El proyecto de sociedad que se quería desarrollar empezaba por la planificación de la ciudad futura, tal y como lo expresaría Pedro Bidagor, jefe de la sección de Urbanismo de la Dirección General de Arquitectura, años más tarde:

Una organización no consiste en un simple trazado de líneas dentro de las que se distribuyen el tráfico, la vivienda y el árbol; no, sino que supone una adaptación de estos elementos materiales a una unidad social: el barrio, que tiene una existencia real con una función, y unos límites concretos, aun cuando hayan surgido de una manera espontánea. Un ejemplo de extraordinaria claridad en este orden de ideas lo constituye el barrio de Salamanca con su trazado de cuadrícula tan claro en el papel, aparentemente limitado por la Avenida del Generalísimo, las Rondas y la Calle de Alcalá. ${ }^{22}$

Con "familia nacional", en suma, me refiero a ese complejo haz de relaciones personales, sociales y burocráticas que conformaron la realidad cotidiana de la ciudad, un "diálogo" entre Estado y sociedad que concretó la destrucción del Madrid moderno y su reconstrucción material y mental en claves completamente diferentes, pero con una cierta presencia de la agencia de los grupos subalternos del régimen. ${ }^{23}$ Veamos cómo se desarrolló este fenómeno.

\section{Tiempos de control}

Como ha quedado expuesto, el final de la guerra supuso para muchos el momento del ajuste de cuentas. Animados desde las instancias oficiales o por cuenta propia, las delaciones formaban parte de la estrategia de miedo y control que, impulsada por el régimen, iba a afianzar los cimientos construidos durante la guerra. A diferencia del resto del país, Madrid, junto con Valencia y Barcelona, formaba parte de ese grupo de grandes ciudades que evitaron la conquista hasta el final de la contienda. Pero la experiencia de la ocupación de otras ciudades en 1937, como Santander o Bilbao, marcó la estrategia de depuración y control de la capital.

Es difícil calibrar lo que significó la entrada de las tropas en Madrid, una ciudad que a la altura de 1939 superaba el millón de habitantes, a pesar del rastro que la muerte había dejado durante la guerra. ${ }^{24}$ ¿Con qué población de las ya estudiadas se puede comparar? Obviamente, el mundo rural no puede servir de modelo por sus dimensiones espaciales y simbólicas, incluso operativas o psicológicas. A priori pasar inadvertido en una gran ciudad es más sencillo,

22 ABC, 9 de abril de 1939. Ángel LLORENTE: Arte e ideología en el franquismo, Madrid, Visor, 1995, pp. 79-85. Pedro BIDAGOR: “La organización de Madrid. Estructura urbana. Zonificación", en Pedro MUGURUZA et al.: El futuro Madrid, Madrid, Publicaciones del Instituto de Estudios de Administración Local, 1945, p. 46.

23 Alejandro PÉREZ-OLIVARES: "Estraperlo y apoyos sociales del franquismo en Madrid: los informes de FET-JONS", en Carme MOLINERO y Javier TÉBAR (eds.): VIII Encuentro Internacional de Investigadores del Franquismo, 2013, CD-ROM. La búsqueda de apoyos, aunque desde una perspectiva únicamente estatal, aparece también en Carme MOLINERO: "Falange y la construcción del régimen, 1939-1945. estatal, aparece también en Carme MOLINERO: “Falange y la construcción del régimen, 1939-1945. del fascismo en la España de Franco (1936-1975), Zaragoza, Institución Fernando el Católico, 2013.

24 Censo de población de 1940. Disponible en http://www.ine.es/inebaseweb/pdfDispacher. do?td=119509. 
pero el Servicio de Recuperación de Documentos hizo una labor sistemática al respecto. Desde el 1 de abril, ocultar el pasado se convirtió en una tarea difícil de llevar a cabo.

Este es el caso de Elisa Fernández de la Mata, personal auxiliar en la Secretaría General de Movimiento. ${ }^{25}$ Su origen acomodado, puesto que su padre era abogado en León, le permite marcharse a Madrid a trabajar y llevar una vida más independiente. A primera vista, no tiene nada que temer: los informes internos hablan de un comportamiento ejemplar en la Sección Femenina de La Bañeza, su pueblo natal, afiliada desde enero de 1934 y donde ocupó puestos de responsabilidad. Pero desde el final de la guerra la desconfianza en la norma general a la hora de pedir informes. Desde la jefatura provincial de León afirman que la Sección Femenina no se constituyó hasta enero de 1936, su documentación es incompleta y no aparece que haya desempeñado cargos. Con motivo de una enfermedad a Elisa le informan que pasará a depender de la Delegación Nacional de Provincias, con la excusa de una reordenación de personal. Estamos en febrero de 1940 y desde entonces toda la maquinaria burocrática y represiva del régimen caerá sobre ella. Un informe juega en su contra. "En relación con el partido es desaprensiva y carece de las mínimas condiciones para el desempeño de cualquier cargo cuyas circunstancias se hacen extensivas al servicio del Glorioso Mov Nacional". Además, se le relaciona con Leopoldo Panizo, un camarada falangista, y a pesar de ser soltera casi siempre está fuera de su domicilio

Poco a poco se va esclareciendo su caso. En otra diligencia de 7 de enero de 1940, aparece la causa principal. Su hermano, apodado "El bicho", persiguió a los camaradas de la región "en los difíciles momentos". Cuando se hunde el frente de Asturias este "marxista exaltado y violento", según el informante, es detenido, ingresa en la prisión de Astorga y poco después liberado. Detenido en La Bañeza, su pueblo de origen, es condenado a muerte en consejo de guerra pero su pena es conmutada gracias a las gestiones realizadas por Leopoldo Panizo.

El informe posterior se centra definitivamente en Elisa. El rumor institucionalizado hace el resto: ha ido a Madrid a mantener el nivel de vida ociosa que con sus padres no podría.

Las personas que me han facilitado estos datos creen que hace esta vida por ser muy viciosa, y solamente desde el comienzo del Alzamiento Nacional, en que comenzó a alternar con los Oficiales de Aviacion que se encontraban en Leon. No tiene necesidad de trabajar para vivir, y si se colocó en esta secretaría general fue al fin de poder vivir en Madrid y tener la libertad que con sus padres no tiene. ${ }^{26}$

No conozco su paso por la Delegación Nacional de Provincias, si también fue apartada tras otro "reajuste" o si fue depurada definitivamente. Pero lo que importa en su caso es la importancia del rumor en la formación de estereotipos excluyentes. La reacción androcéntrica que supuso la guerra civil no sólo reafirmó la masculinidad (o la masculinidad entendida de un modo concreto), sino que moldeó los comportamientos de la mujer hasta devolverla a su "lugar natural" en la sociedad y la familia. ${ }^{27}$

Pero las depuraciones también podían ser un vehículo de comunicación entre la sociedad y el Estado. Sobre todo si el entorno familiar pertenecía a los sectores próximos a la Administración o tenía algún contacto en FET-JONS. En el caso de Joaquín Lafuerza Vázquez, su primo, secretario del ministro de Industria y Comercio, se manifestaba así ante el delegado nacional de provincias:

25 AGA, SGM, DNP, 51/20510, 138, informe de 18 de diciembre de 1939.

$26 \mathrm{Ibid}$., informe de 26 de enero de 1940 .

27 Mary VINCENT: "La reafirmación de la masculinidad en la cruzada franquista", Cuadernos de His-

toria Contemporánea, vol. 28 (2006), pp. 135-151.
Madrid, 21 de noviembre de 1940

Sr. D. José María del Rey Caballero.

Delegado Nacional de Provincias.

Madrid

Muy Sr. mío y distinguido amigo:

Me permito interesar de Vd. la solución de un asunto que creo de toda justicia y por el cual tengo extraordinario interés.

Creo por otra parte, que es de su incumbencia o entra en la órbita de sus atribuciones y por eso me decido a escribirle.

Un primo mío llamado Joaquín Lafuerza Vázquez que vive conmigo en mi misma casa, solicitó hace año y medio su ingreso en Milicias de FET en el Distrito de Chamberí. Durante más de un año hasta hace dos meses, ha venido participando en todos los actos con gran espíritu y con extraordinaria puntualidad en todas sus cosas. Yo puedo ser testigo de su buena conducta y de su plena adhesión a nuestra Causa y desde luego, le avalo en todo lo que sea preciso. Hace dos meses, sin embargo, en el momento en que necesitaba un certificado de la Provincial, se le comunicó que quedaba expulsado de Falange y no ha podido obtener hasta ahora información concreta sobre los fundamentos de esta decisión. Es más, mientras en Milicias se le ha recogido la documentación, se le sigue pasando al cobro el recibo mensual correspondiente. ${ }^{28}$

Esta carta puso en marcha la maquinaria del régimen. El delegado nacional de provincias se puso en contacto con el jefe provincial del Movimiento, quien pidió información al delegado político del distrito de Chamberí. El régimen tenía la capacidad para "tomar el pulso" al espacio público y recabar informes en apenas veinte días, gracias al Servicio de Información e Investigación de Falange. El informante de este servicio le sitúa como simpatizante de la Federación Universitaria Escolar, rival del SEU falangista en la Universidad. Aunque antes de la guerra vivía con sus padres en la plaza de Chamberí, sus ideas le acarreaban constantes disputas en su casa.

Próximo al Consorcio de la Panadería, incautado por la UGT, trató de pasar al servicio de Carabineros, instancia que fue desestimada. Por entonces, 1938, y según algunos testimonios recogidos en el barrio, se manifestaba a favor de los sublevados y pedía el parte de guerra a algunos vecinos. Pero la llamada a filas volvió a hacerle sospechoso: sirvió en Levante y tras finalizar la guerra estuvo quince días recluido en el campo de concentración de Tielmes de Tajuña. Su tío y su primo le avalaron para conseguir un puesto de auxiliar en el Instituto Nacional de Previsión.

Ouizá lo más interesante del caso de Joaquín es la secuencia delito-reconocimiento-arrepentimiento. Según su propia declaración, reconoce su simpatía izquierdista antes de la guerra, pero después de 1937 y en vista de los "crímenes de los rojos" cambió radicalmente su ideología. Joaquín estaba inmerso en el medio ambiente psicológico de la posguerra, trabajaba en un organismo oficial, por lo que debía conocer bien la retórica del régimen. Nada mejor que reconocer su antiguo error y proclamar su arrepentimiento que relacionándolo con el terror del Madrid rojo.

\section{El momento de la recompensa}

Tras la vuelta a la normalidad en las instituciones, donde estaban representados los poderes tradicionales, quedaba una última operación: fidelizar a aquellos sectores que habían otorgado su sufrimiento a la regeneración del país. Con un gesto simbólico, y en ocasiones también una ayuda económica, el régimen trató de crear un espacio político afín a los ideales del Movimiento. 
Un intento que tiene sus cimientos en la propia guerra civil cuando, a raíz del primer gobierno franquista de enero de 1938 , se concede la categoría de militantes de FET-JONS y la medalla de Sufrimientos por la Patria a los prisioneros de la zona republicana. ${ }^{29}$ Creada por po que se creaba una "hermandad de sufrimiento" y se actuaba en lo que se quería que fuera una comunidad política por medio de la recompensa material. Los criterios eran lo suficientemente amplios como para forjar esa comunidad: militares y funcionarios públicos; militantes de partidos integrados en FET-JONS; los reducidos a prisión por favorecer con cualquier acto al Movimiento; padres, hijos y cónyuges de asesinados o muertos en cautiverio... El procedimiento tenía que ser iniciado por los interesados, que elevarían la documentación a la Jefatura Provincial del Movimiento. Es decir, quedaba abonado nuevamente el terreno para el control..$^{30}$

El caso de Madrid era peculiar. La Quinta Columna se llevó todo el reconocimiento pero, ¿qué pasaba con aquellas personas que participaron en la trama civil de la conspiración? E 12 de mayo la Jefatura Provincial elevó consultas a la Delegación Nacional de Justicia y Derecho para incluir también a aquellos que fueron detenidos preparando el golpe. No hubo dudas, en diez días el veredicto estaba claro: "la causa determinante de los sufrimientos a que fueron sometidos dichos camaradas fue precisamente su adhesión al Alzamiento Nacional, antes todavía de producirse este". ${ }^{31}$

Así, las estrategias de control y recompensa se unieron para formar parte de un nuevo tipo de espacio público, modelado por el régimen. Para cualquier forma de compensación, la persona interesada tenía que elevar la documentación que acreditaba su distinción, lo que equivalía a entregar el pasado particular al examen de las autoridades. También era una forma de comunicación entre la sociedad y el nuevo Estado. Un ejemplo lo tenemos en las vacantes de porteros en los Ministerios civiles, para las cuales era imprescindible ser excombatiente por orden de Presidencia del Gobierno de 25 de julio de 1940.32 La documentación se presentaba ante la Jefatura Local, esta la enviaba a las Delegaciones Provinciales de Ex-combatientes y por último era revisada por la Subsecretaría de Presidencia. 200 personas se someterían a este examen, para el que se solicitaban también los servicios de la Delegación de Información e Investigación.

Este tipo de medidas tendían a reforzar los lazos sociales con sectores muy concretos de la población de posguerra. La política de recompensas estaba limitada solo a aquellos que podían certificar haberse sacrificado por el Movimiento, contra la "anti España". Y en el caso de los excombatientes, suponía identificar la Administración con la cultura de guerra de la que nacía el régimen de Franco ${ }^{33}$. Madrid, capital y ciudad al mismo tiempo, con una fuerte presencia de edificios oficiales, veía cómo su mercado laboral quedaba inundado por vacantes exclusivamente reservadas para este tipo de perfil. Para las autoridades del nuevo Estado estaba clara la división entre vencedores y vencidos. Pero, al mismo tiempo que llevaba a cabo este proyecto de segregación social, el régimen penetraba una vez más en los entornos más inmediatos de la convivencia: los barrios.

B. O. E. de 1 de octubre de 1938

30 B. O. E. del 28 de mayo de 1939

31 AGA, SGM, DNP, 51/20534, 89. Para la importancia de la trama civil, Ángel VIÑAS: "La connivencia fascista con la sublevación y otros éxitos de la trama civil", en Francisco SÁNCHEZ PÉREZ (coord.): Los mitos del 18 de julio, Barcelona, Crítica, 2013

32 AGA, SGM, DNP, 51/20570, 92. Circular concurso para cubrir plazas de portero en los Ministerios.

33 Ángel ALCALDE: "Cultura de guerra y excombatientes para la implantación del franquismo en Al-

bacete (1939-1945), Al-Basit. Revista de Estudios Albacetenses, 57 (2012), pp. 37-69.

\section{Consideraciones finale}

Como ha venido demostrando la historiografía más reciente, analizar el régimen desde lo local se presenta imprescindible para calibrar el alcance e intensidad de aspectos fundamentales de su naturaleza: los métodos de control, las políticas de exclusión y recompensa, la búsqueda de nuevos apoyos, el peso de la guerra civil en la sociedad de posguerra... En el caso de Madrid, las dinámicas locales se entrecruzan con unas propias: las de la capitalidad. Tras más de dos años de asedio, Madrid se convirtió en el escaparate del régimen, pues una de sus funciones consistió en liderar la política simbólica del nuevo Estado franquista. En este plano, Madrid experimentó una importante transformación, pues pasó de ser una ciudad traidora a la capital de la Victoria, donde se escenificó el triunfo con más intensidad.

En este punto, entre las políticas de exclusión, las estrategias de control, los intentos por ampliar la base social del régimen y en un contexto de fractura social y psicológica se sitúa mi propuesta analítica. La "familia nacional" permite rastrear los discursos de la guerra que perviven durante la década de los 40, la importancia del pasado inmediato en el lugar que se ocuparía en la sociedad de posguerra, las nuevas lealtades forjadas tras el 1 de abril de 1939 o el proyecto político y social del régimen de Franco en un momento de extrema debilidad. El papel de las instituciones para llevar a cabo esa "familia nacional" fue de una importancia indiscutible, pero la Administración no fue el único actor en liza. En el caso de Madrid, las autoridades eran conscientes de que únicamente mediante el binomio España/anti-España no se solucionarían los graves problemas cotidianos de la población: sanidad, abastecimiento y vivienda; por citar los principales. Así, no sólo era necesario ofrecer una narrativa en negativo del pasado más reciente, también había que desarrollar un proyecto de presente y futuro que sostuviera día a día al régimen nacido de la Guerra Civil.

Esta propuesta nace del encuentro de las dos propuestas que más han ampliado el conocimiento sobre los primeros momentos de la dictadura franquista: los estudios sobre la implicación social de la violencia y los análisis sobre apoyos sociales del régimen. Por un lado, intenta complejizar los ya de por sí refinados análisis sobre las actitudes frente a la dictadura, pero desde una óptica diferente a la del "consenso". Por otro, trata de introducir nuevos elementos para reflexionar sobre las violencias en la esfera pública urbana: el miedo a un enemigo interno identificado desde el régimen, la potencialidad del rumor para crear imágenes de alteridad o la limitada efectividad de los avales en las grandes ciudades, donde la extensión del anonimato espoleó a las autoridades a refinar sus métodos de control. Por último, trato de poner el acento también en el proyecto político de los sublevados el 18 de julio de 1936 , un proyecto que reaccionaba frente a las transformaciones acaecidas en el primer tercio del siglo XX: el crecimiento urbano, el ensanchamiento de los cauces de participación política, la extensión de derechos civiles y políticos o la aparición de nuevos roles de género.

El reto ahora es ir más allá de los planes de control e implementar las políticas de vigilancia y coerción en los núcleos de sociabilidad más inmediata: los barrios. Sólo de esta forma podremos calibrar bien la relación entre las viejas identidades y las nuevas lealtades en el Madrid de la primera posguerra. 


\section{AROUITECTURA, CONSUMO Y SOCIEDAD: "GALERIAAS \\ PRECIADOS"YOTROS GRANDES ALMACENES ENLA}

CIUDAD DE OVIEDO*

Jose $M^{a}$ Rodríguez-Vigil Reguera

Departamento de Historia del Arte y Musicología

Universidad de Oviedo mujeres, tradicionalmente huérfanas de espacios sociales "públicos" y urbanos, así como en demagógico paraíso democrático donde teóricamente cualquier persona con el dinero suficiente podía disfrutar de las ventajas ofrecidas independientemente de su extracción social aunque en la práctica fueran frecuentes numerosas estrategias de segregación. ${ }^{4}$

La variedad de puntos desde los que abordar el estudio de unos grandes almacenes explica la heterogénea bibliografía disponible: el clásico trabajo de H. Pasdermadjian ofrece una primera cronología y análisis evolutivo desde un enfoque eminentemente económico-empresarial que constituye una referencia básica. ${ }^{5}$ En clave histórico-artística, Nikolaus Pevsne planteó hace varias décadas una sintética revisión tipológica de la arquitectura de estos establecimientos, valorando sus peculiaridades técnicas, espaciales y estéticas según criterios en buena medida vigentes. ${ }^{6}$

Animados por los cambios en las tendencias historiográficas y el creciente interés teórico por la sociedad de consumo, 7 desde la década de 1980 diversos autores ampliaron el marco bibliográfico con estudios ejemplares: tal es el caso de Michael B. Miller con su citada monografía sobre los almacenes Bon Marché ${ }^{8}$ o de Susan Porter Benson, autora de un extenso trabajo en el que además de abordar la historia de los grandes almacenes americanos, analiza la situación laboral y social de sus empleadas, reflexionando sobre su hermandad como trabajadoras convirtiéndose también en referencia para los estudios de género. ${ }^{9}$ El libro de Bill Lancaster The De partment Store. A social history revisa la historia de los grandes almacenes británicos proponiendo la existencia de varios comercios-denominados proto-department stores-que preludiarían el posterior modelo francés..$^{\circ}$ Hoy existen importantes síntesis, como la publicación ricamente ilustrada de Jan Whitaker," y aportaciones que superan el habitual contexto "atlántico", como la obra de Helen B. Laurenson para Nueva Zelanda' 0 el reciente artículo de Yavuz Köse sobre los empleados de grandes almacenes en el Estambul tardo-otomano. ${ }^{13}$ Aparte quedarían trabajos de historia arquitectónica y urbana, como las reflexiones de Julien Bastoen sobre la "parisianidad" tipológica del gran almacén ${ }^{14} \mathrm{o}$ la documentada mirada de Richard Longstreth a los grandes almacenes estadounidenses en el ámbito comprendido entre 1920-1960, coincidente con su progresivo debilitamiento frente al emergente shopping mall de la nueva ciudad americana. ${ }^{15}$

4 Cuestión desarrollada en Susan P. BENSON: Counter Cultures. Saleswomen, Managers and Customers in American Department Stores, 1890-1940, Urbana-Chicago, University of Illinois Press, 1986, mers in American Departme

5 Hrant PASDERMADJIAN: The Department Store. Its Origins, Evolution and Economics, London, Newman Books, 1954.

6 Nikolaus PEVSNER: Historia de las tipologías arquitectónicas, Barcelona, Gustavo Gili, 1979.

7 Ténganse en cuenta las reflexiones críticas de autores como Baudrillard, Debord, Bourdieu o Galbraith: es imprescindible la sintesis de Luis E. ALONSO: La era del consumo, Madrid, Siglo XXI de España Editores, 2005. En otro sentido, véase el pasaje "Introduction" en John BENSON: The Rise of Consumer Society in Britain, 1880-1980, Essex, Longman Group UK Limited, 1994, pp. 1-7.

8 Michael B. MILLER: The Bon Marché.

9 Susan P. BENSON: Counter Cultures...

10 Bill LANCASTER: The Department Store, A Social History, London-New York, Leicester University Press, 1995, especialmente pp. 3 y 7-15.

1 Jan WHITAKER.The Department Store.

12 Helen B. LAURENSON: Going Up, Going Down. The Rise and Fall of the Department Store, Auckland, Auckland University Press, 2005.

13 Yavuz KÖSE: "Vertical Bazaars of Modernity: Western Department Stores and Their Staff in Istanbul (1889-1921)", International Review of Social History, 54 (2009), S17, pp. 91-114.

14 Julien BASTOEN:"La parisianité des grands magasins: contribution à l'étude de son interprétation architecturale" en Caminhos e Identidades da Modernidade: 1910, o edificio Chiado em Coimbra (Actas), Coimbra, Camara Municipal de Coimbra, 2010, pp. 55-67.

15 Richard LONGSTRETH: The American Department Store Transformed, 1920-1960, New Haven-Lon-
Trabajo enmarcado en el Proyecto de Investigación "Espacios portuarios y villas costeras: modelos (Ref. MICINN-2011HAR-24464). I.P.: Ma Soledad Âlvarez Martínez, Universidad de Oviedo. El autor es becario del programa FPU (ref. AP2012-2097)

Real Academia Española: Diccionario de la lengua española, $22^{2}$ ed., Madrid, Espasa, 2001, p. 78. ment Store, 1869-1920, Princeton, Princeton University Press, 1981.

3 Jan WHITAKER: The Department Store: History, design, display, London, Thames \& Hudson, 2011, pp. 22-48. 
España es un caso particular en lo que a consumo y grandes almacenes se refiere: como bien han señalado Luis Enrique Alonso y Fernando Conde, pese a los evidentes "intentos" de penetración previos a 1940, en este país resulta cuestionable hablar de una verdadera sociedad de consumo de masas hasta bien entrado el período franquista, entre las décadas de 1950 y 1970, ${ }^{16}$ época que coincide con la explosión y auge definitivo de los grandes almacenes, almacenes populares y demás cadenas comerciales. Aunque en el período comprendido entre 1900 y 1936 ciudades como Madrid y Barcelona ya contaban con novedosos almacenes de grandes dimensiones y moderno planteamiento, podemos admitir que, en términos generales, España careció de una verdadera y extendida "cultura del gran almacén" hasta la segunda mitad del s. XX, implantándose de forma abrupta en régimen de furiosa competencia duopolística a través de dos empresas nacionales y antagónicas, Galerías Preciados y El Corte Inglés, seguidas de otras firmas como los almacenes populares Simago y algunas compañías americanas (Sears, Woolworth) ${ }^{17}$.

En cuanto a la bibliografía específica disponible, mencionaremos en primer lugar la valiosa y reciente aportación de Nuria Rodríguez al conocimiento de la realidad comercial del Madrid del primer tercio del s. XX, incluida en su Tesis Doctoral, donde estudia en detalle diversos establecimientos pioneros de la capital de España anteriores a la Guerra Civil como los Almacenes Madrid-París, Almacenes Rodríguez, Almacenes Quirós o Almacenes San Mateo. ${ }^{18}$ Rubén Díez también ha abordado en un breve trabajo la historia del emblemático establecimiento $\mathrm{Ma}$ drid-París. ${ }^{9}$ Paralelamente, contamos con un artículo de Patricia Faciabén sobre los grandes almacenes de la ciudad de Barcelona ${ }^{20}$. Por último, sendas obras monográficas sobre Galerías Preciados y El Corte Inglés, escritas por Pilar Toboso y Javier Cuartas respectivamente, aportan numerosos datos y una visión general de la historia de ambas empresas, consolidadas durante el franquismo, con un importante enfoque biográfico. ${ }^{21}$

Los espacios de consumo contemporáneos en Asturias constituyen un territorio escasamente explorado. Para conocer la realidad social de dicha región en el entorno de 1900 debe partirse necesariamente de las publicaciones de Jorge Uría; ${ }^{22}$ por su parte, Francisco Erice proporciona valiosas informaciones acerca de empresarios, sociedades mercantiles y comercio en Asturias entre la segunda mitad del s. XIX y las primeras décadas del s. XX, período sobre el cual también ha trabajado Leire Rodríguez desde el estudio de la decoración de interiores, recogiendo algunos datos sobre negocios emblemáticos. ${ }^{23}$ Sergio Tomé ha investigado en de-

don, Yale University Press, 2010

16 Luis E. ALONSO y Fernando CONDE: Historia del Consumo en España: una aproximación a sus orígenes y primer desarrollo, Madrid, Debate, 1994, pp. 65-67, 153 y 212-213.

17 Desarrollado en profundidad por Pilar TOBOSO: Grandes Almacenes y Almacenes Populares en España. Una visión histórica. Documentos de Trabajo. Historia Económica, Madrid, Fundación SEPI, 2002, principalmente las pp. 26-56 y 98-104. Recuperado de Internet (http://dialnet.unirioja.es/) servlet/articulo? codigo $=3065111 \&$ orden $=225540$ \&info=link). 18 Ver el capítulo sexto en Nuria RODRÍGUEZ: La capital de un sueño. Madrid 1900-1936: la formación de una metrópoli europea, Tesis Doctoral, Universidad Complutense de Madrid, 2013. Recuperado de Internet (http://eprints.ucm.es/23049/1/T34801.pdf). Agradezco a Rubén Pallol Trigueros las

19 Rubén DíEZ: “Grandes almacenes modernos: Madrid-París 1920-1935”, en Miguel A. ÁLVAREZ (ed.), Diseño + imagen + creatividad en el patrimonio industrial, Gijón, INCUNA, 2011, pp. 293-301.

20 Patricia FACIABÉN: “Los grandes almacenes en Barcelona”, Scripta Nova, vol. VII, núm. 140 (2003).

21 Pilar TOBOSO: Pepin Fernández. 1891-1982, Galerias Preciados. El pionero de los grandes almacenes, Madrid, LID, 2000; Javier CUARTAS: Biografía de EI Corte Inglés: la historia de un gigante, Barcelona, Dictext, 1992

22 Véase Jorge URÍA: Una historia social del ocio. Asturias 1898-1914, Madrid, UGT y Centro de Estudios Históricos, 1996.

23 Francisco ERICE: La Burguesía Industrial Asturiana (1885-1920). Aproximación a su estudio, Gijón Silverio Cañada, 1980; ID.: Propietarios, Comerciantes e Industriales. Burguesia y Desarrollo Capi- talle la conformación de Oviedo como ciudad burguesa mencionando en su relato algunos comercios primitivos, y más recientemente ha ahondado en las características del comercio de la capital asturiana durante la posguerra y el ulterior desarrollismo, dentro de trabajos que trascienden el ámbito provincial. ${ }^{24}$ También Jesús A. Pérez nos ha legado, con su libro sobre el barrio de Uría, algunos datos cuantitativos de interés para documentar espacios comerciales ovetenses de época franquista. ${ }^{25}$ Disponemos de escuetas apreciaciones en algunas obras divulgativas de geografía y economía asturiana, así como artículos de prensa ciertamente nostálgicos, pero salvo alguna excepción carecemos de aproximaciones particulares: ${ }^{26}$ la historia de los grandes almacenes en Asturias aún está pendiente de ser escrita.

\section{Grandes almacenes y almacenes populares en Oviedo durante el franquismo: datos para su} estudio ${ }^{27}$

Podemos reconocer que hacia la década de 1880 la ciudad de Oviedo ya contaba con una red comercial relativamente desarrollada, bastante numerosa y diversificada. Tal como indican los omnipresentes anuncios en la prensa local y regional (El Carbayón y El Correo de Asturias) así como también informan algunas guías, ${ }^{28}$ en la ciudad existían abundantes establecimientos: tiendas de comestibles y coloniales, almacenes de tejidos, mueblerías, paqueterías, sastrerías, camiserías, ferreterías, zapaterías, bazares, etc. Aunque algunos negocios se ubicaban en el primer ensanche de la calle Campomanes, la actividad comercial se concentraba fundamen-

talista en la Asturias del Siglo XIX (1830-1885), Oviedo, Servicio de Publicaciones de la Universidad de Oviedo, 1995, dos tomos; e ÍD.: "Comercio, comerciantes y dependientes en Asturias (18851914). Notas sobre las actividades mercantiles en un ámbito regional de la España de entresiglos", SEMATA, Ciencias Sociais e Humanidades, vol. 12, (2000), pp. 125-162. Leire Rodríguez cita dichos comercios en relación al suministro de textiles para el tapizado de muebles o la confección de cortinajes y visillos. Ver Leire RODRíGUEZ: “Creadores y difusores del gusto en la decoración de interiores de la Asturias finisecular: industrias, talleres y casas comerciales" en Ana Ma FERNANDEZ (coord.): Decoración de interiores. Firmas, casas comerciales y diseño en Asturias, 1880-1990, Oviedo, Septem Ediciones, 2012, pp. 40-41

24 Sergio TOMÉ: Oviedo, la formación de la ciudad burguesa. 1850-1950, Oviedo, Colegio Oficial de Arquitectos de Asturias, 1988; ID.: “Posguerra y ciudad, la memoria del comercio perdido", Ería, vol. 91 (2013), pp. 111-128; e Í D.: "Comercio y ciudades medias en la España del desarrollismo", Biblio 3 W. Revista Bibliográfica de Geografia y Ciencias Sociales, vol. XVII, núm. 1.003 (5 de diciembre de 2012). Recuperado de Internet (http://www.ub.edu/geocrit/b3w-1003.htm).

25 Jesús A. PÉREZ: El barrio de Uría en Oviedo. De arrabal de enlace a centro comercial de Oviedo, Oviedo, Colegio Oficial de Arquitectos de León y Asturias, 1977.

26 La firma comercial y bancaria Casa Masaveu, que durante la segunda mitad del s. XIX y buena parte del XX gozó de prestigio en Asturias en parte gracias a sus renombradas tiendas, ha sido objeto de un estudio que constituye una rareza en el contexto aludido. Ver Jose R. GARCíA et al. Casa Masaveu: Oviedo, Madrid, Fundación Dragados, 2002. Sobre las crónicas periodísticas, ver Eugenio de RIOJA: "Botas y Al Pelayo. Convivencia en la competencia", La Nueva España, 13 de junio de 2004 (Suplemento Siglo XXI, $n^{\circ} 241$ ). Existe una investigación dedicada a los grandes almacenes La Favorita, propiedad de dos asturianos (García Hnos.) en la ciudad argentina de Rosario, que si bien supera el marco geográfico y social al que aludimos, debe ser mencionada. Ver Covadonga ÁLVAREZ: "Gran tienda La Favorita, de García Hnos. Rosario de Santa Fe. Argentina”, en Ma Cruz MORALES y Moisés LLORDÉN (eds.): Arte, cultura y sociedad en la emigración española a América, Oviedo, Servicio de Publicaciones de la Universidad de Oviedo, 1992.

27 Deseamos hacer constar nuestro agradecimiento a Ana Herrero (Archivo Municipal de Oviedo) Alberto Sanz (Servicio Histórico del Colegio Oficial de Arquitectos de Madrid), Teresa Caballero (Biblioteca del Museo de Bellas Artes de Asturias) y a los distintos informantes mencionados en el texto, por la ayuda prestada en esta parte de la investigación.

28 Consúltese Ángel R. CARTAVío: Guía industrial y comercial de Asturias, Imp. de Vallina y Compañía 1884, pp. 107-116. Ver también Fermín CANELLA: El Libro de Oviedo. Guía de la ciudad y su concejo, Oviedo, Imp. de Vicente Brid, 1887, p. 318. 
talmente a ambos márgenes del eje de calles Rúa-Cimadevilla-Magdalena, ${ }^{29}$ en pleno casco histórico, escenario idóneo para el "ritual" del paseo vespertino.

En dicha zona destacaban tiendas de tejidos, modas y novedades como El Vapor, La Isla de Cuba, el Bazar de Caicoya, J. Pausier, Al San Luis y sobre todo Casa Masaveu: esta última compañía inauguraba en 1904 un Gran Salón Bazar en la calle Cimadevilla que a juzgar por los datos de que disponemos, debía constituir una suerte de excepcional grand magasin en miniatura, durante años tal vez lo más parecido a un auténtico gran almacén que Oviedo pudo conocer..$^{30}$ En cualquier caso, lo cierto es que desde el último cuarto del s. XIX es posible constatar numerosos vínculos entre el comercio ovetense y la vanguardia mercantil nacional y extranjera. ${ }^{37}$

Desde 1890 y durante las tres primeras décadas del s. XX se produce un progresivo desplazamiento de los comercios de la ciudad hacia el nuevo ensanche burgués surgido en torno al eje formado por las calles Fruela y Uría y sus ramificaciones. Dentro del ramo de la moda, los complementos y la decoración del hogar, en la zona fueron asentándose almacenes de tejidos mayoristas y minoristas, sastrerías, pañerías, sederías y tiendas de confecciones como El Mundo, Las Novedades, Blanco y Negro, El Palacio de las Medias, Almacenes Fontela o la sucursal ovetense de Almacenes Simeón, por nombrar algunos.

A partir de 1900, una mirada global a los anuncios recogidos por la prensa local y regional nos permite identificar el intento de los principales comercios de modas y bazares de la ciudad por asimilarse con unos grandes almacenes, copiando su política del precio fijo, empleando inteligentes eslóganes, explotando al máximo el valor propagandístico de los escaparates, organizando ventas especiales o de temporada y aplicando toda clase de descuentos y promociones. De todos modos, sus discretas dimensiones, la modesta diversidad o volumen de su oferta y su escasa complejidad funcional y organizativa como empresa, hace difícil que podamos comparar los establecimientos citados no ya con los enormes department stores anglosajones, sino tan siquiera con los grandes almacenes madrileños o barceloneses anteriores a la Guerra Civil.

En definitiva, en espera de que nuevos hallazgos y reflexiones nos permitan definir con más seguridad esta cuestión, para el caso de Oviedo parece razonable situar la eclosión de grandes almacenes "maduros" a mediados de la dictadura franquista. Pasada la posguerra, desde finales de la década de 1950 y coincidiendo con los incipientes cambios en la norma de consumo se detecta una rápida penetración de nuevas cadenas comerciales y "modelos" de procedencia foránea: almacenes populares, grandes almacenes y fórmulas afines como supermercados de autoservicio, señal del avance de nuevos hábitos y tendencias.

La casa Saldos Arias, con numerosas sucursales en Madrid y otras ciudades españolas,32 podría servirnos para identificar la implantación de la fórmula de los almacenes populares en

29 Sergio TOMÉ: Oviedo, la formación..., pp. 20-25.

30 Véase la extensa crónica de su apertura en El Correo de Asturias, 10-VII-1904. El Gran Salón Bazar de los Masaveu, instalado en el espacio antes ocupado por el Teatro Ovies, contaba con techos "elevadísimos" y una buena iluminación natural gracias a sus grandes ventanales, en cualquier caso reforzada por "potentes focos de luz eléctrica". El interior se organizaba en pisos, por secciones, contaba con vitrinas de cristal y níquel plagadas de objetos variadísimos -perfumes, juguetes, relojes, barómetros, bibelots, menaje, muebles, cuadros-y presentaba una esmerada decoración calificada de "modernista".

31 Las "catedrales del consumo" europeas eran bien conocidas en el Oviedo de fin de siglo: los importantes almacenes parisinos Printemps se anunciaban en la prensa local ofreciendo catálogos ilustrados con sus novedades de temporada, muestrarios de tejidos y facilitando el envío de mercancías. Ver El Carbayón, 14-III-1887, y EI Correo de Asturias, 25-III-1900. Muchos comerciantes ovetenses viajaban con frecuencia a Madrid, Barcelona y las principales ciudades de Francia e ovetenses viajaban con frecuencia a Madrid, Barcelona y las principales ciudades de Francia e
Inglaterra para realizar compras: por ejemplo, Juan Montes, propietario de un acreditado establecimiento, regresaba en 1900 de un viaje comercial por París y Londres con un "completo y variado surtido de géneros última novedad". El Correo de Asturias, 31-III-1900.

32 En 1956 Saldos Arias contaba con veinte establecimientos en toda España. La Nueva España, 29-XII-1956.
Oviedo. Tras una inversión de aproximadamente 30.000 pesetas para adaptar un local en el bajo del $n^{\circ} 10$ de la céntrica calle Suárez de la Riva ${ }^{33}$ se anunció la apertura del nuevo establecimiento, que tendría lugar la tarde del viernes 28 de diciembre de 1956, formándose grandes colas por la afluencia de público: llegaban entonces a Oviedo "los precios más bajos de Europa", según anunciaba su característica publicidad, impactante e hiperbólica. ${ }^{34}$ La tienda tenía un tamaño reducido, pero aspectos tales como sus accesibles estanterías repletas de un sinfín de productos básicos, su elenco de precios bajos y su condición próxima a las tiendas de "gangas" (variety store, five-cent store o five-and-dime) como Woolworth o Ben Franklin, nos permitirían considerar a Saldos Arias un buen ejemplo de almacén popular, orientado a satisfacer los deseos de consumo de clases medias-bajas. 35

En septiembre de 1959 llegaba a Oviedo la firma de moda Cortefiel, entonces iniciando su importante expansión empresarial..$^{6}$ La marca madrileña, vinculada al grupo de producción y distribución Manufacturas del Vestido S.A., abrió un local en el $n^{\circ} 52$ de la calle Uría, invirtiendo en sus obras de adaptación más de 570.000 pesetas. ${ }^{37}$ La tienda, diseñada por el renombrado arquitecto Fernando García Mercadal, contaba con un vanguardista escaparate a modo de pantalla transparente que disolvía los límites entre el interior y la calle, promoviendo la renovación no solo económica sino estética del medio urbano..$^{38}$ La presencia de Cortefiel en Oviedo constituyó un verdadero evento: su publicidad exaltaba las comodidades de una línea industrial de moda asequible y lista para su uso inmediato (prêt-à-porter), ${ }^{39}$ representando un nuevo paso en la transformación de los hábitos adquisitivos de la población y una doble alternativa a la confección de las sastrerías locales y a la habitual autoproducción doméstica apoyada en las abundantes pañerías y sederías. $4^{\circ}$ En 1972 Cortefiel inauguraba una segunda sucursal en Oviedo, acondicionada por el arquitecto local Juan Vallaure.

33 Solicitud de instalación comercial en Archivo Municipal de Oviedo (citado AMO), signatura 13-196-15, expediente 2117/56.

34 La Nueva España, 28 y 29-XII-1956. Dos meses después inauguraban una nueva planta, ampliando su surtido. La Nueva España, 14-II-1957. Abrirían sucursal en Gijón en 1960.

35 Tomé describe las tiendas de Saldos Arias como "una reinterpretación de los antiguos bazares, Tomé describe las tiendas de Saldos Arias como "una reinterpretación de los antiguos bazares,
para la clase media-baja. Vistos desde la actualidad probablemente guardarian cierta semejanza para la clase media-baja. Vistos desde la actualidad probablemente
con las tiendas de los chinos". Sergio TOMÉ: "Comercio y ciudades".

36 En 1966 Cortefiel se jactaba de distribuir sus prendas en los almacenes neoyorkinos Macy's. La Vanguardia Española, 9-XII-1966.

37 Proyecto de obras de reforma de local comercial en AMO, signatura 13-1-244-9, expediente 77/59. La apertura aconteció el 14 de septiembre de 1959. La Nueva España, 15-IX-1959.

38 En 1946, García Mercadal reformaba junto a Ramón Aníbal Álvarez la central de los madrileños Almacenes Quirós, con una diáfana fachada de escaparates que podemos considerar un modelo para el diseño de Cortefiel de Oviedo. "Reforma de un local en la Gran Vía madrileña", Cortijos y rascacielos: casas de campo, arquitectura, decoración, $n^{\circ} 58$ (1950), pp. 4-6.

39 "CORTEFIEL se ha especializado, desde hace muchos años, en crear el traje de calidad para vestir en el acto. Usted, cómodamente, en diez minutos ha elegido y sale a la calle con un modernísimo traje, perfectamente a su medida". La Nueva España, 20-IX-1959.

40 Sobre la autoproducción doméstica de ropa, ver Luis E. ALONSO y Fernando CONDE: Historia del Consumo..., pp. 124 y 160.

41 Anuncio de apertura en La Nueva España, 10-IX-1972. Proyecto arquitectónico de reforma de local comercial en AMO, signatura 11-1-221-4, expediente 136/72. 


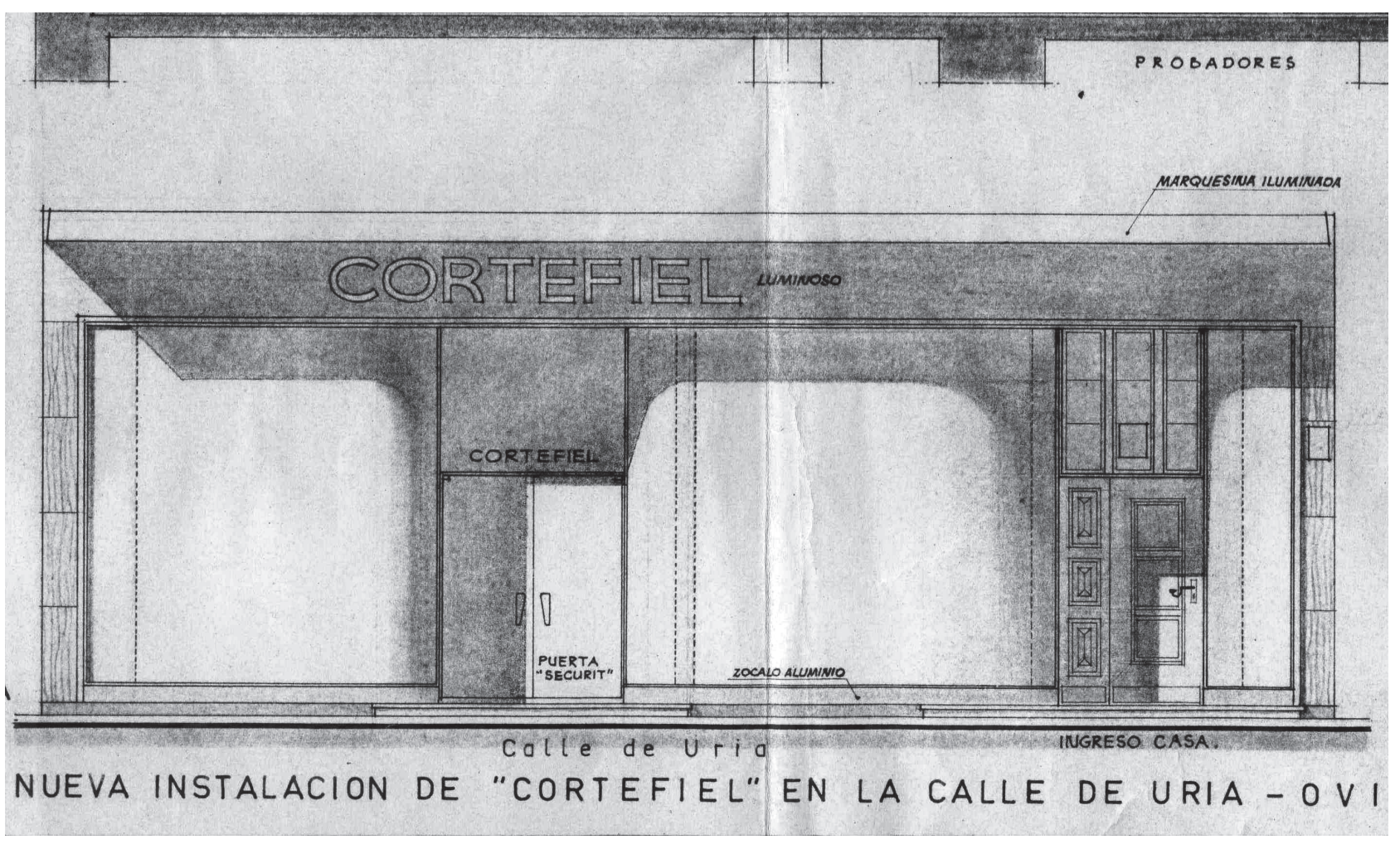

Img. 01 Diseño de Fernando García Mercadal para el escaparate de la primera sucursal de Cortefiel en Oviedo, 1959 (Fuente: AMO, signatura 13-1-244-9, expediente 77/59).

El 15 de febrero de 1960 se constituía en España la cadena de almacenes populares Simago, formada con capital hispano-cubano, presidida casi desde sus inicios por su cofundador Jose Manuel Mayorga y posteriormente vinculada al grupo francés Prisunic. ${ }^{42} \mathrm{Al}$ primer establecimiento madrileño en Embajadores inmediatamente se sumaron sucursales en Santander y Asturias, ampliándose luego al resto del país: orientadas a una clientela de extracción media-baja, sus tiendas combinaban alimentación-autoservicio, bazar y confección. En Oviedo abría sus puertas el 1 de octubre de 1960 en un modesto local en el $n^{\circ} 19$ de la calle Melquíades Álvarez, ofreciendo "más de 10.000 artículos". 43 En 1965 la sucursal se trasladaba a un moderno local con largos escaparates rectos de desarrollo apaisado, adaptado por el ya citado Juan Vallaure -responsable de numerosas obras comerciales en la ciudad-en los bajos $n^{\circ} 15$ y 17 de la calle Uría, arteria principal ovetense. El establecimiento sería ampliado en 1968 al local adyacente en los portales 19 y 21, donde alcanzaría su máximo desarrollo, llegando a los 138 empleados ya en $1977 .{ }^{44}$

Mención aparte merecen dos negocios de origen decimonónico, Al Pelayo y Almacenes Botas, que desde 1940 asumieron una serie de cambios sucesivos hasta convertirse en grandes

42 Rafael CASTRO: Génesis y transformación de un modelo de inversión internacional: el capital francés en la España del s. XX. Tesis doctoral, Universidad Complutense de Madrid, 2011, pp. 203-206. Recuperado de Internet (http://eprints.ucm.es/12055/1/T32626.pdf)

43 La Nueva España, 30-IX-1960. Semanas más tarde Simago inauguraba su primera tienda en Gijón. El Comercio, 19 y 20-X-1960. Alli se estrenaría poco después una pionera escalera automática:“Simago ofrece a todo el público de Gijón para su mayor comodidad un adelanto más del comercio moderno. La escalera móvil (...) Primera en todo el norte de España". El Comercio, g-XII-1960. 44 Proyecto inicial de Vallaure y ampliación de 1968 en AMO, signatura 10-5-62-3, expediente 255/65 y signatura 10-5-3-3, expediente 309/68. Con la ampliación, la tienda duplicó su superficie de exclub simago. . D. Oviedo, Oviedo Imp Críficas Lux, 1971, p.3. Dato sobre el número de empleados en Jesús A. PÉREZ: El barrio de Uría..., p. 74. almacenes muy evolucionados. Al Pelayo abría sus puertas el domingo 23 de abril de 1899, en un humilde bajo del $n^{\circ} 6$ de la calle Altamirano, en pleno casco antiguo, por iniciativa de dos populares comerciantes, José Delgado y Arturo Iglesias, que ya eran conocidos en la capital asturiana por otra tienda de novedades y ornamentos de iglesia llamada Los Chicos. 45

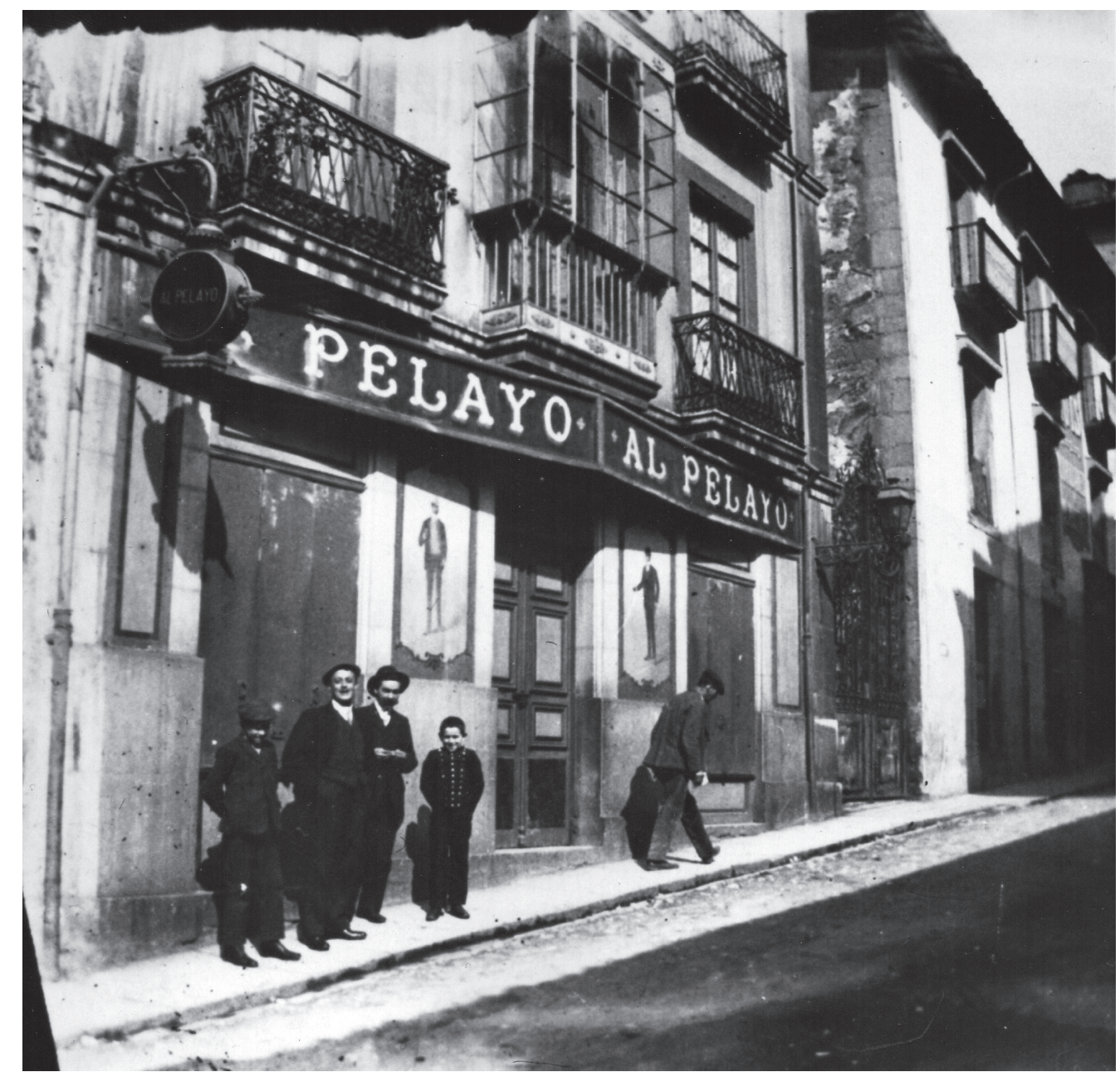

Img.02 El primer local de Almacenes Al Pelayo, en la calle Altamirano 6 , fecha desconocida, ihacia 1900 ? (Fuente: colección particular de Guillermo Brey Ruiz).

Durante sus primeros años el negocio funcionó como sastrería y almacén de confección vendiendo principalmente ropa para sacerdotes y trajes para caballeros y niños a precio fijo. En abril de 1911 la tienda anunciaba su traslado a "un nuevo y bien montado establecimiento" ocupando los bajos del $n^{\circ} 40$-posteriormente registrado 44 - de la calle Uría, ${ }^{46}$ en un elegante edificio en esquina propiedad de la familia Polo. Durante la década de 1920 se encontraban al frente del negocio José Delgado Morodo, hijo de uno de los fundadores, y Máximo Secades Cabeza, carismático empleado de confianza; este último, terminada la Guerra Civil, tomó en

45 “¿Qué es Al Pelayo? Pues ya lo sabe el público ovetense y de ello ha quedado gratamente impresionado. Se trata de un buen surtido establecimiento de ropas hechas, de todas clases y precios, que en la calle de Altamirano (antes Nueva) han abierto el domingo último los activos y simpáticos comerciantes de esta ciudad, comúnmente conocidos por Los Chicos, D. José Delgado y D. ticos comerciantes de esta ciudad, comunmente conocidos por Los Chicos, D. Jose Delgado y D.
Arturo Iglesias (...) Felicitamos a los Sres. Delgado e Iglesias por su feliz idea al establecer el nuevo comercio, que es de esperar les dé excelentes resultados". El Correo de Asturias, 26-IV-1899.

46 Anuncio del traslado en El Carbayón, 22-IV-1911. 
solitario las riendas del establecimiento ${ }^{47} \mathrm{y}$ en veinticinco años fue transformando la vieja tienda -muy convencional, con grandes mostradores y estantes de madera- en unos modernos grandes almacenes por departamentos, distribuidos en varios locales adyacentes, a pie de calle, en los números 44,46 y 48 de Uría, con amplias galerías de escaparate y un mobiliario actualizado. A mediados de la década de 1960, tras numerosas reformas parciales, Máximo Secades adquirió el edificio en esquina de los Polo $\left(n^{\circ} 44\right)$ y lo derribó, construyendo en su lugar un rupturista bloque-torre obra de Francisco y Federico Somolinos, destinado a acoger la importante ampliación de los Almacenes Al Pelayo así como oficinas, concebido en un decidido estilo "internaciona" "y llamado a simbolizar la fuerza del comercio en clave desarrollista $4^{8}$

De los 8 empleados con que contaba antes de 1940, Al Pelayo crecería hasta un número aproximado de 140-160 trabajadores en su época de esplendor hacia 1970. Los almacenes se articulaban entonces en diversas plantas y secciones -moda para señora, caballero e infantil, juguetería, regalos, decoración, perfumería, hogar, tapicería- contando con ascensor y cafetería propios, sendos alardes de modernidad que contrastaban con la idiosincrasia popular proyectada mediante eslóganes como "Prestigio y economía" o "El comercio de Asturias", y campañas como el famoso sistema de venta " $2 \times 1$ ", célebre evento multitudinario causante de grandes aglomeraciones.

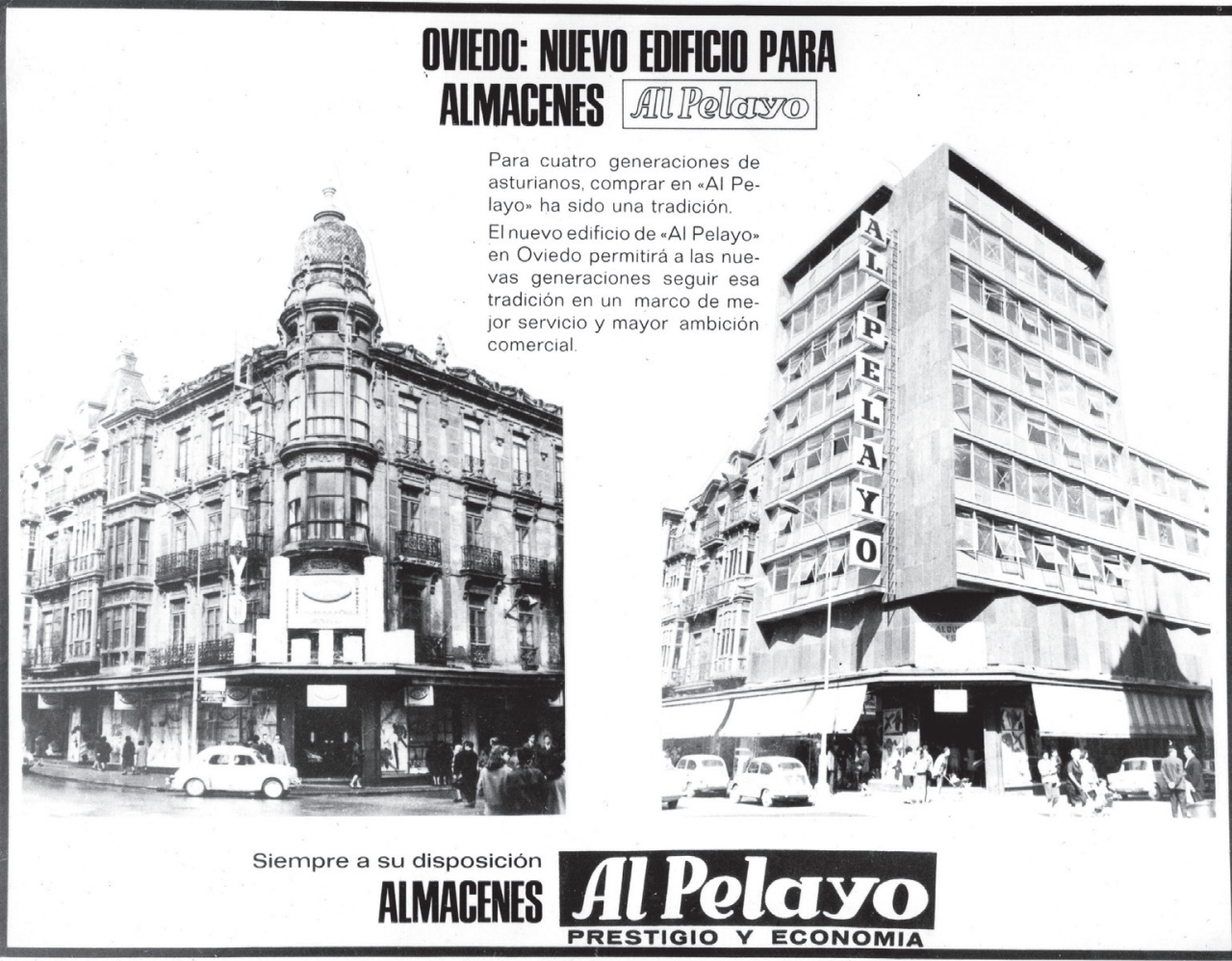

Img.03 Lámina promocional de Almacenes Al Pelayo, a la izquierda el edificio en esquina de la familia Polo $\left(n^{\circ} 44\right)$ y el adyacente 46 a la derecha la nueva obra de los Somolinos, fecha aproximada: 21968 ? (Fuente: colección particular de Guillermo Brey Ruiz).

47 Entrevista a Máximo Secades por José A. CEPEDA: “Hombres con voluntad de superación: Máximo Secades Cabeza", Región - Suplemento Especial 50 Aniversario, 24-VII-1973.

48 Ver $M^{a}$ José CUESTA RODRÍGUEZ et al:: Guía de Arquitectura y Urbanismo de la ciudad de Oviedo Oviedo Colegio Oficialde Arquitectos de Asturias 1998, p 224 Máximo de la ciudad de Oviedo, Oviedo, Colegio Oficial de Arquitectos de Asturias, 1998, p. 224. Máximo Secades solicitó en julio de 1964 licencia para "construir edificio de ocho plantas en la calle Uría esquina Doctor Casal". Ver AMO, ficha de registro del expediente 234/64. Durante el derribo y construcción del nuevo edi8 de abril de 2013 se mantuvieron abiertos por partes, segun Al Pelayo entre al menos 1962 y 1988
Los Almacenes Botas representarían el ejemplo más avanzado de gran almacén en Oviedo antes de la implantación de Galerías Preciados. Podemos remontar sus orígenes al año 1890 cuando un joven Juan Botas Roldán (Castrillo de los Polvazares, 1867 - Oviedo, 1926) asume la dirección del negocio de sus parientes Francisco y Tomás Botas, un almacén de venta mayorista de tejidos establecido en el $n^{\circ} 4$ de la calle Martínez Marina. ${ }^{49} \mathrm{~A}$ partir de entonces y hasta su muerte, Juan Botas Roldán, distinguida figura de la burguesía primisecular asturiana, potenció el negocio ampliando sus instalaciones y desarrollando operaciones comerciales fuera de las fronteras regionales. ${ }^{\circ}$ Desde 1928 la compañía, en manos de sus herederos, actuará bajo la razón social Anónima Botas Roldán inaugurando una primera sección de venta minorista de pañería seis años después. ${ }^{51}$ Tras un primer intento de traslado fallido a causa de los sucesos bélicos, en mayo de 1940 los Almacenes Botas reanudan la venta de algodón, lanas, sedas y paños en un local de importantes proporciones, articulado en dos plantas, en el $n^{\circ} 24$ de la calle Uría. ${ }^{52}$

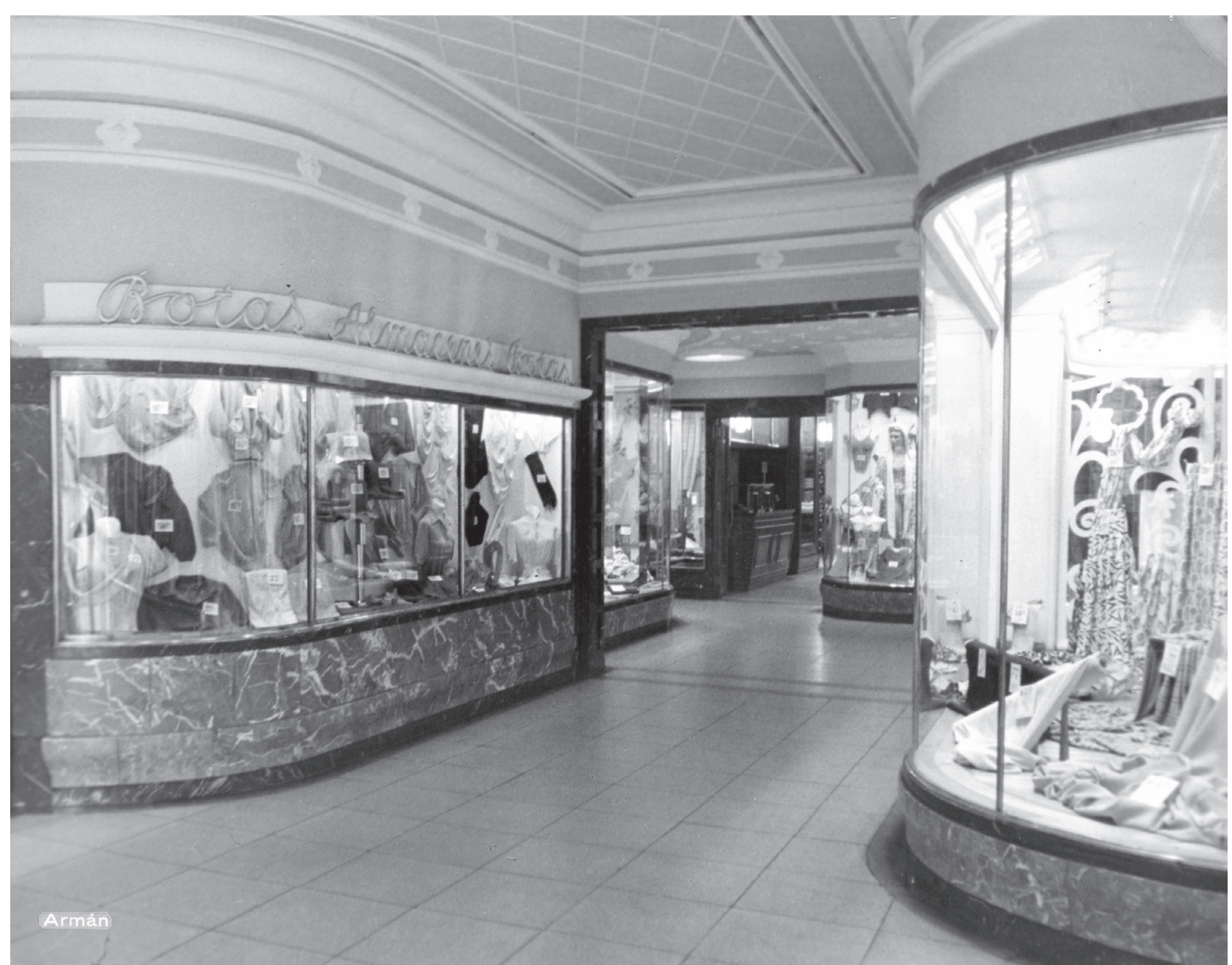

Img. 04 Escaparates de Almacenes Botas en el $n^{\circ} 26$ de la calle Uría, ¿hacia 1945? (Fuente: fondos de depósito del arquitecto Juan Vallaure Fernández-Peña, Museo de Bellas Artes de Asturias).

49 "Se ha disuelto la Sociedad Hijos de Pedro Botas, que en lo sucesivo girará bajo la razón social de Juan Botas y Compañía", El Correo de Asturias, 26-VI-189o.

50 "La esfera de acción de la importante Casa comercial alcanza a toda la provincia de Oviedo y se extiende a parte de las de Galicia, Santander y Castilla." La Esfera: Ilustración Mundial, Madrid, julio de 1918, número extraordinario dedicado a Asturias.

51 Anuncio en Región, 22-IV-1934.

52 Solicitud de traslado de almacén en AMO, signatura 7-10-17-59, expediente 870/40. 
Desde entonces, la tienda no hizo más que crecer extendiéndose en 1943 al local contiguo del $n^{\circ} 26,5^{3}$ y posteriormente a un local trasero en el $n^{\circ} 13$ de Palacio Valdés, creándose un atajo cubierto entre dos calles principales, algo que los hermanos Botas Rodríguez (hijos de Juan Botas Roldán) anunciaron astutamente como una suerte de servicio público. ${ }^{54}$ Aunque durante los años de posguerra los Almacenes Botas ya manejaban la publicidad con seguridad -en 1943 se postulaban como "la casa más importante de España" y en 1945 situaban a Asturias "a la altura de las grandes capitales europeas"-55 el gran salto cualitativo tuvo lugar entrada la década de 1960.

Ciertamente, por iniciativa del sucesor Luis Botas Rezola, ${ }^{56}$ licenciado en Derecho y formado en marketing y distribución en EEUU, los Almacenes Botas asumieron una arriesgada operación adquiriendo un local de tres plantas en el $n^{\circ} 30$ de la calle Uría, conectado interiormente con los demás locales anteriores mediante escaleras: la arquitectura e interiorismo fueron confiados al genial Javier Feduchi Benlliure, quien entonces iniciaba su labor como creador de espacios comerciales para Galerías Preciados. ${ }^{57}$ Oviedo contó en una fecha tan temprana como mayo de $1964^{58}$ con unos grandes almacenes de diseño absolutamente puntero y estética "europea" -su peculiar techo tomaba como modelo el gran almacén Bijenkorf de Rotterdamdotados de un elegante snack-bar americano que introducía un distintivo matiz social al mero acto de comprar: en 1969, sus surtidas secciones abarcaban tejidos, confección, perfumería, complementos, juguetes, electrodomésticos, discos, libros, cristalería, vajillas, muebles e incluso un servicio de decoración de viviendas.

La plantilla de Anónima Botas Roldán pasó de unos 50 empleados en 1945 -sólo en Oviedo- a 360 durante la década de 1970, incluyendo la sucursal de Gijón..$^{59}$ Durante los sesenta, la empresa formaba a sus trabajadores mediante cursos de ortografía, técnica de ventas, contabilidad o aprendizaje de las normas -editadas en un libreto, muy similares a las de Galeríasorganizaba charlas de motivación y publicaba un boletín interno mensual o bimensual que junto con las actividades de su "Botas Club" -viajes, comidas, conferencias- servía para cohesionar y potenciar el sentimiento de pertenencia a la "casa" o "familia". Esta fórmula del club de empresa también funcionó en Simago, compañía que igualmente editaba una revista para sus trabajadores. ${ }^{60}$ Los Almacenes Al Pelayo, algo más modestos en la gestión de sus recursos humanos, contaron con un club que organizaba excursiones y cenas de hermandad para los empleados, quienes además tenían a su disposición una pequeña biblioteca. ${ }^{6}$

53 El arquitecto Juan Vallaure diseñó una fachada "monumental" englobando ambos locales, organizó el interior del local 26 y trazó una fina galería de escaparates con lunas curvilíneas, mármoles y latón. Proyecto de reforma en AMO, signatura 4-6-60-13, expediente 95/43.

54 "Cordialmente les invitamos a visitar las nuevas instalaciones en la calle de Palacio Valdés, número 13. Libre tránsito: a través de nuestros locales, entre las calles de Palacio Valdés y Uría iUtilice este paso! Con mucho gusto le brindamos este servicio". La Nueva España, 28-X-1956.

55 Anuncios en La Nueva España, 5-I-1943 y 29-IV-1945.

56 Nieto de Juan Botas Roldán. Biografía en Gran Enciclopedia Asturiana, Gijón, Silverio Cañada, 1981, tomo 15 (apéndice 1970-1980), p. 170 y La Nueva España, 30-V-2004.

57 El madrileño Javier Feduchi Benlliure (1929-2005) fue arquitecto, interiorista y diseñador de muebles. Sus viajes de juventud le permitieron conocer las más modernas instalaciones comerciales europeas de la época. Destacaremos sus diseños para Galerías Preciados en Eibar (1962), Arapiles (1964) y Callao (1968), asi como el proyecto de la sucursal de Almacenes Botas en Gijón (abierta en 1970).

58 Apertura el 23 de mayo. Ver Boletín de Botas, año III, $n^{\circ}$ 20, junio-julio 1964, pp. 7-15.

59 Ver $A B C, 16-I X-1945$ y Jesús A. PÉREZ: El barrio de Uría..., p. 74.

60 El club ovetense fue el primero de la compañía. Memoria del club Simago..., p. 4 y siguientes. 61 Testimonios de Begoña Fernández de la Vega, 8 de mayo de 2013, Alegría Álvarez Díaz, 7 de agos-
to de 2013 y Manuel López Iglesias, 3 de octubre de 2013 , entrevistas realizadas por Jose RODRÍGUEZ-VIGIL. Los tres informantes trabajaron como empleados de Almacenes Al Pelayo: la primera,

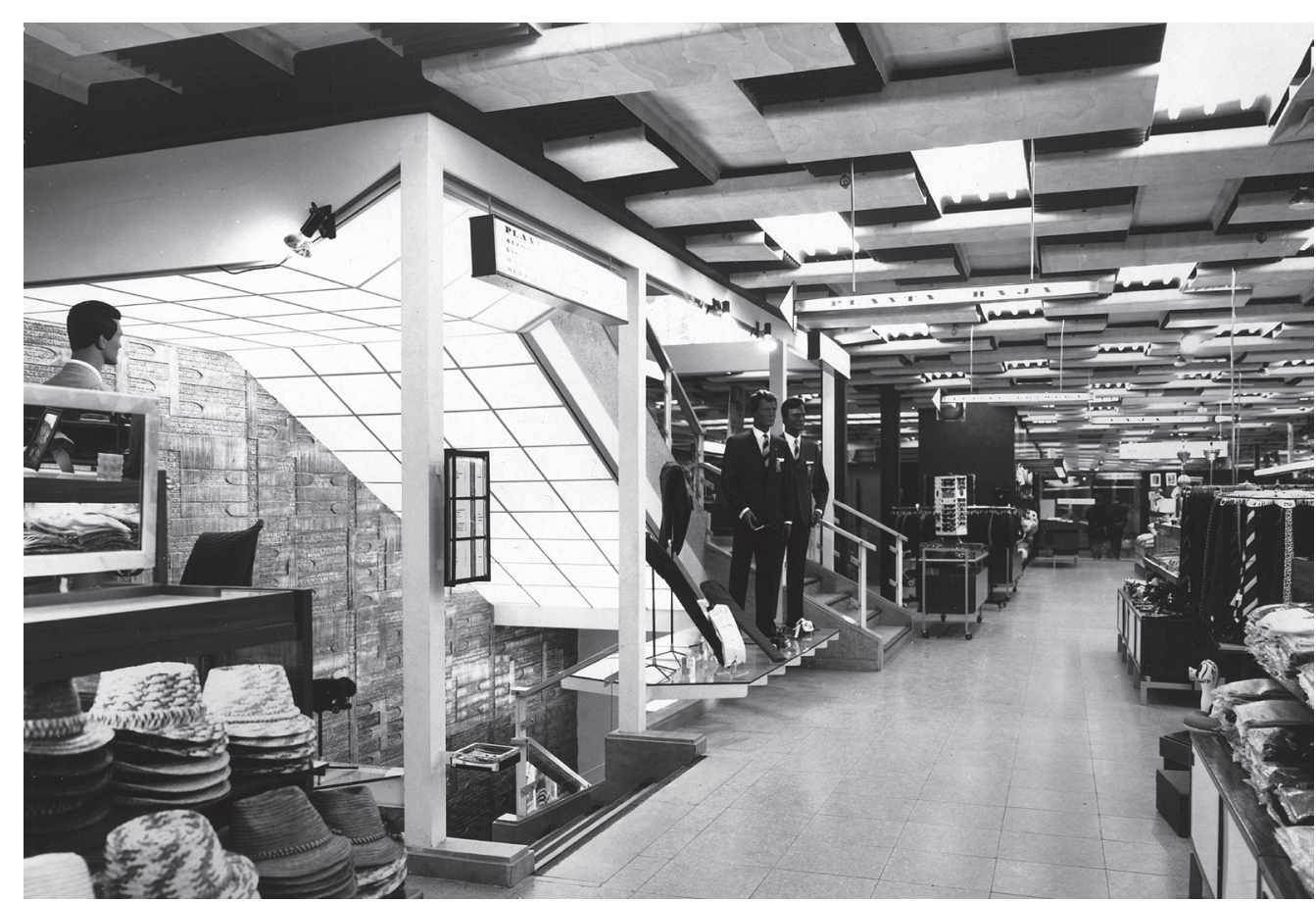

Img. 05 Interior de la ampliación de Almacenes Botas ( $n^{\circ} 30$ de Uría) concebida por Javier Feduchi en 1964 (Fuente: fondos del Legado Javier Feduchi Benlliure, Servicio Histórico del Colegio Oficial de Arquitectos de Madrid).

Cabría señalar el importante componente femenino de las plantillas de estos establecimientos: el boletín de Almacenes Botas citaba ya en 1964 la evidente feminización de su joven capital humano, que se incrementaría en los años posteriores, y en 1971, de los 75 trabajadores socios del Club Simago, 61 eran mujeres: un 81'3 \% del total. . $^{62}$ Muchas jóvenes solteras, entre 16 y 25 años, encontraron en los grandes almacenes ovetenses una primera oportunidad para incorporarse al mercado laboral, dentro del pujante sector servicios, como cajeras o dependientas $^{63}$-rara vez ocupando cargos de mayor responsabilidad- si bien sus carreras por regla general se truncaban con el matrimonio. Como curiosidad, Almacenes Botas contaba con un sofisticado sistema paternalista de prestaciones, el Programa Social Botas, que entre otras cosas otorgaba dotes a sus empleadas cuando se "retiraban" al casarse. ${ }^{64}$

Los establecimientos referidos lideraron una transformación de la mentalidad y hábitos de los consumidores locales: podemos afirmar que cuando Galerías Preciados llegó finalmente a Oviedo encontró el terreno "bien abonado", y que para ganar la partida, únicamente tuvo que subir la apuesta. Tras filtrarse rumores sobre una posible apertura inminente de El Corte Inglés, ${ }^{65}$ Pepín Fernández, fundador de Galerías, anunciaba en marzo de 1973 la instalación de una sucursal de su emporio en Oviedo, rompiendo una promesa realizada a la familia Botas de no situarse jamás en Asturias. ${ }^{6}{ }^{6}$ Una inversión de 1.000 millones de pesetas

entre 1972-1976, la segunda entre 1975-1988 y el tercero desde 1953 hasta 1988.

62 Datos extraídos del Boletín de Botas, año III, $n^{\circ} 16$, enero 1964, p. 14, y de la Memoria del club Simago..., pp. 10-11.

63 Es expresivo el siguiente anuncio de Simago, publicado en La Nueva España, 11-IX-1960: "Simago (...) necesita señoritas dependientas y aprendizas. Condiciones: 1. Solteras. 2 . Menores de 22 años (...)".

64 Por ejemplo, en 1972 el Programa Social Botas destinó a su plantilla un total de 1.385 .290 ptas. para ayudas familiares, escolares y dotes matrimoniales (200.000 ptas. repartidas en 12 dotes). Boletín de Botas, año XII, $\mathrm{n}^{\circ} 108$, febrero 1973, p. 7 .

65 La Nueva España, 4-I-1973. Dicha empresa no llegaría a Oviedo hasta la década de 1980

66 Ver La Nueva España, 31-III-1973. Sobre la “traición” a los Botas, Javier CUARTAS: Biografía..., pp. 571-573. 
y 600 empleados contratados fueron las cifras que deslumbraron a la sociedad ovetense en su inauguración el 15 de mayo de $1975 .{ }^{67}$

Su edificio, construido tras el derribo del chalet Tartiere en una amplia parcela en el $n^{\circ} 9$ de la calle Uría, frente a Almacenes Al Pelayo y muy cerca de Almacenes Botas y Simago fue una obra del citado Javier Feduchi junto a Francisco Bassó reformulando un anterior proyecto madrileño (Goya). ${ }^{68}$ El gran bloque, desornamentado y hermético, sobriamente animado por larguísimos escaparates a pie de calle y una cafetería-mirador dispuesta en el último piso-de nuevo un espacio de socialización y ocio inscrito en un ambiente de consumo- se alejaba estéticamente de cualquier otro edificio del entorno inmediato, emparentando con referentes tipológicos comerciales norteamericanos post-1945. ${ }^{69}$

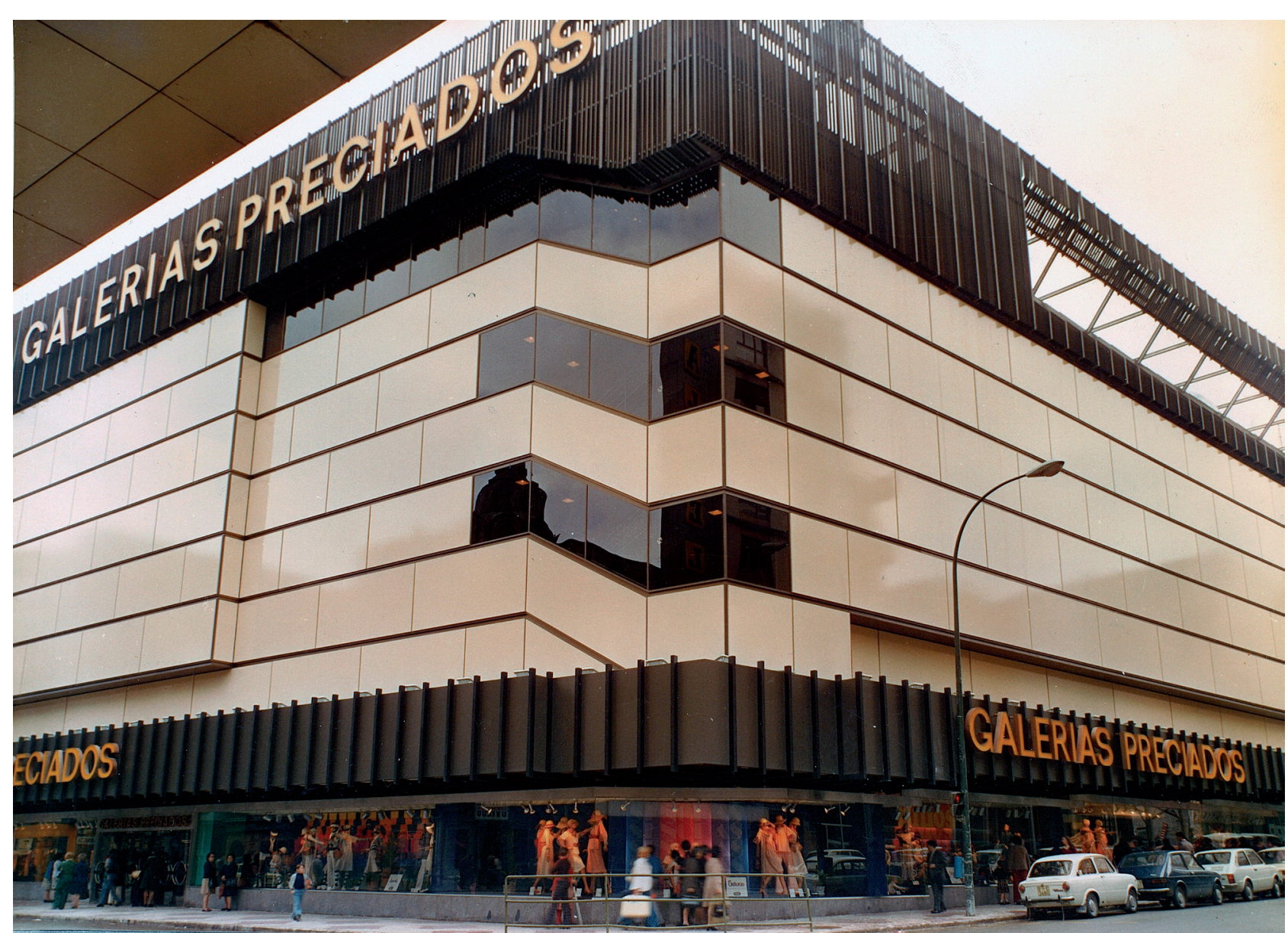

Img. 06 Exterior del edificio de Galerías Preciados de Oviedo en 1975, obra de Feduchi y Bassó (Fuente: fondos del Legado Javier Feduchi Benlliure, Servicio Histórico del Colegio Oficial de Arquitectos de Madrid).

A través de una intensa campaña en prensa, Galerías rindió "tributo" a la ciudad "ofreciéndole" un gran almacén, y dedicaba "un cordial saludo a todos sus colegas de Oviedo", correspondido por la competencia bien con diplomacia ("Saludamos con cordialidad y satisfacción la presencia de Galerías Preciados en Oviedo" de Al Pelayo), bien con evidente hostilidad ("Botas sigue en su sitio")..$^{70}$ Paralelamente Galerías abrió un Hogar del Empleado para sus trabaja-

67 La Nueva España, 16-V-1975

68 Proyecto para construir edificio de grandes almacenes en AMO, signatura 18-1-145-3, expediente $876 / 74$.

69 Richard LONGSTRETH: The American Department..., pp. 49-59.

70 Fragmentos de anuncios de La Nueva España entre los días 2 y 18-V-1975. dores en el $n^{\circ} 21$ de la calle Uría, como hiciera en las demás capitales españolas, destinado a acoger reuniones, conferencias y servir de lugar de esparcimiento para su personal, contando incluso con un bar y comedor, en una linea paternalista ya comentada con anterioridad.

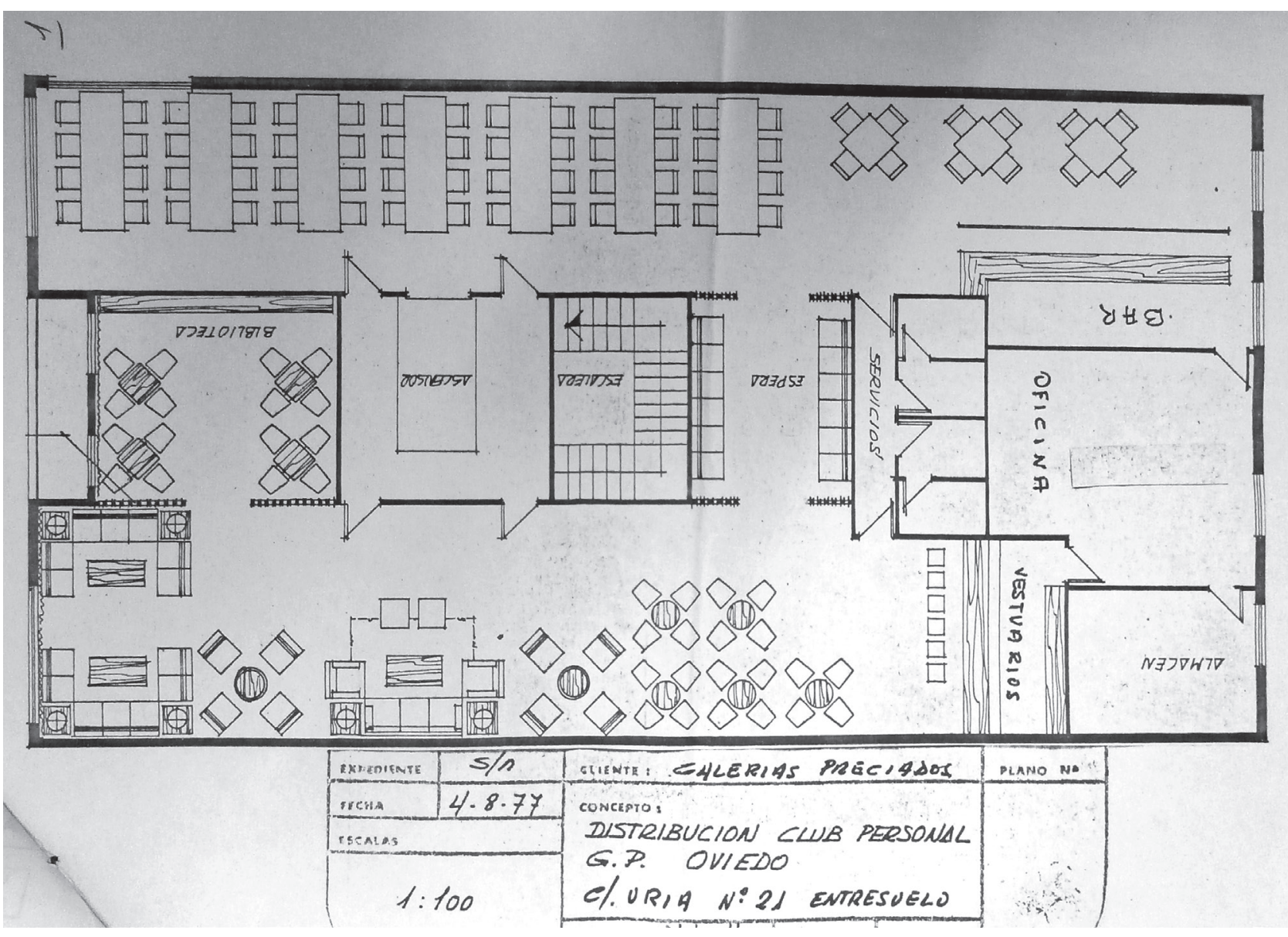

Img. 07 Plano del Hogar del Empleado de Galerías Preciados de Oviedo, en 1977. Se aprecian los espacios para la formación, confraternización y el descanso (Fuente: AMO, signatura 15-158-14, expediente 2959/77).

Hacia 1975 la población ovetense ya había interiorizado plenamente estrategias como la venta a plazos, los cheques regalo o el reparto a domicilio de las compras. Igualmente, habian asumido un calendario comercial paralelo en el que mas herederas de los antiguos "baratos", fechas como la Navidad, San Valentín o el Día de la Madre se convertían en ocasiones de gasto para un público que comenzaba a acostumbrarse, en cuestiones de moda, hábitos y way of life a un patrón fundamentalmente angloamericano filtrado a través de los expositores, eslóganes y marcas. ${ }^{72}$ Galerías consolidó la idea del comercio como espectáculo cultural: Sudamérica, Inglaterra, Rusia o China llegaron regularmente a Asturias desde 1975 mediante promociones, asociando el consumo a cierta curiosidad "antropológica" según una noción del exotismo y del cosmopolitismo un tanto kitsch. Los luminosos, marquesinas, escaparates, anuncios de temporada y decoraciones estacionales, como la iluminación navideña de fachadas, contribuyeron a hacer de la ciudad un llamativo soporte publicitario a gran escala. Aparte, diversos concursos, exhibiciones y exposiciones de fotografía y pintura

71 Apertura de Hogar del Empleado en AMO, signatura 15-1-58-14, expediente 2959/77, incluye plano. 72 Anuncios de Botas publicados en La Nueva España "Euromoda. Moda Op-att(.) div revolucionaria" (5-1V-1966): "No somos británicos pero lo parecemos" " "Nada nos es ajenc mos swing y fuimos pop" (2 y 8-X-1969). 
Botas-73 potenciaron cierta imagen de respetabilidad de estos negocios en el entramado de instituciones ovetenses.

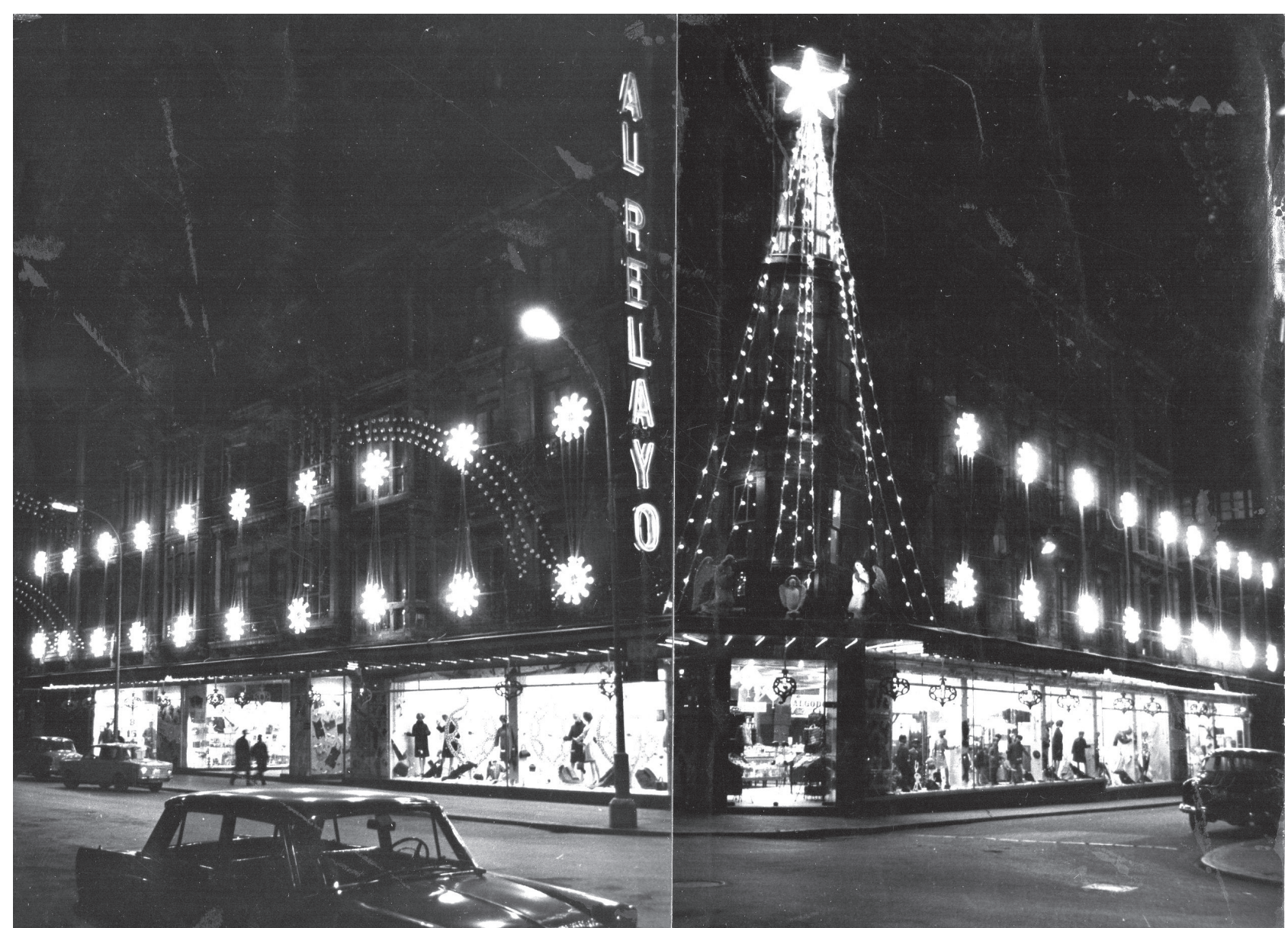

Img. 08 Iluminación navideña de los Almacenes Al Pelayo a mediados de los sesenta (Fuente: colección particular de Guillermo Brey Ruiz).

Con este trabajo hemos pretendido aportar algunos datos sobre una serie de comercios emblemáticos que si bien desaparecidos a día de hoy -a excepción de Cortefiel, que conserva activo uno de sus locales-74 continúan vivos en la memoria colectiva de varias generaciones de trabajadores y consumidores asturianos.

73 Sobre el desfile benéfico, La Nueva España, 29-IV-1961. La primera beca "Juan Botas Roldán" para alumnos de Profesorado Mercantil fue otorgada en el curso académico 1961-62. Ver Boletin de Botas, Año II, $n^{\circ}$ 14, octubre-noviembre, 1963, p.5.

74 Los Almacenes Botas cierran tras una crisis iniciada a finales de 1987. En diciembre de 1988 cierra Almacenes Al Pelayo Calerías Preciados es absorbida en 1995 por El Corte Inglés empresa que Almacénes Al Polay. Cale de Saldos Arias. 


\section{ENMARCANDO EL ESCRACHE:}

\section{CONFLICTO ENTRE NARRATIVAS}

Luis Manuel Sanmartín Cava

Universitat Autònoma de Barcelona (UAB)

\section{Introducción}

En Talking Politics, Silverstein expone que los políticos producen un retrato de su identidad:una imagen que posibilita el encarnado de un mensaje.' Expresado de manera más precisa, el encarnado de un diagrama desde el cual interpretar los eventos del pasado, el contexto presente y las expectativas de la audiencia respecto del futuro. ${ }^{2}$ Esta actividad no es diferente de la elaboración discursiva que los movimientos sociales realizan para adquirir coordinación entre sus miembros.

Por una parte, el objetivo de los políticos en el contexto liberal es conseguir apoyo popular como en las campañas electorales. Cuando este apoyo se logra mediante el encarnado de un diagrama con resonancia social, los políticos representan un mensaje de manera personalista. ${ }^{3}$ Por otra parte, los movimientos sociales aspiran a producir una directa movilización social. ${ }^{4}$ De este modo, los movimientos sociales representan un mensaje invitando a las audiencias a participar en las acciones del grupo. Aunque por motivos distintos, el resultado deseado por parte de partidos políticos y movimientos sociales alrededor de la imagen es el mismo: altera la concepción que la audiencia posee hacia su actividad. Desde esta base teórica, el objetivo de nuestro ensayo es mostrar cómo los procesos de contraenmarcado de partidos políticos y movimientos sociales son desarrollados sobre esta misma alteración.

Para ello, explicaremos en primer lugar cómo los movimientos sociales y los partidos políticos construyen su imagen. En segundo lugar, describiremos cómo funcionan los procesos de contraenmarcado, alrededor de la imagen, a través de la práctica del escrache acometida en el año 2013 en España. Finalmente, cerraremos el ensayo con nuestra conclusión: la ausencia de recepción positiva de los procesos de contraenmarcado desarrollados por el Partido Popular hacia la Plataforma de Afectados por la Hipoteca tienen que ver con el rechazo de las atribuciones de identidad de las audiencias que implicaban.

\section{Enmarcando la imagen: acción e identidad}

La contribución de la teoría de los marcos de referencia al estudio de los movimientos sociales es la concepción de que una insatisfacción social no produce automáticamente una

1 Michael SILVERSTEIN: Talking Politics: The Substance of Style from Abe to 'W', Chicago, Prickly Paradigm Press, 2003, pp. 5-8

2 Ibid., pp. 38-40.

3 Jane HILL: "Read my article: ideological complexity and the overdetermination of promising in American presidential politics" en P. V KROSKRITY (ed.): Regimes of Language: Ideologies, Polities, and Identities, Santa Fe, NM: SAR Press, 2000.

4 Francesca POLLETA y James M. JASPER: “Collective Identity and Social Movements”, Annual Review of Sociology, 27 (2001), pp. 283-286. movilización social. 5 Para lograr dicha participación los movimientos sociales elaboran marcos de referencia (frames) que son "schem[es] of interpretation" que posibilitan a los individuos "to locate, to perceive, identify and label" sucesos en el mundo. ${ }^{6}$ Estos esquemas interpretativos toman la forma de marcos de referencia de acción colectiva: marcos compartidos entre los miembros de un movimiento reivindicativo que permiten una coordinación entre los activistas dotando de similar significado a varios sucesos sociales. ${ }^{7}$ Hay tres marcos de referencia de acción colectiva que son básicos para cualquier movilización: ${ }^{8}$

1. El marco de diagnóstico, que ofrece una narrativa sobre los orígenes y causas de un problema social. Parte del marco de diagnóstico es el enmarcado de injusticia, que se basa en la conversión de las desgracias individuales en consecuencias de una injusticia social.

2. El marco de pronóstico, que establece los objetivos concretos y las estrategias específicas para resolver una injusticia social.

3. El marco de motivación, que abarca las justificaciones para la movilización social y el apoyo al grupo.

Como Hunt afirma, los marcos de referencia de acción colectiva no sólo orientan el comportamiento pragmático, sino que implican retratos de identidad de los diferentes grupos que están relacionados con una injusticia social. 9 Por ejemplo, como explica Taylor, las feministas de las Furias de Washington D.C. consideraban que la preferencia sexual lésbica era fuertemente política porque era una práctica contracultural frente a la hegemonía machista. ${ }^{\circ}$ Siguiendo a Taylor, la construcción discursiva de los movimientos sociales difumina la frontera entre e hacer y el ser." Este fenómeno toma la forma de proyección de atribuciones de identidad que pueden ser organizadas en tres campos distintos: ${ }^{12}$

1. Campo de identidad de los protagonistas, como el conjunto de atribuciones de identidad proyectadas sobre los miembros del movimiento social y sus actuales aliados.

2. Campo de identidad de los antagonistas, como el conjunto de atribuciones de identidad

5 David A. SNOW, Burke E. ROCHFORD, Steven K.WORDEN y Robert D. BENFORD: “Frame Alignment, Micromobilization, and Movement Participation" American Sociological Review 51 (1986) No 464-81 y Verta TAYLOR y Nancy E. WHITTIER:" "Collective Identity in Social Movement Communities: Lesbian Feminist Mobilization" Frontiers of Social Movement Theory (1992), Yale University Press, pp. 104-107.

6 Erving GOFFMAN: Frame Analysis, Harvard University Press, 1974, pp. 21.

7 Stephen ADAIR: "Overcoming a collective action frame in the remaking of an antinuclear opposition". Sociological Forum, 11 (1996), pp. 347-355.William A. GAMSON: Talking Politics, New York, Cambridge University Press, 2002, pp. 6-8.

8 Scott A. HUNT, Robert D. BENFORD y David A. SNOW: "Marcos de acción colectiva y campos de identidad en la construcción social de la protesta" en Joseph GUSFIELD y Enrique LARAÑA (ed.) Los nuevos movimientos sociales: de la ideología a la identidad, Centro de Investigaciones Sociológicas (CIS), 1994, pp. 228-244.

9 Ibid

10 Verta TAYLOR y Nancy E. WHITTIER: “Collective Identity in Social Movement Communities: Lesbian Feminist Mobilization" Frontiers of Social Movement Theory (1992), Yale University Press, pp. 109113.

11 Ibid., pág. 113

12 Scott A. HUNT, Robert D. BENFORD y David A. SNOW: "Marcos de acción colectiva y campos de identidad en la construcción social Existe una verdadera necesidad de que nuestro grupo este aqui. Pienso que sentimos la necesidad de tener un lugar ahi. Podad que nuestró grupo este aqui. Plenso que sentimos la necesidad se télica contundente lo que pensamos de sus y quemar misiones de paz Problemente quien haga esto será arrestado ¿Y qué? A Acaso tensmos algo misiones de paz. Probablemente, quien haga esto sera arrestado. ¿Y qué? ¿Acaso tenemos algo que perder? de la protesta" en Joseph GUsFe 244. 
que son proyectadas sobre los grupos e individuos responsables de la injusticia social.

3. Campo de identidad de la audiencia, como el conjunto de las atribuciones de identidad proyectadas sobre los observadores de una movilización social.

El siguiente ejemplo, extraído del artículo de Hunt sobre marcos de acción colectiva, ofrece la combinación entre el comportamiento pragmático derivado de los marcos de referencia de acción colectiva y sus consecuentes proyecciones de identidad. ${ }^{13} \mathrm{El}$ caso presenta los comentarios de un miembro del Omaha Youth Peace Movement sobre la Fuerza Aérea de los Estados Unidos:

Existe una verdadera necesidad de que nuestro grupo esté aquí. Pienso que sentimos la necesidad de tener un lugar ahí. Podemos ir al Escuadrón y quemar su bandera para mostrar de una forma simbólica y contundente lo que pensamos de sus llamadas misiones de paz.

Probablemente, quien haga esto será arrestado ¿Y qué? ¿Acaso tenemos algo que perder?"

En esta justificación encontramos de manera implícita el marco de diagnóstico, que interpreta como un problema social la actitud belicista de los Estados Unidos. Además, están presentes explícitamente los marcos de pronóstico y motivación. En lo que se refiere al marco de pronóstico, el mismo establece como una táctica aceptable aquellas acciones que ponen de manifiesto, de manera simbólica, el rechazo del uso gubernamental de la Fuerza Aérea. E marco de motivación apelaría a la necesidad compartida de los miembros de estar presentes en ese momento y cometer una acción ofensiva contra la moral del ejército. Pero el elemento clave de la apelación, que se desprende del marco de motivación, es que se establece una distinción tajante entre los individuos realmente comprometidos con la lucha antibelicista y aquellos que son reacios a la acción colectiva por no desear sacrificar ciertos beneficios:

Otros grupos a nuestro alrededor -y no voy a mencionar nombres- simplemente no son capaces de hacer semejante cosa. Están demasiado enganchados en el sistema con sus empleos, reputaciones y tonterías por el estilo. ${ }^{15}$

En otras palabras, el contenido de la justificación analizada por Hunt nos muestra cómo los tres campos básicos de referencia de acción colectiva del movimiento social Omaha Youth Peace Movement confluyen en una atribución de identidad que sirve como elemento delimitador. ${ }^{16}$ Esto es, que los integrantes del grupo se caracterizan por cometer acciones contra el ejército sin importarles el coste personal y/o la pérdida de beneficios. Más aún, que los integrantes del grupo ni siquiera están dentro de un sistema de prebendas que les obligue a dejar de lado sus compromisos reivindicativos. En este sentido, el enmarcado del Omaha Youth Peace Movement encarna como identidad colectiva un diagrama desde el cual entender los sucesos del pasado (actitud belicista del ejército estadounidense), el contexto presente (e momento de la acción social) y las expectativas de futuro (provocar un daño moral a la Fuerza Aérea norteamericana). En síntesis, la construcción de marcos de referencia de acción colectiva producen una imagen como combinación del ser (diagrama que ancla la actividad del grupo en una narrativa compartida, produciendo consecuentemente una identidad colectiva) y el hacer (las movilizaciones y acciones concretas del grupo).

Esta combinación del modelo teórico de la teoría de los marcos de referencia y el encarnado de mensaje proveniente de la obra de Silverstein es aplicable al mundo de los partidos

13 Ibid.

14 Ibid., pág. 233.

15 lbid.

16 Ibid., pp. 233-240. políticos. ${ }^{17}$ Los programas electorales usualmente son creados bajo la noción de que una situación específica es problemática (marco de diagnóstico), ${ }^{18}$ y que votar a un partido político y/o diputado concreto (marco de pronóstico) posibilitaría la introducción de políticas resolutivas (marco de motivación). Este proceso de enmarcado tiende a convertir la previa y/o posible futura gestión de un grupo rival como insatisfactoria, peligrosa e injusta. ${ }^{19}$ Tomemos el caso del anuncio electoral de Bill Clinton durante la campaña de 1992 donde la afirmación de George Bush "read my lips, no more taxes", realizada durante la campaña de 1988, fue presentada como un síntoma de falta de liderazgo (campo de identidad antagonista) en referencia a la ruptura de su promesa con un incremento de los impuestos durante su legislatura (marco de diagnóstico). ${ }^{20}$ De esta forma, la necesidad de un auténtico líder, que cumpliera sus promesas, requería votar a Bill Clinton (marco de pronóstico). Una acción reforzada mediante la promoción propagandística de los bajos impuestos del estado de Arkansas (marco de motivación) donde Clinton había sido gobernador (campo de identidad protagonista). ${ }^{21}$

\section{Contraenmarcado alrededor del Escrache}

Como hemos visto en la anterior sección, la elaboración de los marcos de referencia de acción colectiva implica atribuciones negativas de identidad a los grupos considerados antagonistas. De este modo, una actividad central de los movimientos sociales y los partidos políticos es el contraenmarcado, explicado por Hunt como la producción de esquemas interpretativos que erosionan la efectividad de los marcos de referencia de un grupo antagonista. ${ }^{22}$

En Marzo y Abril de 2013, la política española ha presentado un ejemplo perfecto de contraenmarcado, realizado alrededor de la práctica denominada "escrache". Esta actividad se ins pira en el escrache argentino, donde la organización HIJOS de los años go se reunía frente a los domicilios de figuras sociales y políticas que habían colaborado con la dictadura entre los años 1976 y 1983 en Argentina para que tal información fuera de dominio público. ${ }^{23}$ En este sentido, el escrache era una actividad orientada contra la impunidad política.

Durante marzo y abril de 2013, el movimiento social Plataforma de Afectados por la Hipoteca (PAH) organizo escraches a diputados del Partido Popular que se habían negado a entrar en contacto con los afectados para conocer la necesidad urgente de las demandas plasmadas en la Iniciativa Legislativa Popular (ILP): la dación en pago retroactiva, una moratoria sobre los des-

17 Michael SILVERSTEIN: Talking Politics: The Substance of Style from Abe to 'W', Chicago, Prickly Paradigm Press, 2003.

18 Nikolas ROSE y Peter MILLER: "Political Power beyond the State: problematic of Government" The British Journal of Sociology, Vol. 43 (1992), No. 2, pp. 181-182.

19 Robert MANN: Daisy Petals and mushroom clouds: LBJ, Barry Goldwater and the Ad that Changed American Politics, Louisiana State University Press, 2011, pp. 65-66.

20 Jane HILL: "Read my article: ideological complexity and the overdetermination of promising in American presidential politics." P. V. KROSKRITY (ed.): Regimes of Language: Ideologies, Polities, and Identities, Santa Fe, NM: SAR Press, 2000, pp- 270-274.

21 Darrell M. WEST, Montague KERN, Dean ALGER y Janice M. GOGGIN: "Ad buys in presidential campaigns: The strategies of electoral appeal" Political Communication, Vol. 12 (1995), Issue 3, pp. 275290.

22 Scott A. HUNT, Robert D. BENFORD y David A. SNOW: "Marcos de acción colectiva y campos de identidad en la construcción social de la protesta" en Joseph GUSFIELD y Enrique LARAÑA (ed.): Los nuevos movimientos sociales: de la ideología a la identidad, Centro de Investigaciones Sociológicas (CIS), 1994, pp. 238-239. 23 Sergio GRADEL: “Política, memoria y justicia. Los escraches como acción política de resistencia”,
Revista Electrónica del Instituto de Investigaciones, Año V (2011), Número Especial, pp. 292-293.Pilar Revista Electrónica del Instituto de Investigaciones, Año V (2011), Número Especial, pp. 292-293. Pilar de Abril de 2013, http://elpais.com/elpais/2013/04/14/inenglish/1365953446 509059.html. 
ahucios y la regularización del alquiler social. ${ }^{24} \mathrm{En}$ el relato de la PAH, el escrache se fundamentaba en trasladar la realidad que se experimentaba en las asambleas del movimiento, la misma que estaba siendo ignorada por el Gobierno, a las puertas de los domicilios de los políticos ${ }^{25}$

Este tipo de movilización fue posible de organizar mediante la conversión del endeudamiento hipotecario de desgracia individual a injusticia social (marco de diagnóstico). De hecho, como los activistas Ada Colau y Adrià Alemany explican en su obra Vidas Hipotecadas, uno de los mayores problemas de los afectados para movilizarse es la creencia interiorizada de que estar en un proceso de desahucio es el mayor síntoma de fracaso personal en una sociedad competitivamente individualista. ${ }^{26}$ En este sentido, la narrativa de la PAH tomó como base mostrar cómo los procesos hipotecarios, llegados a 350.000 en el año 2012, ${ }^{27}$ eran el resultado de la combinación entre la burbuja económica inmobiliaria iniciada mediante la liberación del suelo por el ex presidente Aznar en 1995, el acceso fácil al crédito-llegando a concesiones de hipotecas de alto riesgo-y los intereses financieros de la banca alrededor de las deudas hipotecarias. ${ }^{28}$

Desde esta mediación narrativa es posible proponer los escraches (marco de pronóstico) como una práctica tanto útil como legítima: dañando la imagen pública de los políticos, desenmascarando cuáles estaban en contra de las demandas de la PAH a la par que impidiéndoles ignorar a los afectados, se les presionaría para que apoyaran la ILP (marco de motivación). Más aún, los miembros de la PAH se describieron a sí mismos como los ciudadanos que claman por una justicia (campo de identidad protagonista) que está siendo rehuida por el gobierno del Partido Popular (campo de identidad antagonista):

Se acabó la impunidad para aquellos que permiten que se sigan vulnerando los derechos humanos en nuestro país. Los bancos nos ningunean, nos señalan como culpables de nuestra situación, nos engañan en procesos de refinanciación, nos maltratan verbalmente, nos señalan públicamente en el desahucio de nuestra vivienda y nos dejan en la calle sin ninguna alternativa. Ahora nos toca el turno de señalar a los que permiten que esta situación se produzca. ${ }^{29}$

La reacción del Partido Popular fue la re-descripción del escrache como una actividad antidemocrática. Podemos clasificar las construcciones de contraenmarcado como sigue:

1. PAH apoya el terrorismo vasco. La primera en hablar de este modo fue la delegada del Gobierno en Madrid, Cristina Cifuentes, aseverando que la PAH poseía similitudes ideológicas

24 Ada COLAU y Adrià ALEMANY: iSi se puede! Crónica de una pequeña gran victoria, Barcelona, Ediciones Destino, 2013, pág. 93

25 Ibid., pp. 76-77.

26 Ada COLAU y Adrià ALEMANY: Vidas Hipotecadas, de la burbuja inmobiliaria al derecho a la vivienda, Barcelona, Cuadrilátero de libros, 2012, pp. 94-101.

27 Joseba ELOLA y José María IRUJO: "Los jueces sortean la dura ley del desahucio con veredictos vanguardistas", El Pais, 3 de Noviembre del 2012, http://politica.elpais.com/politica/2012/11/03/ actualidad/1351974905_738358.htm

28 Como se explica en la obra de Colau y Alemany, en el momento en que una entidad bancaria se adjudica una vivienda tiene la posibilidad de hacerlo por un $70 \%$ o $60 \%$ del valor a efectos de subasta. La deuda restante más intereses y gastos de demora es arrastrada por el afectado. Debido a que en el tiempo semejante deuda no para de aumentar, a través de intereses generados por la imposibilidad por parte del afectado de cara a saldarla, el mismo se convierte en una fuente permanente de explotación económica. Ada COLAU y Adrià ALEMANY. Vidas Hipotecadas, de la burbuja inmobiliaria al derecho a la vivienda, Barcelona, Cuadrilátero de libros, 2012, pp. 107-122.

29 "Nueva campaña de la PAH: escraches. Pongámosle nombre y apellido a los responsables del \#ge-

nocidioFinanciero" Web de la Pla Po $\mathrm{http}: / /$ afectadosporlahipoteca.com/2013/02/04/final-ilp-campanya-escraches/ con el grupo terrorista ETA..$^{30}$ Esta afirmación fue usada como base por el diputado del PP, Antonio Basagoiti, para comparar directamente el escrache con prácticas pro-etarras:

No se ve ninguna diferencia ni en los gritos, ni en la actitud, ni en el fondo, entre los que venían del mundo de ETA a acosarnos y los que van ahora con la excusa de las hipotecas a acosar a los del PP [...] Ponerse en la puerta de una casa, amedrentar a la familia, señala el portal y poner dificultades ante los vecinos es clavadito a la kale borroka. ${ }^{31}$

Semejante enmarcado proyectaba explícitamente la encarnación del apoyo al terrorismo en la portavoz de la PAH, Ada Colau. Esta estrategia pretendía hacer del rostro más popular del colectivo un blanco visible de desprestigio:32"la PAH y su lideresa últimamente parece que tienen ciertas inquietudes de apoyos a grupos filoetarras o proetarras" (Delegada de Gobierno de Madrid Cristina Cifuentes ${ }^{33}$ )

2. El escrache es una táctica de grupos socialistas radicales. En referencia a las declaraciones de Cristina Cifuentes sobre la relación entre la PAH y ETA, el portavoz adjunto del PP, Rafael Hernando, afirmó que la PAH alentaba una izquierda radical. ${ }^{34}$ Aquí se puede observar una relación entre nacionalismo y socialismo concebidos como radicales. Una relación que, aunque no es concretada, es re-enmarcada por el vicesecretario general de organización del PP, Carlos Floriano:

El vicesecretario general de Organización y Electoral del PP, Carlos Floriano, ha dicho esta mañana en Cáceres sobre el acoso a dirigentes del PP por parte de plataformas de afectados por las hipotecas que "cercan" sus casas "para conseguir con la violencia lo que no consiguen con los votos." 35

30 "Cifuentes vincula a la plataforma contra los desahucios a "grupos filoetarras.", El Mundo, 25 de Marzo de 2013, http://www.elmundo.es/elmundo/2013/03/25/madrid/1364204802.html;"Cristina Cifuentes acusa a Ada Colau de apoyar a "grupos proetarras."', La Vanguardia, 26 de Marzo de 2013, http://www.lavanguardia.com/politica/20130325/54370653400/cristina-cifuentes-ada-colau-apoyar-grupos-proetarras.html;Carmen PÉREZ-LANZAC: "Cifuentes afirma que la PAH ha manifestado su apoyo al entorno de ETA.", El País, 26 de Marzo de 2013, http://politica.elpais.com/ politica/2013/03/25/actualidad/1364203963_208246.html y Carmen PÉREZ-LANZAC: "Cifuentes afirma que la PAH ha manifestado su apoyo al entorno de ETA.", El País, 26 de Marzo de 2013,http://

politica.

32 Podemos encontrar en la obra de Colau y Alemany un breve análisis sobre el ataque de corte personalista que se realizo sobre la portavoz de la PAH. Siguiendo a ambos autores, el desprestigio mediático que se realizó sobre Ada Colau, no sólo aspiraba a desprestigiar al grueso del movimiento sino que pretendía lanzar una advertencia intimidatoria sobre todo potencial activista que tomará la iniciativa de defender públicamente algún tipo de reivindicación social. Asimismo, los portavoces de la PAH argumentan que semejante actitud fue contraproducente debido a las dinámicas asamblearias del movimiento: en las que la posición de Colau no es la de una líder sino la de una representante pública de decisiones tomadas en espacios colectivos caracterizados por lazos de solidaridad grupal. Ada COLAU y Adrià ALEMANY: iSi se puede! Crónica de una pequeña gran victoria, Barcelona, Ediciones Destino, 2013, pp. 83-84

33 "Cifuentes afirma que la PAH ha manifestado su apoyo al entorno de ETA", El Pais, 26 de Marzo de 2013, http://politica.elpais.com/politica/2013/03/25/actualidad/1364203963_208246.htm

34 "El PP respalda a Cifuentes y dice que la PAH alienta a la izquierda radical", La Vanguardia, 26 de Marzo de 2013, http://www.lavanguardia.com/politica/20130326/54369573221/pp-respalda-cifuentes-pah-alienta-izquierda-radical.html.

35 06/04/2013 "El PP: “la izquierda violenta" intenta con escraches lograr lo que les niegan los Abril de 2013, http://politica.elpais.com/politica/2013/04/06/actualidad/1365254441_280642.html. 
3. Escrache es una actividad nazi. Esta proyección ha sido protagonizada principalmente por la Secretaria General del PP y Presidenta de la Junta de las Comunidades de Castilla-La Mancha, María Dolores de Cospedal, con su descripción de los escraches como "nazismo puro". ${ }^{36}$ Esta descripción se basó en la comparación de la práctica nazi de señalar viviendas judías durante el III Reich con las asambleas frente a los domicilios de diputados del PP. Este enmarcado fue replicado por otros políticos, como el Delegado de Gobierno de Galicia, Samuel Juárez "como cuando los nazis marcaban las casas de los judíos" o la líder del PP madrileño, Esperanza Aguirre, que relacionaba el nazismo con el terrorismo etarra: ${ }^{37}$

Esperanza Aguirre, ha publicado en su blog que las personas que participan en las manifestaciones frente al domicilio o lugar de trabajo de los políticos, conocidas como 'escraches', son "imitadores del matonismo de los seguidores de ETA en el País Vasco" y los ha calificado de "energúmenos" y "violentos acosadores".

Aguirre se ha referido también a los integrantes de estos 'escraches' como "simples epígonos de las tácticas de los peores totalitarismos del siglo pasado", como en el caso de las "juventudes hitlerianas" o las "patrullas castristas en Cuba" que, asegura, "trataban y tratan de amedrentar a los que no se someten a sus designios." ${ }^{8}$

Como podemos observar, las declaraciones y afirmaciones de unos políticos populares fueron repetidas por otros miembros del PP, estableciendo diversas relaciones discursivas. En este sentido, no podemos hablar de contraenmarcados aislados, sino de una dinámica interdiscursiva que tendía a condensar todas las proyecciones en un único empaquetado: un conjunto de atribuciones de identidad que se harían referencia entre sí. 39

De esta forma los contraenmarcados elaboraban un estilo comunicativo donde una descripción como "nazi" evocaría -mediante un proceso de razonamiento en cadena establecido por repetición- el radicalismo socialista, el terrorismo vasco y las movilizaciones de la PAH. ${ }^{40}$ Cada proyección de identidad implicaba a otra en una red retórica que ignoraría toda posible incoherencia histórica, ideológica y descriptiva entre sus componentes. Y puesto que la producción del empaquetado se realizaba de manera diacrónica en un proceso en el que las afirmaciones de un político eran re-contextualizadas en el contraenmarcado del siguiente, la responsabilidad del producto final quedaba difuminada entre los distintos miembros. ${ }^{4}$

36 Francesco MANETTO "Cospedal tilde los escraches de "nazismo puro" propio de antes de la Guerra Civil.", El Pais, 13 de Abril de 2013, http://politica elpais.com/politica/2013/04/13/actualiGuerra Civil., El Pais, 13 de Ab
dad/1365848717 $144600 . h t m l$.

37 "Juárez compara los escraches con los señalamientos nazis a los judíos.", El Pais, 16 de Abril de 2013, http://ccaa.elpais.com/ccaa/2013/04/16/galicia/1366105027_051780.html.

38 "Aguirre relaciona los escraches con el “matonismo de los seguidores de E.T.A."', El Mundo, 14 de Abril de 2013, http://www.elmundo.es/elmundo/2013/04/14/espana/1365968066.html.

39 Como nos explica Silverstein, el empaquetado de atribuciones de identidad es una clase de producción discursiva propia de una época marcada por la fuerte presencia de medios de comunicación. Un sobreexceso de canales informativos requiere la síntesis de mensajes que puedan conectar con la audiencia apelando a la identidad. Las declaraciones cortas de prensa son centrales en este tipo de dinámicas. Michael SILVERSTEIN: Talking Politics: The Substance of Style from Abe to 'W', Chicago, Prickly Paradigm Press, 2003, pp. 117-120.

40 Ibid., pp. 20-24.

41 En el papel de Irvine se nos muestra como ejemplo la poesía Xaxaar, un tipo de manifestación cultural que se da en las bodas Wolof focalizada en la humillación de la novia que es produción por una gran cantidad de individuos con distintos roles imposibilitando de este modo el seña miento de un responsae individos con distintos roles imposibilitando de este modo el señalalos efectos propios de la por el carcister of lificultad acte
La confluencia de las distintas re-contextualizaciones en un empaquetado de contraenmarcado tuvo dos consecuencias: por una parte, la producción de una imagen negativa de la PAH que evitó discutir la naturaleza de la ILP.42 Por otra parte, presentando la PAH como un movimiento que establecía precedentes peligrosos para la democracia (campo de identidad antagonista), los políticos del PP pasaban a encarnar la misma democracia ya que los escraches estaban dirigidos contra ellos (campo de identidad protagonista). Dicho movimiento se ve patente en los siguientes comentarios:

"El escrache es profundamente antidemocrático [...] un valor básico en una sociedad democrática es respetar a los demás". Mariano Rajoy, Presidente del Gobierno de España. ${ }^{43}$

“¿Para qué nos sirven las urnas? ¿Para qué sirve la democracia? [...] la violencia nunca, nunca, puede ser utilizada por legítima que sea una causa [...] se convierta en papel mojado la voluntad de los ciudadanos expresada en las urnas en un sufragio universal, directo y secreto porque, al final, el diputado por la fuerza tiene que votar lo que una minoría violenta" Ministro de Justicia Alberto Ruíz-Gallardón. ${ }^{4}$

"Nadie, con un mínimo de sentido democrático, puede ni debe mostrar la menor complacencia ante el espectáculo, que se está convirtiendo en habitual, de unos energúmenos que, con total impunidad, irrumpen en la intimidad familiar o doméstica de algunos políticos del Partido Popular" Líder del PP madrileño Esperanza Aguirre. ${ }^{45}$

Esta dinámica de contraenmarcado fue utilizada para justificar la orden dada por el Ministerio de Justicia a la Dirección General de la Policía Nacional de identificar los escraches como casos de acoso y amenaza. ${ }^{46}$ Además, se realizó la propuesta de un proyecto de ley para retirar la nacionalidad española a los inmigrantes que hayan participado en tal actividad (marco de pronóstico). ${ }^{47}$ Ambas estrategias esquematizaban la idea de que la democracia estaba en peligro (marco de diagnóstico) y por tanto eran necesarias la adopción de nuevas medidas y legislaciones posiblemente impopulares (marco de motivación). Esto es, un anclaje de la actividad de la PAH como socavación de la democracia mediante el marco de diagnóstico producido por los políticos del Partido Popular.

contraenmarcado a la PAH por parte de los diputados del PP. Judith T. IRVINE: "Shadow Conversations: The Indeterminacy of Participant Roles." In Natural Histories of Discourse (ed.): Michael sations: The Indeterminacy of Participant Roles." In Natural Histories of Discourse (ed.)
SILVERSTEIN and Greg URBAN. Chicago, University of Chicago Press, 1996, pp. 132-138.

42 Francesco MANETTO "Cospedal tilde los escraches de "nazismo puro" propio de antes de la Guerra Civil.", El Pais, 13 de Abril de 2013, http://politica.elpais.com/politica/2013/04/13/actualidad/1365848717_14460o.html.

43 Miguel MORA: “Rajoy: “El Escrache es profundamente antidemocrático.", El País, 26 de Marzo de 2013, http://politica.elpais.com/politica/2013/03/26/actualidad/1364325482_485124.html.

44 "Gallardón sobre escraches:"¿Para qué nos sirven las urnas y la democracia?", El Mundo, 9 de Abril de 2013, http://www.elmundo.es/elmundo/2013/04/og/espana/1365494293.html.

45 "Aguirre relaciona los escraches con el "matonismo de los seguidores de E.T.A."', El Mundo, 14/04/2013, http://www.elmundo.es/elmundo/2013/04/14/espana/1365968066.html.

46 "El SUP tacha de "barbaridad" la instrucción de hacer identificaciones en escraches.", El Mundo, 29 de Marzo de 2013, http://www.elmundo.es/elmundo/2013/03/29/espana/1364559137.html y "La instrucción para escraches pone en alerta a la policía.", La Vanguardia, 29 de Marzo de 2013 http://www.lavanguardia.com/politica/20130329/54371781161/la-instruccion-para-escraches-pone-en-alerta-a-agentes-policia.html.

47 Ruiz-Gallardón amenaza con retirar la nacionalidad a inmigrantes que participen en "escra-

ches" y otras protestas." The Huffington Post, 18 de Abril de 2013 http //www huffingtonpost. es/2013/04/18/ruiz-gallardon-amenaza-co_n_3107955.html. 
El contraenmarcado empaquetado del PP tuvo una recepción negativa entre diferentes audiencias. ${ }^{8}$ En primer lugar, la Asociación de Víctimas del Terrorismo (AVT) pidió al Partido Popular que, si bien no estaban a favor del escrache como práctica, dejara de equiparar escraches y terrorismo. ${ }^{49}$ Aún más, la Associació Catalana de Víctimes d'Organitzacions Terroristes (AVCOT) exigió la dimisión de Cristina Cifuentes como Delegada de Gobierno de Madrid por su uso irresponsable de la sensibilidad ciudadana en referencia al terrorismo..$^{\circ}$ En segundo lugar, la asociación de Jueces para la Democracia (JpD) defendió que la actitud verdaderamente antidemocrática era describir como crímenes peligrosos concentraciones pacíficas en las que los participantes no incurrían en acciones violentas. Leemos sobre las comparecencias del portavoz de JpD Joaquim Bosch:"Por ello, Bosch considera "lamentable" que estos colectivos, en los que participan personas que están a punto de perder su casa o que ya la han perdido, además "tengan que soportar campañas gubernamentales de desprestigio.""

En tercer lugar, la orden transmitida desde el Ministerio de Justicia de identificar los escraches como acosos y amenazas fue considerada por el Sindicato Unificado de Policía (SUP) como una lectura "torticera" del Código Civil. ${ }^{52}$ En este sentido, el portavoz del SUP José María Benito declaró: "El Ministerio del Interior lo que pretende con esta circular es criminalizar a priori el escrache, es decir, no diferenciar entre aquéllas acciones que no son violentas -en las que no se produce acoso, amenazas ni coacciones-, de las otras en las que si se producen.". ${ }^{53}$

En cuarto lugar, los miembros de la asociación de víctimas del nazismo Amical Mauthausen comunicaron en referencia a las descripciones de Cospedal: "no es aceptable que un cargo político y público de su relevancia se dedique a banalizar el nazismo". ${ }^{4} \mathrm{Y}$ finalmente, las estadisticas de Metroscopia mostraron que durante Marzo de 2013 el $68 \%$ de la población consideraba el escrache como una táctica protegida por el derecho a la libertad de expresión..$^{55}$

El Profesor en Derecho Constitucional, Gerardo Pisarello, argumentó en un artículo suyo que la masiva tipificación de la estrategia del Partido Popular como una injusta campaña de criminalización se debía a tres factores: un contexto de elevado descrédito del PP por la rup-

48 Ada COLAU y Adrià ALEMANY: iSi se puede! Crónica de una pequeña gran victoria, Barcelona, Ediciones Destino, 2013, pp. 78-79.

49 "La AVT pide no comparar los "escraches" con el terrorismo.", Europapress, 15 de Abril de 2013 http://www.europapress.es/nacional/noticia-avt-rechaza-escraches-pide-no-comparen-terrorismo-20130415130842.html.

50 "Colau estudia denunciar a Cifuentes por vincular a la PAH con el terrorismo.", La Razón, 25 de Marzo de 2013 http://www.larazon.es/detalle normal/noticias/1635308/colau-estudia-denunciar-a-cifuentes-por-vincul\#.UYzGozecLe 4 .

51 "Jueces para la Democracia critica la "torpeza" de Cifuentes al vincular a deshauciados con el entorno de ETA, 27 de marzo de 2013. Telecinco.", Web de Jueces para la Democracia (JpD), 27 de Marzo de 2013, http://www.juecesdemocracia.es/txtComunicados/2013/27marzo13.htm.

52 "La instrucción para escraches pone en alerta a la policía.", La Vanguardia, 29 de Marzo de 2013, http://www.lavanguardia.com/politica/20130329/54371781161/la-instruccion-para-escraches-pone-en-alerta-a-agentes-policia.html y "El SUP tacha de "barbaridad" la instrucción de hacer identificaciones en escraches.", El Mundo, 29 de Marzo de 2013, http://www.elmundo.es/elmundo/2013/03/29/espana/1364559137.html.

53 "La Policía insta a los agentes a sustituir "escrache" por "acoso, amenazas y coacciones", Web de la Sexta Noticias, 22 de Abril de 2013, http://www.lasexta.com/noticias/nacional/policia-insta-agentes-sustituir-escrache-acoso-amenazas-coacciones_2013042200344.html.

54 "El Amical Mauthausen lamenta que Cospedal tildase de "nazismo puro" los escraches.", Europapress, 18 de Abril de 2013, http://www.europapress.es/catalunya/noticia-amical-mauthausen-lamenta-cospedal-tildase-nazismo-puro-escraches-20130418113917.html.

55 José Juan TOHARIA “Escraches: Derecho, no delito.", El País, 11 de Abril de 2013, http://blogs.elpais. com/metroscopia Es tura de sus promesas electorales, el carácter autoritario del manejo policial del conflicto y el comportamiento pacíficamente auto-contenido realizado por miembros de la PAH durante los escraches..$^{56} \mathrm{~A}$ pesar de que consideramos este razonamiento como acertado, también es incompleto. Nosotros proponemos como hipótesis auxiliar que la concepción del proceso de contraenmarcado del Partido Popular como un movimiento de criminalización tiene que ver también con las proyecciones de identidad antidemocráticas que indirectamente recaían en las diferentes audiencias mentadas. La justificación para esta afirmación se basa en que, en un contexto de insatisfacción marcado por una tasa de desempleo del $27 \%$ y la cifra proveniente del Consejo General del Poder Judicial,, 57 de 166.000 desahucios entre 2008 y 2011, los ciudadanos españoles se identifican con las demandas de la PAH, ${ }^{58}$ plasmándose hasta en un $80 \%$ de apoyo a la ILP. ${ }^{9}$ De este modo, describir a la PAH como antidemocrática era inducir en estas audiencias la idea de que los miembros de la PAH estaban en contra de la democracia (campo de identidad de la audiencia).

Esta proyección indirecta habría sido intensificada por un empaquetado que abarcaba atribuciones de identidad -terroristas, nazis, criminales y radicales- que tales audiencias manejaban en relación con quienes suelen ser concebidos como antagonistas en su propio imaginario tal como ocurría con AVCOT, Amical Mauthausen, SUP y JpD. A modo de ejemplo tendríamos la siguiente declaración de la carta a Cospedal, redactada por la activista en defensa de la salud del 15-M Clara Valverde, "Soy víctima del Holocausto nazi y hago escrache": 60

Señora de Cospedal,

Su afirmación de que los ciudadanos que hacemos escrache somos como los nazis es muy ofensiva y una seria falta de respeto. Si no ha estudiado la historia de Europa del siglo XX le animo a hacerlo sin demora. Pero primero quiero que conozca los nombres de algunos de mis familiares que fueron asesinados (la mayoría gaseados) por los nazis: Kürt Gefäll de 38 años; Elsa Gefäll, de 63 años; Rosa Gefäll, de 72 años; Matilde Gefäll, de 67 años; mi tío abuelo Anton Gefäll, de 49 años; mi bisabuela Pauline Feil, ciega de 88 años, y mi tía abuela Hermina "Mina" Gefäll, de 66 años, que cuidaba de su madre Pauline en su pequeño piso de Viena [...].

Los ciudadanos que hacemos escrache llevamos años dedicados a frenar las injusticias y el aumento de las desigualdades que su partido y otros llevan a cabo contra los ciudadanos más indefensos y con menos recursos: los recortes y cambios en las políticas de sanidad y educación (que afectan en especial a los inmigrantes, a los que se quita el acceso a la sanidad), la alta tasa de paro -que es el resultado directo de las "reformas" laborales-, los jóvenes que se tienen que ir a otros países a encontrar trabajo, los grandes dependientes que ya no reciben ayuda para sus cuidados básicos, el alto porcentaje de niños desnutridos, la gente que se está quedando sin casa (una familia cada 15 minutos) y mucha gente que se está suicidando por desesperación.

56 Gerardo PISARELLO \& Jaume ASENS: “La criminalización de la PAH: cuando el que 'escracha' es el poder.", La República, 3 de Abril de 2013, http://www.larepublica.es/2013/04/la-criminalizacionde-la-pah-cuando-el-que-escracha-es-el-poder/.

57 "Se dispara el número de desahucios en Madrid, hasta alcanzar los 80 al día", EI Mundo, 23 de Julio de 2013,http://www.elmundo.es/elmundo/2012/07/23/madrid/1343056678.html.

58 Ada COLAU y Adrià ALEMANY: iSi se puede! Crónica de una pequeña gran victoria, Barcelona, Ediciones Destino, 2013, pág. 51.

59 José Juan TOHARIA “Escraches: Derecho, no delito.", El País, 11 de Abril de 2013, http://blogs.elpais. com/metroscopia/2013/04/el-78-de-los-espa\%C3\%B10les-68-entre-los-votantes-del-pp-85-entre-los-del-psoe-se-muestra-de-acuerdo-con-la-campa\%C $3 \%$ B1a-de.html.

60 Clara VALVERDE: "Soy nieta del holocausto y hago escrache.", El Diario, 14 de Abril de 2013, http:// www.eldiario.es/catalunyaplural/nieta-holocausto-nazi-hago escrache 6 - 121847818.html. 


\section{Conclusión}

Como hemos visto, el contraenmarcado es el anclaje de la actividad de un grupo rival dentro de una nueva imagen que corresponde al marco de diagnóstico de la organización atacante. Este proceso reduce a lo superficial el contenido de los enmarcados del grupo antagonista mediante la capitalización de las sensibilidades de la audiencia, modificando el entendimiento su actividad. En este sentido, los políticos del Partido Popular usaron declaraciones y comentarios, transmitidos por los medios de comunicación, para promover una dinámica de contraenmarcado que tornara irrelevante la ILP, centrándose en el escrache como síntoma de una actitud antidemocrática. En otras palabras, promoviendo un diagrama según el cual, si el escrache se asentaba como práctica habitual, las expectativas democráticas se verían truncadas.

Sin embargo, lo que los políticos del Partido Popular no calibraron fue que el contraenmarcado no sólo afecta a las atribuciones de identidad de los antagonistas, sino también a las de las audiencias. En un contexto de identificación de las distintas audiencias con la PAH, debido tanto al carácter de sus reivindicaciones sociales como a la naturaleza pacífica de sus movilizaciones, proyectar un diagrama antidemocrático sobre su actividad y, por tanto, una identidad colectiva antidemocrática sobre el movimiento, implicaba indirectamente hacer la misma proyección hacia las audiencias. 
Parte 5.

CONSTRUIR COMUNIDADES 


\section{CONSTRUIR COMUNIDADES}

Matthew Kerry

The University of Sheffield

¿Por qué 'comunidades'? Las y los estudiosos suelen coincidir en que se trata de un concepto difícil, complejo, "muy contencioso".' Tiene una larga historia, desde los primeros sociólogos (y el clásico "gemeinschaft" versus "gesellschaft" de Tönnies) hasta el presente. ${ }^{2}$ Es tal la multiplicidad de usos (¿abusos?) del concepto que ha llevado a más de un académico a desecharlo por completo. ${ }^{3}$ ¿Entonces, para qué debatir un concepto tan usado, hasta agotado, o de significados tan múltiples hasta el punto de diluirse por completo?

Ahora bien, tampoco aquí se intenta llegar a una definición exhaustiva del término. Ni se intenta repasar la teoría existente sobre el concepto de 'comunidad'; tal tarea sería imprudente, dada la cantidad de trabajos existentes que aprovechan o desarrollan, de una manera u otra, el concepto de comunidad, aun si sólo se limitara a los estudios históricos propiamente dichos. Es decir, no se pretende ofrecer una introducción global a la idea de comunidad, sino que se propone trazar unas líneas generales (y hasta idiosincráticas y eclécticas) antes de presentar los textos que formaron parte de la mesa-taller 'Construir comunidades'. ${ }^{4}$

Vivimos en la situación paradójica de estar en la época del individualismo y la globalización, en la que la comunidad se proyecta como "un paraíso perdido", pero a la vez estamos rodeados de 'comunidades', desde lo local hasta lo global, y como apelación política es más importante que nunca. ${ }^{5} \mathrm{El}$ estado español está formado por diecisiete comunidades autónomas (sin que la constitución de 1978 defina qué significa vivir en comunidad; se concluye por tanto que es evidente). Desde hace veinte años el Partido Laborista británico, “New Labour", se muestra como un partido comunitario, ya que valora más el principio de comunidad que el de clase. ${ }^{6}$ Por otra parte, los Ilamamientos a favor de la 'comunidad internacional' son frecuentes

Como apunta Cohen, por ejemplo. Véase Anthony COHEN: The Symbolic Construction of Community, London/New York, Routledge, 1985, p. 11

2 Es tradicional (y hasta repetitivo) citar el trabajo clásico de Tönnies (y desarrollado por Weber) y la diferenciación entre "comunidad" (Gemeinschaft) y "sociedad" (Gesellschaft), que son relaciones caracterizadas por, en el primer caso, lo personal y directo, y, en el segundo, lo formal e indirecto. Ferdinand TÖNNIES: Community and Society, David and Charles, Newton Abbot, 2002 [1887]; Max WEBER: Economy and Society, Berkeley/Los Ángeles, University of California Press, 1978 [1922] pp. 40-43.

3 Ya en 1971 dos estudiosos pudieron identificar 94 usos distintos del término. Véase Hester BARRON: “Introduction", The 1926 Miners' Lockout: Meanings of Community in the Durham Coalfield, Oxford, OUP, 2009, p. 4, pp. 5-6.

4 Por ejemplo, Gerard DELANTY: Community, London/New York, Routledge, 2010 [2003].

5 Para el "paraíso perdido", véase Zygmunt BAUMAN: Community. Seeking Safety in an Insecure World, Cambridge, Polity, 2001, p. 3.

6 La fe en la comunidad es "el principio fundacional, el principio que guía al Partido Laborista". Véase Elizabeth FRAZER. The Problems of Communitarian Politics. Unity and Conflict, Oxford, OUP,

1999, p.12, p. 41.

en el discurso político actual. La 'comunidad internacional' es un término "ubicuo", pronunciado por casi todos los líderes mundiales.? En marzo de 2011 el entonces presidente del Gobierno, José Luis Rodríguez Zapatero, pronunció un discurso en el Congreso de los Diputados en el que utilizó la palabra 'comunidad' quince veces. . 'Comunidad' es quizá el término político más privilegiado de nuestro tiempo. Aquí no se dispone del espacio para indagar en un análisis de este uso del concepto de comunidad, muy habitual a nivel internacional. Lo que cabe destaca es la elección en sí del concepto de comunidad, que se emplea para asegurarnos de que e mundo es un sistema cohesivo, que los problemas de resolverán y que todos los ciudadanos del mundo formamos parte de algo más grande que el estado-nación. Como indica Ellis, esta diferenciación entre sociedad y comunidad es clave: "la existencia de una sociedad internacional basada en intereses y valores comunes es algo bastante diferenciado de una comunidad de morales, ética e identidades comunes que implican una comunidad internacional". 9 Intenta crearse la comunidad cuando se apela al sentido de la 'comunidad internacional'.

Resulta claro, por tanto, que el concepto tiene un valor emotivo e implica algo positivo. Como apunta Zygmunt Bauman, la comunidad (o el concepto de comunidad) es algo que "sienta bien".. Es este aspecto, tan intangible, del concepto que se funde con las ideas de inclusión, comodidad, consuelo, seguridad, autoidentificación, (y un largo etcétera), junto con su poder evocativo de transmitir estas sensaciones, el que nos indica por qué sigue siendo tan atractivo. Suele proyectarse como un factor local (positivo) que puede contrarrestar los efectos (negativos) de la globalización. La 'comunidad' es un lugar donde buscamos "seguridad"." Pero ¿son las comunidades positivas per se? No deja de ser algo problemático para los historiadores el que un concepto como instrumento de análisis tenga una carga positiva.

Pero no es sólo una cuestión del presente. Como destaca Delanty, la 'comunidad' puede considerarse como el valor básico de la política. Las ideologías como el fascismo, el comunismo, el republicanismo, el conservadurismo o el sionismo tienen, en su raíz, "conceptualizaciones específicas de la comunidad como ideal normativo", como un objetivo o ideal. Incluso, "el éxito de un movimiento político dependerá, por último, de su capacidad para generar un sentido de 'comunidad"'.12 Por tanto, como base de la política, de las identidades colectivas, y de lo compartido, estudiar la 'comunidad' es una manera de aproximarse a las relaciones sociales (y el concepto de comunidad se relaciona de alguna manera $u$ otra con otros conceptos como la sociedad, el estado, el individuo), pero mientras nos es fácil poder etiquetar o identificar una 'comunidad', encontrar una definición no lo es tanto. Es un término que tiene un carácter "elusivo", como señala Frazer. ${ }^{13}$ Es un término que se resiste a que lo definamos. ${ }^{14}$ Asimismo, se demuestra a través de los estudios de las comunidades, en cuyos títulos figura la idea de la "búsqueda". ${ }^{15}$

No existe consenso sobre su definición; parece que cualquier estudio destaca las dificultades de buscar un consenso dentro de la enorme producción académica existente sobre las comunidades. A pesar de que se suele destacar esta falta de consenso, existe un núcleo de significado o esencia de 'comunidad' en la cual se suele coincidir. Como dice Frazer, hay tres

David C. ELLIS: “On the possibility of 'International Community", International Studies Review, 11 (2009), p. 1, pp. 3-4.

El Pais, 22 marzo 2011. Recuperado de internet. http://elpais.com/elpais/2011/03/22/actualidad/1300785437 850215.htm

9 ELLIS: "On the possibility of 'International Community...", p. 5

10 BAUMANN: Community..., p. 1 .

11 DELANTY: Community..., p. 1; BAUMANN: Community..., p.4.

12 DELANTY: Community..., p. 10, p. 150.

13 FRAZER: The Problems of Communitarian Politics..., p. 5.

14 COHEN: The Symbolic Construction of Community..., p. 11

15 FRAZER: The Problems of Communitarian Politics..., p. 5.

P.


principios "sorprendentemente definitivos" en cuanto a la idea de comunidad. Concretamente se construye entre "seres humanos", se basa en el principio de compartir y por último implica "una actitud por parte de cada uno hacia la comunidad en su conjunto y hacia cada uno de sus miembros". ${ }^{16}$ Asimismo, Delanty, después de identificar cuatro aproximaciones al término en cuestión, concluye que lo que une a los cuatro usos distintos, es la misma idea de "belonging [pertenecer, arraigo]". ${ }^{17}$ Este sentimiento es lo más básico, pero resulta insuficiente como instrumento de análisis. Sin embargo, dado que es difícil definirlo, la cuestión que se plantea es la de si se trata de una tarea útil. Dicho de otro modo, ¿debería de definirse? Aquí nos encontramos con la tentación de buscar una definición reduccionista: ¿supone algún problema el no poder reducirlo a una definición concreta? Los textos que se presentarán más adelante ponen en evidencia la pluralidad de aproximaciones al tema. Se destacan facetas distintas, como pueden ser la comunicación (véase, por ejemplo, la comunicación de Rickett), la emoción (Giori), o factores más estructurales, como las instituciones (D'Amaro). Es en estos puntos de diferencia donde tienen lugar los debates interesantes. ¿Oué papel pueden desempeñar las instituciones cuando los factores estructurales han sido atacados y se defiende que no se puede reducir la comunidad a una (o más) instituciones?18

Por otra parte, ¿cómo se identifica el momento en el que existe la comunidad? ¿Es decir, cómo es, cómo puede ser la materialidad de la comunidad? Si la comunidad se considera como un proceso de construcción y expresión, ¿cómo se expresa esa 'realidad histórica' de una comunidad a nivel de la experiencia? Mientras para Cohen se puede construir una comunidad conscientemente, para otros esta idea electiva de la comunidad y la consciencia de la misma, es problemática. ${ }^{19}$ Bauman defiende que una comunidad nunca puede ser autoconsciente, ya que en ese momento pierde la esencia de la misma comunidad. Es en este sentido, una comunidad se basa en una comprensión orgánica. ${ }^{20}$ Para Frazer, es una experiencia "eufórica" y "fugaz", que no puede forzarse. ${ }^{21}$ La conciencia de la comunidad es algo momentáneo; no se puede sostener. Se rechaza, por tanto, que la comunidad sea una estructura subyacente y estática, sino que es un proceso, experimentado (y construido) activamente. ${ }^{22}$

Es imposible reflexionar sobre el concepto de comunidad sin referirse a los límites, las fronteras de la misma, sobre todo después de la obra de Cohen. Los límites de las comunidades se construyen simbólicamente; no son absolutos ${ }^{23}$ Pero los símbolos no expresan un significado, sino que nos proporcionan la manera de crear ese significado. ${ }^{24}$ Por tanto, existen diversas maneras de interpretar los símbolos (dentro de la misma comunidad), los cuales son maleables e imprecisos, y la idea de comunidad (communality) se refuerza a tra-

16 Ibid., pp. 7-8.

17 Concretamente, las aproximaciones son las siguientes: la primera se asocia sobre todo con los estudios de comunidad (community studies) y se centra en la regeneración y los proyectos a nivel local. Por tanto, estas son comunidades "altamente espacializadas". Otra aproximación destaca que comunidad significa la búsqueda o deseo de pertenecer, y la importancia de la identidad. La que comunidad significa la búsqueda o deseo de pertenecer, y la importancia de la identidad. La tercera, inspirada por la "política posmoderna", utiliza el término desde una perspectiva de con-
ciencia política y acción colectiva. En la cuarta, se destaca el desarrollo de la tecnología y cómo ha cambiado las relaciones en cuanto a distancia, espacio etc. DELANTY: Community..., p. 4.

18 COHEN: The Symbolic Construction of Community..., p. 74

19 Ibid., p. 28.

20 BAUMAN: Community..., pp. 11-12.

21 FRAZER: The Problems of Communitarian Politics..., pp. 83-84.

DELANTY: Community..., p. 95; y en cuanto a las identidades colectivas, Alberto MELUCCI: Challenging Codes: Collective Action in the Information Age, Cambridge, CUP, 1996 pp. 70-77.

23 COHEN: The Symbolic Construction of Community

24 Ibid., p. 15. vés de los ritos. ${ }^{25}$ Según Cohen, 'las personas construyen la comunidad de manera simbólica, creándola como un recurso y repositorio de significados, y un referente para sus identidades' y la comunidad se convierte en un conjunto de referentes simbólicos e ideológicos con los cuales navega el individuo. ${ }^{26}$ Esta conceptualización deja lugar para la heterogeneidad, pluralidad y diferencia dentro de los grupos que podamos considerar como comunidad, a la vez que también permite la autonomía del individuo. La crítica que Delanty hace a la propuesta de Cohen es que no tiene en cuenta la violencia y el poder. ${ }^{27}$ El tener en cuenta factores como éstos no deja de ser importante para reflexionar sobre el aspecto positivo de comunidad, una faceta que no suele cuestionarse. Cómo adecuar la coacción y las relaciones de pode dentro de un esquema que subraya la construcción simbólica de las comunidades es algo que deberíamos de tener en cuenta.

Esta manera de conceptualizar la comunidad, que permite la multiplicidad, el conflicto y la diferencia dentro de la misma, resulta mucho más útil como instrumento de análisis para las y los historiadores..$^{28}$ Por tanto, nos decantamos a favor de las conceptualizaciones que permitan la complejidad, que resalten la comunidad como un concepto abierto. Como Frazer, se rechaza la rigidez y el reduccionismo, y se busca una conceptualización con "límites abiertos y líneas difusas". ${ }^{29}$ Proponemos (siguiendo la línea de Frazer) que quizá analizar sea más provechoso que definir. En la diferencia entre los distintos usos es donde surge un debate muy fructífero. El reduccionismo no resulta una tarea útil. Buscamos maneras de acercarnos a la complejidad, la mutabilidad del término. Esta misma cualidad de comunidad como un concepto plural y contencioso es precisamente lo que nos proporciona el espacio para compartir ideas distintas. Asimismo, sería un error reducir el término; no nos sería de mucha ayuda establecer una línea fija para poder dictar cuáles son comunidades, y cuáles no.

El concepto de comunidad es "elástico"30 y la flexibilidad es necesaria, sobre todo si nos proponemos agrupar propuestas tan diversas en cuanto a extensión geográfica como se encontrarán a continuación, con objetos de estudio que abarcan desde eco-aldeas en Hungría a la población de Argentina. Claro está que cada 'comunidad' supone su propios retos y posee condiciones distintas, y estas comunicaciones ponen de manifiesto la diversidad, la elasticidad del concepto de comunidad y su aplicación por parte de las y los estudiosos. Como esperamos que sea evidente a través de los textos, el diálogo entre las diferentes aproximaciones permite enriquecer cada manera de aproximarse al sujeto.

En la primera agrupación se encuentran tres comunicaciones que analizan el arte, la educación y el sentimiento en la construcción de comunidades. En esta sección, los comunicantes analizan cómo los sujetos crean las comunidades a través de la proyección de ciertas ideas y discursos, y los símbolos creados y diseminados que funcionaban como límites y barreras a la inclusión dentro de la comunidad. Son tres propuestas distintas aunque todas comparten la inclusión dentro de la comunidad. Son tres propuestas distintas aunque todas

Julio Lisandro Cañón Voirin, en su análisis de Argentina entre 1955 y 1983, demuestra cómo se creó una comunidad nacional a través de un discurso 'del orden', un discurso que se construyó en oposición al 'Otro'. Es alrededor de este discurso que se aglutinaban distintos grupos (con intereses compartidos), los cuales dibujaban una línea divisora (simbólica) alrededor de sí. Las instituciones como el Estado y la Iglesia tenían las herramientas para construir la división entre los comunistas y la "gente de orden". Por ejemplo, el papel de la religión se convirtió

25 Ibid., p. 18, p. 21, p. 53, p. 55

26 Ibid., p. 118, p. 57

27 DELANTY: Community..., pp. $47-48$

28 Conviene destacar el riesgo de buscar en el pasado la comunidad que anhelamos en el presente.

29 FRAZER: The Problems of Communitarian Politics..., p. 55, p. 60.

30 DELANTY: Community..., p. 2.

30 DELANTY Community..., p. 2.


en una manera de acceder a esta comunidad nacional y la Iglesia tenía, por tanto, una función reguladora de la comunidad nacional.

Más que centrarse en el caso concreto del nacionalismo catalán, Pablo Giori hace una reflexión teórica sobre el nacionalismo en la que propone cambiar el enfoque desde aproximaciones que califica de demasiado racionalistas hacia el hincapié en lo irracional y las emociones. Repasa algunas de las teorías existentes y aproximaciones recientes, antes de intentar buscar una nueva manera de aproximarse al nacionalismo, ya que considera los planteamientos insuficientes, y le interesan sobre todo la praxis y los comportamientos. Se pregunta, ¿cómo se experimenta una comunidad como individuo? Se adentra en el tema de la dinámica de los grupos, en cuanto a las relaciones sociales y los límites del grupo; quiere entender lo compartido y cómo se construye dentro de los grupos. Giori concluye que vivir en comunidad es "necesario" y defiende que hay que cambiar el enfoque desde las ideas hacia las prácticas. La comunidad no puede entenderse únicamente así, sino también a través de las emociones.

La emoción es un factor que también tiene en cuenta Ariane Martínez Aretxabaleta en su estudio del caso del pintor vasco Anselmo Guinea y su contribución a la cultura política vasca. Resalta el valor del arte como fuente histórica y defiende que el arte no es simplemente la reflexión de la realidad, sino que actúa sobre esa realidad, en una "ida y vuelta, recíproca y dialéctica". Los artistas surgen de la sociedad, están producidos por los discursos, pero a la vez responden a los mismos. El mundo está mediado a través del lenguaje y el arte. Así, el arte puede construir comunidades e identidades colectivas, ya que es productor a la vez que producto. La comunidad, por lo tanto, existe en este punto, el del lenguaje y del arte. Y es la reflexión sobre esta relación, este vaivén entre sujeto y discurso, y el lugar que ocupa (o dónde se construye la 'comunidad') la que une a las tres primeras comunicaciones.

En la siguiente agrupación se cambia el enfoque para considerar la importancia del medio. La importancia del espacio y del lugar no deja de ser importante en el análisis de las comunidades. Paula Escribano y Francesco D'Amaro ofrecen propuestas distintas que lo ponen en evidencia, bien como factor condicionante o como espacio construido conscientemente.

Paula Escribano presenta una perspectiva antropológica sobre una eco-aldea en Hungría basada en un trabajo de campo. Se trata de una comunidad creada conscientemente y en la que existe un esfuerzo muy claro por vivir en un grupo alejado y diferenciado de los alrededores, y no sólo en el sentido geográfico, sino también en los objetivos de la eco-aldea. Se aprecia, por tanto, una idea (bastante) fija de lo que era una comunidad: mutua comprensión, contacto, cooperación (pero no sin sus problemas, como el papel de la mujer). Escribano pone en evidencia la línea divisoria dibujada entre la eco-aldea y el mundo exterior, una línea dibujada constantemente por los habitantes de la eco-aldea a través de un discurso que contrasta los dos.

Francesco D'Amaro se adentra en un estudio comparativo de Valencia y Sicilia, en el que analiza cómo se ha organizado la gestión del agua a través de las instituciones de riego en estos ámbitos geográficos, incluso climatológicos, específicos. Estudia el poder, las tensiones y conflictos, y el papel de la institución como manera de crear y vertebrar la comunidad local. Mientras en Valencia las organizaciones han creado comunidades más formales, con vínculos más fríos e institucionales, y que funcionaban como un escenario para las batallas y negociaciones, en Sicilia, las instituciones han estado mucho más politizadas, revelándose como un "teatro político", o un microcosmo de la sociedad y mundo político exterior. D'Amaro explica cómo en Valencia la institución crea una identidad, dotándola con unos símbolos, construyéndose una comunidad alrededor de sí.

La última agrupación se centra en el exilio y supervivencia en un contexto muy específico, el de la posguerra española, y un grupo social específico, los vencidos de la Guerra Civil española. Son aproximaciones a dos facetas de las consecuencias del conflicto, desde las perspectivas local y transnacional. El conflicto tuvo consecuencias evidentes para las comunidades - enten- didas como las aldeas, los 'ecosistemas humanos' - que formaban parte y estaban dentro de una sociedad traumatizada y dividida en el "tiempo de silencio". ${ }^{31}$

Rosy Rickett se basa en la comunicación epistolar entre España y México entre 1952 y 1975 para conceptualizar, y definir como sujeto de análisis, una comunidad transnacional creada a base de esta comunicación entre los vencidos. Es decir, es un grupo roto o aislado geográficamente, pero dentro del cual los individuos se identifican entre sí a través de aspectos como las experiencias compartidas, la ideología o los lazos familiares. Rickett destaca la importancia de las ideas, del hecho de compartir algo, y es este sentimiento o emoción el que desemboca en esta conceptualización de un grupo muy heterogéneo y fragmentado en muchos aspectos como una comunidad. Por tanto, la carta sería la portadora de la comunidad, símbolo y vehículo de la misma. Las cartas permitían el establecimiento o el mantenimiento de las relaciones. Un objeto físico en que se apoyó o incluso se construyó esta comunidad imaginada de la posguerra, que es a la vez una comunidad para conceptualizar estas relaciones internacionales.

Gloria Román Ruiz se centra en el pequeño estraperlo en Granada. Demuestra cómo los delitos nos pueden llevar a estudiar los comportamientos y la experiencia vivida del Estado y contrapone la diferencia entre los grandes estraperlistas, que disfrutaron de la libertad de quedar impunes, y los infractores de menor grado que sufrieron castigos. El estraperlo se interpreta como resistencia y una manera de sobrevivir dentro de una comunidad con problemas y rupturas. Son estas rupturas las que influyeron en las consecuencias que la acción podría tener, a causa de venganzas y rencor, sobre todo cuando se destaca la fuerza de la represión y cómo se fomentó desde el nivel local. Pero también existía la solidaridad y mutua ayuda entre los vecinos frente a la represión, y la comunidad queda entonces como un espacio entre el Estado y la experiencia vivida por los ciudadanos españoles. Una comunidad que podía ser una red que garantizara la supervivencia o una telaraña peligrosa de posibles delaciones.

Ambas, Román y Rickett, hacen hincapié en la autoidentificación entre individuos en un contexto de sufrimiento, y cómo esta comprensión, mutua, puede (re)tejer y reafirmar redes de solidaridad. Para ellas, la comunidad se construye a través de objetos y comportamientos como hechos simbólicos, que las y los historiadores podemos interpretar desde el presente. Propuestas que junto con las anteriores nos obligan a reflexionar sobre cómo se construyen las comunidades y cómo podemos emplear el concepto de 'comunidad' en la investigación histórica. 


\section{PAN BLANCO PARA LOS VENCEDORES, PAN NEGRO \\ PARA LOS VENCIDOS. LA EXCLUSIÓN DE LOS \\ PEQUEÑOS ESTRAPERLISTAS GRANADINOS DEL \\ "NUEVO ESTADO" FRANOUISTA}

Gloria Román Ruiz

Universidad de Granada

\section{Introducción}

La "Nueva España" construida tras la Guerra Civil no contemplaba la inclusión de todos los españoles. En el proyecto franquista, por el contrario, no hubo cabida para el heterogéneo grupo de los vencidos en la contienda, en el que situamos a los pequeños estraperlistas granadinos. Ellos quedaron marginados, desamparados y condenados a una larga y amarga posguerra que poco tuvo que ver con la vivida por los vencedores. Uno de esos mecanismos de exclusión fue la autarquía económica, a la que atribuimos un doble potencial, el de castigar a los vencidos y el de premiar a los apoyos sociales del régimen con el objetivo de generar el consenso necesario para garantizar la supervivencia de la propia dictadura. En línea con estos objetivos socio-políticos e régimen reprimió las infracciones en materia económica de una forma a todas luces selectiva. La pregunta que cabe hacerse es si esa exclusión de la que hablamos vino solamente de arriba o si, por el contrario, también los ciudadanos de a pie dieron la espalda a los pequeños estraperlistas.

El grupo de los vencidos al que mayoritariamente pertenecían los pequeños estraperlistas de la provincia de Granada, quedó fuera de la "Nueva España" nacida de la Guerra Civil. Tachados de masones y malhechores, habrían de expiar sus culpas. La figura del vencido era en sí la de un súbdito de segunda bajo la dictadura franquista. El reto que aguardaba a estas personas en caso de haber logrado escapar del exterminio físico no era una tarea menor. Sobrevivir con el estigma de "rojo" en una España plagada de trabas y obstáculos especialmente diseñados para ellos pasaba, casi inexcusablemente, por dar el salto a la clandestinidad. La inferioridad con que eran considerados respecto a quienes se habían situado del lado de los nacionales mermará sus opciones de supervivencia.

Para muchos de ellos la disyunción pasó a estar entre la delincuencia o la inanición. Y en esa humana y lógica elección de dar de lado a la norma, cayeron en una marginalidad social aún mayor. En efecto, los estraperlistas fueron víctimas de un discurso franquista que, no desinteresadamente, los repudiaba y los presentaba como culpables de los problemas de abastecimiento que sufría el país. Pero lo cierto es que, si bien los grandes especuladores tenían parte de responsabilidad en la alarmante situación de escasez de suministros, no puede decirse lo mismo de los pequeños infractores. Contra estos últimos habría de volverse, paradójicamente, el lado más afilado de la ley.

A la voluntad nacionalizadora de los rebeldes, articulada a partir de procesos como la recatolización o la reespañolización, vino a sumarse el deseo de desnacionalizar a todos aquellos elementos que no encajaran en la "comunidad nacional" por ellos ideada. Para tornar efectiva esa exclusión, además de construir un agresivo discurso de estigmatización, activaron mecanismos como la autarquía o el castigo selectivo, a los cuales nos referiremos a lo largo de estas líneas. Nos detendremos, por último, en las actitudes y comportamientos sociales adoptados por la población granadina en medio de esa lucha entre los pequeños estraperlistas y el poder franquista. ¿Optaron por traicionarlos o demostraron empatía?

\section{Lo que escondía la autarquía: represión y generación de consenso}

El férreo intervencionismo del Estado en la economía, que pasó por el estricto control de la producción, el transporte y la comercialización de una gran cantidad de productos, y trajo consigo la fijación de precios por tasa y la implantación del racionamiento, ha de ser entendido como un nacionalismo económico extremo, lo cual casaba a la perfección con la ideología fascista del primer franquismo. En teoría, el objetivo de la autarquía económica no era otro que asegurar el suministro a la población más humilde en un contexto posbélico de enormes dificultades. El resultado real, sin embargo, distó mucho de ese solidario propósito. Su intensidad y pervivencia en el tiempo generó desabastecimiento y éste, a su vez, trajo consigo la aparición del mercado negro, popularmente conocido como estraperlo. Si bien no se trataba de un fenómeno nuevo en la historia de España, ni en la Europa de entonces, su generalización masiva y su connotación social lo convertirían en todo un símbolo del período de posguerra.

Las autoridades franquistas no podían ser ajenas a la preocupante escasez de alimentos que estaba costando la vida al pueblo y cuya causa se hallaba, no tanto en la devastación de la guerra', sino en una política autárquica que estaba resultando enormemente desastrosa. ¿Cómo explicar entonces la pervivencia durante más de una década de un sistema intervencionista que se había mostrado totalmente ineficaz a la hora de garantizar los productos básicos a una población hambrienta y necesitada? Contrariamente a lo que pudiera pensarse, la persistente apuesta del régimen por la autarquía no pertenece al ámbito de la irracionalidad. Y es que el intervencionismo económico reportó importantes beneficios a la dictadura en el terreno socio-político.

En efecto, la autarquía fue mucho más que una política económica. El hecho, creemos que no casual, de que perjudicara de forma evidente a los vencidos y beneficiara contundentemente a los vencedores nos hace pensar en la intención dictatorial de utilizarla al tiempo para reprimir y para generar consenso ${ }^{2}$. Este arma de doble filo en que se convirtió la autarquía estaba en perfecta sintonía con el carácter clasista, represivo y poco conciliador de la dictadura. El régimen, consciente del doble potencial autárquico, se mostró reacio a revertir la situación no apostando por la liberalización de la economía hasta los años cincuenta.

Los vencidos fueron relegados a un segundo plano. Con el fin de la contienda todo se volvió contra ellos. Estigmatizados, humillados, represaliados, expropiados y sin ningún tipo de ayu da estatal, sufrieron la escasez de forma especialmente virulenta. Ello los obligó a delinquir para poder subsistir. Es decir, el propio régimen los empujó a infringir las normas que él mismo había dictado. Y es que también de la miseria supieron sacar rédito las nuevas autoridades. Así, al condenar a buena parte de la población al hambre más cruel, el franquismo lograba desarticular cualquier posible oposición, pues preocupados como estaban por llenar sus estómagos y los de sus hijos, aparcaron cualquier deseo de libertad.

De ser descubiertos cometiendo el tan demonizado estraperlo, serán castigados sin miramientos. Así pues, estas personas que, por su extracción socio-económica, se habrían sentido más identificadas con el bando republicano, sufrieron una doble represión física y socioeconómica. Ésta se vio alimentada por una dañina "Cultura de la Victoria"3 que, lejos de apostar por la reconciliación de la población española, hizo leña del árbol caído elaborando un discurso

1 Los efectos de la contienda no fueron tan desastrosos como la propaganda oficial quiso hacer creer. Carlos BARCIELA: "Introducción", en Ramón GARRABOU, José Ignacio JIMÉNEZ BLANCO y Carlos BARCIELA LÓPEZ: Historia agraria de la España Contemporánea. 3. El fin de la agricultura tradicional (1900-1960), Barcelona, Crítica, 1986, p. 383.

2 Debemos este planteamiento, que supuso un giro en la interpretación de la autarquía, al hispanista Michael RICHARDS que así lo expuso en su obra Un tiempo de silencio: la guerra civil y la cultura de la represión en la España de Franco. 1936-1945, Barcelona Crítica, 1999.

3 Claudio HERNÁNDEZ BURGOS: Granada azul: la construcción de la "Cultura de la Victoria" en el primer franquismo (1936-1951), Granada, Comares, 2011. 
de castigo a los "rojos" por los "horrores" perpetrados durante la guerra. La sociedad quedaba dividida entre héroes y villanos. Así lo había querido la dictadura.

Mientras los vencidos eran abocados a vivir al límite de la subsistencia, buena parte de los vencedores estuvieron en condiciones de sacar buen provecho del férreo control franquista de la economía. Su acceso a medios de transporte apropiados así como a grandes almacenes y depósitos les permitió practicar un estraperlo a gran escala, trampolín para su enriquecimiento o incluso ascenso social. En el imprevisto de ser sorprendidos, las autoridades harán la vista gorda o les impondrán sanciones ridículas. Hubo, pues, quienes encontraron en la autarquía un medio para obtener jugosos beneficios. Esta ventajosa situación no podía más que traducirse en consenso y fidelidad hacia la "Nueva España". Con ello el régimen lograba el segundo de los objetivos perseguidos con la autarquía.

La apuesta franquista por la intervención estricta de la economía se revela así como un mecanismo que empujó a los más necesitados, identificados con la derrotada República, fuera de la legalidad. Vino a acentuar la exclusión de los ya excluidos, ahondando aún más en su miseria y marginalidad. Lejos de contribuir a su reintegración, la dictadura estaba hundiendo a quienes seguía considerando como enemigos.

\section{La represión del estraperlo de los pobres frente a la impunidad del estraperlo del lucro}

La represión feroz no fue privativa de la dimensión física, sino que se extendió también a la esfera socio-económica, donde la dictadura se mostró igualmente implacable. Así, a la hora de castigar las faltas de contrabando y defraudación ${ }^{4}$, se imponía actuar con "mano dura”. Eso sí, no con todos por igual, lo cual andaba en la línea anteriormente expuesta de premiar a unos y castigar a otros en función de su posicionamiento durante la guerra.

Tanto la legislación ${ }^{5}$ como la propaganda oficial ${ }^{6}$ se mostraron especialmente duras a la hora de condenar el estraperlo. Esa contundencia fue canalizada a través de un lenguaje agresivo que presentaba a los especuladores como la viva encarnación del mal. En estos términos se expresaban en el diario católico Ideal7: "El especulador, en su afán de allegar sin escrúpulo las mayores riquezas, ha provocado el alza de precios que se deja sentir en nuestra patria. Contra él hay que lanzarse violentamente, en rudo y continuo combate. Su derrota traerá consigo la pronta normalización de nuestra economía".

Contra las faltas y delitos de abastecimientos, considerados "antiespañoles" y propios de individuos desaprensivos sin apego a su Patria, no cabía escatimar esfuerzos. Sin embargo aunque la dictadura no ahorrara en críticas hacia el estraperlo, explicando este fenómeno fuera de la ley en base al "egoísmo" de algunos y al olvido de "sus más elementales deberes de españoles" que delinquían para no perecer de hambre, mientras que las grandes operaciones quedaban impunes, siendo sólo sancionadas de tanto en tanto con multas ejemplarizantes que apare-

4 Faltas que violaran la Ley de Contrabando y Defraudación del 14 de enero de 1929. De su represión se encargaba la Junta Administrativa de Contrabando y Defraudación de Granada, dependiente de la delegación de Hacienda de la provincia y cuyos expedientes (648) han sido estudiados para esta investigación. Incoados entre 1937 y 1952, se hallan hoy disponibles en el Archivo Histórico Provincial (AHP) de Granada.

5 La Ley del 16 de octubre de 1941 llegaba a proclamar incluso la pena de muerte para los delitos económicos.

6 Baste con echar un vistazo a la portada del diario Ideal del 15 de agosto de 1939, en la que se recogía el siguiente mensaje: "Toda severidad es justa y poca para impedir la elevación de los precios". Ideal, 25 de abril de 1942

8 Disposición de 1941. En Miguel Ángel DEL ARCO BLANCO: Las alas del ave fénix: la política agraria del primer franquismo (1936-1959). Granada, Comares, 2005, pp. 108-110. cían en las portadas de la prensa con un claro objetivo propagandístico. El régimen pretendía ofrecer una imagen justiciera en su lucha contra el mercado negro.

Pero no era más que eso, imagen. El Franquismo no fue capaz de convertir aquella ficción discursiva en realidad, pues ello hubiera puesto en riesgo su pervivencia. Ahora bien, pasar la mano en estos casos de gran estraperlo impedía atajar el fenómeno, en tanto que era éste el que ponía en circulación el grueso de la mercancía fraudulenta. El juego era sencillo: tolerancia con el estraperlo del lucro a cambio del consenso de sus protagonistas. La ausencia de casos de gran estraperlo entre los expedientes generados por un organismo represor como la Junta Administrativa de Contrabando y Defraudación es la mejor prueba de que éste quedaba, por lo general, protegido por un halo de impunidad. En efecto, la gran mayoría de los encausados por faltas económicas de este tipo presentaban un bajo perfil socio-económico.

Deducimos esa baja extracción social de los protagonistas de los expedientes estudiados a partir de sus propios testimonios tras ser detenidos, en los que no dudan en presentarse como "pobres de solemnidad"9; de su dedicación mayoritaria a actividades no cualificadas, siendo el campo la ocupación de un $34 \%$ de los mismos ${ }^{10}$; de las pequeñas cantidades defraudadas, de las que dan buena cuenta las sanciones económicas impuestas, un $83 \%$ de las cuales era inferior a 1.000 ptas.; $y$ de dos hechos enormemente significativos. El primero de ellos referente a analfabetismo de los inculpados, de los que hasta el $26 \%$ firmó el acta de aprehensión con la huella dactilar y, el segundo, a la imposibilidad que tuvieron estas personas de hacer efectivo el ingreso de la multa, ascendiendo el impago al $43 \%$ de los casos estudiados".

Sobre esta población débil y desamparada, difícilmente identificada con el "Nuevo Estado", se cebó una represión franquista que adoptó diversas formas. El proceso represivo comenzaba con la incautación de la mercancía. Además, los declarados culpables fueron sancionados con cuantiosas multas que, en caso de no ser satisfechas, fueron cobradas con el despojo de sus escasos bienes o, en su defecto, con el infierno de la cárcel franquista.

La pesada losa de la ley descansaba sobre quienes habían asistido, casi de la noche a la mañana, al desmoronamiento de sus vidas tal y como las concebían antes del 18 de julio de 1936 La guerra se llevó la esperanza y abrió paso al miedo, al dolor y al hambre que, en adelante, habrian de llevar a cuestas. Ante este lamentable espectáculo, jasistieron sus conciudadanos impasibles, o hubo algo que los moviera a aliviar un poco su carga?
9 Archivo Histórico Provincial (AHP), caja 3.324, Hacienda, 208, Leg. XXIV-2-11, Nº.XXIV-2-12; Contrabando, Indultos; 03-08-1949.

10 Para los 234 casos analizados en que conocemos el oficio del inculpado, 64 (27\%) son jornaleros o braceros sin tierras. Por detrás le siguen los vendedores ambulantes ( $8 \%$ ), los agricultores, esto es, arrendatarios o pequeños propietarios ( $7 \%$ ), las mujeres dedicadas a "sus labores" ( $5 \%$ ) y los conductores $(4,70 \%)$ que, por su profesión, gozaban de una condición ventajosa para la práctica conductores $(4,70 \%)$ que, por su profesion, gozaban de una condicion ventajosa para la practica
del estraperlo. Sólo en sexto lugar aparecen los industriales $(4,27 \%)$. En total, un $34 \%$ se dedican al campo y, prácticamente no encontramos ninguna profesión cualificada ni, por supuesto, profesionales liberales.

11 Porcentajes extraídos del análisis de la documentación disponible en: AHP, Hacienda, Contrabando y Defraudación. Cajas: 1.524, 1.555, 1.556, 1.593, 1.594, 1.595, 3.300, 3.314, 3.321, 3.322, 3.323, 3.324, 3.325. 


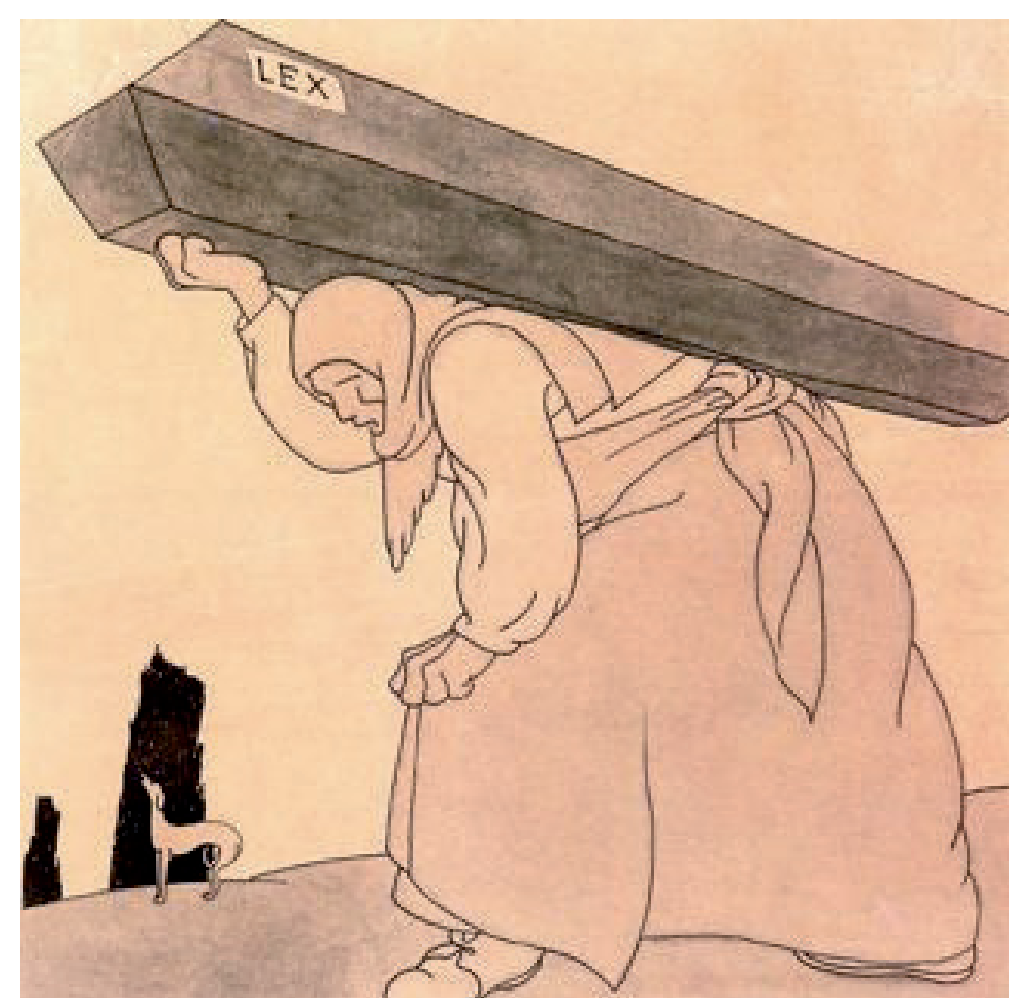

Img. 01 "Canto pesa e como fede". (Fuente: lámina nº 9 del álbum Nos, de Daniel Castelao)

\section{La comunidad ciudadana: entre la delación y la solidaridad}

La autarquía fue un mecanismo de exclusión del vencido orquestado "desde arriba" por el régimen de Franco. Pero, icontaron las autoridades con el apoyo ciudadano a la hora de castigar a los pequeños estraperlistas? Las actitudes y comportamientos de la comunidad granadina en torno al fenómeno osciló entre la colaboración con las fuerzas del orden y la solidaridad con los pequeños infractores, extremos que comprendian una amplia gama de tonalidades cromáticas que puede ayudarnos a entender actuaciones aparentemente contradictorias.

Buena parte de los expedientes a los que hemos tenido acceso comenzaban con un ilustrativo "teniendo noticias confidenciales...", indicador de que el procedimiento represivo había tenido su origen en un chivatazo a las autoridades. Las denuncias de que fueron víctimas los pequeños estraperlistas no pueden comprenderse sin la dominante "Cultura de la Victoria". Ésta creó la atmósfera apropiada para este tipo de actitudes delatoras al apostar por una sociedad dividida y vengativa en la que los simpatizantes con la República habrían de pagar por sus afrentas pasadas. Republicanos y nacionales no serían iguales a ojos de los nuevos gobernantes, máxima que trataría de transmitirse de arriba hacia abajo.

Para lograr tal cosa se articuló un discurso de demonización del otro que bien pudo encontrar eco entre determinados sectores de la población que no dudaron en denunciar a los "rojos", muchas veces por haber practicado estraperlo, convencidos de que merecían un buen castigo. En efecto, "el franquismo consiguió que muchos ciudadanos asumieran el modelo de 'comunidad imaginada' que les proponía"'. El componente nacionalizador de la Guerra Civil, sustentado en los pilares de la patria y la religión fue, pues, evidente. Pero el franquismo introdujo a su vez un elemento desnacionalizador,

12 El concepto de "comunidades imaginadas" es de Benedict Anderson. En Claudio HERNÁNDEZ BURGOS: Franquismo a ras de suelo. Zonas grises, apoyos sociales y actud (1936-1976), Granada, Editorial Universidad de Granada, 2013, p. 139 en la medida en que contribuyó al desarrollo de una imagen mitificada del enemigo [...] Al considerarse únicos representantes de la verdadera España, los sublevados se vieron en la inmediata necesidad de crear una anti-España en la que se englobaran todos los "enemigos" de la patria [...] y, en esencia, todos aquellos que suponían un obstáculo a la nación pensada por los rebeldes y que podían calificarse como 'rojos'. [...] Una imagen, en fin, que presentaba a la 'anti-España' como una amenaza real para la paz y que, apoyándose en un conjunto de convicciones, códigos morales y experiencias previas vividas por los ciudadanos, logró consolidarse y ser compartida por amplios grupos sociales que creyeron en su veracidad'3.

Aquella anti-España a la que pertenecían, entre otros, nuestros pequeños estraperlistas granadinos, quedó excluida de la "comunidad nacional". Esa retórica franquista fue el caldo de cultivo para que cualquier chispa incendiara la mecha. Bastó con un desencuentro político o una rencilla personal. Y, a quienes aún permanecieran indecisos, las nuevas autoridades pusieron en bandeja el siempre tan atractivo móvil económico: garantizaron a los denunciantes una recompensa económica que ascendía al tercio de la sanción impuesta ${ }^{14}$. El triste espectáculo de unos ciudadanos anónimos a los ojos de la historia denunciando a sus iguales estaba servido.

La sociedad española de posguerra se convirtió asi en una "sociedad autovigilada", es decir "una sociedad en la que sus propios vecinos se encargaban de vigilar y delatar a sus iguales" 15 en la que la omnipresencia de las sospechas y el miedo complicaron enormemente la existencia a aquellos que habían mostrado ideas políticas afines a la República. Tal y como preveían los nuevos gobernantes, todos los españoles tomaron parte en la lucha contra el estraperlo. La "complicidad e implicación del ciudadano en la persecución y control social del vencido"16 fue una clara victoria del franquismo. Y es que las denuncias no sólo partieron, tal y como cabría esperar, "desde arriba", sino también "desde abajo". Veamos ejemplos de ambas.

Entre las denuncias "desde arriba" llama la atención la interpuesta por la alcaldía de Zújar en la FPT en la que se afirmaba que habían sido sorprendidas Josefa Gómez García (con cuatro hijos a su cargo) y Francisca Lozano Suárez (con cinco hijos) conduciendo respectivamente tabaco y aceite sin "guía" de circulación. Si bien las inculpadas manifestaron que su capacidad económica era nula, el Ayuntamiento insistió en que Josefa poseía ganado por valor de 4.000 ptas. Contrariamente, en el caso de Francisca se observarán circunstancias para no imponerle sanción, tales como la "escasa trascendencia de la infracción cometida, que se observa poco ánimo de lucro, que es insolvente y que tiene cinco hijos a su cargo" ${ }^{17}$. Se aprecia pues un cierto ensañamiento respecto a Josefa, que bien podía responder al interés económico del Ayuntamiento de Zújar o a una mera cuestión personal.

Pero las autoridades contaron con la valiosa ayuda de los ciudadanos comunes en la lucha contra el pequeño estraperlo. En ocasiones las fuentes pueden resultar esclarecedoras respecto al motivo que llevaba a los denunciantes a delatar a sus convecinos. Así, Remigio Ortega López y Juan Garrido Atienza, vecinos de Granada, se personaban en la casa-cuartel de la Guardia Civil de la capital "manifestando deseaban denunciar con derecho al premio que la

13 Claudio HERNÁNDEZ BURGOS: Franquismo a ras de suelo..., p. 59.

14 Ley de 14 de enero de 1929 (BOE 17/01/1929), Arts. 41 y 42. Los otros dos tercios iban a parar, respectivamente a la Hacienda pública y a los aprehensores o descubridores en concepto de premio.

15 Concepto de Robert GELLATELY. En Sheila FITZPATRICK y Robert GELLATELLY: Accusatory practices: denunciation in Modern European history, 1789-1989, Chicago, University of Chicago Press, 1997 pp. $185-221$.

16 Conxita MIR CURCÓ: Vivir es sobrevivir, Lleida, Milenio, 2000, p. 254

17 AHP, caja 1.595, Hacienda, 118, Leg. XXVI-3-39; Tribunal de contrabando, Expts. Cumplidos en prisión; 28-03-1942. 
Ley de Contrabando concede a los denunciadores (sic)" que en el pueblo de Huétor Vega unos individuos (de los que se ofrecen nombres y apellidos) se dedicaban a la venta de tabaco in dígena y que "para probar estos extremos se personarían ellos en el citado pueblo simulando ser compradores a fin de facilitar la gestión de la fuerza aprehensora"18.

Vemos pues cómo la implicación de los denunciantes llegaba al punto de hacerse pasar por falsos compradores con el objetivo de facilitar el trabajo a las fuerzas aprehensoras que, de esta forma, podían pillar in fraganti a los infractores. En ocasiones esas "noticias" proporcionadas a las autoridades eran falsas y buscaban solamente el perjuicio del inculpado. Lo más relevante de muchos de los casos, que acaban sobreseídos tras reconocerse el infundio, es el hecho de que el denunciante no sufra ningún tipo de sanción en el supuesto de demostrarse la falsedad o mala fe por su parte, algo solamente explicable en base a los deseos del Estado por alentar la delación ${ }^{19}$, actividad ociosa que sacaba lo peor de los seres humanos ${ }^{20}$.

Pero las victorias pocas veces son totales. Y, si bien la aludida colaboración de la sociedad granadina con las fuerzas represivas constituyó un claro triunfo del poder, la colaboración con los pequeños infractores vino a contrarrestar aquel éxito. No todo fueron denuncias de ciudadanos comunes contra sus iguales, sino que las actitudes de solidaridad y encubrimiento adquirieron durante aquellos años un indiscutible protagonismo. La connivencia con el estraperlista de sectores de la comunidad a él vinculados a través de lazos ya fueran familiares, amistosos o vecinales, o incluso de individuos desconocidos, fue una constante. Las actividades clandestinas rara vez eran planeadas, acometidas y afrontadas, en el imprevisto de ser descubiertos, a título individual.

Este comportamiento ha de entenderse en base a la percepción del pequeño estraperlista como un ser que actuaba movido por la necesidad y que despertaba sentimientos de comprensión y solidaridad, a diferencia de lo que ocurría con los grandes estraperlistas, identificados con individuos que se enriquecían a costa de las miserias ajenas. Nos encontramos, pues, ante una sociedad comprensiva con el estraperlo de los pobres, entendido como mecanismo válido para asegurar la supervivencia familiar. Es lo que James Scott denomina "ética de subsistencia" ${ }^{21}$. Así pues, estas prácticas "cuando no responden a ansias de enriquecimiento ilícito sino al aseguramiento de la reproducción familiar, no quedan fuera de la percepción de lo que se considera moral o no reprobable para la comunidad" 22.

Esas actitudes de solidaridad comunitaria en la Granada de posguerra, por otro lado una constante a lo largo de la historia, bien pueden explicarse en base a la pervivencia de algún vínculo forjado en los años anteriores a la Guerra Civil o, simplemente, por la existencia de un sentimiento de agravio común a todos los vencidos. ¿O acaso también entre los vencedores hubo quien tendió una mano a los pequeños estraperlistas? Si bien es algo que no podemos constatar a partir de las fuentes estudiadas, la sociedad, siempre tan compleja y dinámica, bien pudo ofrecer muestras en este sentido. En cualquier caso, por lo que respecta a este sector solidario de la población, no puede decirse que contribuyera a aislar a los pequeños estraperlistas. Muy al contrario, tendieron una mano a quienes el nuevo poder trataba de echársela al cuello.

Aquella simpatía hacia los pequeños estraperlistas se materializó en la ayuda prestada para evitar su detención. Se trató de pequeñas pero valiosas acciones que, en no pocas ocasiones,

18 "Acta de denuncia". AHP, caja 3.300, Hacienda, 208, Leg. XXIV-1-1, R7; Contrabando, Pendientes de liquidación a partícipes, nº $31 ; 10-01-1944$.

19 Conxita MIR CURCÓ: Vivir es sobrevivir...p. 131

o Gutmaro GÓMEZ BRAVO: El exilio interior. Cárcel y represión en la España franquista (1939-1950), Madrid, Taurus, 2009

1 James SCOTT, The Moral Economy of the Peasant: rebellion and subsistance in southest Asia, New Haven, Yale University, 1976

22 Ana CABANA: La derrota de lo épico, Valencia, Publicacions de la Universitat de València, 2013, p. 138. ahorraron mayores complicaciones a los infractores. Así, al dar cobijo a un fugitivo, al fingir desconocer al propietario de la mercancía ilícita, al negar haber presenciado los hechos constituyentes de la falta económica en cuestión, o al no colaborar con las autoridades en la búsqueda de un pequeño estraperlista en "paradero desconocido" ${ }^{23}$, se estaba planteando resistencia al intervencionismo autárquico ${ }^{24}$

Pero si hubo una estrategia de resistencia en la que aparece sin rodeos esa confabulación entre miembros de la comunidad, ésa fue la de arrojar los paquetes por las ventanillas del tren en marcha a la espera de que algún cómplice los recogiera en las inmediaciones de la estación. Así pudieron comprobarlo los guardias que asistieron al lanzamiento de "cinco pequeños saquetes, dos cestos de palmillo y una maleta conteniendo azúcar moreno", suponiendo que "fueron arrojados por algunas mujeres de las que se dedican al ilícito comercio"25. El caso de Concepción Rodríguez Fajardo ejemplifica bien la cooperación familiar a la que nos referimos. Al ser interrogada, explicó que el café que llevaba "se lo arrojó del tren correo de Málaga una hija suya (que lo había adquirido en cantidades muy pequeñas procedentes de racionamientos) que venía en el mismo, a la cual le tenía dado el encargo de que se lo trajera, y que lo quería introducir en Granada para venderlo y poder ayudarse a vivir, por encontrarse viuda" 26.

Todo ello no hace más que remitirnos a un clima de desorden y desacato a las normas mucho más generalizado de lo que la propaganda franquista trató de transmitir a la posteridad.

\section{Conclusiones}

Conocidos son los nulos esfuerzos realizados por el régimen de Franco para construir una sociedad reconciliada con su reciente pasado bélico. La división de España en dos bandos se perpetuó a lo largo de los años, y la Nueva España victoriosa excluyó a la otra mitad derrotada. Es en este contexto en el que cobra sentido el entramado de disposiciones autárquicas. Teniéndolo todo en contra, los vencidos infringieron desesperadamente la ley y pasaron a actuar en la clandestinidad.

Aquellos pequeños estraperlistas fueron perseguidos y duramente castigados. La dictadura no mostró con ellos la piedad que mostró con los grandes especuladores, cuyas actividades ilegales quedaron mayoritariamente impunes. Los intereses políticos del régimen explican el escandaloso desajuste existente entre la actividad propagandistica oficial y su reflejo en la realidad.

En esta misión segregadora, el franquismo contó con el apoyo y colaboración de buena parte de la población, que encontró en las viejas cuentas pendientes, ya fueran personales o políticas, o en la tentación económica un buen motivo para meter en apuros a sus iguales a través de un detestable mecanismo proporcionado por las autoridades, la denuncia.

Pero entre tanta oscuridad, hubo también rayos de luz representados por ese sector de la población que, vinculado (a través de lazos de familiaridad, vecindad o parentesco) o no con los perseguidos, se solidarizó con los pequeños estraperlistas. La eficacia de esta colaboración no ha de ser menospreciada, pues tal y como evidencian algunos testimonios, pudo influir o incluso resultar crucial a la hora de salvar de las garras dictatoriales a quienes estaban a punto de caer en ellas. Ello contrarrestó los empeños del régimen por excluirlos a toda costa.

La exclusión aparece a la vez como causa y como consecuencia del fenómeno del pequeño estraperlo, en lo que constituye un círculo fatal de miseria y marginalidad. Y es que la misma

23 AHP: caja 3.300, Hacienda, 208, Leg. XXIV-1-1, R 7, Liquidación, Contrabando, Pendientes de liquidación a partícipes $n^{\circ}$ 31; 21-05-1946.

24 "Las clases subalternas pusieron en marcha toda una serie de estrategias a la vez de subsistencia y de resistencia para lo cual se valieron de sus propias armas de los débiles". En James SCOTT, Domination and the Arts of Resistance. Hidden Transcripts, New Haven, Yale University, 1990.

25 AHP, caja 1.593; 04-07-1944.

26 AHP, caja 
identificación con la República que los había hecho caer en el estraperlo, se convertiría en un obstáculo a la hora de esquivar a las autoridades o eludir el castigo. Los más humildes quedaron así atrapados en un callejón sin salida, condenados por haberse situado del lado equivocado. Y aquellos no eran tiempos para segundas oportunidades.

En definitiva, vencedores y vencidos recurrieron al estraperlo, pero por motivos y con aspiraciones dispares. Unos y otros fueron descubiertos, si bien con desigual frecuencia. Sobre ambos recayó el castigo franquista. Eso sí, con distinta dureza. Pese a la contundencia del lenguaje empleado en los periódicos y las leyes, los primeros gozaron de impunidad, mientras que los segundos fueron excluidos de la "comunidad nacional". Los vencidos no sólo habían perdido la guerra. Habían perdido cualquier posibilidad de ser considerados parte del Estado surgido de ella. Ellos no tendrían cabida en la "Nueva España". Era el precio a pagar por haber caído, por voluntad o por accidente, en el lado equivocado de una línea que dividía el bien de mal, la España de la anti-España, en fin, el pan blanco del pan negro. 


\section{EL DISCURSO CULTURAL IDEOLÓGICO DE ORDEN.}

\section{ARGENTINA 1955-1983}

ulio Lisandro Cañon Voirin

USC-Xunta de Galicia

En Argentina el fin del régimen peronista (1955), dio paso a un período de inestabilidad, signado por el bloqueo de la vía del diálogo para la resolución de los diferendos. Materialmente objetivado en la sucesión de gobiernos golpistas y gobiernos constitucionales, por cada día de éstos últimos hubo dos de dictadura. Ese contexto enmarca el objetivo general de este trabajo: analizar los discursos y las prácticas empleadas por los sectores dominantes argentinos, entre 1955 y 1983, para reedificar la conducción moral, intelectual y política de la sociedad. Ello refiere a la hipótesis central que subyace al entramado de esta investigación: en Argentina, el derrocamiento de Perón (21/09/55) abrió una crisis orgánica que del terreno político pasó al resto de los ámbitos de la vida en sociedad. ' La crisis estuvo acompañada por la caracterización del bloque golpista sobre la necesidad de disciplinar a una sociedad amenazada por el comunismo.

El objeto particular de esta indagación es presentar un campo muy preciso: el discurso cultural ideológico de orden (DICIO), ${ }^{2}$ particularmente su proceso gestacional (1955-1963). Se trata de un discurso sui generis, en tanto vertebrador de un proyecto aglutinador de las distintas fracciones dominantes de la sociedad argentina, que hizo del principio de orden y de la exclusión del otro, sus imperativos categóricos. En el intento por conformar un nuevo orden hegemónico el discurso adquiere un papel singular, porque con él se erige una realidad, se proyecta una imagen específica del mundo. Las preguntas de investigación que orientan nuestras pesquisas son: ¿cómo se gestó?, ¿cuáles son sus principios básicos?, ¿cómo los transmitió?

Para identificar el proceso hegemónico a través del mosaico ideológico constitutivo de un lenguaje común de orden, hemos recogido como marco general para nuestra investigación el Método Dialéctico. Partimos de la concepción gramsciana de Estado, y de entender a las políticas y prácticas como reorganizadoras de las relaciones sociales. Recogiendo cuatro nociones clave, inscriptas en la tradición gramsciana (ideología, hegemonía, reproducción, resistencias) posteriormente enriquecidas por los aportes del marxismo británico y su expresión en el materialismo cultural. Del conjunto de fuentes primarias editas e inéditas del período, hemos considerado necesario trabajar sobre hemerográficas, fundamentalmente el boletín semanal de la Agencia Informativa Católica Argentina (AICA); documentales pastorales y declaraciones de la Iglesia Católica Argentina; publicaciones y declaraciones provenientes de las Fuerzas Armadas (FF.AA.); y fuentes legislativas. Ordenando y sistematizando en forma lógica la información obtenida, intentamos reconstruir e interpretar los enunciados sociales articuladores del DICIO - su contenido, su dinámica, sus relaciones con los otros.

1 Partimos aquí de las concepciones de Gramsci quien entiende a la crisis orgánica como crisis A clase sobre el conjunto de la sociedad. Cfr: Antonio GRAMSCI: Antología. Selección, traducción y notas de Manuel Sacristán, México, Siglo XXI, 1977.

2 El DICIO es una elaboración conceptual propia, surgida del examen de las fuentes y de reflexionar sobre lecturas previas.
El DICIO, al constituir el marco discursivo del proyecto sustentado por una de las fracciones que coexisten en la sociedad, permite observar los procesos de construcción social de la realidad. ${ }^{3}$ Cada proyecto es una propuesta social, una articulación particular de los elementos económicos, sociales, morales, culturales, educativos e ideológicos para una sociedad determinada en un momento histórico determinado. Tomando en consideración los distintos proyectos actuantes en la sociedad, se hacen evidentes los vínculos recíprocos entre las distintas propuestas, en una relación activa, propia del proceso hegemónico, donde las demandas e intereses de unos y otros se transforman mutuamente. Ello nos sitúa ante el criterio metodológico fundante de nuestro estudio, pues la acción hegemónica se manifiesta como dominio y como dirección. En el caso del $\mathrm{DIClO}$ se trata de un proceso de dominio signado por la cristalización de un pensamiento excluyente, pues sólo entiende al 'otro' no sólo por oposición sino en oposición. Y de dirección intelectual y moral en tanto la colonización del proyecto de orden pretende asimilar a toda la sociedad: toda la función del Estado se transforma, se hace educador. ${ }^{4}$

EI DICIO se gestó en la convergencia de intereses compartidos por grupos sociales con puntos de vista semejantes, movidos a oponerse a una real o imaginaria situación de alteración del orden establecido. Como discurso productor social de sentido, vertebró creencias, valores culturales y códigos de conducta social, argumentativos de prácticas sociales excluyentes y discriminatorias. Su desarrollo se basó en la representación cultural del otro desde una diferencia absoluta, con la estigmatización del otro como núcleo invariable, donde la convivencia con ese 'otro' se hará cada vez más difícil y peligrosa.

El enfrentamiento civilización cristiana versus comunismo, afiligranó los principios básicos de representación del DICIO, en una conceptualización dicotómica, la polarización entre lo positivo y lo negativo. Los registros empleados para interpretar la realidad adyacente se construyeron sobre esa dicotomía y sobre estereotipos destinados a cimentar la comprensión de la realidad en los siguientes términos: el comunismo no se detendría en la búsqueda de su objetivo, un orden comunista mundial. La difusión de esa interpretación desencadenó la preocupación social ante la posible pérdida de la propia identidad, a causa de la subversión cultural, vehiculizada por la denominada infiltración comunista.

Desde nuestra perspectiva, la transmisión del DICIO, fue medular en el proceso hegemónico, porque sus sostenedores diseminaron, y repitieron perseverantemente sus contenidos, colonizando distintos aspectos de la realidad social, conformando un sentido común. Es decir una materialidad con la potencialidad suficiente para prefigurar prácticas propias de una determinada tendencia social, y aunque no puede establecerse en qué proporción lo es del hacer de toda la sociedad, funcionó como mecanismo de integración de las clases subalternas a la cultura e ideología dominante. 5

Paulatinamente las clases dominantes, que lo sustentaron, desplazaron el eje interpretativo de los conflictos sociales hacia una guerra ideológica tal como la entendían las FF.AA. argentinas

la que desarrolla el comunismo internacional para imponer la doctrina marxista en el mundo, abarcando todos los campos de la actividad humana (...) busca un cambio radical en todas las estructuras y hasta en la misma concepción de la vida (...) no podrá finalizar definitivamente con una transacción sino que su fin significara la victoria total de uno de los bandos. ${ }^{6}$

3 Nos referimos particularmente al proceso de internalización de normas y valores básicos, aprehensión del complejo social y cultural. Peter BERGER y Thomas BLUCKMAN: La construcción social de la realidad, Buenos Aires, Amorrortu, 1972.

4 Cfr. Antonio GRAMSCI: Antología. Selección, traducción y notas de Manuel Sacristán, México, Siglo XXI, 1977 .

5 Antonio GRAMSCI: Cuadernos de la Cárcel, Tomo I, México, Era, 1981, p.140.

6 EJÉRCITO ARCENTINO: RC-8-2 Reservado. Operaciones contra Fuerzas Imregulares, Tomo III, Buenos 
Este desplazamiento, confirió nuevas connotaciones al proceso hegemónico, acentuando la cooperación entre instituciones de la sociedad civil (iglesia, partidos políticos, sindicatos estudiantiles, medios de comunicación) y de la sociedad política (FF.AA., fuerzas de seguridad). Todas ellas conformaron un bloque heterogéneo, articulado en la pretensión de un reordenamiento social.

Nos centramos en la pretensión de la clase dominante de conformar un consenso antagónico, en una coyuntura determinada, mediante el proceso discursivo, ${ }^{7}$ entendido como una de las dimensiones de la materialidad ideológica, como una fuerza confrontada a otras fuerzas. Para evitar confundir el objeto de conocimiento con el objeto real intentaremos ubicar el conjunto de enunciados que históricamente le dan sentido. Uno de los intelectuales del ámbito militar argentino, señaló que en 1955 se inició la maniobra de cerco a occidente, consagrada a la abolición de la familia cristiana, la patria, la nacionalidad, y la propiedad privada. ${ }^{8}$ Sostuvo además, que Gramsci enseñó a los subversivos como conseguir el dominio del Estado si previamente realizaban un cambio cultural en los valores tradicionales del país. Concluyendo que la subversión se infiltró en la cultura, la educación, los medios de comunicación, la religión, el arte, etc. ${ }^{9}$ En estos parámetros el marxismo conformó la imagen de un enemigo terroríico, que tanto podía ser el movimiento obrero, el movimiento estudiantil o el intelectual comprometido. Toda expresión contrapuesta al mundo occidental o cristiano, fue nomenclada como subversión comunista. El orden se convirtió en la premisa de una regeneración social y de una nueva cultura para una Argentina restaurada; entendido como un orden socio-político inspirado en la concepción de la civilización occidental y cristiana. En dicha concepción existe un intento de reintroducir la unidad cultural y originaria en el desarrollo de los individuos his tóricos, planteando el problema del individuo completamente destruido por la alienación de desarrollo capitalista, que debe reconstruirse ante el riesgo de que el comunismo lo conquiste. Se trata de un proyecto que considera al individuo como terreno a conquistar y se sustenta en la jerarquía y la conciliación de clases, como definió la ciudad católica uno de los teólogos más importantes del siglo XX, el intelectual y sacerdote católico Julio Meinvielle

un orden normal de vida es un orden esencialmente jerárquico, una jerarquía de servicios y el orden jerárquico integra en la unidad lo múltiple. Así las familias se integran en la unidad de las corporaciones; las corporaciones en la unidad de la nación bajo un mismo régimen político; las naciones en la unidad de la cristiandad por la adoración del mismo Dios. ${ }^{10}$

La denominada Revolución Argentina (1966-1973) intentó establecer ese modelo. En su acta constitutiva denunció la quiebra del principio de autoridad, la ausencia de orden y disciplina, y ante ello las FF.AA. debían intervenir para salvar a la Nación del riesgo "de caer ante el avance del peligro colectivista"."

Años más tarde otra dictadura militar, el Proceso de Reorganización Nacional (1976-1983), reincidió sobre los mismos principios, pretendiendo disciplinar y reorganizar a la sociedad argentina. Se esforzó en comunicar su concepción de orden: "no refiere principalmente a algún orden "establecido" -que puede haber tal que sea "orden" sólo en apariencia, siendo en realidad un

Aires, IGM, 1969, p. 10.

Michelle PECHEAUX: Les verités de la Palice, París, Maspero, 1975

8 Ramón DÍAZ BESSONE: La guerra revolucionaria en la Argentina (1959-1978), Buenos Aires, Círculo Militar, 1987 .

9 Ramón DÍAZ BESSONE: Testimonio de una década, Buenos Aires, Círculo Militar, 1996.

10 Julio MEINVIELLE: El comunismo en la revolución anticristiana, Buenos Aires, Theoria, 1982 [1961], p. 28.

11 Acta de la Revolución Argentina (28/06/1966), Boletín Oficial de la República Argentina, núm 20.970, p. 1. desorden generalizado- o al orden socio-político, sino que apunta al orden natural entero". ${ }^{2}$

A partir de la Revolución Libertadora (golpe de Estado que derrocó a Perón), los custodios civiles, eclesiásticos y militares del orden social difundieron la idea de una más que factible guerra social dirigida por el marxismo. Identificando a los sostenedores de proyectos alternativos como protagonistas de un proceso de deshumanización, que han perdido la categoría de seres humanos y que deben ser eliminados para construir la ciudad católica. Ello formó parte del esfuerzo pedagógico de la clase dominante, en su intento por conseguir la subsunción al orden jerárquico. En esa búsqueda, bajo formas despiadadas o sofisticadas, se hostilizó a todo movimiento encuadrado en la desobediencia, desplegando contra ellos un consenso antagónico. En síntesis el objetivo de la empresa pedagógica sería la conformación del hombre colectivo, alcanzarlo supondría el logro de una unidad cultural-social, por la cual una multiplicidad de voluntades disgregadas, con heterogeneidad de fines, se sueldan con vistas a un mismo fin, sobre la base de una misma y común concepción del mundo. ${ }^{13}$

\section{¿Cómo se gestó el DICIO?}

El derrocamiento de Perón cristalizó la descomposición del andamiaje social donde las clases dominantes instituían el consenso para el ejercicio hegemónico del poder. Con el consecuente aumento de la tensión en las relaciones sociales, percibido por los sectores dominantes, como una amenaza, como una desorganización del estrato social. Precisamente el DICIO reconoce su génesis en dos fenómenos concomitantes que acompañaron a la crisis hegemónica. Éstos son la caracterización formulada por el bloque dominante de la situación social post-peronista, y el proyecto planteado para reconstruir la herrumbrosa estructura sociopolítica.

El relato pormenorizado de la caracterización está dado por los actores principales de la Revolución Libertadora (alianza cívico-militar-religiosa, que derrocó a Perón). A partir de ella la sociedad argentina fue dividida en dos realidades antagónicas y al parecer inconciliables: el cristianismo frente al comunismo. Desde la enunciación formulada por los sostenedores de $\mathrm{DICIO}$ los dos bloques antagónicos quedaron nítidamente separados. Uno de los teólogos más importantes del siglo XX, el sacerdote Meinvielle, concluyó que la inexistencia de un orden respetuoso del derecho natural y cristiano, afecta la difusión del Evangelio. De donde colegia que quien no contribuye a edificar la ciudad de Dios o cristiandad, trabaja para su demolición. Incluso la iglesia podía y debía, aplicar medidas de coerción, que podían llegar hasta la deposición de los gobiernos que perjudiquen el orden natural y cristiano. ${ }^{14}$

En consonancia con tales apreciaciones Mario Amadeo, (miembro del gobierno de la Revolución Libertadora, del gobierno de Arturo Frondizi (1958-1962) y de la Revolución Argentina) expresó la visión compartida por una tendencia social, sobre dos cuestiones. Una "el riesgo de ser superados por la izquierda revolucionaria y marxista" 15 si no se toma en cuenta la demanda por una mayor justicia social. Otra la legitimidad del recurso a la fuerza: "No pretendemos descalificar el uso de la fuerza como factor político ni somos tolstoyanos que nos horroricemos de las medidas de represión cuando son justas" ${ }^{\prime 16}$. En julio de 1955, solicitó el derrocamiento de Perón por las afrentas a la iglesia.

Importa recuperar la concepción de un miembro de las FF.AA., protagonista de la alianza, enlace entre los distintos grupos actuantes en el golpe, el coronel Juan Francisco Guevara (fun-

12 PODER EJECUTIVO NACIONAL: Evolución de la delincuencia terrorista en la Argentina, Buenos Aires, El Gobierno, 1979, pp. 371

13 Cfr. Antonio GRAMSCI: Antonio Gramsci... pp. 388-396.

14 Julio MEINVIELLE: El comunismo...

15 Mario AMADEO: "Hacia una comunidad hispánica de naciones", Cuadernos Hispanoamericanos, 59 (1954), pp. 131-140.

16 lbid., pp. 131-140. 
dador de Ciudad Católica Argentina, traductor del libro El Marxismo-Leninismo (1961), de Jean Ousset, prologado por el arzobispo de Buenos Aires y vicario castrense, cardenal Antonio Cag giano). Guevara atribuyó al peronismo un efecto positivo sobre "las masas obreras, sacándolas de los peligros anarquizantes, socialistas, y marxistas". 17 No obstante lo cual, al igual que su amigo Mario Amadeo consideró que la Libertadora fue hecha para "poner en quicio los valores religiosos, morales y cívicos".18

Los párrafos precedentes destacan el papel de la revolución social como paradigma en el imaginario de los intelectuales de la época. Su aversión ante el triunfo de un espíritu revolucionario y la consiguiente movilización revolucionaria de las masas, constituye el punto de encuentro de los tres sectores. Otro punto de coincidencia está en no descartar los golpes de Estado en la consecución de sus objetivos. En líneas generales para los golpistas Perón condujo inadecuadamente la incorporación de la clase obrera a la vida política institucionalizada, fundamentalmente por haber hecho uso de un resorte hasta entonces descuidado y de una potencia latente increible: la justicia social. Sin embargo algunos sectores del bloque dominante no dudaban en reconocer que la burocratizada conducción sindical del peronismo había evitado la caída de la clase obrera en el comunismo.

Si bien no pueden pasarse por alto las diferencias al interior del bloque golpista, hubo coincidencias de conjunto respecto de la falta del: "orden real y jurídico que fomenta la tranquilidad que es la paz, por ser tranquilidad del orden", tal como señalaron los obispos argentinos al presentar el Libro Blanco de la iglesia. ${ }^{19}$ La proclama de inicio del golpe de Estado sentenció ese desorden por haber servido para "el auge de la corrupción y para la destrucción de la cultura". ${ }^{20}$ El general Lonardi, presidente de facto, completó el cuadro de situación aseverando: "veo una amenaza en el comunismo". ${ }^{21}$ Se presentó al comunismo como la culminación de la revolución anticristiana, en una progresiva zoologización o deshumanización del hombre, partiendo del renacimiento había ido descendiendo hacia un plano de menor densidad cultural: el comunismo.

Tal delimitación de la situación les llevó a centrarse en los presupuestos culturales de la descomposición, y que a futuro sólo podrían evitarla con un programa fundado en una concepción integral del hombre, en tanto ser occidental y cristiano. El ámbito educativo emergió como el espacio donde luchar contra el desorden, y alli se centró la Iglesia, buscando abolir la laicidad educativa. Así lo confirmó el cardenal Caggiano: "La libertad de enseñanza es la más fundamental de todas las libertades". 22

La responsabilidad de la cartera educativa del gobierno golpista recayó en el ex presidente de la Liga de la Juventud Católica Argentina y director de los Cursos de Cultura Católica, Atilio Dell'Oro Maini. Haciendo gala de una claridad meridiana, sintetizó el imaginario de los sectores dominantes, de cómo subsanar la crisis, restableciendo "los conceptos esenciales que dentro de nuestra cultura occidental y cristiana, rigen el desarrollo de las tareas docentes del Estado".. 23 Para ello promulgó el decreto 6.403/55, liquidando el carácter laico de la educación argentina, al autorizar a las universidades católicas a emitir títulos habilitantes.

\section{¿Cuáles son los principios básicos?}

A partir de la caracterización de desorden se estructuró el desarrollo conceptual del pro-

17 Juan Francisco GUEVARA: Argentina y su sombra, Buenos Aires, Del Autor, 1970, pp. 55

18 lbid., p: 76-77.

$19 A B C, 29$ de julio de 1955 .

20 Luis LONARDI: Dios es justo. Lonardiy la revolución, Buenos Aires, Francisco Colombo, 1958, pp. 97.

$21 A B C, 29$ de septiembre de 1955 .

22 Secretaría de Informaciones del Estado: Boletín Semanal Político, Gremial, Económico, Estudiantil,

12 de septiembre de 1958

$23 A B C, 29$ de mayo yecto de orden. Los principios básicos donde se sustentó se figuran "entre la renovación bajo el signo de la tradición y el orden o la revolución bajo el signo de la hoz y el martillo". ${ }^{24} \mathrm{El}$ eje está dado por el entrecruzamiento de ideas de índole religiosa, política, y social, a través de la representación dicotómica orden/caos (cristianismo/comunismo), pero con una única alternativa, un "camino único, y, ese si de verdadera redención, el cristianismo". ${ }^{25}$

El elemento clave era el carácter divino del orden, un orden armónico y jerárquico vigente en la ciudad católica, en la civilización cristiana. El orden social deseado se inspiró en un modelo jerárquico de unión. Unión armónica de las fuerzas del capital y del trabajo, de las fuerzas económicas, políticas y religiosas, del Estado con la iglesia en la edificación de la ciudad católica. Como contrapartida, según este proyecto, el comunismo tiene como objetivo el desorden. Ante ello el cardenal Caggiano, advirtió sobre la necesidad de ofrecerle una resistencia, la doctrina del cristianismo. Los cristianos debían ser ciudadanos de conciencia recta, cumplidores disciplinados de sus deberes. ${ }^{26}$ Ello supone una acción informativa de la iglesia sobre la organización social, estructurando las relaciones familiares, laborales, culturales y políticas.

El desarrollo del DICIO contó con otro elemento fundamental, la estigmatización del otro. Se afianzó una reacción común contra los inconformistas, combatiéndolos con una crudeza verbal inusitada; $y$ organizando un aparato coercitivo oficial y extra oficial. La constante fue presentarlos como una minoría, como pequeños grupos fanatizados, según datos de la propia iglesia sobre un total de 20.965 .000 de habitantes en Argentina, 18.735 .000 eran católicos. ${ }^{27}$

\section{¿Cómo se transmitió?}

En este apartado aboradaremos las poleas de transmisión, que además del discurso, stricto sensu, incluye los soportes de producción de sentido. Es decir los procedimientos para poner en práctica el proyecto, en un proceso de progresivo perfeccionamiento donde intervinieron múltiples agentes, en busca de un consenso que incluyese la movilización en favor del orden. Con un doble objetivo trasladar al conjunto de la sociedad la imagen del individuo participe de las acciones "contrarias a la Historia, a la Filosofía, a la Religión y a las costumbres propias de los países de nuestro Hemisferio". ${ }^{28}$ Y por otro establecer identificadores simbólicos conformadores de la identidad colectiva: occidental y por ende cristiano. Una noción antigua con nuevos contenidos, ser cristiano aparecía como la conformación identitaria genérica a todos los no comunistas.

Distintos espacios se consideraron propicios para transmitir los valores, desde colegios y universidades pasando por asambleas, conferencias, seminarios, movilizaciones, mesas redondas, publicaciones, producciones artísticas, hasta actividades panfletarias. Lo que solicitó la jerarquía eclesiástica argentina en la voz de su representante máximo: "defender los valores espirituales y de denunciar con valentía desde la cátedra, la prensa, la radio, el libro, en nuestras disertaciones y conversaciones; en conferencias y mesas redondas". ${ }^{29}$

Mario AMADEO: "Hacia una comunidad...", pp. 131-140.

25 Emilio BOTERO GONZÁLEZ (Monseñor): Pastoral sobre el comunismo, s.l., s.n., 1960.

26 AICA, 8 de julio de 1960 .

27 CARTÓGRAFO DE LA SAGRADA CONGREGACIÓN DE PROPAGANDA FIDE, estadística de la población religiosa 1960

28 Primera Reunión de Trabajo de Inteligencia Nacional. Santiago, 29 de octubre de 1975, p. 155. Fotograma 00022F 0153. Disponible en World Wide Web: http://www.gwu.edu/ nsarchiv/NSAEBB/ NSAEBB239b/PDF/19751000\%20Primera\%20reunion\%20de\%20Trabajo\%20de\%20Inteligencia\%20Nacional.pdf

29 Antonio CAGGIANO (Cardenal): Sermón pronunciado por el arzobispo de Buenos Aires, el domingo de Pascua de Resurrección (2 de abril de 1961) en la Iglesia Catedral de Buenos Aires, s.n., s.l., 1961. 
Primeramente ubicamos las instituciones movidas por la implementación de un proyecto político de orden y vinculadas a la militancia y práctica católica. Cada una de esas instituciones, con sus propios medios de difusión, tuvo un rol clave, sus intelectuales fueron protagonis-

La iglesia contó con la mayor infraestructura para la tarea, con publicaciones propias y afines, con editoriales, e incluso consideró necesario poner en marcha una agencia informativa propia AICA. Por otra parte poseyó una extensa red de colegios privados, (subvencionados por el Estado), y desde 1958, tras la aprobación del ya citado decreto/ley $6.403 / 55$, tuvo un circuito educativo propio, donde formar a los futuros cuadros dirigentes, sin la interferencia estatal.

El ámbito de transmisión más clásico lo constituyeron las misas de la iglesia, un espacio de comunión y receptividad para presentar lo que la cúpula eclesiástica consideró "la más grande y la peor de las herejías": ${ }^{0}$ el comunismo. Las pastorales -de ineludible lectura en las homilías - trazaron los contornos del accionar considerado perjudicial para la comunidad: "a la enseñanza católica de paz y armonía entre las clases sociales dentro de la más completa justicia, el comunismo responde con la proclama de guerra de clases hasta cambiar la faz de mundo". ${ }^{11}$ El obispo de Santa Rosa, reflexionó sobre el recto proceder de los cristianos al sufragar, recordando que el comunismo, el socialismo y el laicismo son "ideologías inconciliables con el cristianismo y condenadas por la Iglesia, a las cuales el católico no puede dar su adhesión". ${ }^{22}$ En un momento de particular recogimiento para los católicos como es la Pascua de Resurrección, centro de todo el año litúrgico, la Iglesia Catedral de Buenos Aires se convirtió en el escenario donde el cardenal Caggiano sentenció:"El comunismo es el peor de los totalitarismos, en realidad este es el totalitarismo absoluto y completo teórica y prácticamente por sus negaciones, por sus principios y por sus finalidades íntegra y exclusivamente materialistas". ${ }^{33}$ Ante los avances del materialismo la iglesia solicitó una "campaña de moralización en todos los órdenes, en el cine, en la radio, en la televisión, en las revistas inficionadas de materialismo y sensualismo, en los lugares de diversión".34

AICA, fundada por la Conferencia Episcopal Argentina en Asamblea Plenaria en diciembre de 1955, constituyó uno de los soportes implementados exprofeso para la difusión del proyecto. Sus noticias fueron reproducidas por periódicos y revistas provinciales y nacionales; y un gran número de radioemisoras. Desde junio de 1958 destinó un apartado de sus boletines a seguimiento y denuncia de las actividades contestatarias, denominado "Informaciones sobre el Partido Comunista Argentino y organizaciones vinculadas al mismo". Este espacio convocó principalmente a miembros de la prensa católica y a católicos militantes de organizaciones anticomunistas, con un claro objetivo informar "dónde, cuándo y cómo debe lucharse contra el comunismo". 35 Una lucha emprendida para

anular, no sólo su prensa clandestina (...), sino también su faz infiltrativa y que existe en toda la república, empezando por las propias instituciones nacionales, provinciales y comunales; las Universidades y Centros de Estudios; prensa, radio y TV; empresas de aeronavegación, transportes fluvial y terrestre -verdaderos nidos de enlaces comunistas- ${ }^{-36}$

AICA, se ocupó de dar contenido y precisar los contornos de quienes actuaban contra el

30 AICA, 8 de julio de 1960

Emilio BOTERO GONZÁLEZ (Monseñor): Pastoral sobre el comunismo

32 Jorge MAYER (Monseñor): Exhortación Pastoral del obispo de Santa Rosa, s.n., s.l., 1960.

33 Antonio CAGGIANO (Cardenal): Sermón pronunciado,...

34 Miguel RASPANTI (Monseñor): Pastoral, s.n., s.l., 1960.

35 AICA, 28 de octubre de 1960.

36 lbid.

orden, a parte del PC, denunció asiduamente al Consejo Mundial de la Paz, la Federación Sindical Mundial, la Federación Internacional Sindical de la Enseñanza, la Federación Mundial de la Juventud Democrática, la Unión Internacional de Estudiantes. Individualizó a los militantes del PC o sospechados de serlo, cuando alguno de ellos fallecía AICA titulaba bajas, como si del recuento de muertos en una guerra se tratase. Centró su ofensiva en la solicitud de que los comunistas y sus colaboradores fuesen expulsados de la vida en sociedad, solicitando despidos, encarcelamientos o exilios, negándoles la posibilidad de reproducir sus condiciones de vida. Propuso la unión de todas las entidades anticomunistas en la conformación de un "movimiento que fuertemente unido pueda crear un muro de contención".37

Su rol principal, a partir de 1958, consistió en colocar a toda el ala contestataria en el comunismo. Progresivamente todas las manifestaciones contrarias al orden establecido sucumbirán a la denominación de comunista, indiferenciándolas, amedrentando a muchos, y agudizando el rigor de la militancia contestataria. Quienes conformaron un consenso antagónico y libraron la lucha contra los sujetos peligrosos se esforzaron en trazar su perfil característico, para finalmente poder sellar su exclusión de la sociedad.

Otro recurso para la difusión estuvo dado por las emisiones radiofónicas, desde 1959 gran parte del país estuvo cubierto por audiciones radiales católicas, todos los días de la semana hubo alguna.

Dos eventos realizados en Buenos Aires, la Gran Misión (del 24/og/6o al 16/10/60) y el Primer Congreso Mariano Interamericano (del 11/11/6o al 13/11/6o) compartieron el mismo propósito funcionar como campañas de ilustración sobre el peligro comunista. En el Congreso se estudió la forma de enfrentar al comunismo, y se definió la posición de los católicos ante el comunismo. Desde nuestra perspectiva, las conclusiones más importantes fueron la implementación de una empresa de formación a través de los colegios y las universidades católicas: y la promoción de una promover la educación popular, para niños y jóvenes. ${ }^{38}$

Concluidas las experiencias religiosas el presidente Frondizi se refirió al peligro del comunismo y a los factores anticomunistas que existían en Argentina:

el país cuenta con defensas directas contra el comunismo que (...) hacen a la esencia misma de nuestra condición de argentinos. En primer lugar la Iglesia cuya eficaz militancia frente al comunismo acaba de expresarse en las calles de Buenos Aires a través de ese frente al comunismo aca
magnífico Congreso. ${ }^{39}$

De igual manera que los hiciera AICA el presidente definió la identidad del ser argentino en tanto católico, y planteó la actividad del comunismo como un ataque al nosotros colectivo. Ahora nos referiremos a otras dos instituciones comprometidas en el programa de orden Cursos de la Cultura Católica y a Ciudad Católica. El primer punto de reunión y encuentro está dado por los Cursos, uno de sus fundadores y principal promotor fue Atilio Dell'Oro Maini; y Julio Meinvielle uno de los docentes más destacados. Ellos y otros miembros de los Cursos, como Mario Amadeo, desempeñaron actividades y puestos relevantes, tanto en el orden educativo y académico, como político y profesional. De la actividad de este mismo grupo, surgieron varias publicaciones. Los cursos se convirtieron en el Instituto Argentino de Cultura Católica, nexo y paso de los Cursos a la nueva Universidad Católica Argentina, a la que en 1958 y recién fundada se incorporó el mencionado instituto.

37 AICA, 10 de febrero de 1961

$38 \mathrm{Cfr}$. CONGRESO MARIANO INTERAMERICANO: $1^{\circ}$ Sesiones de estudio sobre el comunismo, Buenos Aires, 1960

39 Arturo FRONDIZI: "Factores anticomunistas en la Argentina", en Mensajes presidenciales (19581962), Vol. 4, CEN, Buenos Aires, 1978, pp. 37 
Un núcleo importante de los actores intervinientes en el espacio anterior se unieron a los ejercicios espirituales ignacianos, promovidos por los retiros de la Congregación de los Padres Cooperadores Parroquiales de Cristo Rey. De su versión francesa Cooperateurs Paroissiaux du Christ-Roi surgió Cité Catholique, fundada por Jean Ousset, y ampliamente difundida el padre George Grasset. En 1958 Grasset llegó a Argentina, y se vinculó al coronel Guevara, ambos fundaron Ciudad Católica en Argentina. La misma se pensó como un organismo promotor de un renacimiento católico en el orden de las instituciones sociales y políticas. Al ser un organismo distinto de las asociaciones de la Acción Católica, pudo promover una acción sin comprometer a la iglesia. La Ciudad Católica quiso ser una central cívica de ideas; con un objetivo inmediato formar una élite para la organización de una red de círculos de estudio.

Simultáneamente las experiencias francesas en Indochina (1946-1954) y en Argelia (1954-1962) dieron como resultado los postulados de las FF.AA. francesas sobre la guerra moderna, una teoría contrarrevolucionaria con un enfoque ideológico y global del fenómeno de la insurgencia. Entre 1954 y 1958 más de 150 oficiales del Ejército argentino se adoctrinaron en la guerra moderna en la Escuela Superior de Guerra de Francia, y desde 1958 también lo hicieron en Argelia. A partir de 1957 la Escuela Superior de Guerra de Argentina (ESGA) contó con una misión permanente de asesores franceses. En tanto que se estrecharon los contactos con la Organización del Ejército Secreto y con su referente teológico, el padre Grasset, capellán del Ejército francés en Argelia.

Tras un breve período de consubstanciación con los planteos de la guerra moderna las FF.AA. argentinas incorporaron de forma institucional la doctrina de la guerra antisubversiva, que se volcó en los reglamentos aplicados en dicha guerra. $4^{\circ} \mathrm{Al}$ mismo tiempo los militares argentinos asumieron un papel difusor de aquella teoría, como lo demuestra la celebración, en Buenos Aires, del Curso Interamericano de Guerra Contrarrevolucionaria, entre octubre y diciembre de 1961, en la ESGA.

El Curso Interamericano fue el primero de su tipo en realizarse dentro del continente americano, contó con la asistencia de jefes militares de distintos países de América. Destinado a capacitar en aspectos de la guerra revolucionaria, en el planeamiento, conducción y ejecución de la contrarrevolución. El programa abarcó el estudio de la filosofía marxista; los métodos de penetración en la sociedad; técnicas para prevenir y combatir el comunismo. Para el dictado de las clases se contó con personalidades civiles, militares y eclesiásticas.

Paralelamente se produjo un crecimiento exponencial de la literatura de seguimiento y persecución con los casos de infiltración marxista. Particularmente activo en este inciso se mostró el Círculo Militar, mediante la publicación de títulos como Guerra revolucionaria comunista del coronel Osiris Villegas para poner al alcance del oficial los principios y técnicas de "una lucha de esencia ideológica, aplicados a la Subversión". ${ }^{11}$ El director de publicaciones, coronel Abraham Granillo Fernández, pretendió mejorar la capacitación de las FF.AA ante: "la entrada en escena de la guerra subversiva desatada por el comunismo". ${ }^{42}$ Militares, en activo y retirados, colaboraron y prologaron obras de otras empresas editoriales. El teniente coronel Alberto Garasino prologó La apuesta del Desorden (1971) del General André Beaufre el coronel Orencio Cesar Anaya, colaboró en Guerra Revolucionaria y comunismo (1961) de Alan Yotuel, donde sobresale el temor a la pérdida de la propia identidad. Señalando el poder del "arma ideológica marxista-leninista (...) orientada a la captación mental de los habitantes después de borrarles su adhesión a las concepciones tradicionales y trascendentes". ${ }^{3}$

40 Por ejemplo: RC-9-1 Operaciones contra elementos subversivos (Proyecto). RE-9-51 Instrucción de Lucha contra elementos subversivos. RE-10-51 Instrucción para operaciones de seguridad. RC-16-1 Inteligencia táctica.

41 Osiris VILLEGAS: Guerra Revolucionaria Comunista, Buenos Aires, Círculo Militar, 1962, p. 16.

42 Abraham GRANILLO FERNÁNDEZ: Biblioteca del Oficial. Bodas de oro 1916-1966, Buenos Aires, Círculo Militar, 1966, p. 16

43 Alan YOTUEL: Guerra revolucionaria y comunismo, Tomo III, Buenos Aires, La Mandrágora, 1961, p. 33.

\section{Cierre: colonización del Estado.}

Correlato de la ofensiva persecutoria fue la puesta a punto de una maquinaria de guerra estatal contrarrevolucionaria, que terminó por limitar las libertades individuales, instituyéndose en poder absoluto sobre las personas. A partir de la Revolución Libertadora la fuerza efectiva del Estado para controlar, seguir y reprimir se acrecienta. Las policías no bastan, se acude a las FF.AA., éstas organizan, reestructuran, y ponen en funcionamiento distintos organismos de Inteligencia, dictan cursos, conferencias, publican libros, etc. Principiando por la implantación del estado de sitio (11/11/58), seguido por la prohibición de las actividades comunistas (decreto 4.965/59), y las medidas represivas asociadas al Plan CONINTES. ${ }^{44}$ El arsenal legislativo aumentó con disposiciones tendientes a reprimir las actividades terroristas (ley 15.293/6o); se creó una comisión para investigar las actividades comunistas (decreto 12.681/60). La proyectada Ley de Defensa de la Democracia (1961), ilegalizaba toda acción contestataria, y penaba a quienes no denunciasen las acciones tipificadas en el articulado de la ley. La perspectiva del DICIO recibió una pátina de bronce, al convertirse en subversiva toda actividad "inspirada en doctrinas y directivas foráneas incompatibles con el tradicional estilo de vida de nuestro pueblo". 45 En el marco del Plan CONINTES la SIDE asumió la dirección y planificación en materia de seguridad. Fundamentado en la necesidad de robustecer los instrumentos legales ante "un peligroso avance de actividad comunista y de otros extremismos dirigido a destruir las bases de la sociedad argentina mediante la infiltración". ${ }^{6}$ Bajo la presidencia de Guido (1962-1963), la SIDE, fue reestructurada haciendo hincapié en contener el avance del comunismo como objetivo central y prioritario (decreto $4.500 / 63$ ).

En la embestida coordinada por distintos componentes de la clase dominante, se observa que en su raíz late una búsqueda cultural a la vez que su dimensionamiento en el plano político se hizo apelando a la infiltración comunista. Para estos sectores cualquier actividad contraria al orden establecido significó una cautelosa avanzada del marxismo. Con esto y otros argumentos quiso enmascarar su tendencia liquidacionista, expresado claramente en los términos de su discurso. En este sentido articularon una propuesta, para evitar el avance de las futuras generaciones por el camino de subvertir el orden.

La estrategia asumida por las fracciones dominantes aunó al empresariado católico de la oligarquía terrateniente, a las FF.AA. y a la iglesia. Donde la religión católica se instituyó en soldadora de los cabos de la tradición, como vía de acceso a la sociedad del orden.
44 El Plan CONINTES supuso el accionar conjunto de las fuerzas de seguridad y de las FF.AA. en tareas de represión, y colocar a los civiles bajo la órbita de la justicia militar. (Decreto 2.628/60)

45 Decreto $8.161 / 62$. 


\section{COMUNIDADES EN EL POST-SOCIALISMO:}

\section{EL NACIMIENTO DE UNA ECOALDEA HÚNGARA*}

Paula Escribano Castaño

Universidad Autónoma de Barcelona

\section{Introducción}

Durante los años de la República Popular de Hungría (1949-1989), el país estuvo bajo el mandato del Partido Comunista Húngaro. Este mandato supuso grandes reformas políticas y sociales que conllevaron cambios en la forma de vida rural y urbana de la sociedad.

La primera de ellas fue la planificación urbana. Sergio Fernández nos recuerda cómo desde los 50 se desarrollaron en los países satélite de la U.R.S.S una serie de reformas urbanísticas cuya finalidad era "el deseo de socializar el sistema de vida urbano". Entre otras medidas, se pusieron en marcha comedores, guarderías, baños y lavanderías colectivas, planificados con la finalidad de "liberar a la mujer del embrutecedor trabajo doméstico (...) consiguiendo una incorporación masiva de esta en el trabajo retribuido".

De la misma manera Cris Hann, nos habla sobre los procesos de colectivización forzados de las tierras: "In Hungary, after a decade of intermittent attempts, full collectivization was accomplished between 1959 and 1961" 2 y cómo éstos destruyeron la propiedad familiar de terrenos que según sus estudios, estaban íntimamente ligados a formas de producción y estructuración social.

A partir de 1980, siguiendo a Carmin y Fagan, tiene lugar en los países de Este de Europa un auge de los movimientos medioambientales. Éstos, denunciando el deterioro de la calidad del agua, el aire y la deforestación a gran escala sufrida bajo las políticas económicas de los partidos comunistas, actuaron como catalizadores de las protestas sociales, acelerando así el cambio político. ${ }^{3}$ En el caso de Hungría, la lucha contra la construcción de la presa Gabcikovo-Nagymaros en el río Danubio dio lugar a la formación del movimiento medioambiental Húngaro. ${ }^{4}$ Es entonces cuando se piensa en el potencial de la sociedad civil como elemento trasformador y en los movimientos medioambientales como estructuras que liderarían la transición manteniendo su carácter transparente y democrático. Con la caída del régimen las estructuras sociales y políticas sufren una adaptación progresiva a los modelos del Oeste de

* Quiero agradecer a los habitantes de la aldea de Gyürüfü su colaboración y hospitalidad durante mi trabajo de campo. También dar las gracias a Aurora González y José Luis Molina por su maestría y dedicación en el trabajo que engloba a esta comunicación, el trabajo fin de Máster en Antropología Social de la UAB.

1 Sergio FERNÁNDEZ: “La ciudad socialista y la ciudad sostenible”, Revista bibliográfica de geografia $y$ ciencias sociales vol. X 622 (2005), p.14.

Cris HANN: "From production to property: decollectivization and the family-land relationship in contemporary Hungary", Man, 28 ,(1993), pp. 299-320.

Joann CARMIN y Adam FAGAN: "Environmental mobilisation and organisations in post-socialist Europe and the former Soviet Union", Environmental Politics, 19 (2010), pp. 689-707.

4 Ibid. p.694.
Europa. Los mismos movimientos que lideraban la vanguardia del cambio, pasan a formar parte de estructuras mayores como ONG's u organizaciones gubernamentales, adoptando as una agenda común con el resto de Europa, y dejando de lado problemáticas más locales. ${ }^{5}$

En este mismo periodo de transición, Frances Pine centra sus estudios en la cuestión del género, en concreto muestra el cambio existente en el contenido de las conversaciones con mujeres entre los primeros años de los 90 y posteriormente. En este primer periodo, se centran en el lamento hacia la pérdida de amistades, libertad y posibilidades que la inserción en un sistema laboral les brindaba; para pasar a mediados de la década de los 90 a centrarse en el hogar, los cuidados y la alimentación, siendo esta cuanto más controlada, home made y local, de una mayor calidad. Así la autora tiene en cuenta los estudios que prevén una exclusión en aumento de la mujer de la sociedad civil y la ciudadanía en el este de Europa ${ }^{6}$ y lanza tres cuestiones que pueden ayudar a comprender este universo de significados: el cambio de sistema económico y su influencia en el día a día, un cambio en las esferas de lo privado-público y una oposición a la vez que un contagio en relación con las ideas provenientes del oeste de Europa ${ }^{7}$

Desde este contexto teórico de cambio social y político denominado por la academia post-socialismo y a raíz de los diferentes debates que surgen desde los analistas sociales a la hora de tratar de entender la realidad social, emerge la pregunta de si la construcción teórica del post-socialismo nos brinda un marco lo suficientemente sólido sobre el cual poder desarrollar teorías, y de ser así en qué nos ayuda a entender el nivel macro de acontecimientos la realidad micro de la aldea de Gyürüfü. Algunos debates en este nivel, pasan por la definición de post-socialismo, los posibles atributos de este conjunto geográfico-político social de naciones o grupos, y la denuncia de una diferencia de poder entre la visibilidad de producción académica entre Este y Oeste.

Si entendemos por sociedades socialistas lo que Katherine Verdery entiende, el socialismo (conocido también como comunismo) constituye un tipo de sociedad del siglo XX que comparte dos características principales: el dominio político de un partido revolucionario (normalmente el Comunista) y la extendida nacionalización de los medios de producción, lo que conlleva un predominio de la propiedad estatal y colectiva. Para la autora, la definición de sociedades socialistas:

Excludes societies governed by socialist or social-democratic parties in multi-party systems, such as the Scandinavian welfare states. It includes, among others, the Soviet Union, the East European countries, the People's Republic of China, Mongolia, North Korea, Vietnam, South Yemen, Cuba, Nicaragua, Ethiopia, and Mozambique. Socialist societies came into being with the 1917 Bolshevik Revolution and the establishment of the Soviet Union ${ }^{8}$

Tomando esto como referencia, entenderemos por sociedades post-socialistas, aquellas que han pasado por un periodo socialista, pero que actualmente ya no se encuentran en él. C. Hann ve como características de este conjunto de sociedades una transferencia descontextualizada de los modelos del Oeste de Europa al Este y una búsqueda de la resolución de los problemas

5 Ibid., p.69

6 Ibid., p.97

7 Frances PINE: "Retreat to the household? Gendered domains in postsocialist Poland", en Cris HANN (ed): Postsocialism: ideals, ideologies, and practices in Eurasia, London, Postsocialism. Routledge. 2002. La autora ha realizado durante más de 30 años trabajo de campo en las montañas Tatras, Polonia.

8 Katherine VERDERY. “Anthropology of Socialist Societies", International Encyclopedia of the Socia and Behavioral Sciences, ed. Neil Smelser and Paul B. Baltes. Amsterdam, Pergamon Press (2002) p.1. 
colectivos desde el Estado. ${ }^{9}$ Por su parte, Stenning pone el énfasis en unas características compartidas antes de la inmersión en el libre mercado, ya que las desprendidas de este último proceso en su opinión serían comunes a otras partes del mundo. ${ }^{10}$ Buzalka, destaca la porosidad entre rural-urbano, y una vinculación de lo que él llama post-peasant populism", con un catolicismo de fuerte presencia, al menos en la Polonia rural, donde realiza su trabajo de campo. ${ }^{12}$

En un espectro más amplio, nos hallamos con la dicotomía insider-outsider, o dicho en otras palabras, la lucha por el dominio de la verdad, entre estudiosos internos a los países post-socialistas, y externos a este. Este debate, conocido en la disciplina antropológica y reforzado desde los 80 con la aparición de las teorías post-colonialistas ${ }^{13}$, se traspasa al contexto de Europa del Este y el Oeste. Cris Hann, actual coordinador del Instituto Max Plank de Antropología social, en Alemania, y Michael Buchowski, profesor de Antropología en Polonia en el intercambio de artículos realizado en Anthropology of East Europe review. Buchowski denuncia la existencia de una jerarquía en la producción de conocimiento. Entre otras, cita una falta de atención a los trabajos y etnografías realizadas por investigadores locales. ${ }^{14}$ Pese al contraataque, Hann asume que "the voices of Westerners who write about CEE ${ }^{15}$ are louder than those of the local scholars". ${ }^{16} \mathrm{~A}$ este debate se suman trabajos actuales como el libro editado por L. Kürti y P. Skalník en 2009, Postsocialist Europe: Anthropological perspectives from home, que amplía la crítica sobre la jerarquía existente y denuncia a su vez la lengua Inglesa como única forma de "hacerse oír" en la academia.

Tratando así de aunar en la medida de lo posible el estecentrismo con la voz más local, pasamos a ver la realidad etnográfica de la aldea pará preguntarnos más adelante si el surgimiento de esta puede corresponder a factores derivados de una dinámica más global.

\section{Notas metodológicas}

Realicé trabajo de campo en la aldea de Gyürüfü, situada al sur-oeste de Hungría, en la región de Baranya de febrero a julio de 2012.

El idioma utilizado para la mayoría de conversaciones y entrevistas fue el inglés, tratando de incluir el mayor número de frases en húngaro con el paso de la estancia. Las técnicas empleadas para la recolección de datos fueron: observación participante, entrevistas, cuestionarios, recogida de materiales como artículos, documentales, libros... realizados por los propios miembros, así como la escritura de un diario de campo.

Lo que se expone a continuación, en un intento de síntesis, es el trabajo de análisis y clasificación, centrado en la creación de la aldea de Gyürüfü, debido al tema que nos ocupa en esta ocasión: su intersección en un momento histórico particular y las concepciones de sus fundadores como respuesta a una dinámica más global.

9 Cris HANN, et al.: "Introduction: Post-socialism as a topic of anthropological investigation", en ID. (ed): Postsocialism :ideals, ideologies, and practices in Eurasia, London ,Postsocialism. Routledge. 2002.

10 Alison STENNING: "Post-socialism and the changing geographies of the everyday in Poland", Transactions of the Institute of British Geographers, 30 (2005), pp. 113-127.

11 Según sus palabras, quedaría definido como "a type of modern populist political culture influenced by religion and based on rural social structures, ideologies and narratives", Juraj BUZALKA: "Europeanisation and post-peasant populism in Eastern Europe", Europe-Asia Studies, 60 (2008) p. 758.

12 Ibid., pp. 757-771.

3 Sharad CHARI y Katherine VERDERY: "Thinking between the posts: Postcolonialism, postsocialism, and ethnography after the Cold War", Comparative Studies in Society and History, 51 (2009), pp. 6-34. 14 Michael BUCHOWSKI: "Hierarchies of Knowledge in Central-Eastern European Anthropology", Anthropology of East Europe Review, 22 (2004), pp. 5-14

15 CEE se refiere a los países del centro y este de Europa.

16 Cris HANN: “Correspondence: Reply to Michał Buchowski”, Anthropology of East Europe Review, 23 (2005), pp. 194-197.

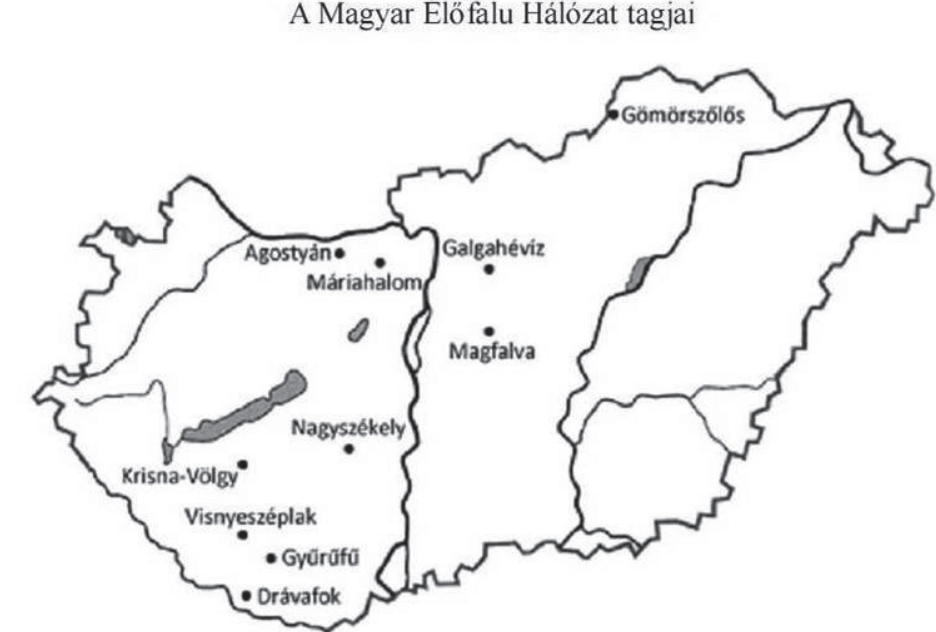

Map. 01 Distribución espacial de las ecoaldeas en Hungría. (Fuente: ELTE. Budapest)

\section{Los fundadores de la aldea y la adquisición de los terrenos}

B. Be. y K.I. son reconocidos y se auto-denominan como los ideólogos y fundadores del proyecto de ecoaldea de Gyürüfü. Se conocieron durante un encuentro internacional organizado por la Unión Europea llamado ecotopía en Hungría, en el verano de 1990. Así introducía B.Be. Su interés inicial por la idea:

It was the middle 8os, and I was an environmental activist, and I started to think why do the protest always against something, we need to do something positive, and as much as I thought about it, the idea of a settlement came to my mind, and I wanted to habit very far away from Budapest, so the city couldn't have any impact on there. ${ }^{17}$

En 1991 decidieron organizar un campamento de verano en la zona que ocupaba el antiguo pueblo de Gyürüfü, ${ }^{8}$ futura localización de la aldea. Tras este periodo cuatro fueron las familias pioneras que comenzaron el proyecto, los dos ideólogos: B.Be y K.I. y dos familias más: la de T.L y F.I. ${ }^{19}$

Si nos detenemos en el bagaje de los componentes de estas cuatro familias podemos resaltar el alto nivel educativo que habían recibido: tres de los cuatro hombres (del cuarto no tenemos referencias) cuentan con carreras universitarias (dos son ingenieros de telecomunicaciones, y el tercero licenciado en veterinaria y doctorado en Geografía. Otros ejemplos de este nivel educativo son el estudio de viabilidad física desarrollado sobre el área de Gyürüfü, los artículos científicos y de difusión publicados de mano de los propios integrantes, la participación en diversos congresos como la 5th Conferencia Internacional sobre Permacultura celebrada en Copenhague. Esto hizo que el proyecto, desde su primera concepción tomara un carácter técnico, desarrollando de manera detallada las bases medioambientales por las que

17 B,Be. Entrevista personal. Duración 50 min. Budapest. Abril 2012.

18 Gyürüfü fue un pueblo forzado al abandono en los años 70 durante la época de endurecimiento de las leyes de colectivización y la centralización del trabajo en los núcleos urbanos. El mantenimiento de las relaciones entre nuevos y antiguos pobladores de la aldea se da a través del cuidado del cementerio.

19 Nos referimos a familias y no a personas ya que es la manera como ellos refieren esta fase del proyecto, al igual que las iniciales que aparecen son del varón de cada familia de la misma manera. En algunas ocasiones en Hungria, la mujer sigue adoptando el apellido del marido al casarse, tomando así en la unidad familiar como referencia el apellido del hombre de la misma. 
se regía, y buscando teorías e investigaciones en las que apoyar su diseño. ${ }^{20}$

Sobre las causas por las que decidieron unirse al proyecto, podemos resaltar el repetido discurso de los participantes sobre la sensación del lugar donde se criaron: el ritmo, la prisa, el estrés, el tráfico....en contraposición a la vida en lbafa, y la proyección de lo que sería la vida en Gyürúfü: equilibrio, tiempo, vida al aire libre, tranquilidad, comunidad, conexión con la naturaleza...

Así F.I valoraba la vuelta a su ciudad natal: "Now, when I get back to my home town I am really feel I am a visitor there, and I can't wait came back here, so I feel I am at home here".21

Uno de los objetivos por los que iniciar el proyecto era la ruptura con la estructura de familia nuclear, contraponiendo un modelo de sociedad basado en la comunidad. "The principal aim is to build up a human scale community pattern which gives high priority to mutual co-operation, personal contacts and understanding without giving up individual freedom and dignity".22 La idea toma forma en 1990, primer año de transición política del país. Sobre esto B.Be destaca el estado de desorden y la incertidumbre sobre el futuro que se vivía.

Well, it was the first year after the political transition, we had a new government, we didn't really know what to do and how to move on, we didn't know about...anything about the new political system ... and we still very young inexperience ... and we had to think about the future in terms on our own lives, and everybody came up with the different solution ... and it was I. and me who ... had the more, most similar thinking about this issues. ${ }^{23}$

Antes de este periodo de cambio social y político, comentaban, la realización de un proyecto similar hubiera sido impensable. No sólo el establecimiento de la comunidad, incluso encontrar compañeros para tal propósito. El rígido control de las estructuras políticas del país no daba lugar a la asociación. En 1989 Hungría abrió sus fronteras ${ }^{24}$, pudiendo hospedar encuentros como el anteriormente nombrado Ecotopía, dejando unos años de cambio y "vacíos legales" en los que se enmarcan las gestiones administrativas de la compra de territorios y el desarrollo del plan maestro de la comunidad que es objeto de nuestro estudio. No existía entonces, en la opinión de Jhon Guyon, diseñador de permacultura invitado desde Gran Bretaña, ninguna aldea planificada en términos similares en el Este de Europa.

Is a very exciting project because this foundation has at his object the determination to create a 21st century village. It seems to be the first village of this kind in east in Europe, and I think, personally, that it's offers a real hope for the full environmental problems set on this part of the world. And for the first time, the people of Eastern Europe are setting out, by himself, without help. ${ }^{25}$

La división espacial del territorio, tenía como principales propietarios a las granjas comunales Los territorios que no habían sido colectivizados para su explotación pertenecían al estado

20 Un ejemplo de esta búsqueda es: B.Be: "Sustainable Rural Development", en Best practices of sustainable rural development in Hungary: Gömörszölöss, Gyürüfü, Boronka Region, Ormánság. Hungary, Lánchíd Kiadó Kft.,1998.

21 Extracto del documental Gyürüfü FUNDATION. Arrival of Settlers [Formato digital]. Ibafa, Hungary, $37,02 \mathrm{~min}(1993)$

22 B.Be: "Sustainable Rural Development...", p.21

23 B,Be: Entrevista personal biográfica. Duración 2h 1omin. Gyürüfü, Mayo 2012.

24 A partir de 1956 tras la revolución Húngara y especialmente después de 1968 con el llamado "comunismo gulash" Hungría llevó a cabo una política de apertura hacia Austria. Este hecho incidió en las políticas sociales. Al contrario que países vecinos dentro del Pacto de Varsovia, los húngaros, por ejemplo, podían salir 3 veces del país al año.

25 Gy $r$ f FUNDATION, Arrival of Settlers..., 1:26/ 1:59.
En el caso particular de Gyürüfü, las tierras que ocupaban el antiguo pueblo formaban parte de las cooperativas de consumo, las antiguas granjas comunitarias. El bosque que rodea la región (aproximadamente $1 / 3$ de la superficie), pertenecía y sigue perteneciendo a la organización forestal gubernamental, administrada desde su extensión local en lbafa. La organización estatal de cazadores también tenía derechos de uso sobre el territorio.

En el año 92 comienza el proceso de negociación para la compra de las tierras y se llega a un acuerdo con el presidente de la cooperativa de producción. En el año 93 pagan por ellas y el título de propiedad es transferido a nombre de La Fundación (forma legal sin ánimo de lucro que tomo la comunidad de Gyürüfü para gestionar los temas legislativos, en especial la propiedad de los territorios). En total 174 ha fueron adquiridas. Entre 1993 y 1994 cambia completamente la legislación sobre la tenencia de la tierra en el país y se prohíbe a fundaciones, 0 cualquier entidad legal la posesión de territorios (exceptuando al estado y gobiernos locales). Esta ley sigue vigente en la actualidad.

So we could buy as much land as we could pay for, between 92 and 93. The rest could not be bought by The Foundation (...) this is a very serious destruction on our project, and this was the reason why we had to buy land on our own money for the local municipality (...) because from the ecological point of view, the hold project was...can saved from 1000 a which is the local watershed design. ${ }^{26}$

En 1996 vuelve a cambiar la legislación. Las cooperativas de producción son disueltas y todos los territorios que abarcaban salen a la venta a bajos precios. Las 500 ha que formaban parte del territorio de Gyürüfü fueron adquiridas por externos a la comunidad antes de que los residentes de la aldea pudiesen comprarlas. La estrategia a seguir fue el intento de intercambio de territorios previa comprar de todas las tierras colindantes. Hasta el día de hoy se hallan en negociaciones (en el momento en el que realicé el trabajo de campo alrededor de $350 h a$ de las 500 pertenecían a Gyürüfü). En cuanto al terreno forestal, alrededor de 500 ha pertenecen al gobierno local, que lo alquila por periodos para su usufructo. La tala de árboles (bien básico para el funcionamiento de la aldea: construcción, calefacción, cocina...) es gestionado desde las organizaciones forestales en colaboración con el gobierno local. ${ }^{27}$

\section{Formación de la comunidad}

Como bien explica B.Be en el capítulo del libro Alternativas sostenibles dedicado a Gyürüfü, el objetivo del proyecto era claramente desarrollar e impulsar un asentamiento rura sostenible a pequeña escala basado en principios de diseño ecológicos. Expresado en otras palabras por F.l; era el deseo de encontrar una comunidad, un estilo de vida y un lugar para llevarlo a cabo. B.Bá., director adjunto del instituto de etnología de Budapest, desde una perspectiva externa al proyecto añadió durante la entrevista, que como objetivo principal los integrantes perseguían "vivir bajo unos principios ecológicos". ${ }^{28}$ No existió, continuaba diciendo, transmisión del conocimiento entre el antiguo pueblo de Gyürüfü y la nueva formación de la aldea, en medio hubo un vacío de 20 años de abandono del lugar. Su intención nunca fue rescatar la forma de vivir de hace 100 años, como hicieron sus vecinos en la comu-

26 B,Be: Entrevista personal biográfica...

27 Tras establecer la aldea, uno de los miembros de la fundación fue nombrado simbólicamente miembro del gobierno local, por lo que la gestión del bosque depende de manera indirecta también de las decisiones de la comunidad.

28 B.Bá, hermano de B.Be realizó las tareas de dirección y cámara durante el rodaje del documental

"Dreaming about a place" (1991). 
nidad de Visnyeszéplak, ${ }^{29}$ si no combinar los avances de la tecnología, con técnicas de agricultura, construcción y diseño ${ }^{30}$. Diseñaron el asentamiento en base a dos principios básicos: el bioregionalismo y la permacultura. ${ }^{31}$

El plan de viabilidad (en el que se estipulaba para 500 ha de altiplanos rodeados de otras 500 ha de bosque, la capacidad demográfica) era de 200 personas, unas 50-60 familias. Este plan fue desarrollado entre 1991 y 1995, año en el que quedó aprobado definitivamente el plan maestro o máster plan, una propuesta de usos y espacios sobre el área, herramienta legal para forzar a los habitantes de Gyürüfü a vivir bajo unos principios ecológicos.

Desde las primeras tentativas de la creación de la aldea, la autosuficiencia fue un objetivo constante. ${ }^{32}$ Se presuponía que los nuevos miembros que entraran a formar parte del proyecto, deberían de desarrollar ciertas habilidades (conocimiento de la flora y fauna, habilidades de construcción, reparación...) y poseer la capacidad para generar auto-empleo. Respecto a la agricultura, la proyección era fomentar un mercado de productos en el interior de la aldea, que pudiera facilitar a algunas familias no depender del trabajo en el exterior.

Como objetivo fundacional no existía como precepto de base una creencia religiosa o de otro tipo que marcara la identidad de la comunidad, más allá de lo que podamos abrir el término de creencia y entender la manera de conceptualizar el medio ambiente, el ecologismo y la permacultura como estilo de vida o filosofía común. En cuanto a las grandes religiones, pensaban que debían pertenecer a la esfera privada de cada persona.

\section{Organización social durante la formación de la comunidad.}

Desde el año 93 hasta el 97 (año en el que comenzaron a funcionar las casas privadas), el estilo de vida que se llevó entre los miembros del proyecto fue en común. Residían en Ibafa, y dedicaban su tiempo a labores conjuntas, como ampliar la línea eléctrica hasta el asentamiento o la construcción de una casa comunitaria. Sobre esto B.Be comenta "Social life is very lively, but up to recently it was mostly concentrated on common work. Kaláka is the Hungarian word for the team working among friends and fellow-villagers, a term usually applied to construction projects, but also to gardening bush, cleaning or other activities". 33 Paralelamente a las tareas más físicas estaban la gestión de los permisos, la compra de las tierras y el desarrollo del master plan. La toma de decisiones se realizaba a través del consenso entre los integrantes del proyecto.

El número de participantes fue variando durante estos cinco años. De las personas que residian en la aldea en el momento de la realización del trabajo de campo, tres varones y una mujer estuvieron desde el principio del proyecto. De los datos extraídos de vídeos y entrevistas, el volumen de población rondó durante los primeros años entre los ocho y los veinte participantes, sin contar con voluntarios o ayudantes esporádicos que pasaban un tiempo bien en

29 La aldea de Visnyeszéplak es una comunidad católica de unos 200 habitantes que se encuentra 50 $\mathrm{km}$ al norte de Gyürüfü. La formación de esta comunidad surge del mismo grupo de discusión sobre temas medioambientales de la universidad técnica de Budapest del que surge nuestra aldea. 30 B.Bá. Entrevista personal Abril. 2012

31 La permacultura, tal y como aparece definida por el diseñador John Guyon “(...) stands for a permanent agriculture or permanent culture. The term was called by the man Bill Morrison, a Tasmanian some years ago. In essence it takes as a philosophy. The fact nature is very much complex and shuttle that we can really understand, ans is more efficient doing its job. An effort in design any system; we should in fact mimic nature. Use nature as a template for the design (...) "El bioregionalismo por su parte, pone el énfasis en buscar entre los recursos naturales dentro de la zona para sacarles el mayor partido (B.Be., 2009).

32 Entendemos por autosuficiencia o autoabastecimiento para este caso en concreto, una forma de vida centrada en la comunidad, en la que productores y consumidores sean las mismas personas, y dependan lo menos posible de productos o servicios externos.

33 B.Be, “Sustainable Rural Development...", p.27.
Ibafa, bien en Gyürüfü para dar apoyo a la consolidación del proyecto con su trabajo.

En cuanto a la organización interna, a través del análisis de documentos podemos descubrir la existencia de una división sexuada en el trabajo y el reparto de tareas, existente desde un primer momento en la aldea de Gyürüfü. Si nos centramos en el documental The arrival of the settlers podemos identificar la división inicial de roles de género. El documento muestra las relaciones sociales en el interior de la comunidad, conflictos, abandonos, y la imagen que de ellos se generó en el pueblo en el que comenzaron la creación de la aldea, Ibafa.

De las 26 escenas en las que se ha dividido el documento, en 5 de ellas aparecen mujeres. Con la excepción de un caso desconocido, tres de las cuatro retratadas ${ }^{34}$ formaban parte de la comunidad, y estaban casadas o emparejadas con otro miembro de la misma. Se puede ver que en el proceso de elaboración del documental, realizado por hombres, no se tiene en cuenta la aparición de las mujeres, más allá de su rol en la familia. De esta manera, tanto las personas entrevistadas, como voces políticas y voluntarios del proyecto son enteramente miembros masculinos.

En cuanto a las mujeres que están representadas, cabe resaltar que en tres de las cinco escenas están acompañadas por un varón. En dos de los casos este varón es su pareja (en el tercero se desconoce). F.A nos habla sobre el sentimiento de maternidad, la crianza, la familia y su marido, acompañada de imágenes en las que tiende la ropa al aire libre. P.M., pareja de K.I., habla sobre su vinculación al proyecto y su vida en pareja. R.A., esposa de B.Be., aparece junto a él sosteniendo un bebe en brazos:

-B.Be: You been grow up in a city and some say you are a typical (fluty pity woman), and now you been living in Ibafa since April. How do you feel?

-R.A: (...) I am unexpected well here, and of course this is parallel because in the mean time (...) we became a family but I am (..) enjoy the environment here, the feeling to be so close to the changes on nature, and I had a strong feeling this is especially important for woman. 35

De esta manera la imagen que este documento, entre otros, exporta del papel de la mujer en la comunidad es el de madre, pareja y trabajadora del hogar.

Sobre la organización económica y financiación del proyecto, en 1993 se crea la primera compañía limitada Gyürüfü Mühely Ltd, cuya actividad dependía principalmente de trabajos relacionados con sistemas informáticos. En 1995 otra compañía surge: Dióliget Bt. (No tenemos la información sobre su actividad). Como debates sobre la mesa, estaban el futuro autosuficiente de la comunidad, la capacidad de crear un sistema alternativo económico como trueque o intercambio, eco-bancos la financiación inicial fue la suma de los capitales individuales de los pioneros y primeros adheridos al proyecto.

En la actualidad la aldea cuenta con 15 núcleos residenciales, de los cuales 14 están habitados. 9 de estos 14 núcleos se encuentran habitados de forma permanente, dos están en proceso de construcción y 3 actúan como segundas residencias. En total habitan 11 varones, 8 mujeres, con 17 descendientes, de los cuales 10 viven en la aldea.

Respecto a la organización social y económica, la aldea no es autosuficiente, aunque cuenta con producción propia de lácteos de vaca y oveja, frutas y verduras y jabón. En 7 de los 9 núcleos habitados parte del dinero se obtiene por trabajos remunerados realizados en el exterior (pueblos o ciudades cercanas).

34 Una de ellas sale dos veces, de ahí las cinco escenas.

35 Gyürüfü FUNDATION: Dreaming about a place..., 15-25/16-05. 


\section{Conclusiones}

A partir de esta breve incursión en la historia de la formación de la aldea de Gyürüfü, hemos tratado de resaltar cuales han sido los factores determinantes que han hecho posible el nacimiento de esta nueva comunidad. Sobre lo escrito cabe resumir algunas características:

- La presencia de organismos internacionales como la U.E y la realización de Ecotopía en los primeros años de la transición, así como la vinculación con personas afines al movimiento ecológico provenientes del oeste de Europa.

- La vinculación de los miembros pioneros de la aldea con el activismo medioambiental.

- Los altos niveles de educación existentes en los comienzos del proyecto.

- El ideal del estilo de vida buscado: rechazo al ritmo de las ciudades y al modelo de familia nuclear, necesidad de asociación y construcción de lazos comunitarios, idealización de la vida en el campo.

- Se produce una ventana de oportunidad durante la transición que posibilita la compra de terrenos y la formación de la aldea dentro de los marcos legales.

- La aportación de un capital individual para los gastos derivados de la creación de la comunidad.

- A parte de estas características centradas en el nacimiento de la aldea, destacamos dos más de especial importancia para la comprensión del fenómeno:

- La existencia de una división sexual del trabajo.

- La creación de dos entidades legales cuyo fin era el mantenimiento económico de la aldea. De todas estas características, el movimiento medioambiental húngaro aparece con un rol determinante, como canalizador de nuevas formas de pensamiento y opositor al régimen existente, pero más allá como lugar de encuentro social donde poder desarrollar nuevos proyectos y alianzas. Este movimiento medioambental, como bien comentaban Carmin y Fagan, ${ }^{36}$ tras la caída del régimen tomó dos caminos diferenciados: su adhesión a la política pública, o su marginalización dentro del conjunto social. Nuestro caso parece encontrarse ante esta segunda opción, dado lo vanguardista del movimiento dentro del país, la financiación privada e inexistente ayuda pública prestada para la iniciativa y el carácter opositor e independiente (podríamos decir incluso desconfiado) ante la transición política y social que estaba teniendo lugar. Sobre esto cabe comentar que en la situación actual, este movimiento tiende a unirse a dinámicas globales de mercado, como es la petición de subvenciones para su continuo desarrollo, o el ofrecimiento de productos y servicios ante un mercado con creciente interés en lo ecológico.

Respecto a las motivaciones para la formación de la comunidad, queda patente la influencia que el cambio de régimen tuvo en el movimiento, así como la creencia en una sociedad o estilo de vida mejor basada en ideas provenientes del Oeste de Europa, como las presentadas en el encuentro de Ecotopía. Ejemplo de esto es la existencia previa de un movimiento ecoaldeano a nivel mundial, en el que la ecoaldea de Gyürüfü se integraría durante sus primeros años de vida.

Para poder comprender si los rasgos aquí enumerados corresponden a atributos más genéricos de este contexto postsocialista, no solo necesitaríamos un estudio más en profundidad de cada uno de estos rasgos, si no quizá un estudio camparativo sobre otros fenómenos similares en el entorno. A pesar de esto, es posible apreciar una dependencia del estado en cuanto al seguimiento estricto de normas y plazos administrativos, la búsqueda de una justificación científica al proyecto y más adelante en el tiempo el uso de las ayudas sociales y búsqueda de intervención estatal en los mecanismos para la resolución de conflictos. ${ }^{37}$ Parece así que lejos de querer

36 Joann CARMIN y Adam FAGAN: "Environmental mobilisation and organisations in post-socialist Europe and the former Soviet Union...", pp. 691,692.

77 Para más información se puede consultar el trabajo fin de Máster de la UAB "Utopías en el post-so37 Para más información se puede consultar el
cialismo: El caso de una eco-aldea húngara". una transformación segregada de la sociedad, lo que se buscó con este proyecto fue un ejemplo a seguir para la población, y una alternativa dentro del contexto socio-político existente. 


\section{DOS EJEMPLOS DE GESTIÓN COMUNITARIA DEL AGUA}

\section{(EN ESPAÑA E ITALIA EN SIGLO XX)}

Francesco D'Amaro*

Universitat de València

Las instituciones de riego son una forma peculiar de abastecimiento del agua para la producción agrícola. Generalmente, se representan como unos organismos de gestión comunitaria aunque a menudo el poder de decisión caiga en un grupo muy restringido de personas. De esta manera, el control de ese recurso ambiental deja algunas perplejidades. En primer lugar, sobre los sistemas de participación de los usuarios: ¿ pueden estos considerarse miembros de una comunidad? En segudo lugar sobre las relaciones internas: ¿en qué manera se desarrolla y soluciona el conflito? Finalmente, sobre la construcción de una comunidad de regantes: ¿cuáles son los elementos de identificación ya existentes y cuáles los que están elaborados por los administradores?

Para contestar a esta pregunta analizaremos la historia de dos agrupaciones de usuarios en el siglo XX: la Comunidad de Regantes "Acequia Real del Júcar" (Valencia-Comunidad Valenciana) y el "Consorzio Idro-Agricolo" di Bagheria (Palermo-Regione Sicilia), las cuales resultan tan diferentes entre ellas que nos permitirán dos acercamientos y dos análisis incomparables en muchos aspectos. Las dos están atadas al éxito de la citricultura de sus territorios (en Valencia también del arroz) y están caracterizadas por un alto grado de conflictividad y de relación con el entorno político local. Hay que recordar que ser miembro de una institución de riego tiene ventajas económicas evidentes, ya que esto permite el cultivo intensivo de la tierra, es decir una producción más rentable y en parcelas más pequeñas. A pesar del diferente desarrollo y éxito la historia de estas instituciones nos puede ayudar a aclarar la manera de interpretar la participación en una comunidad cuando entran en el juego factores económicos considerados vitales.

\section{Formación y contexto}

a búsqueda, la captación y la canalización de las aguas tienen costes muy altos que a veces han obligado a los individuos a compartir gastos y beneficios a través de una institución. La cooperación ha ayudado a obtener resultados imposibles de alcanzar individualmente.' Sin embargo las condiciones existentes, la leyes, las culturas locales, así como el medio ambiente, han producido sistemas de distribución muy diferentes entre ellos, a pesar de compartir un espacio y unos cultivos parecidos. En el siglo XIX, en la mayoría de los territorios mediterráneos de Francia, de España y de Italia del norte, el abastecimiento hídrico para usos agrícolas Ilega

* Becario del Departamento de Historia Contemporánea de la Universidad de Valencia: francesco. damaro@uv.es. Este trabajo se enmarca en el Proyecto de Investigación HAR2011-27392, financiado por la Dirección General de Investigación Científica y Técnica (Ministerio de Economía y Competitividad).

1 Thierry RUF: "Dynamismes comparés et contrastes des sociétés paysannes méditerranéennes et de leurs territoires hydrauliques" en Bernard A. WOLFER (ed): Agricultures et paysanneries du monde. Mondes en mouvement, politiques en transition, Versailles, Q Quae, 2010. de canales de derivación de los ríos. ${ }^{2}$ En Valencia, generalmente, son los mismos usuarios que se ocupan de la construcción, manutención y de la distribución de las aguas de esos canales. No son sujetos aislados sino miembros de una entidad colectiva. El derecho al uso del agua está ligado a la tierra, que la mayoría posee. Ya que, hasta el siglo XVIII, la administración de agua coincide con el término municipal, los ayuntamientos están interesados en financiar la obras de riegos. Cuando los habitantes de las ciudades empiezan a comprar las tierras, el poder sobre el control de los canales pasa de las administraciones locales a los organismos autónomos de usuarios. ${ }^{3}$ Este fenómeno es aún más evidente en las instituciones que abarcan más de un término municipal como en el caso de la Acequia Real del Júcar. Esa entidad nace en el siglo XIII por una concesión real y, entre los siglos XVIII y XIX, por iniciativa de un terrateniente, empiezan las obras de prolongación del canal. ${ }^{4}$ Estás provocan muchos pleitos y la destrucción del nuevo canal por parte de los viejos usuarios. ${ }^{5}$ Terminada la prolongación, los usuarios de la nueva sección del canal tienen una concesión subordinada a la de la primera sección. La presencia de una jerarquía de derechos de uso convierte la Acequia Real en una institución dividida en su interno, por lo menos hasta la mitad el siglo XX.

Del siglo XX es la otra entidad examinada en este trabajo que nace para acompañar el cultivo de cítricos, entonces la principal economía de la costa siciliana. La citricultura se desarrolla gracias al aprovechamiento de las aguas subterráneas de forma privada. Sin embargo, la gran demanda y la gestión privada crean un mercado del agua, plagado de injusticias y violencia. ${ }^{6}$ Si en la Italia septentrional, las asociaciones de riego son ya bastante comunes, en Sicilia la gestión colectiva es casi inexistente. ${ }^{7}$ En el 1924, algunos agricultores de Bagheria y Santa Flavia (al este de Palermo) constituyen un consorcio voluntario de distribución de las aguas proveniente de un embalse recién construido. ${ }^{8}$ Los fundadores provienen de ambientes muy diferentes entre ellos mas la mayoría son pequeños propietarios locales. El objetivo principal es el mantenimiento de un precio bajo y accesible a todos los agricultores, y esto implica la modificación del equilibrio social basado en el dominio privado de los recursos hídricos. ${ }^{9}$

El sentido de una institución de riego depende también de la presencia de otras fuentes. En el valenciano, las acequias eran los sujetos colectivos que protagonizaban las relaciones en el territorio que riegan con las aguas de la misma cuenca. La división en comunidades fortalece la unidad interna ya que los miembros de las demás comunidades cercanas y de los usuarios no agrícolas se perciben como enemigos. Por ejemplo, en el 1851, el conflicto entre Sueca y

2 Rafaele PARETO: Irrigazione e bonificazione dei terreni. Trattato dell'impiego delle acque in agricoltura, Milano, Stabilimento Saldini, 1855, p. 454.

3 Salvador CALATAYUD: "Cambios institucionales en el regadío valenciano, 1830-1866", Ayer, 69 (2008), pp. 225-228.

4 Copia del consejo general del Traste (30/09/1954), Archivo de la Acequia Real del Júcar (desde ahora AArj), L. 291 n. 3. Juan ROMERO, Tomás PERIS y Rafael PELLICER: "Regadíos y estructuras de poder en e Regadios y estructuras de poder, Alicante, Instituto de cultura "Juan Gil-Albert", 1994.

5 Copia del documento sobre la destrucción tumultuaria por los vecinos ed Algemesi (25/02/1955) AArj, L. 291 n. 3.

6 Costantino CALDO: “Mafie e tecniche irrigue in Sicilia", en ÍD. (ed.): La città globale, Palermo, Palumbo, 1984, pp. 143-155; Salvatore LUPO: II giardino degli aranci. II mondo degli agrumi nella storia del Mezzogiorno, Venezia, Marsilio,199o.

Atti della giunta per la inchiesta agraria e sulle condizioni della classe agricola (inchiesta Jacini), vol. XIII, Roma 1884-5, Inchiesta Damiani, tomo I, fasc. I, pp. 164-5

8 Giuseppe BARONE: Mezzogiorno e modernizzazione. Elettricità, irrigazione e bonifica nell'Italia contemporanea, Torino, Einaudi, 1986

9 "Atto costitutivo rilasciato dall'archivio notarile e presentato alla commissione straordinaria" (1924, copia de 1964) Archivo del Consorzio Idro-Agricolo di Bagheria (desde a costitutivi e decreto. 
Cullera, por la cesión forzada de parte del caudal, provoca duras oposiciones que llevan a la intervención de las fuerza militares. ${ }^{10}$ Desde la segunda mitad del siglo XIX, el incremento de las necesidades hídricas empuja hacia una reglamentación de los caudales. Las diferentes comunidades se enfrentan para evitar nuevos conflictos que nacen por la definición controvertida de la concesiones. Además, sobre todo en siglo XX, el Estado plantea un política hidráulica para razionalizar los beneficios y el uso de los recursos públicas. Otros usuarios, por ejemplo las hidroeléctricas, las ciudades y otros agricultores, compiten para obtener las aguas del río. Como respuesta, la Acequia Real impugna sus derechos de uso reconocidos por ley." Para los que no son miembro de la Comunidad, el agua es un bien privado de los regantes.

El caso del Consorzio idro-agricolo di Bagheria es opuesto, ya que la entidad colectiva en este caso representa la nueva forma de gestión. Los viejos proveedores privados, que han contribuido al desarrollo económico local, perciben la entrada de este organismo como una competencia de gran alcance y luchan para oponerse a su desarrollo. Los administradores de Consorzio, en cambio, consiguen que las aguas del gran embalse recién construido lleguen a Bagheria, se ocupan de ejecutar las obras de canalización y presentan su trabajo como una revolución social más que económica. ${ }^{2}$ La diferencia con el viejo sistema no está en el aumento de la cantidad de agua, sin duda muy importante, sino en la gestión asamblearia, es decir, en la unión de los propietarios que se reconocen como usuarios con derecho a recibir los recursos disponibles en el territorio. 13 Sin embargo, esta "revolución" choca con algunos problemas técnicos que surgen a lo largo de las décadas siguientes. Pero también con un contexto en el cual la presencia de la fenomenología mafiosa y el conflicto político local limitan la creación de una verdadera comunidad..$^{14}$

Hay que señalar que, en el valenciano, la tradición comunitaria se refleja también en las asociaciones de propietarios que se forman para la instalación de máquinas de bombeo. ${ }^{5}$ Las nuevas técnicas de captación hídrica se atan al sistema organizativo ya presente. En cambio, en el palermitano, no existen formas consolidadas de gestión colectiva y por varias décadas el mercado del agua es la forma de distribución aceptada. Para encontrar la primera sociedad de agricultores para la captación de agua de pozo se tiene que esperar al principio de los años sesenta. ${ }^{16}$ Podriamos decir entonces, que en un caso se confirman los criterios de redistribución de los recursos comunes en los miembros de un grupo. En el otro, los recursos se compran y esto permite la entrada de otros usuarios ajenos al Consorzio.

10 Salvador CALATAYUD: “Cambios institucionales en el regadío valenciano...”, p. 248.

11 Las directrices de una nueva politica hidráulica y los riegos de nueva politica hidráulica Levante, Asamblea celebrada en Alicante el 26 de febrero de 1933, Madrid ,1933; "Junta general ordinaria [Fenacore]" (07/05/1958), AArj, L. 305 n.1; Nicolás ORTEGA: "La política hidráulica de española hasta 1936", en Ramon GARRABOU y Jose Manuel NAREDO (eds.): El agua hos los sis perspectiva histoica, Madid, Jundaión Aigentaria, 1999, p. 160 .

12 Carta al prefecto (22/12/1930), ACiab, L. Rosalia Parisi di Torrebruna; Francesco D'AMARO: “II controllo delle acque irrigue. La fondazione del Consorzio idroagricolo di Bagheria (anni venti del XX sec.)", I frutti di Demetra, 22 (2010), pp. 5-19.

13 Informe de la reunión de los agricultores contra el Consorzio por el precio del agua (1928), ACiab, L. Decreti Prefettura.

14 Salvatore LUPO: Storia della mafia dalle origini ai giorni nostri, Roma, Donzelli, 2004

15 Luis, Rafael, Antonio e Francisco MORENO: Solicitud a la Acequia Real (3/07/1928), AArj, L. 306 n. 2 , Instancias pendientes; Salvador CALATAYUD: "Los inicios de la mecanización en el regadio valenciano, 1850-1930", Areas, 12 (1990), p. 210.

16 Carmelo SCHIFANI: “Aspetti economici dell'irrigazione in provincia di Palermo", en C. SCHIFANI, G. CHIRONI Y A. BACARELLA: Utilizzazione e costi dell'acqua per irrigazione in Sicilia, Istituto di economia e politica agraria dell'Università di Palermo, 1969, p. 45

\section{La gestión colectiva de un recurso ambienta}

Las actas, las ordenanzas y los pleitos guardados en los archivos no registran todas las interacciones, pero abren una ventana en la complejidad de las relaciones. Le gestión de las aguas supone una continua negociación entre los administradores y los usuarios de las instituciones. Éstas no son colectividad en la cual el interés común está por encima de los individuales ${ }^{17}$. Las comunidades de regantes son más bien asociaciones que necesitan de un sistema de reglas y sanciones para solucionar los conflictos. El vinculo económico sigue siendo el más importante. Ferdinand Tönnies afirmaba que la cohesión es el punto de salida de cualquier agrupación y no el objetivo. Según Zygmunt Bauman, en la realidad, hay que crear una unidad, producirla artificialmente, contrastar las alternativas identitárias. El acuerdo, más bien un contrato renovable, no es natural..$^{18}$ Como argumenta la premio nobel Elinor Ostrom, las instituciones implantan un sistema de reglas claras que orientan la distribución y la manutención, y evitan o solucionan los conflictos. ${ }^{19}$ Sin embargo, aunque fijen reglas más o menos estrictas, éstas pueden volverse obsoletas muy rápidamente y las entidades tienen que adecuarse a los cambios.

Procesos de inclusión y exclusión en la gran acequia del Júcar

Las normas de distribución no son inmóviles e iguales para todos, sino que se establecen cada año según la cantidad de agua disponible. ${ }^{20}$ Esta flexibilidad es esencial cuando los caudales no son fijos, y dependen de varios factores, entre los cuales los otros tipos de usuarios y las condiciones climáticas. La Acequia Real del Júcar se dota de unas ordenanzas desde el principio de sus actividades pero tiene que renovarlas periódicamente, según las evoluciones de la misma institución y las nuevas exigencias. Las ordenanzas del 1845 , por ejemplo, consideran como parte de la Comunidad también los pueblos involucrados en el prolongamiento del canal. ${ }^{21}$ Estas reglas establecen los órganos administrativos y su relación con los usuarios y describen un sistema de sanciones muy elaborado.

La acequias del Júcar son un emblema de la gestión comunitaria. No obstante, el mito de una democracia hídrica mediterránea, contrapuesto al despotismo oriental, va reevaluado. ${ }^{22}$ Sólo una parte de los regantes miembros de la Acequia Real, o sea los grandes terratenientes, pueden participar a la elección de la administración. Este sistema excluye la gran mayoría de los miembros de la Comunidad y todos aquellos que, si bien riegan, no son propietarios de la tierra. Además, aunque tengan el control de los canales secundarios, tampoco las oligarquías locales entran en la Junta, que es una "superestructura al margen de su capacidad de influencia». ${ }^{23}$ Además, la

17 Si usaramos las categorías teorizadas por Tönnies, en una Comunidad el parentesco, la religión o una creencia compartida crean una lealtad individual hacia el grupo, por lo cual no hay reglas o una creencia compartida crean una lealtad individual hacia el grupo, por lo cual no hay reglas estrictas y un control socia
University Press , 2001.

18 Zygmunt BAUMAN: Comunidad: en busca de seguridad en un mundo hostil, Madrid, Siglo XXI de España, 2003.

19 Elinor OSTROM: Governing the commons. The evolution of institutions for collective action, Cambridge University, 1990; Samuel GARRIDO: "Las instituciones de riego en la España del este. Una reflexión a la luz de la obra de Elinor Ostrom", Historia agraria, 53, 2011, pp. 13-42.

20 Se vea como ejemplo "Apendice al Padrón de regantes de Guadasuar con derecho al riego con aguas sobrantes" (1930), AArj, L. 241, n. 1.

21 "Ordenanzas para el gobierno y directión de la Acequia y uso de sus aguas" (1845), AArj, L. 189 n. 15 22 Arthur MAASS y Raymond L. ANDERSON:... and the desert shall rejoice: conflict, growth and justice in arid environments, Cambridge, The Mit Press, 1978; K.A. WITTFOGEL: Le dispotisme oriental, Paris, Les Éditions de Minuit, 1964 .

23 Salvador CALATAYUD: “La gestión del regadío: cambio institucional en la época contemporánea”, en Jorge HERMOSILLA (ed.): Las Riberas del Xúquer: paisajes y patrimonio valencianos, Valencia, 2006, pp. 60-61. 
presencia de una gestión colectiva y de un sistema de reglas y sanciones no debe pensarse como ausencia de conflictividad. Las tensiones se desencadenan a varios niveles - entre los comuneros, entre éstos y la administración de la entidad, entre las instituciones lindantes y entre éstas y los aparatos públicos o los otros usuarios de las aguas - sobre todo durante las crisis hídricas que ponen a prueba los equilibrios sociales. Los enfrentamientos entre dos o más términos municipales de la Comunidad, sobre todo en el siglo XIX, son los más duros y duraderos. ${ }^{24}$ Aún en los años veinte y cuarenta del siglo XX, los usuarios se sublevan por el miedo a que el cambio de cultivo, por el arroz, sea una amenaza de un mayor consumo de agua. 25

De todas formas, todos los usuarios de la Comunidad son 'regantes', propietarios con derecho al uso de las aguas: son los propietarios de todo el patrimonio hidráulico ${ }^{26} \mathrm{y}$ de todas las aguas que derivan del canal principal. Para obtener este derecho, pagan una cuota según la superficie y los cultivos que quieren regar. Se convierten, así, en los usuarios exclusivos de un bien ambiental de difícil exclusión. A pesar de establecer los derechos de uso, los abusos son continuos: los mismos usuarios implantan nuevos cultivos o máquinas de extracción en zonas prohibidas, aprovechan del agua fuera de turno, etc. Pero los que preocupan las administraciones de las comunidades son los riegos clandestinos. La lógica de inclusión y exclusión se complica cuando un elemento externo usurpa las aguas de la Acequia. ${ }^{27}$ ¿Cómo impedir que agricultores que no pertenecen a la comunidad se aprovechen de las aguas de la Acequia? ¿Con qué derecho se les puede sancionar?

Las identidades comunitarias son el producto secundario de una incompleta y continua, como a veces cruel, definición de fronteras. ${ }^{28}$ Todos los que tienen la propiedad fuera del perímetro con derecho, aunque usen las aguas del canal, quedan al margen. Por todo los siglos XIX y XX, los casos de riego clandestino están difundidos y bien documentados. ${ }^{29}$ La misma institución recurre a las autoridades estatales. Muchos ejemplos enseñan la dimensión de un fenómeno difícil de controlar para la administración de la Acequia Real del Júcar: pozos cercanos, robos de agua, plantaciones abusivas, motores de bombeo no autorizados, varias formas de daños a los canales..$^{\circ} \mathrm{El}$ control de los aparatos hidráulicos y de los cultivos, para salvaguardar los usuarios de un sequía, es obsesivo, y puede provocar la sospecha de los mismo usuarios, como el caso del gran arrocero que en los años veinte acusa a la administración de aprovechar de su cargo para sus fines económicos.3

Los campesinos intentan usar todas las aguas posibles para incrementar la producción. Empujan la administración central a legalizar periódicamente los nuevos regadíos. De esta forma, la superficie con derecho a las aguas de la Acequia Real del Júcar pasa de los 13 mil y medio hectáreas de la mitad del siglo XIX a más de 20 mil en la Posguerra. ${ }^{32}$ El relativo aumento de

24 Jurado de Guadasuar a la Junta de Gobierno (4/08/1915), p. 12, AArj, L. 236 n. 5, Copia de los expedientes 54 de 1881 y 34 de 1916; Rafael TASSO: Algunos datos sobre la historia, descripción y actuación de la Acequia real del Júcar, Valencia, Genovés, 1945, p. 17.

25 "Informe de la Junta de gobierno al segundo escrito de Señor Escribá de Romani" (4/11/1925), pp. $41-42$, AArj, L. 236 n. 5. Documentos referentes al espediente sobre acotamiento para cultivo de arroz; V. AArj, EX. 54-1944.

26 "Antecedentes referentes a las norias de Santa Barbar y San Antonio" (s.a), AArj, L. 232 n. 4, Masalavés 1884; v. AArj, Ex. 41-1938.

27 José BARBERÁ FALCÓ: Falcó Informe del Abogado (20/08/1902), AArj, L. 236 n. 5, Documentos referentes al espediente sobre acotamiento para cultivo de arroz.

28 Zygmunt BAUMAN, Comunidad..., p. 17.

29 Libro de pleitos (1866-1897), AArj, L. 207 n.

30 Abusos (1918-1940), AArj, L. 282 n. 4.

31 Rafael ESCRIBÁ DE ROMANÍ: Carta al Sub-secretario del Ministerio del fomento (10/07/1925), p. 13, AAri, L. 236 n. 5, Documentos referentes al espediente sobre acotamiento para cultivo de arroz.

32 "Las aguas del Júcar circulan de nuevo por la Acequia Real", Las Provincias, 11/02/1941; Salvador CA- los miembros de la Comunidad ocurre por la presencia de elementos externos que no tienen derecho fijo al uso de las aguas y que pueden regar ocasionalmente mediante el pago de una cuota. Sólo quienes riegan de hecho durante muchos años adquieren el derecho de uso. Así se convierten en nuevos miembros de la Comunidad. ${ }^{33}$

\section{Participación y conflicto en el consorcio siciliano}

El Consorzio Idro-Agricolo di Bagheria, nacido en los años veinte, se convierte (lentamente) en una entidad con derecho y deber a la mejoría del territorio, como la construcción de las carreteras. ${ }^{34}$ Su tarea más importante consiste en la construcción y manutención de la red hidráulica ya que las infraestructuras no pueden ser gestionadas por un agricultor. La guía de una organización centralizada que permita juntar los recursos hacia un objetivo colectivo parece necesaria, y esta función recae sobre las cooperativas de agricultores y el mismo Consorzio. Sin embargo, esta última institución no puede operar en la indiferencia de los agricultores, tiene que buscar el consenso y su participación concreta.

El statuto del Consorzio contempla esta idea, ya que es aparentemente más democrático que el de la Acequia. El texto, que sale de la primera asamblea en el 1924, dota a cada uno de los miembros de la institución de un voto por cabeza para la elección del Consejo de Administración. Sin embargo, después de dos años, viene modificado en favor de los grandes propietarios, ya que el voto se asigna según el agua concedida. ${ }^{35}$ Las elecciones, aparte de ser una cuestión política, se convierten entonces en un sistema de demarcación social. La oligarquía local puede dominar - con método mafioso según los opositores - la institución más importante de la ciudad, después del ayuntamiento. El debate sobre el cambio del sistema electoral, considerado injusto, es una constante de toda la historia política del Consorzio. ${ }^{36}$ No obstante casi todos los miembros de la entidad tienen derecho a participar en la Asamblea y a votar. Pero ¿quiénes son estos supuestos miembros de la comunidad?

Todos los propietarios de tierra que se encuentren dentro del perímetro del Consorzio están obligados a asociarse, por un decreto del Prefecto de Palermo. ${ }^{37}$ Tienen derecho a un cauda proporcionado a la superficie poseída y pueden comprar las aguas que necesiten. Si hay aguas sobrantes, también algunos elementos externos pueden abastecerse del Consorzio, que se convierte así en otro proveedor del mercado del agua de Bagheria. El recurso hídrico era tan importante para la economía local que, en la segunda Posguerra, la continua solicitud de cambiar el statuto y el sistema de voto ${ }^{38}$ se acompaña al debate sobre el ensanchamiento del perimetro del Consorzio - que efectivamente se verifica - para bajar el precio de las aguas 39

El Consorzio se convierte en un teatro político, reflejando las dinámicas y las figuras ya

LATAYUD y Enric MATEU: "El uso del agua en el cultivo del arroz en el país valenciano (siglo XIX)", en GARRABOU y NAREDO (eds.): El agua en los sistemas agrarios, cit., pp. 255-274

33 Consulta del abogado sobre riegos clandestino (9/03/1904) e Informe sobre el riego clandestino Consulta del abogado sobre riegos clandest
(11/01/1929), AArj, L. 232 n. 4, Masalavés 1884.

34 Declarado Consorzio di Miglioramento Fondiario, por el art. 114 del R.D. 13/02/1933, n. 215; Approvazione dello statuto da parte dell'Assessore dell'Agricoltura e delle Foreste (s.a.), ACiab, L. Pratica relativa alla approvazione del Nuovo Statuto approvato dal'Assemea Cena) ACl' L Pranana dell'11-4-1954.

35 Copia del Statuto enviado al Commissario Prefettizio (31/01/1926), ACiab, L. Statuti vecchi 1926 36 Modificas al Statuto (14/03/1942), ACiab, L. Altre deliberazioni.

37 Decreto Regio para confirmar la inscripción obligatoria (1927), ACiab, L. Atti costitutivi e decreto.

38 Carta del Commissario Prefettizio al Prefetto (6/10/1952), ACiab. L. Elezioni consiglio di amministrazione 1953; Acta asamblea extraordinaria (15/10/1967), ACiab; “Deliberazioni su elezione de presidente e del vicepresidente" (28/11/1975), ACiab; Vincenzo DRAGO: "Inchiesta in un paese dove fioriscono i limoni: acqua, mafia e lotta tra le classi a Bagheria", Inchiesta, 8 (1972), pp. 7-21.

39 Carta de justificación a la intendenza di Finanza, (8/02/1943), ACiab, L. Varie. 
presentes en el ayuntamiento y, más en general, la dialéctica nacional de lucha entre el PCl y la DC. Las asociaciones y los partidos animan las Asambleas, que por lo general son ignoradas por los mismos miembros de la institución. Uno de los administradores describe el Consorzio como un «organismo cansado, que con fatiga se ha arrastrado en el tiempo, desconocido de centenares y centanares de miembros, desconocidos entre ellos. Una administración parasitaria, quizás no sea verdad, pero ésta era la percepción de la mayoría».40

\section{Vínculos intra y extracomunitarios}

Las dos instituciones han actuado como catalizadores de recursos públicos y como líder de las agrupaciones de regantes. El Consorzio de Bagheria, entre los años cuarenta y cincuenta se involucra en las actividades de un centro de coordinación de las aguas de riego en el territorio de Palermo. ${ }^{41}$ Lidera las operaciones de estudios para la racionalización de las aguas, y por eso obtiene financiaciones estatales. No obstante, el tentativo de unión fracasa pocos años después, en la indiferencia general. ${ }^{42}$ Además, las continuas crisis hídricas y la deuda perpetua que sufre la entidad la presentan a los ojos de los agricultores como un polo de especulación sobre el uso del agua. ${ }^{43}$ En consecuencia, los miembros del Consorzio se perciben más bien como usuarios o clientes, que como miembros de una comunidad. La adhesión a otro tipo de agrupaciones, como movimientos, partidos, cooperativas, sigue teniendo una mayor importancia que limita el potencial del Consorzio como instrumento de organización comunitaria.

En la Acequia Real de la primera mitad del siglo XX, varios cambios de las ordenanzas fortalecen el poder de la administración central. ${ }^{44}$ Además, en los años cuarenta, la Comunidad logra adquirir la segunda sección del canal. Como consecuencia no sólo se acaba un «condominio molesto" que provoca continuas instancias, 45 sino que por fin la Comunidad se vuelve simbólicamente "una". Percibirse come parte de una comunidad única y compacta es útil para empujar la solidaridad en los momentos de crisis. Durante las sequías de la Posguerra la administración dirige aún más las operaciones de riego, aclarando en un Edicto las reglas para los embalses y los cultivos. Del otro lado, intenta decidir con los regantes las medidas «razonables, ya que en caso contrario podrían ser rechazadas", de manera que las normas sean compartidas y no impuestas. ${ }^{46}$ La Comunidad, por razones morales y económicas, pone de lado los derechos de las diferentes secciones y los usuarios consienten ceder parte de los caudales. ${ }^{47}$

Pasando la dura prueba de la "pertinaz sequía" con este acercamiento al problema, la Ace-

40 Acta de la asamblea general ordinaria (29/05/1966), ACiab

41 "Nomina dei commissari dei sei comprensori di raggruppamento dei consorzi irrigui dell'agro pa"Nomina dei commissari dei sei comprensori di ragg (10/07/1946), ACiab, L. Decreti Prefettura.

42 Giuseppe SPECIALE: Peppino Speciale. Giornalista, politico, storico, Palermo, Comune di Bagheria, 2006, p. 157.

43 "Notificazione di decisione” (1964), ACiab, L. Domanda per rateazione; “Deliberazione su situazione acqua irrigua” (3/05/1969), ACiab; “Deliberazioni su ripianamento situazione economica consortile" (2/06/1975), ACiab.

44 "Ordenanzas para el regimen y gobierno de la comunidad de regantes de la Acequia real del Júcar" (6/o7/1930), AArj, L. 236 n. 5, Ordenanzas. V. AArj, Ex. 884-1946.

45 "Proyecto del plan a seguir para la absorcion por la Acequia Real de la Svarj" (1944), AArj, L. $219 \mathrm{n}$. 6; Rafael TASSO: Crónica del VII Centanario de la Acequia Real del Júcar y del I Congreso Nacional de Comunidades de Regantes, Valencia, (s.n.), 1972, p. 475

46 AArj, Ex. 54-1944; “El grave problema de la sequía”, Levante, 2/05/1944; “Los regantes de la Acequia Real del Júcar se reunieron ayer en Valencia", Las Provincias, 2/05/1944; "La gran sequía del año actual en la cuenca del río Júcar, Las Provincias, 10/og/1944.

47 Según los tradicionales ordenes de antiguedad, diferentes para las dos secciones, la prolongación de la Acequia de Alcira venía después de la primera sección y de las acequia de Escalona y Carcagente. Ex. 54-1944, AArj. quia Real fortalece su papel con las demás acequias del Júcar. ${ }^{48}$ Se presenta como una entidad eficaz y potente, imprescindible para el sistema económico de aquellos años. De hecho, al gunos experimentos de uníon liderados por la Acequia Real del Júcar tienen salida a nivel de cuenca, para la construcción de obras hidráulicas en la Posguerra. ${ }^{49}$ La Acequia, además, empuja el resto de comunidades de regantes de España a crear un sistema federativo nacional, para la defensa de los intereses comunes..$^{50}$ Estos grupos, que fuesen de cuenca o no, más que gestionar los asuntos de control y distribución de las aguas, funcionan como lobbies aprovechando el capital simbólico sedimentado durante los siglos..$^{51}$ Guían el debate en la prensa e intentan orientar la política hidráulica nacional. La identidad de "regante", frente a la de ciudadano o de agricultor, funciona como un dispositivo de cohesión más fuerte que el de miembro de una comunidad de regantes especifica. ${ }^{52}$ Para incentivar esta identidad, como para anclar al pasado los propios privilegios, se alimenta el mito de la participación corporativa en las tradicionales instituciones de riego y su éxito, no sólo delante de los regantes, sino también de la opinión pública. La Acequia Real celebra su VII centenario, designa un santo patrono, un día anual de fiesta y un escudo de la Comunidad, para crear una historia compartida y vincular cada regante a los demás. ${ }^{53}$ ¿Hay que considerar la construcción de la identidad comunitaria como un instrumento para lubricar el funcionamiento técnico y político de la institución? ¿La existencia de una comunidad de regantes a nivel extra local puede establecer el éxito o el fracaso de la institución misma?

48 Rafael TASSO: Crónica del VII Centanario..., p. 22

49 "Suplica para la constitución de la Mancomunidad Hidrográfica del Júcar" (2/02/1932), Aarj, L. 232 n. 4, Masalavés 1884; VIRIATO: “El Pantano de Alarcon. Es la primera obra hidraulica importante que se construye en España sin que cueste un centimo al Estado. La construyen los regantes de Jucar", Almanaque las Provincias, 1943, p. 87; "La Acequia Real del Júcar", Levante, 1/07/1957, p. 7; Rafael TASSO: Algunos datos sobre la historia..., p. 28; USUJ: Algunos datos referentes a la regulación del rio Júcary al proyectado pantano de Contreras, Valencia, Tipografia Moderna, 1952; Joan F. MATEU: La primera Confederación hidrográfica del Júcar (1934-1942), Valencia, CHJ, 2010, p. 57

50 "Copia borrador estudio de la proyectada reforma de las Confederaciones Hidrográficas" (15/06/1953), AArj, L. 291 n. 3; "Informe sobre la anulacion de las ordenes ministeriales que autorizan y ratifican la constitución de la Fenacore" (8/09/1959), AArj, L. 305 n. 1; Florentino-Augustín DIÉZ: La España del regadío y sus instituciones básicas, Madrid, Fenacore, 1992.

51 Luis SANCHEZ: En defensa de la Acequia Real del Júcar, Madrid, Artes Graficas, 1934; “Los regantes españoles al Ministerio de obras públicas (3/071953), AArj, L. 291 n. 3. V.

52 Carles SANCHIS y Garikoitz GÓMEZ: "La ciudad contra la huerta. El conflicto del agua potable en Valencia (1926-1928)", Cuadernos de Geografía, 91/92 (2012), p. 14

53 AArj, Ex. 2584-1955; "En conmemoracion del VII Centenario de su fundación" (21/05/1964), AArj, L. 284 n. 2, Fallo conjunto de los Concursos por la Comunidad de Regantes de la Acequia Real de (1964), AArj, L. 291 n. 3. 


\section{UNA COMUNIDAD IMAGINADA: CORRESPONDENCIA ENTRE LOS EXILIADOS ESPAÑOLES Y LOS OUE SE QUEDARON EN ESPAÑA. 1952-1975}

Rosy Ricket

The University of Manchester

En los primeros días de 1965, María Tarragona, una refugiada española que vivía en la Ciudad de México, mandó una carta y un giro postal a Mercedes Vall de Conill, que vivía en Barcelona. La Señora Tarragona quería dar apoyo a los que tenían parientes en la cárcel y que no tenían suficientes recursos para vivir. Las cartas y dinero enviados desde México a España formaron parte del trabajo del Comité de Apoyo al Pueblo Español, dirigido por el poeta León Felipe y María Tarragona.' En el Ateneo Español de México (AEM) hay cartas enviadas desde todas partes de España a María Tarragona, fechadas a partir de 1964, y unas listas de nombres y direcciones de los que vivían en España, así como otros detalles. Como escribió Mercedes Vall de Conill, los españoles le agradecieron el apoyo y la amistad de la Señora Tarragona: "Tu acción de recordar a mi hijo Jorge en esas fiestas tengo que considerar que eres una buena amiga, pues en la lejanía, recuerdas los que quedan aquí privados de libertad". ${ }^{2}$ Además, hicieron mención muchas veces al sentimiento de solidaridad que inspiró la correspondencia desde lejos, y describieron los ideales comunes que compartieron la gente de las dos orillas del Atlántico, sobre todo los de libertad y democracia. ${ }^{3}$

Una de las consecuencias de la Guerra Civil española y el exilio republicano fue la separación larga, y a veces permanente, de familias y amigos. Según una estimación a la baja, unos 160.000 refugiados españoles estuvieron fuera de España en 1940.4 Por supuesto, un gran número de los que cruzaron la frontera tenían familiares y amigos que se quedaron en España por varias razones. Como señalan los historiadores que han trabajado sobre temas tan diversos como el desplazamiento de poblaciones en la península de Istria o las comunidades transatlánticas del siglo XVIII, se debe abordar y evaluar lo que significan las migraciones no forzadas y forzadas tomando en cuenta tanto aquellos que se quedaron como aquellos que se fueron. ${ }^{5}$

Véase también Belén SANTOS, Magdalena ORDÓÑEZ y Enriqueta TÚÑON: “Tres Fuentes Para EI Estudio Del Exilio Español En México", Migraciones y Exilios, 8 (2007), p. 102.

2 Carta de Mercedes Vall de Conill (Barcelona) a María Tarragona (Ciudad de México) (17 de enero de 1965), Fondo Histórico del Ateneo Español de México (AEM), Organizaciones Políticas: Comité de Apoyo al Pueblo Español, Caja 42, Exp. 400.12.

3 Véase, por ejemplo: Carta de Enrique Mateos Ferrari (Madrid) a María Tarragona (Ciudad de México) (30 de enero 1970), AEM, Caja 42, Exp. 401.12 y Carta de Encarnación Ventura (Valencia) a María Tarragona (Ciudad de México) (22 de enero 1970), AEM, Caja 42, Exp. 401.5.

La cifra exacta es todavía controvertida, véase el resumen de Dolores PLA BRUGAT: "El Exilio Republicano Español", Aula-Historia Social, 13 (Abril, 2004), pp. 14-34.

5 Sobre la peninsula de Istria véase, Pamela BALLINGER: History in Exile: Memory and Identity at the y sobre las comunidades

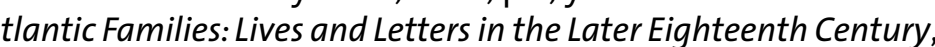
Oxford University Press, USA, 2009, p. 28.
Generalmente, se puede afirmar que la historia de los refugiados o exiliados, también migrantes, desestabiliza la concepción que tenemos de la historia de las naciones como delimitadas geográficamente, como señala Amy Kaminsky: "es implícito en ser un exiliado [la] noción dad nacional, aunque no estén dentro de las fronteras de su país. Por eso, la verdadera historia de un país debe incluir un capítulo sobre los paisanos que ya no viven en el país. De la misma manera, un grupo de refugiados que oficialmente han perdido sus pasaportes, es decir sus nacionalidades, podrían tener mucho en común con los que aún viven en la patria y todavía conservan su documentación. De lo cual se podría deducir que estar fuera de una patria no debe significar que no eres de la patria, y viceversa; así existen y existían otras formas de ser español o española. También podemos sugerir que existan o hayan existido varias "naciones" con la misma apelación; una colección de las comunidades "imaginadas" de Benedict Anderson.7

En los últimos años, de alguna manera como reacción a la economía verdaderamente mundial y la importancia creciente de las "comunidades" y la comunicación por Internet, historiadores e investigadores de diferentes ámbitos se han quedado fascinados por el concepto del transnacionalismo. Es un concepto disputado que ha sido utilizado para explicar y describir fenómenos distintos. ${ }^{8} \mathrm{~A}$ pesar de esto, evoca la importancia de perspectivas e historias alternativas y de las redes de personas en que se hacen borrosas las fronteras entre naciones, regiones y continentes. ${ }^{9}$ Como consecuencia, utilizaremos la palabra "transnacional" para hacer hincapié sobre la existencia de los hilos que unen la historia de distintos grupos de personas y países.

La comunicación epistolar representa uno de estos hilos, en los que se unieron la historia de los vencidos dentro y fuera de España. Como señalaron historiadores como Gemma Caballer y Queralt Solé en su artículo sobre correspondencia entre refugiados catalanes y los que se quedaron dentro de España, los epistolarios como fuente histórica no han sido utilizados suficientemente por los que escriben sobre el exilio español.10 También mantienen que "la bibliografía respecto [al exilio] es extensa pero [...] ha dejado [...] en sus análisis globales los sentimientos personales que hizo aflorar el exilio"." Hasta cierto punto se puede sostener esa descripción de la bibliografía aunque sea algo reduccionista. Sin embargo, destacamos el trabajo de Verónica Sierra Blas, quien publicó en 2009 una historia de los niños refugiados que se fueron a la Unión Soviética. ${ }^{12}$ La historia está basada en las cartas que los niños enviaron a sus padres, cartas que muchas veces nunca recibieron los padres como consecuencia de la censura del régimen de Franco. Ese trabajo presenta un análisis imprescindible del impacto del desplazamiento sobre los niños y sus vidas emocionales. También, nos ha dado una demostración poderosa de la importancia de las comunicaciones epistolares como fuente histórica.

Con respecto al uso de epistolarios para construir una historia más completa del exilio, hay que citar también los textos de otros investigadores. ${ }^{13}$ Por ejemplo, Jesús García Sánchez ha

6 Amy KAMINSKY: After Exile: Writing the Latin American Diaspora, London, University of Minnesota Press, 1999, p. xvii; véase también, Edward SAID: Reflections on Exile, London, Granta, 2001, p. 176.

Benedict ANDERSON: Imagined Communities, Reflections on the Origin and Spread of Nationalism, London, Verso, 2006.

8 Véase, por ejemplo, Patricia CLAVIN: “Defining Transnationalism”, Contemporary European History, 14, 4 (2005), pp. 421-439.

9 Gabriela OSSENBACH and María del MAR DEL POZO: "Postcolonial Models, Cultural Transfers and Transnational Perspectives in Latin America: a Research Agenda", Paedagogica Histórica: International Journal of the History of Education, 47:5 (2011), p. 581

10 Gemma CABALLER Y Queralt SOLE: "La Voluntad Del Retorno: Correspondencia Desde El Exilio Catalán", Bulletin of Spanish Studies, 89, $7 / 8$ (noviembre, 2012), p. 202

11 Ibid., p. 201.

12 Verónica SIERRA BLAS: Palabras huérfanas: Ios niños y la Guerra Civil, Madrid, Taurus, 2009

13 Jesús GARCíA SÁNCHEZ: “La correspondencia de los españoles en Francia (1936-1946)", en Josefina 
estudiado la correspondencia de los refugiados en Francia con sus parientes en España desde 1936 hasta 1946. Describió tanto el impacto de la censura militar del correo en las zonas republicanas y nacionalistas como la censura del correo en los campos de concentración Franceses y durante la ocupación Nazi en Francia. También explicó las dificultades muy comunes para localizar sellos, papel y sobres. Conjuntamente, podemos ver el artículo de Iker González-Allende sobre la exiliada vasca Pilar de Zubiaurre. González-Allende sugirió que las cartas enviadas desde México hasta España 'minan la concepción del aislamiento entre [los republicanos o liberales en] España y los españoles peregrinos en el exilio'. ${ }^{14}$

Así, esta ponencia va a desarrollar sus argumentos sobre las bases ya esgrimidas por estos investigadores. De la misma manera que Caballer y Solé, queremos ofrecer una visión de las emociones que "[se hicieron] aflorar el exilio", pero también queremos sugerir un significado más amplio para esas emociones y experiencias. Además, trataremos un periodo diferente de la mayoría de lo que ya ha sido escrito sobre la comunicación epistolar desde el exilio: nuestro enfoque es para los años $1952-1975$. En primer lugar, aparte de las citadas entrevistas, las fuentes que vamos a citar están fechadas a partir de 1952. Por otra parte, se podría decir que ese periodo representa una nueva etapa en el régimen de Franco: el fin (en 1950-1952) de la resistencia armada de los "maquis" y, hasta cierto punto, el comienzo de un periodo de desarrollo económico después de los años de hambre y "silencio". ${ }^{5}$ Por eso, nuestra base de fuentes presenta una visión de la gente que ya había vivido más de diez años de exilio y dictadura.

\section{Metodología}

Nuestra investigación se basa en cartas y telegramas escritos por particulares en España, Francia y México, guardados en archivos personales y estatales de España y México. Para evitar equívocos me gustaría señalar de forma preliminar que no estamos tratando con un grupo homogéneo o con un único tipo de reacción ante el exilio, sino de ciertos temas interesantes y recurrentes que se plantean en las cartas. Las personas que escribieron las cartas citadas tenían diferentes ideas políticas, caracteres y antecedentes sociales; además, experimentaron destinos muy distintos en los países en donde se encontraron. Así, ofrecemos una visión más parcial para animar a la investigación y la reflexión, entiendo esta ponencia más como un punto de partida que una conclusión final.

La ponencia se basa en cinco colecciones epistolares: el archivo personal de Rafael Heras (Fundación Largo Caballero, FLC, Madrid), los documentos del mencionado Comité de Apoyo al Pueblo Español (Ateneo Español de México, AEM, Ciudad de México), el archivo personal de la Señora Carmen Parga (AEM), el archivo de la familia Apocada Orive (Centro Documental de la Memoria Histórica, CDMH, Salamanca) y el archivo de Carlos Esplá Rizo (CDMH). Dado que nuestro enfoque es la comunicación epistolar, solamente vamos mencionar que se han leído también veinte entrevistas que forman parte de la colección de fuentes orales sobre e exilio en México, y dieciséis de los entrevistados y entrevistadas se hicieron mención importante de las cartas, paquetes y dinero que enviaron a España durante los años 1939-1975. ${ }^{16}$

CUESTA y Benito BERMEJO (eds.): Emigración y Exilio. Españoles en Francia, Madrid, Eudema, 1996, pp. 330-343; Iker GONZALEZ - ALLENDE: "Women's Exile and Transatlantic Epistolary Ties in the Work of Pilar de Zubiaurre," Hispania, 95, 2 (2012), pp. 211-226.

14 GONZALEZ - ALLENDE: “Women's Exile and Transatlantic Epistolary Ties...”, p. 212; Traducción desde el inglés original, los errores son los del autor.

15 Francisco MORENO GÓMEZ: “Huidos, Maquis y Guerrilla: Una Década de Rebeldía Contra La Dictadura." Ayer 43 (January 1, 2001), p. 136; y la expresión 'tiempo de silencio' viene de Michael RICHARDS: A Time of Silence: Civil War and the Culture of Repression in Franco's Spain, 1936-1945, Cambridge, Cambridge University Press, 1998.

16 Véase: CDMH, Copia de la colección de entrevistas del Archivo de la Palabra, El exilio español en
Además, he realizado doce entrevistas con exiliados y exiliadas y sus descendientes que viven en México, durante marzo- mayo de 2013, y todos me dijeron que mantenían contacto a través de cartas con su familia y amigos que se quedaron en España, por lo menos después del fin de la Segunda Guerra Mundial.

Cada grupo epistolar tiene un carácter diferente: las cartas de Rafael Heras o Carlos Esplá, por ejemplo, están guardados por razones más bien políticas, porque estos hombres jugaron papeles bastante importantes durante la Segunda República Española y, por lo menos en el caso de Esplá, en la política del exilio. ${ }^{17}$ El otro lado de la moneda es el archivo de la familia Apocada Orive, que no tenía "valor" para construir una historia política. Esta ponencia trata de todos los tipos de cartas porque queremos explorar la historia social del exilio y de la derrota. ${ }^{18}$ Es decir, no ofrecemos un análisis de la ideología o la política, sino de sus efectos sociales, de su impacto sobre la vida de la gente..$^{19}$

Primeramente, se han leído y transcrito todas las cartas. A veces, algunas palabras quedaron ilegibles, por eso trataremos de indicarlo cuando pueda existir alguna confusión de este tipo. Después de leer las cartas, se han identificado unos temas recurrentes. En cuanto al uso de cartas, hay que considerar algunas cuestiones de metodología. Investigadores como Michael Roper y Martha Hanna han subrayado que la comunicación epistolar representa un género particular de escritura, por eso debemos anticipar unos clichés. ${ }^{20}$ Las cartas sobre las que hemos basado esta ponencia comienzan y terminan con las salutaciones obligatorias, y los mensajes formulados a la familia y amigos mutuos. A pesar de eso, como señalaron los mismos investigadores mencionados, las cartas podrían demostrar cómo los corresponsales se relacionaron con su familia y amigos, el tipo de información que compartieron y la manera en la que exprimieron sus sentimientos y describieron los acontecimientos de sus vidas. Las cartas representan solamente un vista fugaz de sus escritores, sin embargo se puede hacer hincapié en el "análisis del "texto en el momento" y forzar conexiones con temas más amplios. ${ }^{21}$

El aspecto material de la carta es importante también. Del mismo modo que "las familias del Atlántico" que intercambiaron correspondencia desde Inglaterra y los Estados Unidos durante el siglo VXIII, los refugiados españoles utilizaron papel con borde negro para denotar duelo. ${ }^{22}$ Otras señales materiales como las estampillas en el sobre o el otro lado de las tarjetas

México, realizadas por el Instituto Nacional Antropología e Historia (México)

17 Por más información sobre el trabajo y la política de Carlos Esplá, véase, Pedro Luis ANGUSTO VÉLEZ: “El trabajo en la sombra de un Azañista confeso: Carlos Esplá” en Angeles León Egido y Matilde Eiroa San Francisco (eds.): Los grandes olvidados, Los republicanos de izquierda en el exilio Madrid, Centro de Investigación y Estudios Republicanos, 2004, pp. 411-433.

18 Una perspectiva también relacionada con el proyecto para escribir la historia de los exiliados que no pertenecían de la élite, véase: Dolores PLA BRUGAT: Els exiliats catalans: un estudio de la emigración republicana española en México. Colonia Roma, México DF: Instituto Nacional de Antropología e Historia, 1999, p. 15 y Pilar Domínguez Prats: Voces del Exilio: Mujeres Españolas en México (1939-1950), Madrid, 1994, pp. 5-21.

19 No pretendemos dar un análisis completo. Para ello habría que explorar todas las cartas guardadas en los archivos personales de la Fundación Pablo Iglesias, la Residencia de Estudiantes y el Archivo del Gobierno de la II República Española en el Exilio (etc.), sin mencionar quedarían aun los archivos en Cataluña y Francia.

20 Michael ROPER: The Secret Battle: Emotional Survival in the Great War, Manchester, Manchester University Press, 2009; Martha HANNA: 'A Republic of Letters: The Epistolary Tradition in France during World War l', The American Historical Review, Vol. 108, n. 5, 2003, pp. 1338-1361.

21 Véase Prue CHAMBERLAYNE, Joanna BORNAT y Tom WENGRAF (coords.): The Turn to Biographical Methods in Social Science: Comparative Issues and Examples: The Comparative Issues and Examples, Oxford, Routledge, 200o, p. 6.

22 Carta de Sra. Vinas a Rafael Heras, (6 de enero de 1948), Fundación Largo Caballero (FLC), Archivo personal de Rafael Heras, correspondencia privada, ARH-53-5. 
nos informan de la presencia de la censura del correo Franquista, en las cartas fechadas durante los años treinta o cuarenta. Según Jesús García Sánchez, solamente existió este tipo de censura del correo hasta el año 1946, fuera del periodo bajo consideración. ${ }^{23}$

Las cartas y telegramas fueron escritas a mano, con lápiz o tinta, o con una máquina de escribir, sobre papel de baja o alta calidad. A veces los sobres contuvieron fotos, dibujos y mensajes de múltiples miembros de la misma familia. ${ }^{24}$ Por eso, hay que darse cuenta que una misma carta, podría haber sido leída y escrita por mucha gente: "el uso de las cartas como espacios comunes de escritura no puede desligarse de su concepción como objetos de lectura compartida." ${ }^{25}$ Así que la gente analfabeta podía escuchar las noticias a través de sus relativos o amigos. Con respecto a la materialidad de la carta, tomamos en cuenta el tipo de papel, los sobres, la decoración, etc. De la misma manera, una carta escrita en caligrafía muy pequeña probablemente significó que él o la corresponsal, no tenía recursos para obtener mucho papel. Se puede suponer también que las cartas que se encuentran en archivos son las que tenían un significado especial para la gente que las recibió.

\section{¿Sobre qué temas hablaron los vencidos?}

De manera bastante breve, vamos a resumir unos temas recurrentes que se encuentran en las comunicaciones epistolares. Se destacan especialmente las cartas que están guardadas en los archivos, el hecho de que representan una reconstrucción de una línea de comunicación anteriormente cortada. Las narrativas cortas encontradas en las cartas son resúmenes de la vida del corresponsal desde el comienzo de una separación muchas veces muy larga. Por lo tanto, hacemos referencia a la correspondencia de un hombre que se fue a Rusia con una de las expediciones de niños, cuando tenía 11 años en $1937 .{ }^{26}$ En la Nochebuena de 1955 recibió una carta de su familia en España, y en su primer contestación escribió:

De mi vida hay mucho que escribir, y por lo tanto empezaré y poco a poco os describize [sic.] toda. Desde que salí de esa, tuve la gran suerte de caer en buenas manos, las cuales, se preocuparon mucho y me han hecho un bueno [sic.] hombre. Estudié durante 10 años sin preocuparme de quien me vestía ni me alimentaba por lo cual estoi [sic.] muy agradecido. Después de terminar el estudio empecé a trabajar y hoy día trabajando gano un buen sueldo para vivir bien junto con mi familia. En 1950 años, el 11 de Mayo me casé, el nombre de mi mujer, Nina. La suerte me compano [sic.] y el resultado es que es una buena mujer y madre de mi hijo. Nina es buena modista y se preocupa mucho por nosotros. Ella también os pide, así no tenéis nada en contra que toméis en nuestra familia como una hermana más. ${ }^{27}$

En 1954-55 José María Apocada Orive tenía veintiocho años. Había vivido casi toda su vida adulta fuera de España, así que las cartas siguientes están llenas de presentaciones a hermanos desconocidos y niños, solicitudes de más información fotografías y exclamaciones de sorpresa. Se destaca la alegría resultado de todas esas noticias e imágenes, sin embargo, la

23 Jésus GARCíA SÁNCHEZ: “La correspondencia de los españoles en Francia (1936-1946)...”, pp. 342-3 24 Por ejemplo, hay un fotografía de los nietos de la corresponsal adjuntado a la siguiente carta: Carta de María Márquez Cáliz (Talavera de la Reina) a María Tarragona (Ciudad de México) (mayo de 1971), AEM, Caja 42, Exp. 401.64.

25 Verónica SIERRA BLAS: Palabras huérfanas..., p. 265.

6 Para más información sobre cada expedición véase: Verónica SIERRA BLAS: Palabras huérfanas..., pp. 162-164.

27 Carta de José María Apocada Orive (URSS) a sus hermanos (España) (1955-6), Centro Documental de la Memoria Histórica (CDMH), Familia Apodaca Orive, 1914/2, 7 . distancia que separó esas familias había entristecido a la familia y a José María particularmente. Sus padres ya habían muerto en 1954 y parece probable que murieran después de su salida a la Unión Soviética, por eso pidió fotos de sus padres: "si tenéis fotos de amachu u de padre, mándame, porque es tan grande la desgracia de no conocerles, que muy amenudo [sic.] pensando sobre ellos [...] las lágrimas me saltan a los ojos." ${ }^{8}$ En el fondo, las cartas y fotografías compartidas representaron una forma de comunicación importante. De alguna manera esta correspondencia reestableció relaciones y permitió desarrollar otras. Se puede afirmar esa idea cuando se hace hincapié en el hecho de que las cartas están guardadas cuidadosamente por la familia y fueron donadas al archivo por el sobrino de José María en $2011^{29}$

Otro tema especialmente presente en la correspondencia es la manera en que los que se quedaron hablaron de los exiliados. En una carta enviada desde Madrid en 1960 a su amigo Carlos Esplá exiliado en México, Ramón Ariño Fuster, que era el diputado provincial de Madrid durante la Segunda República, describió su reacción frente a "los largos y penosos años de prisión":

Hoy mismo, reintegrado al hogar de los míos después de tanta amargura y triste soledad, de tanta injusticia y crueldad, de tanto olvido, mi pensamiento está con los ausentes por el delito de pensar que la libertad y la democracia es mejor y más conveniente que la tiranía, y también más elegante; por ello me permito encarecerle haga presente a todos los que sufren el dolor de la ausencia patria, el sentimiento de mi adhesión y de mi sentido afecto, sea cual fuere su particular forma de pensar..$^{30}$

Parece que los exiliados representan algo más que un grupo de amigos o correligionarios para Ramón Ariño Fuster, los que "sufren el dolor de la ausencia patria" son un ejemplo de la alternativa a los métodos e ideas de Franco - "cual fuere su particular forma de pensar", el hecho de que los ausentes piensen que la libertad es mejor que la tiranía es lo más importante en este momento de su vida.

Debemos que considerar, además, la posibilidad de que Ramon Ariño Fuster estaba escribiendo para una audiencia que no solo se reducía a Carlos Esplá dado que su carta está escrita en un estilo bastante literario, en lengua formal y a veces poética. Puede que redactara sus palabras para la posteridad - para un libro de cartas para documentar las vidas y tribulaciones de los Republicanos vencidos. Hay que tener en cuenta ese aspecto de la comunicación epistolar entre "elites", aunque desde luego nunca podremos enterarnos de las motivaciones de los corresponsales en el momento de escribir.

En cambio, las cartas que enviaron los españoles que recibieron apoyo desde el Comité de Apoyo al Pueblo Español en México se escriben de manera más informal y coloquial, y contienen descripciones muy interesantes de la vida cotidiana. Más de veinticinco personas diferentes, la mayoría mujeres cuyos maridos fueron encarcelados, contaron lo que era la vida desde la perspectiva de los vencidos. Hicieron hincapié sobre la falta de trabajo, la necesidad de viajar o emigrar para conseguirlo o su carencia de recursos financieros. Explicaron así cómo les

$28 \mathrm{lbid}, 1914 / 2,8$

29 Censo Guía de archivos de España y lberoamérica, recuperado del internet ' $h t t p: / / c e n s o a r c h i v o s$. mcu.es/CensoGuia/fondoDetail.htm?id=1529525'; Parece probable, también, que la correspondencia entre los familiares empezó como consecuencia del programa oficial Franquista de repatriación de “menores"(refugiados que fueron evacuados a la Unión Soviética en 1937) que empezó entre los años 1954-1955. Por eso, debido a la censura imperante en el momento era de suponer que José María nunca hubiese hecho mención de sus inclinaciones políticas ni su afiliación al parque Jose Maria nunca hubiese hecho mención de sus inclinaciones politicas ni su afiliación al par-
tido comunista soviético, hecho que sin embargo si aparece reflejado en el catálogo del archivo. 30 Carta de Ramon Ariño Fuster (Madrid) a Carlos Esplá (México) (25 de diciembre de 1960), CDMH Fondo Documental Carlos Esplá, Correspondencia personal, Caja 56, exp. 00117204 R. 
afectó la inflación de los precios de productos básicos y qué difícil era visitar a sus parientes en la cárcel, muchas veces situadas muy lejos de sus casas, en una época en que el transporte no era barato. Se pueden citar, por ejemplo, las siguientes palabras de la Señora Ayuso Delgado, en 1966:

Muy agradecida por tus atenciones y demás familiares, pues el dinero que mandas [...] faIla una hace para hacer frente a la vida, pues los artículos de comer, vestir y calzar están por las nubes y no digamos de las ventas de las viviendas eso raya ya en locura, pasa decirte que en una casa al lado de la mía los [inquilinos] pagaban 8oopts al mes y al marcharse los nuevos que han entrado pagan ahora 20oopts y sin hacer ningún arreglo. Con este botón de muestra te ibas dando cuenta lo que hay que batallar para poder [mal] vivir.31

Así, podemos enterarnos también de lo que significó para la Señora Ayuso Delgado recibir ese dinero desde México: ella podía sobrevivir. Otras cartas en esa colección nos demuestran también que los que recibían apoyo desde María Tarragona se sintieron más seguros como parte de un rede de personas que compartieron ideales y ayuda.

A través de cartas en los archivos personales vemos también unas pequeñas redes de gente que compartieron información sobre sus amigos y familiares comunes. En una carta que restableció el contacto entre dos miembros del movimiento cooperativo español en 1953, don Félix Zarza explicó cómo supo lo que le había pasado a su amigo Rafael Heras:

Tu carta del 17 me ha producido viva alegría y satisfacción grande: alegría al saber directamente que estás 'vivito y coleando'y satisfacción al comprobar que no te [olvidas] de este viejo amigo. / Yo tampoco te he olvidado y sabía por tu hermano, a quien pregunté por ti las dos veces que tuve ocasión de verle, que estabas bien. Como él no me conocía bien, seguramente no se daría cuenta del interés con que yo inquiría noticias tuyas. ${ }^{32}$

Las cartas también hacen referencia a los paraderos de otra gente, y preguntan por amigos perdidos: un corresponsal desconocido preguntó al mismo Rafael Heras sobre unos amigos comunes en 1953:

Si sabes el paradero de Mauri, haz el favor de facilitármelo, pues hace mucho tiempo que no ha contestado a mis escritos. De vez en cuando me veo con Arroyo, en sus viajes a ésta; por cierto que también está por contestarme. De los amigos de Madrid sólo sé de Freire, y del pobre Tutor, tuve oportunidad de hablarle telefónicamente dos días antes de fallecer. Parece que me dictó el corazón que aquella llamada sería la última ocasión de hablarle. ${ }^{33}$

\section{Conclusiones}

La ponencia ha tratado de mostrar que, a pesar de la distancia, algunas familias, amigos y correligionarios seguían en contacto e imaginaban una España alternativa a la de Franco. La comunicación epistolar nos presenta de manera gráfica el impacto del exilio sobre los propios refugiados y también sobre los que se quedaron en España. Mediante una exploración más profunda de ese tipo de fuente, podríamos construir una visión más completa de la manera en que "los vencidos" "los republicanos" o los que perdieron la guerra (por falta de una expresión más precisa o elegante) se adaptaron a las consecuencias de la guerra día tras día. Sobre todo las cartas, telegramas y transferencias de dinero entre los vencidos nos demuestran los lazos que conectaban esas personas. En el fondo, lo que tratamos de proponer es cómo los vencidos formaron una "comunidad imaginada", una comunidad que existía en el espacio entre países.

Además, podemos definir el acto de escribir una carta dentro de España para enviársela a un "rojo" que está viviendo fuera, como un acto de "la resistencia cotidiana", o un acto de "obediencia falsa", para citar al antropólogo James Scott. ${ }^{34}$ No podemos hacer una comparación entre este tipo de comunicación epistolar y la resistencia organizada contra la dictadura de Franco. Sin embargo, debemos señalar que la ortodoxia del régimen siguió describiendo los exiliados como seres humanos inferiores durante el periodo 1952-1975, a pesar del relajamiento de la censura del correo y la implementación de una serie de amnistías para los republicanos o los vencidos. Por eso, escribir este tipo de carta suponía el equivalente de una refutación a la imagen pintada por el régimen de los amigos y relaciones que estaban ausentes: no eran los enemigos de España, eran españoles. Dentro de esa comunidad coexistían gentes con una pluralidad de creencias e ideologías, tanto aquellos que vivieron dentro como fuera de la Península Ibérica.

32 Carta de Don Félix Zarza (Bilbao, España) a Rafael Heras (Burdeos, Francia), (23de julio de 1952), Fundación Largo Caballero (FLC), Archivo personal de Rafael Heras, Correspondencia con españoles cooperadores, $\mathrm{ARH}-53-5$.

33 Carta de [desconocido] (Valencia, España) a Rafael Heras (Burdeos, Francia), (5 de mayo de 1953), FLC, Correspondencia con españoles cooperadores, ARH-53-5.

34 James SCOTT: Weapons of the weak: everyday forms of peasant resistance, London, Yale University Press, 1986, p. xvi. 


\section{PENSAR LA NACIONALIZACIÓN CULTURAL, LA}

\section{COMUNIDAD Y LOS GRUPOS: ESTADO ACTUAL, FALTAS}

Y PROPUESTAS*

Pablo Giori

Universitat de Girona, España

\section{Teorías del nacionalismo, y una falta}

En las naciones establecidas, la gente olvida el rutinario ondear de la nacionalidad. Las banderas se funden con el fondo, ya que "nuestro" mundo particular es percibido como el mundo. ${ }^{3}$

Michael Bilig

Individualismo y nacionalismo, dos potentes herramientas del mundo moderno, y dos realidades que han hecho mundo. Como bien dijo Eduard Bernays, sobrino de Sigmund Freud, en el documental de Adam Curtis $\mathrm{El} \mathrm{Siglo} \mathrm{del} \mathrm{YO}^{4}$ : hemos sido creados como individuos que deben funcionar como máquinas de la felicidad, tenemos que dividirnos y consumir, así es más sencillo construir el consenso. No es azaroso que estos pensamientos daten, entre tío y sobrino, de la primera mitad del siglo XX, siglo de fascismos, masas, consumo y consenso, entre guerras, guerra y fría. Lo interesante de esta propuesta es que pone en relación la idea de individualidad, somos sujetos únicos, con el control macropolítico, eso que nos hemos ganado, "ser nosotros mismos", es una pérdida que nos vulnera sin que nos demos cuenta. Porque esa es la falacia del sujeto moderno, el sujeto no es en sí mismo ni por sí mismo, el sujeto es siempre intersubjetivo, nos hacemos en sociedad y la sociedad intenta hacernos a su imagen y semejanza. La aseveración de Descartes, cogito ergo sum, se olvida en su simpleza de algo fundamental, no pensamos cualquier cosa, pensamos lo que nuestra sociedad y la historia nos permiten pensar, no pienso libremente, soy presa de mis circunstancias. ${ }^{5}$ La pregunta nunca debería ser quién soy yo, sino quiénes somos nosotros.

Dicho esto, tenemos que entender que entre el sujeto y la sociedad hay una serie de intermediarios: los grupos, las comunidades y las naciones. Vamos a comenzar por los últimos, para luego reflexionar sobre los primeros. Partimos de la idea de que hay algo que la sociología no ha pensado, o ha dado por supuesto en su apriorismo nacional: pertenecemos a un grupo más amplio llamado nación y a una institución más general, el estado, en ocasiones en disputa. Dejaremos de lado los conflictos ${ }^{6}$ y nos centraremos aquí en la idea de nación como grupo, recuperando una serie de apuntes críticos sobre autores clásicos del pensamiento sobre el nacionalismo moderno desde una perspectiva micro: Anderson, Billig y Hobsbawm. Luego revisaremos una serie de nuevas propuestas desde la historiografía española actual para hacer un balance y propuestas.

Benedict Anderson con su ensayo reflexivo Comunidades imaginadas: reflexiones sobre e origen y la difusión del nacionalismo (1983)7, marca el inicio de un nuevo modo de pensar el nacionalismo que ha hecho escuela. En primera instancia deja en claro que seguimos viviendo en la era del nacionalismo y que esto no ha cambiado; aunque muchos quieran creer lo contrario, la nacionalidad es el valor más universalmente legítimo en la vida política de nuestro tiempo. Su propuesta pasa por hacer un recorrido histórico sobre los nacionalismos para entender por qué, en la actualidad, tienen una legitimidad emocional tan profunda. En este sentido, el punto de vista no se encuentra puesto en la dinámica macropolítica o en los grandes procesos

Michael BILLIG: Nacionalisme banal, València, Universitat de València, 2006, pp. 87.

4 Adam CURTIS: El Siglo del Yo (The century of the Self), BBC, Reino Unido, 2002. http://videotecaalternativa.net/el-siglo-del-individualismo-subtitulado

5 José ORTEGA y GASSET: Meditaciones del Quijote, Madrid, Publicaciones de la Residencia de Estudiantes, 1914 .

6 Estos ya se encuentran detallados en Pablo GIORI: Hacer castells, construir nación. Castells, modelo festivo y catalanismo, Tesis de Máster, Universitat de Girona, 2012. http://dugi-doc.udg.edu/handle/10256/5861.

7 Benedict ANDERSON: Comunitats imaginades: reflexions sobre l'origen i la propagació del nacionalisme, Catarroja, Afers, 2005 porte (MECD) del Gobierno de España. El investigador pertenece al proyecto de investigación AAR2012-35322. pablogiori@gmail.com - $h$ ttp://girona.academia.edu/PabloGiori.

Dario “Chimi" Derrache, 8 de junio de 08 , Tucumán, Argentina, entrevista propia. Chimi es el canun grupo durante su juventud. Pablo GIORI: Hcpunk en Tucumán. Una propuesta de interpretación, com.es

2 Eric HOBSBAWN: "La historia desde abajo", en Sobre la Historia, Barcelona, Editorial Crítica, 2002. Jim SHARPE: “La historia desde abajo", en Peter BURKE: Formas de hacer Historia, Madrid, Alianza, 1996. Fernando MOLINA APARICIO: "La nación des de abajo. Nacionalización, individuo e identidad nacional", Ayer, 90 (2013), pp. 39-63. 
transhistóricos, como hasta ese momento se había abordado el tema, sino que busca un cruce entre lo cotidiano y lo social, entre lo individual y lo colectivo. Más allá de su definición ampliamente conocida del nacionalismo, nos interesa remarcar una limitación de la propuesta ya que el autor centra su análisis, paradójicamente, en lo racional, se interesa por la novela y el periódico, lo que es igual a decir la imprenta y la escritura. Pero la nación es mucho más que eso, si bien es factible que se haga imaginable y abstracta con la imprenta, no termina de ser coherente su trabajo con su propuesta inicial, no explica cómo el sentimiento de sacrificio es reproducido en los sujetos. Es cierto que la nación es una comunidad imaginada, además de una comunidad vivida, pero no es cierto que esta imaginación deba estudiarse en los textos, sino que debe estudiarse en lo que la gente hace y siente.

Según lo propuesto por Michael Billig en su libro Banal Nationalism de $1995^{8}$ es necesario volver a pensar el tema del nacionalismo desde otro punto de vista. Existirian para el autor un nacionalismo "peligroso" y un nacionalismo "sensato", tan familiar que los analistas lo pasan por alto. Este nacionalismo omnipresente de los estados-nación ya establecidos se construye día a día en base a unas rutinas prácticas que recuerdan constantemente la identidad nacional sin que los ciudadanos sean conscientes del proceso. Pero el nacionalismo como construcción banal no trabaja solo, sino que construye, al mismo tiempo, una serie de nociones y de prácticas ideológicas banales que lo apoyan, lo justifican y lo reproducen, lo hacen posible, y que podríamos considerar "permanencias inventadas". Ésta no sólo se naturaliza, sino que se construye como parte necesaria de nuestra identidad, algo que no sólo se considera natural poseer, sino también que es natural recordar, nadie nunca olvida su nacionalidad. Esta propuesta es interesante porque relaciona las necesidades del sujeto con las de su comunidad nacional, conectando lo micro con lo macro.

Dentro de este recorrido podemos recuperar las propuestas de Eric Hobsbawm en su libro Naciones y Nacionalismo desde 1780 editado en 1991, que no solamente propone un recorrido por las diversas naciones sino también por las concepciones vigentes sobre el nacionalismo, para proponer la suya. Destacamos aquí un interés esencial del libro: los procesos de construcción y sostenimiento de la nación, los procesos de "invención e ingeniería social que in tervienen en la construcción de naciones". Al mismo tiempo sostiene que la perspectiva de construcción del estado desde arriba tiene que ponerse en diálogo con la construcción desde abajo, para entender cómo la perspectiva estatal se relaciona con "los supuestos, las esperanzas, las necesidades, los anhelos y los intereses de las personas normales y corrientes, que no son necesariamente nacionales y menos todavía nacionalistas".9

Para concluir con las propuestas de este autor, el libro que compila en 1983 con Terence Ranger, La invención de la tradición, ${ }^{10}$ nos da pie para reflexionar cómo el nacionalismo trabaja el pasado, las tradiciones y los aspectos culturales. La idea central del libro es sencilla y ha suscitado múltiples análisis e interpretaciones similares hasta convertirse casi en toda una rama de la historiografía: las tradiciones que parecen o reclaman ser antiguas son a menudo bastante recientes. La repetición es una forma de esta continuidad inventada con el pasado, una legitimación retrospectiva, formalizada y ritualizada. Se toman materiales del pasado para nuevas tradiciones y nuevas funciones haciendo un corte con su significado antiguo, invención no necesariamente de forma pero sí de significado. El hecho histórico de inventar tradiciones con los que nos identificamos cumple cuatro objetivos: establecer cohesión social, legitimar instituciones, estatus o relaciones de autoridad, favorecer la socialización e inculca creencias y sistemas de valores. Durante el siglo XIX y XX había que sustituir la religión por

8 Michael BILLIG: Nacionalisme banal..

9 Eric HOBSBAWM: Naciones y Nacionalismo desde 1780..., pp.19.

10 Eric HOBSBAWM y Terence RANGER (eds.): The invention of traditions, Cambridge, University

Eric HOBSBAWM y Terence RANGER (eds.): The invention of traditions, Cambridge, University
Press, 1983. el civismo, una religión ciudadana, aquella de las ceremonias públicas, de los monumentos y símbolos de masas, de las votaciones y de la educación primaria, las nuevas clases y sus formas, la cultura popular y el deporte de la clase media. Este proceso coincide con el proceso de construcción de la nación y afectará profundamente, las relaciones entre los sujetos, la nación el pasado y las prácticas culturales.

La forma en la que se ha trabajado académicamente hasta ahora el tema comienza a encontrar sus limitaciones al encontrar tres problemas: primero, la necesidad de trabajar desde abajo y con los sectores/clases populares; segundo, el problema de alejarse de la perspectiva institucionalista y; tercero, las nuevas fuentes que hay que incorporar para pensar de otra forma. En España, una serie de investigadores con recorridos personales similares se han encontrado con estas limitaciones y están buscando soluciones, si bien cada uno desde su lugar. La mayoría son jóvenes que hay presentado sus tesis doctorales y primeros libros a partir del año 2000 y que trabajan, de forma más o menos directa, el tema de la nacionalización. Hagamos un recorrido breve sobre estas propuestas, las centrales y más a mano sin intención de agotar el tema, para reconstruir una inquietud y valorar propuestas.

Si bien hay una bibliografía por autor extensa, trabajamos aquí el debate general realizado en los últimos tres años en tres revistas: Ayer, Historia Contemporánea y Segle XX. Esta última revista en su número 4 de 2011 propone un debate sobre los procesos de nacionalización en España, ${ }^{11}$ con textos de Fernando Molina y Miguel Cabo, ${ }^{12}$ Alejandro Ouiroga. ${ }^{13}$ Posteriormente, la revista Historia Contemporánea número 45 de 2012 trabaja la relación entre nacionalismo y homogeneización, con la intención de agrupar una serie de estudios que convergen en una nueva perspectiva..$^{14}$ Los textos más importantes son los de Daniele Conversi, ${ }^{15}$ Ferrán Archilés y Marta García Carrión. ${ }^{16}$ Por último, este año, 2013, la revista Ayer, número 9o, publica un volumen dedicado a la nacionalización en España, ${ }^{17}$ con textos de Alejandro Ouiroga ${ }^{18}$ Ferrán Archilés ${ }^{19}$ y Fernando Molina Aparicio, ${ }^{20}$ entre otros. De este debate extenso en temas y propuestas, con puntos

11 Segle XX: revista catalana d'història, 4 (2011)

12 Fernando MOLINA y Miguel CABO: "Donde da la vuelta el aire: reflexions sobre la nacionalització a Espanya", Segle XX: revista catalana d'historia, 4 (2011), pp.131-142. Ramón LÓPEZ FACAL y Migue CABO (eds.): De la idea a la identidad: estudios sobre nacionalismos y procesos de nacionalización estudios en homenaje a Justo Beramendi, Granada, Comares, 2012.

13 Alejandro OUIROGA: “Les tres esferes. Cap a un model de la nacionalització a Espanya”, Segle XX revista catalana d'història, 4 (2011), pp. 143-160. Alejandro OUIROGA: Haciendo españoles: la na revista catalana dhistoria, 4 (2011), pp. 143-160. Alejandro OUlROGA: Haciendo españoles: Ia na-
cionalización de masas en la dictadura de Primo de Rivera, 1923-1930. Madrid, Centro de Estudios cionalización de masas en la dictadur
Políticos y Constitucionales, 2008.

14 Historia Contemporánea, 45 (2012).

15 Daniele CONVERSI: “Nación, estado y cultura: por una historia política y social de la homogeneización cultural", Historia Contemporánea, 45 (2012), pp. 437-481. Daniele CONVERSI: The Basques, the Catalans and Spain: alternative routes to nationalist mobilization, London, Hurst \& Co., 1997.

16 Ferrán ARCHILÉS y Marta GARCÍA CARRIÓN: "En la sombra del estado. Esfera pública nacional y homogeneización cultural en la España de la restauración", Historia Contemporánea, 45 (2012), pp. 483-518. Ferrán ARCHILÉS e Ismael SAZ: La nación de los españoles: discursos y prácticas del nacionalismo español en la época contemporánea, Valencia, Universitat de Valencia, 2012. Ferrán ARCHILÉS e Ismael SAZ: Estudios sobre nacionalismo y nación en la España contemporánea, Zaragoza, Prensas Universitarias de Zaragoza, 2011. Marta GARCÍA CARRIÓN: Por un cine patrio: cultura cinematográfica y nacionalismo español (1926-1936), Valencia, Universitat de Valencia, 2013. Se podría agregar también el libro de Ismael SAZ: España contra España: los nacionalismos franquistas, Madrid, Marcial Pons, 2003

\section{Ayer, 90 (2013).}

18 Alejandro QUUROGA: “La nacionalización en España. Una propuesta teórica”, Ayer, 90 (2013), pp. 17-38.

19 Ferrán ARCHILÉS: “Lenguajes de nación. Las «experiencias de nación» y los procesos de nacionalización: propuestas para un debate", Ayer, 90 (2013), pp. 91-114

20 Fernando MOLINA APARICIO: “La nación desde abajo. Nacionalización, individuo e identidad na- 
de contacto y de contradicción, queda clara una idea: existe una insatisfacción sobre la forma en que se ha trabajado el tema y hay que buscar soluciones. Yo creo que para superar estos problemas, como queda claro en este trabajo, tenemos que superar el paradigma historiográfico tradicional y recuperar las propuestas de otras ciencias sociales. Así es que considero que hay que hacer menos historia y más sociología y antropología, entrar en la interpretación, pensar de forma relacional y en periodos amplios que abarquen el periodo contemporáneo.

Si volvemos un poco hacia atrás y comentamos un texto fundamental de Ferran Archilés creo que podremos aclarar este punto. El texto ubicado dentro de un libro compilatorio se Ilama "¿Experiencias de nación? Nacionalización e identidades en la España restauracionista" y, además de hablar de este periodo concreto, hace un resumen de la situación de la investigación en el tema..$^{21} \mathrm{El}$ desarrollo es muy interesante ya que propone no solo pensar la propuesta del Estado, de arriba-abajo, sino también la interiorización de la identidad nacional sobre la base de ciertas prácticas culturales: la creación de una literatura nacional, cultura de masas, cine nacional, los toros como fiesta nacional, la zarzuela y los símbolos de la nación (bandera, nombre de calles, esculturas, estatuas, festejos, sistema monetario unificado, etc.). Aquí el concepto central sigue siendo el de interiorización, de afuera hacia dentro, pero no el de coproducción o resistencia, el papel activo del sujeto, aquel que hace cotidiana a la nación por voluntad o necesidad y no por imposición. Esta perspectiva sigue sosteniendo la débil nacionalización, si hubiese sido más fuerte hubiese sido más efectiva, en cambio nosotros creemos que el papel del Estado es mucho menor del aquí planteado y mucho mayor el de la sociedad civil. Ésta es una esfera que suele descuidarse y que nosotros consideramos fundamental para dar sustento, o contradecir, la tarea del estado. Si lo ponemos en perspectiva catalana se aclara: el nacionalismo catalán, más allá de ciertos periodos históricos concretos, se ha potenciado por una red de asociaciones culturales, políticas y económicas de la sociedad civil, en ocasiones distantes del poder institucional regional o nacional. Creemos que es la sociedad civil quien tiene el poder real de bajar el discurso nacional al orden local y de darle sentido; el Estado no puede actuar solo en la tarea maratónica de la nacionalización, necesita de una serie de otras instituciones que ayudan a crear, o a negar, la cotidianeidad del discurso nacional y que lo reproduce, lo adapta, lo oculta, lo pone en todas las cosas, lo hace necesario, etc.

Podríamos decir que el Estado impone el curriculum nacional, pero que es finalmente la maestra (en su vida cotidiana y con su participación social) quien lo propone como algo natural, quien le da el tono de cosa valiosa. Pero no solo la escuela sino toda una serie de grupos e instituciones en las que se encuentran cotidianamente las personas y que pueden apoyar o discutir ese discurso oficial de la nación. Para que no haya fisuras y se crea en algo tiene que sostenerse en todo lo que somos, en nuestra cotidianeidad, en los medios de comunicación en las iglesias, en las canchas de futbol, en las escuelas, así como también en las canchas de futbol, en los teatros, en las colas del supermercado y en la de los cajeros automáticos. Aquí el concepto de coherencia es fundamental, para que un discurso sea poderoso y se naturalice tiene que ser coherente con una serie de discursos, prácticas, valores y organizaciones que lo sostienen y reproducen como una parte fundamental del mundo; si esta coherencia no existe el sujeto inmediatamente duda racionalmente o siente un malestar, hay algo que no encaja, que no cierra, que no es natural y que puede cuestionarse. La tarea fundamental del nacionalismo es hacer cotidiano, eso quiere decir hacerse coherente con el mundo de las personas que quiere nacionalizar, sino no será nunca efectivo. Igualmente tiene que hacerse real tanto en el pensamiento de las personas como en sus sentimientos y en sus acciones, si no existe

cional", Ayer, 90 (2013), pp. 39-63.

21 Ferrán ARCHILÉS: “EExperiencias de nación? Nacionalización e identidades en la España restauracionista", en Javier MORENO LUZÓN (ed.): Construir España: nacionalismo español y procesos de nacionalización, Madrid, Centro de Estudios Políticos y Constitucionales, 2007. pp. 91-114. esta otra coherencia, dudaremos y si dudamos podemos cuestionarlos: cuando sentimos que está mal la discriminación aunque nos creamos superiores, ya tenemos el primer germen de cambio, se ha iniciado la fractura. ${ }^{22}$

Creemos así que las limitaciones de pensar de forma paradigmática dentro de la historiografía es lo no nos permite: 1) pensar de forma relacional el siglo XX como un todo, la mayoría mira únicamente el siglo XIX o etapas particulares; 2) pensar al sujeto nacional dentro de otros grupos y de otras instituciones, la sociedad civil, que son las que finalmente permiten la creación de la nación como una realidad cotidiana, más allá de las propuestas del estado y; 3) romper con el racionalismo y el positivismo historiográfico, hay cosas que no están documentadas pero que son fundamentales, lo que la gente hace, siente y experimenta. Para esto tenemos que redefinir también el concepto de cultura que trabajamos porque si seguimos pensando la cultura desde una perspectiva racional y como producto, no como un proceso en el que los sujetos están interactuando, terminaremos estudiando el cine, los intelectuales y los libros, y no lo que la gente hace, piensa y siente (como analizaba Guinzburg en su libro El queso y los gusanos ${ }^{23}$ por ejemplo). Si seguimos estudiando el discurso y las instituciones tendremos problemas para estudiar el tema de la nacionalización, o de la creación de comunidades, porque nunca lograremos llegar al tema central: cómo esos discursos e instituciones se hacen cuerpo para que los sujetos dejen de ser sujetos y pasen a ser ciudadanos nacionales, parodiando a Weber. ${ }^{24}$ Así las naciones que se proponen desde arriba se negocian, discuten, resisten y reformulan desde abajo.

\section{Una propuesta y algunas ideas}

Creemos que construir una comunidad, en este caso la nación, es construir de forma banal una vida cotidiana donde esta comunidad se hace necesaria y es parte del horizonte de realidad de aquellos que la comparten. Es una comunidad pero también una geografía imaginada, un territorio donde toda esta gente desconocida desarrolla su vida, piensa y siente en algún sentido del mismo modo, o así lo creen. Esta doble imaginación tiene una lógica específica en cada cultura, algunas más amplias, otras más cerradas, unas más homogéneas, otras más diversas, unas en base a este criterio, otras en base a aquel otro. Pero aún nos queda entender cómo es que estas comunidades se reproducen, y algo tendrá que ver el nacionalismo; los instrumentos que se han analizado tradicionalmente, ${ }^{25}$ ya no son suficientes, sabemos que hay algo más.

Creemos que lo que proponemos en este trabajo puede comenzar a ser una respuesta que nos permita diagnosticar el problema, la falta, y recentrar nuestras propuestas de investigación. Cuando trabajamos las comunidades, las naciones y el nation-building no tenemos que pensar únicamente en lo racional, en la cultura en el sentido de pensamiento o escritura, tenemos que pensar también en las prácticas y las emociones: la nación se piensa, pero principalmente se siente y se hace. Tenemos que pensar en la cultura desde una perspectiva antropológica, aunque nuestro paradigma historiográfico no nos haya preparado para ello, porque

22 Creo personalmente que ésta puede ser una buena hipótesis de trabajo alternativa al problema de la débil nacionalización. Habría que pensar el papel de la sociedad civil (y obviamente la pensemos más allá de la burguesía) en la reproducción o contestación del discurso nacional del estado, según territorio y periodo histórico, y nos llevaremos un par de sorpresas.

23 Carlo GUINZBURG: El queso y los gusanos: el cosmos según un molinero del siglo XVI, Barcelona, Muchnik, 1996.

24 Eugene WEBER: Peasants into Frenchmen: the modernization of rural France 1870-1914, Stanford, Stanford University Press, 1976. 25 Ver Xosé Manuel NÚNEÉZ SEIXAS: Los Nacionalismos en la España contemporánea: siglo XIX y XX, Barcelona, Hipótesis, 1999. pp. 21 y 116. Alejandro GRIMSON: La Nación en sus límites: contrabandistas y exiliados en la frontera Argentina-Brasil, Barcelona, Gedisa, 2003. pp. 77. Carolyn BOYD: Historia 
las historias que estamos contando dejan de lado, paradójicamente, la mitad de la historia. La historia militar y de grandes estadistas del siglo XIX se olvidaba de que la historia realmente la hacen, y las guerras las pelean, los de abajo, aquellos muertos de fosas comunes, aquellos sacrificados por los grandes imperios. ${ }^{26}$ La historia positivista reinante durante gran parte de siglo XX dejaba de lado todo lo que no se podía comprobar, lo que no estaba en los documentos de la escritura burguesa no existía, era silencio, fantasmas. La escuela de los Annales va recuperando formas de trabajo y proponiendo nuevas fuentes y objetos, retoma la sociología, la economía y la geografía, pero siguen quedando cosas fuera. El tercer giro de las ciencias sociales creemos que tiene que afectar también a la historiografía; hay que recuperar las propuestas interpretativas y la antropología, recuperar todo el aparato teórico de las ciencias sociales para potenciar el estudio de la historia. ${ }^{27}$ Igualmente cierto es que el resto de las disciplinas tendrían que adquirir también las herramientas de la historiografía, es un intercambio recíproco que beneficie a todos por igual. Lo que hasta aquí hemos dicho parece una obviedad, pero no lo es tanto, esta propuesta es minoritaria y nuestro objeto nos lo pide, tenemos que entenderlo desde una propuesta global, tenemos que estudiar tanto lo que la gente piensa y hace como lo que siente al pertenecer a una comunidad.

En mis investigaciones sobre el caso catalán he intentado aplicar esta propuesta, porque para un amplio sector de la sociedad catalana, y no estamos hablando aqui de los catalanistas, ${ }^{28}$ participar de actividades culturales como los castells, las sardanas, el excursionismo, hablar catalán comer pa amb tomàquet, etc., son formas de hacer nación. ${ }^{29}$ Oue el nacionalismo apoye la difusión de estas prácticas culturales es una forma de generar las condiciones de posibilidad para su propia reproducción; la cercanía existente entre las formas de hacer, sentir y pensar la nación que reproducen estas prácticas son muy similares a las que proponen los nacionalistas, lo que no quiere decir que haya una relación directa entre las prácticas culturales y políticas, sino una indirecta. Hay una correlación cultural en las formas de hacer, pensar y sentir, entre hacer castells y hacer nación, entre pensar castells y pensar nación y entre sentir castells y sentir nación, pero esto no sucede por una intencionalidad racional, no es buscado a propósito ni tiene beneficios calculados. Sobre esta base decimos que una de las cosas que están faltando para entender la nación es no solamente entender su cultura, sino sus prácticas culturales y las experiencias de nación que generan. El franquismo no puede entenderse sin la historia de la tauromaquia, el catalanismo antifranquista sin las sardanas y la Cataluña democrática sin sus castells..$^{\circ}$

Podemos decir entonces que el nacionalismo busca conformar una forma específica de grupo/comunidad (una nación, una comunidad y una geografía imaginaria) en que los miembros comparten una cultura específica (el nacionalismo) que produce, reproduce y enseña a hacer, pensar y sentir el mundo de una manera particular, más o menos compartida con otras culturas (en un solapamiento que busca ocultarse y hacerse hegemónico), una forma compartida de construir un espacio social propio (una nación que sea punto de encuentro y de exclusión) y unas prácticas culturales compartidas que se consideran propias. Ciertamente, y aunque

26 Como bien dice Bertold Brecht en su poema Preguntas a un obrero que lee: "Felipe de España lloró cuando su flota fue hundida. ¿No lloró nadie más?".

27 Algunas pistas encontraremos, si bien nuestra propuesta diverge en varios aspectos, en Peter BURKE: ¿Qué es la historia cultural?, Barcelona, Paidós, 2006.

28 Montserrat GUIBERNAU: Catalan nationalism: Francoism, transition and democracy, London, Routledge, 2004. Paola LO CASCIO: Nacionalisme i autogovern: Catalunya, 1980-2003, Catarroja, Afers, 2008.

29 Joan Luis MARFANY: La cultura del catalanisme. El nacionalisme català en els seus inicis, Barcelona, Empúries, 1996.

30 Pablo GIORI: Hacer castells, construir nación... pp.18-32. Ver Tambien Pablo GIORI: "Castells, sardanesitoros. Les disputes (En Prensa). parezca contradictorio o circular, el nacionalismo es una idea, al mismo tiempo que una forma de hacer las cosas, una forma de pensarlas y una forma de sentirlas, dentro de una coherencia posible, por esta razón es que es una idea que busca conformarse en comunidad que busca reproducirse en sujetos que buscan reproducir la idea que busca producir comunidad, etc. No está de más aclarar que este nacionalismo, uno que se pide a sí mismo, que se autojustifica, trabaja como un nacionalismo banal, lento, imperceptible, que no se nota, que se va haciendo sin decirse y sin ser visto, pasa desapercibido y se instala en el sentido común. Es un estilo de vida que no depende de un objetivo concreto, de un resultado, puede ser un proceso dinámico y perpetuo, si bien no irreversible, puede ir siempre hacia adelante y no llegar nunca a un final es un proceso perpetuo, silencioso y presente, pero que deja huellas.

\section{Nación, comunidad, grupo...}

he conocido mucha gente por la música.

Y casi todos buena gente. ${ }^{31}$

Cristian "Palo" Vázquez

Aclarada la comunidad más amplia de una sociedad, la nación, podemos pensar y propone algunas reflexiones sobre el resto de las comunidades y los grupos en que los sujetos viven su cotidianidad. En la frase de Palo se encuentra la diferencia entre pertenecer a una nación y pertenecer a un grupo: en una nación no podemos conocer a todos nuestros compatriotas, tenemos que imaginárnoslos; en un grupo somos todos hermanos, "buena gente", sabemos a ciencia cierta como son y respondemos por ellos. La cercanía genera una experiencia de colectividad práctica, y practicada, en un grupo; en una nación la experiencia compartida tiene que ser imaginada, es una creencia, un supuesto.

Teorías de grupo hay muchas,,$^{32}$ desde la sociología, la antropología, la psicología y la historia, pero como idea general diremos que el grupo puede pensarse como un mediador entre lo individual y lo social. Los grupos le permiten al sujeto ser social, éstos dan herramientas a pequeña escala para el encuentro con lo social y son una estructura siempre presente como horizonte inmediato de la experiencia. Entonces decimos que como marco gnoseológico de racionalidad nos ayuda a darle al mundo una lógica comprensible, el grupo pre-interpreta el mundo. Visto como instancia de institucionalización, el grupo escribe e inscribe su propio mundo de vida y, a la vez, prescribe, porque la institución es una fuerza de poder que busca reproducirse, en su propia tradición, en esa significación. A los grupos de los que participamos no los tenemos únicamente en la mente, los tenemos principalmente en el cuerpo, nos hacen ser lo que somos y nos ayudan a ser, son nuestro campo y están en nuestra habitus. ${ }^{33}$

Sostiene Ana Quiroga ${ }^{34}$ que la fragmentación social propia del capitalismo y los momentos de crisis son los que más fortalecen la creación de grupos. Las crisis implican una desestructuración del mundo cotidiano, una intensificación de la inseguridad y de la ambigüedad. El grupo desempeña aquí una función yoica de sostén y contención, ante el resquebrajamiento o derrumbe de las órdenes que normalizan y dan estabilidad a la vida social, imprimiendo

31 Cristian "Palo" Vázquez, 23 de mayo de 2009, Tucumán, Argentina, entrevista propia. Palo comentaba en esta entrevista la historia de su banda. Pablo GIORI: Hcpunk en Tucumán..., pp.416

32 Para un panorama general ver Roberto R. ROMERO: Grupo: objeto y teoría, Buenos Aires, Lugar Editorial, 1987, pp. 27-72. David ROSENFELD: "Nuevos enfoques en psicoterapia grupal", Revista Argentina de Psicología, 3 (1970), pp. 41-59.

33 Pierre BOURDIEU y Loïc WACOUANT: Una invitación a la sociología reflexiva, Buenos Aires, Siglo $\mathrm{XXI}, 2005$

34 Ana P. OUIROGA: “El grupo: espacio de encuentro o alienación”, Revista Temas de Psicología Social, $12(1991)$ 
alguna lógica interpretativa al mundo, proyectándole coherencia. El nivel de fragmentación de lo social es lo que da el valor a los grupos y por eso es que nuevas sociedades crean nuevos grupos y nuevos sentidos sociales para los mismos: los hombres siempre han luchado para crear formas de conciencia que conduzcan a reintegrar lo disperso, a hacer vivible el desierto.

A su vez, todos los grupos tienen instrumentos de captación de sujetos, sostenimiento de sus formas, de creación de valor y reproducción de sus dinámicas. Aquello que lo mantiene unido es una idea compartida, es aquello que ha sido teorizado como la "hipótesis de reciprocidad de expectativas" por Schutz: 35 todos los miembros del grupo comparten unas hipótesis, dan por supuestas expectativas y perspectivas compartidas, aunque no sea cierto. Lo importante de esta propuesta es que no son más que hipótesis, los grupos no comparten realmente muchas cosas, y no se dedican a comprobarlo, lo que realmente los une es algo muy frágil y que no tiene materialidad, una creencia. Es decir: a pesar de las diferentes perspectivas, biografías y motivaciones, a las que se debe que los actores no posean idénticas experiencias del mundo tratan sus experiencias como idénticas a todos los efectos prácticos. En este sentido decimos que todos podemos ir hacia el mismo lugar pero cada uno a su modo, a veces hasta de forma contradictoria, pero por alguna razón nos encontramos en los grupos haciendo lo mismo.

Por eso decimos que un grupo no es únicamente una "comunidad de sentimiento", como dijo Michel Maffesoli en su libro Le temps des tribus de $1988,{ }^{36}$ sino que hay muchos aspectos que pueden ayudar a cohesionarnos. Más allá de los aspectos emocionales, nos gustaría recalcar el aspecto cognitivo y práctico de los grupos; en los grupos no solo nos emocionarnos, sino también aprendemos y hacemos cosas. Vemos entonces que en los grupos hay una necesidad de construir lo compartido, como en las naciones se evidencia, y eso en ocasiones puede formalizarse como procesos de homogeneización, de grupalización, de construcción de un futuro o de reconstrucción del pasado. Estos procesos buscan construir lo compartido, pero pueden hacerlo negando al otro o construyendo un nosotros que no entre en colisión con los otros grupos de los que formamos parte. La identidad del sujeto es múltiple, al igual que su pertenencia a grupos, los cuales pueden exigir diferentes grados de lealtad y de exclusividad, como suele suceder con la nación.

\section{Fronteras, exclusividades y emociones}

\section{Aunque sea para nosotros,}

aunque sea que haya diez personas. ${ }^{37}$

Dario "Chimi" Derrache

Hacer y vivir en comunidad es una necesidad humana (vivimos el siglo del individuo, pero también el de la nación) porque ésta ordena la experiencia y da herramientas prácticas para los problemas diarios, pero es también una obligación; aunque quisiéramos evitarlo y neguemos todos los grupos electivos, todos los otros siguen estando ahí y haciéndonos lo que somos, la sociedad, la nación, la familia. No podemos negarlos porque sería negar lo que somos, podemos elegir algunas cosas pero no todo, ni mucho menos, y eso que no queremos nos va haciendo lo que somos. Más allá de las elecciones, también los grupos nos piden lealtades, algunas que buscan ser más exclusivas, como la nación o los clubes de fútbol de una misma ciudad y otras que pueden superponerse sin cuestionarse y complementándose, la familia, los amigos, la escuela. En general y por una necesidad psicológica tendemos a pertenecer a gru-

35 Alfred SCHUTZ: El problema de la realidad social, Buenos Aires, Amorrortu, 1974 36 Michel MAFFESOLI: El tiempo de las tribus. El declive del individualismo en las sociedades de masas, Barcelona, Icaria, 1990.

77 Dario "Chimi" Derrache... explicando como eran los recitales underground. Pablo GIORI: Hcpunk en Tucumán..., pp.268 pos coherentes entre ellos y con lo que nosotros creemos que somos; si algo no es coherente comienza a cuestionarnos, tendremos que resolverlo o caer en la paranoia

Formamos comunidades por necesidad, armamos algo común porque necesitamos de los otros, necesitamos incluirlos, y que nos incluyan, pero también excluirlos. Aunque tampoco es cierto que todos los grupos se hagan en la exclusión, es más, hoy en día la mayor parte de los grupos no pueden pedir exclusividad y no excluyen directamente, no hay puertas, clases o contraseñas. Hoy la exclusión es más sutil, si no pertenecemos nadie nos lo dirá, lo sentiremos en el cuerpo, como quien se sabe fuera de lugar, como quien no entiende las bromas ni los tiempos; parece que no nos excluyen, que nos excluimos. Hay otros grupos, los exclusivos, los de prestigio, los de lealtad, que si excluyen explícitamente porque construyen su valor prohibiendo el acceso a aquellos que no lo poseen y que no pueden compartirlo. Pero estos grupos son cada vez menos importantes cuantitativamente pero, paradójicamente, más importantes cualitativamente, son los grupos más fuertes y que más nos marcan, por ejemplo las naciones.

Hay que tener entonces en cuenta las delimitaciones y los límites porque, desde nuestra perspectiva, sólo los sujetos pertenecientes a los grupos pueden conocer de forma práctica, no teórica, donde terminan los grupos y quienes son aquellos con los que no comparten las mismas expectativas. Si esto se pregunta de forma más o menos explícita ${ }^{8}{ }^{8}$ la sorpresa es grande al reconocer que estas hipótesis y cartas de pertenencia son mucho menos claras y compartidas de lo que se esperaría. Solamente el núcleo duro de un grupo pertenece a éste de forma incuestionable; podríamos hablar de 20 personas de 100 , en mi caso de estudio cuestionándose la pertenencia de los otros 80 según a quien se lo preguntes. Esto complejiza el problema de las fronteras y de las pertenencias a los grupos y nos deja en claro que es más simple estudiar al grupo desde el sujeto, lo que éste le da a aquel, que desde el grupo al sujeto porque siempre habrá dudas sobre su pertenencia.

Finalmente, tenemos aquí también el problema de la importancia de los aspectos cogniti vos, experienciales, sentimentales y prácticos de las comunidades, aspectos todos por los que tendemos a formarlas: para hacer cosas, para comprenderlas, para vivirlas y para emocionarnos. Siempre nos unimos por algo, aunque sea azaroso nuestro ingreso, pero cuando estamos adentro esa comunidad nos marca profundamente y para siempre, nos hace ser lo que somos. Por eso decimos que hacer castells es mucho más que subirse a las espaldas unos de otros, hacer una práctica cultural es comulgar con un pensamiento, acercarse a otros, aprender a hacer, pensar y sentir las cosas de una forma nueva y, en teoría, compartida. El sentido común indica que los grupos emocionales son los más poderosos y esto es un prejuicio racionalista, como no podemos entender porque pertenecemos no podemos salir de su encanto, pero yo creo que esto es una trampa, un miedo a lo desconocido.

\section{Conclusiones para seguir pensando en comunidad}

Las propuestas hasta aquí esbozadas reflexionan en torno al problema de las comunidades insistiendo en dos ideas centrales: es fundamental estudiar los sujetos, los grupos y las comunidades en su interrelación y; necesitamos mirar de otra forma, enriquecer nuestras miradas para pensar los procesos de construcción de comunidades desde una perspectiva global. El problema que nos queda por resolver aun es cómo estudiar concretamente el tema de mi interés, el nacionalismo y la cultura popular, desde esta perspectiva. Tenemos pistas y propuestas, muchas de ellas aqui planteadas, pero aun no podemos encontrar las formas concretas de hacerlo. Cuando comencé a escribir este artículo pensé en que al llegar a su final, como ahora, ya habría encontrado una solución que no ha llegado, habrá que esperar, habrá que aprovechar el Encuentro para discutirlo.

38 Pablo GIORI: Hcpunk en Tucumán...

..., pp.268 
Mientras tanto, sigo viendo día a día la evidencia de las limitaciones académicas y ejemplos de la forma en que festejamos la nación con prácticas culturales cotidianas: bailes nacionales, comidas nacionales, músicas nacionales, enojos y alegrías que emanan de la nación, esa comunidad que imaginamos. Pertenecemos a grupos y esta pertenencia nos cambia la vida: limita y posibilita lo que pensamos, hacemos y sentimos, incluso nos propone futuros posibles para nuestra historia. Por esta razón, si queremos estudiar comunidades tenemos que estudiar tanto las ideas que circulan como las experiencias y sentimientos que se producen en su interior y que son parte constitutiva. Para esto hay que tener en cuenta que los sujetos pueden ingresa a una comunidad tanto por compartir formas de pensar como sentir o de hacer; podemos interesarnos por un aspecto y al ingresar terminamos aceptando el todo, terminamos impregnán donos del grupo y esto nos cambia. Cuando nos identificamos con el grupo, lo que quiere decir hacer, pensar y sentir las cosas del modo hegemónico en que lo hace el grupo, lo hemos incorporado y comenzamos, sin querer, a reproducirlo, nos ha impregnado de su lógica que pasa a ser la nuestra: al ser nosotros mismos, paradójicamente, estamos reproduciendo unas lógicas grupales que generaran la reproducción de nuestro grupo en otros sujetos.

Si es que el mundo funciona así, y nosotros estamos convencidos, habría que replantearnos diariamente la idea de Hobsbawm: tenemos que estudiar la vida cotidiana, la historia desde abajo, la vida de aquellos que se apasionan, sufren y matan por sus comunidades. 
Parte 6.

CIENCIA, MEDICINA Y SOCIEDAD:

DEBATES Y PERSPECTIVAS EN LA HISTORIA DE

$$
\text { LA CIENCIA }
$$




\section{CIENCIA, MEDICINA Y SOCIEDAD: DEBATES Y}

\section{PERSPECTIVAS EN HISTORIA DE LA CIENCIA}

gnacio Suay-Matallana* y Mar Cuenca-Lorente

Instituto de Historia de la Medicina y de la Ciencia López Piñero (CSIC-UV)

La progresiva maduración de la historia de la ciencia como especialidad académica ha estado acompañada por una notable renovación historiográfica con nuevos enfoques, narrativas, fuentes, espacios y personajes. Un ejemplo de ello son los estudios acerca de las relaciones entre género y ciencia, la circulación del conocimiento y las prácticas científicas, las tensiones entre centros y periferias, el papel de los expertos en la toma de decisiones, el análisis de controversias públicas y académicas o el creciente interés por las prácticas de popularización de la ciencia. Estos y muchos otros temas han comportado una nueva valoración de una gran variedad de fuentes poco empleadas en los estudios anteriores, tales como prensa diaria, literatura de ficción, cuadernos de estudiantes y obras de divulgación. Otro rasgo característico de las últimas décadas ha sido la transición desde la historia de las ideas, las narrativas generales y las grandes figuras que han dado paso al estudio de casos particulares, actividades cotidianas y contextos locales en los que se han incorporado un gran número de espacios situados más allá del laboratorio o las instituciones académicas.'

Desde hace varios decenios existe en Valencia una importante comunidad de historiadores de la ciencia, que se ha ido organizando para contar con un centro propio de investigación, el Instituto de Historia de la Medicina y de la Ciencia "López Piñero" desde el que se organiza un programa oficial de máster y doctorado en esta disciplina. ${ }^{2}$ La Facultad de Geografía e Historia de Valencia tiene una trayectoria mucho más dilatada y una extensa red de departamentos, profesores, estudiantes y colaboradores. Sin embargo, las relaciones entre los grupos de historia de la ciencia e historia contemporánea han sido, salvo excepciones, escasas y esporádicas, aunque las tendencias apuntadas anteriormente han propiciado notables oportunidades de colaboración en este sentido. La sesión propuesta pretendía conseguir un triple objetivo: favorecer el debate entre jóvenes investigadores en historia de la ciencia de diversas ciudades españolas, integrar en la discusión a investigadores dedicados a la historia contemporánea y favorecer los intercambios y las sinergias entre los dos grupos de jóvenes historiadores. La recepción de dicha propuesta, no pudo ser más entusiasta, y ello viene reflejado en la elevada participación con la que contó esta sesión. ${ }^{3}$ Otro de los objetivos de esta sesión fue retomar los esfuerzos realizados por anteriores estudiantes de historia de la ciencia, que en 2005 y 2007

Jan GOLINSKI: Making natural knowledge: contructivism and the history of science, Cambridge, Cambridge University Press, 1998

Instituto de Historia de la Medicina y de la Ciencia López Piñero (CSIC-UV) (http://www.ihmc.uvcsic.es/) (15/01/2014)

3 Además de agradecer a los participantes en la sesión su asistencia y contribución, merece destacarse el apoyo ofrecido por los responsables y profesores del Instituto de Historia de la Medicina y de la Ciencia. organizaron encuentros similares en Valencia y Barcelona, obteniendo magnificos resultados. ${ }^{4}$ Como resultado del encuentro celebrado en 2005 en Valencia, se publicó un volumen colectivo titulado Synergia: Primer encuentro de Jóvenes investigadores en Historia de la Ciencia, que posin History of Science. ${ }^{5}$ Ambos trabajos incluyeron las aportaciones, en diferentes idiomas, realizadas a ese congreso agrupándolas en torno a grandes grupos temáticos como la circulación y divulgación del conocimiento científico, las ciencias de la vida política, la institucionalización de la ciencia, la tecnociencia y la sociedad, la astronomía y la filosofía y los estudios sobre los problemas de las ciencias exactas.

Durante esos primeros congresos se plantearon algunos de los problemas principales que afectaban a los jóvenes investigadores en historia de la ciencia, destacando las dificultades para dar a conocer sus resultados así como la heterogénea situación de su disciplina y las dificultades para profesionalizarse al finalizar su doctorado. Tras la celebración de este encuentro se ha detectado que muchos de los problemas anteriores se mantienen casi una década después. Sin embargo, en estos últimos años se ha ido reforzado el vínculo de colaboración entre los grupos investigadores de Valencia y Barcelona, únicas ciudades en nuestro ámbito en el que existen programas completos de postgrado en historia de la ciencia. La celebración de encuentros de esta índole, permiten además, ampliar estas colaboraciones e integrar a miembros de otras universidades que no cuentan con una comunidad tan consolidada, así como intensificar la relación con el colectivo dedicado a la historia contemporánea. En otros países europeos, estas comunidades de investigadores jóvenes están más consolidadas y han prestado más atención a sus miembros menos experimentados, ejemplo de ello son las numerosas summer schools organizadas por grupos de investigación internacionales o las postgraduate conferences que la Bristish Society for the History of Science (BSHS) viene celebrando anualmente desde 1998 con un notable éxito de participación e incluso con la intervención en sus ediciones de 2012 y 2013 (en Warwick y Canterbury, respectivamente) de numerosos asistentes al IV encuentro celebrado en Valencia. ${ }^{6}$

La sesión se organizó agrupando las catorce comunicaciones seleccionadas en tres temas generales: medicina, historiografía y controversias y, finalmente educación y libros de texto. Esta organización previa no pretendía establecer fronteras sino facilitar y motivar los debates. En las conclusiones nos pareció mucho más enriquecedor alterar la organización inicial y adoptar otra estructura con el fin de favorecer las reflexiones y discusiones, mostrar tanto la variedad de enfoques historiográficos presentados como la riqueza de fuentes que cada vez más se utilizan en historia de la ciencia. Pensamos que la sesión cumplió el objetivo principa en el que se pedía que las comunicaciones contribuyeran a la exploración de preguntas y mé-

4 El primero de los encuentros fue organizado a finales de noviembre de 2005 en Valencia y coordinado por los entonces jovenes investigadores Nestor Herrán, Jaume Navarro, Pedro Ruiz-Castell, Tayra Lanuza-Navarro, Ximo Guillem-Llobat y Josep Simon. (http://www.uv.es/jihc/index.html) (15/01/2014). Un par de años después (2007), otro grupo de jóvenes investigadores en historia de la ciencia formado por Juan Carlos Cabrera, Matiana González-Silva, Néstor Herrán, Xavier Mañes y Stefan Pohl, organizaron en Barcelona un nuevo encuentro para discutir los retos profesionales e historiográficos de su especialidad. (http://www.cehic.es/ficha_congresos.php?sitelang=es\&idnoti $=62 \&$ pagina $=2)(15 / 01 / 2014)$

5 Néstor HERRÁN et al. (coords.): Synergia: Primer encuentro de Jóvenes investigadores en Historia de la Ciencia, Madrid, CSIC, 2007. La edición inglesa es: Josep SIMON, Tayra LANUZA-NAVARRO, Pedro Ruiz-Castell, Ximo Guillem-Llobat (eds.): Beyond Borders: Fresh Perspectives in History of Science, Newcastle, Cambridge Scholars Publishing, 2008.

6 Se puede encontrar más información sobre estas conferencias de estudiantes y postgraduados en la siguiente dirección: (http://www.bshs.org.uk/conferences/postgraduate-conference) dos en la siguie
$(15 / 01 / 2014)$ 
todos compartidos entre las diversas ramas de estudios históricos, dando a conocer algunas de las tendencias y líneas de investigación desarrolladas en el campo de historia de la ciencia.

Para el debate final, la lectura y presentación de las comunicaciones motivó que se organizara la discusión por parejas con el fin de que cada uno de los participantes pudiera defender la aproximación historiográfica empleada valorando pros y contras del uso de un enfoque alternativo. Esta estrategia favoreció la participación de los ponentes y de los asistentes a la sesión, generando nuevas preguntas y señalando la necesidad de la continuación de este tipo de encuentros. Marcos Bonet (IHMC- Universitat de València) estudió la relación entre historia de la filosofía de la ciencia reflexionando sobre las dificultades de aplicación de anarquismo epistemológico. Por su parte, Miquel Carandell (CEHIC- Universitat Autònoma de Barcelona) defendió la utilidad de la historia comparada en la discusión de controversias y la búsqueda tanto de las características concretas de cada caso como de conclusiones conjuntas. Elvira Fente (Universidad Complutense de Madrid) tuvo en cuenta la relación entre ciencia y género en su estudio de las transformaciones sociales y culturales del cuerpo femenino. Fátima Ferni (CEHIC- Universitat Autònoma de Barcelona) estudió la relación entre ciencia y poder y la dependencia entre científicos, prensa e industria. Clara Florensa (CEHIC- Universitat Autònoma de Barcelona) se centró en el estudio de la esfera pública y las relaciones entre ciencia, religión y estado. Por otra parte, Carlos Fuertes (Universitat de València- Universidad Europea de València) defendió la historia oral como herramienta didáctica en la historia de la ciencia. Fernando García (Universidad Complutense de Madrid) aplicó el análisis del discurso para analizar la concepción que tenía el estado de la ciencia. Andrea Graus (CEHIC- Universitat Autònoma de Barcelona) utilizó el concepto de boundary-work para estudiar los límites de lo que se considera ciencia. Imanol Herreros (Universidad Autónoma de Madrid) se centró en el análisis iconográfico para estudiar la imagen pública de la ciencia. Rubén Mirón (Universidad de Almería) mostró la complejidad que, en muchos casos, supone el acceso a las fuentes archivísticas, para lo que ofreció una minuciosa panorámica de la dispersión de algunas de ellas. La comunicación de Oscar Montero (CEHIC, Universitat Autònoma de Barcelona), analizó los problemas historiográficas aplicables a un estudio concreto y reflexionó sobre posibles alternativas cómo la microhistoria, los estudios centro y periferia, la historia comparada o la narrativa multidisciplinar. Rosa Muñoz (IHMC-Universitat de València) estudió la circulación de la ciencia y el papel activo de los manuales científicos como elementos clave de la práctica científica fruto de las controversias, negociaciones, adaptaciones, traducciones y apropiaciones existentes entre diversos agentes. Carles Sirera (Universitat de València) integró la cultura material con la historia económica, institucional y la microhistoria para relacionarlas con la historia de la educación en un estudio de caso concreto. Finalmente, Lorena Valderrama (IHMC- Universitat de València) consideró una gran variedad de fuentes como documentos legales, prensa diaria y científica o correspondencia privada para analizar cuestiones cómo las tensiones disciplinares, la circulación de la ciencia o las políticas científicas integrando fuentes diversas.

Los temas de trabajo escogidos por los autores de las comunicaciones reflejan algunas de las tendencias y reflexiones más recientes en historia de la ciencia, y que han implicado grandes cambios en los enfoques y la metodología utilizada en la disciplina. Esta revisión crítica de las narrativas tradicionales contribuye a evitar un posible exceso de estudios de caso demasiado localistas que conlleven la fragmentación de la disciplina al ofrecer un marco de reflexiones internacionales que facilite las comparaciones de los diferentes trabajos. Los estudios comparados, además de integrar contextos, disciplinas y narrativas variadas también pueden ser aprovechados para corregir el excesivo protagonismo de la historiografía anglosajona. ${ }^{7}$

7 Una trabajo reciente y muy completo que refleja las tendencias internacionales más actuales en historia de la ciencia es el siguiente: Ronald E. DOEL y Thomas SÖDEROVIST (eds.): The Historiography of Contemporary Science, Technology, and Medicine: Writing Recent Science, Oxford, Routledge,
Una de las nuevas propuestas narrativas, metodológicas e historiográficas que más interés suscitan en la historia de la ciencia está vinculada al análisis de las controversias científicas, un aproximación transdisciplinar en la que han participado tanto historiadores como filósofos y sociólogos de la ciencia. La idea de la evolución de la ciencia como una serie lineal de logros dirigidos hacia el progreso científico ha sido muy discutida en las últimas décadas. Un autor que ha tenido mucha influencia en esta transformación es Thomas S. Kuhn con su noción de "revolución científica" a través del cambio de "paradigmas". Sin embargo, con la excepción de esos momentos de transformación, Kuhn consideraba que la "ciencia normal" era una actividad fundamentada en amplios consensos de la comunidad científica. Los historiadores posteriores han mostrado que las controversias son mucho más habituales en la ciencia y que su análisis revela aspectos cruciales de la actividad científica. Las controversias se producen tanto entre científicos, bien dentro de literatura especializada o en el seno de instituciones académicas, como entre expertos y profanos, y se acentúan cuando afectan a aspectos sensibles relacionados con la religión, la política o las influencias de la cultura hegemónica. Numerosos autores han propuesto un análisis simétrico de estas controversias, polémicas o disputas científicas que pueda abarcar tanto a las ideas y hechos discutidos como a la presentación de resultados, instrumentos y espacios implicados, así como a la compleja trama de intereses personales, disciplinares y económicos, dentro de los cuales se difuminan los propios límites de la ciencia. ${ }^{8}$

A lo largo del encuentro se mostró la importancia y la variedad de controversias existentes en la ciencia y se sugirieron una gran diversidad de enfoques que pueden emplearse para estudiarlas. Las comunicaciones de los participantes Bonet y Carandell muestran como la historia de la ciencia y sus controversias permite reflexionar sobre los problemas de comunicar la ciencia de una forma más rica y simétrica.

También se valoraron las ventajas de de la historia comparada frente al estudio de casos particulares. Bonet y Carandell señalaron que la falta de comparación provocaba dudas respecto a la utilidad de emplear dos marcos temporales distintos. La discusión demostró que las homologías permiten observar líneas diferentes o dotar a los argumentos de mayor poder de convicción. En otro orden de cuestiones, los participantes también señalaron que uno de los cambios más relevantes en el análisis de controversias científicas ha sido la relevancia ganada por la esfera pública.

2006. Un trabajo más conciso pero adaptado a las preocupaciones del mundo hispanohablante es el siguiente: Josep SIMON y Néstor HERRÁN: “Comunicar y comparar: la historia de la ciencia ante el localismo, la fragmentación y la hegemonía cultural", Memoria y Sociedad, 13 (27) (2009), pp. 143-161. 8 Existen numerosos libros sobre esta cuestión. Algunas de las reflexiones más sugerentes y con multtiples ediciones son: Tristam ENGELHARDT y Arthur L. CAPLAN (eds.): Scientific Controversies:
Case Studies in the Resolution and Closure of Disputes in Science and Technology, Cambridge, CamCase Studies in the Resolution and Closure of Disputes in Science and Technology, Cambridge, Cam-
bridge University Press, 1987 ; Steven SHAPIN y Simon SCHAFFER: Leviathan and the Air-Pump: Hobbes, Boyle, and the Experimental Life, Princeton University Press, 1985; Thomas KUHN: La estructura de las Revoluciones Cientificas, México, Fondo de Cultura Económica, 2006 y Jan GOLINSKI: Science as Public Culture: Chemistry and Enlightenment in Britain, 1760-1820, Cambridge University Press, 1999. Tambien se han estudiado problemas muchos mas concretos como los relacionados con la calidad y pureza de las aguas en el siglo XIX: Christopher HAMLIN: A Science of Impurity: Water Anarysis in Nineteenth Century Britain, Bristol, Adam Hilger, 1990; las disputas existentes en torno a los análisis químicos en torno a una disciplina emergente como la toxicología: José Ramón BERTOMEU-SANCHEZ y Agustí NIETO-GALAN: Chemistry, medicine, and crime: Mateu J.B. Orfila (1787-1853) and his times, Canton, Watson Publishing, 2006; o las controversias vinculadas a la industria del tabaco en el siglo XX: Erik M. CONWAY y Naomi ORESKES: Merchants of Doubt: Bloomsbury Publishing, 2011. 
La comunicación de Bonet fue también un ejemplo del renovado interés por las biografías científicas. El género biográfico cuenta con una larga tradición en historia de la ciencia pero fue abandonado con la llegada de la historia social y cultural que puso en evidencia los excesos de la hagiografía y las limitaciones de las narraciones basadas en la descripción de hazañas de grandes figuras y héroes de la ciencia. En las últimas décadas, al igual que ha ocurrido en otras especialidades históricas, la biografía científica se ha revitalizado y ha ampliado sus usos y significados. Historiadores como Thomas Söderqvist han propuesto que sean consideradas como un género en si mismo que ayude a entender la vida de un científico, y las relaciones entre el contexto social de la ciencia, el proyecto vital del biografiado y su obra científica. ${ }^{9}$

La comunicación de Carandell, dedicada al análisis de los congresos científicos como herramienta de validación de controversias científicas consideró las dificultades que existen para legitimar determinadas posturas académicas dependiendo del entorno espacial. Nuevas propuestas historiográficas han posibilitado un acercamiento desde la geografía hacia la historia de la ciencia y han popularizado el estudio de las "geografías del conocimiento". Este "giro geográfico" ha mostrado cómo el entorno físico en el que se desarrolla la ciencia afecta no sólo a su evolución sino también a sus procesos de producción, circulación y apropiación. La configuración espacial es esencial para entender aspectos relacionados con la legitimación de las prácticas científicas, la construcción de autoridad, la circulación de la ciencia, el desarrollo de redes de personas y objetos, la formación de disciplinas o la construcción de identidades regionales y nacionales..$^{10}$

Un gran número de trabajos se centran en espacios concretos como una ciudad o un laboratorio. El número de espacios considerados por los historiadores de la ciencia se ha ampliado en los últimos años para incluir hospitales, granjas, industrias, balnearios, oficinas, minas, aulas, museos o ateneos, muchos de los cuales han sido tenidos en cuenta por los participantes del encuentro. Su análisis ha mostrado que no son únicamente contenedores pasivos sino que también contribuyen a moldear la ciencia que se desarrolla en su interior. Esta aproximación permite discutir cuestiones como la diversidad de personajes que intervienen en la ciencia (no sólo científicos y profesores sino también ayudantes, alumnos, burócratas, vendedores o públicos), analizar la adquisición de la autoridad científica, la formación de escuelas de investigación y estudiar los procesos de apropiación de la ciencia en contextos diversos."

9 Thomas SÖDEROVIST: "A new look at the genre of scienctific biography", en: Thomas SÖDEROVIST (ed.): The history and poetics of scientific biography, Hampshire, Ashgate, 2007. También es muy recomendable la consulta del monográfico publicado en 2006 por Isis: "Biography in the History of Science", Isis, 97 (2) (2006), pp.302-329 o el publicado por Asclepio en 2005 para el caso español: "Biografías médicas, una reflexión historiográfica", Asclepio, 57 (1), pp.3-188.

10 Algunos de los trabajos que no pueden dejar de citarse sobre esta cuestión son: David N. LIVINGSTONE, Putting science in its place: geographies of scientific knowledge, Chicago, University of Chicago Press, 2013 y David N. LIVINGSTONE y Charles W. J. WITHERS (eds.): Geographies of nineteenth-century science, Chicago, The University of Chicago Press, 2011. El interés sobre esta cuestión también ha llegado a ámbitos más cercanos como por ejemplo el ciclo de conferencias de la Societat Catalana d'Historia de la Ciència i de la Tècnica que sido dedicado en 2014 a las Geografies del coneixement (http://arban.espais.iec.cat/2013/07/04/programa-de-col\%C2\%B 7 loquis-de-laschct-2013-2014-descripcio/\#) (15/01/2014).

11 Un proyecto muy interesante que cubre diferentes espacios en un largo periodo es el coordinado por los profeso por los profesores John Perkins y Antonio Garcia-Belmar titulado Sites of Chemistry 1600-2000 (http://www.sitesofchemistry.org/index.php?option=com_content\&view=article\&id=2\&/tegrupo coordinado por el profesor Agustí Nieto-Gán está trabajando en el proyecto Science and Expertise in the public sphere: Barcelona (1888-1992). (http.//www.chices/ficha proyectos php? Expertise in the public sphere: Barcelona (1888-1992). (http://Www.cehic.es/ficha_proyectos.php?sitelang=es\&pagina=1\&encurs=si\&idnoti $=31)(15 / 01 / 2014)$. Otras propuestas a públicos más amplios y que incluso pretenden relacionar la historia de la ciencia con el turismo cultural son los ciudades como Madrid y Barcelona: (http://www.esmadrid.com/es/portal.do?!DM $=66 \& N M=3 \&$ -
Otra tendencia que ha adquirido interés en los últimos años está relacionada con la "cultura visual". La práctica científica produce una gran diversidad de representaciones visuales que tienen un gran poder para condensar el conocimiento científico y comunicarlo a distintos públicos. El estudio de la de la producción, circulación y uso de representaciones visuales (imágenes, códigos, fotografías, diagramas, modelos, gráficas, etc.) no sólo permite estudiar cuestiones relacionadas con la investigación, la enseñanza o la divulgación sino que también permiten reflexionar sobre la generación del conocimiento científico así como sobre las prácticas y procesos relacionados con su circulación y apropiación. ${ }^{2}$ Las comunicaciones del encuentro incidieron en las magnificas posibilidades que la utilización de las nuevas tecnologías permite aplicar a la cultura visual, como mostraron los estudios de Herreros y García. El primero señaló las ventajas ofrecidas por el análisis iconográfico tomando como ejemplo el uso del cómic o el cine frente a otros métodos más "tradicionales"; mientras que García empleó el análisis del discurso como herramienta principal. Estos estudios señalan también la progresiva introducción de la cultura visual en la historia de la ciencia, y las numerosas investigaciones en las que las imágenes, a pesar de no ser el elemento principal, juegan un papel indispensable en el análisis histórico.

Todas las comunicaciones ofrecieron una discusión sobre el papel de las fuentes empleadas y sus diferentes métodos de análisis. Por ejemplo, Mirón y Fuertes reflexionaron sobre la dificultad para acceder a los documentos científicos existentes en los archivos, así como acerca de las dificultades que implica su análisis crítico. También exploraron las posibilidades docentes que puede ofrecer el uso combinado de documentos de archivo junto con fuentes orales. A lo largo del encuentro también se discutió la tensión entre historia y memoria, aspectos que pueden considerar excluyentes o bien pueden utilizarse por parte de los historiadores como fuentes complementarias, permitiendo combinar subjetividad con la búsqueda de datos.

Los estudios enfocados a la definición y papel de los expertos es otro de los ámbitos que, en los últimos años, ha gozado de un mayor interés por parte de los historiadores de la ciencia. Las grandes expectativas generadas por esta línea de trabajo ha llevado a que incluso sean considerados por algunos autores como la third wave of science studies, al permitir analizar el papel de los expertos en la toma de decisiones en un amplio número de terrenos tales como la lucha contra la enfermedad, contra el crimen o en políticas de alimentación e industria. Estos estudios muestran las siempre complejas relaciones entre ciencia, poder, intereses, objetividad y neutralidad. Además de situarlos en la encrucijada de muchas disciplinas, los estudios sobre expertos permiten estudiar la participación de los científicos en situaciones bien diversas y relacionar sus investigaciones con otros estudios como los referentes a popularización de la ciencia, sus públicos o la comunicación científica, temas con los que comparten en muchas ocasiones, protagonistas, casos, fuentes o aproximaciones. ${ }^{13}$ En algunas de las comunicaciones

$T R=C \& I D R=1791)$ o (http://www10.gencat.net/dursi/AppJava/circuits/index.jsp?circuit=catalunya) $(15 / 01 / 2014)$.

12 Un ejemplo del interés despertado por esta propuesta fue el éxito de la 6th European Spring School on History of Science and Popularization, organizada en 2011 por la European Society for the History of Science y la Societat Catalana d'Histöria de la Ciència i de la Tècnica. (http://www. inmc.uv-csic.es/noticias.php?id=81) (15/01/2014). Fruto de este encuentro se publicaron monográficos como: Ari GROSS y Eleanor LOUSON (eds.): "Visual Representation and Science", Spongraficos como: Ari GROSS y Eleanor LOH (eds.). Wisual Representation and Science", Spontaneous Generations: A Journal for the History and Philosophy of Science, 6 (1) (2012), pp. o01-202 view/1386) (15/01/2014); asi como trabajos especializados como: Josep SIMON y Alfons ZARZOSO (eds.): "Visual representations in science", Endeavour, 37 (3), 2013, pp. 121-149.

13 En los últimos años se han publicado numerosos trabajos de revisión y nuevas propuestas: Harry COLLINS y Robert EVANS: "The Third Wave of Science Studies: Studies of Expertise and Experience", Social Studies of Science, 32(2), (2003), pp. 235-296; Christopher HAMLIN: "Third Wave Science Studies: Toward a History and Philo3), pp. 235-296; Christopher HAMLIN: "Third Wave Science net KOURANY (eds.): The Challenge of the Social and the Pressure of Practice, Science and Values 
presentadas en el encuentro, como las de Florensa y Ferni se observó como estas relaciones de ciencia y poder y su repercusión en la esfera pública juegan un papel fundamental para analizar los denominados "campos fronterizos". Una discusión centrada en ciencia y religión permite, por ejemplo, observar otros espacios que inicialmente permanecen ocultos como la aceptación de ciertas teorías, las estrategias de legitimación o las conexiones existentes tanto entre personas como entre instituciones. La comunicación ofrecida por Graus, en la que jugaba un papel destacado la noción de boundary work, planteó las falacias de considerar una demarcación científica predeterminada. Este enfoque también fue el empleado por Valderrama y Graus en sus comunicaciones. Ambas lo aplicaron a los procesos de formación de o nacimiento de una disciplina, tomando como ejemplo la parapsicología y la sismología. En el caso de Valderrama respondía entre otras cuestiones a una necesidad social, mientras que en de de Graus respondía a intereses de reivindicación y posicionamiento dentro de la ciencia de la propia comunidad. La comunicación de Fente, también mostraba las difusas fronteras entre ciencia y género considerando conceptos como el individualismo postmoderno que pueden influir en la representación del cuerpo femenino y en la identidad de la maternidad.

Precisamente la nueva historiografía sobre expertos, está intrínsecamente relacionada con la circulación de la ciencia, los viajes científicos y una reformulación en torno a los conceptos de centro y periferia. Estos estudios reclaman la consideración de la periferia como un lugar activo de producción del conocimiento científico. Aspectos tales como la enseñanza, los libros de texto o los sistemas legales existentes en un determinado contexto juegan un rol fundamental en la definición de estas prácticas, así como en los mecanismos de apropiación y popularización de la ciencia. Este flujo, multidireccional, de actores, objetos y prácticas experimentales permite por tanto, la exploración de nuevos contextos y la consolidación de una cultura científica propia. ${ }^{14}$ Una de las herramientas que permite analizar la circulación del conocimiento científico son los viajes científicos. Impulsados por intereses personales, políticas educativas estatales, subvencionados por diversas instituciones, o exiliados por razones políticas, estos viajeros se convirtieron en mediadores entre contextos diversos. Su labor fue decisiva tanto en la apropiación de ideas, conocimientos, instrumentos o prácticas, como en su capacidad para mostrar las semejanzas y diferencias en cuanto a la percepción de la ciencia y de la tecnología en otros lugares. Las consecuencias de estos viajes eran también muy diversas, y en ocasiones, suponían la aplicación de nuevas políticas educativas y económicas o servían para elevar el grado de autoridad del propio personaje. ${ }^{15}$

La enseñanza fue otro de los temas que estuvo muy presente en el debate, lo que también refleja el interés que ha merecido esta cuestión entre los historiadores de la ciencia de la última década. Dos de los temas relacionados con la enseñanza que han sido empleados como herra-

Revisited, Pittsburgh, University of Pittsburgh, 2008; Harry COLLINS y Robert EVANS: Rethinking Expertise, Chicago, University Press, 2007; Tal GOLAN: Laws of Men and Laws of Nature, Cambridge, Harvard University Press, 2004

14 Una de las propuestas más ambiciosas es la planteada por el grupo STEP (Science and Technology in the European Periphery) (http://147.156.155.104/?q=node/3) (20/01/14). Formado en 1999 en Barcelona por investigadores de diversas nacionalidades europeas, actualmente cuenta con historiadores procedentes de universidades sudamericanas o asiáticas. Los encuentros bianuales que celebra han dado lugar a numerosas publicaciones. Un ejemplo de ello es: Kostas GAVROLU que celebra han dado lugar a nu nes of Science, 46, (2008), pp. 153-175. Sobre el concepto de boundary work es muy interesante el traof Science, 46, (2008), pp. 153-175. Sobre el concepto de boundary work es muy interesante el tra-
bajo de Thomas F. GIERYN: Cultural Boundaries of Science: Credibility on the Line, Chicago, Chicago University Press, 1999. 15 Una revisión general se encuentra en: Ana SIMÕES, Ana CARNEIRO, Maria Paula DIOGO (eds.): Tradge in Transit", Isis, xlv (2004) pp 654-672. Sobre ciencia y exilio: Josep Luis BARONA (ed): El exilio cientifico republicano, Valencia, PUV, 2010 mientas para analizar la circulación del conocimiento científico han sido los libros de texto y la cultura material. Por una parte, el análisis de los libros de texto puede mostrar el modo en que las teorías novedosas viajaron y fueron apropiadas, sufriendo adaptaciones y modificaciones que repercutieron en la posterior transmisión de las mismas, según los intereses del propio autor y de los lectores a los que se dirigía. La reciente historiografía sobre libros de texto pone de manifiesto el papel de la enseñanza científica como un espacio de creación de conocimiento, en el que los profesores y alumnos juegan un papel activo. Asimismo se ha destacado el pape de estos "nuevos" actores (autores, lectores o editores) y se ha propuesto una revisión, más allá de los estudios tradicionales sobre la enseñanza de las ciencias, centrados en las instituciones, la legislación y las políticas educativas. La nueva historiografía aborda cuestiones tales como la formación de disciplinas, los géneros de literatura escolar como los libros de texto, la cultura material de las aulas, los métodos de control o el papel creativo de profesores y alumnos. ${ }^{16} \mathrm{La}$ cultura material, que cuenta con los instrumentos científicos como grandes protagonistas, ha recibido también un gran impulso. Analizados desde diferentes perspectivas, histórica, didáctica o museística, se ha puesto de manifiesto la necesidad de conservación del patrimonio científico existente en escuelas, institutos y universidades como recurso fundamental para la historia de la ciencia debido a la valiosa información que son capaces de proporcionar sobre fabricantes, usos o públicos destinatarios entre muchos otras cuestiones. ${ }^{17}$ Las comunicaciones de Muñoz y Sirera fueron el perfecto ejemplo de las diferentes perspectivas desde las que se pueden plantear estudios sobre prácticas de enseñanza y cultura material.

16 Algunas lecturas imprescindibles sobre este tema son: Bernadette BENSAUDE-VINCENT: "Textbooks on the Map of Science Studies", Science \& Education, 15(7-8), (2006), pp.667-670.; José Ramon BERTOMEU SANCHEZ et al. (coords.): "Introduction: Scientific and Technological Textbooks in the European Periphery", Science and Education, 15 (7-8), pp. 657-665. Una reciente revision es
la publicada en el Focus de Isis de marzo de 2012: "Focus: Textbooks in the Sciences", Isis, 103 (1), la publicada en el Focus de Isis de marzo de 2012: "Focus: Textbooks in the Sciences", Isis, 103 (1), (2012), pp.83-138. Sobre el papel de los nuevos actores y la diversidad de prácticas existentes en
el siglo XIX son muy recomendables las obras de Agusti NIETO-GALÁN: Los públicos de la ciencia. el siglo XIX son muy recomendables las obras de Agustí NIETO-GALAN: Los públicos de la ciencia. Expertos y profanos a través de la historia, Madrid, Marcial Pons, 2011; Anders LUNDGREN y Bernadette BESAUDE-VINCENT (eds.): Communicating Chemistry. Textbooks and their audiences, 17891939, Canton, MA, Science History Publications (2000) Otro estudio muy interesante es el ofrecido
por Josep Simon sobre la elevada repercusión que tuvieron los libros de texto del autor Adolphe por Josep Simon sobre la elevada repercusión que tuvieron los libros de texto del autor Adolphe tion, circulation and appropriation of Ganot's textbooks in France and England, 1851-1887, London tion, circulation and appropriation of Ganot's textbooks in France and England, 1851-1887, London, Pickering \& Chatto, 2011. Sobre enseñanza, existen varias revisiones como las de David KAISER:Pe-
dagogy and the Practice of Science: Historical and Contemporary Perspectives, Boston, MIT, 2005; dagogy and the Practice of Science: Historical and Contemporary Perspectives, Boston, MIT, 2005; y
la de John L. RUDOLPH: “Historical Writing on Science Education: a View of the Landscape", Studies in Science Education, 44(1) (2008), pp.63-82.

17 Existen diversas comisiones a nivel internacional dedicadas a la conservación y estudio del patrimonio y la cultura material de la ciencia como: Scientific Instrument Society (http://www.sis.
org.uk/) (22/01/14) o UNIVERSEUM (http://universeum.it/) (22/01/14). Algunas de las revisiones org.uk/) (22/01/14) O UNIVERSEUM (http://universeum.it/) (22/01/14). Algunas de las revisiones más recientes se encuentran en obras colectivas como: José Ramón BERTOMEU-SANCHEZ y An tonio GARCIA-BELMAR (eds.): Abriendo las cajas negras: Los instrumentos cientificos de la Univer(eds.): The uses of Spaces, Collections and Archives in Historical Studies. The Laboratorio Chimico (eds): land WITTJE (eds): Learning by doing: Experiments and Instruments in the History of Science Teaching, Wiesbaden, Franz Steiner Verla 2011 En nuestro entorno más cercano se puede citar Comissió d'Instruments Cientifics (COMIC) (http $/ / 1471.156 .155 .108 / c 0 m i c / 3 q=c a / n o d e / 5)(22 / 01 / 14)$. Las colecciones presentes en institutos de enseñanza secundaria han sido objeto de numerosos estudios. Ejemplos de ello son: Ignacio SUAY-MATALANA: "Secondary-school Science Collections in Spain: Castellon and Alicante" Bulletin of the Scientific Instruments Society, 13 (2012), pp.16-22, in Spain: Castellon and Alicante", Bulletin of the Scientific Instruments Society, 13(2012), pp.16-22.;
Josep SIMON y Mar CUENCA-LORENTE: "Science Education and the Material Culture of the Nineteenth-Century CUssroom: Physics and Chemistry in Spanish Secondary Schools", science \& Education, 21 (2) (2010), pp.227-244. 
El trabajo desarrollado por Muñoz se enfocó al análisis de manuales de química de la primera mitad del siglo XIX, considerando entre otras cuestiones, sus usos y variados públicos. Sirera centró su análisis en el sistema de financiación de la enseñanza media en la segunda mitad del siglo XIX y en su repercusión sobre la situación de las colecciones y gabinetes científicos, así como en los efectos de la política educativa en las condiciones laborales del profesorado. Ambos estudios motivaron un interesante debate en el que se reflexionó sobre la importancia de considerar tanto los libros de texto como las colecciones científicas en la realización de una historia global de las prácticas de enseñanza.

La diversidad de nuevos enfoques ha provocado una fragmentación de discursos que dificulta la realización de trabajos históricos de mayor alcance temporal y espacial (big pictures). Los autores de las síntesis más recientes han tratado de ampliar el espacio geográfico e incluir perspectivas más globales, así como una nueva ponderación respecto a los períodos y personajes históricos más relevantes. Se ha tratado de luchar contra el eurocentrismo, y se han revisado críticamente nociones como la idea de progreso, modernidad y objetividad científica. ${ }^{8}$ La comunicación de Montero incluyó muchas de las cuestiones anteriores e incidió en la necesidad de una mayor autocrítica por parte del historiador. Otros ejemplos de estas reflexiones metodológicas también estuvieron presentes en el resto de comunicaciones cumpliendo uno de los principales objetivos del encuentro.

La llegada de metodologías, preguntas, conceptos y fuentes procedentes de otras disciplinas humanísticas muestran la profunda renovación historiográfica de la historia de la ciencia. ${ }^{9}$ Los trabajos presentados en este encuentro reúnen muchos de los enfoques planteados y muestran la necesidad de disponer de espacios de debate para favorecer el intercambio de ideas y problemas. En este sentido, la conferencia supuso una experiencia altamente positiva tanto por la calidad de las ponencias como por el ambiente distendido de la misma. Encuentros de este tipo permiten conocer los proyectos de investigación que se están realizando actualmente así como discutir sobre problemas históricos, personajes y contextos geográficos muy diversos, a la vez que ayudan a establecer fructíferos contactos entre historiadores de la ciencia e historiadores de otras áreas de especialización, de modo que juntos puedan utilizar sus investigaciones y herramientas historiográficas para contribuir a una reflexión crítica sobre los problemas de la sociedad actual.

18 Entre los libros recientes que han tratado de realizar esta perspectiva general y que han tenido una gran acogida son muy recomendables los publicados, también en castellano por Patricia Fara y por Bowler y Morus. Patricia FARA. Breve historia de la ciencia, Barcelona, Editorial Ariel, 2009 y Peter BOWLER y Iwan RHYS MORUS: Panorama general de la ciencia moderna, Barcelona, Editorial Critica, 2007.

19 Estos esfuerzos combinados son visibles en la creación de proyectos tales como la red temática Estos esfuerzos combing dos son visibles en la cieacion de proyectos tales comol Lengua y Ciencia (http://www.lenguayciencia.net/) (22/01/14), que pretende establecer vínculos toria del deres e historiadores de la ciencia. Tambien se obse qua una aproximacion desde la hisand the Law" Isis, 98(2) (2007) pp. 310-350 o el portal Criminocorpus, creado en 2005 en Francia,

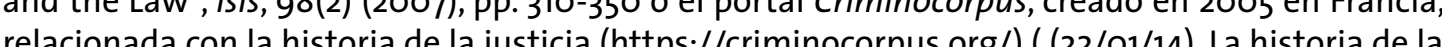
ciencia y el medioambiente es una de las áreas en la que se están produciendo un mayor número de trabajos. Muy interesantes es la iniciativa llevada a cabo por el historiador francés Thomas de traba y el programa de seminarios Environmental History Seminars, con el objetivo de reunir a

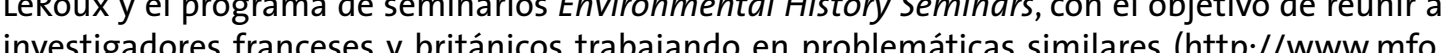
acuk/) (23/01/14). El papel de las mujeres en el mundo de la ciencia como público, ayudantes

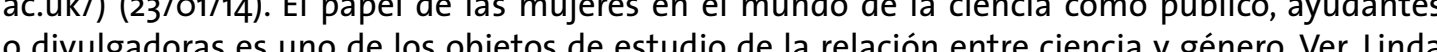
SCHIEBINCER i Tiene sexo la mente? Valencia, PUV 2004 O Donna J HAPAWAY:Ciencia, cyborgsy mujeres. La reinvención de la naturaleza, Valencia, PUV, 1995 


\section{LA HISTORIA DE LA CIENCIA SEGÚN PAUL K. \\ FEYERABEND (1924-1994): EL CASO DE CARLOS}

\section{CASTANEDA}

Juan Marcos Bonet Safont

Instituto de Historia de la Medicina y de la Ciencia «López Piñero"

(Universidad de Valencia-CSIC)

\section{Introducción}

La historiografía de la ciencia, entendida como la narración de los hechos y datos relativos a la actividad científica, depende de lo que se entienda por ciencia y de cómo se conciba esta actividad. En este sentido, la historia de la ciencia está intimamente unida a la filosofía de la ciencia, sea esta una filosofía académica o espontánea. Sin embargo, esta relación, entre la filosofía de la ciencia y la historia de la ciencia, es negada por algunos autores como Karl Popper, quien cree que se puede hacer filosofía de la ciencia desestimando o sin tener en cuenta a la historia de la ciencia. Otros autores matizan tal relación, así para Ronald Giere sería un matrimonio de conveniencia, 'Jack Smart propone que la filosofía de la ciencia puede apoyarse incluso en trabajos históricos de ficción o inventados por el historiador, ${ }^{2}$ y para autores como Thomas Kuhn, Imre Lakatos y Paul Feyerabend la historia de la ciencia juega un papel fundamental en la filosofía de la ciencia y viceversa. ${ }^{3}$ En sentido general, se señala a la obra publicada en 1961, La estructura de las revoluciones científicas, ${ }^{4}$ del historiador y filósofo de la ciencia T.S. Kuhn (1922-1996), como el punto de inflexión desde una filosofía racionalista centrada en la lógica de la argumentación científica a una filosofía de la ciencia sociologicista que pone el peso en los intereses y/o causas sociales en torno al hecho científico y no en la racionalidad/ irracionalidad o en la verdad/falsedad de la ciencia. ${ }^{5}$ Sin embargo, la obra de Kuhn puede in cardinarse dentro de un movimiento mas amplio, que se dio en la década de 1960, entendido como una reacción filosófica post-positivista que propiciaba los trabajos en historia social de la ciencia (y a su vez era influido por estos), los cuales ponían el énfasis en los intereses sociales y no en las razones lógicas de la evolución científica. En este sentido, mencionaremos la obra de autores como Stephen Toulmin, ${ }^{6}$ Russell Hanson, ${ }^{7}$ Imre Lakatos ${ }^{8}$ y Paul Feyerabend.

Ronald GIERE: "History and Philosophy of Science: Intimate Relationship or Marriage of Convenience?", British Journal for the Philosophy of Science, 24 (1973), pp. 282-297.

Jack SMART: "Science, History and Methodology", British Journal for the Philosophy of Science, 23 (1972), pp.266-274.

3 Antonio DIÉGUEZ: Filosofía de la ciencia, Madrid, Biblioteca Nueva, 2005

4 Thomas KUHN: La estructura de las revoluciones cientificas, México, Fondo de Cultura Económica, 1971

5 Carlos SOLís: “Introducción”, en Carlos SOLís (comp.): Razones e intereses. La historia de la ciencia después de Kuhn, Barcelona, Paidós, 1994

6 Stephen TOULMIN: Foresight and Understanding, Bloomington, Indiana University Press, 1961.

7 Russell HANSON: Patters of Discovery, Cambridge, Cambridge University Press, 1958.

8 Imre LAKATOS: "Falsationism and the Methodology of Scientific Research Programmes", en Imre LAKATOS y Alan MUSGRAVE (comps.): Criticism and the Growth of Knowledge, Cambridge, Cambridge University Press, 1970.

9 Paul FEYERABEND: Against Method: Outline o fan Anarchistic Theory of Knowledge, Minneapolis,
En particular, es la visión de como hacer historia de la ciencia de Paul Feyerabend (1924-1994) la que vamos a tratar en este trabajo, para ello recurriremos a un ejemplo programático de este proceder: el caso de Carlos Castaneda (1925-1988). La elección de Castaneda no es casual, Feyerabend elogiaba la obra de este,$^{10} \mathrm{y}$ ambos forman parte de una misma línea epistemológica dentro del amplio campo de la historia de las ideas junto a autores como Edgar Morin, Stephen Toulmin, loan Culianu y Umberto Eco, entre otros. Esta línea está, en algunas ocasiones, débilmente marcada y en otros lugares resulta poderosamente obvia, sin embargo es una línea invisible, una línea fantasma de la cual no tenemos pruebas físicas de su existencia pero que intuimos fuertemente. Esta línea conecta a personas, mas bien conecta sus modos de pensar la historia de las ideas. Estas personas forman una escuela imaginaria dentro de la historia de la ciencia, una escuela que no comparte instituciones materiales como academias o revistas sino que comparte un mismo espíritu humano y más tarde un mismo enfoque epistémico en su abordaje a la historia del pensamiento occidental. En palabras del historiador de la ciencia Robert Merton son los "colegios invisibles", entendidos como un compuesto interactivo de influencias socioculturales, interpersonales y cognitivas sobre los individuos que han provocado desarrollos cognitivos en un área de conocimiento."

\section{La historia de la ciencia según Feyerabend}

Paul Feyerabend obtuvo su doctorado en filosofía en 1951, con una tesis sobre el Círculo de Kraft, basada en las notas y argumentaciones hechas por Feyerabend que había asistido con regularidad a las reuniones del círculo entre 1948 y $1949 .{ }^{12}$ El Circulo de Kraft, dirigido y fundado por Viktor Kraft era, en palabras de Feyerabend, "una versión estudiantil del antiguo Círculo de Viena"13 del que Kraft había sido miembro.14Tras su doctorado, Feyerabend intentó ir con Wittgenstein a Cambridge pero este último murió y Feyerabend se decantó por Londres junto a Popper y Lakatos. En 1958, Feyerabend acepta una oferta de profesor visitante en Berkeley (donde más tarde obtuvo plaza como profesor titular), es aquí donde entra en estrecho contacto con Kuhn. A partir de la publicación en 1970 de Contra el método, la cual fue todo un éxito, Feyerabend obtiene un buen numero de cátedras en diferentes universidades incluyendo la de Bekerley, ${ }^{15}$ cátedras que acepta y rechaza con extrema rapidez. ${ }^{16}$

La restante obra de Feyerabend no añade demasiado a Contra el método, mencionaremos La ciencia en una sociedad libre (1982),,$^{17}$ Adiós a la razón (1984), ${ }^{18}$ ¿Por qué no Platon? (1985) ${ }^{19} \mathrm{y}$

University of Minnesota Press, 1970

10 Marvin HARRIS: El materialismo cultural, Madrid, Alianza Editorial, 1982.

11 Robert MERTON: "Los colegios invisibles en el desarrollo cognitivo de Kuhn", en Carlos SOLís (comp.): Alta tensión, Barcelona, Paidós, 1998.

12 Paul FEYERABEND: Matando el tiempo. Autobiografía, Madrid, Debate, 1995.

13 Ibid., pp.74

14 El Círculo de Viena fue una asociación fundada en el año 1922 y disuelta definitivamente en 1936 Este movimiento, con el nombre original de Círculo de Viena para la concepción cientifica del mun $d o$, se ocupo principalmente de la logica de la ciencia, considerando la flosofía como una disciplina encargada de distinguir entre lo que es ciencia y lo que no, y de la elaboración de un lenguaje Viktor KRAFT. El círculo de Viena, Madrid, Taurus, 1986.

15 Obtuvo cátedra en las universidades de Yale, Bristol, Stanford, Berlín, Kassel, Zurich, Brighton, Lon15 Obtuvo cátedra
dres y Auckland.

dres y Auckland.
Paul FEYERABEND: Matando el tiempo. Autobiografía..., p. XX.

17 Paul FEYERABEND: La ciencia en una sociedad libre, Madrid, Siglo XXI, 1982.

18 Paul, FEYERABEND: Adiós a la razón, Madrid, Tecnos, 1984.

19 Paul, FEYERABEND: ¿Por qué no Platon? Madrid, Tecnos, 1985 
Diálogo sobre el método (1990). ${ }^{20}$ En general, desde su seminal obra Contra el método, pasando por las obras antes citadas, hasta la publicación póstuma de La conquista de la abundancia (1999),, ${ }^{21}$ lo que Feyerabend intenta hacer es articular y defender sus tesis metodologicas (el anarquismo epistemológico) realizando trabajos en historia de la ciencia (en especial, pero no solo, el caso Galileo). Así, para Feyerabend, lo que deben hacer los filósofos de la ciencia es dejar de realizar abstracciones especulativas y dedicarse a un estudio detallado de las fuentes primarias de la historia de la ciencia. ${ }^{22}$

Para empezar, Feyerabend recomienda al historiador de la ciencia nutrirse e inspirarse (como él mismo hace) de las obras de Stuart Mill, Friedrich Hegel, Karl Marx y Vladimir Lenin. El estudio de los autores anteriores ayudara al historiador de la ciencia al proporcionarle una postura ideológica política (léase anarquismo epistemológico) que este debe intentar trasladar a sus trabajos históricos, pero también el historiador de la ciencia debe emular el estilo narrativo de los citados autores ya que, Feyerabend propone contar las historias con un lenguaje claro y sencillo, entendible por todos y alejado de la jerga y expresiones abstractas de difícil comprensión. ${ }^{23}$ En cuanto a autores más cercanos a la historia de la ciencia, Feyerabend recomienda, aunque con reservas, seguir a Kuhn y Lakatos. ${ }^{24}$

Feyerabend señala, incansablemente, a lo largo de toda su obra, que la historia "es siempre más rica en contenido, más variada, más multilateral, más viva y sutil de lo que incluso el mejor historiador y el mejor metodólogo pueden imaginar". ${ }^{25}$ Así las cosas, el historiador debe buscar, indagar y profundizar en detalle en todos los diferentes ángulos de un hecho para que su historia sea "tan compleja, tan caótica, tal llena de error y tan divertida como las ideas que contenga, y estas ideas serán a su vez tan complejas, tan caóticas, tal llenas de error y divertidas como lo son las mentes de quienes las inventaron". ${ }^{26}$ En este sentido, Feyerabend insta a los historiadores a no reducir los límites de sus historias, a no empobrecer los infinitos materiales históricos, a no trabajar con conceptos estables, a dudar siempre de haber encontrado la descripción correcta de los hechos, a atender a los detalles pasados por alto o desdeñados por otros por irrelevantes, a fijarse especialmente en los errores de los actores de sus historias más que en sus aciertos y a tener en cuenta el porcentaje de irracionalidad en la evolución de sus historias. ${ }^{27} \mathrm{El}$ historiador que, según Feyerabend, siga los consejos anteriores, dejará de poseer un conjunto de reglas que lo "guíen a través de todas las sinuosidades de la historia de la ciencia". ${ }^{28}$ Tal historiador carecerá de un modelo a seguir, de un patrón a imitar, de unos lugares (expresiones narrativas) comunes que le den seguridad profesional, porque sin duda se puede "forzar a la historia en un modelo, pero los resultados serán siempre más pobres y menos interesantes que los acontecimientos reales". ${ }^{29}$ En cambio, el historiador de la ciencia debe considerar en su trabajo los "accidentes, prejuicios, condiciones materiales, verbigracia

20 Paul, FEYERABEND: Diálogo sobre el método, Madrid, Cátedra, 1990

21 Paul FEYERABEND: La conquista de la abundancia. La abstracción frente a la riqueza del ser, Barcelona, Paidós, 1999.

22 Paul FEYERABEND: "Philosophy of Science: A Subject with a Great Past", en Roger STUEWER (comp.): Historical and Philosophical Perspectives of Science (Study in Philosophy of Science), Minneapolis, University of Minnesota Press, 1970 .

23 Paul FEYERABEND:Contra el método. Esquema de una teoria anarquista del conocimiento, Barcelona, Ariel, 1974 .

4 Paul FEYERABEND: Matando el tiempo. Autobiografía..., pp. XIV-XV .

25 Paul FEYERABEND: Contra el método. Esquema de una teoría anarquista del conocimiento..., p.7.

26 Ibid., p.11.

27 Ibid., pp.7-36

28 Ibid., p.101.

29 lbid, la existencia de un tipo particular de cristal en un país y no en otro para la explicación de la historia de la óptica, las vicisitudes de la vida de casado, superficialidad, orgullo, inadvertencia y muchas otras cosas". ${ }^{30}$ En síntesis y en concordancia con las ideas de Edgar Morin: lo que e historiador debe intentar es resaltar sin tapujos la complejidad de la evolución y del cambio del pensamiento científico a lo largo de la historia. ${ }^{31}$

Por todo lo anterior, Feyerabend como historiador de la ciencia se fue acercando cada vez más al tratamiento histórico de ideas y teorias (antiguas y actuales) desechadas tanto por e científico como por el historiador, con el objetivo de demostrar que no existen razones lógicas para que estas teorías estén en ningún lugar en parte alguna (usando una expresión de Luis Montiel) en la historia de la ciencia, sino que los factores que han propiciado su olvido, ${ }^{32}$ desprestigio y ocultamiento han sido intereses puramente sociales (y también humanos). ${ }^{33}$

Por último, mencionaremos que Feyerabend recomienda al historiador de la ciencia, al igual que lo hace Kuhn, tener en cuenta la tesis de la inconmensurabilidad de las teorías rivales. Según Kuhn, ${ }^{34}$ ambos llegaron al concepto de la inconmensurabilidad al mismo tiempo pero independientemente y los dos coinciden en que no se puede comparar empíricamente el contenido de teorías rivales con el objetivo de determinar cual es superior o más verdadera. ${ }^{35}$

\section{El caso de Carlos Castaneda}

Carlos César Salvador Aranha Castañeda nació en Cajamarca (Perú) en 1925 y murió en Los Ángeles (California) en 1998, ${ }^{36}$ según el propio Castaneda, nació en Sao Paulo (Brasil) en 1935. ${ }^{37}$ Dos lugares muy diferentes, dos fechas distanciadas en diez años. En este sentido, Carlos Castaneda inventó partes extensas de su biografía, como lugar y fecha de nacimiento (nació en Perú no en Brasil), fecha de fallecimiento de su madre (su madre falleció cuando tenia 24 años no 6 años), profesión del padre (su padre era joyero no profesor de literatura), lugar de estudios (estudió pintura y escultura en Lima no en Milán) y también inventó algunas anécdotas/aventuras como la de haber servido en el ejército estadounidense en España durante una guerra..$^{8}$ Valga lo anterior como ejemplo de la dificultad de un acercamiento biográfico a la persona de Carlos Castaneda.

Lo cierto es que Carlos Castaneda fue un estudiante de antropología en University of California Los Angeles (UCLA), que obtuvo el Bachelor of Arts en 1962, el Master of Arts en 1968 por su primer libro titulado: The Teachings of Don Juan. A Jaqui Way of Knowledge ${ }^{39}$ y el Ph.D..$^{\circ}$ en 1973

30 Paul FEYERABEND: La conquista de la abundancia. La abstracción frente a la riqueza del ser..., pp. 23. 31 Edgar MORIN: Ciencia con consciencia, Barcelona, Anthropos, 1984

32 Luis MONTIEL y Ángel GONZALEZ DE PABLO (coords.): En ningún lugar, en parte alguna. Estudios sobre la historia del magnetismo animal y del hipnotismo, Madrid, Frenia, 2003

33 John LOSEE: Filosofía de la ciencia e investigación histórica, Madrid, Alianza Editorial, 1989.

34 La tesis de la inconmensurabilidad de las teorías científicas apareció formulada en La estructura de las revoluciones cientificas de Kuhn y en Explicación, reducción y empirismo de Feyerabend, ambos publicados en 1962 .

35 Antonio DIÉGUEZ: Filosofía de la ciencia..., pp. 198-209.

36 Según Margaret RUNYAN: Un viaje mágico con Carlos Castaneda, Barcelona, Obelisco, 1999, Carlos Castaneda cambió la "ñ" de su apellido por una "n" cuando obtuvo la nacionalidad en Estados Unidos en 1957.

37 Richard DE MILLE: La aventura de Castaneda. El poder y la alegoria, Madrid, Editorial Snaw, 1976. 38 Marvin HARRIS: Vacas, cerdos, guerras y brujas, Madrid, Alianza Editorial, 1980.

39 Carlos CASTANEDA: The Teachings of Don Juan. A Jaqui Way of Knowledge, Berkeley, University of California Press, 1968

40 Según Pello SALABURU (ed.): Sistemas Universitarios en Europa y EEUU, Madrid, Academia Europea Bachelor of Arts como Grado, Master of Arts como Master y Ph.D. como el titulo de Doctor. 
por la tesis titulada: Sorcery, A Description of the World..$^{41}$ Según Richard de Mille, ${ }^{42}$ el texto de la tesis doctoral coincide casi literalmente con un libro de Castaneda que fue publicado un año antes, en 1972, bajo el titulo de Journey to Ixtlan. The lessons of Don Juan, ${ }^{43}$ entre la publicación de estos dos trabajos se sitúa su segundo libro: A Separate Reality. Further Conversations with Don Juan (1971). ${ }^{44} \mathrm{Si}$ atendemos a las fechas dadas arriba correspondientes a su nacimiento, Castaneda tendría en el momento de obtener su doctorado 48 o 38 años, según una u otra versión. ${ }^{4}$

En 1969, los editores de Ballantine Books lanzaron de forma comercial The Teachings of Don Juan. A Jaqui Way of Knowledge, se vendieron 7.500 ejemplares el mismo año de publicación llegando a alcanzar los primeros lugares de la lista de libros más vendidos. ${ }^{46} \mathrm{En} 1973$ se habían vendido 300.000 ejemplares del libro y continuaba vendiéndose a un ritmo de 16.000 ejemplares por semana y en 1977 se habían vendido cuatro millones de ejemplares. ${ }^{47}$ Tras este éxito inicial, que convirtió a Castaneda en millonario, la posterior obra de este continuo siendo un éxito de ventas, en particular los siguientes tres libros ${ }^{48}$ y en menor medida el resto de su obra, ${ }^{49}$ en este sentido Castaneda había vendido hasta 1998 (año de su muerte) diez millones de copias del total de once libros publicados, ${ }^{\circ}$ a estos hay que añadir la publicación póstuma de su ultimo libro The Active Side of Infinity (1999).

Castaneda sintetiza de la siguiente manera como comenzó todo:

Me hallaba acabando mi licenciatura en UCLA y planeaba asistir a una cátedra de graduación en antropología. Ouería convertirme en profesor y consideré que podía empezar con buen pie publicando un ensayo corto sobre plantas medicinales. Me traía sin cuidado el encontrar a un personaje raro como Don Juan. Estaba en una estación de autobuses, en Arizona, con un compañero de la facultad. Este me señalo a un anciano indio y me dijo que él conocía el peyote y las plantas medicinales. Ouise darme tono y me presenté a Don Juan diciendo: Entiendo que sabe usted mucho sobre peyote. Yo soy uno de los expertos

41 Carlos CASTANEDA: Sorcery, A Description of the World, Tesis Doctoral, University of California, 1973 42 Richard DE MILLE: La aventura de Castaneda. El podery la alegoría..., pp. 76-80.

43 Carlos CASTANEDA: Journey to Ixtlan. The Lessons of Don Juan, New York, Simon and Schuster, 1972.

44 Carlos CASTANEDA: A Separate Reality. Further Conversations with Don Juan, New York, Simon and Schuster, 1971.

45 Entre los autores que han trabajado y perfilado algunos aspectos de la biografía de Carlos Castaneda parece consensuada la fecha de nacimiento de 1925 en Cajamarca, Perú y así queda reflejado en The Scribner Encyclopedia of American Lives, Volume 5: 1997-1999. Charles Scribner's Sons, 2002. Estos datos están avalados por documentos oficiales de inmigración de U.S.A.

46 La restante obra de Castaneda fue publicada por la editorial Simon and Schuster que también adquirió los derechos del primer libro de Castaneda.

47 Sam KEEN: “Sorcerer's Apprentice”, Psychology Today, 6 (1972), pp.90-102.

48 Los ya citados, A Separate Reality. Further Conversations with Don Juan y Journey to Ixtlan. The Lessons of Don Juan junto al cuarto libro: Carlos CASTANEDA: Tales of Power, New York, Simon and Schuster, 1974

49 Carlos CASTANEDA: The Second Ring of Power, New York, Simon and Schuster, 1977; ÍD.: The Eagle's Gift, New York, Simon and Schuster, 1981; İ.: The Fire From Within, New York, Simon and Schuster, 1984; ID.: The Power of Silence: Further Lessons of Don Juan, New York, Simon and Schuster, 1987; ID.: The Art of Dreaming, New York, HarperCollins, 1993; ÍD.: Magical Passes: The Practical Wisdom of the Shamans of Ancient Mexico, New York, Laugan Productions, 1998; e İD.: The Wheel of Time: Shamans of Ancient Mexico, Their Thoughts About Life, Death and the Universe, New York, Laugan Productions, 1998.

50 Juan Carlos GONZÁLES y Anita GRAMIGNA: "El antropólogo como aprendiz. A propósito de Carlos Castaneda y Las enseñanzas de Don Juan, cuarenta años después", Gazeta de Antropología, 25 (2009), http://hdl.handle.net/10481/6869.

51 Carlos CASTANEDA: The Active Side of Infinity, New York, Laugan Productions, 1999 en peyote (había leído The Peyote Cult de Weston La Barre) y creo que le gustaría venir a comer y hablar conmigo. Bien, solo me miro y mi envalentonamiento se derritió. Me quedé mudo y entumecido. Yo era normalmente agresivo y locuaz por eso al quedar silenciado por una mirada era un acontecimiento extraño. Tras ese encuentro comencé a visitarl y, un año más tarde, me comunicó que había decidido transmitirme el conocimiento de la brujería que había recibido de su maestro..$^{52}$

Tras su doctorado (y el éxito de ventas de sus libros), Castaneda obtiene una plaza de profesor en UCLA, sin embargo ya en algunas de las iniciales reseñas al primer libro de Castaneda se ponen de manifiesto los recelos, dudas y posiciones ambivalentes en torno a algunos aspectos concretos de la obra que, todos juntos, parecían apuntar a la veracidad de lo narrado por Castaneda, veracidad que en un principio fue puesta en duda en cuestiones concretas para, con el paso del tiempo, dudar de toda la obra de este y denunciar a Castaneda como un fraude y a su obra como una total invención con extensos pasajes plagiados de otros textos. En este sentido citaremos, por su exhaustividad (todos juntos compilan casi toda la literatura publicada existente sobre el tema) y por ser trabajos monográficos del tema de la controversia de Castaneda, los libros de Richard de Mille, ${ }^{53}$ Daniel Noel 54 y Jay Fikes..$^{55} \mathrm{~A}$ los anteriores hay que añadir los capítulos dedicados al tema en varios libros de Marvin Harris. ${ }^{56}$ Sin embargo no toda la recepción de la obra de Castaneda en el mundo académico fue negativa o recelosa, también hubieron criticas favorables de profesores y especialistas importantes como Edward Spicer, ${ }^{57}$ Paul Riesman ${ }^{58}$ y William Clements. ${ }^{59}$ En este sentido, Castaneda encontró un gran apoyo en los compañeros profesores y mentores intelectuales provenientes del entorno académico de UCLA, ${ }^{\circ}$ los cuales durante un tiempo cerraron filas en torno a Castaneda hasta que un reportaje de investigación de la prestigiosa revista Time ${ }^{61}$ destapó numerosas mentiras de Castaneda sobre su biografía. ${ }^{62}$ Después del reportaje de Time, aumentaron las críticas negativas hacia la obra de Castaneda por parte de académicos de renombre y ante la imposibilidad de Castaneda de disipar las dudas sobre la veracidad de su trabajo ${ }^{63}$ la balanza acabó decan-

52 Sam KEEN: “Sorcerer's Apprentice”..., p.94

53 Aparte del libro ya citado La aventura de Castaneda. El poder y la alegoría, también encontramos: Richard DE MILLE: The Don Juan Papers. Further Castaneda Controversies, Santa Barbara, Ross-Erikson Publishers, 1980.

54 Daniel NOEL: Castaneda a examen, Barcelona, Kairós, 1977.

55 Jay FIKES: Carlos Castaneda, oportunismo académico y los psiquedélicos años sesenta, Indiana, Xlibris, 2009.

56 Marvin Harris: "El retorno de las brujas", en Marvin Harris: Vacas, cerdos, guerras y brujas, Madrid, Alianza Editorial, 1980; e ÍD.: “El oscurantismo”, en Marvin Harris: El materialismo cultural, Madrid, Alianza Editorial, 1982

57 Edward SPICER: "Review of The Teachings of Don Juan", American Anthropologist, 71 (1969), pp.320-322.

58 Paul RIESMAN: "The Collaboration of Two Men and a Plant", New York Times Book Review, 7 (1972, pp. 10-12.

59 William CLEMENTS: “Carlos Castañeda's The Teachings of Don Juan: A Novel of Initiation”, Critique (26), 1985, pp.122-130.

6o Según Richard DE MILLE: La aventura de Castaneda. El poder y la alegoría..., pp.81-86, entre los que apoyaron públicamente a Castaneda del entorno de UCLA se cuenta a los profesores David Silverman, Clement Meighan, Harold Garfinkel y Michael Harner, entre otros.

61 Robert HUGHES y Sandra BURTON: “Don Juan and the Sorcerer's apprentice”, Time, 101 (1973), pp.36-45.

62 Estas mentiras han sido apuntadas más arriba al comienzo del apartado sobre Castaneda, en el final de la pagina 6 y comienzo de la pagina 7.

63 Castaneda afirmó haber perdido todas las notas escritas a mano de su trabajo de campo con Don Juan y nunca se presentaron testigos que confirmaran la existencia de Don Juan o de los diversos 
tándose en contra de este por lo que tuvo que dejar su puesto como profesor en UCLA. ${ }^{64}$ Así las cosas, el rumbo de Castaneda ha seguido la pauta de todos aquellos autores que han sido apartados del mundo académico tras una controversia en torno a la obra de estos, sin el apoyo institucional y la pérdida del prestigio científico la mayoría de estos autores se dirigen prolíicamente al público popular mediante la publicación de libros, conferencias, entrevistas, etc..6 En este sentido, Castaneda impartió charlas y talleres durante un tiempo en Esalen Institute en Big Sur (California), ${ }^{66}$ continuó publicando sus libros hasta el momento de su muerte (casi al ritmo de uno por año) y con el tiempo fundo una especie de secta de alcance internacional en torno a las enseñanzas de Don Juan. ${ }^{67}$

\section{Como contar la historia de Castaneda según el modelo de Feyerabend}

El caso de Carlos Castaneda es difícilmente encontrado en los libros de historia de la antropología, tras la extensa controversia arriba comentada, parece que la comunidad académica ha querido olvidar al polémico Castaneda, condenándolo a él y a su obra al olvido. En el manual, al uso en los estudios de grado en antropología, de Ubaldo Martínez ${ }^{68}$ y en la monumental obra en tres volúmenes de Manuel Marzal no hay siquiera una nota a pie de pagina donde se mencione a Castaneda. ${ }^{69}$ Sin embargo, el historiador de la ciencia, aun más aquel que sigue el modelo de Feyerabend, no puede desperdiciar un caso tan interesante y con tantas implicaciones para la historia social de las ideas como es el caso de Castaneda.

Lo primero es poner en duda que las únicas razones para el ataque y la critica de los profesionales académicos a Castaneda y la posterior caída de este tuvieran solo que ver con argumentos científicos como la poca validez ecológica de la investigación, la poca coherencia interna y/o externa de esta, los fallos metodológicos en el trabajo de campo, la veracidad o falsedad de su trabajo, etc. En cambio, nos tendremos que fijar en los intereses sociales y personales de los atacantes para ir en contra de Castaneda y no en las razones objetivas expuestas por ellos teñidas de cientificidad. Encontrando estas diferencias sociales entre los atacantes a Castaneda y este mismo junto con sus defensores daremos cuenta de ellas, intentando integrar la estructura social y la cognitiva en nuestra narración para una vez estén destacadas claramente la localización social, académica, cognitiva, ideológica y antropológica/científica de los actores en juego proceder a relacionar estas posiciones con la naturaleza y el curso de la controversia. Nuestra historia sobre Castaneda no debe basarse en la visión de este como un accidente o excentricidad dentro de la disciplina de la antropología y no debe ser evaluado como una anormalidad en el ámbito científico, su obra no debe ser analizada en los términos de veracidad y falsedad, pues todo lo anterior reduciría considerablemente las implicaciones históricas sociales del caso Castaneda. Según Feyerabend, debemos buscar la complejidad del asunto en toda su extensión posible, en este sentido intentaremos explicar los orígenes y la génesis del

personajes de los libros de Castaneda.

64 Charlotte HARDMAN: "He may be lying but what he says is true: the sacred tradition of Don Juan as reported by Carlos Castaneda, anthropologist, trickster, guru, allegorist", en James LEWIS y Olav HAMMER (eds.): The

65 Agustí NIETO-GALAN: Los públicos de la ciencia. Expertos y profanos a través de la historia, Madrid, Marcial Pons, 2011.

66 Esalen Institute esta considerado como una de las cunas del movimiento New Age en Estados Unidos, para una historia de esta organización: Jeffrey KRIPAL: Esalen. America and Religion of No Religion, Chicago, The University of Chicago Press, 2007.

7 David KRANTZ: "Carlos Castaneda and His Followers: Finding Life's Meaning in Your Local Bookstore", The Journal of Popular Culture, 39 (2006), pp.576-598.

68 Ubaldo MARTINEZ: Historia de la antropología. Formaciones socioeconómicas y praxis antropológicas, teorias e ideologias, Madrid, UNED, 2010.

69 Manuel MARZAL: Historia de la antropología (3 vols.), Quito, Fondo Editorial, 1998. caso Castaneda centrándonos en ese "colegio invisible" mertoniano (que apuntábamos en la introducción), para dar cuenta de toda la red de influencias socioculturales, interpersonale y cognitivas que gestaron y posibilitaron la obra de Castaneda. En este sentido, y siguiendo estudio de los agradecimientos académicos y los autores citados en la obra de Castaneda.71 Así, nos preocuparemos especialmente por el papel de UCLA en la controversia y las afiliaciones institucionales de los atacantes a Castaneda, poniendo de manifiesto los intereses de unos y otros para el éxito o caída de este ultimo. Así las cosas, nuestro trabajo histórico no puede finalizar hasta que no expliquemos en términos sociales el fenómeno de la controversia en torno a Castaneda y comprendiendo la disputa entre diferentes sectores de la comunidad antropológica al asimilar el aparente conflicto entre la veracidad o falsedad de la obra de Castaneda, teniendo en cuenta que algunas posturas filosóficas post-modernistas disuelven toda controversia en estos términos en el campo de la antropología ${ }^{72}$ a un conflicto entre grupos (UCLA y los otros) competidores por los mismos recursos en una sociedad. ${ }^{73}$ En definitiva, lo anterior constituirá la verdadera materia prima de nuestra narración, pero también pondremos especial atención a la posible o no inconmensurabilidad de las diferentes posturas filosóficas y metodológicas de los actores en conflicto para acabar explicando la controversia integrando las distintas posturas intelectuales de los actores con las posiciones, intereses y valores sociales de estos.

Por ultimo, no podríamos obviar en nuestra historia la recepción y repercusión popular (fuera de la academia) de la obra de Castaneda, pues como ya hemos apuntado, la difusión popular de la obra y el éxito de la misma en este sector está íntimamente relacionado con la condena académica y el menosprecio de la obra por parte de la mayoría de los antropólogos profesionales.

70 Robert MERTON: La sociología de la ciencia: investigaciones teóricas y empíricas, Madrid, Alianza Editorial, 1985 .

71 En el primer libro de Castaneda Las enseñanzas de Don Juan aparecen en el apartado de reconocimientos: Clement Meighan, Harold Garfinkel, Robert Edgerton, William Bright y Pedro Carrasco. Más de treinta años separan este primer libro del ultimo, titulado El lado activo del infinito (1999) durante este intervalo de tiempo Castaneda publicó diez libros más pero ninguno de ellos lleva un apartado de reconocimientos o agradecimientos, es en este su ultimo libro, donde vuelve a agradecer a Clement Meigahn y Harold Garfinkel, a los cuales les dedica la que seria su ultima obra.

72 En este sentido, pueden consultarse las obras, Anthony GIDDENS: Runaway Worl: How Globalization is Resaphing Our Lives, London, Profile Books, 1999; James BOON: Otras tribus, otros escribas. Antropología simbólica en el estudio comparativo de culturas, historias, religiones y textos, México, Fondo de Cultura Económica, 1990.

73 Así puede verse a UCLA como una institución outsider de la elite institucional bien establecida en el campo de la antropología luchando por conseguir prestigio profesional. Las instituciones que mantuvieron su oposición y acque a Castaneda por medio de personajes relevantes afiliadas a ellas fueron principalmente, Columbia University y University of Chicago. 


\section{"HEMOS VENIDO, HEMOS VISTO Y SE NOS HA}

\section{CONOUISTADO": LOS CONGRESOS CIENTÍFICOS COMO}

INSTRUMENTOS DE VALIDACIÓN EN CONTROVERSIAS*

Miquel Carandell Baruzzi

Centre d'Història de la Ciència (CEHIC)

Universitat Autònoma de Barcelona

\section{Introducción}

En la clausura del Congreso de Paleontología Humana de Orce, celebrado en septiembre de 1995, Philip Tobias, un famoso paleoantropólogo sudafricano, afirmó que había llegado unos días antes con una actitud escéptica respecto a la controvertida afirmación de que en Orce había homínidos de más de un millón de años y que, de hecho, un fragmento de cráneo hallado alli era el "primer europeo". Después de ver los yacimientos, seguía Tobias, examinar los huesos y escuchar las ponencias, se iba ahora convencido de que el "Hombre de Orce" no sólo era real sino que era crucial para entender la llegada de los homínidos a Europa. Él mismo sentenció: "Hemos venido, hemos visto y se nos ha conquistado". Según Tobias, el apoyo económico de las instituciones políticas para continuar la investigación debía recibirlo Josep Gibert, principal defensor del “Hombre de Orce", que, a base de "sangre, sudor y lágrimas", había conseguido una gran calidad científica en Orce. Finalmente, Tobias habló también de los medios de comunicación que, a pesar de hacerle la vida imposible durante el congreso, habían hecho una "cobertura excelente" del mismo.

Sociólogos e historiadores de la ciencia han utilizado el concepto de "herramienta" para referirse a elementos utilizados durante controversias científicas para respaldar una determinada posición. 'Este artículo pretende analizar los congresos científicos como una de estas "herramientas", como parte de las estrategias utilizadas por los científicos para la circulación y validación de argumentos controvertidos. Mi análisis se orienta en tres direcciones que ya se apuntan en el párrafo anterior. En primer lugar, estos encuentros sirven para convencer a la comunidad científica, tanto nacional como internacional, de la validez de determinadas investigaciones y teorías. Este es el público al que, en teoría, van dirigidos estos encuentros. En segundo lugar, estos eventos son usados para atraer a la clase política, que, encargada de repartir subvenciones y permisos de excavación, es clave dentro de la práctica científica. A los políticos se les capta habitualmente a través de la capacidad de potenciar económicamente las zonas dónde se encuentran los yacimientos o de la gran visibilidad que en ocasiones consiguen estos eventos. Finalmente, los congresos se usan para reafirmar posiciones en relación a la opinión pública, tanto local como estatal e incluso internacional.

* Quiero agradecer a Mar Cuenca e Ignacio Suay la posibilidad de participar en la sesión "Ciencia y Sociedad"; a Teresa Esquirol y Teresa Requena del Institut de Paleontologia de Catalunya por guiarme por el Archivo Josep Gibert; a Oliver Hochadel por su revisión del texto, y a Clara Florensa por su apoyo y ayuda.

1 Ver por ejemplo: Brian MARTIN y Edward GROTH: Scientific knowledge in controversy: The social dynamics of the fluoridation debate. New York, State University of New York Press, 1991.
Estas tres orientaciones están totalmente conectadas. Una puede ser utilizada para remarcar el discurso de la otra y viceversa. Por ejemplo, el hecho de que investigadores prestigiosos estén en el congreso, es aducido delante de los políticos como signo de la calidad de la investigación. A la vez, tanto políticos como científicos, son utilizados ante los medios de comunitigación. A la vez, tanto políticos como científicos, son utilizados ante los medios de comunipresentada delante de los políticos para justificar sus inversiones en ciencia.

El caso que me ha llevado a esta aproximación ha sido el de la controversia del "Hombre de Orce", de la que ya he analizado su historia. ${ }^{2}$ Para poder ir un paso más allá, en este artículo he decidido realizar una aproximación comparada con un segundo caso de estudio: el debate sobre el yacimiento de Pedra Furada en Brasil. Esta polémica se desarrolló en un marco temporal parecido al de Orce pero en un contexto científico, político y económico diferente. Así, si "Hombre de Orce" podía ser el "primer europeo", Pedra Furada era candidato para albergar al "primer americano". La investigación, liderada por la franco-brasileña Niède Guidon, causó, como el "Hombre de Orce" unos años antes, una encendida polémica tanto en los medios científicos como en los medios generalistas, especialmente después de un congreso internacional. A través de la comparación, se pueden identificar similitudes y también particularidades de cada caso que permiten entender mejor la práctica científica en general y las situaciones polémicas en concreto. De esta manera, también puedo distanciarme del que ha sido de mi objeto de estudio, el caso de Orce, para verlo desde una perspectiva diferente. Por supuesto, no podré profundizar en el caso de Pedra Furada como lo he hecho en el de Orce, ya que el contexto y las fuentes me son más alienas, pero, a pesar de eso, este nuevo caso me servirá para comparar determinados aspectos y me permitirá realizar una aproximación más profunda a ambos casos. En el siglo XIX, los congresos habían tenido una gran importancia en la comunidad científica, relevancia que se había ido perdiendo a lo largo del siglo XX. Este artículo quiere hacer ver que, a finales del siglo XX, estos eventos fueron cruciales en estos dos casos controvertidos.

En la primera parte de este trabajo, introduciré las historias de Orce y Pedra Furada. En la segunda parte, compararé los dos casos centrándome en los congresos. Finalmente, apuntaré en las conclusiones como estos encuentros fueron parte de la retórica científica utilizada en estas dos controversias y como eso implica la intervención de políticos y público genera en la generación de conocimiento científico, desvaneciéndose así las fronteras entre aquello considerado científico, político o público.

\section{Controversias de piedras y huesos}

"El Hallazgo del Siglo": La controversia del Hombre de Orce

En este apartado, resumiré la historia de la controversia del "Hombre de Orce" hasta la realización en 1995 del congreso, para entender cuál era la situación en dicho evento

En junio de 1983, tres paleontólogos del Institut de Paleontologia de Sabadell, Barcelona, Jordi Agustí, Salvador Moyà-Solà y Josep Gibert, presentaban en una rueda de prensa en Granada, junto con políticos de la Diputació de Barcelona y de la Junta de Andalucía, el hallazgo

2 Miquel CARANDELL: “Homínidos, dudas y grandes titulares: La controversia del Hombre de Orce en la prensa española (1983-2007)", Dynamis, 33 (2), (2013). 3 Para más información sobre este caso: José GIBERT: Hombre de Orce: los homínidos que vinieron del sur, Cordoba, Almuzara, 2004. CARANDEL: "Hominidos..." para un análisis histórico. José Antonio DIAZ ROJO: "Retórica científica en la prensa. El hallazgo paleontológico del cráneo de Orce (1983)" Universidad de ValaZ ROJO (ed.) La circulacion del saber cientifico en los siglos XIX Y XX. Valencia: de la controversia. 
del Ilamado "Hombre de Orce".4 Descubierto en el yacimiento de Venta Micena, en la población granadina de Orce, este fragmento de cráneo que apenas media unos 10 centímetros tenía una serie de características que lo hacían humano, a pesar de estar aún pegado a una roca por la parte interna, que no se podía ver. El fragmento fue anunciado cómo el "primer europeo", un homínido de entre o,9 y 1,6 millones de años.

Este descubrimiento impactó en los medios españoles, que recogieron la noticia con titulares como "Revolución científica" o "Hallazgo del Siglo". ${ }^{6}$ Durante el siguiente año, en el que los investigadores y el hueso aparecieron en televisión, radio y prensa, se realizó también la separación de la parte interna.

Durante la limpieza apareció una pequeña cresta que no encajaba con la anatomía humana. ${ }^{8}$ Sorprendidos, los tres investigadores hicieron un viaje a París para enseñar el fragmento a Marie-Antoinette y Henry de Lumley, una pareja de conocidos prehistoriadores que habían visto el fragmento el año anterior, afirmando que era homínido. En este segundo vistazo, $\mathrm{Ma}$ rie-Antoinette, que era experta en anatomía, afirmó que aquello no era humano sino que probablemente era un ejemplar joven de Equus, género de caballos y asnos. ${ }^{9}$ Los de Lumley, des de su posición dominante de prestigiosos científicos franceses, instaron a los tres descubridores a convocar una rueda de prensa para dar a conocer su error. ${ }^{10}$ En este momento, Moyà-Solà y Agustí, que eran más jóvenes, aceptaron la nueva interpretación, pero Gibert, un poco mayor, no lo hizo e insistió en que era necesario seguir investigando para estar totalmente seguros." Al día siguiente, al llegar a Barcelona los tres científicos quedaron traspuestos ante el titular de portada de El País: "Serios indicios de que el cráneo del 'hombre de Orce' pertenece a un asno". ${ }^{2}$

En este momento, empezó una controversia que se produjo en los medios de comunicación y que tuvo a Josep Gibert como el principal defensor del "Hombre de Orce".13 En 1987, Agustí y Moyà-Solà publicaron el primer artículo científico que afirmaba que el "Hombre de Orce" era un asno. Antes del artículo, Moyà-Solà y Agustí, aparecieron en los periódicos expresando su nueva opinión acerca del hueso. ${ }^{14}$ Este hecho muestra como esta fue una controversia científica pero también pública, la opinión pública tuvo un papel destacado en la validación, tanto positiva como negativa, del llamado "Hombre de Orce". 15

Gibert quedó como un científico cuestionado, con problemas para conseguir financiación y permisos de excavación. A la vez, elaboró un discurso en el que se dibujaba como un revolucio-

4 Por ejemplo, Vladimir DE SEMIR: "Tres paleontólogos catalanes descubren el hombre más antiguo de Europa y Asia", La Vanguardia, 12 de junio de 1983.

5 Antes de Orce, los “primeros europeos" eran la mandíbula de Mauer y el "Hombre de Tautavel", que no pasaban del medio millón de años. Ver, por ejemplo, Robin DENNELL y Wil ROEBROEKS: "The earliest colonization of Europe: the short chronology revisited", Antiquity. 70 (1996), pp. 535-42.

6 José AGUILAR: "El hallazgo del Hombre de Orce puede suponer una revolución en el estudio de la especie humana", El Pais, 14 de junio de 1983 y W. LYON: “Huesos Extraños", El País, 15 de junio de 1983.

7 Jordi Agustí, 9 de julio de 2012, Barcelona, entrevista realizada por Miquel CARANDELL.

8 lbid.

GIBERT: El Hombre de... pp. 48

11 Jordi Agustí, 9 julio 2012.

12 Alfredo RELAÑO: "Serios indicios de que el cráneo del «hombre de Orce» pertenece a un asno", El Pais, 12 de mayo de 1984

13 Para más detalle: CARANDELL: "Homínidos....

14 Josep MERCADÉ: "Los colaboradores de Gibert dicen que el cráneo de Orce pertenece a un equino", La Vanguardia, 2 de octubre de 1987

15 CARANDELL: “Homínidos...”, pp. 381-382. nario ignorado por el "establishment" científico. ${ }^{16}$ Así, Gibert, y su pequeño grupo de colaboradores, utilizó un amplio abanico de estrategias para legitimar su posición y sus controvertidas propuestas: escribió artículos en periódicos y revistas, un libro de divulgación, publicó artículos científicos, elaboró una tupida red de contactos nacionales e internacionales y, en 1995 organizó el "Congreso Internacional de Paleontologia Humana de Orce"."7

"Evidencias provocativas": La polémica de Pedra Furada.

La polémica del yacimiento de Pedra Furada en Brasil surgió a raíz de la publicación de un artículo en 1986 en la prestigiosa revista Nature. ${ }^{18} \mathrm{~A}$ pesar de que la confrontación entre aquellos arqueólogos que creen que América estuvo habitada hace más de 20.000 años, y aquellos que mantienen que el hombre llegó hace no más de 15.000 años, viene de lejos, la publicación de este artículo volvió a encender el debate. ${ }^{19} \mathrm{Y}$ es que Guidon había encontrado una "abundante industria lítica" y restos de carbón, que indicarían hogueras prehistóricas, datadas en a menos 32.000 años. ${ }^{20}$

Guidon es una arqueóloga franco-brasileña que creció en Brasil pero estudió Arqueología en Francia. En 1978, descubrió Pedra Furada y, aunque tenía trabajo en Francia, pasaba períodos de excavación en Brasil hasta que en 1991 se estableció definitivamente cerca de los yacimientos. ${ }^{21}$ El abrigo llamado Pedra Furada esta situado en la Serra da Capivara en el noreste de Brasil. Esta zona cuenta con multitud de yacimientos arqueológicos y abrigos con pinturas rupestres. Durante estos años, Guidon también consiguió, mediante una fundación, montar un museo prehistórico, incentivar el desarrollo económico y turismo en la zona, y convertir la Serra da Capivara en Patrimonio de la Humanidad de la Unesco y Parque Natural brasileño. ${ }^{22}$

Asi pues, tras el artículo en Nature, varios científicos criticaron a Guidon tanto en medios especializados como en medios generalistas ${ }^{23}$ Las críticas fueron en varias direcciones: la industria lítica no sería un producto humano sino que procedería del derrumbe de la cueva, los carbones no formarían hogueras sino que provendrían de fuegos naturales y las pretensione de Guidon no pasarían de "provocativas". ${ }^{24}$

El debate internacional se desarrolló sobretodo en los medios científicos, dónde varios profesionales americanos publicaron artículos criticando Pedra Furada. ${ }^{25}$ En Brasil, en cambio, la polémica tuvo lugar en los medios públicos, donde científicos brasileños o que trabajaban en Brasil escribieron artículos en el periódico o cartas al director en los que criticaban a Guidon y sus teorías. ${ }^{26}$ Así se inició una controversia que tuvo su primer clímax durante y después de un

16 Ibid. pp. 376-377.

17 CARANDELL: “Homínidos.." pp. 372.

18 Más información en Elizabeth DRÉVILLON Le Secret de la Roche Percée, Fayard, 2011. Artículo en Nature: Niède GUIDON y Georgette DELIBRIAS: "Carbon-14 dates point to man in the Americas 32.00o years ago", Nature, 321: 769-771, (1986).

19 David WHITLEY y Ronald DORN: "New perspectives on the clovis vs. Pre-clovis controversy", Ame rican Antiquity, 58 (4) pp.626 (1993).

20 GUIDON Y DELIBRIAS: “Carbon-14 dates.".

21 DRÉVILLON: Le Secret... pp.114.

22 Más información en http://www.fumdham.org.br/

23 El caso más claro fue: David MELTZER, James ADOVASIO y Tom DILLEHAY: "On a Pleistocene human occupation at Pedra Furada, Brazil", Antiquity, 68, pp. 695-714, (1994).

24 André PROUS y Emilio FOGAÇA: "Archaeology of the Pleistocene-Holocene boundary in Brazil", Quaternary International, 53/54 (1999) 21-41. pp. 21.

25 Por ejemplo: Thomas LYNCH: "Glacial-age man in South America? a critical review", American Antiquity, 55(1), pp. 12-36, (1990).

26 Por ejemplo: Ricardo BONALUME: "Pesquisadora contesta idade de achados arqueologico", Folha de Sao Paolo, 25 de enero de 1986 
congreso, titulado "Reunião Internacional sobre o Povoamento das Américas", organizado por Guidon y realizado en la Serra da Capivara en Diciembre de 1993.

\section{Los Congresos científicos como herramientas de persuasión}

Comparando estos dos casos, podemos ver como la organización de congresos con la intención de "impresionar" a la comunidad científica y a la opinión pública, se presenta a través de la intención de generar diálogo entre "bandos" de científicos enfrentados. Esto se enmarca en la retórica de que los "rivales" evitan la discusión científica y simplemente niegan dogmáticamente. Así, con el objetivo de generar debate se organizan estos congresos. ${ }^{27}$

Mientras en las cartas que Gibert envía a los científicos que tendrían que participar en el congreso este afirma que el evento podría ser un buen momento para discutir sobre la llegada de los homínidos de África, ${ }^{28}$ en las actas del congreso, Gibert afirma que en el encuentro "lo importante era consolidar el paradigma de Orce" y que "conseguimos que la mayoría de los asistentes se diera cuenta de las inmensas posibilidades de la región"..29

Guidon, por su parte, escribe, por un lado, que el encuentro se realizó para "generate direct dialogue on the peopling of the Americas". Por el otro, en una entrevista realizada para un periódico brasileño antes del congreso, afirma que para convencerse "[...] basta ir la e ver as pedras".30

Esto saca a la luz como, a pesar del discurso del diálogo, cuando organizan estos congresos, lo que quieren Guidon y Gibert es conseguir adeptos para sus "causas". Como escribió Camilo José Cela Conde, hijo del Premio Nobel español, catedrático en la Universidad de las Islas Baleares, interesado en la evolución humana y presente en el congreso de Orce, en artículo en la revista de divulgación Investigación y Ciencia: "El propósito no declarado pero obvio de la conferencia era el de llevar a cabo un debate general acerca de los hallazgos de Orce, con el fin de obtener un reconocimiento de la comunidad paleontológica internacional". ${ }^{11}$

\section{Visitas a yacimientos y comunicaciones}

Tanto en Orce como en Pedra Furada, una de las herramientas de persuasión utilizadas fueron las visitas a los yacimientos y la presentación de comunicaciones. El hecho de llevar a los científicos a visitar los yacimientos es habitual en las ciencias arqueológicas, paleontológicas y antropológicas. No obstante, en estos casos controvertidos, como hemos visto en la anterio cita de Guidon, la visita a los yacimientos ha de servir para que los científicos "vean para creer".

En el congreso de Orce, se organizaron excursiones a varios yacimientos de la zona de Orce, entre ellos Venta Micena, dónde se había encontrado al "Hombre de Orce" y que había sido limpiado y excavado ese año tras 5 años de falta de permisos. De hecho, Gibert utilizó la celebración del congreso para conseguir este permiso. ${ }^{22}$ Según Cela Conde, durante la visita a los yacimientos, algunos miembros del equipo de Gibert, "comunicaron el hallazgo de varios restos, aún pendientes de publicar [...]. Entre ellos estaba BL-o, un molar parcial de un homíni-

27 CARANDELL:"Homínidos.." pp. 373 y Niede GUIDON et al.:"Nature and age of the deposits in Pedra Furada, Brazil: reply to Meltzer, Adovasio and Dillehay" Antiquity 73, pp. 408-21, (1996).

28 Josep GIBERT, Carta de Gibert a Bar-Yoseff. Sabadell. 3 de Octubre de 1993. Arxiu Josep Gibert (a partir de ahora AJG), que se encuentra en el Institut Català de Paleontologia Miquel Crusafont, en Sabadell. Caja 28

29 Josep GIBERT (ed.) Los hominidos y su entorno en el pleistoceno inferior y medio de Eurasia : actas del Congreso Internacional de Paleontología Humana, Orce 1995, Orce: Museo Josep Gibert (1999). 30 "Teoria tradicional é falha, diz Guidon", Folha do Sao Paolo, 11 de abril de 1993.

31 Camilo José CELA CONDE: “¿Comienza África en los Pirineos?” Investigación y Ciencia 232, pp. 34$36,(1996)$

32 Segunda Circular del Congreso de Orce. AJG, Caja 32. Josep GIBERT Carta de Gibert a Manuel García León, Sabadell, 2 de mayo de 1995. AJG, Caja 32. do, y una considerable cantidad de fragmentos de industria lítica". ${ }_{33}$ El "nuevo" molar aparece también en los medios, donde es presentado como la confirmación de las teorías de Gibert y el fin de las polémicas. ${ }^{34}$

En el Congreso de Pedra Furada, se realizaron dos visitas al yacimiento, más otras seis a diferentes abrigos de la zona. ${ }^{35} \mathrm{~A}$ pesar de las afirmaciones de Guidon de que era necesario ver los yacimientos para opinar sobre ellos, ${ }^{36}$ cuando, tras el congreso, surgen las críticas, la misma Guidon y su equipo afirman que con dos breves visitas no se puede adquirir suficiente conocimiento para criticar las excavaciones. 37

En relación a las comunicaciones científicas, en Orce, Gibert y su equipo se reservaron casi un cuarto del programa (18 de 68 presentaciones) para hablar de los diferentes yacimientos y fósiles en los que trabajaban. Seis de estas presentaciones trataron sobre el polémico fragmento de cráneo. ${ }^{38}$ En su libro de divulgación, Gibert plantea estas presentaciones como una "estrategia científica", de la que dice que "todos los asistentes salieron convencidos" de la presencia humana en el pleistoceno en Orce. ${ }^{39}$ Los medios españoles hablaron de estas comunicaciones, destacando que Gibert "tenía razón". $4^{\circ}$ Los huesos e industria lítica fueron expuestos en vitrinas para que tanto público especializado como profano, y periodistas, pudieran examinarlos. ${ }^{41}$ En la plaza de Orce se montó una pantalla gigante para que los habitantes del pueblo pudieran seguir las sesiones científicas..$^{42}$

En Brasil, de las sesiones, la más esperada fue la presentación de Fabio Parenti, colaborador de Guidon que acababa de presentar su tesis doctoral sobre Pedra Furada. Parenti presentaba nuevos datos sobre su análisis a la comunidad científica. La importancia de esta presentación aparece en los medios de comunicación brasileños que también destacan opiniones de otros científicos sobre ella.43

En definitiva, en estas dos controversias se puede ver como las visitas a yacimientos y las sesiones científicas habitualmente van ligadas a una intención de "convencer" a los diferentes públicos de los que hemos hablado, de especialistas a los mismos orcenses. La visita a los yacimientos, es suficiente para convencer, pero si este objetivo no se consigue, una visita no da suficiente base científica para criticar las investigaciones. Por otro lado, los congresos y visitas a yacimientos sirven también para presentar nuevas evidencias no publicadas que sirven para ratificar la posición científica, tanto delante de los expertos visitantes como delante de la opinión pública.

33 CELA CONDE: "¿Comienza..." pp. 35

34 Por ejemplo, noticiario Canal Sur del 1 de septiembre de 1995 o Carlos MORAN "La comunidad científica respalda la tesis de que los restos humanos de Orce son los más antiguos de Europa" $\mathrm{E}$ Ideal 5 de septiembre de 1995 .

35 MELTZER, ADOVASIO y DILLEHAY: “On a Pleistocene...”, pp. 695.

36 "Teoria tradicional..." Folha do Sao Paolo, 11 de abril de 1993.

37 GUIDON et al.: "Nature and age..." pp. 408.

38 Segunda Circular del Congreso de Orce. AJG, Caja 32.

39 GIBERT: Hombre de... pp. 93

4 O Daniel TURBÓN: “Hombre de Orce: Josep Gibert tenía razón”, La Vanguardia, 17 de septiembre de 1995

41 MORAN “La comunidad...".

42 Canal + Notícias, 7 de septiembre de 1995

43 Helio GUROVITZ: "Arquelogia busca origem de primerios brasilerios", Folha do Sao Paolo, 26 de diciembre de 1993. 
Promoción turistica y económica

Un segundo recurso de persuasión que surge de la comparación de ambos casos fue la capacidad de generación de actividad económica en la región en que se encuentran los yacimientos que tienen estos congresos y por extensión, las investigaciones científicas.

En una conferencia en Barcelona a modo de presentación del congreso de Orce, Gibert afirma que: "Este congreso también quiere potenciar el desarrollo económico de la región de Orce a través de su importante patrimonio, mediante el fomento del turismo cultural".44 Un año después del Congreso, Gibert escribe una carta a José Ramón Martínez Olivares, teniente de alcalde de Orce, donde justifica los esfuerzos puestos por el consistorio en sus investigaciones: "Por mi parte, estoy promocionando Orce. Saldrá un extenso reportaje en Science News...", y sigue mencionado artículos en National Geographic, American Journal of Physical Anthropoloy y Journal of Human Evolution. 45

En el libro Le Secret de la Roche Percée de la periodista Elisabeth Drévillon, que trata la vida de Niéde Guidon, la propia investigadora franco-brasileña afirma que hacer de los yacimientos un centro turístico puede atraer sitios de trabajo y mejores condiciones de vida a la zona de Piauí. ${ }^{46}$

Este llamamiento al desarrollo local está relacionado con la voluntad de Gibert y Guidon de legitimarse en Orce y Piauí, de donde no son originarios. Como indica la historiadora Irina Podgrony, en el contexto sudamericano los investigadores europeos se definían a si mismos como del lugar para legitimarse en su puesto de funcionario del estado y para hacer circular conocimientos que ellos mismos establecieron. ${ }^{47}$

Así, Gibert y Guidon quieren "transformase en locales" para disfrutar del beneplácito de las autoridades políticas y también de la opinión pública local. Gibert se convirtió en un personaje conocido en Orce, donde iba cada verano incluso sin permiso de excavación, el museo del pueblo se bautizó como Museo "Josep Gibert" y en la sesión de inauguración del congreso, Leandro Castellar, alcalde de Orce, se refirió a él como "nuestro queridísimo José Gibert". ${ }^{8}$ Aunque trabajó toda su vida en Sabadell, Gibert opositó, sin éxito, a una plaza en la Universidad de Granada. 49

El caso de Guidon es parecido en este sentido. Aunque siempre vivió de su trabajo en el Centre National de la Recherche Scientifique francés, ya desde 1991 se trasladó a la zona de Piauí, de la que es promotora ante las autoridades brasileñas. Guidon consiguió montar una Fundación que gestiona el patrimonio arqueológico, construyó un museo en el que los trabajadores son locales y también logró que el gobierno pagara un pequeño aeropuerto para incentivar el turismo cultural..$^{50}$

Los congresos se presentan como oportunidades de promoción económica ante los diferentes públicos para así reforzar la idoneidad de su realización. Además, los científicos aducen a este desarrollo como parte de sus estrategias de legitimación, tanto a nivel de sus teorías científicas como de sus carreras profesionales.

44 Josep GIBERT: “Conferéncia: Orce i Cueva Victòria. Deu anys d'investigacions paleoantropològiques: objectius i resultats", Museu Arqueologia de Catalunya, Barcelona. Mayo 1995. AJG, Caja 32. 45 Josep GIBERT: Carta de Gibert a José Ramón Martinez Olivares. 23 de octubre de 1996, AJG, Caja 32. 45 Josep GIBERT: Carta de Gibert
46 DRÉVILLON: Le Secret... pp. 136.

47 Irina PODGORNY: "Bones and devices in the Constitution of Paleontology in Argentina at the End of the Nineteenth Century", Science in Context, 18 (2) pp. 264, (2005).

48 CARANDELL: “Homínidos...", pp. 376-377. Vídeo Apertura del Congreso Internacional de Orce. 4 de septiembre de 1995.

9 Josep GIBERT: Carta de Gibert a Enrique García-Olivares. Sabadell, 1 Octubre 1993. AJG, Caja 32.

50 DRÉVILLON: Le Secret....pp. 155.
Expertos, politicos y medios de comunicación

Como hemos ido viendo, expertos, políticos y medios de comunicación son esgrimidos ante públicos variados como un valor añadido, no sólo al mismo congreso, sino también las investigaciones científicas.

Gibert, una y otra vez, dice que la presencia en Orce de estos científicos internacionales da validez a sus investigaciones y teorías. En una carta enviada poco antes del congreso a Joan Albaiges, director general de recerca de Catalunya, Gibert le adjuntó la primera circular, y añadió que el "eco del mismo será notable ya que hay grandes personalidades ya inscritas".

Philip Tobias, el más conocido de los invitados a Orce, concedió varias entrevistas en los medios, donde es presentado como la ratificación las investigaciones de Gibert. ${ }^{2}$ En un artículo para La Riuada, revista local de Móra d'Ebre, un pueblo catalán donde Gibert había vivido de joven, e científico escribió sobre el éxito del congreso citando la presencia de 250 expertos internacionales y de la aceptación de la Reina Sofía, que finalmente no fue al congreso, de ser presidenta de honor. ${ }^{53}$ Este artículo es una prueba más de como Gibert dirigía su discurso a un amplio rango de públicos, de políticos al público local de un pueblo como Móra d'Ebre. ${ }^{54}$ También muestra que una personalidad política como la Reina Sofia, sirve a Gibert en su discurso de legitimación.

Como hemos ido viendo, los medios de comunicación son cruciales en estas controversias en general, y en los congresos en concreto. El congreso de Orce fue seguido casi diariamente en la prensa y televisión españolas e incluso tuvo cierto alcance internacional. ${ }^{55} \mathrm{El}$ de Pedra Furada también apareció en los medios brasileños y en periódicos de todo el mundo..$^{56} \mathrm{Al}$ contrario que en el de Orce pero, en Pedra Furada, es la no-presencia de algunos expertos "rivales" lo que no permite cerrar el debate y por tanto no ratificar totalmente las excavaciones de Guidon. ${ }^{57}$

Los medios repitieron mayormente los discursos que hemos vista hasta ahora, mostrando una fina línea entre los medios científicos y los medios generales y haciendo patente la imposibilidad de separar los diferentes públicos de estos encuentros..$^{58}$

\section{Conclusiones}

En febrero de 1990, en un congreso de la American Association for the Advancement of Science, el conocido paleoantropólogo americano Milford Wolpoff organizó una sesión científica con una conferencia de prensa previa, que pretendía hacer ver a la audiencia que la llama-

51 Josep GIBERT: Carta de Gibert a Joan Albaiges. Sabadell, 2 de enero 1995. AJG, Caja 32.

52 Ouizás la más extensa fue la ofrecida a Canal + ante la vitrina con los restos del "Hombre de Orce". Ouizás la más extensa fue la ofrecida a
Canal + Notícias, 7 septiembre de 1995

53 Josep GIBERT: “De Orce a Móra: 50 anys de la meva vida”, La Riuada, abril 1996.

54 CARANDELL: “Homínidos...” pp. 372.

55 En televisión, Orce apareció, como mínimo, en los noticieros Canal Sur, el canal autonómico andaluz, cinco días además del programa de investigación Los Reporteros. En Tvi habló del congreso en mínimo, dos ocasiones. En Antena 3 y en Canal +, por lo menos en una ocasión. En prensa, El País publicó 5 artículos sobre el congreso y $A B C 6$, que se elevan hasta diez si consideramos su edición de Sevilla. Fuera de España, por ejemplo, Simon DENISON: "1,8 million-year-old human presence claimed in Spain" British Archaeology, 7, (1995) y Wolfram WEIMER:"Wo lebte der erste Europäer?", Frankfurter Allgemeine Zeitung, 7 de septiembre de 1995.

56 Muchos periódicos hablaron del congreso y también de la publicación de las posteriores críticas. Por ejemplo, en Brasil, Helio GUROVITZ: “Arquelogia...”, e internacionalmente, John WILFORD: "Doubts Cast on Report Of Earliest Americans", The New York Times, 14 de febrero de 1995 o Isabel VINCENT: "Research in Brazil suggests early man arrived from several directions up to 50.000 years ago" The Globe and Mail. 1 de enero de 1994.

57 Helio GUROVITZ: “Arquelogia..."

58 Ver: Stephen HILGARTNER.“The dominat view of popularization: Conceptual problems, politica uses", Social Studies of Science, 20 (3), pp. 525, (1990). 
da teoría de la "Eva Mitocondrial", que dice que todo humano actual viene de un grupo africano inicial, era una teoría errónea. El científico defendía, en cambio, su modelo "Multiregional", según el cual, Sapiens surgió simultáneamente en diferentes regiones del planeta gracias a flujo genético, como el más ajustado a la realidad. Wolpoff, que estuvo en Orce hablando precisamente de la "Multiregionalidad", afirmó que en esta sesión "we will tell you all you need to convince you that the Eve hipothesis is dead"(la cursiva es mía)..$^{9}$

Como Guidon y Gibert, Wolpoff quería estar seguro que tanto científicos como opinión pública se pusieran de su lado. Como afirma la socióloga Simone Rödder, en este tipo de controversias, "the necessity of [...] acquisition of public acceptance induce a "legitimation discourse" of science that takes place primarily in the media". ${ }^{60}$ En este artículo pero, la legitimación se hace a través de la celebración de congresos, mezclando de esta manera los públicos de estos eventos con los de los medios generalistas. Así, si en estos congresos se presenta, discute y valida, o no, conocimiento científico, el hecho de que los públicos de los mismos crezcan, hace que en el proceso de presentación, discusión y validación, estén involucrados nuevos públicos y nuevos "actores".

En un reportaje en el programa Reporteros de Canal Sur sobre el congreso de Orce, José María Martín Delgado, consejero de cultura de la Junta de Andalucía y presente en la clausura del congreso, afirma que ahora ya se podrán dar permisos de excavación gracias a que "la comunidad científica ha revalidado la importancia de este hallazgo". ${ }^{61}$ Esta escena saca a relucir estos nuevos "actores". Un político se apoya en los expertos para ratificar unas investigaciones científicas en un medio de comunicación.

Así pues, utilizar la historia comparada me ha permitido, en primer lugar, destapar características concretas de cada controversia. De alguna manera, lo que en un estudio de caso queda camuflado, sale a la luz al compararlo con otro, y se erige ya sea como una peculiaridad o como una similitud, como hemos visto a lo largo del artículo. Comparar permite en cierto sentido, generalizar. Gracias a este tipo de análisis podemos decir con más seguridad, podemos reforzar la hipótesis, de que en este tipo de controversias científicas, los congresos son usados como herramientas de persuasión y convencimiento tanto ante la propia comunidad científica como ante los políticos y, quizás más importante, ante la opinión pública.

59 James SHREEVE: The Neandertal enigma. New York: Avon Books (1986). pp.124-126.

6o Simone RÖDDER: "Reassessing the concept of a medialization of science: a story from the "book

of life", Public Understanding of Science, 18, pp. 453. (2009).

61 Los Reporteros. Canal Sur. Septiembre de 1995. 


\section{MUJER Y CIENCIA: DE HOMBRE DEFECTUOSO}

\section{A CYBORG}

Elvira Fente

Universidad Complutense de Madrid

Dpto. Historia Contemporánea

Introducción

El cuerpo de la mujer se ha disputado y controlado durante siglos. El interés por su conocimiento hizo que fuese constituyéndose como la cuna de la organización social en la que participan hombres y mujeres, desde el comienzo de los tiempos hasta la actualidad, convirtiéndose incluso en un enigma que se popularizó como un misterio cuya respuesta resulta imposible de encontrar

La necesidad de controlar el organismo femenino surge de la diferencia sexual biológica entre machos y hembras, que adquiere un significado social y cultural en la historia. Es, por tanto, una diferencia construida de acuerdo con los principios de una visión mítica del mundo enraizada en la relación arbitraria de dominación de los hombres sobre las mujeres.' En este sentido, fueron numerosas las estrategias creadas por la sociedad para establecer ese control y esa noción de posesión: La coacción sobre la manera de vestir, que obligaba a las mujeres a ocultar el cuerpo para no provocar; la represión moral a través de la educación o de la religión que se encargaban de dar lecciones de buena conducta a la mujer, así como de convencerlas sobre la maldición que suponía vivir en un cuerpo pecaminoso, sucio y delictivo del que tenían que avergonzarse; la institución del matrimonio, que concebía como legal que un hombre fuese propietario del cuerpo de su mujer; la violación y otros delitos sexuales o la tradición en el caso de la mutilación genital. Todos estos mecanismos contribuyeron a una castración psicológica y moral de la mujer sobre su sexualidad y su propio cuerpo.

a otra cara de la manipulación de la sociedad patriarcal es la ejercida por la presión social para la reconstrucción del cuerpo femenino, con la finalidad de convertirlo en un objecto de uso y disfrute del sexo masculino. Existen de nuevo ejemplos en las prendas de ropa hechas para seducir, que impiden la realización de cualquier actividad cotidiana o limitan el movimiento natural del cuerpo, quitándole libertad de expresión y convirtiéndolo en un objeto hecho solo para ser admirado. Los corsés o los tacones, son entre muchos otros, inventos que impiden esa movilidad. Las mujeres chinas se sometieron durante siglos al vendado de sus pies, porque los pies pequeños eran más femeninos y bonitos para una mujer y, además, los métodos para impedir que creciesen provocaban malformaciones que les impedían huir. Los avances científicos favorecieron esa tiranía, por facilitar esa transformación de los cuerpos y ofrecer la posibilidad de ajustarlos a los roles de sometimiento exigidos, haciendo realidad las obsesiones de muchas mujeres por ajustarse al canon de belleza marcado por la sociedad patriarcal.

La tecnología como herramienta de transformación del cuerpo pasó los límites de la construcción y de la transformación material para hacer posible la intervención en los procesos de control de la vida humana. El dominio del cuerpo derivó en la manipulación de los órganos sexuales, y se determinó que el útero fuese considerado como una representación de lo femenino, física y moral, y también un objeto de estudio y de análisis, por ser portador de enfer-

1 Pierre BOURDIEU: La Dominación Masculina, Anagrama, Barcelona. 2000 medades como la histeria, ${ }^{2}$ culpable de emociones y sentimientos incompatibles y contrarios a la sociedad creada por el hombre, y origen, por tanto, de las diferencias de comportamiento social etiquetado como propiamente femenino.

Los avances científicos corrieron en la misma linea moral impuesta por el patriarcado. Bajo el velo de una ética protectora, parecían querer perpetuar la dominación que se ejercía sobre la mujer, a través de la escuela, la iglesia o el matrimonio, a través del cual el hombre se apropiaba del útero de la mujer para controlar la función reproductora y su descendencia. En el caso de la ciencia, el poder sobre los órganos sexuales femeninos comienza por su medicalización, privando a la mujer de su autonomía en todos los aspectos vinculados a la reproducción humana. El conocimiento tampoco se pudo liberar de los numerosos discursos, de las múltiples conceptualizaciones y reconceptualizaciones que se hicieron a lo largo de la historia sobre el cuerpo de la mujer y su función, incluso cuando ya pasó su etapa fértil. Las consecuencias son, como ya ocurrió con el estudio de la histeria, la consideración de los procesos biológicos normales derivados de la gestación o de la reproducción como un problema, por el que la mujer se hace dependiente de la medicina para paliar esos efectos.

En los años sesenta, el movimiento feminista comienza a denunciar esa lectura jerarquizada de la biología. Las mujeres reclaman el fin de su represión y explotación. Reivindican recuperar el poder y el control sobre sus propios cuerpos y que se las reconozca como seres autónomos y dueñas de si mismas. La despenalización del adulterio, del aborto o de la venta de anticonceptivos se convierte en los primeros objetivos del feminismo para la autonomía sobre el propio cuerpo. Incluso si esos objetivos se consiguieron, la dominación masculina continuó su discurso sobre la necesidad de control de la reproducción y pasó las fronteras de la medicina con una gran curiosidad, pero con un desconocimiento total del objeto de estudio.

Desde la perspectiva feminista, también se puede observar una cultura contemporánea donde existen las ciencias extremas: desde extremismos del espectro identitario hasta una idea de lo femenino más extremista, en los universos inventados, pero también en los límites de la realidad. El interés científico de estas cuestiones llega a través de la Literatura, de la mano de una mujer, Mary Shelley, con un gran sentimiento de culpabilidad por tener la convicción de ser la causante de la muerte de su madre al nacer. Shelley incorpora en su novela Frankenstein varias referencias a su progenitora, Mary Wollstonecraft, y a su libro Vindications of the rights of women ${ }^{4}$ entre las que se encuentran aquellas relacionadas con la cuestión de la creación y de la maternidad. La mayoría de las respuestas de la crítica al libro de Shelley fueron interpretaciones sobre el pensamiento de la autora que parecía denunciar y cuestionar la ambición del hombre de querer usurparle a la mujer el don de la maternidad. Pero desde aquí se seguirá una propuesta feminista y diferente sobre la intervención de la ciencia en la creación de seres humanos, a considerar que el argumento de la novela viene motivado por esa culpa y por la obsesión de Shelley ante los riesgos que corrían las mujeres al quedarse embarazadas o en el momento de dar a luz. ${ }^{5}$ Las muertes eran provocadas la mayoría de las veces por infecciones transmitidas por los propios médicos al manipular los cuerpos de las mujeres, para traer al nuevo ser humano a mundo. La profecía de Shelley tiene continuidad en multitud de escritos. Uno de los más conocidos es el cuerpo teórico e híbrido entre máquina y organismo $0^{6}$ cuyas reflexiones tienen su fruto en la reformulación social y antropológica del concepto de maternidad.

2 Sigmund FREUD: La histeria, Alianza editorial, Madrid, 1967

3 Mary SHELLEY: Frankenstein o el moderno Prometeo, Cátedra, Madrid, 2003

4 Mary WOLLSTONECRAFT: Vindicación de los derechos de la mujer, Cátedra-Instituto de la Mujer, Madrid, 2000 .

5 María Xosé QUUEIZÁN: Mary Shelley e a súa criatura artificial, Edicións Xerais de Galicia, Vigo. 2011. 6 Dona HARAWAY: Simians, Cyborgs and Women: The Reinvention of Nature, New York: Routledge, and London: Free Association Books, 1991 


\section{Función reproductora}

Tomando como base el imaginario tradicional, la ciencia médica convirtió a la mujer en madre o en cuerpo reproductor obviando su parte humana. La ignorancia de los médicos y científicos hizo de la medicalización del cuerpo de la mujer un proceso de sometimiento a una experimentación necesaria para descubrir las anormalidades y perigos de ese Otro cuerpo diferente del masculino, que era el referente social de normalidad. Así, los tratamientos para problemas relacionados con la salud femenina, a saber, el aprendizaje y la intervención legitimada en todo lo que tenía que ver con el sistema reproductor, obedecían en sus comienzos a intereses patriarcales. El desconocimiento de los médicos sobre los cuerpos de las mujeres no impedía que estos tomaran decisiones sobre la mejor manera de actuar, desde la medicina, para que esos cuerpos funcionaran correctamente, sin tener en cuenta la opinión de las propias mujeres que, por otra parte, desconocían su cuerpo tanto como los médicos que las trataban. Hay que decir que ese desconocimiento también contribuía a la manipulación de los procesos biológicos de los cuerpos sometidos a tratamiento, lo que suponía un incremento del poder sobre ellos.

La ciencia médica reducía, por tanto, el cuerpo de la mujer a su función biológica de reproducción para su control social, un control que se incrementaba al excluir a las mujeres de cualquier participación en los procesos de generación de conocimientos. Con la incorporación de expertas y profesionales a la investigación científica, los objetivos parecían evolucionar hacia un deseo de cubrir y proteger verdaderamente las necesidades humanas de esos cuerpos reproductores, al tiempo que cobraban importancia las implicaciones de los cambios tecnológicos, sobre todo, en el campo de la reproducción y de la sexualidad.

Con todo, en la sociedad actual, la mujer sigue teniendo que pelear con las cuestiones éticas, morales, políticas, legales o psicológicas pensadas para ella, pero sin ella, para acoger esos cambios tecnológicos que siguen suscitando posturas diferentes, bien favorables y positivas que buscan la mejora de la calidad de los cuidados de la mujer, del tratamiento de la reproducción y, en definitiva, un mayor respeto de la autonomía de la mujer en lo tocante a la maternidad; bien con argumentos que rechazan la exposición excesiva del cuerpo femenino a la ciencia como un organismo reproductor que incluso, algún día, puede llegar a entorpecer los fines científicos de crear vida en un laboratorio, por lo que se comenzasen a utilizar los úteros de cristal o las matrices artificiales, más fáciles de manejar que un cuerpo humano.

La gestión de los cuerpos femeninos y el poder sobre la existencia humana, así como la rápida expansión de las tecnologías de reproducción asistida, ¿contribuyen a una mayor autonomía de la mujer en la sociedad? ¿o son, por el contrario, un mecanismo de control presentado bajo un velo de protección de la vida?

\section{Nuevas Tecnologías de Reproducción}

Los avances tecnológicos en el campo de la reproducción asistida conducen a una reinterpretación social de la maternidad y a nuevas conceptualizaciones derivadas de la trayectoria de análisis llevada a cabo a lo largo de los años. La naturaleza humana se considera cada vez más como tecnológicamente comprensible y reproductible, las mujeres luchan por dejar de ser entidades meramente biológicas, esencia de lo natural, fuera de lo social y de lo histórico, frente a los hombres, sinónimo de cultura, sociabilidad y política. ¿Es el proceso de desnaturalización de la mujer una evolución histórica análoga a su reconfiguración como objeto en los desarrollos tecnológicos de reproducción?

Los avances científicos en las técnicas de reproducción asistida hacen que se tenga que pensar en una nueva forma de legislación, no solo en lo referente a las aplicaciones de esos avances sobre el cuerpo de la mujer sino, también en lo que se refiere a las relaciones de parentesco entre padres e hijos. Si se cumple la hipótesis del útero de cristal, esos nuevos seres humanos, mitad máquinas, frenarán todo el proceso biológico y de transformación hormona que se produce en el cuerpo de la mujer y que para los más románticos supone la base del vínculo afectivo entre madre e hijo. Con la figura del cyborg, esos lazos evolucionarán hacia un apego con las personas que proporcionan seguridad y apoyo, fruto de la necesidad física y emocional de los seres humanos para su existencia. Como se pode seguir en los diálogos de 'La piel que habito,'7 en una secuencia del metraje, el personaje de Marisa Paredes rechaza acoger a su hijo, que alude al amor maternal para despertar la compasión de su madre. Ella responde "no soy tu madre, yo solo te parí,, una respuesta que confirma la transformación total de concepto de maternidad en la sociedad.

Por tanto, se producen cambios en el terreno científico-médico con respecto a las nuevas tecnologías de reproducción y sus influencias en la evolución de los diferentes contextos histórico, social e político. Intervienen factores ético-morales a los que se enfrentan estos avances y se debaten a su vez con el pensamiento feminista y su concepción de la ciencia como una aliada de la mujer.Y se producen también transformaciones sociales y culturales que articulan la redefinición de maternidad y dan paso a la aparición de nuevos términos como maternidad social o paternidad biológica, derivadas de estos avances. Finalmente, el objetivo último es estudiar la posibilidad existente en la actualidad y en un futuro de la gestación de nuevos seres humanos fuera del útero materno, como manera de diferenciar a la mujer del animal, lo que para algunas feministas supone la llegada de la verdadera igualdad entre mujeres y hombres, al separarla de su función biológica reproductora. ${ }^{9}$

\section{El mito de la mujer salvaje}

Es necesario hacer un análisis de la percepción del cuerpo y de la anatomía femenina a lo largo de la historia. ¿Qué son las mujeres? La reproducción o la función reproductora de los cuerpos femeninos es una cuestión de interés desde tiempos inmemoriales que llega hasta la actualidad a través de la cultura popular. Los estudios sobre el funcionamiento del cuerpo de la mujer responden a una preocupación cultural muy extendida. Las mujeres son, dice el escritor Dante Medina, el ser imaginario preferido en la sociedad..$^{\circ}$ La moura en Galicia, xana en Asturias, anjana en Cantabria, mari en el País Vasco o encantades en Cataluña y así sucesivamente. Por citar algunas fuera de la península, se les llama korrigans, en el folclore de Gran Bretaña, anguanas en Italia ofées en Francia.

Todas estas figuras míticas de la mujer, mujeres simbólicas, muestran diferentes nombres para una misma figura femenina, por lo que se puede decir que todas las culturas tienen un prototipo de mujer salvaje. No son más que idas y venidas de la cultura popular de hace más de 2.500 años, que contribuyen a asentar una cultura dominante, mediante historias construidas con fragmentos de historias anteriores, hiladas adecuadamente para perpetuarse en el imaginario popular mundial. El conjunto de todos estos textos de diversa procedencia sobre la mujer parece construir el gigante e histórico poliedro del patriarcado. ¿Qué son las mujeres? ¿De dónde salen? ¿Por qué hay que controlarlas? Tienen una capacidad reproductora que los hombres no tienen, ¿son peligrosas si no se controlan? Estas leyendas son la evidencia de la propagación del pensamiento masculino dominante sobre mujeres espirituales, buenas, amorosas y fuertemente vinculadas a la naturaleza." Hay teorías que señalan a las hadas como descendientes de antiguas divinidades celtas (la diosa Dana) y otras que apuntan sus orígenes hacia las Dianas romanas. ${ }^{12}$

7 Pedro ALMODÓVAR: La piel que habito, España, 2011

8 lbid.

9 María Xosé QUEIZÁN: Anti Natura, Xerais, Vigo, 2008

10 Dante MEDINA: La seducción y sus espejos, Mexico, Mantis Editores, 2001.

11 Jesús CALLEJO: Hadas, EDAF, Madrid, 1995

12 bid. 
Las mouras gallegas o encantadas, del mismo modo que el resto de las figuras femeninas míticas, pertenecen a un género universal que va adaptando las leyendas en función de las características del lugar donde se va a desarrollar, para hacer mucho más creíble la interpretación del mensaje que se quiere transmitir a la población. Así, nace por ejemplo el mito de las pecadoras, de las depredadoras sexuales o comehombres o toda una serie de cultos a las divinidades femeninas del mar junto con el poder fertilizante de las aguas.

Estos patrones universales del folclore sobre la mujer cambiaron con la intervención del conocimiento científico, y se convirtieron en norma con las evidencias y los juicios de valor de médicos y filósofos. Ser mujer significa directamente reproducción.

Marcela Lagarde hace referencia a la creación histórica de la mujer basada en su sexo: "Se refiere al género femenino y a su condición histórica, expresa el nivel de síntesis más abstracto:su contenido es el ser social genérico. Cuando se usa la voz de la mujer se alude al grupo sociocultural de las mujeres". ${ }^{3}$ Fortalecen esta afirmación las instituciones organizadoras de la sociedad, la familia o la religión. La diferencia anatómica entre hombres y mujeres es la base de los textos filosóficos para confeccionar una teoría patriarcal que considera el cuerpo femenino como defectuoso, por estar invertido. Entonces, ¿qué es la mujer? ¿Cómo se integró esta cuestión en el discurso de la ciencia médica? El debate actual necesita una ojeada retrospectiva para comprender por qué el destino biológico o físico de la mujer ${ }^{14}$ define a la hembra en una sociedad como ser humano de naturaleza orgánica destinada a ser madre, ${ }^{15}$ en todos los aspectos de su vida.

Pensamiento y ciencia se alimentan mutuamente e influyen recíprocamente en las teorías de ambos campos, al punto que resulta imposible distinguir cuál de las dos disciplinas intervienen primero sobre la otra. El sexólogo Thomas Laqueur expone, basándose en textos médicos y de filosofía natural, ejemplos de cómo la ciencia atribuye diferencias sociales y culturales en función del sexo. ${ }^{16}$ Laqueur establece dos etapas en la historia de las representaciones científicas de hombres y mujeres. La primera de ellas va desde la llustración griega hasta el siglo XVII. Los textos griegos y latinos clásicos, así como las ilustraciones de las anatomías renacentistas se centran en la aportación de material para justificar la teoría del sexo único. el Corpus Hippocráticum constituye la obra fundadora de la medicina occidental. Se trata de un texto de unos sesenta tratados médicos sobre el estado de la medicina griega en los siglos $V$ y IV a.C. a través de los que se dibuja la imagen de la mujer tal como la veía un médico como Hipócrates o sus contemporáneos.

El mundo clásico consideraba el sexo masculino como sexo único. Se trata de una época que se toma como referencia por ser cuando nació la civilización occidental, y por el peso de sus teorías en la construcción de la imagen de la mujer a lo largo de la historia. Servirá también para entender, en términos de medicina, las razones que sostienen la inferioridad de la naturaleza femenina con respecto a la masculina. Es lo que se conoce como medicina basada en la evidencia, que se configura a partir de una construcción multidimensional del hombre y de la mujer (biológica, psicológica, filosófica, social y espiritual), por lo que tal vez sea la ciencia la disciplina que más depende de la multiplicidad de saberes.

Se toman como base las funciones biológicas para determinar la inserción de cada sexo en la realidad económica, política, cultural y social, y asi transformar en legítima la división de

13 Marcela LAGARDE: “Aculturación femenista” en Eliana LARGO (Ed.): Género en el Estado. Estado del género, Isis Internacional Ediciones de las Mujeres $\mathrm{N}^{\circ} 27$, Santiago de Chile. Reimpreso por el Centro de Documentación sobre la mujer, Buenos Aires, 2000, pp. 135-150.

14 Simone de BEAUVOIR: Le deuxième sexe, Gallimard, Paris, 1949.

15 Elisabeth BADINTER: L' amour en plus. Flammarion, Paris, 2010.

16 Thomas LAQUEUR: Making Sex: Body and Gender From the Greeks to Freud, Harvard University Press, 1990 obligaciones en función del sexo. Esa es la razón por la que la mujer ocupó una posición determinada en el mundo occidental con respecto al conocimiento, donde su rol estuvo subordinado y relegado al desempeño de otros papeles en la sociedad. Se produce una naturalización de las desigualdades sociales y subjetivas de los géneros. Los estudios sobre esta cuestión hicieron evidentes estas estrategias de discriminación en los cuerpos teóricos, en las metodologías de investigación y en las prácticas institucionales de las ciencias humanas, que históricamente homologaron el hombre como hombre y la mujer como diferente y, en consecuencia, como malo. Esto viene resumiendo la concepción griega de la diferencia sexual que se encuentra en la ideología de los filósofos de la época.

Las funciones biológicas fueron llevadas al rango de esenciales, universales y eternas, basándose en el supuesto isomorfismo entre funciones sexuales y reproductivas para determinar el conjunto de tareas, atribuciones y obligaciones públicas y privadas para cada género. La filosofía, la biología y la ciencia médica unieron sus fuerzas para el estudio de la naturaleza, de la estructura, de las patologías y del cuerpo de la mujer, un ser categorizado e identificado como diferente a lo genérico masculino, bien por los componentes biológicos y anatómicos de las diferencias físicas constitutivas del hombre y de la mujer, bien por los aspectos psicológicos, sociales y culturales de la feminidad y de la masculinidad.

En cuanto a ese poder de modificar o de manipular los cuerpos femeninos, queda la duda de si todos estos avances tecnológicos contribuyen a una mayor autonomía de la mujer, pues el hecho de liberar a las mujeres de su función biológica reproductora supone para algunas feministas la llegada de la verdadera igualdad; o si por el contrario, estos avances son un paso más hacia el control de la reproducción o de la procreación.

Robyn Rowland apunta que cuando el útero de cristal esté operativo, los médicos podrian trabajar en ese útero artificial de una forma más eficaz sobre el feto y garantizar su inmunidad a enfermedades sin la necesidad de intervenir ni de manipular el cuerpo de la mujer que, en el fondo, es un obstáculo y que, cuando eso ocurra, se podría esterilizar a las mujeres desde su nacimiento. ${ }^{7}$ Este es un planteamiento que propone activar un mecanismo de control total sobre la reproducción. Esta afirmación es la misma que sostenía Aristóteles, cuando, basándose solamente en la observación, concluía que la mujer era un mero recipiente para alimentar a futuro hombre que iba a nacer, pues, solamente nacían hombres, ya fueran hombres perfectos, o defectuosos, en cuyo caso se les llamaba mujeres.

\section{El útero de cristal}

El útero de cristal es el ultimo paso de un proceso que comenzó con la inseminación artificial, la fecundación in vitro, la donación de óvulos, las madres de alquiler y la clonación. Todos estos procesos culminan con la creación del útero de cristal. Siendo positivos, pensando que todos estos cambios contribuyen a la mejora de la calidad de vida de las mujeres y de los seres humanos en general, habría que empezar a pensar en como se va a reformular ciertos conceptos, especialmente el concepto de maternidad; cómo se van a legislar los derechos de los padres y de los hijos, porque llegará un momento en que existirá, si lo que propone Rowland es cierto, en que todos los bebés saldrán algún día de un útero artificial, y en que haya una generación de bebés que no haya salido del cuerpo de una mujer.

Hoy en día, un bebé puede tener hasta cinco progenitores, de los que tres son mujeres. Habría por un lado, la madre y el padre biológicos, que serían la donante de óvulos y el donante de esperma; por otro lado estaría la madre de alquiler, que es quien trae al mundo el bebé; $y$ finalmente, están los padres que van a criar ese bebé.

17 Robin ROWLAND: "Reproductive Technologies: the final solution o the woman question?", en Rita ARDITTI, Renate DUELLI, Shelley DUELLI (eds.): Test-tube women. What futur for motherhood? Pandora Press, Boston, 1984 
Suponiendo que existiera el fin del embarazo humano, ya no se hablaría del nacimiento de un hijo como una prolongación del ser, no se hablaría del apego entre padres e hijos, ni de los vínculos de sangre o de lazos carnales. No habría una continuidad generacional. En cuanto a la madre no existirian todas esas sensaciones de las que hablan las personas defensoras de esencialismo, entre madre e hijo, como los latidos del corazón o la producción de leche materna. Todas esas conexiones se pierden. Se eliminarían las emociones, que son el fallo en la construcción del ser humano; el error cometido por Frankenstein en la creación de su monstruo.

El cuerpo humano se considera una cárcel de carne manipulable, donde lo que se busca es

la liberación del sufrimiento y de la muerte. El sufrimiento, la muerte o la imperfección son características que forman parte de la condición humana. Con el cyborg, aunque sigue siendo humano en parte, se superan todos estos defectos. En el fondo es lo que acercaría al ser humano a la figura del cyborg, como si las emociones perturbasen esa perfección.

Si mujer se identifica o se ha identificado a lo largo de la historia con reproducción y procreación, habría que redefinir lo que significa ser mujer. Tal vez desaparezca esta palabra. Si con el útero de cristal se alcanza la perfección, como decía Aristóteles, nacerían solamente cuerpos de hombres perfectos, puesto que es el único sexo válido. Se alcanzaría la perfección hasta tal punto que ya no nacerian hombres defectuosos, que es como se llamaba a las mujeres. 


\section{INTERESES Y CONTRADICCIONES EN LA \\ INTRODUCCIÓN DE LA LACTANCIA ARTIFICIAL EN \\ ESPAÑA. ALEXANDRE FRIAS I ROIG Y LA REVISTA \\ PUERICULTURA (1921-1936)}

Fátima Ferni Álvarez

Centre d'Història de la Ciència (CEHIC)

Facultat de Medicina, Universitat Autònoma de Barcelona

\section{Introducción}

Es bien conocido que a principios del siglo XX, como consecuencia del desarrollo industrial, hubo un aumento del deterioro de las condiciones de vida de la población trabajadora europea. En Cataluña, familias enteras emigraron de los núcleos rurales a las zonas industrializadas en busca de trabajo en fábricas y talleres. Estos individuos al llegar a las grandes ciudades se vieron abocados a vivir en barrios obreros que no contaban con las más mínimas condiciones higiénicas, hacinados en viviendas insanas y con una alimentación escasa y adulterada fruto todo ello de la falta de inversión pública en infraestructuras urbanas y un salario insuficiente para cubrir sus necesidades vitales básicas."

Estas familias se encontraban con serias dificultades para consumir una dieta suficiente y equilibrada. ${ }^{2}$ Las consecuencias de estas carencias eran más graves para los niños, como nos muestran sus elevadas tasas de mortalidad en este periodo. El consumo de alcohol entre la clase trabajadora representaba en ocasiones la única forma de ingerir "calorías baratas" y poder rendir las numerosas horas laborales sin descanso semanal. Estos "hábitos populares" fueron denunciados por los médicos higienistas como un elemento más que favorecía toda clase de enfermedades entre la población obrera haciendo extensiva su denuncia al consumo de alcohol que, según ellos, era habitual también por parte de sus hijos pequeños. ${ }^{3}$ En Cataluña, la costumbre de dar de beber vino a los niños fue descrita en numerosas ocasiones por autores que detectaron este problema en sus estudios medico-topográficos de diversos pueblos y ciudades de la región. ${ }^{4}$ Como ejemplo se puede citar el caso del médico de Tremp, que afirmaba que en este pueblo, ya desde final del siglo XIX, "al niño de teta, para que medre, le dan vino". El médico de Tortosa, por su parte, denunció en 1913 que la costumbre de dar vino o aguardiente a los niños de pocos meses radicaba en la creencia de que estas bebidas "les fortalece". Finalmente, otras "costumbres populares" consistían en darles a los niños de pecho muñequillas o melindres empapados en vino para así mantenerlos entretenidos durante horas y horas sin dar molestias a sus madres. Gloria NIELFA: “Trabajo, legislación y género en la España contemporánea: los orígenes de la legislación
laboral”, en Lina GÁLVEZ MUÑOZ y Carmen SARASÚA GARCIAA (eds.): : Privilegios o eficiencia?: Mujeres y laboral", en Lina GÁLVEZ MUNOZZ y Carmen SARASUA GARCIA (eds.): : Privilegios o eficiencia?: Mujers

2 Jesús CONTRERAS: "Prácticas alimentarias en la España de 1905", en Nestlé en España. 1905-2005. Re2 Jesús CONTRERAS: “Prácticas alimentarias en la España de 1905", en Nestlé en España. 1905-2005. ReRicardo CAMPOS MARÍN: Alcoholismo, medicina y sociedad en España (1876-1923), Madrid, Consejo Superior de Investigaciones Científicas, 1997.

4 Llorenç PRATS: La Catalunya rància: les condicions de vida materials de les classes populars a la Catalunya de la restauració segons les topografies mèdiques, Barcelona, Alta Fulla, 1966

Ibid., pp. 185.

6 lbid., pp. 229-230
Otra de las características que definían a la clase obrera, según los higienistas de la época, era su analfabetismo, imperante especialmente entre las mujeres, lo que incidía, según estos testimonios médicos, en una deficiente adquisición de conocimientos acerca de la higiene infantil.7

A pesar de la acelerada industrialización de algunos núcleos, como Barcelona y algunas poblaciones colindantes, la sociedad catalana era una sociedad de base mercantilista que conservaba todavía costumbres muy arraigadas. Esta sociedad presentaba profundas diferencias sociales -entre ellas, la tensión entre el proletariado urbano y la burguesía fabril- tras las que se apreciaba en algunos sectores el creciente desarrollo industrial. Los distintos roles dependían estrictamente de factores tales como el género, la edad, la clase social o el lugar de procedencia; así, el papel principal estaba reservado al hombre como pilar de la sociedad, defensor del estado y prolongador de la saga familiar. La mujer era considerada por los sectores más conservadores de la sociedad ${ }^{8}$ como un ser de segunda categoría, sin autonomía ni preparación, ${ }^{9}$ y el niño como un recurso que podía aliviar las dificultades económicas familiare mediante su trabajo..$^{\circ}$ Las mujeres se integraron en el mundo laboral fuera del hogar, con la consecuente alteración de la forma de vida familiar y con un impacto negativo, sobre todo, en la alimentación de los hijos."

En este contexto, las estadísticas sobre lactancia materna reflejan que en 1910, el $90 \%$ de los niños españoles eran amamantados por sus madres. Sin embargo, por entonces se inició un descenso paulatino de esta práctica, de manera que en los años cuarenta tan sólo amamantaban un $25 \%$ de las mujeres. ${ }^{12}$

En la presente comunicación analizaremos los factores que favorecieron el progresivo abandono de la lactancia natural por parte de las madres españolas en tan corto periodo de tiempo. En primer lugar, analizaremos el papel de la medicina en torno a la salud materno-infantil, cuya vertiente más intervencionista en este periodo fue la organización de las campañas contra la mortalidad infantil. Nos centraremos en el caso de Reus dónde se llevó a cabo quizás una de las iniciativas más novedosas en Cataluña al abordar todos los elementos medico-sociales apuntados en la época en pro de la salud de la madre y el niño.

\section{Las campañas contra la mortalidad infantil y la lactancia artificial}

Podemos encontrar los fundamentos de las campañas que contra la mortalidad infantil se desarrollaron en España, en la siguiente intervención del Dr. Martínez Vargas en el Congreso de Pediatría de Palma de Mallorca celebrado en 1914: "proteged a los niños: sanos, son la alegría del hogar, el consuelo de la vejez, la perpetuidad de la raza, la savia de la nación. Sin ellos, el hogar es solitario, la vejez desvalida, la raza se extingue y las naciones desaparecen".13

En esta cita podemos destacar los motivos poblacionistas y eugenésicos que cifraban la riqueza del país en la calidad y cantidad de su población. Evitar la mortalidad infantil por tanto suponía aumentar la riqueza y bienestar del Estado liberal además de atemperar la lucha de

7 Josep BERNABEU-MESTRE: “Higiene y Pedagogía: El primer Congreso Español de Higiene Escolar (Barcelona, 1912)", en Enrique PERDIGUERO GIL: Salvad al Niño, Valencia, Seminari d'Estudis sobre la Ciencia, 2004 .

8 Salvio FELÍU I DARNACULLETA: Historial escrito para conmemorar el LXX aniversario de la fundación Salvio FELLU i DARNACULLETA: Historial escrito para conmemorar el LXX aniversario de la fundación
de la Sociedad Barcelonesa de Amigos de la Instrucción, Barcelona, Sociedad barcelonesa de amide la Sociedad Barcelonesa de

9 Marcel PRUNIER: “A.B.C. de la puericultura moderna”, Generación Consciente, 43 (1927).

10 Luis S. GRANGEL: Historia de la pediatría española, Barcelona, Asociación Española de Pediatría, 1980

11 Teresa M. SALA: La vida cotidiana en la Barcelona de 1900, Madrid, Silex, 2005

12 María José AGUILAR CORDERO: Lactancia materna, Madrid, Elsevier España, 2005, p. 12

13 Andrés MARTínEZ VARGAS: “Código de la Madre”, La Medicina de los Niños, 173 (1914), pp. 155-158. 
clases y la integración pacífica de las familias obreras en el nuevo mundo industrial. ${ }^{14}$

De esta forma, en España, se promulgaron distintas leyes destinadas a la protección la salud materno-infantil. Por un lado, se promulgó la Ley de Protección a la mujer trabajadora y embarazada, ${ }^{5}$ datada originalmente en 1898 y modificada en 1902 , que obligaba a los industriales a respetar el período de lactancia de las madres; y, por otro, en 1904 se promulgó la Ley para la Protección de la Infancia y Represión de la Mendicidad. Además, en 1914, se celebró en Madrid la primera Asamblea Nacional de Protección a la Infancia y, en 1929 se publicó el decreto del Seguro Obligatorio de Maternidad, que estableció la exención laboral en el periodo anterior y posterior al parto. ${ }^{16}$

Junto a las leyes de protección a la madre y el niño, surgieron iniciativas privadas dentro del sistema de asistencia liberal (beneficencia, privada o pública) en las que en su estrategia de lucha contra la mortalidad infantil dieron una vital importancia al problema de la mala e insuficiente alimentación infantil, e incorporaron la leche de otro mamífero sustitutiva o complementaria de la materna.

En Francia, entre 1890 y 1894, en el marco del paradigma bacteriológico protagonizado primordialmente por Louis Pasteur (1822-1895) y bajo el auspicio de médicos obstetras y pediatras -Pierre-Contant Budin (1846-1907) en Paris y Gaston Variot (1855-1930) en Nancy- surgieron diversas iniciativas a fin de controlar a los lactantes en centros especializados. Las madres acudían a estos centros con el fin de controlar periódicamente el peso y talla, así como la salud y alimentación, del niño. Se incluían en la visita explicaciones sobre los cuidados del lactante. ${ }^{17}$ Fue en Fecamp en donde surgió la asociación denominada la "Goût de Lait"18 bajo el auspicio del Leon Dufour (1856-1928) para ayudar a las madres con escasez de recursos que no podían lactar, y para paliar los problemas derivados de la lactancia no materna. Su finalidad última era remediar el hambre de los niños huérfanos o abandonados, así como los de aquellas familias sin recursos que no podían contratar nodrizas que alimentaran a sus hijos.

En España, aparecieron iniciativas similares. Así, en 189o, el Dr. Francesc Vidal Solares (18541922) $)^{19}$ abrió en Barcelona un consultorio para niños de pecho y, en 1892, en el Hospital de Niños Pobres, creó un "Servicio Lácteo". ${ }^{\circ}$ En ambos centros se suministraban biberones a los niños desnutridos, abandonados y pobres; por ello, fue considerado precursor de Dufour en el $1 /$ Congreso Internacional de las Gotas de Leche celebrado en Bruselas en $1907^{2}$

En 1905, se celebró el primer congreso internacional de las Gouttes de Lait. El congreso fue organizado y presidido por Variot, ${ }^{22}$ y a él acudieron Rafael Ulecia (1850-1912), como delegado del gobierno español, y Andrés Martínez Vargas (1861-1948).

14 Esteban RODRÍGUEZ OCAÑA y Jorge MOLERO MESA: “La cruzada por la salud. Las campañas sanitarias del primer tercio del siglo XX en la construcción de la cultura de la salud”, en Luis MONTIEL: (Ed.) La salud en el estado de bienestar. Análisis histórico, Madrid, Editorial Complutense, 1993, pp. 133-148.

15 Sonsoles CABEZA: Cuadernos de Historia Moderna y Contemporánea, Madrid, Universidad Complutense, 1985 .

16 El decreto se promulgó el 22 de marzo de 1929, pero no se hizo efectivo hasta el 1 de octubre de 1931. En Sonsoles CABEZA: Cuadernos..., p. 149 .

17 Catherine ROLLET: “La protection de l'enfance en France”, en Enrique PERDIGUERO: Salvad al..., pp. 41-42.

18 Andrés MARTíNEZ VARGAS: Historia de la pediatría en España, Madrid, Publicaciones de "Acta Pediátrica Española", 1946

19 José María CALBET I CAMARASA y Jacint CORBELLA: Diccionari biogràfic de metges catalans, Barcelona, Fundació Vives Casajuana / Seminari Pere Mata, Universitat de Barcelona, Vol. III, 1981, pp. 160-161.

20 Oriol CASASSAS y Joaquim RAMIS: Metges de nens. Cent anys de pediatria a Catalunya, Barcelona, La Magrana, 1993.

21 Andrés MARTÍNEZ VARGAS: Historia de la..., p. 63.

22 Andrés MARTÍNEZ VARGAS: Historia de la..., p. 173.
No cabe duda que las instituciones de la Gota de leche representaron una gran ayuda para los niños huérfanos y para las madres con pocos recursos, básicamente con el reparto gratuito de leche de vaca, actividad que indirectamente fomentaba el uso de la lactancia artificial en los niños de teta. En 1907 se suministraron 126.387 litros de leche en la Gota de Leche de Barcelona pagados con fondos municipales y donaciones filantrópicas. ${ }^{23}$

La puericultura surgió y se afianzó a principios del siglo XX. En el caso español, la creación en 1923 de la Escuela Nacional de Puericultura ${ }^{24}$ en Madrid supuso un hito en su reconocimiento como ámbito específico dentro de la medicina.

Los puericultores eran médicos pediatras que ampliaban su formación con los aspectos higiénicos, preventivos y de promoción de la salud de la infancia. La labor de la puericultura era divulgar y extender las normas higiénicas correspondientes al cuidado y protección de la infancia, entre las madres, así como vigilar el régimen alimenticio durante la lactancia.

\section{Alexandre Frias i Roig y la revista Puericultura}

Un caso significativo fue la campaña a favor de la salud materno-infantil llevada a cabo en Reus por parte del pediatra Alexandre Frias i Roig (1878-1963), 25 discipulo del también pediatra Andrés Martínez Vargas (1861-1948). En esta ciudad de Tarragona, Alexandre Frias impulsó una intensa campaña contra la mortalidad infantil desde 1909, centrándose en la divulgación de los principios de la puericultura entre las madres que se intensificó con el primer instituto integral de Puericultura de España en 1921. Según Frias, la puericultura, como "rama trascendental de la Higiene", tenía una función social que debía desarrollarse a través de la ayuda que proporcionaba el sistema benéfico. ${ }^{26}$

El Dr. Frias atendía en Reus un consultorio de enfermedades de la infancia desde el que emprendió una campaña de profilaxis con el fin de paliar la excesiva mortalidad infantil. En las salas del Registro Civil de Reus, repartía gratuitamente entre las madres que acudían a inscribir a sus hijos un folleto titulado Consells a les mares per a ben criar a sos fills. Tras un viaje de estudios por Europa en 1913, incorporó lo aprendido dando mayor importancia a la propaganda y planteando la necesidad de fundar una institución de protección a la infancia en Reus según las últimas orientaciones europeas. Consecuentemente, en 1917, colaboró en la creación de l'Associació Reusenca de Caritat, con la finalidad de ayudar a las madres embarazadas a preparar la canastilla del recién nacido y suministrar leche de vaca a los niños de las familias obreras. De acuerdo con Frias, los problemas digestivos derivados de una alimentación inadecuada, junto a la falta de esquemas higiénicos elementales, facilitaban el contagio de las enfermedades infecciosas e influían en la alta tasa de mortalidad infantil de la época. ${ }^{27}$

En 1919, Frías culminó su campaña con la creación del que fue el primer instituto integral de puericultura de España. El Instituto de Puericultura de Reus estaba constituido por un servicio de vigilancia científica de los niños de pecho y un "servicio de lactario" para los niños sometidos a la lactancia mixta o a una lactancia exclusivamente artificial. Este último disponía de una dependencia habilitada tanto para el control de las mujeres embarazadas como para la

23 Josep Lluis BARONA: “El Consejo Superior de Protección a la Infancia”, en Enrique PERDIGUERO: Salvad al..., p. 131. También, era habitual el reparto de leche en hospitales y otras instituciones benéficas tanto a niños como a adultos enfermos. Véase el caso de la Institución Maternal Catalana. Pamela MENESES SANDOVAL: La mujer-madre en el discurso médico-sanitario de comienzos del siglo XX. El proyecto de la Institución Maternal Catalana, UAB, Trabajo Fin de Master, 2012.

24 Raquel ÁLVAREZ PELÁEZ: "La búsqueda de un modelo institucional de protección a la infancia: Institutos, guarderías y hogares infantiles. España 1900-194", en Enrique PERDIGUERO: Salvad al..., pp. 155-193. 25 Oriol CASASSAS y Joaquim RAMIS: Metges de nens..., p. 282

26 Raquel ÁLVAREZ PELÁEZ: “La búsqueda de...”, p. 187

27 Alexandre FRIAS: “Institut de Puericultura de Reus. Història”, Puericultura, 1 (1921), pp. 7-43. 
educación de las madres lactantes mientras amamantaban a sus hijos. El instituto también colaboraba asiduamente con el servicio municipal de inspección médico-escolar, tanto en el ámbito higiénico como en el educativo. ${ }^{28}$

En 1921 Frias introdujo el último eslabón de su proyecto con la edición de la revista Puericultu$r a,{ }^{29}$ fuente principal utilizada en este estudio, que publicó dieciséis volúmenes hasta el estallido de la Guerra Civil en $1936 .^{3^{\circ}}$ En sus fascículos se intercalaban los artículos con anuncios de productos farmacéuticos, de laboratorios de análisis microbiológicos y de preparados alimenticios para niños, madres y enfermos. La edición de la revista contó con el apoyo económico de numerosos representantes de la burguesía local, que colaboraban suscribiéndose a la revista. También contaba con el apoyo de diversos laboratorios farmacéuticos, sobre todo de aquellos que fabricaban productos, como las leches artificiales, relacionados con la salud materno-infantil. ${ }^{31}$

En la revista aparecían regularmente artículos escritos por médicos de distintas ciudades españolas, así como traducciones de artículos médicos internacionales, algunas de ellas con un desfase temporal importante. En ocasiones, se reflejaban en sus páginas las ponencias presentadas en congresos médicos, tanto nacionales como internacionales, en los que se abordaban temas relacionados con la infancia. Se dirigía a los profesionales de la salud y a las madres en tanto que cuidadoras y educadoras de sus hijos, pero también a los políticos y a toda la sociedad. Entre ellos nos encontramos con escritos encaminados a la unificación de criterios respecto a temas tan variados como: alimentación inadecuada, lactancia materna, artificial o mixta, problemas en la digestión del niño, enfermedades infecciosas y digestivas, nodrizas y lactancia mercenaria, esterilización de la leche, nutrientes de la leche o vacunaciones entre otros. También se encuentran escritos que tratan de la enseñanza a las futuras madres, con títulos como "La enseñanza de la puericultura en las escuelas primarias", $3^{2}$ "Puericultura en las escuelas de nenas" 33 o"De la educación de las madres" ${ }^{34}$ El objetivo de la revista era divulgar entre la clase médica no especializada, enseñanzas prácticas de puericultura sobre todo entre los médicos rurales. 35

En su vertiente divulgadora, cabría destacar, durante los últimos años de publicación de la revista, la sección "Puericultura Práctica", aparecida en 1932, de periodicidad aproximadamente bimensual y que permaneció hasta la desaparición de la revista al estallar la Guerra civil en 1936. En esta revista que se podía adquirir por subscripción existía una sección dirigida directamente a las madres, probablemente con la esperanza de que les llegara el mensaje a través de lecturas colectivas en centros obreros dado el alto índice de analfabetismo. Esta publicación constaba de artículos de dos o tres páginas, escritas en catalán por Josep Roig Raventós (1883-1966), ${ }^{36}$ jefe del Servicio de Tocología y Pediatría de la Maternidad de Barcelona. Sus artículos, por medio de un lenguaje asequible y sencillos ejemplos prácticos, pretendian hace llegar a las mujeres, los conocimientos elementales concernientes a la higiene en el cuidado y desarrollo del niño y muy especialmente, aquellos que demostraban las ventajas de mantener la lactancia materna en los niños menores de nueve meses. ${ }^{37}$

28 Albert ARNAVAT, Montserrat PAGĖS, Xavier AMORÓS: L'Institut..., p. 36

29 Ibid., p. 14.

O Véase una descripción somera de la revista en Albert ARNAVAT, Montserrat PAGÈs, Xavier AMORÓS: L'Institut....pp. 28-29.

31 Ibid., p. 23.

32 Alexandre FRIAS: "La enseñanza de la puericultura en las escuelas primarias", Puericultura, 99 (1929), pp. 37-43

33 Alexandre FRIAS: "Puericultura en las escuelas de nenas", Puericultura, 155 (1933), pp. 171-174.

34 Trillat VIGNE: “De la educación de las madres", Puericultura, 166 (1934), pp. 151-153.

35 Alexandre FRIAS: “Nuestro propósito", Puericultura, 1 (1921), pp. 2-3.

36 José María CALBET I CAMARASA y Jacint CORBELLA:Diccionari biogràfic..., p. 50.

37 Fátima FERNI: "La revista Puericultura (Reus, 1921-1936) como medio educativo para las madres",

\section{Prensa diaria, industria láctea y lactancia artificial}

La leche fresca a finales del siglo XIX y principios del XX era considerada un producto perecedero y mortífero. ${ }^{38} \mathrm{La}$ leche sufre un rápido proceso de descomposición y la falta de higiene en el ordeño ${ }^{39}$ introducía microorganismos en ella. En el primer tercio del siglo XX ya se conocía que la leche contenía en su composición proteínas y minerales. Sin embargo, no siempre existía el conocimiento popular que la leche era un cultivo ideal para muchos bacilos como el de la tuberculosis, la fiebre de malta o las bacterias del grupo coli, implicadas en la mayoría de síndromes diarreicos. 40

A principios del siglo XX, en el norte y centro de Europa el consumo de leche era mayor que en España..$^{41}$ El clima y la presencia de grandes extensiones de pasto favorecían la cría y comercio de ganado. La producción de leche de vaca en Europa era elevada y su coste bajo ya que el transporte a las urbes era eficiente. En España las leyes agrarias dificultaron la expansión ganadera. Sin embargo, en Cantabria existieron los llamados "ganaderos de salón" 42 que a finales del siglo XIX vieron en la ganadería la posibilidad de negocio como sucedía en otros países de Europa. Entre estos ganaderos cabe resaltar la figura de Alfredo Alday (1850-1923) que en el año 1879 tuvo la iniciativa de desecar terrenos pantanosos convirtiéndolos en terrenos adecuados para el crecimiento de pastos. Importó vacas frisonas de Francia, Suiza, y Holanda que trasladó hasta Santander en barco y tren, aumentando la productividad de leche de vaca. Fue pionero en la adquisición de tecnología agraria importándola de Europa y realizó transporte de leche refrigerada a núcleos de población como Madrid y Barcelona.

Fue en la provincia de Santander, dadas las buenas condiciones climáticas y de subsuelo en dónde la empresa Nestlé en el año 1905, instaló su fábrica de La Penilla que se convirtió en referente en relación a la producción de leche de fórmula. Dado el desconocimiento de la composición de la leche materna y de los mecanismos de asimilación de la misma por el lactante algunos químicos, ${ }^{43}$ médicos, pediatras y puericultores favorecieron los estudios comparativos sobre la leche materna y la leche de vaca.

La industria láctea - químicos y farmacéuticos - intervino en la educación higiénica de la mujer desde el embarazo 44 ya que implicó el bienestar higiénico de los individuos del futuro. Por un lado, sus campañas publicitarias se centraron en la madre durante el proceso fisiológico de lactancia materna mediante preparados que estimulasen la producción natural de leche mediante preparados especializados. ${ }^{45}$ Por otro lado, se fijaron en una alimentación infantil de fácil administración que fuera alternativa a la fisiológica materna.

Gimbernat, 53 (2010), pp. 123-130.

38 Peter J. ATKINS: "White poison: the health consequences of milk consumption, 1850-1930", Socia History of Medicine, 5 (1992), pp. 207-227.

39 José Manuel GONZÁLEZ GARCÍA: La tuberculosis bovina como zoonosis en la España contemporánea (1850-1950), Tesis doctoral, Universitat Autònoma de Barcelona, 2003. Véase, en especial, el $n e a(1850-1950)$, Tesis doctoral, Universitat Autonoma de Barcelona, 2003. Vease, en especial,
capitulo titulado "La leche como vector de transmisión de la tuberculosis bovina", pp. $73-101$.

40 Josep MAS ALEMANY:"Mamitis de les vaques lleteres, des del punt de vista de la sanitat pública", Anales de la Real Academia de Medicina de Barcelona, 12 (1930), pp. 168-171.

41 Josep PUJOL, Roser NICOLAU y Ismael HERNÁNDEZ: “El consumo de la leche fresca en Cataluña entre mediados del siglo XIX i 1935: la difusión del nuevo alimento", Historia Agraria, 42 (2007), p. 305 .

42 Rafael DOMÍNGUEZ MARTíN: “La financiación del sector agrario en Cantabria (1850-1930)”, Areas. Revista de Ciencias Sociales, 21 (2001), pp. 123-143.

43 T.B. MEPHAM: “«Humanizing» Milk: The formulation of artificial feeds for infants (1850-1910)", Medical History, 37 (1993), p. 227.

44 "Lactogenina", La Vanguardia, 4 de diciembre de 1930.

45 "ROB VIDA 2. Laboratorio MIRET", La Vanguardia, 21 de julio de 1922 
La leche de vaca se impuso en instituciones públicas a los niños como alimento alternativo a la leche materna. Se podía observar como las instituciones adquirían tecnología para eliminar los riesgos mortales de la leche de vaca como se observa por el elevado número de biberones suministrados por la lactancia de Barcelona en $1931.4^{46}$ De una parte, la industria químico-farmacéutica reflejaba su competencia en los productos que se le debían administrar al niño para facilitar una mejor digestión de la leche de vaca y así lo expresaban los anuncios dirigidos a las madres publicados en la prensa diaria. ${ }^{47}$ De otra parte, la industria buscaba un sistema para higienizar la leche de vaca: ozonizarla, esterilizarla, pasteurizarla y "adaptarla". Los químicos y farmacéuticos, desde la confirmación de la existencia de gérmenes en la leche de vaca quisieron demostrar su competencia en los procesos de adecuación de la leche de vaca previos a la administración de la misma en biberones. Existía entre los profesionales el conocimiento de la adulteración de la leche y la propagación de enfermedades contagiosas por la mala higiene en el ordeñado ${ }^{8}$ por lo que fueron frecuentes las discusiones sobre los problemas de la leche fresca esterilizada y los beneficios de la pasteurización o de la leche condensada. ${ }^{99}$ En Barcelona, por ejemplo, la Granja Soldevilla utilizaba la esterilización como medio de conservar la "leche maternizada" que repartía a diario en la mayoría de los barrios de esta ciudad, tal y como reflejaba su publicidad. ${ }^{\circ}$

Sin embargo, la industria láctea centró su publicidad en la leche condensada tanto en la prensa médica como en la diaria ya que era un sistema de fácil utilización por las mujeres. Estas campañas fueron avaladas y controladas por algunos médicos posiblemente en connivencia con las industrias ${ }^{51}$ (ver imagen 1 )

Así pues, la industria láctea se sumó a las campañas médicas e institucionales dirigidas a la disminución de la mortalidad infantil con su publicidad en la prensa médica destacando las ventajas higiénicas de sus productos. La introducción de técnicas artificiales para el tratamiento de la leche de vaca se hizo a través de términos como "humanización" o "maternización" incluía la esterilización, refrigeración, centrifugación, desnatado, dilución, desecación, edulcoración, pasteurización y envasado. La industria buscó, a través de la técnica y la publicidad, la aceptación social de la leche de vaca como la más parecida a la de la mujer..$^{52} \mathrm{El}$ resultado fue la aparición del nuevo término "leche maternizada" 53 para denominar la leche de vaca preparada para la ingesta a los niños mediante biberones.

No debemos olvidar que en el caso de una lactancia artificial era el profesional de la pediatría ${ }^{54}$ quien debía pautar las dosis de biberón para lo cual previamente se educaba a la mujer en las nociones de higiene infantil a fin de que aprendiese a preparar el biberón. En muchas ocasiones los propios médicos se ofrecían para corroborar como profesionales de la ciencia las bondades de los productos farmacéuticos bien fueran para la mujer o para el niño.

46 "Instituciones Municipales. La Casa de Maternología", La Vanguardia, 22 de septiembre de 1931

47 "Maltarina", La Vanguardia, 11 de diciembre de 1924 "Natel" (publicidad), La Vanguardia, 23 de julio de 1929

48 Ismael HERNÁNDEZ: La difusión de un nuevo alimento: producción y consumo de leche en España, 1865-1936, Tesis doctoral, Universitat Autònoma de Barcelona, 2003, p. 289.

49 J VIADER y J BOATELLA: “Llets condensades catalanes”, Rev. Soc. Catalana Hist. Farm. 7 (2012), p. 8.

50 "Leche maternizada. Granja Soldevila", La Vanguardia, 17 de enero de 1923.

51 "El niño", $A B C$ Sevilla, 5 de diciembre de 1929

52 Anuncio, La Vanguardia, 12 de mayo de 1923.

53 Alfredo OPISSO: "La lactancia artificial de los niños", La Vanguardia, 28 de octubre de 1916.

54 José COLOM RIBÉ: "Alimentación simultánea y mixta por el método de Martínez Vargas", La Van-

guardia, 19 de noviembre de 1916.

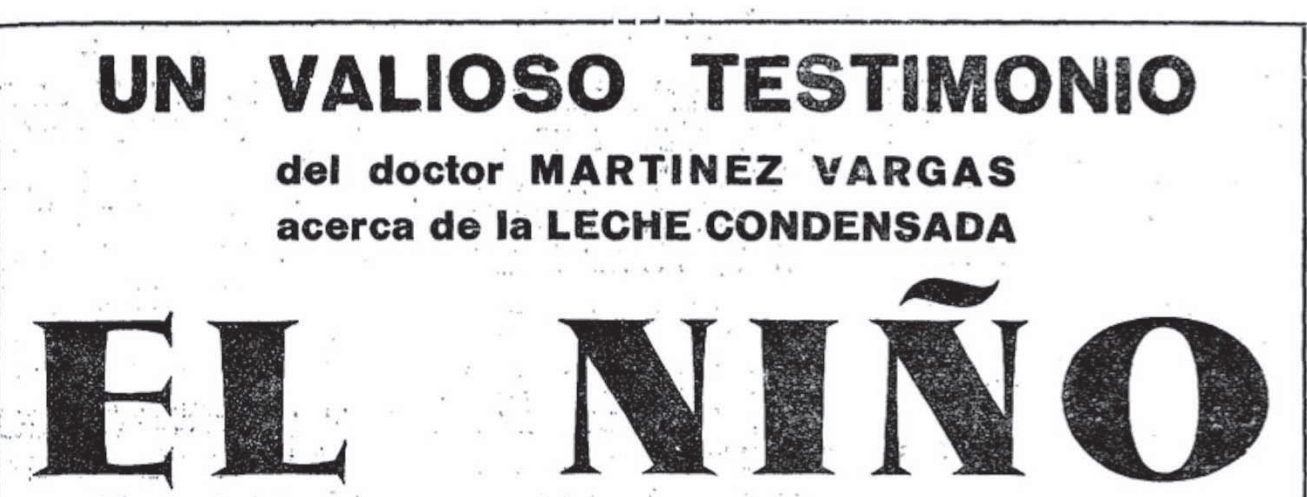

El que suscribe, catedrático de Enfermedades de la Infancia de la Facultad de Medicina de Barcelona,

CERTIFIGA: Que visitó, a poco de inaugurada, la fábrica de leche condensada EL NIÑO, en Toxrelavega (Santander), y pudo apreciar una esmerada puleritud en todas las operáciones, desde la recepción de la leche de vacas seleccionadas hasta el envase en los botes y: el cierre de éstos, todo lo cual me dío la garania de una correcta preparación y de una perfecta conervara

Con objéto de averiguar la digestibilidad de esta leche y su eficacia nutritiva en la alimentación de los niños, he hecho varios ensayos guímicos y clínicos con los primeros he comprobado ane tiene gran riqueza crema y conserva los phe he sus fermentos y vitaminas; con los otras preparaciones lácteas.

Tanto en la lactancia mixta simultánea que ideé en 1900, con la que por poca cantidad que dé el seno materno se puede criar muy bien un niño, cemo en la lactancia artificial absoluta, la leche condensada EL NIÑNO proporciona las mayores facilidades $\mathrm{y}$ me ha producido los mejores resultados; la lactarcia ha sido correcta sin in intolerancia, sin yómitos y y sin dispepsia. En algunos atróficos he alcanzado un aumento de peso diario de 50 , de 60 grames y más, hasta recuperar el peso normal. En varios niños raquíticos preexistentes, y poco hace en un niñor at edo de escorbuto in breve plazo, to que demuestra que conserva las vitaminas.

En resumen, tengo para mi que la leche condensada EL NINU, por su preparación y conservación, ha resuelto el problema de la lactancia artificial, ya como medio auxiliar cuando-la madre da una secreción insuficiente o poce menos que nula, ya como único medio de atender a la alimentación de todos los niños, cualquiera que sea sul edad.

\section{OR. MAARTIMEZ YAPGSS}

Img 01 Anuncio publicitario en el cual un médico avala una marca de leche condensada para la lactancia artificial. Fuente: $A B C$ Sevilla, 5 de diciembre de 1929.

\section{Conclusiones}

Los conocimientos y prácticas que provenían de la higiene materno-infantil en el primer tercio del siglo XX señalaban a la leche materna como el mejor alimento para el desarrollo de los infantes al contener todos los nutrientes necesarios para garantizar su crecimiento en estado de salud. Al mismo tiempo, la carestía de la vida y la miseria en la que vivía la clase obrera convertían a la leche materna en un alimento gratuito. Sin embargo, la lactancia artificial se fue abriendo paso en España a pesar de lo apuntado y de la legislación que pretendía salvaguardar un horario dentro de la jornada laboral para que las madres pudieran dar el pecho a 
sus hijos. En este proceso, podemos destacar varios factores que favorecieron la sustitución de una lactancia por otra. En primer lugar, la introducción de la lactancia artificial en España estuvo favorecida por la estrategia seguida por las campañas contra la mortalidad infantil a tener el reparto de leche de vaca como uno de sus ejes principales. El discurso higiénico que se hacía llegar a las madres en las gotas de leche y que recomendaba la lactancia materna se veía en entredicho con la práctica del reparto de leche en ese mismo lugar. La leche fue utilizada por las gotas de leche como reclamo para las madres que no podían adquirirla en el mercado y poder así completar sobre ellas la labor de adoctrinamiento higiénico que perseguían estos centros benéficos. Por otra parte, la falta de recursos de las campañas contra la mortalidad infantil, dentro del esquema de asistencia liberal, unido a intereses profesionales y quizás económicos de los médicos implicados, facilitó la entrada de la industria láctea en las discusiones en torno a lactancia artificial, un campo excepcional de negocio para estas. De esta forma, en las revistas especializadas como Puericultura, se reprodujeron las contradicciones apuntadas para las gotas de leche. Mientras los artículos que se publicaban defendían la lactancia materna, la publicidad que financiaba parte de la edición de la revista, incidía en la bondad de la leche de vaca incorporando el término "maternizada" como un eslogan científico-comercial que facilitaría la incorporación de la misma a los hábitos alimentarios de la población. Esta publicidad, divulgada también de forma masiva en la prensa diaria con la connivencia de pediatras de prestigio podría explicar, junto con lo anteriormente reseñado, el éxito y rapidez con la que fue acogida la lactancia artificial en nuestro país ya en los años 30 del siglo pasado. 


\section{POR UNA CIENCIA CATÓLICA EN ESPAÑA: LA \\ ASOCIACIÓN MENÉNDEZ PELAYO, UNA RED DE}

CONTACTOS*

Clara Florensa

Centre d'Història de la Ciència (CEHIC-UAB)

\section{Introducción}

Con el silencioso proceso de gestación que suele acompañar a las obras que no reclaman popularidad ni apariencias para su labor, se ha desarrollado y finalmente ha nacido la ASOCICIÓN MENÉNDEZ PELAYO, que agrupa a insignes personalidades de la cultura española.

Así anunciaba la revista Espirtu en $1958^{2}$ el nacimiento de esta asociación que acogía grandes nombres de la ciencia y las artes de la sociedad española. A pesar de la descripción de Espiritu, parece ser que, en un cierto momento, dicha asociación consiguió hacer bastante ruido, y que esta era precisamente su intención. Alertados por un materialismo creciente, una tecnologización de la sociedad y una desespiritualización de la cultura, pretendían reconstrui el puente entre ciencia, filosofía y espiritualidad; pretendían una recristianización de la cultura. Creando una red de intelectuales católicos, en todas las ramas y aspirando a recolectar gente lo más influyente posible, querían construir una ciencia católica en España. Lejos de ser silenciosos, pretendian organizar encuentros, conferencias, charlas, simposios y difundir los trabajos de sus socios lo máximo posible porque, a su parecer, los intelectuales católicos, "nuestros auténticos prestigios", habían quedado relegados a "una zona de sombra, mientras otros prestigios de oropel son enfocados incansablemente por la luz de los reflectores. Y se imponen muchas reivindicaciones". 3 Su existencia, pues, lejos de ser silenciosa, buscó en realidad popularidad, influencia y la máxima difusión: los miembros que formaran ese "equipo", tenían que estar "dispuestos a dejar su impronta en la vida y la cultura actuales". 5

Pero, a pesar de sus esfuerzos, esta asociación ha desaparecido sin dejar huella en el relato histórico. No se encuentra en las biografías de sus más destacados miembros, ni en la historia de la ciencia y la cultura españolas del momento. Encontrar documentos sobre ella está resultando ser una ardua tarea. Por lo que podemos decir que su muerte sí fue, sin duda, silenciosa. En este artículo me propongo hacer un primer paso para recuperar la memoria de esta asociación, de los objetivos que la motivaron, de la gente que la promovió y la integró así como

* La investigación asociada a este artículo se ha realizado bajo el marco del proyecto "Scientific authority in the public sphere in twentieth-century Spain (HAR2012-36204-CO2-01)".

Juan ROIG GIRONELLA: “Editorial: El temor a la verdad”, Espíritu, 7:25 (1958), p. 2.

2 Una fuente recuperada data su nacimiento en, o previo a, 1957: REDACCIÓN: “Vicente Marrero Suárez 1922-2000", Proyecto filosofía en español, 2003, http://www. filosofia.org/ave/001/a15o.htm.

3 Federico REVILLA: “El tema del evolucionismo en las Conversaciones de Poblet", Punta Europa, 59 (1960), pp. 95-103, p. 95

4 ASOCIACIÓN MENÉNDEZ PELAYO: Circular No. 9, Febrero-Marzo, Madrid, s.n., 1960

5 AMP: Circular No. 4, Junio, Madrid, s.n., 1958. de sus actividades. Faltará mucho trabajo por hacer. A pesar de ello, pienso que es importante recuperarla para poder componer un mejor cuadro de las redes de contactos, de las influencias y, en definitiva, de la forma de entender la cultura y la ciencia de aquellos que la representaron en un periodo histórico. La recuperación de piezas del puzzle como esta puede permitir recomponer con mayor fidedignidad la concepción del momento de lo que era y debía ser la ciencia. Su pérdida u omisión, al contrario, pueden generar una imagen sesgada de la realidad, sin olvidar que, a pesar del silencio en el relato histórico en relación a esta asociación, los que formaron parte de ella estuvieron en activo muchos años, alargándose sus carreras incluso tras la caída del régimen franquista.

\section{Ciencia y religión durante el primer franquismo: el CSIC de Albareda e Ibáñez}

La idea de una ciencia espiritual en absoluta consonancia con la fe católica, entendida como una actividad para aproximarse a Dios no era en absoluto extraña en la España de Franco. A nivel institucional, el Consejo Superior de Investigaciones Científicas (CSIC), creado por Franco para gestionar y dirigir la investigación científica del país, se fundó precisamente bajo estas premisas. En 1940, en el discurso de apertura de dicha institución científica, su primer director, José Ibáñez Martín (1939-1967) proclamó “Oueremos una ciencia católica”. El alcance científico de dicha afirmación quedaba claro cuando añadía: "Liquidamos, por tanto, en esta hora, todas las herejías científicas que secaron y agostaron los cauces de nuestra genialidad nacional y nos sumieron en la atonía y la decadencia".

La decadencia y la corrupción se asociaban con los periodos de República y gobiernos de izquierdas que habían precedido el gobierno de Franco en la historia de España. En el discurso de régimen esta asociación fue enormemente repetida a través del aparato propagandístico. En lo referente a la investigación, la academia, la enseñanza y los medios de comunicación, los periodos republicanos y liberales habían tendido a permitir la libertad de cátedra, la supresión de censura en la imprenta y, de este modo, la difusión de doctrinas no acordes con el dogma de la Iglesia Católica.7 Las palabras del ministro Martín pretendían erradicar en la ciencia española, y a través de ella, cualquier atisbo de estas tradiciones republicanas o liberales. Así, Martín junto a José María Albareda (1902 - 1966), secretario del CSIC hasta su muerte, y miembro del Opus Dei, denunciaban que la inclinación de la política científica española hacia las izquierdas contribuía a la corrupción de la sociedad española mediante la propagación de ideas materialistas, ateas o agnósticas. ${ }^{8}$ Esto había propiciado que los científicos "aislados en torres de marfil" se desentendieran de sus "deberes para con Dios y para con los hombres" y guiados por la soberbia y egoísmo habían "querido desconectar la Ciencia" dejándola al margen de las "necesidades y de los dolores de los pueblos".9 Según ellos, a través de esa política, la ciencia se había convertido en el vehículo de la "irreligión, las modas extranjeras y los fanatismos partidistas", todos ellos conceptos contrarios al catolicismo, tradicionalismo y la autarquía promovidos en el primer franquismo. ${ }^{10}$

6 Memoria del CSIC, 1942, pp. 177-195. Citado por Carlos J. ELÍAS: “Influencia de la historia de España (siglos XIX y XX) en el periodismo especializado en ciencia", Revista latina de comunicación social, 39 (2001), pp. 16

7 Francisco BLÁZQUEZ PANIAGUA: El Evolucionismo en España y la Sintesis Neodarwinista (19391970), Universidad Autónoma de Madrid, 2004. En especial, pp. 130-134.

8 Antoni MALET: "José María Albareda (1902-1966) and the formation of the Spanish Consejo Superior de Investigaciones Científicas", Annals of Science, 66:3 (2009), p. 319. Para un estudio detallado del papel de Albareda en el CSIC y en la ciencia y la investigación españolas del franquismo ver: Ibid., pp. 307-332.

9 José María ALBAREDA: Consideraciones sobre la investigación cientifica, Madrid, CSIC, 1951, p. 434 Citado en Ibid., p. 325

10 Antoni MALET: “José María Albareda...", p. 319. La traducción es mía. 
Su política científica iba encaminada, pues, a corregir esos errores. Como podía leerse en el diario $A B C$ del 3 de enero de 1951, en boca de Rafael Calvo Serer:" "tras la victoria de las armas venía lo más difícil: había que depurar las costumbres, esa tradición, esa cultura, de lo mucho que en ellas se había mezclado de vicioso, de corrupto". El mecanismo para conseguirlo que encontraron Albareda e Ibáñez fue el de concebir el CSIC como un organismo que no podía ser imparcial o ideológicamente no sesgado. Su objetivo era "poner la ciencia y la alta cultura al servicio del Movimiento Nacional" y de Dios..$^{12}$ La libertad no formaba parte de la nueva concepción de ciencia en la España de Franco. La enseñanza y actividad científica debía funcionar guiada y controlada por los intereses de la nación y subordinada al "conocimiento divino" 13 Un modelo de gestión científica autoritario y paternalista que bebía sin duda del modelo político totalitario del régimen franquista y del modelo organizativo altamente jerarquizado del Opus Dei, al cual pertenecía Albareda. ${ }^{14}$ Además, y "ante todo" había de conseguirse "la restauración de la clásica y cristiana unidad de las ciencias, destruida en el siglo XVIII". La escisión de ciencia y espiritualidad y la disociación de ciencia y cultura como entidades independientes constituían para su concepción un orden antinatural y pernicioso. Había que subsanar ese "divorcio y discordia" y promover el "árbol total de la ciencia", devolviendo a las ciencias su "régimen de sociabilidad". Todo ello podía conseguirse con un "franco y seguro retorno a los imperativos de coordinación y jerarquía" e imponiendo en la cultura el orden inspirado en el "glorioso Movimiento" que conjugaba "las lecciones más puras de la tradición universal y católica con las exigencias de la modernidad". 15

La importancia del pensamiento e ideología respecto a la ciencia que compartían lbáñez Martín y Albareda se propagaban más allá de la institución que gobernaban, y de ahí la incumbencia de tratarlos en detalle en este artículo. Como veremos, su concepto de la investigación científica (ampliamente concebida) y de cómo debía ser su política de gestión, abarcó academia, universidad y enseñanza primaria y secundaria: el CSIC no sólo controlaría la investigación sino también la Universidad, eligiendo entre los candidatos para las cátedras y puestos asociados y decidiendo qué líneas de investigación merecían o no de inversión del Estado. Más allá del ámbito académico, además, Ibáñez Martín fue ministro de Educación de Franco durante 12 años (1939-1951). Desde su cargo, rediseñó por completo el sistema educativo es pañol, desde la educación primaria hasta la educación superior. ${ }^{16}$ Bajo esta ideología, en la enseñanza primaria y secundaria varios conceptos "molestos" para la ortodoxia católica fueron eliminados o sustituidos. "Aparición del hombre" fue sustituido por "creación del hombre" y el lema "A Dios por la ciencia" se extendió por manuales de enseñanza y libros de popularización de la posguerra. ${ }^{77}$ Ello era el resultado de la política científica de Ibáñez y Albareda que había recuperado la antigua metáfora de la naturaleza como un segundo libro de la revelación, la

11 Rafael Calvo Serer (Valencia, 1916 - Pamplona, 1988) fue un intelectual y escritor, primer catedrático de Historia de la Filosofía española y Filosofía de la Historia en España y miembro destacado del Opus Dei. Calvo Serer y Florentino Pérez-Embid (de quien hablaremos más adelante) fueron
durante los años cincuenta dos de los estrategas más influyentes del Opus Dei y los dos se vincularín a finales de esta década a la AMP. REDACCIÓN. “Rafael Calvo Serer Dig1988”, Proyecto filosofía en español, 2003, http://www.filosofia.org/ave/001/a143.htm.

12 lbid., p. 321.

3 lbid., p. 325

14 Para más detalles sobre el modelo de organización del Opus Dei y su relación con la política de gestión científica del CSIC ver Ibid., 307-332.

15 Preámbulo del decreto-ley de la creación del CSIC. Boletín Oficial del Estado, Madrid, 24 de noviembre de 1939. Citado de: Jesús YNFANTE: La prodigiosa aventura del Opus Dei: génesis y desarollo de la santa mafia, Ruedo Ibérico, 1970. Recuperado de internet (http://www.opuslibros.org/ libros/Santa_mafia/capitulo_II_1.htm).

16 Antoni MALET: "José María Albareda...", p 319.

17 Francisco BLÁZOUEZ: El Evolucionismo..., pp. 291 y 212-218. lectura del cual llevaba a la humanidad hacia Dios..$^{18}$ Esta concepción acompañó y fundamentó los criterios de depuración (tanto personal como conceptual o intelectual) que se realizó en la ciencia y la enseñanza durante la dictadura. La metáfora higiénica se usó repetidamente en el discurso del régimen y se incluía en la retórica de la "Santa Cruzada", vinculando el apoyo al Movimiento con la defensa de un "sano" catolicismo. En palabras de Calvo Serer en 1950, esta labor depuradora podía entenderse como "un catolicismo que emprende victoriosamente la tarea de recristianizar su cultura".19

\section{La apertura del régimen y el nacimiento de la AMP}

En un contexto como este, parece superflua la aparición de una asociación como la AMP. Pero la política científica del CSIC y de sus líderes, es decir, la del régimen, no consiguió mantenerse monolítica durante toda la dictadura. Lejos de ello, la apertura empezada en los años 50 con la inclusión de España en organizaciones internacionales como la FAO, la ONU, o la UNESCO y la normalización de las relaciones diplomáticas, ${ }^{\circ}$ las presiones internacionales y la liberalización del mercado que empezaban a vislumbrarse terminada la Segunda Guerra Mundial, favorecieron una cierta "modernización" que comportó, según sectores tradicionalistas de la sociedad, un aumento del materialismo y de la separación entre ciencia y espiritualidad. Además, la heterogeneidad ideológica no había logrado ser borrada del mapa entre la población del país, a pesar de la depuración posterior a la Guerra Civil. Sectores con tendencias liberales, progresistas, de izquierdas y laicas seguían manteniéndose vivos en la sombra, y esta apertura parecía dar alas a su resurrección de las cenizas. Esto era intolerable para los creyentes en "la Cruzada" y, más preocupante, una amenaza. Según Florentino Pérez Embid²1 "ahora sufrimos el peligro de una reintoxicación izquierdista, de vacilación, de desconfianza; cuando parece que va a hacerse imposible continuar homogéneamente la historia de España, es necesario reafirmar nuestras convicciones y llevarlas al ánimo de todos los españoles. De lo contrario resultará estéril el Movimiento Nacional".22 En este ambiente resonaban las palabras de Albareda alertando del poder que albergaba la investigación científica, que, si se la dejaba "orbitar libremente" 23 podía convertirse en "una arma lenta pero de largo alcance y de privilegiada posición, para atacar encubiertamente los ideales básicos de la España Una, Grande y Libre". ${ }^{24}$

La AMP nació pues de un cambio que era percibido como un peligro o amenaza para el status quo del régimen. Según un sector de la sociedad tradicionalista, antiaperturista y favorable a la ideología totalitaria y paternalista de los fundamentos del Movimiento Nacional era necesario volver al control de la ciencia desde unos criterios cristianos y nacionales ${ }^{25} \mathrm{En}$ e sentir de la Asociación, había que actuar y posicionarse "ante la nueva mitología de las dialéc-

\section{Antoni MALET: “José María Albareda...", p. 323.}

19 Jesús YNFANTE: La prodigiosa aventura...

20 Francisco BLÁZOUEZ: El Evolucionismo... pp. 210-211. Ver también: TUSELL: La España de Franco, Madrid, Historia 16, 1999 y PAYNE: El primer franquismo. los años de la autarquía, Madrid, Temas de hoy, 1997.

21 Florentino Pérez Embid (Huelva, 1918 - Madrid, 1974), destacado miembro del Opus Dei, fue responsable máximo de la censura franquista como director general de Información con Gabriel Arias Salgado de 1951 a 1957. A partir de 1957 se vincularía a la AMP. Fue también consejero nacional de Educación (1953-1963), procurador en Cortes y presidente del Ateneo de Madrid entre 195 y 1956 y fundó las revistas Ateneo y Atlántida y la Biblioteca del Pensamiento Actual.

22 Jorge LOMBARDERO: "¿Laín liberal? A los veinticinco años de un descargo de conciencia”, El Catoblepas, 2, 2002, p. 12.

23 Antoni MALET: "Jose Maria Albareda.... p. 325. La traducción es mía.

24 ARdE, 8548/2/2. Citado en: Ibid., p. 320 .

25 Como podemos leer en REDACCIÓN: “Rafael Calvo Serer...": “ideólogos políticos tales como Calvo

Serer, Pérez Embid y Vicente Marrero, ... venían a defender de nuevo España contra el liberalismo y el marxismo". Todos ellos estarían vinculados a la AMP. 
ticas materialistas de la técnica sin Dios...". ${ }^{26}$ En una de las actividades de la AMP realizada en Cataluña, se manifestaba la preocupación por estos cambios observados en la década de los 50 y la necesidad de iniciativas como la AMP:

Barcelona y su comarca - Cataluña - necesitan focos de pensamiento conectados con todas las corrientes de su vida social: es tan grande el empuje de su vitalidad corpórea, tan arrolladora su expansión material, tan fuerte como centro de producción, consumo y potencia de captación que sin el contrapeso espiritual de poderosos instrumentos de cultura religiosa, humanística, científica podría perder el equilibrio por el costado de los valores más contingentes. ${ }^{27}$

Se percibía una laicización de la sociedad en todas las ramas de la cultura y una escisión de la cultura y la religión. También desde la AMP recogían la preocupación de que una mente no orientada era una mente perdida o peligrosa ${ }^{28} \mathrm{y}$, en consonancia con las ideas de Albareda, denunciaban que el desorden en el mundo había sido causa de ello: "la actual subversión universal tiene sus raíces en la mala semilla sembrada por intelectuales". ${ }^{29}$ La percepción de que crecía el volumen de gente "desatendida" en este aspecto hacía más urgente una acción de "fidelización" y recaptación de viejos, nuevos y "vacilantes o desconfiados" adeptos a la original idea de cultura del régimen. De la preocupación por esta tendencia social y su efecto en la cultura en general, y en la ciencia en particular, surgió la iniciativa de crear la Asociación Menéndez Pelayo. ${ }^{30}$

\section{Organización de la $\mathrm{AMP}^{3}$}

La institución que lleve a cabo la realización del ideal que soñó Menéndez Pelayo debe congregar todos los intelectuales españoles de las diferentes ramas de la cultura que, identificados con los principios ortodoxos de la religión y de la Patria, sepan dar el sello de autenticidad nacional a la futura obra de nuestro saber. ${ }^{32}$

\section{La Junta Nacional}

La Junta Nacional de la AMP la formaban 12 hombres de influencia en el régimen. Como veremos, todos ellos ocuparon cargos o puestos de relevancia política, institucional, académica o mediática durante la dictadura. Muchos de ellos relacionados de una forma u otra con el CSIC, catedráticos de universidad y/o políticos constituían un grupo de hombres de ideología común situados en la derecha más conservadora del franquismo, que emprendieron acciones contra la apertura del régimen, el liberalismo mostrado por algunos falangistas, y se involucraron en la restitución de la monarquía de los Borbones como línea sucesoria de Franco. Las

26 RC: "Pauta", Apostolado sacerdotal, 21:226-227 (1964), p. 2

27 Ibid., p. 1 .

28 Antoni MALET: “José María Albareda...", p. 325

29 RC: "Pauta", p. 2.

30 En el resto del artículo, AMP.

31 La Organización de la AMP aquí presentada es la que he podido reconstruir a partir del material fragmentario que he recopilado La información referente a las secciones de la AMP y sus miembros, a los cargos dentro de la jerarquía de la Asociación y a los socios está sacada prácticamente integramente, de las circulares recuperadas. Las relaciones de estas personas se han corroborado con innumerables referencias cruzadas en sus obras, biografías y coincidencias en el relato histórico. El listado de los integrantes de la Junta de la AMP procede de la biografía de Vicente Marrero en REDACCIÓN: "Vicente Marrero ...", única fuente encontrada donde aparece detallada.

32 AMP: Circular No. 4 relaciones y encuentros en el relato histórico de estos personajes son muchos. Intentaremos mostrar aqui esta red de relaciones, influencias y poder, en la cúpula de la AMP y sus vínculos con la cultura y la ciencia española del momento.

Tres hombres encontramos en la Junta Nacional de la AMP que estuvieron, a la vez, ocupando puestos importantes en el CSIC, en cargos políticos relevantes y profundamente implicados en la causa monárquica desde el seno del Consejo Privado de Juan de Borbón, el presidente del cual, José María Pemán 33 sería socio de la AMP. Estos hombres son Gonzalo Fernández de la Mora y Mon (Barcelona, 1924 - Madrid, 2002), Antonio Millán Puelles (Cádiz,1921 - Madrid 2005) y Ángel González Álvarez (León, 1916 - Madrid, 1991). De los tres, fue probablemente este último el que ostentó mayor responsabilidad e influencia en el CSIC. Filósofo, catedrático de Metafísica de la Universidad de Madrid en 1954 y miembro del Opus Dei34 fue director de dos institutos del CSIC y presidente de varios de sus patronatos, entre ellos el Menéndez Pelayo (1964-67). A la muerte de Albareda, en 1966, fue él quien le sustituyó en su cargo de Secretario General del CSIC (1967-1973). También fue nombrado vicedirector de Arbor, la revista divulgativa del CSIC de carácter general, no específica de ninguno de sus patronatos, creada para mostrar y promocionar la ciencia española. Justo por debajo de González en el mando de CSIC encontramos a otro miembro de la Junta de la AMP, Rafael Balbín Lucas (1910-1978). Éste filólogo, catedrático de la Universidad de Oviedo desde 1943, ocupó el cargo de vicesecretario general del CSIC en 1950 y también formó parte del grupo de redactores de Arbor. Respecto a sus cargos en el gobierno, González fue Procurador en Cortes en 1958 y ocupó puestos de elevado rango en materia de educación en el gobierno, siendo nombrado Director General de Enseñanza Media (1962-1967). ${ }^{35}$

Bajo la vicedirección de Ángel González Álvarez en Arbor, Fernández de la Mora y Mon, diplomático, político y ensayista, entró a formar parte en 1948, del consejo de redacción, invitado por Calvo Serer (entonces redactor de la revista). En 1952, de la Mora ocupó el cargo de vicedirector del Departamento de Culturas Modernas del CSIC, cuyo director era el mismo Calvo Serer. ${ }^{36} \mathrm{~A}$ parte de la revista Arbor, De la Mora estuvo vinculado a otras publicaciones como, $A t$ lántida, y la editorial Rialp próximas al Opus Dei -del cual sin embargo no fue miembro-, en los consejos de dirección y de redacción de las cuales encontramos gran densidad de miembros de la AMP. Precisamente en la editorial Rialp se publicarían la mayor parte de los libros del otro hombre del trío, Antonio Millán Puelles. Filósofo y escritor vinculado al Opus Dei, Millán Puelles fue catedrático de la Universidad de Madrid desde 1951 y Consejero del CSIC, entre otros cargos en esta institución, desde 1964 y designado profesor de Don Juan Carlos, cuando ya estaba previsto que fuera el sucesor del Franco. Volviendo a de la Mora, fue también responsable de la revista de pensamiento Ateneo desde 1952, al frente de la cual le sustituiría Santiago Galindo (también socio de la AMP) cuando Torcuato Luca de Tena le solicitó que se incorporara al $A B C$. En este diario, donde ocuparía el cargo de jefe de la sección editorial entre otros, realizó una prolongada labor de editorialista y crítico. Desde su faceta mediática y divulgativa, de la Mora lanzaba "violentas diatribas contra el aperturismo y la democracia". ${ }^{37}$ Progresivamente

33 José María Pemán y Pemartín (Cadis, 1897-1981) fue un escritor y activista político, caracterizado por su conservadurismo católico, que apoyó las dictaduras de Miguel Primo de Rivera y del genera Franco asi como la opción monárquica de Juan de Borbón.

34 Según Jesús YNFANTE: La prodigiosa aventura..

35 Yolanda BLASCO y Ma Fernanda MANCEBO: Oposiciones y concursos a cátedra de historia en la universidad de Franco (1939-1950), Universitat de València, 2011, p. 72 y COLECTIVO 36: "Introducción a ..." 36 REDACCIÓN: "Rafael Calvo..."

37 Como podemos leer en su biografía de la Wikipedia, "se alineó junto a figuras como Rafael Calvo Serer Florentino Pérez Embid, Vicente Marrero, Vicente Rodriguez Casado y Antonio Millán Pue"les", todos ellos miembros di AMP.WIKIPEDIA: “Conzalo Fernández de la Mora”, http://eswikipedia.org/wiki/Gonzalo_Fern\%C3\%Andez de la Mora. 
se fue acercando al círculo de poder franquista. Ejerció influencia legislativa colaborando en la preparación de la Ley Orgánica en 1965 y llegó a ser nombrado Ministro de Obras Públicas en $1970.3^{38}$ Fue socio fundador de la AMP y perteneció a una de las familias ideológicas más extremas de la derecha española. ${ }^{39}$

Acompañando a González Álvarez en altos cargos del gobierno relacionados con la enseñanza encontramos a dos integrantes más de la Junta Nacional de la AMP: Arsenio Pacios López i el Rev. P. Alejandro Díez Macho. Arsenio Pacios López (1911-?), pedagogo y profesor leonés, fue le primer catedrático de Didáctica de la universidad española en 1958. Al ser nombrado Inspector General de Enseñanza Media en 1956, fue una de las primeras promociones del Cuerpo de Inspectores destinados a diferentes institutos españoles para asegurar la implantación de la Ley de reforma de la Enseñanza Media de 1953. También fue Consejero del Consejo Nacional de Educación desde 1956, Presidente de la Sección dedicada a la Enseñanza Primaria de este Consejo en 1964 y Director de la Escuela de Formación de profesorado de Grado Medio en 1966. En su labor diplomática, fue Delegado Oficial del Gobierno Español en materias de educación. ${ }^{40}$ Por otro lado, el P. Alejandro Díez Macho, MSC (Palencia, 1916 - Barcelona, 1984), hebraísta de reconocimiento internacional, fue también Consejero de Educación Nacional para la Sección dedicada a Universidades y Alta Cultura. Los únicos Consejeros de Educación Nacional de la Universidad de Barcelona fueron, fuera del Rector de la Universidad, los catedráticos Millás Vallicrosa (también socio de la AMP) y Díez Macho. En relación con los objetivos de la AMP, estos dos catedráticos iniciaron en noviembre de 1955 la campaña para obtener la incorporación de la Facultad de Teología en la Universidad Española. Durante el curso 1951-52 Díez Macho fundó y dirigió en Barcelona las "Conversaciones Católicas de Intelectuales", en las que se reunieron representantes conspicuos de la intelectualidad de la Universidad y de fuera de ella, para discutir los temas culturales con tangencia religiosa, simiente en Barcelona de la AMP y de las Conversaciones de Intelectuales de Poblet, que ésta organizaría durante 9 años a partir de $1959 .{ }^{4}$

Otros miembros de la Junta Nacional fueron destacados académicos en sus campos, especialmente activos en la divulgación y la organización de congresos internacionales, conferencias, cursos y estancias, fundación de universidades de verano, revistas e instituciones puente entre países...de forma coherente con los objetivos de la AMP de difusión, y construcción de una red de intelectuales de pensamiento común y apostolado de esta ideología.

En cuanto al tema de los medios de comunicación y las posibilidades de difusión se ha mostrado más arriba que muchos de los miembros de la Junta Nacional tenían alguna relación u otra con revistas o editoriales. En este sentido cabe destacar a dos de sus integrantes. En primer lugar, al reverendo P. Eustaquio Guerrero López, SI (Guadalajara 1893-1978), filósofo y escritor jesuita, que desde 1939 a 1963, fue redactor de la revista Razón y Fe, en la que publicó más de 100 artículos. Publicó también prolíficamente en Punta Europa, Verbo, Cristiandad, y fue autor de numerosos libros sobre la educación religiosa en España. ${ }^{42}$ Pero en este aspecto fue clave, como veremos más adelante, la presencia de Lucas María de Oriol y Urquijo

38 WIKIPEDIA: “Gonzalo..."

39 "Opción política que defendió durante toda su vida". G.F.S.E.:"Fernández de la Mora y Mon, Gonzalo (1924-2002)", http://www.menbiografias.com/app-bio/do/show?key=fernandez-de-la-mora-y-mon-gonzalo.

40 Ángel LORENTE: “Arsenio Pacios López y los primeros inspectores de enseñanza media del Estado, Bordón, 58 (2006), pp. 201-217.

ESPLANDIÁN: “Alejandro Díez Macho. La figura intelectual de un joven profesor aramaista", Punta Europa, 3 (1956), pp. 141-159

42 Juan VALLET DE GOYTISOLO: “In Memoriam. El Rvdo. P. Eustaquio Guerrero, S.I.”, Verbo, 168 (1978), pp. 995-998.

43 Oriol fue promotor, en los años setenta, de la asociación política Frente Institucional cuyo ideario estaba en los lemas "Dios, Patria, Fueros y Rey" y "lealtad al espíritu de la Cruzada". "Encrucijada
( $i$-2003) en la Junta de la AMP. Oriol fue miembro de una familia de políticos, empresarios e industriales vascos que ejercieron gran influencia en la España de Franco. El 19 de octubre de 1976 El País ofrecía un análisis del poder de la familia Oriol, de la cual decía: "La familia, Orio (...) aparece en el panorama español actual con presencia activa en puestos claves de la política y las finanzas", con "multiplicidad de empresas -algunas de primerísimo rango- en que aparece su apellido". ${ }^{44}$ Lucas María Oriol, además de su éxito como empresario, tuvo un peso importante en la prensa escrita del momento: colaboró en los diarios El Alcázar y El Imparcial y fue impulsor de la fundación de las revistas Punta Europa y Finisterre. También fue editor y presidió el Consejo de Administración de Prensa Económica, empresa editora de Nuevo Diario y el semanario económico Desarrollo. 45

En suma, la influencia de la Junta de la AMP se extendía a través de ramas diversas de la red de poderes del régimen franquista, y desde puestos de relevancia política y social, pudiendo abarcar desde la prensa a la investigación científica, desde la universidad a la enseñanza primaria, desde la alta cultura a los ateneos populares.

\section{Socios, sede y circulares}

En el año 1961 la Asociación contaba con más de 100 socios, entre ellos, catedráticos, rectores, decanos...de más de diez universidades diferentes del país. Desde su primer año, la AMP fue creando secciones en el territorio español, cada una de ellas con su Junta Directiva (de 6-9 miembros), que tenía que ser aprobada por la Junta Nacional. Entre los años 1958 y 1961 las fuentes recuperadas dan constancia de nueve secciones: una en Cataluña y Baleares, una en Canarias, una en la Rioja, una en León, una en Calatayud, otra en Logroño y la intención de fundar una en Oviedo. Cada una de las secciones se encargaba de cumplir con los objetivos de difusión, reclutamiento, organización de reuniones y actividades, promoción del trabajo de los miembros y mecenazgo de nuevos cerebros, reportando todo ello a la Central de la Asociación. La sede de la AMP se encontraba en Madrid, en la calle Montalbán, 14, en un edificio, delante del Parque del Retiro y a pocos metros de la Puerta de Alcalá. El edificio era propiedad de la familia Oriol, de la cual era miembro Lucas María Oriol, de quien hemos hablado más arriba. Esta dirección había pasado a ser también la de la revista Punta Europa (y también de Ediciones Punta Europa) desde enero de 1958, en el momento que nacía la AMP. Esta revista mensual publicada entre 1956 y 1967, estaba estrechamente ligada a la AMP. En su "equipo, fraternalmente unido a nuestra Asociación"46, según decía la Circular número 9, había una alta densidad de miembros y simpatizantes de la AMP. Sin ir más lejos, fue promovida por el ya mencionado Lucas María de Oriol, y fue dirigida por Vicente Marrero Suárez (miembro activo y destacado de la AMP). ${ }_{47}$

Es probable, pues, que desde la editorial de Punta Europa se editaran las circulares y trípticos de actividades que la AMP elaboró para enviar a sus socios y que, desde 1959, disponían de número de Depósito Legal. Estas circulares, ideadas para ser enviadas a todos los socios, fueron conformando con el tiempo su estructura: relación de admisiones de nuevos miembros, resumen de las decisiones importantes de las reuniones de la Junta Nacional, noticias de artículos o crónicas de actividades de la Asociación, relación de actividades de los socios y una breve biografía de uno de los socios relevantes para finalizar. Al irse formando las secciones en distintas regiones españolas, las crónicas de cada sección fueron apareciendo en las circulares en una nueva sección titulada: "La Asociación Menéndez Pelayo en la vida de sus secciones".

española", El País, 12 de mayo de 1976.

44 "El apellido Oriol, en la política y en las finanzas", El Pais, 19 de octubre de 1976.

45 "Lucas María de Oriol y Urquijo, empresario", El Pais, 13 de agosto de 2003.

46 AMP: Circular No. 9 .

47 "Punta Europa 1956-1967", http://www.filosofia.org/hem/med/mo19.htm. 
El reglamento

La importancia del intento reside en que aspira a recristianizar la cultura, cuya secularización o laicización ha alcanzado todas las zonas de la ciencia y el arte. ${ }^{48}$

Como versaba el artículo 1 de su reglamento

La Asociación Menéndez Pelayo tiene por objetivo agrupar a los católicos de profesión o tuales, secundarse mutuamente en sus trabajos y laborar y desarrollar un pensamiento netamente católico, que abarque a todas las ramas del saber científico.

Con este objetivo en mente, todos los socios debían comprometerse, según el artículo tercero, "a consagrar sus mejores esfuerzos, en sus peculiares esferas científicas, al estudio, defensa y propaganda de los ideales católicos, con absoluto sometimiento a las doctrinas de la glesia Católica". De cara a los socios, la AMP debía proporcionar a cada uno de ellos un criterio cristiano seguro, fiable, testado. Los socios debían extender ese criterio a todas sus actividades cuotidianas, sociales y profesionales, específicamente en aquellas intelectuales, en un acto de "caridad", por el "amoroso y a veces difícil servicio a la verdad".

La razón explicitada en el reglamento de la necesidad de crear esta Asociación era la voluntad de subsanar una serie de actitudes y prácticas que los socios de la AMP percibían como debilidades de la comunidad de intelectuales católicos de la sociedad del momento. El reglamento denunciaba la existencia de una actitud de despreocupación:

nos desconocemos unos a otros o por lo menos no cooperamos con la ayuda mútua que duplicaría nuestras fuerzas y eficiencia, hasta a veces por desidia y falta de atención dejamos perecer la vocación de jóvenes de valor, que no hallan un rescoldo donde pueda germinar su llamamiento a ocupar algún día un puesto en el campo del intelectual católico y por nuestra apatía no cuidamos que se pongan de relieve las figuras que serían los medios para agrupar iniciativas, personas y obras, y para iniciar movimientos de intelectualidad.

También se instaba a acudir en ayuda de la Iglesia en su necesidad de ponerse al día con los avances de las ciencias. En relación a ello se criticaba que "nos preocupamos poco de cooperar con la Iglesia para ir a la vanguardia de las conquistas de las ciencias y de la cultura, a fin de armonizarlas constantemente con la doctrina de nuestra madre Iglesia dentro de un conjunto doctrinal coherente".

Finalmente se advertía sobre la actitud de aquellos que "siendo "intelectuales" y "católicos", sin embargo "distan mucho de ser "intelectuales católicos"'. El Reglamento denunciaba tanto las actitudes doctrinales como prácticas de este tipo de intelectuales que, según los valores de la AMP, a menudo tomaban posiciones que estaban lejos de "merecer siempre la aprobación y aliento de nuestra made la Iglesia". Esto, a su parecer, abría una brecha, "un abismo entre ambos términos", el de intelectual y el de católico, que la AMP pretendía hacer inseparables, y favorecía un concepto entre el público general del intelectual católico como desfasado, innecesario.

Consecuencia de todo ello era una desvalorización en la sociedad del momento del intelectual católico. Según su opinión, el ser católico no añadía valor, si no parecía que más bien al contrario, al hecho de ser un prestigioso intelectual o científico y esto afectaba a las nuevas generaciones. Así, la cuestión era que no se repitiese "nunca más el triste hecho de que a un joven se le presente la disyuntiva de verse condenado al ostracismo y al vacío si toma posiciones de intelectual católico, mientras se le abren las puertas del aplauso, del éxito y del porvenir, si se desvía hacia los sectores equivocados".

La obligación de los socios de la AMP, según se especificaba en el artículo 2 era desarrollar "todas las actividades que sean idóneas para el logro de su finalidad". Las actividades que propuestas en el reglamento para conseguir sus objetivos, abarcaban tres ámbitos. El primero era la creación activa de una red de intelectuales católicos. Los socios debían "buscar y relacionar aquellos católicos volcados al cultivo de Ciencias, Letras o Artes que hayan demostrado o demuestren una especial dedicación a las tareas culturales y religiosas", con especial interés en aquellos personajes influyentes de la intelectualidad española. El segundo era la creación de nuevas vocaciones o fomento de las ya existentes. Querían propiciar que los jóvenes católicos cursaran carreras sobretodo de ciencias para poder contribuir a la creación de una ciencia católica y a su vez potenciar la imagen del intelectual católico. Para ello pretendían constituir una fundación de la que poder "echar mano para la ayuda económica de muchas iniciativas dentro del campo católico intelectual, que ahora se malogran" y ayudar "poderosamente" a los jóvenes "con becas en España y en el extranjero", "proporcionándoles instrumental científico" o facilitándoles los medios para "iniciarse en público en la vida intelectual".

El tercero era la difusión. Esto se proponían hacerlo de tres formas. Una, ayudando cada socio, según los medios a su alcance, al máximo rendimiento científico o cultural de los afiliados. Otra, organizando coloquios, conferencias, reuniones en los que se trataran temas de cultura y religión. Estos congresos, a parte del objetivo de reanimar en los asistentes el ideal común de la AMP, pretendían ser foros de debate para ayudar a la construcción de una doctrina científica acorde con la católica y viceversa. Debían servir para "confrontar constantemente tres elementos: nuestras posiciones actuales, las conquistas de las ciencias y la cultura en su continua evolución, y las directrices de la Iglesia, a fin de que ella pueda servirse de nuestro trabajo de elaboración para la progresiva formación de la doctrina católica". Y la última, estableciendo revistas u otros medios editoriales para la divulgación o estudio de temática cultural católica y para revalorizar la figura del intelectual católico y su prestigio en la sociedad. Pretendían elaborar un boletín que "haga conocer, apreciar, difundir entre el público la personalidad y la labor de los intelectuales católicos...con tal que su posición, sin ambigüedades y sin coartadas, sea la de un claro intelectual católico". Por último, había que "fomentar el apostolado entre las clases cultas", de forma que los ideales de la AMP se difundieran en la sociedad como una mancha de aceite. Este esfuerzo de difusión iba encaminado a crear una "opinión pública de la intelectualidad" para "fomentar una corriente de aprecio, admiración y caudillaje".

El reglamento también establecía quién podía entrar a formar parte de la AMP. Para ser socio de esta "Asociación de intelectuales unidos por un mismo ideal católico" había que ser, por supuesto, intelectual. Esto es, poseer "una cultura superior o de tipo universitario, garantizada por grados obtenidos en centros estatales o no estatales y manifestada ya en el ejercicio de la docencia, ya en el de la profesión, ya en libros, o cualquiera otras publicaciones de reconocido mérito". Pero esto no era suficiente: "para ingresar uno en la Asociación ha de ser intelectual católico. Esto es, hombre conocido en su ambiente como católico en su fe y en sus costumbres","ortodoxo en sus creencias", "sin la nota de pecados públicos y escandalosos"y que "en su actuación profesional y pública, da siempre señales de tener como norma los criterios cristianos, especialmente el de atenerse en todo, con espíritu filial, a los mandatos y directrices de la Santa Iglesia." 
Tejiendo la red, uniendo fuerzas

Cada miembro se interesará en la aportación de nombres y adhesiones realmente estimables, procurando en ello la mayor altura de propósitos. Se recomienda un criterio de eficacia y no de número. 49

Desde la sede central, a través de cartas y circulares, la AMP pedía a sus socios que colaboraran facilitando información de sus actividades laborales para poder publicitarlas por sus redes cicion "nos remitan noticia de sus publicaciones, conferencias, etc., para facilitarnos la publicación del noticiario de sus actividades"..$^{\circ}$ Valían libros, artículos, cursillos, conferencias... La idea era que "a través de la noticia de ellos podemos vislumbrar con qué eficacia un grupo de intelectuales, unidos en el mismo espíritu, puede influir en la vida española". ${ }^{5}$

La labor "intelectual-apostólica" se servía de la red de publicaciones y medios de comunicación vinculados o simpatizantes de la AMP. Pero, para conseguir extenderse, la Asociación debía "conquistar" todos los vehículos de expansión posibles, "con vistas a dotar de mayor resonancia cuanto hacen nuestros asociados y ofrecerles un campo más extenso". Desde la central se pedía al socio que

nos informe sobre los extremos siguientes: Publicaciones en que colabora, su título, carácter y periodicidad; si tiene en alguna de ellas cargo de redactor, redactor-jefe, director, etc.; Casas, editoriales y colecciones con las cuales está en relación; Entidades culturales, artísticas, etc., e instituciones docentes, en las cuales puede influir para la organización de cursillos y conferencias. ${ }^{52}$

A pesar del periodo de crecimiento de la Asociación en sus primeros años de vida, 53 la AMP insistía a sus miembros que su expansión podría ser mucho mayor si todos los asociados "se preocuparan de atraer a nuestra común tarea a sus amigos y conocidos intelectuales católicos". ${ }^{4}$ Esta misión no era entendida como una simple actividad de difusión sino como un verdadero apostolado: "Cada uno de nosotros responde ante su propia conciencia, y ante Dios, de su acción o inacción". 55 Y así lo expresaban explícitamente: "Sentimos la Asociación como unión de apostolado". ${ }^{6}$ Por ello, pedían a sus socios que indagaran sobre las posibilidades de expansión de la Asociación en su localidad, comarca y provincia, sobre el número aproximado de "intelectuales reconocidamente católicos que hay en ellos" así como que enviaran sugerencias sobre los posibles "modos de atracción y plan de acción".57 La voluntad de expansión no se limitaba al territorio español: en la circular 4, se proponía la organización de ciclos de conferencias para invitar a las figuras más prestigiosas del catolicismo europeo e hispanoamericano. Así, decían, "la AMP se abriría la puerta para salir a su vez al extranjero, llevando su propia concepción españolísima, tan

49 AMP: Circular No. 13 ...

50 AMP: Circular No. 10, Octubre, Madrid, s.n., 1960

51 Carta de Arcadio Larrea Palacín (secretario técnico de la AMP) a Miquel Crusafont (Catedrático,

Director de la sección de Paleontología del Museo de Sabadell y socio de la AMP) (30 de Abril de 1959), Fons Crusafont, AMC 007C/CP/1132.

\section{Carta de Arcadio..}

53 lbid.

54 lbid.

55 lbid.

56 Carta de Arcadio..

57 Ibid. injustamente considerada - por lo general- fuera de nuestras fronteras"..$^{8}$

La información que recogía de sus socios, la AMP la diseminaba por su red de prensa escrita. A parte de Punta Europa, la Asociación estaba vinculada de una manera u otra, a una amplia red de revistas y periódicos, ya fuere porque sus miembros las dirigían, porque formaban parte del consejo directivo o de redacción o porque eran asiduos colaboradores. Encontramos socios de la AMP en los consejos directivos, de redacción o colaborando asiduamente en: $A B C$, $L O$ Vanguardia Española, Revista de Actualidades y Artes, El Alcázar y El Imparcial, Hechos y Dichos, Atlántida, Razón y Fe, La Gaceta, Espíritu, Estudios Bíblicos, Estudios Eclesiásticos, Apostolado Sacerdotal, Ecclesia, Verbo, Cristiandad o Cromosoma $X$ y en la Editorial Rialp. Y revistas y publicaciones dirigidas por miembros de la AMP como Ateneo, Finisterre, Nuevo Diario, Desarrollo, Archivos leoneses (del CSIC), Collegite, Altamira, Convivium, Estudios Riojanos o Catolicismo (de Brasil). A parte de la influencia en estos medios concretos, las actividades de la AMP gozaron de amplia cobertura en la prensa española general a través de notas de prensa distribuidas por las agencias de información oficiales, como Cifra.

La repercusión de tal red de influencia mediática es evidente: las referencias cruzadas, los elogios de unas publicaciones a otras por su línea editorial, por algún artículo concreto o por la incorporación de cierto colaborador eran la forma de incrementar su prestigio y reconocimiento social. Para poner solamente un ejemplo, Pérez Embid, entonces Director General de Propaganda del Ministerio de Información y Turismo, estaba al cargo de la colección "Temas Españoles", auspiciada desde su Dirección General. En esa colección sólo un folleto fue escrito por él: el número 215, titulado "Revistas culturales de Postguerra". En este folleto, Pérez Embid dedicó a Punta Europa, recién aparecido el primer número de la revista, un espacio dominante en la cubierta (fue una de las cuatro cubiertas de revista que aparecieron en portada), y más de dos páginas de elogio en el interior. ${ }^{59}$

No hay cabida en este artículo para detallar las actividades que efectivamente llevó a cabo la AMP (que merecen un artículo aparte) pero hay que mencionar que los miembros de la Asociación fueron realmente prolíficos en la organización de Conferencias, Simposios, Cursos de Verano, Jornadas y todo tipo de actividades en el campo de las ciencias, las letras y las artes, acordes con los ideales de la AMP, y que todas ellas fueron ampliamente reportadas y difundidas por la red de comunicaciones de que la Asociación disponía. ${ }^{60}$

\section{Conclusiones}

Onésimo Díaz Hernández, en su libro Rafael Calvo Serer y el grupo Arbor, la revista generalista del CSIC, habla de la configuración de un "sistema de hombres con ideas" que colaboraron de manera estrecha en esa revista y en otras empresas culturales durante el franquismo, con vinculación a la causa monárquica y que ganaban oposiciones y premios. ${ }^{61}$ Los nombres que aparecen en dicho grupo, sus tendencias religiosas e ideológicas y sus formas de actuar se solapan de tal forma con los que encontramos en la AMP, recuperada del olvido en este estudio, que se hace casi inevitable pensar que ésta fue, si no un aglutinador de todos ellos y sus actividades, al menos sí una de las empresas culturales que emprendió ese "equipo de acción cultural".

menos sí una de las empresas culturales que emprendió ese "equipo de acción cultural".
El giro aperturista del régimen que se vislumbraba después del desenlace de la Segunda Guerra Mundial y el miedo a un abandono al liberalismo, al positivismo y al materialismo que arrinconase el tradicionalismo católico del primer franquismo hizo reaccionar a un grupo de

58 AMP: Circular No. 4...

59 "Punta Europa...".

6o Para un ejemplo ilustrativo de actividad de la AMP y de su difusión, ver Clara FLORENSA: "Espais de debat entre ciència i religió durant el franquisme: les "Conversaciones Intelectuales de Poblet"'. En: VIII Encuentro de Investigadores del Franquismo, Barcelona, CEFID, 2013.

61 Onésimo DíAZ: Rafael Calvo Serer.. 

disgregación del núcleo dentro del grupo Arbor, por la destitución de su director en 1953 y de buena parte de su equipo con él, generó la necesidad de buscar otras vías de expresión.

Este estudio demuestra que la AMP acogió en su seno a diversos de los implicados en la que se ha llamado la "etapa más militante y politizada" de Arbor: Rafael Calvo Serer, instigador y líder del proyecto desde el cargo de director de la revista; Balbín Lucas, integrante del consejo de dirección; Pérez Embid su secretario; Vicente Marrero, vicesecretario y Fernández de la Mora, Millán Puelles, Gutiérrez Ríos, Roberto Saumells, García Escudero, Esteban Pujals, José Mora, Millán Puelles, Gutiérrez Ríos, Roberto Saumells, García Escudero, Esteban
Pemartín y José Ma. Pemán redactores o integrantes del consejo de redacción. ${ }^{62}$

Después del cambio ideológico en la revista ocasionado por la sustitución Rafael Calvo Serer por Otero Navascués en la dirección, muchos de estos personajes con una ideología y objetivos comunes se agruparon en la AMP y colaboraron en la fundación y redacción de la nueva revista Punta Europa que dirigiría el vicesecretario destituido de Arbor, Vicente Marrero, también socio de la AMP. Una nostalgia del espíritu de la cruzada y del tradicionalismo católico propio del Arbor de la etapa de Serer, y una voluntad de defenderlo y difundirlo de nuevo se encuentran muy vivas en el programa e ideario de la AMP así como en las páginas de Punto Europa, que acogieron numerosas veces los escritos de los miembros de la Asociación.

La Asociación pretendía crear una red de intelectuales católicos para rescatar el ideal de ciencia y cultura con que se fundó el CSIC: unida, espiritual y guiada por la Patria y por Dios. Hicieron de ello misión de apostolado: todos los socios debían involucrarse activamente en la expansión de la Asociación y en la difusión de sus postulados. Y así llegaron a sobrepasar el centenar de socios en su segundo año de existencia. En la Junta Nacional de dicha Asociación encontramos políticos, dirigentes del CSIC, diplomáticos, catedráticos... un grupo de hombres influyentes y poderosos unidos por un proyecto político-cultural. Más de 30 revistas y publicaciones estaban vinculadas de alguna u otra forma a la AMP, de manera que sus actividades fueron ampliamente anunciadas y reportadas en la prensa del país. La Asociación se encargaba también de difundir los trabajos de los socios por sus redes informativas. En definitiva, construyeron una telaraña de referencias cruzadas y halagos boomerang destinados a incrementar su popularidad.

Pero esta Asociación ha permanecido en el olvido histórico. No se habla de ella en las biografías de sus miembros ni aparece en la historia de la ciencia y cultura de la época. A pesar de ello, las personas que la integraron buscaron a través de ella el prestigio y la popularidad, y deja huella en la historia. Y probablemente les ayudó, porque ellos lo consiguieron; la Asociación, no. Han quedado los halagos y el prestigio pero se han derretido los hilos que los movieron. Este estudio pretende recuperar estos hilos, la memoria de esta red de contactos e influencias que en una época clave del franquismo fue apoyo y vehículo de expresión y difusión de la ideología de un grupo poderoso de la derecha más conservadora que quería, a través de la ciencia y la cultura, perpetuar un ideal tradicional católico que consideraban estaba en peligro.

62 Yolanda BLASCO y Ma Fernanda MANCEBO: Oposiciones... p. 74. y Onésimo DíAZ: Rafael Calvo Serer

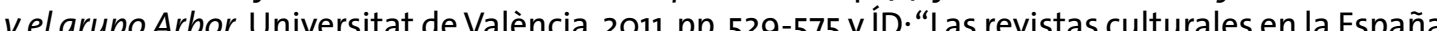
de la posguerra (1939-1951): una aproximación", CIAN, 10:1 (2007), pp. 208-210. 


\section{PROPUESTAS DIDÁCTICAS PARA UNA HISTORIA \\ SOCIAL DE LA ODONTOLOGÍA A TRAVÉS DE LAS}

FUENTES ORALES

Carlos Fuertes Muñoz

Universitat de València-Universidad Europea de Valencia

Quizás pueda sorprender la presentación de un texto sobre "propuestas didácticas» en un encuentro sobre «investigación", pero, ciertamente, entendemos que docencia e investigación deberían ligarse mucho más de lo que en ocasiones se hace. De hecho, entendemos la práctica docente como práctica de investigación, y en suma, las clases como otra forma más de comunicar los resultados de nuestro trabajo indagador. Al tiempo, como trataremos de argumentar en este texto, consideramos que los trabajos realizados por los estudiantes universitarios pueden potenciar a su vez la recuperación y construcción de fuentes útiles para la investigación.

Particularmente, el objetivo de nuestra comunicación es poner en común nuestro proyecto docente para la asignatura Antropología e Historia de la Odontología, de primer curso del Grado en Odontología de la Universidad Europea de Valencia. Teniendo en cuenta mi formación como Licenciado en Historia y mi actual línea de investigación en didáctica de la historia, mi deseo es abrir vías de comunicación y debate entre historiadores contemporaneístas e historiadores de la medicina y la ciencia, desde la premisa del enriquecimiento mutuo que puede derivarse de dicho contacto tanto a nivel de prácticas docentes como a nivel de investigación. En primer lugar, justificaré brevemente la necesidad de una mayor reflexión sobre la didáctica de la historia en la universidad, particularmente, sobre la didáctica de la historia de las ciencias de la salud. En un segundo apartado, expondré las premisas teórico-metodológicas a través de las cuáles articulo la docencia de esta asignatura, fundamentadas en metodologías activas y en una perspectiva de historia social de la odontología que considero absolutamente necesaria. En un tercer apartado, el más extenso, expondremos una propuesta didáctica de construcción de fuentes orales por parte de los alumnos, fuentes que, a su vez, podrán ser utilizadas posteriormente para la investigación sobre la historia social de la odontología.

\section{Por una didáctica de la historia en la universidad}

Una de nuestras principales motivaciones para exponer en este encuentro nuestro proyecto docente es la constatación de la necesidad de una mayor reflexión sobre la didáctica de la historia en la universidad. En efecto, pese a la consolidación en las universidades españolas del área de didáctica de la historia, lo cierto es que frente al abrumador predominio de las investigaciones relativas a la educación secundaria, y en menor medida, primaria e infantil, apenas se han desarrollado proyectos de investigación o publicaciones de experiencias docentes relativas a las

El autor participa en el proyecto "De la dictadura nacionalista a la democracia de las autonomías", HAR 2011-27392, del Ministerio de Ciencia e Innovación. Sobre los avances y limitaciones de las y Rafael VAuLs: “L Didáctica de la Historia en España: estado reciente de la cuestión", Didáctica de las Ciencias Experimentales y Sociales, 25 (2011), pp. 17-35. especificidades de la enseñanza de la historia en la universidad. ' Ciertamente, esta reflexión sobre la enseñanza de la historia en la universidad no parece haber interesado ni a los especialistas en didáctica de la historia que trabajan en las facultades de magisterio y educación ni, lamentablemente, a los propios profesores de materias históricas en la universidad, tan poco habituados estos últimos a la reflexión sobre su función docente. ${ }^{2}$

Particularmente, dado que la historia de la medicina y la ciencia está concentrada únicamente en el currículum univeristario, nos encontramos con una preocupante escasez de reflexiones sobre una cuestión elemental, agravada además por la escasa motivación que numerosos alumnos de las carreras de ciencias naturales y ciencias de la salud tienen hacia asignaturas que consideran "marías" con escasa aplicación "práctica" en su futuro laboral. Desde luego, dada la necesidad de un mayor desarrollo del debate académico sobre la didáctica de la historia de las ciencias de la salud, que debiera canalizarse a través de publicaciones, asociaciones, páginas web o congresos, conviene destacar la labor que en este sentido viene impulsando desde hace años la Societat Catalana d'Història de la Ciència i la Tècnica en sus diversos encuentros. Asimismo, otra buena noticia es la existencia, desde 2010, de la lista de correo Vesalius, que pretende poner en contacto a los docentes de las materias de historia de las ciencias de la salud en las universidades españolas, a fin de favorecer la comunicación y difusión de recursos, textos y eventos.

Por otra parte, pese a la escasez de reflexiones específicas sobre didáctica de la historia en la universidad, entiendo que los docentes universitarios de materias históricas podemos beneficiarnos de las múltiples propuestas y experiencias de innovación publicadas por profesores de historia en la educación secundaria, especialmente en el bachillerato. ${ }^{3}$ En efecto, entendemos que, convenientemente adaptadas, muchas de estas propuestas pueden ser de gran utilidad para motivar al alumnado universitario y lograr un aprendizaje más significativo y eficaz a largo plazo, que debiera ser una motivación fundamental del profesorado universitario, al menos tan importante como sus tareas investigadoras. Quizás va siendo hora de que pasemos de la queja por la desmotivación de los alumnos universitarios, a la «investigación educativa» y la innovación docente que permitirá revertir al menos parcialmente tal situación, pues son numerosos los ejemplos que muestran que hay estrategias docentes más exitosas que otras.

\section{Por una historia social de la odontología}

Junto al deseo de impulsar una mayor reflexión sobre la didáctica de la historia en la universidad, la segunda motivación que nos inspira a plantear este texto es la existencia de una serie de carencias en el estado actual de las investigaciones y la enseñanza sobre la historia de la odontología. Merece la pena en este sentido reproducir una extensa cita del historiador venezolano Jesús Saturno, firme partidario de la necesidad de una historia social de la odontología, pues sintetiza a la perfección muchos de los problemas de la disciplina:

Sobre los avances y limitaciones de las investigaciones en didáctica de la historia en España, véase el excelente balance de Joaquin PRATS y RafaelVALLS: La Didáctica de la Historia en España: estado reciente de la cuestión", Didáctica de las Ciencias Experimentales y Sociales, 25 (2011), pp. 17-35.

2 Una aguda crítica sobre las prácticas docentes de los profesores universitarios de Historia, formulada hace casi treinta años, pero tristemente aún hoy en no pocos aspectos aplicable, en: Roberto FERNÁNDEZ DÍAZ: "La didáctica de la historia en la Universidad: el reino de la nada", Manuscrits: revista d'història moderna, 2 (1985), pp.145-165.

3 A este respecto, pueden ser de gran utilidad revistas cómo las siguientes: íber. Revista de Didáctica de las Ciencias Sociales; Enseñanza de las Ciencias Sociales. Proyecto Clio (clio rediris es); Con-ciencia Social, Didéctica de las Ciencias Experiment 
Tradicionalmente se ha identificado como Historia de la Odontología (o cualquier otra profesión) a un recuento cronológico acerca de sus personajes más relevantes, de sus logros científicos-técnicos, de la fundación de sus instituciones educativas y gremiales, de la aparición de sus textos cardinales, de sus congresos y sus publicaciones periódicas. Es una sucesión de fechas, acontecimientos y protagonistas que -como fotos de un álbum familiar- ilustran un laborioso pero optimista viaje hacia "el progreso", viaje que para nada toma en cuenta al medio y las circunstancias (sociales, culturales, políticas, económicas, etc.) que lo rodean y, necesariamente, lo han condicionado (...) Muchos historiadores de la odontología evaden ciertos temas, generalmente contemporáneos, mientras en otros, centenarios, se limitan a transcribir con nuevas palabras lo dicho por sus predecesores (...) Parece pesar el mandato positivista acerca de las historias sectoriales, construidas como monografías desconectadas del contexto social. Así, la crónica de la Odontología resulta una reseña intimista de lo que los dentistas y sus predecesores han hecho a lo largo de los siglos en su oficio, con sus manos, sus hierros, materiales y medicamentos, reseña a la cual se van sumando sus héroes (Hipócrates, Galeno, Santa Apolonia, Fauchard...), sus villanos (barberos, sacamuelas, intrusos) y, más tarde, sus instituciones consagratorias: la Escuela, la Facultad, el Gremio... ${ }^{4}$

En efecto, con una escasa influencia de las corrientes más renovadoras en historia de la medicina y la ciencia, así como más en general, en la historiografía en su conjunto, buena parte de las publicaciones españolas y extranjeras sobre historia de la odontología se caracterizan por asumir una necesaria, aunque limitada, perspectiva «interna» sobre la evolución de la profesión a través del recuento detallado de los avances técnicos, los profesionales más ilustres y las fechas clave relacionadas con cambios en los planes de estudios, descubrimientos médicos, creación de nuevo instrumental o tratados innovadores. ${ }^{5}$ De este modo, en el año 2001, un análisis comparado sobre la enseñanza de la odontología en diversos países europeos, concluía que, pese a su notable importancia potencial en la formación (especialmente desde el punto de vista ético y cívico) de los jóvenes odontólogos, las materias relacionadas con las humanidades y las ciencias sociales debían renovar sus perspectivas y prácticas más habituales a fin de lograr una recepción más efectiva entre los estudiantes ${ }^{6}$

De cara a lograr este objetivo de motivación del alumnado hacia el estudio de la historia de la odontología, así como más en general, la renovación del conocimiento sobre el tema entendemos que puede ser muy conveniente la asunción de determinados cambios, los cuales estamos tratando de poner en práctica con nuestros alumnos. Por un lado, es fundamental en nuestra opinión apostar por una visión más "externa" "contextual» y "sociocultural» de la historia de la odontología, que complemente la perspectiva «interna» que predomina hoy en día, la cuál, como hemos dicho, consideramos necesaria y seguramente inevitable en una primera fase de desarrollo de la disciplina, pero que podría beneficiarse con estas transformaciones. Una historia que ponga en relación a los profesionales de la salud bucodental con la sociedad para la que trabajan, atendiendo a cuestiones como la evolución del prestigio e imagen socia

4 Jesús SATURNO CANELÓN: “Mañosa historia”, Acta Odontológica Venelozana, Vol.36, nº 2 (1998).

5 Véase, para el caso español, por ejemplo, los por otra parte detallados y rigurosos manuales de Julio GONZÁLEZ IGLESIAS: Historia de la odontoestomatología española, Madrid, Ediciones Avances Médico-Dentales, 1994, o Javier SANZ SERRULLA: Historia General de la Odontología Española, Barcelona, Masson, S.A., 1999. Una visión más general, más atenta tanto al contexto social como a la relación de la odontología con el resto de las ciencias de la salud, en José María LÓPEZ PIÑERO: Lecciones de Historia de la Odontología, Valencia, Instituto de Estudios Documentales e Históricos sobre la Ciencia, 1990.

6 Diarmuid B. SHANLEY (ed.): Dental education in Europe, Budapest, Dental Press, 2001 de los odontólogos, los condicionantes socioculturales que rigen la relación entre dentistas y pacientes o las prácticas populares relacionadas con la salud bucodental.7 Oue, entre otras cosas, estudie los avances en el conocimiento y el instrumental odontológico en el contexto más amplio de la historia de la técnica y del pensamiento y la práctica científico-médica. Oue, por ejemplo, analice el problema de la exclusión casi total de la salud bucodental del sistema sanitario público español -y de muchos otros países- dentro del marco general de la historia de la construcción del «Estado del bienestar».8

Por otro lado, sin obviar la importancia de la historia más remota de los conocimientos, técnicas y prácticas populares relacionadas con la salud bucodental, entendemos que puede resultar adecuada una mayor atención a la época contemporánea y la "historia actual», debido al hecho de que la reflexión sobre la realidad más cercana y similar a la de los jóvenes estudiantes suele generar mayor motivación debido tanto a una mayor facilidad para comprenderla, como a la sensación de una mayor utilidad de cara, precisamente, a una mejor comprensión del mundo en el que viven.

Igualmente, entendemos que resulta de gran ayuda la utilización didáctica de recursos atractivos, fuentes y prácticas que sustituyan al método expositivo tradicional hegemónico en la enseñanza de la historia, favoreciendo de ese modo clases participativas que permitan lograr un aprendizaje más significativo de la materia, así como el desarrollo de habilidades reflexivas y de investigación entre los alumnos. En este sentido, el visionado crítico de películas y documentales, análisis de fragmentos de bibliografía, prensa general y especializada o documentos archivísticos de la época, así como las visitas a museos científico-médicos o al Colegio Profesional de Odóntologos y Estomatólogos de Valencia, son algunas de las actividades mediante las que se pretenden lograr los objetivos formulados.

Las fuentes orales como recurso para la enseñanza y la investigación de la historia social de la odontología

Entre los diversos recursos y actividades que pueden favorecer el cambio planteado, nos detendremos a continuación en una propuesta didáctica que, a nuestro juicio, muestra a la perfección la simbiosis entre docencia e investigación que defendíamos al inicio de nuestro trabajo. Se trata de la realización por parte de los alumnos de una entrevista biográfica a un odontólogo o paciente de edad avanzada como modo de aproximarse a la historia reciente de la odontología. Entrevista que, a su vez, dará como resultado una fuente oral que podrá ser utilizada en futuras investigaciones por parte de especialistas de distintas disciplinas, e incluso por parte de los propios alumnos en futuros trabajos de curso sobre diversas temáticas.

El potencial de las fuentes orales para la profundización en la historia social del pasado reciente ha sido puesto de manifiesto por numerosos autores, desde que en los años sesenta se iniciará su lenta extensión en la práctica de la investigación histórica, precisamente como reacción a una historiografía que, por otorogar la mayor importancia a las fuentes documen-

7 Sobre estos temas, resultan de gran interés trabajos como el análisis de la evolución de la representación artística de la figura del odontólogo y del acto de la extracción dental, en: David KUNZIE: "El arte de sacar muelas en los siglos XVII y XIX. :De martirio público a pesadilla privada y lucha política?", en Michel FEHER, Ramona NADDAFF y Nadia TAZI (eds.): Fragmentos para una historia politica?", en Michel FEHER, Ramona NADDAFF y Nadia TAZI (eds.): Fragmentos para una historia
del cuerpo humano. Madrid, Taurus, 1992, vol.3, pp. 28-89; o el análisis de entrevistas a pacientes y del cuerpo humano. Madrid, Taurus, 1992, vol.3, pp. 28-89; o el analisis de entrevistas a pacientes y
dentistas de Sarah NETTELTON: Power, pain and dentistry. Buckingham, Open University Press, 1992.

8. Francisco Javier CORTÉS MARTINICORENA, Santiago CERVIÑO FERRADANES y Elís CASALS PEIDró. Servicios públicos de salud bucodental en España: legislación y cartera y elias CASALS PEIDRO: Servicios públicos de salud bucodental en España: legislación y cartera de servicios en las Comunidades Autónomas. 2005, Madrid, SESPO, 2005; Susan T. REISINE: "Social, psychological and economic impact of oral health conditions, diseases and treatments", en LOis K. COHEN y Patricia 1995, pp.387-425. 
tales conservadas en archivos públicos, tendía a reproducir la perspectiva de las élites masculinas, aquellas que tradicionalmente habían detentado el poder en las instituciones políticas, eclesiásticas o militares. En efecto, resulta evidente que la construcción de «historias de vida» entrevistando a personas alejadas de la primera fila de la actividad política, militar, etc., es una herramienta clave para ampliar nuestra visión del pasado, incluyendo las experiencias y percepciones subjetivas de la "gente corriente", entre ellos, los profesionales sanitarios, o los usuarios de sus servicios. ${ }^{9}$

Asimismo, además de en las tareas de investigación histórica, en las últimas décadas el uso de las fuentes orales se ha extendido también en la educación formal, pues se ha constatado que, debidamente utilizadas, pueden favorecer una mejora sustancial en el proceso de enseñanza-aprendizaje de la historia. Por un lado, las fuentes orales, por su naturaleza "interactiva", ayudan a que el alumno visualice fácilmente cómo se debe trabajar con cualquier otra fuente histórica: realizando preguntas que hay que preparar bien, «leyéndola» e interpretándola atentamente. De este modo, el trabajo con fuentes orales promueve un papel activo de alumno-investigador frente a todo documento, que le será útil en un futuro trabajo con fuentes de otro tipo: escritas, audiovisuales, materiales, etc. Por otro lado, los relatos autobiográficos de personas de carne y hueso que vivieron los hechos estudiados suelen ser bastante más atractivos para los estudiantes y desde luego tienen mayor capacidad de generar empatía que un texto o una explicación del profesor. En efecto, los testimonios orales provocan una fuerte impresión de realidad y una «estimulación afectiva» que está prácticamente ausente del resto de fuentes históricas, y que es una de sus grandes aportaciones para lograr un aprendizaje significativo. Asimismo, las fuentes orales permiten acercarse a una historia "concreta", con protagonistas o "sujetos reales", evitando una visión despersonalizada del pasado, en la que los actores sociales son meras abstracciones o generalizaciones ("los dentistas", "los pacientes") que difcultan así la comprensión de la complejidad y pluralidad de la historia. ${ }^{10}$

Si bien el uso didáctico de las fuentes orales se ha extendido especialmente en el ámbito de la educación secundaria, contamos con publicaciones sobre ciertos proyectos relativos a la educación infantil y primaria, así como a la educación universitaria. ${ }^{11}$ Teniendo en cuenta estas diversas experiencias, así como nuestra propia experiencia anterior con alumnos de "Introducción a la Historia" (Grado en Historia del Arte), hemos diseñado para el próximo curso 2013-2014 un proyecto de construcción de fuentes orales con los alumnos de "Antropología e Historia de la Odontología". Como premisa fundamental, tenemos en cuenta que los especialistas en el uso didáctico de las fuentes orales insisten en que, en realidad, algunas de las «aportaciones» de la historia oral a la enseñanza de la historia que hemos señalado, sólo se darán si apostamos por un uso «activo» de las fuentes orales, yendo más allá de los usos

Una visión general sobre el uso de las fuentes orales en la investigación histórica en Paul THOMPSON: Historia oral. La voz del pasado, València, Edicions Alfons el Magnànim. El desarrollo de la historia oral en el ámbito de la historia de la medicina y la ciencia ha dado lugar a interesantes trabajos que han profundizado en el giro sociocultural experimentado en las últimas décadas en este campo de conocimiento. Un buen ejemplo para la historia de la salud y la atención sanitaria en Gran Bretaña, en Joanna BORNAT: Oral history, health and welfare, London, Routledge, 2000.

10 Estas y otras reflexiones sobre las aportaciones de las fuentes orales a la enseñanza de la historia, en Laura BENADIBA y Daniel PLOTINSKY: Historia oral. Construcción del archivo histórico escolar: una herramienta para la enseñanza de las ciencias sociales, Madrid, CEP (especialmente, pp. 119-124). 11 En el caso de la educación universitaria hemos podido localizar particularmente abundantes expe-
riencias docentes de análisis del pasado a través de las fuentes orales realizadas desde el ámbito de la Historia de la Educación: Miguel BEAS MIRANDA "Propuestas metodológicas para la Historia de la Educación", Cuadernos de Historia de la Educación, 1 (2002), pp.9-34; Matías BEDMAR e Inamculada MONTERO: "Historia Oral, recurso para la educación intergeneracional", Universitas Tarraco- "pasivos" en las aulas en forma de documentales o visitas aisladas e informales de distintas personas, recursos que si bien pueden ser útiles como refuerzo de la información o como disparadores de algunos temas, no sacan todo su partido a la historia oral, pues no introducen a ten coproducir su propio conocimiento. En este sentido, resulta mucho más interesante la realización, durante un tiempo considerable (a ser posible, todo un cuatrimestre), de un proyecto de construcción de fuentes orales que siga la metodología sistemática y rigurosa de la historia oral, siempre bajo la atenta supervisión del docente que deberá preocuparse de «capacitar» a los alumnos para la adecuada realización de entrevistas biográficas.

El proyecto constará de diversas fases, siguiendo la metodología habitual en las investigaciones con fuentes orales. ${ }^{12}$ En primer lugar, durante las primeras sesiones del curso, a partir de la lectura y debate de diversos textos teóricos sobre las fuentes orales, así como mediante el análisis de fragmentos de entrevistas transcritos y audiovisuales, familiarizaremos a los alumnos con las bases teóricas y metodológicas propias de la historia oral. En una segunda fase, se procederá a la investigación previa y la preparación de la entrevista, combinando diversas sesiones y actividades de formación sobre la historia de la odontología contemporánea con particular atención al caso español, con algunas tareas de tipo más práctico. Así, respecto a las actividades prácticas, elaboraremos una «carta de presentación» del proyecto para presentar los objetivos del mismo a potenciales informantes; una "ficha de informante», la cuál rellenará éste con sus datos personales cuando le contactemos y nos servirá para conservarla posteriormente en nuestro archivo junto a la entrevista; o en fin, el propio cuestionario, el cuál, partiendo siempre de una perspectiva amplia de historia social y cultural de la odontología y relacionada con los contenidos trabajados en clase, deberá adaptarse en función de si el informante escogido se trata de un odontólogo o de un paciente. En esta misma fase realizaremos entrevistas a modo de prueba en el aula, con informantes de "confianza" seleccionados por el profesor y que, en entrevistas realizadas por varios alumnos y grabadas, servirán para realizar una posterior puesta en común sobre errores y aspectos positivos detectados.

En una tercera fase, tras la «investigación» y «preparación» de la entrevista, cada alumno procederá a la selección de su «informante», para lo cuál podrán recurrir bien a conocidos o bien a desconocidos localizados en clínicas, el Colegio de Odontólogos u otros espacios profesionales o asociativos. A fin de convencer al potencial informante del valor de su testimonio, deberán insistir en la necesidad de sus historias de vida para enriquecer la Historia con mayúsculas, rompiendo asi la extendida tendencia a la minusvaloración de las propias experiencias vitales por parte de la mayoría de la población que ha vivido ajena a los cargos de poder institucional. Una vez localizado y «convencido», se le pedirá que rellene la «ficha de informante» previamente elaborada, solicitando asimismo su consentimiento para la conservación de la grabación resultante en el archivo de la facultad. Algo, esto último, no siempre fácil de obtener, especialmente cuando las entrevistas tocan determinados temas más o menos polémicos o conflictivos, pero que, de conseguirse, permitiría la posterior utilización de dichas fuentes, tanto a nivel didáctico en cursos posteriores, como de cara al desarrollo de investigaciones históricas o proyectos de divulgación. 12 Una buena guía práctica para el trabajo con fuentes orales en Pilar FOLGUERA: Cómo se hace historia oral, Madrid, Eudema. En otro lugar he reflexionado de un modo práctico y autocrítico sobre el proceso de construcción de fuentes orales: Carlos FUERTES: "Actitudes politicas de las clases populares durante el desarrollismo. Un estudio local de historia oral en Paterna (Valencia)", en Ana Cabana, Daniel Lanero y Victor Manuel Santidrản (eds.), VII Encuentro de Investigadores sobre el Franquismo, Santiago de Compostela, Fundación 10 de Marzo, 2011, pp. 368-379. Para las particularidades de la realización de proyectos de investigación con fuentes orales en el aula, resulta imprescindible el manual de Laura BENADIBA y Daniel PLOTINSKY, redactado pensando en la edutrión inantil y primaria, pero metodologicamente válido -cón las debidas adaptaciones-para 
En la cuarta fase, los alumnos deberán concertar una cita para realizar la entrevista con su informante, a ser posible en su domicilio o clínica, a fin de que este se sienta más cómodo. La entrevista deberá ser convenientemente grabada, a ser posible en formato audiovisual, pues la imagen permite captar la fundamental comunicación no verbal. Una buena manera de refrescar la memoria de nuestro informante puede ser haberle solicitado previamente que traiga a nuestra cita diversos "documentos personales" de su pasado, tales como fotografías, cartas, carnets profesionales, títulos académicos, etc. o, por ejemplo, dientes de leche o prótesis en el caso de que se haya optado por entrevistar a pacientes. La entrevista deberá iniciarse con una invitación a que el entrevistado cuente a grandes rasgos cómo ha sido su vida. Tras este relato inicial espontáneo, el entrevistador procederá a la realización de las diversas preguntas contenidas en su cuestionario, tratando de no repetir aquellas que ya hayan sido formuladas "espontáneamente", así como, especialmente, tratando de evitar que la entrevista se convierta en una «encuesta» rígida y formal. Lejos de ello, se insistirá a los alumnos en que la entrevista debe ser una conversación relajada, en la que el cuestionario debe servir de apoyatura, y las preguntas del entrevistador de guía, pero lo más importante es saber escuchar y crear un buen ambiente para que el informante se explaye en sus anécdotas y opiniones.

En una quinta fase, en fin, se procederá a la transcripción y catalogación de las entrevistas. sin duda, una tarea áspera, pero que posteriormente facilitará a los alumnos el análisis en profundidad de la entrevista, mediante la lectura de la transcripción y la selección de citas para la elaboración de un comentario crítico, que, a su vez, será expuesto en clase en forma de presentación oral apoyada en el visionado de fragmentos de la entrevista representativos de las distintas cuestiones que se desee destacar. Gracias a la tarea de transcripción y catalogación, además, una vez finalizado el curso dichas entrevistas serán conservadas en el archivo de

la facultad, facilitando enormemente su utilización en futuras investigaciones. En suma, un proyecto que creemos puede dar buenos resultados para la mejora tanto de la enseñanza de la historia de la odontología en la universidad como de la investigación sobre el tema, siendo, convenientemente adaptado, perfectamente aplicable a otros campos de la historia de la medicina y la ciencia, y más en general, de cualquier rama del conocimiento histórico. 


\section{CSIC: EL DISCURSO INSTITUCIONAL SOBRE LA CIENCIA UNA APROXIMACIÓN AL CONCEPTO DE CIENCIA EN LA ESPAÑA FRANOUISTA'}

Fernando García Naharro

Universidad Complutense de Madrid

\section{Introducción}

A pesar del pretencioso título que encabeza estas páginas, en ellas no pretendemos nada más que realizar un acercamiento tangencial al concepto de ciencia "oficial" desplegado desde las altas esferas del régimen franquista al comienzo del mismo. Para ello nos valdremos de documentos oficiales del Consejo Superior de Investigaciones Científicas (CSIC), institución creada por el régimen y uno de los actores principales en la construcción de la política científica española durante el franquismo. Estos documentos serán, principalmente, "Estructura y Norma de la Investigación Nacional" (donde figura el texto de la ley de creación del Consejo (24-11-1939) el reglamento de funcionamiento (10-02-1940) y las disposiciones complementarias) y la primera Memoria anual de la actividad científico-técnica del Consejo Superior de Investigaciones Científicas, correspondiente a los años 1940-1941, ${ }^{3}$ como testimonio "oficial" de los primeros pasos de la institución.

Con estos documentos, y a través de nuestro análisis, pretendemos realizar una reconstrucción histórica que nos permita comprender el sentido de los discursos en relación con su contexto de producción, sin atarnos a una aproximación estrictamente lingüística, sino tratando de atender a sus condiciones de posibilidad, así como a las múltiples determinaciones que operan en la construcción del sentido del discurso. A su vez, trataremos de atender a las potencialidades, como instrumento de poder, de dichos discursos y las posibles implicaciones que en el campo intelectual pueden suponer, es decir, a las implicaciones que éstos pueden tener en las condiciones de posibilidad del conocimiento científico de la época; todo ello para tratar de desentrañar los diferentes procesos implicados en la construcción de sentido del discurso, con la esperanza de comprender mejor la evolución de las ideas científicas en la España franquista.

\section{CSIC: Ciencia institucional y política científica}

En la década de 1940 el CSIC era una institución joven. Fundado el 24 de noviembre de 1939 por el régimen franquista sobre las instituciones y el legado de la Junta para Ampliación de Estudios e Investigaciones Científicas (JAE), institución antecesora, creada por Amalio Gimeno, ministro de Instrucción Pública y Bellas Artes, en 1907. Una institución, la JAE, heredera de los principios de la Institución Libre de Enseñanza, que representó para la ciencia española todo un avance, pero que ahora vería truncada su obra, decretándose el cese

1 Esta comunicación ha sido posible gracias a la financiación del Ministerio de Economía y Competitividad. Se inserta en los trabajos del proyecto (HAR2011-29343) “LA POLITICA DEL LIBRO Y LA INDUSTRIA EDITORIAL EN ESPAÑA (1966-1986)"

2 CSIC: Estructura y norma de la investigación nacional: (texto de la ley, reglamento y disposiciones complementarias del Consejo Superior de Investigaciones Científicas), Madrid, Tip. Samarán, 1940. oficial de sus actividades durante la Guerra Civil y su posterior disolución en 1939, quedando todos sus centros ligados al CSIC.

El presidente de esta nueva institución fue el Ministro de Educación, José Ibáñez Martín quien contaría con la estrecha colaboración de José María Albareda como secretario general. Desde entonces, el CSIC será el actor principal en la construcción de la política científica española (desplazando asi de sus funciones al Instituto de España que subsistirá "como enlace de las Reales Academias y de éstas con el Ministerio" 4 ) hasta finales de los cincuenta, cuando aparezca entonces la Comisión Asesora de Investigación Científica y Técnica (1958), la primera de una serie de iniciativas estatales para dotar a España de una política científica coherente. 5 Uno de los objetivos del CSIC será hacer olvidar el legado de la JAE y de sus investigadores: así, como señalan López Piñero, González Blanco y Jiménez Blanco, en 1955 sólo el 5\% de los investigadores habían publicado antes de $1940 .^{6}$

No podemos olvidar que la destrucción de una cultura aparece como la destrucción de su memoria, la eliminación de textos y nexos que los unen a la cultura de un país. Ésta será una de las consecuencias de la represión que podemos ver claramente en los últimos trabajos de Enrique Otero Carbajal ${ }^{7}$ y Josep Lluis Barona, ${ }^{8}$ donde se describe la destrucción y diáspora de la comunidad científica creada en la edad de plata de la cultura española, en la primera mitad del siglo XX.

\section{Concepto de ciencia}

Como investigadores debemos entender que el concepto y los límites de la ciencia y el trabajo científico han ido cambiando a lo largo del tiempo. Como Josep Lluis Barona nos recuerda en su libro "Ciencia e Historia" el concepto de ciencia es variable en el tiempo y en el espacio: así, el concepto aristotélico de ciencia que giraba en torno a todo aquel conocimiento que es necesario y eterno, difiere del concepto escolástico de ciencia, donde el conocimiento verdadero se alcanza abordándolo desde una perspectiva teológica. Más adelante, en el siglo XVIII, en Europa, con la aparición de la metafísica o búsqueda de una estructura lógica del saber, se volverá a redefinir el concepto de ciencia o la manera de hacer ciencia, demostrando una vez más la importancia de determinar en la ciencia la relación entre la teoría y los hechos. 9 Por lo tanto, haríamos mal en tomar como dado el concepto de ciencia; no podemos considerarlo como mero conjuntos de hechos empíricos esperando a ser descubiertos por los científicos, debemos atender por tanto a la manera en que los científicos hacen ciencia y a la relación que subyace entre teoría y hechos, $y$, si es posible, al proceso por el cual algo se convierte en un hecho.

A través de las memorias del CSIC no tenemos acceso a ese proceso realizado por los científicos, pero sí al discurso, a la idea de ciencia que desde dicha institución se promueve. A través de los discursos realizados por científicos y por el propio Ministro de Educación podemos captar claramente la relación entre la ciencia y la política nacional; una ciencia que se quiere inspirada en los principios del Movimiento y en la tradición católica como guía para la consecución del correcto conocimiento científico.

4 BOE $28 / 11 / 1939$

Alejandro NIETO: "Presentación" en Alejandro NIETO et al. (coords.): Apuntes para una política científica. Dos años de investigación en el CSIC: 1980-1982, Madrid, CSIC, 1982, pp. 11-14.

6 Pedro GONZÁLEZ BLANCO; José JIMÉNEZ BLANCO; José María LÓPEZ PIÑERO: Historia y sociología de la ciencia en España, Madrid, Alianza, 1979, p. 131.

7 Luis Enrique OTERO CARBAJAL: La destrucción de la ciencia en España, Madrid, Editorial Complutense, 2006.

8 Josep Lluís BARONA: El exilio cientifico republicano, Valencia, Publicacions de la Universitat de València, 2010.

9 Véase Josep Lluís BARONA: "Sobre el concepto de ciencia" en Ciencia e Historia. Debates y tendencias en la historiografia de la ciencia, Godella, Seminari d'estudis sobre la ciencia, D.L.1994, pp. 11-21.
3 CSIC: Memoria de la Secretaria General (1940-1941), Madrid, CSIC, 1942. 
Algo que podemos leer en la ley fundacional del Consejo (24 de noviembre de 1939) donde se aboga por la:

Restauración de la clásica y cristiana unidad de las ciencia, destruida en el siglo XVIII. Para ello hay que subsanar el divorcio y discordia entre las ciencias especulativas y experimentales y promover en el árbol total de la ciencia su armonioso incremento y su evolución homogénea, evitando el monstruoso desarrollo de alguna de sus ramas, con anquilosamiento de otras (...) Hay que imponer, en suma, al orden de la cultura, las ideas esenciales que han inspirado nuestro Glorioso Movimiento en las que se conjugan las lecciones más puras de la tradición universal y católica con las exigencias de la modernidad. ${ }^{10}$

Dichos principios, que inspiraron el nuevo régimen, entroncaban con los pensadores de la ideología contrarrevolucionaria europea de finales del siglo XVIII y con toda una tradición científica previa a la llustración. Se pretendía volver así a sustentar el conocimiento en la referencia al saber divino como criterio de autoridad, enraizado en el símbolo del árbol de la ciencia de tradición luliana, un "arbor scientiae" que será el emblema del CSIC, ese granado "en cuyas diversas ramas se aluda en lengua latina a las manifestaciones científicas que el Consejo cultiva"."

\section{Arbor scientiae}

El símbolo del árbol de la ciencia, con una larga tradición porfiriana, representa la combinación de la naturaleza y los objetos intelectuales enraizados en una misma materialidad; un símbolo estrechamente relacionado con la figura de Raymundo Llulio (o Ramón Llull (12321315)) escritor y filósofo nacido en el reino de Mallorca, quien, entregado a la reflexión filosófico-religiosa y a la predicación evangelizadora, escribió la obra El Arbre de sciència (Árbol de la ciencia) un extenso tratado enciclopédico en el que se da noticia de todas las ciencias, un libro general que pretendía servir para entender todas las ciencias, aportando los principios básicos que las rigen, a los cuales su autor llegó por la Gracia de Dios. ${ }^{22}$

El libro se divide en diez y seis partes que conjuntamente componen el árbol de la ciencia (Árbol Elemental, Árbol Vegetal, Árbol Sensual, Árbol Imaginal, Árbol Humanal, Árbol Moral, Árbol Imperial, Árbol Apostolical, Árbol Celestial, Árbol Angelical, Árbol Eviternal, Árbol Maternal, Árbol Christianal, Árbol Divinal, Árbol Exemplifical, Árbol Questional) todos y cada uno de ellos divididos a su vez en siete partes (raices, troncos, brazos, ramos, hojas, flores y frutos) y siguiendo una lógica unidireccional y teleológica que nos lleve, desde la naturaleza y las propiedades de los elementos propuesta en el árbol elemental, hasta concluir en el árbol questional que nos aporte "el arte y el modo de proponer las cuestiones y de darles solución". ${ }^{3}$

10 CSIC: Estructura y norma de..., pp. 9-10.

11 Ibid., p. 94.

12 "Un libro general, que pudiese ayudar para entender todas las ciencias. Porque el entendimiento confuso conduce, y ocasiona gran peligro, y privación de devoción grande para honrar a Dios, conocerle, amarle y servirle, y para procurar la salvación para el prójimo. Respondió Raymundo, Señor Monje, mucho tiempo he tratado de inquerir la verdad de un modo y de otro, y últimamente por gracia de Dios he llegado a el fin y conocimiento de la verdad, que tanto desee saber, la cual he puesto y declarado en mis libros" (Raymundo LULIO: El árbol de la ciencia, Bruselas, Francisco Foppens, impresor y mercader de libros, 1663, p. 2).

13 " $\mathrm{Y}$ se da conocimiento y luz para inquerir y buscar las verdades de lass cosas, y para destruir $\mathrm{y}$ confundir los errores que se ponen en muchos libros: por los cuales muchos hombres están en las tinieblas como ciegos" (Raymundo LULIO: El árbol de la..., p. 3).
Una obra marcadamente teológica, en cuyo introductorio "De las definiciones de las cien formas" ${ }^{14}$ pueden leerse afirmaciones de corte esencialista como las siguientes:

"La esencia es aquello, por lo cual es el ser: como el hombre lo es por la humanidad, y el ente por la entidad" (p. Ixxiii) "La naturaleza es principio, por el cual los entes naturales son producidos naturalmente. $Y$ esta es dupla, es a saber naturaleza naturalizante, como Dios; y naturaleza naturalizada, como la criatura" (p. Ixxvi) "La materia es principio esencial, a el cual compete propiamente la pasión:y por cuya razón es pasiva la sustancia compuesta" (p. Ixxxii) "La razón es la luz de el entendimiento para conocer las realidades de las cosas" ( $p$. Ixxxv) "La significación es la revelación de los secretos con la señal de las cosas demostradas" (p.xciv) “La definición es manifestación cierta y expresa de las cosas y de sus propiedades" (p.xcvi) “La Ciencia es el conocimiento necesario y verdadero de las cosas, conseguido por el verdadero entender"(p. cvi) "La teología es ciencia, que prepara el entendimiento y voluntad humana a conocer y amar a Dios nuestro Señor" (p. cviii) "La Philosofía es Ciencia, por la cual el entendimiento es iluminado para conocer la primera causa, por cuyos efectos conocemos las operaciones secretas naturales o morales de los Philosofos"(p. cviii) "Y todo va escrito según la corrección de nuestra S.Madre la Iglesia" (p. cxxv). ${ }^{15}$

A este discurso es al que el franquismo pretende relacionarse mediante el ejercicio semiótico de la citación, quizá jugando, como señalaba Foucault, a anular uno de los términos de la relación ${ }^{16}$ en un ejercicio de metonimia en donde la parte sustituya al todo, en donde la parte citada de la tradición sustente y sustituya (oculte) al discurso propio del régimen, quien despliega esa imagen, esa alegoría del árbol de la ciencia que ahora retoma, pero que a la vez adapta nutriéndola de los principios fundamentales del Movimiento sedimentados ya en la tierra'7 que "señala al Cielo, que es decir a Dios, la Verdad"18 como principio básico de la nueva ciencia.

\section{Ciencia al servicio de la patria}

Enraizado el Árbol de la Ciencia en el corazón de la Patria, recibe su vida por las raíces, que se dividen al infinito por toda la tierra hispana; se yergue luego, potente y frondoso extendiendo sus ramas de protección a todos los que laboran y a todos los que tienen derecho a exigirle sombra y protección. ${ }^{19}$

Ese renacer de valores religioso ${ }^{20}$ no impide que el lenguaje imperial (e incluso bélico) propio del momento, también esté muy presente en los discursos para enfatizar la ligazón del CSIC

14 Véase "Introductorio" en Raymundo LULIO: El árbol..., Bruselas, Francisco Foppens, impresor y mercader de libros, 1663.

El propio texto para su publicación, cuenta con la "Approbatio ecclesiastica" (p. cxxvii).

16 "¿Quién no observa que se trata de anular cada vez uno de los términos de la relación y no de suprimir la relación misma? Relación que no cesa de modificarse a través de los tiempos (...) en lo que se llama globalmente un comentario, el desfase entre el primer y el segundo texto juega cometidos que son solidarios" (Michel FOUCAULT: El orden del discurso, Buenos Aires, Tusquets, 1992, p. 23).

17 “El árbol se enraíza en España, conduciendo hacia Dios, señor de las Ciencias" (CSIC:Memoria de la Secretaría General (1940-1941), Madrid, CSIC, 1942, pp. 114-115). En su discurso, Ibáñez Martín toma palabras de Pio XII, discurso a la l'Academia delle Scienze, 30 noviembre de 1941.

18 lbid., p. 6.

19 Ibid., p. 6.

20 "Los actos religiosos con los que hemos inaugurado las tareas de este Consejo significan la expresión más auténtica de la plena armonía entre la fe y la cultura, que hoy renace con todo vigor" (CSIC: Memoria de la Secretaría General (1940-1941), Madrid, CSIC, 1942. pp. 1-2). 
(y por ende de la ciencia oficial) a los objetivos propios del régimen. Así, en la reunión inaugural del 28 de noviembre de 1940, el entonces ministro de Educación, José lbáñez Martín, dijo:

Aquí tenéis, señor (Franco), alineados en fila, dispuestos en las falanges y "centurias" de sus Patronatos e Institutos, el nuevo ejército de la ciencia española, dispuesto para la gran batalla de la cultura, ansioso para realizar el plan de renacimiento y restauración científica nacional, guardando la disciplina del Estado, y con un espíritu unitario de servicio al país...Ellos (los investigadores) quieren ser sus más leales y activos colaboradores para la gran y soñada empresa de restaurar nuestro imperio, el Imperio de España, que está en la fuerza universal de su ciencia. ${ }^{21}$

Una ciencia a la que, en algunos momentos, se pretende señalar como valor supremo, pero que acaba quedando relegada a los dictámenes de la religión católica y de los intereses del régimen:

El Estado actual construye su orden institucional dentro de la más rigurosa jerarquía de valores. De todos ellos, en el orden científico, el más alto es el que corresponde a la investigación. Pero el cultivo de la ciencia deberá aplicarse a las realidades vivas que tiene planteadas el Estado (...) El Consejo es hoy un poderoso instrumento puesto al servicio de los valores espirituales del Estado (...) La investigación es un deber nacional (...) El sentido de unidad y solidaridad que la Falange incorpora a la vida del Estado inspira fundamentalmente nuestra obra (...) El Consejo conoce exactamente cuáles son sus deberes, y en la hora actual de España, reiterando su juramento de fidelidad al que hoy rige los destinas de nuestra Patria.

Todo ello mezclado también con la retórica de la ciencia libre, separada de la gente común, recluida en los laboratorios donde sólo los científicos pueden acceder, a salvo de todo tipo de influencias y perturbaciones; ese ethos del que hablaba Merton, garantía de la independencia y autonomía de la ciencia, eludiendo cualquier influencia externa pero estando siempre provista de todo lo necesario para desarrollar ese conocimiento científico-certificado, ${ }^{23}$ bajo la sombra de ese árbol del CSIC que "se yergue luego, potente y frondoso, extendiendo sus ramas de protección a todos los que laboran y a todos los que tienen derecho a exigirle sombra y protección". ${ }^{24}$ Así en el prólogo de la memoria correspondiente a 1940 podemos leer:

Con fervor ascético comenzó sus labores el Consejo Superior de Investigaciones Científicas, aun antes de la inauguración solemne proclamada por el Caudillo el día 28 de octubre de 1940 (...) sus Patronatos, Institutos y Comisiones han llegado a todos los problemas que se han podido abarcar en admirable unidad de labor que nunca se hubiera soñado, con la rigidez de método y de técnica que impone la ciencia y en un afanoso servicio a España, bajo el signo del Caudillo. ${ }^{25}$

21 Fragmento recogido en Pedro GONZÁLEZ BLANCO, José JIMÉNEZ BLANCO, José María LÓPEZ PIÑERO: Historia y sociología de..., p. 131.

22 CSIC: Memoria de la..., p. 2.

23 Rubén BLANCO, Juan Manuel IRANZO: "Ambivalencia e incertidumbre en las relaciones entre ciencia y sociedad", Papers 61, 2000, p. 90.

24 CSIC: Memoria de la..., p. 6.

25 lbid., p. 5.
A través de estas palabras se nos presenta al CSIC como institución plenamente científica, que cumple con los "rígidos" preceptos técnico-metodológicos propios de la ciencia, pero a su vez, como una institución al servicio de los intereses nacionales, donde la figura de Franco no sólo encarna a la figura del caudillo como jefe del Estado, sino también a la del "mecenas" de la ciencia, convirtiéndose así en su protector e impulsor (a través de iniciativas como los premios Francisco Franco $^{26}$ ):

Del Caudillo, decimos, que no sólo se preocupa hondamente por todos los problemas espirituales y materiales que interesan a la investigación, sino que la ampara y apoya con su presencia e iniciativas, según muestran tanto su asistencia a nuestras solemnes sesiones como por los premios y recompensas señalados a la investigación..$^{27}$

Esto nos habla también del contrato social de la ciencia ${ }^{28}$ entablado entre la comunidad científica y el Estado, donde éste último es el encargado de velar por los intereses de la investigación a través de las formas de patronazgo y mecenazgo que desde el Estado se desarrollan: financiando las investigaciones y aportando los cauces oficiales de publicación de resultados, así como reconocimientos profesionales y honoríficos a los expertos de la ciencia. Por su parte la comunidad científica deberá velar por la consecución de un conocimiento verdadero atado a esa la rigidez de método y de técnica que impone la ciencia, pero también por los intereses y el prestigio nacional, en un afanoso servicio a España, bajo el signo del Caudillo:

Por eso es lógico también - sin que la lógica disminuya el fervor de la adhesión y la hondura del entusiasmo- que el Consejo traiga sus tareas, sus planes y sus anhelos de superación reflexiva y exaltada al Caudillo de España, que ejerce, por ley y por renovado mérito de su continua protección, el alto Patronato del Consejo. ${ }^{29}$

\section{El discurso sobre la ciencia}

Éstas son sólo algunas pinceladas entresacadas de los discursos oficiales que se pueden encontrar tanto en "Estructura y Norma de la Investigación Nacional" como en la primera Memoria Anual del CSIC. Un discurso que hemos empezado a ver y que tendrá continuidad a lo largo del régimen, incidiendo en algunos aspectos y matizando otros en función de las transformaciones internas del régimen a lo largo de su trayectoria. En esta primera aproximación, lo que podemos observar es la conformación de una idea de ciencia determinada, oficial y hegemónica, con unas características a las que todo conocimiento pretendidamente científico debería atenerse. De alguna forma, para ser ciencia se debería estar en la verdad del discurso científico de la época franquista:

Ciencia para la verdad (...) Ouedan ya para siempre al margen de la esfera de nuestra actividad científica los esfuerzos intelectuales que caminen por sendas de error. Los errores no pueden constituir ciencia" (...) "Nuestra ciencia es exclusivamente para la verdad, la

26 "Inmediatamente, en los comienzos del curso académico, se va a publicar la convocatoria para los dos premios "Francisco Franco", de 50.000 pesetas (uno para las disciplinas de Ciencias y otro para las de Letras), y de los cinco premios de 5.000 pesetas. En la próxima reunión ordinaria de Pleno, el año próximo, no habrá el aliciente de la inauguración, pero habrá el interés de otorgar estos premios, en los que va no sólo el nombre, sino la viva expresión del afectivo Patronato que el Caudillo ejerce sobre toda la obra del Consejo" (Ibid., p. 9).

27 Ibid., p. 5-6.

28 BLANCO, Rubén, IRANZO, Juan Manuel: “Ambivalencia e incertidumbre en...”, pp. 93-97.

29 CSIC: Memoria de la..., p. 113 
única que -al decir del Apóstol- nos hace libres y la que, llevándonos de la mano a la causa, altísima y primera, nos permite atisbar los secretos de la Divina Sabiduría. ${ }^{\circ}$

A través del discurso oficial sobre la ciencia, se parte de la idea tradicional de que la ciencia descubre en la naturaleza los hechos científicos, esos secretos de la Divina Sabiduría; una visión esencialista donde el lenguaje no es más que una representación del mundo, ${ }^{31}$ ocultando en realidad la importancia que ese discurso tiene en la concepción de la ciencia y lo científico, ocultando que, como señala Steve Woolgar, "aquellos rasgos propuestos como característicos de la ciencia surgen de las prácticas de definición de los mismos participantes" 32 Por ello, debemos prestar atención al discurso, entendido como articulador del conjunto de condiciones que permiten las prácticas, como generador de escenarios que facilitan o dificultan las posibilidades de acción, al tiempo que hace emerger reglas y sostienen relaciones. ${ }^{33}$ De ah el importante rol que desempeña el enmarcado ${ }^{34}$ en el lenguaje político: consiste en elegir el lenguaje que encaja en la visión del mundo que quieres transmitir. Desde esta perspectiva se entiende que el discurso produzca objetos de conocimiento al dotarlos de sentido. 35 De ahí que en nuestro análisis aboguemos por ver en esa pretendida ciencia esencialista, una función nominalista oculta en esa concepción pasiva de ciencia como descubrimiento, donde el lenguaje sólo refleja, representa, algo preexistente ya en el mundo.

Decía Wittgenstein: "El lenguaje es un instrumento. Sus conceptos son instrumentos" $\left(S_{569}\right)$ "Los conceptos nos conducen a investigaciones" $\left(S_{570}\right){ }^{36}$ Es el lenguaje (y el sentido que le aporta nuestro modo de vida) el que crea el mundo; un mismo problema puede verse de formas diferentes según la mirada que le apliquemos, porque toda observación (incluida la científica) está teóricamente cargada; valga como ejemplo la disputa clásica entre Kepler y Brahe en torno al Sol como centro fijo del universo o como cuerpo celeste que se movía alrededor del planeta Tierra como eje fijo. ${ }^{37}$ No es nuevo, las "visiones del mundo" juegan un pape destacado en el desarrollo de la ciencia moderna, algo que podemos observar desde el trabajo clásico de Max Weber hasta los trabajos de autores como R. K. Merton.

Como todo constructo social, la ciencia también está influida por el trasfondo ideológico, por esas "visiones del mundo" que subyacen en el ejercicio de los científicos y que se plasman en sus resultados. A día de hoy, a la hora de realizar un análisis profundo (una descripción densa del asunto, que diría Clifford Geertz) no podemos aceptar la excepcionalidad epistemológica, platónica, sociológica y económica de la visión clásica de la ciencia, esa de la que nos hablan Bimber y Guston (1995), ${ }^{38}$ concebida como ente externo, independiente de la política, autorre-

30 CSIC: Memoria de la..., pp. 31-32.

31 Heinz VON FOERSTER: "Visión y conocimiento: disfunciones de segundo orden", en Dora FRIED SCHNITMAN: Nuevos paradigmas, cultura y subjetividad, Barcelona, Paidós, 1994, pp. 95-103.

32 Steve WOOLGAR: Ciencia: abriendo la caja negra, Barcelona, Anthropos, 1991, p. 32.

33 Lupicinio IÑIGUEZ RUEDA: Análisis del discurso. Manual para las ciencias sociales, Barcelona, UOC, 2006, p. 83

34 Véase Erving GOFFMAN: Frame analysis: los marcos de la experiencia, Madrid, Centro de Investigaciones Sociológicas, 2006; George LAKOFF: No pienses en un elefante: lenguaje y debate político, Madrid, Editorial Complutense, 2011.

35 Véase Stuart HALL (ed.): Representation: Cultural Representations and Signifying Practices, London, Sage Publications, 1997 .

36 Ludwig WITTGENSTEIN: Investigaciones filosóficas, Barcelona, Crítica, 2010, p. 359

37 Ejemplo tomado de Norwood RUSSELL HANSON: “Patterns of Discovery", Cambridge University Press, 1958. Citado por Harold I, BROWN: La nueva filosofía de la ciencia, Madrid, Tecnos, 1988, pp. 107-109.

38 Bruce BIMBER, David H. GUSTON: "Politics by the same means: government and science in the United States", en Sheila JASANOFF, Gerald E. MARKLE, James C. PETERSEN y Trevor PINCH (eds.): gulada eficientemente a través de su funcionamiento y alejada de toda influencia externa, incluso de la del propio científico; esa visión idílica e irreal que se defiende desde el discurso oficial del régimen franquista y que sustenta la idea de la especificidad de la ciencia como

Un espacio (el de la investigación) oscuro y solitario, ${ }^{\circ 0}$ al que no tienen acceso los esfuerzos intelectuales que caminen por sendas de error, representados en primer lugar por los fantasmas del pasado más cercano, los científicos republicanos, que se vieron obligados a abandonar el país:41 "los hierofantes de la impiedad y de la antipatria -culpables máximos del desastre cultural, social y político de que acabamos de salir indemnes por obra del genio de V. E.y la sangre de la juventud".42 Pero también todo aquel que se aleje de la virtud de la ciencia católica:

Liquidamos, por tanto, en esta hora todas las herejías científicas que secaron y agostaron los cauces de nuestra genialidad nacional y nos sumieron en la atonía y decadencia (...) Igual olvido y desprecio para cuantos endiosaron la razón humana, erigiéndola en supremo principio de todo conocimiento. Nuestra ciencia, la ciencia española de nuestro Imperio, la que desea impulsar con vigor máximo la nueva España, repudia la tesis kantiana del racionalismo absoluto y no se degrada en reconocer que el hombre no puede llegar por continuo progreso a la posesión de toda la verdad. Vive dichoso de aplicar su esfuerzo intelectual cotidiano a llevar a Dios dentro de sí, a cifrar en él como aspiración máxima de su existencia las ideas de belleza, de arte, de filosofía y de patria, a la par que los ideales de las virtudes evangélicas, cual compendio de la ciencia de la vida. ${ }^{43}$

Así, el discurso genera también un lugar para el sujeto conocedor (el científico, el intelectual) ese testigo modesto del que nos habla Haraway, "ventrílocuo legítimo autorizado del mundo de los objetos, sin agregar nada de sus opiniones, de su influenciante corporeidad".44 Un científico o intelectual legítimo, aquel "hombre de fe en la ciencia española" de quien es obra el CSIC. Otra cuestión interesante sería atender a si, más allá de ese vir modestus, las mujeres (y en su caso, qué mujeres) tenían el estatus de independencia suficiente y legítimo para poder optar a ser testigo modesto. Lamentablemente es algo que excede al modesto objetivo (a pesar del pretencioso título) de este trabajo que, precipitadamente, concluye aquí.

Handbook of science and technology studies, Thousand Oaks: Sage, 1995.

39 Donna J. HARAWAY. Testigo Modest@ Segundo Milenio. Hembra conoce Oncoratón, Barcelona UOC, 2004, p. 43.

40 "La investigación está integrada, en su mayor parte, por trabajo oscuro. En la sólida investigación, lo que se ve es fruto de largo y prolongado esfuerzo invisible (...) la exhibición ataca a la esencia misma de la investigación, porque es mirar hacia fuera, hacia el efecto, hacia el derrame de teatralidad, con pérdida del interno vigor. La exhibición echa a perder aún las cosas bellas, sencillas y normales (...) La investigación es la vida de la ciencia, y la vida procede de un principio interno" (CSIC: Memoria de la..., p. 110)

41 "Un grupo de ellos, ligados estrechamente a la Casa de España en México, fue el encargado de fundar la revista que reunió al exilio científico español, Ciencia. Revista hispano-americana de Ciencias puras y aplicadas. El 1 de marzo de 1940 aparecía el primer número de esta revista bajo la dirección de Ignacio Bolívar Urrutia y con tres redactores principales, Cándido Bolivar Pieltain, Isaac Costero y Francisco Giral" (Antecedentes del CSIC: La JAE (http://www.csic.es/web/guest/16)).

42 CSIC: Memoria de la..., p. 29.

43 Ibid., p. 32.

44 Donna J. HARAWAY: Testigo Modest@..., p. 42 
"El árbol imperial de la ciencia española creció lozano en el jardín de la catolicidad y no se desdeñó de aposentar en su tronco como esencial fibra y nervio, la ciencia sagrada y divina, de cuyo jugo se nutrió al unísono todo el espeso ramaje". 45 Sirvan estas palabras de José lbáñez Martín como fragmento ilustrativo del sentido del discurso que a lo largo de estas páginas hemos intentado desgranar, tratando de atender a sus potencialidades como instrumento de poder, asi como a las implicaciones que en el campo intelectual pueden suponer. Muchas son las preguntas y pocas las respuestas que a lo largo de estas páginas se han vertido sobre el concepto de ciencia oficial en la España franquista. Excesivo sería sacar conclusiones de tan escasas fuentes y superficiales análisis, tan sólo considero oportuno subrayar las virtudes que un acercamiento de este tipo puede aportar a la hora de analizar estos hechos contingentes, estos "conocimientos situados", que aparentemente pretenden no serlo.

Apostar por un análisis de simetría como el que propone Haraway, "comprometido tanto con el conocimiento de la gente y las posiciones de las que puede venir el conocimiento y a quienes es destinado este conocimiento, como con la disección de las condiciones de producción del conocimiento" 46 reporta, a mi juicio, más ventajas que inconvenientes. Algo que no debe hacernos olvidar que nos movemos en un terreno siempre asimétricamente construido, en donde las posiciones de unos dependen y sustentan las de otros; de ahí la importancia de un análisis simétrico, pero que, en la práctica, no olvide que cada posición habilita unas condiciones de posibilidad distintas e incluso opuestas para cada uno de ellos. 


\section{CIENCIA Y PSEUDOCIENCIA: EL BOUNDARY-WORK}

\section{COMO HERRAMIENTA HISTORIOGRÁFICA}

Andrea Graus

Centre d'Història de la Ciència, Universitat Autònoma de Barcelona

\section{Las fronteras construidas de la ciencia}

La pseudociencia representa un objeto de estudio espinoso para los historiadores de la ciencia, tanto o más que para los propios científicos. En las llamadas Science wars de los años 90 del pasado siglo, estos últimos mostraron tener una especial alergia hacia los campos tachados de pseudocientíficos.' Los estudios apodados mediante este nombre surgieron como reacción a los análisis posmodernos, de carácter socioconstructivista, que cuestionaban la supuesta objetividad y neutralidad de la ciencia.

En el libro Cultural boundaries of science (1999), el sociólogo Thomas F. Gieryn sometió las Science wars a un análisis propio, hoy muy extendido, que apodó boundary-work, ${ }^{3}$ Mediante la metáfora de los mapas, los cuales van limitando - a la vez que definiendo- un territorio, Gieryn creó una analogía entre la cartografía y el boundary-work. Así en la ciencia, como en otros ámbitos, los distintos actores construyen sus "mapas" para decidir que es ciencia y que no. "El problema", nos dice Gieryn, "no es que no exista una 'ciencia real' detrás de las representaciones cartográficas, sino que hay demasiadas 'ciencias reales"'. ${ }^{4}$ El constructivismo sociológico no es pues una forma de nihilismo. Lo que viene a advertirnos Gieryn es que, en cualquier hecho, instrumento o disciplina científica no hay una etiqueta previa que ponga "verdadero", sino que esta clase de epítetos se añaden en el momento de cartografiar - y definir- este hecho, instrumento o disciplina.

Tras someter las Science wars a análisis, mediante el uso del boundary-work, Gieryn concluyó que éstas no son más que:

...concursos de credibilidad en los cuales los partidos rivales manipulan los límites de la ciencia con tal de legitimar sus creencias sobre la realidad y asegurar su conocimiento creando una autoridad epistemológica provisional provista de influencia, prestigio y recursos materiales.

Según Gieryn, estos concursos de credibilidad — dentro y fuera de las Science wars - se dividen en tres géneros en donde cada uno representa un tipo distinto de boundary-work. El pri-

1 Véase, por ejemplo: Paul GROSS y Norman LEVITT: Higher superstition: The academic left and its quarrels with science, Balitmore, John Hopkins University Press, 1994.

2 Sobres los estudios históricos y culturales que presentaron la ciencia como un objeto construido véase, por ejemplo: Trevor PINCH: "Science as golem", Academe, 82, (1996), p. 16

3 Thomas F. GIERYN: Cultural boundaries of science: Credibility on the line, Chicago, University of chicago Press. Véase también: Thomas F. GIERYN: "Boundaries of science", en Gerald E. MARKLE, et al. (coords.): Handbook of Science and Technology Studies, London/New Delhi, Sage, 1995.

4 Thomas F. GIERYN: Cultural boundaries of science..., p. 19.

5 Ibid., p. 337. mero se caracteriza por la estrategia de la expulsión, donde autoridades rivales compiten por ganarse un estatus científico. En estos casos se acostumbran a enfrentar la ciencia ortodoxa con la heterodoxa. Sin embargo, ninguna de las partes quiere desacreditar la autoridad epistemológica de la ciencia en si, sino expulsar aquellas disciplinas que, a su parecer, no perten cen a ella. El segundo tipo de boundary-work implica la expansión. En este caso suele incluir a aquellos que, en nombre de la ciencia, quieren extender sus fronteras a otros dominios o, por el contrario, cuando la religión o el conocimiento popular cuestionan el derecho de la ciencia a juzgar la veracidad de algunas cuestiones. Finalmente, el tercer género se caracteriza por la protección de la autonomía. Estos casos acontecen cuando poderes fuera de la ciencia como el político, intentan usar la autoridad de los científicos de manera que comprometen su labor al mezclarlos con intereses sociopolíticos o económicos. ${ }^{6}$

Hay que tener en cuenta que en el proceso de atribuir la etiqueta "ciencia" a un dominio concreto, se atribuye, al mismo tiempo, la etiqueta de "pseudociencia" a aquello que queda fuera de él. En su reciente libro, titulado The pseudoscience wars (2012) —en referencia a las mencionadas Science wars - el historiador de la ciencia Michael D. Gordin analiza el caso de psicoanalista ruso-judío Immanuel Velikovsky (1895-1979) mediante el uso del boundary-work. En su opinión, pseudociencia es un término de abuso, un epíteto con el que desacreditar ciertas doctrinas. Según argumenta, dicha noción se ha construido alrededor de la idea de la mimesis: para los científicos ortodoxos, la pseudociencia es aquello que imita a la ciencia sin serlo realmente. Por ello, no hay nada que unifique las pseudociencias excepto el hecho de que científicos de varias disciplinas hayan decidido condenarlas al ostracismo. En este sentido, Gordin insiste en la necesidad de examinar la historia de los debates sobre la pseudociencia para comprender qué se entiende por ciencia.?

Someter estas categorías a un análisis historiográfico permite relacionarlas con los procesos político-sociales gobernantes, tal y como propone Gieryn. Uno de los aciertos de The pseudoscience wars (2012) es que nos muestra cómo, en un momento determinado, los científicos entendieron su estatus, sus posicionamientos ideológicos y el futuro de sus disciplinas dentro de la sociedad. Como argumenta Gordin, la ciencia ortodoxa, entendida como una forma de autoridad, necesita de la demarcación científica para definirse en contraposición a aquello que se tacha de pseudociencia. Por ello Gordin postula que si queremos tener una ciencia, tenemos que aceptar que siempre habrá doctrinas excluidas que luchen por su aceptación. El proceso de demarcación científica es irremediable, ya que la ciencia se basa, en parte, en la exclusión de otros dominios. La existencia de la pseudociencia deviene así inevitable, por lo que combatirla se vuelve problemático. ${ }^{8}$ Por lo tanto, la historia de la ciencia es, a su vez, la historia de la pseudociencia. Diferenciar entre ambas resulta tan ineficiente como intentar definir qué es la ciencia sin tener en cuenta su desacreditado alter ego pseudocientífico.

El problema filosófico de la demarcación científica forma parte de un debate histórico, pero no deja de ser un tema candente. Gieryn y Gordin no le ven solución, ya que presuponer que pueda existir un criterio de demarcación científica significa mantener una visión naturalista de la ciencia, como algo descubierto en vez de construido. ${ }^{9}$ Como historiador, Gordin dice estar

6 Ibid., pp. 15-17.

Michael D. GORDIN: The pseudoscience wars: Immanuel Velikovsky and the birth of the modern fringe, Chicago, London, The University of Chicago Press, 2012.

8 Ibid., pp. 195-213.

9 Un ejemplo de la visión naturalista vs. la constructivista puede hallarse en la historiografía del inconsciente. En 1970 el historiador Henri F. Ellenberger publicó su hoy clásico The discovery of the y Martin Liebscher editan Thinking the unconscious, donde el titulo se eligió para expresar el rechazo de la aproximación de Ellenber gry a puesta por un análisis histórico y socioconstructivista. Henci F. ELENBERCER: El descubrimiento del inconsciente: Historia y evolución de la psiquiatría dinnimica, 
más interesado en cómo ciertas personas y grupos usaron los términos ciencia y pseudociencia para perseguir sus fines, que no en juzgar si estas etiquetas fueron usadas "correctamente" según los estándares de nuestra época. ${ }^{10}$ Sin embargo, muchos han sido los filósofos e historiadores que se han adentrado en el tema de la demarcación científica, empezando por Karl Popper (1902-1994), quien fue el primero en dar un nombre a este problema.

Según Popper, el criterio para determinar el estatus científico de una teoría es su falsabilidad, su refutabilidad o su testabilidad." Desde entonces, el problema de la demarcación se ha ido complejizando mediante las teorías del historiador Thomas Kuhn (1922-1996) o el sociólogo Robert Merton (1910-2003). En el primer caso, si los paradigmas deciden qué es ciencia y qué no, podría interpretarse que todo aquello que queda fuera del paradigma se concibe como pseudociencia. En el segundo caso, y desde una visión sociológica, la ciencia se distinguiría por sus normas de institucionalización, las cuales someten a los científicos a un sistema de premios y sanciones, juicios y comportamientos. ${ }^{12}$ Sin querer entrar de lleno en el debate filosófico, Gordin y Gieryn plantean que quienes pretendan resolver el debate ciencia-pseudociencia, deberían empezar por fijarse en cómo la comunidad científica decide qué forma parte de su ámbito y qué no, es decir, deberían adentrarse en el boundary-work. ${ }^{3}$

\section{El boundary-work y la historia de la (pseudo)ciencia}

En este apartado me centraré en algunos estudios destacados que, desde la historia de la ciencia y mediante el boundary-work, se han propuesto estudiar campos hoy tachados de pseudocientíficos. En este caso, me referiré a lo que hoy llamamos comúnmente parapsicología, la cual tuvo sus orígenes en unas disciplinas nacidas a finales del siglo XIX y principios del XX, especialmente: el psychical research anglosajón y la métapsychique francesa, conocida como metapsíquica en España. ${ }^{14}$

Aunque el término parapsicología se popularizó a partir de 1930 a través de los estadounidenses Joseph Rhine (1895-1980) y William McDougall (1871-1938), fue acuñado en 1889 por el filósofo y psicólogo alemán Max Dessoir (1867-1947). Bajo la influencia del psychical research, Alemania se convirtió en un país pionero en esta clase de investigaciones con médiums a lo largo de las primeras décadas del siglo XX. La historiadora de la ciencia Heather Wolffram examina e caso alemán mediante el uso del boundary-work en su libro The stepchildren of science (2009).15

Wilhem Wundt (1832-1920), considerado como uno de los fundadores de la psicología experimental, apodó la parapsicología de su tiempo como "la hijastra de la ciencia".16 Sin embargo, como muestra Wolffram, otras personalidades científicas alemanas, como Albert von Schrenck-Notzing (1862-1929), confiaron en que el estudio de los médiums contribuiría a difuminar las fronteras entre la ciencia y la metafísica, las cuales se habían fortalecido mediante

Madrid, Gredos, 1976. Angus NICHOLLS y Martin LIEBSCHER (coords.): Thinking the unconscious: Nineteenth-century German thought, Cambridge, Cambridge University Press, 2010.

10 Michael D. GORDIN: The pseudoscience wars..., p. 18.

11 Karl POPPER: Conjectures and refutations: The growth of scientific knowledge, New York, Routledge, $2002[1963]$, p. 48.

12 Thomas S. KUHN: The structure of scientific revolutions, Chicago, University of Chicago Press, 1996 [1962]. Robert K. MERTON: The sociology of science: Theoretical and empirical investigations, Chicago, University of Chicago Press, 1973 .

3 Michael D. GORDIN: The pseudoscience wars..., p. 195-213. Thomas F. GIERYN: Cultural boundaries of science..., pp. 18-25.

14 Sobre la historia de la parapsicología véase: John BELOFF: Parapsychology. A concise history, London, The Athlone Press, 1993

15 Heather WOLFFRAM: The stepchildren of science. Psychical research and parapsychology in Germany, c. 1870-1939, Amsterdam, New York, Editions Rodopi, 2009.

16 Ibid., p. 5 . el triunfo del positivismo y el materialismo a lo largo del siglo XIX. Según Wolffram, la actitud negativa de Wundt no estaba relacionada con el hecho de que la parapsicología o el psychical research obligaran a traspasar los límites de la ciencia ortodoxa. Por el contrario, su malesta se debía a que estos invadían el terreno y la autoridad epistemológica de otras disciplinas en competición por adquirir el preciado estatus de ciencia, particularmente: la psicología. ${ }^{77} \mathrm{En}$ este sentido, la actitud de Wundt debe interpretarse como una forma de boundary-work, es decir, una estrategia para demarcar su campo de las tentativas de investigadores de lo paranormal como Schrenck-Notzing.

El acierto del análisis de Wolffram -también presente en el citado libro de Gordin-es que nos muestra que los procesos de demarcación no solo se dan en la pugna entre la ciencia y la pseudociencia, sino también dentro de los campos considerados como pseudocientíficos. Si la parapsicología era - y es - la amenaza pseudocientífica de la psicología, el espiritismo y el ocultismo lo eran - y lo son - para la parapsicología. En este sentido, las estrategias de boundary-work examinadas por Gieryn (expulsión, expansión, protección de la autonomía) son aplicables tanto en el primer como en el segundo caso. Según expone Wolffram, en Alemania los parapsicólogos restringieron enormemente los miembros de su comunidad, así como la metodología y teorías aceptadas para el estudio de la facultad del médium: la mediumnidad. De este modo, intentaron desmarcarse de los espiritistas y ocultistas, que aún confiaban en que sus creencias serían probadas por quienes consideraban las futuras autoridades científicas de una nueva y definitiva psicología. ${ }^{8}$

Este proceso de demarcación dentro de la parapsicología también se dio en el contexto francés. En los años 20 del pasado siglo la alternativa francesa al psychical research, la metapsíquica, prohibió a los espiritistas asistir a sus congresos. El promotor de esta iniciativa fue el médico Eugène Osty (1834-1938), por entonces director del Institut Métapsychique International de Paris, aún hoy en funcionamiento. ${ }^{19}$ El historiador Matthew Brady Brower se ha interesado por este caso en su libro Unruly spirits (2010), donde también ha usado el boundary-work como herramienta historiográfica. ${ }^{\circ}$ Su análisis de la heterodoxia científica, representada por la metapsíquica, se basa en

la asunción de que un campo de conocimiento tan general y de largo alcance como la "ciencia" alcanza su identidad solo en relación a aquello que excluye, prohíbe, y por otra parte apela para diferenciarse de los sistemas de conocimiento en competición. ${ }^{21}$

En la misma línea de Gordin, Brower nos advierte que para comprender qué se entiende por ciencia es tan o más importante saber qué se entiende por pseudociencia. Ambas son las caras de una misma moneda, por lo que el historiador de la ciencia, a diferencia del científico, caras de una misma moneda, por lo que el historiador de la ciencia, a diferencia del científico,
se ve obligado a asumir dicha dicotomía y evitar presentar solo una de las dos caras como la importante o, peor aún, la verdadera. Por ello, la historia de las consideradas pseudociencias, como la parapsicología, el magnetismo o, incluso, el hipnotismo, contribuye a entender cómo se definió la ciencia en un momento determinado. El uso del boundary-work en esta clase de estudios no es pues una simple herramienta para identificar las estrategias que los científicos

17 lbid., p. 15

18 Ibid., p. 16

19 Véase, por ejemplo: Sofie LACHAPELL,"Attempting science: the he creation and early development of the Institut métapsychique international in Paris, 1919-1931", Journal of the History of Behavioral Sciences, 41, 1, (2005), pp. 1-24.

20 Matthew Brady BROWER: Unruly spirits. The science of psychic phenomena in modern France, Urbana, Chicago and Springfield, University of Illinois Press, 2010.

21 Ibid., p. XX 
siguieron para demarcar sus disciplinas. Por el contrario, cumple un objetivo acaso más importante: nos permite constatar los procesos sociopolíticos imbricados en la construcción de aquello llamado ciencia y que, por usar la metáfora de Friedrich Nietzsche (1844-1900), se alza como una catedral construida sobre la inestabilidad de las aguas. ${ }^{22}$

\section{La pseudociencia y el historiador de la ciencia}

Llegados a este punto merece la pena reflexionar sobre tres cuestiones sugeridas por el boundary-work: primero, si es legítimo diferenciar entre la historia de la ciencia y la de la pseudociencia; segundo, si es historiográficamente acertado tachar una disciplina de pseudocientífica cuando no fue considerada asi en el momento histórico al cual nos referimos; y tercero, si tiene sentido que el historiador de la ciencia use una categoría como pseudociencia.

Considero que la respuesta al primer punto puede hallarse en el primer apartado, pero creo que es importante volver a remarcarlo. Si nos atendemos a las fuentes citadas y, especialmente, a Gordin, no hay ciencia que exista sin su "gemelo malvado". ${ }^{23} \mathrm{Al}$ mismo tiempo, no hay ciencia que se haya determinado a sí misma como pseudocientífica. En este sentido, la categoría pseudociencia está más ligada a aquello que se presenta como ciencia que no a aquello que se tacha de pseudocientífico. Del mismo modo, no existe ningún científico que se presente como pseudocientífico por el hecho de dedicarse a una ciencia heterodoxa. Un parapsicólogo solo es un pseudocientífico a ojos de un psicólogo, no bajo su propia mirada. Entonces, a diferencia de la ciencia, uno no puede hacer pseudociencia, son otros quienes te atribuyen el hacerla.

Por ello, no tiene sentido diferenciar entre la historia de la ciencia y la historia de la pseudociencia. Hablar de una significa necesariamente hablar de la otra. Como apunta Brower, la ciencia crea su identidad en la medida en que demarca todo lo que no es, es decir, en la medida en que construye la pseudociencia. ${ }^{24} \mathrm{El}$ historiador de la ciencia debe estar atento a este proceso para comprender bien su objeto. Por ello, las historiografías sobre el magnetismo, el hipnotismo, el psychical research o la metapsíquica cuentan con un objeto privilegiado para saber qué se entendió por ciencia al estudiar qué se excluyó de ella.

La segunda cuestión antes señalada implica el referirse a una disciplina como pseudocientífica en un momento en que esta no tenía dicha consideración. Por ejemplo, aunque hoy en día se considera que la parapsicología es una pseudociencia, a principios del siglo XX la metapsíquica y el psychical research nunca fueron considerados como tal. A grandes rasgos, se definía estas disciplinas como un proyecto científico aún por consolidar. El premio Nobel de medicina Charles Richet (1850-1935), quien acuñó el término métapsychique, se refería a ella como "ciencia embrionaria". ${ }^{25}$ Teniendo en cuenta este hecho, creo que representa un anacronismo referirse a la metapsíquica o al psychical research como pseudociencias. Si en su momento no gozaron de este estatus, resulta impropio atribuírselo desde el presente cuando se está haciendo una investigación histórica.

La tercera cuestión concierne al sentido que tiene usar la categoría pseudociencia -y todo lo que implica - dentro de la historia de la ciencia. Si nos atenemos a Gordin, la primera nace de los mecanismos de exclusión de la segunda. En este sentido, si como historiadores nos referimos a, por ejemplo, la parapsicología como pseudociencia, ya nos estamos posicionando de lado de la ciencia ortodoxa y hegemónica. Considero que este hecho constituye un grave error

22 Friedrich NIETZSCHE: Sobre verdad y mentira en sentido extramoral. Trad. Joan B. Llinares i Germán Meléndez, Valencia, Diálogo, 2005, p. 105

23 Michael GORDIN: The pseudoscience wars..., pp. 1-18.

24 Matthew Brady BROWER: Unruly spirits..., p. XX.

25 Charles RICHET: Carta de Charles Richet a Humbert Torres (s.d., 1919?), Fons Humbert Torres, Uni-

versitat de Lleida, sin catalogar. al cual el historiador puede verse empujado, quizá de forma inconsciente, por los estándares científicos de la época. Por ejemplo, Brower, el historiador antes citado en relación a la me tapsíquica francesa, comete esta clase de desliz, el cual puede observarse en la siguiente cita:

Para los investigadores crédulos que aceptaron la llamada hipótesis espiritista, el estudio de los médiums se entendió como un medio para confirmar la supervivencia del alma como hecho natural. Para los muchos investigadores críticos aunque abiertos de mente que ocuparon un lugar entre estos dos extremos, los fenómenos remarcables de las sesiones espiritistas fueron meras curiosidades, seductores en cuanto sugerían la existencia de facultades mentales y propiedades de la materia las cuales seguían, por el momento, fuera del foco de luz de la ciencia. ${ }^{26}$

Esta dicotomía entre "investigadores crédulos" e "investigadores críticos aunque abiertos de mente" podría sustituirse por pseudocientíficos vs. científicos. Desde mi punto de vista, el historiador de la ciencia no es el encargado de poner esta clase de etiquetas, sino que tiene que identificar quiénes las usaron, de qué manera y con qué fines. En este caso, estos "investigadores crédulos" fueron, entre otros, Frederic W. H. Myers (1843-1901) y Humbert Torres (1879-1955). Es decir, figuras altamente respetadas dentro de la psicología y la medicina de su tiempo, e incluso, en el caso de Torres, dentro de la política. Fueron crédulos a ojos de otros investigadores, y así lo tiene que mostrar el historiador. Si se presentase del modo en que lo ha hecho Brower, la ciencia pasada no consolidada en la actualidad podría definirse como una pseudociencia o una historia de credulidad.

En conclusión, el uso del boundary-work representa una herramienta muy útil para el historiador de la ciencia, sobre todo en relación a los debates ciencia-pseudociencia. Sin embargo, el uso de este análisis debe ir acompañado de una reflexión respecto a estas categorías por parte del historiador. Una gran ventaja del boundary-work es que invita a esta clase de reflexión. Así, incita al historiador a dejar a un lado sus prejuicios para evitar que la historia de la ciencia se convierta en un criterio de demarcación, es decir, que contribuya a cimentar las fronteras entre ciencia y pseudociencia en vez de indagar en los mecanismos sociopolíticos implicados en su construcción. 


\section{LA VISIÓN POPULAR DE LA CIENCIA ESPAÑOLA \\ DURANTE EL FRANOUISMO Y SU IMPACTO EN EL \\ SISTEMA NACIONAL DE CIENCIA E INNOVACIÓN. \\ UN ANÁLISIS DESDE EL MUNDO DE LA IMAGEN}

manol Herreros Chandro

Doctorando en Historia Contemporánea por la UAM

\section{Ciencia, cultura e historia}

Una de los pocas características que podemos asegurar como únicas del ser humano es la de poseer una historia. La cultura, la tecnología o la técnica, los sentimientos, el lenguaje, etc, están presentes en mayor o menor medida en el resto de especies que pueblan la tierra, pero solo los seres humanos vivimos en la historia. Solo los seres humanos guardamos un registro simbólico de nuestras vivencias y las de nuestros antepasados y las transmitimos mediante la cultura. Solo el ser humano es capaz y siente la necesidad de interpretar su momento presente a través de los códigos simbólicos heredados del pasado.

Del mismo modo que la historia es privativa del ser humano, la ciencia es otro de estos rasgos puramente humanos. La aplicación de soluciones técnicas a necesidades concretas se produce en otras especies más allá de la humana. La elaboración de esquemas mentales abstractos que diseccionen, analicen e incluso modifiquen la naturaleza es algo puramente humano No obstante este rasgo tan exclusivamente humano, la ciencia como conocimiento racional y sistemático, es algo propio de los últimos siglos,' mientras que la tecnología ha estado presente desde los comienzos del proceso de hominización y de nuestra andadura como especie.

La ciencia, la tecnología y la historia son productos culturales desarrollados por la sociedad, no pudiendo entenderse a ninguno de ellos desgajado y existente de manera autónoma. Esto, si bien siempre se ha entendido asi para la historia, no lo ha sido para la ciencia y la tecnología. Hasta la publicación en 1962 de La Estructura de las revoluciones científicas de Thomas Khun, se había mantenido de forma artificial y con cada vez más numerosas críticas una concepción de la ciencia que la entendía como autónoma. En esta visión que acabaría inevitablemente por derrumbarse, es la ciencia como mundo aislado, la que lleva a las sociedades humanas hacia nuevas cotas de progreso. La ciencia, según esta visión, modelaría el devenir de la sociedad, la cual asistiría de manera pasiva a la evolución del mundo científico.

Hoy día el historiador y el sociólogo de la ciencia, el científico y, en menor medida, el ciudadano que no se desenvuelve en ninguna de las categorías anteriores entiende que la ciencia responde a las necesidades generadas por la sociedad (sin que esto signifique que la propia ciencia no pueda acabar generando a su vez necesidades a la sociedad). La ciencia y la tecnología, al igual que la historia, responden a las inquietudes y necesidades, en suma a las preguntas de la sociedad concreta en la que se desarrollan.

¿Pero cómo se relacionan estas disciplinas con la sociedad? ¿Influye directamente la sociedad en la generación de los diferentes desarrollos científicos o se hace a través del poder y las instituciones del estado? Más aún, ¿condiciona el propio estado las necesidades de la sociedad a través de la percepción que se le da a esta del proceso científico?

1 Javier ORDÓNEZ: Ciencia, tecnología e historia, Madrid, Instituto Tecnológico y de Estudios Superiores de Monterrey y Fondo de Cultura Económica, 2001, p. 11
En el caso de nuestro objeto de estudio, como es el de una España sometida a la censura, parece que la imbricación entre poder, cultura popular y desarrollo científico y tecnológico debería ir orientados en este sentido.

Para establecer las relaciones de dependencia establecidas en este juego de relaciones de causa y efecto atenderemos tanto a la concepción oficial de la ciencia como a su visión popular.

\section{La concepción oficial de la ciencia}

[...] hay que imponer, en suma, al orden de la cultura, las ideas esenciales que han inspirado nuestro Glorioso Movimiento, en las que se conjugan las lecciones más puras de la tradición universal y católica con las exigencias de la modernidad [...]

Extracto de la Ley de 24 de noviembre de 1939 creando el CSIC. ${ }^{2}$

La ciencia del nuevo régimen (1939-1975)

Con la victoria en la contienda civil, el nuevo régimen implantó su propia visión del futuro económico, político, religioso, intelectual y científico que debía de desarrollar España. Especialmente particular va a ser la concepción que sobre la economía y el papel de la ciencia en la sociedad van a tener los nuevos gobernantes. Si en lo económico la autarquía va a ser el modelo definitorio del régimen en sus primeros años (con todo lo que este modelo económico implica no sólo a nivel económico, sino también en lo social y muy marcadamente en el sistema de ciencia e innovación), en lo cultural, va a tratar de llevarse a cabo una ortodoxia focalizada en las diferentes concepciones político-sociales de las diferentes familias del régimen. ${ }^{3}$ En el caso concreto de la ciencia, la misión de reconstruir a imagen del régimen el sistema científico va a recaer sobre el CSIC, institución de marcado carácter católico. ${ }^{4}$

EI CSIC, es solo un botón de muestra de la concepción que de la ciencia y la tecnología tenía el nuevo régimen. La depuración de la universidad y la renovación del profesorado bajo la égida de la Ley Universitaria de 1943 (que daba preponderancia a la iglesia dentro de la universidad), 5 van a dejar claro que para la nueva España la fe y la obediencia van por delante de la ciencia y la innovación. Las universidades se centralizan y catequizan, la ciencia pasa a manos del CSIC y ésta se somete a criterios de corte práctico y político. El personal investigador, tanto de la universidad como de los centros de investigación: CSIC, JEN (Junta de Energía Nuclear) INTA (Instituto Nacional de Tecnologías Aeronáuticas) etc., se escogieron mayoritariamente por criterios de lealtad y filiación política en lugar de calidad investigadora o capacidad de innovación, ${ }^{6}$ mientras que las mentes más brillantes de la ciencia española se vieron condenadas al exilio o se agostaron en un duro y penoso exilio interior alejados de sus cátedras y al margen de la investigación.

La "ciencia autárquica" (1939-1959)

El modelo económico autárquico impuesto en un primer momento por cuestiones de ideología del régimen y mantenido y reforzado tras el final de la Segunda Guerra Mundial con el aislamiento internacional de España va a tener un fiel reflejo en el desarrollo de la nueva

2 Boletín Oficial del Estado (BOE), 28 de noviembre de 1939, número 332, páginas 6668-6671.

3 Charles ESDAILE y Javier TUSELL: “Época Contemporánea 1808-2004", en John LYNCH (coord.): Historia de España, Madrid, Crítica, 2007. p. 540

4 Ibid, p. 540 .

5 En doce años se había renovado el $75 \%$ del profesorado, y no bajo criterios de excelencia investigadora. La ley de 1943 transforma a la universidad española en un auténtico "erial intelectual" al no hacer mención alguna a las políticas de investigación, etc. Leoncio LOPEZ-OCON CABRERA: Breve historia de la ciencia española, Madrid, Alianza Editorial, 2003. p. 393.

6 lbid. 
ciencia española, algo que pese al abandono de este modelo económico en 1959 va a lastrar de manera profunda el desarrollo posterior de la misma.

El 24 de noviembre de 1939 se aprueba la Ley de Ordenación y Defensa de la Industria Nacional, a través de la cual se adoptaba y santificaba el modelo de producción económica de la autarquía. Modelo que va a tener su principal vehículo de acción en el INI (Instituto Nacional de Industria), fundado el 25 de septiembre de 1941. Paralelamente, en 1939, se funda el CSIC (Centro Superior de Investigaciones Científicas.) Desde un primer momento el CSIC va a estar profundamente relacionado con la política económica autárquica. En 1948, a través del " $\mathrm{Pa}$ tronato Juan de la Cierva", el CSIC destinará 15.985 .000 pesetas a la investigación en ciencias aplicadas. La ciencia tenía que estar al servicio de la política autárquica. La enorme Numancia en la que se debía convertir España necesitaba de una ciencia nacional de carácter eminentemente práctico, 7 razón por la cual, el estado a través del CSIC, sólo potenciaría aquellas ramas con aplicaciones inmediatas. Así, en la los porcentajes de carreras efectuados por investigadores en el CSIC serán los siguientes en estos primeros años: Ouímica (42\%), Farmacia (19\%) Ingeniería ( $2 \%$ ), Medicina (12\%), Matemáticas (2\%), Derecho ( $13 \%$ ), Biología (11'5\%), Física $2 \%$ ), Filosofía y letras $(12,7 \%){ }^{8}$

Como cabía esperar, la química será fundamental en una economía que pretendía desarrollar un modelo económico autárquico pero que carecía de uno de los recursos fundamentales en los procesos productivos modernos: el petróleo. Los proyectos destinados a la consecución de combustible fósil de origen nacional serán de lo más diverso, constando entre ellos el patronazgo de una fórmula de gasolina sintética diseñada por el austriaco Albert Elder Von Filek, fabricada a base de fermentos de plantas, agua y un "ingrediente desconocido", 9 o la instalación de un central de producción de gasolina a través del uso de esquistos de pizarra bituminosa. Este último intento, aunque técnicamente posible, supuso el desarrollo de un proyecto que se transformaría en un sumidero para las cuentas del INI, ya que entre 1941 y 1945, la refinería de Puertollano absorbería dos terceras partes del presupuesto de esta institución..$^{\circ}$

El esfuerzo de estos años por lograr obtener una autonomía plena en lo económico y lo científico se saldó con un estrepitoso fracaso." Según el historiador Luis Enrique Otero Carvajal las razones de dicho fracaso fueron tres:

- La destrucción de infraestructuras provocadas durante la guerra, y la perdida de capital humano ocurrida durante la misma y en las depuraciones de la posguerra debilitaron de manera irreparable el sistema de ciencia e innovación. La guerra dejó una enorme escasez de recursos, lo cual no permitió que la inversión en ciencia y tecnología fuese la necesaria.

- La autarquía y el aislamiento internacional obligaron a que la ciencia se desarrollase en un ámbito básicamente utilitario. Era ciencia de necesidad, en la que el voluntarismo debía sustituir la falta de fondos.

- El INI y el CSIC invirtieron en sectores considerados estratégicos para el régimen tales como

7 Juan Maria GÓMEZ ORTIZ: “España Bajo el régimen de Franco (1939-1975)”, en Juan Maria GÓMEZ ORTIZ (coord.): Historia de España, Barcelona, 1985, p. 184

José Manuel Sánchez Ron:Cincel, martillo y piedra. Historia de la ciencia en España (siglos XIX X XX), Madrid, Taurus, 1999, p 357.

9 En una proporción del $75 \%$ de agua, $20 \%$ de plantas fermentadas, y un $5 \%$ de ingredientes desconocidos. "Hacia la autarquía nacional en materia de carburantes", en La Vanguardia Española, 21 de enero de 1940, p. 6.

10 Joseph FONTANA: "La utopía franquista: la economía de Robinson Crusoe", Cuadernos de Historia del derecho, Volumen Extraordinario (2004), pp. 97-103. <<http://revistas.ucm.es/index.php/ CUHD/article/view/CUHD0404330097A/19637>> [Consultado el 20 de enero de 2013]

11 Luis Enrique OTERO CARVAJAL: "La destrucción de la ciencia en España. Las consecuencias del triunfo militar de la España franquista ", Historia y comunicación social, 6 (2001), p. 211. la automoción y la industria armamentística (CASA [Construcciones Aeronáuticas Sociedad Anónima], CETME [Centro de Estudios Técnicos de Materiales Especiales], CETA [Centro de Estudios Técnicos de Automoción ], etc.) pero en realidad no primaban la originalidad y la capacidad de inventiva, sino la capacidad de adaptación y copia de la tecnología extranjera. ${ }^{12}$

La falta de inversiones, el descabezamiento de la universidad y las instituciones científico técnicas, el ascenso de los científicos afectos al régimen en lugar de los mejor preparados, etc. hicieron que en los primeros 20 años de la dictadura franquista el modelo de ciencia e innovación español fuese prácticamente inoperante. Con el comienzo de la apertura económica en 1959 y el ascenso de los tecnócratas del Opus Dei al gobierno, llegará un nuevo impulso a la ciencia, que si bien seguirá siendo de corte mayoritariamente utilitarista recibirá un mayor número de inversiones, ${ }^{13}$ y lo que es más importante, permitirá que los científicos españoles puedan volver a realizar de manera gradual estancias en el extranjero, se creen institutos de investigación, etc.

\section{La cultura científica popular}

Entendemos por cultura científica popular el conocimiento científico técnico que tiene la mayor parte de los ciudadanos de una nación no relacionados con el mundo profesional de la ciencia o la tecnología. Este tipo de conocimiento se genera a través de dos vías esenciales: la educación reglada y la cultura de masas.

Respecto del papel de la enseñanza reglada en la creación de una determinada cultura tecnológica popular parece no haber discusión. En tanto en cuanto el estado garantice una serie de conocimientos científicos básicos a través de los programas de estudios, la sociedad estará encaminada en mayor o menor medida a la comprensión de la ciencia y la tecnología. Así, por ejemplo, los programas de estudios desarrollados en Francia a lo largo del siglo XIX, encaminaban a la formación de alumnos con una educación humanista, en la cual importaba tanto los conocimientos técnicos como las disciplinas artísticas y humanísticas. Esto generaba un perfil de alumno conocedor de una gran amplitud de materias pero sin especialidad en ninguna. Por otro lado, el modelo clásico alemán generaba una educación segmentada, en la que la mayor parte del alumnado de enseñanzas medias acabaría finalizando sus estudios en institutos técnicos, reservándose para la élite el acceso a las universidades, ${ }^{14}$ algo que generaba una creciente base de ciudadanos con conocimientos técnicos específicos y por tanto participantes de una cada vez mayor cultura científica popular.

Otro elemento fundamental en la formación de la cultura tecnológica popular fue la in fluencia de los medios de comunicación de masas. El comic, el cine, la televisión, la literatura, quienes ayudaron a generar en el consumidor cultural una valoración concreta sobre el proceso científico y sobre la tecnología. ${ }^{5}$

Pero, ¿qué utilidad tiene la formación y la existencia de una cultura científica popular amplia? Autores como Zorina Khan defienden que el hecho de que exista una "democratización

12 Ibídem, p. 192

13 La OCDE estimaba que para el final del periodo autárquico la investigación en la universidad española era prácticamente inexistente y que el $85 \%$ del exiguo gasto en I+D del estado se canalizaba a través del CSIC. Luis Enrique OTERO CARVAJAL: La ciencia en España un balance del s.XX Cuadernos de Historia Contemporánea, 22 (2000), p. 192.

14 Fritz K. Ringer: “Dos culturas académicas: Francia y Alemania hacia 1900.", Revista de Educación, No Extra 1 (1989), pp. 135-164. 15 Todo ello en un país que tardó en entrar en la cultura Pop debido a la resistencia de sus autoridades. El inicio de este tipo de cultura fue la primera victoria de los españoles frente a la dictadura. toria de España, Madrid, Crítica, 2007, p. 624 . 
de la cultura" que permita la creación y extensión de una cultura científica popular permite el aumento de la mentalidad inventiva. ${ }^{6}$

Así pues, el correcto desarrollo y fomento de una cultura tecnológica popular permitiría (al menos eso evidencia el caso estadounidense) el desarrollo de un gusto social por la ciencia y la tecnología que debería tener su reflejo tanto en el mayor número de estudios científico técnicos como en el número de ítems patentados por habitante. No obstante, respecto del aumento de creaciones patentadas, en mi opinión es dudoso que al menos en el momento actual este dato fuese a mejorar sustancialmente. Si tenemos en cuenta que desde mediados del pasado siglo XX la ciencia dio el salto de manos de los inventores y genios y sus pequeñas empresas para pasar a la "Gran Ciencia", cabe plantearse hasta que punto una cultura científica popular podría repetir los resultados del caso americano en el siglo XIX.

Los primeros contactos científicos: la educación básica.

A la altura de 1950 el 89'93\% de la población entre 26 y 30 años estaba alfabetizada, mientras que un $57^{\prime} 51 \%$ de los niños de 7 años se encontraban en esta misma situación. ${ }^{7}$ En este proceso de alfabetización y escolarización creciente de la sociedad española comenzamos nuestro estudio sobre la generación de la cultura científica popular. Entre 1954 y 1966 los manuales básicos para la educación en España serán las conocidas Enciclopedias Álvarez. Estas enciclopedias, editadas primero en solitario por ELMA y a la que posteriormente se uniría la editorial Miñon, abarcaban desde los estudios de primer grado a los denominados de "Iniciación Profesional", esto es, la mayor parte del espectro académico que un español medio de las décadas de los 50 y 60 iba a conocer. Estas enciclopedias, más allá de su revisión y evidente uso propagandístico de la historia española al servicio del régimen, contendrán todos aquellos conocimientos académicos que se consideraba que un alumno debía tener. Si tomamos el manual de Primer Grado de dicha enciclopedia veremos que la proporción que se dedica a los saberes técnicos o científico técnicos es nula..$^{1}$ No se dedica página alguna en el texto de formación del alumno a la explicación de cuestiones de ciencia y tecnología. En el manual de segundo grado, se dedican a estas cuestiones 11 páginas de un total de 481 que conforman del libro de texto. Se dedican así mismo un total de 36 páginas a la explicación de cuestiones tales como las funciones del cuerpo humano, geografía, etc. Estas 48 páginas en total forman la totalidad del apartado "Ciencias naturales" del libro y que serían impartidas en dos años diferentes. De los conocimientos que más directamente podemos catalogar dentro de una formación de "cultura científica y tecnológica" tenemos que se centran básicamente en la explicación del funcionamiento de la energía eléctrica, añadiendo una breve explicación de cómo se debe realizar una instalación eléctrica básica. Como queda claro, la educación en ciencia y tecnología de los alumnos entre 6 y 12 años era más bien reducida.

El mundo de la imagen. La ciencia en el comic y el cine.

Aunque la educación básica es fundamental para establecer la base de una cultura tecnológica y científica popular, esta no es su única ni principal vía de desarrollo. En la formación de esta cultura científica popular influye muy especialmente desde la década de los

16 Zorina KHAN: Intellectual Property and Economic Development: Lessons from American and European History, Maine, National Bureau of Economic Research and Bowdoin College, 2002. Recuperado de internet (http://www.iprcommission.org/papers/pdfs/study_papers/spia khan_study.pdf)

7 Narciso DE GABRIEL: “Alfabetización y escolarización en España. (1887-1950)", Revista de Educación, núm. 314 (1997), pp. 217-243

18 Antonio ALVÁREZ PÉREZ: Enciclopedia intuitiva, sintética y práctica. Primer Grado, Valladolid, Miñon, 1964. y Antonio ALVÁREZ PÉREZ. Enciclopedia intuitiva, sintética y práctica (Adaptada al cuestionario oficial). Segundo Grado, Valladolid, Miñon, 1962. años 60 la cultura audiovisual. El comic, el cine, y en menor medida la televisión, serán claves en la formación de la cultura científica popular española en un contexto de extensión de la moderna cultura de masas.

Para el estudio de la formación de esta cultura tecnológica popular en España tenemos una gran variedad de fuentes, especialmente desde el mundo del comic o la viñeta infantil. Hay que tener en cuenta que hasta la popularización de la televisión en la década de los 6o, la viñeta fue indiscutiblemente la reina del espacio lúdico y que desde su posición privilegiada fue extraordinariamente influyente en la creación del imaginario público de los duros años de la posguerra. ${ }^{19} \mathrm{El}$ tebeo fue para muchos jóvenes españoles de aquellos años algo más que una forma de entretenimiento; fue una ventana para entender el mundo y una puerta para escapar de él, un texto divertido pero también una forma de aprendizaje. ${ }^{20}$ Aunque la temática científica o tecnológica aparece más o menos soslayada en muchas series de caricaturas como en Mortadelo y Filemón en esta presentación nos centraremos en la más emblemática (aunque no la única) de las viñetas de tema científico: "Los Inventos del TBO".

No obstante, merece la pena hacer un breve repaso sobre la visión que se da de la ciencia y la tecnología en Mortadelo y Filemón. Dicha visión es bastante reveladora de la percepción social española sobre la misma. En estas historietas hay dos tipos básicos de desarrollos científicos: el desarrollado nacionalmente por el Profesor Bacterio, biólogo que sin embargo es capaz de desarrollar todo tipo de maquinaria, y la tecnología introducida del extranjero. La tecnología extranjera que usan los agentes son siempre copias ineficientes de sofisticados aparatos extranjeros. Los aparatos tecnológicos o los compuestos químicos, etc. desarrollados en el país siempre plantean problemas pues o bien resultan ineficientes, o bien los agentes son incapaces de comprender el funcionamiento de los mismos y los usan de manera equivocada.

Los Grandes Inventos del TBO

“Los Grandes Inventos del TBO”, “Inventos Prácticos” o “Los Inventos del TBO”, fue el nombre que con algunas variaciones tuvo la sección más longeva de la publicación periódica infantil el TBO. Esta sección comenzaría su andadura en el año 1943 de la mano del dibujante Nit, ${ }^{2}$ aunque hasta lo largo de la década de los 80 participarían en el desarrollo de esta sección los dibujantes Tínez (Juan Martínez Buendía, 1893-1957), Marino Benejam i Ferrer (1890-1975), Francesc Tur Mahen (1895-1960), y Ramón Sabatés Massanell (1915-2003).

La sección, presentada por el personaje de ficción Profesor Franz de Copenhague, desarrollaba una serie de inventos de carácter más técnico que científico en los cuales se planteaban problemas comunes de la vida cotidiana a los cuales se les daba una solución técnica de mayor o menor extravagancia. La temática de los inventos variará desde máquinas corta puros automáticas a sistemas contra criadas comilonas, pasando por el desarrollo de escopetas de caza autoapuntables, máquinas para planchar los pantalones, métodos antimareos, o incluso periódicos infantiles comestibles. En todos ellos había latente un reflejo de las necesidades materiales de la época en la que eran publicados. Así, en los años 40 y 50 la temática de aparatos o máquinas estaba orientada fundamentalmente a la obtención de comida (como una escopeta que caza y cocina o un manzano inalcanzable para evitar el robo a los agricultores, un mecanismo para nadar y pescar a la vez, mecanismos para dar a los niños de comer en el colegio, una máquina que transforma los restos de suelas de zapatos en vino, contenedores de agua camuflados para sacar más líquido del permitido en la cola de la fuente, etc) o evitar las miserias del

19 Antonio ALTARRIBA ORDÓÑEZ: La España del Tebeo, Madrid, Espasa Calpe, 2001, p. 13. 20 lbid.

21 Entre 1941 y 1946 la revista se publicará de manera irregular, comenzando a publicarse con continuidad mensual desde 1946. 
frío (aparato limpia moquillos, jarabe efecto abrigo, etc). A medida que la serie avance en el tiempo irán surgiendo nuevos inventos acordes a las nuevas necesidades. La serie a lo largo de los 60 presenta inventos para evitar las aglomeraciones y atascos, camiones de reparto que no necesitan aparcar e interrumpir el tráfico para descargar, perros ganaderos para evitar que los peatones provoquen atascos. Se desarrollan incluso inventos que permitan evitar la escasez de combustible que se vivía periódicamente en nuestro país hasta entrados los 60 . Tales inventos eran los coches movidos con el vapor de una cafetera, un coche sin motor que funcionaba con un garfio que se debía enganchar en otros que estuviesen ya en circulación, etc.

El propio protagonista de esta sección, Franz de Copenhague era un inventor que pretendía reflejar al moderno gremio de científicos de la era atómica vestido con su bata blanca, su nombre de origen germánico y sus constantes alusiones a la necesidad de simplicidad en la invención..$^{22}$ Es más, el propio Franz de Copenhague aparece patentando sus inventos en la oficina internacional de patentes (las escopetas autoapuntable excelsior modelos A y B), mostrando así en cierto modo al público infantil como era el proceso por el que se protegían los productos de la actividad inventiva. Podemos ver incluso en la figura del profesor Franz de Copenhague un reflejo del estado de nuestra ciencia durante el franquismo, una expresión plástica desde el mundo del comic del "que inventen ellos" de Unamuno (1864-1936).

Aunque como ya hemos dicho los inventos del TBO presentan soluciones mecánicas y téc nicas a problemas cotidianos, en algunas ocasiones planteaban cuestiones tales que podrían ser objeto de estudios científicos de biología (dentro de los parámetros del propio TBO). Así, el profesor Franz de Copenhague experimentaba a menudo con gallinas y vacas en busca de mayor productividad del animal, productos ya procesado o huevos con cáscara de cristal que permitieran ver el estado y calidad de los mismos con vistas a su consumo.

Se pueden distinguir en general en esta publicación dos grandes tipos de soluciones a los problemas cotidianos. Por una parte, estarían invenciones técnicas de un marcado carácter fantástico tales como los huevos de cáscara transparente o los jardincillos colgantes plegables para disfrutar del verano en la ciudad, etc. Aparatos y soluciones sin ningún tipo de verosimilitud ni forma de poner en práctica en la vida real. Por otro lado, y siempre dentro de los parámetros de ingenio y humor que exigen una publicación infantil de este tipo, estarían aquellos inventos que tienen un carácter más "real". Estos inventos más creíbles desde un punto de vista técnico corresponden a los dibujantes Nit y Sabatés, ambos peritos técnicos, que desarrollaron en la viñeta inventos complejos y mecánicamente sofisticados para fines absolutamente absurdos o banales. ${ }^{23}$ Es más, algunos de estos inventos de corte más realista fueron puestos en práctica. Nit presentó al público una máquina para cortar puros que había sido desarrollada a partir de los diseños del TBO en una exposición en Valencia resultando funcional ${ }^{24}$ No sería el único, ya que por ejemplo los aparcamientos para vehículos en pisos o las sandías cuadradas que se presentaron como soluciones del TBO son hoy una realidad.

Según el editor y crítico de cómic Joan Navarro i Badia, los inventos del TBO plasmarían a la vez el asombro, fascinación y escepticismo por la mecanización de la sociedad española de posguerra. Esta frustración y atracción por la tecnología queda patente en otras historietas como La Familia Ulises, donde la abuela, Doña Filomena, nunca termina de entender bien el

22 Joan NAVARRO: Los Grandes Inventos del TBO. Profesor Franz de Copenhague, Barcelona, Ediciones B, 1989

23 lbid.

24 La máquina se encuentra actualmente en exposición permanente en el Museo del Juguete de Figueras. Robert LLORCA: "Ramon Sabatés, dibujante, inventor y perito mecánico", El reportaje,
Informatiu Theknos, 5 (Abril de 2002). Recuperado de Internet (http://www.jrmora.com/archivo/ reportaje pdf). Una imagen delinvento encuestion puede consultarse en (http//wm/ajmora. com/blog/wp-content/uploads/2008/06/maquina-puros.gif) uso de los "atrefactos" que usa en la casa de su familia en la ciudad. 25 En sus mejores tiempos, la tirada del TBO rondaba los 300.000 ejemplares, lo que no significa que solo tuviese este número de lectores. El TBO, los comics, aunque baratos, eran caros para la mayoría de las economías domésticas españolas de los años cuarenta y cincuenta, razón por la que pasaban de mano en mano multiplicando así el número de lectores más allá del número de ventas. ${ }^{26}$ Ta vez el valor en educación científica y técnica que para la formación de una cultura tecnológica popular pudiera tener esta publicación es cuanto menos dudoso, pero para muchos españoles fue su única educación en estos campos hasta su acceso a los estudios medios o superiores.

El mundo del Cine

Podemos acercarnos al mundo de la ciencia desde el cine a través de dos vías: el cine documental y el cine de ocio. El principal representante de este género será Guillermo Fernández López Zúñiga (1909-2005) quien tras su vuelta del exilio en París en 1957 participó en la dirección, escritura de guión, montaje o producción de las películas y cortos: "La aventura de Api" (1964), "Florinda y el viento" (1965), "Un pequeño colonizador verde" (1968), "El mejillón en Galicia" (1970), "El gran crucero" (1970) "Guerra en el naranjal” (1971), "La mosca de las frutas" (1971), "Encinares" (1973), “La lagarta” (1974) o "El agua en la vida” (1974). ${ }^{27}$ Todas ellas tuvieron una buena aceptación por la critica recibiendo numerosos premios nacionales e internacionales. No obstante, la repercusión que estas películas tuvieron en el gran público fue escasa si se compara con las películas de ocio.

Es en estas películas donde podemos ver la mentalidad del español respecto de la ciencia y la tecnología en las décadas de los 50 y 6o. Podemos hablar de dos momentos diferenciados. En la década de los 50, antes de la firma de los pactos hispano norteamericanos y el comienzo de la llegada masiva de productos de los EE.UU. a España, las referencias a la ciencia en el mundo del cine demuestran un panorama desalentador. En "Historias de la radio" (1955), aparece la figura de dos inventores que pretenden patentar un "piñón a doble deflector" que han desarrollado. La falta de recursos económicos les empuja a participar en una carrera por Madrid disfrazados de esquimal para conseguir el dinero que cuesta el registro de la patente antes de que "los de la aeronáutica" se les adelanten. El reflejo que se da de la labor del científico en esta película es revelador. Los inventores trabajan en un sótano lóbrego, deben el alquiler no tienen dinero para el registro de patentes, y no tienen más medios que su inteligencia y unos viejos instrumentos. Se presenta la vida del inventor como una vida de sacrificio y carencias. Por otro lado se plantea una cuestión que ya apuntamos con anterioridad, el paso de la ciencia del genio individual a la gran ciencia. Una empresa sin nombre determinado pero dedicada a la aeronáutica aparece de telón de fondo, dándose a entender que es quien copa el desarrollo científico y la obtención de patentes frente a los inventores protagonistas. Más revelador del sentimiento que el español tenía hacia la labor científica en los años 50, de su apreciación popular, lo tenemos hacia el final de esta historia. El inventor sube las escaleras del estudio de radio compitiendo con un hombre. En determinado momento ambos caen al suelo y mantienen una conversación en la que el inventor le pide a su competidor que le deje ganar porque "un invento es algo de interés nacional". El rival le responde que sin pistones se puede vivir pero no sin mujeres. A la respuesta de "yo no tengo mujer" el rival responde "claro, por eso inventa usted pistones". ${ }^{28}$ La escena deja patente que la ciencia y la tecnología, al nivel

25 Antonio ALTARRIBA ORDÓÑEZ: La España ..., p. 32

26 Ibid. pp. 14-15.

27 ASECIC, 2009. Recuperado de internet (http://www.asecic.org/index.php?module=audDivSe-

$c \& \sec =44 \&$ lang $=1$ )

28 José Luis SAENZ DE HEREDIA: Historias de la radio, España, 1955 

como pueden ser los devaneos amorosos.

Las películas posteriores a los años 50, una vez inmersa España en el desarrollismo, varían su visión sobre la ciencia. Esta deja de ser algo puramente nacional y de carácter miserable para comenzar a apreciarse continuamente la tecnología extranjera. En "Las que tienen que servir" (1967), unas criadas españolas trabajan al servicio de unos americanos afincados en Torrejón de Ardoz. La visión que se da de la ciencia y la tecnología extranjera, aunque cómica, es de un marcado carácter futurista. Se presenta la tecnología americana de un modo complejo y casi a estilo de los inventos del TBO. Aunque se habla de varios desarrollos técnicos, la principal pieza de tecnología que aparece en la película es una cocina automática que realiza todo el proceso de cocinado, limpieza, etc. Aunque se hace una constante referencia a la capacidad inventiva de los estadounidenses y las ventajas de esta, se plantean dos cuestiones. En primer lugar, la tecnología aparece siempre vinculada al desarrollo de instrumentos y aparatos para el desarrollo de la vida doméstica. En segundo lugar, no deja de haber una cierta crítica velada a estos desarrollos técnicos en el tratamiento humorístico que se hace de ellos. Podemos encontrar también en "Los subdesarrollados" (1968) y "Vente a Alemania, Pepe" (1971) referencias al progreso tecnológico extranjero frente a la falta de este en el ámbito nacional. Una de las escenas más reveladores se produce al comienzo de "Vente a Alemania, Pepe" cuando el emigrante, de vuelta temporalmente en España, habla de la capacidad inventiva de los alemanes en los términos siguientes: "Cuando no tienen nada que inventar, tienen una máquina que se aprieta un botón y se inventa lo que tenían que inventar ellos" "Es como el milagro de Lourdes pero mecanizado".29

\section{Conclusiones}

Aunque se produce desde la década de los cincuenta del pasado siglo un aumento constante en la inversión total en I+D, y en número de ítems patentados, no hay datos objetivos que permitan marcar en que medida influyó en ello el desarrollo de una cultura científica popular al calor de la introducción de los medios de comunicación de masas en España. El análisis del comic, cine y literatura de ocio relacionados con directa o indirectamente con la ciencia o la tecnología únicamente puede aportar al estudio la perspectiva y la percepción que el español tenía sobre el hecho científico y sobre los usos de la tecnología. Por otro lado, si que parece claro que hay una relación directa entre política científica oficial y cultura tecnológica popular. El desarrollo de una ciencia eminentemente aplicada y con pocos recursos materiales desde comienzos de la dictadura tendrá su reflejo en el mundo de la imagen. El mundo del cine y la viñeta representan el cliché de la capacidad inventiva del resto de naciones frente a la española y la tecnología (nacional o extranjera) ligada directamente a la solución de problemas de índole cotidiana. La tecnología, al menos en la literatura infantil se conceptúa como una serie de elementos mecánicos que actúan de manera encadenada para lograr objetivos que aunque necesarios para facilitar la vida cotidiana pueden lograrse sin tecnología. Por su parte, la figura del inventor también aparece como partícipe de la dicotomía extranjero eficiente/ nacional ineficiente. 


\section{FUENTES ARCHIVÍSTICAS PARA EL ESTUDIO}

FRANCIA (1936-1945)

Rubén Mirón González

Universidad de Almería

\section{SANITARIO DEL EXILIADO ESPAÑOL EN EL SUR DE}

Teniendo en cuenta la redistribución que vivieron los refugiados españoles en territorio galo a partir de junio de $1939,{ }^{4}$ nos hemos centrado en el estudio de las fuentes de los siguientes departamentos: Aude, Ariège, Hérault, Pyrénées-Atlantiques, Pyrénées-Orientales y Tarn-et-Garonne. Para ello se han visitado los Archivos Nacionales (París y Fontainebleau), el Archivo del Ministerio de Asuntos Extranjeros y un total de ocho archivos departamentales. ${ }^{5} \mathrm{Al}$ centrarnos en la cuenca mediterránea no se visitó el archivo de los Pyrénées-Atlantiques. Por otro lado hemos incorporado los departamentos de Tarn, Bouches-du-Rhône y Haute-Garonne; los dos últimos no contaron con campos propiamente españoles pero los dos barcos-hospitales anclados en Marsella y los campos-hospitales de Noé y Récébédou es motivo suficiente para que sean visitados dichos archivos.

En definitiva, el objeto de este trabajo es mostrar un balance de los fondos de los archivos nacionales y departamentales de Francia, fruto del trabajo para la tesis que estoy desarrollando, pudiendo servir estas fuentes a futuros investigadores que conectan con esta línea de investigación dentro del marco de la Historia Social. Es un trabajo que comenzó en la primavera de 2012 con la consulta de guías españolas ${ }^{6}$ y francesas, ${ }^{7}$ viéndose completado con la realización de una estancia doctoral de tres meses de duración en París y sur de Francia. o cultades con que nos encontramos los investigadores del Exilio son, sin duda, la dispersión y fragmentación de las fuentes.

El desconocimiento de dónde extraer los datos es todavía mayor si se trata de reconstruir todo lo relacionado con la situación sanitaria y asistencia de los refugiados en los campos de sur de Francia, dado que la producción historiográfica a este respecto es escasa, por no deci inexistente. La mayoría de estudios han sido publicados en la primera década de la actua centuria cuyos esfuerzos han sido dedicados a las biografías de los médicos exiliados o el trabajo de las enfermeras exiliadas a los países latinoamericanos, más que poner el acento en la publicación y localización de las fuentes archivísticas propiamente dichas. ${ }^{2}$

Al hilo de lo planteado, la política sanitaria del exilio español ha sido una dimensión poco explorada, tal vez también por la dificultad que entraña localizar informes lo suficientemente amplios donde podamos evaluar, entre otros factores, el comportamiento político que llevó al gobierno francés a negociar con los efectivos franquistas la repatriación de miles de refugiados enfermos, y por otro lado, analizar el control sanitario que hubo dentro de los campos, localizar estadísticas de los enfermos y heridos y la organización hospitalaria para su asistencia, identificar al personal sanitario español también exiliado o analizar la labor humanitaria de los organismos internacionales que se preocuparon por la situación de los españoles, etc. Acudir a la objetividad que nos aportan las fuentes archivisticas es casi una obligación, por lo que con este trabajo pretendemos identificar y organizar aquellas fuentes francesas que nos ayuden a comprender el fenómeno del exilio español desde el prisma socio-sanitario.

1 La ardua labor de catalogación y clasificación de los fondos de de la Segunda República en el exilio culminó en 1993 y 1996 con la publicación de los inventarios del Fondo de París y del Fondo Hemerográfico respectivamente y quedó recogida en la obra de Alicia ALTED VIGIL: El archivo de la República española en el exilio 1945-1977 (Inventario del Fondo de París), Madrid, FUE, 1993.

2 A este respecto, la obra más completa pertenece a Francisco GUERRA: La Medicina en el exilio republicano, Madrid, Universidad de Alcalá, 2003. Ver también Juan José MARTíN FRECHILLA: "El dispositivo venezolano de sanidad y la incorporación de los médicos exiliados de la Guerra Civil Española", História, Ciências, Saúde-Manguinhos, 15 (2008), PP. 519-541; José Francisco TINAO MARTíN-PENA: “Los História, Ciências, Saúde-Manguinhos, 15 (2008), PP. 519-541; José Francisco TINAO MARTINN-PENA: "Los
médicos del exilio republicano en Venezuela", Historia Actual Online, 7 (2005). Pp. 43-54; Encarna médicos del exilio republicano en Venezuela", Historia Actual Online, 7 (2005). Pp. 43-54; Encarna sanitarias al desarrollo de la Enfermería venezolana", en Josep Lluís BARONA: Ciencia, salud pública y exilio (España 1875-1939), Valencia, Seminari d'Estudis sobre la Ciència, 2003, p. 99-130.

3 Estas son las variables de las que nos ocupamos en nuestro trabajo de investigación que, a modo de tesis doctoral versa sobre la asistencia socio-sanitaria de los exiliados españoles de rezg en los campos del sur de Francia.

\section{Archivos nacionales}

Los fondos del Archivo Nacional de Francia están distribuidos en tres centros situados en París, Fontainebleau y Pierrefitte-sur-Seine. Enumerados por orden cronológico, el último fue inaugurado en enero de 2013, con la intención de aglutinar toda la documentación relativa a las administraciones centrales desde 1790. Hasta entonces esta documentación se encontraba distribuida entre los centros de París y Fontainebleau. ${ }^{8}$ El grueso de documentación que nos interesa se localiza en la sede parisina Centre d'Accueil et Recherche des Archives Nationales (CARAN), concretamente en la Sección del siglo XX que abarca el período 1914-1958; los fondos posteriores a 1958 se encuentran en el Centre des Archives Contemporaines (CAC) de Fontainebleau, del que hablaremos más adelante.

En París se sitúa gran parte de la documentación ministerial así como diversos fondos de organismos del Armisticio, el Comité de la II Guerra Mundial y organizaciones internacionales

4 Ministro de la Defensa Nacional y de la Guerra: Au sujet du functionnement des camps de refugies espagnols, 15 Jun 1939, Archivo del Ministerio de Asuntos Extranjeros de Francia, serie Europa 19181940, España 1930-1940, doc.189, pp.95-98.

5 Archivo Departamental de Aude (ADAU), Archivo Departamental de Ariège (ADARI), Archivo Departamental de Bouches-du-Rhône (ADBR), Archivo Departamental de Haute-Garonne (ADHG), Archivo Departamental de Hérault (ADHE), Archivo Departamental de los Pyrénées-Orientales (ADPO), Archivo Departamental de Tarn (ADTA) y Archivo Departamental de Tarn-et-Garonne (ADTG). Acrónimos utilizados a lo largo del trabajo.

6 Juan Carlos JIMÉNEZ DE ABERÁSTURI CORTA: "Fondos documentales para el estudio de la Guerra Civil y el Exilio republicano en el Archivo Nacional de Francia 1931-1981", Bilduma, 2008, pp.7-95 José Luis DE LA GRANJA y Santiago DE PABLO: Guía de fuentes documentales y bibliográficas sobre la Guerra Civil en el País Vasco (1936-1939), Eusko Ikaskuntza, Donostia-San Sebastián, 2009; DoIores FERNÁNDEZ: "Fuentes para el estudio del exilio republicano español en Francia". Migraciones y Exilios, 8 (2007), pp.55-68; María Jesús BERZAL TEJERO: “Fuentes documentales para el exilio en Francia (1939-1945) en los Archivos Nacionales, Departamentales y en el Archivo del Ministerio de Asuntos Exteriores". Tabula, 8 (2005), pp.121-141.

7 Brigitte BLANC, Henry ROUSSO y Chantal DE TOURTIER-BONAZZI: La Seconde Guerre Mondiale. Guide des sources conservées en France, 1939-1945. París, Direction des Archives de France, 1994 Pierre-Jacques DERAINNE y Patrick VEGLIA. Les étrangers en France Guide des sources d'archives publiques et privées XIX-XX siecles, París, Génériques, 1999 (T.I, II y III), 2005 (T.IV).

8 Teniendo en cuenta que la mayoría de documentación presentada en este trabajo es del Ministerio de Interior, es conveniente que se confirme su ubicación para futuras visitas a los Archivos Nacionales. 
para los refugiados entre otros. Desde esta perspectiva, la serie de mayor interés para nuestro objeto de estudio es la F: Ministerios y Administraciones. La subserie Fra del Ministerio de Interior (Administración general) recoge cientos de informes emitidos por los departamentos que relatan la situación del refugiado español. La sanidad, al igual que la seguridad, era uno de los principales problemas de estado que aterrorizaba a los prefectos departamentales. La asistencia socio-sanitaria de los refugiados analizada a través de las cartas y comunicaciones proporcionadas en esta serie nos lleva al descubrimiento de la asistencia realizada en barcos-hospitales como fórmula de garantía que evitaría la propagación de epidemias a la población autóctona. Las penurias de los españoles vivida en los distintos campos de concentración queda reflejada en los legajos de cada departamento desde 1939 hasta 1942.

Por lo que respecta a la policía, se constituyó en una pieza clave en el control del "problème espagnol". 9 En este sentido, la Direction de la Police du Territoire et des Etrangers fue la encargada de registrar y notificar al ministerio del interior de forma periódica los datos referentes a los refugiados españoles. En la subserie $\mathrm{F} 7$ ha quedado aglutinada toda esta información departamental en un total de 10 legajos..$^{10}$ Nos encontramos ante un auténtico censo de entrada en Francia, lo que nos permitiría identificar a todos aquellos refugiados sanitarios más allá del colectivo médico. Pero la realidad es que no siempre reflejaban la profesión y tendríamos que complementarlo con otro tipo de documentación como las fichas de los campos, ya que no todos los departamentos reflejan la misma información. Los registros son por campos de concentración, centros de acogida o municipios; encontrando listados de hospitalizados, mutilados y enfermos que nos ayudan a identificar aquellos espacios donde estaban siendo asistidos los refugiados desde principios de 1939

Respecto a los campos, existe una serie que versa sobre la Inspección General de los mismos. Unos legajos diversos que guardan informes sanitarios sobre la organización del material, la Cruz Roja, gastos de hospitalización, tablas de personal sanitario y fotografías de barracones, enfermerías, letrinas... Al igual que los listados departamentales, existen 18 legajos con información respecto a toda Francia. Esto nos permite vislumbrar la situación de cada región francesa antes de profundizar sobre sus archivos departamentales."

En todo momento debemos tener en cuenta que estamos ante la realidad que querían mostrar los gendarmes y los prefectos franceses al ministro del interior, por lo que estos in formes deben ser contrastados con otros tipos de fuentes como periodísticas o de organismos internacionales externos. En esta línea, la serie AJ de Fondos Diversos se constituyen en una pieza clave en nuestra labor crítica como historiadores. Por ejemplo en la subserie $72 \mathrm{AJ}$ correspondiente a documentos del Comité de Historia de la Segunda Guerra Mundial, existe un informe del Institut für Zeitgeschichte de Munich sobre la situación de los refugiados españoles traducido al francés de 1964. En él se trabajan tres puntos: la Guerra Civil Española, el éxodo y los refugiados en la Francia no ocupada; encontrando cifras de heridos y enfermos. En la subserie AJ41, de los servicios del Armisticio, destacan los informes de distintos organismos internacionales que prestaron asistencia como la Ligue de mutilés et invalides de la Guerre d'Espagne o el Canadian National Institute for the Blind, realizando una auténtica labor filantrópica a favor del pueblo republicano español. Nos sorprende la presencia de otros países como Grecia, Países Bajos o Nueva Zelanda. Esta respuesta internacional, la cual es extensa y

9 Nombre que adoptó oficiosamente esta situación a partir de la Gran Retirada de 1939 y que fue alargándose su uso a lo largo del tiempo. A modo de ejemplo citaremos una circular del Ministro del Interior a los Prefectos de febrero de 1940 que comienza diciendo: "Les circonstances commandent d'apporter au problème des réfugiés espagnols une solution définitive...". Archivo Departamental de Tarn, 4M18-13.

10 Archivo Nacional de Paris (CARAN), F7, 14725 a 14735

11 Ibid., F7, 15093 a 15111 una constante dentro de los archivos franceses, es el reflejo de la preocupación externa de lo que estaba sucediendo en Francia con los refugiados.

Como hemos comentado anteriormente, en el CAC de Fontainebleau se almacena la documentación posterior a 1958. En cambio fue receptor de un fondo anterior y de especial interés para el estudio del exilio republicano español denominado Archives Restituées par la Russie. Fondo que fue confiscado por las tropas nazis en 1940, recuperado por la URSS en 1945 y devuelto a Francia en el 2000. La mayoría de documentación es del Ministerio del Interior y complementa lo que hemos relatado sobre los fondos del CHAN. En cambio guarda un fondo de gran riqueza cualitativa de la Commission d'aide aux enfants espagnols réfugiés. Su estado de catalogación es deficiente, por lo que requiere un gran esfuerzo de síntesis por parte del investigador, pero en cambio da mucho juego respecto a futuros trabajos historiográficos sobre niños en el exilio. Las cartas de padres pidiendo la repatriación de sus hijos son estremecedoras. Maestras y enfermeras cuidaban de los niños mientras estos realizaban dibujos sobre la realidad que les había tocado vivir. A su vez eran las encargadas de dibujar su silueta plantar para demandar calzado a las organizaciones internacionales. Toda la documentación generada a consecuencia de esta realidad la podemos encontrar en el fondo mencionado.

\section{Archivo del ministerio de asuntos extranjeros}

A pesar de la política de no-intervención liderada por Francia e Inglaterra, éstas actuaron de forma activa desde un punto de vista diplomático. En todo momento estuvieron al tanto de la situación española durante la contienda civil, así lo demuestra cientos de informes y cartas que se movilizaron desde diferentes embajadas con la intención de denunciar y paliar la desdichada realidad del bando republicano. Toda esta documentación del Ministerio de Asuntos Extranjeros pertenece a los Archivos Diplomáticos, situándose su edificio en la comuna de La Courneuve, escasos kilómetros al norte de París. Aunque el trabajo que se presenta es sobre Exilio y la mayoría de documentación de este archivo es sobre la Guerra Civil, sería un descuido por nuestra parte no intentar comprender los fundamentos del pánico francés hacia los republicanos antes de que cruzaran los Pirineos desde un punto de vista sanitario. Las medidas de vacunación y cuarentena instauradas por el Ministerio del Interior como respuesta a la Gran Retirada no fueron producto de la casualidad. El Ministerio de Asuntos Extranjeros llevó una monitorización constante del estado sanitario del bando republicano durante la contienda. Toda esta información se encuentra dentro de la serie Europa 1918-1940/España 1930-1940, diversos libros que además tratan las acciones humanitarias despertadas ante los bombardeos de zona republicana.

A la vez la embajada francesa funcionó como receptor de quejas por parte de organismos internacionales que veían que el envío de sus ayudas hacia España eran dificultadas por las políticas de su propio gobierno. En este sentido, el Ministerio de Asuntos Extranjeros tuvo una labor mediadora importante, buscando una respuesta operativa a todas estas trabajas que se iban presentando. A modo de ejemplo, el Spanish Medical Aid Committe denunció la incautación de varios vehículos sanitarios en el puerto de Marsella que fueron enviados para la evacuación de Valencia en 1939.

Para finalizar con este archivo recomiendo la consulta de la serie del Servicio francés de la Sociedad de las Naciones, 1917-1940. En el legajo 2048 se guarda un informe del Comité International de Coordination et d'Information pour l'Aide a l'Espagne Republicaine. Fue elaborado para la reunión del Consejo de la Sociedad de las Naciones del 22 de mayo de 1939 y se constituye en una pieza de gran valor a la hora de desmoronar la realidad española que querían mostrar muchos de los prefectos y gendarmes franceses. También encontramos otro documento inédito que pone en tela de juicio el discurso recurrente inicial sobre la imprevisión de la llegada de medio millón de refugiados a Francia. Se trata de una carta del embajador de la república francesa en España que informa al ministro de asuntos extranjeros sobre la "desvandá" de Málaga de 1937, avisando que ese mismo éxodo podría darse no muy tarde sobre el sur de Francia. 
L'expérience de Malaga vient de montrer la rapidité avec laquelle une grande ville peu être prise malgré les forces accumulées pour la défendre et malgré les difficultés du terrain. [...] Il est donc à prévoir que si les évènements militaires continuent à se développer suivant leur rythme actuel, et surtout s'ils s'accélèrent comme il arrive souvent à la fin d'une campagne, de véritables émigrations en masse tendront à se produire précipitamment. [...] Mais le problème principal se posera évidemment le jour où des milliers, peut-être des dizaines de milliers de jeunes gens et d'adultes, craignant les représailles des chefs militaires contre lesquels ils ont luté politiquement ou les armes à la main, afflueraient à notre frontière des Pyrénées-Orientales, de l'Ariège (Andorre) et de la Haute-Garonne (Val d'Aran).12

Como hemos visto hasta ahora, en los archivos de índole nacional encontramos fuentes con contenido sanitario que nos sirven para dar luz sobre un matiz del exilio poco estudiado. Pero estas fuentes archivísticas resultan insuficientes, ya que nos siguen quedando dudas sobre lo que estaba ocurriendo a nivel departamental. Hablar de sanidad es hablar de realidades asistenciales, esto requiere un esfuerzo por aproximarnos lo máximo posible a toda aquella documentación que pudiera haberse generado como consecuencia del fenómeno que estudiamos. En este sentido, los archivos departamentales se van a constituir en una pieza clave para enriquecer nuestro trabajo que ya ha sido aproximado a nivel nacional.

\section{Archivos departamentales}

La diáspora republicana de 1939 sobre territorio francés ha hecho que al menos un 85\% de sus archivos departamentales dispongan de documentación sobre esta temática. ${ }^{13}$ Visitar los 103 archivos sería un trabajo impensable para un sólo investigador, por lo que durante la estancia opté por centrarme en aquellos departamentos que más número de refugiados albergaron. En ese sentido la pista nos la da los campos de concentración con predominancia española. Siguiendo la documentación del archivo de Asuntos Extranjeros, comprobamos como a partir de junio de 1939 los exiliados españoles fueron redistribuidos en los campos de: Agde, Argelès-sur-Mer, Barcarès, Bram, Gurs, Saint-Cyprien, Septfonds y Vernet. ${ }^{14}$ Campos que corresponden a los departamentos que vemos en el siguiente mapa.

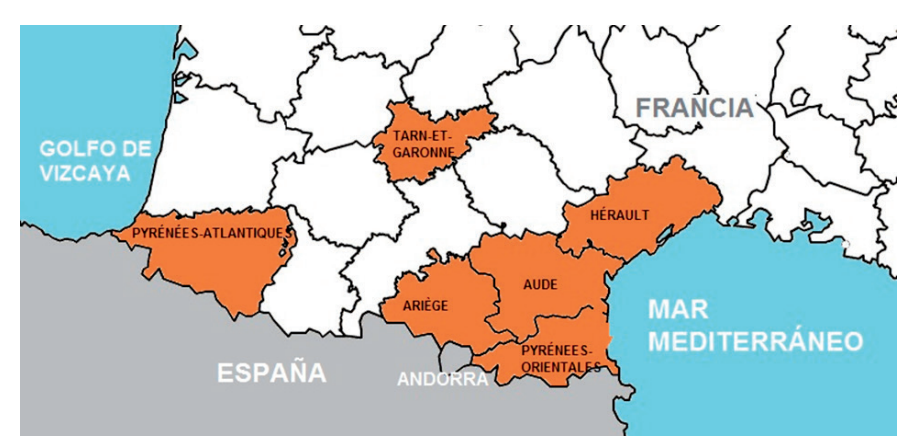

llus. 01 Distribución de refugiados españoles por departamentos franceses, junio de 1939 (Fuente: elaboración propia).

Respecto a la clasificación de los fondos departamentales, cabe destacar que disponen de una nomenclatura predeterminada a nivel nacional, esto nos facilita el movimiento en los diferentes archivos. La mayoría de documentación que nos interesa se encuentra catalogada dentro de las series $M$ (administración general y económica) ${ }^{15}$ y W (archivos posteriores a 1940). Además debemos sumar por su importancia las series J (archivos de origen privado) $X$ (asistencia y previsión social) y Fi (fotografía). Dependiendo de los recursos y del impacto histórico que haya tenido este acontecimiento en el departamento, vamos a encontrar un mayor o inferior grado de catalogación. En este sentido Ariège, Aude y Hérault muestran un alto grado de control de sus fondos sobre nuestro tema de estudio, poniendo a disposición de los usuarios muy buenas herramientas de trabajo como guías o inventarios actualizados. En cambio los Pirineos Orientales y Haute-Garonne sigue catalogando sus fondos, siendo preciso consultar sus salas de inventarios. ${ }^{16}$

Ya durante la Guerra Civil los departamentos limítrofes con España empezaron a recibir los primeros refugiados. Durante un par de días debían decidir si volvían a España y el tipo de frontera elegida; nacional o republicana. La alternativa a la repatriación era la redistribución por departamentos de primera y segunda urgencia. ${ }^{17}$ Estas primeras medidas y circulares están recogidas en la subserie $5 \mathrm{M}$ (Policía Política, Guerra de España) del ADARI. ${ }^{18}$ Quedan registradas a su vez las primeras respuestas humanas, donde franceses ofrecían sus casas para alojar refugiados españoles y se recontaban las camas disponibles en las principales ciudades. A esto se sumaban las primeras medidas higiénicas acordadas entre Ministerios de Sanidad e Interior, siendo una de las primeras dudas planteadas por los prefectos, así como quién se iba a hacer cargo del gasto sanitario de los refugiados. Este tipo de información del periodo de la Guerra Civil también la vamos a encontrar el ADAU en la subserie $4 M D$ y en el ADTA en la $4 M$, departamentos que pedían incluso asesoramiento a sus vecinos respecto cómo podían ayudar a los refugiados. En el caso del ADTA, al no contar con campos de refugiados españoles la clasificación de su información referente a la recepción de refugiados durante la Guerra Civil es excepcional, conservando las circulares perfectamente ordenadas entre 1938 y 1940.

15 MD en el caso de Aude.

16 Claudine PAILHĖS et al.: De l'exil espagnol à la libération. Les années 1939-1945 en Ariège. Répertoire méthodique des sources d'archives conservées aux Archives Départementales, Foix, Conseil général de l'Ariège, 2010; Archives départementales de l'Hérault: La Retirada. Exode des réfugiés espagnols de la Guerre Civile d'Espagne. Relevé des cotes conservées aux Archives départementales de l'Hérault». Montpellier: Archives départementales de l'Hérault, 2012.

17 Durante la Guerra Civil se establecieron 31 departamentos de acogida de "primera urgencia" y 14 de "segunda urgencia" ver Geneviève DREYFUS-ARMAND: El exilio de los republicanos españoles en Francia. De la guerra civil a la muerte de Franco, Barcelona, Crítica, 2000, p.39.

18 Ver acrónimos en nota 5 nistro de asuntos extranjeros.17 de febrero de 1937, Archivo del Ministerio de Asuntos Extranjeros (AMAE), Service Franc

13 Victoria ARIAS ROCA: "Los archivos de departamentos franceses: fuentes para el estudio de los refugiados españoles de la Guerra Civil" en Jornadas sobre movimientos migratorios provocados por la Guerra Civil, Salamanca, 15 a 17 de diciembre de 1988. Documento disponible en Archives
Départementales des Pyrénées-Orientales, serie 1 J, legajo 672. Ministro de la Defensa Nacional y de la Guerra. Au sujet du fonctionnement des camps de refugies espagnols, 15 Jun 1939. AMAE, de la Guerra. Au sujet du fonctionnement des camps de ref.
serie Europa 1918-1940, España 1930-1940, doc. 189, p. 95-98.

14 AMAE, Europa 1918-1940, España 1930-1940, doc. 189, p. 95-98. 
La visión del "pobre refugiado" pronto cambiaría a ser un auténtico problema con la entrada de 270.000 milicianos en febrero de 1939, entre los que se encontraban miles de heridos." Los hospitales de campaña creados a nivel fronterizo pasaron a ser insuficientes y la asistencia en hospitales civiles una auténtica obligación. Los registros de estos hospitales los podemos consultar en la serie X, como es el caso del Hospital Saint-Louis de Perpignan, el hospital civil de Montauban o el hospital auxiliar número 1 y 2 de Toulouse. En cambio en el ADPO los libros de registros de entrada y salidas del hospital civil se encuentran en la subserie $1787 \mathrm{~W}$. Llama la atención el estado del tomo correspondiente a 1939, siendo el 29 de enero cuando ingresa el primer miliciano herido de bala que muere ese mismo día. A partir de entonces decenas de milicianos entre 20 y 35 años ingresaban cada día, compartiendo el establecimiento con la población francesa, una situación que desbordó el funcionamiento normal de este hospital civil al menos hasta agosto del mismo año. En el ADHE la información respecto a los hospitales departamentales que recibieron refugiados se encuentra en la serie $4 \mathrm{M}$, a diferencia de los otros departamentos que están en las series X y W.

Pero los centros asistenciales no se resumieron a establecimientos clásicos e improvisadas enfermerías en centros públicos o estaciones de tren, sino que se instauró el acondicionamiento de barcos-hospitales como medida de extrema urgencia durante los primeros meses tras la Gran Retirada en los puertos de Marsella y Port-Vendres. En este sentido el ADBR era la clave para conocer más sobre dichos barcos, la sorpresa fue ver que apenas guardan tres legajos en la serie $\mathrm{W}$, de los cuales uno se encuentra en paradero desconocido según explicaciones del propio archivo departamental. Afortunadamente guardan una documentación de gran valor cualitativo, las cartas que recibieron los refugiados hospitalizados en los barcos de Marsella. La referencia es $4 M 962$, aunque sólo se permite su consulta en microfilm (2Mi1398).

El siguiente fenómeno del que disponemos una gran cantidad de documentación es de los campos de concentración. Gracias a ella se pueden hacer estudios internos sobre las condiciones de vida o la asistencia socio-sanitaria. Una lamentable situación que ya ha sido identificada por algunos estudios historiográficos y testimonios orales, ${ }^{20}$ pero insuficientes si tenemos en cuenta la gran diversidad de documentación de la que disponemos. A excepción de Tarn, los departamentos que presentamos en este trabajo guardan información respecto a sus campos en la serie W en su mayoría. Los informes sanitarios por parte de los médicos jefes de los campos son una constante en el tiempo, así como el control de material de las enfermerías, la gestión económica, la contratación de personal y las estadísticas de enfermos en los distintos establecimientos sanitarios de los campos.

Otro tema controvertido sobre el que no se ha escrito es el de las muertes de españoles refugiados en suelo francés. Una realidad que sigue silenciada desde el punto de vista historiográfico y que no resulta tarea fácil su abordaje teniendo en cuenta la disparidad de fuentes que hemos encontrado respecto a ello. Teniendo en cuenta el maquillaje constante de los informes por parte de los prefectos, sentimos la necesidad de acudir a fuentes mucho más fidedignas. En este caso cabe destacar la importante labor de análisis que debemos realizar sobre los registros hospitalarios mencionados, así como el de las enfermerías de los campos de concentración. Esto puede verse complementado con estadísticas sanitarias firmadas por los médico-jefes de algunos campos, los mismos médicos que denunciaban la escasez de recursos a la hora de ejercer su trabajo. Es por ello que debemos seleccionar nuestros informantes a la hora de preguntar a las fuentes sobre un tema tan delicado como son las muertes de refugiados españoles durante los primeros años de exilio.

19 AMAE, serie Europa 1918-1940, España 1930-1940, doc. 189, p. 62

20 Marie-Claude RAFANEAU-BOJ: Los campos de concentración de los refugiados españoles en Francia

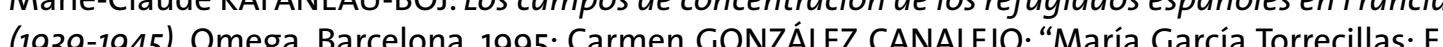
paradigma de las mujeres en el exilio republicano (1936-1943)", Arenal, 16 (2009), pp.175-187.
Para terminar nuestro análisis sobre los archivos departamentales, nos centraremos en los fondos fotográficos e iconográficos que ponen a nuestra disposición en las series $\mathrm{Ph}$ o Fi. El más accesible es el del ADPO, siendo recientemente publicado en un monográfico que engloba los fondos de Chauvin (27Fi), Bohny-Reiter (1Ph1) y Belloc (1Ph2). ${ }^{21}$ Respecto al fondo Chauvin, recoge la visita de los ministros del interior y sanidad a los Pirineos en los primeros momentos del éxodo, destacando fotografías junto a heridos, mutilados y enfermeras republicanas asistiendo a sus compatriotas. También se reflejan las labores higiénicas diarias que se realizaban en los campos de Argelès-sur-Mer y Barcarès. El fondo Belloc complementa este aspecto y además nos muestra cómo eran transportados algunos heridos por la frontera mediante el uso de mulos. Respecto al fondo Bohny-Reiter trata un aspecto muy diferente, la ayuda suiza a favor de los niños evacuados. Estamos ante fotografías que buscaban denunciar la situación de desnutrición e insalubridad que vivían estas pequeñas víctimas de la guerra civil. Llama la atención una fotografía donde vemos una decena de niños semidescalzos que contrasta con otra imagen donde se les ve alegres y estrenando un nuevo calzado con el que poder jugar, las plantillas dibujadas por sus cuidadoras había dado sus frutos. Respecto al ADAU también encontramos fotografías sobre los campos de Pigné (2Fi818-819), Bram y Agde (21Dv2). Ambos fondos se encuentran digitalizados, pero al ser de origen privado no está permitida su reproducción o publicación sin el consentimiento de sus reales poseedores.

\section{Conclusiones}

Los estudios que incitan las fuentes presentadas en esta aportación están orientados a repensar la historiografía actual del Exilio desde un punto de vista socio-sanitario. Aunque es cierto que los archivos presentados son los más importantes, no debemos olvidar aquellos departamentos que fueron denominados de primera y segunda urgencia durante la Guerra Civil. Sería interesante ampliar nuestros horizontes hacia los mismos, permitiendo incluso la realización de estudios locales sobre la condición humana de los refugiados en los diferentes puntos de la geografía francesa. Para ello proponemos cuatro áreas de investigación, que juntas nos encaminarían a estudios integrales, siempre que las fuentes nos lo permitieran. Las áreas propuestas son: las condiciones de vida, los establecimientos asistenciales, los colectivos sanitarios y los organismos de ayuda internacional; tanto dentro como fuera de los campos de concentración.

21 Margali RIEU (dir): Enllà de la pàtria. Au-delà de la patrie. Exil et internement en Rousillon (1939-1948). Catalogue des sources iconographiques sur la Retirada et les camps, Perpignan, Trabucaire, 2011. 


\section{INTERSECCIONES ENTRE HISTORIA LOCAL,}

\section{HISTORIOGRAFIA Y NARRACIÓN MULTIDISCIPLINAR}

Òscar Montero Pich

Doctorando Universitat Autònoma de Barcelona- Cehic

La prisión Modelo de Barcelona abrió sus celdas en 1904, en el hoy conocido barrio barcelonés del Eixample, entre las calles Entença y Nicaragua. Su construcción estaba planificada desde la década de 1870 , después de una larga y sentida necesidad para dar respuesta a aumento delincuencial de la ciudad, que las instituciones catalanas vincularon al aumento de emigración.' La planificación de la Modelo de Barcelona, desde su arquitectura hasta su funcionamiento interno y la corrección de los delincuentes, fue encargada a un comité de expertos que basó su estudio en las prisiones más famosas de Europa. Entre estas observaciones se encontraban algunos de los parámetros del panóptico de Jeremy Bentham (1748-1832). ${ }^{2}$ No fue un hecho aislado. Según Foucault, la mayoría de construcciones penitenciarias de mitad del siglo XIX, concebían referencias al panóptico de Bentham. ${ }^{3}$

Tanto el panóptico de Bentham, como el informe técnico encargado de abrir la nueva prisión Modelo, nos hablan de una nueva forma de entender los espacios penitenciarios. Las nuevas construcciones incorporaron medidas como la individualización del preso según delito edad o crimen, su alfabetización o los mecanismos de corrección de aquellos presos clasificados como corregibles. ${ }^{4}$ La figura del preso cambió de status. Por un lado se humanizó su estancia, por el otro, se patologizó su comportamiento delictivo.

La nueva institución penitenciaria de Barcelona intentó llevar a cabo un programa científico promovido por reformistas y juristas penitenciarios que atacara de raíz la reincidencia, identificada como uno de los grandes problemas sociales. La reincidencia del preso afectaba a la productividad del país y manifestaba el fracaso penitenciario del preso y, por ende, su integración a la sociedad. Para solventar los problemas de productividad y de integración, la dirección de la Modelo delegó a los patronatos religiosos, como el de Sant Vicenç de Paul o la compañía de Jesús, la corrección moral del preso en un proceso de instrucción y educación moral. En ellos se pretendía formar e instruir al reo mediante la implementación de talleres de aprendizaje, como el taller de juguetes, de panadero o de alpargatería. Al mismo tiempo se ponía en práctica una escuela y una biblioteca, con el objetivo de paliar el analfabetismo de la

1 En la Revista Médica de Barcelona aparecen varios artículos relacionados con la preocupación de las instituciones científicas catalanas con el aumento de emigración e inmigración y de la delincuencia. Ver A. SALVAT NAVARRO: "El problema de los barrios de barracas insalubres en Barcelona", Revista Médica de Barcelona, 1-V-1, sesiones 13 y 21 de marzo de 1924, pp.471-473.

2 Fue diseñada por los arquitectos Salvador Vinyols i Josep Doménech i Estapé. Su construcción demoró 16 años. (1888-1904).

3 Michel FOUCAULT y Ma Jesús MIRANDA: “El ojo del poder" en: Jeremias BENTHAM, El Panóptico, Madrid, La Piqueta, 1979, p.11

Documento hallado en los archivos 31 i 34 del Arxiu Nacional de Catalunya (ANC), CPB-PM, inventario 236 . población reclusa. ${ }^{5}$ Por último, la corrección moral de todos los reclusos se examinaba a través de visitas semanales, realizadas por los socios del patronato de presos, tanto a los reclusos como a sus familiares, con el objetivo de escrutar su ideología y su moral. ${ }^{6}$

No obstante, no solo las órdenes religiosas estuvieron interesadas en la prospección moral del delincuente. Cabe destacar que a finales de los años veinte, se realizaron un conjunto de test experimentales entorno a la moral delincuencial dirigidos principalmente por Joaquim Fuster (1901-1983), en menor medida, supervisadas por Emili Mira (1896-1964). Aunque solo fueron estudios, el objetivo de los test era analizar la moral del delincuente para, posteriormente, clasificarla y tratarla. 7 Los test se realizaron entre 1929 i 1935, en un número de entre 100 a 360 delincuentes reincidentes voluntarios. Algunos, como el Qüestionari de Woodworth (1930), eran preguntas cerradas sobre diversos aspectos de su vida, dónde la normalidad o anormalidad dependía del número de respuestas correctas que los psicólogos consideraban en relación a las respuestas dadas por un grupo de afianzada moralidad. ${ }^{8}$ Otros eran test situacionales. En La prueba de Fernand-Jackobshon (1929) se les hacía poner en orden una serie de delitos, de menor a mayor gravedad, y en el de La prueba de penalizaciones (1931), el delincuente se encargaba de juzgar diversos casos delictivos, siendo su dictamen el objeto de estudio de los expertos. ${ }^{9}$

Probablemente, cuando se pregunta a historiadores de la ciencia sobre el marco dónde debería ubicarse esta normativización hecha al prisionero en la prisión Modelo, parece ineludible la referencia a Foucault, y al posestructuralismo..$^{10}$ Tanto la actuación de los patronatos religiosos en la corrección de los delincuentes, como la medición de la moral en los presos realizadas por Fuster, y Mira, parecen ejemplos suficientes que encajan a la perfección con la crítica que realizó el autor francés a la psiquiatría y a los mecanismos de poder. Así, conceptos como las estructuras de estado, la patologización de los prisioneros y su corrección, los regímenes de verdad o la subjetividad se entrelazan bien entre ellos, dando un calado profundo en el análisis del proceso de normativización. Esta historiografía, además, acentúa como la tecnología psicológica puesta en escena en la prisión Modelo de Barcelona, y el mismo conocimiento científico, no es neutral, ni está al margen de implicaciones políticas e ideológicas. Por tanto, no es de más decir que, ciertamente, la idea de relacionar una tesis sobre normativización del prisionero con la crítica social de Foucault o las subsiguientes matizaciones de posestructuralistas como Kurt Danziger o Nikolas Rose, no solo es ineludible, sino que parece adaptarse bien." El problema o la observación que me gustaría exponer, no tiene que ver con

5 Cajas 39 y 41, Archivo del Tribunal Superior de Justicia de Catalunya (ATSJC), Barcelona.

6 "Puntos esenciales y consideraciones sobre la importancia de la institución, que de hecho ya actúa, pero que se trata de organizar debidamente a fin de obtener el mayor rendimiento posible en su labor de regeneración de presos y libertos, mediante su cristianización y a materiales, ANC, fondo del Patronat de Ntra. Sra. de la Mercè, archivador 31.

7 La delincuencia y sus causas se convertían asi en uno de los temas relevantes de las ciencias sociales. Para saber más del tema: Rafael HUERTAS: Los laboratorios de la norma, Medicina y regulación social en el Estado liberal, Barcelona, Octaedro, 2008. Raquel ÁLVAREZ y Rafael HUERTAS: ¿Criminales o Locos?, Cuadernos Galileo de Historia de la Ciencia, $n^{\circ} 6$, Cehic, 1987. Ricardo CAMPOS MARIN "La psiquiatría en la ciudad: higiene mental y asistencia extramanicomial en España en la década de 1920", Frenia, Vol. IV, 2004

8 Joaquim FUSTER, "Resultats obtinguts en els delinqüents amb el qüestionari de Woodworth", Barcelona, 6é congrés de Metges i Biòlegs de llengua catalana, 1930.

9 Joaquim FUSTER: “Comentarios al empleo de la prueba de Fernald-Jackobshon en los delincuentes", Archivos de Neurobiología, Madrid, 1929. Joaquim FUSTER: “Contribución al estudio experimental de la psicología del delincuente. La prueba de la penalización de los delitos", Tesis doctoral Universidad Autónoma de Barcelona, 1931.

10 Michel FOUCAULT: Vigilar y Castigar, Madrid, Siglo XXI, 1986

11 Kurt DANZIGER: Constructing the Subject: Historical Origins of Psychological Research, Cambridge: 
la incorporación de las ideas de Foucault en este caso. Tiene que ver con la historia local, y en cómo la historiografía general y no comparada puede llegar a desvirtuar el marco histórico al que se refiere una tesis, si no se tiene el suficiente esmero en adaptarlas bien.

Dentro de la prisión Modelo de Barcelona, podemos observar, en un análisis más detallado, estos mecanismos de transformación del alma del delincuente. Sin duda alguna, podríamos observarlo en los diagnósticos de Fuster o bien en las evaluaciones de los visitadores de los patronatos religiosos, mecanismos que cierta historiografía ha llamado tecnología psicológica. ${ }^{22}$ No es objetivo de esta disertación valorar si estos mecanismos incorporados de la historiografía foucaultiana, son aptos para el estudio local. Tan solo persistiremos en señalar algunas de las críticas que ya señalaban algunos autores entorno al ensayo de Foucault. En primer lugar se ha señalado que Foucault deja poco espacio para las resistencias o que reduce el espacio creado por otros grupos minoritarios contra las prácticas y discursos dominantes. ${ }^{13}$ En este sentido, solo es posible responder a esta crítica desde la microhistoria.

Barcelona ha tenido una historia particularmente relacionada con el anarquismo. Desde la bomba del Liceu, ocurrida en 1896 hasta el estallido de la guerra civil, la vinculación de la ciudad con el anarquismo fue intensa, compleja y problemática. ${ }^{14}$ Aunque el movimiento anarquista nunca dejó de ser importante encontramos episodios quizás poco conocidos como el pistolerismo entre 1917 y 1923, la ilegalización de la CNT y su paso a la clandestinidad durante el régimen de Primo de Rivera (1923-1930) o la toma de carteras ministeriales en el gobierno de Largo Caballero en 1936. El movimiento anarquista supuso más que la incorporación de un mero sujeto reivindicativo, una alternativa real al poder burgués. Y como tal, la revolución del proletariado fue una amenaza real y sentida por las clases dirigentes. ${ }^{55}$ En este sentido, han salido estudios históricos recientes con un análisis más profundo del mundo anarquista, que señalan cómo el movimiento anarquista no era un ente pasivo, sino que construía su propio discurso, tanto en lo político como en lo social o en el sexual, y de acuerdo a esto, construyó también sus propias prácticas. ${ }^{16}$

Durante el período estudiado en la tesis (1904-1936), el registro de individuos clasificados como anarquistas en las cárceles catalanas fue regular. Pero especialmente copioso a parti de la ilegalización del sindicato anarquista por Primo de Rivera y la promulgación del código penal de 1928.17 Todas estas peculiaridades modifican esencialmente la adaptación de la tesis

Cambridge University Press, 1990. Nikolas ROSE: Governing the Soul: The Saphing of the Private Self, London, Routledge, 1990 .

12 Belén JIMENEZ ALONSO: La construcción psicosociológica de la subjetividad marginal en España de finales del siglo XIX y principios del XX. Tesis doctoral, Madrid, Universidad Nacional de Educación Distancia (UNED), 2010.

13 Nos referimos sobre todo a su obra Vigilary Castigar, Madrid, Siglo XXI Editores, 1986

14 Para saber más del tema: Eduardo GONZÁLEZ CALLEJA, Fernando DEL REY: "Violencia política y pistolerisme a la Catalunya de la primera posguerra mundial. Propostes d'analisi', L'Avenç, n' ${ }^{\circ} 192$, mayo 1995 Pp.34-45; Albert BALCELLS: Violencia social i poder politic: sis estudis sobre la Catalunya contemporánea, Barcelona, Ecsa, 2001; José Luis OYÓN, La quiebra de la ciudad popular: espacio urbano, inmigración y anarquismo en la Barcelona de entreguerras, 1914-1936, Barcelona, Serbal, 2008.

15 Ana Ma CERVERA: “Crisi de la política dinástica i radicalització de la dreta (1920-1930)", L’avenç, 186 (1994), pp.18-21.

6 Un análisis del discurso anarquista sobre sexualidad lo encontramos en: Richard CLEMINSON: Anarquismo y Sexualidad (España, 1900-1939), Universidad de Cádiz, 2008. También en el IV encuentro de jóvenes investigadores en historia contemporánea, celebrada en septiembre del pasado año, con mesas como: "Siembra, cosecha y agotamiento de los campos libertarios: los estudios sobre el anarquismo en el siglo XXI", València, 2013, (http://valencia2013.net/).

17 Asílo muestran los testimonios documentados de Ángel Pestaña (1886-1937) o de Joan Montseny Asilo muestran los testimonios documentados de Angel Pestaña (1886-1937), o de Joan Montseny zación de los test psicológicos, y las acciones de los visitadores religiosos. Obra del Patronato de al marco historiográfico de Foucault. Como algunos historiadores (Cleminson, Aisa...) han señalado, los anarquistas siguieron, incluso en prisión, discursos y prácticas propios diferentes a modelo dominante. En este sentido, es pertinente abrir un paréntesis para hacernos algunas preguntas: ¿cómo es y cómo se perfila esta tecnología científica frente a los grupos organizados en prisión? ¿Cómo cambian las relaciones entre los evaluadores y los delincuentes cuando tratan a prisioneros anarquistas? ¿Cambia el discurso empleado? ¿Cuáles son las condiciones con las que estos prisioneros anarquistas permanecen en prisión? ¿Se prestan voluntarios para acometer los test o las entrevistas con los religiosos? ¿Qué clase de poder tenían dentro de la prisión y que poder tenían fuera de ella?

El siguiente documento fotográfico, por ejemplo, muestra anarquistas posando en un ejercicio de nudismo.

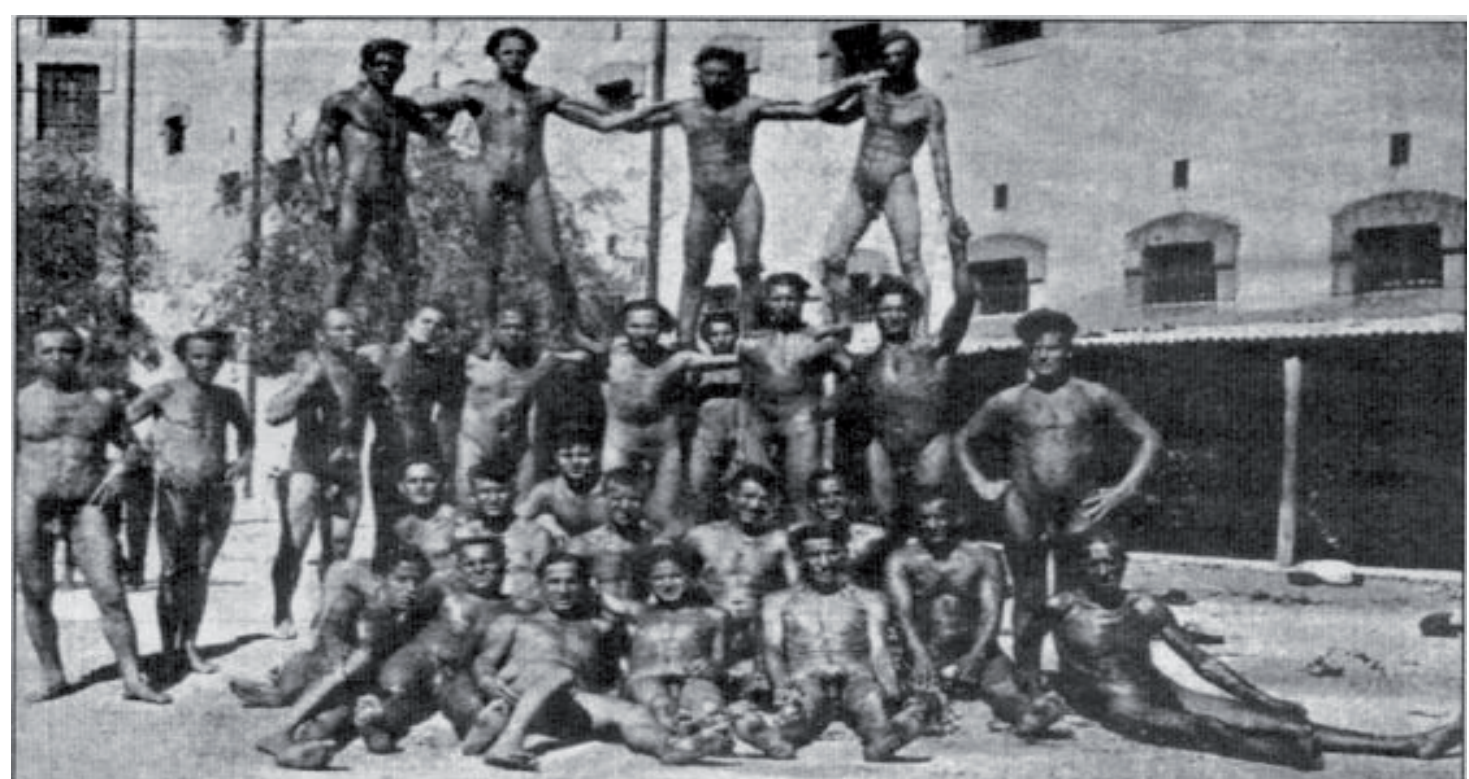

Img. 01 S.n. Grupo de prisioneros que practican nudismo en el patio de la prision Modelo de Barcelona, 1933. (Fuente): www.nod050.org/briega/?q=node/2030. La autoria de la foto se desconoce. La Web www.naturalismo.org/adn/ediciones/2003/invierno/html vincula el documento con la revista naturista Etica, que pasó a nombrarse Inicials (1929-1936). Ferran AISA, también apoya esta versión en su libro Cultura anarquista a Catalunya (2006) concretando en el mes de septiembre de 1933 la aparición de la foto en la revista Inicials.

La foto, anónima, está hecha en la prisión Modelo de Barcelona en 1933. Esta foto, junto con otros documentos y relatos de los propios prisioneros anarquistas, hacen replantearnos el discurso de Foucault en la Modelo de Barcelona o al menos, matizarlo: paradójicamente, el discurso de los denominados de resistencia está asentado y posee unas características muy propias que sólo se pueden visualizar estudiando la historia de la propia institución penitenciaria. Otro ejemplo que ejemplifica la resistencia activa de los prisioneros, son los documentos de los patronatos religiosos con dirigentes anarquistas. Es el caso de Joan Montseny (1864-1942). Montseny, secretario general de la Federación General de Obreros Toneleros, se le conocía por su faceta de escritor e impulsor de La revista blanca (1923-1936). En esta revista, el naturismo fue uno de los ejes que acabó desarrollando, sobre todo, su hija Federica Montseny (1905-1994). Es interesante constatar como entran en contacto el catolicismo conservador del Patronato de Presos, a través de sus visitadores, con un defensor de posturas anarco naturalistas como Joan Montseny, a través de la permuta de propaganda católica y anarquista. Las revistas, pasaron así

Presos Adultos bajo la advocación de Nuestra Señora de las Mercedes (1904 a 1931), ANC, CPB-PM inventari 236 , arxivador 31. 
a ser moneda de intercambio entre los dos bandos. Se trata por tanto de un escrutinio diferente al analizado por Foucault, porque aquí el prisionero no solo no es pasivo, también intenta razonar con su evaluador, intentando como mínimo, consensuar posiciones antagónicas. ${ }^{18}$

Volviendo al terreno del anarquismo, y según Cleminson, las ideas de naturalismo, vegetalismo, pacifismo o el nudismo, formarían parte de un contexto más amplio, no solo anarquista. El nudismo por ejemplo, formaría parte del marco europeo de la sexualidad. Consecuentemente, este discurso y prácticas diferentes al discurso del poder, señalaría cómo diferentes grupos asimilaban y reinterpretaban de manera colectiva, usando precisamente herramientas de otros colectivos. O bien dotan de otra significancia formas dominantes, en una especie de bricolaje. Este planteamiento, formulado por Michel de Certeau, permite trazar formas dominantes y series subordinadas, y ver como bajo la dominancia o la hegemonía de ciertas prácticas y discursos perviven un conjunto de prácticas dispersas. ${ }^{19}$

Otra de las críticas, precisamente de Certeau, a esta crítica estructuralista es por ejemplo el privilegio que Foucault da a los mecanismos que han organizado el funcionamiento de poder, eso es, la disciplina y el dispositivo de disciplina por encima del aparato que ejerce el poder. Otra vez las preguntas nos obligan a recurrir a la microhistoria de la prisión Modelo. ¿Quien dirigió la prisión?, ¿Tenía alguna ideología concreta? ¿Qué estructuras soportaba esta dirección? ¿Cómo afectaron los cambios políticos a la institución penitenciaria? ¿Ouiénes eran clasificados como presos de preferencia y quien dictaban estas clasificaciones? Como se ha mencionado anteriormente, encontramos períodos fuertemente violentos antes de 1936 como el quinquenio de 1917 a 1923 o los duros años de la represión primoriberista. Tanto las huelgas generales como la ilegalización de la CNT, son puntos de inflexión en el movimiento anarquista que lleva a muchos de ellos, como ya se ha dicho, a entrar en prisión. No obstante, muchos de ellos entraban con una orden de preferencia. Es el caso por ejemplo, del anarquista Joan Peiró (1887-1942), que en 1920 gozaba de un estatus de preferencia, con ventajas bastante notables frente a los restantes presos comunes o sociales, como cuatro horas de patio diarias en lugar de la media hora habitual, o una comunicación diaria en vez de una comunicación semanal..$^{2}$ Encontramos, incluso períodos (1936-1937) dónde un anarquista, Josep Vicente Sebastián, llegó a dirigir la prisión modelo de Barcelona, y dónde los visitadores, aunque con otros propósitos, visitaban a los miembros de derecha y religiosos. ${ }^{21}$ Es decir, todas estos mecanismos de poder, esta disciplina de la que habla Foucault se problematiza cuando se recurre a la microhistoria, sin la cual el ejercicio historiográico quedaría muy sesgado.

Otros discursos historiográficos: historia comparada, narrativa multidisciplinar y el debate centro/periferia

Hasta ahora se ha planteado, a partir de la crítica estructuralista o posestructuralista de Foucault, cómo cualquier matriz de la filosofía de la ciencia o marco historiográfico, puede quedar en entredicho si no se adapta al contexto local del objeto de estudio y a su propia reglamentación. ${ }^{22}$ Si bien no es nuevo el tema, y ha llovido mucho desde Foucault, encontramos

18 Archivos 31 i 34, ANC, CPB-PM, inventario 236

19 Michel De CERTAU: The practice of Everyday life, University of California Press, Los Angeles/London, Berkeley, 1984.

20 Oriol JUNOUERAS: “La presó model entre 1914-1936”, en Josep Ma SOLÉ i SABATÉ (ed): História de la Presó Model de Barcelona, Lleida, Pagès Editors, 2000.

21 Ibid p.149 y Rosario FONTOVA: La model de Barcelona. Históries de la presó, Barcelona, Generalitat de Catalunya, Departament de Justícia, 2010, p.78

22 Según wikipedia, Foucault rechazó las etiquetas de posestructuralista o postmoderno, definiéndose como crítica social de la modernidad con raíces en Kant. Recuperado de internet: (www. wikipedia/wiki/Michel_Foucault).

2ira/wiki/Michel_Foucault).

otras voces más actuales que cuestionan también los modelos usados de historia de la ciencia ante el localismo y la fragmentación. Uno de los colectivos que ha ejercido este tipo de críticas ha sido el grupo de historiadores centrados en el debate entre el centro y la periferia, entre los países anglosajones y el resto de países autodenominados periferia.

Algunos historiadores asociados a este movimiento, como Néstor Herran o Josep Simon, plantean el debate en diversas direcciones: ${ }^{23}$ en primer lugar, hacen una descripción y valoración de las críticas a una historiografía basada en la big picture. Y en cómo la necesidad de síntesis de gran alcance comporta muchas dificultades a la hora de establecer referentes, tanto temporales como geográficos. También exponen que, actualmente, ha habido un giro hacia lo local, asociado a una mayor sofisticación historiográfica que ha acabado fragmentando el contexto histórico y la misma disciplina histórica. Esta observación les sirve para exponer su preocupación principal, que es la supuesta falta de un marco general y bien definido. Esta exposición sirve a Herran y Simon para hablar de problemas comunes en ambas historiografías. Por ejemplo, del trabajo a nivel internacional, y en como la lengua determina el impacto de estos trabajos. Esto generaría los desequilibrios observados en cierta historiografía inglesa al desconocer otros trabajos de alcance internacional. En resumen, las grandes visiones de la ciencia pierden representatividad y los enfoques locales, ahora predominantes, raramente tienen contextos nacionales. Como solución, estos dos historiadores reivindican como programa historiográfico la historia comparada. Según los historiadores: "El análisis micro histórico es sólo útil si se integra con parámetros macro históricos y viceversa". ${ }^{24}$ Esta tarea de internacionalización, admiten, no es tarea fácil. Exige dominio de lenguas, de historiografías nacionales, de programas universitarios que promuevan estos intercambios y la participación en proyectos internacionales con colegas extranjeros. Aparte de dicha formación, una de las opciones que argumentan para poder hacer historia comparada y combatir la hegemonía de otros contextos productivos como el anglosajón, es el modelo de centro-periferia, que, actualmente, gira en torno al colectivo STEP.25

Aunque suscribo casi todas las reflexiones realizadas por estos dos historiadores, se plantean algunas dudas respecto a la historia comparada y la forma de llevarla a cabo. En prime lugar, la enseñanza de la historia y del marco historiográfico depende de las circunstancias históricas. Es lógico centrarse en esos episodios locales en contextos nacionales dónde han permanecido borrados. Por otro lado, ¿Qué es una historia comparada? ¿Acaso la historia de la prisión Modelo no es ya una historia comparada? En esta tesis, por ejemplo, se realiza un análisis local con actuaciones locales pero de ámbito internacional: en sus cimientos está Bentham la adaptación arquitectónica del Panóptico, el estudio de la criminalidad y el estudio del anarquismo, todos ellos tienen un carácter internacional. Es decir, esta microhistoria que refleja un microcosmos, tiene proyección transnacional. El problema no es creer que una historia comparada de cualquier hecho micro histórico es mucho más rica si se compara con parámetros macro históricos. Cierto es. El problema se plantea cuando se expone que solo se podrá hace con intercambios internacionales, con el dominio de lenguas y con la participación en proyectos internacionales. ¿Pueden abordar las universidades, los másteres y los doctorados este tipo de planteamientos? ¿Puede el estado o las instituciones o la filantropía hacerse cargo de las becas necesarias? Quien no pueda cumplir con esos requisitos deseados, ¿Podrá hacer historia comparada?

23 Néstor HERRAN y Josep SIMON: "Comunicar y comparar: la historia de la ciencia ante el localismo, la fragmentacion y la hegemonia cultural", Memoria y Sociedad, revista de historia, Bogotá, Vol.13, $n^{\circ} 27$, Universidad Javerina, julio-diciembre de 2009, pp.147-161.

24 lbid p. 150

25 Science and Technology in the European Perifhery, 2013, (http://step2012.phs.uoa.gr/index.html) 
Otro aspecto que plantean Herran y Simon, relacionándolo con la historiografía es el tema de la narrativa multidisciplinar. Ambos historiadores se preguntan cómo debe articularse la interacción de la historia de la ciencia con otras disciplinas, y afirman que los historiadores de la ciencia no han sido capaces todavía de dejar las narrativas monolíticas. Ciertamente es una cuestión todavía pendiente en la historia de la ciencia. Una historia multidisciplinar podría ser parte de la solución a la historia comparada que plantean. Los problemas que se plantean en esta narrativa van desde definir cuáles son las disciplinas que pueden ayudar a formar un contexto más rico y plural, hasta la propia formación del historiador. El hecho de relacionar diversas disciplinas transnacionales podría ayudar a introducir parámetros macro históricos. Sin embargo, con la narrativa humanistica, el historiador se ve obligado a saber más de más cosas. No sólo de historia de la medicina, sino de historia del arte en todas sus variedades; pintura, fotografía, cine, de literatura, mitología, religión o de cualquier otra disciplina que ayude a formar un marco más complejo para captar la complejidad de ciertos contextos y épocas.

Quisiera terminar este apartado, reflexionando sobre el movimiento STEP, en cuya génesis se encuentra el estudio de las transferencias internacionales y la apropiación local o el estudio de la ciencia colonial. Todas ellas son fruto de la reflexión sobre la comunicación. Sin embargo, pese a que la mayoría de sus miembros son originarios de los autodenominados contextos periféricos, solamente se admite la lengua inglesa como lengua vehicular en sus comunicaciones. ¿No es paradójico que, por un lado se critique la hegemonía y/o los enfoques de la ciencia anglosajona, y por otro lado el congreso se reduzca a la exposición y a la publicación de artículos en lengua inglesa? ¿No es contradictorio? La solución, como cabria de esperar, no es fácil, como tampoco lo es la construcción de una historia comparada ni la introducción de una narrativa multidisciplinar. 


\section{LOS LIBROS DE TEXTO DE QUÍMICA EN ESPAÑA \\ EN LA PRIMERA MITAD DEL SIGLO XIX: ESCRIBIR \\ COMUNICAR, NEGOCIAR, CONSTRUIR CIENCIA*}

María Rosa Muñoz Bello

Instituto de Historia de la Medicina y de la Ciencia "López Piñero"

(Universitat de València-CSIC)

\section{Introducción}

Los libros escolares se han convertido en los últimos años en un importante objeto de investigación. El estudio de los libros de texto suele realizarse desde perspectivas muy diversas desde la historia de la educación, del libro o de la lectura.' En historia de la educación, existen varios grandes proyectos nacionales con el fin de catalogar y estudiar los manuales escolares. En Francia, en la década de 1980 se inició un proyecto pionero realizado por el Departamento de Historia de la Educación del InstitutNationale de RecherchePédagogique (INRP). Como resultado de este proyecto se han creado dos bases de datos: Emmanuelle, que enumera la producción de libros de texto escolares franceses desde 1789 y Emmanuelle 5, que enumera y analiza las publicaciones científicas relacionadas con la investigación sobre los libros de texto. ${ }^{2}$ El proyecto Emmanuelle y las publicaciones del investigador A. Chopin se han convertido en obras de referencia en las últimas décadas. A partir de 1990 otras Universidades e instituciones inspirándose en este primer proyecto iniciaron el estudio de los manuales escolares.En España se ha de destacar el denominado proyecto MANES, desarrollado por el Departamento de Historia de la Educación y Educación Comparada de la Facultad de Educación de la Universidad Nacional de Educación a Distancia (UNED), con la pretensión de catalogar y estudiar los manuales escolares publicados en España, Portugal y Latinoamérica entre los años 1808 y 1990. A este proyecto se han sumado numerosas universidades, primero españolas y posteriormente de otros países. 3

En Historia de la ciencia, en los últimos años, ha habido un interés creciente en el estudio de los libros de texto. Estas investigaciones se encuadran dentro de los estudios de las prácticas de enseñanza. Dentro de éste área existe un número creciente de investigaciones dedicadas al estudio de los libros de texto desde diferentes puntos de vista. Los estudios realizados muestran la importancia de considerar el contexto cultural de la pedagogía de la ciencia. No se puede entender el carácter disciplinar de la ciencia moderna sin considerar el papel

* Este trabajo es parte del proyecto de tesis doctoral en Historia de la Ciencia "Los libros de texto de química en España, 1788-1845”y del Proyecto financiado por el MinisterioHUM2006-07206-CO3-02.

1 Una importante revisión de la evolución de la investigación sobre libros de texto en los últimos treinta años es realizada por Alain CHOPPIN: "História dos livros e das ediçoesdidáticas: sobre o estado da arte", Educ. Pesqui., . Sept./Dec. 30 (2004), pp.549-566, http://www.scielo.br/scielo. php?script=sci_arttext\&pid=S1517-97022004000300012\&lng=en\&nrm=isoúltima consulta realizada 26 junio 2013

2 http://www.inrp.fr/she/choppin_emmanuelle.htm última consulta realizada 21 enero 2014

3 http://www.uned.es/manesvirtual/portalmanes.htmlúltima consulta realizada 26 junio 2013. Sobre el proyecto MANES véase Miguel SOMOZA: “El 'Proyecto MANES' y la investigación sobre

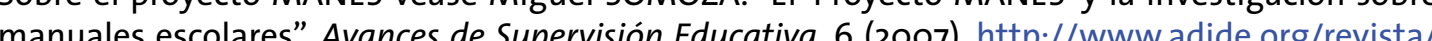
imang t6vVuzúltima consulta realizada 20 enero 2014 de la pedagogía de la ciencia. ${ }^{4}$ Las investigaciones desarrolladas han mostrado el interés que presentan los libros de texto como objeto de estudio en sí mismos. ${ }^{5}$ Tradicionalmente se ha considerado que la actividad científica no estaba relacionada con la escritura de los libros de texto. Los trabajos realizados han demostrado que la escritura de los libros de texto es inherente a la actividad científica. Son objetos de estudio en los que convergen diversos factores políticos, económicos, ideológicos y en su construcción intervienen diversos actores: autores, público, editores, gobiernos. ${ }^{6}$ Las investigaciones realizadas han mostrado que los libros de texto influyen en la configuración de las nuevas disciplinas. La aparición de los libros de texto es indicativa del nacimiento de una nueva disciplina pero además los primeros libros influyen en sus contenidos y métodos. Por tanto, el libro de texto puede servir para reflexionar sobre el desarrollo actual de una disciplina científica y su influencia sobre su desarrollo futuro. ${ }^{7}$ Los libros de texto pueden servir como herramientas de soporte, legitimización y justificación de los procesos científicos, constituyendo elementos clave para analizar los mecanismos por los que se adquieren las creencias sobre las diferentes ciencias. ${ }^{8}$ El libro de texto influye de diferentes maneras en diferentes públicos, científicos o no, a veces produciendo conocimiento especializado y en otras ocasiones contribuye a un conocimiento más general. Su estudio puede incrementar nuestros conocimientos sobre la diversidad de las ciencias en diferentes épocas y espacios. ${ }^{9}$ Los libros escolares pueden convertirse en herramientas esenciales para obtener el reconocimiento internacional lo que ayuda a reconsiderar las relaciones entre centro y periferia..$^{10}$ Es decir, los libros de texto son un elemento que facilita la integración de la ciencia en la cultura. El estudio de los libros de texto puede incrementar nuestros conocimientos sobre la diversidad de las ciencias en diferentes épocas y espacios.

4 Véase Kathryn M. OLESKO: “Science Pedagogy as a Category of Historical Analysis: Past, Present and Future", Science \& Education, 15 (2006), pp. 863-880; David KAISER: Drawing Theories Apart: and Future, Science \& Education, 15 (2006), pp. 863-880; David KAISER: Drawing Theories Apart: KAISER: Pedagogy and the practice of science: Historical and contemporary perspectives, Bavton MIT 2005. Andrew WARWICK Masters of theory: Cambridge and the rise of mathematical physics, Chica, sity Press, 2003.

5 Bernadette BENSAUDE-VINCENT y Anders LUNDGREN (eds.): Comunicating Chemistry: Textbooks and their Audiences, 1789-1939, Canton, History of Science Publication, 2000 y José Ramón BERTO$\mathrm{MEU}$, et al. [ed.]: Science textbooks in the European periphery: Science and education (special issue) 15 (2006), pp. 662-880.

6 Véanse los diversos estudios realizados por Bernadette BENSAUDE-VICENT, Antonio GARCIA BELMAR, José Ramón BERTOMEU: Antonio GARCIA BELMAR, José Ramón BERTOMEU y Bernadette BENSAUDE: “The Power of Didactic Writings: French Chemistry Textbooks of the Nineteenth-Century", en David KAISER (ed.): Pedagogy and the Practice of Science..., pp. 219-253; ID.: l'émergenced'une science des manuels. Les livres de chimie en France (1789-1852), Paris, Editions des Archives Contemporaines, 2003; Antonio GARCIA BELMAR y José Ramón BERTOMEU: “Atoms in French Chemistry Textbooks during the First Half of the Nineteenth Century: The Elémens de ChimieMédicale by MateuOrfila (1787-1853)", Nuncius, 19 (2004), pp. 77-119, y José Ramón BERTOMEU: “Llibres de text ipràctiquesd'ensenyament de la química (1700-1900). Part I: Manuals, disciplines escolars i protagonistes de la educacció científica. Part II: Manuals, disciplines escolars i protagonistes de la educacció científica", Educació Química, 3 (2009), pp. 37-46 y 4 (2009), pp. 4-12.

7 John NISBE: "Early Textbooks in Educational Research: the birth of a discipline", European Educational Research Journal, 1(2002), pp. 37-44, Georgette TAYLOR: "Marking Out a Disciplinary Common Ground: The Role of Chemical Pedagogy in Establishing the Doctrine of Affinity at the Heart of British Chemistry", Annals of Science, 65(2008), pp. 465-486.

8 Marga VICEDO: "Introduction: The Secret Lives of Textbooks", Isis, 103 (2012), pp. 83-87.

9 David KAISER: "A Tale of Two Textbooks: Experiments in Genre", Isis, 103 (2012), pp. 126-138.

10 Michael D. GORDIN: "Translating Textbooks: Russian, German, and the Language of Chemistry" Isis, 103 (2012), pp. 88-98. 
Teniendo en cuenta las aportaciones anteriores, el objetivo de este artículo es mostrar que el estudio de los libros de texto de química en España en la primera mitad del siglo XIX aporta información sobre el desarrollo cotidiano de la ciencia en un determinado contexto social y cultural. Los manuales de química son resultados de múltiples factores: la aparición de nuevas instituciones, el surgimiento de nuevos públicos, intereses ideológicos y económicos de determinados grupos o la adaptación a los programas oficiales. Su estudio permite avanzar en el conocimiento sobre la función que han tenido los libros como herramientas de soporte y legitimación y justificación de los procesos científicos. El estudio de los libros de texto liga la ciencia a la cultura en la que se producen y puede ayudar acomprender mejor los mecanismos de circulación de las ideas científicas.

\section{Libro de texto o libro de divulgación}

Parece ser que el término "textbook" aparece a principios del siglo XVIII pero adquiere el significado actual a finales del siglo XIX.Muchas investigaciones sobre los libros de texto comienzan con la constatación de la dificultad de su definición como objeto de estudio." A finales del siglo XVIII no es fácil distinguir entre un libro de texto, una enciclopedia o un libro popular de ciencia. ${ }^{2}$ Las fronteras que delimitan los diferentes géneros no son siempre claras y muchas veces son debidas a negociaciones entre autores y público pudiendo divergir de las expectativas de sus productores. Los libros de texto pueden ser textos científicos y otros pueden pasar de la popularización a las aulas. ${ }^{13}$ Mientras que en otras ocasiones los libros concebidos como obras didácticas se convierten en obras populares.14

Miguel López, médico vallisoletano, al ser nombrado catedrático de química en la Universidad, publicó en 1840 sus Lecciones elementales de fisica y química con el fin de "poner al alcance de todas las personas lo más importante de la Física y Ouímica". ${ }^{15}$ La obra no disfrutó de un gran éxito comercial y apenas fue conocida fuera del contexto local en la que se utilizó. Miguel López consideraba la formación científica básica para alcanzar el bienestar. Al igual que Miguel López otros profesores compartían sus ideas. José Luis Casaseca y Silván (1800-1869), profesor en el Real Conservatorio de Artes de Madrid, deseaba hacer accesible la química a un público mucho más amplio del que concurría a sus clases concretamente a una creciente clase media e incluso a las mujeres:

Popularizar la instrucción, propagando entre todas las clases de la sociedad, y más particularmente entre las que no tienen tiempo de dedicarse al estudio, los conocimientos positivos de toda especie que pueden recibir su aplicación en las diferentes posiciones de la vida del hombre, y que en la actualidad no debe ignorar la clase media.

Tomaremos por consiguiente de las ciencias físicas y matemáticas, de la química, de la economía doméstica, industrial y rural, aquellas nociones sencillas que pueda compren-

11 V., por ejemplo, la introducción de J.H. Brooke al libro de Bernadette BENSAUDE-VINCENT y Anders LUNDGREN (eds.): ComunicatingChemistry..., o la discusión, basada en diversas situaciones nacionales, ofrecida en la introducción de José Ramón BERTOMEU, et al. [ed.]: Science textbooks..., pp. $662-880$

12 Richard YEO: Encyclopaedic Visions: Scientific Dictionaries and Enlightenment Culture, Cambridge University Press, Cambridge, 2001 y Roger COOTER y Stephen PUMFREY:"Separate Spheres and Public Places: Reflections on the History of Science Popularization and Science in Popular Culture", History of Science, 32 (1994), pp. 237-267.

13 M. Susan LINDEE: “The American Career of Jane Marcet's Conversations on Chemistry", Isis, 82 (1991), pp. 8-23

14 KAISER, David. "A Tale of ..., pp. 126-138.

15 Miguel LÓPEZ: Lecciones elementales de física y química, Valladolid, Imprenta Nueva, 1840, advertencia del autor. der fácilmente todo el mundo, y pondremos su explicación al alcance del bello sexo; pues somos de opinión que las mujeres tienen el mismo derecho á la instrucción que los hom bres, y aun hallarán en esta obrita datos que deben interesarlas más particularmente. ${ }^{16}$

En 1826, para conseguir mejorar la instrucción en química, tradujo la obra de Fredrick Accum (1769-1838) Chemical Amusement, a Series of Curious and Instructive Experiments in Che mistry Which Are Easily Performed and Unattended by Danger (1817). ${ }^{7}$ Esta obra había sido concebida por Accum para mejorar el aprendizaje de los alumnos a través de la experimentación. También, de enero de 1831 a marzo de 1832, Casaseca publicó una serie de cuadernos periódicos dedicados a la divulgación científica y que se podrían considerar complementarios a su labor docente, El Propagador de Conocimientos Útiles, en los que incluía pequeños experimentos, algunos realizados por Accum que completaban la formación de sus alumnos.

La obra escrita por Miguel López no llegó a trascender de los límites del aula a pesar de las intenciones del autor. En cambio, la obra traducida por Casaseca, publicada con el título de Recreaciones químicas,,$^{18}$ pudo pasar a formar parte del material utilizado por sus alumnos de Conservatorio. Los libros de texto no siempre están alejados de otros públicos de la ciencia y obras de divulgación pueden acceder al interior del aula. Es difícil establecer las fronteras entre un libro de texto y una obra de popularización. El cambio de funciones de estas obras puede mostrar como se desarrolla el conocimiento científico y se produce la circulación de las ideas científicas.

\section{Nuevos espacios y nuevos personajes}

A finales del siglo XVIII se produjo un aumento considerable de instituciones relacionadas con la enseñanza de la química. Inicialmente la Corona española intentó mejorar la formación científica mediante la creación y financiación de varias instituciones: Cátedra de Química Aplicada a las Artes, Real Escuela de Mineralogía, Real Laboratorio de Química, Real Escuela Práctica de Química y Real Museo de Ciencias Naturales. Junto con la labor realizada por la Corona otras entidades también se interesaron por la enseñanza de la química, las Sociedades Económicas de Amigos del País y la Junta de Comercio de Barcelona. Con la financiación de las Sociedades Económicas se abrieron cátedras de química en varias ciudades españolas: Bergara, Zaragoza, Valencia o Granada. La Junta de Comercio de Barcelona costeó la apertura en esa ciudad de la cátedra de química en 1805 que estaría a cargo del farmacéutico Francisco Carbonell i Bravo (1768-1837).Por otro lado, en un primer momento la química estaba muy vinculada con la enseñanza de la farmacia y la medicina. A finales del siglo XVIII el aprendizaje

16 José Luis CASASECA: El Propagador de conocimientos útiles, o colección de datos interesantes aplicables a las necesidades y a los goces de todas las clases de la sociedad, puesto al alcance de todos, y sacados de los escritos y observaciones de los más célebres sabios extranjeros. Por Don José Luis Casaseca, Profesor de química aplicada a las artes en el Real Conservatorio de Madrid, Redactor corresponsal de varias corporaciones cientificas de Paris y de Londres, etc., Madrid, Imprenta de O.E. Alvarez, 1831, t. I, Introducción

17 La obra fue publicada por primera vez en 1817 y será objeto de múltiples ediciones y traducciones al francés, alemán e italiano. Casaseca utilizó para su traducción la cuarta edición de 1821

18 Fredrick ACCUM: Recreaciones quimicas que contienen una serie de experimentos curiosos é instructivos que pueden Recreaciones quimicas que contienen una serie de experimentos curiosos e instructivos que pueden ejecutarse con facilidad y sin el menor peligro. Obra adornada con láminas y con-
siderablemente aumentada, por .... Individuo de la Real Academia de Irlanda. Traducida del inglés al castellano de la cuarta edición de 1821 con notas por Don José Luis Casaseca, catedrático de quísica aplicada a las artes en el Real Conservatorio de artes de Madrid, licenciado en ciencias de la facultad de Paris, Redactor del Diario de Farmacia e Individuo corresponsal de la sociedad de Farmacia y de la de Paris, Redactor del Diario de Farmacia e Individuo corresponsal de la sociedad de Farmacia y de la sociedad Quimico-Médica de la misma capital, de la sociedad de Historia Natural de Mompeller (sic), de la sociedad de Fomen 
de la farmacia dejó de tener un carácter gremial y se crearon los Colegios de Farmacia en los cuáles la enseñanza de la química tenía un papel fundamental en los nuevos currículums. Los intentos de mejora de los estudios médicos llevaron a la creación de los Colegios de Medicina y Cirugía y la inclusión de la química en sus planes de estudio. A lo largo de la primera mitad de siglo XIX se realizaron diversas reformas educativas que supusieron la regularización de la enseñanza de la química dirigida a los artesanos con la aparición de los Conservatorios de Artes, la aparición de la enseñanza secundaria y las Facultades de Ciencia. El aumento de instituciones para la enseñanza de la química y de alumnos interesados en su aprendizaje provocó un aumento en la producción de libros. ${ }^{19}$ Así, en 1788 se creó el Real Laboratorio de Ouímica para el que fue nombrado catedrático Pedro Gutiérrez Bueno (1743-1822). Éste publicó sus apuntes con el título Curso de química, teórico y práctica, para la enseñanza del Real Laboratorio de Química de esta Corte:

Siendo imposible retener lo que se oye explicar una vez, y difícil remediar este inconveniente haciendo copiar los manuscritos, nos propusimos desde que se dio principio á la enseñanza pública de la química en el Real Laboratorio de esta Corte, formar y dar al público unos elementos de esta ciencia fundados en los últimos descubrimientos. ${ }^{20}$

No fue la única obra que Gutiérrez Bueno escribió dirigida a los alumnos de estas nuevas instituciones, en 1802 tras ser nombrado catedrático de química del nuevo Colegio de Cirugía de Madrid publicó su Curso de química, dividido en lecciones para la enseñanza del Real Colegio de San Carlos. ${ }^{21}$ Las obras que fueron publicadas se adaptaron a los nuevos alumnos dando lugar, incluso, a la aparición de un nuevo tipo de libros más interesados en la enseñanza práctica de la química bajo el título de Ouímica Aplicada a las Artes o a una formación más básica dirigida a los alumnos de la nueva enseñanza secundaria.. ${ }^{22}$ Así por ejemplo Francisco Carbonell Bravo, profesor de la cátedra de química de la Junta de Comercio de Barcelona tradujo la obra de A. Chaptal Química Aplicada a las Artes (1816-1821) y el responsable de la cátedra de química aplicada a las artes de Granada, Francisco de Paula Montells i Nadal (1813-1894) publicó su Curso elemental de Química Aplicada a las Artes (1840-45). Los nuevos profesores de química nombrados para ocupar las cátedras de los recién creados institutos de secundaria o de las nuevas facultades de Filosofía publicaron obras específicas más breves y "sencillas":

Cuando en 1842 emprendí la tarea de formar el pequeño trabajo que con el titulo de NOCIONES ELEMENTALES DE OUÍMICA hice para los alumnos de la clase de segundo año de Filosofía, no fijé otro objetivo que el de compendiar los rudimentos de esta interesante ciencia, de suyo árida y difícil, haciéndoles más sencillo ó menos repugnante su estudio. ${ }^{23}$

19 Rosa MUÑOZ: Los libros de texto de Química en España, 1788-1845, Trabajo de Investigación. Departamento de Historia de la Ciencia y Documentación, Universitat de València, 2005

20 Pedro GUTIERREZ BUENO: Curso de química, teórico y práctica, para la enseñanza del Real Laboratorio de Química de esta Corte, Madrid, Antonio Sancha, 1788, p. $^{*} 3$.

21 Sobre los libros utilizados en las instituciones de medicina y cirugía veáse José Ramón BERTOMEU y Antonio GARCíA BELMAR: "Los libros de texto de química destinados a estudiantes de medicina y cirugía en España (1788-1845)", Dynamis, 20 (2000), pp. 457-489.

22 Véase Antonio GARCIA BELMAR y José Ramón BERTOMEU: “Pedro Gutiérrez Bueno (1745-1822), los libros de texto y los nuevos públicos de la química en el último tercio del siglo XVIIII", Dynamis,21(2001), pp. 351-374.

23 Fernando SANTOS DE CASTRO: Nociones elementales de Química, $2^{\circ}$ ed., Sevilla, Francisco Alvárez, 1845 , advertencia del autor.
Las obras inicialmente publicadas eran mayoritariamente traducciones de autores franceses pero a mitad del siglo XIX surgieron autores españoles al amparo de las nuevas instituciones. Los primeros autores, como Gutiérrez Bueno o Carbonell i Bravo, eran personajes importantes dentro de la química en España, realizaron con la publicación de sus obras un esfuerzo para promover sus enfoques teóricos y prácticos específicos. Estuvieron en contacto con instituciones europeas y con los químicos más célebres. A finales de la primera mitad del siglo XIX, los autores eran jóvenes que en muchas ocasiones se encontraban en el inicio de su carrera docente, como Fernando Santos de Castro (1809-189o). Se trataba de jóvenes que se formaron en las instituciones en las que impartían clase para la que crearon sus obras. Muchos de ellos no llegaron a realizar brillantes carreras científicas, ni gozaron de renombre en el exterior. Estos jóvenes autores son personajes poco conocidos, en algunas ocasiones, casi anónimos. Se fueron convirtiendo en personajes desconocidos. A lo largo de la primera mitad del siglo XIX los autores de libros de texto de química adquieren un perfil característico más homogéneo que el que poseían a principios de siglo. Los grandes personajes de finales del siglo XVIII fueron convirtiéndose en personajes poco conocidos. ${ }^{24}$

\section{Controversias, negociaciones y adaptación}

Ante la falta de obras en castellano para la enseñanza de la química se inició una intensa labor de traducción de obras mayoritariamente escritas originalmente en francés. Los traduc tores realizaron una importante labor de adaptación de estas obras para satisfacer las necesidades y el gusto del nuevo público. 25 Pocos traductores realizaron una redacción de máxima fidelidad de la obra original. Debido a los rápidos avances de los conocimientos químicos en esta época se vieron obligados a constantes modificaciones añadiendo nuevos datos con notas a pie de página o apéndices al final. Uno de los mayores problemas con los que se encontraron los traductores fue la adaptación de voces técnicas de las cuáles no existía su equivalente en castellano. Melchor Guardia y Ardevol, describía la situación del siguiente modo:

Cualquiera que se dedique a traducir conocerá fácilmente la dificultad de traducir bien los libros de una ciencia en que apenas se halla ninguno escrito en nuestra lengua y que acaba de padecer una revolución en el lenguaje, lo que parece que me autorizaría alguna vez para introducir el nombre de alguna cosa que no le tenga entre nosotros, aunque creo que ya no llegará este caso, y también para merecer disculpa, pues en caso de errar, estos mismos errores serán un beneficio, pues serán como otros tantos escollos conocidos en que no se estrellarán los demás. ${ }^{26}$

En 1788 Pedro Gutiérrez Bueno tradujo, para ser empleada en sus clases, la nueva nomenclatura química que acababa de ser publicada en Paris. ${ }^{27}$ Tras la publicación de esta primera traducción surgieron numerosas propuestas de modificación lo que dio lugar a una gran va-

24 Rosa MUÑOZ: "Autores y traductores de libros de texto de química en España, 1788-1845", Actesd'Història de la Ciència i de la Tècnica, Nova època, 2 (2009), pp. 411-418.

25 José Ramón BERTOMEU y Rosa MUÑOZ: "Los avatares de la traducción científica: los manuales de química franceses en castellano (1788-1845)", en: Carlos DE MIGUEL, Carlos HERNÁNDEZ y Julia PINILLA (eds.): Enfoques de teoría, traducción y didáctica de la lengua francesa. Estudios dedicados a la profesora Brigittelépinette, PUV, 2010, pp.61-81.

26 Guyton de MORVEAU: Elementos de química teórica y práctica, puestos en nuevo orden, después de los más modernos descubrimientos, por mm...., individuos de la Academia de Dijon, y traducidos al castellano por Don Melchor Guardia y Ardevol, Madrid, Benito Cano, 1788, prólogo.

27 Método de la nueva nomenclatura química. Madrid: Sancha; 1788. p. V (Prólogo de Pedro Gutiérrez

Bueno). Existe una reimpresín reciente, con estudio introductorio de Ramón $\mathrm{Pago}$ en Madrid: Fundación Ciencias de la Salud, 1994 . 
riedad de opciones que se difundieron en los libros en esos años. ${ }^{28}$ Los problemas asociados con las "voces técnicas" junto con la calidad del lenguaje fueron algunos de las principales argumentos empleados por los censores para permitir la publicación de estas obras. ${ }^{29}$ Las discusiones sobre la calidad de la traducción o de la utilización "de un buen lenguaje químico" era incluso debatida en la prensa de la época ${ }^{30}$ y utilizado como reclamo publicitario, lo que indica un amplio público interesado por estas obras, mucho más extenso del que asistía a las clases.

La traducción será exâcta y concisa; se pondrán en ella algunas voces nuevas, tanto para significar cosas desconocidas hasta ahora, ya en España, ya en otros países, como para nombrar debidamente las que estaban mal denominadas entre los químicos. Se seguirá en quanto parezca bien indicado, la nomenclatura de Mr. Morveau, adoptada también por Mr. De Fourcroy; pero como esta es una obra elemental y la primera que en España da una idea exâcta de la ciencia química, se pondrá el mayor cuidado en servirse solamente de voces castizas, fáciles de pronunciar, que no puedan tomarse en sentidos diversos, y que no repugnen ni al genio de nuestra lengua ni al buen gusto. ${ }^{31}$

Esta diversidad terminológica estuvo acentuada por la constante renovación del vocabulario químico durante la primera mitad del siglo XIX, de modo que fue necesario realizar modificaciones y ampliaciones de las reglas establecidas a finales del siglo anterior. El mayor problema se encontró en los compuestos formados por los mismos elementos en proporciones diferentes, es el caso de los óxidos y las sales. Es importante recordar que, debido al uso del criterio de la composición para nombrar las sustancias, el nombre de los óxidos dependian de los nombres de las sales. Para solucionar este problema, se realizaron varias propuestas que fueron recogidas posteriormente en los manuales de química. Las más importantes fueron introducidas por Louis Proust (1754-1826), Thomas Thomson (1773-1852), Jacques Thenard (17771857) y Jacob Berzelius (1779-1848)..32

En la década de 1790, Louis Proust introdujo las expresiones latinas "ad maximum" y "ad minimum" para indicar la proporción de oxígeno en los compuestos del hierro. Aunque las ideas terminológicas de Proust aparecen en muchas obras de química españolas de las dos décadas siguientes, tuvieron poca relevancia.

En su famoso tratado System of Chemistry, Thomas Thomson para denominar los óxidos propuso emplear prefijos con la "primera sílaba de los numerales griegos", de modo que e "protoxide" sirviera para indicar el metal combinado con el mínimo de oxígeno, el "deutoxide" el siguiente con más oxígeno y así sucesivament hasta el "peroxide", que designaba al meta "completamente oxidado" (thoroughlyoxidised). 33 Las ideas de Thomson fueron conocidas en

28 José Ramón BERTOMEU y Rosa MUÑOZ: "Resistencias, novedades y negociaciones: la terminología química durante la primera mitad del siglo XIX", Dynamis, 30(2010), pp. 213-238; ID.: "Sulfureto siglo XIX", Revista de Investigación Lingüistica. KIL.13, (2010), pp. 275-302.

9 José Ramón BERTOMEU y Rosa MUÑOZ: "Traducción y censura: el manual de química de Jean-Antoine Chaptal (1756-1832)", Cuadernos del Instituto Historia de la Lengua, 3(2009), pp. 27-61.

o Sirvan como ejemplo los artículos publicados en MEMORIAL LITERARIO (1793), pp. 139-146 y Critica, Crónica Científica y Literaria, 116 (1818), p.1 Está firmado por A.O.

31 DIARIO DE MADRID, 57 (1788), 26 febrero, p. 225

32 José Ramón BERTOMEU y Rosa MUÑOZ: “Resistencias, novedades y negociaciones....", pp. 223-227.

33 Thomas THOMSON: A System of Chemistry, Edinburgh, Bell \& Bradfute; 1807 vol. 1 . 140 . Thomson seña ding to circumstances. The mode of naming them from their colour therefore, wants precision, and is apt to mislead;
España a través de la traducción del gran tratado de química de Jacques Thenard que fue una de las obras más influyentes de la primera mitad del siglo XIX. La obra fue rápidamente traducida para las lecciones impartidas en el Real Laboratorio de Madrid. 34 Se preparó una versión reducida y notablemente modificada del original, donde el traductor J. Acosta, ayudante del laboratorio, se apartaba bastante de la nomenclatura sugerida por el autor francés, la cual sustituía, en ocasiones, por propuestas anteriormente realizadas por Louis Proust. Las diferentes opciones tomadas por el traductor muestran el amplio margen que disponían los traductores para ayudar a difundir nuevas voces o contribuir a la persistencia de voces antiguas. Todo ello contribuyó a aumentar el número de sinónimos existentes para designar una sustancia. Por ejemplo, el profesor del Real laboratorio de química de Madrid, Juan Mieg (1780-1859), publicó en esos años unas lecciones, donde empleaba la expresión "oxîdulo" con la que designaba "en general un grado muy débil de oxidación", si bien reconocía que "en el día" se empleaban con este mismo fin "los nombres de oxîdead minimumóproto-oxîde". 35 La expresión "oxîdulo" era un diminutivo empleado en Francia y Alemania para designar los compuestos con menor proporción de oxígeno pero, como el propio Mieg señalaba, había quedado obsoleta cuando "los químicos han reconocido que algunas substancias metálicas son susceptibles de unirse con e oxîgeno en más de dos proporciones". ${ }^{36}$ Esta crítica era también aplicable a las propuestas de Louis Proust que sólo permitían nombrar dos óxidos formados por una sustancia con más ("ad máximum") o menos ("ad mínimum") oxígeno. Por ello, otro autor de manuales de esos años, Miguel Piñol sugería abandonar las expresiones de Proust y abrazar las nuevas propuestas de Thomson y Thenard. En sus comentarios se puede observar la diversidad de nombres de óxidos que debían manejar los químicos españoles en esos años:

para manifestar los grados de oxigenacion que reciben los cuerpos orgánicos e inorgánicos, los Ouímicos españoles se valen de las demostraciones propias del mismo idioma como es primer grado, segundo, tercero, cuarto, etc. y tambien de los nombres derivados del idioma latino ad minimum y ad maximum y las terminaciones en oso para la denominacion de los ácidos débiles; en ico para la de los ácidos mas oxigenados, y de sobre oxigenados para la de los ácidos con su mayor oxigenacion: los Químicos franceses se valen para determinar estos grados de oxigenacion de las terminaciones protóxidos, deutóxidos, tritóxidos, tetróxidos, etc. y al mayor grado de oxigenacion, peróxidos, derivados sin duda del idioma griego. ${ }^{37}$

Las nuevas denominaciones de Thomson y Thenard fueron difundidas a través de la traducción de la obra terminológica de Joseph Bienaimé Caventou (1795-1877), plenamente dedicada a presentar la nueva nomenclatura y las clasificaciones de Jacques Thenard, con una larga lista de sinónimos..$^{8}$

La llegada de estas nuevas propuestas no supuso la eliminación de las antiguas sino la multiplicación de sinónimos, dejando cierto margen para posibles errores y confusiones.

Language of Chemistry, London, Heinemann, 1962, p. 217

34 LECCIONES elementales de Quimica Teórica y Práctica, Madrid, Imprenta Real, 1816-1819.

35 Juan MIEG: Lecciones elementales de química para uso de los principiantes, Madrid, Catalina Piñuela, 1816, pp. 216-217.

36 Ibid., pp. 257-258.

37 Miguel PIÑOL: Elementos de física-química, Madrid, Villalpando, 1820, pp. 30-31. 38 Joseph Bienaimé CAVENTOU: Nueva nomenclatura química, según la clasificación adoptada por los que no están al corriente de los nombres nuevos, Madrid, Calle de la Greda, 1818.

\begin{abstract}
same metal having the same colour". Citado por Maurice P. CROSLAND: Historical Studies in the

.
\end{abstract}


A lo largo de la primera mitad del siglo XIX convivieron voces antiguas con propuestas novedosas muchas veces relacionadas con los intereses particulares del público destinatario o de diferentes comunidades profesionales. La sustitución de las voces antiguas resultaba complicado en el caso de la medicina y la farmacia, tanto por la existencia de una larga tradición de uso como por el hecho de que muchas de estas voces expresaban propiedades médicas o físicas, las cuales resultaban mucho más interesantes para médicos y boticarios que las cambiantes informaciones sobre la composición elemental de los compuestos. ${ }^{39}$ La nueva nomenclatura exigía un conocimiento amplio y actualizado de los avances de la química. La persistencia de las voces antiguas en los manuales escolares obliga a considerar los intereses de los distintos públicos receptores. Los libros de texto reflejan las diferentes estrategias seguidas por los traductores para satisfacer las expectativas del público destinatario.

La publicación de una nueva edición de las obras no siempre fue decisión únicamente del traductor. Los intereses comerciales asociados a la producción y circulación del libro condicionaron la actualización de algunas de estas obras. Juan Manual Munárriz (1761-1831)para actualizar la traducción realizada por Higinio Antonio Lorente de la obra de A. Chaptal Elementos de química (1802-1803) tuvo que optar por la publicación de un suplemento para no perjudicar los intereses de Lorente y un librero llamado Calleja. ${ }^{\circ}$ Lorente había vendido su obra al librero Calleja "con la expresa condición de no poderla reimprimir hasta que acabe de vender los ejemplares existentes". El suplemento se vendió "distribuido en 3 tomitos, para que pued[ier] an encuadernarse al fin de cada uno de los Elementos".4"

Las modificaciones que realizaron los traductores en sus obras y las distintas opciones que eligieron no siempre estuvieron determinadas por las necesidades de actualización o por la defensa de sus teorías, en ocasiones existieron también condicionantes económicos o profesionales.

\section{Libro de texto: objeto controlado, objeto de control}

A lo largo de la primera mitad del siglo XIX los libros de texto no eran controlados únicamente mediante la censura previa, surgió otro control ejercido por el gobierno a través de las listas de libros o la recomendación del libro único y la publicación de los programas oficiales. ${ }^{2}$ Durante este período de tiempo se sucedieron varios planes de estudios universitarios. ${ }^{43}$ Pero no sólo la enseñanza universitaria fue objeto de continuas reformas. Se realizaron varios intentos para promover la enseñanza de la química en los obreros y artesanos basándose en la retórica de la utilidad de la ciencia, en 1824 se creó el Real Conservatorio de Artes en Madrid y sus enseñanzas se ampliaron con la reforma educativa de 1833 a otras ciudades españolas. Se enseñaba mecánica, geometría, física y química que se consideraban más apropiadas para las clases bajas. El plan de estudios establecía la necesidad de prescindir de la parte puramen- te abstracta y abandonar las tentativas que pertenecían a la historia de la ciencia. ${ }^{44}$ Se debía realizar la exposición de los principios de estas ciencias con la indicación de sus aplicaciones. Prescribía la necesidad de "libros breves y claros; que contengan todo lo necesario, y nada más que lo necesario; libros que son harto difíciles de escribir. Tal vez la Inglaterra debe mucha parte de su riqueza á la multitud de libros breves, claros y sencillo que de largo tiempo han facilitado esta instrucción en aquel país." 45

Casaseca profesor en el Conservatorio de Madrid tradujo la obra de Eugène Desmarets (1787-1842), Compendio de química y de sus aplicaciones á las artes al considerarla la más apropiada, de acuerdo con las normas establecidas por el gobierno, eliminó las referencias históricas y se centró en las aplicaciones que resultaran de mayor utilidad en España:

Así pues el mejor libro para la enseñanza que está a mi cargo, seria un compendio breve de la ciencia, escrito con claridad, y despojado de toda la parte puramente histórica, as como de todos aquellos cuerpos que solo son curiosos: que manifestase los pormenores más interesantes de las aplicaciones, tratando brevemente de las que presenten menos ventaja en España, y extendiéndose circunstanciadamente sobre aquéllas que sean de una utilidad conocida. ${ }^{46}$

Casaseca era buen conocedor de las escuelas de artes de Inglaterra y consideraba que estas habían contribuido a mejorar los hábitos de los artesanos y obreros:

La esperiencia ha demostrado que la escuela de artes de Edimburgo ha contribuido á consolidar las virtudes de los unos librando al mismo tiempo á los otros de la seducción y del vicio. Se ha tenido ocasión de observar a los obreros dedican sus horas de descanso a estudio de las cuestiones abstractas de matemáticas y de química, que, por el contrario, suele disgustar á los estudiantes de las universidades. ${ }^{47}$

En cambio, Montells i Nadal, profesor de la cátedra de química del Conservatorio de Granadapublicó Curso elemental de Ouímica Aplicada a las Artes..$^{48}$ Incluía una seccióndedicada a la historia de la química y un mayor contenido teórico que la obra de Casaseca. En sus clases concurrían alumnos interesados en continuar posteriormente estudios universitarios, especialmente Medicina para los que era obligatorio los conocimientos previos de química. ${ }^{49}$

Las opciones tomadas por Casaseca y Montells no debian ser únicamente por las prescripciones del gobierno sino a la necesidad de adaptar los contenidos de sus obras a sus alumnos Pero es evidente que no existía uniformidad en la selección de estos contenidos.
39 Rosa MUÑOZ y José Ramón BERTOMEU: “La terminología química en los diccionarios de medicina y farmacia de la primera mitad del siglo XIX", en Graça RIO-TORTO (eds.): Léxico de la Ciencia: Tradición y Modernidad, Lincom Europa, LARB 3, 2012, pp. 237-251.

40 Ángel GONZÁLEZ: La Censura gubernativa en España 1800-1833 (1934), Madrid, Tipografía de Archivos, Olózaga, 1934, vol. I, pp. 107-109, que señala que se denegó la licencia el 11 de septiembre de 1800

41 GACETA DE MADRID, 116,18 de diciembre de 1801, pp. 1267-1269.

42 Más datos en Ángel GONZÁLEZ: La Censura gubernativa .... y José Ramón BERTOMEU: “La censura gubernativa de libros científicos durante el reinado de José I en España (1808-1813)", Hispania, 54 (1994), pp. 917-954 43 Pueden consultarse los diferentes planes de estudio que se aprueban a lo largo del período estudiado en http:// www. filosofia.org/mfa/index.htmúltima consulta 26 junio 2013. Sobre la Politica (1808-1833). Madrid, Consejo Superior de Investigaciones Científicas, C.S.I.C, 1970.
44 GACETA DE MADRID, 22 (1833), p.92 y GACETA DE MADRID, 23 (1833),pp. 97-98.

45 GACETA DE MADRID, 117 (1827), p. 467

46 José Luis CASASECA: Química. Compendio de esta ciencia y de sus aplicaciones a las artes, por Mr. Desmarest, antiguo alumno de la Escuela Politécnica: traducida del francés al castellano de orden de S.M., para servir de texto a los Alumnos del Real Conservatorio de artes, y arreglado a los conocimientos actuales en la ciencia, Madrid, Imprenta de D. León Amarita, 1828, t. I, p. 4.

47 José Luis CASASECA: "Escuela de artes de Edimburgo", El Propagador de conocimientos útiles..... Cuaderno 3, p. 187

48 Francisco MONTELLS: Curso elemental de química aplicada a las artes, Granada, Benavides, 1840-45.

49 El estudio sobre la Cátedra de Ouímica en el Conservatorio de Artes de Cranada en José M CAND "Las cátedras granadinas del Conservatorio de Artes (1833-1845)", Dynamis, 2 (2003), pp. 245-267. 
A mediados del siglo XIX comienza a diferenciarse un currículum más abstracto y teórico dirigido a los alumnos universitarios de otro más práctico dirigido a los artesanos que comienzan a configurar las estructuras de los libros ante la necesidad de los autores de adaptarse a los públicos destinatarios y a las normas dictadas por el gobierno.

\section{Conclusión}

Como hemos visto los libros de texto no siempre están alejados de otros públicos de la ciencia y obras de divulgación concebidas para un público general pueden acceder al interior del aula y tener múltiples lecturas como ocurrió con la obra de Casaseca Química recreativa. El cambio de funciones de estas obras puede mostrar mucho sobre el desarrollo científico y los mecanismos de circulación de las ideas científicas.Se trata de objetos "plásticos" que son moldeados por múltiples factores. La creación de nuevas instituciones de enseñanza de la química produjo una necesidad de nuevas obras. Así, la producción de manuales escolares aumentó a finales de la primera mitad del siglo XIX. Los autores de este tipo de obras adquirieron un perfil más homogéneo, se van convirtiendo en personajes desconocidos ignorados por la historia. Inicialmente la falta de obras produjo un aumento en el número de traducciones. Los libros de texto reflejan las diferentes estrategias seguidas por los traductores para complacer los intereses del público destinatario. Las modificaciones que realizaron los traductores en sus obras y las distintas opciones que eligieron no siempre estuvieron determinadas por la constante renovación de conocimientos científicos o por la defensa de sus teorías, en ocasiones existieron también condicionantes económicos, como es el caso de la actualización realizada por José Manuel Munárriz de la obra de Chaptal o por los intereses de determinados colectivos profesionales. Las páginas de los manuales escolares no albergan únicamente las ideas aceptadas por la comunidad científica. Son espacios de discusión y reflejo de las concepciones teóricas de sus autores. Las controversias mostradas en los libros de texto, no se limitan al público de las aulas, trascienden al público general a través de la prensa. Las diferentes opciones terminológicas adoptadas por los autores sirvieron de discusión en las páginas de los diarios de la época. A partir del estudio de los libros de texto se puede conocer no sólo el desarrollo de conceptos científicos, sino también acerca de las relaciones entre la ciencia, el Estado y la sociedad. Los contenidos de los libros no sólo son determinados por el Estado, también los autores toman sus decisiones en la selección de los contenidos y los adaptan al público destinatario. Para el historiador de la ciencia son fuentes esenciales para indagar sobre el desarrollo cotidiano de la ciencia en su contexto social y cultural. Lo que ocurre dentro de las aulas está relacionado con lo que sucede fuera de ellas. El conocimiento de las múltiples funciones desarrolladas por los manuales escolares puede aportarnos nuevos enfoques sobre los mecanismos de circulación de las ideas científicas. Los libros de texto aún tienen muchos aspectos que mostrar a los historiadores. 


\section{FINANCIANDO LA CIENCIA EN EL SIGLO XIX:}

\section{EL CASO DEL INSTITUTO PROVINCIAL DE VALENCIA}

\section{6-1902}

Carles Sirera Miralles

Universitat de València

\section{Introducción}

La presente comunicación describe con detalle el sistema de financiación de la enseñanza media desde su creación en 1845 hasta 1902 con el propósito de estimar la cuantía de dinero público invertido en instrumental científico y qué prioridad suponía esta partida dentro del sistema educativo, así como la importancia social de éste en su totalidad. Por esta razón, además de hacer una radiografía del marco legislativo y sus consiguientes reformas, realizaremos un estudio de caso centrado en el instituto provincial de Valencia para determinar los fondos disponibles empleados para sostener los gabinetes científicos. A este respecto, el establecimiento de enseñanza media también es relevante porque sus gabinetes científicos han sido objeto de estudio' y puede servir como modelo para futuras investigaciones.

\section{El marco legislativo}

El Plan Pidal de 1845 y su posterior reglamento de 8 de julio de 1847 establecieron que los institutos provinciales se sufragarian mediante las rentas generadas por los bienes de las instituciones religiosas dedicadas a la enseñanza incorporados tras el proceso desamortizador las asignaciones que las diputaciones provinciales o los municipios estimasen oportuno, los fondos que el Gobierno decidiese asignar y, finalmente, gracias a las tasas de matrícula y de expedición de títulos.

Por lo tanto, a pesar del deseo centralizador de los moderados, el sistema surgió aceptando la pluralidad de escenarios y situaciones que de facto se habían producido desde el final del reinado de Fernando VII, cuando muchos municipios habían fundado centros educativos partiendo de la iniciativa local y los habían dotado con los bienes y rentas de antiguas corporaciones educativas clausuradas o extintas. En consecuencia, dependiendo de los bienes disponibles en cada provincia y de la actitud de las autoridades políticas del lugar, se habían erigido establecimientos públicos con grandes diferencias de recursos económicos, situación que se alargaría hasta 1887, año en el que se optaría por la centralización homogenizadora.

Del mismo modo, las disposiciones públicas sólo indicaron un número mínimo de materiales imprescindibles para la enseñanza sin entrar en grandes detalles o especificaciones, descargando en los políticos locales la responsabilidad de dotar adecuadamente los nuevos centros educativos. El Reglamento para la ejecución del Plan de Estudios decretado por S. M. en 8 de julio de 1847 dictaba que:

1 José Ramón bertomeu et al.: "Las colecciones de instrumentos científicos de los institutos de en(2011) pp. 167-193.
Art. 110. Los institutos de segunda enseñanza y Facultades de filosofía tendrán ademas: $1^{\circ}$. Los instrumentos de matematicas necesarios para la enseñanza de esta ciencia, como igualmente una colección de sólidos para las demostraciones de geometría.

$2^{\circ}$. Los globos, mapas y demas que requiere la enseñanza de geografía.

$3^{\circ}$. Los cuadros sinópticos que faciliten el estudio de la historia.

$4^{\circ}$. Teodolitos, planchetas y otros instrumentos necesarios para el alzado de planos y demas operaciones de la geometría práctica.

$5^{\circ}$. Un gabinete de física con todos los aparatos que exige la enseñanza elemental de esta ciencia.

$6^{\circ}$. Un laboratorio de química con los aparatos y reactivos necesarios.

$7^{\circ}$. Un patio donde se puedan hacer las operaciones químicas que exigen el aire libre.

$8^{\circ}$. Una coleccion clasificada de mineralogia.

$9^{\circ}$. Otra coleccion de zoología en que existan al menos las principales especies, y láminas que representen los diferentes seres de la naturaleza y cuyo conocimiento convenga dar á los alumnos.

$10^{\circ}$. Un jardin botánico y un herbario dispuesto metódicamente. ${ }^{2}$

Como es evidente, el grado de cumplimiento de estas exigencias variaría de acorde con los recursos disponibles y la voluntad política, pero, como mínimo, los institutos agregados a una universidad por estar radicados en la capital de un distrito universitario, como el de Valencia, podían compartir sus colecciones científicas. Esto, sin embargo, suponía también un problema, porque el Plan Pidal no reconoció autonomía administrativa a los institutos agregados a universidad y, en consecuencia, carecían tanto de bienes propios como de la capacidad o libertad de adquirir los que estimasen necesarios.

En este mismo sentido, debe destacarse que el Plan Pidal marcaba unos objetivos mínimos de materiales y colecciones, pero no especificaba cómo debían invertirse los ingresos generados por las rentas y las matrículas. Es lógico suponer que la partida de gasto prioritaria serían las nóminas de los profesores y después irían las del personal subalterno, si bien una vez satisfechas estas necesidades no era posible saber qué pagos debían atenderse ni cómo debía invertirse el remanente. De hecho, tampoco estaba claro quién tomaría esas decisiones, ya que de la lectura de las normativas legales se podía deducir que era una decisión discrecional del director o consensuada por el claustro. Por otra parte, esta clase de problemas tenía un carácter secundario ante las posibles resistencias de las diputaciones provinciales a asigna fondos a los institutos, ya que el Plan Pidal no les obligaba propiamente a ello. En definitiva, si en algunos municipios lograr el pago de las nóminas podía ser una tarea política titánica, lograr partidas presupuestarias para el material científico sería una entelequia.

Por todo esto, la Ley Moyano de 1857 y, especialmente, su Reglamento de 1859 prestaron una atención preferente al régimen económico de los institutos. En primer lugar, concedieron a todos los institutos provinciales autonomía administrativa al conferirles una secretaría completamente independiente de la universidad. Asimismo, se decretaron normas claras para garantizar la transparencia en la gestión de los bienes propios de los establecimientos, que debían ser arrendados mediante subasta pública. De igual modo, se decretó que las diputaciones provinciales cubrirían el déficit resultante de los gastos e ingresos propios y que éstas tendrían libertad para sufragar los Estudios de Aplicación (enseñanzas técnicas) que considerasen oportuno ofertar en los institutos. Finalmente, el Gobierno aprobaría partidas presupuestarias adicionales para la dotación de bibliotecas e instrumental científico de los institutos.

2 Reglamento para la ejecución del Plan de Estudios decretado por S. M. en 8 de julio de 1847, Madrid, Imprenta Nacional, 1847, pp. 31-32. 
No obstante, esta mayor claridad burocrática tampoco significaba igualar los recursos de los centros, porque las fuentes principales de ingreso eran las matrículas y derechos de expedición de títulos, más los bienes propios. En teoría, desde la reforma del plan de estudios de 1861, un estudiante que cursara el bachillerato en un instituto público aprobando todos los exámenes y solicitase sus títulos académicos hacía un desembolso aproximado de unos 1.000 reales (250 ptas). El problema es que el número de alumnos inscritos variaba extraordinariamente de una ciudad a otra. A modo de ejemplo:

\begin{tabular}{|c|c|c|c|c|c|c|}
\hline & $1859-71$ & $1859-68$ & $1859-75$ & $1872-80$ & $1859-77$ & $1859-1901$ \\
\hline CÁCERES & 133 & -- & -- & -- & -- & -- \\
\hline LOGROÑO & -- & 252 & -- & -- & -- & -- \\
\hline GIRONA & -- & -- & 97 & -- & -- & -- \\
\hline MALLORCA & -- & -- & -- & 389 & -- & -- \\
\hline MADRID-NOVICIADO & -- & -- & -- & -- & 2.203 & -- \\
\hline MADRID-SAN ISIDRO & -- & -- & -- & -- & -- & 2.169 \\
\hline CIUDAD REAL & -- & -- & -- & -- & -- & 264 \\
\hline BADAJOZ & -- & -- & -- & -- & -- & 143 \\
\hline PALENCIA & -- & -- & -- & -- & -- & 337 \\
\hline SALAMANCA & -- & -- & -- & -- & -- & 447 \\
\hline CASTELLÓN & -- & -- & -- & -- & -- & 284 \\
\hline ALICANTE & -- & -- & -- & -- & -- & 675 \\
\hline VALENCIA & 1.354 & 1.311 & 1.330 & 1.575 & 1.356 & 1.686 \\
\hline
\end{tabular}

Cuad. 01 Media de alumnos matriculados en institutos estudiados 1859-1901. FUENTE: Memorias del Instituto Provincial ${ }^{3}$

Emilia domínguez rodríguez: Cáceres y la enseñanza secundaria (1822-1869), Salamanca, Kadmos, 1991, pág. 157.

Forencio ramírez ochagavia: Instituto Sagasta de Logroño, 25 años de historia (1843-1868), Logroño, Ochoa, 2001, pág. 49

Felicidad sánchez pascua: El Instituto de Segunda Enseñanza de Badajoz en el siglo XIX, Badajoz, Diputación Provincial de Badajoz, 1985, pág. 75.

Ángel jara barreiro: La Segunda enseñanza en la Mancha: el instituto de Ciudad Real: 1837-1967, Ciudad Real, Diputación de Ciudad Real, 2001, pág. 210.

A. colom cañellas: Assaig d'Història de l'Educació a la Mallorca contemporània, Palma, Servei de Publicacions i intercanvi Científic de la Universitat de les Illes Balears, 1991, pág. 251.

José María herández díaz: “Los alumnos de segunda enseñanza en el siglo XIX”, Historia de la educación, 5 (1986) pp. 251-273.

Joan olóriz serra: Política i educació: ensenyament de Girona, 1845-1900, Tesis Doctoral, Girona,

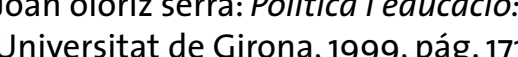

Alfonso navarro jurado: Historia del Instituto de Segunda Enseñanza San Isidro de Madrid (18451936), Tesis Doctoral, Madrid, Universidad Complutense de Madrid, 1991.

Carmen rodríguez guerrero. El Instituto de Segunda enseñanza del Noviciado de Madrid de 1845 1877, Tesis Doctoral, Madrid, UNED, 2004, pág. 400

$M^{\mathrm{a}}$ Concepción álvarez

1901), Palencia, Diputación Provincial de Palencia, 1997, pp. 134-176. Doctoral, Valencia, Universitat de Valencia, 1993, pág. 180.

M. Ángel esteve gonzález: La enseñanza en Alicante durante el siglo XIX, Alicante, Instituto de Cultura Juan Gil-Albert, 1991.
Por otra parte, el monto total también dependía de si cursaban enseñanza oficial o privada, porque, en el siglo XIX, los estudiantes de colegios privados debían financiar la enseñanza pública, en vez de cómo ocurre en el siglo XXI, que usamos dinero público para financiar centros privados. Los estudiantes de enseñanza privada pagaban el $50 \%$ de las tasas de matrícula y como sólo podían examinarse ante los catedráticos del instituto provincial, debían abonar los derechos de examen, así como los costes de la expedición de títulos. Esto significaba que estos estudiantes aportaban ingresos, si bien no suponían un gasto en costes de material, mantenimiento del edificio e incluso nóminas de profesores auxiliares.

Por esta razón, cuando Manuel Orovio accedió en 1866 al ministerio de Fomento en representación de los neocatólicos decretó una reforma de la enseñanza media que concedió exención de tasas a los inscritos en enseñanza privada o doméstica. Además, se reformaron las planes de estudio para desterrar las matemáticas y se equiparó a los seminarios conciliares con los institutos provinciales con el propósito de, en el medio plazo, propiciar la quiebra económica de los institutos públicos y sus sustitución por los seminarios. ${ }^{4}$ Estas medidas, sin embargo, sólo estuvieron vigentes dos cursos, porque la Revolución Gloriosa de 1868 supuso su inmediata derogación. Por otra parte, el decreto de 29 de septiembre de 1874 simplificó el sistema de pagos de tasas al estipular que cada asignatura tendría un importe de matrícula de 8 ptas. que, añadidas a las 5 ptas. por derechos de examen, daría unas 13 ptas. por las 12 asignaturas del plan de estudios con latín que pervivió hasta 1880, una cantidad que sumada al resto de derechos ascendía a un total de 238 ptas. por alumno y estudios completados de tal forma que incluso se debía producir una pequeña reducción en los ingresos en beneficio de los estudiantes.

Este esquema se modificó en 1877 , cuando el conde Toreno aprobó sus decretos de de 6 de julio, 10 de agosto y 15 de agosto que impusieron un gravamen extra de 5 ptas. a las tasas de matrícula, si bien los derechos de examen se redujeron de 5 ptas. a 2' 5 ptas. Esto supuso elevar el coste total de completar el Bachillerato a 300 ptas., un incremento del $26 \%$ respecto de 1874 aunque el gravamen de 5 ptas. se justificó como una necesidad para mejorar los equipamientos de los establecimientos públicos y para crear un sistema de becas, porque un $25 \%$ del tota recaudado se destinaría a la compra de materiales científicos y otro $25 \%$ a dotar las pensiones económicas que recibirían los alumnos faltos de recursos con mejores calificaciones. Un recargo adicional que debían pagar tanto los estudiantes matriculados en los institutos provinciales como aquellos que cursaban enseñanzas privadas y que, por tanto, redundaba en beneficio directo de los centros públicos. Por lo tanto, estas nuevas medidas vinculaban de forma directa el abono de tasas con la inversión en compra de instrumentos científicos y becas para garantizar que estos objetivos tuviesen un mínimo de recursos para su atención.

Sin embargo, la Ley de Presupuestos de 30 de junio de 1887 dispuso en su artículo 7 que los institutos de enseñanza media pasaran, así como las rentas que generaban y los sueldos de los profesores, a depender completamente del Estado en detrimento de las diputaciones provinciales. Esto significó que el Estado pasó a detentar la propiedad de los patrimonios que habían heredado los institutos de las extintas corporaciones religiosas y a gestionar sus rentas, si bien dejó a las diputaciones como titulares de los edificios para no asumir los costes derivados de su mantenimiento, mientras que también ingresaba directamente los derechos académicos, excepto los derechos de examen, a cambio de remitir a los directores cartas de pago mensuales que cubrían los honorarios del profesorado. Estas cantidades se descontaban de los pagos en impuestos que recolectaban las diputaciones para el Gobierno, que, a su vez debían cubrir el déficit que los establecimientos educativos generasen.

Finalmente, el artículo 27 de la Ley de presupuestos de 30 de junio de 1890 dispuso la venta en pública subasta de todos los bienes incorporados y su posterior reconversión en títulos de

4 Carles sirera miralles: "Neocatolicismo y darwinismo en las aulas: el caso del instituto provincial de Valencia”, Ayer, 81 (2011) pp. 241-262. 
deuda pública, cuyos intereses serían asignados a los institutos respectivos. De este modo, se esperaba evitar que en un futuro los supuestos herederos de los bienes desamortizados los reclamasen con éxito ante unos tribunales que, en el contexto de reconciliación con los sectores agraviados por las revoluciones liberales que primó en los primero años de la Restauración, podían mostrarse receptivos a estas demandas.

Por lo tanto, fue en 1890 cuando se ultimó el proceso de centralización económica definitiva de los institutos provinciales. A partir de ese año, el Gobierno asignaría partidas fijas de presupuesto y los centros no gestionarían ni recolectarian sus propios fondos. En teoría, debía garantizarse un empleo más fiable de esos recursos y compensar las diferencias económicas entre los institutos provinciales. Sin embargo, las consecuencias reales de esas medidas se estudiarán al analizar el caso de Valencia.

\section{La gestión administrativa del instituto provincial de Valencia}

El Reglamento de 1859 significó el nacimiento del instituto provincial de Valencia como una entidad administrativa independiente de la universidad al dotarlo de secretaría y archivo propios. No obstante, este centro nació sin recursos, porque los bienes de las extintas corporaciones educativas habían pasado al Real Colegio de San Pablo. En consecuencia, el instituto de Valencia compartía sede física con la universidad y se veía en la "necesidad de ir trasformando sucesivamente un reducido almacén de la Universidad en una especie de gabinete, que si no tiene todas las condiciones que son de desear, contendrá al menos con desahogo y alguna regularidad cuanto vamos adquiriendo".5

La única fuente de ingresos eran las aportaciones de los alumnos inscritos más una subvención de 6.000 reales ( 1.500 ptas.) para la compra de materiales, percibidos directamente del Gobierno de la Nación por tratarse de un instituto anexo a una universidad, aunque los 54.965 reales consignados para el curso $1859-60$ bastaron para satisfacer todos los gastos ${ }^{6} \mathrm{y}$, a partir de 1861 , el aumento de estudiantes, más una nueva dotación de 20.000 reales proveniente de la diputación para atender las necesidades de los nuevos estudios de aplicación elevó el presupuesto a 105.533 reales (26.383 ptas.).7 Desgraciadamente, las reformas de Orovio que declararon exentos de tasas a los estudiantes de enseñanza privada y doméstica supusieron una pérdida de más de 30.000 reales, ${ }^{8}$ que se sumó a la decisión del Estado de negarse a conceder ninguna subvención a los centros incorporados a las universidades para dejarlos completamente en manos de las diputaciones. Unas medidas que, como ya hemos señalado, buscaban la asfixia económica de los institutos para favorecer su desmantelamiento.

Por el contrario, la derogación de las disposiciones de Orovio por Ruiz Zorrilla en 1868 supuso un incremento del $43 \%$ en la entrada por derechos de matrícula. ${ }^{9}$ Pero, más significativo, fue la incorporación forzosa del Real Colegio de San Pablo decretada por la Junta Revolucionaria. A raíz de esta medida, en 1868 el instituto pasó de no tener un emplazamiento fijo a ocupar un edifico valorado en 332.500 ptas. y poseer el de Na-Monforta, situado en la calle Barcas, y es-

5 Memorias del instituto provincial de 2. ${ }^{a}$ enseñanza. Curso de1863 á1864, Valencia, Imprenta de José Rius, 1864, pág. 11

Memorias del instituto provincial de 2. ${ }^{a}$ enseñanza. Curso de1859 á 1860, Valencia, Imprenta de José Rius, 1861 .

7 Memorias del instituto provincial de 2. ${ }^{a}$ enseñanza. Curso de1860 á 1861, Valencia, Imprenta de José Rius, 1862 .

8 Memorias del instituto provincial de 2. ${ }^{a}$ enseñanza. Curso de1867 á 1868, Valencia, Imprenta de José Rius, 1868, pág. 18.

9 Memorias del instituto provincial de 2. ${ }^{a}$ enseñanza. Curso de1892 á 1893, Valencia, Imprenta de José Rius, 1893 , Cuadro $n^{\circ} 21$. timado en 85.000 ptas. $^{10}$ Asimismo, recibió el conjunto de propiedades del antiguo el colegio, cuyo valor total de los títulos de deuda pública era de $681.656^{\prime} 61$ ptas. que devengaban unos intereses de poco más de 17.000 ptas. Anuales." Estas cantidades sumadas a las rentas de los bienes rústicos supusieron un aumento medio anual de los ingresos de 20.000 ptas. para el periodo 1868-188o. Esto, junto a la derogación de las medidas de Orovio y el destacado papel que tomó la diputación en la extensión de los estudios prácticos durante el Sexenio, hizo que en el curso $1868-69$ el presupuesto del instituto se incrementase de 52.666 ptas. a 109.245 '5 ptas., ${ }^{12}$ un alza de más del $100 \%$. El total de bienes recibidos del Real Colegio de San Pablo se detalla en el siguiente cuadro:

\begin{tabular}{|c|c|}
\hline PATRIMONIO & VALOR EN PTAS \\
\hline FINCAS URBANAS Y RÚSTICAS & $607.344,81$ \\
\hline DEUDA PÚBLICA DEL ESTADO & $647.868,38$ \\
\hline MOBILIARIO INSTITUTO & $31.365,77$ \\
\hline MOBILIARIO NA-MONFORTA & $2.406,81$ \\
\hline TOTAL & $\mathbf{1 . 2 8 8 . 9 8 5 , 7 7}$ \\
\hline
\end{tabular}

Cuad. o2 Inventario de bienes del real colegio de san pablo 1872. FUENTE: AHILLV Inventario 18731881 ESAISLVV $n^{\circ} 111$

La Revolución Gloriosa supuso pasar en pocos años de una estrechez paralizante a una notoria abundancia que permitió la creación de la Escuela Industrial de Artesanos, así como sostener una escuela de enseñanza primaria anexa al instituto, donde unos 200 niños recibían instrucción completamente gratuita, además de ofertar los peritajes mecánico, químico y agrícola o los estudios de náutica. Igualmente, a partir de 1877 , gracias a los decretos de Toreno, se pudo contar con fondos adicionales. Entre 1878 y 1887 , veintisiete jóvenes se beneficiaron de pensiones otorgadas por el instituto y a tal fin se destinaron 24.247 ptas., aunque los profesores hubiesen podido dedicar un monto total de 41.800 ptas. el $25 \%$ del total recaudado por derechos académicos. Sin embargo, prefirieron gastar esa diferencia en la compra de materia científico, porque consideraban que no había suficientes jóvenes merecedores de estas ayudas. Por otra parte, en estos mismos años el claustro hizo un desembolso anual promedio en compra de material e instrumental científico de 18.240 ptas., una elevada cantidad que revelaba que la prioridad del claustro era dotar adecuadamente al centro para equipararlo con los primeros institutos de Europa. Más de 180.000 ptas. se destinaron en diez años a la compra de libros, suscripción de boletines científicos y a la dotación de los gabinetes científicos, un poco más del $17 \%$ de la partida de gastos de esa década.

Por el contrario, la incorporación de 1887 se tradujo en una drástica reducción de la partida de gastos, porque el Estado pasó a controlar el presupuesto destinado a la adquisición de instrumental y libros. En vez de disponer del $25 \%$ de la recaudación por derechos académicos, se fijó una cuota anual de 7.000 ptas. para la compra de material ordinario tanto de oficina como científico, el $38 \%$ de lo empleado anteriormente. Es posible que en los institutos de provincias más pequeñas y con menos estudiantes esas 7.000 ptas. fueran un avance considerable, pero los establecimientos más grandes sufrieron una merma considerable en estas partidas. Es decir, la centralización de 1887 se hizo para beneficiar a los institutos desatendidos por sus diputaciones

10 Archivo Histórico del Instituto Lluís Vives, Inventario 1873-1881 esaislvv $n^{\circ} 111$.

11 Archivo de la Diputación Provincial de Valencia, E. 9.1, Caja 4.

12 Memorias del instituto provincial de 2. ${ }^{a}$ enseñanza. Curso de1892 á 1893, Valencia, Imprenta de José Rius, 1893 , Cuadro $n^{\circ} 21$ 
provinciales, pero al coste de perjudicar a los de mejor situación económica. El cuadro 3 resume esta situación al ilustrar el porcentaje respectivo de los ingresos según los pagos de los alumnos, las rentas generadas por el patrimonio propio o los fondos provenientes de la diputación:

\begin{tabular}{|c|c|c|c|c|}
\hline PERIODO & ALUMNOS & PATRIMONIO & DIPUTACIÓN & GASTO PROMEDIO \\
\hline $1868-1877$ & $44,2 \%$ & $26 \%$ & $26,5 \%$ & 83.718 ptas \\
\hline $1877-1887$ & $58,1 \%$ & $17,1 \%$ & $28,9 \%$ & 105.112 ptas \\
\hline $1887-1901$ & $99,8 \%$ & $28 \%$ & $24,5 \%$ & 88.164 ptas \\
\hline
\end{tabular}

Cuad. 03 Ingresos del instituto provincial sobre gasto 1868-1901. FUENTE: Memorias del Instituto Provincial de Valencia.

En un primer momento, este conjunto de cifras puede resultar incomprensible, aunque resume toda la problemática que aparejó la financiación de la enseñanza media. Durante 1868 77 , el pago de las tasas, más las rentas generadas por el patrimonio propio, hubiesen bastado para sufragar los estudios generales y los estudios de aplicación sin necesidad de incurrir en un déficit significativo para los fondos provinciales. No obstante, la diputación aprovechó la autonomía conferida por el Sexenio a las corporaciones locales para ampliar la oferta académica del instituto a cambio de asignarles una subvención de 20.000. ptas. anuales y, de este modo, desvió parte de los impuestos de los contribuyentes para fomentar los estudios técnicos.

Por otro lado, los decretos de Toreno de 1877 implicaron un encarecimiento de la educación que recayó sobre el alumnado, a pesar de que fueron los matriculados en los colegios privados los más perjudicados. Pero, a su vez, también fueron los estudiantes los primeros beneficiados, ya que en los institutos grandes fue posible equipar adecuadamente los gabinetes de física, química y ciencias naturales, además de las bibliotecas y salas de estudio. ${ }^{13}$ La incorporación de 1887, empero, arbitró un nuevo reparto de las cargas económicas que, si en un principio debía garantizar el puntual cobro de las nóminas y el correcto funcionamiento de todos los institutos, en Valencia resultó fatídico, aunque la diputación mantuvo una aportación de 19.612 ptas. una cuantía inferior a la destinada en los últimos años, que había ascendido a más de 40.000 ptas. anuales. Esta ayuda, con el volumen de matrículas existente ese año, servía para paliar por completo el déficit generado por sostener el instituto con todos los estudios de aplicación incorporados, más sus complementos salariales, pero no alcanzaba para costear la Escuela Industrial de Artesanos, que fue el primer servicio educativo sacrificado.

Posteriormente, en 1891, los conservadores iniciaron una política de reducción de costes que en Valencia implicó la supresión de los estudios de náutica, de la escuela de primaria gratuita abierta desde 1868 , del peritaje mecánico y de las consignaciones para el mantenimiento del servicio de bibliotecas, además de no renovarse las bajas que se producían en el personal subalterno. En consecuencia, el monto enviado en las cartas de pago era considerablemente menor, aunque, paradójicamente, en esos años mejoraba el número de inscritos en la enseñanza media y, por ende, el Estado recaudaba más por este concepto. Este superávit podía haber servido para reducir la asignación de la diputación, pero ésta se vio en la disyuntiva de disminuir su partida y ver empequeñecido el establecimiento oficial o sustituir a la administración central, y optó por esta última alternativa.

Por lo tanto, el instituto de Valencia reportaba beneficios al Gobierno que, en la práctica, había expropiado al centro su patrimonio y no devolvía siquiera el $100 \%$ de los pagos efectuados

13 Carmen rodríguez guerrero: El Instituto de Segunda enseñanza del Noviciado de Madrid de 1845 a 1877 Tesis Doctoral, Madrid, UNED, 2004 . pp 462-493.José Ramón bertomeu et al: “Las coleccio1877, Tesis Doctoral, Madrid, UNED, 2004, pp. 462-493.José Ramón bertiano de Madid de ña", Historia de la educación: Revista interuniversitaria, 30 (2011) pp. 167-193. por el alumnado. Esto, empero, se podría entender si ese superávit hubiese tenido como fin atenuar el déficit que arrastraban centros más pequeños. De hecho, esa era una de las razones que movieron al estamento docente a demandar la incorporación y los liberales, cuando la dictaron en 1887 , tenian presente que ese debía ser su fin. Pero, como denunció en repetidas ocasiones político Eduardo Vincenti, Director General de Instrucción Pública por los liberales entre 1892 y político Eduardo Vincenti, Director General de Instrucción Pública por los liberales entre 1892 y ingresos para el Tesoro, porque las rentas devengadas eran superiores con creces al dispendio total que requería su sostenimiento. Según sus estimaciones, desde 1887 hasta el primero de julio de 1894 el Estado había ganad0 3.070 .828 ptas con este tramo de la instrucción pública ${ }^{14} \mathrm{Como}$ es lógico, estimar la importancia adquirida por esta partida presupuestaria para el sostenimiento de la Hacienda Pública excede las pretensiones de la presente comunicación, que sólo puede destacar la triste paradoja que se produjo en el curso 1898-1899, cuando los impuestos de guerra aplicados a las tasas académicas las encarecieron aproximadamente un $10 \%$. Ese año el instituto recaudó para el Estado más de 180.000 ptas., pero sólo consumió 87.000 ptas. Se puede decir que estudiar el bachillerato fue una forma de sufragar el esfuerzo bélico y, posiblemente, la educación secundaria cargaba con deudas de los ministerios de guerra y marina.

Por otro lado, a partir de 1887 el incremento del gasto se debió exclusivamente a la mejora de los sueldos de los catedráticos por razón de sus quinquenios de antigüedad. Se contrató pocos docentes y, en muchos casos, fue la diputación quien asumió sus gratificaciones. Del mismo modo, la adquisición de instrumental científico nuevo para los gabinetes se paralizó y tan sólo se pudo comprar el material indispensable para su mantenimiento, al mismo tiempo que las reparaciones y mejoras del edificio se hicieron menos frecuentes, porque requerían de previa autorización de la Dirección General de Instrucción Pública, si bien no se puede decir que el estado de conservación del establecimiento fuese catastrófico.

En este punto, resulta evidente que la centralización presupuestaria dictada en 1887 , junto a la política de reducción de costes aplicada por los conservadores desde 1891, tuvo consecuencias nefastas en la provincia de Valencia. Si la diputación provincial desde 1860 había seguido una política educativa expansiva focalizada principalmente a favorecer la instrucción formalizada de los trabajadores manuales cualificados que albergaba un centro industrial-artesanal como Valencia, el cierre de la Escuela Industrial de Artesanos en 1887 supuso un considerable retroceso, agravado por la dejadez mostrada por el ministerio hacia los peritajes. En esta tesitura, la diputación sólo pudo intentar suplir las carencias del gobierno central y resignarse a abandonar el papel protagonista que tuvo en 1868 con la puesta en marcha de nuevos estudios. Una evolución que se visualiza en el siguiente gráfico: 
Gráfico 1

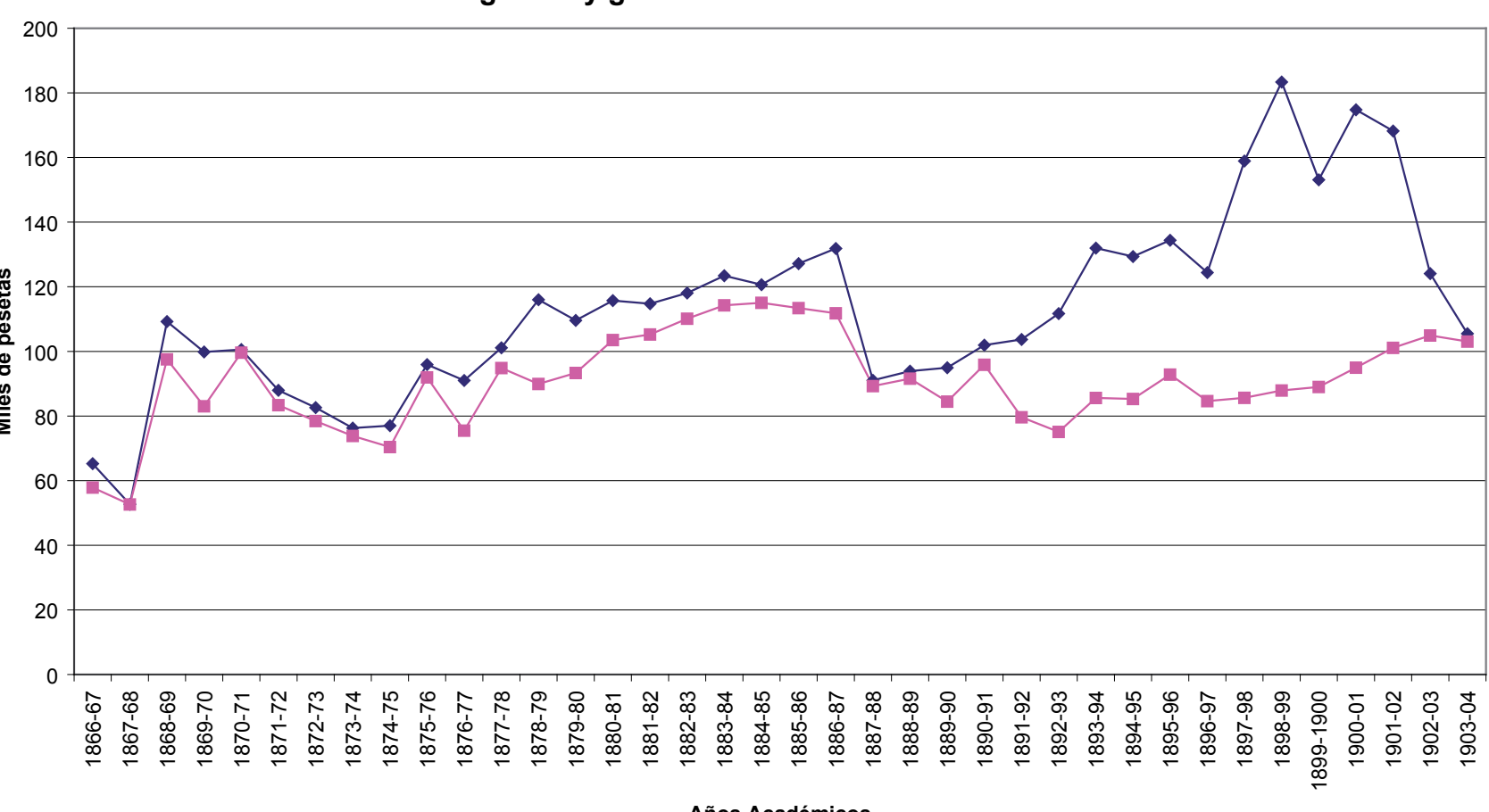

Como puede observarse, después de 1887 se interrumpe bruscamente la etapa expansiva de incremento de la inversion en educación que, en un primer momento, parece acompasarse con una reducción de los ingresos debido a la reducción de las aportaciones de la diputación. No obstante, al poco se inicia un proceso ascendente de los ingresos gracias a las aportaciones de los alumnos, mientras que el gasto educativo se estanca. Ese superávit en el balance producido en la década de 1890 fue el método empleado por el Gobierno para transformar la enseñanza media en una fuente de recursos económicos. La calidad educativa se degradó sin que se redujeran las tasas académicas que, por el contrario, se incrementaron durante la guerra de Cuba.

\section{Elementos para la reflexión}

En primer lugar, el presente estudio refuta el axioma tan arraigado en España de equiparar centralización con eficiencia y progreso. La completa centralización administrativa de los institutos decretada en 1887 tuvo efectos nefastos en el instituto provincial de Valencia, cuyas rentas fueron empleadas para financiar al Gobierno en detrimento de la oferta educativa pública en la provincia.

En segundo lugar, esta investigación diagnostica una década de oro para la ciencia en la enseñanza media, el periodo de 1877-1887, que, gracias a los decretos de Toreno, permitió al centro valenciano invertir elevadas partidas presupuestarias en la compra de instrumental y libros. La ventana de oportunidad que supusieron esos años para la cultura científica en España puede ser una línea de análisis productiva en el futuro.

En tercer lugar, es también un elemento de reflexión destacable interrogarse respecto de la valoración que los catedráticos de instituto y universidad hicieron de esa etapa, de la imagen pública que proyectaron respecto de la necesidad de mantener esas inversiones para lograr una adecuada dotación de los establecimientos públicos. Su actitud y comportamiento colectivo ante los cambios decretados en 1887 y las consecuencias que estos tuvieron es también un tema de discusión pertinente. En este sentido, sería interesante profundizar en la investi- gación de los profesores como cuerpo profesional, ya que en 1887 lograron una de sus mayores reivindicaciones, la promoción estricta por antigüedad mediante quinquenios. ${ }^{15}$ Por lo tanto, sería interesante estimar la valoración que de ese esfuerzo económico en material científico yidentro de sus asociaciones profesionales un debate sobre la necesidad de priorizar las condiciones laborales o mejorar el nivel de la ciencia en España en sus reivindicaciones ante la administración. 


\section{CONSTRUIR UN PAÍS EN LA CATÁSTROFE: CIENCIA,}

\section{POLÍTICAS PÚBLICAS Y TERREMOTOS}

Lorena B. Valderrama

Instituto de Historia de la Medicina y la Ciencia López Piñero (CSIC-UV)

\section{Introducción}

La historiografía reciente ha abordado las relaciones ciencia, sociedad y terremotos durante el siglo XIX y el siglo XX, desde variados ejes. Por un lado se encuentran los trabajos que relacionan el desarrollo de la ciencia de los terremotos a finales del siglo XIX e inicios del siglo $X X$ con variados intereses a nivel local y global. Por ejemplo, el desarrollo de la sismología en Austria Imperial comienza a ser una preocupación en la segunda mitad del siglo XIX, ante el temor de la destrucción del imperio por los terremotos entendiéndolos a escala nacional. ' En Suiza durante el mismo periodo, este desarrollo está marcado por una nueva forma en la cual la sociedad entiende y se relaciona con su geografía nivel nacional considerando las particularidades locales de cada región. ${ }^{2}$ En cambio, el caso del desarrollo de la sismología a finales del siglo XIX en Alemania Imperial, está caracterizada por una preponderancia hacia los instrumentos que permiten percibir terremotos en distintas partes del mundo y a través de ellos comprender la estructura interna de la tierra, enmarcándose en una visión global tanto de los terremotos, como de la sismología. ${ }^{3}$

Otros trabajos van más en la línea de estudiar el terremoto en su impacto en la vida humana, como sería el caso de la construcción. Clancey (2006) ha estudiado en este sentido la relación de sismólogos, ingenieros y arquitectos en el Japón imperial bajo la dinastía Meiji a finales del siglo XIX, tomando el fenómeno físico y social del terremoto como eje de desarrollo, cambio y movilidad en el proceso de construcción de la nación japonesa. ${ }^{4}$ Ligado también a la relación entre sismología y construcción, se encuentra también el trabajo de Geschwind (2001), en el cual los sismólogos californianos de principios del siglo XX, promueven y orientan sus acciones a repercutir en políticas públicas de construcción.

Coen (2013) en su último libro The Earthquake Observers. Disaster Science from Lisbon to Ri-

1 Deborah COEN: “Fault Lines and Borderlands: Earthquake Science in Imperial Austria”, en Mitchell G. ASH y Jan SARUMAN (eds.): The Nationalization of Scientific Knowledge in the Habsburg Empire 1848-1918, Hampshire, Palgrave Macmillan, 2012; Deborah COEN: The Earthquake Observers: Disaster Science from Lisbon to Richter, Chicago, University of Chicago Press, 2013.

2 Deborah COEN: "The Tongues of Seismology in Nineteenth-Century Switzerland", Science in Context, 25 (2012), pp. 73-102; Deborah COEN: The Earthquake Observers: Disaster Science from Lisbon to Richter, Chicago, University of Chicago Press, 2013.

3 Andrea WESTERMANN: "Disciplining the Earth: Earthquake Observation in Switzerland and Germany at the Turn of the Nineteenth-Century", Environment and History, 17 (2011), pp. 53-77.

4 Gregory CLANCEY: Earthquake Nation, The cultural politics of Japanese Seismicity, 1868-1930, Berkeley, University of California Press, 2006; Gregory CLANCEY: “The Meiji Earthquake: Natuire Nation and the Ambiguities of Catastrophe", Modern Asia Studies, 40 (2006), pp. 909-951.

5 Carl-Henry GESCHWIND: California Earthquakes: Science, Risk and the Politics of Hazard Mitigation, Baltimore, John Hopkins University Press, 2001. chter sintetiza estos trabajos, poniendo énfasis en otros actores como los observadores legos, los testigos y los anunciadores de terremotos, como también en otras fuentes como es el caso de la prensa. Su planteamiento se centra en el desarrollo de la sismología del siglo XIX e inicios del XX, enmarcada del pensamiento ilustrado, cuyo quiebre epistemológico está dado por el terremoto de Lisboa en 1755. De esta forma, según Coen (2013) durante el siglo XIX e inicios del $X X$, en diversas partes del mundo la inquietud por comprender los terremotos habría respondido a diversos intereses políticos, sociales y científicos, planteando distintas formas de observar, registrar y estudiar los terremotos. En este periodo se encuentran y tensionan las visiones de lo local y lo global, de la observación humana y la observación mediante instrumentos y de las inquietudes e intereses de los científicos en regiones expuestas a terremotos destructivos y los intereses de los científicos en regiones menos sísmicas. ${ }^{6}$

El trabajo que presento se enmarca en estas discusiones historiográficas: un desarrollo de la sismología en la periferia (Chile) ligada a un proyecto de interés estatal de mitigar la destrucción de los terremotos, en un país expuesto frecuentemente a estos fenómenos. Como se puede observar en la páginas siguientes, este estudio de caso permite vislumbrar intereses políticos, sociales y científicos en el desarrollo de una ciencia de los terremotos aplicada a la construcción, pero al mismo tiempo permite atender a otros actores que formaron parte de este proceso de institucionalización de la disciplina como es el caso de los observadores legos y los anunciadores de terremotos. Para esto se analizaron diversas fuentes primarias, como los Decretos relativos al Servicio Sismológico Nacional y el Ministerio de Instrucción Pública (Archivo Nacional de Chile); los Boletines del Servicio Sismológico desde 1909 hasta 1923 (Archivo Montessus de Ballore, Universidad de Chile); las noticias aparecidas en el diario El Mercurio de Santiago y en El Mercurio de Valparaíso entre 1909 y 1922 (Archivo de Microformatos Camilo Henríquez, Biblioteca Nacional); la prensa científica nacional concentrada en las revistas las Actes de la Société Scientifique du Chili, y los Anales de la Universidad de Chile (Archivo Andrés Bello); y la correspondencia privada de Montessus de Ballore, específicamente las 62 misivas enviadas a Montessus de Ballore desde Chile entre 1903 y 1922 (Archivo Montessus de Ballore, Universidad de Chile).

\section{El terremoto anunciado}

El miércoles 15 de agosto de 1906 apareció en El Mercurio de Santiago un anuncio al que al parecer nadie le prestó mucha atención. ${ }^{7}$ El Capitán Arturo Middleton, Jefe de la Oficina Meteorológica de la Armada de Chile, avisaba en una carta enviada el 6 de agosto al principal diario del puerto más importante del Chile de la época, que para la mañana del día 16 de agosto de ese mismo año se esperaban fenómenos "atmosféricos y sísmicos" en Valparaíso. ${ }^{8}$ Por la tarde del día predicho, un violento terremoto remeció la ciudad porteña con tal fuerza, que tres mil personas murieron, cerca de veinte mil resultaron heridos y se produjeron incendios por toda la ciudad que duraron hasta cuatro días. ${ }^{9}$

El "anunciado" terremoto se sintió a lo largo de tres mil doscientos kilómetros en el país. No se había producido uno tan fuerte desde 1880 . Se sumaba a ello que, a diferencia de los

6 Deborah COEN: The Earthquake Observers: Disaster Science from Lisbon to Richter, Chicago, University of Chicago Press, 2013.

7 Alfredo RODRIGUEZ y Carlos GAJARDO: La catástrofe del 16 de agosto de 1906 en la República de Chile, Santiago de Chile, Imprenta Barcelona. 1906, pp. 41.

8 Arturo MIDDLETON: "Pronóstico sobre fenómenos atmosféricos", El Mercurio de Valparaiso, 15 de agosto de 1906

9 Alfredo RODRÍGUEZ y Carlos GAJARDO: La catástrofe del... pp. 41-174. El terremoto equivaldría hoy a uno Re 8 de ma y Caud $C$ án los datos entregados por el Servicio Sismológico de Chile. Disponible en: http://ssn.dgf.uchile.cl/. 
terremotos del siglo XIX, éste había afectado principalmente al centro financiero y comercial de un país, en ese entonces, eminentemente exportador. ${ }^{10}$

El terremoto de Valparaíso había destruido el puerto más importante de país." De esta forma, se le presentó al presidente de entonces, Pedro Montt (1849-1910), el desafío de la reconstrucción, al mismo tiempo que una oportunidad de potenciar el desarrollo de obras públicas en el país desde el gobierno central. ${ }^{12}$ Sin embargo, la catástrofe también fue una oportunidad para el gobierno nacional de expandir su control sobre los gobiernos locales de las ciudades, en materia de construcción y paisaje urbano. ${ }^{13}$

Dominar los terremotos y mitigar sus efectos, por tanto, se convirtió en un aspecto clave para el proyecto de construcción del gobierno nacional y esta necesidad posibilitó la creación del Servicio Sismológico de Chile, una entidad estatal en red a cargo de registrar, estudiar e informar de la sismicidad del país.

\section{La Comisión Científica de Estudios del Terremoto de 1906}

En 1906, la observación sísmica del país aún no estaba institucionalizada. En ese entonces, en Chile había algunos profesores, marinos, astrónomos y geólogos que entre sus observaciones habían incluido el registro, descripción y explicación de algunos de los grandes fenómenos sísmicos del siglo XIX. Tal es el caso de quienes trabajaban en el Observatorio Astronómico $\mathrm{Na}$ cional, como su director, el astrónomo e ingeniero francés Alberto Obrecht y el ingeniero y Primer Astrónomo del mismo observatorio, Ernesto Greve; los geólogos, Julio Schneider (profesor de la Universidad de Chile), Lorenzo Sundt y Ricardo Poenish, también astrónomo; los profesores del Instituto Pedagógico de Chile, Hans Steffen, quien dictaba la clase de Geología, y Jermán Ziegler, quien dictaba la clase física; y Francisco Vidal Gormaz, Capitán de Navío de la Marina Chilena. Todos ellos habían realizado o participado en algún momento de estudios y observaciones de distintos fenómenos sísmicos y tras el terremoto de 1906, fueron nombrados por el Gobierno de Chile miembros de la Comisión Científica de Estudios del Terremoto de 1906.14

A esta Comisión se le encomendó la tarea de estudiar las características y consecuencias del terremoto en todas las zonas del país. El gobierno necesitaba saber qué había sucedido exactamente, cómo había sucedido, dónde había sucedido específicamente y qué consecuencias había tenido en cada lugar. Sin embargo, debido a la fuerza del terremoto, el único sismógrafo con que contaba el Estado, instalado en el Observatorio Astronómico Nacional, había quedado inutilizado. Así pues, la comisión quedó sin la posibilidad de medir el evento y sólo

10 Carmen CARIOLA SUTTER y Osvaldo SUNKEL: La historia económica de Chile 1830-1930: Dos ensayos y una bibliografia, Madrid, Ediciones Cultura Hispánica. 1982. El valor estratégico en el puerto de Valparaíso para el comercio internacional y la importancia de la minería y agricultura de Chile en los mercados de América y Europa, permitieron al país desarrollar durante el siglo XIX una creciente actividad en el campo económico internacional.

11 Alfredo SÁNCHEZ y Cecilia JIMÉNEZ: "Valparaíso: la ciudad-puerto más importante de Chile y la vulnerabilidad de su patrimonio arquitectónico a los riesgos sísmicos", Estudios Geográficos, $72 \mathrm{n}^{\circ}$ 271 (2011), pp. 559-589.

12 Francisco OVALLE: Don Pedro Montt. Ex-Presidente de la República de Chile, Santiago de Chile, Imprenta Universitaria, 1918

13 Luego del terremoto de 1906, el gobierno nacional, a cargo de Manuel Montt, lideró el manejo de la emergencia y las políticas de construcción de obra pública a gran escala, desplazando de estas labores al gobierno local de la ciudad. De igual forma se impuso paulatinamente ante las autoridades de Valparaíso en materia de normativas locales y la zonificación, aspectos que se habían ignorado previamente por el gobierno a nivel pais (Samuel MARTLAND: "Reconstructing the City, Constructing the State: Government in Val paraiso after the Earthquake of 1906", Hispanic American Historical Review, $87, \mathrm{n}^{\circ} 2$ (2007), pp. 221-254)

14 El anuncio apareció en prensa citando el decreto del día 23 de agosto ("Estudios de los fenómenos seísmicos", El Mercurio de Santiago, 25 de agosto de 1906). pudieron contar con los registros de péndulos caseros que poseían algunos particulares, los cuales a juicio de la comisión "apenas sirvieron para precisar en algunos puntos las indicaciones sobre la dirección principal del movimiento". ${ }^{5}$

Ante la carencia de datos exactos con respecto a la magnitud del terremoto y sus características (hora exacta, duración, dirección, tipos de movimientos, réplicas, tipos de ruidos, otros fenómenos accesorios, etc.), la Comisión decidió repartir un cuestionario de diecisiete preguntas a dos mil quinientas personas en todo el país, entre ellas a intendentes, gobernadores, rectores de liceos, colegios, seminarios e institutos, ingenieros, gobernadores marítimos, capitanes de puerto, cónsules extranjeros en Chile, cónsules y agentes consulares chilenos en la República Argentina, jefes de estaciones ferroviarias y de oficinas telegráficas, comandantes de policía, guardianes de faros, a las compañías de vapores y varias personas particulares instruidas. Sin embargo, la tasa de respuesta fue de tan sólo un seis por ciento (ciento cincuenta y cinco cuestionarios). También la comisión completó su informe con datos provenientes de cientoveinte informes remitidos a la Oficina del Tiempo y diecisiete comunicaciones referentes a observaciones en las costas de la región central de la Dirección de Territorio Marítimo. Sin embargo, a juicio de la Comisión, todas estas informaciones contaban con notables diferencias entre sí y "numerosas imprecisiones". Por ejemplo, con respecto a la cantidad de sacudidas durante el terremoto, dos reportes suministrados por observadores de Rancagua diferían en cuanto al número de sacudidas y su duración: José Vergara relató que fueron tres sacudidas las que constituyeron el terremoto, el cual habría durado cuatro minutos y medio, mientras que otro informante (Julio Escudero) dijo que fueron diez sacudidas y sólo la más grande constituyó el terremoto, con una duración de al menos cinco minutos. ${ }^{16}$ Por esta razón, la Comisión tuvo que organizarse para recorrer de norte a sur el país, observar las consecuencias del terremoto y realizar entrevistas que permitieran dilucidar las características de éste.

Pese a las dificultades de las cuales la comisión dio cuenta, el trabajo de la comisión permitió de algún modo reconstruir una gran fotografía del terremoto y sus efectos en el país. Como forma de institucionalizar y extender este trabajo, el entonces rector de la Universidad de Chile, Valentín Letelier (1852-1919), quien había presentado ante el Consejo de Instrucción Pública la propuesta de la creación de una entidad pública que se dedicara exclusivamente al estudio de los sismos y a la formación de la sismología en el país. Esto se materializó en el Servicio Sismológico de Chile. ${ }^{77}$

Para dirigir dicho servicio, se contrató al ingeniero francés Fernand Jean Batiste Marie Montessus de Ballore (1851-1923), quien era en ese entonces Director de Estudios de la École Polytechnique de París. ${ }^{18}$ Montessus de Ballore se había comenzado a interesar por el estudio de los terremotos en 1881 cuando fue enviado a El Salvador en una comisión militar. Había ganado prestigio en el ámbito de la sismología tras publicar sus investigaciones sobre los terremotos en centro américa en diversas revistas europeas, obteniendo en 1888 un premio de la Academia de Ciencias de París a la mejor tesis en sismología. ${ }^{19}$ También pertenecía a la Internationalen seismologischen Gesellschaft (Asociación Internacional de Sismología), creada en Francia en 1901 que agrupaba a sismólogos de distintas partes del mundo con el fin de construir un

15 Hans STEFFEN: "Contribuciones para un estudio científico del terremoto del 16 de agosto de 1906", Anales de la Universidad de Chile, 120 (1907), pp. 634-713.

16 Ibid., pp. 648

17 Ibid.; Federico GREVE: Historia de la sismología en Chile, Santiago de Chile, Universidad de Chile, 1964; Rolando MELLAFE, Antonia REBOLLEDO y Mario CARDENAS.: Historia de la Universidad de Chile, Santiago de Chile, Ediciones de la Universidad de Chile, 1992.

18 Armando CISTERNAS: "Montessus de Ballore, a pioneer of seismology: The man and his work", Physics of the Earth and Planetary Interiors, 175 (2009), pp. 3-7.

19 Armando CISTERNAS: "Montessus de Ballore y la sismología en Chile", Revista de la Sociedad Chilena de Historia y Geografía, 171 (2007), pp. 197-204. 
catálogo global de sismos que permitiera determinar las características sismológicas de cada zona del mundo. En este sentido hacia el año 1906 había catalogado más de ciento setenta mil sismos a nivel mundial, engrosando el catalogo mundial del geofísico Robert Mallet (18101881), el cual sólo alcanzó los 6831 terremotos. ${ }^{20}$

\section{El Servicio Sismológico de Chile}

El contrato de Montessus de Ballore, firmado en septiembre de 1907, lo nombraba funcionario público por tres años (renovables). Dentro de sus obligaciones estaba el instalar observatorios sismológicos públicos en el país; enseñar sismología y arquitectura sismológica en instituciones públicas y emitir informes al gobierno sobre sismología y construcción sísmica. ${ }^{2}$ El 15 de abril de 1909 comenzó a dictar el Curso de Sismología Aplicada en la Escuela de Ingenieros de la Universidad de Chile, con el fin de formar a los futuros arquitectos e ingenieros en la construcción resistente a terremotos. ${ }^{22}$

En tanto, el primero de mayo de 1908 se fundó en la capital el Observatorio Sismológico de Santiago. El Servicio Sismológico de Chile comenzó a funcionar el 9 de junio del mismo año, quedando Montessus de Ballore a cargo de ambas instituciones. El observatorio central se constituyó como el organismo central para el estudio de los terremotos en Chile y para la sistematización de toda la información producida en el país, convirtiéndose en el centro de la administración de todo el servicio. Se abasteció con instrumental de primer orden traído desde Europa, el cual se estaba utilizando en diversos observatorios del mundo, como es el caso del Sismoscopio Avisador-Registrador Agamennone, cronómetros murales para marcar la hora de los sismogramas, un péndulo horizontal Stiattesi para registrar terremotos mundiales, Péndulos Horizontales Bosch-Omori que se habían hecho famosos después del terremoto de California de 1906 y varios péndulos mecánicos Wiechert, para registrar eventos de entre ochocientos y mil kilómetros de distancia, los cuales a juicio de Montessus de Ballore eran "baratos i de manejo relativamente sencillo". ${ }^{23}$ Ese mismo año se crearon cuatro observatorios de segunda clase, dotados con instrumental para medir eventos locales de hasta un radio de mil kilómetros, ubicados en las principales ciudades del norte y sur del país. Para 1909 el Servicio Sismológico estaba conformado por estos cinco observatorios más veintinueve estaciones sísmicas que funcionaban en las principales ciudades e islas del país, encargadas de medir terremotos locales con sismoscopios Agamennone. ${ }^{24}$

Los encargados de estos treinta y cuatro observatorios y estaciones sísmicas fueron contratados como funcionarios públicos para hacerse cargo del instrumental asignado y reportar periódicamente al Observatorio Sismológico de Santiago. ${ }^{25}$ Aún no se ha podido recabar toda la información con respecto a las personas que ocuparon estos cargos, sin embargo a través de la correspondencia recibida por Montessus de Ballore durante su dirección de Servicio Sismológico, se sabe que, por ejemplo, algunos eran profesores de colegio, editores de periódicos o investigadores independientes. A todos ellos se les hizo llegar un instructivo o manual de observación y manejo del instrumental. En tanto, los observatorios y estaciones fueron instalados en sus lugares de trabajo o en sus viviendas particulares.

20 Deborah COEN: The Earthquake Observers: Disaster Science from Lisbon to Richter, Chicago, University of Chicago Press, 2013.

21 Decreto (interno) del Ministerio de Instrucción Pública de la República de Chile $N^{\circ} 4.061$ del 5 de Decreto (interno) del Ministerio de In
junio de 1908. Archivo Legal de Chile.

22 Armando CISTERNAS: “Montessus de Ballore, a pioneer of seismology...", pp. 3-7.

23 Fernand MONTESSUS DE BALLORE: Boletín del Servicio Sismológico de Chile. Años... pp. 196.

24 lbid., pp. 1-2.

25 Decreto (interno) del Ministerio de Instrucción Pública de la República de Chile № 4.061 del 5 de junio de 1908. Archivo Legal de Chile.
Tal fue el caso de Aníbal Cobo, profesor de ciencias naturales del Liceo de Copiapó quien se hizo cargo en 1908 del Observatorio de Copiapó ubicado en el norte del país. ${ }^{26}$ Mientras que una estación sísmica fue instalada en la casa de José Toribio Medina (1852-1930), historiador bibliófilo y profesor de la Universidad de Chile, radicado en el centro del país, en la localidad de San Francisco de Mostazal. ${ }^{27}$ En tanto, en el extremo sur del país, quien se hizo cargo de Observatorio Sismológico Estatal de Punta Arenas fue Domingo Larraín Torres, químico analista, director de la Biblioteca Científica del Laboratorio Químico Municipal y director del diario El Magallanes. ${ }^{28}$ Tres años después, este observatorio fue trasladado al Colegio Salesiano San José de la misma ciudad, quedando a cargo de Monseñor José Fagnano, fundador del Observatorio Meteorológico de Punta Arenas. ${ }^{29}$

Otras personas se sumaron a esta tarea de observación y registro sísmico. Merecen especial mención los quinientos treinta informantes que vivían en cuatrocientos veinticinco poblados del país y que conformaron una red "informantes", "corresponsales" y "observadores benévolos". ${ }^{\circ}$ Algunos de ellos eran personas pertenecientes a la elite social, intelectual y comercial de la época, quienes de forma voluntaria y de vez en cuando enviaban sus reportes y observaciones a Montessus de Ballore, quien los recogía y los incorporaba al listado de terremotos anuales en el Boletín del Servicio Sismológico. También se sumaron a esta tarea algunos funcionaros públicos como maestros de escuela o los jefes de Estación de Ferrocarriles del Estado, guardianes de Faro de la Armada, Telegrafistas del Estado, las oficinas salitreras de las provincias de Tacna y Antofagasta y los jefes de Estación del Ferrocarril Internacional Antofagasta-La Paz. ${ }^{31} \mathrm{~A}$ ellos se les hizo llegar material escrito como folletos, opúsculos, manuales o libros sobre el estudio de los terremotos y la observación sísmica. Por ejemplo, el Reglamento para la Observación de los Temblores por los Telegrafistas del Estado, emitido por la Dirección General de Telégrafos de Chile en 1911, establecía que sus funcionarios debían reportar un telegrama a la Oficina Central de Telégrafos cada vez que sintieran un terremoto. Para ello debían señalar en el comunicado sólo los siguientes datos: nombre de la ciudad o población, nombre del día de la semana y hora y minutos según el reloj de la estación. Además luego del sismo debían registrar el evento en un cuadro mensual que se les facilitó junto a un instructivo y enviarlo cada mes a instancias supriores. ${ }^{32}$ La correspondencia científica analizada da cuenta de todo

26 Carta de COBO, Aníbal a MONTESSUS DE BALLORE, Fernand del 6 de mayo de 1908. Caja $\mathrm{N}^{\circ}$ Ce (A-E). Sección Correspondencia Científica. Archivo Montessus de Ballo. Sevicio Sismológico

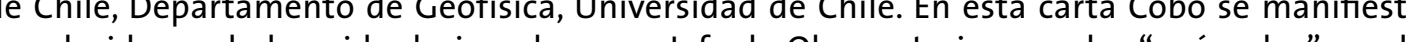
ignado como Jefe de Observatorio y por los "opúsculos" que le

27 Carta de TORIBIO MEDINA, José a MONTESSUS DE BALLORE, Fernand del 8 de enero de 1910. Caja $\mathrm{N}^{\circ} 2$ (F-M). Sección Correspondencia Científica. Archivo Montessus de Ballore. Servicio Sismológico de Chile, Departamento de Geofísica, Universidad de Chile.

28 Carta de LARRAÍN, Domingo a MONTESSUS DE BALLORE, Fernand del 20 de noviembre de 1908. Caja $\mathrm{N}^{\circ} 2$ (F-M). Sección Correspondencia Científica. Archivo Montessus de Ballore. Servicio Sismológico de Chile, Departamento de Geofísica, Universidad de Chile. Por ejemplo en esta carta, Larraín señala que recibió los instrumentos, las "instrucciones y el folleto ajunto" que el mismo Montessus de Ballore le envió.

29 Carta de FAGNANO, José a MONTESSUS DE BALLORE, Fernand del 11 de julio de 1911. Caja №2 (F-M). Sección Correspondencia Científica. Archivo Montessus de Ballore. Servicio Sismológico de Chile, Departamento de Geofisica, Universidad de Chile.

30 Fernand MONTESSUS DE BALLORE: "Boletín del Servicio Sismológico de Chile № 2. Primer Semestre de 1909. Primera Parte", Anales de la Universidad de Chile, 125 (1909), pp. 819-918.

31 Fernand MONTESSUS DE BALLORE: Boletín del Servicio Sismológico de Chile Año 1910, Santiago de Chile, Imprenta Cervantes, 1911. ÍD.: "Memoria sobre la Labor del Servicio Sismolójico desde el Mes de Mayo de 1910", Anales de la Universidad de Chile, 128 (1911), pp. 885-889.

32 Reglamento para la Observación de los Temblores por los Telegrafistas del Estado, Dirección Ge- 
ello y de la relación de subordinación que tenían estos, ante la autoridad de Montessus de Ballore, como director del Servicio Sismológico de Chile.

De igual forma, todos los reportes que producían estos informantes, unidos a los informes que emitían los cinco observatorios y las diecinueve estaciones sísmicas, eran sistematizados y condesados anualmente en el Boletín del Servicio Sismológico, el cual se publicó de forma continuada desde 1909 a 1922. Esta publicación servía como instrumento informativo público detallado de la sismicidad de cada poblado del país, permitiendo balances estadísticos de la frecuencia y localidad de los terremotos. Además, el Boletín incluía entre sus páginas artículos de diversas autorías sobre ingeniería resistente a terremotos, estudios explicativos sobre los terremotos y volcanes y descripciones de grandes terremotos. Fue difundido entre actores políticos del país, publicado en capítulos en diversas revistas nacionales y también enviado a la Seismological Society of America, la publicación más importante en materia sismológica en ese entonces. ${ }^{33}$

El objetivo el trabajo de la red que componía el Servicio Sismológico y del Boletín era principalmente "deslindar con exactitud las regiones más o menos peligrosas del país". ${ }^{44} \mathrm{~A}$ largo plazo esta información permitía saber en qué zonas construir y cómo, teniendo en cuenta la frecuencia, intensidad y distribución geográfica de los terremotos en cada zona del país.

\section{La demanda por la predicción}

Además de la monitorización de este tipo de eventos, la formación en sismología y al asesoramiento al gobierno en materia sísmica, Montessus de Ballore, como director del Servicio Sismológico de Chile también estudió la relación de los fenómenos sísmicos con las lluvias, tempestades, hora del día, estación del año, conjunciones lunares o planetarias, etc. Este tipo de estudios, si bien no eran extraños en el campo de la sismología de finales del siglo XIX e inicios del siglo XX, no eran parte del trabajo principal de Montessus de Ballore, más abocado a estudio de la distribución geográfica de los terremotos. Se podría argumentar, por tanto, que de alguna manera este tipo de estudios respondió a una demanda social de la época, puesto que la gran mayoría de las alarmas públicas sobre posibles terremotos surgían de estudios que relacionaban los sismos con la influencia de fenómenos atmosféricos y astronómicos.

Como ya se mencionó en apartados previos, el terremoto de 1906 había sido anunciado por el Capitán Arturo Middleton. El método utilizado por Middleton estaba basado en la teoría "soléctrica" del Capitán de Marina Mercante inglés, Alfred Jopling Cooper (1848-1923), que destacaba la influencia de la electricidad del Sol, el magnetismo de la Luna y las conjunciones astrales en el origen de los terremotos. Las teorías de Cooper se habían popularizado en Chile, a través de la publicación del ayudante de la Gobernación Marítima, piloto $1^{\circ}$ de la Armada José Manuel Campbell, quien en el Anuario Hidrográfico de la Marina de Chile de 1901 publica una "traducción y arreglo" de la teoría de Cooper. ${ }^{35}$

Con posterioridad al terremoto de 1906, la prensa local y capitalina reportó que el terremoto había sido anunciado con varios días de anticipación por la Oficina Meteorológica de la Armada de Chile y que el método utilizado para realizar tal predicción había sido el de Cooper. Al analizar las noticias aparecidas sobre este anuncio se puede observar que la prensa no puso

neral de Telégrafos de Chile, 4 de agosto de 1911, 3 p. Caja Otras Publicaciones. Archivo Montessus de Ballore. Servicio Sismológico de Chile, Departamento de Geofísica, Universidad de Chile.

33 John BRANNER: "The seismological service of Chile", Bulletin of the Seismological Society of America, 1 (1911), pp. 25-26

34 Fernand MONTESSUS DE BALORE: "La Última Sesión de la Asociación Internacional de Sismología Celebrada en Manchester", Anales de la Universidad de Chile 130 (1912), pp. 841-51.

35 José Manuel CAMPBELL: "Teoría Meteorolójica para predecir con meses de anticipación las tempestades i los feń́menos seismicos. Traducción y apreglo", Anuario Hidrogrúfico de la Marind Chile, 23 (1901), pp. 485-499. en duda la fiabilidad, credibilidad y exactitud del estudio, pese a que el posible fenómeno "atmosférico o sísmico" estaba anunciado para la mañana del 16 de agosto y no para la tarde, que es cuando sucedió. Tampoco el anuncio hacía mención a la enorme intensidad con que se percibió. ${ }^{6}$ A raíz de estas noticias, comenzó un acalorado debate mediático entre quiene estaban a favor de los métodos predictivos de Cooper y la posibilidad de poder predecir este tipo de eventos, y quienes no. Principalmente, durante el mes de agosto de 1906, partidarios y detractores de las teorías predictivas enviaron contundentes cartas, respuestas, aclaraciones, explicaciones y réplicas a los principales periódicos de la época, El Mercurio de Santiago y E Mercurio de Valparaiso.37 Sin embargo, el tema fue desplazado prontamente por otras noticias, como las referidas a la reconstrucción del puerto.

Tan sólo seis años después del terremoto de Valparaíso, el anuncio de un nuevo "movimiento" de la tierra volvió a inquietar a los porteños. El 29 de agosto de 1912 se filtró en la prensa una carta de Cooper dirigida al Consulado Inglés en Valparaíso, en el cual señalaba que según los cálculos realizados mediante su teoría predictiva, se esperarían fenómenos sísmicos para el 30 de septiembre..$^{38}$ La filtración de la carta en la prensa provocó la alarma en la población que tan sólo seis años atrás había visto como se destruía su ciudad producto de un terremoto. Las noches previas a la fecha anunciada, la gente durmió en la calles, generando, con ello, problemas sanitarios y desórdenes públicos..$^{39}$

Montessus de Ballore, el sismólogo pagado por el Estado de Chile, fue entrevistado al respecto. El sismólogo deslegitimó contundentemente todas estas predicciones y cualquier posibilidad de predecir los terremotos. Su postura fue apoyada en la prensa diaria por algunos encargados de estaciones sísmicas del país y por el Observatorio Astronómico Nacional. ${ }^{\circ \circ} \mathrm{De}$ igual forma este debate se trasladó a los medios de prensa científica, en los cuales Montessus de Ballore también defendió férreamente el rol de la estadística en sismología, la inexistencia de la relación entre los sismos y los astros y la importancia de la formación en geología para el estudio de los sismos. ${ }^{4}$

36 Ver por ejemplo: “No más terremotos": El Mercurio de Valparaíso, 24 de agosto de 1906 y “No más terremoto", El Mercurio de Valparaiso 27 de agosto de 1906.

37 Para más detalles de quienes estaban a favor de los anuncios basados en la teoría de Cooper ver: Teodoro MELTZER: "Las causas del terremoto" El Mercurio de Santiago, 18 de agosto de 1906; ÍD. "Los fenómenos del 16", El Mercurio de Santiago, 19 de agosto de 1906; Conrado FERRANDO: "Sobre el orijen y causas del terremoto", El Mercurio de Santiago, 20 de agosto de 1906; Teodoro MELTZER "Sobre los fenómenos seísmicos", El Mercurio de Santiago, 20 de agosto de 1906; "El terremoto", El Mercurio de Santiago, 26 de agosto de 1906; "El terremoto", El Mercurio de Valparaiso, 29 de agosto de 1906. Para ver quiénes estaban en contra se puede revisar: Alberto OBRECHT y Ernesto GREVE: "Sobre los fenómenos seísmicos", El Mercurio de Santiago, 19 de agosto de 1906; Alberto OBRECHT: “Declaraciones", EI Mercurio de Santiago, 19 de agosto de 1906; Augusto MELTZER: “Los fenómenos seísmicos", El Mercurio de Valparaíso, 30 de agosto de 1906.

38 Una reproducción textual de la carta enviado por Alfred J. Cooper al cónsul de Su Majestad Británica en Valparaíso, que fue filtrada en el diario vespertino "Las Últimas Noticias" el día 29 de agosto de 1912 se puede leer en “La Carta de Mr. Cooper", El Mercurio de Santiago, o5 de septiembre de 1912.

39 Los habitantes de Valparaíso -incluso los de la alta sociedad-abandonaron sus hogares y acamparon en plazas y terrenos baldíos del puerto y sus cerros colindantes, lo cual demandó el patrullaje de militares a fin de "resguardar el orden" ("Las prescripciones de Cooper", EI Mercurio de Santiago, 30 de septiembre de 1912).

40 Ver por ejemplo: "El anuncio de día crítico", 30 de agosto de 1912; Albert OBRECHT: "Las predicciones de Mr. Cooper, teoría sin ningún valor", El Mercurio de Santiago, 7 de septiembre de 1912 Carlos MÁROUEZ: “Los terremotos, la absurda profecía de Mr. Cooper", El Mercurio de Santiago, 8 de septiembre de 1912; Fernand MONTESSUS DE BALLORE: "La previsión no cooperista del tiempo", EI Mercurio de Santiago, 26 de septiembre de 1912; ID.: "Profecías sobre temblores", El Mercurio de Santiago, 31 de agosto de 1912

41 Fernand MONTESSUS DE BALLORE: "Memorias Sismológicas", Anales de la Universidad de Chile, 
Sin embargo, en la comunidad científica también se encontró con algunos defensores de la teoría de Cooper. Por ejemplo, miembros de la Sociedad Científica de Chile exigieron al Servicio Sismológico revisar a las teorías de Cooper, argumentando una mala interpretación de los postulados de Cooper y un "atrincheramiento" por parte de las instituciones estatales -como el Servicio Sismológico y el Observatorio Nacional- por miedo a equivocarse en el ámbito de los pronósticos..$^{42}$ El Instituto de Ingenieros, en tanto, se mostró en contra de la teoría de Cooper y a favor de la cautela y precaución de ambas instituciones. 43

El debate público y el caos público generado por el pánico colectivo en el puerto debido a la predicción de 1912, produjo que tanto el gobierno como el Consulado Inglés se vieran envueltos en tratar calmar a la población que ya dormía en las calles esperando el terremoto anunciado. A través de una carta enviada al Consulado, el mismo Cooper se retractó de su pronóstico y en otra carta dirigida al Observatorio Astronómico Nacional, aludió a una "mala interpretación" de sus palabras, reconociendo públicamente que no se podían predecir terremotos "con certeza". ${ }^{44}$ Finalmente, el movimiento sísmico no se produjo, y la prensa dejó de tocar el tema.

\section{Conclusiones}

La revisión de las fuentes que en este trabajo se han analizado permite esbozar algunas conclusiones con respecto a la institucionalización de la sismología en Chile a inicios del siglo XX. En primer lugar, este proceso respondió a una necesidad gubernamental de contar con información precisa y detallada de los terremotos de Chile, sus efectos materiales y la forma en la cual se podrían mitigar a largo plazo. La Comisión Científica de Estudios del Terremoto presentó el primer esfuerzo por tratar de recabar la información que permitiera dar cuenta de las dimensiones del terremoto en las distintas zonas del país, intentando racionalizar el evento a través de relato de la ciencia y planteando la necesidad de enfrentar de un modo distinto los movimientos telúricos y el ineludible control de las políticas públicas frente a la catástrofe.

La creación del Servicio Sismológico de Chile, como institución estatal, permitió responder de forma sistemática a la necesidad de conocer las características y efectos de los terremotos en cada lugar del país. Al mismo tiempo, esta información le permitió al gobierno de Montt centralizar dicha información y administrar nacionalmente, desplazando a las autoridades locales en el manejo de la emergencia y en las políticas públicas de construcción, además de determinar la vulnerabilidad sísmica de cada zona del país y de contar con preparación estata en el ámbito de la construcción a-sísmica.

Esto fue posible gracias a una enorme red de estaciones y observatorios distribuidos por todo el país, pero también gracias a las informaciones provenientes de personas particulares voluntarias y otros funcionarios públicos que sin contar con instrumental de observación, pudieron registrar y reportar todos los eventos sísmicos sentidos en distintas zonas del país. A través de este trabajo colectivo, normado, centralizado y dirigido por el Servicio Sismológico, se consiguió no sólo la producción del conocimiento sísmico en la época, sino también el disciplinamiento de la observación sísmica en el país.

A la demanda gubernamental por conocimiento especializado y sistematizado en estas materias se le sumó la demanda social por la predicción sísmica. La sismología institucionali-

130 (1912), pp. 835-841. ÍD.: "Sobre el papel de la Estadística Gráfica en Sismología”, Actes de la Société Scientifique du Chili. 22 (1913), pp. 31-33.

42 Roberto RENGIFO: "Sismología. Anuncio de temblores", Actes de la Société Scientifique du Chili. 22 (1913), pp. 21-24.

43 Ver: "La nota del mes. Los pronósticos del Capitán Cooper", Anales del Instituto de Injenieros, 1 (1912), 442-447.

44 "El Capitán Cooper desvanece toda idea de predicción de temblores en Chile", El Mercurio de San-

tiago, 15 de septiembre de 1912 . zada a través del Servicio Sismológico intervino así en el debate social nacional en torno a los terremotos y la posibilidad de predecirlos. Los fracasos de dichos anuncios, una intensa presencia en los medios de comunicación nacional y la deslegitimación pública de los defensores de los métodos "predictivos" que relacionaban los terremotos con eventos astronómicos, permitió construir gradualmente la legitimidad social del Servicio Sismológico, como la institución pública encargada de estudiar dichas materias y la voz autorizada en materia sismológica a nivel nacional. 
Parte 7.

LOS AGENTES DEL CAMBIO. DE LA CRISIS DEL

FRANOUISMO A LA CONSOLIDACIÓN DE LA

DEMOCRACIA: PARTICIPACIÓN SOCIAL, CULTURAS

COLECTIVAS Y PRÁCTICAS POLÍTICAS. 


\section{LOS AGENTES DEL CAMBIO. DE LA CRISIS DEL FRAN- \\ OUISMO A LA CONSOLIDACIÓN DE LA DEMOCRACIA: \\ PARTICIPACIÓN SOCIAL, CULTURAS COLECTIVAS Y \\ PRÁCTICAS POLÍTICAS}

Maria Valls

Universitat de València

Natxo Escandell

Universitat de València

\section{Introducción}

Pensar en transición es pensar en cambio. El estado español experimentó desde finales de los sesenta un gran cambio económico, que llevó aparejado una enorme transformación cultural y social. Con todo ello se inició un camino sin retorno hacia la descomposición del régimen franquista con la introducción de comportamientos y valores democráticos en una sociedad a la que eran prácticamente desconocidos. Entender la transición implica entenderla desde todos sus puntos de vista. Es esto lo que hemos intentado llevar a cabo en la mesa taller "Los agentes del cambio. De la crisis del franquismo a la consolidación de la democracia: participación social, culturas colectivas y prácticas políticas": poner en relevancia el peso que tuvieron los movimientos sociales en el proceso de cambio político, social y cultural que se dio durante los años de la transición y el tardofranquismo.

Según nuestro parecer, la transición, además de cambio, significó experimentación. A pesar del escaso margen dejado por el Estado franquista, se abrieron nuevos cauces de participación favoreciendo el surgimiento de espacios de sociabilización en los que se gestaron actitudes críticas contra el régimen. Vecinos, mujeres, estudiantes, obreros e incluso medios de comunicación supieron aprovechar estos recientes mecanismos para plantear sus luchas particulares y poder lograr sus objetivos. También los partidos de izquierda y los partidos nacionalistas, desde su situación de completa ilegalidad, encontraron en los movimientos sociales las herramientas necesarias para posicionarse en contra del franquismo y mostrarse partidarios del cambio. Si hablamos de los objetivos de todos estos agentes, a grandes rasgos, podemos comprobar cómo prácticamente todos los movimientos sociales tienen una finalidad en común acabar con el régimen franquista e instaurar una democracia participativa y una ciudadanía igualitaria. De este objetivo común y cómo se comprobó en la mesa taller, surgieron lazos de unión de diferente duración e intensidad entre los movimientos sociales.

\section{Problemáticas y nuevas tendencias para la historia social de la transición}

Actualmente existe una extensa bibliografía sobre el tardofranquismo, la cultura de la protesta, la reivindicación democrática y, en general, sobre la transición y todo lo que supuso el proceso de democratización. Sin embargo, consideramos que la mayor parte de esta bibliografía continúa centrándose en los grandes cambios estructurales que sacudieron el estado a mediados de la década de los sesenta (industrialización, urbanización, cambio social y protagonismo de las élites políticas), situándolos como clave explicativa de los acontecimientos posteriores. Estas explicaciones macro-estructurales perciben las movilizaciones sociales como un fenómeno de incidencia menor o relativa, cuando no un resultado, de todo e desarrollo de la transición. No obstante, existe una corriente historiográfica que le otorga un mayor protagonismo al factor social y lo percibe como esencial para poder explicar cómo se produjo el proceso de transición. Últimamente están apareciendo trabajos en esta línea'que vienen a reforzar la idea de que la interacción de lo social con lo político es fundamental para poder entender cómo se van incorporando las demandas de la ciudadanía en la agenda política. Resulta interesante señalar que estas investigaciones históricas vienen a llenar un hueco en lo que se refiere al estudio de los movimientos sociales urbanos, campo tradicionalmente trabajado desde la sociología, y que necesita ser abordado desde este enfoque interdisciplinar para comprender la dimensión completa del fenómeno.

Nuestro objetivo en la mesa-taller era intentar superar algunas de las deficiencias clásicas y acercarnos a la historia social de la transición tratando de prestar atención a aquellos movimientos sociales cuyo estudio ha sido relegado a un segundo plano. Los motivos de este pseudo-olvido pueden ser varios, tal vez las demandas de estos pequeños grupos sociales ya estaban recogidas en otros movimientos de mayor envergadura, no como su razón de ser pero sí como una reivindicación más. De igual manera, podemos pensar que su ausencia se sustenta en que no llegaron a los objetivos marcados, siendo así considerados unos movimientos efímeros y sin el resultado esperado por parte de sus integrantes. De este modo, creemos que estos movimientos han de tenerse en cuenta ya que aglutinaban a identidades sociales y políticas con intereses y demandas que concernían a todas las capas de la sociedad. Sólo con todos y cada uno de ellos se logrará crear un auténtico antifranquismo que se mostrará eficaz no sólo para lograr los objetivos materiales, sino para involucrar a toda la población en la lucha por la ciudadanía democrática.

Una sensación compartida tras el desarrollo de la mesa taller, así como con los debates posteriores, es que la máxima problemática con la que se enfrentan los investigadores transicionistas es la carencia de archivos o las dificultades - generadas desde la propia administraciónpara el acceso a ellos. Por otra parte, un problema añadido es que mucha de la documentación presente en los archivos se encuentra dispersa, fragmentada o incompleta, lo que supone una tarea extra al historiador que, en muchas ocasiones, ha de realizar una labor previa de cata y organización de la documentación. Por otra parte, por la proximidad temporal del periodo estudiado, muchas investigaciones se prestan a ser completadas o elaboradas a partir de la historia oral. Sin duda, esto es una ventaja y un elemento que enriquece cualquier trabajo sobre la transición, no obstante, no hemos de olvidar - y así se manifestó en diversas ocasiones a lo largo de la mesa taller - el hándicap que supone la carga subjetiva tiene toda fuente oral. Desde las diferentes temáticas de estudio abordadas, se señaló la facilidad con la que el relato oficial reformula el relato individual. Es por este motivo que convenimos que el recurso a las fuentes orales ha de servir como complemento, guía y orientación para el uso de otro tipo de documentación.

Los agentes del cambio. Principales aportaciones de las comunicaciones presentadas

Recientemente, el vacío historiográfico que atañía a la movilización social frente a la Dictadura se ha ido llenando, pero no lo ha hecho de una forma homogénea, ni en cuanto a temática ni la cronología. Si bien estudiantes y obreros han sido, como hemos visto, dos de los

1 Francisco COBO ROMERO y Teresa María ORTEGA LÓPEZ: "La actitud de los asalariados. Nuevas interpretaciones sobre los móviles de la protesta labraly la oposición democrática al Franquismo", terpretaciones sobre los móviles de la protesta laboral y la oposición democrática al Franquismo", en Glicerio SANCHEZ RECIO (eds.): Eppure si muove: la percepción de los cambios en España (19591976), Madrid, Biblioteca Nueva, 2008. Carme MOLINERO y Pere YSAS (coords.): Construint la ciuta democràtica. El moviment veïnal durant el tardo franquisme i la transició, Barcelona, Icària, 2010 Rafael OUIROSA-CHEYROZE: "El protagonismo de la sociedad en la conquista de la democracia" en Rafael QUIROSA-CHEYROZE: La sociedad española en la Transición. Los movimientos sociales en el proceso democratizador, Madrid, Biblioteca Nueva, 2011. Pamela RADCLIFF: Making democraHampshire, New York, Palgrave Macmillan, 2011. 
agentes del cambio que más interés han despertado entre los historiadores, el papel de los vecinos ha estado tradicionalmente relegado a un segundo plano. No debemos negar que a nivel estatal existen notables acercamientos a la cuestión vecinal, aunque muchos de ellos caen en los lugares comunes sobre el aprendizaje de la democracia o las escuelas de libertad, creando así relatos reduccionistas que restan importancia al fenómeno y lo alejan de su verdadero papel como interactor con el factor político. No obstante, en la actualidad están apareciendo una serie de trabajos que pretenden superar estas deficiencias y abordar el movimiento vecinal subrayando su aportación como elemento de deslegitimación franquista y su papel en la construcción de un régimen democrático. "En esta línea se encuentran los trabajos realizados para las ciudades de Valladolid ${ }^{2}$, Barcelona ${ }^{3}$ y Jaén ${ }^{4}$ que ahondan en esta perspectiva contribuyendo también a la creación de una historia global del movimiento en España. Con ellos, se va imponiendo una línea de estudio revisionista sobre el proceso de transición que da un mayor peso a los actores colectivos, alejándose así de explicaciones mecanicistas con un protagonismo total de las élites y percibiendo la transición como un proceso dialéctico entre "los de arriba" y "los de abajo".

Precisamente, una de las características de esta línea de estudio es la aparición de trabajos sobre movimiento vecinal en ciudades que hasta el momento carecían de este tipo de investigaciones. Un ejemplo es el que presenta Fátima Martínez en su trabajo "El movimiento vecina en la Galicia urbana (1970-1980)" donde estudia el caso de la ciudad de Vigo. La situación de Galicia a finales de los sesenta no dista mucho de la que presenta el resto del estado (suburbanización, especulación urbanística, inmigración masiva, etc.), no obstante la aparición del fenómeno es mucho más tardía pero no por ello menos fuerte. Sin embargo, si hay una particularidad que lo diferencia es la organización del territorio en parroquias, lo que confiere a la división del espacio urbano una dimensión especial, en cuanto la parroquia se convierte en un contexto de relación y de creación de nexos con sus vecinos. Justamente, como se puede constatar en la comunicación, es a partir del caso de la parroquia de Valladares a través del cual Fátima Martínez analiza las particularidades de las experiencias de lucha de los vecinos gallegos, no tan centradas en hacer frente al desarrollismo franquista, sino en cómo se va configurando el tejido urbano y la necesidad de los vecinos de querer formar parte de él.

Otro caso particular lo plantea Jon Martínez en su comunicación "El movimiento vecinal en Álava durante la transición". Al igual que ocurre con Galicia, el fenómeno de la movilización vecinal es más tardío debido, entre otras cosas, a la menor conflictividad política y laboral que presenta esta provincia. No obstante, como queda reflejado al texto en varias ocasiones, las prácticas reivindicativas en los diferentes barrios son muy interesantes y, más allá de los logros materiales, se convierten en un factor clave en la dinamización de la vida social de los barrios. Muy interesante resulta el caso de la localidad de Llodio donde, en el intento de llevar a cabo un modelo de gestión municipal asambleario por parte de los vecinos, observamos la relación dialéctica que se establece entre "los de arriba" y "los de abajo". Aunque su duración fue breve, nos demuestra en un caso particular como las asociaciones de vecinos actuaron como un elemento clave de educación y aprendizaje democrático. Con la aproximación a la

2 Constantino GONZALO MORELL: Movimiento vecinal y cultura política democrática en Castilla y León. El caso de Valladolid (1964-1986), Tesis doctoral inédita, Universidad de Valladolid, 2011.

Iván BORDETAS JIMÉNEZ: Nosotros somos los que hemos hecho esta ciudad. Autoorganización y movilización vecinal durante el tardofranquismo y el proceso de cambio político, tesis doctoral, Universitat Autònoma de Barcelona, 2012. 4 Javier CONTRERAS BECERRA: "La democracia se asienta en los barrios. Modelos de ciudadanía en beca SAAVEDRA (eds.): Nuevos horizontes del pasado: culturas politicas, identidades $y$ formas de representación, Santander, Publican, 2011. experiencia de Llodio se pone en relevancia la importancia que tiene el estudio de la microhistoria para el desarrollo del relato global de la historia de la transición.

Al analizar el estado de la cuestión historiográfica sobre movilización social en la transición, observamos como muchos de los trabajos se centran en dos de los movimientos que mayor peso tuvieron: el movimiento estudiantil y el movimiento obrero. Una perspectiva de estudio de ambos movimientos es la que presenta Rosario Fombuena en su comunicación "Lagunas de autoridad. Relaciones e influencias entre las 'fuerzas del trabajo' y 'las fuerzas de la cultura", en la que se analizan las relaciones entre obreros y estudiantes poniendo énfasis en las influencias que recibieron desde el contexto internacional. Tanto estudiantes como obreros beben de las reivindicaciones y prácticas del mayo del 68 francés resultado, en parte lógico, por la proximidad geográfica y porque era en Francia donde se habían radicado las principales estructuras organizativas de la oposición franquista. No obstante, lo que resulta más sorprendente, es observar como calaron en el ideario reivindicativo de estudiantes y obreros la cuestión del feminismo y, sobre todo, las demandas pacifistas norteamericanas contrarias a la invasión del sudeste asiático. Aunque este tipo de reivindicaciones no formaban parte de la columna vertebral de las demandas de ambos movimientos, les otorgaban un gran atractivo para la población en general que vio en ellos un factor de cambio moderno y dinámico.

Sin duda, uno de los agentes del cambio más relevantes durante la transición es el de las mujeres. El movimiento feminista estuvo plenamente inmerso en el proceso de cambio político y social en una doble lucha, por una parte, en la lucha compartida con los otros movimientos sociales de poner fin a la dictadura franquista y, por otro, en una lucha propia para las mujeres de conseguir una ciudadanía plena e igualitaria. Los primeros trabajos que abordan estos temas, las obras ya clásicas de Giuliana di Febo o Amparo Moreno ${ }^{5}$, se centraban básicamente en las resistencias de las mujeres frente al franquismo y los frentes de lucha abiertos al principio de la democracia. A finales de los noventa, empezaron a aparecer aproximaciones al tema que tenían en cuenta el feminismo desde tres puntos de partida: como un conjunto teórico explicativo; una agenda práctico-política y, en tercer término, una masa de acciones no particularmente dirigida ${ }^{6}$. Esta triple posibilidad de enfoque dio un empuje definitivo a los trabajos sobre feminismos durante la transición, empuje que se mantiene hasta la actualidad y que va creciendo en cuanto a aproximaciones metodológicas y técnicas. En estas nuevas investigaciones ha sido relevante la búsqueda de nuevas fuentes, resaltando del valor de los testimonios de las protagonistas, de los archivos personales, apostando por enfoques históricos e interdisciplinares con objeto de buscar nuevos y renovadores estudios sobre las organizaciones y sus actuaciones.

Precisamente, dentro de esta tendencia de explorar nuevas fuentes se encuentra el trabajo de Elena Díaz "La reformulación de las identidades de género en los espacios urbanos durante el tardofranquismo, y su contribución al proceso de transición a la democracia", centrado en la contribución del papel de las amas de casa. Resulta muy interesante observar cómo, en ausencia de otros cauces de participación como las universidades o agrupaciones políticas, las amas de casa encontraron en sus propias asociaciones el medio de participar en todo el proceso de cambio de la transición. Las asociaciones favorecieron la incorporación a la vida asociativa, pública y reivindicativa a un espectro muy variado de mujeres la mayoría de ellas de clase media trabajadora y con responsabilidades familiares. Todas ellas, como reivindica Elena Díaz, colaboraron activamente en la reformulación de las identidades de género que se dieron durante

5 Giuliana DI FEBO: Resistencia y movimiento de mujeres en España: 1936-1976, Barcelona, Icaria, 1979. Amparo Moreno: Mujeres en lucha. El movimiento feminista en España, Barcelona, Anagrama, 1977.

6 Isabel MORANT (coord.): Historia de las mujeres en España y América Latina, Madrid, Cátedra, 2005 vol. IV, pág.415. 
el proceso de transición pero también, al igual que el resto de agentes sociales del cambio, en la consecución de una ciudadanía igualitaria y en la lucha contra la Dictadura.

Una cuestión que ha despertado mucho interés entre la historiografía sobre feminismo es el análisis del sujeto político femenino, eje central del trabajo de Maialen Aranguren, "La construcción del sujeto político durante la transición". En él, se analizan las tres tendencias teóricas del sujeto femenino durante la transición - doble militancia, feminismo radical y feminismo de la diferencia- estableciendo los puntos de encuentro entre todos. Para ello, siguiendo la línea de los recientes estudios sobre transición, busca aproximarse a ellos a través de las fuentes escritas de diversos encuentros de mujeres durante estos años, como las Jornadas Estatales de la Mujer. De todo ello se deriva que, pese a que los marcos discursivos de las tres tendencias eran divergentes, todos ellos compartían la concepción de la mujer como una categoría única de un sujeto autónomo y fuerte, enfatizando los elementos que las unían en vez de los que las separaban.

Por último, destacar la comunicación de Sandra Blasco "Las asociaciones de barrio y las vocalías de mujeres: Un foto activo del feminismo zaragozano", en la cual se analiza el feminismo en la ciudad de Zaragoza, como una minoría activa de oposición al régimen de carácter transversal muy vinculada a otros movimientos sociales. En su análisis, la autora parte de los años sesenta con las asociaciones de amas de casa y con la creación en la clandestinidad de Movimiento Democrático de Mujeres. Este movimiento estaba organizado por barrios y formado por vocalías de mujeres para la filtración de ideas feministas y sociales, llegando hasta la transición con la ADMA y sus posteriores escisiones en el territorio aragonés. Al igual que Elena Díaz, destaca el papel de las asociaciones de amas de casa como un agente catalizador del antifranquismo que, a partir de sus vínculos con otros movimientos sociales, dinamiza la oposición al régimen entre mediados de los años sesenta y principios de los ochenta.

Para una comprensión total de los movimientos sociales durante la transición, habría que preguntarse cuál fue el papel desarrollado por los medios de comunicación. Este ha sido un tema que ha despertado mucho interés entre los historiadores y periodistas, en tanto que actuaron como canales entre la ciudadanía y los acontecimientos, en algunos casos como impulsores pero también en muchas ocasiones obstruyendo y limitando la acción de los agentes sociales. Además, consideramos que dada su compleja situación como agente movilizador (o desmovilizador) y como fuente de estudio, necesita ser enfocado desde una perspectiva pluridisciplinar en la línea de los últimos trabajos de Cheyrouze 7 , en los que se tienen en cuenta todas las perspectivas que forman parte del proceso comunicativo.

Por lo que a la aportación de Carles Senso se refiere "Valencia Semanal. De información contra el posfranquismo a altavoz del PSOE", muy significativa es la problemática ya citada respecto a la ausencia de estudios previos. Con esta premisa se inicia la segunda jornada de la mesa-taller. A partir de sus estudios se puede analizar el papel que juegan los diferentes medios de comunicación, siempre en favor de una corriente de opinión relacionada con algún partido político. En el caso de la revista Valencia Semanal, su creación queda ligada al nacionalismo valenciano de raíz fusteriana, próxima a la socialdemocracia y a la izquierda europea. Aunque con el tiempo, ya sea por su poca influencia dentro del panorama valenciano, por la negativa de muchos empresarios a colaborar con una revista que consideraban catalanista o por sus problemas económicos, acabará en unos posicionamientos próximos al PSOE, llegando a actuar como altavoces de concretas corrientes de opinión, sobretodo las más lejanas al valencianismo político. Dicha revista contará con un gran elenco de periodistas que publicaran en sus páginas diferentes puntos de vista de los problemas que la transición democrática no resuelve con el ahínco que la sociedad pide en el País Valenciano. Además, las revistas que como Valencia Semanal no salían a

7 Rafael QUIROSA-CHEYROUZE: Prensa y democracia: los medios de comunicación en la Transición, Madrid, Biblioteca Nueva, 2009. la calle diariamente tuvieron que hacer frente a una fuerte crisis que derivaría en la disolución de muchos medios de comunicación, entre ellos, el aquí analizado.

El tema de los medios de comunicación durante el periodo transicional también ha sido tratado a partir de la aportación de Cristina Alquézar mediante su comunicación "La revista Esfuerzo Común. La crisis de la dictadura franquista y la construcción de una cultura política democrática (1968-1974)". Aunque esta publicación dista mucho de Valencia Semanal en sus posicionamientos, se asemeja a ésta en que desde un principio nace como una herramienta de difusión, relacionada con el carlismo autogestionario de Zaragoza, llegando a ser también un espacio de libertad antifranquista. La autora construye su relato a partir de la denominada historia social renovada que reflexiona sobre el concepto de cultura política, sirviendo sus estudios como ejemplo de conjunción entre lo social y lo político. Es decir, la revista analizada es un instrumento político que interactúa con la sociedad, influyéndola y condicionando la opinión pública.

Otro de los aspectos que condicionan los estudios respecto a la transición y la democracia en el estado español, como hemos dicho, además de las fuentes orales, son los problemas de acceso a los archivos, así como su ausencia en aspectos concretos. De esto nos habla Juan Carlos Colomer con su comunicación "Elecciones por tercios y renovación de un consistorio franquista. Valencia (1969-1979)", que trata la importancia de la dicotomía entre el franquismo autoritario y la democracia. De sus análisis se desprende la idea de que hay una reacción democrática porque hay una acción autoritaria, sobre todo a partir del año 1973, cuando la campaña electoral para las elecciones por tercios tuvo una gran influencia en la sociedad, la cua actuó en consonancia con los deseos de libertad del momento, acelerando el proceso en favor de un estado democrático e iniciando en final del régimen franquista. El autor, a partir de sus estudios argumenta la idea de la desinformación de la sociedad por parte de un sistema que ve peligrar su status quo y que necesita de su autoritarismo y su fuerza represiva para detener el auge de una sociedad deseosa de mejoras tanto sociales como políticas y económicas.

Esta ruptura democrática a la cual parece ser que aspira la sociedad valenciana, para Alfonso Natividad no fue tal. El autor, con su comunicación "Del antifranquismo a la democracia. La aportación del valencianismo político a la ruptura democrática valenciana: 1974-1977" argumenta esta postura analizando las demandas de la sociedad y aquellas realizadas por las élites políticas. Para el comunicante, además de no darse la conocida como ruptura democrática, tampoco se dieron las condiciones necesarias para el surgimiento de un nuevo valencianismo político basado en las teorías del ensayista Joan Fuster. El autor se reafirma en el fracaso político del nacionalismo valenciano apoyándose en los resultados electorales, pero argumentando que dicho fracaso no se dio en el campo social y cultural, donde el valencianismo sí consiguio asentarse. De esta comunicación se desprenden dos ideas principales más relacionadas con el devenir del nacionalismo valenciano durante los primeros años de la transición: la primera idea viene ligada del importante papel de los agentes sociopolíticos valencianos que actuaron en favor de una identidad diferenciada, creando diferentes plataformas para así unir esfuerzos o incluso enfrentándose a las ya creadas de ámbito estatal. La segunda, viene derivada de la importancia de Joan Fuster y sus teorías sobre la identidad valenciana diferenciada, que condicionarán la política valenciana durante todo el periodo. Para Alfonso Natividad, en un momento en el que se estaba articulando un discurso anticatalanista por parte de la derecha sociológica, las teorías del ensayista que ligaban el valencianismo al catalanismo no tuvieron el calado esperado, provocando el fracaso político.

La comunicación de Antonio Muñoz "Denuncia y reivindicación a través de la canción en Andalucía" también trata los temas de pertenencia de los colectivos, en este caso, mediante la conocida como nueva canción andaluza, de carácter reivindicativo y muy ligado a las demandas sociales de libertad y democracia que combinaba música y poesía. A través de esta comunicación, basada en los marcos de referencia interpretativa, se observa la gran eficacia simbólica de los cantautores andaluces, entre los que destaca el colectivo Manifiesto Canción 
del Sur, Carlos Cano o Benito Moreno. Resulta interesante observar como con sus canciones aumentarán el sentimiento andalucista en diferentes sectores de la población, siguiendo la estela de otros territorios estatales como Cataluña, el País Vasco o el País Valenciano. Además, estos cantautores llegarán a ocupar una posición principal dentro del espacio mediático progresista, llegando incluso a implicarse en diferentes proyectos políticos. De la aportación de Antonio Muñoz se debería destacar la especificidad del caso andaluz frente a la nova cançó, ya que tuvo que coexistir con otros géneros como la copla y el flamenco, más ligados al régimen franquista y en la óptica opuesta a las reivindicaciones sociales y de libertad que reivindicaba la nueva canción andaluza. De hecho, tal como comenta el autor, el franquismo utilizó estos estilos musicales para restar protagonismo a la nueva canción. Si se analiza la repercusión mediática, tanto la copla como el flamenco, contaban con los canales propios del aparato franquista, mientras que la nueva canción andaluza quedaba fuera de éstos, por lo que tuvo que buscar plataformas nuevas de carácter democrático y antifranquista

Otro movimiento social que tuvo su importancia dentro del panorama sociopolítico español durante el periodo de transición, fue el pacifismo y el antimilitarismo, aspectos desarrollados por Carlos Ángel Ordás en su comunicación "Pacifismo antimilitarista, no-violento y desobediente. El movimiento pacifista y antimilitarista en el tardofranquismo y la transición Contextos, estrategias y relaciones". Aunque como dice su autor, el mayor problema que nos encontramos al tratar este movimiento social es la escasa información al respecto y la ausencia de estudios previos referentes al movimiento pacifista y antimilitarista, cierto es que se hace necesario una aproximación más profunda similar a la desarrollada en otros territorios europeos y que, como también se analiza en la comunicación de Rosario Fombuena, influenciaron los movimientos dentro del estado español. Unos movimientos que, si bien son analizados como un todo, se debe destacar que con el tiempo se separan, siendo obviados por los partidos de la izquierda tradicional que no era partidaria de las posturas de la desmilitarización del estado. A los problemas para hacer más visible los movimientos en favor de la paz y de la no militarización se deben sumar la carencia de lugares de sociabilización de éstos, que perjudicaron el normal desarrollo de las plataformas y organizaciones. Con todo esto, los movimientos pacifistas y antimilitaristas crecieron sobre todo en los años ochenta, con el Movimiento de Objeción de Conciencia y con la cuestión de la entrada en la OTAN, haciendo que dichos movimientos sociales hayan continuado en los años posteriores.

Relacionado con el movimiento pacifista y antimilitarista se encuentra la izquierda revolucionaria, analizada Joel Sans en la comunicación "L'esquerra revolucionària i el seu paper en la mobilització social i el canvi polític dels anys 70: estat de la qüestió i alguns apunts per al seu estudi". Este texto trata de forma clara el estado de la cuestión actual referente a la izquierda revolucionaria y extraparlamentaria, haciendo un análisis a las visiones realizadas por la historiografía, que ha tratado mínimamente el tema. Este es uno de los problemas del que nos habla Joel Sans ya que, tanto en la bibliografía como la historiografía, encontramos ausencias significativas referentes a los estudios de la izquierda revolucionaria. El autor acepta (como en anterioridad Alfonso Natividad había hecho con el valencianismo), la poca presencia política de la izquierda revolucionaria en términos generales y el importante peso que tuvo en la parte social y de movilización, tal y como demuestran los diferentes lazos de unión que se pueden encontrar entre los partidos aquí tratados y otros movimientos sociales, entre los que destacan el vecinal y el obrero. El vínculo fue tan estrecho que, con la crisis de la izquierda revolucionaria, llegaron los problemas a los movimientos sociales relacionados con ésta. El autor relaciona estos apuntes con el aumento del peso de la izquierda revolucionaria dentro de los estudios actuales referidos al momento de la transición, siempre teniendo en cuenta su menor protagonismo en referencia tanto al PCE como al PSUC, pero no por eso menos importante para entender el proceso de transición democrática de los años setenta.

Por último, y ligando el tema de la conjunción de la praxis política y social, deberíamos destacar "Municipalismo y cambio político (1976-1979): la construcción de la democracia en el mundo rural", de Cristian Ferrer. El autor marca como punto inicial de sus teorías la importan cia de la acción social para el aprendizaje de la acción política dentro del marco rural catalán de que denomina "espa Ley de Asociaciones del régimen franquista. Además, a partir del debate surgido, podemos encontrar ciertos paralelismos de acción entre aquello que hemos denominado "agrarismo" y los movimientos vecinales: las acciones de los colectivos sociales impregnan toda demanda social, cultural, económica y, por extensión, de carácter político, haciendo que en el mundo rural todas estas praxis actúen de manera conjunta en favor de una mejora en las condiciones de vida de los habitantes. A partir de esta discusión, vemos diferentes líneas de debate que surgen relacionadas con la aceptación de la microhistoria como agente útil en el estudio de la transición y con la lucha de clases como motor de cambio social en la España tanto rural como urbana. Nos planteamos así qué hace que la lucha pase de ser "de clase" a una lucha generalizada, entendida por todo un colectivo como una necesidad.

\section{Conclusiones}

Para finalizar, tras lo expuesto en la mesa taller, podemos concluir que no existen movimientos sociales menores o en un segundo plano ya que, aunque sus objetivos particulares no hayan sido alcanzados, todos participan de un proceso general de modernización social y cultural. Todos estos agentes sociales se perciben por parte de la sociedad como un espacio natural de interacción en el que no resulta extraño a la población relacionarse en él. De aquí que se pueda explicar cómo se pasa con total naturalidad de reivindicar unos objetivos materiales y cercanos que afectan directamente a su entorno más inmediato a pasar a reivindicar unos objetivos "macro" que son comunes a todos los movimientos sociales. A partir de las comunicaciones presentadas en la mesa taller y de los debates posteriores, estamos convencidos de que la investigación de los movimientos sociales que aceleraron la transición política a la democracia en España debe realizarse sobre una perspectiva interdisciplinar y pluridimensional. Con esta aproximación más compleja pretendemos poner de relieve el carácter determinante que adquirieron estos movimientos en la etapa final de la dictadura, creando sistemas de valores y actitudes con los que se establecieron nuevas redes de sociabilidad y espacios de libertad en los que se preparó el terreno para la llegada de la democracia. 


\section{LA REVISTA ESFUERZO COMÚN, LA CRISIS DE LA \\ DICTADURA FRANOUISTA Y LA CONSTRUCCIÓN DE \\ UNA CULTURA POLIITICA DEMOCRÁTICA (1968-1974)*}

Cristina Alquézar Villarroya

Universidad de Zaragoza

Tras más de dos décadas de investigaciones sobre el período de la Transición a la democracia en España, acompañadas de renovaciones historiográficas tan importantes como la introducción de la historia social y la reformulación de la misma desde diversos enfoques culturales, se hace muy difícil no entender la Transición como el producto de la crisis del régimen franquista.' La lucha de la clase política franquista por mantenerlo vivo se convirtió en un pulso político entre aquéllos y una parte de la sociedad española que se movilizó para intentar acabar con una dictadura cuya legitimidad, a la altura de finales de los años sesenta, había perdido prácticamente toda fundamentación. A mediados de la década siguiente, se sucedieron varios intentos frustrados de reforma desde el propio régimen para intentar encauzar las protestas y reivindicaciones a favor de la instauración de la democracia. En ello consistió ese pulso que acabaría inclinándose hacia la opción democrática cuando en 1977 se convocaron las elecciones que darían paso a un proceso constituyente.

Así, los movimientos sociales, los viejos y los nuevos, aparecen como uno de los agentes protagonistas indiscutibles del proceso democratizador. Las prácticas políticas llevadas a cabo por estas fuerzas sociales fueron múltiples y de ese modo diferentes objetos de estudio historiográfico han ido proliferando y diversificando. En 2005, el II Congreso Internacional "Historia de la Transición en España. Los inicios del proceso democratizador" destacó el papel que jugaron los medios de comunicación "por su importancia como motor de cambio de la realidad española de los años setenta". A raíz de esas conclusiones se celebraría, dos años más tarde, el III Congreso titulado "El papel de los medios de comunicación",3 que del mismo modo subrayó la influencia de los medios en el devenir del proceso, debido, entre otras cosas, a su relación con la construcción de una conciencia histórica democrática.

Un estudio más completo puede encontrarse en "Esfuerzo Común, una revista carlista de oposición al régimen franquista (1960-1974)" en Revista de Historia Jerónimo Zurita, 88 (2014), en prensa

Pere Ysàs defiende que la Transición no se entiende si no se presta atención a la crisis final del franquismo, es decir, a las movilizaciones sociales antifranquistas que aquél ya no pudo controlar y a los problemas internos de la propia cúpula franquista. La acción colectiva, las movilizaciones sociales contra el régimen, según él, representaron un factor esencial en el fin de la dictadura: porque con su constante presencia en la calle rompía con uno de los pilares de la legitimidad franquista, la "Paz de Franco",y porque precisamente esa ocupación en la calle impidió que el proyecto reformista de Arias Navarro siguiera adelante a la altura del verano de 1976, abriendo el camino de la deseada democratización que, hasta el momento, había permanecido cerrado. Pere YSÀs: "La crisis de la dictadura franquista", en Carmen MOLINERO (ed.): La transición, treinta años después. De la dictadura a la instauración y consolidación de la democracia, Barcelona, Península, 2006.

2 Forma parte de los congresos organizados por el Grupo de Investigación “Estudios del Tiempo Presente" de la Universidad de Almería, dedicados específicamente al período final de la dictadura franquista y de la Transición y cuyo director es Rafael Quirosa-Cheyrouze.

3 Rafael QUIROSA-CHEYROUZE: Prensa y democracia. Los medios de comunicación en la Transición,

Madrid, Biblioteca Nueva, 2009.
Este texto se inserta en esa línea de investigación mostrando los primeros pasos de un estudio sobre la función que desempeñó la revista carlista Esfuerzo Común en relación a la crisis del franquismo y el establecimiento de la democracia.

\section{El estudio de una revista como práctica política antifranquista}

Esta investigación se ha planteado desde los parámetros de la llamada nueva historia política o, si se quiere, la historia social renovada y, por ello, se ha reflexionado sobre el concepto "cultura política" 4 y se ha asumido como uno de sus bases metodológicas. Ante la múltiples concepciones, fruto de las variadas disciplinas que han hecho suyo el concepto, se entiende aquí, tal y como opina Ismael Saz, ${ }^{5}$ que muchas de ellas son válidas y que lejos de contradecirse, son complementarias. Se apuesta, pues, por un eclecticismo que adopta tanto los enfoques discursivos -la referencia aquí es Baker- como los más descriptivos -en la línea de Bernstein y Sirinelli-. Según el planteamiento del primero, entendemos cultura política como un "conjunto de discursos o prácticas simbólicas", ${ }^{6}$ y según los segundos, como "un conjunto de representaciones que configura un grupo humano en el plano político, una visión del mundo compartida una común lectura del pasado y una perspectiva de futuro", que en definitiva, por otra parte, conforman un conjunto de "creencias, valores, memoria específica, vocabulario propio y una sociabilidad particular, ritualizada o no".7 Ouizá la explicación de Bernstein sea la más inteligible desde nuestra formación como historiadores. Este autor defendía que existían unos valores o factores subyacentes en la acción política que, si bien no eran causas determinantes, sí que debía tenerse en cuenta en el análisis para poder entenderla de una manera más profunda. Se trata, en definitiva, de "un sistema de representaciones que permite hacer inteligibles comportamientos políticos que de otra manera no lo serían".

De este modo, el estudio de una revista cobra relevancia histórica como instrumento político que condiciona la opinión pública y su posterior acción. Y así lo entiende Gloria García González cuando se refiere a las revistas antifranquistas como actores principales "en la construcción de un clima favorable a la protesta, donde ésta pudiera estar justificada", pues, dice, ofrecían discursos que dieron sentido, explicaron y justificaron la protesta como único medio

4 Se trata de una reflexión necesaria, ya que a la altura del final de la primera década del dos mil, se sigue advirtiendo de la necesidad de reflexión teórica acerca de este concepto, de la necesidad de problematizarlo para evitar caer en una mera descripción de situaciones y actuaciones que, además, son introducidas después en etiquetas sin explicación ninguna. A falta, pues, de esta base teórica, lo que el historiador al menos debe realizar es hacer un uso transparente y consciente del concepto. Se advierte de este peligro y se exige este esfuerzo en los siguientes textos: Migue Ángel CABRERA: “La investigación histórica y el concepto de cultura política”, en Manuel PÉREZ LEDESMA y María SIERRA (eds.): Culturas politicas: teoría e historia, Zaragoza, Institución Fernando el Católico, 2010, pp. 19-85; Javier DE DIEGO ROMERO: "El concepto de cultura política en ciencia política y sus implicaciones para la historia", Ayer, 61 (2006), pp. 233-266; Francisco Javier CASPÍsTEGUI: “La llegada del concepto de cultura política a la historiografía española", en Alberto SABIO et al., (coords.): Usos de la historia y políticas de la memoria, Zaragoza, Prensas Universitarias de Zaragoza, 2004, pp. 167-186.

5 Ismael SAZ: "Las culturas políticas del nacionalismo español", en Manuel PÉREZ LEDESMA y María SIERRA (eds.): Culturas políticas... p. 328.

6 Keith Michael, BAKER: "El concepto de cultura política en la reciente historiografía sobre la Revolución Francesa", Ayer, 62 (2006), pp. 89-110

7 Ismael SAZ: “Las culturas políticas...”, pág. 328. Texto original: Jean-François SIRINELLI: “Éloge de la complexité", en Jean Pierre RIOUX y Jean-François SIRINELLI (dirs.): Pour une historie culturelle, Paris, Seuil, 1997, pp. 433-441

8 Miguel Ángel CABRERA: “La investigación histórica..., pág. 19. Texto original: Serge BERNSTEIN "Nature et fonction des cultures politiques", en Serge BERNSTEIN (dir.): Les cultures politiques en France, Paris, Seuil, 2003, pp. 7-31 
a través del cual era posible encauzar al país por la vía de la modernidad, o como "portador de una identidad nacida tanto de su práctica social, la movilización, esencialmente, como de la representación simbólico-mediática que alcanzaban sus páginas". Su aportación fue, continúa decisiva, puesto que fue uno de los generadores del marco interpretativo común, una misma cultura política, de la que participaron distintos colectivos sociales y que les permitió entender la situación del país en unas claves de cambio político muy similares. ${ }^{9}$

Las revistas antifranquistas, por tanto, estaban inmersas en un combate por ganarse a la opinión pública frente a la propaganda y política informativa y cultural del régimen. Los periódicos y revistas, en concreto, lograron convertirse en foros públicos que fijaban agendas de debate y equipaba al lector con argumentos para la discusión, de ahí que se les haya llamado "parlamentos de papel".$^{\circ}$ Las revistas en concreto salieron muy favorecidas. Éstas florecieron por doquier, frente a la prensa del Movimiento, que descendió a marchas forzadas ante un nuevo competidor que ofrecía lo que la sociedad pedía, respondiendo a la creciente demanda informativa de los españoles y a sus nuevas ansias de consumo cultural.

Cualquier régimen necesita para sobrevivir un consenso que le garantice la adhesión social, es decir, altas dosis de legitimidad. En España esa adhesión se había conseguido, en un primer momento, gracias a la represión y, después, a los beneficios conseguidos tras el desarrollo económico. Sin embargo, no era suficiente, especialmente tras los cambios sufridos por la sociedad española. Así, el régimen franquista debió jugar con los discursos, con los imaginarios de la población y con los prismas culturales, a través de los cuales aquella entiende la realidad, justifica su existencia y actúa conforme a ello. Lo cierto es que el control de los medios de comunicación ha sido siempre la piedra angular de las dictaduras. Los gobernantes, de esa manera, pueden controlar lo que los gobernados conocen e impedir así que se genere una opinión pública capaz de criticar y cuestionar el ejercicio del poder. Así las cosas, estalló la batalla por ganarse a la opinión pública, que se erigió como un pulso entre el gobierno, que mantiene los resortes del poder, pero que pierde el control de la información y de la libertad de expresión, incapaz de acabar con la disidencia, y la oposición.

El trabajo de Muñoz Soro sobre Cuadernos para el diálogo" defiende estas tesis y afirma que las revistas se convirtieron en un espacio de libertad conquistado frente a la resistencia a cambio del régimen, donde, a través de ciertos mecanismos de socialización, se desarrolló una cultura cívica democrática que generaría el cambio cultural que precedió o acompañó a la movilización social y al cambio político. Así, se entiende que el estudio de esta revista es el estudio de la crisis del franquismo y del protagonismo de la oposición antifranquista. Y es, a partir de ahí y del modelo metodológico que ofrece la monografía de Muñoz Soro, desde donde se ha partido para interpretar y explicar la revista Esfuerzo Común.

\section{Las funciones de la revista Esfuerzo Común}

Uno de los primeros pasos que se ha dado al comenzar el estudio de Esfuerzo Común ha sido delimitar los años en que se puede considerar que la revista participó con mayor claridad y efectividad de la prácticas antifranquistas. El proyecto político del propietario, Ildefonso Sánchez Romeo, siguió una trayectoria similar, salvando las distancias, a la que trazó Ruiz-Giménez a través de su revista Cuadernos para el Diálogo. Según Muñoz Soro, aquél había partido de la voluntad de reformar las instituciones "desde dentro", solicitando que el régimen fuera al

9 Gloria GARCÍA GONZÁLEZ: “En la calle y en el papel, por la ruptura democrática. Triunfo, 19761977", en Rafael QUIROSA-CHEYROUZE: Prensa y democracia..., pp. 210-215.

- Elisa CHULIÁ: El poder y la palabra. Prensa y poder político en las dictaduras. El régimen de franco ante la prensa y el periodismo, Madrid, UNED, Biblioteca Nueva, 2001, p. 215

11 Javier MUÑOZ SORO:Cuadernos para el diálogo (1963-1976). Una historia cultural del segundo franquismo, Madrid, Marcial Pons, 2006. menos lo que declaraba ser y aplicara la doctrina vaticana que debía inspirar sus Leyes Fundamentales, para ir de manera gradual hacia un régimen de naturaleza diferente. Sin embrago explica, desde 1966, en este caso desde 1968, la revista renunció a ese discurso "desde dentro" y se alineó decididamente en el antifranquismo. ${ }^{12}$

El origen de Esfuerzo Común debe buscarse en los intereses políticos del abogado zaragozano Sánchez Romeo quien, a comienzos de los años sesenta, creó una revista dedicada a asuntos económicos con el fin de difundir sus ideas cooperativistas, basando sus argumentaciones en el ideario carlista ${ }^{13}$ y en la doctrina católica renovada tras el Concilio Vaticano II. Sin embargo, el nuevo carlismo, a lo largo de los años sesenta, se fue desplazando hacia el bando de la oposición hasta colocarse claramente en él tras la expulsión de Carlos Hugo, en diciembre de 1968. Justo unos meses después, Esfuerzo Común se convertía en una revista de información general acentuando así su carácter político. De esta manera, a partir de ese año, esta publicación asumió claramente la función de órgano de evolución y difusión del nuevo ideario carlista. Pero además, teniendo en cuenta el giro que había dado parte de ese grupo político, adoptaría asimismo la función de órgano de lucha antifranquista. Unos años más tarde, en 1971, el periodista Tomás Muro tomó las riendas de la dirección, modernizando la revista y permitiendo que ésta se asentara como una revista de información general antifranquistas más de la época como Triunfo, Cuadernos para el Diálogo o la aragonesa Andalán -salvando las distancias, pues la calidad y proyección de Esfuerzo Común fue menor-. Se le dotaría de un consejo de redacción, de unas secciones fijas, de un tamaño mayor, más acorde con el resto de publicaciones, y se convertiría en quincenal, ganando el dinamismo requerido en aquellos momentos.

Si seguimos el esquema trazado por Muñoz Soro a la hora de analizar Cuadernos para e Diálogo, debe contemplarse una doble función desempañada por estas revistas. La primera decisiva, según explica, para la transición a la democracia, fue la labor de deslegitimación y crítica de la dictadura. Así, la lectura de los números publicados a partir de 1968 muestra un discurso que se va clarificando para acercarlo a la realidad denunciando más nítidamente la verdadera naturaleza del franquismo ante sus pretensiones de presentarse ante el mundo como un Estado de Derecho, una democracia “orgánica"y un régimen en constante proceso de apertura y "perfeccionamiento": 14

Arias Navarro: aperturismo acotado (...) La situación es nueva, pero tiene un alcance y unos límites bien precisos. (...) Nosotros nos hemos incluido entre los de la mínima esperanza (...) Confiamos, eso sí, en la sinceridad de las manifestaciones (...) Nuestra duda se refiere únicamente a la posibilidad de conseguir su realización dentro del marco señalado que sigue siendo totalmente inamovible. (...) ¡Ojalá que nuestras dudas sobre las auténticas posibilidades de la proclamada apertura no se vieran confirmadas (...)! Si el pueblo está maduro políticamente, como ha sido oficialmente reconocido y sancionado, no vacilamos en afirmar que las promesas formales que se han hecho hasta el momento son un tanto reducidas y recelosas. (...) ¡Ya veremos cómo son esas elecciones de alcaldes y presidentes de diputaciones y las diferencias que existen con respecto a las formas de

12 Javier MUÑOZ SORO: Cuadernos para el diálogo..., p. 196

13 Aunque aquí no se ha desarrollado, se entiende que la historia de una revista no se explicaría sin la historia de la vida de las personas que estuvieron detrás. Por ello, la investigación en la que $s$ inserta este texto ha intentado realizar una biografía colectiva del propietario, del director y de algunos colaboradores habituales. El objetivo es conocer las razones de su afiliación y de su participación en la revista, su idea de la significación de ésta para el carlismo, para el período y para su trayectoria personal, así como los temas relativos a la confección de la revista, su proyección o al impacto de la censura.

14 Javier MUÑOZ SORO: “La parábola de Cuadernos para el Diálogo: De la pasión política a las instituciones", en Rafael QUIROSA: Prensa y democracia..., p. 187. 
elección [?] actualmente en vigor! Ponemos nuestro interrogante porque para algunos, muy pocos por cierto, pero que pueden hacerse oír y leer, actualmente ya se elige; y, por añadidura, a los mejores. (...) Está claro que la apertura prometida no tiene nada que ver con la concesión de las libertades formales que existen en Europa (....).15

Por otro lado, Muñoz Soro señala una segunda función, la pedagógica, la de conformar dentro de la sociedad civil una "opinión pública", así como la construcción de una cultura democrática, que no fue dada por el cambio socioeconómico, sino buscada y creada. ${ }^{16}$ Esfuerzo Común, como hizo Cuadernos para el Diálogo, utilizó sus páginas, por un lado, para informar sobre los nuevos movimientos sociales, con especial incidencia, la conflictividad obrera y universitaria. Este tipo de artículos eran además esenciales para minar al régimen, cuya legitimidad se basaba en gran parte en su logro de una paz sin conflictos. Además, a causa tanto de las raíces de la revista como de la condición religiosa del director, Tomás Muro, la temática religiosa tuvo en esta etapa de la revista un lugar especial. Se mostraba el nuevo panorama de la Iglesia católica y las nuevas corrientes de pensamiento cristianas. Esta publicación también mostró interés por las manifestaciones culturales, puesto que lo cultural había adquirido en aquellos años un importante valor político.

Este tipo de publicaciones, además, tuvieron un empeño por recuperar el pasado español, construido sobre un discurso de reconciliación, aquél que, lejos de pretender conciliarse con la dictadura, trataba de concentrar todas los esfuerzos para acabar con ella. En Esfuerzo Común se observa la evolución de su discurso sobre la guerra civil, desde un primer momento en que, sobre todo, para Sánchez Romeo, quien había luchado en la guerra, es un referente constante, loable y justificador de su evolución, hasta llegar a entenderlo como un acontecimiento que se debía, utilizando las palabras de Santos Juliá, "echar al olvido":17

El reto histórico de la democratización: (...) Las asociaciones suponen para la derecha española, la necesidad de reorganizarse, la necesidad de volver a pesar políticamente, la necesidad de ser no sólo ya una fuerza latente económica o numéricamente (...) La oposición, con ella tendrá que hablar, al fin y al cabo. En 1936 era la mitad de España, una mitad de la que la otra mitad no puede prescindir (.) (.) El comunismo es hoy un mito creado consciente o inconscientemente por hombres del régimen que lo utilizaban para mantener su exclusiva, su monopolio. (...) Por eso puede decirse que es aun muy largo el camino que será necesario recorrer para que el pueblo y el estado lleguen a encontrarse. Impiden ese encuentro muchas cosas, lo impide una guerra civil que no se ha superado un exilio republicano muy presente, y sobre todo una sociedad durante décadas anestesiada, inundada de falsa propaganda, que iba desde los fantasmas hasta el slogan de que el pueblo español es un pueblo especial, no un pueblo europeo con el que en consecuencia habría que proceder con libertades, sino un pueblo al que habría que controlar, en un país que dista mucho de ser todavía de todos los ciudadanos. ${ }^{18}$

Por otro lado, recuperaron las culturas y lenguas regionales, así como la defensa de sus derechos. Según Pere Ysàs, muchos son los factores que ayudan a explicar el proceso de cambio

15 Esfuerzo Común, 185 (1 de marzo de 1974), pp. 5-6.

16 Javier MUÑOZ SORO: “La parábola..., pág. 188-189. Javier MUÑOZ SORO: “Modernización y control social en el franquismo: la censura contra la revista Cuadernos para el diálogo", Historia del presente, 1 (2002), p. 30 .

17 Para un mayor conocimiento del concepto: Santos JULIÁ: “Echar al olvido. Memoria y amnistía en la transición", Claves de razón práctica, 129 (2003), pp. 14-25

18 Aquilino GONZÁLEZ NEIRA: Esfuerzo Común, 185 (1 de marzo de 1974), pp.14-16. de una dictadura a una democracia y entre ellos merece especial atención el fenómeno de los nacionalismos o regionalismos cuya dinámica marcó en gran medida el carácter, los objetivos, el discurso y, en general, la cultura política de gran parte de la oposición democrática y marco, como consecuencia, pues la oposición fue un agente clave del proceso, la definitiva construcción de un nuevo estado democrático, que será el "de las autonomías". ${ }^{9}$

En este marco también puede situarse a Esfuerzo Común, ya que la defensa de lo regional fue uno de sus rasgos característicos desde casi sus inicios, en 1960, hasta $1974^{20}$. Así, esta revista se convirtió, junto a Andalán, ${ }^{21}$ en uno de los primeros órganos que, durante el franquismo, defendió una personalidad política y cultural propia aragonesa. En realidad, la pretensión de las personas que se encontraban detrás de la revista, muchas de ellas de origen distinto al aragonés, fue abanderar la causa regionalista de cada una de las regiones de España. Muestra de ello son los números especiales sobre las diferentes regiones españolas que se publicaron desde abril de 1972 y que continuaron tras 1974. El primero fue el dedicado a Aragón

Aragón tierra y justicia: Esfuerzo Común es una revista nacida en Aragón; a pesar de sus firmes pretensiones de universalidad temática, quiere también quedarse en Aragón (...) En esta tarea ingente y ardua, fundamentalmente política, queremos colaborar con todos los aragoneses que se sienten orgullosos de su patria. (...) Con todos los aragoneses que luchan y suspiran por dar aliento al Aragón perdido, con todos los hombres de arriba y abajo, los de enfrente y los de al lado. Queremos reconstruir Aragón con un sano criterio regional, autónomo e integrador y un sólido fundamento cristiano y democrático. (...) Queremos un Aragón pacífico, abierto a todos, comprensivo y libre. Un Aragón sin libertades políticas sería un Aragón desfigurado, un Aragón sin libertades sindicales sería un Aragón anémico, un Aragón sin libertad regional sería un Aragón colonizado, un Aragón sin libertad religiosa sería un Aragón de cristianismo convencional pagano (...).22

\section{Los efectos de la censura}

La presente investigación intenta arrojar luz sobre los modos en que las revistas antifranquistas podían agravar la crisis de la dictadura y asentar las bases culturales e ideológicas de la democracia y, así, se ha afirmado que la revista Esfuerzo Común ejercía esa función. Sin embargo, también es cierto que su capacidad de influencia, de hacerse eco de sus denuncias y críticas al régimen, así como de sus ideas democráticas y autogestionarias carlistas, no puede considerarse relevante debido, sobre todo, a su escasa difusión. ${ }^{23}$

Ahora bien, lo que sí puede sostenerse es el hecho de que fue una revista de oposición al régimen y que esta característica le llevó a ser, en numerosas ocasiones, el blanco de la diana ante los ojos del censor hasta el punto de ser conocida por el sobrenombre de "Secuestro Común". ${ }^{24}$ De esta forma, ese nuevo nombre y lo que suponía, la falta de libertad y la existencia de disidencia, proveniente además del interior del propio régimen, fue lo que logró extenderse entre la opinión pública.

9ere YSÀs: "Democracia y autonomía en la transición española”, Ayer, 15 (1994), pp. 77-108

20 A pesar de que la revista continuó hasta los años ochenta, esta investigación sólo se ha ocupado de los años comprendidos entre 1960, año de creación, y 1974, año en que Tomás Muro abandonó la dirección, considerando que entonces termina la etapa que aquí nos interesa.

21 Andalán fue la revista antifranquista más importante durante los años setenta en Aragón.

22 Esfuerzo Común, 142 ( 1 de abril de 1972), pp. 11-41.

23 Una de las razones es que esta revista nunca se llegó a vender en los quioscos. Su distribución se realizaba a través de la suscripción.

24 Eloy FERNÁNDEZ CLEMENTE y Carlos FORCADELL: Historia de la prensa aragonesa, Zaragoza, Guara Editorial, Colección Básica Aragonesa, Caja de Ahorros de Zaragoza, Aragón y La Rioja, 1979, p. 239. 
La Ley de prensa de 1966, la llamada "Ley Fraga”, formó parte de uno de los anteriormente citados proyectos de reforma del régimen que fracasaría en su intento por buscar formas de legitimidad democrática, a través de la apertura de las estructuras del régimen a sectores más amplios. Era imposible satisfacer el anhelo de libertad de expresión de la sociedad española sin poner en peligro la propia supervivencia del régimen, cuya naturaleza era incompatible con la supresión de la censura que con la nueva ley simplemente pasó de ser preventiva a ser represiva.

La nueva ley no sólo no pretendía establecer una situación de semitolerancia ni pudo controlar, por ese motivo, la información y la libertad de expresión, sino que además dio pie a que la oposición se beneficiara de ella forzando los límites de la ley, consiguiendo sacar adelante revistas como ésta. En este caso, además, la censura resultó cara al régimen, pues el sobrenombre "Secuestro Común" suponía la deslegitimación de un régimen que deseaba aparentar su modernización y su adaptación a la situación social, pero que chocaba con su propia realidad. Esfuerzo Común se convirtió así en una imagen cargada de significados que se añadirían al imaginario de la cultura política antifranquista, reforzando esa identidad.

A partir de la llegada de Tomás Muro y de la renovación del equipo de redacción, que supondría la entrada de jóvenes colaboradores, Esfuerzo Común sufrió seis secuestros, tres citaciones judiciales, una inspección extraordinaria y cuatro multas. Las consecuencias negativas que aquello conllevaba, especialmente las económicas, representaban graves impedimentos para que la revista ejerciera libremente la libertad de expresión. Sin embargo, a pesar de los costes, lo consiguieron, decidiendo proseguir con una actividad que consideraban fundamental como elemento desestabilizador del régimen.

El primer número secuestrado fue el segundo publicado por el nuevo equipo en noviembre de $1971 .{ }^{25} \mathrm{El}$ motivo del secuestro había sido la supuesta acusación que Esfuerzo Común realizo contra el jefe del Estado por querer hacer impunes a los imputados por el caso MATESA, as como a los posibles delitos de coacción electoral denunciados con motivo de las elecciones a Procurados Familiares. Por ello, se acusaba a Sánchez Romeo "de un presunto delito de injurias al jefe de Estado, según el tipo punible previsto en el artículo 147 del código penal". Tal y como relatan ellos mismos, presentaron declaración en el juzgado tanto él como Muro. El juez, finalmente, dictó un nuevo auto: "no procede decretar la medida de prisión provisional". No obstante, el expediente fue remitido al TOP, ya que los hechos eran delito de otro artículo, el 165 bis b del código penal. ${ }^{26}$

En la primavera del año siguiente, 1972, “mes y medio más tarde de que hubiese sido difundido el número de la revista correspondiente al 15 de abril, fuimos avisados desde el Juzgado, esta vez el número dos de Zaragoza" ${ }^{27}$ para prestar declaración por los artículos "Disgregaciones" "Ouince días de actualidad política" "Cuando la realidad social obliga a la protesta" "Consejo de guerra a cinco carlistas". El primer artículo decía lo siguiente:

Disgredadores. (...) son disgredadores quienes son violentos en la exposición de sus razones, quienes tratan de imponer sus concepciones doctrinales. (...) Incluso cuando se trata de hacer frente a una situación tiránica, hay que expresarse correctamente. No por temor al correctivo, cuyo riesgo hay que afrontar valientemente, sino porque es imposible salir de la violencia por medio de la violencia sin que ésta quede instaurada de nuevo. (...) Disgregan los que impiden a sus hermanos que puedan ejercitar los derechos inalienables de la persona humana, los que excluyen a los demás de la participación en el poder que ellos hipotecan (...) En los regímenes dictatoriales, desgraciadamente, hay pocas oportu-

25 "Uno de octubre, indulto", Esfuerzo Común, 134 (noviembre de 1971), pp. 3-5. nidades de exponer razones, aun cuando se extremen las buenas formas. Todo se disgrega en ellos y su futuro está lleno de incertidumbre. ${ }^{28}$

En diciembre de 1973, Muro fue sancionado con otra multa de 50.000 pesetas, resultado del expediente formulado a mediados de septiembre contra todos los números en que habían aparecido las "Lecciones de carlismo en enseñanza programada". El motivo fue la siguiente frase: "el orden constitucional y el sistema político de gobierno para "el pueblo de las Españas", ya que mostraba:"su incompatibilidad sustancial en los puntos más esenciales con el sistema político establecido en nuestro vigente ordenamiento constitucional (...) Y todo ello difundido en "Esfuerzo común" con ánimo de propaganda y de proselitismo que incide negativamente sobre la unidad nacional y de los hombres de España por el efecto disgregador que resulta de postular los partidos políticos y los sindicatos horizontales y de propugnar el paso hacia un Estado federal desde la realidad histórica del Estado unitario".

\section{Algunas notas a modo de conclusión}

El estudio de la revista Esfuerzo Común muestra una vez más que las explicaciones sobre ciertos procesos políticos pueden, o deben, ampliarse y completarse a través de investigaciones que partan de las metodologías y objetos de estudio que plantea la nueva historia política. En este caso concreto se ha estudiado una revista con el propósito de aportar nuevos conocimientos sobre las prácticas políticas antifranquistas y su participación en la crisis del franquismo.

Esta aproximación, por otro lado, pertenece a una investigación más amplia que tiene como objeto de estudio último la propia revista y cuya intención es otorgarle un lugar y una significación histórica. Sin embargo, si esta clase de estudios son de alguna utilidad desde el punto de vista historiográfico es precisamente por su potencial para profundizar en problemáticas más amplias. Así, esta investigación sirve para completar los escasos estudios realizados acerca del carlismo autogestionario de los años sesenta y setenta y, por otro lado, para reflexionar sobre la participación de los medios de comunicación antifranquistas en la desestabilización del régimen y asentamiento de la democracia, motivo por el que se ha escrito este texto.

Asimismo se ha pretendido defender aquí la utilidad del concepto cultura política, para lo que se ha propuesto una posible definición y se han expuesto una serie de textos, la principal fuente utilizada, y otra clase de significantes que nos han permitido comprobar la pertinencia del uso de esta categoría. Así, se ha llegado a varias conclusiones entre la que se ha querido destacar el hecho de que el sobrenombre "Secuestro Común" quedara grabado en la memoria de aquéllos que participaron de la cultura política antifranquista, sumándose así a su imaginario. Por un lado, ese nombre significaba que la unidad de las familias políticas franquistas se había desquebrajado y, por otro lado, reflejaba los grandes límites de la nueva ley de prensa y de las políticas "aperturistas", constituyéndose en un referente de cohesión identitaria y en guía, entre lo racional y emocional, de futuras acciones políticas. 
"Ellas siempre estaban allí. En todas las luchas contra la dictadura, en todas las movidas durante la Transición, en la universidad, en los sindicatos, en los partidos políticos, en los barrios y más adelante en el pacifismo y en el ecologismo. Codo con codo con los/las luchadores/as. Luego quisieron crear sus propios y específicos cauces para reivindicar su problemática y carencias y surgieron colectivos y asociaciones feministas".

\section{Asociacionismo femenino en el tardofranquismo}

Académicamente, este artículo se inserta dentro de la Historia cultural, de la "historia desde abajo", del empuje historiográfico y del recuerdo de aquellas personas invisibilizadas, olvidadas y casi inexistentes para la historia oficial'; aquella historia que ha marcado, en consecuencia, la concepción de un periodo como el de la Transición española a la Democracia y los primeros años de la misma, sin su presencia.

El surgimiento del movimiento feminista zaragozano se desarrolló al calor de los grupos antifranquistas. Ya, en los años sesenta, Zaragoza se consolidó como polo de desarrollo a través de un notable crecimiento del sector industrial y la puesta en marcha de importantes obras para la ciudad (como la inauguración del nuevo edificio del Ayuntamiento o la reforma del Paseo de la Independencia); A su vez, en los primeros años de la década de los setenta, la dictadura se debilitaba al no poder controlar las "hordas" huelguísticas y la movilización popular en favor de la democracia y por la amnistía de los presos, que también se plasmó, como en todas las grandes ciudades del país, en la capital aragonesa. Como explica Burriel3: "En aquellos días posteriores a la muerte de Franco en la cárcel de Torrero había alrededor de cincuenta presos políticos. Las concentraciones ante su puerta pidiendo amnistía pronto empezaron a sucederse por encima de las prohibiciones y los grises". La huelga y ocupación de la fábrica de Fibras Esso en $1973^{4}$, los conflictos por los convenios en INDASA, TUSA, TUDOR, la ma-

1 Estela ORTEGA: Los años de la ilusión. Protagonistas de la Transición. Zaragoza 1973-1983, Zaragoza, Mira Editores, 1999. p. 177

2 No solamente mujeres sino aquellas generaciones enteras que quedaron atrás en estos años de miedo e incertidumbre ante el cambio, tras una dictadura que marcó sus pautas de entender el mundo durante cuarenta años. Aquella que, en relación a los ideales que intentó componer la II República, quedaron sepultados por la amnistía, el consenso y la retórica lucha fraticida que llevaron al olvido un periodo de nuestra historia, la "desmemoria" que argumenta Santos JULIÁ: “Cosas que de la Transición se cuentan" Madrid, Ayer, 79 (2010), pp. 297-319; también Thierry MAURICE: "La movida ou l' impossible mémoire du franquisme", Esprit, (agosto 2010), pp. 103-118.

3 Adolfo BURRIEL: "El partido comunista de España en Aragón durante la Transición democrática", Crónica de los partidos políticos aragoneses en la transición, Zaragoza, Asociación de ex parlamentarios de las Cortes de Aragón, 2003. p. 376.

4 Alberto SABIO: Peligrosos demócratas. Antifranquistas vistos por la policía política, Madrid, Cáte- siva huelga del metal y la construcción en 1975 junto a las jornadas por la carestía de la vida y la primera manifestación contra el Trasvase fueron parte de la agenda de protesta zaragozana.

De igual forma, como en otras ciudades españolas, comenzaba a elevarse la voz de distinto partidos políticos -muchos de ellos a la izquierda del PCE (como el PTE, el MC o la LCR)- de donde saldrían algunas de las militantes del feminismo zaragozano. La universidad era un hervidero de manifestaciones y, a partir de 1972, los barrios comenzaron a organizarse en las asociaciones de vecinos realizando protestas en la calle pidiendo amnistía y libertad. 5 Junto a esto, un aragonesismo creciente (en defensa de la tierra, de la estación de Canfranc, frente al trasvase y dentro de movimiento antifranquista) que reivindicaba un estatuto de autonomía y una dignidad identitaria para Aragón, similar a otras autonomías en la nueva Constitución, alcanzó su punto álgido con la manifestación del 23 de abril de 1978, a la que acudieron más de 100.000 personas. ${ }^{6}$

Al igual que en el resto del país, el apogeo del feminismo en Aragón se produjo a partir de la proclamación del Año Internacional de la mujer en 1975, el cual posibilitó que tuvieran luga las Primeras Jornadas estatales por la Liberación de la Mujer en Madrid. Como explica Amparo Moreno, estas jornadas fueron "el primer paso hacia el desarrollo de un amplio movimiento feminista en España". ${ }^{A}$ p partir de este momento, grupos específicos de mujeres, muchas de ellas pertenecientes a los pioneros asociacionismos de los barrios, empezaron a organizarse para consolidar un movimiento feminista aragonés autónomo. Tras la experiencia del Movimiento Democrático de la Mujer (con sede en las librerías Pórtico y Hesperia) ${ }^{8}$ el cuál incorporó a mujeres dentro del régimen en protesta por la carestía de vida, el paro y la petición de indultos para los presos que comenzaron a dar charlas por parroquias, generalmente en los barrios del Picarral y Oliver, donde incorporaron una concienciación femenina en temas como los anticonceptivos, el divorcio o la igualdad de oportunidades en la educación y el trabajo.

La unión de aquellas mujeres que prestaban su solidaridad con los presos a las que se sumaron otro grupo de católicas progresistas, sentó las bases para una movilización en los barrios obreros. Por ello, el MDM actuó en estrecha colaboración con el naciente movimiento vecinal a través de la cual se solaparían diferentes actos de resistencia contra el régimen. Ejemplos de ello son la celebración del $1^{\circ}$ de mayo, la recaudación de dinero para las familias que tenían algún familiar preso en la cárcel de Torrero, el intento de celebración del primer 8 de marzo como Día de la Mujer en la Residencia Universitaria Azaila ("Fue durante tres o cuatro horas un oasis de libertad donde la censura había quedado abolida"10), la ocupación de Iglesias como la de San Pablo en 1968 frente a las torturas del régimen, la protesta en silencio por el Juicio de Burgos en 1970...

dra, 2011, pp 183-184.

5 En septiembre de 1972 se publicaba el primer número de Andalán en el cuál se demostró ese enorme esfuerzo colectivo por desmontar, de una vez por todas, el franquismo.

6 Ángel Vicién en 1978. “Autonomía plena para Aragón”, Al levantar la vista. 30 años de cantautores aragoneses.Zaragoza, Prensa Diaria aragonesa, 2006, p 39. El estatuto de autonomía se aprobó el 13 de agosto de 1982. Ver Anexo 1

7 Amparo MORENO: Mujeres en lucha. El movimiento feminista en España, Barcelona, Anagrama, $1977, \mathrm{p} 21$

8 Amparo BELLA: El feminismo en Zaragoza 1975-1982, Zaragoza, Máster en estudios de las mujeres (Asignatura de Teoría Feminista), 1997, p.6. Trabajo encontrado en Fondo de la Asociación Cultural Liberazion, Sección feminismo. La Asociación Cultural Liberazión cedió su fondo documental a la Universidad de Zaragoza en el año 2011. En él se encuentra numerosa documentación sobre el feminismo aragonés de las décadas de los años setenta y ochenta, el cual ha sido utilizado para esta investigación.

9 Carlos SERRANO y Rubén RAMOS: Aragonesismo en la Transición Zaragoza, Zaragoza, Prensas Universitarias de Zaragonza, 2003.

10 Amparo BELLA: El feminismo en Zaragoza 1975-1982... p.14. 
Paulatinamente, esta solidaridad con la agenda diaria del antifranquismo fue compaginándose con unas reivindicaciones que afectaban exclusivamente a la mujer, lo que provocó una primera discusión sobre cuales eran las reivindicaciones que el movimiento debía recoger en sus estatutos: El MDM nunca recogió las propuestas feministas que se desarrollaron a partir de mitad de los años setenta: Su proyecto iba encaminado a solucionar aquellos problemas que afectaban a la vida cotidiana en los barrios, en los cuales muchas mujeres tenían gran importancia y, a raíz de ello, protestar contra el sistema desde el antifranquismo. A partir de 1972, con la creación de vocalías de mujeres en las asociaciones de vecinos, con la mayor actividad en los barrios de El Picarral y San José, se unieron dos tipos de reivindicación: las relacionadas con el consumo, por un lado; y, por otro, aquellas que provenían de una discriminación sexuada (como la falta de guarderías o centros de educación para adultas) que impedían que las mujeres pudiesen formarse y acceder al mercado laboral, es decir, eran las consecuencias directas de aceptar el estereotipo de género franquista.

Fue en relación, más bien, a lo que eran las mujeres, que estaban muy metidas en casa y descubrimos que eso no era bueno para el desarrollo de las mujeres, y entonces nos empezamos a juntar. Lo que necesitábamos era, pues, más cultura y nos lanzamos con la idea, también, de formar un centro de adultas."

Tras la celebración del Año internacional de la mujer en 1975 y las I Jornades catalanes de la dona en Barcelona al año siguiente, comenzaron en Zaragoza una serie de reuniones de mujeres que empezaron a compartir ideas, experiencias y crear unos puntos que sirviesen de base para creación de un espacio propio, la asociación ADMA, la cual se legalizó en 1977.

\section{La ADMA: La primera organización feminista en Aragón}

En la primavera de 1976, una treintena de mujeres comenzaron a realizar reuniones nocturnas en una pizzería de la calle Felix Latassa para trabajar el tema del feminismo y crear una organización que aglutinara sus diferentes reivindicaciones. La unificación de estas diferentes vías de conciencia (amas de casa, militantes en partidos políticos, mujeres universitarias, católicas progresistas, mujeres anónimas...) desembocó en la creación del primer intento de asociacionismo feminista en Zaragoza: la Asociación Democrática de la mujer aragonesa (ADMA). La asociación luchaba inicialmente en la clandestinidad, con la denegación de sus estatutos por el ministerio de la gobernación, hasta que en 1977 consiguió la legalidad.

Yo no tenía conciencia feminista, no sentía directamente la problemática de las mujeres, tal vez por estar ocupada en otros temas en aquel momento imprescindibles. Llegó el feminismo más tarde y fundamentalmente por algunas mujeres del partido como Empar Pineda. El MC se planteó el tema con bastante honestidad pero, a parte de esto, había mujeres muy sensibilizadas y empezamos a reunirnos en la pizzería de la Calle Latassa. ${ }^{13}$

Estudiantes, amas de casa, profesionales, militantes de izquierda, católicas de base... la experiencia de la ADMA fue un conglomerado de ilusión y entusiasmo por el reconocimiento de los derechos y de las diferencias del sujeto mujer a través de la posibilidad de crear espacios propios, un cauce de participación, concienciación y sobre todo un lugar de apoyo donde ex-

11 Amparo BELLA: El feminismo en Zaragoza 1975-1982... p.14

12 Anexo 2. Fondo Cultural Liberazion.

13 Teresa AGUSTín: "Mercedes Gallizo. Los ojos claros de una mujer imprescindible" Andalán, 464465 (1986), p. 20 plicarse y "ser comprendidas" por otras personas que, como mujeres, tenían frustraciones y sufrían injusticias similares en un primer paso para el cambio como es el reconocimiento de la desigualdad. Las mujeres de la ADMA "conviven tan ricamente desde simples democráticas hasta militantes del Partido Socialista en Aragón (PSA), Partido Comunista de España (PCE), Partido Socialista Obrero Español (PSOE), Movimiento Comunista (MC) o Partido del Trabajo de España (PTE); pasando por algunas republicanas. Todo consiste en unas normas democráticas y un sólido espíritu unitario y de trabajo"14. En su manifiesto inicial explican esa ilusión de compartir y trascender juntas definiendo la organización como unitaria, interclasista y democrática. El nº 244 de Esfuerzo Común explicaba de esta forma su importancia: "la ADMA no es la única asociación de mujeres de Aragón (están las mujeres separadas, amas de casa mujeres juristas....) pero sí la que, por su idea, por sus objetivos, no se limita a agrupar sólo a una profesión o una situación personal, pretende abarcar a todas las aragonesas con un ideal democrático e interesadas en los problemas específicos de su condición de mujeres." ${ }^{15}$

Los estatutos de la ADMA incorporan el espíritu del MDM, revindicando la creación de servicios colectivos (guarderías, escuelas, lavanderías, comedores, servicios sanitarios, etcétera) y, a su vez un salario igual a los hombres, despenalizar el trabajo nocturno para la mujer, despenalizar los anticonceptivos y el adulterio ${ }^{16}$ o la coeducación. Gloria Labarta explica cómo ella no creía en una afiliación política porque "los partidos subordinaban la petición femenina a las premisas de la ideología de los mismos". Por ello, cuando crearon la ADMA, el objetivo era el de abolir toda clase de discriminación para la mujer, "debía ser una experiencia colectiva de toma de contacto con el problema. Hablar y conversar de temas prohibidos, de tabús, de aquello que no representaba una importancia para la sociedad y nos hacía caer en un silencio cómplice. Buscar un espacio donde nadie nos mandara callar"17

En esta organización se aglutinaron mujeres de preso, mujeres de diferentes partidos políticos -muchas de ellas ligadas al PCE- y también amas de casa. Por un lado, se aglutinaron los intereses de protesta en torno a unas condiciones jerarquizadas y de subordinación que sufrían por una razón de género; y, por otro, intereses dentro de los partidos políticos que supuso una fractura dentro del grupo. Las discrepancias entre el pensamiento tradicional marxista y el feminismo radical quedaron patentes en todo el país tras los dos encuentros estatales anteriores. Es evidente que las distintas integrantes de ADMA no eran un cuerpo homogéneo ya que cada una pertenecía a un ámbito de actuación diferente y tenía, de forma inicial, una concepción de lucha distinta. Amparo Bella destaca cómo en Zaragoza estas diferencias tuvieron lugar de forma tardía, es decir, la organización tuvo una mayor cohesión en torno a unos objetivos comunes de toma de conciencia y búsqueda de una identidad sobre la que construir el movimiento.

La experiencia sirvió no sólo en adquirir un significado de lo que era el "ser mujer" en la época, sino también una nueva manera de hacer política en contacto e intercambio con otras mujeres. Finalmente, la ADMA aglutinó alrededor de 200 militantes que participaron en diversas campañas públicas, por las que adquirieron visibilidad, sobre todo a través del caso de

14 Amparo BELLA: "La lucha por la amnistía y el MDM en Zaragoza. 1960-1976", Ignacio PEIRÓ y Pedro RÚJULA: En construcción. Historia local contemporánea, Daroca, Centro de Estudios Darocenses, 2003, pp. 353-366

15 A. ENFEDAOUE: "ADMA. Hacia la liberación de la mujer", Esfuerzo Común, 244 (15 de diciembre de 1976).

16 El primer reportaje realizado al respecto de los delitos de adulterio y amancebamiento es el de Carmen Sarmiento. Censurado en 1976 y rescatado dos años después, recorre los principales casos que llevaron a su despenalización, incluyendo una entrevista a María Ángeles Muñoz, acuitada de adulterio en Barcelona. Recuperado de internet (http://www.rtve.es/alacarta/videos/informe-semanal/informe-semanal-adulterio/321649/).

17 Gloria Labarta, 10 de enero de 2013, Zaragoza, entrevista realizada por Sandra Blasco. Gloria Labarta fue la abogada que llevó el caso de Inmaculada Benito, el primer juicio favorable para una 
Inmaculada Benito, la primera mujer que fue absuelta en un delito de adulterio y cuyo proceso y campaña pública con el lema "Yo también soy adúltera", sirvió como causa de despenalización del mismo. El caso tuvo trascendencia nacional e inauguró una nueva forma de lucha: la autoinculpación.

\section{LA AMM, la UML y el FF}

A partir de la llegada de las elecciones de 1977, la ADMA se vio sacudida por los intereses de los diferentes partidos de la izquierda aragonesa que pretendian incorporar la asociación a los intereses del partido. Por ello, en la primavera de ese año se optó finalmente por la escisión de la unidad de la asociación en tres nuevas asociaciones: LA AAM, la UML y el FF.

La AAM (Asociación Aragonesa de la mujer) estaba constituida por profesionales de distintos ámbitos (abogadas, médicos, psicólogas...) y algunas amas de casa. Estaba asociada a las instituciones políticas y decía que su campo de actuación se centraba en cumplir con las aspiraciones democráticas para la mujer: "presionar para que se tuviese en cuenta al $62 \%$ de la población". Su dinamismo se mantuvo hasta el año 1979, momento en el que se integraron en el gobierno del PSOE-PSA.

La UML y el FF se integraron entre lo que se denominó las "radicales de color morado". Ambas tuvieron gran trascendencia en los barrios de la ciudad donde llevaban a cabo intercambio de experiencias e ideas con otras mujeres que no militaban en las asociaciones y ambas difundieron información y fomentaron debates en torno al uso de anticonceptivos, lo que les llevó a profundizar en la idea de la sexualidad libre que fue un aspecto crucial entre sus integrantes y que llevó a preocuparse por la petición y reivindicación de otros derechos como el divorcio, la violencia de género o el aborto. Nos empezamos a cuestionar los temas del placer y así, poco a poco, ibas tomando conciencia de ti misma, de las diferencias, de las relaciones con los hombres, un poco fue a través de la sexualidad y de pensar sobre tu propia vida." ${ }^{18}$

La UML desapareció paulatinamente debido a la enorme fuerza del Frente Feminista, que aglutinaba transversalmente a todas las mujeres de la ciudad y que tuvo una intensa actividad pública durante la década de los ochenta.

El Frente Feminista tuvo un papel crucial a partir de los años ochenta donde su actividad en los barrios sirvió para informar y concienciar a muchos hombres y mujeres de diferentes temas cruciales que afectaban tanto al barrio y a la calidad de vida en el mismo como a las condiciones de desigualdad que provocaba la legislación y la mentalidad de la población en torno a temas como: la sexualidad libre, la despenalización del adulterio (conseguido finalmente en el año 1981), la legalización del aborto, la igualdad salarial, el sexismo, la violencia de género, etcétera. Además, incorporó una terminología más específica, introduciendo por un lado el concepto de patriarcado y, por otro, el término de explotación.

Todas las asociaciones feministas que se crearon durante la Transición a la Democracia, tuvieron en sus filas a mujeres que provenían de los barrios zaragozanos, amas de casa, que habían tomado conciencia de una desigualdad de género en el sistema en el que se les pretendía integrar. Toda esta labor dentro de los barrios se llevó a cabo con diferentes formas de protesta femeninas; como realizar recogidas de firmas pidiendo más guarderías o haciendo sentadas de las madres con sus hijos en el Ayuntamiento. También se pedía más información respecto a los temas de sexualidad, los cuales habían sido un tabú en el periodo franquista. Toda esta labor actuó entrelazada la manera de actuar del movimiento feminista entre sus diferentes organizaciones.

18 Zoya Gorriz, Julio de 1997, Zaragoza, entrevista realizada por Amparo Bella.
En aquella época había unas necesidades muy básicas en el barrio y empezamos viendo la urgencia de una guardería. Ni cortas ni perezosas la pusimos en marcha con tres madres que se ofrecieron en unas condiciones laborales muy precarias, sin seguridad social. Se pudo llevar a cabo por la cesión de los locales de la parroquia de Belén, que tenía una actitud muy abierta frente a las reivindicaciones que haciamos para el barrio.

Pronto descubrimos la necesidad de formarnos para seguir haciendo el cambio de estructuras que necesitaba la sociedad. Se creó en el barrio un Centro de Adultas para que las madres pudiéramos sacarnos el graduado escolar. Contactamos con profesores de la universidad y se ofrecieron a formarnos con una actitud muy positiva y una mirada crítica hacia los problemas sociales. Hoy todavía sigue este centro haciendo un servicio al barrio y yo sigo dando clase de alfabetización a personas de 70 años, todo un logro. ${ }^{9}$

\section{La actividad del Frente Feminista}

"Y salían a la calle, como una década antes sus maridos, a la búsqueda de ese lugar bajo el sol único que sólo a ellas les correspondía".20

A partir del año 77, el Frente Feminista ocupó la actividad central de la movilización de mujeres en Zaragoza. Se trataba de corregir los errores puristas que habían provocado la disolución de la ADMA y crear, de una vez por todas, una organización que realmente fuese "independiente y unitaria" ${ }^{21}$. La mayoría de las mujeres del Frente pertenecían al MC y también muchas de ellas habian pertenecido a la experiencia feminista anterior. El frente nació al margen de organismos oficiales y de partidos políticos: quería integrar a cualquier mujer que se sintiese discriminada por razón de sexo y género. Superaron las barreras de la ADMA a través de la aceptación de la doble militancia, siempre que se respetase la autonomía de la asociación.

"Se admite que cada mujer elija mantener una militancia en otras organizaciones políticas, siempre que los intereses del Frente Feminista no se vean subordinados a los de dichas organizaciones." "La mayoría, yo diría que el 90\% veníamos de grupos antifranquistas" (...) "Eso tenía unas connotaciones políticas que, sin lugar a dudas, tardamos bastantes años en saber desprendernos de ellas".23

Hay un cambio metodológico y conceptual al incorporar, no sólo la lucha de clases como motor de cambio de la Historia, sino también el uso de la categoría de patriarcado: explicando la discriminación por razón de sexo dentro del sistema como parte de la consagrada supremacía masculina. Su objetivo era actuar directamente sobre la legislación franquista y concienciar a la sociedad: demostrar que ni estaban locas ni eran exageradas como algunas personas les reprochaban. En su documento fundacional afirmaban que "además de la explotación de unas clases sobre otras clases y grupos sociales, padecemos la opresión del hombre sobre la mujer a través de todas las instituciones que tienen su base en la sociedad patriarcal, y que tan bien ha sabido aprovechar el capitalismo." 24

19. Pilar Añón en Zaragoza Rebelde. Recuperado de internet (http://www.zaragozarebelde.org/vocalia-de-mujeres-picarral).

20 Lidia FALCÓN: Mujer y poder politico. Fundamentos de la crisis ideológica y de objetivos del Movimiento Feminista, Madrid, Vindicación Feminista Publicaciones, 1992

21 Bases de la ADMA utilizadas por el Frente Feminista. Anexo 2

22 Utilizan de referencia las bases de la ADMA. Ellas, inicialmente, se reconocen como una organización sin estatutos.

23 Concha Rodriguez y Rosa Fernández, 1997, Zaragoza, entrevista realizada por Amparo Bella a dos militantes del Frente Feminista.

24 Concha Rodriguezy Rosa Fernández idem. 
Mantuvieron una estrecha relación con las asociaciones de vecinos, (especialmente con las vocalías de mujeres de La Jota y El Picarral ${ }^{25}$ entre los años 1977 y 1984); y, sobre todo, tras la creación de la Coordinadora de Mujeres de barrio en 1981 -a través de la cual propiciaron la creación de talleres para mujeres- que les dio una vía de escape al silencio propio del discurso de domesticidad y la posibilidad de expresar sus propias experiencias como mujeres de una época determinada. Como explicó Mercedes Gallizo en Mujeres aragonesas en lucha: feminismos y feministas, siglos XVIII-XX: "Una concienciación por los barrios para instar a que las mujeres saliesen de sus casas y contaran sin temor su experiencia dentro del sistema como madres y esposas. Para que expusieran libremente y buscaran soluciones a esa ansia de vida de Betty Friedan". Comenzaron pidiendo mejoras en las condiciones de vida, subida de salarios, creación de guarderías para poder acceder al igual que los hombres al mercado laboral ... auténticos reductos feministas en los barrios de la ciudad que se unieron a la militancia del Frente, sobre todo, a través de la trascendencia del caso de Inmaculada Benito.

Para esto fue crucial el apoyo del ayuntamiento de Zaragoza a partir de las elecciones autonómicas de 1979. Así mismo, se llevó a cabo una continua coordinación con la Secretaría de la mujer de CCOO, UGT o USO; sobre todo a raíz de las campañas unitarias del 8 de marzo. Las mujeres más políticas y que practicaban la doble militancia tuvieron un papel crucial en esa puesta en marcha de la labor en los barrios: crearon cursos de corte y confección, gimnasia para mujeres, talleres y conferencias sobre teoría feminista o charlas y debates sobre los problemas que afectaban a la ciudadanía zaragozana; un refugio propio de participación y transmisión de experiencias con el que colaboró el nuevo ayuntamiento de Zaragoza, tras el cambio con las elecciones autonómicas, que se implicó con esta causa y ayudó económicamente en su realización. "Servía para contarnos esa historia común que mayores y jóvenes teníamos como mujeres. Es necesario concienciar a la sociedad actual de que los cambios son muy costosos y, sin embargo, los retrocesos se producen de forma demasiado fácil." ${ }^{6}$

Una sensibilización y una ilusión enorme puesta en la lucha, así como, la esperanza de calar en la sociedad, de una cohesión social contra el gobierno de Suárez, y más tarde contra las leyes del PSOE, que no representaban los intereses del conjunto social ni reconocía los derechos de las mujeres ante la diferencia sexual; la llamada "amnistía para las mujeres" con la UCD no era posible. Eran mujeres "osadas y atrevidas" ${ }^{27}$, que sacaron a la luz e hicieron públicos y visibles temas que estaban totalmente prohibidos. Transgredieron los límites de lo que el sistema anterior había considerado como correcto y rompieron con sus estereotipos: "las feministas no éramos extremas, simplemente queríamos la igualdad." Con una organización totalmente asamblearia, sin normas jerárquicas y con el objetivo de visibilizar las luchas feministas experimentando otras similares y acordes al post 68 .

A su vez, articularon un discurso para hacer frente a la violencia contra las mujeres desde la legislación franquista hasta las concepciones mentales tradicionales por parte de los sujetos. El lema "lo personal es político" apuesta, de nuevo, por un cambio desde dentro en la forma de concebir la vida: lo que Temma Kaplan Ilama a una democracia "en el país y en la casa". Esto fue posible gracias a la Coordinadora estatal de organizaciones feministas (1977) que se fundó, a nivel estatal, con la perspectiva de llevar a cabo una acción más eficaz de los colectivos: Debía favorecer el intercambio de ideas y experiencias y como explicaba Rosa "fue el paraguas feminista de todo el país." ${ }^{28}$

25 Concha Rodríguez y Rosa Fernández... ídem.

26 Gloria Labarta, 10 de enero de 2013, Zaragoza, entrevista realizada por Sandra Blasco.

27 José Luis LEDESMA et al.: Una transición en femenino, España, 2013

28 Rosa Fernández, 18 de diciembre de 2012, Zaragoza, entrevista realizada por Sandra Blasco.

\section{Las luchas}

"Con el corazón en la calle". ${ }^{29}$

A partir de la década de los ochenta, la actividad del Frente empieza a centrarse en la concienciación social y la visibilización de nuevas luchas (el divorcio, la violencia machista, el aborto o la sexualidad libre). Participan en los medios de comunicación y, sobre todo, es la propia prensa (Aragón Exprés- hasta 1983- Heraldo de Aragón, Andalán...) la que les da fuerza al saca a la luz entrevistas y artículos de su actividad. Como explica Rosa Fernández "ya no todos nos trataban de histéricas o locas. Ya no todos decían que las mujeres cacareábamos como gallinas." $3^{\circ}$ En consonancia con las Jornadas estatales que se realizaban a través de la Coordinadora, el Frente Feminista realizaba una intensa actividad teórica de investigación; Para ello, llevaban a cabo reuniones semanales que se realizaban abiertas al público -los martes- donde se analizaban textos o noticias relacionadas con la discriminación de la mujer, así como, también empezaban a familiarizarse con nuevas obras traducidas (libros sobre feminismo de la igualdad y feminismo de la diferencia que llegaban desde la Coordinadora de mujeres) junto a autoras cruciales del momento en la teoría del feminismo de segunda ola. El feminismo de los años setenta es un híbrido entre movimiento antifascista y movimiento con una identidad de género; el movimiento feminista de los ochenta ya no lucha por conseguir una democracia sino porque la democracia conseguida ofrezca un empoderamiento femenino, un marco de igualdad real en la legislación pero también, un marco que cale hondo, hasta los cimientos, en la forma de entender el mundo y las relaciones entre los ciudadanos.

A su vez, el Frente estaba dividido en comisiones de trabajo ${ }^{31}$ con el objetivo de tener un mayor rendimiento de cara a la visibilización de todas las actividades realizadas y preparar los debates semanales. Se creó la Comisión de Sexualidad, Comisión Antiagresiones, Comisión de Educación, Comisión de lectura, Comisión de trabajo y, finalmente, se creó la Comisión de Antimilitarismo a mitad de los años ochenta, y en consonancia con la participación del Frente en las luchas de otros movimientos sociales zaragozanos. Las militantes se involucraron en ellos, sobre todo, a través de los campamentos de "Mujeres por la Paz" ${ }^{2}$ que unificaba a sus integrantes en torno a la lucha pacifista, antimilitarista y feminista. Posteriormente, esta unificación tuvo gran calado en la defensa de los insumisos a finales de los años ochenta y durante la década de los noventa.

Las Comisiones llevaban a cabo la preparación de todas las actividades realizadas en la ciudad (cursos, seminarios, jornadas, ciclos de cine, conferencias, talleres...) y también todas campañas públicas que se realizaban en consonancia con el resto de ciudades españolas. E Frente Feminista era muy uniforme en sus campañas y seguía las formas de lucha típicas de los nuevos movimientos sociales a través de manifestaciones pacíficas, sentadas en la cárcel o en los juzgados, concentraciones, marchas o la autoinculpación. En las campañas más

29 Título sacado de un documental con el mismo nombre realizado por Zaragoza rebelde sobre los movimientos sociales de la década de los ochenta en Zaragoza.

30 Concha Rodríguez, 18 de diciembre de 2012, Zaragoza, entrevista realizada por Sandra Blasco. 31 Utilizo una clasificación propia acorde a la documentación del Fondo Cultural Liberazión. 32 La primera muestra de repulsa hacia las bases se produjo en Zaragoza en 1976 a través del lema cia la perpetuación de la estancia civil provocaron que se extendiese el movimiento llamado "yanquis go home" el cua a ablación mayor expresión el se extendiese el movimiento lamado yanquis go hom el cual alcanzó su mayor expresion el 29 de mayo de 1983 , donde más de 25.000 personas cogidas de la mano du1986 y tendría el apoyo de 15000 personas, según Julián Ruiz en Zaragoza ayer y hoy. Estampas noticias, Delsan Cuarte de Huo pera, 2005 . La actividad de las mujeres pacifistas y antimilitaristas fue muy intensa. Anexo 6 
importantes y, sobre todo, todos los 8 de marzo 33 , se abogaba por una estrecha colaboración con los sindicatos (UGT, USO, CC) sobre todo, a partir de los años 1982 y 1983, y también con las agrupaciones de Mujeres Libertarias, el Colectivo Lisistrata y a partir de 1986, en estrecha colaboración con el Colectivo de lesbianas de Zaragoza.

El Frente tuvo su primera sede en la Plaza San Miguel y, a partir de mitad de los años ochenta, se trasladaron al "Cuartel Palafox". Las conclusiones sacadas de estas actividades eran difundidas a través de la revista Cuadernos de feminismo y, posteriormente, a partir de los años noventa, editaron una nueva revista llamada Mujeres. Ambas son el resultado la labor realizada por la Coordinadora de Mujeres de Zaragoza y por la inclusión de mujeres obreras y jóvenes universitarias dentro del activismo. Las Jornadas de Granada también aparecen en Mujeres como un campo de apertura y de formas de lucha para alcanzar objetivos concretos dentro del ámbito local; en concreto, la visibilización de los problemas como sexualidad, agresiones, cultura de las mujeres, coeducación o lesbianismo pero sin embarcarse en la problemática de considerar la asociación ligada a algún partido político, como supuso el llamado "desencanto" en el resto del país. Como explican en un comunicado sobre las Jornadas realizadas en Barcelona en 1985:

La única forma de desarrollar el proceso de concienciación de las mujeres, imprescindible para conseguir nuestra liberación. los diez años de lucha feminista. Recuperar el papel de las mujeres en la Historias y la cultura. Con el movimiento sufragista, la realización de semanas culturales, la elaboración de la revista, en el 8 de marzo, en el 1de mayo, campañas en el terreno de la educación, la sexualidad, etc (...).34

Además, en el año 1984, la creación de la Librería de Mujeres por dos militantes del Frente dio unas posibilidades enormes a la difusión de las actividades. 35 Se realizaban allí charlas y debates sobre la situación internacional (hubo varias jornadas sobre la situación del pueblo saharaui, al ser un tema de gran interés por una gran parte de la sociedad y al querer dar muestras de solidaridad entre las mujeres feministas y pacifistas con la causa), analizaban el Código Penal y, sobre todo, tras la llegada del PSOE al gobierno, la frustración de las aspiraciones feministas que esto supuso o la inexistente actividad de cambio por las agresiones a mujeres o por el tema del aborto, que tuvieron como respuesta inmensas campañas de apoyo a aborteras y a mujeres víctimas de agresiones como un paso hacia la concienciación social. Como explica Amparo Bella ${ }^{36}$ "[la Librería de Mujeres] fue un lugar de reunión, cultura, formación para las mujeres, un espacio que ha permitido la comunicación de muchas en seminarios, debates, reuniones, presentaciones de libros, premios literarios y la posibilidad de desarrollar investigación feminista a partir de su fondo bibliográfico." El Frente Feminista prolongó su actividad hasta principios del siglo XXI pero fue en la década de los ochenta cuando tuvo la mayor actividad de movilización feminista. La característica que imperó en el transcurso de los años ochenta fue la de articular un movimiento sólido y con capacidad de difusión que "calara en la calle" y no sólo en las leyes.

Para analizar en su totalidad la evolución del Frente Feminista en los años ochenta, es necesario ir, una a una, explorando las diferentes luchas lo cual, espero, sea el reto de futuras

33 Manifestación del 8 de marzo. Anexo 3

34 "Ponencia Frente Feminista" Jornadas Feministas estatales de Barcelona. Diez años de lucha del Frente Feminista, Barcelona, 1-3 noviembre de 1985. Fondo cultural Liberazión.

35 Hay más información en la página web de Zaragoza Rebelde a través de la publicación “El feminismo a través de los libros" de Pilar Lainez. Recuperado de internet. (http://www.zaragozarebelde. org/el-feminismo-a-traves-de-los-libros).

36 Amparo BELLA: “Órdenes y desórdenes del feminismo zaragozano", en DUODA, 17 (1999), p 116. investigaciones. Batallas como la ley del divorcio, la ley del aborto, la eliminación de los abusos deshonestos del código penal, la violencia machista, el sexismo, la pornografía, el lesbianismo o la reproducción asistida, entre otras... sirven para alumbrar las dificultades de pertenecer a género femenino en esta época, dificultades que no nos son ajenas hoy día. No es sólo una lucha por la igualdad, la discriminación invade cada rincón de sus vidas y de sus pensamientos, de sus actos, sus reproches, temores y culpabilidades. El enorme trabajo del Frente reside ahí, en dar cabida a esas violencias ocultas; las cuales, poco a poco, con humildad, esperanza y concienciación van desenmascarando. Osadas, trasgresoras y tremendamente dinámicas, estas mujeres aragonesas son nuestra referencia para concebir el mundo actual y construir el futuro acorde a la utopía de la fraternidad entre los seres humanos.

\section{Conclusiones}

“¿Tu verdad? No, la Verdad,

Y ven conmigo a buscarla.

La tuya, guárdatela."

Antonio Machado

El feminismo aragonés tuvo una enorme actividad en la década de los años setenta y ochenta, amparado por el feminismo nacional y representado, a partir de 1977, por Frente Feminista. Ésta fue la organización que articuló una mayor agenda de actividades relacionadas con el feminismo aragonés: trajo consigo un apogeo y una mayor vinculación social de la sociedad con este tipo de reivindicaciones. Basaron su organización en la autonomía respecto a otros grupos,s asociaciones o partidos políticos, y siguiendo la herencia de la ADMA, aceptaron la lucha de clases como motor de la Historia e incorporaron la terminología de patriarcado a su discurso. Además, reconocían la doble militancia y su objetivo primordial era ser capaces de luchar por un sujeto-mujer autónomo y con capacidad de expresar públicamente ese activismo político. A su vez, acogieron las formas de protesta de los nuevos movimientos sociales con el objetivo de alcanzar una identidad propia antifranquista desde el arquetipo femenino. "Más que dar un sentido a su existencia, buscaban simplemente existir", en palabras de Amparo Bella.

Compaginar la lucha antifascista y la lucha feminista fue uno de los retos de la década de los setenta. El de los ochenta, se vio inmerso en conseguir más cambios en la legislación, una vez aprobada la Ley del divorcio y con esperanzas en la promulgación de otras futuras leyes como el aborto o la eliminación del código penal de los abusos deshonestos (y su equiparación a la violación). Una de las evidencias que corroboran que la Transición no trajo consigo derechos inmediatos para las mujeres y que la modificación de la legislación franquista fue parcial, es precisamente que, en la década de los ochenta, los derechos se adquirían con cuentagotas a medida que la movilización y la concienciación social avanzaban. Además, el advenimiento de estos cambios en las leyes no iba acompañado, necesariamente, de un cambio de mentalidad social, es decir, las mujeres separadas, las prostitutas, las lesbianas... seguían siendo estigmatizadas por la sociedad y desamparadas por el Estado. Solamente, estos colectivos de mujeres se esforzaron por crear espacios de ayuda y compresión, de información al ciudadano, de fraternizar unas sobre otras y comprender que los diferentes problemas que ocurrían, eran así, únicamente, por su condición femenina. A su vez, hay una reivindicación del placer femenino, de una autoestima sexual hasta entonces desconocida y un empoderamiento de los propios cuerpos. Una ruptura con el pasado, desde abajo, que reivindica asuntos hasta entonces considerados tabú, en relación a la vida privada.

En definitiva, las mujeres de los años sesenta y setenta debían sentar unos precedentes que habían sido eliminados por el fascismo. De ahí que, inicialmente, la lucha se plantease en clave antifranquista y no en clave feminista. En Zaragoza, las mujeres de la ADMA y posteriormente el Frente Feminista llevaron a cabo una labor crucial para lograr este tipo de cambios. 
bre como cambiar la situación a la que se habían visto sometidas en el pasado. De igual forma, llevaban a cabo una intensa actividad de formación teórica del feminismo, faceta de la que pocos ciudadanos tenían conciencia y menos tras la difamación en los medios de comunicación de las ideas feministas y su equiparación con el machismo.

El Frente Feminista apostó por una unión de sus integrantes desde el principio, al ver cómo se disolvía la ADMA y los conflictos entre la doble militancia que se dieron en las Jornadas de Granada, y aceptó las bases de la asociación anterior -independiente y unitaria- permitiendo que las mujeres militasen en los partidos políticos y en el propio Frente. Esto fue un punto crucial, pues muchas asociaciones de otras ciudades acababan fracasando por discrepancias en la forma de actuación, sobre todo tras las primeras elecciones democráticas. El caso de Inmaculada Benito, la unidad con la que se apoyo a la mujer acusada de adulterio, y la victoria al no probarse el delito cometido dio una indudable fuerza a las mujeres zaragozanas que comenzaron a trabajar por conseguir una Ley de divorcio y una Ley de aborto. A su vez, el advenimiento de estas leyes demostró que era necesario incidir también en un cambio de la mentalidad de los ciudadanos que, en muchas ocasiones y fruto de la cultura política heredada, seguía siendo ecléctica y más acorde a una dictadura que a la Democracia en la que se encontraban. Finalmente, la creación del Colectivo de lesbianas en 1985 fue un importante comienzo de la visibilización de la lesbiana política, aquella que con su presencia avanzaba en la superación de ese estigma para lograr una vida plena y "sin armarios", gracias a la fuerza que dio Empar Pineda en su visita a la Librería de mujeres y que, además, supuso una resistencia crucial para con esa mentalidad arcaica y esa forma obsoleta de cómo organizar el mundo a través de la sexualidad. Las jornadas, las campañas del 8 de marzo, las manifestaciones, la colaboración con el pacifismo y el antimilitarismo, su inclusión en la vida política de esos años y su repulsa a las élites de los partidos que discriminaban al conjunto social con sus políticas, las soluciones propuestas a los diferentes problemas como la creación del Comité Antiagresiones, el gimnasio de mujeres o la apertura de locales alternativos donde poder actuar en libertad, etcétera. En un momento histórico donde a las mujeres se les había negado por ley la participación pública en la sociedad, todos estos aspectos son logros cruciales de cara a afrontar el futuro y la sociedad que queramos crear, una sociedad basada en la fraternidad y la solidaridad entre los seres humanos que no se podrá llevar a cabo sin conocer las carencias de nuestro pasado reciente.

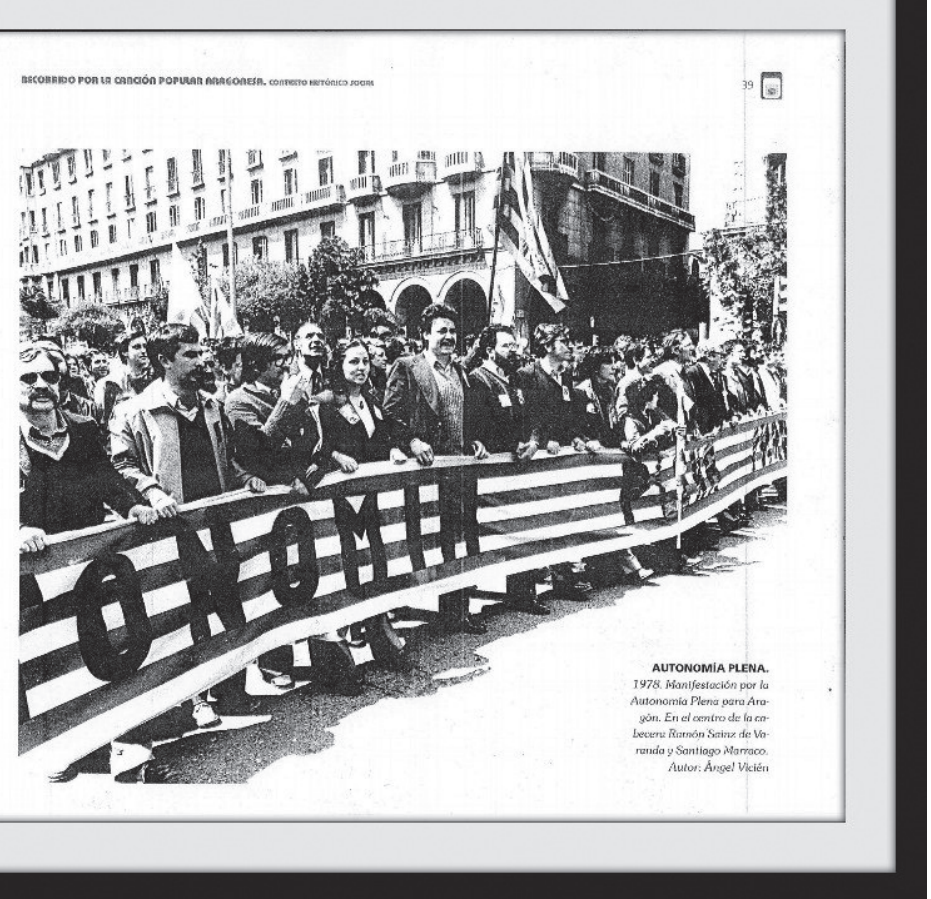

Anex. 01 Imagen de Ángel Vicién en 1978. "Autonomía plena para Aragón” en Margarita BARBACHANO: Al levantar la vista. 30 años de cantautores aragoneses, Zaragoza, Prensa Diaria Aragonesa, 2006, p 39

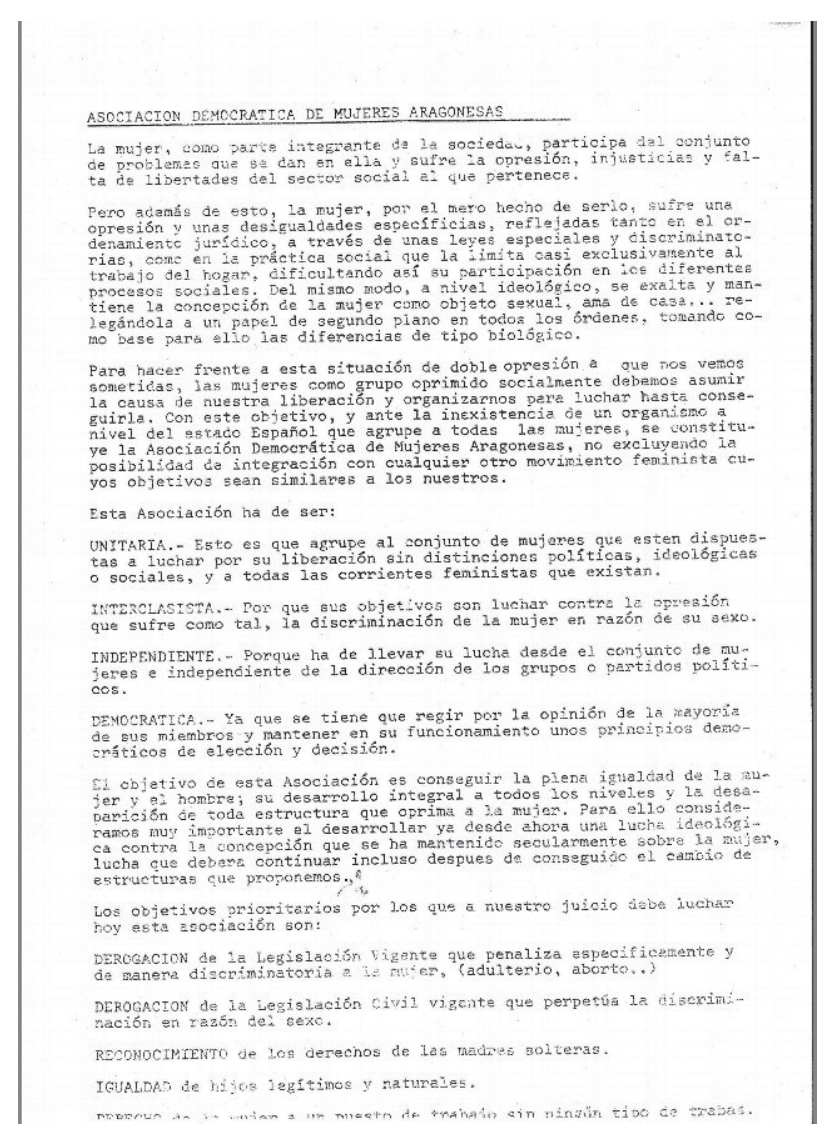




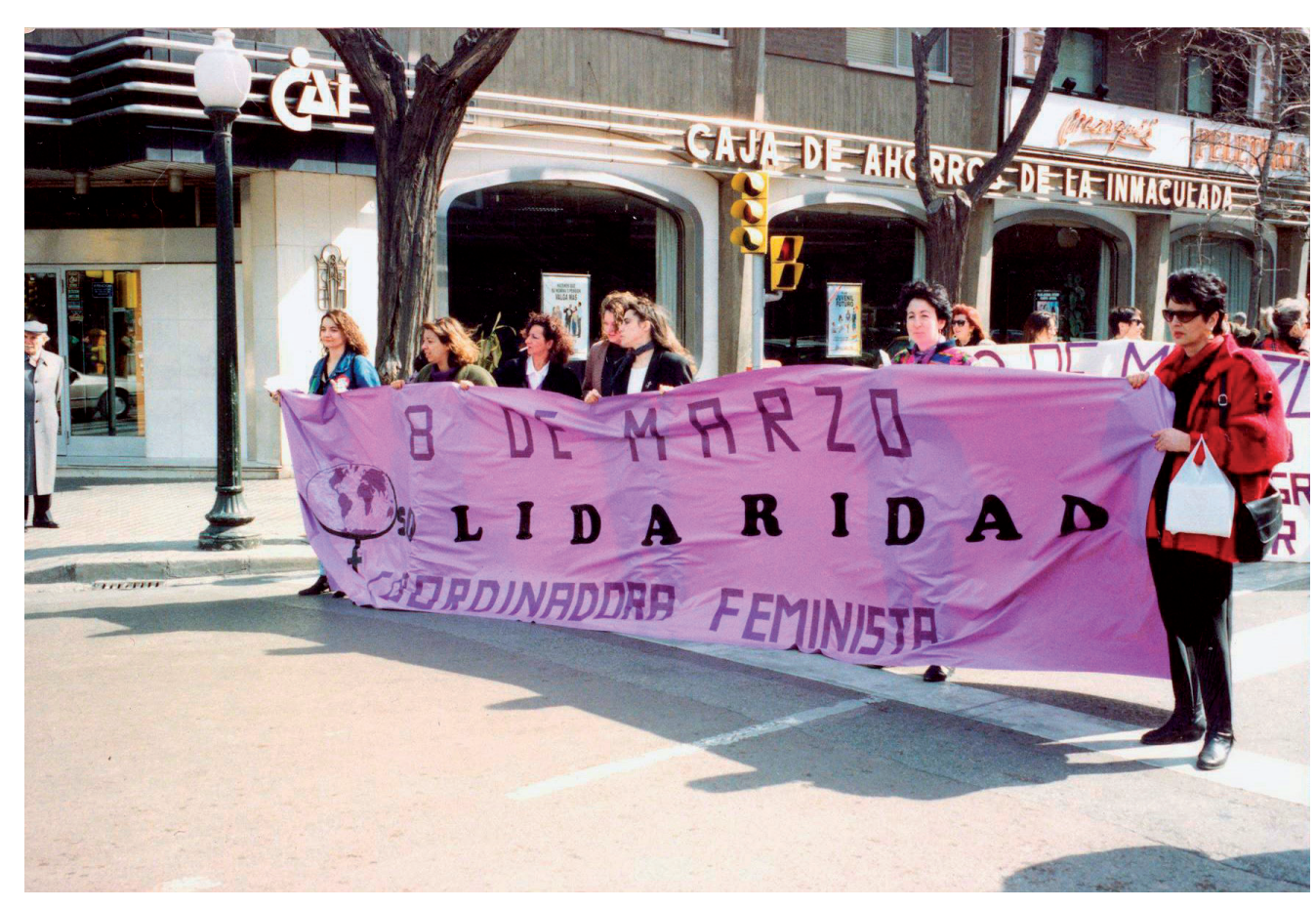

Anex. 03 Manifestación del 8 de marzo en el Paseo de la Independencia (Zaragoza). Archivo personal de Rosa Fernández y Concha Rodríguez.

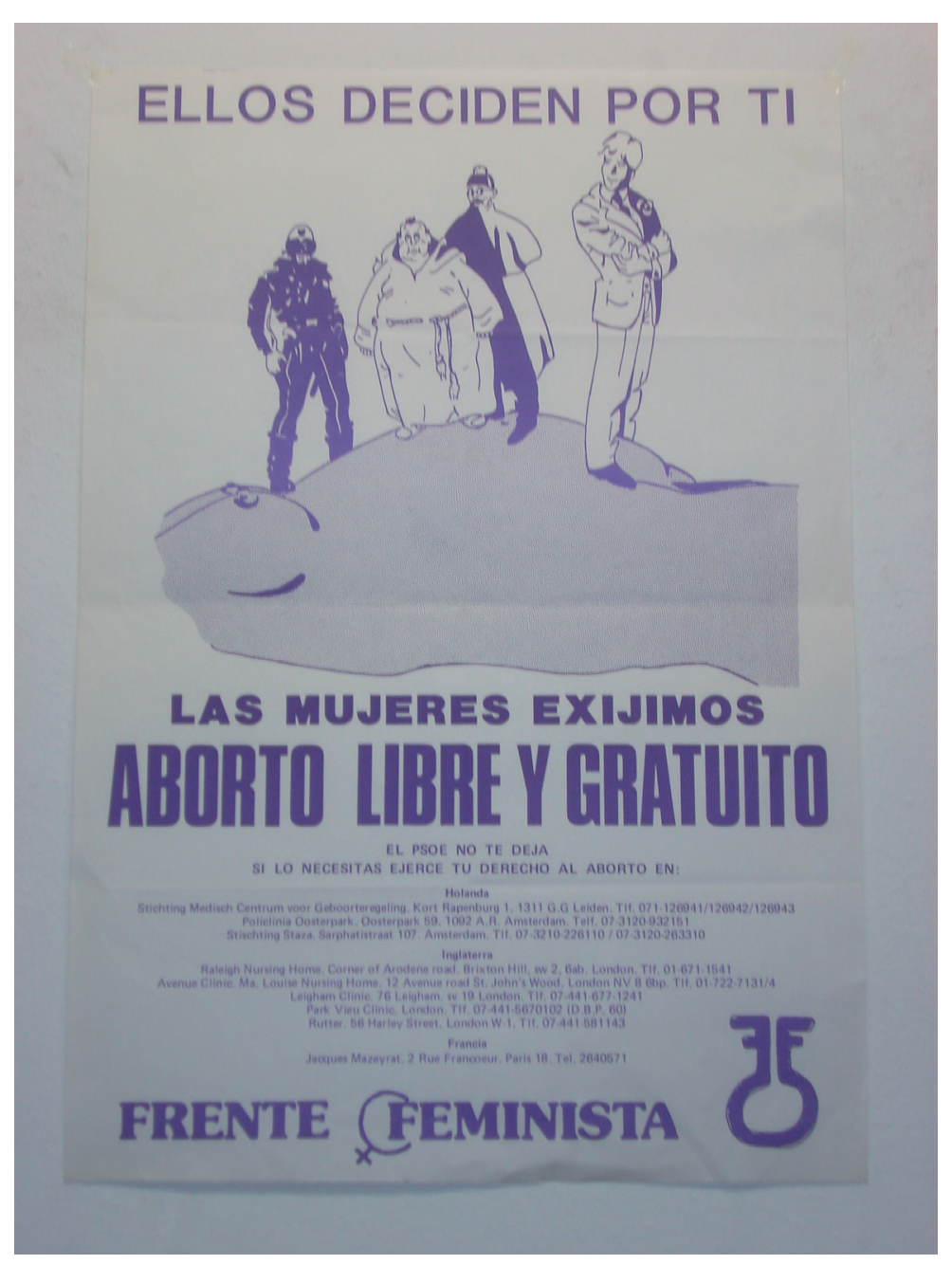

Anex. 04 Cuartilla informativa del Frente Feminista en contra de la Ley del aborto del PSOE (1985). Fondo Cultural Liberazión

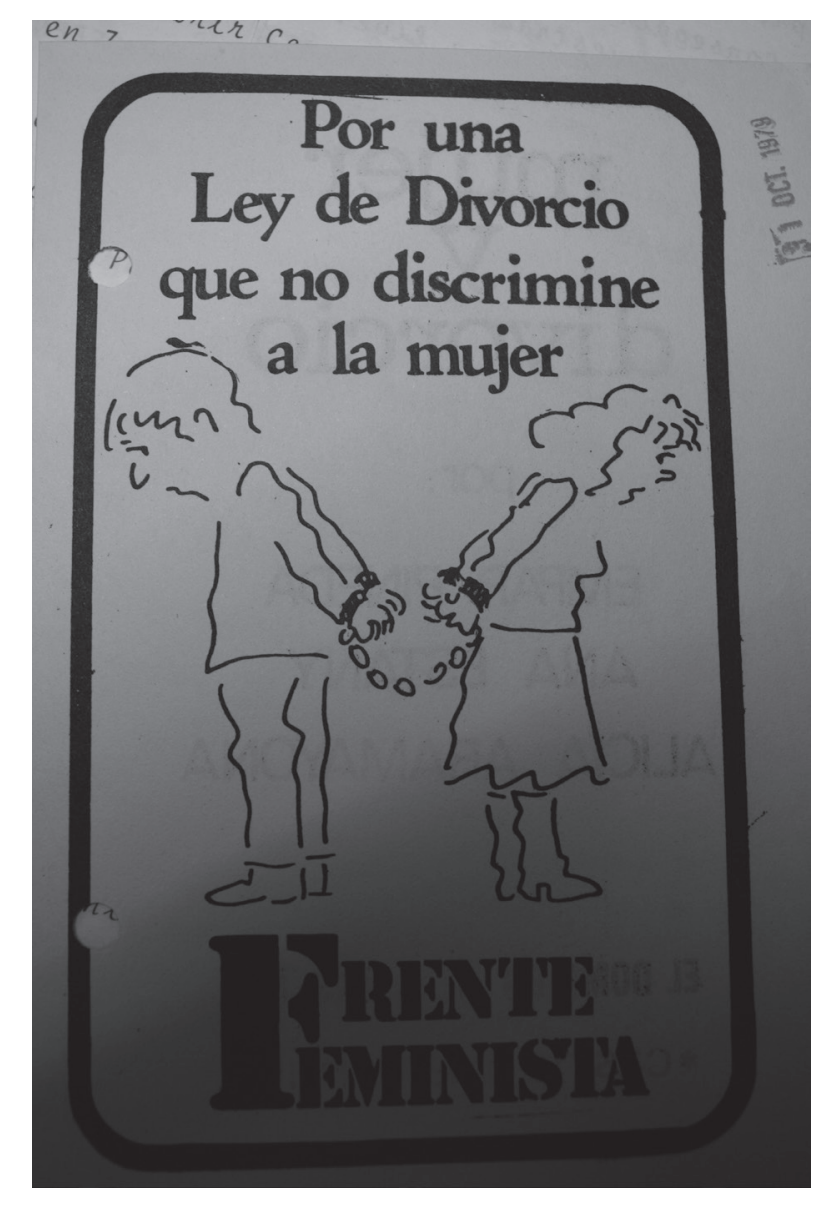

Anex. 05 Cuartilla reivindicativa del Frente Feminista en favor de una ley de divorcio con garantías para la mujer. Fondo Cultural Liberazión

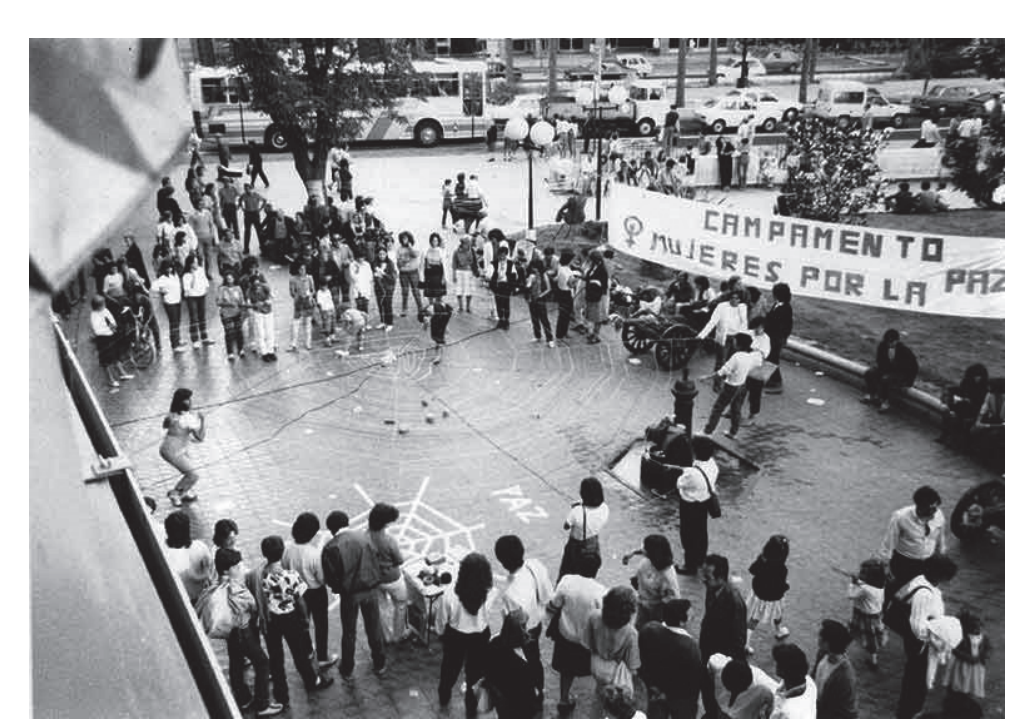

Anex. 06 Campamento de mujeres por la paz. Zaragoza, 1986. http://www.zaragozarebelde.org/ campamento-mujeres-paz 


\section{ELECCIONES POR TERCIOS Y RENOVACIÓN DE UN}

\section{CONSISTORIO FRANOUISTA. VALENCIA (1969-1979)}

Juan Carlos Colomer Rubio

Universitat de València

La presente comunicación pretende realizar un recorrido por las elecciones de renovación por tercios del Ayuntamiento de Valencia, especialmente el familiar, durante su celebración en el tardofranquismo para analizar el papel de las mismas en el devenir político general y la propia relación de la población ante estos procedimientos electorales. Partimos de un hecho evidente: la bibliografía existente sobre los organismos políticos a lo largo de la dictadura franquista plantea interrogantes sobre las pautas de funcionamiento y evolución de una de las principales instituciones locales del régimen: el Ayuntamiento. A ello debemos añadir los escasos datos existentes sobre dichos procesos por tercios conducentes a su parcial renovación y que tuvieron lugar desde 1948 hasta 1973.' Estas elecciones resultan, por tanto, un laboratorio excepcional para comprender el funcionamiento del propio régimen. Para su análisis optamos por una reducción de la escala de observación a Valencia, campo de estudio del que suscribe la presente comunicación. ${ }^{2}$ Además, realizamos el estudio de los procesos electorales

* El autor participa del proyecto "De la dictadura nacionalista a la democracia de las autonomías: política, cultura, identidades culturales" [HAR2011-27392] financiado por el Ministerio de Economía y Competitividad.

1 Resultan una excepción las reflexiones realizadas por: Roque MORENO FONSERET: “Las elecciones del tercio familiar en el régimen franquista", en Roque MORENO FONSERET (coord.): Plebiscitos $y$ elecciones en las dictaduras del sur de Europa (siglo XX), Alicante, Marfil, 2003, pp. 135-162; e ID." "Las consultas franquistas: la ficción plebiscitaria", en Roque MORENO FONSERET y Francisco SEVIILANO CALERO (ed.): El franquismo: visiones y balances, Alicante, Publicaciones de la Universidad de Alicante, 1999. Debemos destacar, por otro lado, los estudios locales realizados para los casos de Pamplona, Barcelona, Almería, Valladolid o Aragón, entre otros. Véese: María del Mar LARRAZA: "El Pamplona, Barcelona, Almería, Valladolid o Aragón, entre otros. Véase: María del Mar LARRAZA: "El
ayuntamiento pamplonés en el tardofranquismo", en VV.AA. (eds.): Actes del congrés la transició ayuntamiento pamplonés en el tardofranquismo", en VV.AA. (eds.): Actes del congrés la transició
de la dictadura franquista a la democrácia, Barcelona: UAB-CEFID, 2005, pp. 68-79; Martí MARíN de la dictadura franquista a la democràcia, Barcelona: UAB-CEFID, 2005, pp. 68-79; Martí MARÍN CORBERA: Els ajuntaments franquistes a Catalunya: política i administració municipal, 1938-1979, Eleida, Pagès, 2000; Monica FERNANDEZ AMADOR: "Las elecciones municipales del franquismo CO (eds.): Crisis, dictaduras, democracia: I Congreso Internacional de Historia de Nuestro Tiempo, CO (eds.): Crisis, dictaduras, democracia: ( Congreso Internacional de Historia de Nuestro Tiempo,
Logroño, Editorial de la Universidad de La Rioja, 2007, pp. 267-278; David ENCINAS RODRÍGUEZ: El Ayuntamiento de Valladolid en la Transición (1973-1987). Politica y gestión, Tesis doctoral, Universidad de Valladolid, 2008; Jesús María PALOMARES IBÁÑEZ: “Las elecciones de la Democracia Orgánica: el Ayuntamiento de Valladolid (1951-1971)", Investigaciones históricas: Época moderna Organica: el Ayuntamiento de Valladolid (1951-1971)", Investigaciones históricas: Epoca moderna
y contemporánea, 25 (2005), pp. 211-262; Carlos DOMPER: "Entre la fuerza del mastodonte y la res contemporánea, 25 (2005), pp. 211-262; Carlos DOMPER: "Entre la fuerza del mastodonte y la re1948-1973", en Miguel Ángel RUIZ CARNICER (ed.): Falange. Las culturas políticas del fascismo en la España de Franco (1936-1975), Zaragoza, Institución Fernando el Católico, 2013, pp. 1111-130.

2 La presente comunicación se inserta en un proyecto de tesis más amplio sobre el Ayuntamiento de Valencia en el tardofranquismo y transición a de tesis más amplio sobre el Ayuntamiento diferentes alcaldias, el personal politico de los consistorios y la transformación de la institución en el proceso democratizador (1969-1979). del final del régimen, momento en el que el sistema entró en cierta parálisis y la municipalidad tuvo que enfrentarse al auge de movimientos críticos como el vecinal.

Por tanto, dicha comunicación pretende reconstruir el proceso de elección de concejales valencianos, escasamente trabajado en el periodo reseñado. Ello nos permitirá conectar la problemática general de la compleja trama formal que constituyeron estas elecciones con la evolución y crisis de la institución municipal franquista que prolongó su actividad hasta 1979, años después de la muerte del dictador. ${ }^{3}$

\section{Las elecciones por el tercio familiar en el franquismo}

Una de las misiones fundamentales del nuevo Estado franquista tras la victoria en la guerra civil fue el control de las corporaciones locales, principal referencia política de la ciudadanía. Así, a partir de la Ley de Bases de Régimen Local de 1945 se establecieron las directrices que debían regir los municipios españoles y la forma de participación de los ciudadanos en los mismos. Unificando la posibilidad de participación por medio del municipio que ya se afirmaba en el artículo diez del Fuero de los Españoles; la elección de una parte de los ediles o concejales de cada ayuntamiento correspondía a los representantes de los vecinos articulados en los denominados cabezas de familia de cada localidad, entendiendo tales a las personas a cuyo cargo habían otras y que necesariamente debían vivir en el mismo domicilio. Dicha elección se realizaba a través de la celebración de comicios populares de carácter obligatorio entre los inscritos en el censo electoral de cabezas de familia. Como es sabido, otra parte del consistorio era designada por los organismos sindicales radicados en el término municipal y la elección del último tercio, el de corporaciones, se efectuaba conjuntamente por los concejales de los otros dos grupos entre los miembros de las entidades económicas, culturales y profesionales no encuadradas en la Organización Sindical o, en su defecto, entre vecinos de reconocido prestigio, a partir de una lista propuesta por el gobernador civil.4

$Y$ estos planteamientos no se modificaron en toda la dictadura. Dichas elecciones "semicompetitivas" o "no competitivas" del tercio sindical, familiar y de corporaciones respondían a un intento por dotar de cierta legitimidad de cara al interior y al exterior del régimen, unido a una defensa de los principios de la democracia orgánica. Pero lo cierto es que el procedimiento de elección resultaba muy desigual -directa en el caso de los cabezas de familia, o de segundo grado los del sindical, pasando por la cooptación del tercio de corporaciones- incurriendo, por tanto, en un principio de contradicción frente a la presumible igualdad de oportunidades dictada en las Leyes Fundamentales. 5

A partir de lo señalado por varios autores, la tendencia general de participación en estos procesos electorales fue muy inferior al de los referéndums, ${ }^{6}$ algo que preocupó a las propias autoridades franquistas, sobre todo en la década de los años sesenta y que se intentó resolver gracias

3 Cabe destacar que, para el caso valenciano, la ausencia de importante documentación, incluidas las memorias de gestion de Gobierno Civil (1971-1973), cuyo paradero actualmente resulta desconocido, resulta un obstáculo para el desarrollo de la presente investigacion. Los vacíos documentales existentes se han podido suplir con documentación alternativa que no sustituye, estamos seguros, la riqueza de la documentación oficial original.

4 Para una buena explicacion del procedimiento es recomendable: Rafael OUIROSA-CHEYROUZE MÚÑOZ y Mónica FERNÁNDEZ AMADOR: Poder local y Transición a la democracia en España, Granada, CEMCI, 2010.

5 Dicho sistema electoral no es original de la dictadura franquista, está presente en otros regímenes dictatoriales. Un buen marco comparativo en: Roque MORENO FONSERET: "Las consultas franquistas...".

6 Según señala Roque Moreno, por datos obtenidos en la prensa, la participación en las elecciones municipales osciló entre un $80 \%$ en las primeras elecciones de 1948 y 1951 a aproximadamente un $40 \%$ registrado en los últimos comicios de la dictadura (1970 y 1973) Jbid, p 80 . 
a la ampliación del sufragio a las mujeres casadas y retirando el festivo al día de la votación.7

Otro aspecto interesante es el referido a las campañas electorales que quedaron reguladas por decreto, prohibiéndose la participación de cualquier asociación en el desarrollo de la campaña o del escrutinio. La campaña electoral era más bien pobre, debían ser actos públicos y muy controlados, inclusive la propaganda y las cuñas publicitarias. Además, la legislación obstaculizaba la labor de los candidatos independientes pues no gozaban del apoyo de sectores en el poder. La lucha electoral era prácticamente inexistente, aunque eso no quiere decir que de manera excepcional se sucediera una encorsetada batalla y que, en ocasiones, el elegido resultase ser el candidato "no oficial".

Pese a las campañas que dejaban entrever un proceso destacable de divergencia, lo cierto es que las autoridades del franquismo llegaron a manipular los resultados con el objetivo de controlar unos procesos electorales que tan sólo pretendían dar legitimidad interior y exterior, enmascarar de presumible democracia lo que en realidad eran mecanismos de cooptación totalmente arbitrarios. Sin la manipulación se corría el riesgo claro de la pérdida de control de los ayuntamientos y, a partir de 1967 con las elecciones a procuradores por el tercio de corporaciones para las Cortes, una consecuente erosión del poder desde dentro, y el surgimiento público de una pluralidad discursiva que podía erosionar el régimen. Esta práctica de manipulación fue una constante, incluso con la limitación de candidatos, y produjo el resultado claro de pérdida de confianza de gran parte del espectro electoral que consideró las prácticas de elección como "mera pantomima". A ello debemos añadir el propio contexto internacional que cuestionó las elecciones municipales como no democráticas ni garantes del aperturismo político que pretendían. Para el caso de la ciudad de Valencia, como se vio en los procesos del tardofranquismo, los resultados de las diferentes elecciones municipales se correspondieron a lo demandado por el propio alcalde que configuraba previamente su equipo y, exceptuando alguna situación concreta, utilizó dichos procesos para rodearse de un entorno afín a sus intereses.

Como hemos visto, los propios procesos partían viciados desde el origen con la selección de candidatos a participar, todos eran investigados por su pasado político, descartando los que no podían concurrir por haber pertenecido a fuerzas relacionadas con la izquierda republicana. Además, en las grandes ciudades, los candidatos debían hacer frente a los gastos derivados de unas campañas electorales muy caras y tener una vinculación con el sistema probada y respetada. Salirse de las disciplina del partido suponía un suicidio político y la imposibilidad de concurrir en el proceso. Cuando, a pesar de todos los escollos, llegaba a presentarse una candidatura independiente -situación que se multiplicó una vez el régimen entró en parálisis-, el principal objetivo era evitar que llegase al día de las elecciones. Los recuentos también podían ser amañados e incluso forzar posteriormente la salida de concejales o de procuradores si disentían con "el sentir general".

7 Tenemos constancia que la escasa participación en las elecciones preocupaba mucho al régimen y dicho interés estuvo en la base de la organización de los cursos "problemas políticos de la vida local" con Herrero Tejedor como Delegado Nacional de Provincias en 1960. Estos cursos se prolongaran con Herrero Tejedor como Delegado Nacional de Provincias en 1960. Estos cursos se prolonHemos tratado sobre este tema en: Juan Carlos COLOMER RUBIO: "Los cursos "problemas politicos de la vida local": una respuesta del franquismo a la gestión municipal en tiempos de cambio cos de la vida local": una respuesta del franquismo a la gestión municipal en tiempos de cambio (1960-1977)" en Rafael QUUIROSA-CHEYROUZE MUNOZZ, Luis Carlos NAVARRO PEREZ y Mónica FERLAS organizaciones politicas, Almería, Editorial de la Universidad de Almería, 2011. 8 José VIDAL BENEYTO: Elecciones municipales y referéndum, Madrid, Tanagra, 1966. La labor fiscalizadora de Vidal Bence electorales falta de preparación técnica de los componentes de la mesa ausencia de papeletas de voto de independientes, coacción de los indecisos ante la urna la carencias evidentes en a organización material de las eleccions. Un estudio similar, atendiendo al proceso de 1973 de Barcelona,
Pese a todo lo anterior, lo cierto es que estos procesos nos permiten comprobar algunos datos sobre las diferentes actitudes políticas o la distribución de corrientes de opinión que otro tipo de fuentes no nos pueden proporcionar. Es por ello que cada proceso nos indicará la preeminencia de unos sectores políticos frente a otros, los apoyos con los que contaba el alcalde o la afección que la población de derecho pudo tener hacia dichos procesos, más bien mínima si atendemos a la alta abstención producida a lo largo de toda la historia del régimen.

\section{La renovación y crisis municipal en el franquismo valenciano (1970-1973)}

Como en otras ciudades españolas, el proceso de renovación por mitades se dio en Valencia en los siguientes años: 1948, 1951, 1954, 1958, 1960, 1963, 1966, 1970, 1971, 1973. Exceptuando las elecciones de 1958 y 1971, con un año de retraso y repetición respectivamente, todos los procesos siguieron la lógica temporal marcada por el corpus legal franquista.

Pese a todo y llegados a 1969, el ciclo de renovación del consistorio por mitades se rompió cuando el Gobierno, acosado por la situación política general de inestabilidad en un año fundamental, decidió posponer la convocatoria por tercios. Además, consciente de la escasa participación electoral, decidió incorporar novedades en la participación, como la inclusión de las mujeres casadas como miembro elector y elegible gracias a la aprobación, en 1966, de la Ley Orgánica del Estado. Junto con ello, se estableció y reguló, más si cabe, la campaña electoral definida, por primera vez, en el decreto de convocatoria electoral. En el caso de Valencia, la situación política existente tras la dimisión del alcalde, en noviembre del año anterior, tampoco favoreció una renovación tranquila del consistorio. ${ }^{9}$

Por tanto, hasta el otoño de 1970 no se convocaron elecciones municipales y éstas fueron particularmente accidentadas en la ciudad de Valencia. Con una escasa participación de electorado y con presencia de 20 elegibles, dieron como resultado la victoria de los candidatos más afines al régimen.

Lo importante en dicho proceso electoral fue la consecuencia que comportó su desarrollo. A dicha concurrencia solamente quedaron apeados dos candidatos, uno de ellos, Josefa Ahumada Camps, "por previa renuncia". ${ }^{\circ}$ Ésta última, vieja conocida de los procesos de representantes por el tercio familiar -llevaba presentándose ininterrumpidamente a los comicios desde 1963- pertenecía a Acción Católica y residía en uno de los barrios más populares de la ciudad: el distrito marítimo. Su influencia en dicha zona era total pues ejercía una gran labor asistencial en una de las parroquias más importantes del barrio. Además, en 1965, ya había puesto en marcha un centro escolar con una función eminentemente social. De hecho, para muchos de sus convecinos su influencia pública era fundamental en el barrio y su personalidad política clave en el distrito, donde permanecía una fuerte sensación de abandono de las políticas municipales llevadas a cabo en la dictadura.

Por tanto, su creciente influencia en procesos anteriores y el resultado obtenido en la última contienda -con 26.655 votos rozando y la victoria- llevó a las autoridades locales a planear una argucia legal para excluirla del censo electoral y, posteriormente, del proceso. Podemos detectar claramente motivos políticos y de género detrás de la decisión. El componente católico y mujer de la candidata chochaba con el personal influyente de la institución, masculino y fuertemente falangista. No es extrañar que, desde esta óptica, una vez elegida tras el recurso,

lo encontramos en: Ramón M. CANALS et al.: Les eleccions municipals a Barcelona del 16 d'octubre 1973: assaig de sociologia electoral, Barcelona, Facultad de Derecho, 1975.

9 Sobre dicha dimisión ya nos hemos ocupado en textos anteriores, véase Juan Carlos COLOMER RUBIO: “'Gestionar desde la izquierda'. Adolfo Rincón de Arellano y su proyecto político falangista", en Miguel Ángel RUIZ CARNICER (ed.): Falange..., pp. 95-110.

10 "Un candidato a concejal por el tercio familiar ha renunciado" Las Provincias (Valencia), 12 de noviembre de 1970. 
como luego veremos, se le encomiende la concejalía responsable de limpieza de la ciudad. Llama la atención que la otra mujer candidata -María Josefa Valverde Martínez- no fuera excluida, ello se explicaría por la procedencia de la candidata, de fuera de la ciudad, y la escasa influencia que a nivel político representaba.

De este proceso electoral, aparte de la situación anteriormente descrita, llama la atención la escasa participación electoral, sólo votó un 55 ' 8 \% del censo de cabezas de familia y sus resultados, muy desiguales en número de votos entre los ganadores y el resto de candidatos, evidenciaban la manipulación que el régimen realizaba. Los concejales elegidos cumplían el patrón favorito del sistema franquista: figuras de reconocido prestigio e influencia en la capital -entre ellos dos médicos y un escritor, junto con un antiguo concejal de la etapa de Rincón de Arellano-."

Josefa Ahumada recurrió la decisión de forma inesperada por la vía judicial y, contra todo pronóstico, ganó la apelación el 20 de enero de 1971, teniendo que repetir tanto las elecciones por el tercio familiar como el de corporaciones, dado que en las últimas habían votado los concejales electos en 1970. En una clara reivindicación política afirmó: "Mi mayor satisfacción es poder decir que, por mi actuación, en un amplio sector se va a ver que España es un Estado de Derecho y que se admite la apelación".12

La nueva elección en el tercio familiar se celebró el 21 de marzo de 1971. La fecha resultó doblemente nefasta por dos motivos: por un lado, la celebración de las elecciones coincidía con la festividad fallera justo la semana anterior, con lo que la supuesta campaña electoral quedó muy deslucida. A ello debemos señalar que justo el día 19 de marzo, día de la cremà de los monumentos falleros y durante el disparo de unos fuegos artificiales en la plaza del Ayuntamiento, una carcasa afectada por la humedad desvió su rumbo e impactó sobre el público, produciendo una fuerte avalancha humana que trajo como resultado un balance de dos muertos y 234 heridos, algunos de fuerte consideración. Ello llevó al consistorio a redoblar los esfuerzos por gestionar la tragedia y el final de las fiestas, descuidando todo el proceso electoral. Este descuido y la consiguiente desmovilización por las fechas de los comicios, trajeron un resultado totalmente inesperado para los dirigentes franquistas locales.

Para el proceso se presentaron menos candidatos que en el anterior, un total de 12, repitiendo sólo los que obtuvieron suficientes votos en la elección anterior. Además, concurrieron escaso número de votantes -un $29 \%$ del censo- y ello ayudó a que el resultado electoral fuese notablemente diferente: la autora de la impugnación obtuvo el mayor número de votos y entraron dos concejales críticos y totalmente desafectos: Higinio Pérez Arce y Daniel González Tregón. Los concejales electos del anterior proceso, propiamente del establishment local: Ripol Rebollo, Mayquez Noguera y Alamá resultaron excluidos. Otros dos hombres del régimen que ya habían ganado el anterior proceso, Belenguer Salcedo y Pascual Lainosa, volvieron a salir elegidos aunque con un número menor de votos.

Debemos destacar que entre los ganadores encontramos a figuras de un fuerte carácter crítico con el consistorio, lo que nos llevaría a señalar que el recurso de Ahumada si permitió la celebración de un proceso electoral menos controlado y transparente, dentro de, claro está los que permitió el régimen en estas circunstancias. Las elecciones por tercios tuvieron una consecuencia clara: el Estado salía derrotado frente a una tímida apertura electoral no pretendida. Pese a todo, en el tercio de corporaciones, por el peso del alcalde y de los concejales

11 La victoria recaerá en los cercanos al Movimiento: Luis Belenguer Salcedo, Francisco Ripoll Rebollo, Ramón Pascual Lainosa, José Luis Mayquez Noguera y José Vicente Alamà.

12 Mientras tanto, el alcalde sólo pudo contar con los concejales del tercio sindical, algunos de su máxima tanto, el alcalde sólo pudo contar con los concejales del tercio sindical, algunos de su máxina con fue nom cía Berlanga, fue nombrado primer teniente de alcalde y otro, Francisco Alarco Alarco, principal PUCHE: 50 alcaldes. El Ayuntamiento de Valencia en el siglo XX, Valencia, Prometeo, 1979. presentes en el consistorio, volvieron a ser elegidos los cuatro ganadores anteriores, todos ellos personas de relevancia fundamental en la gestión política de la ciudad. Estos concejales venían a sustituir a los elegidos en el otoño de 1963 que debían de haber cesado en febrero de 1970 , pero que, entre aplazamiento y suspensión de las elecciones, estuvieron 14 meses más en el cargo con la fuerte interinidad que ello suponía.

Del nuevo consistorio surgido tras la renovación parcial de 1971 llama la atención, siguiendo situaciones anteriores, que los elegidos por el tercio familiar asumieron carteras menores, sobre todo los cooptados tras la repetición del proceso electoral de 1971. Desde esas carteras, su peso político fue muy reducido, aunque eso no limitó sus críticas dentro de los plenos municipales y el desarrollo de políticas activas dentro de sus concejalías. ${ }^{13}$

El último proceso electoral por el tercio familiar fue el celebrado en noviembre de 1973 y que debía renovar cuatro vacantes. A dicho proceso se presentaron 21 candidatos y se rechazaron algunas posibles candidaturas, entre ellas, la del crítico Daniel González Tregón, cuyo mandato era tan sólo de tres años. La novedad de este proceso es que, por primera vez, la ciudad quedaba dividida en distritos electorales y las elecciones ya no se celebrarían en domingo, sino en martes para favorecer la participación. A estas elecciones se presentaron dos mujeres, toda una novedad para el proceso, y la verdadera competición será en uno de los distritos de la ciudad, el botánico, donde el puesto de concejal resultó verdaderamente disputado.

La campaña electoral fue de las más publicitadas en toda la prensa de la época, con grandes anuncios que animaban a la votación y, junto con ello, notables reportajes de las familias y perfiles de los candidatos. Una auténtica movilización que mejoró los resultados de participación pero que evidentemente no llegaron a los índices esperados -tan solo votó el $50 \%$ del censo- $y$ las personalidades cooptadas, pese a la lealtad evidente demostrada a los principios del Movimiento, apenas tuvieron un papel importante en el reparto de responsabilidades posterior. Podemos concluir que, a la altura de 1973, el régimen había perdido sus esperanzas de lograr una auténtica vertebración de la población de los municipios por medio de la representación municipal por tercios de cabezas de familia Quedaba la única salida posible: una reforma legislativa que ahondara en la participación electoral y aumentase el poder de los concejales del municipio, de lo meramente consultivo a la verdadera acción política. ${ }^{14}$

A modo de conclusión: evolución de las elecciones por tercios en un Ayuntamiento franquista

La ficción electoral que propugnó el franquismo con las elecciones y referéndums no deben llevarnos a perder de vista un horizonte final. fueron las únicas vías de consulta a la ciudadanía que la dictadura llevó a cabo a lo largo de casi 40 años de historia. Por tanto, una lectura minuciosa de las mismas -especialmente en el segundo franquismo-, permite observar la importancia que tuvieron para el régimen y la visión que los ciudadanos y ciudadanas tenían de las mismas.

13 Es el caso de Higinio Pérez Arce-Ares que desarrolló un plan de alumbrado en múltiples zonas de la ciudad lo que conllevó a la multiplicación de puntos de luz en muchas barriadas. Este conceja junto con Daniel González Tregón, fue de los que inició las demandas en pro de la consolidación del antiguo cauce del rio Turia como zona verde en lugar de una autovia, enfrentándose a los deseos de parte de la corporación y del propio alcalde.

14 Según se deduce de un informe político enviado desde la Delegación Nacional de Provincias, estas Segun se deduce de un informe politico enviado desde la Delegación Nacional de Provincias, estas elecciones fueron definitorias para el régimen a la hora de evaluar el grado de desafección de la población. Así, a nivel nacional, el porcentaje de participación resultó del $42,73 \%$ "poco positivo" para las autoridades del régimen. Además, la participación de la juventud en el proceso, tanto en los candidatos con mayor número fe candidatos elegidos considerados desafectos al sistema fuer que la provincia total de 17 Véase “Informe sobre las elecciones municipales, tercio familiar, sindical y corporativo, celetotal de 17. Vease "Informe sobre las elecciones municipales, tercio familiar, sindical y corporativo, celeralde Administración; Fondo Secretaría Ceneral del Movimiento; Secretarí Técnica; Sign. 51/18418. 


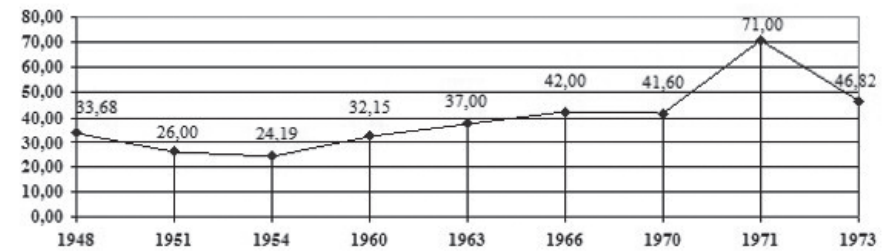

Las elecciones por el tercio familiar conducentes a la renovación de uno de los tercios que componían el pleno municipal, fueron, desde 1948 , la vía de acceso de una población socializada en las pautas y métodos de la dictadura. La ciudadanía nunca creyó en el proceso pero eso no reduce la idea que algunos vieran estas convocatorias como una forma de transformar la política en los municipios, implicándose totalmente y realizando fuertes campañas electorales.

Por lo que respecta a la participación (Gráfico 1), a medida que el régimen se iba distanciando de su punto fundacional, la guerra civil, los procesos electorales fueron perdiendo apoyo popular y el sistema tuvo que buscar nuevas legitimidades para ir sumando participantes en los procesos. Ello se tradujo, por un lado, en destacar el perfil técnico y no político de los candidatos y, por otro, remarcando la necesidad de los procesos como vía de mantenimiento de las cuotas de desarrollo técnico y progreso de las ciudades como el caso de Valencia. La elección de los concejales por el tercio familiar supuso participar de la ciudad, ayudar en su crecimiento, sentirse miembro de la comunidad política que proponía el régimen. Y esa nueva legitimidad fue también la base de su fracaso pues sabemos que, cada vez más, esa comunidad política franquista era más exclusiva que inclusiva, también en los propios procesos electorales por el tercio familiar.

Por lo que se refiere a los candidatos, los propios procesos y, en definitiva, la relación establecida entre la ciudadanía y las convocatorias electorales es una tarea a evaluar desde la historiografía. Conocemos, cada vez más, que la búsqueda de candidatos jóvenes que renovasen la institución municipal fue una máxima de las autoridades para evitar la desconexión con la ciudadanía pero lo cierto es que, pese a que el perfil de los candidatos fue derivando en cierta familiaridad con personas "de la calle o la plaza" frente al modelo elitista de los primeros procesos por el tercio familiar, la mayoría de la población seguía viendo estos procesos como teledirigidos por las autoridades, como efectivamente sucedía y, por tanto, farsa y burla de lo que realmente eran los procesos competitivos en otras realidades políticas. Si a todo ello añadimos la impronta personalista del alcalde que llevaba al ostracismo a la gestión concejil, tenemos la base de pérdida de peso de los candidatos y, en definitiva, de todo el proceso electoral por tercios.

Podemos afirmar, en último lugar, que las instituciones franquistas se vieron superadas por la realidad sociopolítica imperante al final del régimen y tuvieron que modificar el corpus legal que regía estos procesos. La nueva Ley de Bases de Régimen Local, aprobada en noviembre de 1975, pese a que mantenía la estructura por tercios, ampliaba el sufragio y lo convertía en universal para el tercio familiar, con ello se pretendía aumentar la participación sin abandonar los preceptos de la democracia orgánica propiamente franquista. Evidentemente queda fuera de nuestro análisis lo sucedido a posteriori: una larga marcha hacia las elecciones municipales de 1979 donde recalaron parte de los antiguos elegibles por el tercio familiar ya encuadrados en los partidos políticos legales. 


\section{ENTRE LA CONCIENCIA FEMENINA Y LA CONCIENCIA \\ FEMINISTA: EL MOVIMIENTO DE LAS AMAS DE CASA \\ DURANTE EL TARDOFRANOQUISMO}

Elena Díaz Silva*

Universidad Autónoma de Madrid tribunas gracias a la extensión del parlamentarismo, permiten confirmar la existencia de resistencias a ese sistema. La trasgresión se lleva a cabo a través de la toma de la palabra, una acción que, hasta entonces, también era considerada una prerrogativa masculina.

Manuel Castells en su ya célebre La ciudad y las masas. Sociología de los movimientos sociales urbanos, identificaba a la ciudad como un espacio para la reivindicación y la rebelión, y señalaba a las mujeres de Glasgow como protagonistas indiscutibles en la huelga de alquileres que se desarrolló entre 1914-1915. Un movimiento de mujeres que no llegó a convertirse en un movimiento feminista ${ }^{6}$, y que ejemplificaría lo que Tema Kaplan ha definido como "conciencia femenina":

La conciencia femenina se centra en los derechos del género, en los intereses sociales y en la supervivencia. Quienes tienen conciencia femenina aceptan el sistema de géneros de su sociedad; de hecho, esa conciencia emana de la división del trabajo por sexos, que asigna a las mujeres la responsabilidad de conservar la vida. Pero al aceptar esta tarea, las mujeres con conciencia femenina exigen los derechos que estas obligaciones llevan consigo. La acción colectiva para asegurar aquellos derechos que resultan de la división sexual del trabajo, tiene a veces consecuencias revolucionarias puesto que politiza las redes de relaciones de la vida cotidiana. ${ }^{7}$

La movilización a través de la "conciencia femenina" se encuentra en los albores del movimiento de las amas de casa que comienza a organizarse a mediados de los años sesenta coincidiendo con los primeros síntomas de recuperación ciudadana y la aparición del movimiento vecinal en las grandes ciudades y sus extrarradios, como veremos a continuación.

\section{El movimiento vecinal y la recuperación ciudadana durante el tardofranquismo}

A los partidos políticos, sindicatos y al movimiento estudiantil que se desarrolla principalmente en las universidades, hay que sumar la importancia de un nuevo movimiento social de carácter urbano: el movimiento vecinal que comienza a desarrollarse desde mediados de los años sesenta en torno a los barrios situados tanto en las afueras o extrarradios de las grandes ciudades, como en su interior. El proceso de urbanización y proletarización que tuvo como consecuencia las transformaciones económicas durante el periodo conocido como Desarrollismo se encuentra en los orígenes del movimiento vecinal, un movimiento heterogéneo aunque de origen popular que, no obstante, fue capaz de incorporar a personas de diferentes ideologías e incluso clases sociales ${ }^{8}$.

La movilización en los barrios de Madrid compartía unas características que son comunes a toda España: la inmigración del campo a la ciudad, la creación de una masa de asalariados y mano de obra "barata" que comenzó a asentarse en los extrarradios de las grandes ciudades, las cuales experimentaron a su vez un considerable crecimiento urbano y demográfico. El análisis de la movilización en los barrios durante el tardofranquismo no puede desligarse,

6 "Con todo, no hay constancia de que el movimiento expresara reivindicaciones feministas. Las mujeres eran los actores, no los sujetos de la protesta. Reclamaban el derecho a vivir para sus familias y eran los agentes de una protesta orientada hacia el consumo, como continuación de su papel de agentes consumidores dentro de la familia, aun cuando al mismo tiempo fueran obreras. En sus exigencias, no abordaban la cuestión de la desigualdad basada en el sexo...". Manuel CASTELLS: Movimientos sociales urbanos, Madrid, Siglo XXI de España, 1974, pp. 66-67.

7 Temma KAPLAN: "Luchar por la democracia: formas de organización de las mujeres entre los años cincuenta y los años sesenta", en Ana AGUADO (ed.): Mujeres, regulación de conflictos sociales y cultura de la paz, Valencia, Institut d'Estudis Universitaris de la Dona, 1999, pp. 89-107, p.91.

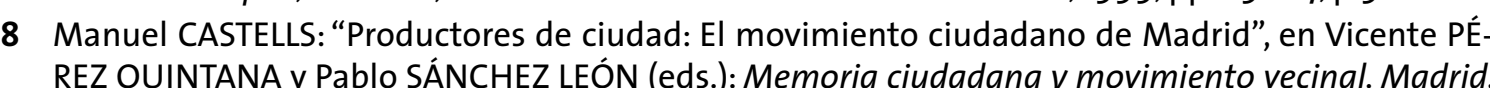
1968-2008, Madrid, Los libros de la Catarata, 2008, pp. 54-78. (lavandería o cocina) de una forma comunitaria y sin segregación de género.

4 Michelle PERROT: Femmes publiques, Paris, Textuel, 1997

5 Michelle PERROT: Mujeres en la ciudad, Barcelona, Andrés Bello, 1997 
por lo tanto, de este proceso de aumento de la clase obrera, ligado al desarrollo económico y la industrialización en España.

En los orígenes del movimiento vecinal se encuentra también la aprobación de la ley de asociaciones, ${ }^{9}$ que forma parte del proceso aperturista y modernizador que inician los tecnócratas del Opus Dei. La Ley de asociaciones fue presentada como "un nuevo hito en el proceso político evolutivo del Movimiento Nacional", y formaba parte de la estrategia de legitimación de cara al exterior, una prueba del aperturismo del Régimen. A pesar de esta ley, la constitución de una asociación no era tarea fácil teniendo en cuenta que los fines de la asociación a constituir no tenían que ir en contradicción con "Ios Principios Fundamentales del Movimiento, y demás Leyes fundamentales, los sancionados por las leyes penales, los que atenten contra la moral, el orden público o cualquiera otros que impliquen un peligro para la unidad política y social de España", tal y como se establecía en el artículo tercero. Este proceso de apertura fue acompañado de un aumento de la represión hacia todos los grupos opositores, como respuesta a los primeros síntomas de recuperación de la sociedad civil, crecientemente politizada y movilizada'io.

En un primer momento las asociaciones de vecinos se constituyeron como plataformas de lucha contra los poderes locales que ignoraron las necesidades de los vecinos asentados en las nuevas poblaciones y barrios que encontraban prácticamente en la marginalidad, teniendo en cuenta la falta de servicios básicos como alumbrado público, centros educativos, centros de salud, centros deportivos, una adecuada red de transporte e incluso la falta de viviendas. A la creación de estos núcleos urbanos sin servicios básicos había contribuido, no solo la ineficacia de los poderes locales (ayuntamientos) y estatales, sino también la codicia de un sector constructor/ promotor inmobiliario que no desaprovechó la oportunidad que ofrecía la oleada de emigrantes desplazados desde las poblaciones rurales en busca de trabajo y una vida mejo en las ciudades, y que dio lugar a una gran especulación, y un alza desmesurado del precio del suelo y de la vivienda. Las protestas de las asociaciones de vecinos también iban dirigidas contra el Gobierno, y las condiciones de vida impuestas por el desarrollismo: los bajos salarios y el alza de precios, sobre todo de los alimentos, que se agudizó durante la crisis del petróleo.

Por otro lado, las asociaciones de vecinos ofrecieron el paraguas legal necesario que permitiría a las organizaciones políticas y sindicales ampliar sus bases sociales infiltrándose en las asociaciones e incorporando a los vecinos y vecinas de los barrios, tanto a la lucha contra la Dictadura como a la lucha contra el capitalismo. La estrategia del "entrismo"" y la propia evolución de los vecinos y su progresiva concienciación política a la que se accedió, como diría Manuel Castells, de una forma "natural" y no "ideológica", es decir como una ampliación de la reivindicaciones ciudadanas, convertirá al movimiento vecinal en una nueva y eficaz plataforma de lucha contra la Dictadura, escuela de democracia "porque la gente que no era política descubrió que la democracia era una necesidad, no una consigna de rojos"12, y un enclave democrático ${ }^{13}$.

9 España. Ley 191/1964, de 24 de diciembre, de asociaciones, Boletín Oficial del Estado , 28 de diciembre de 1964, núm. 311, pp. 17334-17336

10 Ismael SAZ: "Y la sociedad marcó el camino. O sobre el triunfo de la democracia en España (19691978)", en Rafael QUIROSA-CHEYROUZE (ed.): La sociedad española en la transición. Los movimientos sociales en el proceso democratizador, Madrid, Biblioteca Nueva, 2011, pp. 29-42.

11 La infiltración en el movimiento vecinal fue iniciativa del PCE, y de otros partidos de extrema izquierda maoístas y trotskistas. Destaca Manuel Castells, cómo los líderes vecinales y militantes políticos tuvieron que llevar a cabo un esfuerzo durante los primeros años por mantener la autonomía de los movimientos vecinales frente a las presiones que sufrían por parte de los jefes de sus partidos para instrumentalizar el movimiento. Manuel CASTELLS, “Productores de ciudad...”, pp. 76-78.

12 Ibid., p. 26.

13 Término para designar un espacio democrático institucionalizado inserto dentro de un régimen autoritario y que actuarí como can lizar las aspiraciones de democratización de la socieded actuando como palanca de transición a la democracia. Sobre la cuestión, léase la obra de Bruce
El Régimen se encontraba al tanto de los efectos que había tenido la aprobación de la ley de asociaciones: "La subversión en los barrios y en el ámbito laboral son las dos principales palancas que emplean los grupos de oposición para conseguir derrocar el Régimen actual español"14, destacaba un informe policial. Dicho informe hacía alusión, tal y como lo recoge Martínez i Muntada en su artículo, a la existencia de una creciente movilización en los barrios organizada en torno a las asociaciones de vecinos, y que tenía como siguientes objetivos: "Separar al pueblo de la autoridad; Convencer a la población de la necesidad de derrocar al Régimen actual; Paralizar la vida ciudadana cuando convoque la Huelga General; Crear órganos paralelos de poder"15.

Aunque el informe policial no hacía alusión a la participación de las mujeres en el movimiento vecinal, éstas también participaron de la subversión en los barrios dentro de las propias asociaciones de vecinos, bien a través de las asociaciones de amas de casa.

\section{De la conciencia femenina a la conciencia feminista: El movimiento de amas de casa en el} tardofranquismo

En sus últimas etapas, el régimen favoreció la organización de este tipo de asociaciones de orientación familiar (vecinos y/o amas de casa) que, lejos de establecer una contradicción con los principios fundacionales del régimen, pretendían confirmar el sistema de organización social vigente, y la participación ciudadana a través de organismos corporativos que apuntalasen la suerte de ficción democrática que el Régimen había establecido con la aprobación de las leyes que trataban de institucionalizar el régimen ${ }^{16}$.

La revalorización del rol de la mujer casada y de ama de casa en el discurso, contribuía a una mejora en la situación de las mujeres a corto plazo ${ }^{17}$, contribuyendo, sin embargo, a perpetuar la segregación sexual. Por ello, las primeras asociaciones de amas de casa que aparecen en España no se pueden calificar como feministas. Manifestándose como defensoras del rol doméstico, nacieron con la vocación de fomentar las redes de solidaridad informal y apoyo mutuo entre las mujeres de clase media y obrera en los barrios de las grandes ciudades: espacios que se sitúan entre la compleja dicotomía de lo público y lo privado, y donde, como una prolongación del hogar, las mujeres desempeñan sus funciones también como una prolongación de sus deberes como madres y esposas, y en beneficio de su familia y la comunidad. La lucha por mantener su identidad cultural ${ }^{18}$ resulta evidente si analizamos una de sus principales reivindicaciones

GILLEY: “Democratic enclaves in authoritarian regimes”, Democratization, 17 (2010), pp. 389-415.

14 Informe de origen policial: "Plan barrios: estudio sobre la subversión en los barrios", en Ricard MARTÍNEZ I MUNTADA: "El movimiento vecinal en el tardofranquismo. Acción Colectiva y Cultura Obrera. Propuestas y problemas de interpretación", María Encarna NICOLÁS MARÍN y Carmen GONZÁLEZ MARTÍNEZ (coord.): Ayeres en discusión. Temas clave de Historia Contemporánea Hoy, Murcia, Servicio de Publicaciones de la Universidad de Murcia, 2008, p. 1. Sobre la cuestión, léase también: ÍD, "Movimiento vecinal, antifranquismo y anticapitalismo", en Historia, trabajo y socie-

15 lbid.

16 Entre otras cosas, España. Ley Orgánica del Estado 1/1967, de 10 de enero, Boletín Oficial del Estado, 11 de enero de 1967, núm. 9, pp. 466-477, pretendía "dar entrada [en las Cortes, consideradas como el órgano superior de participación del pueblo español en las tareas del Estado] a un nuevo grupo de Procuradores representantes de la familia, elegidos por los cabezas de familia y las mujeres casadas, de acuerdo con el principio de igualdad de derechos políticos de la mujer".

17 En este contexto se inscribe también la aprobación de la España. Ley 56/1961, de 22 de julio, sobre derechos políticos, profesionales y de trabajo de la mujer, Boletín Oficial del Estado, 24 de julio de 1961, núm. 175, pp. 11004-11005.

18 Destacamos por ejemplo la aparición en 1960 de la revista femenina: Ama, revista para las amas de casa, editada por la Comisaría de Abastecimientos y Transporte (CAT), en la que se daban consignas para las amas de casa en la línea de lo establecido por el régimen y las autoridades, pri- 
durante los primeros años: la campaña a favor de la profesionalización del trabajo doméstico. Promovida en 1968 por las mujeres de la Sección Femenina, y las procuradoras en Cortes: Pila Primo de Rivera (a su vez Delegada Nacional de la Sección Femenina), Belén Landáburu, Teresa Loring, Mónica Plaza, entre otras, el proyecto de Ley sobre el trabajo doméstico y extradoméstico de la mujer casada con responsabilidades familiares, levantó una oleada de protestas entre las mujeres más progresistas del país con posibilidad de llevar a cabo esa oposición y crítica de una forma pública y más que notoria. Mercedes Formica, María del Campo Alange y otras tantas, reaccionaron enérgicamente a través de los medios de comunicación contra una medida que, aseguraban, frenaría la promoción femenina, proponiendo el reparto de las tareas domésticas y por lo tanto, la extinción de la figura del ama de casa, cuyas funciones deberían ser asumidas por la unidad familiar en su conjunto, y en condiciones de igualdad entre sus miembros.

La idea de romper con el modelo de feminidad impuesto por el franquismo: el modelo decimonónico de "ángel del hogar", no se encontraba pues entre los objetivos de estas asociaciones. A través del análisis de sus publicaciones se puede comprobar el interés por mantener dicho ideal y por adecuarlo a la nueva realidad social. La incorporación de la mujer a la vida laboral y económica era un hecho indiscutible, incluso favorecido por el propio Régimen, ávido de mano de obra barata y sin cualificación que apuntalase su proyecto desarrollista. Entre la modernidad (que suponía la incorporación a la vida pública, política, cultural y económica del país) y la tradición, las mujeres como, principales consumidoras, se convirtieron en un blanco fácil para la publicidad a quienes iban dirigidos sus anuncios y agresivas campañas. Desde productos de uso y consumo como electrodomésticos o cosméticos, hasta estudios, cursos y formación profesional, las campañas publicitarias incluían consignas en las que se recordaba a las mujeres sus funciones primordiales y esenciales como esposas y madres principalmente. "Se acabaron las fatigosas horas del pluriempleo de su marido. Ahora usted, ama de casa, puede ganar hasta 30.000 pesetas al mes sin alejarse de su casa, sin abandonar a sus hijos", prometía un anuncio del Instituto Profesional de estudios Superiores de Belleza y Estética, publicado en Trocha, el Boletín de la Federación Nacional de Amas de Casa dirigida por Ascensión Sedeño.

Por otro lado, y en lo que respecta a la movilización a través de las llamadas a la "conciencia femenina", el carácter reivindicativo de la Federación se limitaba a la denuncia por la subida constante de los precios. Sus críticas y campañas en favor del abaratamiento de los precios, aunque sin estridencias, contaban sino con el apoyo al menos con la protección de las autoridades públicas, jugando así un papel importante en la simulación de una normalidad democrática. Erigiéndose en defensoras de las mujeres en su papel de consumidoras y principales proveedoras de alimentos y demás productos de uso y consumo en los hogares españoles, contribuían a la perpetuación de unos modelos y estereotipos tradicionales que iban quedando obsoletos. En lo que respecta a la agenda reformista, estas asociaciones se limitaron a aplaudir con denuedo los cambios introducidos durante el tardofranquismo en lo que respecta a la revisión y mejora situación jurídica de las mujeres. En ese sentido, la Federación de Asociaciones de Amas de Casa, y Trocha, su principal órgano de difusión, apoyaban tanto las campañas emprendidas por la Asociación de Mujeres Juristas lideradas por María Telo, como su proyecto de reforma que incluía como novedad principal y más revolucionaria, la eliminación de la conocida como "licencia marital". mando la transmisión de valores como el ahorro o la austeridad en el consumo y gasto diarios. Ese discurso oficial contrasta, sin embargo, con la profusión de anuncios en los que se animaba a los españos, y cspecialmente a las españolas, en una sociedad de consumo y a las prácticas modernas de consumo importadas desde los Estados Unidos. Sobre esta última cuestión, léase: Victoria DE GRAZIA: Irresistible Empire. America's Advance through esta última cuestion, leaCambridge, Massachusetts; London, England, The Belknap Press of Harvard University Press, 2005.
Pese a la imagen tradicional que la figura del ama de casa comporta, sus asociaciones favorecieron la incorporación de las mujeres a la vida asociativa, pública y reivindicativa, además de ofrecer la cobertura legal necesaria para aquellas mujeres que tenían una mayor concienciación política y feminista, y que no podían formar una asociación por sí mismas sino era asumiendo los riesgos de la clandestinidad. Este es el caso de las militantes del Movimiento Democrático de Mujeres (MDM), una organización de origen y filiación principalmente comunista que surgió en 1965 . El proceso de infiltración de las militantes del MDM en estas asociaciones es paralelo al que se produjo en las asociaciones de vecinos, en las que se infiltraron militantes de las organizaciones políticas y sindicales con el objetivo de ampliar las bases sociales del movimiento de oposición al Régimen.

Para conocer en qué medida influyó la infiltración de militantes de organizaciones como el MDM entre las amas de casa y en su progresiva "radicalización" sería interesante contrastar la documentación escrita con las fuentes orales. Para ello, he utilizado las transcripciones de unas entrevistas realizadas en la década de los ochenta como parte de un proyecto inconcluso que pretendía analizar la reorganización del feminismo en España durante la Dictadura y hasta los años 8o, y que puede ser consultado el Centro Documental de la Memoria Histórica (CDMH), donde se encuentra depositado el archivo del CIFFE (Centro de Investigación y Formación Feminista) ${ }^{19}$. En este sentido, nos interesaría destacar a las posibilidades que ofrecen dichas entrevistas, asumiendo tanto el riesgo y las dificultades (incluso técnicas) que suponen el empleo de fuentes orales, para el análisis del proceso de reformulación de las identidades de género en la España tardofranquista, en concreto el que afectó a las amas de casa. Un análisis que permita reintegrar al movimiento de las amas de casa en la Historia, y en los procesos sociales de cambio que hicieron posible la transición a la democracia.

La mayor parte de las entrevistadas al respecto de su implicación en este movimiento señalaban las dificultades que, como amas de casa, habían tenido para salir del aislamiento que suponía el hogar, las dificultades para poder contactar con otras mujeres con las que compartir inquietudes y problemas derivados de la conciencia ciudadana y/o femenina: la falta de servicios públicos (guarderías, colegios, centros de salud) y de infraestructuras (desde el alumbrado hasta pasos de peatones y semáforos que regulasen el tráfico en esas ciudades o barrios en proceso de crecimiento descontrolado). En los barrios y los alrededores de Madrid algunas mujeres habían comenzado a reunirse y a organizarse en un número bastante reducido para llevar a cabo actividades de carácter lúdico o deportivo. Así lo confesaba Araceli Paredes, miembro de la asociación de amas de casa de Getafe en su entrevista ${ }^{20}$ en la que cuenta cómo habían comenzado a reunirse en torno a cinco o seis mujeres "para hacer gimnasia", y cómo los objetivos y las actividades de la asociación habían ido cambiando con el paso de los años hasta implicarse en la lucha de los obreros en huelga, y de los presos políticos, contribuyendo a la extensión de las redes de solidaridad, apoyo y resistencia tejidas en torno a las cárceles (y en el interior de las mismas) por las familiares de los presos políticos.

Una de las entrevistadas recordaba cómo pese a su concienciación política y su deseo de implicarse solidariamente en las huelgas y manifestaciones que se multiplicaban desde mediados de los años sesenta, las clandestinas Comisiones Obreras le había impedido "afiliarse" al no tener un empleo remunerado ${ }^{21}$. Resultan muy diversas las vías por las cuales las amas de casa acabaron militando en el MDM y otras organizaciones políticas opositoras al franquismo.

19 Centro Documental de la Memoria Histórica, Archivo del Centro de Investigación y Formación Feminista (CDMH-CIFFE), Entrevistas a mujeres de la Comunidad de Madrid (1ª parte), Sign. 93,1.

Araceli Paredes, 3 de febrero de 1988, Madrid, entrevista realizada por Mercedes Comabella. Aracel era ama de casa y miembro de la Asociación de Amas de Casa de Getafe, provincia de Madrid.

21 Paloma González, 3 y 10 de marzo de 1986, Madrid, entrevista realizada por Mercedes Comabella. Paloma González era ama de casa y miembro de la Asociación de Amas de Casa de Moratalaz. 
Algunas de las entrevistadas referían el momento exacto en el que decidieron implicarse en la lucha contra la Dictadura: el proceso de Burgos o la ejecución de Julián Grimau en 1963 se convirtieron en acontecimientos o hitos que consiguieron movilizar a muchos españoles y españolas que hasta el momento venían formando parte de la conocida como mayoría silenciosa $a^{22}$

Además de las denuncias por la subidas de precios decretadas por el Gobierno o la falta de guarderías, estrategia utilizada, según Mercedes Comabella, una de las principales militantes del movimiento ${ }^{23}$, para acercarse a las mujeres con escasa o nula concienciación política y/o de clase, las militantes comenzaron a incluir críticas dirigidas al Régimen: la ausencia de derechos y libertades democráticas, principalmente, aprovechando para reivindicar la legalización de los anticonceptivos, del aborto, del divorcio e incluyendo así cuestiones que afectaban específicamente a la mujer bajo la Dictadura. Desde reuniones celebradas en iglesias, casas particulares o incluso en mitad del campo, a mítines espontáneos a los puertas de los colegios o en el interior de los mercados, sus campañas que consistían, en palabras de la propia Mercedes Comabella, "en aprovechar un semáforo en rojo para saltar a la calle y cortar el tráfico durante unos minutos y salir pintando porque venía la policía", consiguieron llamar la atención de las autoridades, a cambio paradójicamente, de un notable y amplio rechazo social.

La adopción de esta estrategia de lucha basada en encierros, boicots, manifestaciones, y todo tipo de actividades subversivas llegaron a convertirse en un desafío para el Gobierno y en un problema para el mantenimiento del orden público. Así aparecía recogido en un documento en el que se describía lo que el Régimen consideraba como un "ataque subversivo al mundo femenino", dirigido desde Organizaciones Internacionales pantalla como la FDIM (Federación Democrática Internacional de Mujeres). Según éste documento, este ataque subversivo estaba contribuyendo a mantener a las mujeres en un "estado de agitación y politización" ordenando sus formas de participación en "la lucha subversiva", entre las que las autoridades franquistas incluían: la actuación directa en los barrios ("manifestaciones, difusión de propaganda, pintadas, panfletos y comandos"), la agitación en los mercados, el apoyo a los presos políticos, las denuncias sobre temas relacionados con la mujer: "hijos de trabajadoras, salarios, periodos de gestación e igualdades, señalando la poca atención, la desigualdad, la injusticia de las medidas adoptadas o del abandono por parte del gobierno [...]", y acusando a "las organizaciones más vinculadas a la mujer", como la Sección Femenina, Cáritas o Auxilio Social, "de que la caridad era insuficiente si no va unida a la atención higiene y preocupación que exige la mujer y sus hijos". El documento recogía también una relación de las publicaciones que, según el Régimen, estaban "dedicadas directa o indirectamente a la infiltración en el mundo femenino" entre las que se encontraban: Mundo Obrero, La mujer y la Lucha (Boletín del MDM), Horizonte (Unión de Juventudes Comunistas de España), Mujer (Boletín mensual del Grupo Femenino Socialista de México PSCE), Notas (Secretariado Femenino del PSOE en el exilio francés), Hora de Madrid y Amistad (Boletín Informativo de la Asociación Femenina de Amistad Franco-Española) ${ }^{24}$.

La infiltración de las militantes del MDM en las asociaciones de amas de casa dirigidas por Ascensión Sedeño no estuvo exenta de dificultades. Al proceso de depuración que comenzó en 1967 cuando en la V Asamblea de la Federación Nacional de Amas de Casa la policía tuvo que

22 La ejecución de Julián Grimau en 1963 fue el detonante de una marcha y manifestación que se desarrolló en la madrileña calle Goya protagonizada por mujeres que portaban crespones negros, y convocada por varias asociaciones entre las que se encontraban algunas asociaciones de amas de casa, las independientes y "subversivas"

23 Alex NIÑO: "Reportaje: Madrid-Pekín, 30 años de viaje. Merche Comabella rememora la lucha feminista madrileña de hace tres décadas", El País, 12 de septiembre de 1995.

24 "Documentos básicos que ven marcando la línea de actuación de la subversión al mundo femenino. 1968-1970". En Archivo General de la Administración; Fondo de la Sección Femenina; (3)51.4; Anexo 1; Caja 512. intervenir para desalojar a algunas "infiltradas" que habían manifestado su disconformidad con las actividades y los objetivos de la asociación, hay que sumar las dificultades que comenzaron a tener las asociaciones no integradas en la Federación, es decir, las castellanas o indecripción en el registro de asociaciones. Las autoridades comenzaron a demorar su autorización en vista del proceso de infiltración de la izquierda, y en vistas de su conversión ya no sólo en "escuelas de ciudadanía", sino también en escuelas de resistencia y oposición al franquismo.

El movimiento de las amas de casa durante el Año Internacional de la Mujer: un ejemplo de práctica política

Este movimiento de mujeres continuó durante esos años sus campañas contra la subida de los precios, en favor del aumento de los salarios y denunciando la carestía de la vida a través de las más variopintas movilizaciones amparadas por el paraguas legal de las asociaciones de amas de casa. Pese a las detenciones, el paso por las comisarías, por la temible Dirección General de Seguridad e incluso por prisión, las movilizaciones y campañas emprendidas por las amas de casa continuaron destacando el año 1975, año que Naciones Unidas había decidido proclamar como Año Internacional de la Mujer. Amparadas pues en la limitada cobertura legal que les había ofrecido la conmemoración de este año internacional a la que el Régimen de Franco había decidido sumarse con un objetivo puramente propagandístico ${ }^{25}$, las asociaciones de amas de casa emprendieron en febrero una campaña de denuncia contra la subida de los precios animando a través de unos folletos distribuidos entre la población madrileña a la abs tención de realizar "cualquier tipo de compra" los días 20 y 21, y "apagar" la luz de 19'30h a 20h como medida de protesta y presión ${ }^{26}$. Esta "Ilamada de acción cívica conjunta en señal de protesta por la escalada de precios y su repercusión en las economías familiares", fue firmada (y sellada) por las 14 delegaciones (Distritos de Madrid y pueblos de la provincia) de la Asociación provincial "Castellana" de Amas de Casa y Consumidoras, así como por la Asociación de Amas de casa del Distrito de Tetuán y adyacentes, y varias delegaciones de las Amas de Hogar en los distritos de: Ventas, Chamartín, Moratalaz, Aluche y Getafe. De igual forma estaba apoyado por las Asociaciones de Vecinos de los barrios de Madrid: Progreso, Aluche, San Blas-Simancas, Colonia "La Paz" y Moratalaz; la Asociación de Mujeres Separadas, la Asociación Española de Mujeres Universitarias y el Club de Amigos de la UNESC, siendo ampliamente difundida por los medios de comunicación ${ }^{27}$. Los "vecinos de Madrid", denunciaban en dicha nota la subida del índice del coste de vida para 1974 que oficialmente se había establecido en un 17,61\%. Considerando que esa cifra no correspondía con la realidad, denunciaban que realmente la subida había sido de un $34 \%$ en productos de alimentación y un $23 \%$ en luz y gas. En el documento se reclamaba un aumento de los salarios de 5000 pesetas, y una reunión con el Presidente de Gobierno, Arias Navarro. La respuesta del Régimen ante tal desafío no se hizo esperar, unos días antes de la celebración de la jornada de huelga y protesta, se procedió a la detención de cinco amas de casa (de las delegaciones de Torrejón de Ardoz y Alcorcón) que repartían octavillas invitando a la jornada de huelga. Unos días después, la Dirección General de Seguridad comunicaba a las Asociaciones que suscribieron el manifiesto una sanción administrativa que suponía la suspensión de sus actividades durante un periodo de tres meses. La Dirección General de Seguridad alegaba que el contenido de dicho escrito constituía "una invitación a

25 Sobre la cuestión, léase: Elena DIAZ SILVA: “El Año Internacional de la Mujer en España: 1975", Cuadernos de Historia Contemporánea, 31 (2009), pp. 319-339.

26 CDMH-CIFFE; Expediente sobre el MDM; Sign. 45/5.

27 "Nota para la opinión pública". CDMH-CIFFE signatura: 36/6. Manifestaciones en apoyo o denuncia firmadas por la Asociación Castellana de Amas de Casa y Consumidoras junto a otras asociaciones entre 1973 y 1984 
alterar el orden público y la convivencia social”28, acusándoles también de tener relaciones con grupos políticos clandestinos.

La sanción a las amas de casa levantó una oleada de solidaridad entre las fuerzas progresistas del país. Desde el Colegio de Arquitectos de Madrid, el de Abogados o Ingenieros Aeronáuticos, hasta políticos como el Procurador Manuel María Escudero y Ruera. En los fondos del CIFFE se conservan algunas de las cartas de apoyo recibidas a lo largo de esas semanas, en las que además de manifestar la repulsa por la sanción (no solo administrativa) a las amas de casa, y el resto de asociaciones que habían suscrito el manifiesto, se defendía la huelga y la manifestación como un instrumento de protesta democrática ${ }^{29}$ y se reclamaba la necesidad de abrir los cauces de participación para canalizar las exigencias ciudadanas ${ }^{30}$

Pese a intentar mantener esa estrategia, manteniéndose al margen del resto del movimiento de oposición al Régimen, las asociaciones de amas de casa (castellanas e independientes) continuaron trabajando en esa misma línea. La siguiente campaña que llevaron a cabo tan solo unos días antes de la muerte de Franco, fue la de solicitar la amnistía para los presos políticos. Actuando como altavoz de las reivindicaciones de los familiares de los represaliados por el Régimen, dirigieron un escrito a las autoridades solicitando la amnistía que hiciese posible los "reencuentros familiares" 31 , aprovechando para denunciar la detención de trece presidentes de asociaciones de vecinos "como triste ejemplo de por dónde discurren hoy los canales de participación en nuestro país". Solicitaban, de igual forma, que se garantizasen los derechos humanos, "reconocidos en la Declaración de Naciones Unidas: derechos de reunión asociación, expresión, manifestación y huelga"; así como la implantación de las libertades democráticas, representando pues un claro ejemplo de práctica política e implicación en la lucha contra la dictadura.

\section{Conclusiones}

El movimiento de las amas de casa se fraguó en un contexto de progresiva toma de conciencia político/feminista entre un determinado colectivo, difícil de definir y clasificar, compuesto en su mayoría por mujeres de clase media o trabajadora, sin estudios universitarios y con responsabilidades familiares que obstaculizaban, en la mayoría de los casos, la posibilidad de alcanzar una independencia económica y personal, el primero de los pasos que según la teoría feminista, conduciría a la liberación de las mujeres. En ausencia de otros cauces de participación como podían ser las universidades, o las organizaciones políticas o sindicales, siento estos los principales resortes del movimiento de oposición al Régimen, las amas de casa constituyen un fenómeno digno de ser analizado en su contexto y complejidad. Esta comunicación pretende animar al debate sobre la contribución de las amas de casa al proceso de reformulación de las identidades de género, a una redefinición de los espacios (público/privado) en las ciudades. La práctica militante de las amas de casa simboliza la toma o conquista del espacio

28 CDMH-CIFFE; Expediente de la Asociación Castellana de Amas de Casa y Consumidores; Resolución sancionadora de la Dirección General de Seguridad (Ministerio de Gobernación), dirigida a la Asociación de Amas de Casa del Distrito de Tetuan y Adyacentes. Fechado en Madrid, a 24 de Febrero de 1975, con la firma del Director General, y el sello de la Dirección General de Seguridad, Sign., 41/1 y 43/4.

29 CDMH-CIFFE, Expediente sobre la suspensión de actividades decretada por la Dirección General de Seguridad a Asociaciones de Amas de Casa, Culturales y de Vecinos de Madrid y su periferia, Sign. 47,3 .

30 "Sanción a las amas de casa", en Cuadernos para el diálogo, 138 (marzo de 1975), pág. 41

31 CDMH-CIFFE, Manifestaciones en apoyo o denuncia firmadas por la Asociación Castellana de Amas de Casa y Consumidoras junto a otras asociaciones entre 1973 y 1984 , Escrito entregado en
la Presidencia del Gobierno el día 19 de noviembre de 1975 , firmado en Madrid, a 17 de noviembre de 1975 por varias asociaciones de Amas de Casa (castellanas e independientes), Sign. 36.6. público y su democratización. Resulta destacable también su contribución a la lucha contra la dictadura, pese a la imagen que ha trasmitido la historiografía, tal y como denunciaba la historiadora Pamela Radcliff, siendo además a duras penas reconocido por el resto de agentes sociales protagonistas del cambio:

Su vinculación con el Movimiento, junto con el 'anacronismo' que conllevaba la imagen del 'ama de casa' tan apegada al 'antiguo régimen' como a la sociedad tradicional, volvieron casi imposible que los progresistas vieran en esas asociaciones una forma de 'escuelas de democracia ${ }^{32}$

La necesidad, por lo tanto, de revalorizar estas prácticas militantes realizadas desde los márgenes es un primer paso para la democratización del conocimiento y de la Historia. En este sentido, esta comunicación ha pretendido hacer visible la diversidad de los agentes sociales que tomaron parte en el proceso de transición a la democracia.

Pamela RADCLIFF: "Ciudadanas: las mujeres de las asociaciones de vecinos y la identidad de género en los años setenta", en Vicente PÉREZ QUINTANA y Pablo SÁNCHEZ LEÓN (eds.): Memoria ciudadana y movimiento vecinal..., pp. 54-78. Cita de la pág. 58. Sobre la problemática para la inclula misma autora: Pamalansición de las asociaciones de amas de casa y su invibillad, léase de in Spain's transition to democracy", Journal of Social History, 36 (2002), pp. 77-100. 


\section{MUNICIPALISMO Y CAMBIO POLÍTICO (1971-1979): \\ MANONSTRUCCIÓN DE LA DEMOCRACIA}

EN EL MUNDO RURAL*

Cristian Ferrer González

Universitat Autònoma de Barcelona dolencias endémicas y una creciente "subversión" a menudo traducida en movilización popular en pro de la democracia que, finalmente, imposibilitó la continuidad de la dictadura más allá de la muerte del dictador. ${ }^{3}$ Mediante el estudio microhistórico del Montsià, pretendemos aportar evidencias respeto a dicho proceso movilizador generalizado en el tardofranquismo, ya que, a nuestro juicio, éste tuvo su propia plasmación en los territorios rurales.

\section{Una lucha a todos los niveles: cultural, económica y por ende política}

Dado que el franquismo en los pequeños pueblos adquirió características propias, cabe asumir, pues, que el antifranquismo actuó también mediante unos cauces autóctonos y genuinos. ${ }^{4}$ Así mismo, uno de los aspectos fundamentales para el desarrollo de nuestra tesis sobre el cambio político en el mundo rural guarda relación con la sociedad civil. Existe consenso acerca que el franquismo había destruido la sociedad civil preexistente a la guerra, desarticulando las redes sociales sobre las que las clases populares tenían entretejidas sus vidas. ${ }^{5} \mathrm{El}$ Nuevo Estado franquista tuvo, pues, que promover la creación de una sociedad civil fundada
sobre una también nueva hegemonía político-cultural: la franquista. Tras haber perdido el poder estatal durante la Segunda República, la Iglesia reclamó la iniciativa y protagonismo en lo que podríamos Ilamar "la nueva sociedad civil franquista". El nacionalcatolicismo, en este sentido, aspiraba a tejer una sociedad civil formada por un conjunto de organismos "privados" que posibilitaran la dirección intelectual y moral de la población mediante la formación de que posibilitaran la dirección intelectual y moral de la po
consentimiento y adhesión de las masas al Nuevo Estado. ${ }^{6}$

Cabe considerar que en un sistema pluralista la sociedad civil se articula mediante organizaciones sociales o asociativas -tales como culturales, sindicales, políticas, económicas, educativas, religiosas-, mientras que en un sistema de aspiración totalitaria, como lo fue el Estado franquista, dicha articulación entre la infraestructura y la superestructura se halla monopolizada por el propio Estado. En este sentido, el Nuevo Estado extendió su control sobre todos los canales conformadores de una sociedad civil autónoma, especialmente en la educación y la religión, puesto que son las que gozan de mayor influencia en los mecanismos de socialización y por su poder de movilización social.? De este modo, durante un prolongado período de tiempo, el Estado desarticuló de manera efectiva los mecanismos para destruir la hegemonía cultural franquista, ya que la propia sociedad "respondía" -consciente o inconscientementeen "defensa" del régimen. Esa sociedad civil dependiente del Estado -relacionado con lo que se ha denominado "franquismo sociológico"- actuaba, por consiguiente, como "base ética" o como "trinchera" del régimen en la defensa de la sociedad política; es decir, garantizaba el sostén ideológico de la dictadura entre la sociedad. Dicho consenso y dirección moral del conjunto social se justificaba mediante la difusión ideológica de los intereses y valores de la casta dominante, ésta es, la de los vencedores de la Guerra Civil. ${ }^{8}$

Pere YSÀS SOLANES: Disidencia y subversión. La lucha del régimen franquista por su supervivencia 1960-1975, Barcelona, Crítica, 2004, pp. 205-211.

4 Un ejemplo del gran abanico de actitudes antifranquistas del mundo rural en Óscar José MARTín GARCÍA: A tientas con la democracia. Movilización, actitudes y cambio en la provincia de Albacete 1966-1977, Madrid, Catarata, 2008.

5 Montserrat DUCH PLANA: "Sociabilitat popular a la Catalunya del segon franquisme: espais de llibertat en construcció", en Ramon ARNABAT MATA y Josep SANTESMASES OLLÉ: 1960-1980. Transicions i canvis a les terres de parla catalana, Barcelona, CCEPC, Institut Ramon Muntaner i Cossetània, 2012, pp. 517-530.

6 No es lugar para debatir sobre consenso/disenso bajo el franquismo, sin embargo he abordado el tema y expongo mi parecer en Cristian FERRER GONZÀLEZ: Lluitadors quotidians..., pp. 43-48

7 Rafael DÍAZ-SALAZAR: El proyecto de Gramsci, Madrid, HOAC, 1991, p. 251.

8 Probablemente resulte excesivo hablar de "defensa del régimen" por sectores de las clases populares. Diversos estudios desmienten el automatismo de esa visión gramsciana de hegemonía mos-

de la democràcia al Montsià (1972-1979), Lleida, Patronat «Josep Lladonosa»/La Mañana, 2014.

Para el fenómeno en el ámbito urbano Cf. Carme MOLINERO RUIZ: "Una gran apuesta: la oposi-

cio, identidad e historia social, Sevilla, Atrapasueños, 2009. 
A lo largo del texto discutiremos de lo que, a nuestro parecer, representaron los campos de batalla claves de la lucha opositora al franquismo en el mundo rural. Pese a que habían existido movimientos antifranquistas en la comarca del Montsià a lo largo de toda la dictadura, fue coincidente con la enfermedad y muerte del dictador que se produjo una maduración y extensión de la oposición antifranquista operativa. La expansión de lo que Gramsci llamó un nuevo "sentido común" alternativo a la oficialidad se impuso en el imaginario colectivo de la mayoría de la población, fruto de creencias compartidas difundidas mediante el activismo cultural crítico y la lucha por la mejora de las condiciones laborales en el campo. Costosas pero progresivas victorias que se lograrían ante la impotencia de un régimen que había perdido su preeminencia en el mundo de las ideas y también en el material. Des del ámbito de la cultura contra-hegemónica, primero, y gracias a las brechas abiertas por al asociacionismo católico -de base asamblearia-, así como la proliferación de actividades lúdicas -tales como teatros, actos deportivos, conciertos, recitales- ajenas a los espacios contemplados por la dictadura, se coadyuvaría a crear y extender percepciones de la realidad compartidas de carácter antifranquista. Añadiéndose y complementando a la labor cívico-cultural, irrumpió la lucha campesina en el Sindicato Vertical. La creación y expansión de la Unió de Pagesos (UP) articuló las demandas populares y encauzó la lucha de clases hacia las organizaciones corporativistas del franquismo agrario, consiguiendo grandes victorias como el dominio de la Hermandad de Labradores y Ganaderos de Amposta por una coalición auspiciada por los comunistas en 1975. Por último, el empoderamiento popular derivado de dichas victorias en el vertical y la consolidación de percepciones de la realidad antifranquistas hegemónicas entre la sociedad civil hicieron que la población perdiera gran parte del miedo impuesto durante décadas y que se atreviera a lanzar el desafío por el control efectivo de los espacios públicos, hasta entonces monopolizados por el poder político y religioso.

La conjunción de prácticas contestatarias de cristianos de base y el movimiento antifranquista produjo, de una manera continua a partir de 1976, un aumento cualitativo de la oposición en el Montsià que iría ganando adeptos, espacios y, finalmente, cotas de poder. Dicho poder debe entenderse en términos de hegemonía cultural, social y finalmente política. Es decir, hallamos una relación bastante directa entre la expansión de una cultura alternativa a la del régimen, el aumento opositor en los distintos organismos y espacios tradicionalmente monopolizados por el franquismo ${ }^{9}$, finalmente, el control de las corporaciones locales a partir de las elecciones municipales de 1979

\section{La batalla cívicocultural: contra-hegemonía y democracia}

Un hecho primordial para la articulación de acciones colectivas que expresaban intereses y concepciones del mundo similares entre sus miembros guarda relación con la sociedad civil y, con ella, el asociacionismo que la articula. Primeramente, conviene delimitar qué entendemos por asociacionismo y qué papel les atribuimos en la lucha a nivel cívicocultural. Tomamos aquí una concepción amplia del término, entendido como un fenómeno que articula lo que Manuel Castells llama "relaciones de experiencia", es decir, las lógicas de relación entre las personas. Sin embargo, estas lógicas de sociabilidad existentes se veían limitadas a la hora

trando el gran abanico de contestaciones que no pudieron ir más allá. La idea sería que la ausencia de resistencia abierta no implica automáticamente la aceptación de los valores de los grupos dominantes. Espero poder abordar satisfactoriamente el tema en mi tesis doctoral en desarrollo. Al respeto Cf. Ana CABANA y Miguel CABO: "James C. Scott y el estudio de los dominados: su aplicación a la historia contemporánea", Historia Social, 77 (2013), pp. 73-93, especialmente las pp. 77-78. Organismos y espacios privados como son los centros o asociaciones culturales y clubes deportivos, o relaciona dos con la vida pública como los sindicatos, las cooperativas o las propias plazasy calles en los pueblos. de establecerse en organizaciones formales debido al control totalitario del Estado. Sería, primero, con la sociabilidad "natural" a través de las parroquias o bares y, posteriormente, con la expansión en los años sesenta de asociaciones especializadas de Acción Católica o a través de los clubes deportivos y culturales, que cientos de jóvenes del Montsià desarrollarían valores de pertenencia, identidad y solidaridad, eso es, de toma de conciencia social y por ende, para el franquismo, de determinación política. ${ }^{10}$

Puesto que en los pueblos, hasta muy tarde, resultaba sumamente complicada la oposición abierta mediante la movilización social y que las acciones, digamos, vandálicas como realizar pintadas o repartir octavillas resultaban altamente arriesgadas en localidades donde todos sus miembros eran de sobras conocidos, "la confrontación al régimen se produjo en buena medida a través de las entidades legales de carácter cultural y religioso existentes. Primero, en el seno de la Juventud Agrícola Rural Católica (JARC) y las parroquias, y paralelamente a su crisis y desarticulación, en los centros culturales locales, a menudo informales. ${ }^{12}$ Frecuentemente, la contestación cultural se originó gracias a la labor de curas jóvenes influenciados por el ecumenismo del Concilio Vaticano II, los cuales devinieron "intelectuales orgánicos" para unos jóvenes e inexpertos antifranquistas al recoger, encauzar y expresar "las demandas populares (...) creando una nueva visión de la realidad que, apoyada en la renovación de la cosmovisión religiosa de las masas, logra revolucionar la conciencia social y la mentalidad de éstas". 13

Sumándose a las actuaciones impulsadas desde los movimientos cristianos de base, proliferaron acciones de carácter cultural y recreativo a través de "plataformas alternativas que transcurrían al margen o independientemente a la oficialidad impuesta",14 que contribuirían a dinamitar los mecanismos de reproducción ideológica del régimen. En dichos centros culturales -incluso históricamente vinculados a sectores sociales franquistas-convergerían personas que si bien no militaban directamente en ninguna organización política, sí tenían ya una clara actitud comprometida con el antifranquismo. Este es el caso del exitoso Centro Cultural y Recreativo de Ulldecona, en el que confluyeron todos los opositores locales -católicos, estudiantes, obreros, nacionalistas- que se harían con la junta directiva de la entidad en $1975^{15}$ y que extenderían el modelo por otras poblaciones de la comarca. ${ }^{16} \mathrm{~A}$ partir de entonces, el Centro devino la plataforma antifranquista operativa de la villa desde donde se realizaría una confrontación cultural crítica mediante actuaciones teatrales, recitales de Nova Cançó y acciones destinadas a "hacer pueblo" con un espíritu contestatario. Un pueblo que poco tenía que ver con el mundo gris del franquismo, y que, al tomar conciencia de sí mismo, dinamitaría la apatía sobre la que se sustentaba la dictadura.

10 A este sentido, puede suscitar comparaciones el estudio de Gustavo ALARES LÓPEZ: "Sembrar demoracion mocracia: la ruptura con el paternalismo franquista en los núcleos de colonizacion turolenses", en Jose Ma ORTIZ de ORRUNO, Javier UGARTE y Antonio RIVERA BLANCO (coords.): Movimientos
sociales en la España contemporánea, Vitoria, Abada, 2008, pp. 343-350.

11 Alberto SABIO ALCUTÉN: "Politización campesina y sindicalismo agrario progresista en España, 1970-1980", Historia Agraria, 38 (2006), p. 80 .

12 Asi se extrae del testimonio de Eloi Elies Miralles, 3 de junio de 2013, Freginals, entrevista realizada por Cristian Ferrer González a quien fuera activista social, cultural y militante de la UP.

13 Rafael DÍAZ-SALAZAR: El proyecto de Gramsci... p. 381. En la Diócesis de Tortosa ese papel clave para abrir espacios alternativos a la oficialidad en el seno de la Iglesia lo jugaría el cura Josep Gonell, impulsor de la JARC a partir de 1964. Si es de interés véase un libro de memorias escrito por $\mathrm{e}$ propio Josep GONELL SOLSONA: Crònica de joventut, en lletra menuda, Barcelona, Forum, 2002.

14 Traducido del catalán. Antonieta JARNE: L'oposició al franquisme a Lleida, Lleida, Pagès, 1998, pp. 173-174.

15 Cristian FERRER GONZÀLEZ: “Ulldecona i el canvi polític: dictadura, contra-hegemonia i democràcia (1964-1983)", Raïls, 30 (2014), en prensa.

16 Eloi Elies Miralles, 3 de junio de 2013, Freginals, entrevista realizada por Cristian Ferrer González. 
Efectivamente, constatamos diferencias cualitativas en el ámbito lúdico entre dónde asentó un fuerte asociacionismo cultural y otros lugares en que no se pudieron abrir brechas a la cultura dominante. En las Fiestas Mayores de Ulldecona en 1976, por ejemplo, se realizó la obra de teatro Hair y actuaciones musicales gratuitas de Lluís Llach y La Trinca en la plaza mayor, ${ }^{77}$ mientras que las actividades festivas en los pueblos vecinos no fueron más allá de las misas, procesiones, e incluso, conmemoraciones de la "liberación de la Villa cuando la Cruzada Nacional". ${ }^{8}$ Sostenemos que no resulta banal la actividad lúdica local -aún a riesgo de sobredimensionarla- ya que podía marcar la diferencia para personas que habían crecido con la cultura oficial y que, quizás gracias a una noche, llegaban a comprender que podía haber algo más allá del franquismo, puesto que existía una alternativa que no solo era posible, sino necesaria. No hay que olvidar que en los propios centros culturales se articularían experiencias compartidas que, a menudo, conducirían a la construcción de imaginarios colectivos de carácter democrático que gracias a unas fiestas o a lo largo de distintas jornadas lúdico-culturales, estas concepciones compartidas llegarían a expandirse más allá de los propios miembros del Centro.

No es extraño que mucha de la gente que había logrado escapar de su subalternidad en el seno de la JARC evolucionara hacia movimientos abiertamente antifranquistas tras la "crisis de representación política de clase" de las bases católicas, que en la diócesis de Tortosa se plasmaría irreversiblemente entre 1972 y $1974 .{ }^{19}$ Después de la superación de los límites impuestos para el asociacionismo católico, la mayoría de activistas de la JARC pasaron a engrosar movimientos más amplios como el Partit Socialista (Congrés), arraigado en los ambientes estudiantiles de Tortosa; el Partit Socialista Unificat (PSUC), de mayor expansión y militancia por el Montsià entre ambientes campesinos, obreros y profesionales; $y$, especialmente, los católicos se alinearían con los independientes de la Assemblea de Catalunya. ${ }^{20}$ Incluso nacionalis tas ideológicamente alejados de la izquierda marxista acabaron participando de las acciones clandestinas de los socialistas y sobretodo de los comunistas por ser, al fin i al cabo, la oposición realmente existente. En un informe al Comité Central del PSUC se explicaba que, durante la clandestinidad, "el partido ha tenido que trabajar casi solo, lo cual suponía que toda persona que se moviese fuera llamada, lógicamente, comunista aunque no lo fuera, porque nunca han faltado personas que a título individual participaran en la resistencia contra el régimen".

Las asociaciones culturales no se dedicarían únicamente a labores de activismo cultural crítico. El Centro Cultural y Recreativo de Ulldecona, por ejemplo, serviría de enlace para otras acciones y a través de él se distribuiría propaganda y material diverso proveniente de Barcelona para organizar, entre otras, la Marxa de la Llibertat, auspiciada por el cura catalanista-progresista Lluís $M^{a}$ Xirinachs. ${ }^{22}$ La marcha, dividida en columnas y adherida a los puntos básicos

17 "Programa oficial de los actos y festejos" (septiembre de 1976), Arxiu Històric Provincial de Tarragona (AHPT), Fons d'Ordre Públic, Expedients d'autorització de festes populars, Sig. 2304

18 "Programa de actos y festejos de Santa Bàrbara" (mayo de 1976), AHPT, Fons d’Ordre Públic, Expedients d'autorització... Sig. 2238.

19 Josep GONELL SOLSONA: Crònica de joventut... pp. 143-144. Para un estudio sobre la crisis de las secciones especializadas de Acción Católica Cf. Feliciano MONTERO: La Acción Católica y el franquismo. Auge y crisis de la Acción Católica especializada, Madrid, UNED, 2000.

20 Jaume Antich Balada, 20 de julio de 2012, Ulldecona, entrevista realizada por Cristian FERRER GONZÀLEZ a quien fuera presidente de la JARC del Obispado de Tortosa, presidente del Centro Cultural y Recreativo de Ulldecona, independiente en la Assemblea de Catalunya, primer secretario del Partit dels Socialistes local, primer alcalde democrático y diputado en el Congreso de 1982 a 1996.

21 Traducido del catalán. "Informe de la la Conferència del P.S.U.C. de les comarques del Baix Ebre $i$ del Montsià" (1978), Arxiu Nacional de Catalunya (ANC), Fons PSUC, Baix Ebre-Montsià: Comitè Comarcal. Sig. 1-230-T, Caja 5444, P. 5

22 Para una breve crónica de la Marxa de la Llibertat, Cf. Ángel COLOM COLOM y Jordi ROSÉS CASTRO: 40.000 hores detinguts. Marxa de la llibertat, Barcelona, Pax, 1977, ýngel COLOM COLOM: Marxa de la Assemblea de Catalunya, "llibertat, amnistia, estatut d'autonomia", no había sido prohibida explícitamente por el gobierno Suárez y se preparó de forma abierta. La organización de la columna Rafael de Casanova para el Baix Ebre y el Montsià, había estado encomendada al antiguo dirigente de la JARC, Jaume Antich. Ésta debía partir de la Sénia para realizar una caminata de más de cien quilómetros y culminar en el monasterio de Poblet. Sin embargo, la marcha no llegó a producirse al topar con más de doscientos efectivos de la Guardia Civil y la Policía Armada a su salida de la Sénia. Lo que debía ser el inicio de unas jornadas cívicas y democráticas acabó con violencia policial, más de treinta detenciones -hacinadas en una pequeña celda sin camas ni ventilación-y la imposición de fuertes sanciones a la organización comarcal de la Marxa. ${ }^{23}$ Pese a la regresión de la hegemonía franquista, el régimen dejaba clara su voluntad por controlar la calle.

\section{Construir la democracia en la calle: el desafío por el control del espacio público}

La movilización social había ido in crescendo durante toda la década de los setenta por doquier. Las reivindicaciones de mejoras salariales en el campo, derivadas de la política de liberalización de los precios agrícolas, y las protestas en contra de las abusivas cuotas de la Seguridad Social Agraria (SSA), ${ }^{24}$ habían provocado manifestaciones importantes de jornaleros en Amposta en 1971 y 1972. Pese a la durísima represión, la movilización campesina logró que los jornaleros del Montsià percibieran los mejores sueldos agrícolas de toda Cataluña, ${ }^{25}$ así como que la Cámara Oficial Sindical Agraria (COSA) provincial acordara aumentar para 1973 la renda mínima a 100.000 pesetas a partir de la que establecer el pago obligatorio a la SSA. ${ }^{26} \mathrm{El}$ aprendizaje político para los trabajadores resultaba evidente: la movilización social funcionaba.

Debe entenderse el movimiento campesino del Montsià como un esfuerzo por modificar las normativas sociales, políticas y económicas vigentes, puesto que en todo comportamiento colectivo existen, de hecho, tensiones estructurales subyacentes. Por consiguiente, como veremos, algunos campesinos se unieron para actuar cooperativamente al comprender que algo funcionaba mal en su ambiente social, $u$ otros se irían sumando al movimiento al juzgar que ellos también padecían las injusticias de las convenciones sociales, políticas y económicas existentes. Con ese fin, se realizarían actos de reafirmación colectiva "conquistando" los espacios públicos tradicionalmente ocupados por el régimen. Dichas demostraciones de fuerza fueron llevadas a cabo por movimientos que, aún en el mundo rural, podrían considerarse verdaderamente de masas. ${ }^{27}$ Éstos tenían su origen en el ámbito laboral para luchar por la mejora de sus condiciones de vida, pero a la vez contribuían, mediante sus prácticas asamblearias y

de la llibertat, Barcelona, Pax, 1977.

23 Informe de la Dirección General de Seguridad referente a las detenciones por la Marxa de la Llibertat (Tortosa, 8 de julio de 1976), Fondo Particular de Jaume Antich (FPJA). Una explicación más extensa de la Marxa de la Llibertat en Cristian FERRER GONZÀLEZ: "Ulldecona i el canvi polític..." Íd.: Lluitadors quotidians..., pp. 96-102

24 Para las condiciones de la Seguridad Social Agraria en Alberto SABIO ALCUTÉN: “Politización campesina y sindicalismo agrario progresista en España, 1970-1980", Historia Agraria, 38 (Abril 2006), p. 80; Ana CABANA y Daniel LANERO: "Movilización social en la Galicia rural del Tardofranquismo (1960-1977)", Historia Agraria, 48 (2009), pp. 111-132.

25 Andreu MAYAYO I ARTAL: De pagesos a ciutadans. Cent anys de sindicalisme i cooperativisme agraris a Catalunya, 1893-1994, Barcelona, Afers, 1995, pp. 199-210; también en: "Informe de la la Conferència del P.S.U.C. de les comarques del Baix Ebre i del Montsià" (1978), ANC, Fons PSUC, Baix Ebre-Montsià: Comitè Comarcal. Sig. 1-230-T, Caja 5444, p. 6.

26 "Libro de Actas" (15 de marzo de 1973), AHPT, Fondo de la COSA, Caja 58, p. 12

27 El primero de mayo de 1975, por ejemplo, se realizó una manifestación jornalera en Amposta con la participación de más del $25 \%$ de la clase trabajadora del campo. Porcentaje difícilmente alcanzable en el mismo período en las áreas industriales. 
sus éxitos políticos, a la expansión de una percepción de la realidad inseparable de la democrática capaz de atraer a amplias capas de población.

Sin embargo, estos movimientos colectivos, que evidentemente tenían motivos estructurales para actuar, necesitaban aún de lo que Benjamín Tejerina llamó factores precipitantes -accidentales o buscados- para crear entre la población una sensación de urgencia que acelera la movilización social y potencia el desarrollo de creencias generalizadas. ${ }^{28}$ Qué duda cabe que la enfermedad y muerte de Franco hizo asumir a gran parte de la población de Montsià que la dictadura podía acabar, por lo que proliferaron numerosas acciones, como hemos visto con la Marxa de la Llibertat, que implicaron a una cada vez mayor cantidad de personas para luchar por la democracia.

Aunque fueron las clases populares quienes impulsaron la movilización social, cuando ésta se fue extendiendo y agudizando, lógicamente atrajo a sectores acomodados, por lo que se fue diluyendo el inicial proyecto de clase del antifranquismo. La movilización social y la consiguiente extensión de la hegemonía democrática eran deudoras, sin embargo, del impulso de la clase obrera, y ésta tuvo, con independencia del resultado final del cambio político, el protagonismo histórico en las luchas por la democracia. El caso de los campesinos y jornaleros de Amposta representan un caso paradigmático. Gracias a la extensión de percepciones antifranquistas entre sectores no estrictamente trabajadores, aunque promulgado por ellos, se propició la rotura del "bloque histórico de los propietarios franquistas" y su sustitución por un "nuevo bloque democrático" agrupado alrededor de la figura del potentado Josep PaniseIlo, que conseguiría hacerse con el control de la Hermandad local en verano de 1975, debido al inestimable apoyo del PSUC. ${ }^{29} \mathrm{El}$ control de la Hermandad por parte de la candidatura democrática se debió a la larga y constante movilización campesina en defensa de sus intereses de clase, pero no de forma exclusiva ni excluyente, ya que, cada vez más sectores campesinos pudientes se inclinaron también hacia el antifranquismo al comprender que el régimen era incapaz de seguir garantizando sus intereses de clase.

Tras la maduración de dicho proceso, se afianzaros grandes asambleas de campesinos en el seno de las Hermandades - puesto que eran la mejor forma de evitar la represión y progresivamente se convirtieron también en un signo de identidad colectiva. Durante los primeros meses de verano de 1975 volvieron a reunirse para debatir sobre la precaria situación económica de las familias que vivían de la tierra, producto, en su opinión, de una mala praxis política. Los trabajadores acordaron realizar una huelga de cuatro días en la recogida del tomate hasta conseguir un precio mínimo de 5 pesetas el quilo. La rotunda negativa de los dirigentes verticalistas acrecentó la idea entre el campesinado y algunos propietarios de la necesidad de constituir un ente sindical autónomo y de clase. Pese al boicot por parte del franquismo agrario y la derrota de la huelga, de nuevo, resultaba inseparable el componente económico y político de la movilización laboral y, con ello, se evidenciaba el desfase de la organización sindical oficial respeto a la cambiante realidad social.

En una de las tensas asambleas previas a la huelga, un jornalero se atrevió a increpar a presidente de la Cámara Arrocera, Francesc Margalef, por lo que fue expulsado, tras lo cual cerca de trescientos campesinos abandonaron la asamblea en solidaridad con el compañero

28 Benjamín TEJERINA: "Los movimientos sociales y la acción colectiva. De la producción simbólica al cambio de valores", en Pedro IBARRA y Benjamin TEJERINA (ed): Los movimientos sociales. Transformaciones politicas y cambio cultural, Madrid, Trotta, 1998, pp. 114-115.

29 "Elecciones sindicales en Amposta" (5 de julio de 1975), ANC, Fons del PSUC, Cambra Arrossera d'Amposta Sig. 1-230 T, Caja 1677. La can jidatura democrática fue recibida con gran entusiasmo d'Amposta, Sig. 1-230-T, Caja 1677. La candidatura democrática fue recibida con gran entusiasmo por la población, que asi lo transm posta, Sig. 22-43-014, Caja 8 . excluido. La confrontación abierta con el régimen era ya inevitable puesto que las cartas del antifranquismo habían sido mostradas en las elecciones al vertical de mayo de 1975, derrotando, al fin, al cacique Margalef y expulsándolo de la presidencia sindical..$^{30}$ Tras el éxito político de los campesinos, se empezó una acción reivindicativa a otros niveles con tal de extender las protestas. Des del Sector Social de la Hermandad se mandó una carta al rey Juan Carlos I en diciembre de 1975 reclamándole una amnistía general para los presos y exiliados políticos, las libertades democráticas y de expresión para así cumplir con los derechos humanos. Asimismo, las exigencias sobrepasaban las reivindicaciones estrictamente políticas y le demandaban que se paliara el desequilibrio económico en España para establecer una genérica justicia social en beneficio de "esta inmensa mayoría, que no es silenciosa sino silenciada". ${ }^{11}$

A principios de 1976 el sindicato campesino unitario, independiente y horizontal de Cataluña, la UP, se fundó en las comarcas de la desembocadura del Ebro sobre las bases campesinas especialmente católicos de la JARC, comunistas y socialistas, anteriormente encuadradas bajo unas efímeras Comisiones Campesinas. Eran trabajadores que habían estado movilizándose durante la última década por sus derechos, salarios y, en general, contra la dictadura. Sincrónicamente, cerca de quinientos jornaleros se manifestaban en Amposta bajo el lema "Volem treball", elevando cartas al alcalde Josep Fàbregas en las que le denunciaban como el responsable político de dicha situación. ${ }^{32}$ En los meses de marzo y abril la situación se radicalizó debido a la creciente precarización del campesinado catalán. En sucesivas asambleas masivas en Tarragona se acabó pidiendo la dimisión del presidente provincial de la COSA y del Ministro de Agricultura, y se amenazó con ir a la huelga general agraria mediante el motín y el colapso de las vías de comunicación con tractores. .3 $^{3}$

El 11 de mayo de 1976 más de diez mil campesinos se desplazaron hasta el Gobierno Civil de Tarragona agrupados bajo la consigna "Volem viure de la terra". Según los testimonios, la marcha a través de la Rambla Nova hasta la plaza Imperial Tarraco fue acompañada por aplausos de los viandantes. Incluso los universitarios de provincias, ubicados en la Facultad de Química y Letras en la misma plaza, extendieron una enorme pancarta en la que se leía "la Universitat amb els Pagesos", 34 haciendo evidente la extensión de la solidaridad popular y la consolidación de un, digamos, "antifranquismo sociológico" que dinamitó la "base ética" que hasta la fecha había garantizado, como se ha explicado, el sostén ideológico del régimen.

En efecto, el propio término "franquismo sociológico" puede llevar a equívoco puesto que "nos remite al complejo de estructuras socioeconómicas y de intereses concretos, creados, mantenidos o potenciados por el sistema franquista", al tiempo que "puede comprenderse como conjunto de actitudes sociopolíticas, regularidades de comportamiento personal y colectivo e inercias de pasividad o indecisión fomentadas por cuarenta años de perseverante ejercicio de poder personal". 35 Por otra parte, Conxita Mir afirma que fue el impacto de la Guerra Civil y la represión de posguerra, así como la participación en la misma, la que configuró un

León BENELBAS, Xavier GARCIA y Joan TUDELA: Unió de Pagesos. El Sindicat del Camp, Barcelona Alternativa, 1977, pp. 74-75; "Elecciones sindicales en Amposta" (5 de julio de 1975), ANC, Fons del PSUC, Cambra Arrossera d'Amposta, Sig. 1-230-T. Caja 1677

31 “A Su Majestad Don Juan Carlos I, Rey de España” (diciembre de 1975), ANC, Fons del PSUC, Cambra Arrossera d'Amposta, Sig. 1-230-T. Caja 1677.

32 Carta enviada a Josep Fàbregas, alcalde de Amposta, por la Unión de Trebajadores de l'Hermandad local con fecha del 20 de enero de 1976, transcrita a "Notícies", La Terra, junio de 1976.

33 Asamblea General de la COSA (1976), AHPT, Fondo de la COSA de Tarragona, Llibre d'Actes, sig. 58.

34 Andreu MAYAYO i ARTAL. De pagesos a ciutadans... p. 208.

35 Carlos OLLERO: "Cambio político, monarquía parlamentaria y consolidaciones de la democracia", Cuenta y Razón, 17 (1984). 
bloque de consenso que estaría en la base del "franquismo sociológico". ${ }^{36}$ Ciertamente, resulta complejo y complicado metodológicamente -cuando no resbaladizo- escapar de la historia y entrar en el terreno de la psicología social. Sin embargo, una cosa es que el régimen hubiera sido incapaz de captar y articular "nuevas" adhesiones y la otra es que la actitud de pasividad -los "indiferentes"- no operara como a "base ética", como apoyo moral y fáctico, no tanto de franquismo sino del status quo, el cual era en sí mismo el franquismo. Esta fue la base ética, el apoyo social, el consenso que desarticuló el antifranquismo en haber conseguido la politización social y la hegemonía entre la sociedad civil.

Conscientes de ello, el gobierno Suárez atendió a la contención de la exaltada situación campesina de muchos puntos de la España rural mediante la promesa de organizar nuevas agrupaciones agrícolas como sustitutas de las Hermandades, esperando poder encauzar las demandas del campo. La UP de las comarcas tarraconenses, en una misiva dirigida a Mombiedro de la Torre, presidente estatal de las Hermandades, le reprochaban que aquellos que siempre habian mantenido posiciones contra

...los intereses de los payeses, quieran reivindicar en estos momentos la libertad, la democracia, y convertirse (...) en defensores de la base cuando ellos siempre y en todo momento han obtenido cargos y prebendas a base de nombramientos a dedo, o bien en elecciones que solamente han existido sobre el papel, y si se han llevado a cabo han estado siempre manipuladas y sin ninguna garantía de imparcialidad. ${ }^{37}$

Ante dicho proyecto de reforma sindical sin democracia que prometía el gobierno, la UP se mantuvo en el posicionamiento de lucha por las libertades democráticas totales, sin exclusiones sindicales ni políticas.

Los plutócratas que monopolizaban la COSA de Tarragona, por su parte, habían prometido dimitir en bloque si para verano de 1976 no se habían producido reformas políticas y económicas en el campo. Las dimisiones nunca se produjeron y las promesas de los franquistas quedaron en papel mojado, por lo que la UP siguió el pulso en la calle a lo largo del año. Rotas todas las posibilidades de entente, entre el 27 de febrero y el 5 de marzo de 1977 se produjo una salida generalizada de tractores en las carreteras catalanas. Lo que luego sería conocido como la Primera Tractorada había empezado en el Pla d'Urgell -en solidaridad con los campesinos riojanos- y pronto prendió como la pólvora, llegando al Montsià el primero de marzo con la adhesión a la lucha de las centrales sindicales obreras.

La retirada de los trescientos tractores de las carreteras del Montsià fue tomada por cada asamblea local evidenciando, de nuevo, la efectiva educación campesina a través de la lucha. Aunque la experiencia de la tractorada se repitió de nuevo en 1978, el aprendizaje de la primera no tendría parangón. Como bien relataba el órgano de la UP, la tractorada, en este sentido, representó

36 Conxita MIR: Vivir es sobrevivir. Justicia, orden y marginación en la Cataluña rural de posquerra, Lleida, Milenio, 200o, p. 20.

37 Traducido del catalán. Citado en León BENELBAS, Xavier GARCIA y Joan TUDELA: Unió de Pagesos... p. 108 ...la constatación práctica de la existencia de una solidaridad payesa bien arraigada, de una capacidad de organización y sentido de disciplina y una clara consciencia democrática que se ha manifestado en todo momento en la manera de tomar decisiones sin ningún tipo de imposición ni dirigismo, estimulando en todo momento la participación de todos los payeses y convirtiéndolos (...) en auténticos protagonistas activos y conscientes de estas jornadas de lucha..$^{38}$

Finalmente, en el mes de abril la movilización social hizo imposible el no reconocimiento de las organizaciones obreras y el gobierno aprobó el derecho a asociación sindical. ${ }^{39}$ Pese a la legalización formal de los sindicatos obreros, las sucesivas leyes sobre Cámaras Agrarias herederas de las Hermandades franquistas- excluyeron la posibilidad real de la participación campesina al no garantizar aún elecciones sindicales democráticas en el campo, que en Cataluña no se darían hasta $1994.4^{\circ}$ En este contexto se produjo el boicot de las elecciones a las Cámaras Agrarias de 1978, vistas por la UP como el intento del franquismo para perpetuarse en el poder. ${ }^{41}$ Los sectores corporativistas amenazaron con clausurar aquellas cámaras locales "donde no se celebren elecciones (...) y ser integradas en la [Cámara Agraria de la población] más próxima" si no se elegían compromisarios. ${ }^{2}$ Pero los campesinos no se dejaron intimidar y el cómputo de abstención en el Montsià llegó al 79\%.43 Pese al boicot, en algunas poblaciones, diversas personalidades relacionadas con las luchas políticas vinculadas al antifranquismo comparecieron como independientes para hacer frente a los corporativistas del Sindicat de la Pagesia i la Ramaderia, heredero del verticalismo franquista. ${ }^{44}$

Más allá de las luchas campesinas mediante la ocupación del espacio público, en múltiples ocasiones se dieron otros actos de carácter de reivindicación catalanista que conviene mencionar debido a su carácter aglutinador interclasista y como dinamitador de la concepción joseantoniana de la nación que preconizó el franquismo. Durante la celebración de la Diada Nacional catalana en 1976 se produjeron ocupaciones de los espacios públicos en numerosos pueblos del Montsià. En Ulldecona, por ejemplo, la Diada coincidió con el final de las fiestas mayores, por lo que se aprovechó el desfile de clausura para confeccionar una carroza denunciando la represión sufrida por la Marxa de la Llibertat, en la que se enarbolaron señeras, cua arma de lucha, frente a las autoridades franquistas locales y provinciales. ${ }^{45} \mathrm{El}$ antifranquismo

38 Traducido del catalán. “Editorial”, La Terra, marzo de 1977.

39 España. Ley 19/1977, de 1 de abril, sobre regulación del derecho de asociación sindical. Boletín OfiEspaña. Ley 19/1977, de 1 de abril, sobre regulación del der
cial del Estado, 4 de abril de 1977, núm. 80, pp. 7510-7511.

40 Andreu PEIX i MASSIP: "Vint-i-cinc anys de la Unió de Pagesos (1974-1999). El camí cap a la llibertat sindical al camp", Quaderns Agraris, 25, (1999), p. 76.

41 Antonio HERRERA GONZÁLEZ de MOLINA: "Otra lectura de la Transición española es posible. La democratización del mundo rural", Ayer, 74, (2009), pp. 231-233.

42 Nota informativa del SPR (18 de abril de 1978), ACMO, Fons de la Cambra Agrària de Freginals, Sig. 22-43-062, Caja 3. Amenaza sustentada en España. Real Decreto 320/1978, de 17 de febrero, por el que se desarrolla y perfecciona el Real Decreto 1336/1976, de 2 de junio, y se regulan las elecciones a Cámaras Agrarias. Boletín Oficial del Estado, de 7 de marzo de 1978, núm. 56, pp. 5399-5402.

43 Andreu MAYAYO i ARTAL. De pagesos a ciutadans... p. 227.

44 En las elecciones de Freginals consta Federico Elies como independiente, pese a estar vinculado a la UP, dónde se enfrentó al resto de compromisarios y de hecho perdió por las desigualdades que mantenía el sistema: "Elecciones a Cámaras Agrarias 1978. Freginals" (26 de mayo de 1978), ACMO Fons de la Cambra Agrària de Freginals, Sig. 22-43-004, Caja 8. Su hijo Eloi había abandonado la UP tras la Segunda Tractora debido al componente interclasista que había adquirido el sindicato, cosa que explica la participación de su padre en las elecciones. Sobre la conexión entre el Sindicat de la Pagesia i Ramadera y el verticalismo franquista $C f$. Cristian FERRER GONZÄLEZ: Lluitadors quotidians..., pp. 142-144.

45 Josep Vericat Estellé, 26 de julio de 2012, Ulldecona, entrevista realizada por Cristian FERRER GON- 
ampostino, por su parte, decidió cortar la vía de entrada a la ciudad a través del puente colgante sobre el Ebro y, con ayuda de una grúa, se colgó una inmensa señera en una de las arcadas de piedra del puente que, debido a un error de cálculo, llegaba a tocar al suelo y tuvo que ser recolocada a toda prisa por los manifestantes. ${ }^{46}$ Los ayuntamientos poco podían hacer más que llamar a la Guardia Civil para contener a una población que había perdido gran parte del miedo impuesto durante décadas.

Pese a la euforia, la apertura del proceso constituyente y los Pactos de la Moncloa no aportaron mejoras efectivas para las demandas campesinas. Ese fue el motivo de fondo de la Segunda Tractorada en marzo de 1978. Las reivindicaciones económicas seguían inseparablemente conexas con las políticas, siendo la supresión de las Cámaras Agrarias la mayor de ellas. Consideramos esa gran "sublevación agraria”, como la definió el Diario Español, como el último intento de ruptura sindical en el campo. La UP entendía que

la movilización popular es la única alternativa viable para que el Gobierno atienda las reivindicaciones planteadas que, en esencia, son las siguientes: fijación de unos precios mínimos de garantía, anulación del decreto-ley de creación de las Cámaras Agrarias y cese inmediato de todos los cargos sindicales; abolición, por decreto-ley, del sistema de financiación de la Seguridad Social Agraria por peonadas teóricas; congelación de todos los desahucios hasta que no se apruebe la nueva Ley de Contratos de Labranza y cese de las importaciones de vino, frutas y productos lácteos ${ }^{47}$.

Tras una semana de duro paro y boicot, las presiones de los agricultores fueron parcialmente satisfechas y el ministerio de Agricultura se avino a negociar con los campesinos. En muestra de buena fe, la UP permitió el reabastecimiento de los mercados que habían estado bloqueados durante la huelga, pese a las cargas policiales y las detenciones de más de veinte agricultores sufridas en Reus y Tarragona ciudad. La situación de tensión interna había llegado a un punto crítico y las posiciones que si antes de la huelga eran ya crispadas, después de una semana de paro total eran abrumadoras. Sólo en las poblaciones más importantes del Montsià, los campesinos retiraron masivamente efectivo de las cajas de ahorros por valor de dieciocho millones de pesetas. La situación había llegado al extremo que algunos alcaldes franquistas -probablemente en un afán por legitimar su cargo, y en un intento por recuperar o ganar adeptos- amenazaron con dimitir si el gobierno negaba el diálogo a los agricultores. ${ }^{48}$ Nuevamente, las asambleas comarcales decidieron sobre la continuidad de la huelga. Más allá del resultado final, no cabe duda que la población había aprendido que la democracia -política y social-implicaba luchar por lo que se consideraba justo, aunque fuera trasgrediendo la legalidad.

\section{La conquista de la legalidad y el ejercicio de la democracia}

a inviabilidad de la reforma del franquismo y la apertura de un -imprevisto- proceso constituyente tras las elecciones generales de 1977, hacía irreversible el cambio de régimen. Las legalizaciones de partidos, sindicatos y, en general, espacios para la auto-organización popular consolidaron pequeños espacios de democracia, ahora en expansión. El periodo comprendido entre 1977 y 1979 representaría una larga "campaña municipal" en que el antifranquismo se

ZÀLEZ a quien fuera militante socialista durante el tardofranquismo y la democracia.

46 Pepito Fabra Miralles, 4 de junio de 2013, Freginals, entrevista realizada por Cristian FERRER GONZALEZ a quien fuera el único militante del PSOE durante el franquismo y la transición a la democracia y Eloi Toldà $i$ Andreu, 17 de junio de 2013, Amposta, entrevista realizada por Cristian FERRER GONZÁLEZ a quien fuera militante comunista durante el franquismo y la democracia.

47 "Unió de Pagesos convoca una nueva tractorada", La Vanguardia Española, 8 de marzo de 1978.

48 "Los agricultores catalanes, pendientes de Madrid", La Vanguardia Española, 15 de marzo de 1978. esforzó por seguir movilizando. Qué duda cabe que los gobernantes tenían muy presente el 14 de abril de 1931 en su memoria, por lo que retrasaron los comicios locales hasta nada menos que abril de 1979. La movilización popular hizo inviable la reforma de la dictadura a nivel general, pero también tuvo consecuencias cuantificables en los municipios del Montsià.

Mayormente, allí dónde se dio una oposición operativa -vinculada a los distintos movimientos del antifranquismo- éstos consiguieron hacerse con las primeras alcaldías democráticas como en los casos de Alcanar, Amposta, la Sénia, Freginals o Ulldecona. Ciertamente el conti nuismo seguía contando con notables apoyos, como en la Galera, dónde el antifranquismo $n$ siquiera llegó a comparecer. El cambio político en el Montsià, en este sentido, no fue distinto a las cientos de comarcas y miles de municipios del Estado español. En todo caso, el estudio microhistórico de esta comarca - una entre muchas- viene a constatar que la democracia no es un mero producto exportable, sino que debe ser construida obedeciendo a parámetros y ritmos propios íntimamente relacionados con las luchas sociales. 


\section{LAGUNAS DE AUTORIDAD. RELACIONES E INFLUENCIAS} ENTRE LAS “FUERZAS DEL TRABAJO" Y LAS “FUERZAS

DE LA CULTURA"

Rosario Fombuena Borrás

Universitat de Valencia

\section{Introducción}

Los movimientos estudiantiles, las organizaciones obreras y las asociaciones vecinales se constituyeron en los tres pilares basales a partir de los cuales se organizó la oposición social a la dictadura franquista. Aunque las tres corrientes contrarias al poder tuvieron trayectorias diferenciadas entre sí, en determinados momentos de su andadura se encontraron y, conscientes de que su lucha tenía un objetivo común, intentaron establecer flujos de relación que en ocasiones fructificaron y en otras se quedaron en meros intentos de conexión.

Mientras que el movimiento vecinal tenía un componente inequívocamente social que pretendía articular alternativas concretas para la gestión de la vida cotidiana y los espacios urbanos, el movimiento obrero podía ser considerado como el principal agente de acción colectiva con unas aspiraciones directamente vinculadas a reivindicaciones laborales y salariales. Por otro lado el movimiento estudiantil, que tuvo unos inicios menos politizados pero que posteriormente asumiría un mayor componente político, se convirtió en el manantial que proporcionó suficiente material ideológico y humano para nutrir al resto de movimientos de protesta. Los activistas que en un primer momento habían participado en las movilizaciones estudiantiles de los años 60 fueron los que más tarde, y una vez finalizada su etapa de formación universitaria, se incorporaron tanto a las asociaciones vecinales como a las organizaciones obreras para continuar con una febril labor reivindicativa y de oposición al régimen.

Durante este periodo convulso y lleno de altibajos, obreros y estudiantes mantuvieron una serie de relaciones que fueron complejas, desiguales y, en determinados momentos, no demasiado estables. Ambos movimientos fueron testigos de los acontecimientos que se estaban desarrollando en los agitados últimos años de la década de los 60 a nivel mundial por lo que recibieron unas influencias e inspiraciones provenientes del exterior que les afectaron en diferente medida y adaptaron de distinto modo a la particular realidad española. El diferente trascurrir de las dos corrientes de acción y sus desiguales concepciones y demandas provocaron que el entendimiento entre ellos no fuera sencillo y el consenso fue buscado más por conveniencia de alguno de los dos sectores en un momento determinado que por convicción, ya que los integrantes de estos grupos poseían visiones identitarias muy divergentes que dificultaban el establecimiento de puentes de unión o la confluencia de objetivos.

La cuestión de las relaciones entre los estudiantes y los obreros especialmente durante las movilizaciones que se produjeron en la década de los 60 ha sido tratado, entre otros autores, por Alain Touraine quien circunscribe sus estudios a los acontecimientos que se produjeron en el Mayo del 68 francés, pero algunas de sus conclusiones pueden servir para abordar este estudio desde la perspectiva española. Según Touraine las relaciones entre ambos movimientos fueron más bien escasas, considera este autor que los estudiantes eran unos "actores privilegiados" en los acontecimientos que se desarrollaron en estos años que él denominó "nueva lucha de clases".' A pesar de esta afirmación, encontró una serie de coincidencias entre los distintos movimientos que sí eran comunes: en primer lugar se refiere al componente generacional, la juventud, similar en ambos casos. También coincidían en su visión crítica de la realidad social, lo cual puede ser aplicado especialmente al caso español y a la perspectiva que ambos sectores tenían acerca de la política española franquista. Touraine también apuntó que el incremento del paro entre los jóvenes de proveniencia obrera pero también en los estudiantes que empezaban a encontrar ciertas dificultades en su incorporación al mercado laboral, fue otro nexo de unión concurrente. A estos aspectos se podría añadir la aplicación, tanto por parte de los obreros como de los estudiantes, de un punto de vista intelectual que les permitía globalizar la situación y ponía en entredicho todo el sistema. ${ }^{2}$

La mayoría de los estudiantes y obreros españoles que participaron en las movilizaciones que se venían produciendo en el país desde la década de los 50, compartían el posicionamiento de que era necesario ir más allá de reivindicaciones económicas, laborales o académicas particulares de cada uno de los sectores implicados, ya que la principal demanda implicaba emprender una reforma estructural que modificaría las relaciones del poder y la autoridad y cuya máxima aspiración debería ser la democratización de la sociedad, primero a través de la implantación de este sistema en fábricas y universidades y posteriormente en el sistema político español. En este punto, los estudiantes eran quizás más conscientes de que necesitaban unir sus reivindicaciones a las de los otros sectores sociales que estaban ya movilizándose en contra de la dictadura para de este modo amplificar sus mensajes, ser más efectivos y alcanzar a un sector más amplio de la población. ${ }^{3}$

En contraposición a esta interpretación en el que se encuentran ciertas similitudes entre ambas facciones, Adrien Dansette afirmó que las divergencias fueron mayores que las similitudes ya que, según él, los estudiantes poseían una imagen abstracta del obrero al que consideraban que, dada la pretendida superioridad intelectual de los estudiantes, debían ser estos últimos los que les guiaran hacia la revolución. Si bien es cierto que el desconocimiento de las mutuas perspectivas fue notorio, no por ello se dejaron de impulsar acciones que intentaron aunar ambos movimientos en una única dirección deseable para todos. Como afirmó en el año 1968 Daniel Cohn-Bendit, uno de los líderes del Mayo francés, en una conversación con Jean Paul Sartre: "La unión de los estudiantes y obreros sólo puede hacerse en la dinámica de la acción si el movimiento de los estudiantes y el de los obreros conservan cada uno su impulso y convergen hacia un mismo objetivo. Por el momento existe una desconfianza natural y comprensible de los obreros". ${ }^{4}$

Algunos autores consideraron que el primer paso para lograr una unión que forjara la colectividad y condujera a una acción colectiva efectiva entre estudiantes y obreros en el caso español pasaba por la construcción de un imaginario común que posibilitara este trayecto. Esta es la perspectiva abordada por Rafael Cruz quien afirmó que este factor se desencadenó cuando ambos movimientos realizaron una diagnosis del hecho interpretado como injusto y al cual era necesario dar una respuesta, en este caso la dictadura. Sigue Cruz la tesis de Galton al señalar la personalización de los posicionamientos con un "nosotros" contra un "ellos", "buenos" contra "malos". La acción colectiva que desencadenaría esta asunción de premisas comunes legitimarían los beneficios objetivos que se obtendrían por esta unión. ${ }^{5}$

Alain TOURAINE: Le Communisme utopique. Le mouvement de Mai 68, Paris, Seuil, 1972.

2 Antonio SAÉNZ DE MIERA: Aquel mayo del 68, Cáceres, Universidad de Extremadura, 2008.

3 José María MARAVALL:Dictadura y disentimiento politico. Obreros y estudiantes bajo el franquismo, Madrid, Tesis Alfaguara, 1978, p. 174

Daniel COHN-BENDIT: "El intangible legado de Mayo del 68", Le Nouvel Observateur, 20 de mayo de 1968. Recogido en Cuadernos para el diálogo, 30 (2008), págs. 6-13

5 Rafael CRUZ y Manuel PÉREZ LEDESMA (eds.): Cultura y movilización en la España Contemporánea, 
Si se abordan los movimientos antifranquistas como una acción colectiva es necesario tomar como referencia a Sidney Tarrow cuando afirma que los movimientos sociales son una especie de maraña entrelazada de pequeños grupos, redes sociales y conexiones entre ellos. Las protestas de un grupo, según afirma Charles Tilly, estimulan a otros grupos descontentos a manifestar sus protestas y a movilizarse tomando unos objetivos democratizadores en este caso. $Y$ en el caso de este estudio esta argumentación parece ser cierta ya que tanto estudiantes como obreros primero tomaron ejemplo de algunas de las movilizaciones que se estaban produciendo más allá de las fronteras, copiando métodos, prácticas e incluso ciertas reivindicaciones, pero además vieron que la fuerza de la acción de cualquiera de los sectores contestatarios al régimen servía para propiciar nuevas movilizaciones del resto. Todos estos aspectos se sucedían teniendo en cuenta el especial clima político y de represión que se vivía en el país y que, evidentemente, dificultaba cualquier acción o propuesta emprendida y que caracterizaba de un modo diferenciado las movilizaciones que se produjeron en España en estos años.

\section{La situación en Valencia}

En los últimos años de la década de los 60 y primeros años 70, el protagonismo de la lucha antifranquista sufrió un cambio en el rol principal debido a la pérdida del empuje de las protestas obreras desmanteladas por la gran presión que el régimen infligió sobre las mismas. Fueron los estudiantes los que en estos momentos se situarían en primera línea de las movilizaciones de protesta con unos posicionamientos mucho más radicalizados que en las etapas iniciales del movimiento estudiantil. Según Maravall la revuelta juvenil se había convertido en una acción corporativa polarizada que había acercado posicionamientos con el movimiento obrero y el ciudadano. Para este autor esta aproximación se produjo, además de por los motivos ideológicos o políticos que podrían ser evidentes y por la imperiosa necesidad de unión, por la estancia en prisión de algunos estudiantes lo que les permitió entrar en contacto con los sindicalistas presos y obtener una amplitud de miras y conceptos de los que carecían hasta el momento.

La confluencia de ambos movimientos iniciada tímidamente por los estudiantes también se hizo necesaria desde el punto de vista sindical que advirtió la necesidad de acortar distancias entre los dos. Así lo manifestó Marcelino Camacho cuando afirmó que era necesario aliar las fuerzas del trabajo y de la cultura influenciado, tal vez, por planteamientos similares del Partido Comunista de España. Las fuerzas sindicales contaban con unos referentes ideológicos relacionados directamente con el comunismo y los dirigentes del partido pronto se dieron cuenta de la necesidad de contar con todos los aliados posibles en su lucha contra el franquismo. En 1967 Santiago Carrillo, Secretario General del partido, dirigía una carta a Dolores lbárruri en la que se expresa en los siguientes términos:

En la discusión del Comité Ejecutivo hemos convenido en la necesidad de esbozar en la próxima reunión la perspectiva de lo que llamamos un frente de las fuerzas del trabajo y la cultura (...) que puede irse creando a través de los contactos de la Comisiones Obreras, el movimiento campesino, los estudiantes y las diversas formas de organización de los intelectuales. En un momento determinado, cuando la coordinación haya llegado a un grado de madurez, y cuando la coyuntura política lo aconseje, puede aparecer formalmente constituido en la escala nacional y provincial por representantes de las diferentes capas sociales. Una de las originalidades de este frente, en el que los artesanos y los comerciantes e industriales podrían encontrar también lugar, es que sería no un partido, sino una especie de frente laboralista amplísimo.?

Madrid, Alianza, 1997, p. 22.

Sidney TARROW: El poder en movimiento: los movimientos sociales, la acción colectiva y la política: Madrid, Alianza, 2004, p. 50.

Santiago CARRILLO en Xavier DOMÉNECH SEMPERE: “El cambio Político (1962-1976). Materiales para una perspectiva desde abajo", Historia del Presente, 1 (2002), pp. 46-67.
La necesidad de ampliar la base social de la protesta para llegar a un mayor número de sectores y conseguir unos mejores resultados aparece también en algunos de los boletines clandestinos editados por del Partido Comunista de España que en 1969 publicaban: "En nues tro país, el régimen cuenta (...) con la hostilidad de obreros y campesinos y progresivamente de la oposición de amplios sectores de la intelectualidad, entre los que cabe destacar a los estudiantes". ${ }^{8}$ Este hecho, la ampliación de los movimientos contestatarios a nuevos sectores de la sociedad, consiguió que las protestas antifranquistas no decayeran en las décadas posteriores a pesar de la especial persecución por parte de las autoridades del régimen a algunos de los movimientos implicados en estas críticas. Esta es la opinión también de las profesoras Teresa Carnero y Aurora Bosch quienes afirman: "Los sindicatos habían tomado la iniciativa en el proceso de crítica al régimen que iniciaría una larga transición, las huelgas lideradas por CCOO y el Partido Comunista en enero de 1976 en Madrid fueron decisivas las incorporaciones de nuevos sectores sociales en la lucha por la sociedad democrática". 9

Esta aparente unión de ambos movimientos merced al objetivo común de derrocar al régimen no estuvo exenta de desencuentros, rivalidades y cierta incomprensión mutua. Para Sergio Rodríguez Tejada este acercamiento de los obreros a las causas estudiantiles estuvo provocado también por una cuestión de oportunismo: "La situación de debilidad en que se encontraba el movimiento obrero en Valencia y el interés del partido [PCE] por el movimiento estudiantil realzaban la importancia de contar de nuevo con una organización universitaria".." Este maridaje resultaría complejo de colegir por lo que es necesario un amplio ejercicio de intelección que permita conocer los puntos comunes y las divergencias entre ambos.

\section{Influencias}

Francia, Estados Unidos, también México... eran muchas las naciones que en la segunda mitad de la década de los años 60 del siglo XX atravesaron momentos de convulsión social que en determinados casos estaban relacionados con una cuestión aparentemente generaciona y que, inevitablemente, tuvieron una serie de repercusiones que se extendieron a otros países. Hay que destacar la particular situación política que en esos momentos vivía España con un régimen que, además de constreñir las libertades individuales, fiscalizaba con celo cualquier injerencia que llegaba de más allá de sus fronteras. A pesar de esta vigilancia, los ecos de estos movimientos penetraron en el país donde los sectores opositores recogieron algunas de las demandas que corrian por el extranjero y las adaptaron a la realidad española del momento.

Así, por ejemplo, las protestas que se produjeron en Francia en el mes de mayo de 1968 tuvieron una gran influencia en todo el mundo. La repercusión internacional de los acontecimientos franceses, difundidos masivamente gracias a los modernos medios de comunicación de masas, consiguió que las barricadas francesas fueran el elemento inspirador que impactó en otros acontecimientos que estaban germinando en otros países. Además, en España, el descrédito de la prensa oficialista del régimen había dado paso a unos medios más concienciados que colaboraban en la difusión de una información alternativa a una población cada vez más preparada y deseosa de conocer otras realidades. La "dramatización mediática" que medios como la televisión, hicieron de estas protestas sirvió como espejo en el que se veían

8 Anónimo: Verdad (Valencia), marzo de 1969

Teresa CARNERO y Aurora BOSCH: "La democracia en las culturas políticas del siglo XX: participación, acción política, prácticas políticas y aspectos comparativos", en José Alfonso MORCILO LLOSA (coord.): Nuevos horizontes del pasado. Culturas politicas, identidades y formas de representación. Actas del X Congreso de la Asociación de Historia Contemporánea, Santander, Universidad de Santander, 2010, p. 200

10 Sergio RODRÍGUEZ TEJADA: Zonas de libertad. Dictadura franquista y movimiento estudiantil en la Universidad de Valencia. Vol. II (1965-1975), Valencia, Universidad de Valencia, 2011, p. 46. 
reflejados muchos de los movimientos antiautoritarios que coincidian en el tiempo: "[...] Pudieron verse y aprender unos de otros, tomaron nota de soluciones creativas que a ellos no se les habían ocurrido, las transformaron a su vez y las pusieron en circulación de nuevo"."

Del Mayo Francés aprendieron tácticas, razonamientos y métodos de protesta que luego aplicaron en los diferentes escenarios en los que estaban en colisión. En opinión de Benito Sanz, la evidente proximidad geográfica de España y Francia fue decisiva en esta relación de ascendencia, a la que también se sumó el hecho de que era en el país vecino donde se habían radicado y desarrollado las principales estructuras organizativas de la oposición franquista. ${ }^{12}$

Gracias a este flujo de información que se estableció entre los diferentes países y a pesar de las evidentes limitaciones en cuanto a la libertad de la misma que sufría España, las movilizaciones españolas también adoptaron en su discurso algunas de las reivindicaciones de otros movimientos de protesta: "Los estudiantes españoles tomaron ejemplo de sus compañeros de Berkeley o Berlín que exigian el ejercicio libre de actividades dentro de los recintos universitarios". 13 Lo que en naciones como Estados Unidos o Alemania resultaba un ejercicio democrático básico, en España esta pretensión tenía unas aspiraciones que iban más allá del ámbito simplemente académico debido al régimen dictatorial imperante. Siguiendo la calificación de las etapas del movimiento estudiantil que en su día realizó Maravall, estas reivindicaciones de ámbito estrictamente académico pertenecerían a una primera etapa de las movilizaciones estudiantiles circunscritas principalmente a los años 50 aproximadamente, centró sus reivindicaciones en asuntos relacionados casi exclusivamente con el funcionamiento del sistema académico universitario. Posteriormente los sectores opositores irían ampliando su abanico de demandas extendiéndolas a otros planos ya no vinculados únicamente con el sistema educativo, sería la que Maravall califica como tercera etapa del movimiento en la que se evoluciona hacia una politización y radicalización de las protestas con unas peticiones de tipo social y político que tenían como eje vertebrador la voluntad de acabar con la dictadura del General Franco. ${ }^{14}$ La explosión social a nivel mundial que se produjo en el año 68 proporcionó un mayor contenido político a los diferentes movimientos de protesta, además de radicalizar sus exigencias. El rechazo a la "agresión imperialista" cometida por los Estados Unidos en Vietnam se convirtió en un punto recurrente en los discursos de las protestas estudiantiles de todo el mundo y también en los españoles. En este punto es importante no olvidar la concepción que tenía gran parte del imaginario cultural y político opositor en España sobre los Estados Unidos después de los Pactos de Madrid firmados en 1953, hecho que les convenció de que se trataba de un gobierno que apoyaba y legitimaba internacionalmente al régimen franquista. La animadversión hacia Norteamérica estaba más orientada hacia los poderes políticos y económicos y no hacia unos valores culturales que eran seguidos, admirados y deseados. Estos posicionamientos antiimperialistas son encontrados en algunas de las publicaciones clandestinas tan profusas en la época. En la Universitat de València ese mismo año empezó a funcionar el Comité Antiimperialista (CAUV), que publicaba diferentes boletines en los que difundía artículos extranjeros sobre el rechazo a la Guerra de Vietnam. También el clandestino Partido Comunista hacía referencia a estos hechos en alguna de sus publicaciones atribuyendo los acontecimientos a las contradicciones propias del capitalismo. ${ }^{5}$ Comisiones Obreras,

11 Ibid.p. 160

12 Benito SANZ DÍAZ: Rojos y demócrata: la oposición al franquismo en la Universidad de Valencia: 1939-1975, Valencia, Institució Alfons el Magnànim, 2002, p. 165

13 Eduardo GONZALEZ CALLEJA: "Rebelión en las aulas: un siglo de movilizaciones estudiantiles en España (1865-1968)" en Ayer, 59 (2005), p.44

14 José María MARAVALL: Dictadura y disentimiento..., p. 277

15 ¿Qué hacer? Órgano del Comité Provincial de Valencia del Partido Comunista de España, Valencia, I (1968) p.1. por su parte, hacía referencia a las manifestaciones contrarias a las guerras emprendidas en Asia por los Estados Unidos ${ }^{16}$ y en menor medida a otras reivindicaciones aparecidas en otras latitudes como el feminismo.

A pesar de la voluntad de incorporar las reivindicaciones de otros movimientos extranjeros a las protestas emprendidas en España, los movimientos antifranquistas no perdieron de vista su objetivo principal, la desaparición de la dictadura: "Los estudiantes españoles tenían un referente más doméstico y propio, más inmediato y circunstancial, que se resumía en buscar cuanto antes una salida del autoritarismo para llegar desde ahí al "socialismo". ${ }^{17}$

Tanto las pretensiones de cambio democrático de los estudiantes como las demandas laborales del movimiento obrero se hicieron eco de parte de las reivindicaciones internacionales al coincidir con una etapa de cierto aperturismo del régimen, lo cual permitió una mayor permeabilidad a las nuevas formas de vida y a los valores que estaban emergiendo en muchos paises de la Europa Occidental y de América. Estas nuevas ideas se introdujeron en España mediante el fenómeno de la emigración, la llegada del turismo, pero también los intercambios culturales que se produjeron por la entrada de nuevos materiales de lectura y también el incremento de las salidas al extranjero, tanto a título individual como colectivo. En este punto es interesante destacar el Programa de Liderazgo de Estudiantes Extranjeros del American Field Service, organización norteamericana que se encargó desde los primeros años de la década de los 60 , a programar viajes de intercambio cultural de determinados estudiantes valencianos a los Estados Unidos. Los estudiantes seleccionados por la Comisión de Coordinación Cultural Valenciano-Norteamericana eran algunos de los miembros más destacados de la Universitat de València y esos viajes les permitieron entran en contacto directo con la realidad estudiantil de un país en el que en esos precisos momentos estaba experimentado una fuerte politización en sus movimientos estudiantiles. Benito Sanz, quien trata sucintamente este punto, afirma que aunque en un inicio estos viajes fueron sufragados únicamente a miembros del Partido Socialista Valenciano, posteriormente se ampliarían a otros integrantes de la democracia independiente o cristiana, sin que en ningún caso fueron admitidos miembro de Partido Comunista Español..$^{18}$ Asimismo los anfitriones norteamericanos actuaron con precaución cauterizante al dificultar los encuentros de los visitantes españoles con algunas de las figuras comunistas norteamericanas de la época. No deja de ser paradójico este tema, ya que la universidad española manifestaba una mayoritaria influencia de posicionamientos ideológicos comunistas que colisionaban de frente con el exacerbado anticomunismo que en estos años se extendía en los Estados unidos: “[...] unos jóvenes procedentes de una universidad de provincias situada en un estado europeo de segunda fila sometido a una dictadura llegaron a Estados Unidos sabiendo quiénes eran Aptheker, Baran y Sweezy, y deseando conocerlos" 19

La coyuntura política que existía en España marcó de manera definitoria la trayectoria de estos movimientos que adaptarían el rechazo al régimen franquista y las demandas democratizantes a sus reivindicaciones como columna vertebral de cada uno de ellos. A pesar de que el resto del mundo estaba surcando por potentes movilizaciones sociales de diferente índole las influencias que se reflejaron en el panorama nacional fueron más bien tenues. Podría destacarse la adaptación que se hizo de las demandas pacifistas norteamericanas contrarias a la invasión militar en el sudeste asiático, que en España tomaron un manifiesto acento antiimperialista por la concepción que se tenía del papel jugado por los Estados Unidos durante la

16 Libertad. Boletín de las Comisiones Obreras (Valencia), julio 1970, p.11.

17 Elena HERNÁNDEZ SANDIOCA, Miguel Ángel CARNICER RUIZ y Marc BALDÓ LACOMBA: Estudiantes contra Franco (1939-1975). Oposición política y movilización juvenil, Madrid, La Esfera de los Libros, 2007, p. 257.

18 Benito SANZ DíAZ: Rojosy demócratas... p. 165.

19 Sergio RODRÍGUEZ TEJADA: Zonas de libertad..., p.27. 
Guerra Civil y su falta de condena al régimen de Francisco Franco, tal y como ya se ha mencionado. De forma también ligera se propagó la cuestión del feminismo que había surgido en los Estados Unidos y que caló en España muchos años después, así como la pretendida revolución sexual que, hasta fechas muy posteriores y no con la misma fuerza que en el resto del mundo, se desarrolló en el país. El objetivo principal de las diferentes movilizaciones contrarias al régimen era tan potente que no admitía desvíos prolongados en sus reivindicaciones, que a pesar de deseables no tenían la misma fuerza que el deseo de acabar con la dictadura.

\section{Confluencias}

Afirma Alberto Carrillo Linares que una de las claves para entender la verdadera importancia de los movimientos de protestas antifranquistas estudiantiles es que hay que ser consciente del intenso nivel de contestación que estos mantuvieron durante años. ${ }^{20}$ Era en el ámbito universitario en donde se incorporaban los nuevos valores ideológicos y culturales necesarios para normalizar unos códigos referentes en los sistemas democráticos occidentales. La conceptualización teórica que se desarrollaba en la Universidad era necesaria para dotar de contenido a una nueva cultura política que estaba surgiendo entre los opositores a la dictadura del General Franco. “... para mover, primero hay que conmover..." ${ }^{21}$

Estos procesos enmarcadores fueron vitales para dinamizar las protestas en unos momentos en los que otro de los movimientos antifranquistas no estaba en sus mejores condiciones. Los obreros habían sido reprimidos con una feroz violencia que nunca llegaron a experimentar los estudiantes, a los que se les consentía una mayor libertad para expresar su descontento: "A los estudiantes se les consentía que se dirigieran en público a las autoridades para expresar su descontento en mucha más medida que a cualquier otro colectivo, con excepción quizás de los miembros de la Iglesia". ${ }^{22}$

A pesar del potente vínculo que unía a todos los sectores opositores que era el deseo de acabar con la dictadura, las estrategias de acción común que establecieron los dos movimientos estuvieron condicionadas por la diferenciación en sus conceptos ideológicos, culturales y sociales. Mientras que los estudiantes, gracias a su procedencia social y su estatus económico podían alargar las protestas de un modo más laxo, los obreros no se podían permitir esta flexibilidad en sus acciones por lo que las estrategias de funcionamiento de unos y otros no podían ser de ningún modo similares. Además las asociaciones obreras contaban con una mayor y más amplia trayectoria histórica y la brutal y permanente represión policial que sufrieron les hicieron adoptar otros métodos para continuar con su oposición al régimen, entre ellos estaba la de aproximarse a los movimientos estudiantiles. Este acercamiento entre estos dos pilares de la oposición franquista fue observado con recelos por las autoridades que de ningún modo podían permitir una convergencia de ambos:"En el plazo inmediato, el régimen siempre temió mucho más a la protesta obrera pero, en cierta medida, perdió de vista los efectos destructivos del otro movimiento, que fue mucho más corrosivo, del entramado profundo sobre el que se construye una sociedad". ${ }^{23}$ En ocasiones se ha considerado que este acercamiento fue más bien unilateral, de los estudiantes hacia los obreros a los que consideraban como referentes en la lucha, y así lo demuestran numerosos artículos que aparecían en las publicaciones universitarias en los que se mostraba el interés de los estudiantes por la problemática obrera. Aunque existió la voluntad de tender puentes con las luchas de la clase trabajadora, los

20 Alberto CARRILLO LINARES: "Movimiento estudiantil antifranquista, cultura política y transición política a la democracia" en Pasado y Memoria, Revista de Historia Contemporánea, 5 (2006), p. 163 21 Ibid., p. 156

22 Sergio RODRIGUUEZ TEJADA: Zonas de libertad..., p.432.

23 Alberto CARRILLO LINARES: “Movimiento estudiantil...", p. 159. estudiantes tenían un innegable origen pequeñoburgués que condicionaba la visión idealizada que tenían de los obreros al que consideraban el verdadero héroe de la lucha de clases. E año 1967 fue un período especialmente convulso en las movilizaciones antifranquista y en el que los estudiantes tomaron una parte muy activa en todas ellas. En la manifestación del 1 de mayo, por ejemplo, los estudiantes unieron sus fuerzas con las de los trabajadores y salieron a la calle juntos en la primera manifestación que se producía en la ciudad de Valencia desde el final de la Guerra Civil. Sobre ambos cayó la brutal represión policial con que fue respondida la protesta y que hasta la fecha había sido mucho más rigurosa para los primeros.

Como afirma Rodríguez Tejada la convergencia de ambos movimientos fue vista con mucha preocupación por las autoridades que intentaron por todos los medios debilitar e inutilizar estas fuerzas opositoras con fuerte represión policial pero también con maniobras propagandisticas envenenadoras. A pesar de la aparente "solidaridad unilateral" de los estudiantes hacia los trabajadores quienes en muchas de sus publicaciones y asambleas tenían presente la problemática obrera, estos últimos, conscientes de la necesidad de aunar esfuerzos para la lucha, también intentaron atraer un discurso más elaborado para sus publicaciones que pudiera incluir a los estudiantes: "Fue en torno al 1 de Mayo cuando se gestó la idea de sacar una publicación dirigida a los trabajadores, en la que idealmente pudiesen escribir "intelectuales" (universitarios) y "obreros" a pie de igualdad. [...] Surgió así Tribuna Obrera. Periòdic del País Valencià". ${ }^{24}$ Aunque las diferencias en cuanto a los orígenes, planteamientos y metas del movimiento estudiantil y el movimiento obrero fueron tan diferentes, ambos intentaron en algunas ocasiones establecer cauces comunes de acción para conseguir el objetivo final que ambos se habían fijado: la derrota de la dictadura. En ocasiones estos acercamientos fueron propiciados por la situación de debilidad de alguno de los sectores o en ocasiones por cierto sentimiento de admiración, pero nunca se lograron estructuras estables o fluidas entre ambos.

\section{Conclusiones}

La coyuntura política que existía en España marcó de manera definitoria la trayectoria de los movimientos de oposición que adaptarían el rechazo al régimen franquista y las demandas democratizantes a sus reivindicaciones como eje vertebrador del funcionamiento de cada uno de ellos. La consciencia de necesidad de unión en esta lucha democratizadora se hizo más evidente entre el movimiento obrero y estudiantil ya que ambos eran conscientes de que para lograr una amplificación de las demandas necesitaban llegar a sectores más amplios de la sociedad y esto se podía conseguir gracias a la colaboración con los diferentes sectores que ya contaban con una organización. Tanto estudiantes como obreros solicitaban a través de sus publicaciones estos apoyos y animaban a la organización de acciones comunes en contra del régimen franquista. Así se puede observar en los boletines clandestinos de Comisiones Obreras por ejemplo, pero también en las cabeceras de los de los estudiantes quienes observaban con admiración algunas de las acciones emprendidas por los obreros.

Las autoridades franquistas observaban con estricta vigilancia el pretendido acercamiento entre dos de los sectores más importantes de oposición al régimen a los que intentaron equiparar al fenómeno generacional de protesta que se estaba produciendo a nivel internacional, pero la preocupación porque ambos encontraran un entendimientos práctico llevó a que se idearan campañas de intoxicación propagandística con la intención de minar la ansiada convergencia de ambos movimientos, además de utilizar todos los recursos disponibles del gobierno para debilitar y dividir a cualquiera que mostrara posicionamientos contrarios a la autoridad.

La situación política española era demasiado específica como para permitir seguir la oleada movilizadora que pareció atravesar muchas naciones durante la década de los 6o. Aunque 
eran muchos los países sacudidos por potentes movilizaciones sociales de diferente índole, las influencias que se reflejaron en el panorama nacional fueron más bien tenues. Por proximidad geográfica y social los movimientos españoles recibieron una mayor influencia de las también fueron destacables las adaptaciones que se hicieron en España de las demandas pacifis en España de las demandas pacifstas norteameicanas contrarlas a la invasion militar en el sudeste asiático, que tomaron un marcado acento antiimperialista por la concepción que se tenía del papel jugado por los Estados Unidos durante la Guerra Civil y su falta de condena al régimen de Francisco Franco. De forma también ligera se propagó la cuestión del feminismo que había surgido en los Estados Unidos y que caló en España muchos años después tal y como sucedió con la pretendida liberación sexual.

Todas estas cuestiones provocan la singularidad de los movimientos sociales antifranquistas que se dieron en España entre los años finales de los 60 y los primeros años de la década de los 70, hasta la muerte de Franco. Es difícil establecer una correlación entre unos movimientos que tuvieron cada uno de ellos su impacto en unas facetas distintas, pero lo que es cierto es que ambos fueron las piedras sobre las que se desarrollaron muchas de las acciones de protesta que tuvieron su eco en el resto de la sociedad española. Cada uno de ellos aportó una visión, una temática y un funcionamiento diferenciado, pero necesario para socavar un régimen totalitario que impedía cualquier actividad opositora. 


\section{EL MOVIMIENTO VECINAL EN ÁLAVA}

\section{DURANTE LA TRANSICIÓN}

Jon Martínez Larrea

UPV-EHU

\section{Introducción}

El objeto de este trabajo es analizar el surgimiento del movimiento vecinal en la provincia de Álava, este proceso comienza en los últimos años del Franquismo, pero se desarrolla especialmente durante la transición, por eso es interesante analizar el papel democratizador que jugó el movimiento, el cual en múltiples ocasiones entró contradicción con la práctica institucional.

En cierto modo, el movimiento vecinal ha quedado en un segundo plano para la historiografía hasta fechas recientes, pero nuevos trabajos sobre el tema están recalcando el papel jugado por este en el cambio político.

El concepto de movimiento ciudadano o vecinal es amplio y sería un error circunscribirlo exclusivamente a las Asociaciones de Vecinos (AAVV), pero como afirmaba Jesús Omeñaca "la entidad que hasta hoy ha sido más representativa, por ser la más numerosa en cuanto a socios, y por abarcar en sus estatutos la defensa de los intereses populares (urbanismo, precios, sanidad, cultura, deportes, etc.) es la Asociación de Vecinos".2

En lo que respecta a la provincia de Álava durante los últimos años del Franquismo la conflictividad política y laboral fue menor que en las provincias vecinas, esto podría explicar el retraso en la difusión del movimiento vecinal a este territorio. Mientras en grandes urbes como Madrid, Barcelona o Bilbao, el movimiento vecinal había sido un factor importante que aceleró la crisis del franquismo, llegando en el caso bilbaíno a derribar a la alcaldesa Pilar Careaga, en el territorio alavés estaba dando sus primeros pasos. Iván Bordetas resalta que:

El movimiento vecinal representó, al fin y al cabo, una heterogénea red de organizaciones sociales con base en el barrio y centradas en la cuestión urbana que nucleó y permitió dar voz, no obstante, a las demandas de ruptura con la dictadura de amplios sectores de la población, particularmente las clases populares, configurándose como uno de los nodos centrales de una sociedad amplia y masivamente movilizada en los principales centros urbanos del país.

1 Sin ánimo de ser exhaustivos citaremos las obras colectivas: Carme MOLINERO y Pere YSAS (coords.): Contruint la ciutat democratica. El moviment veinal durante el tardofranquisme i la transició, Barcelona, Icaria, 2010; Victor PEREZ OUINTANA y Pablo SANCHEZ LEON, (eds.): Memoria ciudadana y movimiento vecinal, Madrid 1968-2008, Madrid, Libros de la Catarata, 2009; y las tesis: Iván BORDETAS JIMENEZ: Nosotros somos los que hemos hecho esta ciudad. Autoorganización y movilización vecinal durante el tardofranquismo y el proceso de cambio politico, Tesis Doctoral, Universitat Autonòma de Barcelona, 2012 (http://ddd.uab.cat/pub/tesis/2011/hdl 10803 96186/ ivjide1.pdf) y Constantino GONZALO MORELL: Movimiento vecinal y cultura política democrática en Castilla y León: el caso de Valladolid (1964-1986), Tesis Doctoral, Universidad de Valladolid, 2011 (http://www.vecinosvalladolid.org/IMG/pdf/tesis_doctoral_constantino_gonzalo_morell.pdf).

2 Jesús OMENACA: Movimiento ciudadano: crisis, Bilbao, G. Ellacuría, 1977, p.71

3 Iván BORDETAS JIMENEZ: Nosotros somos... p. 597
Para entender el surgimiento y difusión del movimiento vecinal hay que reseñar el espectacular crecimiento poblacional que experimentó la provincia a partir de los años sesenta, la capital pasó de 52.445 habitantes en 1950 a 173.137 en 1975. Este crecimiento fue el resultado de un rápido proceso de industrialización, que atrajo a miles de personas procedentes de distintas partes de la península. Este crecimiento, fue más o menos ordenado, debido en cierta parte a la participación pública tanto en la planificación como en la construcción, pero los barrios que fueron surgiendo padecían multitud de deficiencias en lo relativo a equipamientos. ${ }^{4}$

En el caso de Llodio, núcleo influenciado por el crecimiento del Gran Bilbao, la población pasó de 3.000 a 20.000 habitantes entre 1940 y 1975. Esta población se fue asentando en nuevos barrios como Ugarte y Lateorro, sin equipamientos ni servicios, y desconectados entre ellos. Hasta 1970 no se aprobó el plan de ordenación urbana, anteriormente ni siquiera existía una delimitación entre el suelo urbano e industrial. ${ }^{5}$

\section{Surgimiento de movimiento vecinal en Álava}

En Vitoria y otros lugares de la provincia comienzos de los años sesenta desde el Movimiento se impulsó la constitución de Asociaciones de Cabezas de Familia, para intentar encauzar a amplios sectores de la población dentro de sus estructuras, pero su actividad fue más bien escasa y sus objetivos no fueron cumplidos.

Distinto fue el caso de los Centros Sociales de Adurza y Errekaleor, que asumieron funciones similares a las que poco después asumirán las asociaciones de vecinos. El Centro Social de Adurza se creó en 1960, a iniciativa de sectores católicos progresistas, especialmente del sacerdote Carlos Abaitua. Además de servir como medio de integración para los recién llegados y para la dinamización social, fue pionero en la democratización por dos cuestiones, por un lado su junta directiva era elegida democráticamente por los vecinos del barrio, ${ }^{6}$ y por otro promocionó la candidatura de tres personas ajenas al régimen en las elecciones del tercio familiar de 1963 que resultaron elegidas.7

A su vez es reseñable la existencia en Vitoria de los mayorales de vecindad en Vitoria, una especie de representante elegido por los vecinos. ${ }^{8}$ Estas vecindades surgidas en la Edad Media, perdieron en el siglo XIX la mayoría de sus facultades y bienes, pero siguieron existiendo hasta mediados del siglo XX. Javier Fernández de Betoño recuerda que "en cada vecindad había una hornacina con una virgen o un santo y entonces cuando el santo o la virgen que sería se hacía la fiesta, y colaboraban, claro, los comercios que había entonces...". ${ }^{9} \mathrm{~A}$ pesar de que su papel era más bien simbólico, a través de las fiestas consiguieron mantener vivo el espíritu de comunidad entre los vecinos y vecinas de las distintas vecindades.

4 Aitor GONZALEZ DE LANGARICA MENDIZABAL: La ciudad revolucionada. Industrialización, inmigración, urbanización (Vitoria, 1946-1965), Vitoria, Ayuntamiento de Vitoria-Gasteiz, 2007

5 Instituto de PROMOCIÓN DE ESTUDIOS SOCIALES (IPES): Laudio 78, resumen del estudio sociológico, Llodio, Ayuntamiento de Llodio, 1978

6 José María SEDANO: “Entrevista a Sebastián Fernández de Villaverde y Echevarría, presidente de Centro Social Adurza", Adurza, 1 (1965), p. 3

7 Aitor GONZALEZ DE LANGARICA MENDIZABAL y Carlos CARNICERO HERREROS: "La acción socia dentro de la Iglesia durante el franquismo: el caso del Secretariado Social Diocesano de Vitoria (1956-1969)", en José María ORTIZ DE ORRUÑO LEGARDA, Javier UGARTE TELLERIA y Antonio RIVERA BLANCO (coords.): Movimientos sociales en la España contemporánea, Vitoria, Abada, 2008, pp. $1035-1058$

8 Colectivo EGIN AYLLU: Pasado y futuro de las vecindades vitorianas: una experiencia de comunidad vecinal. Relectura apasionada y sugerencias de futuro para una forma de autoorganización popular Vitoria, Irrintzi, 2013

9 Javier Fernández de Betoño (Vitoria), 2 de julio de 2013. Fundador y miembro de la Junta Directiva de la Asociación Aranako 
En Llodio en 1970 surgió la Asociación de Familias, la cual también impulsó en 1973 una candidatura a las elecciones municipales que recibió el 70\% de los votos. Además de aborda cuestiones urbanísticas, según el Norte Expres esta asociación "canaliza las iniciativas de otros grupos locales prestándose a la función de coordinadora entre los planes de ellos. A esto añadía que entre sus actividades merecen especial atención las relacionadas con la cultura, estudio de la problemática de los barrios, urbanismo, temas sanitarios, deportivos, sociales...". ${ }^{\circ}$ La asociación consiguió unir a distintas asociaciones en torno a reivindicaciones comunes como una Casa de Cultura, equipamientos deportivos para los barrios o la revisión de la situación sanitaria del pueblo.

La organización denunció al ayuntamiento por un acuerdo al que había llevado a cabo con los Marqueses de Urquijo, por el que el ayuntamiento compraba unos terrenos a estos por un precio a excesivo a la vez que les devolvía la cesión de un Patronato de edificios. La justicia les dio la razón, por lo que el Patronato de dichos edificios quedaba en manos del municipio de Llodio, los cuales serán solicitadas por la asociación para instalar la Casa de Cultura. Esta victoria ayudó a la denuncia de la falta de legitimidad del ayuntamiento y pedir que en este los cargos "sean elegidos por elección directa de todos los llodianos, entre candidatos presentados libre y voluntariamente, sin tercios..."."

Esta asociación levantaba sospechas entre las autoridades, como demuestra un informe de la Guardia Civil de 1976 que analizaba los antecedentes y la conducta de los miembros de la Junta Directiva, de los diez analizados solo cuatro no levantaban sospechas, entre los otros seis, tres habían tenido problemas con la justicia, desde un sacerdote multado por "pronunciar una homilía tendenciosa" a otra persona detenida "por participar en una reunión ilegal"; del resto, a pesar de su falta de antecedentes, se hacían las siguientes consideraciones, "por lo que respecta a sus ideas deja bastante que desear, siendo de ideas avanzadas en el nacionalismo vasco-separatista" o "parece simpatizar con las CC.OO".12

Mientras tanto, en Vitoria en el barrio de Arana un grupo de vecinos comenzaron a reunirse en 1971:

Empezamos a reunirnos en la parroquia, y gente pues que había en la parroquia, había abogados, gente un poco, que después en política, (...) gente que estaba más formada que el resto de nosotros (...) Empezamos a movernos un poco con el tema de los derechos reael resto de nosotros (...) Empezamos a movernos un poco con el tema de los derechos reay conseguimos, pues qué, que esos derechos no nos lo cobrasen, o cobrasen menos de lo que había que cobrar (...) entonces no llegaba el agua con suficiente presión a las casas (...), había defectos de construcción (...) había cosas de tipo de equipamiento...13

Se pusieron en contacto con Caritas, que elaboró un estudio, en el que realizaba un esquema teórico de las distintas fases y recursos necesarios para la constitución de una asociación que dinamizase la vida social. En dicho informe se constataba que:

Dinamizar la vida social de las comunidades lleva consigo aplicar soluciones (colectivamente aplicadas) a tales problemas de comunidad (referentes a la educación y formación, sanidad-higiene, vivienda y hábitat, condiciones de trabajo y otros problemas en

10 Norte Expres (Vitoria), 24 de marzo de 1976. La edición completa del diario Norte Expres se pueden consultar en http://www.liburuklik.euskadi.net/handle/10771/12322\#.UTYN2RyMwYz

11 Norte Expres (Vitoria), 22 de junio de 1976

12 Informe sobre la Junta Directiva de la Asociación de Familias de Llodio, 20 de abril de 1976, Archivo Histórico Provincial de Álava (AHPA), Fondo Subdelegación del Gobierno, sig. 0000-1571-33

13 Javier Fernández de Betoño (Vitoria), 2 de julio de 2013 torno al equipamiento de servicios comunes)

Una anomía progresiva suele aparecer en estos rápidos agrupamientos de gentes (...) Las dificultades de integrar y adaptar a estas gentes de "aluvión" y en un poblamiento nuevo no son abordadas por lo general. Se hacen polígonos pero no invierte ni se ayuda a organizar ahí una comunidad. ${ }^{14}$

Se crearon diferentes comisiones que fueron el germen de la Asociación de Cabezas de Familia, que en 1974 se transformaría en la Asociación de Vecinos Aranako. La cual dos años después consiguió un local cedido por la Caja de Ahorros Municipal, que se convirtió en un centro social para el barrio, en el que se daban clases de euskera, teatro, danzas o trabajos manuales. Contando socios individuales y familiares unas 2.000 personas pertenecían al centro en $1977 .{ }^{15}$ Si bien en un principio no levantaba sospechas entre las autoridades, a partir de $1976 \mathrm{co}-$ menzó a realizar charlas de temas políticos, y en octubre realizó una de las primeras manifestaciones legales que se celebraron en Vitoria. El motivo fue la muerte de un niño cuando atravesaba la carretera que separaba el barrio de una campa cercana, por eso reclamaban la existencia de una pasarela en condiciones. ${ }^{16}$

\section{Los barrios despiertan}

La preocupación de las autoridades por las actividades de las AAVV que se estaban convirtiendo en un problema para el régimen, se puede constatar en una circular mandada por el Director General de Política Interior a los gobernadores civiles en 1976, en la que se aconsejaba que "se ejerza una acción constante y eficaz respecto a sus actividades reales, con el fin de conoce y controlar las actividades, que en frecuentes casos vienen desviándose de los fines promocionales y representativos con que están concebidas, para invadir el campo de actuación política de signo partidista y clandestino, con notoria desnaturalización de sus fines propios". Por eso reclamaba poner especial atención en los antecedentes de los promotores de cada asociación. ${ }^{77}$

En Vitoria las luchas obreras que se desarrollaron a comienzos de 1976, y que desembocaron en los trágicos acontecimientos del 3 de marzo, supusieron un despertar de la conflictividad social y una difusión de los métodos asamblearios. Las reclamaciones fueron superando el marco exclusivamente laboral y se agregaron denuncias contra la especulación inmobiliaria y la contaminación de los barrios obreros..$^{8}$ Como resalta Carlos Carnicero "se extendió el "movimiento asambleario" a los barrios con el fin de aunar las reivindicaciones de las fábricas a las de los vecinos que habitaban las barriadas obreras"..$^{19}$ Además el asamblearismo como modo de organización se extendió más allá del movimiento obrero.

Poco después de los trágicos sucesos un grupo de vecinos de Zaramaga comenzarán a reunirse y "cansados de esta semiclandestinidad han optado por constituirse en Asociación". ${ }^{20}$ En su primera asamblea la asistencia fue notable, llegando a 1.200 personas, según relata

14 CARITAS DIOCESANA DE VITORIA: "Proyecto de desarrollo comunitario, Organización de la Comunidad de Arana", p 21, Vitoria, 1971, Archivo de la Asociación de Vecinos Aranako (AAVA)

15 Norte Expres (Vitoria), 8 de febrero de 1977

16 Asociación de Vecinos ARANAKO: “Nota de la Asociación de Vecinos 《<ARANAKO〉 a la radio local, para ser difundida los días y del presente mes de octubre", Vitoria, 9 de octubre de 1976, AAVA

17 "Circular de la Dirección General de Política Interior a los gobernadores civiles sobre actuación de asociaciones constituidas al amparo de la ley 191/1964 del 24 de diciembre", 21 de diciembre de 1976, AHPA, Fondo Delegación Provincial de Familia, Caja 10.7

18 Punto y Hora de Euskal Herria, 1 al 15 de abril de 1976

19 Carlos CARNICERO HERREROS: La ciudad donde nunca pasa nada, Vitoria, 3 de marzo de 1976, Vitoria, Gobierno Vasco, 2009. p. 142

20 Punto y Hora de Euskal Herria, 7, 1 al 15 de julio de 1976 
un informe policial se citaron los problemas del barrio, "mencionando como primordiales los de contaminación del ambiente en la Barriada por los gases y humos de la factoría "Forjas Alavesas", y los de falta de escuelas, jardines, asistencia sanitaria, etc...". Posteriormente tomaron la palabra "representantes de otras asociaciones de Vitoria y otras capitales, explicando el funcionamiento de las mismas, por medio de comisiones, no teniendo ni ellas ni las Juntas Directivas poder decisorio, el cual será atributo de las Asambleas". ${ }^{21}$

El problema de la contaminación se convirtió en la principal reivindicación de esta asociación, que realizó diversas protestas que iban desde la colocación de pancartas blancas con puntos negros en los balcones con lemas como "No más humos" o "Ecología o muerte", ${ }_{22}$ hasta la convocatoria de manifestaciones; la primera tuvo lugar en septiembre de 1977, y pese a no estar autorizada consiguió reunir a 7.000 personas, aunque finalmente fue disuelta por la policía. ${ }^{23}$ Una semana después una nueva convocatoria, esta vez legalizada, congregó a una gran multitud, las cifras varían desde las 15.000 personas de Norte Expres ${ }^{24}$ a las 50.000 de Egin, que afirmaba que "No se recuerda manifestación de tal calibre desde el funeral de los muertos del 3 de marzo".

La empresa presentó el proyecto de construir un nuevo horno, más grande, pero a su vez con medidas depuradoras. A pesar de las suspicacias, el problema de los humos fue desapareciendo, pero subsistió el de los ruidos, que no se subsanará hasta la década siguiente.

A finales de 1976 fue legalizada la asociación Gure Auzune del barrio de El Pilar, y el año siguiente fue el del boom del movimiento ciudadano. 1977 ha sido un año que algunos estudiosos vieron como el del inicio de la crisis del movimiento ciudadano, a nuestro entender si analizamos el caso alavés, sería más bien el de su auge, ya que surgieron nuevas asociaciones en barrios como Aranbizkarra (Hauzoko Etxea), San Cristóbal (Hegoaldekoak), Abetxuko (Uribe-Nogales), Txagorritxu-Gazalbide (Txagorribidea), Casco Viejo (Gasteiz Txiki) y Betoño. En e caso de Ariznabarra una Comisión de cultura y un grupo de jóvenes preocupados por la marginación denominados Algo funcionaron de forma paralela a la asociación. A su vez los Centros Sociales de Adurza y Errekaleor se convirtieron en Asociación de Vecinos. En 1978 surgieron nuevas asociaciones en Coronación, Aranbide, Judimendi, Desamparadas, Ali y Aretxabaleta.

Un caso paradigmático es el de Aranbizkarra, ya que la asociación comenzó a gestarse, a mismo tiempo que los vecinos comenzaron a residir en el barrio, se creó una "comisión de vigilancia" formada por distintos profesionales para que las viviendas que se iban a entregar se ajustasen a los proyectos acordados. Tras analizar las deficiencias que había en los edificios y en los equipamientos del barrio (falta de alumbrado, de servicios como guarderías, plagas de ratas, falta de limpieza...) intentaron solucionarlas por medio del dialogo con las autoridades y con el promotor, pero una vez que esta vía fracasó pasaron a utilizar las vías judiciales. ${ }^{26}$

Las asociaciones tuvieron escasa influencia en el ámbito rural, pero surgieron algunas en Araia, Salvatierra o Amurrio, donde subsistió la Asociación de Cabezas de Familia. Esto se puede explicar tanto por la escasez poblacional en el mundo rural alavés como por la pervivencia de modelos de participación directa como el concejo.

Este crecimiento no estuvo exento de tensiones, estas se centraron en las relaciones entre las asociaciones y los distintos partidos políticos. En general las asociaciones intentaron no identificarse con partidos concretos, si bien muchos militantes de partidos de izquierda participaban activamente en la vida de las AAVV.

21 COMISARIA DEL CUERPO GENERALDE POLCIA: "Cuenta haberse producido una reunión" Vitoria,

28 de julio de 1976, AHPA, Fondo Sub., sig. O000-122.1.18

22 Norte Expres (Vitoria), 17 de septiembre de 1977

23 Norte Expres (Vitoria), 24 de septiembre de 1977

24 Norte Expres (Vitoria), 1 de octubre de 1977

25 Egin (Hernani), 1 de octubre de 1977

26 Norte Expres (Vitoria), 30 de junio de 1977
En algunos casos como en Aranako surgieron dos grupos, "unos que aparte de ser Socios y miembros de alguna Comisión, son militantes de grupos políticos, y otros que no están de acuerdo en que dichas personas formen parte de la Junta Directiva". ${ }^{27}$ Se acordó que no podían ocupar la presidencia o vicepresidencia las personas que ocupen idénticos cargos en partidos $\mathrm{u}$ otras asociaciones. ${ }^{28}$

Las distintas asociaciones tenían un modo de organizarse más o menos similar, eran dirigidas por una Junta Directiva elegida por la asamblea general de todos los socios y existían diferentes comisiones que se encargaban de temas específicos. Hubo algunas como la de Zaramaga que dejaron de cobrar cuota para que todo el barrio pudiese participar, o Aranbizkarra donde surgió una coordinadora de portales, con la intención de que todos los vecinos estuviesen representados. ${ }^{29}$

En algunos casos como Txagorritxu o Coronación la chispa que unió a los vecinos fue una lucha contra la construcción de un edificio, en otros no había un detonante exclusivo; más bien la suma de problemas relacionados con las deficiencias urbanísticas, la falta de equipamientos, las deficiencias en las viviendas, ausencia de higiene y la sensación de marginación con respecto al centro; unidos a la difusión de las experiencias de otros barrios, la progresiva liberalización política y un aumento de la conflictividad, tanto a nivel laboral como político, hicieron que en apenas dos años el movimiento vecinal vitoriano se difundiera rápidamente. A esto hay que unirle como afirma Iván Bordetas:

La iniciativa de diversos grupos de personas (...) que elaborarían un discurso y una práctica colectiva reivindicativos. Así, lo importante no serían tanto las problemáticas concretas, que ya venían de lejos cuando eran más acuciantes debido al contexto de penuria generalizada en que se daban, sino la existencia de esos agentes de concienciación que actuaron sobre unas determinadas redes sociales ya tejidas en los barrios. ${ }^{30}$

Las asociaciones fueron un factor clave en la dinamización de la vida social de los barrios, a través de múltiples actividades culturales, las fiestas de los barrios y otras formas de acción colectiva; esto sirvió como factor de integración a los obreros de distintas procedencias que residían en ellos. Rafael Ruiz de Zarate resalta la importancia de las actividades culturales realizadas por la asociación Gasteiz Txiki, “lo principal era que el barrio convivía, (...) todo eso unía al barrio”. ${ }^{11}$

En cuanto a los métodos de lucha utilizados, compatibilizaron la negociación con las autoridades y las protestas. Además de manifestaciones y concentraciones utilizaron otros medios como el encierro en el ayuntamiento para denunciar la subida del precio de los autobuses,

27 "Reunión Conjunta Comisión Junta Rectora del Centro Social y Junta Directiva de la Asociación de Vecinos Aranako", Vitoria, 7 de junio de 1977, AAVA

28 "Reunión conjunta Comisión Junta Rectora del Centro Social y Junta Directiva de la Asociación de Vecinos", Vitoria, 30 de mayo de 1977, AAVA

29 Asamblea Extraordinaria de la Asociación de Vecinos de Aranbizkarra, Vitoria, 25 de noviembre de 1977, Archivo de la Asociación de Vecinos Zazpigarren Alaba, Libro de Actas de la Asociación Hauzoko Etxea.

30 Iván BORDETAS JIMÉNEZ: "Ni tú ni yo somos nadie si tú y yo no somos nosotros": los orígenes del movimiento vecinal en Catalunya, en Ángeles BARRIO ALONSO, Jorge de HOYOS PUENTE, Rebeca SAAVEDRA ARIAS (coords.): Nuevos horizontes del pasado: culturas politicas, identidades $y$ formas de representación Santander, Publican, 2011, CDROM. (http.//www unican es/NR/rdonformas de representacion, Santander, Publican, 2011, CDROM. (http://www.unican.es/NR/rdonC3\%BAniyosomosnadiesit\%C3\%BAyyonosomosnosotroslosor\% C3\%ADgenesdelmovimientovecinalenCatalunya.pdf)

31 Rafael Ruiz de Zarate (Vitoria), 26 de junio de 2013. Presidente de la Asociación Gasteiz Txiki. Cuando estabamos dando los últimos retoques a este trabajo nos ha llegado la noticia de su falleci- 
quema de basuras y corte la N1 como protesta por la falta de limpieza en Aranbizkarra, o la negativa al pago de las contribuciones especiales en Aranbide.

\section{Coordinadora Interbarrios}

Las Asociaciones de Vitoria crearon en septiembre de 1977 la Coordinadora Interbarrios, en esta se acordó que los acuerdos tomados no serían obligatorios, sino indicativos, para evitar posibles divisiones. Sin embargo, las diferencias no tardaron en aflorar cuando el ayuntamiento les propuso su integración en el Comisión de Acción Social; mientras unas desconfiaban y veían este gesto como un intento de domesticarlas y aprovecharse de su trabajo, otras eran partidarias de participar. ${ }^{32}$

Finalmente se llegó a un acuerdo para participar siempre "que dicha presencia no esté condicionada a la existencia de alcalde de la zona; que puedan estar en ella representantes de todas las Asociaciones y, como un segundo paso, solicitar el acceso de las mismas a la totalidad de las comisiones municipales". ${ }^{33}$ Desde esta Comisión se lanzó una campaña de colaboración ciudadana favor de la limpieza en la ciudad, en la que colaboraron activamente las asociaciones. A su vez dividieron los problemas entre los de fácil y difícil solución, entre los primeros estaban los de basuras o transportes, y entre los segundos, guarderías, servicios públicos, centros sociales o ambulatorios. Acordaron negociar de forma conjunta con el ayuntamiento para solucionar dichos problemas. A pesar de esto algunas asociaciones no participaron en la Comisión.

La creación de Consejos de Barrio, que sustituyeron a los anteriores alcaldes de barrio, también fue visto de distinta forma por las distintas AAVV, desde Gasteiz Txiki en principio se negaban a aceptar estos Consejos, porque a su juicio "el fin que se persigue es el de anular las Asociaciones de Vecinos".34 Un mes más tarde matizaban su postura y proponían Utilizar, en la medida de lo posible, la Oficina Municipal para la consecución de beneficios para el barrio", si bien mantenían su independencia con respecto a cualquier organización..$^{35}$ Otras asociaciones como la de Adurza fueron partidarias desde un principio de participar en dichos Consejos. Esta iniciativa había sido propuesta por los concejales que en los últimos años del Franquismo habían accedido al consistorio por el tercio familiar, entre los que destacaba el futuro alcalde, José Ángel Cuerda.

Las asociaciones de Aranbizkarra y Txagorribidea plantearon dentro de la coordinadora una alternativa a la gestión municipal, inspirada en el ejemplo de Llodio, en el que dos representantes de cada asociación participarían con voz y voto junto a los concejales en los plenos municipales, ${ }^{36}$ pero esta proposición fue rechazada mayoritariamente por el resto de asociaciones, al entender que el movimiento vecinal era demasiado joven y no tenía suficiente representación en la ciudad. ${ }^{37}$

Las diferentes comisiones también se coordinaron en temas como el urbanismo, la necesidad de locales para la juventud, la reclamación de centros sanitarios o contra la carestía de vida, compuesta exclusivamente por mujeres. Estas últimas plantearon al gobernador que una comisión de estas estuviera presente en la Junta Rectora de precios, pero tuvieron que espera hasta la constitución del ayuntamiento democrático en 1979 para que dos representantes fueron admitidas en la misma. Esta coordinadora realizó una serie de charlas sobre el aumento de precios, en las que surgieron diferentes propuestas, una de estas fue la de coordinarse con la Unión de Agricultores y Ganaderos de Álava (UAGA), siguiendo el ejemplo de Navarra, para

32 Norte Expres (Vitoria), 22 de octubre de 1977

33 Norte Expres (Vitoria), 11 de noviembre de 1977

34 "Reunión de la Asociación Gasteiz Txiki” , Vitoria, 25-9-1978, Archivo de la Asociación Gasteiz Txiki (AAGT) Libro de Actas

35 Reunión de la Asociación Gasteiz Txiki", Vitoria, 30-10-1978, AAGT, Libro de actas

36 Norte Expres (Vitoria), 25 de noviembre de 1977

37 Norte Expres (Vitoria), 16 de diciembre de 1977 vender productos directamente saltándose los intermediarios..$^{38}$ Esta iniciativa se formalizó en la llamada "Operación Patata", realizada en colaboración con la UAGA, que sirvió para vender directamente del labrador al consumidor.

Como resalta Claudia Cabrero "uno de los principales cambios que introdujo la acción colectiva femenina fue precisamente el de convertir cuestiones como la lucha contra la carestía y por unas condiciones de vida, en la lucha comunitaria, por el interés general y con incidencia real en la resistencia a los mecanismos de control social y acumulación del capital". ${ }^{39}$

En lo que respecta al feminismo, es un hecho general la implicación que tuvieron en las asociaciones las mujeres, y la creación en estas de comisiones especificas que trataron abiertamente problemas como el aborto, el divorcio o la denuncia de las violaciones. Estas se coordinaron entre sí y trabajaron en común con la Asamblea de Mujeres de Álava.

Manuel Castells lo define como “'feminismo práctico", es decir, la verificación en la lucha cotidiana de que, en muchos casos eran las mujeres las que llevaban la organización. En cierto modo, eran las verdaderas dirigentes del movimiento, aunque luego siempre aparecían los homEn cuanto al ecologismo, hay que destacar el caso de Zaramaga en su lucha contra la contaminación, pero también la implicación de las asociaciones en lucha contra la Central Nuclear de Lemoniz, algunas de estas se sumaron al boicot a lberduero, por lo que tuvieron que sufrir cortes de luz en sus locales.

Otro aspecto reseñable es el papel importante en la difusión de la cultura vasca a través de clases de euskera y otras expresiones culturales, que tenían un importante lugar en las fiestas de cada barrio. Si a esto añadimos que los nombres de prácticamente todas las asociaciones estaban en euskera, vemos que su posicionamiento fue claro en favor de la difusión de la cultura vasca.

\section{Elecciones municipales}

Ante las elecciones municipales de 1979, la Coordinadora Interbarrios se pronunció a favor del "Reconocimiento de las AA.VV. por las fuerzas políticas y en los futuros Ayuntamientos, as como la futura Ley de Régimen Local que esperemos se promulgue en un futuro inmediato". Además exigían soluciones en el ámbito de la sanidad, el fomento del euskera, alternativas para la juventud, equipamientos sociales para los barrios, y solucionar el problema de la carestía de la vida. ${ }^{41}$ Además promovió mesas redondas en las que participaron todos los candidatos, y en las que se incidió especialmente en las problemáticas de los barrios.

En Vitoria también se dio la tendencia de que líderes de la asociaciones se presentasen en las listas de los partidos, el caso más evidente fue el de la candidatura independiente, apoyada por HB, en la que participaron Severino Rodríguez de Yurre, presidente de Txagorribidea, y Guillermo Perea, de Aranbizkarra. El PNV también presentó al presidente de la asociación de Zaramaga, Luís María Aldaiturriaga, además todos los partidos tuvieron en cuenta las reivindicaciones de los barrios a lo hora de elaborar sus programas. La asociación de Zaramaga se mostró crítica frente "a la manipulación de las necesidades actuales están haciendo ciertos grupos electorales, regalándonos falsas ilusiones, que luego en la práctica, será muy difícil que

38 Norte Expres (Vitoria), 30 de marzo de 1978

39 Claudio CABRERO BLANCO: "Género, antifranquismo y ciudadanía. Mujeres y movimiento vecina en la Asturias del desarrollismo y el tardofranquismo", en Historia del Presente, 16 (2010), pp. 9-26, p. 22

40 Manuel CASTELLS, "Productores de ciudad: el movimiento ciudadano en Madrid", en Víctor PEREZ QUINTANA y Pablo SANCHEZ LEON, (eds.): Memoria ciudadana y movimiento vecinal, Madrid 1968-2008, Madrid, Libros de la Catarata, 2009, p.28

41 Norte Expres (Vitoria), 12 de marzo de 1979 
se cumplan", por eso no apoyaban ninguna candidatura concreta. ${ }^{42}$

Tras las elecciones el pleno del nuevo ayuntamiento de Vitoria, gobernado por José Ángel Cuerda del PNV, aprobó una moción que regulaba las relaciones entre el ayuntamiento y el movimiento ciudadano; se reconocía que estas tuviesen derecho a ser informadas y a tener voz en las comisiones municipales, pero no en los plenos; por otro lado, se asumía la posibilidad de celebrar referéndums en casos de gran trascendencia, pero no la posibilidad de revocar los cargos municipales. 43

Esta moción fue rechazada por los independientes y tampoco fue del agrado de la Coordinadora que semanas después emitió una nota en la que remarcaban que no habían recibido ninguna comunicación oficial del ayuntamiento y que su presencia en las comisiones se veía dificultada al desarrollarse en horas laborables, a la vez que volvían a insistir en la petición de tener voz en los plenos. 44

La relación de Cuerda con las AAVV no estuvo exenta de polémicas, llego a afirmar que "los grupos políticos que no han alcanzado escaños parlamentarios o municipales o lo han conseguido en medida muy escasa, siguen actuando en las asociaciones de vecinos". Pretendía no generalizar y se mostraba dispuesto al dialogo, pero a su vez calificaba de "tentación monopolística y totalitaria que las AAVV quisieran ostentar la representación exclusiva de sus barrios". 45

La actitud de Cuerda fue dialogante en otros aspectos como la cesión de locales a las asociaciones, que sirvieran como centros sociales donde realizar sus actividades o la mejora de los equipamientos de los barrios. La capacidad de movilización y presión de las AAVV consiguió triunfos importantes como modificar planes parciales de distintos barrios, aumentando de las zonas verdes y reduciendo el número de edificaciones; ${ }^{46}$ también persuadieron al ayuntamiento de la idea de construir dos grandes cívicos para toda la ciudad, consiguiendo la construcción de centros más pequeños en cada barrio.

La cesión de locales no estuvo exenta de polémica y Cuerda exigió "a todas las entidades que dispongan para sus actividades de locales cedidos por el Ayuntamiento, y por tanto públicos, que retiren aquellos carteles o pancartas que reflejan posturas ideológicas, sociales, políticas, que de alguna manera suponen una monopolización por parte de algunos grupos de estos locales". ${ }^{47}$ Ante la amenaza de retirar las pancartas que se encontraban en la sede de Gasteiz Txiki, miembros de distintas AAVV se encerraron en dicha sede y trece asociaciones realizaron una manifestación en favor de la libertad de expresión. La amenaza de expulsión no se cumplió pero en otras sedes el ayuntamiento cambió las cerraduras de las sedes.

La coordinación entre asociaciones rebasó el marco municipal y en diciembre de 1979 se celebró la I Asamblea de Asociaciones de Vecinos de Euskadi. Esta se celebra poco después de las elecciones municipales, y en la misma expresaron una visión crítica sobre las nuevas corporaciones, especialmente con la actuación del PNV y del PSOE en estas. A estos les achacaban la falta de dialogo y de participación de las asociaciones, por lo que exigían capacidad de participación y de control sobre la actuación municipal.

A su vez también hacían autocrítica de sus actuaciones, constataban la bajada en cuanto al número de socios activos y planteaban:

42 Norte Expres (Vitoria), 28 de marzo de 1979

43 "Acta de la sesión ordinaria celebrada por el Excmo. ayuntamiento pleno", Vitoria, 4 de junio de 1979, Archivo Municipal de Vitoria-Gasteiz, Libro de actas del Ayuntamiento pleno, abril-diciembre 1979, sign. 386

44 Norte Expres (Vitoria), 20 de junio de 1979

45 Norte Expres (Vitoria), 24 de diciembre de 1979

46 Norte Expres (Vitoria), 7 de julio de 198

47 Egin (Hernani), 6 de febrero de 1981 una mayor clarificación de las tareas que hay entre manos, si se diera menos importancia a las comisiones de trabajo que en algunas ocasiones tienen un valor testimonial y dispersa los efectivos de las AA.VV., si se prioriza más el pleno de socios activos, como núcleo fundamental de trabajo y (...) si nos abriéramos más hacia el barrio y mejoráramos nuestra propaganda. ${ }^{48}$

En la misma línea dentro de la Coordinadora Interbarrios se planteó un debate sobre "la posible restructuración de las AA.VV., organizadas hasta ahora en comisiones fijas que se orientan a temas específicos, pero generales".49

Hay que apuntar algunas asociaciones no participaban con demasiada regularidad en las reuniones de la Coordinadora, y que los diferentes modos de entender la labor de las asociaciones chocaron en más de una ocasión. En 1981 desde la Coordinadora se reconocía que "Se ha puesto de manifiesto la dificultad de llevar adelante una buena labor de Coordinación, que ha desembocado a menudo en errores, al no existir una vinculación concreta entre lo que se discutía en la Coordinadora y lo que realmente ocurría en los barrios". ${ }^{50}$

Las diferentes formas de entender el papel de las asociaciones de vecinos chocaron dentro de la asociación de Zaramaga en abril de 1980 cuando surgió un enfrentamiento entre dos sectores, uno representado por su vicepresidente que acusaba a la dirección de centrarse especialmente en cuestiones políticas, y el otro encabezado por el presidente que apostaba por que las asociaciones deben "conservar su aire reivindicativo haciendo suyos temas ciudadanos como amnistía, centrales nucleares, etc." ${ }^{51}$

Estas diferencias desembocaron una tensa asamblea, en la que salió ganadora la línea más combativa, que modificó los estatutos plasmando que "la AV de Zaramaga es una organización que lucha por los derechos de los vecinos; tanto a niveles concretos como a niveles generales, se definía como una organización pluralista, "que no quiere decir apolítica"'. 52

A comienzos de la década de los ochenta el movimiento vecinal fue perdiendo poder de convocatoria por diversos factores entre los que debemos destacar las divergencias internas, la creación de nuevos ayuntamientos legitimados por las urnas, el aumento de los servicios sociales, la falta de renovación generacional y el surgimiento de nuevos movimientos juveniles.

No obstante, el movimiento consiguió triunfos importantes, además de conseguir equipamientos para los barrios, fue capaz de modificar planes parciales en los nuevos barrios, como en el caso de Santa Lucia donde consiguió un aumento de las zonas verdes. ${ }^{53}$

\section{Llodio, Alternativa de gestión municipal}

En enero de 1977 nueve concejales presentaron una moción en el pleno, en la que aducían la falta de representatividad del ayuntamiento y planteaban la participación directa de los vecinos en las decisiones del ayuntamiento..$^{54}$ La primera labor que se puso en marcha fue la elaboración de un estudio sociológico y de un plan de actuación para subsanar las deficiencias urbanísticas de Llodio, llegando a la conclusión de la necesidad de un gasto extraordinario de 1.500 millones de pesetas, de los que 600 fueron aportados por la Diputación de Álava a fondo perdido.

48 ASAMBLEA DE AAVV DE EUSKADI: Por el control de la gestión municipal, $1^{\text {a }}$ Asamblea de AAVV de Euskadi, $7^{\mathrm{a} S}$ Encuentros estatales de AAVV, Bilbao, 1979, p. 11

49 Norte Expres (Vitoria), 10 de noviembre de 1979

50 Punto y Hora de Euskal Herria, 215, del 26 de febrero al 5 de marzo de 198

51 Norte Expres (Vitoria), 15 de abril de 1980

52 Norte Expres (Vitoria), 23 de junio de 1980

53 Norte Expres (Vitoria), 7 de julio de 1981

54 Pleno del ayuntamiento, Llodio, 21 de enero de 1977, Archivo Municipal de Llodio (AMLL), Libro de

actas, sig. 3416P (8/11) 
El mecanismo de lo que se llamó "Alternativa de gestión municipal", basada en asambleas en los distintos barrios en las que participaban entre 1.500 y 2.000 personas, se dividió el municipio en ocho asambleas, y en estas surgieron diferentes comisiones. Además cada asamblea manda a dos representantes a la Comisión Mixta, estos se reúnen con cuatro de los representantes de las distintas asociaciones del pueblo y los concejales. En definitiva el pleno municipal se convirtió en un simple formalismo que servía para formalizar las decisiones que se tomaban en las distintas asambleas. El objetivo era claro la "instauración de un auténtico poder popular (...) Este proceso de desarrollo democrático corresponde al pueblo, a cuyo servicio debe estará el Ayuntamiento como mero representante del mismo".55

Los vecinos remitieron una carta a todos los partidos para preguntarles si están de acuerdo con el modelo de gestión alternativo, AP y UCD no respondieron, el PNV lo veía admisible hasta que se celebrasen elecciones, el PCE estaba a favor pero consideraba que la participación de los vecinos era escasa, el PSOE creía que la gestión la debe llevar a cabo el ayuntamiento, pero veía bien que el pueblo podría controlarlo. Mientras que HASI, EMK y LKI eran partidarios de este modelo, ya que lo veían como un modelo de democracia popular.

Esta gestión no estuvo exenta de contradicciones, ya que algunos concejales no colaboraron de forma entusiasta y partidos como el PNV fueron críticos con su desarrollo.

En las elecciones municipales la candidatura Gure Aukera, apoyada por HB, EE, LKI y EMK y encabezada por Pablo Gorostiaga, agrupó a los partidarios de continuar la alternativa de gestión municipal. A pesar de ser la candidatura más votada y la que consiguió la alcaldía, no pudo seguir adelante con la alternativa asamblearia, ya que el pleno rechazó ratificar el sistema de participación popular; al no tener mayoría absoluta, y unir sus votos UCD, PNV y PSOE, su proposición fue rechazada, ${ }^{56}$ lo que supuso prácticamente el fin de esta alternativa.

\section{Conclusiones}

Como afirman Víctor Pérez y Pablo Sánchez:

El movimiento vecinal es una suerte de movimiento de movimientos: incorpora reivindicaciones económicas, sociales, políticas, y culturales muy variadas, algunas de ellas relativas a los servicios característicos del Estado del Bienestar -como sanidad, educación, vivienda y dotaciones deportivas públicas- pero otras nuevas emergentes -como el interés por la ecología urbana y la sostenibilidad- que sitúan el movimiento vecinal en el eje que une lo global con lo local. Aunque todos estos objetivos están incorporados a las movilizaciones vecinales, su seña de identidad es otra, y remite al que continúa siendo el gran déficit de la democracia española y por extensión occidental: el hincapié en la necesidad de complementar los procedimientos representativos con la participación activa de los ciudadanos en la toma de decisiones. ${ }^{57}$

En el caso alavés, fue sin duda, un factor de democratización social, pero su idea democracia participativa chocó con la democracia representativa de las nuevas corporaciones y con las diferencias internas del movimiento. Un ejemplo práctico de la democracia directa fue la alternativa de gestión municipal de Llodio, la cual a pesar de sus contradicciones y de su corta duración, demostró que era posible habilitar mecanismos de participación popular en la gestión municipal.

55 Pleno del ayuntamiento, Llodio, 2 de mayo de 1977, AMLL, Libro de actas, sig. 3416P (8/11)

56 Pleno del ayuntamiento, Llodio, 10 de mayo de 1979, AMLL, sig. 1008C

57 Victor PEREZ OUINTANA y Pablo SANCHEZ LEON: “Introducción: Cuarenta años de movimiento ciudan" On Vítor PEREZ OUINTANA Y PablO SANCHEZ LEON (eds): Memoria ciudadanaymovimiento vecinal, Madrid 1968-2008, Madrid, Libros de la Catarata, 2009, p.15
Si bien el movimiento vecinal no fue capaz de garantizar una participación popular en la gestión municipal, influyó tanto en la mejora de equipamientos (guarderías, centros sanitarios, etc.) como en la modificación de distintos planes parciales logrando una descongestión de edificios y el aumento de las zonas verdes. Tanto las zonas verdes como los centros cívicos, símbolos de la Vitoria actual, fueron en cierta medida resultado de la lucha y la presión del movimiento vecinal. A su vez fueron cauce de integración a los nuevos vitorianos y capaces de dinamizar la vida social en los distintos barrios, dotándolos de una identidad propia.

Coincidimos con Víctor Urrutia en que las Asociaciones de Vecinos "han sido importantes cauces de cohesión social en sus respectivas comunidades, creando nuevos espacios de interacción vecinal". ${ }^{8}$ Esto tuvo una especial importancia en el caso alavés ya que se trataba de nuevos barrios, en los que vivía un porcentaje muy alto de vecinos procedentes de la inmigración. Desde las asociaciones además se creó una identidad barrial, a base de movilizaciones y actos culturales.

Las diferencias a la hora de entender el papel de las asociaciones de vecinos marcaron los intentos de coordinación y provocaron polémicas internas. Por un lado, se mostraban las posturas que defendian, que además de las problemáticas urbanas, las asociaciones debían tener entre sus preocupaciones otros temas generales como podían ser la amnistía o la lucha antinuclear. Por otro, estaban los que pensaban que la prioridad de las asociaciones debía centrarse en los temas urbanos, y consideraba otros temas como políticos. Los primeros eran partidarios de combinar las movilizaciones con las negociaciones, los segundos de dar prioridad a estas.

Estas diferencias, y la perdida de referencialidad del movimiento nacional a nivel vasco y estatal, por diversos motivos, entre los que debemos reseñar: el surgimiento de los nuevos ayuntamientos democráticos, una progresiva desmovilización social (aunque menor en el contexto vasco), la huida de importantes cuadros hacia los partidos e instituciones, el auge de nuevos movimientos sociales, etc., hicieron perder al movimiento gran parte del protagonismo con el que contó a finales de la década de los setenta. Sin embargo las asociaciones no desaparecieron, y desde distintas perspectivas continuaron siendo las portavoces de las reclamaciones vecinales e interactuando con los distintos movimientos sociales.

8 Victor URRUTIA ABAIGAR. El movimiento vecinal en el área metropolitana de Bilbao, Oñate, Instituto Vasco de Administración Pública, 1985, p.22 


\section{DENUNCIA Y REIVINDICACIÓN A TRAVÉS DE LA}

\section{CANCIÓN EN ANDALUCÍA}

Antonio Muñoz de Arenillas Valdés

Institut d'Études Politiques Rennes

\section{Introducción}

Este trabajo pretende mostrar cómo se desarrolló la canción reivindicativa en Andalucía, en un periodo comprendido entre el final de la dictadura franquista y los primeros años de la democracia. Trataré el fenómeno de la nueva canción, usando el ejemplo del colectivo Manifiesto Canción del Sur.' Posteriormente relacionaré su labor con la de una nueva generación de cantaores de flamenco que dotaron de un contenido social y político al cante jondo. Estos cantautores y cantaores andaluces constituyen un objeto de estudio interesante, pues su producción artística recogía la realidad de su entorno mostrándola de manera crítica, contribuyendo a la difusión de un conjunto de ideas y símbolos, presentes en el imaginario colectivo de los movimientos sociales que lucharon por la libertad y la consecución de derechos en un periodo clave de la historia reciente de España y Andalucía.

He elegido a Manifiesto Canción del Sur como ejemplo representativo de la nueva canción en Andalucía porque presenta unas características similares a las desarrolladas por otros conjuntos en otras zonas de España. En Cataluña, Els Setze Jutges nació en 1962 con los objetivos de difundir la cultura y la lengua catalanas a partir de una actitud profundamente crítica frente a la realidad española de esos años. Caso similar al vivido en el País Vasco: cuando Mikel Laboa volvió de Barcelona tras realizar parte de sus estudios universitarios, pretendió formar un colectivo similar a Els Setze Jutges, adecuado a la sociedad y cultura vascas. En 1966 nació un grupo coral y multiartístico denominado Ez Dok Amairu. En Madrid, en 1967, con el mismo deseo de aglutinar a diferentes cantautores bajo unas premisas artísticas e ideológicas comunes, nació el grupo Canción del Pueblo; en este caso para intentar recuperar la música popular castellana, aunque con la misma intención crítica hacia la realidad española de la época. ${ }^{2}$

\section{El "marco dominante" de la oposición y los cantautores}

Para el estudio del contenido político y las implicaciones movilizadoras de la nueva canción, utilizo la teoría de los marcos de referencia interpretativa ${ }^{3}$ como marco teórico. Ésta teoría se inserta en nuevas tendencias de la sociología que conceden una gran importancia, en la formación y desarrollo de los movimientos sociales, a factores "internos": aspectos culturales

1 No se puede ceñir la nueva canción andaluza a las actuaciones de Manifiesto Canción del Sur, ya que hubo otras manifestaciones que gozaron de cierta repercusión: el grupo Jarcha, el cantautor sevillano Benito Moreno, entre otros. Por falta de espacio no puedo referirme a otros ejemplos, que estoy estudiando en el marco de mi tesis.

2 Ver Fernando GONZÁLEZ LUCINI: ...y la palabra se hizo música. La canción de autor en España, Vol. 1, Madrid, Fundación Autor, 2006. Ésta es una obra fundamental, donde se realiza un recorrido amplio por la nueva canción de toda España.

3 Esta teoría se explica ampliamente en la siguiente obra, a la que aludiré en repetidas ocasiones:

Enrique LARAÑA: La construcción de los movimientos sociales, Madrid, Alianza Editorial, 1999. y de identidad; por encima de otros considerados "externos" o ajenos a estos movimientos, como las oportunidades políticas objetivas, recursos disponibles, etc. Un sujeto pertenece a un determinado movimiento social y realiza acciones dentro de él, en la medida en que existe una identificación personal al conjunto de valores colectivos del grupo al que pertenece. Por ello es necesario atender a los procesos cognitivos y simbólicos internos que se gestan en el interior de los movimientos sociales. El ideario colectivo está formado por esta interiorización de los símbolos, valores, normas morales, provocando cambios en los marcos de acción colectiva y los modelos organizativos de los movimientos. ${ }^{4}$ Los marcos de referencia interpretativa son el conjunto de herramientas conceptuales, discursivas y significativas usadas por los componentes de un mismo movimiento social en su interpretación idealizada del mundo.

Los movimientos sociales son permeables a los cambios en las sociedades. De tal forma que se producen cambios a su vez en su evolución y estructura interna, en sus objetivos, ideas y estrategias, en sus relaciones con las autoridades institucionales y con sus seguidores; por otro lado, estos cambios son el resultado de la sedimentación de ideas, valores, símbolos, etc. dentro de los movimientos, resultantes de cambios anteriores y tienen repercusiones sobre cómo conciben la realidad personas y grupos -y en sus comportamientos-. Por ello, una redefinición de conceptos, ideas con respecto a una determinada situación, puede provocar la aparición de un nuevo movimiento social. Situaciones asumidas como "normales" pueden replantearse como "injustas", ${ }^{6}$ en el marco de una nueva interpretación crítica de la realidad. Entonces, surge la necesidad de actuar en base a los intereses del colectivo, para modificar la realidad previamente conceptualizada. En este sentido, hay que destacar la capacidad de los movimientos sociales para crear nuevas normas y significados sociales, 7 actuando como agencias difusoras de nuevas ideas.

Así, los cantautores tuvieron una notable relevancia en un contexto clave de cambios importantes en los procesos congnitivos y simbólicos referentes a la comprensión de la realidad circundante de amplios sectores de la sociedad-periodo comprendido entre el tardofranquismo y los titubeantes inicios de la democracia-, aunque hay que decir que también se beneficiaron del momento de cambio sociocultural existente. Por un lado, se impregnaron de conjunto de ideas, normas morales y valores presentes en movimientos sociales y, por otro, contribuyeron a la difusión de este ideario colectivo de lucha por la libertad y los derechos, a través de la letra de sus canciones. Evidentemente, este ideario no se refiere al marco de referencia de un movimiento social concreto, sino a un marco dominante, que cumple las mismas funciones que aquél "pero a mayor escala ya que tiene carácter genérico y es compartido por distintos movimientos sociales" 8 La percepción mutua entre un movimiento, -o para el caso que nos ocupa, determinados cantautores-y un público receptivo a su ideario, objetivos y estrategias, provoca un sentimiento generalizado en ellos de "cambio posible". Los componentes de un movimiento social y sus potenciales seguidores asimilan una serie de cuestiones como conflictivas y las ven susceptibles de ser modificadas. El cambio no tiene por qué afectar a conjunto de la sociedad, sino simplemente a algún aspecto del conjunto de normas y relaciones sociales. ${ }^{9}$ Por tanto, las estructuras organizativas de los movimientos sociales son mucho

4 lbid., pp. 93-125.

Micromobilization and Movement Participation", en American Sociological Review, 5 (1986), pp. 464-481.

6 Enrique LARAÑA: La construcción de los movimientos sociales..., p. 57

7 Joseph GUSFIELD: "La reflexividad de los movimientos sociales: revisión de las teorías sobre la sociedad de masas y el comportamiento colectivo", en Enrique LARAÑA, Joseph GUSFIELD (coords.) Los nuevos movimientos sociales. De la ideología a la identidad, Madrid, CIS, 1994, pp. 93-118.

8 Enrique Laraña: La construcción de los movimientos sociales... P. 25.

9 Ibid., p. 94. 
más que su dimensión formal, visible. Estas estructuras son el resultado de la interacción, la negociación y el conflicto sobre la asunción colectiva de sus objetivos y las posibilidades de alcanzarlos -oportunidades y límites de las acciones colectivas-. Así se construye la identidad colectiva, bajo la que se fundamenta la unidad del movimiento y dota a los individuos de un sentimiento de pertenencia a aquél. ${ }^{10}$

Por otro lado, en las sensaciones e imágenes transmitidas a un público y a potenciales seguidores, reside la eficacia simbólica de los movimientos para promover cambios en la sociedad. Aquí cobra una gran importancia el mayor espacio mediático ocupado por los cantautores en revistas progresistas o especializadas, prensa generalista, programas de radio y televisión etc. En este sentido, el concepto de identidad pública" tiene mucha utilidad. Los mass media cumplen varias funciones: 1) relacionan los hechos que protagonizan los movimientos con un marco de referencia, de tal forma que esta relación es percibida por la opinión pública, estableciendo relaciones con dichos movimientos; 2) su papel es fundamental en la "dramatización" de esos hechos, de la que se desprenden asignaciones de liderazgo de los movimientos a ciertas personas y la intensificación de la sensación de conflicto con las instituciones pertinentes..$^{2}$ Los cantautores eran conscientes de su impacto mediático en la sociedad y sobre todo en sus -potenciales- seguidores. Entra en escena una "dimensión teatral" que puede modular las apariciones públicas de los cantantes, quienes son objetos de observación y reflexión por parte de la sociedad española de los años sesenta y setenta. Los cantautores ven influidos así su capital artístico y político, porque son conscientes de la reacción que generan entre el público y la imagen que se proyecta de ellos a través de los medios de comunicación.

Asimismo, los cambios sociales también afectan a la esfera privada de la vida cotidiana de las personas. En consecuencia, este tipo de cuestiones pasan a formar parte del conjunto de reivindicaciones de los nuevos movimientos sociales. Cuestiones que antes no se discutían o si se hacía, era sólo en el ámbito privado, sobrepasan éste y se defienden en ámbitos públicos. Así, surgen marcos de injusticia vinculados a asuntos a priori privados..$^{13}$ En este sentido, aparecieron en la España de los años sesenta y setenta, una serie de reivindicaciones vinculadas a una nueva concepción del amor, de las relaciones sexuales, etc., que sobrepasan los límites morales de la dictadura franquista. La producción artística de los cantautores, era uno de los medios a través de los cuáles se recogían y difundían estas nuevas concepciones vinculadas a esferas privadas de la vida de las personas. En el mayor o menor éxito de la difusión y aceptación de estas nuevas normas sociales, radica la capacidad de un movimiento social para crear nuevas normas y producir cambios en la sociedad.

En este sentido, el "análisis del discurso" es capital. En estos supuestos téoricos, provenientes de teorías constructivistas y de la sociología cognitiva, es fundamental analizar el lenguaje, entendido como entramado de conceptos y de símbolos a través de los cuales se organiza la realidad misma. ${ }^{14} \mathrm{El}$ uso de determinadas palabras, conceptos, en contextos semánticos específicos está estrechamente vinculado a los marcos de referencia interpretativa y de acción de un movimiento.

10 Ibid., pp. 99-105.

11 Hank JOHNSTON, Enrique LARAÑA y Joseph GUSFIELD: "Identidades, ideologías y vida cotidiana en los nuevos movimientos sociales", en Enrique Laraña, Joseph GUSFIELD (coords.): Los nuevos movimientos sociales..., pp. 3-41.

12 Ver Joseph GUSFIELD: “La reflexividad de los movimientos sociales...", pp. 93-118.

13 Enrique LARAÑA: La construcción de los movimientos sociales..., pp. 182-186.

14 Ver Aaron CICOUREL: El método y la medida en sociología, Madrid, Editora Nacional, 1982; Hank JOHNSTON: “A Methodology for Frame Analysis. From Discourse to Cognitive Schemal, 198; Hank JOHNSTON : A Merthodology for Frame Analysis. From Discourse to Cognitive Schemata" en Hank Minnesota, 1995, pp. 217-246.
En resumidas cuentas, debe combinarse el análisis de los cambios en la estructura de oportunidades políticas con otros cambios de carácter cultural, para explicar adecuadamente la formación de los movimientos sociales. Y para ello, es necesario estudiar las dimensiones simbólicas, culturales de estos movimientos, en especial los procesos de identificación colectiva. En este sentido, los cantautores contribuyeron enormemente a la difusión entre su público del conjunto de ideas, valores, símbolos y significados pertenecientes al marco dominante compartido por la oposición a la dictadura.

\section{La nueva canción andaluza: el ejemplo de Manifiesto Canción del Sur}

En la segunda mitad de los años cincuenta, una serie de acontecimientos marcan el que puede ser el comienzo del fenómeno cultural conocido como nueva canción o canción social."15 El primero es un término utilizado en un artículo escrito por Lluís Serrahima -uno de los padres intelectuales de la nova cancó catalana- en la revista Germinàbit, en 1959, reclamando que se hicieran canciones que hablaran de la situación existente en nuestro país en esos años. ${ }^{16} \mathrm{E}$ segundo término pretende hacer una analogía con la poesía social, corriente poética predominante en los años cincuenta. No en vano, poetas como Blas de Otero y Gabriel Celaya, reivindicarían el papel de la poesía (y del registro oral) como medio de denuncia y expresión de reivindicaciones. Otro hecho fundacional de este movimiento cultural y contestatario se produce en 1956, cuando Paco lbáñez, exiliado en París, pone música al poema "La más bella niña", de Luis de Góngora. ${ }^{17}$ Asimismo, en 1959 un jovencísimo y desconocido Raimon compondría la canción "Al vent", un prematuro himno reivindicativo de la época. Este conjunto de hechos y el marco de cambio sociocultural que experimentaría la sociedad española en los años sesenta, supondrían la aparición en prácticamente toda España de un conjunto de cantantes que reivindicaban derechos básicos y denunciaban la situación política del país.

Andalucía no fue ajena a esta realidad social, política y cultural vivida en todo el país, gracias a la labor de jóvenes poetas y cantantes opuestos a la dictadura. Aunque es cierto que en la región andaluza, el fenómeno echó a andar un poco más tarde, a finales de los sesenta. El artífice fue el poeta granadino Juan de Loxa, empedernido defensor -como Blas de Otero o Gabriel Celaya- de hacer llegar la poesía al mayor número de gente posible, mediante el paso de registro escrito al oral. Con este objetivo, fundó en 1967 Poesía 70, programa radiofónico dedicado en su totalidad a la poesía, emitido desde Granada en Radio Popular, con alcance para llegar a toda Andalucía. Un año después, creó una revista de poesía de nombre homónimo, con el objetivo de difundir la obra de poetas andaluces afincados en Granada capital. Debido a la censura, solo pudo publicar tres números.

Siguiendo este mismo objetivo, nace Manifiesto Canción del Sur. Otras experiencias vividas en otras regiones de España habían demostrado que la música, la canción, era un magnífico medio para acercar la poesía a la gente. Y Juan de Loxa contagió su ilusión a un grupo de jóvenes que participaron en este proyecto común: Antonio Mata, Carlos Cano, Antonio "Nande" Ferrer, Pascual Pérez de Chaparro, Enrique Moratalla, Juan Titos, Juan José Ceba, Ángel Luis Luque, Esteban Valdivieso, Miguel Ángel González, Raúl Alcover, Aurora Moreno, Ignacio Tinaud, Francisco del Pino, José María Agüí o Ignacio Carrillo de Albornoz y los componentes del grupo Principio y Fin. Así, en Andalucía, a finales de los años sesenta, surgió una nueva canción que

15 El debate en torno al nombre del fenómeno no es pertinente en este momento. A este respecto me parece interesante -aunque difiero en su elección- el artículo de Roberto TORRES BLANCO: "Canción protesta: definición de un nuevo concepto historiográfico", Cuadernos de Historia Contemporánea, 27 (2005), pp. 223-246.

16 Lluís SERRAHIMA: “Ens calen cançons d'ara”, en Germinäbit, (1959). Germinàbit era una pequeña revista de difusión muy limitada, perteneciente a la Escolanía de Montserrat.

17 Fernando GONZÁLEZ LUCINI: ...y la palabra se hizo música..., pp. 25-36. 
puso música a poetas como García Lorca, Machado, Aleixandre, Alberti, Martínez de la Rosa, Fernando Pessoa, Celaya, Guillén, Francisco Javier Egea o el propio Juan de Loxa; además de realizar composiciones propias. Cabe destacar que Manifiesto tuvo un rasgo exclusivo dentro de la nueva canción: el programa de radio Poesía 70, emitido para toda Andalucía y con un alto índice de audiencia -la radio era un importante vehículo de difusión-.

El nombre del colectivo hace referencia a una concepción particular del sur: no se refiere a una realidad geográfica concreta, sino a una determinada situación política, social, económica y cultural mucho más amplia, que comprendía aquellas regiones que se sentían maltratadas por un norte opresor. Desde esta concepción del sur, en estrecha relación con el momento político preautonómico, se desarrolla un sentimiento andalucista en la nueva canción andaluza, que reivindica un espacio propio, recuperar todo lo robado por el centralismo político, social, económico y cultural. Diversas canciones del colectivo muestran este andalucismo y denuncian la situación social de la región andaluza. En esta línea se inserta la recuperación de la cultura musical de la región, devolverle su voz a Andalucía. ${ }^{18}$ No en vano, varios integrantes de Manifiesto Canción del Sur estuvieron implicados en proyectos políticos. En 1974, ésta era la posición partidista de cada uno de los componentes de Manifiesto: Ángel Luis Luque y Enrique Moratalla pertenecían a una célula granadina de la Alianza Socialista de Andalucía (ASA); Juan de Loxa y Miguel Ángel González compartían los planteamientos del PCE; Carlos Cano, en la época muy cercano al periodista Antonio Burgos ${ }^{19}$ y Alejandro Rojas Marcos, se encontraba dentro del círculo de influencia de lo que sería el Partido Socialista de Andalucía (PSA); Antonio Mata, recién salido del servicio militar, era muy próximo al anarquismo y defendía un independentismo radical. En 1976, la ASA se transformó en el PSA, siendo legalizado en marzo de 1977. La implicación de Carlos Cano con este partido fue estrecha, como demuestra su participación en el disco editado por el PSA con motivo de su campaña política a las elecciones constituyentes de 1977, donde apareció por primera vez el "Himno de Andalucía". Carlos cantó en dicho disco "A duras penas"-ya editada en un disco homónimo-y la inédita "Por un poder andaluz".20 Sin olvidar otras canciones suyas referidas a la situación del pueblo andaluz -"La miseria"- o al carácter particular de su tierra -"Verde, blanca y verde"-

No hay duda alguna sobre el mayor peso mediático de Carlos Cano -en algunos casos, el único cuyo trabajo parecía tener resonancia en los medios- sobre el resto de sus compañeros de Manifiesto. Haré referencia a varias declaraciones del cantautor granadino en prensa de la época sobre diversas cuestiones aquí comentadas. Sobre su vinculación al nacionalismo andaluz, y el problema de que le "encasillen" comenta: "Acepto ese riesgo y ese reto en lo que de seriedad contiene, ya que es con la Verde y Blanca donde mi canción adquiere toda su proyección y se hace coherente y consecuente con su pueblo". ${ }^{21}$ Carlos Cano transmite aquí la imagen de un artista identificado con su tierra -apelación al "pueblo" incluida- y consciente de que el público, los medios, van a vincular su producción artística a un proyecto político -la demanda de Autonomía para Andalucía-. Es más, deja entrever que su canción alcanza su máxima plenitud cuando queda vinculada a dicha causa. El artista incluso reivindica su papel dentro de la defensa del andalucismo político: "Lo que ocurre, aunque algunos no lo sepan, que hace solamente tres años el panorama andalucista en nuestra tierra era Blas Infante, el PSA y un

18 Fernando GONZÁLEZ LUCINI: De la memoria contra el olvido. Manifiesto Canción del Sur, Madrid, Junta de Andalucía, Consejería de Cultura/lberautor, 2004, pp. 63-74.

19 Tanto él como Antonio Ramos Espejo escribían la mayoría de los artículos de Triunfo sobre Andalucía.

20 Fernando GONZÁLEZ LUCINI: De la memoria contra el olvido..., pp. 142-144.

21 Antonio BURGOS: “Carlos Cano, o la recuperación de la copla andaluza”, Triunfo, 715 (9 de octubre

de 1976), pp. 52-53 movimiento cultural, entre los cuales me encontraba yo" ${ }^{22}$-estas declaraciones corresponden a 1979-. El cantante granadino es plenamente consciente de la inclusión de sus canciones dentro de una corriente política determinada -afirmación de una identidad andaluza propia-y as lo transmite en sus declaraciones.

Es evidente que desde Manifiesto Canción del Sur se defendía una postura política -o varias, según se mire- en defensa de la región y el pueblo andaluces dentro de un contexto preautonómico clave. El colectivo fue incluido en una obra coral, perteneciente a una colección titulada "Pueblos del Estado Español", donde se pretendía reivindicar el carácter multinacional de España, a partir de la defensa de las particularidades de diversas regiones del país. En la obra dedicada a Andalucía, participan entre otros políticos, investigadores, periodistas, artistas, etc. Juan de Loxa, Carlos Cano y por último, Ángel Luis Luque en nombre de Manifiesto. En una obra dedicada al derecho a la autonomía, en este caso concreto a la cuestión andaluza, la inclusión del colectivo Manifiesto muestra el peso de su capital político dentro del mundo cultural andaluz. Ángel Luis Luque muestra la clara implicación política del colectivo -y la consciencia de sus miembros de pertenecer a un movimiento cultural con un implícito contenido político-cuando afirma: “<<Manifiesto Canción del Sur〉> ha sido el primero -por llamarlo de algún modo- en la búsqueda de una canción popular que aporte las claves que hagan posible, desde nuestro restringido campo de actuación, el camino hacia la emancipación del pueblo andaluz".23

Ahora bien, si nos referimos al capital artístico del colectivo, como conjunto no tuvo demasiado éxito si lo comparamos, por ejemplo, con la posterior carrera en solitario de Carlos Cano, quien gozó de una aceptable presencia en medios nacionales. Estos reflejaron la relativa asiduidad de sus actuaciones musicales y la existencia de un público afín. Mientras que Manifiesto fue un grupo irregular en su trayectoria artística.

Conviene hacer una breve referencia a su nacimiento y evolución histórica, para posteriormente remitirme a varias citas de Carlos Cano donde explica las razones de su salida del conjunto -razones que pueden explicar la escasa actividad del colectivo, en comparación con la repercusión de otros similares en otras regiones de España, como Els Setze Jutges, por ejemplo-.

Juan de Loxa, tras la creación del programa de radio Poesía 70 y la revista de poesía homónima, e influenciado por el movimiento de la nueva canción, en ese momento desarrollándose por toda España, decidió crear un colectivo que participara de este género musical, a imagen de otros ya creados en varias regiones españolas. Era un admirador de varios cantautores españoles como Paco Ibáñez, Raimon, Elisa Serna o Chicho Sánchez Ferlosio y seguía otros creadores latinoamericanos, de gran influencia en la nueva canción española, como los chilenos Violeta Parra y Víctor Jara, o el argentino Atahualpa Yupanqui. Era necesario reivindicar, también en Andalucía, la auténtica cultura popular y la libertad perdida. Juan de Loxa conoció en Granada a un jovencísimo Carlos Cano, dedicado por entonces a escritos surrealistas. Animado por el primero, el joven granadino decidió componer canciones y dio su primer recital en la Casa de América de Granada en 1968, interpretando canciones sobre textos de Nicolás Guillén y letras propias. Otra figura fundamental fue Antonio Mata. Este joven jiennense era estudiante uniaño de 1968, al que asistieron entre el público Juan de Loxa y Carlos Cano. Estos dos últimos comentaron con Antonio Mata su proyecto y meses más tarde nacía Manifiesto Canción del Sur, cuyo acto fundacional se celebró en el Aula Magna de la Facultad de Medicina de Granada, el 14 de febrero de $1969 .{ }^{24} \mathrm{~A}$ partir de este año, se unirían al colectivo varios estudiantes de la

22 Antonio RAMOS ESPEJO: “Crónicas Granadinas". Carlos Cano: sólo una lagrimita de Jomeini", Triunfo, 868 (15 de septiembre de 1979), pp. 42-43.

23 Ángel Luis LUOUE: "Manifiesto Canción del Sur" en Manuel LOMBAO, Miguel Ángel SACALUGA (Coords.): Andalucia, Colección Pueblos del Estado Español, Barcelona, La Gaya Ciencia, 1977 p. 144 24 Se recogía así el guante lanzado por Alberti, quien desde Roma exhortaba: “'Oué cantan los poe- 
Universidad de Granada, ya citados anteriormente. Entre ese año y el siguiente participaron en varias ocasiones en el programa de Radio Popular dirigido por Juan de Loxa, lo que contribuyó a darles a conocer y les abrió la posibilidad de dar varios recitales en diversos lugares de la capital granadina y en Sevilla, primero; y en el resto de Andalucía, después. ${ }^{25}$

Sin duda, dos actuaciones en nombre del colectivo en París suponen el punto álgido de su carrera musical. En un ambiente político enrarecido, se celebró en la capital francesa un homenaje mundial a García Lorca el 14 de diciembre de 1972. Además de Carlos Cano, el evento contó con la participación de otros artistas españoles como Amancio Prada, Enrique Morente y Manuel Gerena. Carlos Cano comenzó el acto explicando su pertenencia a Manifiesto Canción del Sur y los objetivos de este colectivo. Él mismo reconoció: "en los días que Manifiesto estuvo en París se había conseguido muchísimo más que en los tres años de su existencia en Andalucía". ${ }^{26}$ Tras el homenaje a García Lorca, Carlos Cano permaneció en París hasta 1974. Asimismo, el día antes del acto en homenaje a García Lorca, el 13 de diciembre de 1972, tuvo lugar en la librería "Shakespeare and Co.", de París, otro evento, en este caso organizado por Manifiesto pero esta vez para conmemorar el 70 aniversario del nacimiento de Alberti. Participaron Enrique Morente, Juan de Loxa y Carlos Cano. ${ }^{27}$ El propio Carlos decía en 1975: "Mi primera actuación "seria" fue participar en un vergonzoso homenaje a Lorca en París". ${ }^{28}$

Tras el regreso de Carlos Cano a Granada, en 1974, y sobre todo a lo largo de 1975, Manifiesto Canción del Sur despertó un mayor interés entre el público. Sin embargo, en 1976 el colectivo se disolvió. Se conjugaron diversos factores de carácter personal y político. Se abría una etapa más personalista, que en el caso de Andalucía, supuso la consolidación de Carlos Cano y, al mismo tiempo, la marginación de otros, caso de Antonio Mata. El cantautor granadino adoptó la firme decisión de dedicarse profesionalmente a la música, frente a los miembros del resto del colectivo, que anteponían criterios políticos a cuestiones económicas o profesionales, entendiendo su participación en el mismo como una militancia política. También hubo razones ideológicas de fondo: como he explicado más arriba, los miembros del colectivo se fueron adhiriendo a diferentes partidos políticos de izquierda, según iban saliendo de la clandestinidad para proclamar sus planteamientos ideológicos. Dentro de este contexto político se desarrolló un intenso debate ideológico en torno al nacionalismo andaluz y a su posible concreción en un futuro Estatuto de Autonomía 29 -aprobado en 1981 .

El propio Carlos Cano explicó así su salida de Manifiesto:

Ahora puedo apreciar como en esa etapa, a nivel de letras y música, dábamos palos de ciego, aunque la letra estaba claro que tenía que tomar una actitud en contra del folklorismo y de la "payasada" que había con lo andaluz [..]. En el setenta y tres, abandono el 〈〈MANIFIESTO CANCIÓN DEL SUR〉 y me dedico yo solo a buscar el porqué de la canción popular andaluza [...]. [A la pregunta: ¿Por qué abandonaste el manifiesto?] Primero, porque yo era el único que me dedicaba profesionalmente a la canción y era el único que sa-

tas andaluces de ahora?/ ¿Qué miran los poetas andaluces de ahora?/ ¿Qué sienten los poetas andaluces de ahora?..." en Rafael ALBERTI: "Balada para los poetas andaluces de hoy", en Poesía (1920-1938), (1939-1963), (1964-1988), ed de Luis CARCIA MONTERO, Col Obras Completas, Madrid, Aguilar 1988, p. 769 .

25 Fernando GONZÁLEZ LUCINI: De la memoria contra el olvido..., pp. 104-115.

26 lbid., p. 128.

27 lbid., pp. 126-129.

28 Francisco ALMAZÁN: “Carlos Cano: "una canción andaluza de hoy", Triunfo, 666 (5 de julio de 1975), pp. 56-57. El calificativo de "vergonzoso" hace referencia a las Illamadas a la no politización del acto por parte de la UNESCO y del entonces embajador español en París, Antonio Garrigues.

29 Fernando GONZÁLEZ LUCINI: De la memoria contra el olvido..., pp. 137-143. lía a cantar fuera [...] Segundo, porque no estoy de acuerdo con su práctica y con su teoría sobre lo que debe ser canción popular [...].30

Diferencias artísticas y el deseo de dedicarse profesionalmente a la música provocaron la salida del cantautor granadino de Manifiesto. Tras este hecho, los componentes del colectivo siguieron realizando diversas actividades culturales, aunque de manera cada vez más desarticulada, hasta su definitiva disolución a principios de 1976.

\section{Andalucía: "nacional-folklorismo" y "flamenco reivindicativo"}

La nueva canción andaluza presenta unas particularidades propias vinculadas al flamenco. La nueva canción surgió en la región como reivindicación de una auténtica cultura andaluza contra la utilización alienante que de la copla hacía el régimen franquista. ${ }^{31}$ Este fenómeno fue conocido como "nacional-folklorismo". Desde las altas instancias del régimen se promovió un sucedáneo del flamenco y de la copla, imponiéndose así una mal llamada "canción española" como expresión musical más representativa de todo el país. Las diferencias culturales y su diversidad quedaban así anuladas bajo una única identidad cultural. Así, el régimen se sirvió del flamenco y de la copla andaluza, impregnándolos de toda la superficialidad posible despojándolos por tanto de su carácter crítico y su profundo contenido social. ${ }^{22}$ Cuando hablo de "nacional-folklorismo", me refiero a la producción musical de cantantes como Manolo Escobar, Conchita Piquer, Juanito Valderrama..

Por otro lado, dentro del arte flamenco, existía un debate 33 muy pertinente para el presente trabajo, en los años sesenta y setenta. Varios cantaores se proclamaron defensores de la tradición del cante jondo -Antonio Mairena, por ejemplo- y reivindicaron la "pureza" del flamenco. Desde esta pretendida "pureza" se criticaba el uso de nuevas letras de contenido social o político, olvidando que el flamenco, en sus orígenes, narraba situaciones desde estos puntos de vista. El debate surgió cuando una nueva generación de cantaores ${ }^{34}-$ Menese, Morente, Gerena...- usaron el cante flamenco como vehículo de denuncia social, bien mediante la interpretación de nuevas letras -diferentes a las tradicionales- o bien adaptando poemas al cante. Así, desde parámetros puramente artísticos -el uso de unas letras nuevas que rompían con la supuesta tradición del flamenco- se entró -indirectamente- en un plano político: las nuevas creaciones denunciaban situaciones concretas estrechamente relacionadas con la situación de la España de la época. Este aspecto vincula a estos nuevos cantaores que pretenden recuperar el contenido sociopolítico del flamenco, readaptado a los nuevos tiempos, con la intencionalidad política de la nueva canción.

30 "Carlos Cano" en Manuel LOMBAO, Miguel Ángel SACALUGA (Coords.): Andalucia..., p. 136. También explica su salida en Francisco ALMAZÁN: "Carlos Cano: "una canción andaluza de hoy"... p. 56 donde realiza una dura crítica del colectivo andaluz.

31 Véase la anterior cita de Carlos Cano.

32 Este fenómeno se explica de manera sucinta en Fernando GONZÁLEZ LUCINI: ...y la palabra se hizo música... Vol. 2, pp. 9-13. Es muy ilustrativo al respecto: Antonio BURGOS: "Manolo Escobar, último baluarte del nacional-folklorismo. El "búnker" de la canción", Triunfo, 693, 8 de mayo de 1976, pp. 42-45

33 Ver Francisco ALMAZÁN: "El cante del pueblo: tras los festivales de flamenco", Triunfo, 384 (11 de octubre de 1969), pp. 14-21; íD: “El cante del pueblo", Triunfo, 385 (18 de octubre de 1969), pp. 1521; İD: "La pureza del folklore", Triunfo, 437 (17 de octubre de 1970), p. 40; ID: "5o años de naciona 21; ID: "La pureza del folklore", Triunfo, 437 (17 de octubre de 1970), p. 40; ID: "50 años de nacional
flamenquismo. Granada 1922-1972", Triunfo, 510 (8 de julio de 1972), pp. 32-34; José Luis PANTOJA ANTÚÑEZ:"Renovación del flamenco", Triunfo, 453 (6 de febrero de 1971), pp. 44-45; José Luis ORTIZ: "El pensamiento político del cante flamenco", Triunfo, 584 (8 de diciembre de 1973), pp. 62-64. 34 Estos cantaores se mostraban así mismos comprometidos con las clases sociales más desfavore-
cidas. Sirva de ejemplo: Francisco ALMAZÁN: "Enrique Morente", Triunfo, 443 ( 28 de noviembre de 1970), pp. 58-59; İD: "José Menese", Triunfo, 479 (4 de diciembre de 1971), pp. $44-45$. 
El flamenco, como manifestación cultural típicamente andaluza, tenía su propio espacio dentro del campo artístico. Desde la nueva canción andaluza se realizaron trabajos que pretendían recuperar sonoridades tradicionales del pueblo andaluz -como se hizo en otras regiones-, pero, si nos atenemos a la prensa generalista o ha publicaciones culturales de carácter amplio, ese "espacio" aparecía ocupado por el flamenco. Andalucía poseía -y posee- un género musical con una fuerte carga identitaria y ese no es otro que el cante jondo-el que se reivindicaba como auténtico, como "arte grande", alejado de cualquier banalización o manipulación ideológica-. Manifiesto Canción del Sur, no podía tener, como movimiento recuperador de la música popular y de sonoridades tradicionales, la misma repercusión mediática que el flamenco, arte éste último que ocupaba muchas más páginas en la prensa -favorecido sin duda por su vinculación a la "marca España" de la época-. No pretendo aquí minusvalorar la actividad de Manifiesto, extremadamente necesaria para introducir la nueva canción en Andalucía, simplemente apunto que en los años setenta, el flamenco era un duro "competidor":35 contaba con un público bastante más amplio y en muchos casos, sin duda menos politizado, lo que contribuyó a una mayor cantidad de actuaciones y más difusión en los medios, ${ }^{36}$ además de ocupar un espacio preeminente en el imaginario identitario andaluz.

\section{Conclusiones}

Manifiesto Canción del Sur y el resto de los colectivos partícipes de la nueva canción en España, presentan una serie de características comunes:

- Nacimiento en el ámbito universitario, con el apoyo de diferentes fuerzas sociales y políticas -movimiento obrero, intelectuales de izquierda, organizaciones cristianas progresistas, partidos políticos de izquierda-

- Artistas partícipes de un género musical que descansa en la comunión poesía-música, asentada en las raíces del folclore y la cultura musical de cada región.

- Los integrantes de estos colectivos actuaban de manera conjunta según la disponibilidad de cada uno de ellos.

- Estrechamente relacionado con las artes plásticas, no en vano, múltiples carpetas de discos fueron diseñadas por pintores o escultores.

- Objetivos comunes: recuperación y difusión de la literatura, modificación estética de las canciones huyendo del folclorismo y simplismo de la llamada "canción española", reivindicación de las culturas nacionales periféricas, creación de una sensibilidad colectiva contra la dictadura y a favor de valores democráticos, la transmisión de esperanza en un futuro libre de las ataduras del sistema franquista. En definitiva, servir de apoyo y amplificar el impacto de los movimientos sociales, en su lucha de resistencia y derrocamiento de la dictadura franquista, desde una renovación de la cultura y el arte. ${ }^{37}$

Manifiesto fue, por tanto, partícipe de un primer momento en el que la nueva canción se manifestaba a través de la formación de diferentes colectivos de cantantes organizados por regiones. Como he mencionado anteriormente, la experiencia andaluza se desarrolló de manera tardía: el nacimiento "oficial" de Manifiesto fue en 1969, mismo año de la disolución del colectivo catalán, un año después del fin de la efímera experiencia madrileña y tres años antes del término de las actuaciones del colectivo vasco. En la década de los setenta, la

35 Hablo en terminos de "competencia" para referirme al campo artistico. Cantaores "reivindicativos" y cantautores no competian entre sí en el plano político, es más, en muchas ocasiones compartían cartel.

36 Así se muestra en Francisco ALMAZÁN: "La escalada del flamenco", Triunfo, 402 (14 de febrero de 1970), p. 45; ÍD: "Nocturno y alba de un mundo", Triunfo, 447 (26 de diciembre de 1970), p. 67.

37 Fernando GONZÁLEZ LUCINI: De la memoria contra el olvido..., pp. 46-50. nueva canción inició una nueva etapa en la que las individualidades -como norma generaltomaron un mayor protagonismo.

Por otro lado, en Andalucía, la versión autóctona de la nueva canción, -representada por colectivos como Manifiesto Canción del Sur e individualidades como Carlos Cano y Benito Moreno, entre otros-; convivía con el flamenco dentro del campo artístico. Este hecho enriquecía musicalmente a la región pero, restaba protagonismo a la nueva canción, si atendemos a la repercusión mediática de uno y otro género musical. Ahora bien, si hablamos de denuncia social y reivindicaciones en las canciones, tanto los Carlos Cano, Antonio Mata, etc. como el cante jondo de los Menese, Morente y Gerena realizaron aportes discursivos, simbólicos, etc. al marco dominante de la oposición al franquismo; al mismo tiempo que reivindicaban una cultura andaluza propia, alejada del "nacional-folklorismo" franquista. 


\section{DEL FRANOUISMO A LA DEMOCRACIA. LA}

APORTACIÓN DEL VALENCIANISMO POLÍTICO A LA

RUPTURA DEMOCRÁTICA VALENCIANA: 1974-1977

Alfonso Natividad Hernandis

Universitat de València lugar a un sinfín de investigaciones científicas sobre el pasado y presente del país en aquellos años. Son jóvenes que redefinen la identidad de su territorio contraponiéndola al modelo identitario franquista con el que habían sido adoctrinados, lo que les llevará a construir una nueva manera de entender su país que, paradójicamente, no solo se alejará de la construcción que el franquismo había hecho del País Valencià, sino también del imaginario colectivo republicano, del que bebía la oposición antifranquista del PCE. ${ }^{2}$ Esa nueva idea de país convertía la lengua catalana en el eje central del sentimiento nacionalista valenciano. Por primera vez la cultura catalana será vista como un vehículo para avanzar hacia la normalidad nacional, lo que facilitará la proliferación de la novela y del ensayo, del teatro y la canción y, en fin, de la enseñanza universitaria en catalán, ${ }^{3}$ a pesar de la rígida censura franquista.

Este nuevo valencianismo no tardará en articularse políticamente, lo que dará lugar al nacimiento, en los mismos años 6o, del Partit Socialista Valencià (PSV) y de Unió Democràtica de País Valencià (UDPV) partidos claramente influidos por las tesis fusterianas y que, por tanto, ligaron la lucha por la democracia y la cuestión nacional valenciana. Y esa será la diferencia fundamental del nuevo valencianismo con el hegemónico PCE: mientras los primeros harán política en catalán y en clave exclusivamente valenciana casi por primera vez en la historia el PCE planteaba la ruptura democrática y la lucha contra el régimen sin preocuparse por la cuestión nacional valenciana, de la que hasta ese momento eran profundos desconocedores. ${ }^{4}$

La presencia del valencianismo político, de todas formas, no parecía inquietar al PCE, que mantenía una clara superioridad en número de militantes y una mayor influencia en el movimiento obrero valenciano, sin embargo, y a pesar de que el valencianismo político era claramente minoritario en cantidad de militantes, su influencia político-social se dejó notar rápidamente dada la calidad intelectual de los mismos. Profesores universitarios e intelectuales en la mayoría de los casos, su dinamismo y solvencia teórica dará fuerza a sus reivindicaciones que, progresivamente, penetrarán en el seno del PCE del País Valenciano, pues ambos grupos compartían los mismos escenarios de oposición lo que facilita que los debates e intercambios de ideas entre comunistas y valencianistas fueran constantes. La preocupación por la cuestión nacional valenciana irá siendo asumida, en mayor o menor medida, por las fuerzas políticas de obediencia estatal, hecho que será clave en los primeros compases de la Transición, ya en los años previos a la muerte del dictador. ${ }^{5}$

La difícil unidad del antifranquismo valenciano. La mesa democrática y la junta democrática de España en el País Valencià

Más allá de las distintas sensibilidades existentes sobre el hecho nacional valenciano, la sensación de que el régimen del general Franco estaba llegando a su fin obligaba a las distintas fuerzas antifranquistas a aunar esfuerzos para facilitar la ruptura democrática en España. La necesidad de aunar fuerzas y buscar consensos para acabar con el régimen dictatorial, sin embargo, no surgirá en un primer momento a nivel estatal, sino más bien irá tomando forma en los distintos territorios del Estado, especialmente en aquellos con una mayor conciencia nacional. Así, siguiendo el ejemplo de la Assemblea de Catalunya, nacida en 1971, nacerá en el País Valencià la Taula Democràtica de València (1973), formada inicialmente por UDPV, el Par-

Joan MARTICASTELLO: "Valencianistes socialistes i socialistes valencianistes. Els camins del PSPV Afers, 67 (2010), pp. 595-618

3 Alfons CUCÓ: Roig... p.33

4 Llorenç SOLER: Del roig al blau. La transició valenciana, València, Publicacions de la Universitat de València, 2004. 5 Vicent Soler, 17 de junio de 2013, València, entrevista realizada por Alfonso NATIVIDAD, Facultat cialista del País Valenciano en la Transición.
Alfons CUCÓ: Roig i Blau. La Transició Democràtica valenciana, València, Tànndem Edicions, 2002, pp. 28-29 
tit Carlista del País Valencià (PCPV), los Grups de Acció i Reflexió Socialista (GARS, embrión del futuro PSPV) y el PCE, al que se sumarían la organización comunista Bandera Roja, el Partido del Trabajo de España (PTE) y el Partido Socialista Popular (PSP). Líderes de esta mesa serán los dirigentes del PCE Antonio Palomares e Isidoro (Doro) Balaguer; Dionisio Vacas y Antonio Montalbán de CCOO; los socialistas nacionalistas Vicent Ventura y Joan Josep Pérez Benlloch Joaquín Muñoz Peirats y Francesc de Paula Burguera del liberalismo nacionalista valenciano; Vicent Miquel Diego, Ernest Sena y Vicente Ruiz Monrabal de la UDPV y carlistas como Laura Pastor, entre otros. La Taula tendrá una vida muy corta y escasa actividad política, si bien se dotó de un programa mínimo de notable influencia futura: libertades democráticas, amnistía, Estatuto de Autonomía para el País Valenciano, libertad sindical y convocatoria e inicio de Cortes Constituyentes elegidas por sufragio universal. ${ }^{6}$ Como se puede observar, la Taula ligaba la necesidad del reconocimiento de la identidad política valenciana con la ruptura democrática en España: no se trata de que unas Cortes Constituyentes facilitaran la autonomía valenciana, más bien se pretendía que dicha autonomía fuera inicialmente reconocida, como paso previo a la convocatoria de elecciones a Cortes Constituyentes: se debía reconocer de forma inmediata la personalidad política valenciana. La Taula, primera plataforma opositora que contará en su seno con todas las fuerzas antifranquistas de relevancia del país, tanto de obediencia estatal como puramente valencianas logra ligar la reivindicación democrática con la reivindicación nacional valenciana, lo que demuestra que el valencianismo político de periodo, si bien minoritario numéricamente frente al hegemónico PCE, había logrado que su mensaje penetrara en buena parte del antifranquismo. Las posiciones valencianistas se verán reforzadas al aceptar la Taula la idea de que la ruptura democrática solo podía lograrse en el País Valencià si, junto a ella, el pueblo valenciano era dotado de un Estatuto de Autonomía que le permitiera avanzar hacia el autogobierno.

Sin embargo era de esperar que la oposición antifranquista a nivel estatal acabara creando su propia plataforma unitaria de oposición al régimen. Así en 1974 nacerá la Junta Democrática de España (JDE), que impulsada por el PCE logrará aglutinar a su alrededor a un gran número de opositores al régimen a derecha e izquierda, así como a diversos intelectuales. La JDE se presentó con un programa mínimo de 12 puntos para la ruptura democrática, entre los cuales el punto 9 reconocía "bajo la unidad del Estado español, la personalidad política de los pueblos catalán, vasco, gallego y de las comunidades regionales que lo decidan democráticamente", por lo que el derecho del País Valencià a la autonomía en el momento de la ruptura democrática quedaba supeditado a una decisión "futura" de los valencianos, truncando las reivindicaciones valencianistas. La concreción valenciana de la JDE será la Junta Democrática del País Valenciano (JDPV) integrada por el PSP, el PCE, el PTE, la OCE (Bandera Roja), miembros del Partido Demócrata y Liberal del País Valenciano (PDLPV), Independientes, CCOO, Justicia Democrática y Movimiento Democrático de Mujeres. La otra plataforma política unitaria creada a nivel estatal, la Plataforma de Convergencia Democrática, tendrá poco peso en el País Valenciano.

La opción valencianista al "sucursalismo" de la JDPV: el consell democràtic. El impacto de los 10 de Alaquàs

Ante la poca sensibilidad del PCE y de los partidos adheridos a la JDE a la cuestión valenciana, cuando se formó JDPV los partidos valencianistas decidieron no participar en ella y crear una nueva plataforma unitaria nuevamente de obediencia exclusivamente valenciana ante el escaso éxito de sus reivindicaciones para que el País Valencià tuviera el mismo trato que Ca-

6 Josep Maria FELIP I SARDÀ: "1975-1976. Los años previos a la Transición democrática valenciana“, en Benito SANZ F Francesi ROMEU (eds):Mer ciana, Valencia, Publicacions de la Universitat de València, 2007, p. 115 talunya, Euskadi o Galicia, ligando la ruptura democrática al derecho de autogobierno de los valencianos: se trataba de mantener vivo el espíritu de la Taula Democràtica?

De la mano de Vicent Ventura, un antiguo falangista reconvertido al socialismo nacionalista, los partidos contrarios a la estrategia de la JDE inician las reuniones para la formación de una plataforma unitaria alternativa: el Consell Democràtic del País Valencià (CDPV). Integraban el CDPV: UDPV, PSPV, Socialistes Valencians Independents (SVI), Partit Socialista d'Alliberament Nacional dels Països Catalans (PSAN), Movimiento Comunista del País Valenciano (MCPV), PCPV, Unificación Comunista de España (UCE), UGT y Unión Sindical Obrera (USO). La raíz del enfrentamiento con la JDPV era la defensa por parte del CDPV de la especificidad de la "vía valenciana" en la Transición democrática, esto es: la constitución de la Generalitat Provisional como paso previo al proceso de autodeterminación del pueblo valenciano, que debía decidir libremente qué tipo de relaciones quería mantener con España y con el resto de países de cultura catalana. ${ }^{8}$

Pero será un hecho externo a los conflictos políticos entre los antifranquistas el que acabe por otorgar definitivamente una mayor visibilidad social a la vía valencianista de ruptura democrática y altere la historia de la naciente Transición valenciana. El 24 de junio de 1975, en la casa de ejercicios espirituales La Purísima de Alaquàs, los futuros miembros del Consel se disponían a celebrar la tercera y definitiva reunión que debía perfilar el contenido programático del mismo. Alli se encontraban Joan Josep Pérez Benlloch (PSPV), Ernest Lluch y Vicent Soler (SVI, grupo que convergería en el PSPV), Josep Guia y Francesc Candel (PSAN), Josep Corell (USO), Laura Pastor (PCPV), Carlos Martínez Llaneza de la oposición de izquierdas al PCE (OPI), Xavier Navarro (UCE) y Carles Dolç (MCPV). Mientras se avanzaba en la redacción del documento constitutivo del Consell la policía irrumpió en el recinto; la Brigada Político Social llevaba siguiendo a varios de los allí reunidos unos días, lo que facilitó la detención de los integrantes del Consell en Alaquàs, para la que no se escatimaron medios, rodeando el edificio de efectivos policiales. Los detenidos serán trasladados a la Prefectura Superior de Policía de la calle Fernando el Católico de Valencia, lo que, a modo de curiosidad, les proporcionará un tiempo valioso para por el camino comerse, literalmente, la agenda del profesor Josep Guia evitando así nuevas detenciones 9 . Los detenidos pasarán las 72 horas de rigor en la Prefectura, siendo trasladados al tercer día a la Audiencia Territorial, lo que les permitió comprobar el notable impacto que su detención había producido en la sociedad civil valenciana.

El apoyo a los detenidos por parte de la oposición antifranquista será unánime más allá de las distintas opciones ideológicas imperantes en el periodo. Así, por ejemplo, el 12 de julio el diario Las Provincias publicaba un manifiesto firmado por 93 profesores universitarios en apoyo a los 10 de Alaquàs (como serán rápidamente conocidos los detenidos el 24 de junio), entre los firmantes destacará el nombre de Manuel Sánchez Ayuso, del PSP, partido integrante de la JDPV o Manuel Broseta Pont, clave en el futuro para la formación de la Taula de Forces Polítiques i Sindicals..$^{\circ} \mathrm{A}$ su vez personalidades de la derecha valenciana o del mundo empresarial, como Joaquín Maldonado o Emilio Atard se movilizarán en apoyo de los detenidos; algo estaba cambiando en el país. Efectivamente, a raíz de la detención de los 10 de Alaquàs el tiempo histórico se aceleró en el País Valencià; acusados de asociación ilegal y de defender el autogobierno de los valencianos en un futuro régimen democrático (siendo los primeros detenidos del país por pedir el autogobierno del mismo), lograrán poner la cuestión nacional en el orden del día del antifranquismo."

7 Vicent SOLER: "Els 10 d'Alaquàs", en Quaderns d'investigació d'Alaquàs, XX (2001), p. 93

8 Josep Maria FELIP I SARDÄ: "1975-1976. Los años previos..." p. 118

9 lbid., p. 95

10 "Escrito de noventa y tres profesores", Las Provincias, 12 de julio de 1975.

11 Josep GUIA: “La Transició política al País Valencià des d'una perspectiva independentista”, en Pelai 
Pero, más allá del impacto de los 10 de Alaquàs, la realidad mostraba que en el verano de 1975 nos encontramos en el País Valencià con dos plataformas "unitarias" antifranquistas que rivalizaban por ver quien convocaba más actos, aglutinaba más gente o representaba mejor el sentir del país. ${ }^{12}$ Era evidente que esta situación no podía alargarse durante mucho tiempo por lo que rápidamente la rivalidad se transformó en deseos de cooperación y unión. Se creó entonces un Comité de Enlace entre el CDPV y la PDPV formado por dos personalidades de la Junta, Doro Balaguer (PCE) i Manuel Broseta (DI), y por dos del Consell, Carles Dolç i Josep Guia. Dicho Comité de Enlace será el que coordine la convocatoria conjunta de una gran manifestación por la amnistía de presos y exiliados para el 16 de enero de 1976, la última duramente reprimida por la policía en ese periodo. Finalmente el 14 de abril de 1976 el CDPV (al que se había incorporado el PSOE) y la JDPV se fusionan naciendo la Taula de Forces Polítiques i Sindicals del País Valencià (TFPSPV), plataforma unitaria de base exclusivamente valenciana que vuelve a plantear la necesidad de que la ruptura democrática y el autogobierno valenciano vayan unidos, tal y como reclamaba el CDPV.

Podríamos decir, por tanto, que el suceso de los 10 de Alaquàs logró que la cuestión de autogobierno valenciano se convirtiera en central en el debate político del país, facilitando que los partidos antifranquistas de corte estatal acabaran defendiendo en el País Valenciano la necesidad de unir autonomía y ruptura democrática: parecía un triunfo claro de las fuerzas valencianistas.

\section{La taula de forces polítiques i sindicals del país valencià. El final del sueño valencianista}

El nacimiento de la nueva Taula y su asunción de las tesis valencianistas defendidas por el CDPV sobre la necesidad de unir democracia y autonomía hacían presagiar que el País Valencià lograría ser reconocido en el conjunto del Estado como la cuarta "nacionalidad histórica", lo que permitiría la creación de una Generalitat y la elaboración de un estatuto de autonomía en el momento en el que ese diera la ruptura democrática. A lo largo del año 1976, y hasta el triunfo del referéndum para la Reforma Política de Suárez, pocos dudaban de ello.

En efecto, los acuerdos constitutivos de la TFPSPV aceptaban una posición común para todos los partidos políticos valencianos, que pasaba por aceptar conceptualizar al País Valenciano como una nacionalidad oprimida, compartir como objetivo político de la ruptura democrática la instauración de la Generalitat Provisional, elecciones libres a una asamblea constituyente del País Valenciano que elaborara un Estatuto de Autonomía y comprometerse en la defensa y recuperación de la cultura propia valenciana, colaborando en este ámbito con el resto de territorios con los que se comparte cultura, pero, eso sí, renunciando al marco nacional común de los Países Catalanes, tal vez la única verdadera cesión que los partidos integrantes del CDPV debieron aceptar en el proceso de creación de la Taula. ${ }^{13}$ La aceptación de los principios propios de los partidos políticos de base fusteriana por aquellos partidos de obediencia estatal (especialmente el PCE y el PSOE), facilitó el proceso de "valencianización " de dichos partidos. En noviembre de 1976 nacerá oficialmente el Partit Comunista del País Valencià (PCPV-PCE), y a su vez el PSOE, que hasta entonces en el País Valencià únicamente tenía implantación provincial, constituyó la Federación del País Valenciano, asumiendo ambos partidos como propias las tesis pactadas tras la formación de la Taula. A esta "valencianización" de los partidos estatales hay que unirle el rotundo éxito de la manifestación convocada por la Taula para el 12 de julio de 1976 en la que se pedía amnistía, libertad, estatuto de autonomía y

PAGÈS (dir.): La transició democràtica als Països Catalans. História y memória, Valencia, Publicacions de la Universitat de València, 2005, pp. 260-261.

12 Ibid, p. 26

13 Josep Maria FELIP I SARDÀ: “1975-1976. Los años previos...” p. 128 sindicato obrero. La presencia de más de 100.000 personas en la manifestación dejaba bien a las claras que la sociedad valenciana apostaba por la necesidad de la ruptura democrática po la vía autonomista: democracia y autonomía se imbricaban a los ojos de miles de ciudadanos como partes inseparables de una misma aspiración. ${ }^{14}$ Todo unido contribuía a conferir al periodo de la Transición un clima nacionalitario inédito en la historia política valenciana. El futuro del valencianismo parecía asegurado.

Sin embargo la posición común de los partidos políticos valencianos representados en la Taula distaba mucho de ser asumida a nivel estatal. Más o menos en las mismas fechas en las que nace la TFPSPV lo hará en España la Plataforma de Organismos Democráticos (POD): fusión de la Junta Democrática de España y la Plataforma de Convergencia Democrática, in tegrará en su seno a la práctica totalidad de los partidos de la oposición antifranquista. El documento base constitutivo de la POD planteará, nuevamente, el derecho a la autonomía y a la autodeterminación únicamente de las tres nacionalidades históricas de España: Galicia Euskadi y Catalunya, lo que provocará la inmediata protesta de la TFPSPV, que en un documento enviado a la POD reivindicará el reconocimiento del País Valencià como cuarta nacionalidad histórica con los mismos derechos que las otras tres, solicitando una nueva redacción del punto referente a la autodeterminación de las nacionalidades españolas como condición previa a su entrada en la POD y la aceptación de su documento base. Esta postura crítica al documento de creación de la POD fue conocida públicamente como el "Document de València."

La Comisión Permanente de la POD en la que se encontraban los valencianos José Luís Albiñana (PSOE) y José Sanmartín (PTE) se reunió en Canarias el 4 de noviembre de 1976 para tratar de buscar una solución al conflicto abierto con la TFPSPV. Tras duros debates la cuestión se zanjó aceptando la Comisión la propuesta de la Taula, ampliándola eso sí a las Islas Canarias, propuesta que fue incluida en el Documento-Base de la Comisión Negociadora con los Poderes de Estado en caso de que tal negociación para el restablecimiento de la democracia fuera posible.

Sin embargo, y a pesar del éxito de las reivindicaciones valencianistas, quedaba claro que los partidos estatales no se sentían cómodos ante las exigencias del valencianismo político que debía pelear constantemente su posición como cuarta nacionalidad histórica ante unos partidos que, si bien en Valencia parecían alinearse con las tesis valencianistas, en Madrid defendían posicionamientos muy diferentes. Este hecho quedó constatado cuando, después de fracaso de la campaña abstencionista de la POD sobre el referéndum para la Reforma Política en diciembre de 1976, se constató que no habría ruptura democrática en España y que los cambios debían ser negociados directamente con el gobierno de Adolfo Suárez. En ese contexto, la "Comisión de los 10" enviada por la POD a negociar con el gobierno ya no incluía a ningún representante valenciano y, a pesar de las presiones que recibió de la TFPSPV, acabó aceptando que el derecho a la autonomía se concediera exclusivamente a las tres nacionalidades históricas, posponiendo a los demás territorios a reivindicar su derecho a la autonomía una vez alcanzada y consolidada la democracia. ${ }^{16}$

La TFPSPV estaba tocada de muerte. Los partidos valencianos de obediencia estatal (especialmente el PSOE y el PCE) aceptarán la nueva posición negociada con Suárez apelando al "pragmatismo" político y a la necesidad de consolidar la democracia en España, mientras, los partidos más sensibles a las reivindicaciones nacionalistas (PSPV, UDPV, PCPV, MCPV y PDLPV) así como intelectuales independientes de la talla de Manuel Broseta, no aceptarán la renuncia a lo pactado en Canarias y exigirian la total equiparación del País Valencià a las

14 Benito SANZ DíAZ y Josep Maria FELIP I SARDÀ: La construcción política de la Comunitat Valenciana: 1962-1982, Valencia, Institució Alfons El Magnànim, 2006, p. 163

15 Josep Maria FELIP I SARDÀ: 1975-1976. Los años previos..." p. 122

16 Luís Bernat PRATS MAHIQUES: "Nació Transició i democràcia cristiana. La UDPV entre els anys

1974 i 1978", Afers, 67, (2010), pp. 619-640 
tres nacionalidades históricas. Los partidos valencianistas solo tendrán una vía para lograr volver a imponer sus tesis: mostrar una clara fuerza electoral en las elecciones que se estaban preparando para el verano de 1977 .

Sin embargo las elecciones del 15 de junio de 1977 supondrán un duro revés para las fuerzas valencianistas: todas ellas sin excepción obtendrán unos resultados misérrimos incompatibles con la obtención de representación parlamentaria, serán las fuerzas políticas de obediencia estatal tanto de izquierda (PSOE, PCE, PSP) como de derecha (UCD, AP) las que obtendrán representación en las Cortes Constituyentes. Los partidos valencianistas perdían el peso específico que en el tardo-franquismo y el inicio de la Transición habían tenido. Serán ahora dos partidos estatales (PSOE y UCD), sujetos a la disciplina debida a sus direcciones estatales, los que deberán lidiar con la contradicción irresoluble de acatar las directrices que desde Madrid les hacían llegar tratando de implementar, a su vez, un "programa añadido" de reivindicaciones valencianistas que cada vez les resultará más incómodo. El viejo sueño del valencianismo político de lograr la restauración de la Generalitat y el autogobierno valenciano en las mismas condiciones que las denominadas nacionalidades históricas parecía ya una verdadera quimera. El programa político valencianista, tan al alcance de la mano entre 1975-1976, parecía repentinamente liquidado y amortizado.

\section{Concusiones: el éxito del valencianismo más allá del fracaso. La "valencianización" de la ciu-} dadanía valenciana

El 16 de junio de 1977 todo parecía indicar que el valencianismo había fracasado en su intento de avanzar en el reconocimiento del País Valencià como cuarta nacionalidad histórica de España, al no lograr que la llegada de la democracia y la restauración de la Generalitat fueran indefectiblemente de la mano. Y efectivamente el valencianismo político fracasó en ese objetivo, fracaso que se consumó con el tardío Estatut d'Autonomia concedido al País Valencià (desde entonces oficialmente Comunitat Valenciana, una renuncia identitaria más acordada por los partidos de obediencia estatal) aprobado por la denominada "vía lenta" constitucional (art. 143) a diferencia de la "vía rápida" constitucional (art. 151) concedida a las nacionalidades históricas a las que, paradójicamente, si bien no se sumó nuestro país sí lo acabaría haciendo Andalucía.

Sin embargo el supuesto fracaso del valencianismo esconde un "éxito" político pocas veces reconocido: fue gracias al valencianismo político, a su lucha por el reconocimiento de la singularidad nacional valenciana, a su defensa de la lengua y cultura propia del país; fue gracias a ellos que a día de hoy los valencianos gozamos de un gobierno autonómico, la lengua del país se enseña en las escuelas y es considerada por muchos como lengua de cultura; los partidos políticos estatales defienden en el país, en mayor o menor medida, la cultura e identidad propia de Valencia y, en fin, una parte de la ciudadanía valenciana ha adquirido consciencia de que España no es "Castilla ampliada" sino una suma de nacionalidades con especificidades propias que bien merecen ser defendidas. Sin el valencianismo político nacido en los años 60 que propició una "valencianización" indudable de la política autóctona y una modernización del lenguaje político valenciano, hubiéramos corrido el riesgo de que nuestro país, a día de hoy, pensara su autonomía únicamente en clave administrativa, ninguneara su profunda riqueza cultural y desconociera su historia, para cuyo conocimiento tanto hicieron las generaciones de valencianistas de tardo-franquismo. Ese fue el logro del valencianismo de la Transición que se mantiene hasta el presente: mantener vivo al país en un clima cada vez más hostil, que no es poco. 


\section{L'ESOUURRA REVOLUCIONÀRIA I EL SEU PAPER \\ EN LA MOBILITZACIÓ SOCIAL I EL CANVI POLÍTIC \\ DELS ANYS 70: ESTAT DE LA QÜESTIÓ I ALGUNS \\ APUNTS PER AL SEU ESTUDI*}

Joel Sans Molas

Universitat Autònoma de Barcelona

Tot i ser, en el seu conjunt, la segona força política de l'antifranquisme després del PCE i PSUC, les organitzacions de l'esquerra revolucionària han estat poc reconegudes en el relat històric sobre els anys 70 i la transició. Precisar que per esquerra revolucionària m'estic referint a les organitzacions marxistes que hi havia a l'esquerra del PCE i del PSUC; entre les més importants en el seu arrelament social serien el PTE, ORT, MC, LCR, OIC i OCE-BR.' En aquesta comunicació realitzaré una anàlisi crítica de les visions que ha presentat la historiografia respecte aquestes organitzacions. Davant la impossibilitat, per motius de l'espai disponible, de fer al mateix temps tant un estat de la qüestió dels estudis sobre l'esquerra revolucionària com una interpretació sobre el seu paper i importància, em centraré en el primer aspecte i el següent només l'apuntaré.

La primera consideració que cal fer és que l'esquerra revolucionària a l'Estat espanyol ha es-
La tat escassament estudiada fins al moment. No només hi ha una absència d'obres específiques sobre el fenomen polític que representà sinó que també els manuals d'història de la transició n'han parlat poc o, fins i tot, l'han obviat. Aquest buit no és exclusiu de l'esquerra revolucionària; altres components de l'antifranquisme com el moviment feminista, el moviment veïnal o la cultura radical han tingut fins fa poc temps un reduïda atenció per part de la historiografia.

Hi ha una diversitat de motius a l'hora explicar la manca d'estudis extensos sobre l'esquerra revolucionària, a banda de l'orientació general de la historiografia respecte certes manifestacions. En primer lloc, el fet que les seves organitzacions no aconseguissin representació en el congrés dels diputats en les eleccions generals de 1977 i de 1979 ha contribuït a descartar-les a ulls de qui analitzen la política en clau de representació institucional. Els resultats, propers al $3 \%$ en ambdues eleccions, ${ }^{2}$ no eren, però, representatius del seu pes militant i mobilitzador. En segon lloc, i més en general, el projecte de l'esquerra revolucionària d'una ruptura forçada per la mobilització va sortir derrotat $i$, per tant, xoca amb el consens polític que es va forjar al voltant de la transició. Es per això que és un actor difícil d'encabir en les visions historiogràfiques dominants sobre un canvi conduït des de les elits polítiques $i$, fins $i$ tot en lectures crítiques, que consideren que el camí de la ruptura no pactada amb el règim no era possible en el balanç de forces existents. I, per últim, ha afectat que les principals organitzacions no es mantinguessin en el temps (les que van sobreviure durant els anys 80 , la LCR i la MC, van desaparèixer a principis de la dècada següent), fet que ha ajudat que la seva petjada històrica quedés amagada.

* Comunicació vinculada al projecte d'investigació: "Las alternativas a la quiebra liberal en Europa: socialismo, democracia, fascismo y populismo, 1914-1991" (Ministerio de Ciencia e Innovación, HAR2011- 25749). L’autor té una beca FPU del Ministerio de Educación.

1 Són les següents: Partido del Trabajo de España, Organización Revolucionaria de los Trabajadores, Movimiento Comunista, Liga Comunista Revolucionaria, Organización de Izquierda Comunista y Organización Comunista de España- Bandera Roja.

2 Dades per al conjunt de candidatures a partir de: Ministerio del Interior. Resultados electorales:

(http://www.infoelectoral.mir.es/min/home.html).

\section{Estat de la qüestió}

Dins de la principal bibliografia existent sobre l'esquerra radical dels anys 70 hi ha pocs llibres ben elaborats sobre el fenomen. De fet, fins al moment no hi ha cap investigació monogràfica publicada sobre alguna de les principals organitzacions de l'esquerra radical ja sigui pel conjunt de l'Estat espanyol o per el conjunt d'organitzacions per a una zona geogràfica delimitada. Hi ha un cert nombre d'articles que, tot i estar en augment, encara configuren una visió massa fragmentada sobre el fenomen. En aquest estat de la qüestió mirarem en primer lloc les obres més clàssiques.

El principal llibre de referència fins el moment sobre l'esquerra radical a l'Estat espanyol és $L a$ lucha final (1995) escrit per Consuelo Laiz. ${ }^{3}$ Aquest llibre recorre una heterogeneïtat d'organitzacions prestant una especial atenció al fenomen de la violència política. Això fa que aplegui projectes tant diferents com el nacionalisme radical i armat d'ETA, petites organitzacions marxistes com el el PCE $(m-l)$ i el PCE $(r)$, que seran conegudes sobretot pels seus braços armats (el FRAP i els GRAPO), i organitzacions marxistes, com el PTE, I'ORT, I'MC i la LCR, que aconseguiran una certa base social. El llibre fa un recorregut per la gènesi i l'evolució de les diferents organitzacions, des dels anys 50, amb la creació d'Ekin i ETA, fins a la transició, i tanca la cronologia l'any 1979. Ca destacar com a aportacions de Laiz una exposició sistemàtica dels programes i de l'evolució dels posicionaments de les organitzacions a partir de la seva pròpia premsa i documents. L'autora també fa una periodització força orientativa, que assenyala diverses fases de les organitzacions: formació des dels anys 60 fins a 1973, consolidació entre 1974 i 1975, acció entre 1975 i 1976 i crisi a partir de 1978 (amb algunes diferències de cronologia segons l'organització).

Ara bé, tot i ser el principal estudi del conjunt de l'esquerra revolucionària fins al moment, aquest llibre pioner presenta diverses limitacions. En primer lloc, l'enfoc és eminentment politològic: centra l'atenció en la ideologia, l'estructura organitzativa i l'evolució de les posicions polítiques de cada organització, pràcticament per separat i sense gaires referències al context històric. Aquest tipus d'aproximació no recull aspectes importants de cara a fer una narrativa des de la història política i social com serien la mida de les organitzacions, la seva influència, la intervenció en els moviments i les lluites, la relació amb el canvi polític... en definitiva, l'impacte històric que van tenir. A banda, en la selecció d'organitzacions, a més de la mescla de projectes polítics força distants, es recullen organitzacions petites com el PCE $(m-l)$ o el PCE $(r)$ per la seva acció armada, i es deixa fora a d'altres, com l'OIC, que tingueren una major implantació social.

En segon lloc, l'anàlisi que desenvolupa Laiz de les organitzacions pateix d'una visió simplificada de les idees de Marx i Lenin (seguint a politòlegs com Philippe Raynaud, Maurice Duverger $\mathrm{o}$ a l'historiador liberal François Furet) que tendeix a considerar el marxisme intrínsecament determinista o que usa de forma rígida i fora de context certes afirmacions de Lenin, les quals justament van ser molt canviants segons cada moment polític. ${ }^{4}$ En la meva opinió, això limita la comprensió de la ideologia i les formes d'actuació de les organitzacions de l'esquerra revolucionària. Per últim, val la pena considerar la tesi de Laiz pel que fa a l'existència i desaparició de l'esquerra revolucionària. L'autora escriu:

Las ideas políticas arraigan y prosperan en la sociedad cuando existen condiciones reales que las hacen verosímiles, pero si aquéllas se alejan de la realidad, pierden su eficacia. (...) Durante la dictadura, se constituyen distintos grupos políticos a la izquierda de partido comunista que obtienen cierta influencia social, pero en los años de la transi-

3 Consuelo LAIZ CASTRO: La Lucha final: los partidos de la izquierda radical durante la transición española, Madrid, Los Libros de la catarata, 1995

4 Sobre les dificultats de citar a Lenin en relació als girs dels seus posicionaments polítics i per veure 列 del partido (1893-1914), Barcelona, El Viejo Topo, 2011. 
ción política no logran ajustar su discurso a las nuevas condiciones de la democracia y por ello desaparecen como tales. ${ }^{5}$

Estos partidos son un fenómeno que transcurre en el último tramo de la dictadura de Franco y que se explica por su comportamiento en el transcurso de la transición. Por eso, apoyándonos en las culturas políticas que se forman en esas dos etapas de la sociedad es-

pañola, es cómo podemos encontrar la respuesta a su fulminante desarrollo y disolución. ${ }^{6}$

És cert que l'esquerra revolucionària es desenvolupa majoritàriament en les condicions del franquisme i de la seva lluita social i que tenen dificultats a adaptar-se al canvi polític de la transició. Tanmateix, Laiz sembla indicar que l'esquerra revolucionària ha estat un producte específic de la lluita antifranquista però que hauria deixat de tenir sentit en la nova democràcia parlamentària, en una "sociedad modernizada", en les seves paraules. Aquesta explicació dóna un pes determinant al context, i converteix en pràcticament inevitable la crisi termina de l'esquerra revolucionària. Això treu importància al factor subjectiu del comportament de les pròpies organitzacions i no ajuda a entendre perquè algunes organitzacions desapareixen (PTE i ORT) i d'altres se sostenen (MC i LCR). Altrament, les diferències polítiques entre aquestes organitzacions i la forma com responen a la transició crec que són elements rellevants per intentar explicar-ho. La menció que fa segons la qual si les idees polítiques "se alejan de la realidad, pierden su eficacia", tendeix a atribuir a aquestes organitzacions, de forma poc matisada, una visió irreal del terreny que trepitjaven. A banda, cal considerar que l'esquerra revolucionària apareix amb força des de finals dels anys 60 en països en què no hi havia una situació de dictadura com Alemanya, França, Gran Bretanya i, especialment, Itàlia. Per tant l'emergència de l'esquerra revolucionària no és un producte específic de la lluita antifranquista, sinó un fenomen internacional dels anys 60 i 70 .

L'altre llibre de referència sobre l'esquerra radical és el coordinat per José M. Roca, El proyecto radical. ${ }^{8}$ Publicat el 1994 va ser la primera obra que recollia l'esquerra revolucionària després d'alguns treballs dels anys 70 . El rang d'organitzacions que aplega és més ampli, abraçant pràcticament totes les organitzacions que varen existir, $i$ tracta algunes qüestions que no apareixen específicament en el llibre de Laiz, com és la relació que estableixen amb el sindicalisme i el moviment estudiantil. També, dóna dades sobre la militància de les organitzacions: considera com a principals organitzacions al PTE, ORT, MC i LCR, amb diversos milers cada una, i situa en 50.000 membres el conjunt de l'esquerra revolucionària. Càlculs posteriors indiquen que aquesta xifra està inflada però és una primera aproximació que ajuda a entendre el pes d'aquestes organitzacions.

El llibre entra a fer una major anàlisi que el de Laiz sobre els problemes de desenvolupament de l'esquerra revolucionària i de la seva crisi a finals dels anys 70 . També assenyala aspectes interessants, com la sobredimensió que fa l'esquerra revolucionària de les pròpies forces i de les possibilitats de canvi radical en la societat. Tot i així, algunes categories usades per a aquestes explicacions són qüestionables. Sobretot en els principals capítols del llibre, escrits per Roca, es tendeix a presentar l'esquerra revolucionària com una aventura juvenil, dogmàtica i immadura. Roca descriu d'aquesta forma la "extrema izquierda sociológica":

5 Consuelo LAIZ CASTRO: La Lucha final... p. 13

6 Ibid. p. 15

7 Ver por ejemplo: Crhis HARMAN: The fire last time. 1968 and after, Londres, Bookmarks, 1998 y Massimo TEODORI: Las nuevas izquierdas europeas, Barceloma, Blume, 1978

8 José Manuel ROCA (coord): El proyecto radical. Auge y declive de la izquierda revolucionaria en España (1965-1992), Madrid, Los libros de la catarata, 1994.
Rinde un culto inmoderado a alguno de los teóricos clásicos, posee una percepción libresca que podríamos denominar optimismo histórico y en el marxismo como ciencia de las ciencias, idealiza a la clase obrera, tiene una marcada vocación estatalista (estatofilia) considera el partido el centro de la actividad social (partitolatria); (...) profesa el productivismo, practica el sectarismo e impregna su praxis de revolucionarismo, (...) ofreciendo una variada gama de dogmatismos - de autor, de obra, del espíritu y de la letra, o de todos ellos a la vez-que polemizan entre sí. ${ }^{9}$

Aquest retrat no podia caure en una major caricaturització del que va ser l'esquerra revolucionària. És cert que hi van haver-hi actituds dogmàtiques, sectàries i de manca de profunditat teòrica en el si de l'esquerra revolucionària. Ara bé, en primer lloc, això va succeir sobretot en el seu període inicial, entre 1967 i 1974, i s'ha d'entendre el context, marcat per una dictadura, la franquista, que havia suposat un tall amb la tradició del marxisme revolucionari i per les dificultats de desenvolupar una tasca militant en l'atomització que imposava la clandestinitat. Posteriorment les principals d'aquestes organitzacions van desenvolupar, en general, unes polítiques més madurades. En segon lloc, no es poden generalitzar totes aquestes característiques al conjunt de les organitzacions. Fer-ho no ens permet entendre les dinàmiques de l'esquerra revolucionària ni trobar una explicació al fet que les seves polítiques van connectar amb diverses desenes de milers de persones.

Un altre llibre dels mateixos anys, aquest cop centrat específicament en una sola organització i amb una major comprensió del fenomen és El Front Obrer de Catalunya, escrit per Ramón Alquezar, José Luis Martín Ramos, Xavier Marcet, Josep M. Vergara i Julio Garcia Alcalá. ${ }^{\circ}$ Aquest llibre, que recull les comunicacions del VI Jornades Història del Socialisme, de 1994, és una bona aproximació per entendre la cultura política de la nova esquerra revolucionària que es va ana formant a finals dels anys 60 . Una investigació més sistemàtica la proporciona la tesi doctoral de Julio García Alcalá sobre les organitzacions front, en la que es recullen en major detall els últims moments del FOC i l'evolució posterior dels seus militants." Si bé el FOC queda ja lluny del canvi polític de la transició, ambdues obres permeten veure un dels nínxols polítics dels quals sortirà part de l'esquerra revolucionària posterior, com són els casos de la LCR i l'OIC.

A un altre nivell trobem alguns llibres de finals dels anys 70, publicats en el moment en què les organitzacions encara estaven vives. Entre ells tenim Quins són els Partits Politics de Catalunya, Els grups politics a Catalunya i Los partidos marxistes. ${ }^{12}$ Els tres són una recopilació de les principals posicions polítiques del moment de les organitzacions de l'esquerra, entre elles les revolucionàries, alguns aspectes cronològics $i$ algunes dades de les seves militàncies, en general poc fiables pel fet d'estar proporcionades per les mateixes organitzacions amb una intenció propagandística. Són llibres d'un valor principalment documental i de curiositat històrica.

Si aquests han estat els principals llibres que hi ha hagut durant força temps sobre l'esquerra revolucionària, en els últims vuit anys s'ha anat omplint mica en mica aquest camp tant poc estudiat fins al moment. Tenim un augment del articles i comunicacions que l'estan

9 Ibid.p. 76

10 Ramón ALOUEZAR, et al: El Front Obrer de Catalunya, Barcelona, Fundació Rafael Campalans, 1994 Pp. 59-70.

11 Julio GARCÍA ALCALÁ: Un modelo en la oposición al franquismo: las organizaciones frente (FLP-FOC ESBA), tesis doctoral, Universitat Complutense de Madrid, 1997.

12 Jaume COLOMER et al: Els grups politics a Catalunya. Partits i programes. 2. Esquerra, extrema esquerra i organismes unitaris, Barcelona, Avenç, 1976; Llús M. BONET i LLOVET: Quins són els Partits Politics de Catalunya, Barcelona, La Gaia Ciència, 1997; i Ruiz, F. y Romero, J. (comp.): Los partidos marxistas, Barcelona, Anagrama, 1997. 
tractant, dos llibres publicats i també hi ha d'algunes tesis doctorals en procés d'elaboració. ${ }^{13}$

El primer llibre a tenir en compte és Pan, Libertad y trabajo (2011), coordinat per José Luis Martín Ramos. ${ }^{14}$ Podem considerar-lo un dels llibres més sòlids publicats sobre el fenomen de l'esquerra revolucionària, si bé centrat en una organització específica, el PTE, que de fet va ser la major d'elles. Està escrit a quatre mans per José Luis Martín Ramos, Manuel Gracia, Marta Campoy i Ramón Franquesa. Tots els autors van tenir una relació militant - amb diferents graus d'intensitat- amb el PTE, encara que tant Martín Ramos com Ramón Franquesa escriuen també en qualitat d'historiadors. El Ilibre ressegueix la creació del PTE a partir d'una escissió del PSUC el 1967, la seva evolució i maduració i la seva brusca crisi final el 1979-80. Tot i el passat militant dels autors el llibre és rigorós i compta amb fonts orals i estudi de documentació de l'organització, encara que és una mica desigual en els seus quatre capítols. Els capítols III i IV, que comprenen el període 1975-1979 i que analitzen el desenrotllament de les posicions polítiques del PTE durant la transició, fan una lectura crítica d'aquestes i proporcionen les principals claus explicatives de la crisi final del partit.

L'altre llibre recent, de 2010, és El Maoísmo en España y el tribunal de orden Público (19641976) de Horacio Roldán Barbero. ${ }^{5}$ La principal aportació d'aquesta obra és l'anàlisi del marc legislatiu repressiu i, especialment, el còmput de les sentències del Tribunal de Orden Público que van afectar l'esquerra, amb una atenció especial en les diferents organitzacions maoistes. Les dades que aporta Roldán mostren un pes significatiu de l'esquerra maoista i assenyalen la dedicada atenció repressiva que li van prestar les autoritats franquistes. Ara bé, algunes interpretacions del llibre acusen una metodologia dubtosa, com és fer una translació automàtica entre el nombre de sentències que van afectar a cada organització la importància que aquesta va tenir. Això el porta a escriure: "El estudio pormenorizado de estas sentencias es, precisamente, el que nos permite hoy reconocer el papel puntero del PCE $(\mathrm{m}-\mathrm{I})$ en la contestación revolucionaria". ${ }^{16}$ Donar un paper preeminent al PCE $(\mathrm{m}-\mathrm{I})$ sense tenir en compte que l'elevat nombre de sentències que va patir són degut a l'actuació del seu braç armat provoca una visió distorsionada de quines van ser les principals organitzacions. A banda, Roldán tendeix, d'una forma més brusca que Laiz, a veure l'aparició de l'esquerra revolucionària com un producte de contextos anòmals, un producte que tendirà a desaparèixer quan es retorni a la normalitat. En aquest sentit escriu: "Sólo una torpe gestión del moderno capitalismo, por incompetencia, avidez o desprecio a los más débiles, haría posible el resurgimiento del marxismo, y más singularmente, del marxismo-leninismo". 17

Quant a d'altres treballs sobre l'esquerra revolucionària podem destacar que en el Congrés Internacional d'Història de la Transició a Espanya (Almeria, 2011) amb el títol de Las organizaciones políticas es van presentar quatre comunicacions sobre l'esquerra radical, fet que en si mostra el creixent interès vers aquest fenomen polític per part de la historiografia.

La primera a comentar, escrita per Albert Planas, abraça el període 1968-1980 a Catalunya, si bé manté una perspectiva estatal. ${ }^{18} \mathrm{El}$ text assenyala que l'esquerra revolucionària va jugar

13 Entre les tesis doctorals en marxa trobem la d'Albert Planas sobre l'esquerra radical a Catalunya durant els anys 70 , la de Josep Maria Soler sobre Bandera Roja, la de Ricard Martínez sobre la LCR,
la de Fernando Díaz Haro, La izquierda radical durante la transición en Almería (1975-1982) i la d'un la de Fernando Díaz

14 José Luis MARTíN RAMOS (coord): Pan, Trabajo y Libertad. Historia del Partido del Trabajo de España, Barcelona, Viejo Topo, 2011

15 Horacio ROLDÁN BARBERO: El Maoísmo en España y el tribunal de orden Público (1964-1976), Córdoba, Universidad de Córdoba, 2010

16 Ibid. p. 18.

17 lbid. pp. 44-45

18 Albert PLANAS I SERRA: "La izquierda marxista radical en la transición. Catalunya, 1968-1980" a

Rafael OUIROSA-CHEYROUZE, Luis Carlos NAVARRO y Mónica FERNÁNDEZ (coords): Las organi- un paper actiu en l'antifranquisme que va contribuir a l'erosió de la dictadura. Conté dades sobre el nombre de militants, situant el conjunt de l'esquerra revolucionària en un màxim de 30.000 membres a partir de fonts policials i dóna xifres sobre la repressió cap a aquestes organitzacions. Ofereix una anàlisis del sorgiment de l'esquerra revolucionaria tenint en compte el context polític europeu i franquista i proporciona una explicació de la manca de representació parlamentària en les eleccions de 1977 basada en el curs de la transició, en el "dogmatismo revolucionario de les organizaciones marxistas-leninistas" 19 i en la desunió de les forces polítiques. Les interpretacions que fa Planas són interessants en el seu conjunt, encara que en alguns moments tendeix a fer una estigmatització poc matisada de certs trets negatius, com aquesta esmentada referència al dogmatisme.

La comunicació de Fuensanta Escudero i Carmen González estudia l'esquerra revolucionària a Múrcia al llarg dels anys $70^{20} \mathrm{i}$ mostra l'evolució de les reivindicacions d'aquestes organitzacions. Com apareix en altres treballs -entre ells el de Laiz- assenyala com les organitzacions que sobreviuen a la transició ho fan centrant el seu camp d'actuació en els nous moviments socials com l'ecologista, el feminista, l'homosexual o l'antinuclear. Entre els aspectes que contribueixen a la crisi de l'esquerra revolucionària senyalen la qüestió del "lastre de un aprendizaje politico en clandestinidad" ${ }_{21}$ o la manca de democràcia interna en les organitzacions (al meu parer, però, aquest element es trobaria en moltes de les organitzacions però no en totes elles, com per exemple la LCR).

Tenim també el treball de Sergio Rodríguez Tejada, que estudia les pràctiques militants de finals dels anys 60 i dels anys 70 a partir del cas de la Universitat de València. ${ }^{22}$ L'autor assenyala la importància de les organitzacions de l'esquerra radical en aquests termes: "jugaron un papel fundamental en la lucha por salir de la dictadura, contribuyendo decisivamente a la activación de nuevos espacios de participación y nuevas experiencias en centros educativos, factorías y barrios". ${ }^{23}$ Afirma, encertadament, que una comprensió l'esquerra revolucionària passa per d'endinsar-se en el moment històric i veure el sentit de les seves actuacions per no limitar-se a condemnar per endavant la seva causa. Un dels conceptes que usa per entendre el fenomen és el de "pluralidad de microculturas politicas revolucionarias", ${ }_{4}^{4}$ en un sentit similar a la metàfora usada per Planas que descriu l'esquerra revolucionària com un conjunt, un arxipèlag, en què cada organització és una illa.

La quarta aportació al congrés, de Joel Sans, fa una anàlisi de conjunt de l'esquerra revolucionària plantejant un marc interpretatiu de la seva crisi ${ }^{25}$. Com a factors principals d'aquesta assenyala l'estabilització de les institucions amb la democràcia parlamentària,

zaciones politicas. Congreso Internacional Historia de la Transición en España. Almería, Servicio de Publicaciones de la Universidad de Almería, 2011. pp. 609-620.

19 Albert PLANAS I SERRA: "La izquierda marxista radical .." p. 616

20 Fuensanta ESCUDERO ANDÚJAR i Carmen GONZÁLEZ MARTÍNEZ: “Jóvenes y rebeldes: el idealismo efímero de la extrema izquierda" a Rafael QUIROSA-CHEYROUZE, Luis Carlos NAVARRO y Mónica FERNÁNDEZ (coords): Las organizaciones politicas... Pp. 507-534

21 Fuensanta ESCUDERO ANDÚJAR y Carmen GONZÁLEZ MARTíNEZ: "Jóvenes y rebeldes: el idealismo...", p. 526

22 Sergio RODRÍGUEZ TEJADA: "Nueva izquierda, extrema izquierda: bases intelectuales y prácticas militantes de las organizaciones revolucionarias al inicio de la transición española" a Rafael QUIROSA-CHEYROUZE, Luis Carlos NAVARRO y Mónica FERNÁNDEZ (coords): Las organizaciones politicas... pp. 631-648

23 Sergio RODRÍGUEZ TEJADA: “Nueva izquierda, extrema izquierda...”, p. 631

24 lbid., p. 632

25 Joel SANS MOLAS: “Entre las instituciones y la movilización: la crisis de la izquierda radical durante la Transición" Rafael OUIROSA-CHEYROUZE, Luis Carlos NAVARRO y Mónica FERNÁNDEZ (coords): Las organizaciones políticas... pp. 649-666. 
el canvi d'actitud dins la classe treballadora, la crisi de militància i les pròpies polítiques de l'esquerra revolucionària. Coincideix amb les dades de Planas al atribuir al conjunt de les organitzacions entre 25.000 i 30.000 membres.

Un altre text recent sobre l'esquerra revolucionària és l'article de Ricard Martínez "La izquierda revolucionaria de ámbito estatal, de los sesenta a los ochenta" ${ }^{26}$ Tot i la limitada extensió es tracta del millor treball de síntesi fet fins al moment sobre les diverses organitzacions de l'esquerra revolucionària. Analitza les organitzacions en una perspectiva històrica que té en compte el context i desenvolupa breument les seves estratègies enfront la transició. Finalment, confronta les tesis sobre la suposada moderació durant els anys 70 i ressalta la dimensió anticapitalista present dins l'antifranquisme.

Sobre la LCR hi ha hagut últimament diversos treballs, vinculats a l'activitat de la revista Viento Sur. Tenim així dos epílegs sobre la LCR de Miguel Romero i Pepe Gutiérrez en el Ilibre Trotskismos que serveixen com a textos introductoris a l'organització. ${ }^{27}$ I uns articles ja més documentats sobre la Lliga de Miguel Romero, Martí Caussá i Ricard Martínez i Muntada en l'especial de Viento Sur "La izquierda contra el franquismo" que donen una visió de conjunt dels punts més destacats durant la transició i contribueixen a començar a cobrir el buit historiogràfic sobre aquesta organització. ${ }^{28}$ En aquest número especial de Viento Sur també tenim un treball de José Antonio Errejón sobre el PTE, sobretot centrat en el moment de la transició. ${ }^{29}$ Totes aquests autors van ser militants de les organitzacions sobre les que escriuen. Com veiem, gran part de la reconstrucció història de les organitzacions està vinculada a persones que hi van formar part, $i$ uneixen memòria i història.

Relacionat també amb la LCR tenim el text "Mito y realidad de la transición política española. Una mirada desde la izquierda radical" de Jaime Pastor. ${ }^{30}$ Es tracta d'una anàlisi de la transició des del punt de vista de l'esquerra radical, especialment l'explicació que dóna la LCR sobre per què no hi va haver-hi ruptura. Té en compte d'altres aspectes interessants com els canvis de cultura política que es donen en la transició, amb una explicació del 'desencís'. Un últim text sobre la LCR és el treball de recerca de Master d'Albert Planas La Lliga Comunista Revolucionària (LCR) a la Transició, 1975-1980,31 amb una bona base de fonts primària a partir de la premsa i documents del partit que permet veure l'evolució política d'aquesta organització i que aporta per primera vegada dades solvents sobre la seva l'afiliació.

L'antropòloga Josepa Cucó ha escrit des del camp de l'antropologia sobre l'esquerra revolucionària, especialment sobre l'MC..$^{22}$ L'enfocament des d'un altre camp de les ciències socials

26 Ricard MARTíNEZ: “La izquierda revolucionaria de ámbito estatal, de los sesenta a los ochenta: una brevísima historia" a Viento Sur, 125 (2013), pp. 108-118.

27 D. BENSAÏD, M. ROMERO, P. GUTIÉRREZ: Trotskismos, Barcelona, EI Viejo Topo/ Viento Sur, 2007

8 Són els texts: Martí CAUSSA: “La LCR y la izquierda radical (1966-1975)”, Miguel ROMERO: “El choque contra la Transición", i Ricard MARTíNEZ i MUNTADA: "La LCR más allá del franquismo: de la 'unidad trotskista' al Partido de los Revolucionarios y la fusión con el MC (1978-1991)" tots ells a Viento Sur, 115 (2011), pp. 56-63 y 64-71, respectivament.

29 José Antonio ERREJÓN: “El Partido del Trabajo de España” a Viento Sur, 115 (2011), pp. 79-86

30 Jaime PASTOR: "Mito y realidad de la transición política española. Una mirada desde la izquierda radical" a Pelai PAGĖS (dir.): La transició democrătica als Països Catalans, València, Universitat de València, 2005, pp. 229-237.

31 Albert PLANAS I SERRA: La Lliga Comunista Revolucionària (LCR) a la Transició, 1975-1980, Treball de Recerca pel Màster en Estudis Historics, Universitat de Barcelona, 2009. 32 Josepa CUCÓ: "De jóvenes radicales a alternativos maduros. Apuntes antropológicos sobre la evolución del Movimiento Comunista en España", en M. CUNHA y L. CUNHA (org.), Intersecçôes Ibéricas. Margens, passagens e fronteiras, Lisboa, 90 Graus Editora, 2007, pp. 313-336.; iD. : "Recuperando una memoria en la penumbra. El Movimiento Comunista y las transformaciones de la extrema conté conceptes interessants, encara que és qüestionable la seva visió que realça l'MC pel fet de ser-suposadament- la única organització que s'aconsegueix mantenir fins al present, si bé ho fa a través d'una xarxa d'exmilitants vinculats pel treball en ONGs. Un altre treball sobre I'MC és el de Gustavo Hervella García, que recull la política d'aquesta organització sobre la qüestió nacional, amb la defensa de l'autodeterminació, i la seva relació amb el nacionalisme, especialment en el cas gallec. ${ }^{33}$

I per acabar amb aquests articles al voltant d'organitzacions cal assenyalar el de Gaudencio Remon Barrade sobre els posicionaments i participació de la ORT en els espais unitaris estatals que es creen a finals del franquisme, la Junta Democràtica i la Plataforma de Convergencia Democrática. ${ }^{34}$

Com he comentat hi ha una manca de llibres sobre les organitzacions en un àmbit territorial acotat, encara que hi ha algunes excepcions. Pel cas d'Alacant comptem amb uns estudis bàsics de Francisco Moreno Sáez sobre el PTE, I'MC (aquest especialment desenvolupat) i l'ORT que supleixen parcialment aquest buit. 35 També tenim un estudi específic de Fernando Díaz Haro sobre l'esquerra revolucionària en el barri de la Pescadería, a Almería, interessant per veure qüestions com l'arrelament local a nivell veïnal i obrer i el seu manteniment en el temps. ${ }^{36}$

Si fins ara hem tractat els treballs específics sobre l'esquerra revolucionària, aquesta també apareix en estudis sobre sectors de l'oposició antifranquista, especialment quan són d'història local. Aquí el gruix d'obres augmenta i no entrarem a fer-ne una relació que seria inevitablement incompleta.

Sobre l'esquerra revolucionària a Europa hi ha pocs estudis que facin una visió de conjunt tot i que és un marc molt interessant de cara a un estudi comparatiu. ${ }^{37}$ El llibre de referència, Las nuevas izquierdas europeas (1956-1976) de Massimo Teodori, ${ }^{8}$ si bé cobreix el que succeeix a Gran Bretanya, Alemanya, Itàlia i França, deixa fora l'Estat espanyol. Aquest Ilibre permet UPV), 1 (2007), (http://www.ehu.es/CEIC/pdf/29.pdf); íD: “De como un partido de la izquierda revolucionaria se convierte en ONG" a Josepa CUCO i B. Santamarina (coords.): Politicas y ciudadania iD.: "Permanecer mutando:"Revuelta y las transformaciones de un antigopologia, 2010, pp. 25-45; , en "Percedes IABARDO VELASCO et al (coords.): Antropologia de orientación pública: visibilizacióny compromiso le Antropolog,

33 Gustavo GARCÍA HeRVELLA: "La izquierda marxista-leninista: el Movimiento Comunista, M.C. y el nacionalismo 1972-1982", a AA.VV.: Actes del Congrés la transició de la dictadura franquista a la democràcia. Barcelona, 20, 21 i 22 d'octubre de 2005, Barcelona, Universitat Autònoma de Barcelona i Centre d'Estudis sobre les Ėpoques Franquista i Democràtica, 2005, pp. 165-174.

34 Gaudencio REMON BARRADE: "La Organización Revolucionaria de Trabajadores (ORT) ante la Junta Democratica y la Plataforma de Convergencia" en Estudios de Ciencias Sociales, 8 (1995), pp. 259-280

35 Francisco MORENO SÁEZ: "El Moviment Comunista del País Valencià", “El Partido del Trabajo de España" $i$ “Organización Revolucionaria de Trabajadores" en Partidos, sindicatos y organizaciones ciudadanas en la Provincia de Alicante durante la transición (1974-1982), Alicante, Archivo de la Democracia (http://www.archivodemocracia.ua.es/index.asp?idioma=_val\&s=articulos).

36 Fernando DÍAZ HARO: "El barrio de Pescadería y el arraigo de la izquierda radical. Un curioso caso de supervivencia en la Transición almeriense (1974-1984)" comunicació al // Congreso Internacional Historia de la Transición, novembre 2005, Universidad de Almería.

37 Tot $\mathrm{i}$ així hi ha treballs en l'àmbit d'un país o d'organitzacions concretes, especialment en el cas italià, però també portuguès i francès. Veure per exemple: Carlo VALLAURI: I gruppi extraparlamentari di sinistra: gènesi e organizzazione, Roma, Bulzoni, 1976; M. MAFFI: Le origini della sinistra mentari di sinistra: genesi e organizzazione, Roma, Bulzoni, 1976; M. MAFFl: Le origini della sinistra extraparlamentari, Milano, Mondadori, 1976; Mino MONICELLI: Lultrasinistra in Italia 1968-1978, 1964-1974, Lisboa, Tinta da China, 2011; Jean-Paul SALLES: La ligue communiste revolutionnaire 1964-1974, Lisboa, Tinta da China, 2011; Jean-Paul SALLES: La ligue communiste revolutionnaire
(1968-1981). Instrument du Grand Soir ou lieu d'apprentissage?, Rennes, Éditions Presses Universitaires de Rennes, 2005

38 Massimo TEODORI: Las nuevas izquierdas. 
veure una aproximació als moviments socials, els canvis en la cultura política i els principals corrents ideològics que sorgeixen en el període. De Chris Harman tenim el llibre The fire last time, sobre les lluites que es desenvolupen després del maig francès, en el qual apareix el rol de l'esquerra revolucionària en els esdeveniments de cada país i els seus dilemes estratègics, sobretot a nivell europeu però no exclusivament. ${ }^{39}$ Aquest autor també va desenvolupar una anàlisis de fort potencial explicatiu sobre l'esquerra revolucionària en un article de 1979, "Crisis of the European revolutionary left". $4^{\circ}$ En un sentit similar tenim l'article de Pierre Rousset, més recent, "The evolution of the European radical left and some current controversies", que entra en les diferències estratègies de l'esquerra radical entre els anys 1960s i 1990 os i assenyala alguns 'tests' que van haver de superar per mantenir-se després dels anys $70 .{ }^{41}$ Els dos últims autors mencionats han format part de corrents revolucionaris. Això no treu a aquests treballs una aproximació rigorosa i, per altra banda, aporten una visió de conèixer el fenomen 'des de dins'.

A partir de la bibliografia comentada podem assenyalar que el PTE i la LCR compten ja amb una certa historiografia, especialment la primera organització. Les altres organitzacions queden més mal cobertes ja que només existeixen alguns estudis parcials sobre l'MC il'ORT i uns treballs puntuals on aparegui l'OCE(BR) i l'OIC.42 Els dos principals temes interpretatius que apareixen a la bibliografia disponible són, en primer lloc, què és allò que porta a la formació d'aquesta nova esquerra revolucionària i al seu creixement $i$, en segon lloc, per què es produeix la seva crisi sobtada que va frustrar la trajectòria militant de tantes persones. Es reconeix també la importància de veure les organitzacions de l'esquerra revolucionària de l'Estat espanyol com part d'un fenomen internacional i de tenir en compte el context històric específic del franquisme per entendre els seus problemes de desenvolupament. Per a un òptim coneixement de l'esquerra revolucionària faltarien estudis específics sobre cada una de les organitzacions, també estudis d'història local i estudis dels sectors i moviments on les diferents organitzacions més van intervenir.

\section{Alguns apunts per al seu estudi}

Per acabar voldria recollir algunes de les idees mencionades en aquest estat de la qüestió i apuntar-ne d'altres sobre què ens aporta l'estudi de l'esquerra revolucionària per a la comprensió històrica del moment polític i social dels anys 70 . Hem vist com hi ha una creixent revalorització del pes que va tenir l'esquerra revolucionària, el seu arrelament social i la seva aportació a la lluita antifranquista, tot i que a nivell general no es pot oblidar que sempre va tenir un pes menor que el PCE i PSUC. Val la pena no només constatar una militància quantitativament propera a tres desenes de milers pel conjunt de l'Estat, sinó també assenyalar qualitativament que aquesta era molt activa i va tenir una incidència destacada -especialment en determinats llocs de l'àmbit local-en el moviment obrer, estudiantil, veïnal i feminista. La seva influència en l'articulació de les forces polítiques de l'antifranquisme i en els sectors intel.lectuals va ser comparativament menor a la seva influència en les lluites, tot que el PTE, ORT i MC van participar a les plataformes unitàries de l'oposició. És per això que

39 Chris HARMAN: The fire last time..

40 Chris HARMAN: "Crisis of the European revolutionary left". A International Socialism, 4 (1979), http://chrisharman.blogspot.com/200g/11/crisis-of-european-revolutionary-left.html.

41 Pierre ROUSSET: "The evolution of the European radical left and some current controversies" a IV Online magazine, IV, 370 (2005), http.//wwwinternationalviewpoint.org/spip.php?article869. Hi ha una versió reduida en castellà a: Pierre ROUSSET: “Dos generaciones en la evolución de la izquierda radical europea" a Manuel GARÍ, Jaime PASTOR i Miguel ROMERO (eds.): 1968: el mundo pudo cambiar de base, Madrid, Catarata, 2008, pp. 327-348. La entrada de Bandera Roja en el PSUC", en Revista HmiC, 8 (2010), http: // webs2002 uab discordia. La entrada de Bandera Roja en el PSUC", en Revista HmiC, 8 (2010), http://webs2002.uab.es/hmic/ Bals: Miquel LOPEZ CRESPÍ: No era això:memòria política de la transició. leida El Jonc, zoo l'estudi d'aquestes organitzacions ens pot donar elements per augmentar la comprensió sobre els moviments socials i sobre la relació -a vegades complexa- que s'estableix entre moviments i partits polítics. En el cas del moviment obrer, hi ha tot un seguit de lluites radicals, sobretot en l'any crucial de 1976 , amb unes dinàmiques que no es poden entendre sense tenir en compte el paper que hi van tenir les organitzacions revolucionàries; són els fets de Vitòria del març de 1976, la vaga del metall de Sabadell de la tardor del mateix any o les mobilitzacions en el sector de l'ensenyament que portaran a la creació del sindicat STEs. ${ }^{43}$ En totes elles va ser central el component d'organització assembleària del conflicte que compartien aquestes organitzacions. A banda, destacar el cas d'Euskadi, el territori on l'esquerra revolucionària va tenir la seva major implantació $i$ una incidència important en tot el cicle mobilitzador de finals dels anys 70 , cicle que quant a la lluita obrera va ser d'una intensitat superior que a la resta de l'Estat. Faria falta un estudi comparatiu entre aquest territori i d'altres de l'Estat per veure la possible correlació positiva entre la major implantació de l'esquerra revolucionària i el major nivell de lluita obrera. ${ }^{44}$

Una altra qüestió mencionada prèviament és l'interès que presenta inserir, per al seu estudi, l'esquerra revolucionària en un camp anticapitalista més ampli, que va tenir una especial efervescència a finals dels anys $70.45 \mathrm{En}$ aquest camp hi podriem incloure també la CNT (que va tenir un creixement molt ràpid), l'autonomia obrera, diversos col-lectius de base i molts activistes no organitzats políticament. L'esquerra revolucionària la podem entendre així com un producte de la radicalització política dels anys 60 i 70 i com a tal ens constata l'existència i dimensions d'aquest camp anticapitalista. Al mateix temps, les organitzacions revolucionàries van ser també un agent d'aquesta radicalització $i$ li van donar forma i discurs polític.

Per últim, afegir que l'estudi de l'esquerra radical ens permet veure el procés de canv polític des d'altres angles. Per una banda, ens assenyala l'existència de tot un sector polític i social significatiu que s'oposava al model de transició que es va produir i, per tant, indica que hi havia forces que empenyien en una altra direcció. De fet, dins del camp de l'esquera només les organitzacions revolucionàries van mantenir l'esforç d'empènyer cap a la ruptura fins a principis de 1977, quan en canvi el PCE-PSUC ja havia entrat al llarg de 1976 en una dinàmica de canalització i de contenció de la mobilització de cara a la negociació. ${ }^{6}$ Per altra banda, perquè ens permet llegir el canvi des del punt de vista de les forces polítiques que van ser marginades del consens forjat durant la transició i per tant, repensar les cruïlles històriques i potencialitats que presentava aquell moment. Quan avui en dia el règim de la transició comença a estar posat en entredit pren de nou rellevància veure què van dir i fer els qui van ser pioners en el seu qüestionament.

43 Tomás ECHAVE ARAQUISTAIN: Vitoria 76, Vitoria, Tomás Echave Araquistain, 1977; Xavier DOMĖ-

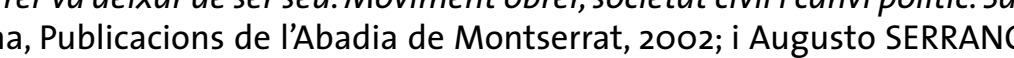
OLMEDO (coord.): Sindicalismo autónomo y a sambleario en la enseñanza. 25 ( $y$ más) años de STES, Madrid, Confederación de STEs, 2003. pp. 11-54

44 Idea que s'apunta a Daniel ESCRIBANO: Aquí falta el Partit! Aproximació a les estratègies de l'esquerra radical en el moviment obrer al final del franquisme, Treball per al Diploma d'Estudis Avançats, 2005

45 Es pot veure l'abast del pensament radical a: Jordi MIR GARCÍA: "Salir de los márgenes sin cambia las ideas. Pensamiento radical, contracultural y libertario en la Transición española" en Ayer. 8 (2011), pp. 83-108.

46 Així el PSUC no va ajudar a generalitzar la vaga del metall de Sabadell en vaga general la tardor Aixi el PSUC no va ajudar a generalitzar la vaga del metall de Sabadell en vaga general la tardor de 1976 i va defensar la seva finalització. Xavier DOMEENECH SAMPERE: Ouan el carrer va deixar... p. 301-323. Una polttica del PCE, la de deixar de banda la Acción Democrática Nacional, que s'explica Madrid, Eneida, 2012, pp. 331-333. 


\section{EL MOVIMIENTO VECINAL EN LA GALICIA URBANA (1970-1980)}

Fátima Martínez Pazos ${ }^{1}$

Tal y como puede apreciarse en el título de esta comunicación, el objetivo fundamental es la presentación del movimiento vecinal en Galicia. Este trabajo se enmarca en un proyecto más amplio, la realización de una tesis doctoral, en el cual se analizarán distintas ciudades del arco atlántico gallego, tales como A Coruña, Ferrol, Vigo o Santiago de Compostela. El marco cronológico que se plantea para ello, es el momento de mayor relevancia para este movimiento, es decir el tardofranquismo y la transición, momento de su nacimiento y posterior debilitamiento. Hay que señalar, sin embargo, que la investigación que aquí presento se encuentra en un momento bastante inicial al no tener un vaciado documental lo suficientemente amplio, debido tanto a la amplitud como a la dispersión geográfica que presentamos para este proyecto. Es por ello, que muchos de los planteamientos que presentamos no han obtenido la debida repuesta, y tal vez, existan muchas más preguntas que respuestas. En esta comunicación tan sólo se pretende presentar una parte de este proyecto y alguna hipótesis que se plantean para su desarrollo a través de un estudio de caso.

Como bien conocemos todos, los orígenes del asociacionismo vecinal beben del enorme proceso urbanizador ocurrido a partir de la década de los años sesenta y que supone una transformación fundamental en la sociedad española del momento. Y es que en esta década pasamos de ser una población mayoritariamente agraria a urbana, en un periodo de tiempo muy pequeño $y$, todo esto, en el contexto de un régimen muy inmovilista. Superado este por la situación, se crean grandes urbes a las que no llegan los servicios necesarios para su adecuado desarrollo. La necesidad de reclamar servicios y derechos tales como un hospital, una escuela, alumbrado o, simplemente, el asfaltado de una carretera, permite que coincidan personas de muy distinto tipo en el seno de estas sociedades. El propio estado franquista se ve obligado a atender estas reclamaciones, promoviendo la Ley de Asociaciones del 24 de diciembre de 1964, quedando de esta manera legalizadas.

${ }^{1}$ Becaria predoutoral Xunta de Galicia. 
Debido, en parte, a estos aspectos, no es extraño que este movimiento haya sido estudiado profusamente en las principales ciudades, tal y como son el caso de Madrid, Barcelona, Bilbao o Valencia, ampliándose en los últimos tiempos a distintas ciudades de Andalucía o de Castilla y León.

Para esta comunicación planteo conocer, primeramente, una visión general de los movimientos urbanos. Después, presentaremos un caso específico de la ciudad de Vigo, que nos ayudará a comprender algunas de las características que se presenta en el movimiento gallego.

\section{LOS MOVIMIENTOS URBANOS. UNA PERSPECTIVA GENERAL}

Si atendemos a la historiografía publicada en otros países, nos damos cuenta enseguida que el fenómeno de las asociaciones urbanas no es en absoluto exclusivo de España.

El crecimiento urbano es general en todo el mundo, por lo menos en Occidente, en los años del conocido "milagro económico”, muestran que, por su intensidad, se trata de un momento con numerosas tensiones y contradicciones que terminan derivando en nuevos movimientos sociales. Estos nuevos movimientos están amparados, claramente, en los nuevos espacios de sociabilidad que se crean en estas urbes, distintas al contexto agrario conocido anteriormente. De este modo, encontramos numerosos ejemplos ${ }^{2}$, como son los Comitari di quarteri, Sunia (Sindicato Nacional Unitario de Inquilinos y Asignatarios) o UI en Italia; GAM (Grupos de Acción Municipal en Francia), protagonizada por las clases media; o los “squatters", movimientos de ocupación de viviendas que están presentes tanto en EEUU como Alemania y Reino Unido. Se encuentran también casos en América Latina, como es el caso chileno. En ellos, puede rastrearse las mimas reclamaciones que se presentan en el caso español: reclamaciones de sus derechos como ciudadanos; mejoras en los servicios de las ciudades o viviendas con condiciones dignas para todos.

Lo que diferencia el caso español de otros movimientos contemporáneos es, claramente, en el contesto que se desarrolla. El

\footnotetext{
2 Urrutia Abaigar, Víctor, El movimiento vecinal en el área metropolitana de
} Bilbao, ed . Herri-Arduralaritzaren Euskal Erakundea, 1985, 322 pp. Pp. 19-20. 
régimen franquista se caracteriza por ser tremendamente inmovilista y represivo, provocando que estas asociaciones se transformen, prontamente, en una vía de expresión para muchas de las ideologías que se encontraban prohibidas en ese momento. Así, hoy en día son conocidas como uno de los principales movimientos opositores, junto al movimiento estudiantil y el obrero. Su funcionamiento interno democrático, favorece la praxis democrática a un sector de la población muy poco presente en cualquiera de los otros dos ejemplos, tal y como es el caso de las mujeres.

El estudio de este sujeto histórico, tal y como ya hemos señalado anteriormente, se ha centrado en el análisis de grandes ciudades como Madrid, Barcelona o Bilbao. En los últimos años, sin embargo, se han dado a conocer los casos de ciudades más pequeñas, mostrando aspectos muy interesantes para la historiografía de este movimiento. El caso gallego, quizá por muchos de estos tópicos que han estado presentes para este proceso, no ha sido estudiado hasta el momento. El tamaño de sus ciudades, que en absoluto llegan a las cifras de otros casos, no las ha hecho merecedoras de muchos estudios sobre su sistema urbano. Pero a veces, los pequeños casos también ayudan a comprender otros aspectos que son necesarios para comprender la verdadera dimensión de nuestro objeto de estudio.

Entre las características del caso gallego, uno muy claro es su componente tardía, ya que no existe ninguna asociación legalizada antes del año setenta y cinco. Aun así, en muy poco tiempo adquiere una fuerza poderosa, estando presente en muchos de los ámbitos municipales que trataremos en esta investigación. Otro aspecto, es la adaptación de estructuras espaciales fundamentales en el territorio desde la Edad Media y que también sufren las presiones de este movimiento urbanizador para, en cierto modo, adaptarse y formar parte de estas ciudades. Para lograr una idea más clara, veamos el estudio de caso que se presenta a continuación.

\section{LA ZONA PERIURBANA: LAS ASOCIACIONES DE VECINOS DE BASE PARROQUIAL.}

En Galicia los municipios se organizan en base a varias parroquias que suelen coincidir con la antigua organización eclesiástica. Este sistema, que bebe sus raíces de la Edad Media, entró en crisis en la década de los sesenta, años de grandes cambios tanto en el medio rural como urbano. Para que lo entendamos mejor, la 
parroquia suponía algo más que una mera división eclesiástica o espacial. Tiene también una dimensión más amplia, suponiendo además el espacio de conocimiento, el espacio cotidiano, en el que se relacionan los vecinos ${ }^{3}$. En Vigo existe un sistema de parroquias que aún hoy en día están muy presentes en el imaginario de sus vecinos. Es por ello que encontramos asociaciones vecinales que coinciden con estas limitaciones y que, también, muestran sus diferencias.

Cuando nos referimos a una ciudad como Vigo, hay que tener en cuenta muchos elementos fundamentales a lo largo de su historia. La primera de ellas, es que no se introduce en la historia urbanística española hasta bien entrado en siglo XIX, pero una vez que comienza su proyecto industrial y urbano, el ritmo de crecimiento de la ciudad será muy rápido. De 23259 habitantes en 1900, contaba en 1970 con 197.144 habitantes ${ }^{4}$, lo que significa que su población se multiplica por ocho en tan sólo setenta años. Tengamos en cuenta, además, que desde sus orígenes de pueblo pesquero se convierte en la ciudad más

${ }^{3}$ Ma Pilar de Torres Luna, "A Parroquia e a Xeografía de Galicia" en A Parroquia en Galicia. Pasado, presente e futuro.Ed. Xunta de Galicia, 2009, 429 pág.

${ }^{4}$ Hernández Borge, Julio "Dinamismo y estructura de la población en la provincia de Pontevedra (1900-1970), ed. Secretariado de publicaciones de la Universidad de Santiago, Santiago de Compostela, 1972, 141 pág. importante de Galicia, con uno de los desarrollos urbanos más rápidos de Europa.

Para comprender mejor el desarrollo urbano de Vigo, hay que empezar por la incorporación de los antiguos Concellos de Bouzas y Lavadores. Primeramente, el concello de Bouzas se incoprpora a Vigo en el año 1904, y con él las parroquias de Alcabre, Navia, Coruxo, San Miguel de Oia, Comesaña, Matamá y Coia ${ }^{5}$. El concello de Lavadores, por otro lado, se integrará en el año 1941, aportando con ello las parroquias de Teis, Santa Cristina, Candeán, Bembrive, Beade, Valadares y Zamás.

La incorporación de todos estos territorios junto al espectacular urbanístico al albor de la incipiente industria que comienza a desarrollarse en la ciudad, configurarán un espacio urbano con muchas particularidades que muestra una nueva cara de este movimiento. Es cierto, que muchos de estos territorios no se enfrentan a los problemas de vivienda o de masificación que se pueden

\footnotetext{
${ }^{5}$ Viñas, Ángel (coord.) Guía cidadá de Vigo y su área metropolitana. Ed. Faro de
} Vigo, 2002,672pp, pág. 115. 
encontrar en las zonas más urbanas, pero sí que tienen otras necesidades que crearon un tejido asociativo de gran actividad en estos años. De hecho, las primeras organizaciones en ser legalizadas se encuentran en estas zonas ya que su incorporación provoca numerosos problemas en el desbordado sistema municipal franquista. Así Souto ${ }^{6}$ se refiere, por ejemplo, a movimientos de población que suponían demasiado tiempo; pérdida de valoración del uso agropecuario en sus territorios; fuertes procesos de transformación de la población rural; por supuesto, falta de asfaltado; malas comunicaciones con la ciudad etc.

Añadamos a todos estos aspectos uno más: la gestión del monte de propiedad comunal. La provincia de Pontevedra tiene en su haber uno de los mayores porcentajes de monte comunal. La reivindicación de sus gestión por parte de los vecinos, muy amplio a partir de la década de los sesenta, se une a sus demanda por lo que en muchos casos veremos cómo los órganos de gestión nacen en el propio seno de las asociaciones vecinales. $\mathrm{Y}$ a todo esto, se añade la influencia del movimiento obrero.

${ }^{6}$ Souto González, Xosé Manuel, "Vigo: empresa e proxecto urbano. As perspectivas de na cidade e área de influencia" en Análise empresarial, nำ12, 1991, pág.15-24

\section{EL CASO DE LA ASOCIACIÓN DE VECINOS DE} VALLADARES.

La parroquia de Valladares o Valadares, ya que existe enorme controversia en cuanto a su toponimia, ocupa una superficie de casi 13 kilómetros cuadrados y se encuentra presidida por los montes Alba y Galiñeiro. Es por tanto, un territorio de una gran extensión.

La asociación de vecinos, como tal, tiene una larga gestación. Se origina a partir de la convergencia de tres factores: un teleclub, una junta parroquial y una junta gestora vecinal. En la documentación que tenemos asociaciones vecinales ${ }^{7}$, ya se señalan como puntos problemáticos para esta zona la asistencia sanitaria, abastecimientos de aguas o la pavimentación. Veamos pues cuáles son los comienzos de este caso.

Los teleclubs fueron promovidos en las zonas rurales a partir de mediados de la década de los años sesenta y se trataban de lugares donde los vecinos podían reunirse para poder ver la televisión, siendo uno de los principales promotores Manuel Fraga Iribarne, Ministro de Información y Turismo. En este caso específico, también participa de

${ }^{7}$ Caja 45219, Asociaciones de Vecinos y Juveniles. Archivo Municipal de Vigo. 
sus inicios la Fundación Barrié de la Maza ${ }^{8}$. No es difícil imaginarse, que con estos orígenes sea esta una sociedad con una vertiente muy cultural desde el principio, poco orientada a los problemas vecinales de la parroquia.

Fundado por Ignacio Costas Piñeiro, retirado de la comandancia de la Marina, la idea se inicia cuando se hace cargo del Club Deportivo Valladares. La sociedad que se funda en el año setenta y uno, sigue desde un principio una orientación muy conservadora estableciendo, por ejemplo, el veto al acceso de mujeres. Los cambios comienzan a notarse cuando se cambia la directiva, el 2 de abril de 1977, teniendo como presidente a Guillermo Álvarez Pérez ${ }^{9}$, ya que se introducen reivindicaciones de tipo más vecinal. Durante este mandato se llevaron a cabo obras como la introducción de la traída de aguas o el teléfono; creación del Colegio Infantil o los comienzos de la Vocalía de la mujer.

Pero adquirir esta dimensión vecinal resultó ser un largo camino no exento de obstáculos, como la intervención del Concello

\footnotetext{
${ }^{8}$ La fundación Barrié de la Maza fue creada el cinco de noviembre de mil novecientos sesenta y seis, a partir de la iniciativa de Pedro Barrié de la Maza, Conde Fenosa.
}

de Vigo provocó, al oponerse a que la financiación se canalizara a través del teleclub, la creación de una junta parroquial. A través de esta se llevan a cabo las reclamaciones que se pueden considera más vecinales, tal y como explican en su libro ${ }^{10}$. Lo que en otros lugares eran conocidas como asociaciones de vecinos, allí era una junta parroquial, agrupándose en su seno tanto el propio teleclub, los alcaldes de barrio o las comisiones de barrio. En esta junta se inician, también, las demandas por la gestión de montes vecinales, situación muy habitual en las asociaciones con las características de Valladares. Sin embargo, con el paso del tiempo, para los vecinos se hace patente la ineficacia de esta junta, provocando que finalmente sea el Teleclub el que lleve adelante muchas de las peticiones. Salvando todos los obstáculos democráticos que presenta desde un primer momento, parece que logra desarrollar cierta conciencia vecinal en la parroquia, siendo un lugar de encuentro para una parte importante de los vecinos. Tal vez por la creación de su centro, un verdadero trabajo cooperativo o por las actividades de recaudación de fondos, termina siendo una

\footnotetext{
9 VV.AA A asociación vecinal de Valladares. Asociación de Veciños de Valladares, sin editar.

${ }^{10}$ A asociación vecinal de Valladares. Asociación de vecinos de Valladares, sin editar.
} 
sociedad a la que acuden muchos vecinos para canalizar sus reclamaciones, como es el caso del agua.

La traída de aguas municipal es una de las grandes carencias de las parroquias más rurales. A la altura del año setenta y seis, prácticamente sólo estaba instalada en el centro urbano de la ciudad, en una clara muestra de su ineficacia para poder dotar a las zonas más periféricas con respecto al centro. En el caso de la parroquia de la que aquí nos ocupamos, se trataba de un proyecto que también cubría a las parroquias de Beade y Castrelos. Hasta ese momento se servían de pozos y manantiales, traídas de agua privadas, de los que aproximadamente el 80\%, según publica la prensa, estaban contaminados. El proyecto llevaba ya varios años planteado, pero ante la falta de presupuesto, llegan al acuerdo de que los vecinos se hagan cargo de parte de los costes de la obra. Al existir constancia de que las tuberías todavía no pasaron por sus casas a la altura del año $1977^{11}$, las asociaciones de vecinos de Beade y Castrelos, además del Teleclub de Valladares, se unen para demandar sus derechos sobre esta obra y que el servicio municipal de aguas cumpla con lo prometido. En un escrito que es remitido por el secretario de la Asociación a la prensa ${ }^{12}$ , se pueden leer acusaciones afirmaciones interesantes.

Señalan que "No van a caer en la trampa de "divide $y$ vencerás”, sistema totalmente superado en aquella zona, en donde las tres directivas han sido elegidas democráticamente”

Hay que recordar que en estos momentos el Concello todavía se encontraba gobernado por una corporación que no había sido escogido democráticamente, por lo que en esta acusación ya se puede ver cómo ellos sí que se justifican en función a su elección más justa.

Mientras que los vecinos invertimos en una obra que quedará para explotar por el servicio que usted preside, la nada despreciable cantidad de 14.000.000 millones de pesetas y que el total aproximado de 60.000.000 de pesetas ¿Señor presidente no le parece suficiente inversión por parte de los vecinos?.

Además, agregan una serie de preguntas en las que muestran todo su descontento y desconfianza con respecto a esta corporación y el servicio municipal de aguas.

12 La Voz de Galicia, 28/10/1977.

${ }^{11}$ EL proyecto era anterior al alcalde García Picher, que llegó a la alcaldía a la altura del año 1974. 
Aprovechando esta ocasión para informar al señor presidente que el proyecto de suministro de agua a Castrelos es anterior al actual alcalde, y que no se llegó a realizar por haber sido torpedeado en el servicio que usted preside. ¿Por qué no investiga al responsable de que llevemos tantos años sin agua, que para más desgracia tenemos que dejar pasar por el centro de nuestra parroquia? ¿En los años que llevan ocupando esos tan deseados cargos el señor presidente y gerenta, no tuvieron tiempo de realizar esta obra?

Terminan su protesta, además, con una serie de interesante preguntas:

¿Cómo Tolera que se siga distribuyendo agua para consumo de boca, en bidones de grasa y aceite? ¿Cómo consiente que un servicio municipal obligue a unos vecinos a servirse de pozos $y$ manantiales que en un $80 \%$ están contaminados; cuando además estos vecinos están dispuestos a contribuir en las obras con un elevado tanto por cien del coste?

En este escrito se pueden observar como la toma de conciencia de los derechos por parte de los vecinos se hace patente, tan sólo un año después de que se legalizara la primera asociación en la ciudad.
Además, la capacidad que muestra el Teleclub de articular a los habitantes de la parroquia, incluso a pesar de haber tenido una trayectoria relativamente alejada de este tipo de protestas hasta este momento, también es llamativa.

El conflicto no termina aquí y, de hecho, se siguen encontrando referencias en las que se llega a pedir la dimisión de la corporación municipal, acusando al alcalde de demagogia y señalando que el servicio municipal de aguas no se encontraba realmente municipalizado. Como veremos, este tipo de peticiones no le faltan al alcalde en un año de gran enfrentamiento con los vecinos que culmina en la propia dimisión de este último. Esta crisis comienza con el intento, por parte del ayuntamiento, de vender una parcela de propiedad municipal ${ }^{13}$ para lograr el rescate de una concesionaria. Todo esto provoca la movilización de las asociaciones de vecinos, que a estas alturas ya se encontraban unidas en una coordinadora que lleva adelante la protesta. En el pleno municipal celebrado el 28/10/1977 el alcalde termina dimitiendo, siendo sustituido Emma González Bermella.. Las protestas no acaban aquí, y en los días posteriores piden la dimisión de la corporación municipal y celebrar elecciones

\footnotetext{
${ }^{13}$ Esta se encontraba situada en la zona de Torrecedeira.
} 
anticipadas. Sin embargo, esto último no se logra y las elecciones no se celebrarán hasta el año setenta y nueve, como en el resto del estado. Lo que no se pone en duda es que la influencia sobre la vida municipal queda, desde luego, demostrada.

\section{CONCLUSIONES}

Los asociaciones de vecinos o, parecidas, no son exclusivos del estado español, sino que son muy generales debido a las propias tensiones que se desarrollan con el proceso urbanizador. El caso español se diferencia por el contexto en el que se produce, convirtiendo estas asociaciones en lugares donde confluyen muchas ideologías pero, también, suponen una oportunidad para muchas personas que nunca habían tenido la oportunidad de participar en este tipo de movimientos. Lo que en muchos lugares era una manera de lograr una mayor participación ciudadana, en España era pedir los derechos más básicos y, posteriormente, durante la Transición, lograr una ampliación de estos derechos como ciudadanos.

El caso gallego muestra, a su vez, que estos procesos son extensibles a lugares con menor tamaño y el que, de hecho, las zonas más tradicionales también son parte activa. El ejemplo de una parroquia como la de Valladares, con una asociación promovida por el propio movimiento, muestra como el proceso urbanizador afecta a las zonas de muy distinta manera. Aunque no existen problemas de masificación o de vivienda, sí que presenta una serie de problemas que provocan la reacción de los vecinos, estando más dirigidas a la forma de ser incluidas en la ciudad. El hecho de que sea una asociación de base parroquial muestra, así mismo, la pervivencia de una de una división espacial que todavía pervive desde la Edad Media, pero que así mismo se transforma al pertenecer a un concello con enormes espacios urbanos.

Con esta tormenta de ideas, muchas de las cuales todavía tienen que ser analizadas más profundamente, pretendo presentar un poco las características de mi trabajo. Sin embargo, está claro que se encuentra en un momento muy inicial, por lo que espero que todo esto pueda ser más enriquecedor en un futuro próximo. 